\title{
STATE OF THE CLIMATE IN 2017
}

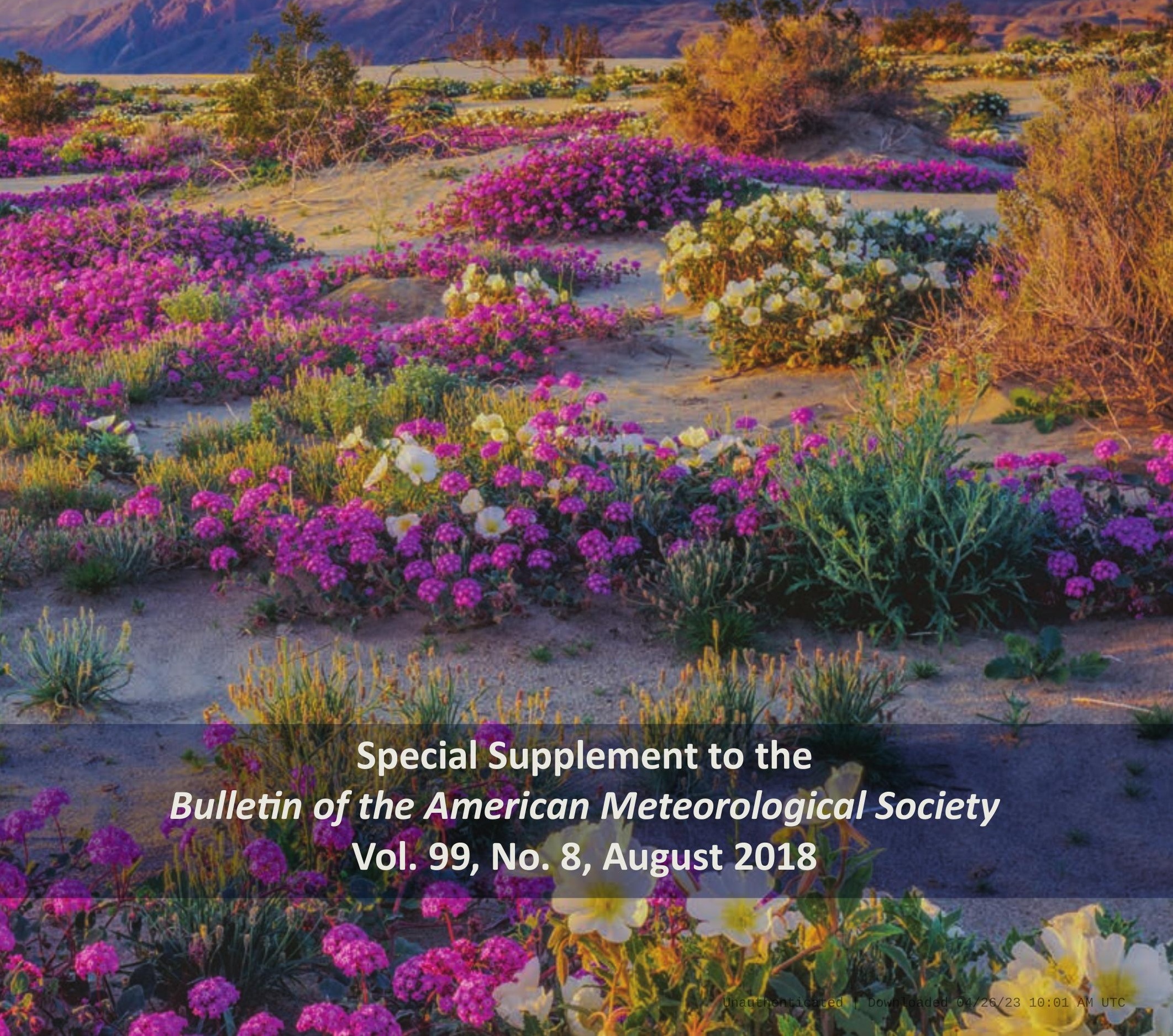




\section{STATE OF THE CLIMATE IN 2017}

Editors

Jessica Blunden

Derek S. Arndt

Gail Hartfield

\section{Chapter Editors}

Peter Bissolli

Howard J. Diamond

Robert J. H. Dunn

Catherine Ganter

Nadine Gobron

Martin O. Jeffries

\author{
Gregory C. Johnson \\ Tim Li \\ Ademe Mekonnen \\ Emily Osborne \\ Jacqueline A. Richter-Menge
}

Technical Editor

Mara Sprain

BAMS Special Editor for Climate

Richard Rosen
Ahira Sánchez-Lugo

Ted A. Scambos

Carl J. Schreck III

Sharon Stammerjohn

Diane M. Stanitski

Kate M. Willett

American Meteorological Society 
COVER CREDITS:

FroNt: @Ron_ Thomas/Spring desert wildflowers in Anza Borrego Desert State Park, CA/Getty Images.

BACK: Smoke and Fire in Southern California: Thick smoke was streaming from several fires in Southern California when the Moderate Resolution Imaging Spectroradiometer (MODIS) on NASA's Terra satellite acquired a natural-color image in the afternoon on December 5, 20I7. On the same day, the Multi Spectral Imager (MSI) on the European Space Agency's Sentinel-2 satellite captured the data for a false-color image of the burn scar. Active fires appear orange; the burn scar is brown. Unburned vegetation is green; developed areas are gray. The Sentinel-2 image is based on observations of visible, shortwave infrared, and near infrared light.

NASA Earth Observatory images by Joshua Stevens, using MODIS data from LANCE/EOSDIS Rapid Response and modified Copernicus Sentinel data (2017) processed by the European Space Agency. Story by Adam Voiland.

Instrument(s):

Terra - MODIS

Sentinel-2

How to cite this document:

Citing the complete report:

Blunden, J., D. S. Arndt, and G. Hartfield, Eds., 2018: State of the Climate in 2017. Bull. Amer.

Meteor. Soc., 99 (8), Si-S3I0, doi:I0.II75/20I8BAMSStateoftheClimate.I.

Citing a chapter (example):

Richter-Menge, J., M. O. Jeffries, and E. Osborne, Eds., 2018: The Arctic [in "State of the Climate in 2017”]. Bull. Amer. Meteor. Soc., 99 (8), SI43-173, doi:I0.II75/20I8BAMSStateoftheClimate.I.

\section{Citing a section (example):}

Osborne, E., T. Cronin, and J. Farmer, 2018: Paleoclimate records: Providing context and understanding of current Arctic change [in "State of the Climate in 2017"]. Bull. Amer. Meteor. Soc., 99 (8), SI50-SI52, doi:I0.II75/20I8BAMSStateoftheClimate.I. 
Abernethy, R., Met Office Hadley Centre, Exeter, United Kingdom

Ackerman, Steven A., Cooperative Institute for Meteorological Satellite Studies, University of WisconsinMadison, Madison, Wisconsin

Adler, R., University of Maryland, College Park, Maryland

Albanil Encarnación, Adelina, National Meteorological Service of Mexico, Mexico

Aldeco, Laura S., Servicio Meteorológico Nacional, Buenos Aires, Argentina

Alfaro, Eric J., Center for Geophysical Research and School of Physics, University of Costa Rica, San José, Costa Rica

Aliaga-Nestares, Vannia, Servicio Nacional de Meteorología e Hidrología del Perú, Lima, Perú

Allan, Richard P., University of Reading, Reading, United Kingdom

Allan, Rob, Met Office Hadley Centre, Exeter, United Kingdom

Alves, Lincoln M., Centro de Ciencias do Sistema Terrestre, Instituto Nacional de Pesquisas Espaciais, Cachoeira Paulista, Sao Paulo, Brazil

Amador, Jorge A., Center for Geophysical Research and School of Physics, University of Costa Rica, San José, Costa Rica

Anderson, John, Department of Atmospheric and Planetary Science, Hampton University, Hampton, Virginia

Andreassen, L. M., Section for Glaciers, Ice and Snow, Norwegian Water Resources and Energy Directorate, Oslo, Norway

Argüez, Anthony, NOAA/NESDIS National Centers for Environmental Information, Asheville, North Carolina

Armitage, C., Woodland Trust, Grantham, United Kingdom

Arndt, Derek S., NOAA/NESDIS National Centers for Environmental Information, Asheville, North Carolina

Avalos, Grinia, Servicio Nacional de Meteorología e Hidrología del Perú, Lima, Perú

Azorin-Molina, César, Regional Climate Group, Department of Earth Sciences, University of Gothenburg, Gothenburg, Sweden

Báez, Julián, Dirección de Meteorología e Hidrología de la DINAC and Universidad Católica Ntra. Sra. de la Asunción, Asunción, Paraguay

Bardin, M. Yu., Institute of Global Climate and Ecology of Roshydromet and Russian Academy of Sciences, and Institute of Geography of Russian Academy of Sciences, Russia

Barichivich, Jonathan, Universidad Austral de Chile, Valdivia, Chile; Center for Climate and Resilience Research (CR)2, Chile

Baringer, Molly O., NOAA/OAR Atlantic Oceanographic and Meteorological Laboratory, Miami, Florida

Barreira, Sandra, Argentine Naval Hydrographic Service, Buenos Aires, Argentina

Baxter, Stephen, NOAA/NWS Climate Prediction Center, College Park, Maryland

Beck, H.E., Department of Civil and Environmental Engineering, Princeton University, Princeton, New Jersey
Becker, Andreas, Global Precipitation Climatology Centre, Deutscher Wetterdienst, Offenbach, Germany

Bedka, Kristopher M., NASA Langley Research Center, Hampton, Virginia

Behe, Carolina, Inuit Circumpolar Council Alaska, Anchorage, Alaska

Bell, Gerald D., NOAA/NWS Climate Prediction Center, College Park, Maryland

Bellouin, Nicolas, University of Reading, Reading, United Kingdom

Belmont, M., Seychelles National Meteorological Services, Pointe Larue, Mahé, Seychelles

Benedetti, Angela, European Centre for Medium-Range Weather Forecasts, Reading, United Kingdom

Bernhard, G. H., Biospherical Instruments, San Diego, California

Berrisford, Paul, European Centre for Medium-Range Weather Forecasts, Reading, United Kingdom

Berry, David I., National Oceanography Centre, Southampton, United Kingdom

Bhatt, U. S., Geophysical Institute, University of Alaska Fairbanks, Fairbanks, Alaska

Bissolli, Peter, Deutscher Wetterdienst, WMO RA VI Regional Climate Centre Network, Offenbach, Germany

Bjerke, J., Norwegian Institute for Nature Research, Tromsø, Norway

Blake, Eric S., NOAA/NWS National Hurricane Center, Miami, Florida

Blenkinsop, Stephen, School of Engineering, Newcastle University, Newcastle-upon-Tyne, United Kingdom

Blunden, Jessica, NOAA/NESDIS National Centers for Environmental Information, Asheville, North Carolina

Bolmgren, K., Swedish University of Agricultural Sciences, Uppsala, Sweden

Bosilovich, Michael G., Global Modelling and Assimilation Office, NASA Goddard Space Flight Center, Greenbelt, Maryland

Boucher, Olivier, Institut Pierre-Simon Laplace, CNRS/UPMC, Paris, France

Bouchon, Marilú, Instituto del Mar del Perú, Callao, Perú

Box, J. E., Geological Survey of Denmark and Greenland, Copenhagen, Denmark

Boyer, Tim, NOAA/NESDIS National Centers for Environmental Information, Silver Spring, Maryland

Braathen, Geir O., WMO Atmospheric Environment Research Division, Geneva, Switzerland

Bromwich, David H., Byrd Polar and Climate Research Center, The Ohio State University, Columbus, Ohio

Brown, R., Climate Research Division, Environment and Climate Change Canada, Downsview, Ontario, Canada

Buehler, S., Universitaet Hamburg, Hamburg, Germany

Bulygina, Olga N., Russian Institute for Hydrometeorological Information, Obninsk, Russia

Burgess, D., Geological Survey of Canada, Ottawa, Ontario, Canada 
Calderón, Blanca, Center for Geophysical Research, University of Costa Rica, San José, Costa Rica

Camargo, Suzana J., Lamont-Doherty Earth Observatory, Columbia University, Palisades, New York

Campbell, Ethan C., School of Oceanography, University of Washington, Seattle, Washington

Campbell, Jayaka D., Department of Physics, The University of the West Indies, Jamaica

Cappelen, J., Danish Meteorological Institute, Copenhagen, Denmark

Carrea, Laura, Department of Meteorology, University of Reading, Reading, United Kingdom

Carter, Brendan R., Joint Institute for the Study of the Atmosphere and Ocean, University of Washington, and NOAA/OAR Pacific Marine Environmental Laboratory, Seattle, Washington

Castro, Anabel, Servicio Nacional de Meteorología e Hidrología del Perú, Lima, Perú

Chambers, Don P., College of Marine Science, University of South Florida, St. Petersburg, Florida

Cheng, Lijing, International Center for Climate and Environment Sciences, Institute of Atmospheric Physics, Chinese Academy of Sciences, Beijing, China

Christiansen, Hanne H., Geology Department, University Centre in Svalbard, Longyearbyen, Norway

Christy, John R., University of Alabama in Huntsville, Huntsville, Alabama

Chung, E.-S., Rosenstiel School of Marine and Atmospheric Science, University of Miami, Key Biscane, Miami, Florida

Clem, Kyle R., Institute of Earth, Ocean, and Atmospheric Sciences, Rutgers, the State University of New Jersey, New Brunswick, New Jersey

Coelho, Caio A.S., CPTEC/INPE Center for Weather Forecasts and Climate Studies, Cachoeira Paulista, Brazil

Coldewey-Egbers, Melanie, German Aerospace Center (DLR) Oberpfaffenhofen, Wessling, Germany

Colwell, Steve, British Antarctic Survey, Cambridge, United Kingdom

Cooper, Owen R., Cooperative Institute for Research in Environmental Sciences, University of Colorado Boulder, and NOAA/OAR Earth System Research Laboratory, Boulder, Colorado

Copland, L., Department of Geography, University of Ottawa, Ottawa, Ontario, Canada

Costanza, Carol, Antarctic Meteorological Research Center and Space Science and Engineering Center, University of Wisconsin-Madison, Madison, Wisconsin

Covey, Curt, Lawrence Livermore National Laboratory, Livermore, California

Coy, Lawrence, Science Systems and Applications, Inc., NASA Goddard Space Flight Center, Greenbelt, Maryland

Cronin, T., U.S. Geological Survey, Reston, Virginia

Crouch, Jake, NOAA/NESDIS National Centers for Environmental Information, Asheville, North Carolina

Cruzado, Luis, Servicio Nacional de Meteorología e Hidrología del Perú, Lima, Perú
Daniel, Raychelle, The Pew Charitable Trusts, Washington, D.C.

Davis, Sean M., Cooperative Institute for Research in Environmental Sciences, University of Colorado Boulder, and NOAA/OAR Earth System Research Laboratory, Boulder, Colorado

Davletshin, S. G., Russian Institute for Hydrometeorological Information, Obninsk, Russia

de Eyto, Elvira, Marine Institute, Newport, Ireland

de Jeu, Richard A. M., EODC GmbH, Vienna, Austria

De La Cour, Jacqueline L., NOAA/NESDIS Coral Reef Watch, College Park, Maryland, and Global Science and Technology, Inc., Greenbelt, Maryland

de Laat, Jos, Royal Netherlands Meteorological Institute (KNMI), DeBilt, Netherlands

DeGasperi, Curtis L., King County Water and Land Resources Division, Seattle, Washington

Degenstein, Doug, University of Saskatchewan, Saskatoon, Saskatchewan, Canada

Deline, P., EDYTEM Lab, University Savoie Mont Blanc, Chambéry, France

Demircan, Mesut, Turkish State Meteorological Service, Ankara, Turkey

Derksen, C., Climate Research Division, Environment and Climate Change Canada, Downsview, Ontario, Canada

Dewitte, Boris, Centro de Estudios Avanzado en Zonas Áridas, and Universidad Católica del Norte, Coquimbo, Chile, and Laboratoire d'Etudes en Géophysique et Océanographie Spatiales, Toulouse, France

Dhurmea, R., Mauritius Meteorological Service, Vacoas, Mauritius

Di Girolamo, Larry, University of Illinois at UrbanaChampaign, Urbana, Illinois

Diamond, Howard J., NOAA/OAR Air Resources Laboratory, Silver Spring, Maryland

Dickerson, C., Department of Environmental Sciences, University of Virginia, Charlottesville, Virginia

Dlugokencky, Ed J., NOAA/OAR Earth System Research Laboratory, Boulder, Colorado

Dohan, Kathleen, Earth and Space Research, Seattle, Washington

Dokulil, Martin T., Research Institute for Limnology, University of Innsbruck, Mondsee, Austria

Dolman, A. Johannes, Department of Earth Sciences, Earth and Climate Cluster, VU University Amsterdam, Amsterdam, Netherlands

Domingues, Catia M., Institute for Marine and Antarctic Studies, University of Tasmania, Antarctic Climate and Ecosystems Cooperative Research Centre, and Australian Research Council's Centre of Excellence for Climate System Science, Hobart, Tasmania, Australia

Domingues, Ricardo, Cooperative Institute for Marine and Atmospheric Studies, University of Miami, Miami, Florida

Donat, Markus G., Climate Change Research Centre, University of New South Wales, Sydney, New South Wales, Australia 
Dong, Shenfu, NOAA/OAR Atlantic Oceanographic and Meteorological Laboratory, and Cooperative Institute for Marine and Atmospheric Science, Miami, Florida

Dorigo, Wouter A., Department of Geodesy and Geoinformation, Vienna University of Technology, Vienna, Austria

Drozdov, D. S., Earth Cryosphere Institute, and Tyumen State University, Tyumen, Russia

Dunn, Robert J. H., Met Office Hadley Centre, Exeter, United Kingdom

Durre, Imke, NOAA/NESDIS National Centers for Environmental Information, Asheville, North Carolina

Dutton, Geoff S., Cooperative Institute for Research in Environmental Sciences, University of Colorado Boulder, and NOAA/OAR Earth System Research Laboratory, Boulder, Colorado

Eakin, C. Mark, NOAA/NESDIS Coral Reef Watch, College Park, Maryland

EIKharrim, M., Direction de la Météorologie Nationale Maroc, Rabat, Morocco

Elkins, James W., NOAA/OAR Earth System Research Laboratory, Boulder, Colorado

Epstein, H. E., Department of Environmental Sciences, University of Virginia, Charlottesville, Virginia

Espinoza, Jhan C., Instituto Geofisico del Perú, Lima, Perú

Famiglietti, James S., Jet Propulsion Laboratory, California Institute of Technology, Pasadena, California

Farmer, J., Department of Geosciences, Princeton University, Princeton, New Jersey

Farrell, S., Earth System Science Interdisciplinary Center, University of Maryland, College Park, Maryland

Fauchald, P., Norwegian Institute for Nature Research, Tromsø, Norway

Fausto, R. S., Geological Survey of Denmark and Greenland, Copenhagen, Denmark

Feely, Richard A., NOAA/OAR Pacific Marine Environmental Laboratory, Seattle, Washington

Feng, Z., Atmospheric Sciences and Global Change Division, Pacific Northwest National Laboratory, Richland, Washington

Fenimore, Chris, NOAA/NESDIS National Centers for Environmental Information, Asheville, North Carolina

Fettweis, X., University of Liège, Liège, Belgium

Fioletov, Vitali E., Environment and Climate Change Canada, Toronto, Ontario, Canada

Flemming, Johannes, European Centre for Medium-Range Weather Forecasts, Reading, United Kingdom

Fogt, Ryan L., Department of Geography, Ohio University, Athens, Ohio

Folland, Chris, Met Office Hadley Centre, Exeter, and School of Environmental Sciences, University of East Anglia, Norwich, United Kingdom, and Department of Earth Sciences, University of Gothenburg, Gothenburg, Sweden, and International Centre for Applied Climate Sciences, University of Southern Queensland, Toowoomba, Queensland, Australia
Forbes, B. C., Arctic Centre, University of Lapland, Rovaniemi, Finland

Foster, Michael J., Cooperative Institute for Meteorological Satellite Studies, University of Wisconsin-Madison, Madison, Wisconsin

Francis, S. D., National Weather Forecasting and Climate Research Centre, Nigerian Meteorological Agency, Abuja, Nigeria

Franz, Bryan A., NASA Goddard Space Flight Center, Greenbelt, Maryland

Frey, Richard A., Cooperative Institute for Meteorological Satellite Studies, University of Wisconsin-Madison, Madison, Wisconsin

Frith, Stacey M., Science Systems and Applications, Inc. and NASA Goddard Space Flight Center, Greenbelt, Maryland

Froidevaux, Lucien, Jet Propulsion Laboratory, California Institute of Technology, Pasadena, California

Ganter, Catherine, Bureau of Meteorology, Melbourne, Victoria, Australia

Geiger, Erick F., NOAA/NESDIS Coral Reef Watch, College Park, Maryland, and Global Science and Technology, Inc., Greenbelt, Maryland

Gerland, S., Norwegian Polar Institute, Fram Centre, Tromsø, Norway

Gilson, John, Scripps Institution of Oceanography, University of California San Diego, La Jolla, California

Gobron, Nadine, European Commission, Joint Research Centre, Ispra, Italy

Goldenberg, Stanley B., NOAA/OAR/AOML Hurricane Research Division, Miami, Florida

Gomez, Andrea M., NOAA/NESDIS Coral Reef Watch, College Park, Maryland, and Ecosystem Science Lab and NOAA-CREST, New York, New York

Goni, Gustavo, NOAA/OAR Atlantic Oceanographic and Meteorological Laboratory, Miami, Florida

Grooß, Jens-Uwe, Forschungszentrum Jülich, Jülich, Germany

Gruber, Alexander, Department of Geodesy and Geoinformation, Vienna University of Technology, Vienna, Austria; Department of Earth and Environmental Sciences, KU Leuven, Heverlee, Belgium

Guard, Charles "Chip" P., NOAA/NWS Weather Forecast Office, Guam

Gugliemin, Mario, Department of Theoretical and Applied Sciences, Insubria University, Varese, Italy

Gupta, S. K., Science Systems and Applications, Inc., Hampton, Virginia

Gutiérrez, Dimitri, Instituto del Mar del Perú, Callao, Perú

Haas, C., Alfred Wegener Institute, Helmholtz Centre for Polar and Martine Research, Bremerhaven, Germany

Hagos, S., Atmospheric Sciences and Global Change Division, Pacific Northwest National Laboratory, Richland, Washington

Hahn, Sebastian, Department of Geodesy and Geoinformation, Vienna University of Technology, Vienna, Austria

Haimberger, Leo, Department of Meteorology and Geophysics, University of Vienna, Vienna, Austria 
Hall, Brad D., NOAA/OAR Earth System Research Laboratory, Boulder, Colorado

Halpert, Michael S., NOAA/NWS Climate Prediction Center, College Park, Maryland

Hamlington, Benjamin D., Center for Coastal Physical Oceanography, Old Dominion University, Norfolk, Virginia

Hanna, E., Department of Geography, University of Lincoln, Lincoln, United Kingdom

Hansen, K., Geological Survey of Denmark and Greenland, Copenhagen, Denmark

Hanssen-Bauer, L., Norwegian Meteorological Institute, Blindern 0313, Oslo, Norway

Harris, Ian, National Centre for Atmospheric Science, University of East Anglia, Norwich, and Climatic Research Unit, School of Environmental Sciences, University of East Anglia, Norwich, United Kingdom

Hartfield, Gail, NOAA/NWS Weather Forecast Office, Raleigh, North Carolina

Heidinger, Andrew K., NOAA/NESDIS/STAR University of Wisconsin-Madison, Madison, Wisconsin

Heim, Jr., Richard R., NOAA/NESDIS National Centers for Environmental Information, Asheville, North Carolina

Helfrich, S., NOAA/NESDIS Center for Satellite Applications and Research, College Park, Maryland

Hemming, D. L., Met Office Hadley Centre, Exeter, United Kingdom; Birmingham Institute of Forest Research, Birmingham University, Birmingham, United Kingdom

Hendricks, S., Alfred Wegener Institute, Helmholtz Centre for Polar and Martine Research, Bremerhaven, Germany

Hernández, Rafael, Instituto Nacional de Meteorología e Hidrología de Venezuela (INAMEH), Caracas, Venezuela

Hernández, Sosa Marieta, Climate Center, Institute of Meteorology of Cuba, Havana, Cuba

Heron, Scott F., NOAA/NESDIS Coral Reef Watch, College Park, Maryland, and ReefSense Pty Ltd, Townsville, Queensland, Australia

Heuzé, C., Department of Marine Sciences, University of Gothenburg, Sweden

Hidalgo, Hugo G., Center for Geophysical Research and School of Physics, University of Costa Rica, San José, Costa Rica

Ho, Shu-peng (Ben), COSMIC, UCAR, Boulder, Colorado

Hobbs, William R., Antarctic Climate and Ecosystems Cooperative Research Centre, University of Tasmania, Tasmania, Australia

Horstkotte, T., Department of Ecology and Environmental Sciences, Umeå University, Umeå, Sweden

Huang, Boyin, NOAA/NESDIS National Centers for Environmental Information, Asheville, North Carolina

Hubert, Daan, Royal Belgian Institute for Space Aeronomy (BIRA), Brussels, Belgium

Hueuzé, Céline, Department of Marine Sciences, University of Gothenburg, Gothenburg, Gothenburg, Sweden

Hurst, Dale F., Cooperative Institute for Research in Environmental Sciences, University of Colorado Boulder, and NOAA/OAR Earth System Research Laboratory, Boulder, Colorado
Ialongo, Iolanda, Finnish Meteorological Institute, Helsinki, Finland

Ibrahim, M. M., Department of Meteorology, Al-Azhar University, Egypt

ljampy, J. A., Nigerian Meteorological Agency, Abuja, Nigeria

Inness, Antje, European Centre for Medium-Range Weather Forecasts, Reading, United Kingdom

Isaac, Victor, Environment and Climate Change Canada, Toronto, Ontario, Canada

Isaksen, K., Norwegian Meteorological Institute, Blindern, Oslo, Norway

Ishii, Masayoshi, Climate Research Department, Meteorological Research Institute, Japan Meteorological Agency, Tsukuba, Japan

Jacobs, Stephanie J., Bureau of Meteorology, Melbourne, Victoria, Australia

Jeffries, Martin O., Office of Naval Research, Arlington, Virginia

Jevrejeva, Svetlana, National Oceanography Centre, Liverpool, United Kingdom

Jiménez, C., Estellus, Paris, France

Jin, Xiangze, Woods Hole Oceanographic Institution, Woods Hole, Massachusetts

John, Viju, EUMETSAT, Darmstadt, Germany, and Met Office Hadley Centre, Exeter, United Kingdom

Johns, William E., Rosenstiel School of Marine and Atmospheric Science, Miami, Florida

Johnsen, Bjørn, Norwegian Radiation Protection Authority, Østerås, Norway

Johnson, Bryan, NOAA/OAR Earth System Research Laboratory, Global Monitoring Division, and University of Colorado Boulder, Boulder, Colorado

Johnson, Gregory C., NOAA/OAR Pacific Marine Environmental Laboratory, Seattle, Washington

Johnson, Kenneth S., Monterey Bay Aquarium Research Institute, Moss Landing, California

Jones, Philip D., Climatic Research Unit, School of Environmental Sciences, University of East Anglia, Norwich, United Kingdom

Jumaux, Guillaume, Météo France, Direction Interrégionale pour l'Océan Indien, Réunion

Kabidi, Khadija, Direction de la Météorologie Nationale Maroc, Rabat, Morocco

Kaiser, J. W., Max Planck Institute for Chemistry, Mainz, Germany

Karaköylü, Erdem M., NASA Goddard Space Flight Center, Greenbelt, Maryland, and Science Application International Corporation, Beltsville, Maryland

Kato, Seiji, NASA Langley Research Center, Hampton, Virginia

Kazemi, A., Islamic Republic of Iranian Meteorological Organization, Iran

Keller, Linda M., Department of Atmospheric and Oceanic Sciences, University of Wisconsin-Madison, Madison, Wisconsin

Kennedy, John, Met Office Hadley Centre, Exeter, United Kingdom 
Kerr, Kenneth, Trinidad and Tobago Meteorological Service, Piarco, Trinidad

Khan, M. S., Geological Survey of Denmark and Greenland, Copenhagen, Denmark

Kholodov, A. L., Geophysical Institute, University of Alaska Fairbanks, Fairbanks, Alaska

Khoshkam, Mahbobeh, Islamic Republic of Iranian Meteorological Organization, Iran

Killick, Rachel, Met Office Hadley Centre, Exeter, United Kingdom

Kim, Hyungjun, Institute of Industrial Science, University of Tokyo, Japan

Kim, S.-J., Korea Polar Research Institute, Incheon, Republic of Korea

Klotzbach, Philip J., Department of Atmospheric Science, Colorado State University, Fort Collins, Colorado

Knaff, John A., NOAA/NESDIS Center for Satellite Applications and Research, Fort Collins, Colorado

Kohler, J., Norwegian Polar Institute, Tromsø, Norway

Korhonen, Johanna, Freshwater Centre, Finnish Environment Institute (SYKE), Helsinki, Finland

Korshunova, Natalia N., All-Russian Research Institute of Hydrometeorological Information - World Data Center, Obninsk, Russia

Kramarova, Natalya, NASA Goddard Space Flight Center, Greenbelt, Maryland

Kratz, D. P., NASA Langley Research Center, Hampton, Virginia

Kruger, Andries, South African Weather Service, Pretoria, South Africa

Kruk, Michael C., ERT, Inc., NOAA/NESDIS National Centers for Environmental Information, Asheville, North Carolina

Krumpen, T., Alfred Wegener Institute, Helmholtz Centre for Polar and Martine Research, Bremerhaven, Germany

Ladd, C., NOAA/OAR Pacific Marine Environmental Laboratory, Seattle, Washington

Lakatos, Mónika, Climatology Division, Hungarian Meteorological Service, Budapest, Hungary

Lakkala, Kaisa, Finnish Meteorological Institute, Arctic Research Centre, Sodankylä, Finland

Lander, Mark A., University of Guam, Mangilao, Guam

Landschützer, Peter, Max Planck Institute for Meteorology, Hamburg, Germany

Landsea, Chris W., NOAA/NWS National Hurricane Center, Miami, Florida

Lankhorst, Matthias, Scripps Institution of Oceanography, University of California, San Diego, La Jolla, California

Lavado-Casimiro, Waldo, Servicio Nacional de Meteorología e Hidrología del Perú, Lima, Perú

Lazzara, Matthew A., Department of Physical Sciences, School of Arts and Sciences, Madison Area Technical College, and Space Science and Engineering Center, University of Wisconsin-Madison, Madison, Wisconsin

Lee, S.-E., Korea Meteorological Administration, South Korea

Lee, T. C., Hong Kong Observatory, Hong Kong, China
Leuliette, Eric, NOAA/NWS NCWCP Laboratory for Satellite Altimetry, College Park, Maryland

L'Heureux, Michelle, NOAA/NWS Climate Prediction Center, College Park, Maryland

Li, Bailing, Hydrological Sciences Laboratory, NASA Goddard Space Flight Center, Greenbelt, Maryland; Earth System Science Interdisciplinary Center, University of Maryland, College Park, Maryland

Li, Tim, Department of Atmospheric Sciences, Universtiy of Hawaii, Honolulu, Hawaii

Lieser, Jan L., Antarctic Climate and Ecosystems Cooperative Research Centre and Institute for Marine and Antarctic Studies, University of Tasmania, Hobart, Tasmania, Australia

Lin, I.-I., National Taiwan University, Taipei, Taiwan

Liu, Gang, NOAA/NESDIS Coral Reef Watch, College Park, Maryland, and Global Science and Technology, Inc., Greenbelt, Maryland

Liu, Hongxing, Department of Geography, University of Cincinnati, Cincinnati, Ohio

Locarnini, Ricardo, NOAA/NESDIS National Centers for Environmental Information, Silver Spring, Maryland

Loeb, Norman G., NASA Langley Research Center, Hampton, Virginia

Long, Craig S., NOAA/NWS National Centers for Environmental Prediction, College Park, Maryland

López, Luis A., Instituto de Hidrología, Meteorología y Estudios Ambientales de Colombia, Bogotá, Colombia

Lorrey, Andrew M., National Institute of Water and Atmospheric Research, Ltd., Auckland, New Zealand

Loyola, Diego, German Aerospace Center (DLR) Oberpfaffenhofen, Wessling, Germany

Lumpkin, Rick, NOAA/OAR Atlantic Oceanographic and Meteorological Laboratory, Miami, Florida

Luo, Jing-Jia, Australian Bureau of Meteorology, Melbourne, Victoria, Australia

Luojus, K., Finnish Meteorological Institute, Helsinki, Finland

Luthcke, S., NASA Goddard Space Flight Center, Greenbelt, Maryland

Lyman, John M., NOAA/OAR Pacific Marine Environmental Laboratory, Seattle, Washington, and Joint Institute for Marine and Atmospheric Research, University of Hawaii, Honolulu, Hawaii

Macias-Fauria, M., School of Geography and the Environment, University of Oxford, Oxford, United Kingdom

Malkova, G. V., Earth Cryosphere Institute, Tyumen Science Center, Tyumen, Russia

Manney, Gloria L., NorthWest Research Associates, and New Mexico Institute of Mining and Technology, Socorro, New Mexico

Marcellin, Vernie, Dominica Meteorological Service, Dominica

Marchenko, S. S., Geophysical Institute, University of Alaska Fairbanks, Fairbanks, Alaska

Marengo, José A., Centro Nacional de Monitoramento e Alertas aos Desastres Naturais, Cachoeira Paulista, Sao Paulo, Brazil 
Marín, Dora, Servicio Nacional de Meteorología e Hidrología de Perú, Lima, Perú

Marra, John J., NOAA/NESDIS National Centers for Environmental Information, Honolulu, Hawaii

Marsh, Benjamin L., NOAA/NESDIS Coral Reef Watch, College Park, Maryland, and ReefSense Pty Ltd, Townsville, Queensland, Australia

Marszelewski, Wlodzimierz, Department of Hydrology and Water Management, Nicolaus Copernicus University, Toruń, Poland

Martens, B., Laboratory of Hydrology and Water Management, Ghent University, Ghent, Belgium

Martin, A., Department of Zoology, University of Oxford, Oxford, United Kingdom

Martínez, Alejandra G., Instituto Geofísico del Perú, Lima, Perú

Martínez-Güingla, Rodney, Centro Internacional para la Investigación del Fenómeno de El Niño, Guayaquil, Ecuador

Martínez-Sánchez, Odalys, NOAA/NWS San Juan, Puerto Rico

Massom, Robert A., Australian Antarctic Division, and Antarctic Climate and Ecosystems Cooperative Research Centre, University of Tasmania, Hobart, Tasmania, Australia

May, Linda, Centre for Ecology and Hydrology, Edinburgh, United Kingdom

Mayer, Michael, Department of Meteorology and Geophysics, University of Vienna, Vienna, Austria; European Centre for Medium-Range Weather Forecasts, Reading, United Kingdom

Mazloff, Matthew, Scripps Institution of Oceanography, University of California, San Diego, La Jolla, California

McBride, Charlotte, South African Weather Service, Pretoria, South Africa

McCabe, M. F., Water Desalination and Reuse Center, Division of Biological and Environmental Sciences and Engineering, King Abdullah University of Science and Technology, Thuwal, Saudi Arabia

McCarthy, Mark, Met Office Hadley Centre, Exeter, United Kingdom

McVicar, Tim R., CSIRO Land and Water Flagship, Canberra, Australian Capital Territory, and Australian Research Council Centre of Excellence for Climate System Science, Sydney, New South Wales, Australia

Mears, Carl A., Remote Sensing Systems, Santa Rosa, California

Meier, W., National Snow and Ice Data Center, University of Colorado, Boulder, Boulder, Colorado

Meijers, Andrew J. S., British Antarctic Survey, Cambridge, United Kingdom

Mekonnen, Ademe, Department of Energy and Environmental Systems, North Carolina A \& T State University, Greensboro, North Carolina

Mengistu Tsidu, G., Department of Earth and Environmental Sciences, Botswana International University of Science and Technology, Palapye, Botswana, and Department of Physics, Addis Ababa University, Addis Ababa, Ethiopia
Menzel, W. Paul, Space Science and Engineering Center, University of Wisconsin-Madison, Madison, Wisconsin

Merchant, Christopher J., Department of Meteorology, University of Reading, Reading, and National Centre for Earth Observation, University of Reading, Reading, United Kingdom

Meredith, Michael P., British Antarctic Survey, Cambridge, United Kingdom

Merrifield, Mark A., Joint Institute for Marine and Atmospheric Research, University of Hawaii, Honolulu, Hawaii

Miller, Ben, Cooperative Institute for Research in Environmental Sciences, University of Colorado Boulder, and NOAA/OAR Earth System Research Laboratory, Boulder, Colorado

Miralles, Diego G., Laboratory of Hydrology and Water Management, Ghent University, Ghent, Belgium

Mitchum, Gary T., College of Marine Science, University of South Florida, St. Petersburg, Florida

Mitro, Sukarni, Meteorological Service Suriname, Paramaribo, Suriname

Moat, Ben, National Oceanography Centre, Southampton, United Kingdom

Mochizuki, Y., Tokyo Climate Center, Japan Meteorological Agency, Japan

Monselesan, Didier, CSIRO Oceans and Atmosphere, Hobart, Tasmania, Australia

Montzka, Stephen A., NOAA/OAR Earth System Research Laboratory, Boulder, Colorado

Mora, Natalie, Center for Geophysical Research and School of Physics, University of Costa Rica, San José, Costa Rica

Morice, Colin, Met Office Hadley Centre, Exeter, United Kingdom

Mosquera-Vásquez, Kobi, Instituto Geofísico del Perú, Lima, Perú

Mostafa, Awatif E., Department of Seasonal Forecast and Climate Research, Cairo Numerical Weather Prediction, Egyptian Meteorological Authority, Cairo, Egypt

Mote, T., Department of Geography, University of Georgia, Athens, Georgia

Mudryk, L., Climate Research Division, Environment and Climate Change Canada, Downsview, Ontario, Canada

Mühle, Jens, Scripps Institution of Oceanography, University of California, San Diego, La Jolla, California

Mullan, A. Brett, National Institute of Water and Atmospheric Research, Ltd., Wellington, New Zealand

Müller, Rolf, Forschungszentrum Jülich, Jülich, Germany

Myneni, R., Department of Earth and Environment, Boston University, Boston, Massachusetts

Nash, Eric R., Science Systems and Applications, Inc., Lanham, Maryland

Nerem, R. Steven, Colorado Center for Astrodynamics Research, Cooperative Institute for Research in Environmental Sciences, University of Colorado Boulder, Boulder, Colorado 
Newman, L., SOOS International Project Office, Institute for Marine and Antarctic Studies, University of Tasmania, Hobart, Australia.

Newman, Paul A., NASA Goddard Space Flight Center, Greenbelt, Maryland

Nielsen-Gammon, John W., Texas A\&M University, College Station, Texas

Nieto, Juan José, Centro Internacional para la Investigación del Fenómeno de El Niño, Guayaquil, Ecuador

Noetzli, Jeannette, WSL Institute for Snow and Avalanche Research, Davos, Switzerland

Noll, Ben E., National Institute of Water and Atmospheric Research, Ltd., (NIWA), Auckland, New Zealand

O'Neel, S., USGS, Alaska Science Center, Anchorage, Alaska

Osborn, Tim J., Climatic Research Unit, School of Environmental Sciences, University of East Anglia, Norwich, United Kingdom

Osborne, Emily, NOAA/OAR Arctic Research Program, Silver Spring, Maryland

Overland, J., NOAA/OAR Pacific Marine Environmental Laboratory, Seattle, Washington

Oyunjargal, Lamjav, Hydrology and Environmental Monitoring, Institute of Meteorology and Hydrology, National Agency for Meteorology, Ulaanbaatar, Mongolia

Park, T., Department of Earth and Environment, Boston University, Boston, Massachusetts

Pasch, Richard J., NOAA/NWS National Hurricane Center, Miami, Florida

Pascual-Ramírez, Reynaldo, National Meteorological Service of Mexico, Mexico

Pastor Saavedra, Maria Asuncion, Agencia Estatal de Meteorología, Madrid, Spain

Paterson, Andrew M., Dorset Environmental Science Centre, Ontario Ministry of the Environment and Climate Change, Dorset, Ontario, Canada

Paulik, Christoph, VanderSat B.V., Haarlem, the Netherlands

Pearce, Petra R., National Institute of Water and Atmospheric Research, Ltd., Auckland, New Zealand

Peltier, Alexandre, Météo-France en Nouvelle-Cáledonie, Noumea, Caledonia

Pelto, Mauri S., Nichols College, Dudley, Massachusetts

Peng, Liang, State University of New York, Albany, New York

Perkins-Kirkpatrick, Sarah E., Climate Change Research Centre, University of New South Wales, Sydney, New South Wales, Australia

Perovich, Don, Thayer School of Engineering, Dartmouth College, Hanover, New Hampshire

Petropavlovskikh, Irina, Cooperative Institute for Research in Environmental Sciences, University of Colorado Boulder, and NOAA/OAR Earth System Research Laboratory, Boulder, Colorado

Pezza, Alexandre B., Greater Wellington Regional Council, Wellington, New Zealand

Phillips, C., Department of Atmospheric and Oceanic Sciences, University of Wisconsin-Madison, Madison, Wisconsin
Phillips, David, Environment and Climate Change Canada, Toronto, Ontario, Canada

Phoenix, G., Department of Animal and Plant Sciences, University of Sheffield, Sheffield, United Kingdom

Pinty, Bernard, European Commission, Joint Research Centre, Ispra, Italy

Pinzon, J., NASA Goddard Space Flight Center, Greenbelt, Maryland

Po-Chedley, S., Lawrence Livermore National Laboratory, Livermore, California

Polashenski, C., USACE, ERDC, Cold Regions Research and Engineering Laboratory, and Thayer School of Engineering, Dartmouth College, Hanover, New Hampshire

Purkey, Sarah G., Scripps Institution of Oceanography, University of California, San Diego, La Jolla, California

Quispe, Nelson, Servicio Nacional de Meteorología e Hidrología del Perú, Lima, Perú

Rajeevan, Madhavan, Earth System Science Organization, Ministry of Earth Sciences, New Delhi, India

Rakotoarimalala, C., Madagascar Meteorological Service, Antananarivo, Madagascar

Rayner, Darren, National Oceanography Centre, Southampton, United Kingdom

Raynolds, M. K., Institute of Arctic Biology, University of Alaska Fairbanks, Fairbanks, Alaska

Reagan, James, Earth System Science Interdisciplinary Center/ Cooperative Institute for Climate and Satellites-Maryland, University of Maryland, College Park, Maryland, and NOAA/ NESDIS National Centers for Environmental Information, Silver Spring, Maryland

Reid, Phillip, Australian Bureau of Meteorology, and Antarctic Climate and Ecosystems Cooperative Research Centre, Hobart, Tasmania, Australia

Reimer, Christoph, EODC, Vienna, Austria

Rémy, Samuel, Institut Pierre-Simon Laplace, CNRS / UPMC, Paris, France

Revadekar, Jayashree V., Indian Institute of Tropical Meteorology, Pune, India

Richardson, A. D., School of Informatics, Computing and Cyber Systems and Center for Ecosystem Science and Society, Northern Arizona University, Flagstaff, Arizona

Richter-Menge, Jacqueline, University of Alaska Fairbanks, Fairbanks, Alaska

Ricker, R., Alfred Wegener Institute, Helmholtz Centre for Polar and Marine Research, Bremerhaven, Germany

Rimmer, Alon, Yigal Allon Kinneret Limnological Laboratory, Israel Oceanographic and Limnological Research, Migdal, Israel

Robinson, David A., Department of Geography, Rutgers University, Piscataway, New Jersey

Rodell, Matthew, Hydrological Sciences Laboratory, NASA Goddard Space Flight Center, Greenbelt, Maryland

Rodriguez Camino, Ernesto, Agencia Estatal de Meteorología, Madrid, Spain

Romanovsky, Vladimir E., Geophysical Institute, University of Alaska Fairbanks, Fairbanks, Alaska 
Ronchail, Josyane, Université Paris Diderot/Laboratoire L'OCEAN-IPSL, Paris, France

Rosenlof, Karen H., NOAA/OAR Earth System Research Laboratory, Boulder, Colorado

Rösner, Benjamin, Laboratory for Climatology and Remote Sensing, Faculty of Geography, University of Marburg, Marburg, Germany

Roth, Chris, University of Saskatchewan, Saskatoon, Saskatchewan, Canada

Roth, David Mark, NOAA/NWS Weather Prediction Center, College Park, Maryland

Rusak, James A., Dorset Environmental Science Centre, Ontario Ministry of the Environment and Climate Change, Dorset, Ontario, Canada

Rutishäuser, T., Swiss Academies of Arts and Science, Berne, Switzerland

Sallée, Jean-Bapiste, Sorbonne Universités, L'OCEAN-IPSL, Paris, France, and British Antarctic Survey, Cambridge, United Kingdom

Sánchez-Lugo, Ahira, NOAA/NESDIS National Centers for Environmental Information, Asheville, North Carolina

Santee, Michelle L., Jet Propulsion Laboratory, California Institute of Technology, Pasadena, California

Sasgen, L., Climate Sciences Department, Alfred Wegener Institute, Bremerhaven, Germany

Sawaengphokhai, P., Science Systems and Applications, Inc., Hampton, Virginia

Sayad, T. A., Department of Meteorology, Al-Azhar University, Egypt

Sayouri, Amal, Direction de la Météorologie Nationale Maroc, Rabat, Morocco

Scambos, Ted A., National Snow and Ice Data Center, University of Colorado Boulder, Boulder, Colorado

Scanlon, T., Department of Geodesy and Geoinformation, Vienna University of Technology, Vienna, Austria

Schenzinger, Verena, Department of Meteorology and Geophysics, University of Vienna, Austria

Schladow, S. Geoffrey, Tahoe Environmental Research Center, University of California at Davis, Davis, California

Schmid, Claudia, NOAA/OAR Atlantic Oceanographic and Meteorological Laboratory, Miami, Florida

Schmid, Martin, Eawag, Swiss Federal Institute of Aquatic Science and Technology, Kastanienbaum, Switzerland

Schreck III, Carl J., North Carolina State University, Cooperative Institute for Climate and Satellites-North Carolina, Asheville, North Carolina

Selkirk, H. B., Universities Space Research Association, NASA Goddard Space Flight Center, Greenbelt, Maryland

Send, Uwe, Scripps Institution of Oceanography, University of California, San Diego, La Jolla, California

Sensoy, Serhat, Turkish State Meteorological Service, Ankara, Turkey

Sharp, M., Department of Earth and Atmospheric Sciences, University of Alberta, Edmonton, Alberta, Canada

Shi, Lei, NOAA/NESDIS National Centers for Environmental Information, Asheville, North Carolina
Shiklomanov, Nikolai I., Department of Geography, George Washington University, Washington, D.C.

Shimaraeva, Svetlana V., Institute of Biology, Irkutsk State University, Russia

Siegel, David A., University of California-Santa Barbara, Santa Barbara, California

Silow, Eugene, Institute of Biology, Irkutsk State University, Russia

Sima, Fatou, Division of Meteorology, Department of Water Resources, Banjul, The Gambia

Simmons, Adrian J., European Centre for Medium-Range Weather Forecasts, Reading, United Kingdom

Skirving, William J., NOAA/NESDIS Coral Reef Watch, College Park, Maryland, and ReefSense Pty Ltd, Townsville, Queensland, Australia

Smeed, David A., National Oceanography Centre, Southampton, United Kingdom

Smeets, C. J. P. P., Institute for Marine and Atmospheric Research Utrecht, Utrecht University, Utrecht, Netherlands

Smith, Adam, NOAA/NESDIS National Centers for Environmental Information, Asheville, North Carolina

Smith, Sharon L., Geological Survey of Canada, Natural Resources Canada, Ottawa, Ontario, Canada

Soden, B., Rosenstiel School of Marine and Atmospheric Science, University of Miami, Key Biscane, Miami, Florida

Sofieva, Viktoria, Finnish Meteorological Institute (FMI), Helsinki, Finland

Sparks, T. H., Coventry University, Coventry, United Kingdom

Spence, Jacqueline M., Meteorological Service, Jamaica, Kingston, Jamaica

Spillane, Sandra, Met Éireann, Irish Meteorological Service, Dublin, Ireland

Srivastava, A. K., India Meteorological Department, Jaipur, India

Stackhouse, Jr., Paul W., NASA Langley Research Center, Hampton, Virginia

Stammerjohn, Sharon, Institute of Arctic and Alpine Research, University of Colorado Boulder, Boulder, Colorado

Stanitski, Diane M., NOAA/OAR Earth System Research Laboratory, Boulder, Colorado

Steinbrecht, Wolfgang, German Weather Service (DWD), Hohenpeissenberg, Germany

Stella, José L., Servicio Meteorológico Nacional, Buenos Aires, Argentina

Stengel, M., Deutscher Wetterdienst, Offenbach, Germany

Stephenson, Kimberly, Department of Physics,

The University of the West Indies, Jamaica

Stephenson, Tannecia S., Department of Physics, The University of West Indies, Jamaica

Strahan, Susan, Universities Space Research Association, NASA Goddard Space Flight Center, Greenbelt, Maryland

Streletskiy, Dimitri A., Department of Geography, George Washington University, Washington, D.C.

Strong, Alan E., NOAA/NESDIS Coral Reef Watch, College Park, Maryland, and Global Science and Technology, Inc., Greenbelt, Maryland 
Sun-Mack, Sunny, Science Systems and Applications, Inc., Hampton, Virginia

Sutton, Adrienne J., NOAA/OAR Pacific Marine Environmental Laboratory, Seattle, Washington

Swart, Sebastiaan, Department of Marine Sciences, University of Gothenburg, Gothenburg, Sweden, and Department of Oceanography, University of Cape Town, Rondebosch, South Africa

Sweet, William, NOAA/NOS Center for Operational Oceanographic Products and Services, Silver Spring, Maryland

Takahashi, Kenneth S., Servicio Nacional de Meteorología e Hidrología del Perú, Lima, Perú

Tamar, Gerard, Grenada Airports Authority, St. George's, Grenada

Taylor, Michael A., Department of Physics, The University of the West Indies, Jamaica

Tedesco, M., Lamont-Doherty Earth Observatory, Columbia University, Palisades, New York, and NASA Goddard Institute of Space Studies, New York, New York

Thackeray, S. J., Centre for Ecology and Hydrology, Lancaster, United Kingdom

Thoman, R. L., NOAA/National Weather Service, Alaska Region, Fairbanks, Alaska

Thompson, Philip, Joint Institute for Marine and Atmospheric Research, University of Hawaii, Honolulu, Hawaii

Thomson, L., Department of Earth Sciences, Simon Fraser University, Burnaby, British Columbia, Canada

Thorsteinsson, T., Icelandic Meteorological Office, Reykjavik, Iceland

Timbal, Bertrand, Singapore Meteorological Service, Singapore

Timmermans, M.-L., Yale University, New Haven, Connecticut

TImofeyev, Maxim A., Institute of Biology, Irkutsk State University, Russia

Tirak, Kyle V., NOAA/NESDIS Coral Reef Watch, College Park, Maryland, and Global Science and Technology, Inc., Greenbelt, Maryland

Tobin, Skie, Bureau of Meteorology, Melbourne, Victoria, Australia

Togawa, H., Tokyo Climate Center, Japan Meteorological Agency, Japan

Tømmervik, H., Norwegian Institute for Nature Research, Tromsø, Norway

Tourpali, Kleareti, Aristotle University, Thessaloniki, Greece

Trachte, Katja, Laboratory for Climatology and Remote Sensing, Faculty of Geography, University of Marburg, Marburg, Germany

Trewin, Blair C., Australian Bureau of Meteorology, Melbourne, Victoria, Australia
Triñanes, Joaquin A., Laboratory of Systems, Technological Research Institute, Universidad de Santiago de Compostela, Santiago de Compostela, Spain, and NOAA Atlantic Oceanographic and Meteorological Laboratory, and Cooperative Institute for Marine and Atmospheric Studies, Rosenstiel School of Marine and Atmospheric Science, University of Miami, Miami, Florida

Trotman, Adrian R., Caribbean Institute for Meteorology and Hydrology, Bridgetown, Barbados

Tschudi, M., Aerospace Engineering Sciences, University of Colorado, Boulder, Boulder, Colorado

Tucker, C. J., NASA Goddard Space Flight Center, Greenbelt, Maryland

Tye, Mari R., Capacity Center for Climate and Weather Extremes (C3WE), National Center for Atmospheric Research, Boulder, Colorado

van As, D., Geological Survey of Denmark and Greenland, Copenhagen, Denmark

van de Wal, R. S. W., Institute for Marine and Atmospheric Research Utrecht, Utrecht University, Utrecht, Netherlands

van der A, Ronald J., Royal Netherlands Meteorological Institute (KNMI), De Bilt, Netherlands

van der Schalie, Robin, VanderSat B.V., Haarlem, Netherlands

van der Schrier, Gerard, Royal Netherlands Meteorological Institute (KNMI), De Bilt, Netherlands

van der Werf, Guido R., Faculty of Earth and Life Sciences, VU University Amsterdam, Netherlands

Van Meerbeeck, Cedric J., Caribbean Institute for Meteorology and Hydrology, Bridgetown, Barbados

Velden, Christopher S., Cooperative Institute for Meteorological Satellite Studies, University of WisconsinMadison, Madison, Wisconsin

Velicogna, I., University of California, Irvine, California

Verburg, Piet, National Institute of Water and Atmospheric Research, Hamilton, New Zealand

Vickers, H., Norut Northern Research Institute, Tromsø, Norway

Vincent, Lucie A., Environment and Climate Change Canada, Toronto, Ontario, Canada

Vömel, Holger, Earth Observing Laboratory, National Center for Atmospheric Research, Boulder, Colorado

Vose, Russell S., NOAA/NESDIS National Centers for Environmental Information, Asheville, North Carolina

Wagner, Wolfgang, Department of Geodesy and Geoinformation, Vienna University of Technology, Vienna, Austria

Walker, D. A., Institute of Arctic Biology, University of Alaska Fairbanks, Fairbanks, Alaska

Walsh, J., International Arctic Research Center, University of Alaska Fairbanks, Fairbanks, Alaska

Wang, Bin, Department of Atmospheric Science and IPRC, University of Hawaii, Honolulu, Hawaii

Wang, Junhong, State University of New York, Albany, New York 
Wang, Lei, Department of Geography and Anthropology, Louisiana State University, Baton Rouge, Louisiana

Wang, M., Joint Institute for the Study of the Atmosphere and Ocean, University of Washington, Seattle, Washington

Wang, Ray, Georgia Institute of Technology, Atlanta, Georgia

Wang, Sheng-Hung, Byrd Polar and Climate Research Center, The Ohio State University, Columbus, Ohio

Wanninkhof, Rik, NOAA/OAR Atlantic Oceanographic and Meteorological Laboratory, Miami, Florida

Watanabe, Shohei, Tahoe Environmental Research Center, University of California at Davis, Davis, California

Weber, Mark, University of Bremen, Bremen, Germany

Webster, M., NASA Goddard Space Flight Center, Greenbelt, Maryland

Weller, Robert A., Woods Hole Oceanographic Institution, Woods Hole, Massachusetts

Westberry, Toby K., Department of Botany and Plant Pathology, Oregon State University, Corvallis, Oregon

Weyhenmeyer, Gesa A., Department of Ecology and Genetics/Limnology, Uppsala University, Uppsala, Sweden

Whitewood, Robert, Environment and Climate Change Canada, Toronto, Ontario, Canada

Widlansky, Matthew J., Joint Institute for Marine and Atmospheric Research, University of Hawaii, Honolulu, Hawaii

Wiese, David N., Jet Propulsion Laboratory, California Institute of Technology, Pasadena, California

Wijffels, Susan E., Woods Hole Oceanographic Institution, Woods Hole, Massachusetts

Wilber, Anne C., Science Systems and Applications, Inc., Hampton, Virginia

Wild, Jeanette D., INNOVIM, NOAA Climate Prediction Center, College Park, Maryland

Willett, Kate M., Met Office Hadley Centre, Exeter, United Kingdom

Willis, Josh K., Jet Propulsion Laboratory, California Institute of Technology, Pasadena, California

Wolken, G., Alaska Division of Geological and Geophysical Surveys, and International Arctic Research Center, University of Alaska Fairbanks, Fairbanks, Alaska
Wong, Takmeng, NASA Langley Research Center, Hampton, Virginia

Wood, E. F., Department of Civil and Environmental Engineering, Princeton University, Princeton, New Jersey

Wood, K., Joint Institute for the Study of the Atmosphere and Ocean, University of Washington, Seattle, Washington

Woolway, R. Iestyn, Department of Meteorology, University of Reading, Reading, United Kingdom

Wouters, B., Institute for Marine and Atmospheric Research Utrecht, Utrecht University, Utrecht, Netherlands

Xue, Yan, NOAA/NWS National Centers for Environmental Prediction, Climate Prediction Center, College Park, Maryland

Yin, Xungang, ERT Inc., NOAA/NESDIS National Centers for Environmental Information, Asheville, North Carolina

Yoon, Huang, Department of Oceanography, University of Hawaii, Honolulu, Hawaii

York, A., Alaska Fire Science Consortium, International Arctic Research Center, University of Alaska Fairbanks, Fairbanks, Alaska

Yu, Lisan, Woods Hole Oceanographic Institution, Woods Hole, Massachusetts

Zambrano, Eduardo, Centro Internacional para la Investigación del Fenómeno El Niño, Guayaquil, Ecuador

Zhang, Huai-Min, NOAA/NESDIS National Centers for Environmental Information, Asheville, North Carolina

Zhang, Peiqun, Beijing Climate Center, Beijing, China

Zhao, Guanguo, University of Illinois at Urbana-Champaign, Urbana, Illinois

Zhao, Lin, Cold and Arid Regions Environmental and Engineering Research Institute, Lanzhou, China

Zhu, Zhiwei, Nanjing University of Information Science and Technology, China

Ziel, R., Alaska Fire Science Consortium, International Arctic Research Center, University of Alaska Fairbanks, Fairbanks, Alaska

Ziemke, Jerry R., Goddard Earth Sciences Technology and Research, Morgan State University, Baltimore, Maryland, and NASA Goddard Space Flight Center, Greenbelt, Maryland

Ziese, Markus G., Global Precipitation Climatology Center, Deutscher Wetterdienst, Offenbach am Main, Germany

\section{EDITORIAL AND PRODUCTION TEAM}

Griffin, Jessicca, Graphics Support, Cooperative Institute for Climate and Satellites-NC, North Carolina State University, Asheville, North Carolina

Hammer, Gregory, Content Team Lead, Communications and Outreach, NOAA/NESDIS National Centers for Environmental Information, Asheville, North Carolina

Love-Brotak, S. Elizabeth, Lead Graphics Production, NOAA/NESDIS National Centers for Environmental Information, Asheville, North Carolina

Misch, Deborah J., Graphics Support, TeleSolv Consulting LLC, NOAA/NESDIS National Centers for Environmental Information, Asheville, North Carolina
Riddle, Deborah B., Graphics Support, NOAA/NESDIS

National Centers for Environmental Information, Asheville, North Carolina

Slagle, Mary, Graphics Support, TeleSolv Consulting LLC, NOAA/NESDIS National Centers for Environmental Information, Asheville, North Carolina

Sprain, Mara, Technical Editor, LAC Group, NOAA/NESDIS National Centers for Environmental Information, Asheville, North Carolina

Veasey, Sara W., Visualization Team Lead, Communications and Outreach, NOAA/NESDIS National Centers for Environmental Information, Asheville, North Carolina 
List of authors and affiliations.. ...i

Abstract. $x v i$

I. INTRODUCTION . I

Sidebar I.I: EsSential Climate VARIABLES.

2. GLOBAL CLIMATE. . .5

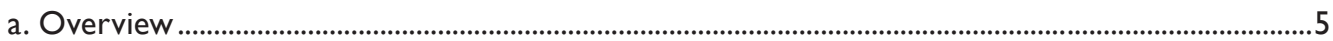

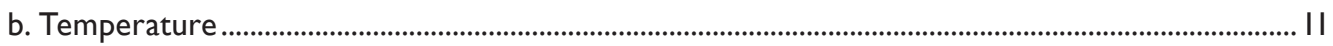

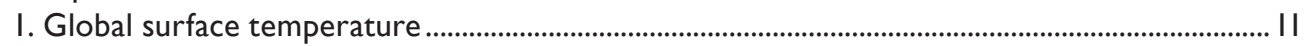

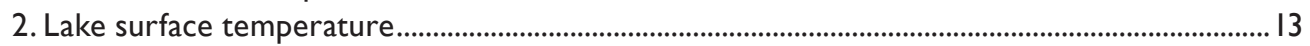

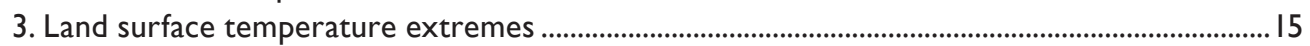

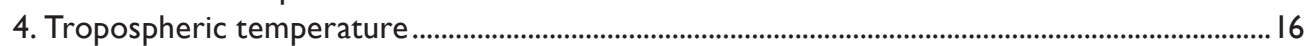

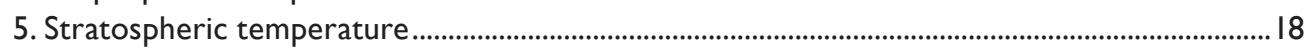

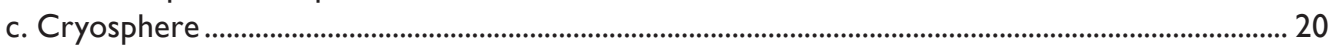

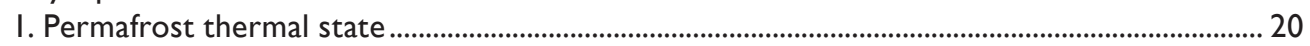

2. Northern Hemisphere continental snow cover extent................................................................. 22

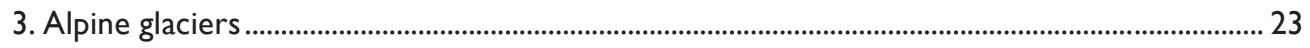

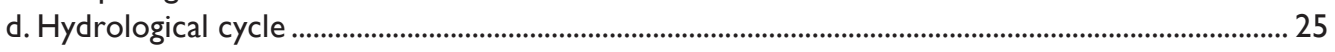

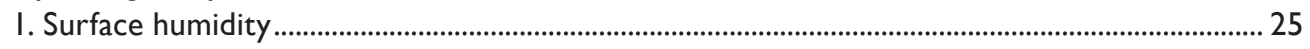

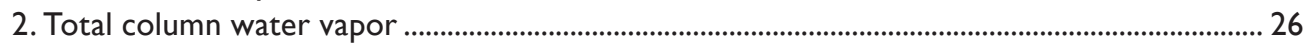

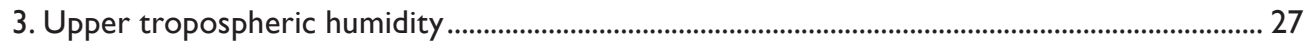

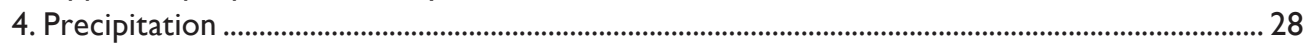

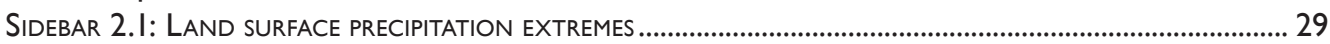

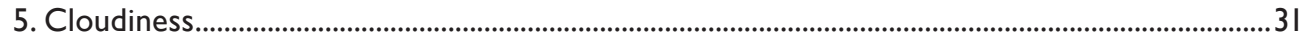

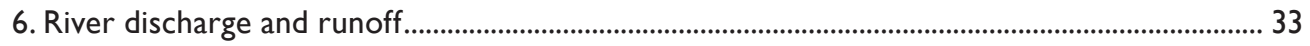

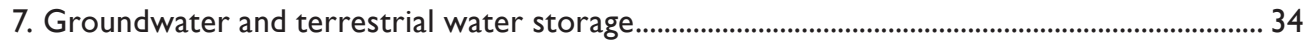

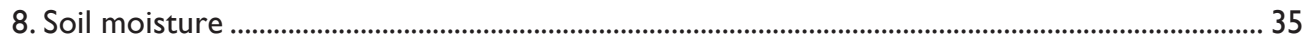

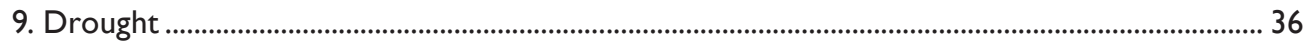

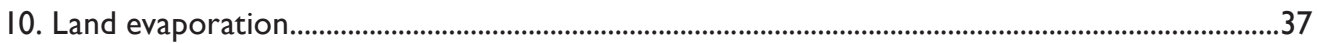

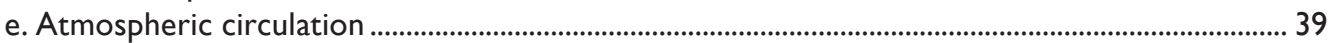

I. Mean sea level pressure and related modes of variability ............................................................ 39

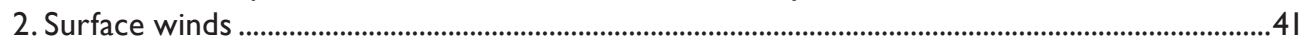

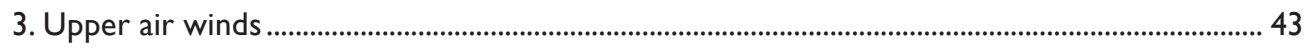

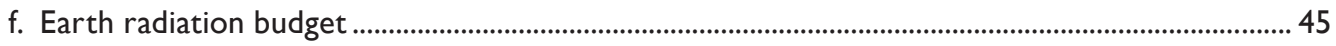

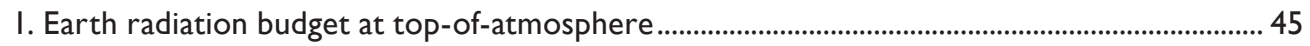

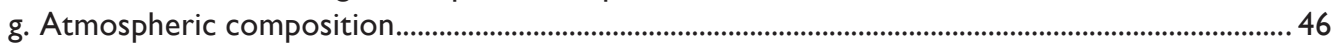

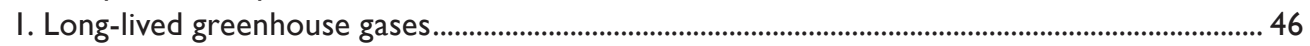

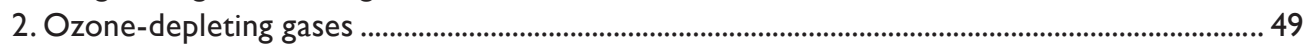

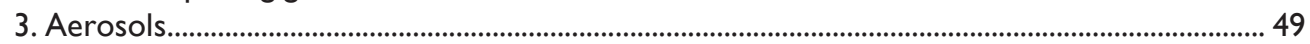

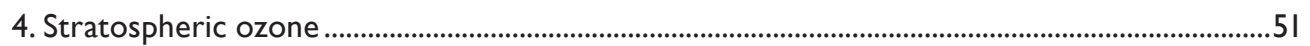

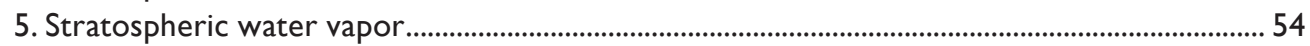

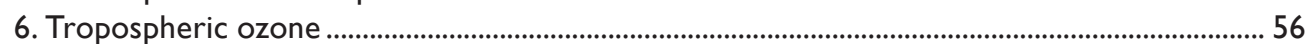

Sidebar 2.2: The Tropospheric Ozone AsSeSSMent RePORT ......................................................................5 58

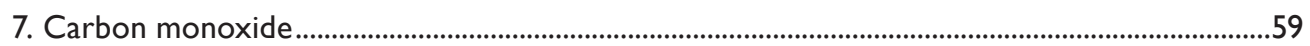

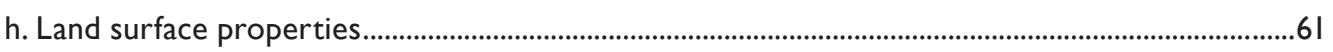

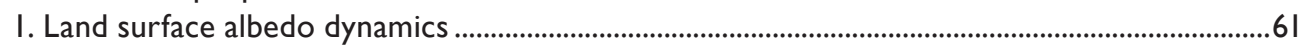

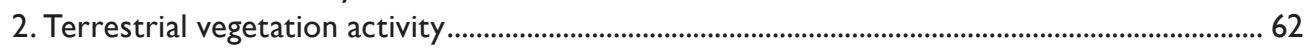

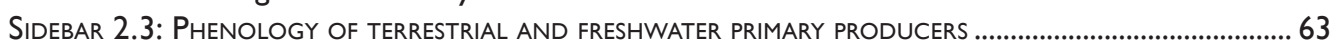

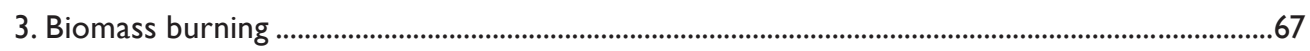




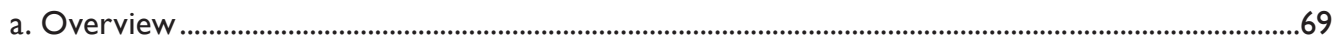

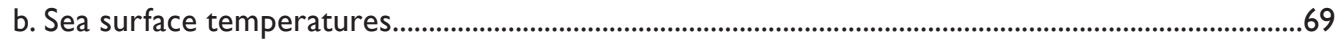

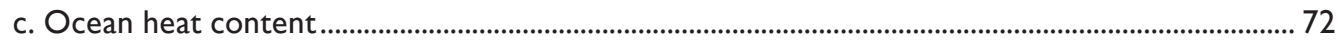

SidebAR 3.I: UNPRECEDENTED THREE YEARS OF GLOBAL CORAL BLEACHING 20I4-20I7.................................74

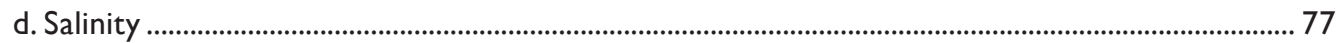

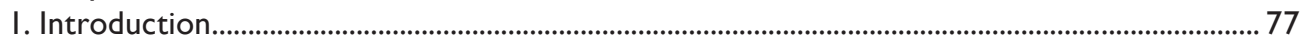

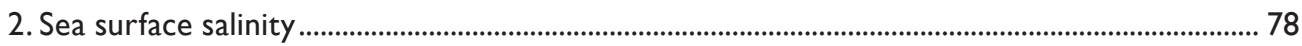

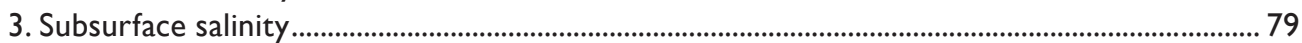

e. Global ocean heat, freshwater, and momentum fluxes .................................................................8I

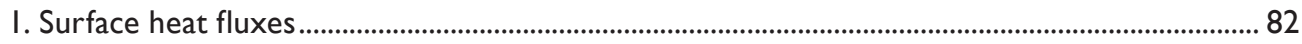

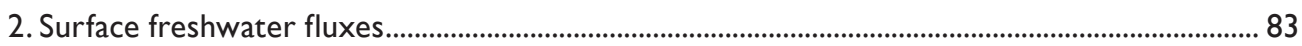

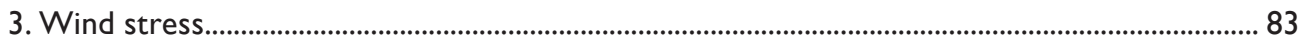

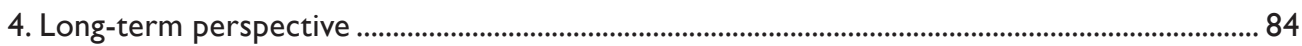

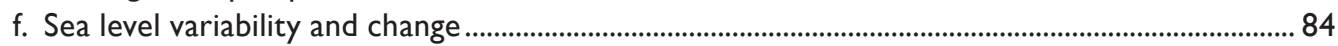

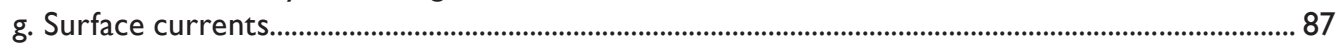

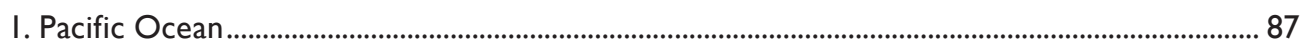

Sidebar 3.2: Nu'a Kal: Flooding in HaWall Caused by a “stack” of oceanographic processes...........88 88

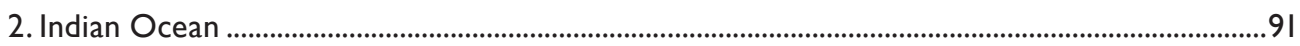

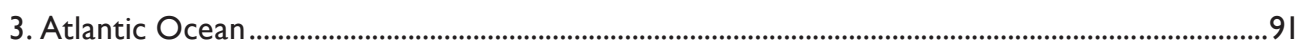

h. Meridional overturning and oceanic heat transport circulation observations in the

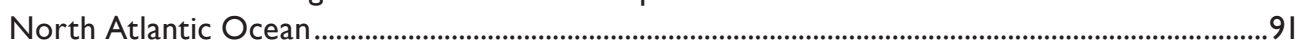

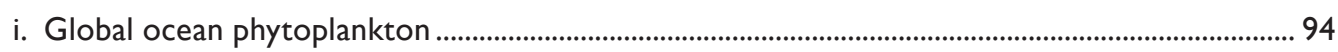

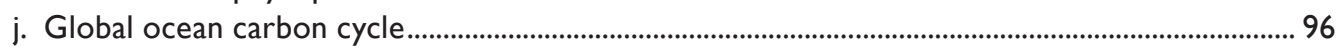

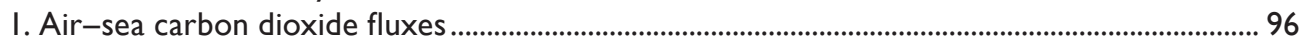

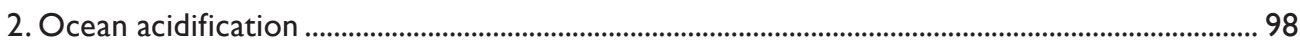

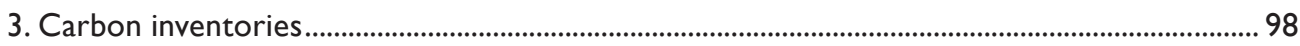

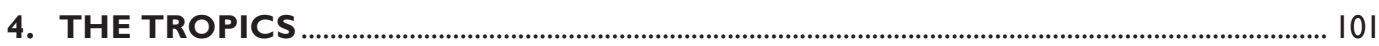

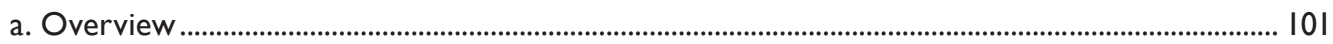

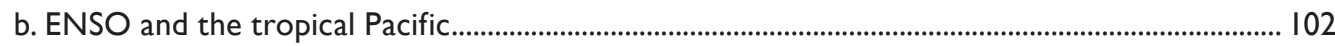

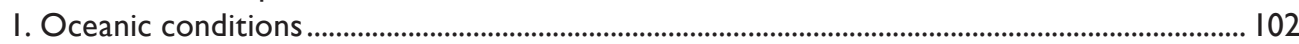

2. Atmospheric circulation: Tropics and subtropics ................................................................... 102

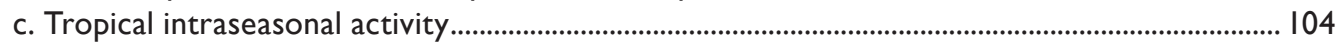

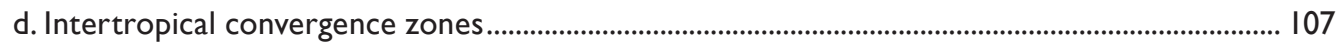

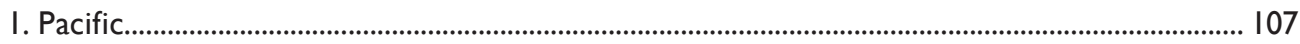

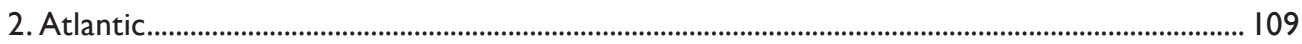

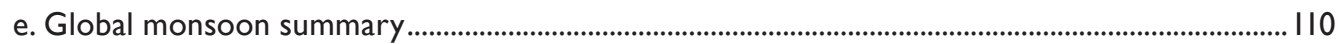

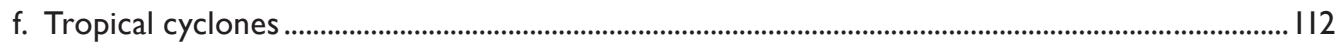

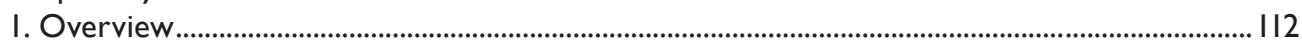

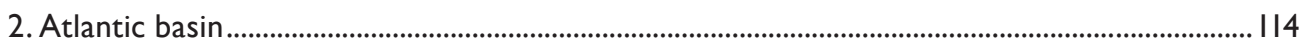

3. Eastern North Pacific and Central North Pacific basins ......................................................... II8

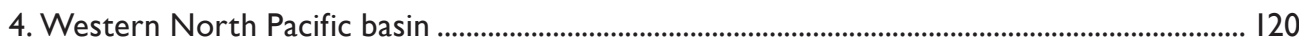

5. North Indian Ocean basin ........................................................................................................... 124

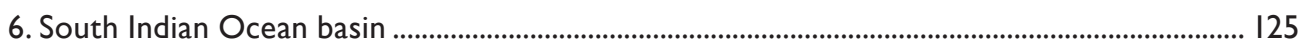

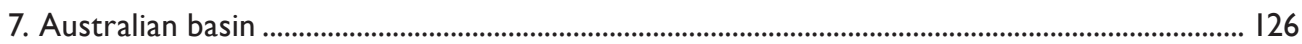

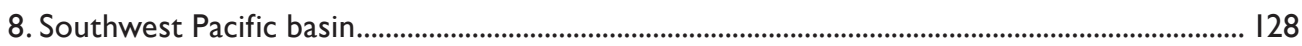

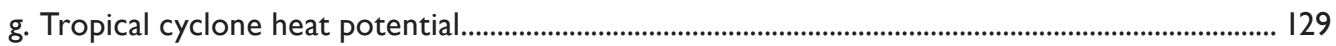

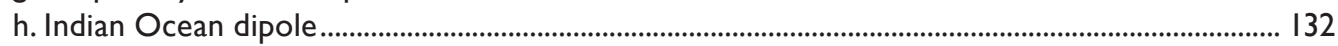

SidebAR 4.I: HURRICANE IRMA: REWRITING THE RECORD BOOKS ............................................................... I36

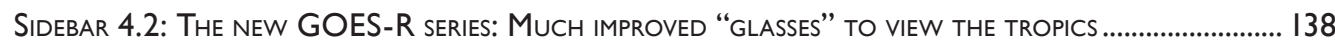

Sidebar 4.3: Hurricane Harvey: The hallmark storm of a busy and Wet 2017

HURRICANE SEASON FOR THE UNITED STATES ....................................................................................... 140 


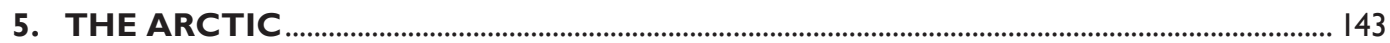

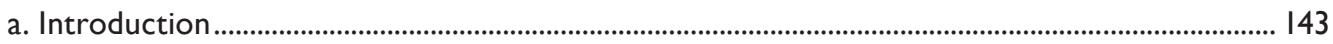

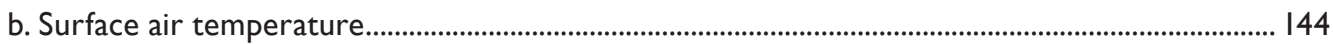

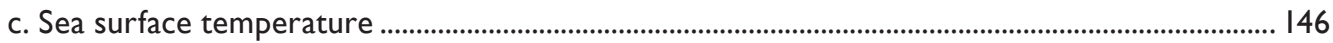

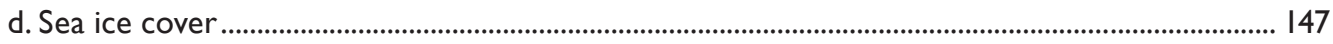

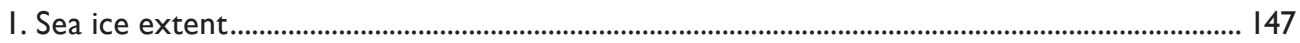

2. Age of the ice

3. Sea ice thickness and snow depth.............................................................................................. 149

Sidebar 5.I: Paleoclimate records: Providing context and understanding

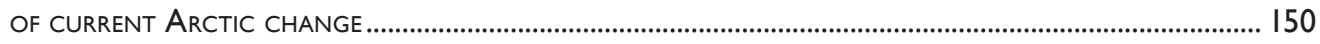

e. Greenland ice sheet...................................................................................................................... 152

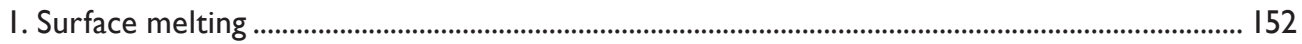

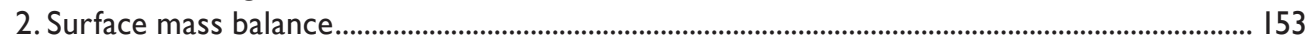

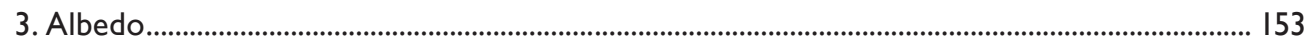

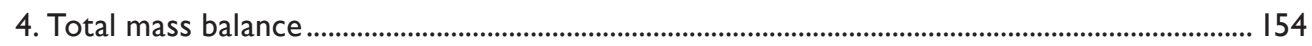

5. Marine-terminating glaciers................................................................................................... 154

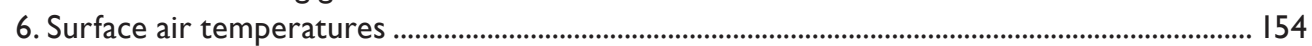

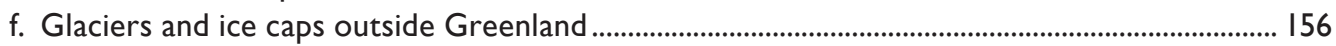

SIDEBAR 5.2: INDIGENOUS KNOWLEDGE AND THE COPRODUCTION OF KNOWLEDGE PROCESS:

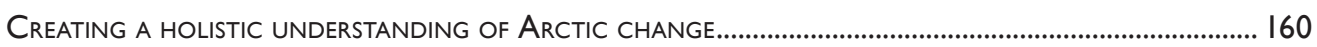

g. Terrestrial permafrost............................................................................................................. 161

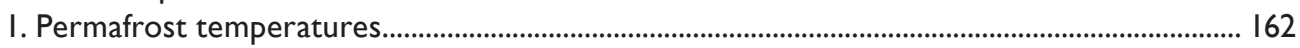

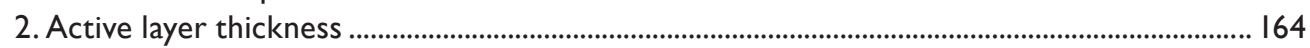

h. Tundra greenness ........................................................................................................................... 165

Sidebar 5.3: WildLand fire In boreal and ArCtic North America.................................................... 167

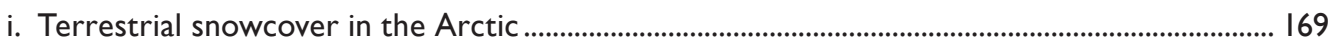

j. Ozone and UV radiation................................................................................................................. 17 I

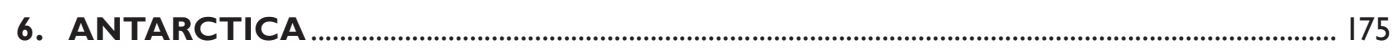

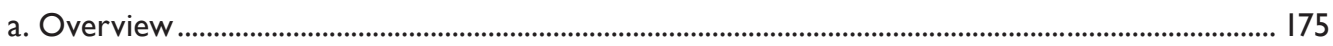

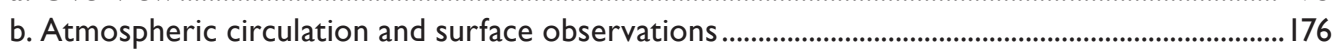

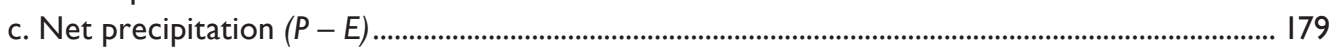

d. Seasonal melt extent and duration ................................................................................................. 181

e. Sea ice extent, concentration, and seasonality ………………………………............................... 183

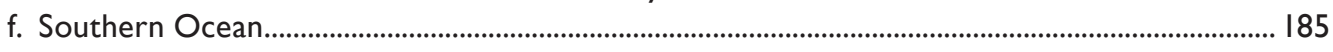

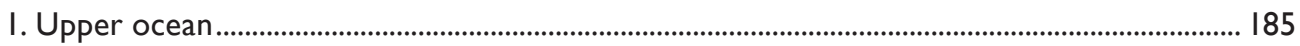

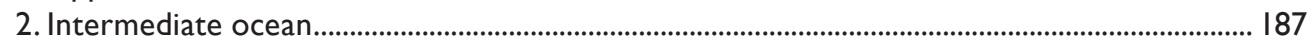

3. Biogeochemical status: Continued ocean acidification ............................................................... 187

Sidebar 6.I: Return of the Maude Rise polynya: Climate litmus or SEA ICE ANomaly? .......................... 188

g. 2017 Antarctic ozone hole............................................................................................................... 190

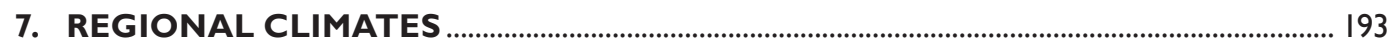

a. Overview
b. North America
I. Canada
2. United States
3. Mexico Central America and the Caribbean
I. Central America
SIDEBAR 7.I: IMPACTS FROM HURRICANES IRMA AND MARIA IN THE CARIBBEAN 


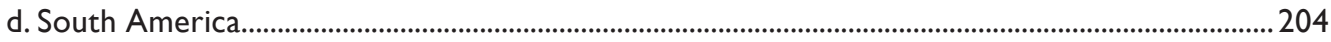

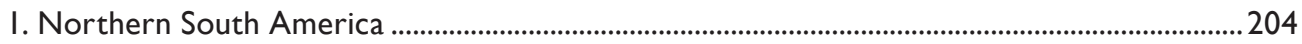

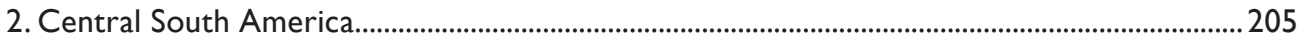

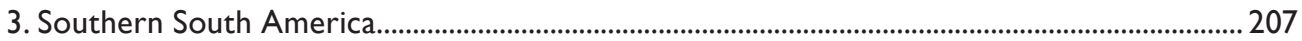

Sidebar 7.2: THE 2017 COASTAL El NiÑo

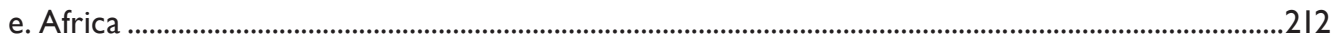

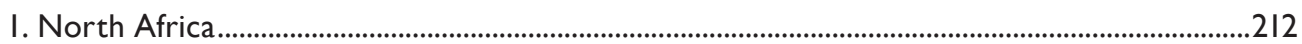

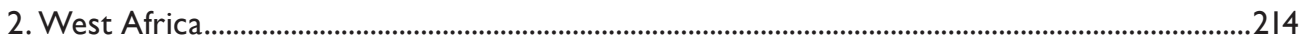

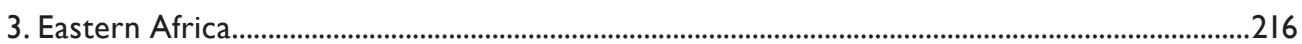

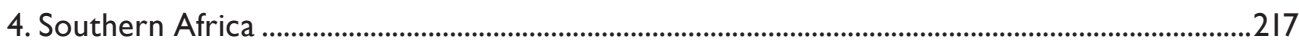

5. Western Indian Ocean island countries............................................................................................ 220

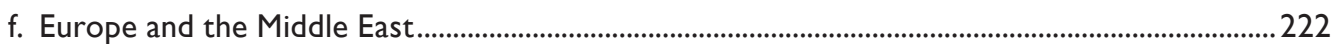

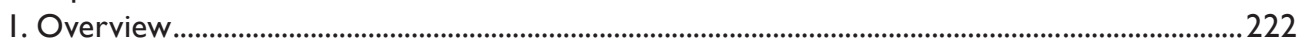

2. Central and western Europe...................................................................................................... 224

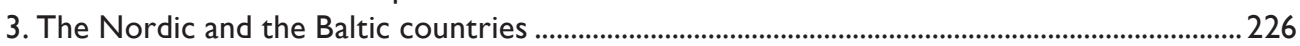

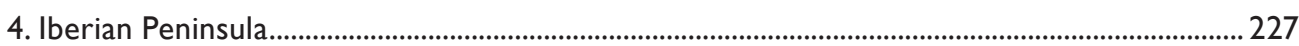

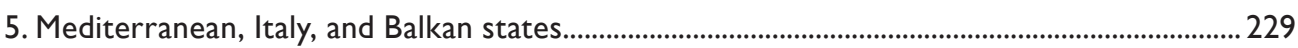

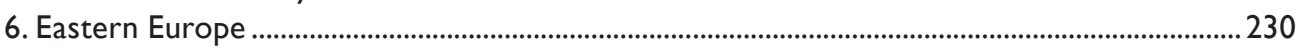

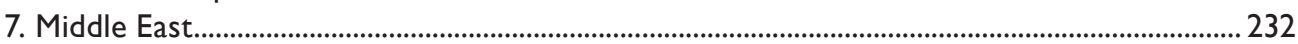

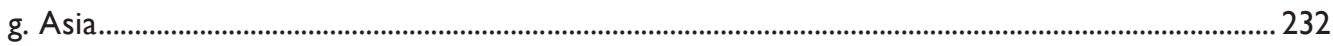

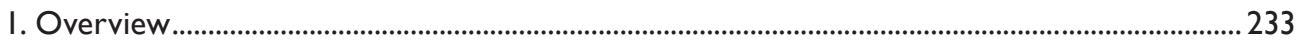

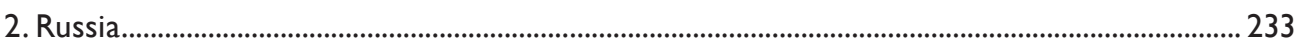

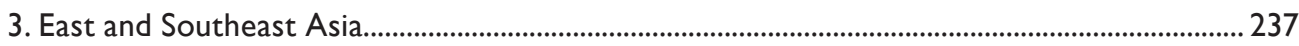

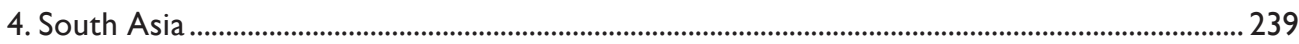

5. Southwest Asia .............................................................................................................................. 242

Sidebar 7.3: Abnormal West China autumn rainfall in 2017 and Persistence of

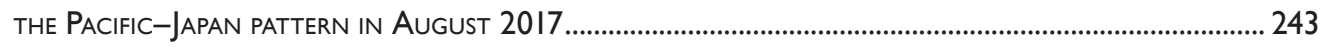

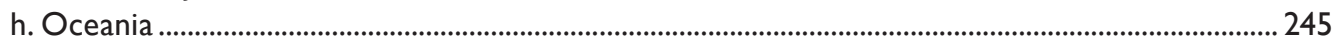

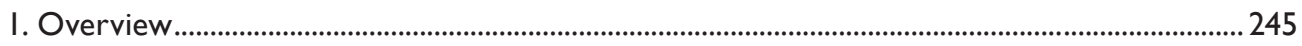

2. Northwest Pacific and Micronesia................................................................................................ 245

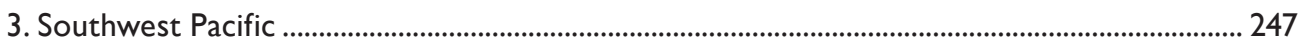

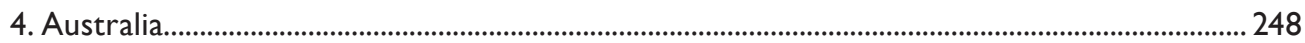

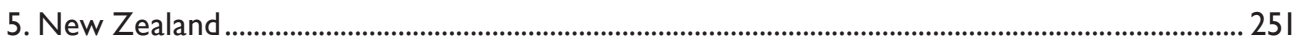

SIDEBAR 7.4: SUMMER ARRIVES EARLY IN AUSTRALIA AS THE AUSTRAL SPRING BREAKS RECORDS .......................... 253

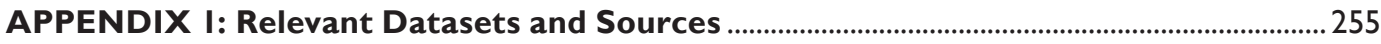

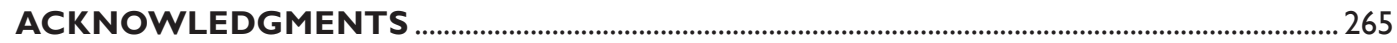

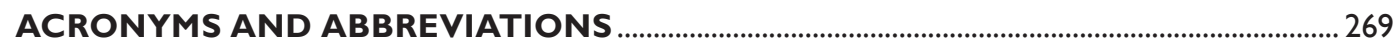

REFERENCES 


\section{ABSTRACT—J. BLUNDEN, G. HARTFELD, AND D. S. ARNDT}

In 2017, the dominant greenhouse gases released into Earth's atmosphere-carbon dioxide, methane, and nitrous oxidereached new record highs. The annual global average carbon dioxide concentration at Earth's surface for 2017 was 405.0 $\pm 0.1 \mathrm{ppm}, 2.2 \mathrm{ppm}$ greater than for 2016 and the highest in the modern atmospheric measurement record and in ice core records dating back as far as 800000 years. The global growth rate of $\mathrm{CO}_{2}$ has nearly quadrupled since the early 1960s.

With ENSO-neutral conditions present in the central and eastern equatorial Pacific Ocean during most of the year and weak La Niña conditions notable at the start and end, the global temperature across land and ocean surfaces ranked as the second or third highest, depending on the dataset, since records began in the mid-to-late 1800s. Notably, it was the warmest non-El Niño year in the instrumental record. Above Earth's surface, the annual lower tropospheric temperature was also either second or third highest according to all datasets analyzed. The lower stratospheric temperature was about $0.2^{\circ} \mathrm{C}$ higher than the record cold temperature of 2016 according to most of the in situ and satellite datasets.

Several countries, including Argentina, Uruguay, Spain, and Bulgaria, reported record high annual temperatures. Mexico broke its annual record for the fourth consecutive year. On 27 January, the temperature reached $43.4^{\circ} \mathrm{C}$ at Puerto Madryn, Argentina-the highest temperature recorded so far south $\left(43^{\circ} \mathrm{S}\right)$ anywhere in the world. On 28 May in Turbat, western Pakistan, the high of $53.5^{\circ} \mathrm{C}$ tied Pakistan's all-time highest temperature and became the world-record highest temperature for May.

In the Arctic, the 2017 land surface temperature was $1.6^{\circ} \mathrm{C}$ above the 1981-2010 average, the second highest since the record began in 1900, behind only 2016. The five highest annual Arctic temperatures have all occurred since 2007. Exceptionally high temperatures were observed in the permafrost across the Arctic, with record values reported in much of Alaska and northwestern Canada. In August, high sea surface temperature (SST) records were broken for the Chukchi Sea, with some regions as warm as $+11^{\circ} \mathrm{C}$, or $3^{\circ}$ to $4^{\circ} \mathrm{C}$ warmer than the longterm mean (1982-present). According to paleoclimate studies, today's abnormally warm Arctic air and SSTs have not been observed in the last 2000 years. The increasing temperatures have led to decreasing Arctic sea ice extent and thickness. On 7 March, sea ice extent at the end of the growth season saw its lowest maximum in the 37 -year satellite record, covering $8 \%$ less area than the 1981-2010 average. The Arctic sea ice minimum on 13 September was the eighth lowest on record and covered $25 \%$ less area than the long-term mean.

Preliminary data indicate that glaciers across the world lost mass for the 38th consecutive year on record; the declines are remarkably consistent from region to region. Cumulatively since 1980, this loss is equivalent to slicing 22 meters off the top of the average glacier.

Antarctic sea ice extent remained below average for all of 2017, with record lows during the first four months. Over the continent, the austral summer seasonal melt extent and melt index were the second highest since 2005, mostly due to strong positive anomalies of air temperature over most of the West Antarctic coast. In contrast, the East Antarctic Plateau saw record low mean temperatures in March. The year was also distinguished by the second smallest Antarctic ozone hole observed since 1988.

Across the global oceans, the overall long-term SST warming trend remained strong. Although SST cooled slightly from 2016 to 2017 , the last three years produced the three highest annual values observed; these high anomalies have been associated with widespread coral bleaching. The most recent global coral bleaching lasted three full years, June 2014 to May 2017, and was the longest, most widespread, and almost certainly most destructive such event on record. Global integrals of 0-700$\mathrm{m}$ and $0-2000-\mathrm{m}$ ocean heat content reached record highs in 2017, and global mean sea level during the year became the highest annual average in the 25 -year satellite altimetry record, rising to $77 \mathrm{~mm}$ above the 1993 average.

In the tropics, 2017 saw 85 named tropical storms, slightly above the $1981-2010$ average of 82 . The North Atlantic basin was the only basin that featured an above-normal season, its seventh most active in the 164-year record. Three hurricanes in the basin were especially notable. Harvey produced record rainfall totals in areas of Texas and Louisiana, including a storm total of $1538.7 \mathrm{~mm}$ near Beaumont, Texas, which far exceeds the previous known U.S. tropical cyclone record of $1320.8 \mathrm{~mm}$. Irma was the strongest tropical cyclone globally in 2017 and the strongest Atlantic hurricane outside of the Gulf of Mexico and Caribbean on record with maximum winds of $295 \mathrm{~km} \mathrm{~h}^{-1}$. Maria caused catastrophic destruction across the Caribbean Islands, including devastating wind damage and flooding across Puerto Rico. Elsewhere, the western North Pacific, South Indian, and Australian basins were all particularly quiet.

Precipitation over global land areas in 2017 was clearly above the long-term average. Among noteworthy regional precipitation records in 2017, Russia reported its second wettest year on record (after 2013) and Norway experienced its sixth wettest year since records began in 1900. Across India, heavy rain and flood-related incidents during the monsoon season claimed around 800 lives. In August and September, above-normal precipitation triggered the most devastating floods in more than a decade in the Venezuelan states of Bolívar and Delta Amacuro. In Nigeria, heavy rain during August and September caused the Niger and Benue Rivers to overflow, bringing floods that displaced more than 100000 people.

Global fire activity was the lowest since at least 2003; however, high activity occurred in parts of North America, South America, and Europe, with an unusually long season in Spain and Portugal, which had their second and third driest years on record, respectively. Devastating fires impacted British Columbia, destroying 1.2 million hectares of timber, bush, and grassland, due in part to the region's driest summer on record. In the United States, an extreme western wildfire season burned over 4 million hectares; the total costs of $\$ 18$ billion tripled the previous U.S. annual wildfire cost record set in 1991. 
I. INTRODUCTION-D. S. Arndt, J. Blunden, and G. Hartfield

This is the 28th issuance of the annual assessment now known as State of the Climate, published in the Bulletin since 1996. As a supplement to the Bulletin, its foremost function is to document the status and trajectory of many components of the climate system. However, as a series, the report also documents the status and trajectory of our capacity and commitment to observe the climate system.

The year was nominally characterized as "ENSO neutral," although most metrics indicate La Niña or nearly La Niña status early and late in the year. As is typical for this series, the characterization of ENSO status varies slightly by discipline, region, and available pertinent data. Readers may notice some variation in the characterization and timing of ENSO status from section to section.

If the report's authors and their datasets are the lifeblood of this series, the chapter editors are surely the heart. They drive the development of their chapters, keeping pace with the evolution of available data, available authors, and the state of the science. The majority of sections of this report are updates. Although new technologies, new analysis methods, and new datasets contribute dynamism to this volume, it is inevitable that some passages, particularly those that describe observational or analytical methods, borrow heavily from the text of previous reports. Changes in this year's report, relative to recent years, include: explicit treatments of ocean acidification observations in both the Global Oceans chapter's global ocean carbon cycle section and the Antarctica chapter's Southern Ocean section; a subdividing of the Arctic chapter's section on sea ice cover to include explicit and separate analyses of ice age, extent, and thickness, including snow depth; a diversification of authors and nations addressed in the African section; and streamlining and combining of subsections within several chapters.

This edition's 16 sidebar articles remind us that the climate is not experienced in annual averages, and that living systems, including humans, experience climate change and variability most deeply in the form of impacts and extremes. Several sidebars deal with extreme precipitation, how it is assessed, or weather systems that delivered extreme precipitation during 2017. A multiyear look at this decade's repeated coral bleaching episodes provides a thorough, if sobering, assessment. Other sidebars address the profound physical and human toll of the 2017 North Atlantic hurricane season. Some feature new and advanced technologies for observing the climate system, while others highlight the value of less familiar observation approaches: those dealing with phenology, paleoclimate records, and, for the second consecutive State of the Climate report, indigenous knowledge.

Our cover this year reflects the interplay between the climate and living systems in the state of California. The early-2017 "superbloom" depicted on the front cover was an immediate response to the first productive wet season in several years for the region. Unfortunately, much of that new additional biomass became fuel for raging wildfires later in the year, as depicted on the back cover. The two covers illustrate these dichotomous outcomes-sublime and serene on the front, destructive on the back-with the same color palette.

We are saddened at the news of Dr. Olga Bulygina's passing in June, as this document was being assembled. Dr. Bulygina was a constant in the building, sharing, and analysis of climatological datasets. She was a reliable and skillful author of the Russian section for many editions of the State of the Climate, including this one. We will remember her fondly, and we wish her family and her colleagues well.

An overview of findings is presented in the Abstract, Fig. 1.1, and Plate 1.1. Chapter 2 features global-scale climate variables; Chapter 3 highlights the global oceans; and Chapter 4 discusses tropical climate phenomena including tropical cyclones. The Arctic and Antarctica respond differently through time and are reported in separate chapters (5 and 6, respectively). Chapter 7 provides a regional perspective authored largely by local government climate specialists. A list of relevant datasets and their sources for all chapters is provided as an Appendix. 


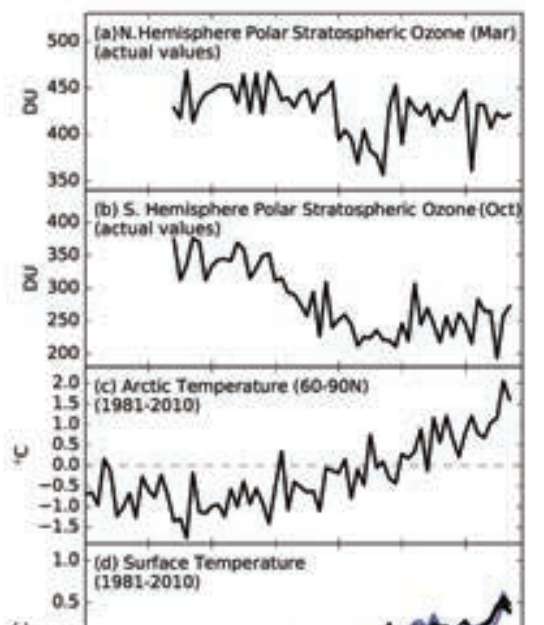

Y.0.

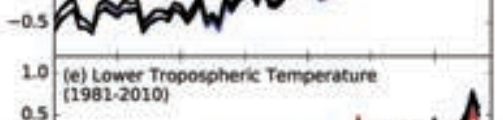

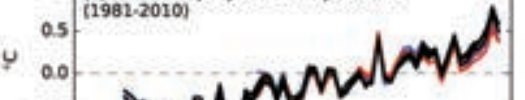

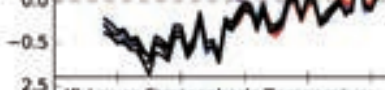

(n) Lower Stratospheric Temperature

1.5
1.0
0.5
0.0
-0.5

(g) Extremes tWarm Days and Coolnights(dotted) 20 (1961-90)

है: 15

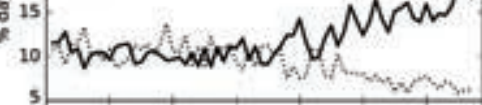

2. Dh) Arctic Sea ice Extent (max and min (dotted)]

[1981.2010]

焉

2.5. 0) Antarctic Ses ice Extent max and min/dottedf

2.0 $11981-2010$

E 1.5

3 1. 0.5 .

$\times 0.0$

$-1.0$

6. 5 Glacier Cumulative Mean Specific Ealance

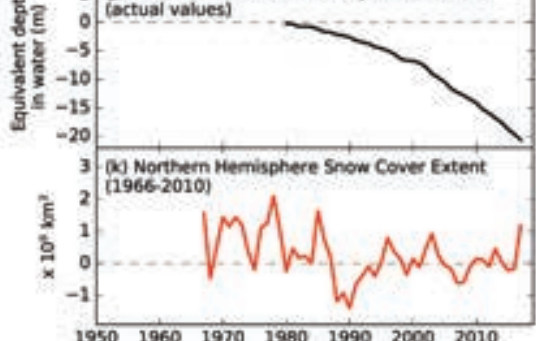

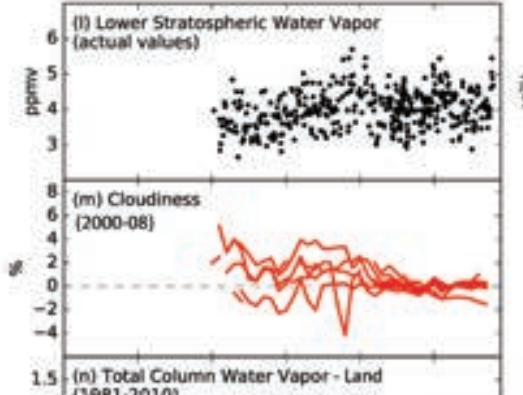

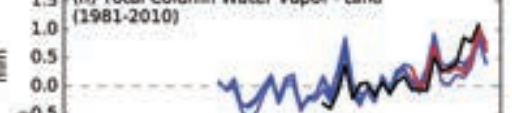

$-0.5$

$-1.0$

20 (0) Total Column Water Vapor-Ocean

2.0 (1981.2010)

E 0.5

0.0

-0.5
-1.0

0.8 (p) Upper Tropospheric Humidity

0.6 (2001-10)

E 0.4

0.2
0.0
-0.2

-0.2
-0.4

0.6

$\begin{array}{cc}0.4 \\ 9 & 0.2 \\ 0 & 0.0\end{array}$

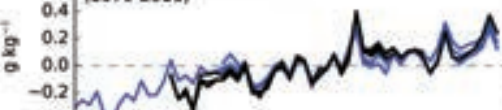

0.6 (in) Specific Humidity - Ocean

0.6 (1979-2010)

$\left.0_{-0.2}^{0.2}\right|_{0.0} ^{0.4}$

$-0.4$

2.0 (s) Relative Humidicy - Land

1.5 (1979-2010)

E 1

- $0.5 \mathrm{~N}$

(t) Relathe Humidity-Ocean

1.0. (1) Relative 12979

* 0.5 .

$-0.5$

60 (u) Precipitation - Land
$40.961 .90)$

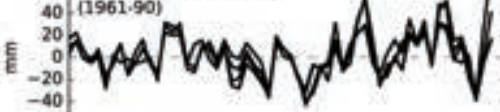

$-60$

\begin{tabular}{ll}
40 \\
$\frac{1}{5} \quad 20$ \\
\hline
\end{tabular}

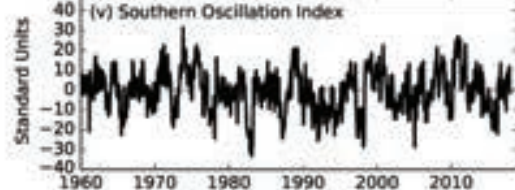

100 ( 1 ) Ocean Heat Content $(0.700 \mathrm{~m}\}$

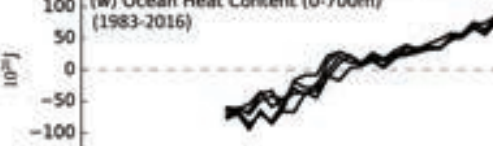

$100(x)$ Sea Level Rise

(actual values

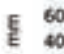

20

315 (y) Tropospheric Ozone

310 (actual valuesi

है 305 .

300

है 2950

0.6 (2) Troposcheric Wind Speed at $850 \mathrm{hP}$ ?

$0.4(1981-2010)$

$\sum_{-0.2}^{0.2}$

$-0.4$

0.3 (aa) Land Wind Speed

0.2 (1981-2010)

E.0.1.

$-0.2$

0.4 tabj Ocesn Wind Speed

(ac) Biomass Burning

730

点2.5

15

(ad) Soil Moisture

$0.005(1901.2016)$

$0.000=\ldots$.

6. 1.0 (ae) Terrestrial Water Storage

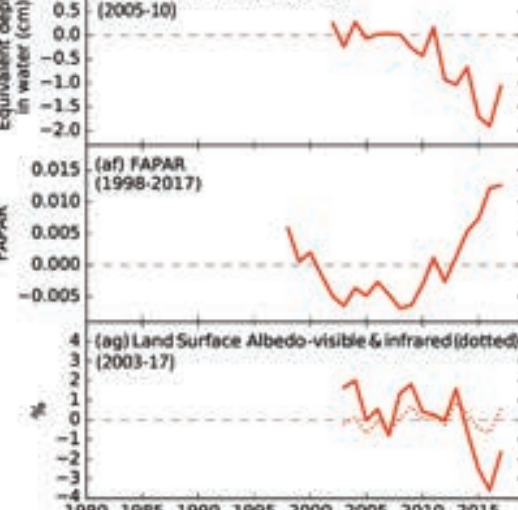




\section{ESSENTIAL CLIMATE VARIABLES — J. BLUNDEN, R. J. H. DUNN, D. S. ARNDT,}

AND G. HARTFIELD

Time series of major climate indicators are again presented in this introductory chapter. Many of these indicators are essential climate variables (ECVs), originally defined in GCOS (2003) and updated again by GCOS (2010). The following ECVs, included in this edition, are considered "fully monitored," in that they are observed and analyzed across much of the world, with a sufficiently longterm dataset that has peer-reviewed documentation:

- Atmospheric Surface: air temperature, precipitation, air pressure, water vapor, wind speed and direction

- $\quad$ Atmospheric Upper Air: Earth radiation budget, temperature, water vapor, wind speed and direction

- Atmospheric Composition: carbon dioxide, methane, other long-lived gases, ozone

- Ocean Surface: temperature, salinity, sea level, sea ice, current, ocean color, phytoplankton

- Ocean Subsurface: temperature, salinity

- Terrestrial: snow cover, albedo
ECVs in this edition that are considered "partially monitored," meeting some but not all of the above requirements, include:

- Atmospheric Upper Air: cloud properties

- Atmospheric Composition: aerosols and their precursors

- Ocean Surface: carbon dioxide, ocean acidity

- Ocean Subsurface: current, carbon

Terrestrial: soil moisture, permafrost, glaciers and ice caps, river discharge, groundwater, ice sheets, fraction of absorbed photosynthetically active radiation, lakes, biomass, fire disturbance

Remaining ECVs that are desired for the future include:

- Atmospheric Surface: surface radiation budget

- Ocean Surface: sea state

- Ocean Subsurface: nutrients, ocean tracers, ocean acidity, oxygen

- Terrestrial: water use, land cover, leaf area index, soil carbon

PLATE I.I. Global (or representative) average time series for essential climate variables through 2017. Anomalies are shown relative to the base period in parentheses although base periods used in other sections of the report may differ. The numbers in the square brackets that follow in this caption indicate how many reanalysis (blue), satellite (red), and in situ (black) datasets are used to create each time series in that order. (a) N. Hemisphere polar stratospheric ozone (March) [0,0,I]; (b) S. Hemisphere polar stratospheric ozone (October) [0,0,I]; (c) Arctic air temperature $\left(60^{\circ}-90^{\circ} \mathrm{N}\right)[0,0,1]$; (d) Surface temperature [0,0,4]; (e) Lower tropospheric temperature [3,2,4]; (f) Lower stratospheric temperature [3,3,4]; (g) Extremes [warm days (solid) and cool nights (dotted)] [0,0,I]; (h) Arctic sea ice extent [max (solid) and min (dashed)] [0,0,I]; (i) Antarctic sea ice extent $[\max ($ solid) and $\min ($ dashed) $[0,0,1] ;$; (j) Glacier cumulative mean specific balance $[0,0,1] ;(k) N$. Hemisphere snow cover extent $[0,1,0]$; (I) Lower stratospheric water vapor $[0,0,1] ;(m)$ Cloudiness $[0,8,0] ;(n)$ Total column water vapor - land $[3,1,1]$; (o) Total column water vapor - ocean $[3,2,0]$; (p) Upper tropospheric humidity $[0,2,0]$; (q) Specific humidity - land [3,0,4]; (r) Specific humidity - ocean [3,I,3]; (s) Relative humidity - land [3,0,4]; (t) Relative humidity - ocean [3,0,2]; (u) Precipitation - land [0,0,4]; (v) Southern Oscillation index [0,0, I]; (w) Ocean heat content $(0-700 \mathrm{~m})[0,0,5]$; (x) Sea level rise $[0,0,1] ;(y)$ Tropospheric ozone $[0,1,0] ;(z)$ Tropospheric wind speed at $850 \mathrm{hPa}$ for $20^{\circ}-40^{\circ} \mathrm{N}$ [4,0,1]; (aa) Land wind speed [0,0,1]; (ab) Ocean wind speed [3, I,0]; (ac) Biomass burning $[0,3,0]$; (ad) Soil moisture $[0,1,0]$; (ae) Terrestrial groundwater storage $[0,1,0]$; (af) Fraction of absorbed photosynthetically active radiation (FAPAR) $[0,1,0]$; (ag) Land surface albedo - visible (solid) and infrared (dashed) $[0,1,0]$. 


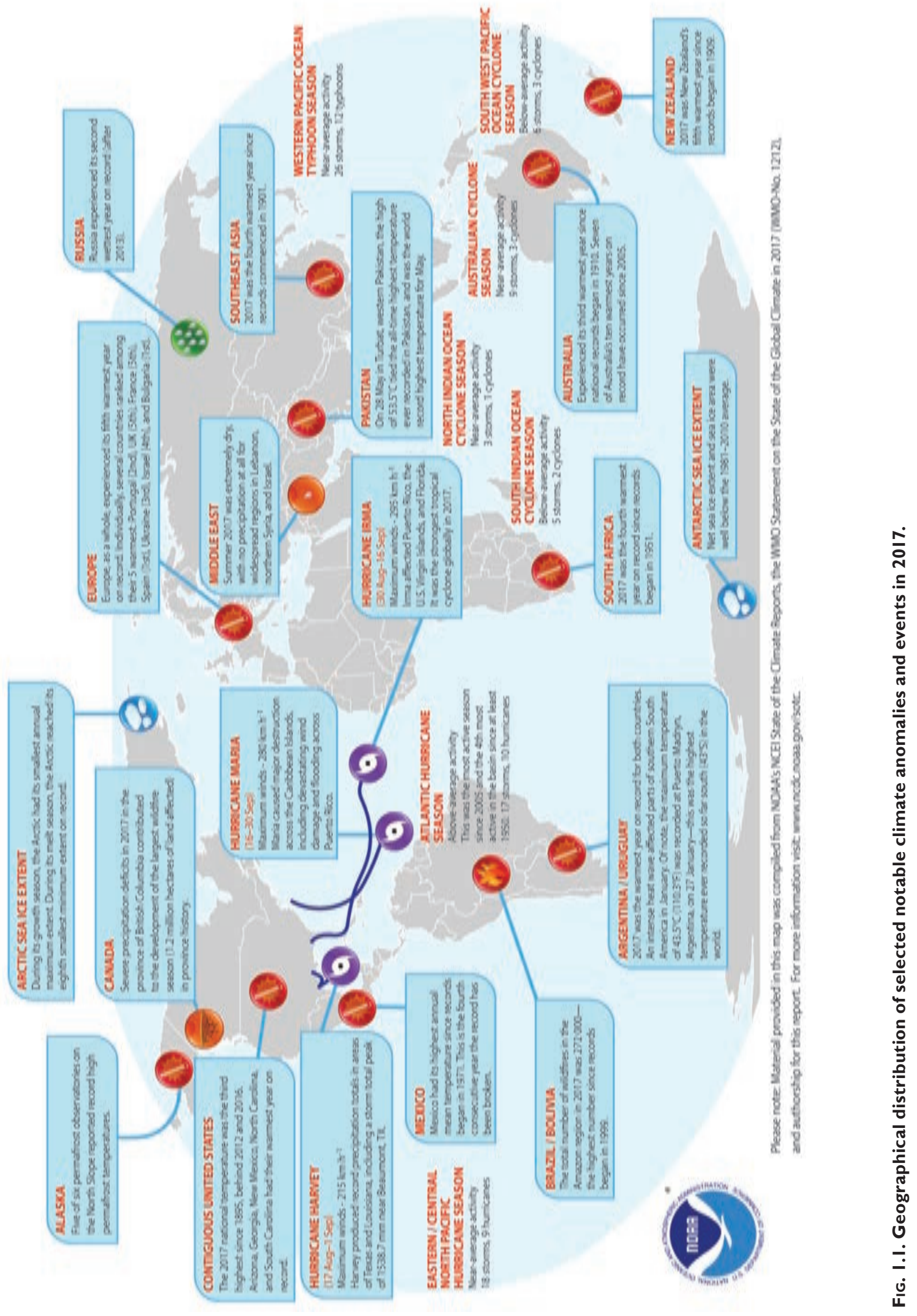


2. GLOBAL CLIMATE-R. J. H. Dunn, D. M. Stanitski, N. Gobron, and K. M. Willett, Eds.

a. Overview-R. J. H. Dunn, D. M. Stanitski, N. Gobron, and K. M. Willett

The global land and ocean surface temperature was remarkably high in 2017. Depending on the dataset considered, the past year ranked as the second or third highest since records began in the mid-to-late 1800 s at $0.38^{\circ}-0.48^{\circ} \mathrm{C}$ above the $1981-2010$ average. Notably, as ENSO conditions were neutral throughout much of 2017, it was the warmest year not influenced by El Niño in the instrumental record, as well as being warmer than any year before 2015 .

Unsurprisingly, lake surface temperatures, frequencies of land surface temperature extremes, and tropospheric temperatures also had high, but not record-breaking, global anomalies in 2017. Many other essential climate variables (ECVs; Bojinski et al. 2014) and other measures of the climate system responded to the predominantly above-average temperatures (see also Plate 1.1). Exceptionally high temperatures were observed in the permafrost across the American and European Arctic, with record values observed in large parts of Alaska and northwestern Canada. Preliminary data indicate that glaciers across the world continued to lose mass for the 38 th consecutive year on record; the declines are remarkably consistent from region to region. Cumulatively since 1980 , this loss is the equivalent of slicing 22 meters off the top of the average glacier.

The continued warmth resulted in a humid year over both land and oceans in terms of specific humidity, but more arid in terms of relative humidity over land. Total column water vapor corroborated the surface specific humidity record, dropping slightly compared to the previous year over both land and ocean, but still remaining above average in most locations. A similar drop from 2016 was observed over the land surface area affected by drought. Global land evaporation was much lower than 2016 and below the long-term average for the year. However, precipitation over global land areas was above the long-term average (by 15-80 $\mathrm{mm}$ depending on the dataset used).

This year we include a sidebar (2.1) on precipitation extremes. Extreme precipitation is multifaceted, depending on the timescales over which it is assessed and the average conditions experienced by a given region. A particular focus is on Hurricane Harvey, where 5-day total rainfall amounts broke previous station records in some locations in Texas by over a factor of three.
Anomalously high upper-level divergence along with strong tropical easterly wave disturbances may have contributed to the high levels of storm activity during the Atlantic hurricane season. More generally, upper-air winds from radiosonde measurements continued to show no strong trend, with reanalyses indicating a slight increase in average wind speed (see Dee et al. 2011b about the use of reanalyses for climate monitoring). Surface winds over land continued a slow increase from the multidecadal decrease in globally averaged wind speeds observed since the $\sim 1960$ s, most clearly seen in central and eastern Asia. Over the oceans, there is disagreement between satellite and reanalysis estimates as to whether wind speeds were above or below average.

The emissions and atmospheric abundance of most ozone-depleting substances continued to decline due to the positive effects of the Montreal Protocol and its Amendments; however, the atmospheric abundance of CFC-11 declined more slowly than expected from mid-2015 to mid-2017, potentially leading to a delay in the recovery of stratospheric ozone.

Annual mean total stratospheric ozone levels in 2017 were above average over almost the entire Southern Hemisphere, with Antarctic values more than 10 Dobson units above the 1998-2008 average. This is due to a weakened polar vortex when the quasi-biennial oscillation (QBO) was in the east phase in late 2017, an enhanced Brewer-Dobson circulation transporting ozone into the middle to high latitudes, and the small size and depth of the ozone hole. The long-term upward trend of hemispheric and global average tropospheric ozone continued into 2017.

There were lower concentrations of aerosols in 2017 over highly populated areas in Europe, North America, and China. Trends of total aerosol optical depth (AOD) since 2003 have been negative over Amazonia, the eastern U.S., southern Europe, northern Africa, China, and Japan, possibly from declining deforestation and anthropogenic aerosol emissions as well as reduced dust episodes in desert regions; but trends were positive over the Indian subcontinent.

Near-record high stratospheric water vapor anomalies occurred by the middle of 2017 after a record low in December 2016, as confirmed by both the Aura Microwave Limb Sounder satellite measurement and balloon-borne frost point hygrometer soundings. This was possibly caused by tropical upwelling linked to the QBO.

A sidebar (2.2) describes the first Tropospheric Ozone Assessment Report (TOAR), completed in October 2017, highlighting a wide range of tropospheric ozone metrics produced using data from thousands 
(a) Surface Temperature

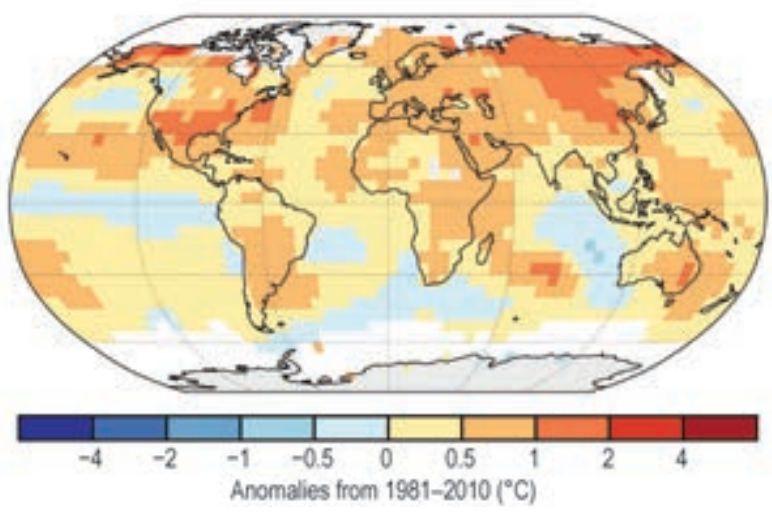

(c) Warm Days (TX90p)

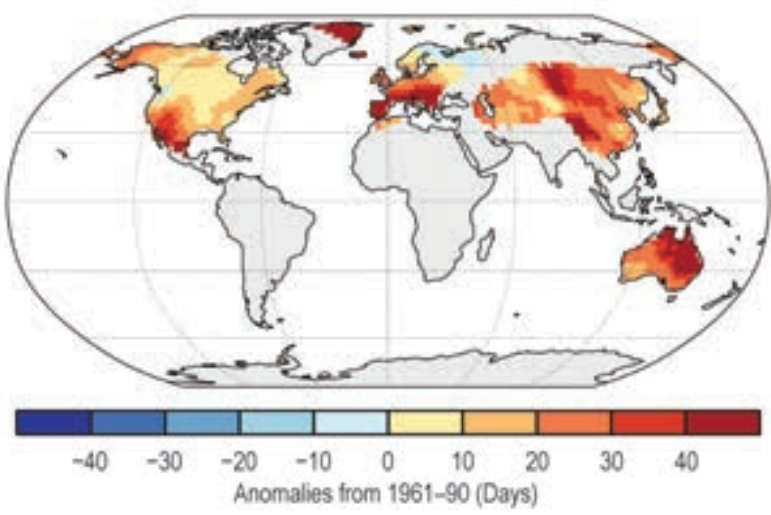

(e) Lower Tropospheric Temperature

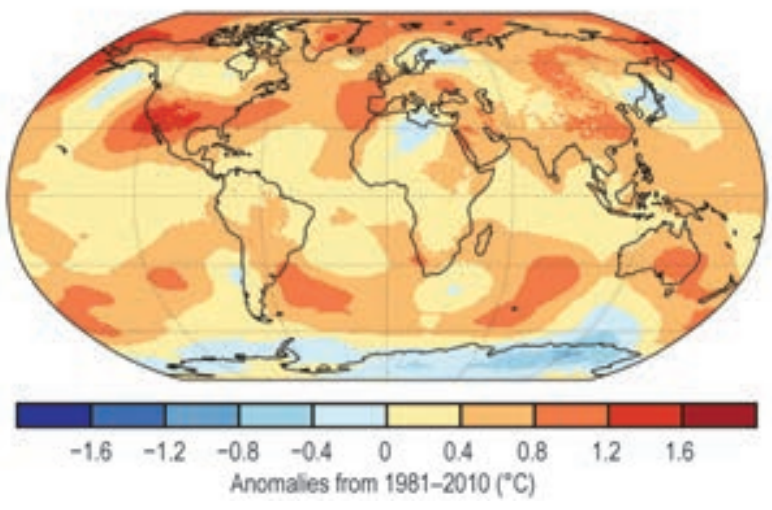

(g) Soil Moisture
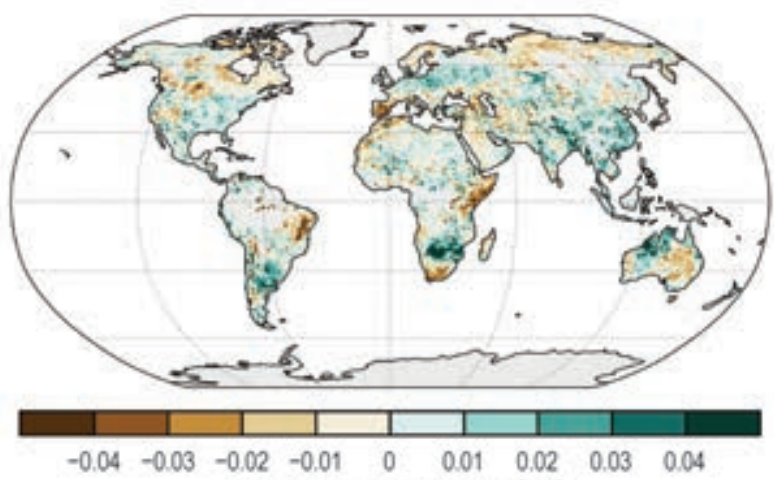

Anomalies from 1991-2014 ( $\left.\mathrm{m}^{3} \mathrm{~m}^{-2}\right)$ (b) Lake Temperatures

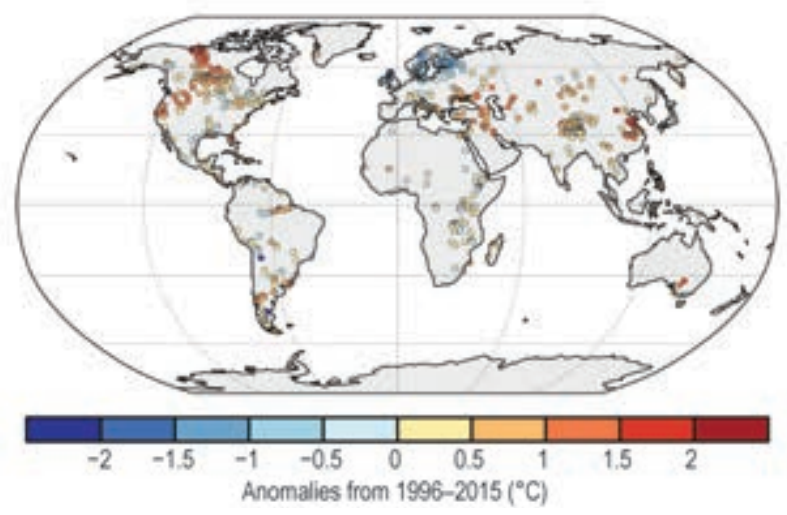

(d) Warm Nights (TN90p)

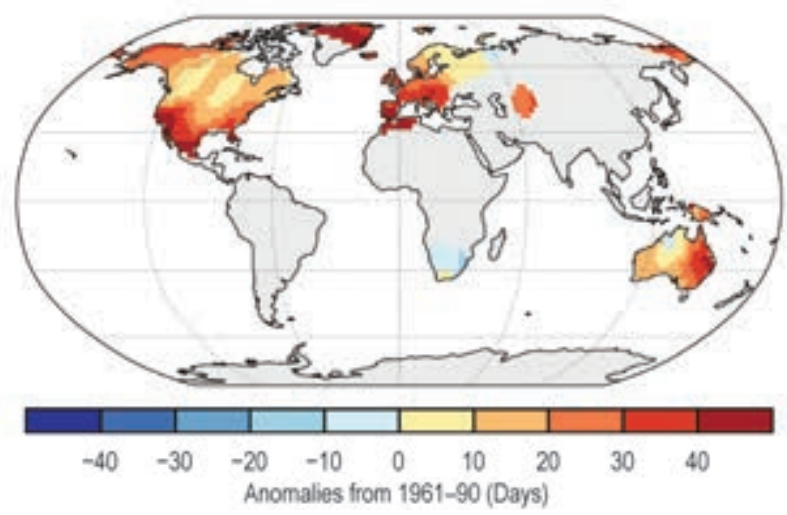

(f) Lower Stratospheric Temperature

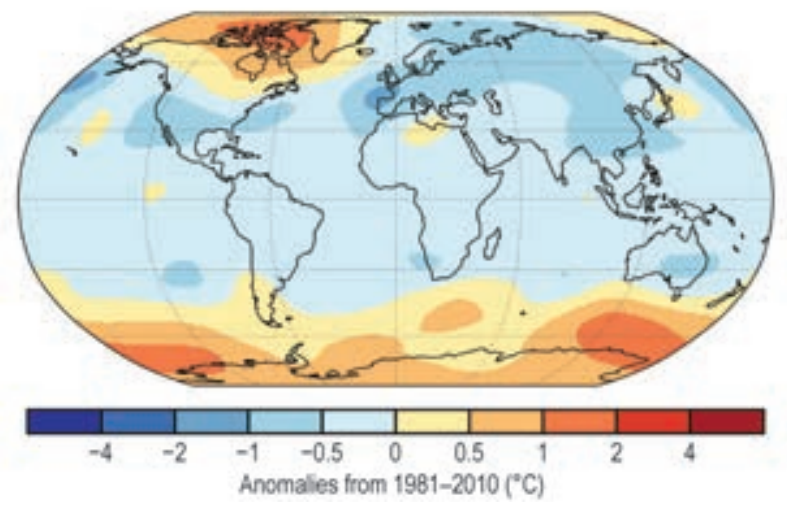

Plate 2.I. (a) NOAA/NCEI surface temperature (NOAAGlobalTemp); (b) Satellite-derived lake surface water temperature); (c) GHCNDEX warm day threshold exceedance (TX90p); (d) GHCNDEX warm night threshold exceedance (TN90p); (e) ERA-Interim lower tropospheric temperature grid anomalies; (f) ERA-Interim gridpoint lower stratosphere temperature anomalies; (g) ESA CCI average surface soil moisture anomalies; 
(h) Terrestrial Water Storage

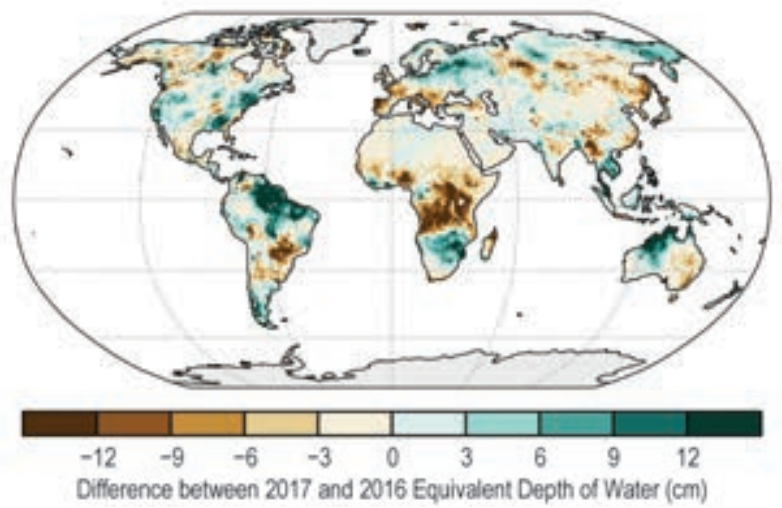

(j) Percentile of the Annual Precipitation Total

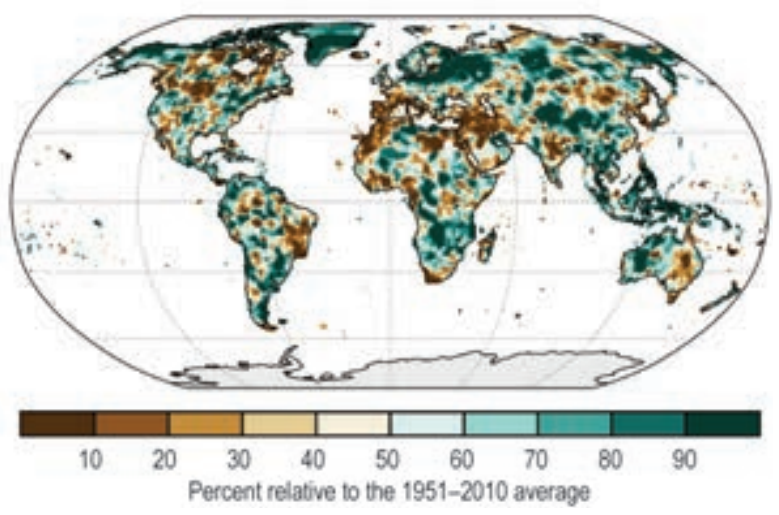

(I) Runoff

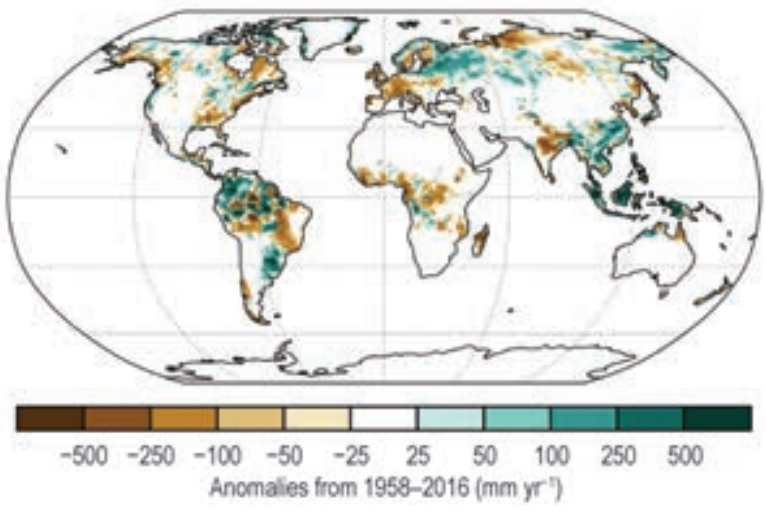

(n) Surface Specific Humidity

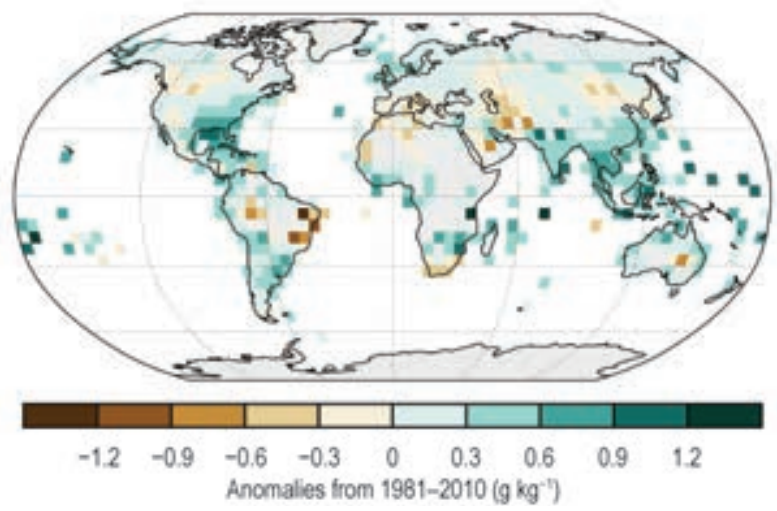

(i) Precipitation

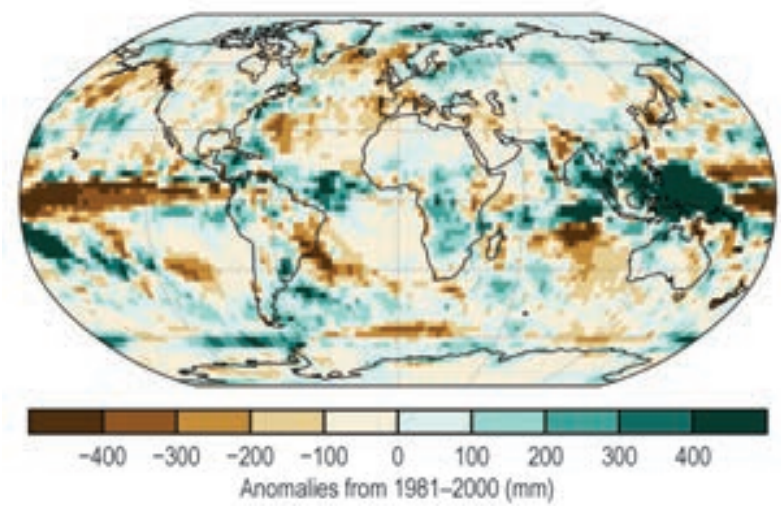

(k) Maximum 1 Day Precipitation Amount (Rx1day)

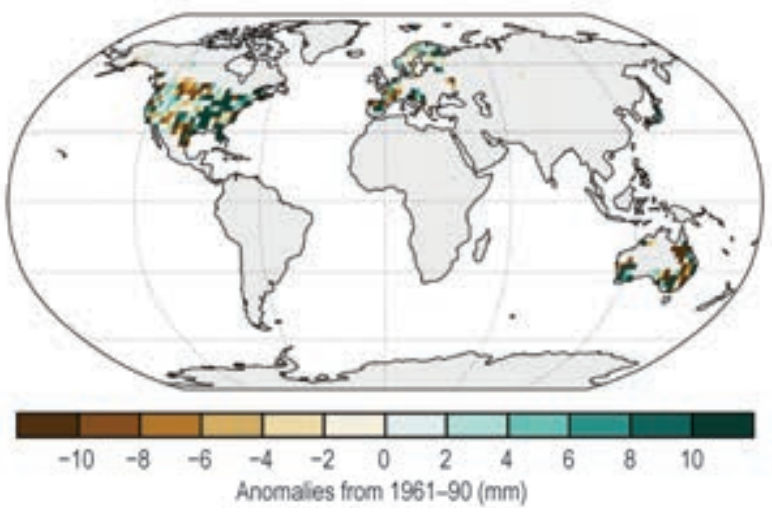

(m) River Discharge

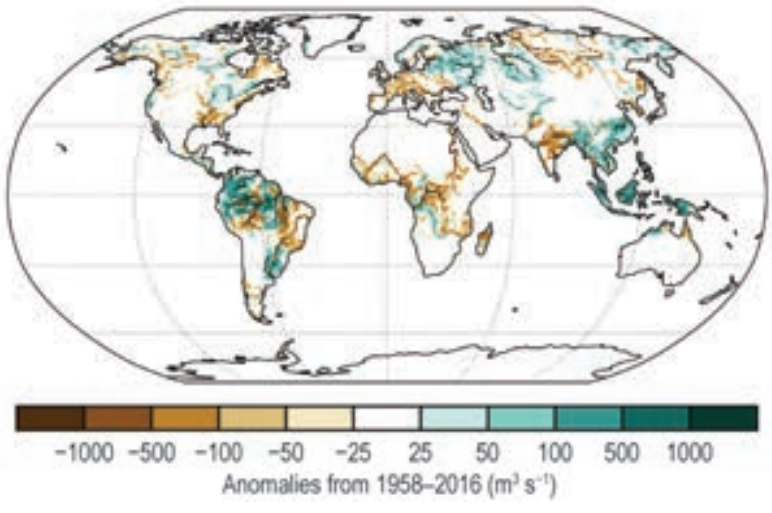

Plate 2. I. (CONT.) (h) GRACE difference in annual mean terrestrial water storage between 2016 and 2017; (i) GPCP v2.3 map of annual mean precipitation anomalies; (j) Percentile of annual precipitation total from 2017 GPCC First Guess Daily; (k) GHCNDEX 2017 anomalies for maximum I day precipitation total (RxIday); (I) JRA-55 global distribution of runoff anomaly; (m) JRA-55 global distribution of river discharge anomaly; (n) HadISDH annual average anomaly surface specific humidity over land; 
(o) Surface Relative Humidity

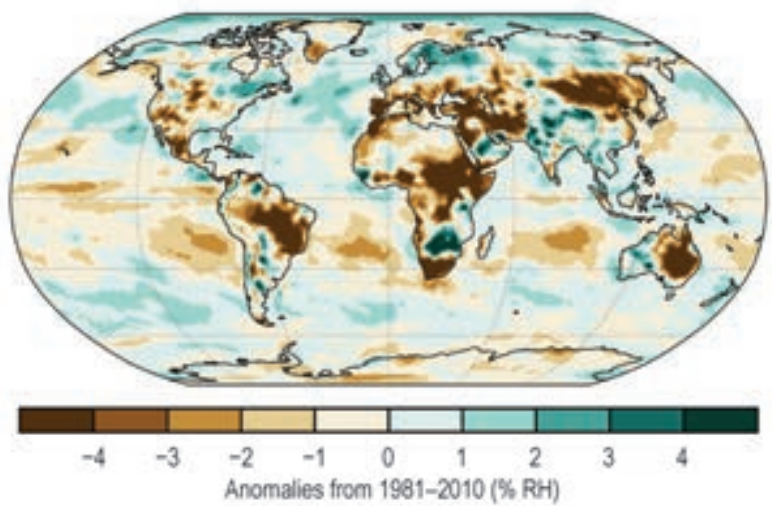

(q) Upper Tropospheric Humidity

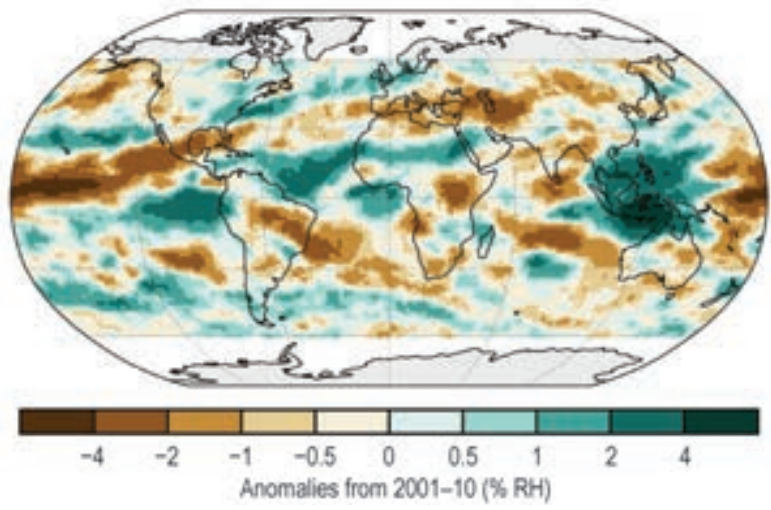

(s) Drought

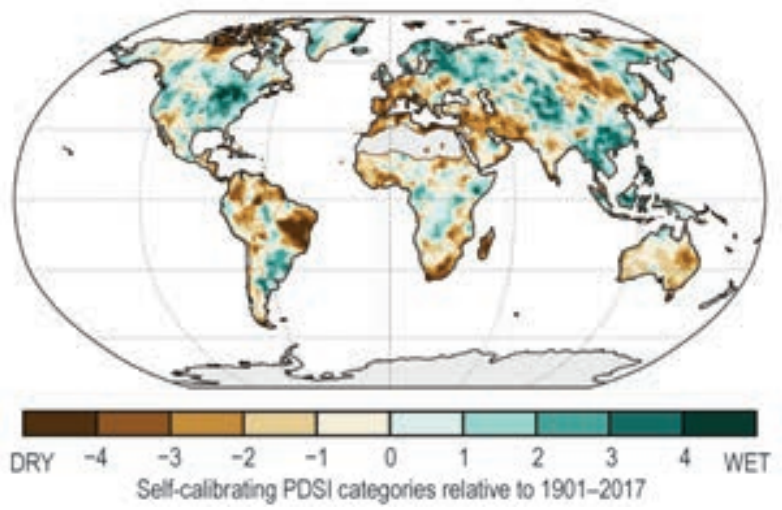

(u) Sea Level Pressure

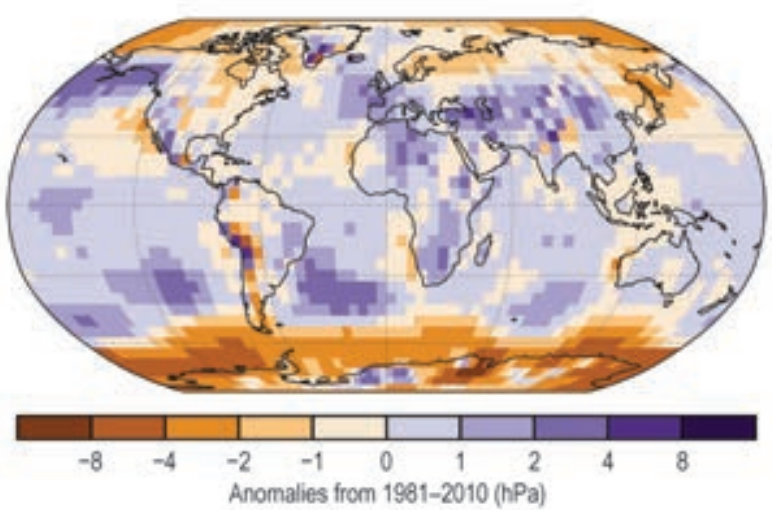

(p) Cloudiness

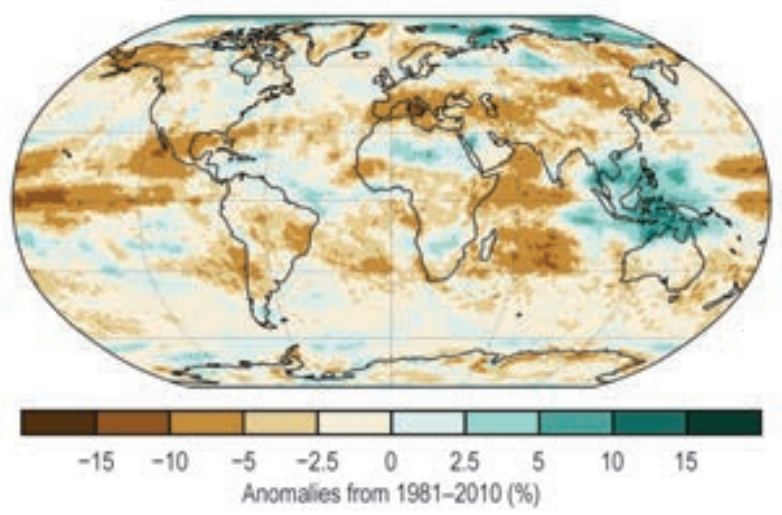

(r) Total Column Water Vapor

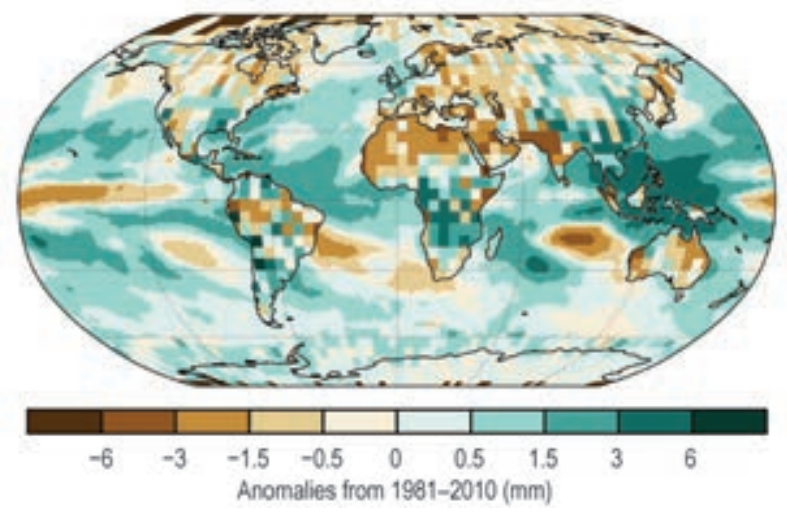

(t) Land Evaporation

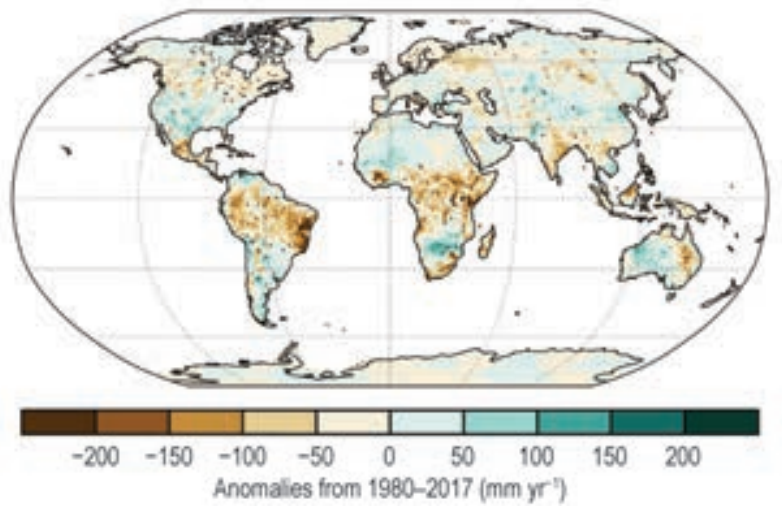

Plate 2. I. (cont.) (o) ERA-Interim annual average anomaly surface relative humidity; (p) PATMOS-x/ AVHRR global cloudiness anomaly; (q) Microwave UTH anomalies; (r) Total column water vapor anomaly from satellite radiometers (oceans) and COSMIC (land); (s) Mean scPDSI for 2017. Droughts are indicated by negative values (brown), wet episodes by positive values (green); (t) GLEAM land evaporation anomalies; (u) HadSLP2r sea level pressure anomalies; 
(v) Surface Winds

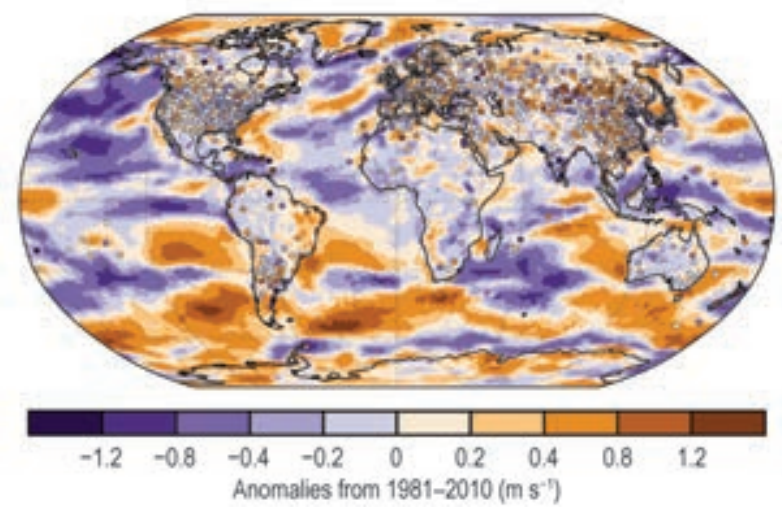

(x) Tropospheric Column Ozone

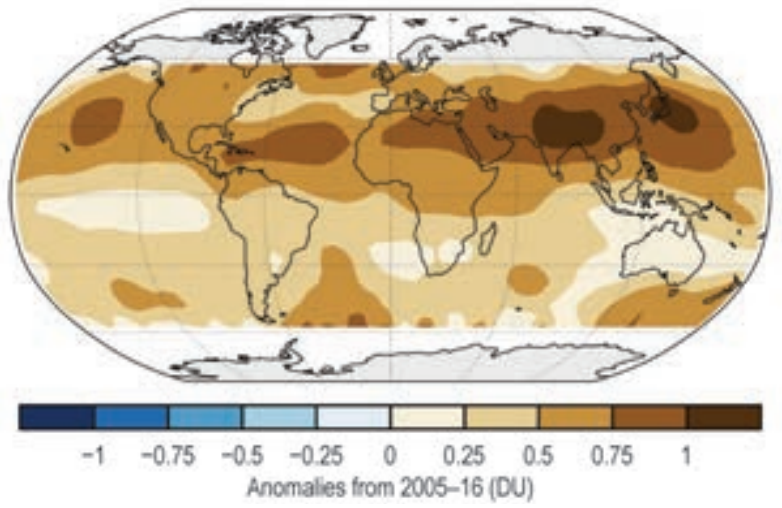

(z) Total Aerosol

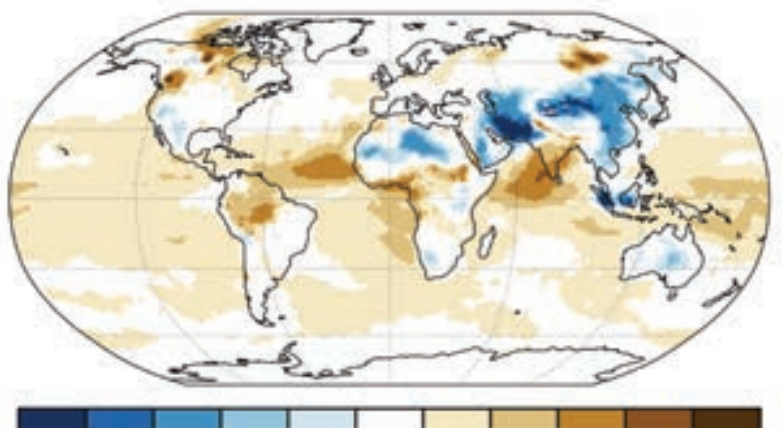

$\begin{array}{llllllllll}-0.14 & -0.1 & -0.06 & -0.04 & -0.02 & 0.02 & 0.04 & 0.06 & 0.1 & 0.14\end{array}$ Ancmalies from 2003-16 (AOO) (w) Upper Air (850-hPa) Winds

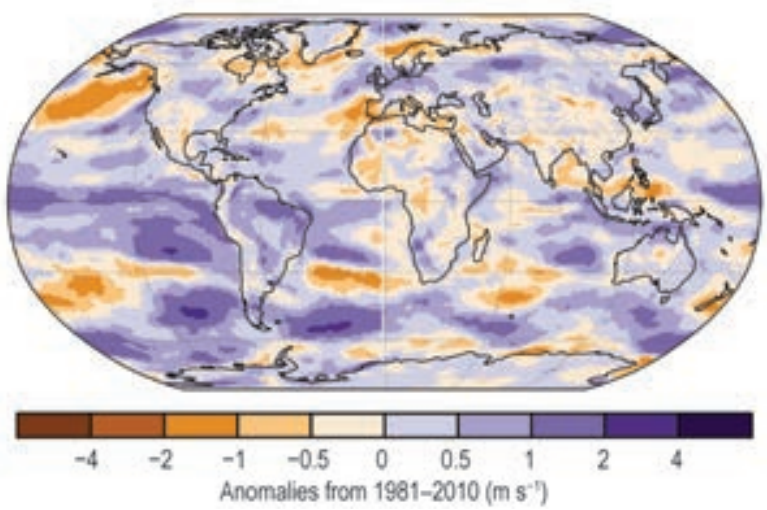

(y) Stratospheric (Total Column) Ozone

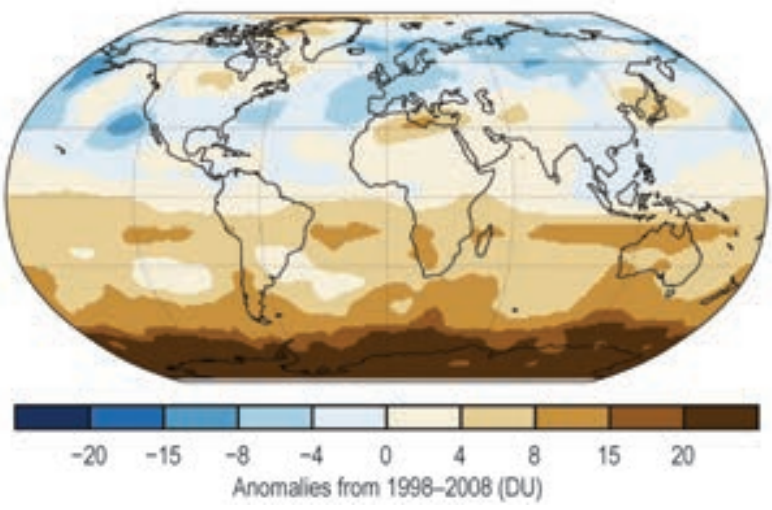

(aa) Dust Aerosol

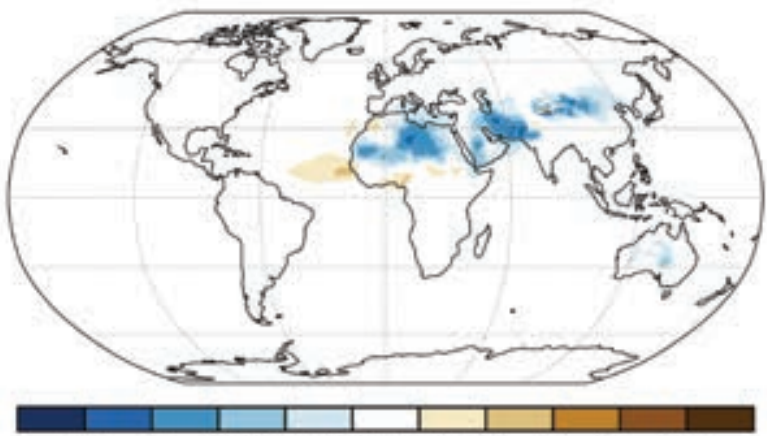

$\begin{array}{llllllllll}-0.14 & -0.1 & -0.06 & -0.04 & -0.02 & 0.02 & 0.04 & 0.06 & 0.1 & 0.14\end{array}$ Anomalies from 2003-16 (AOO)

Plate 2.I. (CONT.) (v) Land surface wind speed anomalies (circles: observational HadISD2 and Australian datasets, and worldwide shaded grids: MERRA-2); (w) ERA-Interim upper air winds; (x) Global distribution of OMI/MLS tropospheric column ozone annual mean anomalies (in Dobson Units) for year 2017 relative to the 2005-2016 average field. White areas poleward of $60^{\circ} \mathrm{N}$ and $60^{\circ} \mathrm{S}$ were flagged as missing due to lack of sufficient $O M I$ ozone measurements during winter polar night to calculate annual averages; (y) GOME-2 2017 total column ozone anomalies [using GOME, SCIAMACHY, and GOME-2 (GSG) for 1998-2008 climatology]; (z) Anomalies of total AOD at $550 \mathrm{~nm}$; (aa) Anomalies of dust AOD at $550 \mathrm{~nm}$; 
(ab) Biomass Burning Aerosol

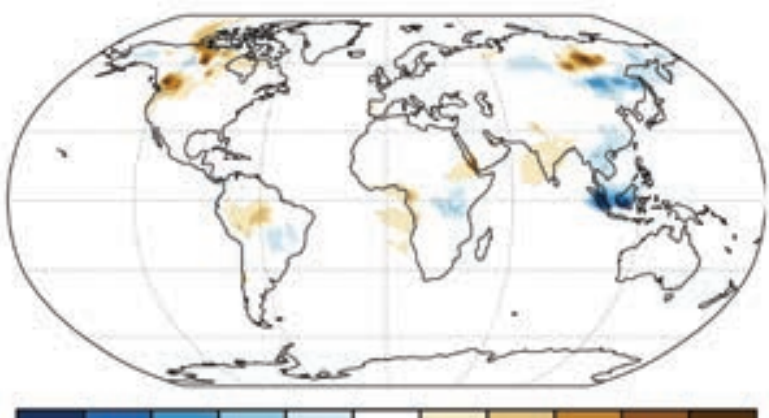

$\begin{array}{llllllllll}-0.14 & -0.1 & -0.06 & -0.04 & -0.02 & 0.02 & 0.04 & 0.06 & 0.1 & 0.14\end{array}$ Anomalies from 2003-16 (AOO)

(ad) Land Surface Albedo in the Near-Infrared

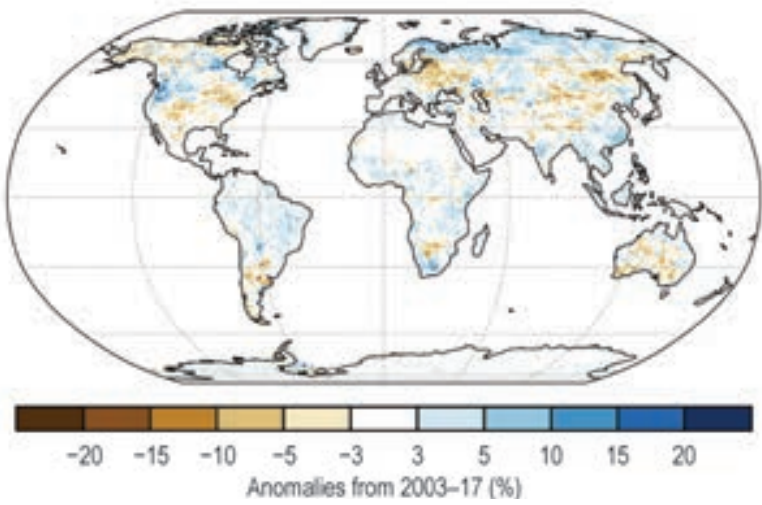

(af) Carbon Emissions from Biomass Burning
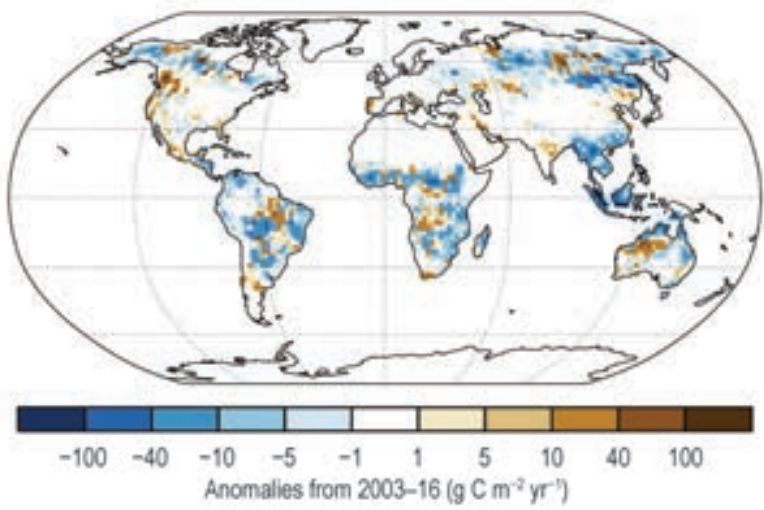

(ac) Land Surface Albedo in the Visible

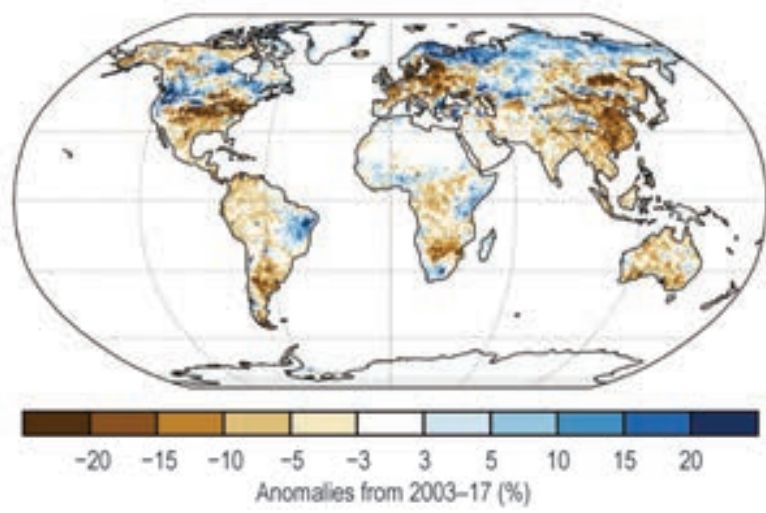

(ae) Fraction of Absorbed Photosynthetically Active Radiation

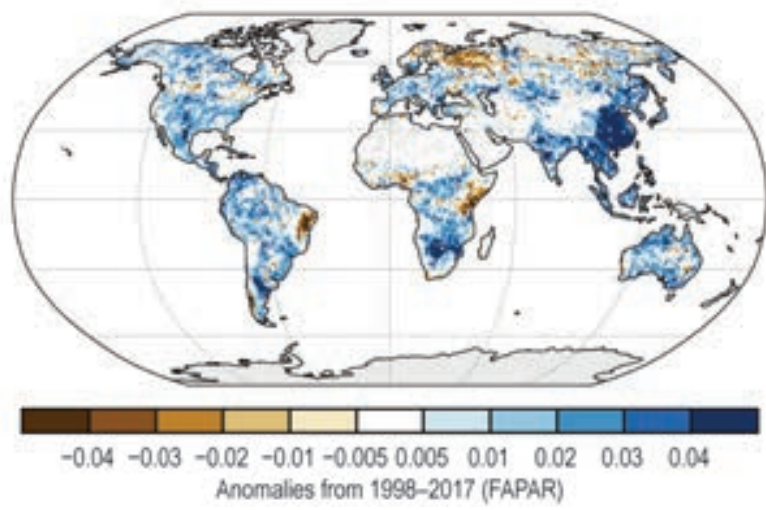

(ag) Carbon Monoxide

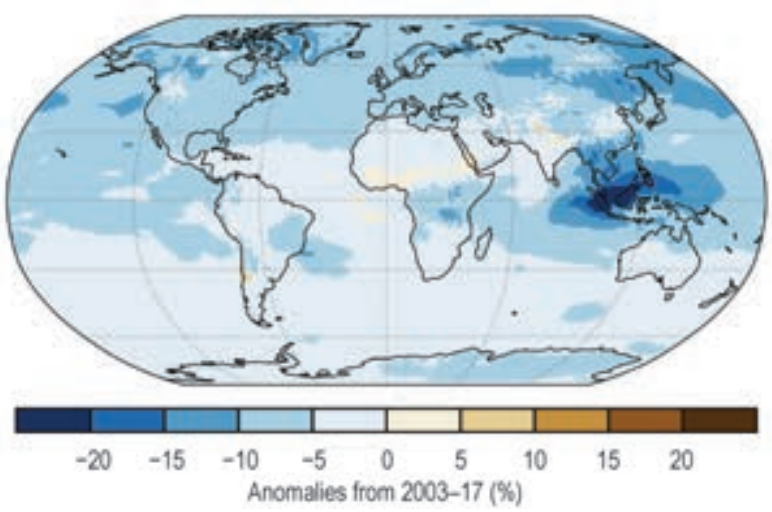

PLATE 2.I. (CONT.) (ab) Anomalies of biomass burning AOD at $550 \mathrm{~nm}$; (ac) Visible broadband albedo anomalies; (ad) Near-infrared broadband albedo anomalies; (ae) FAPAR anomalies; (af) GFASvl.4 carbonaceous emission from biomass burning; (ag) CAMS total column CO anomalies. 
of global surface sites. The metrics are focused on the impacts of tropospheric ozone on human health, vegetation, and climate, and are based on the TOAR's large database of surface hourly ozone observations.

In 2017, there were no regional biomass burning events that had a global impact on the annual carbon monoxide (CO) regional burden, evidenced by the fact that 2017 had the lowest CO burden since 2003. In Indonesia and central Africa, the CO burden was considerably lower than in previous years due to reduced fire activity. Globally during 2017, the levels of fire activity (as opposed to impacts or losses) were the lowest since at least 2003,15\% below the 2003-16 average. However, stronger activity occurred in North America, Europe, and Siberia, with an unusually long season in Portugal and northwestern Spain, and the worst fires experienced in recent history in British Columbia in terms of burned area.

A sidebar (2.3) focusing on land surface phenology observations in the Northern Hemisphere is also included. In contrast to meteorological and hydrological observations, which give a physical description of the current climate, phenology information shows how the natural environment is responding as the state of the climate changes over time.

A common theme across a number of sections is the lack of available data to adequately monitor the climate and make assessments of change. While naturally an issue for this publication, we believe it is worth highlighting more widely. Some examples from this chapter include surface humidity, where no observational marine product is currently available; terrestrial water storage, where no satellite observations currently exist past June 2017; and subdaily (extreme) precipitation. Furthermore, there are several ECVs where various estimates are not in good agreement with each other or with reanalysis products. Limited availability of high-quality, high-resolution, and timely datasets is impinging on the ability to monitor the climate in these cases. Improved (open) access to data, continued stable monitoring, and near-real time data releases all help in allowing accurate assessments of current changes.

Time series and anomaly maps for many variables described in this chapter are shown in Plates 1.1 and 2.1 respectively. Many sections refer to online figures that can be found here (http://doi.org/10.1175 /2018BAMSStateoftheClimate.2).

\section{b. Temperature}

I) Global surface temperatures-A. Sánchez-Lugo, C. Morice, P. Berrisford, and A. Argüez

The 2017 global surface temperature was the second or third highest annual global temperature since records began in the mid-to-late $1800 \mathrm{~s}$ at $0.38^{\circ}-0.48^{\circ} \mathrm{C}$ above the $1981-2010$ average (Table 2.1; Fig. 2.1), according to four independent in situ analyses (NASA-GISS, Hansen et al. 2010; HadCRUT4, Morice et al. 2012; NOAAGlobalTemp, Smith et al. 2008, Huang et al. 2015; JMA, Ishihara 2006). The 2017 value was lower than the record set in 2016 and, depending on the dataset, 2015, both of which were years influenced by a strong El Niño episode. In contrast, ENSO-neutral conditions were present across the tropical Pacific Ocean during much of 2017, transitioning to La Niña in October. Despite this, global temperature anomalies were high throughout the year, resulting in the warmest non-El Niño year on record. Separately, the global land annual temperature ranked as either the second or third highest on record, again, depending on the dataset, and the globally averaged sea surface temperature (SST) was third highest.

TABLE 2.I. Temperature anomalies $\left({ }^{\circ} \mathrm{C}\right.$ ) and uncertainties (where available) for $2017 \mathrm{wrt}$ the $198 \mathrm{I}-2010$ base period. Temperature anomalies provided in the table are the central values of a range of possible estimates. Uncertainty ranges are represented in terms of a $95 \%$ confidence interval. Note that the land values computed for HadCRUT4 used the CRUTEM.4.6.0.0 dataset (Jones et al. 20I2), the ocean values were computed using the HadSST.3.I.I.0 dataset (Kennedy et al. 201 la, 20llb), and the global land and ocean values used the HadCRUT4.6.0.0 dataset.

\begin{tabular}{|c|c|c|c|c|c|c|c|}
\hline Global & NASA-GISS & HadCRUT4 & $\begin{array}{c}\text { NOAA- } \\
\text { Global Temp }\end{array}$ & JMA & ERA-Int & JRA-55 & MERRA-2 \\
\hline Land & +0.73 & $+0.66 \pm 0.13$ & $+0.70 \pm 0.15$ & +0.69 & +0.73 & +0.70 & +0.47 \\
\hline Ocean & +0.35 & $+0.30 \pm 0.07$ & $+0.31 \pm 0.16$ & +0.28 & +0.45 & +0.38 & +0.36 \\
\hline $\begin{array}{c}\text { Land and } \\
\text { Ocean }\end{array}$ & $+0.48 \pm 0.05$ & $+0.38 \pm 0.08$ & $+0.41 \pm 0.15$ & +0.38 & +0.53 & +0.48 & +0.39 \\
\hline
\end{tabular}




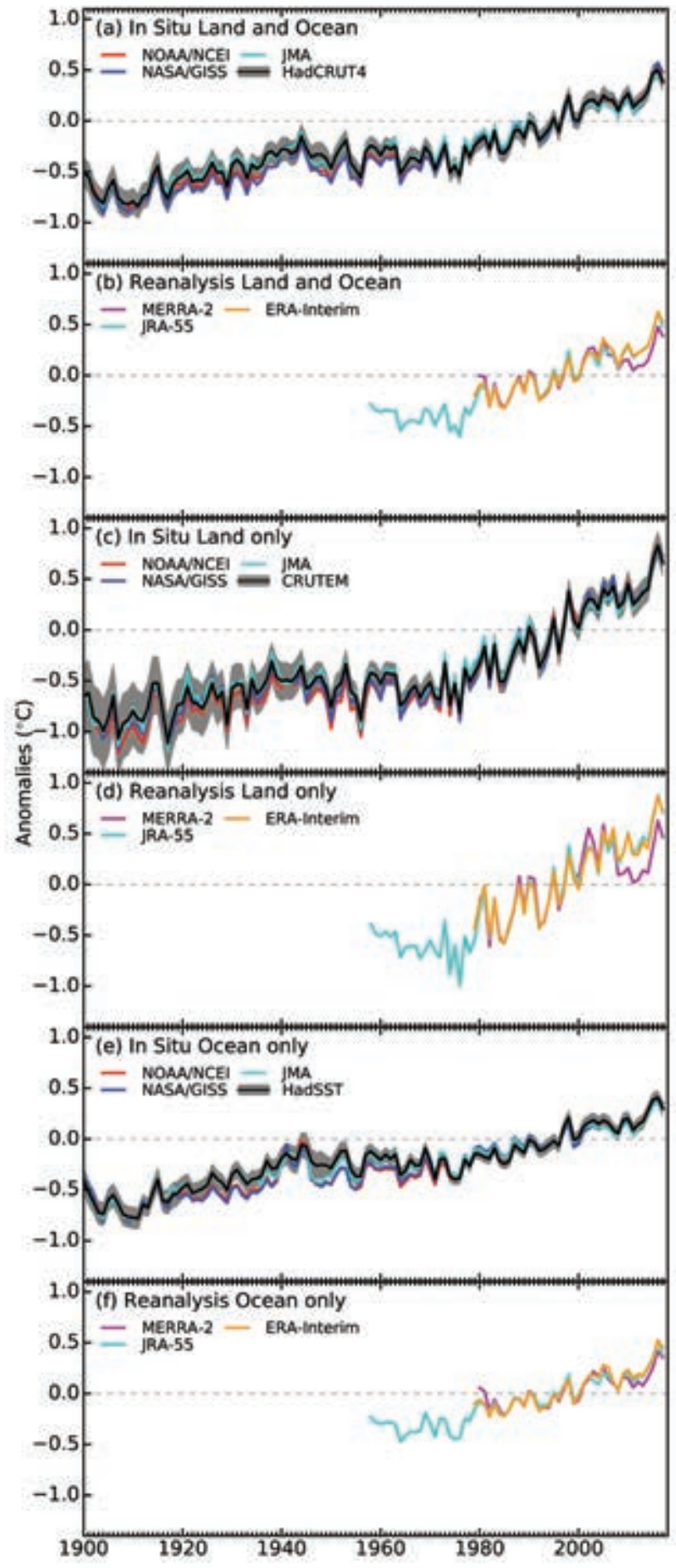

FIG. 2.I. Global average surface temperature anomalies ( ${ }^{\circ} \mathrm{C}$; 198I-2010 base period). In situ estimate are shown from NOAA/NCEI (Smith et al. 2008), NASAGISS (Hansen et al. 2010), HadCRUT4 (Morice et al. 20I2), CRUTEM4 (Jones et al. 20I2), HadSST3 (Kennedy et al. 20Ila,b), JMA (Ishihara 2006). Reanalyses estimates are shown from ERA-Interim (Dee et al. 20Ila), MERRA-2 (Bosilovich et al. 20I5; Gelaro et al. 20I7) and JRA-55 (Ebita et al. 20II; Kobayashi et al. 2015).
The global surface temperature analyses assessed here are derived from air temperatures observed at weather stations over land and SSTs observed from ships and buoys. Differences between analyses are mainly due to how each methodology treats areas with little to no data, such as the polar regions, and how each analysis accounts for changes in measurement methods [for more details see Kennedy et al. (2010); Hansen et al. (2010); Huang et al. (2015); and Sánchez-Lugo et al. (2017)]. The ranges of temperature anomalies provided in this summary are ranges of best estimates for the assessed in situ analyses. These ranges do not include uncertainty information from each in situ analysis, which can be found in Table 2.1.

The ten warmest years on record have all occurred since 1998, with the four warmest years occurring since 2014. Incrementally adding years to the analysis starting from 1988, each year initially ranks among the ten warmest years on record (with the exception of 2011, which ranked among the top twelve years at the time). The median value for the initial ranking since 1988 for a newly ended year is second or third highest, suggesting that the current ranking of 2017 is consistent with recent tendencies.

In addition to the ranking, it is illustrative to distinguish between warmer and colder years relative to the sustained trend (e.g., looking at the residuals from an ordinary least squares regression, Fig. 2.2). The average rate of change of global average surface temperature since 1901 is $0.7^{\circ}-0.9^{\circ} \mathrm{C}$ century ${ }^{-1}$. However, this rate of change has nearly doubled in the period since $1975\left(1.5^{\circ}-1.8^{\circ} \mathrm{C}\right.$ century $\left.^{-1}\right)$. Relative to the trend, the years 2008 and 2011 (both years influ-

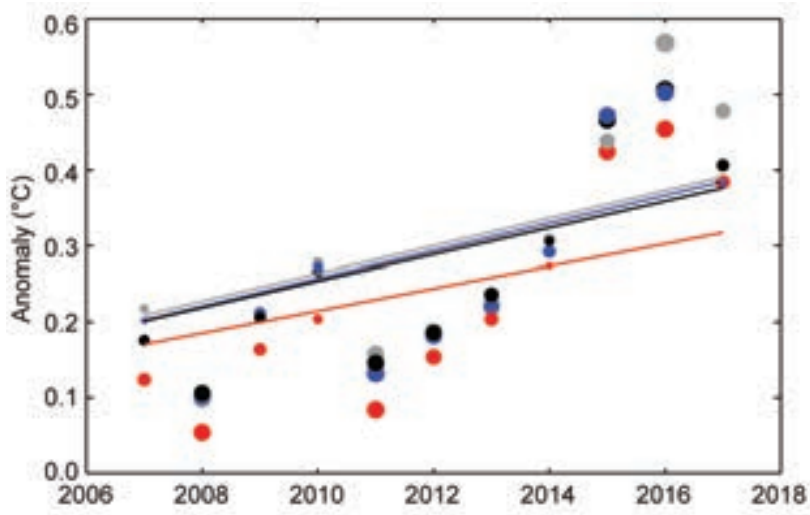

FIG. 2.2. Annual global temperature anomalies $\left({ }^{\circ} \mathrm{C}\right.$; displayed as dots) from 2007-17. Lines represent the linear trends over the 1975-2017 period, while the size of the dot represents the trend residuals. The black, gray, red, and blue colors represent the NOAAGIobalTemp, NASA GISS, JMA, and HadCRUT datasets, respectively. 
enced by a strong La Niña) were considerably cooler than surrounding years and below the overall trend line, whereas 1998 and 2016 were not only considered the warmest years on record when reported, but their values are considerably above the trend line. The year 2014, on the other hand, was considered to be the warmest year on record at the time, even though its value is near the 1975-2017 trend line. The 2017 anomaly is near the trend line for the HadCRUT4 series ( $\sim 50$ th percentile) and above the trend in the other in situ datasets ( 60 th to 80 th percentile). While the value of residuals may shift with the addition of each new year of data, the current data suggest that the 2017 annual global temperature and ranking are consistent with the progression of the upward trend since the mid-1970s.

During 2017, much-warmer-than-average conditions were present across most of the world's land and ocean surfaces, with limited areas (parts of the north, central, and eastern Pacific Ocean, the southern Atlantic Ocean, eastern Indian Ocean, and a small area in western North America) experiencing near- to cooler-than-average conditions (Plate 2.1a).

Global average surface air temperatures are also estimated using reanalyses. Reanalysis produces datasets with uniform temporal and spatial coverage of the whole globe, but can suffer from regional model biases and the effects of changes in the observation network during the analysis period. However, surface temperatures from reanalyses should be consistent with observations in regions of good observational coverage. Here we consider three reanalyses: ERAInterim (Dee et al. 2011a), JRA-55 (Ebita et al. 2011; Kobayashi et al. 2015), and MERRA-2 (Bosilovich et al. 2015; Gelaro et al. 2017). The ERA-Interim 2-m temperature was adjusted by merging analyses over land with short forecasts over ocean and subtracting $0.1^{\circ} \mathrm{C}$ from the latter before 2002, in order to account for a change in SST provider, following Simmons et al. (2017) and Simmons and Poli (2014). ERA-Interim provides data from 1979, JRA-55 from 1958, and MERRA-2 from 1980.

According to the reanalyses, the annual global 2-m temperature for 2017 was the second highest since their records began and was between $0.39^{\circ} \mathrm{C}$ and $0.53^{\circ} \mathrm{C}$ above average, depending on the reanalysis (Table 2.1). The temperatures for the warmest year, 2016, ranged between $0.47^{\circ} \mathrm{C}$ and $0.62^{\circ} \mathrm{C}$ above average.

ERA-Interim and MERRA-2 for 2017 also show warmer-than-average conditions over many regions of the world (Online Figs. S2.1-S2.3), particularly over higher northern latitudes. A few regions were cooler than average, including Antarctica. The 2017 global ocean temperature is the second highest on record in all three reanalyses, whereas over global land the temperature is the second highest in JRA55 and ERA-Interim but only the fourth highest in MERRA-2, where temperatures were lower than in 2016, 2005, and 2002.

2) Lake surface temperature-R. I. Woolway, L. Carrea, C. J. Merchant, M. T. Dokulil, E. de Eyto, C. L. DeGasperi, J. Korhonen, W. Marszelewski, L. May, A. M. Paterson, A. Rimmer, J. A. Rusak, S. G. Schladow, M. Schmid, S. V. Shimaraeva, E. A. Silow, M. A. Timofeyev, P. Verburg, S. Watanabe, and G. A. Weyhenmeyer

Observed lake surface water temperature anomalies in 2017 are placed in the context of the recent warming observed in global surface air temperature (Section 2b1) by collating long-term in situ lake surface temperature observations from some of the world's best-studied lakes and a satellite-derived global lake surface water temperature dataset. The period 1996-2015, 20 years for which satellite-derived lake temperatures are available, is used as the base period for all lake temperature anomaly calculations. Warm-season averages (i.e., time periods without ice cover: July-September in the Northern Hemisphere above $23.5^{\circ} \mathrm{N}$ and January-March in the Southern Hemisphere below $23.5^{\circ} \mathrm{S}$ ) are analyzed in line with previous lake surface temperature analyses (Schneider and Hook 2010; O'Reilly et al. 2015; Woolway and Merchant 2017). Temperatures of lakes located within $23.5^{\circ}$ of the equator are averaged over the whole year.

Satellite-derived lake surface water temperatures for 688 lakes are used in this analysis to investigate global variations in lake surface water temperature. Satellite-derived surface water temperatures were retrieved during the day using the methods of MacCallum and Merchant (2012) on image pixels filled with water according to both the inland water dataset of Carrea et al. (2015) and a reflectance-based water detection scheme (Xu 2006). The satellite temperatures represent midmorning observations throughout the record (except at the highest latitudes, where observations may be available at other times of day). The observations were generated using data from the ATSR (Along Track Scanning Radiometer) series including ATSR-2 (1995-2003) and the Advanced ATSR (AATSR) (2002-12), extended with MetOp-A AVHRR (2007-17). In this study, lake-wide average surface temperatures are used to remove the intralake heterogeneity of surface water temperature responses to climate change (Woolway and Merchant 2018). 
In 2017, satellite-derived lake surface temperatures were lower than observed in 2016 by $0.3^{\circ} \mathrm{C}$ in the 688-lakes average (Fig. 2.3a), though the mean anomaly for 2017 was still $+0.4^{\circ} \mathrm{C}$ above the baseline, continuing the long-term lake surface warming trend identified in previous analyses (e.g., Woolway et al. 2017) and reflecting the observed increase in global surface air temperature (section 2b1). Lake surface water temperatures in 2017 were the second highest since 1995 (the earliest satellite data used), behind only 2016. Eight of the ten warmest years for lake surface waters in the record have occurred since 2007 (1998 and 2001 rank fifth and ninth, respectively).

Lake surface water temperatures in 2017 were not above average in all regions (Figs 2.3b,c; Plate 2.1b). Below-average lake surface temperatures prevailed throughout north and northwestern Europe (Plate 2.1b; Fig. 2.4) in summer, where lake surface temperatures were up to $1^{\circ} \mathrm{C}$ cooler than the 20 -year base period mean. The satellite data and in situ lake
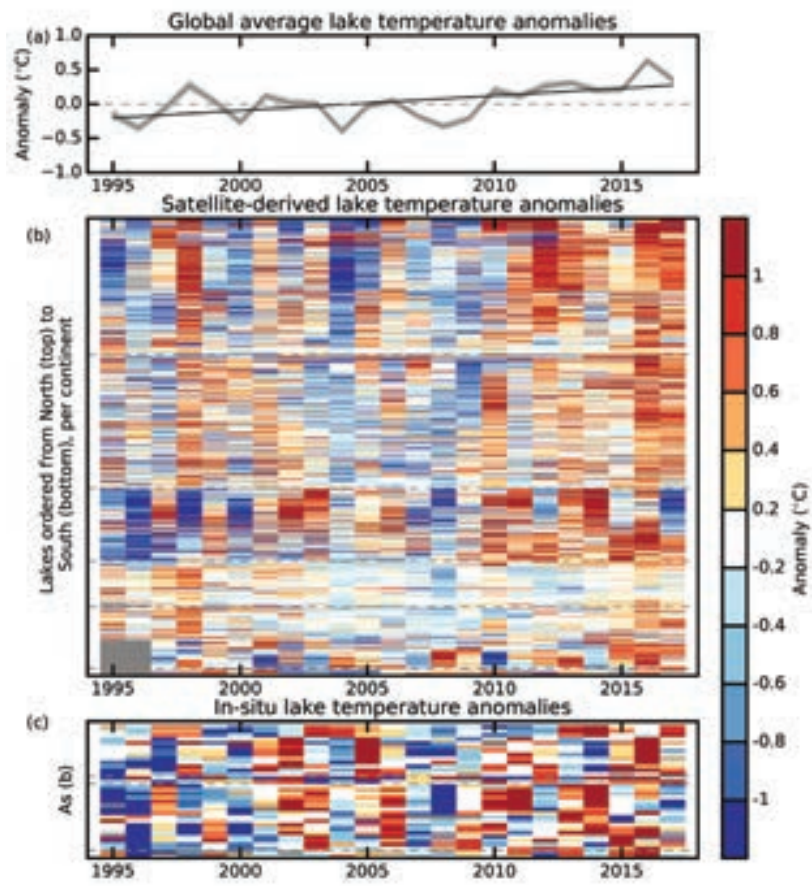

Fig. 2.3. Annual lake surface water temperature anomalies 1995-2017 ( ${ }^{\circ} \mathrm{C}$; relative to 1996-2015). (a) Global average (with $95 \%$ confidence intervals) satellite-derived lake surface temperature anomalies; (b) satellite-derived lake surface temperature anomalies for $\mathbf{6 8 8}$ lakes; and (c) in situ lake surface temperature anomalies for $\mathbf{3 4}$ globally distributed lakes. Annual lake surface water temperatures anomalies are calculated for the warm season (Jul-Sep in NH; Jan-Mar in SH), except within $23.5^{\circ}$ of the equator, where the averages are taken over the whole year. temperature anomalies agree in this respect. For example, in situ measurements of temperature anomaly in Vättern (Sweden) were $-0.03^{\circ} \mathrm{C}$ (i.e., below the 20 -year base period mean) in summer 2017. There is a clear contrast between Scandinavian lake surface temperature anomalies and those in central Europe, with lake temperature anomalies in the latter region up to $1^{\circ} \mathrm{C}$ higher than average (Plate 2.1b; Fig. 2.4). This is also confirmed by in situ lake temperature anomalies, for example, $+0.7^{\circ} \mathrm{C}$ in 2017 for Lake $\mathrm{Zu}$ rich (Switzerland). Above-average lake surface temperature anomalies are also observed from the satellite data in northwest Canada and the western United States, confirmed by in situ data (e.g., $+0.8^{\circ} \mathrm{C}$ in Lake Washington). Lakes in the central and eastern U.S. experienced near-normal lake surface temperatures in 2017, with some regions showing below-average

(a)

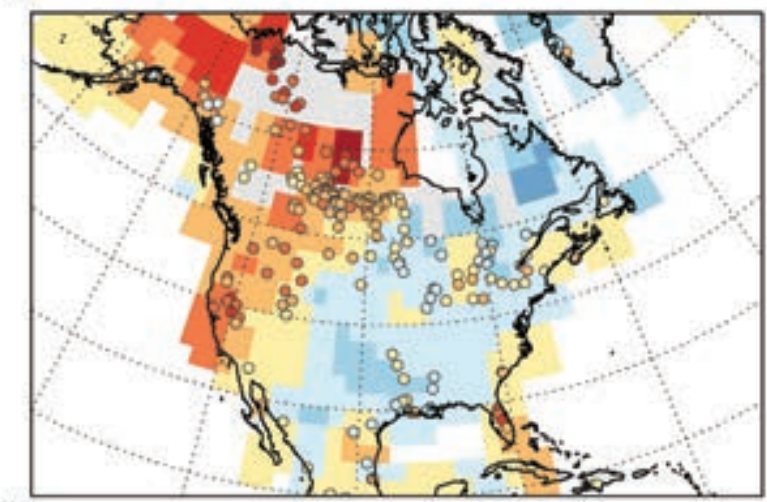

(b)
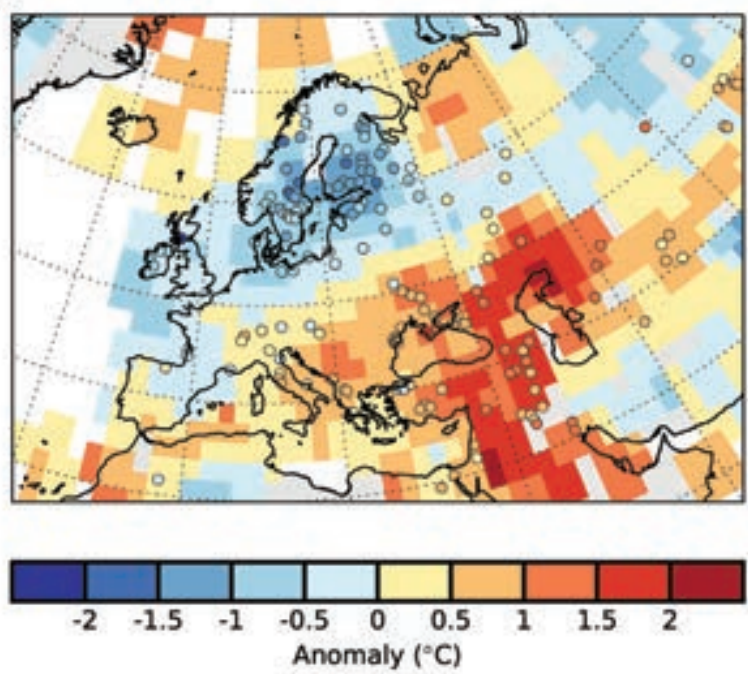

FIG. 2.4. Comparisons of satellite-derived lake surface water temperature anomalies (colored dots) to air surface temperature anomalies (calculated from the NASA GISS Surface Temperature Analysis) in (a) North America and (b) Europe in 2017. Temperatures anomalies ( ${ }^{\circ} \mathrm{C}$; relative to $\left.1996-2015\right)$ are calculated for the NH warm season (Jul-Sep). 
lake surface temperatures. These regional differences in lake surface temperature anomalies in 2017 reflect the July-September average surface air temperature anomalies (relative to 1996-2015), calculated from the NASA GISS surface temperature analysis (Fig. 2.4; Hansen et al. 2010; GISTEMP Team 2016). In summary, surface air and lake water temperatures in 2017 were generally coherent.

\section{3) LAND surface temperature extremes-}

S. E. Perkins-Kirkpatrick, M. G. Donat, and R. J. H. Dunn

Changes in temperature extremes are important for climate monitoring due to their sensitivity to relatively small changes in average conditions. Small changes in average temperature can induce much larger changes in the intensity and frequency of corresponding heat extremes. Land surface temperature extremes during 2017 were characterized by overall increased occurrences of warm temperatures and reduced occurrences of cooler temperatures compared to long-term averages. A number of anomalously high temperature events occurred in 2017, in both maximum and minimum daily temperatures. As in previous reports, the GHCNDEX quasi-global gridded dataset (Donat et al. 2013b) is used to monitor global temperature extremes over land. This is quasiglobal, as an absence of data over some locations hinders the robust calculation of extremes indices and their trends. A suite of temperature and precipitation extremes indices (Zhang et al. 2011) is first calculated from observed daily station time series in the GHCNDaily archive (Menne et al. 2012), before interpolating the indices on global grids. Some of the fields of extremes indices have limited spatial coverage, especially across central and eastern Asia, for those derived from minimum temperatures compared to those from maximum temperatures. Therefore, complete coverage derived from the ERA-Interim reanalysis (Dee et al. 2011a) is shown separately in Online Figs. S2.7-S2.9.

Results are presented for a selection of the temperature indices in GHCNDEX: TX90p (frequency of warm days when daily temperatures exceed the 90th percentile of daily maximum temperatures calculated over the 1961-90 base period), TX10p (cool day frequency, daily temperatures below the 10th percentile), TN90p and TN10p (warm and cool night frequency, respectively), and TXx, TXn, TNx, and TNn (extrema of annual maximum and minimum temperatures, respectively; see online supplement for full definitions). Averaged over areas where there are observations, there were fewer warm days (TX90p) and more cool nights (TN10p) in 2017 compared to 2016 . However, such values are still typically well above and below the climatologically defined threshold of 36.5 days per year, respectively (Fig. 2.5).

Over areas where observations exist, the annual occurrence of warm days (TX90p) and nights (TN90p; Plates 2.1c,d) was typically well above the climatological average. In particular, eastern Asia experienced 20 more warm days than the threshold, whereas southern Europe and eastern Australia experienced more than 40 additional warm days. The frequency of warm nights was less than warm days over Australia and southern Europe but was still 10-30 days and 30-40 days more than the threshold, respectively. Conversely, the U.S. and Canada experienced slightly more warm nights than warm days.

Cool days and nights (TX10p, TN10p; Fig. 2.6) were less frequent than the threshold over some regions, with around 20 fewer cool nights over the U.S. and Canada and 30 fewer nights for Europe. For northern regions with available data, annual minima during both daytime and nighttime (TXn, TNn, Online Figs. S2.4c,d) were very high. The respective annual maxima, however, did not always display similar anomalies (TXx, TNx; Online Figs. S2.4a,b).

The frequency of warm daytime temperatures (TX90p; Online Fig. S2.5) varied across the seasons. During boreal winter (DJF 2016/17), warm day occurrences much higher than the threshold occurred over northern Europe and eastern China, Russia, and Australia. However, western Australia and the

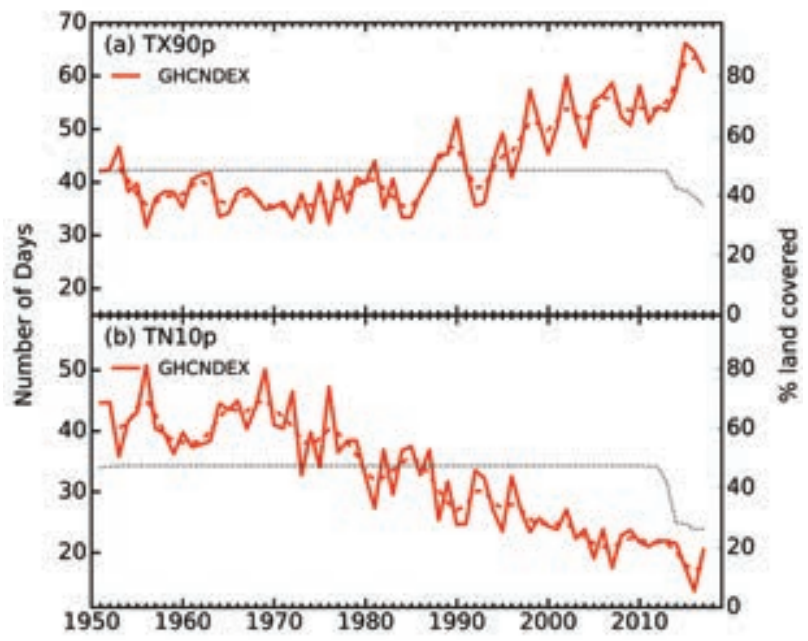

Fig. 2.5. Global average time series of the number of (a) warm days (TX90p) and (b) cool nights (TNIOp) from GHCNDEX relative to 196I-90. (This reference period is used for consistency with other ETCCDI index products.) By construction, these indices have an average of 36.5 days over the reference period. The dotted black line shows the percent of land area with data. Units: days. 
(a) TX10p Cool Days

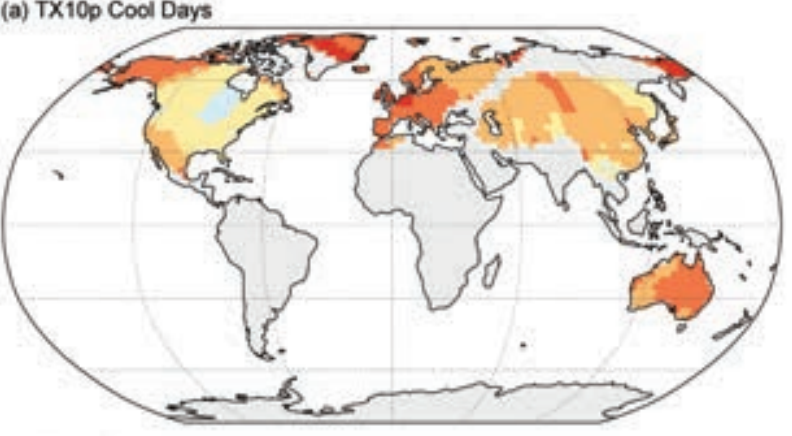

(b) TN10p Cool Nights

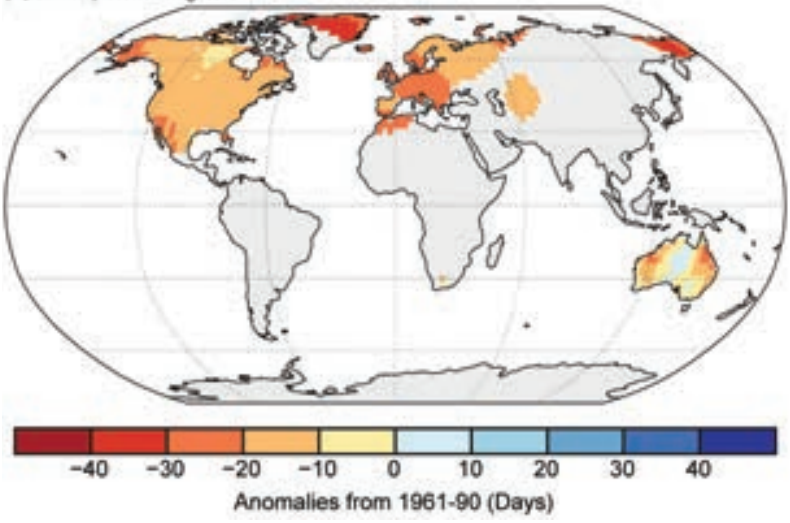

FIG. 2.6. (a) Cool days (TXIOp) and (b) cool nights (TNIOp) anomaly maps for 2017 (GNCHDEX).

western U.S. and Canada experienced occurrences of warm days lower than the threshold. Near-average or higher than the threshold occurrences of warm days occurred during boreal spring (MAM), particularly over northwest Russia and China, where more than ten extra warm days were observed.

With the exception of the eastern U.S. and northern Europe, all areas with available data saw around five or more warm days than average in the boreal summer (JJA). During this period, numerous warm temperature events occurred worldwide: Australia experienced its warmest winter on record based on daily maximum temperature observations (www.bom.gov.au/climate/current /season/aus/archive/201708.summary.shtml, accessed 16 February 2018). However, over Southern Australia cool day occurrences during the austral winter (TN10p; Online Fig. S2.5) were higher than average, indicative of very dry conditions early in the season. A severe heatwave also impacted the southwest U.S. during June, resulting in temperatures so high that some aircraft in Arizona and California were grounded (www.climate.gov/news-features /event-tracker/heat-roasts-western-united-states, accessed 16 February 2018). Also during June, extreme temperatures of at least $50^{\circ} \mathrm{C}$ were reported for multiple locations in the Middle East (https://public.wmo.int/en/media/news /records-fall-amid-heatwaves, accessed 16 February 2018). A heatwave engulfed southern and eastern Europe during late July and early August, causing human casualties.

Boreal autumn (SON) saw higher-than-threshold occurrences of warm days (TX90p) over most regions except for northern Russia and Europe, where around five fewer warm days than the threshold occurred. For most regions, the anomalous frequency of seasonal warm days was larger than that of seasonal cool days (TX10p; Online Figs. S2.5e-h); however, there were still fewer cool days than the climatological average, giving warm anomalies.

During each season, the vast majority of the globe experienced two to five fewer cool nights than the threshold (TN10p; Online Figs. S2.5m-p) but higher numbers of warm nights (TN90p; Online Figs. S2.5i-1), with scattered areas experiencing warm nights close to the climatological average.

With the exception of JJA, much of the globe experienced minimum daytime temperatures (TXn; Online Figs. S2.6e-h) that were at least $2^{\circ} \mathrm{C}$ above the 1961-90 average. During JJA, such anomalies were up to $2^{\circ} \mathrm{C}$ below the climatological average over northeast Europe and East Asia. The former were caused by cyclonic activity, especially in June. The signature of these events is also evident in the reduced frequency of warm days (TX90p) during JJA (Online Figs. S2.5a,b). Anomalies $2^{\circ} \mathrm{C}$ below average were also experienced over East Asia during SON. Minimum nighttime temperatures (TNn, Online Figs. S2.6m-p) were consistently warm throughout most seasons and were quite large $\left(3^{\circ} \mathrm{C}\right.$ or higher) over the U.S., Canada, and Europe during MAM and DJF.

4) Tropospheric temperature-J. R. Christy, S. Po-Chedley, and $C$. Mears

Following the record high global lower tropospheric temperature (LTT) in 2016, LTT decreased by more than $0.1^{\circ} \mathrm{C}$ in 2017 . The annual, globally averaged LTT (the bulk atmosphere below $10-\mathrm{km}$ altitude) was, depending on the dataset, $+0.38^{\circ}$ to $+0.58^{\circ} \mathrm{C}$ above the $1981-2010$ mean. 2017 was generally the second or third warmest year since measurements began in 1958 (Fig. 2.7) and the warmest non-El Niño year.

Direct measurements of LTT by radiosonde datasets have reasonable spatial coverage since 1958. Radiosonde data are complemented by satellites and reanalysis products since late 1978, except JRA55 reanalyses which begin in 1958 . These datasets are described in Christy (2016). These bulk-layer 


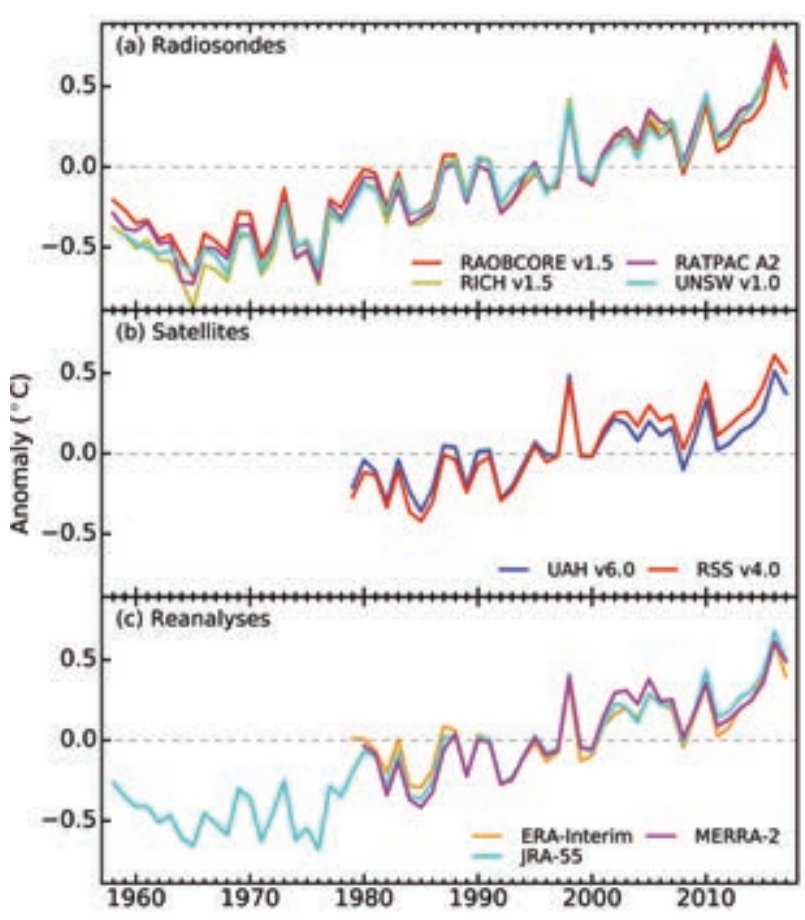

Fig. 2.7. Anomalies of global mean LTT $\left({ }^{\circ} \mathrm{C} ; 198 \mathrm{I}-2010\right.$ base period): (a) radiosondes, (b) satellites, and (c) reanalyses.

atmospheric temperatures are closely related to the heat content of the atmospheric climate system and thus are valuable indicators for quantifying heat energy changes expected from rising concentrations of greenhouse gases and other forcings.

The latitude-time depiction of the LTT anomalies (Fig. 2.8) beginning in 1979 illustrates major tropospheric responses to El Niño events, most clearly evident in the tropics $(1983,1987,1998,2010$, and 2016). The major El Niños in 1998 and 2016 reveal comparable magnitudes of peak anomalies, but 2016 is set against higher background temperatures. Since 2013, few zonal average anomalies have been negative.

Annual global LTT anomalies are closely tied to El Niños and La Niñas, which can be characterized by the Multivariate El Niño Southern Oscillation Index (MEI; Wolter and Timlin 2011) shown in Fig. 2.8a. As noted, 2017 followed a major El Niño (MEI > 2 in early 2016) yet its global LTT experienced a small decline of less than $0.2^{\circ} \mathrm{C}$ while previous year-to-year declines were greater (e.g., 1999 was over $0.4^{\circ} \mathrm{C}$ cooler than the El Niño year of 1998). Part of the reason was the rise of El Niño-like characteristics (MEI > 1.4) by May 2017 before La Niña conditions ensued. The LTT anomaly, which generally lags the MEI by 3-5 months, apparently responded with record high values in September and October, thereby mitigating the late-year La Niña cooling effect in the annual average.

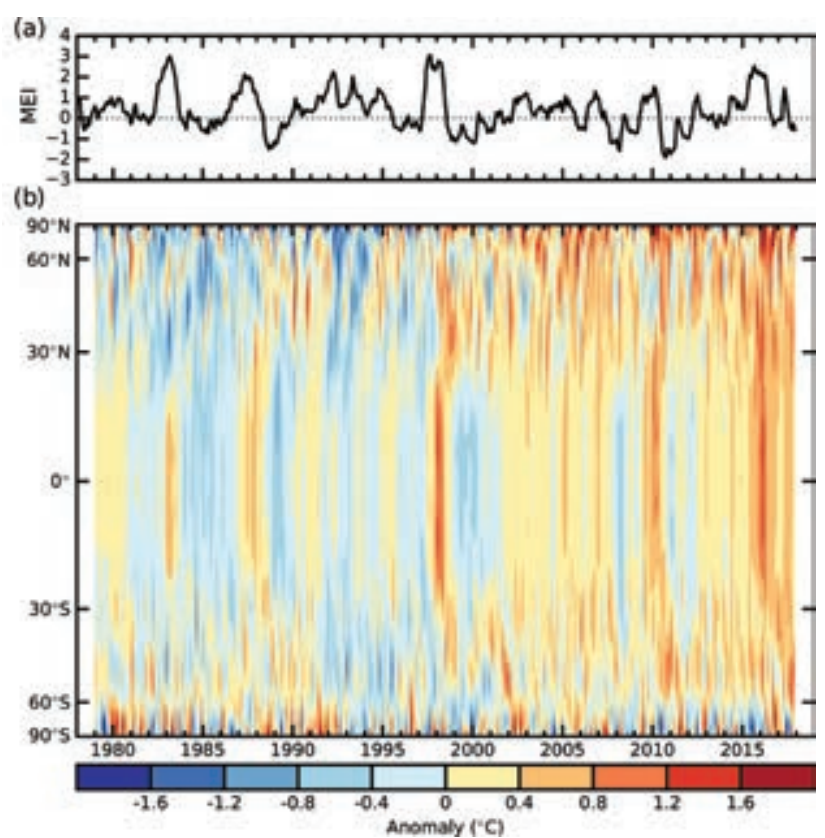

FIG. 2.8. (a) Multivariate ENSO index (MEI; Wolter and Timlin 20II). (b) Latitude-time depiction of ERA-I LTT anomalies ( ${ }^{\circ} \mathrm{C}$; base period of 198I-2010, cosine latitude weighting).

Annually averaged LTT was above average over most of the globe in 2017 (Plate 2.1e). Regionally, warm anomalies for the year occurred throughout the Arctic poleward of $65^{\circ} \mathrm{N}$. The midlatitude belts in both hemispheres featured areas with mostly abovenormal temperatures with centers in southwestern North America, southwestern Europe, central China, the northern Pacific Ocean, southern midlatitude oceans, and eastern Australia. The Antarctic was generally cooler than average as were other scattered locations. (Plate 2.1e).

The long-term global LTT trend based on radiosondes (starting in 1958) is $+0.17^{\circ} \pm 0.02^{\circ} \mathrm{C}$ decade $^{-1}$. Starting in 1979 and using the average of radiosondes, satellites, and reanalyses (weighted one-third each), the trend is fairly similar, at $+0.16^{\circ} \pm 0.04^{\circ} \mathrm{C}$ decade $^{-1}$. The range represents the variation among the individual datasets which serves as a proxy for the structural uncertainty seen in Fig. 2.7 and Table 2.2. Efforts to document and understand the differences among datasets continue. Accounting for the magnitude of the year-to-year variations results in a statistical confidence range of $\pm 0.06^{\circ} \mathrm{C}$ decade $^{-1}$, meaning that the trends are significantly positive.

The positive trends noted in this assessment represent the net effect of both anthropogenic (e.g., increasing concentrations of greenhouse gases) and natural forcings. For example, major volcanic eruptions injected solar-reflecting aerosols into the strato- 


\begin{tabular}{|c|c|c|c|c|c|c|}
\hline \multirow[b]{2}{*}{ Start Year: } & \multicolumn{2}{|c|}{ Global LTT } & \multicolumn{2}{|c|}{ Tropical LTT } & \multicolumn{2}{|c|}{ Tropical TTT } \\
\hline & 1958 & 1979 & 1958 & 1979 & 1958 & 1979 \\
\hline \multicolumn{7}{|c|}{ Radiosondes } \\
\hline RAOBCORE & +0.15 & +0.15 & +0.14 & +0.13 & +0.14 & +0.13 \\
\hline $\mathrm{RICH}$ & +0.19 & +0.20 & +0.18 & +0.17 & +0.17 & +0.17 \\
\hline RATPAC & +0.18 & +0.20 & +0.15 & +0.15 & +0.15 & +0.15 \\
\hline UNSW (to 2015) & +0.17 & +0.16 & +0.15 & +0.11 & +0.13 & +0.10 \\
\hline \multicolumn{7}{|c|}{ Satellites } \\
\hline UAHv6.0 & - & +0.13 & - & +0.12 & - & +0.12 \\
\hline RSSv4.0 ${ }^{\mathrm{b}}$ & - & +0.19 & - & +0.15 & - & +0.19 \\
\hline NOAAv4.0 & - & - & - & - & - & +0.21 \\
\hline UWvi.oc & - & - & - & - & - & +0.17 \\
\hline \multicolumn{7}{|c|}{ Reanalyses and Climate Models after Reanalyses } \\
\hline ERA-I & - & +0.13 & - & +0.10 & - & +0.13 \\
\hline JRA-55 & - & +0.16 & - & +0.13 & - & +0.14 \\
\hline MERRA-2 & - & +0.17 & - & +0.14 & - & +0.15 \\
\hline CMIP5 Mean & +0.21 & +0.27 & +0.22 & +0.29 & +0.25 & +0.31 \\
\hline
\end{tabular}

${ }^{a}$ The UAH LTT vertical profile is slightly different than the others with much less emphasis on surface emissions and slightly more in the midtroposphere. Calculations indicate UAH LTT would be $+0.01^{\circ} \mathrm{C}$ decade $^{-1}$ warmer if using the traditional LTT profile represented by other datasets here.

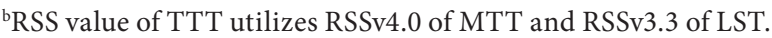

'UW value of TTT utilizes MTT from UWv1.0 and LST from NOAAv4.0.

sphere in 1963, 1982, and 1991, depressing global temperatures for a few years each time. The latter two events, being early in the current 1979-2017 period, tilted the global trend since 1979 to be more positive by about $+0.06^{\circ} \mathrm{C}$ decade $^{-1}$ (Christy and McNider 2017). There is evidence that other time-varying factors such as internal climate variability related to oceanic processes, a recent reduction in solar irradiance, and/or the presence of aerosols from natural (e.g., minor volcanic activity) and anthropogenic sources also affected the temperature and likely had a role in reducing post- 2000 values and thus contributed to the so-called "warming hiatus" from 2000 to 2014 (Wuebbles et al. 2017).

Christy (2017) examined tropical trends for the layer centered in the midtroposphere (MTT), where trends are expected to respond rapidly to increases in greenhouse gases. However, the tropical MTT profile includes a small portion of the stratosphere where long-term cooling has occurred (not shown). This influence leads to an MTT trend that is cooler than would be measured in the troposphere alone by approximately $0.03^{\circ}-0.04^{\circ} \mathrm{C}$ decade $^{-1}$. Following the method of Fu et al. (2004), this year's results are provided from a weighted average of the MTT and LST channels that largely removes the stratospheric portion, producing a better estimate of the full troposphere itself,

Examining the various datasets of the tropical TTT trend for 1979-2017 (Table 2.2), it is noted that the magnitude of the trend is similar to LTT in most cases and always greater than MTT (not shown). Using the average of 102 climate model simulations from the IPCC CMIP-5 (Flato et al. 2013), we see that because of the incorporation of more influence of the upper level tropospheric layers, for which trends are more positive than the lower troposphere (Christy 2017), the TTT trends slightly exceed those of LTT in most cases.

5) Stratospheric temperature-J. R. Christy and C. Covey

The stratosphere is the atmospheric layer above the tropopause $(\sim 17 \mathrm{~km}$ altitude near the equator, $\sim 9 \mathrm{~km}$ at the poles). Its upper boundary is $\sim 50 \mathrm{~km}$. Radiosondes have observed the stratosphere, typically up to $\sim 20 \mathrm{~km}$, with coverage sufficient for global 
averaging since 1958. Since 1978 satellites have carried microwave sounding units (MSUs) to monitor the intensity of radiances which is directly related to lower stratospheric temperature (LST). The MSU LST channel detects emissions from $\sim 14$ to $\sim 27 \mathrm{~km}$ with maximum signal at $\sim 18 \mathrm{~km}$; thus in the deep tropics there is some upper tropospheric influence. Stratospheric sounding units (SSUs) monitor layers completely above the tropopause.

In 2017, the annual globally averaged LST rose about $0.2^{\circ} \mathrm{C}$ from its value in 2016 , which was the record low in six of the nine datasets (Figs. 2.9a-c). Episodes in which the tropopause rises into typically stratospheric levels lead to cooler MSU LST values because upper tropospheric air is cooler than the stratospheric air it displaces. This occurred during the major El Niño event of 2016. The 2017 anomaly was approximately $-0.4^{\circ} \mathrm{C}$, but varied among the datasets analyzed here by $\pm 0.2^{\circ} \mathrm{C}$.

Observed long-term globally averaged LST time series in Figs. 2.9a-c include three volcanic

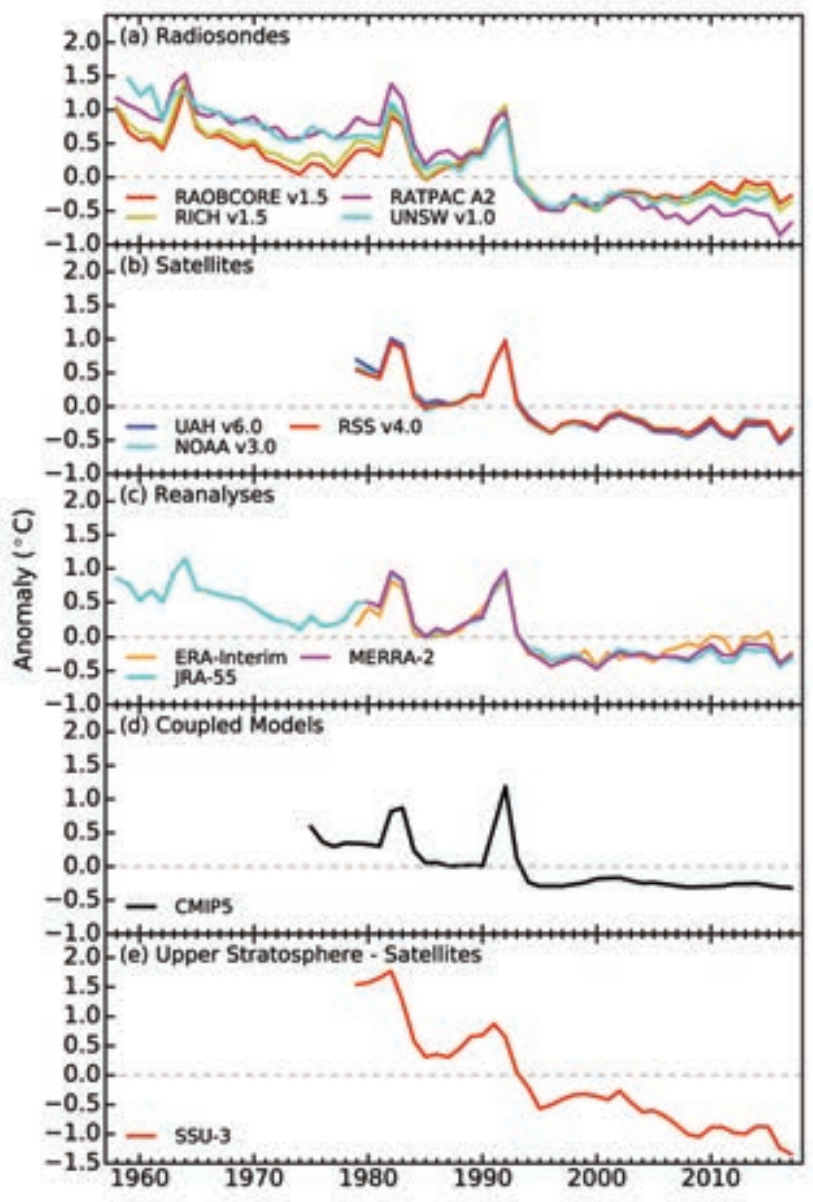

FIG. 2.9. Time series of annual LST anomalies $\left({ }^{\circ} \mathrm{C}\right.$; 198 I-20 I 0 base period): (a) radiosondes, (b) satellites, (c) reanalyses, and (d) coupled climate models. (e) Upper stratospheric temperature anomalies. events (1963 Mt. Agung, 1982 El Chichón, and 1991 Mt. Pinatubo), whose stratospheric aerosols each led to warming spikes. After Pinatubo (and perhaps El Chichón), LST declined to levels lower than prior to the eruption, giving a stair-step appearance. Ozone depletion and increasing $\mathrm{CO}_{2}$ in the atmosphere contribute an overall decline, so trends in global LST are clearly negative until approximately 1996.

In Figs. 2.9a-c, the global trends through 2017, based on the average of all displayed datasets, are $-0.29^{\circ},-0.27^{\circ}$, and $+0.01^{\circ} \mathrm{C}$ decade $e^{-1}$ for periods beginning in 1958, 1979, and 1996, respectively. The satellite time series are in exceptional agreement with each other $(r>0.99)$ and with reanalyses (highest $r$ with JRA-55 > 0.96). The radiosonde datasets are limited by geographical coverage; even so, satellites and radiosondes achieved $\mathrm{r}>0.95$.

Absence of lower stratospheric cooling in the global mean since 1996 is due to recovery of the ozone layer, especially at high latitudes, as the Montreal Protocol and its Amendments on ozone-depleting substances has taken effect (Solomon et al. 2017; Randel et al. 2017). The pattern of LST anomalies in 2017 is depicted in Plate 2.1f. Warmer-than-average conditions occurred poleward of $50^{\circ} \mathrm{S}$ and over the north polar Western Hemisphere $\left(180^{\circ} \mathrm{E}\right.$ to $\left.360^{\circ} \mathrm{E}\right)$. In general below-average temperatures prevailed elsewhere, consistent with the generally negative trends in Figs. 2.9a-c.

Two prominent features of LST are sudden stratospheric warmings (SSWs) and the quasi-biennial oscillation (QBO). SSWs usually appear during the northern polar night. Figures 2.10a,b shows pentad (5-day average) LST anomalies for the north and south polar caps $\left(65^{\circ}-85^{\circ}\right.$ latitude average, values smoothed 1-2-1 in time). Excursions over the North Pole often exceed $10^{\circ} \mathrm{C}$, with $5^{\circ} \mathrm{C}$ departures in almost every year. 2017 did not experience an event $>5^{\circ} \mathrm{C}$ in the north, but in pentad 66, near the end of 2016, both polar caps exceeded $5^{\circ} \mathrm{C}$ (unsmoothed). Because these events are related to the breakdown of the polar night vortex, they occur less frequently and with less intensity over the South Pole due to its more zonally symmetric circulation. Sudden cooling episodes also occur and are related to the impact of ozone depletion in spring over the south polar cap.

The QBO is typically defined by the time-height pattern of zonal wind anomalies in the tropics, but it can also be detected in the LST temperature anomalies. The QBO alternates between westerly (warm) and easterly (cold) wind shear regimes in the tropical stratosphere in which the feature propagates downward from the upper stratosphere and dissipates near 


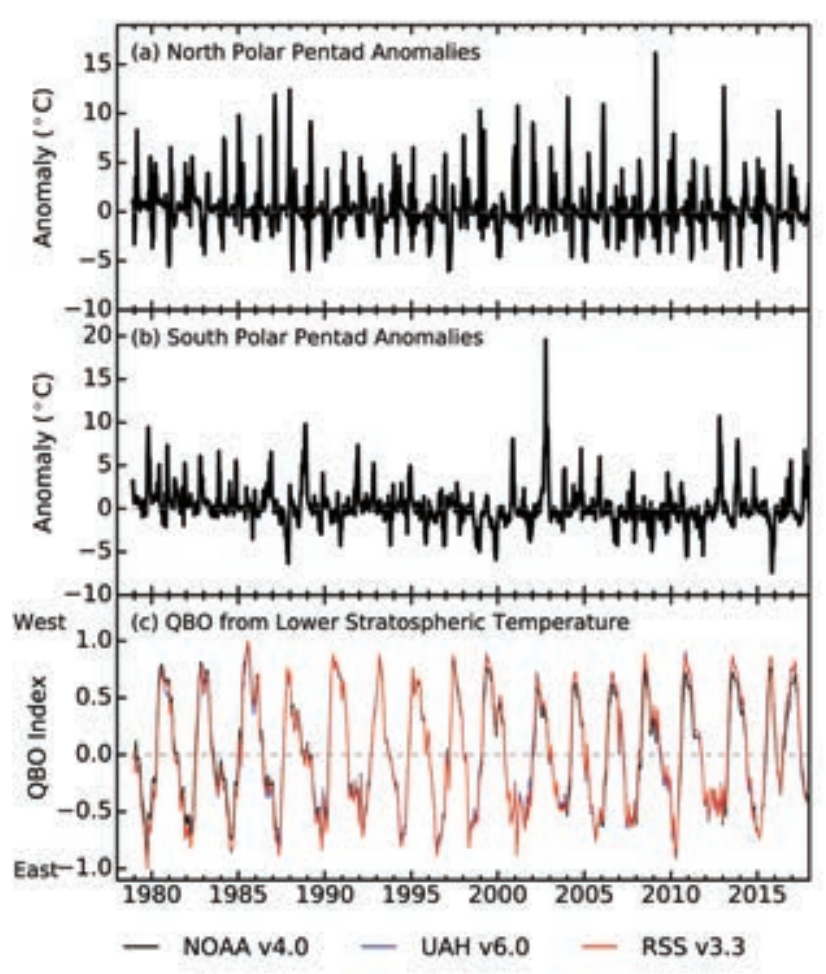

FIG. 2.I0. Time series of pentad (5-day averages, smoothed by I-2-I in time) LST anomalies ( ${ }^{\circ} \mathrm{C}$ ) for (a) northern and (b) southern polar caps bounded by $65^{\circ}$ and $85^{\circ}$ latitude. (c) Monthly time series of QBO index as averaged from UAH, RSS, and NOAA LST.

the tropopause. Figure 2.10c extends the temperaturebased QBO index of Christy and Drouilhet (1994) through 2017.

The 16 QBO periods in Fig. 2.10c indicate a mean length of 27.4 months. The longest ( 35 months) ended in April 2002, and the shortest by a substantial margin (17 months) concluded in March 2017. The cycle that finished in 2017 included the weakest (warmest) easterly regime in this 39-year history.

There is relatively high confidence in explaining the variations of global mean stratospheric temperature. When climate models used in the IPCC AR5 (Flato et al. 2013) are provided with forcing estimates related to changes in ozone, carbon dioxide, volcanic aerosols, solar variability, etc., the multi-model mean agrees with the satellite observations to a high level $(\mathrm{r}>0.96)$. Figure $2.9 \mathrm{~d}$ shows the mean of 102 CMIP-5 simulations of the LST time series. Aquila et al. (2016) examined forcing agents and concluded that about $1 / 3$ of the decline was due to increasing concentrations of greenhouse gases and $1 / 3$ to ozone-depleting substances. At higher levels of the stratosphere, in the layer monitored by the SSU channel $3(\sim 40-50$ $\mathrm{km}$ altitude; Fig. 2.9e), the observed trend is approximately $-0.7^{\circ} \mathrm{C}$ decade $^{-1}$ of which $75 \%$ is estimated to result from enhanced greenhouse gas concentrations and most of the remaining decline from ozone loss (Aquila et al. 2016).

\section{c. Cryosphere}

I) Permafrost thermal state-J. Noetzli, H. H. Christiansen, P. Deline, M. Gugliemin, K. Isaksen, V. E. Romanovsky, S. L. Smith, L. Zhao, and D. A. Streletskiy

Permafrost is an invisible component of the cryosphere in polar and high mountain areas and is defined as earth materials (eg., soil, rock) that exist at or below $0^{\circ} \mathrm{C}$ continuously for at least two consecutive years. Long-term monitoring of its conditions primarily relies on ground temperatures measured in boreholes. Overlying the permafrost is the active layer, which thaws in summer and refreezes in winter. Globally, permafrost observation data (thermal state and active layer dynamics) are collected in the database of the Global Terrestrial Network for Permafrost (GTN-P; Biskaborn et al. 2015), which is part of the Global Climate Observing System (GCOS) of the World Meteorological Organization (WMO).

The long-term trend of rising permafrost temperatures worldwide continued in 2017. There is, however, considerable regional variability, mainly depending on the temperature range, surface characteristics, and ground ice content at the site. The general picture is that a more substantial increase is observed in regions with cold continuous permafrost compared to areas with warm permafrost at temperatures within $2^{\circ}-3^{\circ} \mathrm{C}$ of the freezing point. This is mainly a result of latent heat effects associated with melting of ground ice. The lowest permafrost temperatures - and thus highest warming rates-were observed in the high Arctic of northern Alaska, Canada, Svalbard, and Russia, as well as in shaded flanks of high mountain peaks. Record high temperatures were observed in 2017 for nearly all sites in Alaska and in northwestern Canada. In other areas (northeastern Canada, Nordic countries), permafrost temperatures measured in 2016/17 were among the highest ever recorded (updates from Christiansen et al. 2010; Romanovsky et al. 2017; Smith et al. 2015, 2017; Ednie and Smith 2015; Boike et al. 2018). A detailed description of permafrost conditions in the Arctic and sub-Arctic is provided in Section $5 \mathrm{~g}$. Here, the focus is on updated results from mountain permafrost (European Alps, Nordic countries, and central Asia) and permafrost in continental Antarctica (Streletskiy et al. 2017).

In mountain permafrost in the European Alps most boreholes are located between 2600 and $3000 \mathrm{~m}$ a.s.l. (above sea level), with permafrost temperatures typically above $-3^{\circ} \mathrm{C}$. Permafrost temperatures have generally increased in the upper $20 \mathrm{~m}$ (Fig. 2.11), espe- 

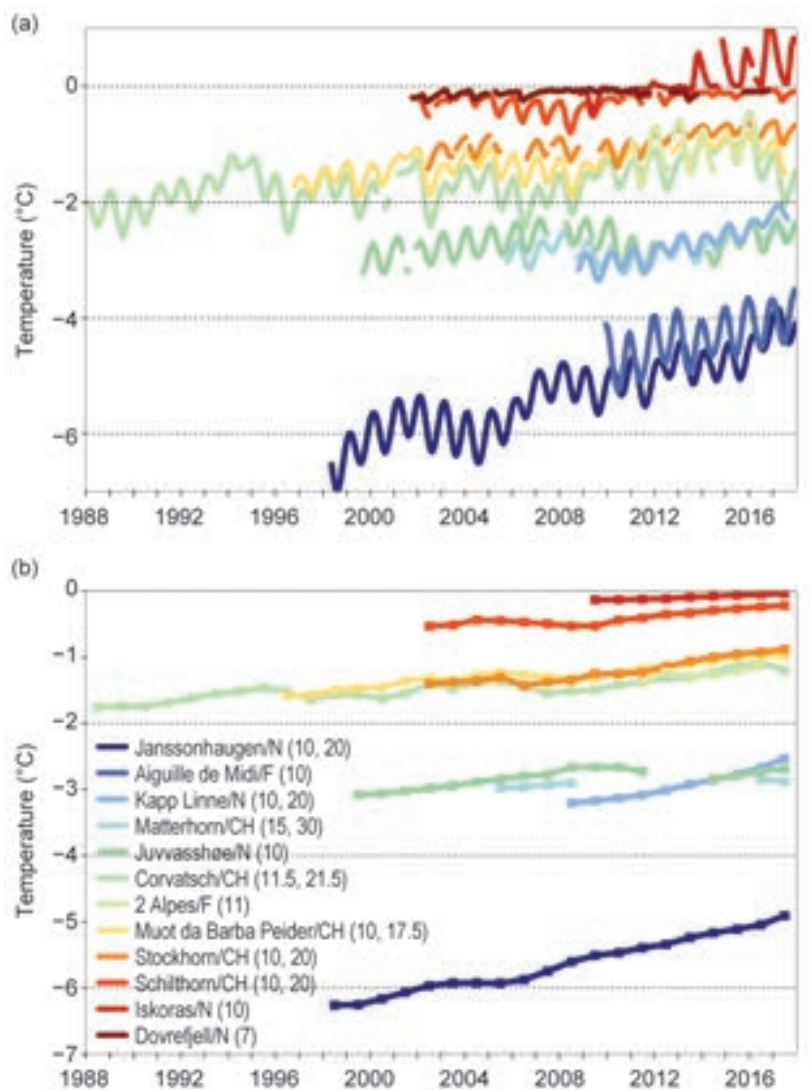

Fig. 2.II. Temperature $\left({ }^{\circ} \mathrm{C}\right)$ measured in permafrost boreholes in the European Alps and Nordic countries at depths of (a) $\sim 10 \mathrm{~m}$ (monthly means) and (b) $\sim 20 \mathrm{~m}$ (annual means). (Sources: Swiss Permafrost Monitoring Network PERMOS; Norwegian Meteorological Institute and the Norwegian Permafrost Database NORPERM; French Permafrost Monitoring Network PermaFRANCE.)

cially since 2009 and accentuated in 2015 (PERMOS 2016). The past two winters (2015/16 and 2016/17) interrupted this warming trend: a late and thin snow cover resulted in lower permafrost temperatures in debris slopes and on rock glaciers, which were visible down to about 20-m depth (updated from PERMOS 2016; Noetzli et al. 2018, paper to be presented at 5 th European Conf. Permafrost, EUCOP), for example, in the borehole on Corvatsch-Murtèl. This short-term cooling has also led to a decrease of rock glacier creep velocities relative to the previous years at multiple sites in Switzerland (updated from PERMOS 2016; Noetzli et al. 2018, paper to be presented at 5th European Conf. Permafrost, EUCOP). Rock temperatures in shaded flanks of the highest peaks can be as low as temperatures measured in the Arctic (Fig. 2.11; Noetzli et al. 2016). They closely follow air temperatures and the influence of snow is negligible (Gruber et al. 2004; PERMOS 2007), but only few and relatively short time series are available. In the Aiguille du Midi
Mont Blanc (France), permafrost temperature at 10-m depth continued to increase in the past two years and is expected to be at a very high level compared to the past decades (Fig. 2.11; updated from Magnin et al. 2015).

In Nordic countries, mountain permafrost temperatures continued to increase (updated from Isaksen et al. 2007; Christiansen et al. 2010). In southern Norway (Juvvasshøe) ground temperatures in 2017 were near-record high, a warming that followed a period of cooling between 2010 and 2013. Monitoring (since 2008) in northern Norway (Iškoras) shows evidence of thawing permafrost with ground temperatures well above $0^{\circ} \mathrm{C}$ at 10 -m depth since 2013/14 (Fig. 2.11). In the warm permafrost of the higher elevations of central Asia, ground temperatures are estimated to be in the range of $-2^{\circ}$ to $-0.5^{\circ} \mathrm{C}$ (Zhao et al. 2017) and have increased by up to $0.5^{\circ} \mathrm{C}$ decade $^{-1}$ since the early 1990s (update from Zhao et al. 2010). On the Qinghai-Tibetan Plateau (Fig. 2.12), the increase in ground temperature at $10-\mathrm{m}$ depth
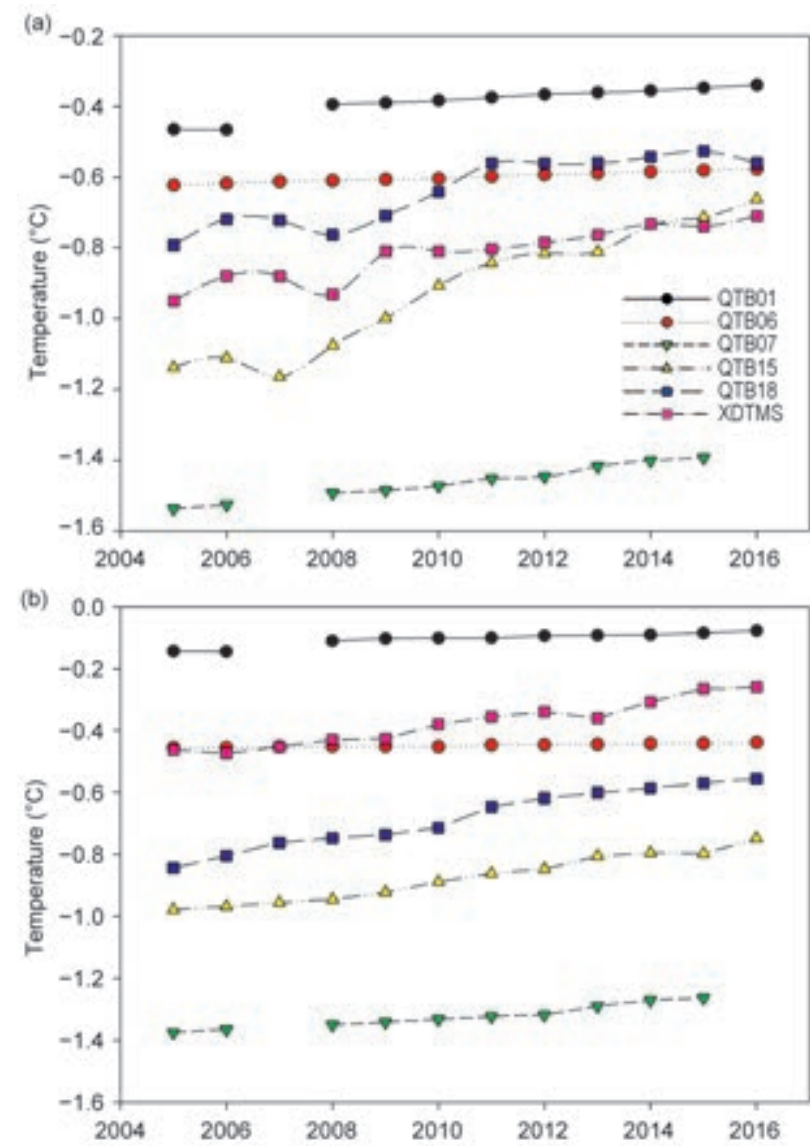

Fig. 2.12. Temperature $\left({ }^{\circ} \mathrm{C}\right)$ measured in permafrost boreholes along the Qinghai-Xizang Highway on the Tibetan Plateau at (a) 10 and (b) 20 m depth. (Source: Cryosphere Research Station on Qinghai-Xizang Plateau, CAS.) 


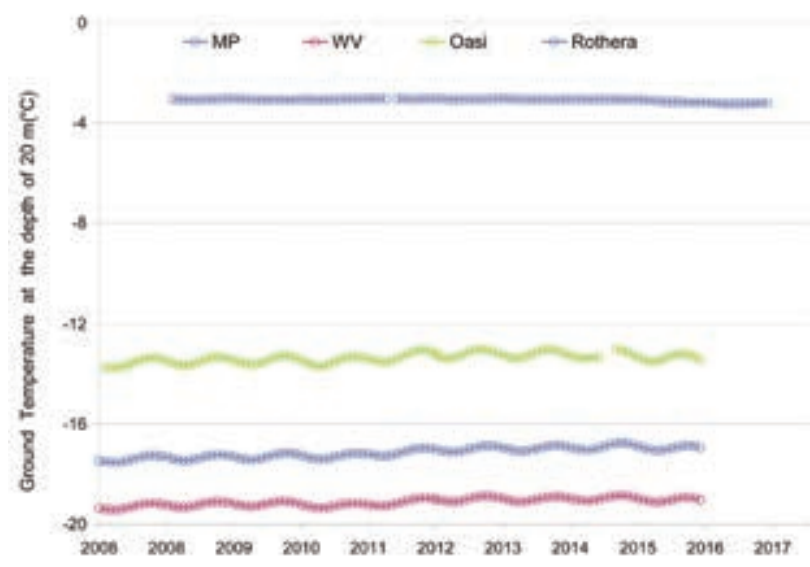

FIG. 2.I3. Observed borehole temperatures $\left({ }^{\circ} \mathrm{C}\right)$ in Antarctica at 20-m depth (monthly means): WV = Wright Valley; MP = Marble Point; Oasi in continental Antarctica; and Rothera in maritime Antarctica. (Source: Insubria Permafrost Database.)

reached $0.5^{\circ} \mathrm{C}$ (site QTB15) between 2005 and 2016, and up to $0.3^{\circ} \mathrm{C}$ at $20-\mathrm{m}$ depth. Along the latitudinal transect in Victoria Land, continental Antarctica [between $77^{\circ} 31^{\prime} S$, Wright Valley (WV in Fig. 2.13) and $74^{\circ} 41^{\prime} \mathrm{S}$, Oasi] permafrost temperature at 20 - $\mathrm{m}$ depth is among the lowest recorded during the period of observation. It continued to increase despite stable air temperatures since 1960, and the temperature rise is more pronounced at the southern coast (Marble Point; MP in Fig. 2.13). In contrast, temperatures measured in the Rothera borehole $\left(67^{\circ} \mathrm{S}\right)$ in the northern Antarctic Peninsula decreased in the past two years. This is mainly due to regional cooling of the atmosphere and the influence of snow cover (Guglielmin et al. 2014).

An increasing trend in active layer thickness (ALT) since the mid-1990s is observed in most permafrost regions except the Antarctic Peninsula, where ALT has been stable or even decreased since 2009 (Hrbáček et al. 2018). Extremely warm summer conditions in the Arctic in 2016 resulted in extremely high ALT values. They were reinforced in North America in the summer of 2017 resulting in the ALT close to the recorded maximum. In contrast, in Europe and along the Russian Arctic coast, the cold summer of 2017 led to a decrease in ALT relative to the previous year to values around the long-term mean (see Chapter 5 for more details).

\section{2) Northern Hemisphere continental snow cover EXTENT-D. A. Robinson}

Annual snow cover extent (SCE) over Northern Hemisphere (NH) lands averaged 25.8 million $\mathrm{km}^{2}$ in 2017. This is 0.7 million $\mathrm{km}^{2}$ more than the 48 -year average (mapping extends back to late 1967; however, several early years in the record are incomplete) and ranks as the eighth most extensive cover on record (Table 2.3 and Fig. 2.14). This is 1.2 million $\mathrm{km}^{2}$ greater than the 2016 mean extent. Snow extent over both Eurasia and North America, including the
TABLE 2.3. Monthly and annual climatological information on Northern Hemisphere and continental snow extent between Nov 1966 and Dec 2017. Included are the numbers of years with data used in the calculations, means, standard deviations, 2017 values and rankings. Areas are in millions of $\mathrm{km}^{2}$. 1968, 1969, and 197I have I, 5 , and 3 missing months respectively, thus are not included in the annual calculations. North America (N. Am.) includes Greenland. Ranks are from most extensive (I) to least (ranges from 48 to 52 depending on the month).

\begin{tabular}{|c|c|c|c|c|c|c|c|}
\hline \multicolumn{2}{|c|}{ extensive (I) to least (ranges from 48 to 52 depending on the month). } \\
\hline Years & $\begin{array}{c}\text { Mean } \\
\text { SCE }\end{array}$ & $\begin{array}{c}\text { Std. } \\
\text { Dev. }\end{array}$ & 2017 & $\begin{array}{c}\mathbf{2 0 1 7} \\
\text { NH } \\
\text { Rank }\end{array}$ & $\begin{array}{c}\text { Eurasia } \\
\text { Rank }\end{array}$ & $\begin{array}{c}\text { N. Am. } \\
\text { Rank }\end{array}$ \\
\hline Jan & 51 & 47.2 & 1.6 & 49.2 & 6 & 7 & 13 \\
\hline Feb & 51 & 46.0 & 1.8 & 46.0 & 22 & 19 & 37 \\
\hline Mar & 51 & 40.5 & 1.9 & 40.1 & 28 & 27 & 32 \\
\hline Apr & 51 & 30.5 & 1.7 & 31.2 & 16 & 21 & 21 \\
\hline May & 51 & 19.3 & 2.0 & 20.7 & 12 & 12 & 18 \\
\hline Jun & 50 & 9.6 & 2.4 & 9.3 & 27 & 20 & 40 \\
\hline Jul & 48 & 4.0 & 1.2 & 3.5 & 28 & 36 & 19 \\
\hline Aug & 49 & 3.0 & 0.7 & 2.9 & 21 & 28 & 14 \\
\hline Sep & 49 & 5.4 & 0.9 & 6.2 & 10 & 12 & 15 \\
\hline Oct & 50 & 18.4 & 2.7 & 21.2 & 9 & 11 & 7 \\
\hline Nov & 52 & 34.1 & 2.1 & 36.0 & 9 & 17 & 7 \\
\hline Dec & 52 & 43.7 & 1.9 & 43.6 & 33 & 31 & 24 \\
\hline Ann & 48 & 25.1 & $\mathbf{0 . 8}$ & $\mathbf{2 5 . 8}$ & $\mathbf{8}$ & 11 & 15 \\
\hline
\end{tabular}




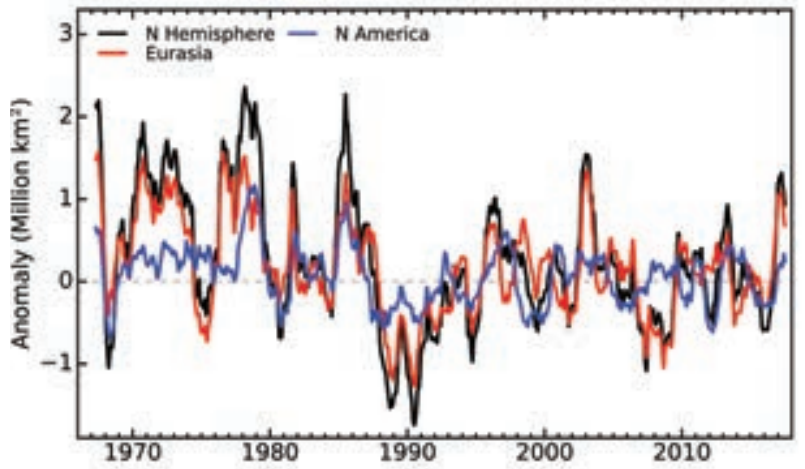

FIG. 2.14. Twelve-month running anomalies of monthly snow cover extent $\left(\times 10^{6} \mathrm{~km}^{2}\right)$ over $\mathrm{NH}$ lands as a whole (black), Eurasia (red) and North America (blue) plotted on the 7th month using values from Nov 1966 to Dec 2017 . Anomalies are calculated from NOAA snow maps. Mean hemispheric snow extent is $\mathbf{2 5}$.I million $\mathbf{k m}^{2}$ for the full period of record. Monthly means for the period of record are used for 9 missing months between 1968 and 1971 in order to create a continuous series of running means. Missing months fall between Jun and Oct, no winter months are missing.

Greenland ice sheet, is considered in this analysis. Monthly SCE in 2017 ranged from 49.2 million $\mathrm{km}^{2}$ in January to 2.9 million $\mathrm{km}^{2}$ in August. SCE is calculated at the Rutgers Global Snow Lab from daily SCE maps produced by meteorologists at the National Ice Center (a U.S. joint NOAA, Navy, and Coast Guard facility), who rely primarily on visible satellite imagery to construct the maps.

January $2017 \mathrm{NH}$ SCE was over 2 million $\mathrm{km}^{2}$ above average, which exceeds the average by greater than one standard deviation (SD) and ranks sixth highest of the past 51 Januaries. Eurasia (EU) maintained above-average SCE in February, ranking 19th highest, while SCE over North America (NA) decreased considerably to 15 th lowest. Given the greater land area of EU than NA, this resulted in a $\mathrm{NH}$ continental ranking of $22 \mathrm{nd}$ highest. Conditions across the two continents evened out in March, with each having the 21st highest SCE in April. Melt over both continents was delayed compared to many recent springs, with May SCE the 12th most extensive. Seasonally, spring (March-May) NH SCE was the largest since 2003 and the third most extensive since 1987. June 2017 SCE over Northern Hemisphere land was close to the long-term average, yet the most extensive since 2004, and by far the most extensive since 2007. June cover disappeared rather quickly over NA early in the month, resulting in the 11th smallest SCE on record, while Eurasia SCE was slightly above average but the largest since 2003 and third largest since 1997.
There was an early onset of the 2017/18 snow season across the NH, with $\mathrm{NH}$ September cover the tenth most extensive for the month on record. This behavior continued through the remainder of autumn over both EU and NA, with NH SCE ninth most extensive on record for both October and November, each month close to one SD above average. Autumn (September-November) NH SCE was the third highest among the 49 years with complete data, behind 2014 and 1996. As winter began, the pace of the southward snow advance into the middle latitudes slowed, resulting in the 20th least extensive $\mathrm{NH}$ snow cover of the past 52 Decembers.

SCE over the contiguous United States was well above average in January 2017, the 13th most extensive on record; however, cover decreased considerably in February and was 12th lowest on record for the month, remaining below average throughout spring. Autumn cover started out on the high side but rankings declined through the end of 2017, with December SCE ranking 20th lowest.

Maps depicting daily, weekly, and monthly conditions, daily and monthly anomalies, and monthly climatologies for the entire period of record may be viewed at the Rutgers Global Snow Lab website (http://snowcover.org). Monthly SCE for the NH, EU, NA, contiguous US, Alaska, and Canada are also posted, along with information on how to acquire weekly areas and the weekly and monthly gridded products. Section 5: describes SCE as well as snow cover duration and snow water equivalent.

\section{3) Alpine glaciers - M. Pelto and the WGMS network}

The World Glacier Monitoring Service (WGMS) record of mass balance and terminus behavior (WGMS 2017) provides a global index for alpine glacier behavior. Glacier mass balance is the difference between accumulation and ablation, reported here in $\mathrm{mm}$ of water equivalence (w.e.) and is a GCOS headline indicator. Mean annual glacier mass balance in 2016 was $-847 \mathrm{~mm}$ for the 37 long-term reference glaciers and $-761 \mathrm{~mm}$ for all 140 monitored glaciers (Fig. 2.15). Of the reporting reference glaciers, only one had a positive mass balance. Preliminary data reported to the WGMS in 2017 from Austria, Canada, China, France, Italy, Kazakhstan, Norway, Russia, Switzerland, and United States indicate that 2017 will be the 38th consecutive year of negative annual balances with a mean loss of $-1036 \mathrm{~mm}$ for 29 reporting reference glaciers, with three glaciers reporting a positive mass balance (http://wgms.ch /latest-glacier-mass-balance-data/, accessed 2 Feb 2018). 


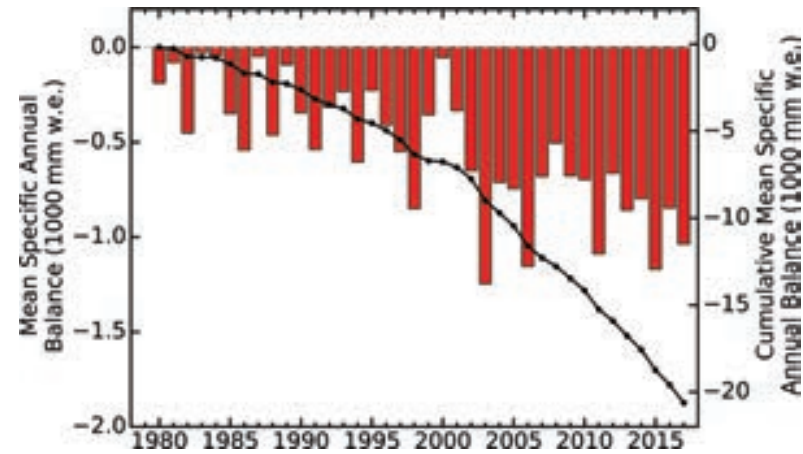

FIG. 2.15. Global alpine glacier annual mass balance record ( $\mathrm{mm}$ w.e.) of reference glaciers submitted to the WGMS 1980-2017 (see also: http://wgms.ch/latest -glacier-mass-balance-data/).

The ongoing global glacier retreat affects human society by raising sea levels, changing seasonal stream runoff, and increasing geohazards (Huss et al. 2017a). Huss and Hock (2018) indicate that approximately half of 56 glaciated watersheds globally have already passed peak glacier runoff. Rounce et al. (2017) identify the widespread expansion of glacier lakes due to retreat in Nepal from 2000 to 2015, which pose a glacier lake outburst flood hazard.

Glacier retreat is a reflection of strongly negative mass balances over the last 30 years (Zemp et al. 2015). Marzeion et al. (2014) indicate that most of the recent mass loss, during 1991-2010, is due to anthropogenic forcing. The cumulative mass balance loss from 1980 to 2016 is $-19.9 \mathrm{~m}$, the equivalent of cutting a $22-\mathrm{m}$ thick slice off the top of the average glacier (http: //wgms.ch/latest-glacier-mass-balance-data, see Figure 2). The trend is remarkably consistent from region to region (WGMS 2017). WGMS mass balance based on 41 reference glaciers with a minimum of 30 years of record is not appreciably different from that of all glaciers at $-19.1 \mathrm{~m}$. The decadal mean annual mass balance was $-228 \mathrm{~mm}$ in the $1980 \mathrm{~s},-443 \mathrm{~mm}$ in the $1990 \mathrm{~s},-676 \mathrm{~mm}$ for the $2000 \mathrm{~s}$, and $-896 \mathrm{~mm}$ for 2010-17 (WGMS 2017). The declining mass balance trend during a period of retreat indicates alpine glaciers are not approaching equilibrium, and retreat will continue to be the dominant terminus response.

Exceptional glacier melt was noted across the European Alps in 2017, along with high snowlines (Fig. 2.16), and contributed to large negative mass balances of glaciers on this continent (Swiss Academy of Sciences 2017). In the European Alps, annual mass balance has been reported for nine reference glaciers from Austria, France, Italy, and Switzerland. All had negative annual balances exceeding $-1000 \mathrm{~m}$ with a mean of $-1664 \mathrm{~mm}$. This continues the pat- tern of substantial negative balances in the Alps that continue to lead to terminus retreat. In 2016, in Switzerland 94 glaciers were observed: 82 retreated, 7 were stable, and 5 advanced (Huss et al. 2017b). In 2016, Austria observed 84 glaciers: 82 retreated, 1 was stable, and 1 advanced; the average retreat rate was $25 \mathrm{~m}$ (Lieb and Kellerer-Pirklbauer 2018).

In Norway and Svalbard, terminus fluctuation data from 36 glaciers with ongoing assessment indicate that in 2016, 32 retreated, 3 advanced, and 1 was stable. The average terminus change was $-12.5 \mathrm{~m}$ (Kjøllmoen et al. 2017). Mass balance surveys with completed results for 2017 are available for nine glaciers; six of the nine had negative mass balances with an average loss of $-80 \mathrm{~mm}$ w.e. In western North America, data for 2017 have been submitted from eight reference glaciers in Alaska and Washington in the United States, and British Columbia in Canada. Seven of these eight glaciers reported negative mass balances with an overall mean of $-1020 \mathrm{~mm}$. Winter and spring 2017 had above-average snowfall, but ablation conditions were above average. In Alaska mass losses from 2002 to 2014 have been -52 \pm 4 gigatons $\mathrm{yr}^{-1}$, as large as any alpine region in the world (Wahr et al. 2016).

In the high mountains of central Asia, four glaciers reported data from China, Kazakhstan, and Nepal.

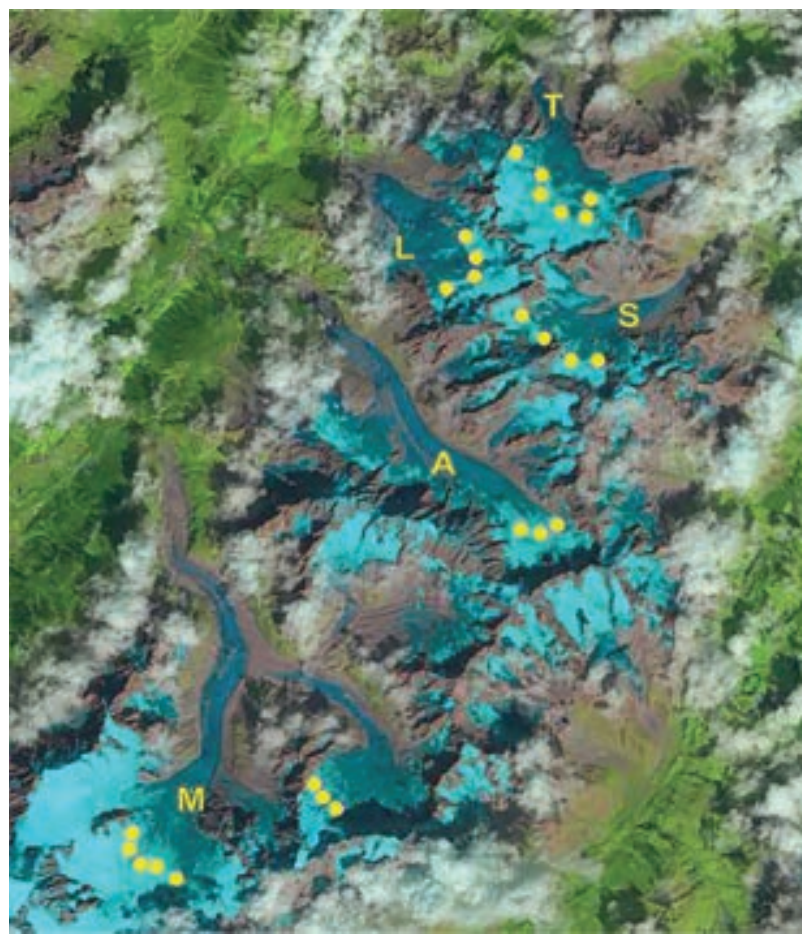

Fig. 2.16. Landsat image from 19 Aug 2017 illustrating the snowline on Mont Blanc glaciers with one month left in the melt season ( $M=$ Mer de Glace; $A=$ Argentière; $S$ = Saleina; $L=$ Le Tour; $T$ = Trient). 
All four were negative, with a mean of $-674 \mathrm{~mm}$. This is a continuation of regional mass losses, such as reported by King et al. (2017) who found for 2000-15 the mean annual mass balance of 32 glaciers in the Mount Everest region was $-520 \pm 220 \mathrm{~mm}$.

The mass balance of the Arctic glaciers reported in the WGMS is described in Section $5 f$.

\section{d. Hydrological cycle}

I) Surface humidity - K. Willett, D. Berry, M. Bosilovich, and A. Simmons

2017 was a humid year over land and ocean in terms of surface specific humidity ( $q$; Figs. $2.17 \mathrm{a}-\mathrm{d}$ ). Over land it was comparable with the El Niñodriven peak in 2010 but lower than those of 1998 and 2016. Interestingly, compared with other postEl Niño years of 1999 and 2011, the decline from the El Niño-driven peak was much smaller. However, 2017 saw generally neutral ENSO conditions with weak La Niña conditions both at the beginning and end of the year, whereas 1999 and 2011 each had a strong La Niña present. Over ocean, the moisture levels at the surface over the last $\sim 3$ years have been higher than at any other time during the record according to the reanalyses. There are currently no in situ-only datasets for comparison beyond 2015, but this feature is consistent with high global sea surface temperatures (Section 2b1) and total column water vapor (Section 2d2).

Despite high surface moisture levels (specific humidity), in terms of relative humidity $(\mathrm{RH})$, the atmosphere remained drier than average over land and near average over oceans (Figs. 2.17e-h). ERA-Interim and JRA-55 reanalyses show low RH anomaly values, comparable with the lowest years on record. The HadISDH in situ RH product is similar interannually to ERA-Interim and JRA-55, but more moderate. MERRA-2 is similar interannually but with significant deviations that are thought to be linked to variability in precipitation forcing (Reichle and Liu 2014; Willett et al. 2016).

Month-to-month, ERA-Interim and HadISDH also track similarly. Variability was low over ocean during 2017, but over land both $\mathrm{RH}$ and $q$ declined throughout the year. December had the driest monthly mean anomaly with respect to both variables.

Global average HadISDH is consistently higher than ERAInterim for both variables. HadISDH has gaps over the particularly dry regions of South America, Africa, and Australia and also over Antarctica where dry anomalies are widespread in ERA-Interim (Plate 2.1 and Online Fig. S2.12). This is a large source of uncertainty for in situ products and may explain some of the difference. Indeed, when spatially matched, ERA-Interim and HadISDH are more similar (Figs. $2.17 \mathrm{a}$ and e dotted). The data sparse regions and regions of poor data quality are also where reanalyses differ most (Plate 2.1b and Online 
Figs. S2.10 and S2.11) due to model differences and how/which observational datasets are used.

Spatially, ERA-Interim and HadISDH are similar. The annual average $\mathrm{q}$ anomaly patterns for 2017 were predominantly moist but more muted than in 2016 (Plate 2.1a; Online Figs. S2.10 and S2.11). The strongly moist anomalies over India to China and south to Southeast Asia were still prominent but to a lesser degree. Dry anomalies were more widespread and quite zonal; there were bands of dry anomalies around $30^{\circ}-60^{\circ} \mathrm{N}$ and $0^{\circ}-30^{\circ} \mathrm{S}$. Dry anomalies over eastern Brazil, South Africa, and Iran/Afghanistan/ Pakistan persisted from 2016. Additional dry anomalies developed over eastern Australia and Spain during 2017, stronger in ERA-Interim than HadISDH. The dry anomaly over East Africa, a data sparse and therefore uncertain region, was stronger than 2016 in ERA-Interim but not MERRA-2.

Spatial patterns of RH were predominantly negative (Plate 2.1b; Online Fig. S2.12) and broadly similar to both 2016 and the long-term drying trend patterns. Humid anomalies were apparent over southern Africa around Botswana and Zimbabwe in 2017 that were dry in 2016. All regions showing dry $q$ anomalies in 2017 had spatially more extensive corresponding dry RH anomalies over land and ocean. This shows the importance of looking at both variables in tandem. While a region may be moister than average it could be relatively drier if the regional temperature anomaly is particularly high. The combination of moisture, closeness to saturation, and temperature can lead to different societal impacts in terms of water availability for people and plants, flooding, and heat stress.

There is currently no in situ-only marine product (Willett et al. 2017). The decline in spatial coverage and data quality has made it difficult to continue or develop new in situ marine humidity monitoring products and resulted in the use of background forecast fields instead of analysis fields for ERA-Interim marine humidity in this section. Although satellite products can provide measures of water vapor, and total column water vapor (TCWV) has good interannual agreement with global surface $q$, these are not directly comparable with in situ observations and records are shorter. Surface $q$ can be derived from brightness temperature based on empirical relationships with in situ data. Several datasets were compared alongside the in situ-only NOCSv2.0 marine $q$ product (Berry and Kent 2009, 2011; Prytherch et al. 2015) and to reanalyses (Schröder et al. 2018). Considerable differences were found. Over land, derivations are complicated by the diverse surface properties. The ability to monitor the climate fully depends on a comprehensive suite of observations with sufficient numbers that are long term and of climate quality (Thorne et al. 2018).

2) Total column water vapor-C. Mears, S. P. Ho, J. Wang, and L. Peng

As Earth's surface and the lower troposphere warm, the total column water vapor (TCWV) is expected to increase under the assumption of nearconstant relative humidity, and in turn amplify the initial warming through positive water vapor feedback. Thus, measurements of TCWV provide an important check to estimates of temperature increase in addition to the role of changing TCWV in the global hydrological cycle. In 2017, total column water vapor (TCWV) retreated from record levels in 2016 but remained above the 1981-2010 climatological average in most locations. Estimates are available from satellite-borne microwave radiometers over ocean (Mears et al., 2018), COSMIC GPS-RO (Global Positioning System-Radio Occultation) over land and ocean (Ho et al. 2010a,b; Teng et al. 2013; Huang et al. 2013), and ground-based GNSS (Global Navigation Satellite System) stations (Wang et al. 2007) over land. An anomaly map for 2017 (Plate 2.1r) was

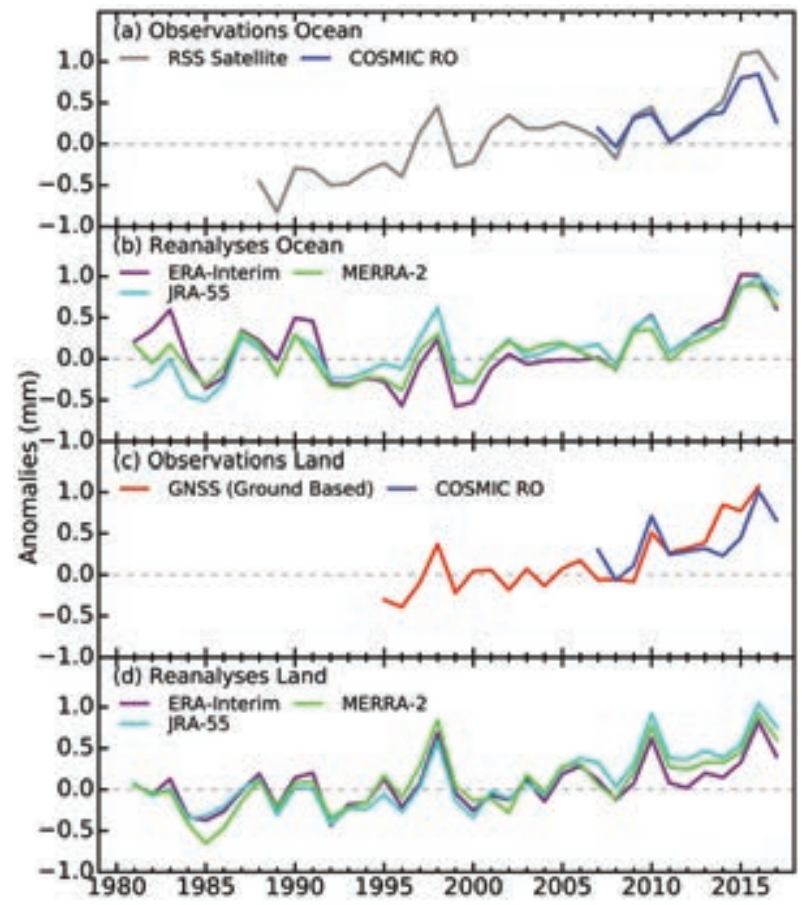

FIG. 2.18. Global mean total column water vapor annual anomalies ( $\mathrm{mm}$ ) for (a),(b) ocean only and (c),(d) land only for observations and reanalysis (see Fig. 2.I for reanalysis references) averaged over $60^{\circ} \mathrm{N}-60^{\circ} \mathrm{S}$. Shorter time series have been adjusted so that there is zero mean difference relative to the mean of the three reanalyses over the 2006-14 period. 
made by combining data from satellite radiometers over ocean and COSMIC GPS-RO over land. Much of the globe showed small wet anomalies, except for dry anomalies in the central tropical Pacific Ocean and the southeastern tropical Indian Ocean, and a large wet anomaly in the western Pacific warm pool and over the maritime continent, consistent with the presence of La Niña conditions. The patterns in TCWV over the ocean are confirmed by COSMIC ocean measurements and by output from the MERRA-2, ERA-Interim, and JRA-55 reanalyses (not shown). Over land, the patterns from COSMIC are in general agreement with the reanalysis output.

Over the ocean, the TCWV anomaly time series (Figs. 2.18a,b) from reanalysis and microwave radiometers show maxima in 1982/83, 1987/88, 1997/98, 2009/10, and 2015/16 associated with El Niño events. The 2015/16, anomaly is the largest recorded in all datasets. The radiometer data show a discernible increasing trend, while the different reanalysis products show a wide range of long-term trends over the entire period but agree well with the radiometer data after the mid-1990s. The COSMIC data show the same general features as both the radiometer and reanalysis data after COSMIC began in 2007. After the 2015/16 peak, all datasets show a return to drier conditions due to the onset of La Niña but remained wetter than the 1981-2010 normal for almost all latitudes.

Over land, average anomalies from the groundbased GNSS stations are used in place of the satellite radiometer measurements (Figs. 2.18c,d). The various reanalysis products, COSMIC, and GNSS are in good agreement. A land-and-ocean Hovmöller plot derived from JRA-55 (Fig. 2.19) indicates a long-term increase in TCWV at all latitudes, with less variability outside

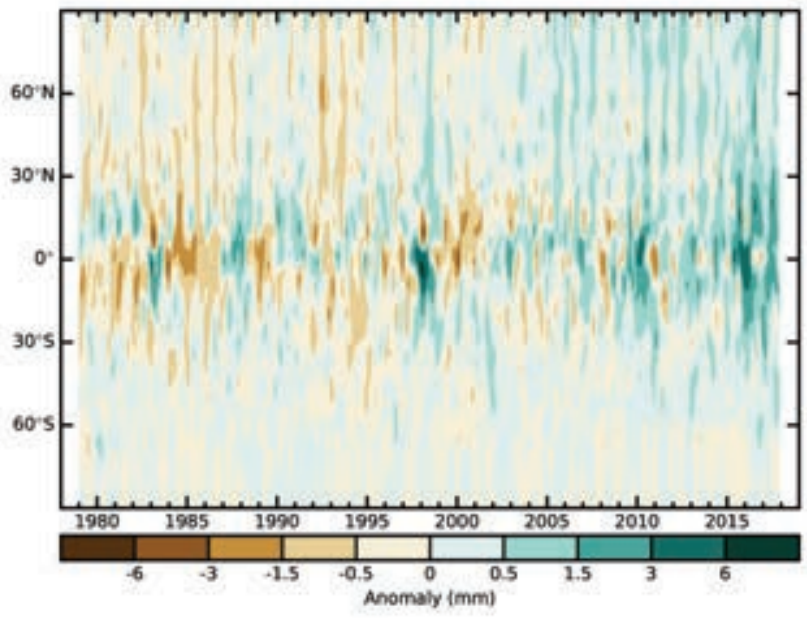

Fig. 2.19. Hovmöller plot of TCWV anomalies $(\mathrm{mm}$; base period 198I-20I0) including both land and ocean derived from the JRA-55 reanalysis the tropics. Previous strong El Niño events (1983/84 and 1997/98) showed pronounced drying events in the years following the El Niño events, which were not seen after the 2015/16 event.

3) UPPER tROPOSPHERIC HUMIDITY - V. 0. John, L. Shi, E.-S. Chung, R. P. Allan, S. A. Buehler, and B. J. Soden

In the atmosphere as a whole, water vapor is the principal greenhouse gas (Held and Soden 2000). Despite water vapor in the upper troposphere being insignificant by total mass when compared to the total column, it nevertheless contributes a major part to the feedbacks present in the climate system. Thus, upper tropospheric water vapor is responsible for most of the tropospheric radiative cooling (Manabe and Möller 1961), and the radiative effect of water vapor is proportional to relative changes in the amount of water vapor in the upper troposphere (John and Soden 2007).

Following John et al. (2017), upper tropospheric (relative) humidity (UTH) is monitored on a global scale by two independent global satellite UTH datasets: (1) the High Resolution Infrared Sounder (HIRS) dataset (Shi and Bates 2011) and (2) the microwavebased UTH dataset (Chung et al. 2013). In these datasets, UTH represents a Jacobian weighted average of relative humidity in a broad layer which is roughly between 500 and $200 \mathrm{hPa}$ but varies depending upon atmospheric humidity profile. Both datasets have been constructed through careful bias corrections and intersatellite calibration. As the microwave-based UTH dataset only begins in 1999, anomalies are computed relative to the $2001-10$ base period.

Figure 2.20 shows the area-weighted mean deseasonalized anomaly time series of UTH for $60^{\circ} \mathrm{N}-$ $60^{\circ} \mathrm{S}$ using two observational datasets as described later in this section: one from HIRS and the other

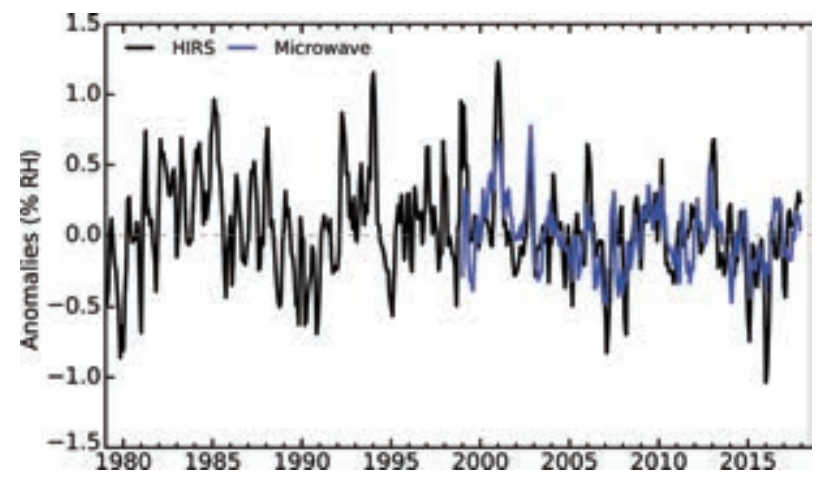

FIG. 2.20. Time series of UTH anomalies (\% RH; $200 \mathrm{I}-$ 10 base period) using HIRS (black) and microwave (blue) datasets. Time series are smoothed to remove variability on time scales shorter than three months. 


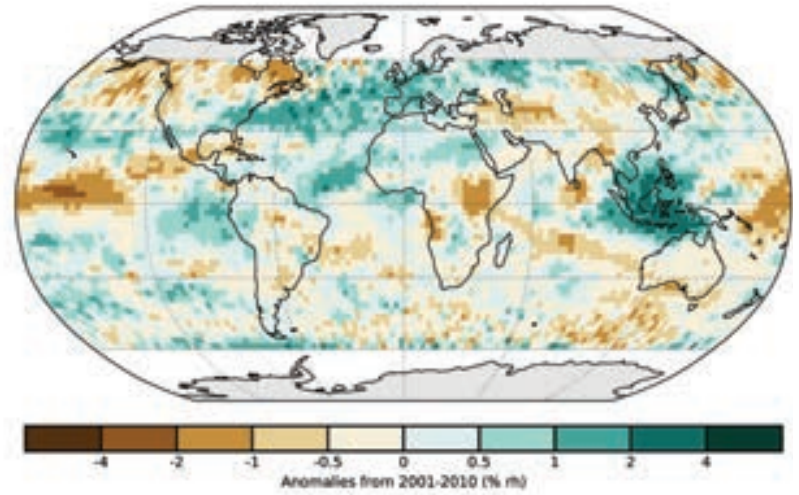

FIG. 2.2I. Annual average UTH anomalies (\% RH, 200 I-I 0 base period) for 2017 based on the "clear-sky" HIRS UTH dataset.

from microwave humidity sounder measurements. The anomalies are close to zero in 2017 and are fairly similar to the previous year, even though 2016 began with an El Niño whereas there were neutral or weak La Niña conditions in 2017. To maintain the same relative humidity, warmer air has to contain more water vapor (have a higher specific humidity). Therefore, the presence of a near-zero decadal trend in the UTH requires an increase in absolute (specific) humidity in step with the warming upper troposphere (Section 2b4) and hence is consistent with a positive water vapor feedback (Chung et al. 2016). Good agreement between the two independent datasets despite their differences in sampling - microwave data having an almost all-sky sampling whereas HIRS data sample mainly clear-sky scenes-provides confidence in the observed long-term behavior of UTH (John et al. 2011). The higher short-term variability in the HIRS time series arises from the sampling issues discussed by John et al. (2011). The spatial variation of annual average UTH anomalies for 2017 (Plate 2.1q for microwave data and Fig. 2.21 for HIRS data) shows dry anomalies over the central Pacific and moist anomalies over the maritime continent, which reflect neutral ENSO conditions during the year; however, the moist anomaly seen in the eastern Pacific is typical for El Niño conditions. The dry anomaly over the Indian subcontinent is an indication of the below-normal monsoon rainfall in 2017 (Sections 2d9, 7g4).

4) Precipitation - R. S. Vose, R. Adler, A. Becker, and X. Yin Precipitation over global land areas in 2017 was clearly above the long-term average (Fig. 2.22). All available datasets are consistent on this point, but there is a wide range of estimates across the analyses (ranging from 15 to $80 \mathrm{~mm}$ above average). The datasets with the most complete global coverage, that is, the gauge-based product from the Global Precipitation
Climatology Centre (GPCC; Becker et al. 2013) and the blended gauge-satellite product from the Global Precipitation Climatology Project (GPCP; Adler et al. 2003), both depict 2017 as about $15 \mathrm{~mm}$ above average. The operational version of the gauge-based Global Historical Climatology Network (GHCN; Peterson and Vose 1996) dataset is somewhat wetter, with an anomaly of about $40 \mathrm{~mm}$, while a new experimental version of GHCN (with five times as many stations) has an anomaly of about $80 \mathrm{~mm}$ (implying 2017 was the wettest year in the historical record). Notably, when the blended gauge-satellite GPCP product is adjusted using a new gauge analysis for 2014-present, the anomaly for 2017 increases to about $30 \mathrm{~mm}$, which would be the wettest year in the satellite era. Large areas with above-normal precipitation in 2017 (Plate 2.1i) include northwestern North America, northern Eurasia, interior sub-Saharan Africa, southeastern Asia, the Maritime Continent, and western Australia. Areas with below-normal precipitation include southern Alaska, central Canada, southeastern Brazil, western Europe, eastern Africa, northern India, the Korean peninsula, and eastern Australia (Plate 2.1i). Relative to 2016, aridity was much less pronounced in many areas, particularly Central America, South America, and southern Africa.

According to GPCP, precipitation over the global ocean surface in 2017 was near the long-term average for the satellite era. In the tropics, the annual anomaly pattern (Plate $2.1 \mathrm{i}$ ) reflects much wetterthan-normal conditions stretching from the eastern Indian Ocean across the Maritime Continent to the western equatorial Pacific Ocean, with much drierthan-normal conditions extending eastward across the rest of the equatorial Pacific. Indeed, the seasonal anomaly patterns during 2017 (not shown) indicate that similar features in the Pacific Ocean/Maritime Continent area existed in varying strengths during

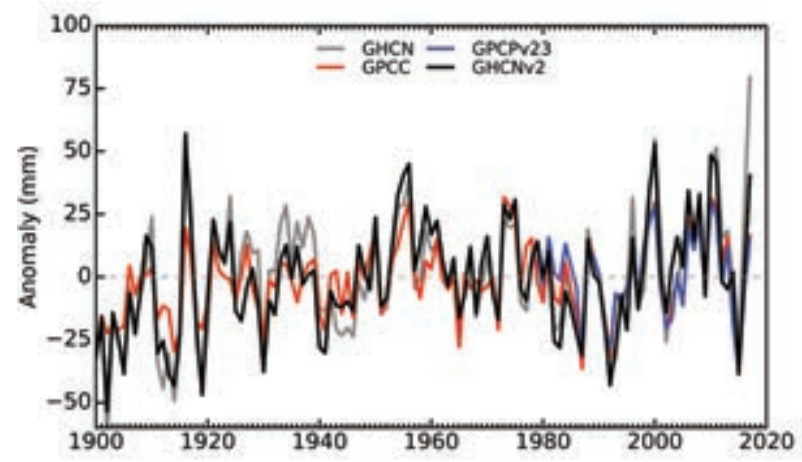

FIG. 2.22. Globally averaged precipitation anomalies $\left(\mathrm{mm} \mathrm{yr}^{-1}\right)$ over land areas relative to the 196I-90 base period (except GPCP v2.3, which is 1981-2000). 


\section{SIDEBAR 2.I: LAND SURFACE PRECIPITATION EXTREMES-M. R. TYE, S. BLENKINSOP, M. DONAT, I. DURRE, AND M. ZIESE}

2017 was a mixed year in terms of extreme precipitation, with remarkable tropical and post-tropical cyclone precipitation at one end of the scale and extended droughts at the other (see Sections $2 \mathrm{~d} 4,2 \mathrm{~d} 9$, respectively). The range of events demonstrates that extreme precipitation is not evenly distributed across the globe (Herold et al. 2015), while anthropogenic climate change has likely increased their probability of occurrence (e.g., Risser and Wehner 2017). Annual precipitation totals were above the $90 \%$ percentile in coastal east Asia, western and northern Australia, northeastern Europe, parts of northern North America, Central America, and southeastern South America (Plate 2. Ij; see also Section $2 \mathrm{d4})$. The year was also notable for the large proportion of moderate to heavy extreme precipitation (i.e., days with accumulations $\geq 90$ th and 95 th percentiles; Zhang et al. 20II) with respect to previous years.

Robust and reliable global datasets for extreme precipitation that include data throughout 2017 are limited, particularly for sub-monthly resolutions. Here we make use of the Global Historical Climatology Network Daily (GHCND; Menne et al. 2012), GHCND-based GHCNDEX (Donat et al. 20I3a) and GPCC-FirstGuess Daily (Schamm et al. 2013) gridded extremes to calculate the precipitation indices summarized in Table SB2.I. However, near-realtime updates including 2017 are primarily available from North America, Europe, Australia, and parts of Asia for GHCNDEX.

The highest daily precipitation totals are typically found as orographically enhanced rainfall in tropical regions, making only indices such as RxIday or R95P (Table SB2.I) meaningful for global comparisons. During 2017 some of these regions also experienced anomalously high precipitation events that resulted in significant impacts, such as RxIday (Plate 2.Ik, Online Fig. S2.17) for 3I March-I April in Colombia (130 mm in Mocoa).

While boreal spring 2017 saw high seasonal precipitation totals across all continents (Section 2d4), individual indices do not reflect the full picture of extremity. For instance, although atmospheric rivers (e.g., Dettinger et al. 20II) were very active along the U.S. West Coast early in the year, RxIday and Rx5day rank low for that region with respect to climatology (Plate 2.Ik). The year as a whole is notable for the moderate extreme indices. That is, the anomalies in total precipitation (PRCPTOT) appear to be attributable more to anomalies in RI0mm and/or R20mm than, say, R95P (Plate 2.Ij, Fig. SB2.I, Online Fig. S2.18).

Munich Re (2018) summarized 2017 global loss events within four hazard categories. From the meteorological and hydrological events hazard categories, the precipitation induced insured losses from Severe Tropical Cyclone Debbie (27 March-6 April) in eastern Australia and New Zealand, and Hurricane Harvey (25 AugustI September) in Texas and Louisiana are unprecedented. Hurricane Harvey set numerous daily rainfall records at NOAA weather stations throughout the area, with RxIday exceeding $600 \mathrm{~mm}$ and $\mathrm{R} \times 5$ day at almost double previous records (Fig. SB2.2; see online supplemental information; see Sidebar 4.3 for more details on Harvey). Severe Tropical Cyclone Debbie strengthened to a Saf-

TABLE SB2.I. Extreme precipitation indices from the Expert Team on Climate Change Detection and Indices (ETCCDI).

\begin{tabular}{|c|c|c|c|}
\hline Index & Name & Definition & Unit \\
\hline PRCPTOT & Total annual precipitation & Annual wet day $(R \geq I \mathrm{~mm})$ precipitation total & $\mathrm{mm}$ \\
\hline RxIday & Max I day precipitation amount & Annual maximum I day precipitation & $\mathrm{mm}$ \\
\hline Rx5day & Max 5 day precipitation amount & $\begin{array}{l}\text { Annual maximum consecutive } 5 \text { day } \\
\text { precipitation }\end{array}$ & $\mathrm{mm}$ \\
\hline RIOmm & Number of heavy precipitation days & Annual count when precipitation $\geq 10 \mathrm{~mm}$ & days \\
\hline $\mathbf{R} 20 \mathrm{~mm}$ & Number of very heavy precipitation days & Annual count when precipitation $\geq 20 \mathrm{~mm}$ & days \\
\hline R95P & Very wet days & $\begin{array}{l}\text { Annual total precipitation from days }>95 \text { th } \\
\text { percentile of wet days }\end{array}$ & $\mathrm{mm}$ \\
\hline
\end{tabular}


fir-Simpson category 3 storm before making landfall over the North Queensland coast. While Debbie is considered to be one of the costliest and most deadly cyclones to affect Australia (Insurance Council Australia 2017), associated $\mathrm{R} x \mathrm{Iday}$ and $\mathrm{R} \times 5$ day totals have been exceeded

(a) Total Precipitation

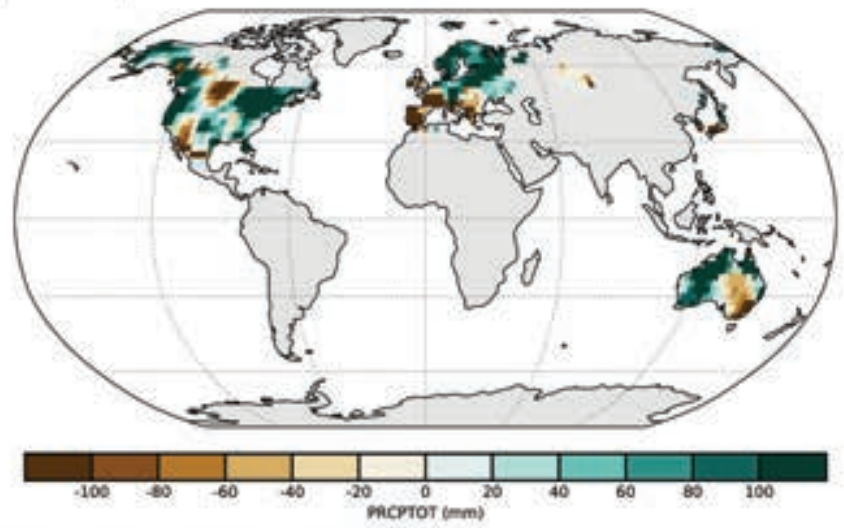

(b) Number of Heavy Precipitation Days

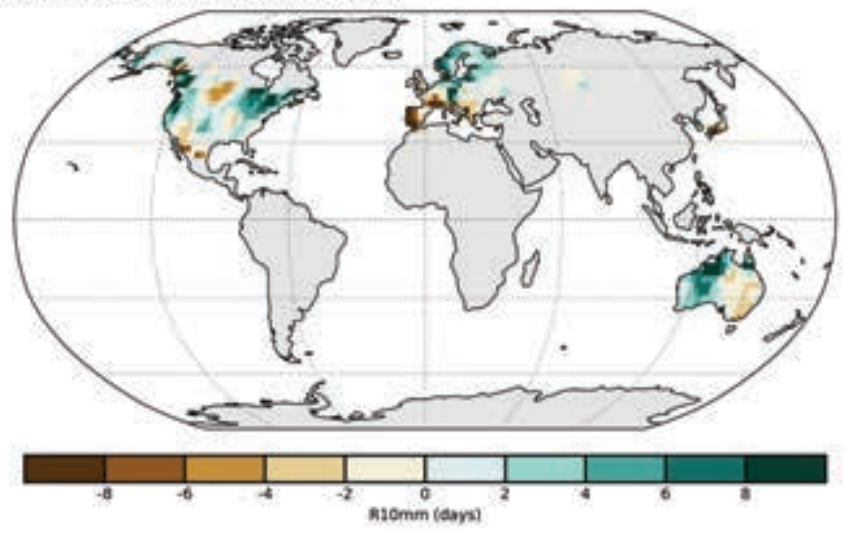

(c) Number of Very Heavy Precipitation Days

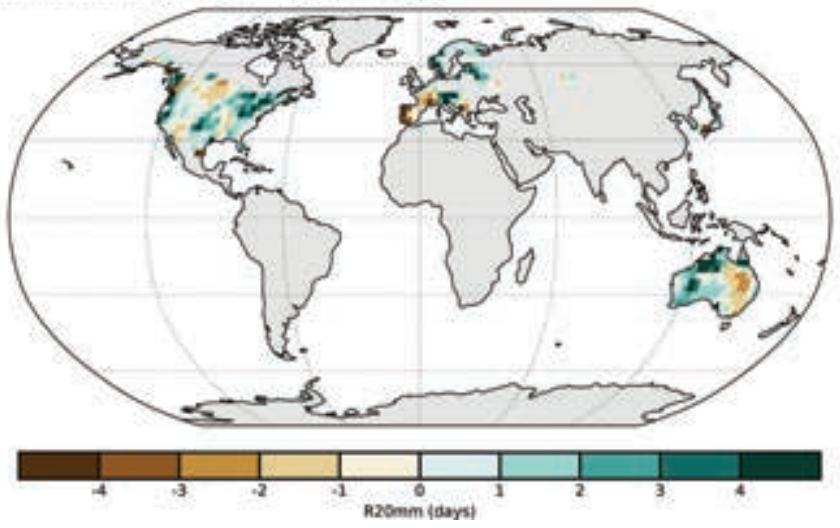

FIG. SB2.I. 2017 anomalies (196I-90 base period) from GHCNDEX for (a) PRCPTOT (mm), (b) RIOmm (days), and

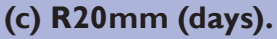

at least three times at several locations since 1918 (Online Fig. S2.19). Other events such as those in South Asia (monsoon rains June-October), Peru (wet season floods January-March), and Sierra Leone (landslides 14 August) were notable for their longevity and/or high human cost.

Further information is available at http://floodlist. $\mathrm{com} /$ ? $=2017$ \&submit $=$.

Many of the events witnessed in 2017 originated from stationary mesoscale convective systems (MCS). MCSs are organized systems of thunderstorms, larger than individual storms but smaller than extratropical cyclones. They can last for over 12 hours and can rival tropical cyclones for impacts due to their intensity and repetition leading to soil saturation, and they contribute up to $\$ 20$ billion (U.S. dollars) economic losses each year (Munich Re 2016). Across the North American Midwest, where the conditions are often suitable for generating these events, it is notable that the pattern of extreme deviations from climatology (negative and positive) for R10 mm and R20mm are similar to PRCPTOT. That is, the greatest contributions to the annual total came from more moderate extremes. Many of the flood inducing extremes in 2017 (Brakenridge 2018) appear to be derived from these moderate extremes, suggesting that more attention should be paid to "nuisance events" (i.e., unusual but not so rare that they are unknown within the record; Schroeer and Tye 2018, manuscript submitted to J. Flood Risk Manage.). It should be noted that the available data, such as GHCNDEX, are often too coarse to resolve MCSs and may miss these extremes.

Limited availability of in situ high-resolution rainfall observations has confounded long-term assessments of changes in sub-daily extreme precipitation (significant in generating flash floods; Westra et al. 2014). Historical analyses of change have typically been conducted on regional scales using a variety of methods (Online Fig. S2.20) making it difficult to assess the state of the climate and to place notable events in context. However, studies do indicate a tendency towards more intense extremes. A global data collection exercise is underway (Lewis et al. 2018, manuscript submitted to J. Climate) under the INTENSE (Intelligent Use of Climate Models for Adaptation to Nonstationary Hydrological 
Extremes) project (Blenkinsop et al. 2018, manuscript submitted to Adv. Sci. Res.) and will result in a qualitycontrolled sub-daily dataset. This will include the production of comparable sub-daily extreme indices to those in Table SB2.I to enable the monitoring of these events. New analyses using these data have indicated continental-scale increases in the intensity of hourly rainfall (Barbero et al. 2017; Guerreiro et al. 2018, manuscript submitted to Nat. Climate Change). Observational evidence, coupled with that from climate models, suggests that heavy rainfall will

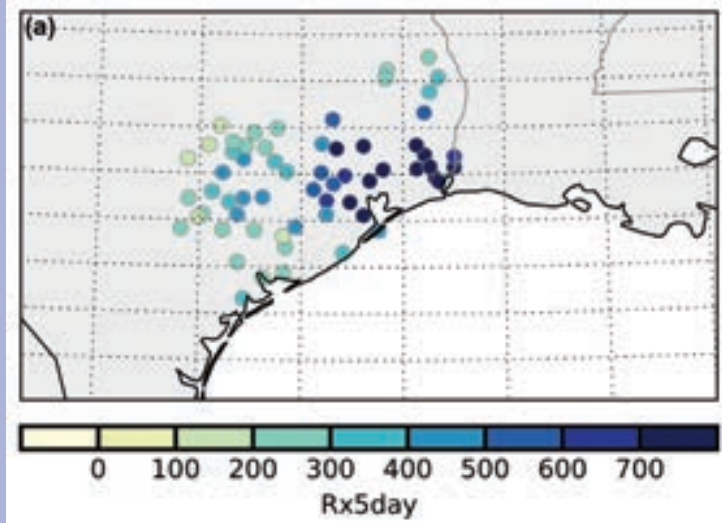

intensify with temperature according to or exceeding the Clausius-Clapeyron (CC) relation (a rate of $\sim 6 \%-7 \%{ }^{\circ} \mathrm{C}^{-1}$ ) (Trenberth et al. 2003; Pall et al. 2007), although changes in dynamics may lead to regionally higher or lower rates of intensification. Improved quality and global coverage of sub-daily observations will enable a much needed advance in understanding of how local thermodynamics and largescale circulations interact to generate short-duration intense rainfall (Pfahl et al. 20I7).

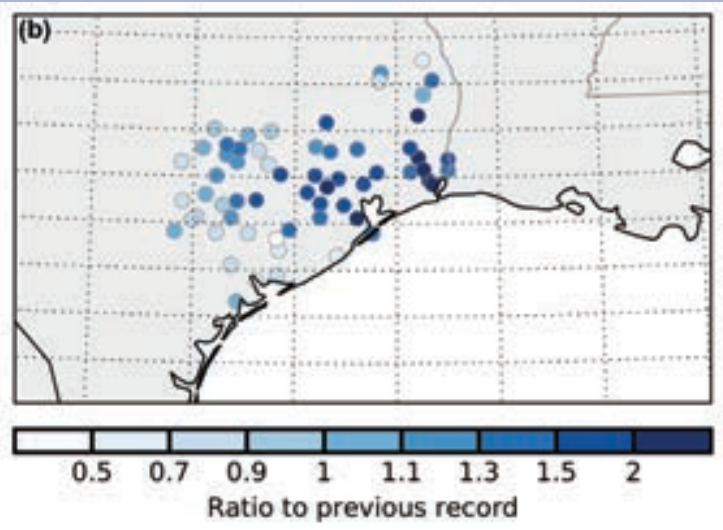

FIG. SB2.2. (a) Rx5day from GHCNDEX for Hurricane Harvey and (b) ratio of the 2017 value to the previous maximum in the record.

the entirety of 2017. Large parts of the North Pacific, North Atlantic, South Atlantic, and south Indian Oceans had notable negative anomalies, whereas parts of the South Pacific convergence zone and the equatorial Atlantic Ocean were wetter than normal. A negative anomaly feature across the very southern tip of the African continent was also apparent, where Cape Town, South Africa, experienced its driest year since 1933.

For an assessment of precipitation extremes in 2017, see Sidebar 2.1, and for more detailed discussion on regional precipitation quantities, see Chapter 7.

5) Cloudiness - M. J. Foster, S. A. Ackerman, K. Bedka, L. Di Girolamo, R. A. Frey, A. K. Heidinger, S. Sun-Mack, C. Phillips, W. P. Menzel, M. Stengel, and G. Zhao

Cloud observations are important for monitoring climate because they modulate energy flow through reflection of incoming solar radiation and absorption of outgoing terrestrial radiation, and they affect global water distribution through storage and precipitation of atmospheric water. Global cloudiness in 2017 decreased incrementally $(\sim 0.2 \%)$ from that of 2016. This analysis is based on several satellite cloud records including PATMOS-x/AVHRR (Pathfinder Atmospheres Extended/Advanced Very High Resolution Radiometer; Heidinger et al. 2014), Aqua MODIS C6 (Moderate Resolution Imaging Spectroradiometer Collection 6; Ackerman et al. 2008), CALIPSO (Cloud-Aerosol Lidar and Infrared Pathfinder Satellite Observation; Winker et al. 2007), CERES (Clouds and the Earth's Radiant Energy System; Minnis et al. 2008; Trepte et al. 2010) Aqua MODIS, MISR (Multiangle Imaging SpectroRadiometer; Di Girolamo et al. 2010), and SatCORPS (satellite cloud and radiative property retrieval system; Minnis et al. 2016). All of these records show a decrease in cloudiness from 2016 to 2017 ranging from $0.1 \%$ to $0.34 \%$, depending on the dataset. Figure 2.23 shows global cloudiness from 1981 to present with additional records: HIRS High Cloud (High Resolution Infrared Sounder; Wylie et al. 2005; Menzel et al. 2016), CLOUD_CCI (Cloud Climate Change Initiative AVHRR-PM v3.0; Stengel et al. 2017), CLARA-A2 (cloud, albedo and radiation dataset; Karlsson et al. 2017), and PATMOS-x/Aqua MODIS that do not currently extend through 2017. While there is interannual and inter-record variability in the early part of the record, there is an overall 


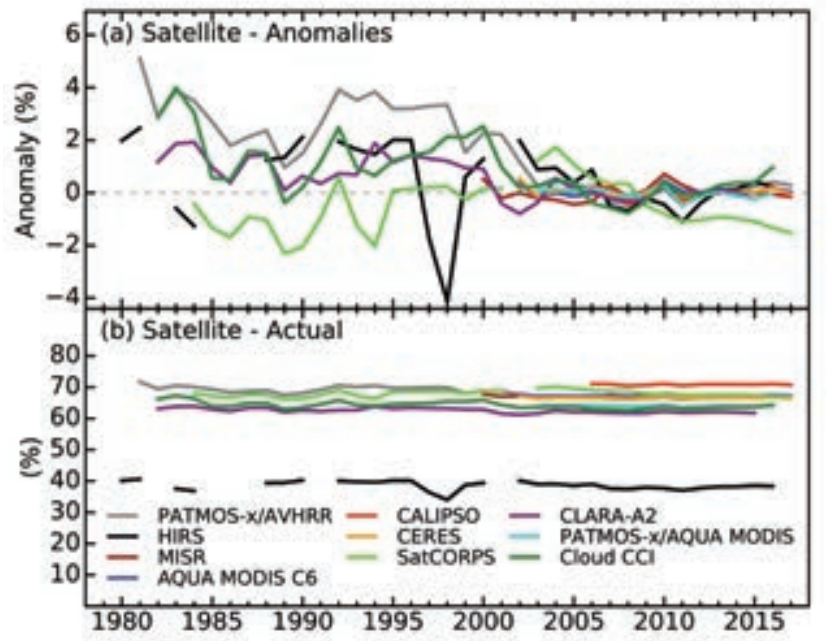

FIG. 2.23. (a) Annual global cloudiness anomalies (\%) for 1981-2017, defined as the annual value minus the mean, derived between 2003 and 2015, a period common to the satellite records excluding CALIPSO, where the entire record was used instead. (b) Annual actual global cloudiness (\%). The datasets include PATMOSxIAVHRR, HIRS High Cloud, MISR, Aqua MODIS C6, CALIPSO, CERES Aqua MODIS, SatCORPS, CLARAA2, PATMOS-x/Aqua MODIS, and CLOUD_CCI.

tendency for convergence after 2000. Much of the convergence can be explained by the use of a common baseline of 2003-15, though it does not explain interannual variability. Online Figure S2.13 plots the records that extend back before 2000 and removes the common baseline, which results in the spread among the records to be similar throughout. Figure 2.23b shows absolute cloudiness and the overall interannual stability of these records. It also shows there is no consensus on global cloudiness trends. We should note the HIRS record is noticeably lower because it focuses on detecting high cloud. It is included here because comparison with anomalies is still valuable, and it is the only non-AVHRR record we have that extends back into the 80 s and 90 s.

Although global-scale events such as ENSO and volcanic eruptions may be responsible for some early-record interannual variability, it is likely that much of the interannual and most of the inter-record variability relates to the combinations of satellites and sensors used in the records. Four of the records that extend back into the 1980s-PATMOS-x/AVHRR, SatCORPS, CLARA-A2, and CLOUD_CCI-are derived from the AVHRR sensor flown on NOAA POES. The morning satellites flown in the 1980s and 1990s lack a second infrared channel and have a greater tendency to drift from their original orbit thereby shifting the local overpass time and potentially cre- ating an aliasing effect. Therefore, when generating a cloud data product, the selection of which satellite records to include is significant. SatCORPS, CLARAA2, and CLOUD_CCI are derived from afternoon satellites, while PATMOS-x/AVHRR uses afternoon and morning satellites. PATMOS-x, SatCORPS, and CLARA-A2 have a diurnal correction applied (Foster and Heidinger 2013). This correction usually takes the form of a cloudiness adjustment to a single local overpass time based on a linear regression. Several international collaborative efforts exist with the goal of better characterizing these differences and addressing some of these issues, including the Global Energy Water Cycle Experiment (GEWEX) Cloud Climatology Assessment (Stubenrauch et al. 2013), the International Clouds Working Group (ICWG; formerly the EUMETSAT Cloud Retrieval Evaluation Workshops; Wu et al. 2017), the WMO Sustained and Coordinated Processing of Environmental Satellite data for Climate Monitoring (SCOPE-CM; Kearns and Doutriaux-Boucher 2015) AVHRR Climate Initiative, and the WMO Global Space-based InterCalibration System (GSICS).

There were a few noteworthy cloudiness anomalies (those found to be significant at the 5\% level) in 2017 relative to the PATMOS-x/AVHRR base period of 1981-2010. Almost all of these anomalies were less cloudy than average with two exceptions of cloudier-than-average areas over the Arctic Ocean. Global cloudiness patterns frequently correspond with large-scale circulation patterns. SST and lowlevel wind anomalies between the central equatorial Pacific and Indonesia characteristic of ENSO drive convection, which, in turn, drives global cloudiness

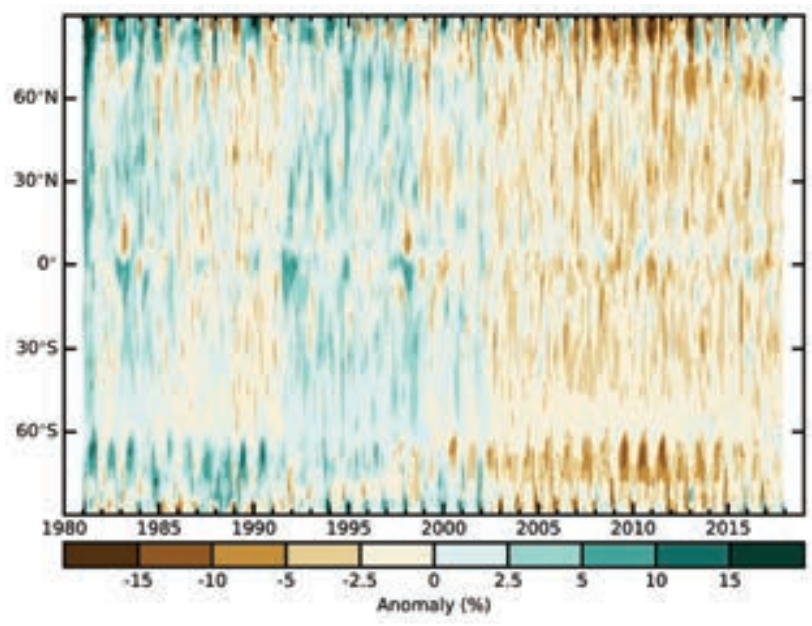

Fig. 2.24. Annual global cloudiness anomalies (\%; relative to $198 \mid-2010$ ) from the PATMOS-x/AVHRR record calculated using the same method as Fig. 2.23 but zonally for each degree latitude. 
distribution. El Niño events often correspond with cloudier conditions over the central equatorial and southeastern Pacific, while La Niña events correspond with less cloudy conditions. This can be seen in Fig. 2.24 where cloudiness anomalies are consistent with phases of ENSO in the PATMOS-x/AVHRR record. In 2017 the ENSO index was largely neutral, beginning and ending the year with weak La Niña conditions. Seasonal cloudiness reflects this evolution (Online Fig. S2.14). Due to this pattern, Plate 2.1p shows cloudiness anomaly patterns between the western Pacific and Indonesia generally consistent with weak La Niña conditions but lacking significance at the $5 \%$ level, with the exception of small areas off the west coasts of Mexico and Chile. The Indian Ocean dipole (IOD) is an interannual weather pattern that affects the tropical Indian Ocean. 2017 saw sporadic negative phases of the IOD at the beginning and end of the year, which typically correspond with cooler sea surface temperatures in the western Indian Ocean that likely contributed to below-average cloudiness seen in the northern and southwestern parts of the Indian Ocean. Continental below-average cloudiness frequently corresponds with warm and dry conditions as experienced in Alaska, western Europe, and large portions of Russia and China.

\section{6) River DisCharge AND RUNOFF-H. Kim}

After evapotranspiration, induced by the available energy at the land surface and from moisture update from the root zone by the photosynthesis of vegetation, the remaining precipitated water is transported by gravity. The water eventually forms narrow and meandering rivers, transporting it to the oceans. Freshwater in the channel network is the first source for water resources required by humans and their activities and industries.

Sixty years (1958-2017) of global runoff and river discharge were estimated by off-line land surface simulations on the ensemble land surface estimator (ELSE; Kim et al. 2009). The simulation configuration remains the same as in the previous report (e.g., Kim 2017), and atmospheric boundary conditions were extended by combining the Japanese global atmospheric reanalysis (JRA-55; Kobayashi et al. 2015) and the Global Precipitation Climatology Centre (GPCC) Monitoring Product version 5 (Schneider et al. 2015).

In 2017, the global distributions of runoff (Plate 2.11) and discharge (Plate $2.1 \mathrm{~m}$ ) anomalies show that large areas of South America, Southeast Asia, eastern Europe, and western and eastern Siberia were under significantly wet conditions. In contrast, Africa, central Siberia, India, the eastern United States, and eastern Europe including the Mediterranean were under drier conditions compared to their normal climate. Among these, the African, European, and Siberian regions tended to experience a similar state as the previous year. Long-term variability of global runoff is shown with the El Niño-Southern Oscillation (ENSO) and the Pacific decadal oscillation (PDO; Mantua et al. 1997) in Fig. 2.25. It has been found that the La Niña phase of ENSO and a neutral phase of PDO result in global runoff that is weakly wetter than the long-term average. The ENSO and PDO indices explain approximately $50 \%$ of the variability of the global runoff (Kim 2017). After a strong positive phase of the 2015/16 ENSO, the weak La Niña conditions in 2017 and the relatively weak positive phase of the PDO led to slightly wetter conditions.

Figure 2.26 indicates a monthly time series deviation (i.e., excess or deficiency) runoff from the long-term mean of seasonal variations globally and on each continent. South America shows the typical seasonal variation of a wet year that has excessive runoff in the earlier season (i.e., February-April) compared to the wet season in dry years (i.e., May-July). The Amazon River is wetter than normal except in a few sub-basins such as the Rio Madeira, the Rio Tocantins, and the Rio Araguaia. The Rio Parana and the Rio Sao 


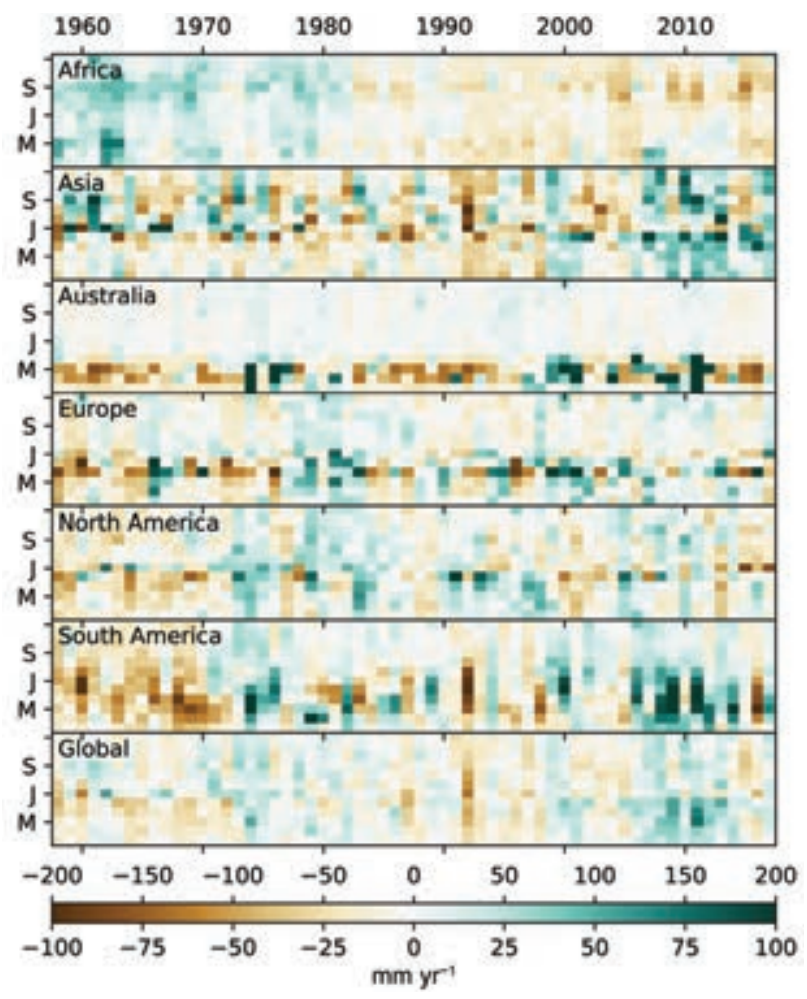

FIG. 2.26. Interannual variability of global and continental runoff $\left(\mathrm{mm} \mathrm{yr}^{-1}\right)$ for 1958-2017. The $x$ - and $y$-axes correspond to annual and seasonal variations, respectively. Europe and South America refer to the upper scale of the color bar, and the others refer to the lower scale.

Francisco maintained the same wet and dry conditions as in the previous year, respectively. In Asia, the dry condition of high latitude regions in 2016 was alleviated slightly. The state of the $\mathrm{Ob}$ and Kolyma Rivers (Siberia) shifted from dry to wet. However, the Yenisey River still remained dry and the Lena River took on dry conditions. Over mid- and low latitudes in Asia, many regions were wetter than normal (e.g., the Yangtze, Huang He, Chao Phraya, Mekong Rivers), while Amur and Ganges-Brahmaputra were drier than normal. Europe showed a considerable deviation from the climatological seasonality, with considerably drier conditions during the early half of the year; the phase shifted radically into a wet-year condition beginning in June. North America was in a weak dry condition, and most of the rivers in the region, including the Mississippi (U.S.) and Mackenzie (Canada), were facing a water deficit. Africa has been experiencing a persistent dry condition since the 1980s, and Australia has had near-neutral to dry conditions after a historic wet year in 2011.
7) Groundwater and terrestrial Water storage-

M. Rodell, D. N. Wiese, B. Li, and J. S. Famiglietti

Precipitation that falls on the land and does not immediately evaporate or run off becomes terrestrial water storage (TWS; the sum of groundwater, soil moisture, surface water, snow, and ice). Groundwater and total TWS exhibit larger variations on multiannual timescales than the near-surface TWS components (Li et al. 2015). Both are difficult to monitor using in situ observations, but from 2002 to 2017 the Gravity Recovery and Climate Experiment (GRACE; Tapley et al. 2004) satellite mission mapped TWS variations on a monthly basis at regional scales, worldwide. During the last few years of the mission, on-board battery issues caused frequent, multimonth measurement gaps, and no TWS data are available past June 2017. To create the 2016-2017 difference map (Plate 2.1h) output from a GRACE data assimilating land surface model (Li et al. 2018, manuscript submitted to Water Resour. Res.) was used.

Changes in TWS between 2016 and 2017, plotted as equivalent heights of water in Plate $2.1 \mathrm{~h}$, integrate the effects of other hydroclimatic conditions (see Plates 2.1i, $\mathrm{n}, \mathrm{o}, \mathrm{p}, \mathrm{t}$, and v). All continents experienced a somewhat even mix of TWS increases and decreases, with many reversals. The Amazon basin recovered from huge, widespread water losses in 2016, with large gains in the eastern part of the basin. However, southern Brazil endured significant TWS reduction. Across the Atlantic the reverse scenario occurred-with large-scale, deep drying in central and eastern Africa and wetting to the south. Southern Europe suffered serious drought-related water losses, most notably in Portugal, while northern Europe was normal to wet. Northwestern Australia regained water lost in the

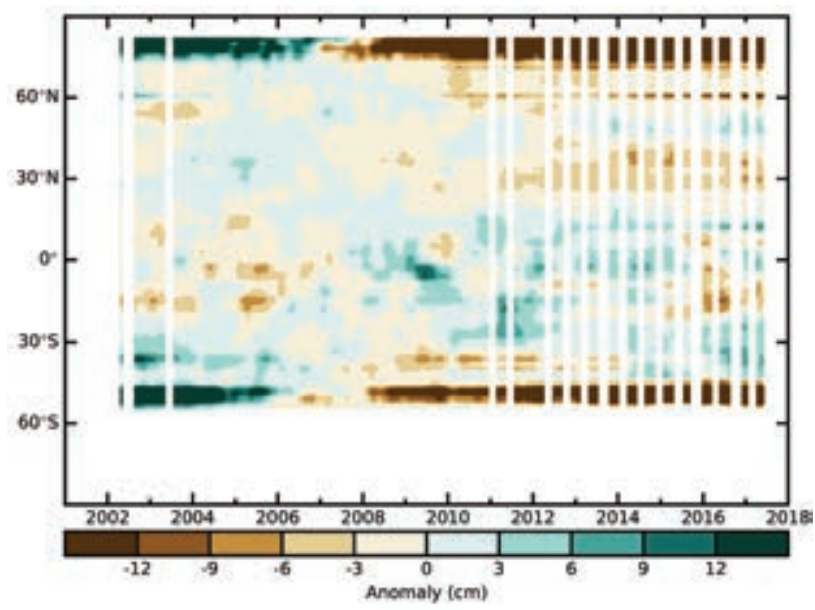

Fig. 2.27. Zonal mean terrestrial water storage anomalies (cm, equivalent height of water, 2005-10 base period) from GRACE. White areas indicate months when data were unavailable. 


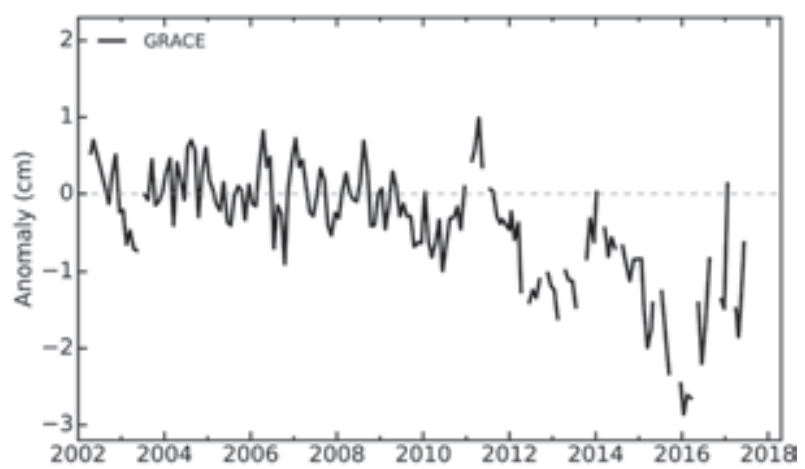

FIG. 2.28. Global average terrestrial water storage anomalies from GRACE (cm, equivalent height of water, 2005-10 base period).

previous year, while conditions in the southeast were generally dry. TWS changes in North America were also mixed. The heavy winter rains that led to flooding and mudslides in central and southern California aided in its recovery from long-term drought. Much of the eastern and mountain regions of the U.S. also gained TWS, while Canada and Mexico were generally dry, including drought in British Columbia that contributed to its most extensive wildfire season on record (see Section 7b1). Central and southern Asia exhibited patchy drying, while heavy rains in the Indochina peninsula increased TWS dramatically. Eastern Siberia also was wetter than normal. While GRACE has measured significant reductions in TWS in Antarctica, Greenland, southern coastal Alaska, and Patagonia (the latter two are apparent at $60^{\circ} \mathrm{N}$ and $46^{\circ}-55^{\circ} \mathrm{S}$, respectively, in Fig. 2.27) due to ongoing ice sheet and glacier ablation, these processes are not properly simulated by the model and the regions must be ignored in Plate $2.1 \mathrm{~h}$.

Figures 2.27 and 2.28 plot zonal mean and global mean deseasonalized monthly TWS anomalies from GRACE (excluding Greenland and Antarctica). Reduced dryness in the southern tropics (Fig. 2.27) is associated with the TWS increases in the Amazon, southern Africa, and northwestern Australia. While only five months of GRACE data are plotted in Fig. 2.28, GRACE data assimilation output (not shown) indicate that recovery from the January 2016 global TWS minimum continued in 2017, owing largely to the increases in the Amazon.

8) Soll moisture-W. A. Dorigo, T. Scanlon, A. Gruber, R. van der Schalie, C. Reimer, S. Hahn, C. Paulik, W. Wagner, and R. A. M. de Jeu

The ESA Climate Change Initiative soil moisture (ESA CCI SM) product combines observations from a large number of historical and present-day passive and active microwave instruments in a synergistic way (Dorigo et al. 2017b; Gruber et al. 2017; Liu et al. 2012). The latest dataset version (COMBINED v04.3) merges 11 different sensors between late 1978 and December 2017 into a single harmonized long-term dataset with reduced uncertainties and fewer data gaps compared to the single sensor products. The dataset has been validated against a large number of land surface models and in situ datasets used for a wide range of applications (Dorigo et al. 2017b). Based on the ESA CCI SM the yearly and monthly anomalies are computed here with respect to a 1991-2016 climatology.

For several regions, spatial soil moisture anomaly patterns in 2017 (Plate 2.1g) were remarkably drier or wetter than normal. While after several dry years in a row (Blunden and Arndt 2017) soil moisture conditions in the northeast of South Africa were partly alleviated in 2017, drought conditions in the region around Cape Town intensified in the course of the year (Online Fig. S2.15; see Section 7e4). Dry soil moisture conditions already observed in 2016 in the Greater Horn of Africa (Blunden and Arndt 2017) persisted into 2017 and reportedly led to a displacement of more than 1 million people, according to a report from the World Meteorological Organization. On the other hand, soil moisture contents were higher than normal for most other parts of southern Africa, particularly during the first half of the year, and contributed to severe flooding, for example, in Botswana. Very dry soils were also observed in Morocco and southern Europe. Italy suffered particularly severe rainfall deficits and had its driest January-September period on record.

While soil moisture conditions in most parts of Brazil were around average, some parts of northeastern Brazil showed strong anomalous negative soil moisture conditions for the sixth consecutive year [see previous State of the Climate reports, e.g., Dorigo et al. (2017a)]. Wet conditions were observed for southern South America and the west coast of Peru, which strongly contrasts with the anomalously dry conditions that were observed in this region in 2016 (Dorigo et al. 2017a). Also, most of the southern and eastern United States were much wetter than normal. In particular, August was very wet (Online Fig. S2.15) with Hurricane Harvey making landfall in southern Texas. On the other hand, the Canadian Prairies and adjacent northern border areas of the United States were anomalously dry, mainly during the summer months (Online Fig. S2.15).

In 2017, soils in large parts of Southeast Asia were much wetter than normal. The monthly anomaly images reveal that this pattern persisted throughout 
the year (Online Fig. S2.15). A much wetter-thanaverage start to the year in many parts of western and northern Australia (Online Fig. S2.15) resulted in net average soil moisture conditions in 2017 that were wetter than usual for these areas. At the same time, most parts of eastern Australia were drier than average, reflecting precipitation amounts that were well below average (see Section 7h3).

The year 2017 was mostly dominated by a neutral state of ENSO (see Section 4b). ENSO anomalies are known to potentially cause continent-wide deviations in terrestrial water storages (Bauer-Marschallinger

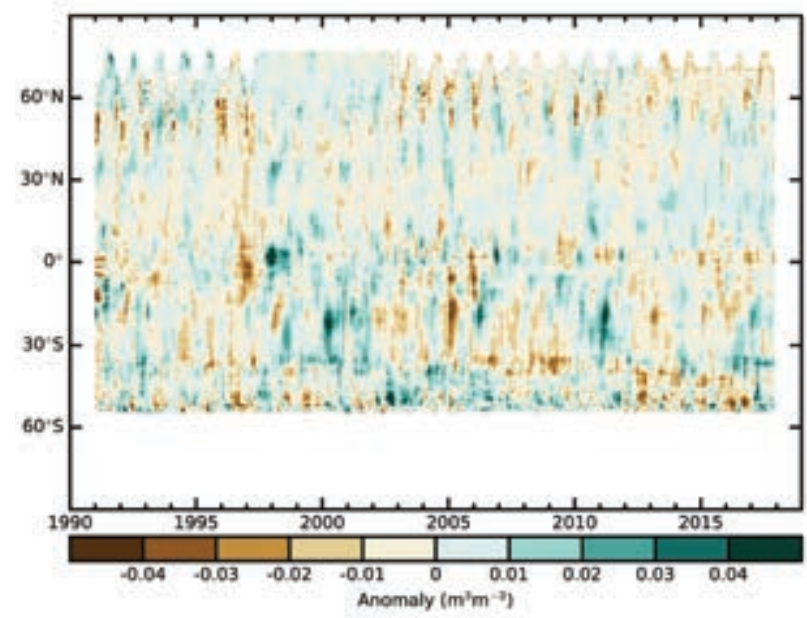

FIG. 2.29. Time-latitude diagram of surface soil moisture anomalies $\left(\mathrm{m}^{3} \mathrm{~m}^{-3}\right.$, base period: 1991-2016). Data were masked as missing where retrievals are either not possible or of low quality (dense forests, frozen soil, snow, ice, etc.). (Source: ESA CCI Soil Moisture.)

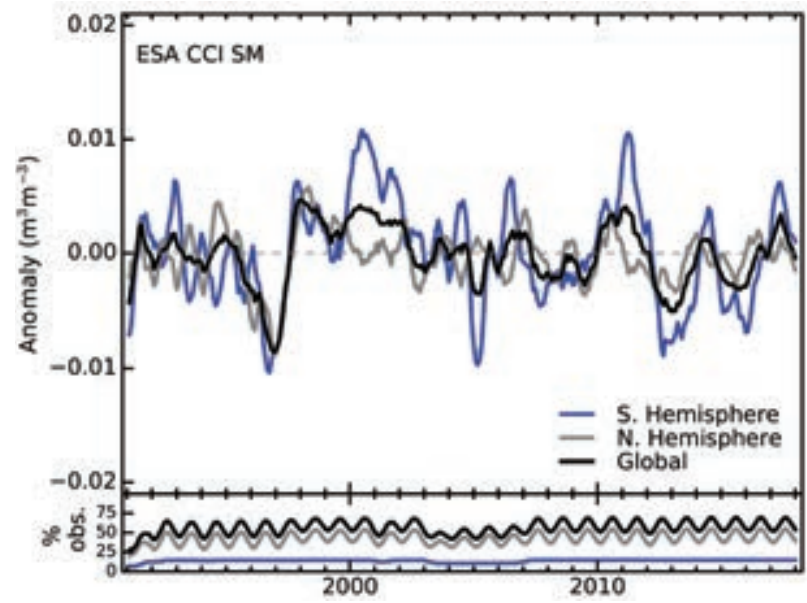

FIG. 2.30. Time series of average global surface soil moisture anomalies for $1991-2017\left(\mathrm{~m}^{3} \mathrm{~m}^{-3}\right.$, base period: 1991-2016). Data were masked as missing where retrievals were either not possible or of low quality (dense forests, frozen soil, snow, ice, etc.). (Source: ESA CCI Soil Moisture.) et al. 2013; Boening et al. 2012; Dorigo et al. 2017b; Miralles et al. 2014). Although soil moisture conditions in the Southern Hemisphere were on average wetter than normal, deviations were far from being as pronounced as in 2000 or 2010/2011 (Figs. 2.29 and 2.30), which were episodes associated with strong La Niña events. In the Northern Hemisphere, average soil moisture was close to normal in 2017 (Fig. 2.30).

No evident large-scale long-term global soil moisture trends can be observed (Fig. 2.30). However, this does not exclude the existence of long-term trends at the regional or local scale (An et al. 2016; Rahmani et al. 2016; Wang et al. 2016). However, anomalies and trends in average global soil moisture should be treated with caution, owing to dataset properties changing over time and the inability to observe beneath dense vegetation, mountain areas, or frozen or snow-covered soils (cf. gray regions in Plate $2.1 \mathrm{~g}$ and Online Fig. S2.15).

9) Drought-T. J. Osborn, J. Barichivich, I. Harris, G. van der Schrier, and P. D. Jones

Hydrological drought results from a period of abnormally low precipitation, sometimes exacerbated by additional evapotranspiration (ET), and its occurrence can be apparent in reduced river discharge, soil moisture, and/or groundwater storage, depending on season and duration of the event. Here, an estimate of drought called the self-calibrating Palmer drought severity index (scPDSI; Wells et al. 2004; van der Schrier et al. 2013) is presented, using precipitation and Penman-Monteith potential ET from an early update of the CRU TS 3.26 dataset (I. Harris et al. 2014). Moisture categories are calibrated over the complete 1901-2017 period to ensure that "extreme" droughts and pluvials relate to events that do not oc-

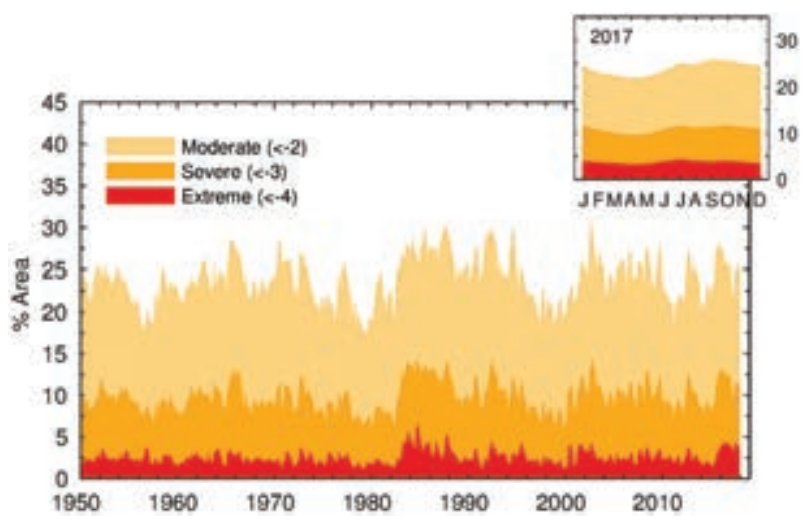

FIG. 2.3I. Percentage of global land area (excluding ice sheets and deserts) with scPDSI indicating moderate $(<-2)$, severe $(<-3)$, and extreme $(<-4)$ drought for each month of 1950-20I7. Inset: each month of 2017. 
cur more frequently than in approximately $2 \%$ of the months. This affects direct comparison with other hydrological cycle variables in Plate 2.1s that use a different base period.

After a notable peak in the overall area of drought across the globe in the second half of 2015 and all of 2016 (Osborn et al. 2017), drought area declined sharply by early 2017 (Fig. 2.31) before increasing to above average once more (though still below the 2016 area). Extreme drought conditions affected at least $3 \%$ of global land area in every month of 2017, which was matched only by 1984,1985 , and 2016 , but the geographical extents of moderate and severe droughts were not so unusual. The area where scPDSI indicates moderate or worse drought began at $24 \%$ in January, fell below $22 \%$ by April, before rising to around 25\% in the latter months of 2017. Altogether, three months had moderate or worse drought affecting more than $25 \%$ of the global land area, which has been matched or exceeded in 34 other years since 1950. The area of severe plus extreme droughts exceeded $10 \%$ for ten months during 2016, which has been matched or exceeded in 12 other years since 1950. The 2017 values should be interpreted cautiously because they may be modified by additional observations that will become available in due course. Drought area is just one of several ways to measure drought conditions; for example, Heim (2017) shows that area-integrated drought severity or duration yields different rankings for the major droughts of the 20th and 21st centuries over the contiguous United States since 1900.

Extensive severe or extreme droughts affected all continents except North America during 2017 (Plate 2.1s). Starting in the Western Hemisphere, persistent moderate-to-severe drought conditions

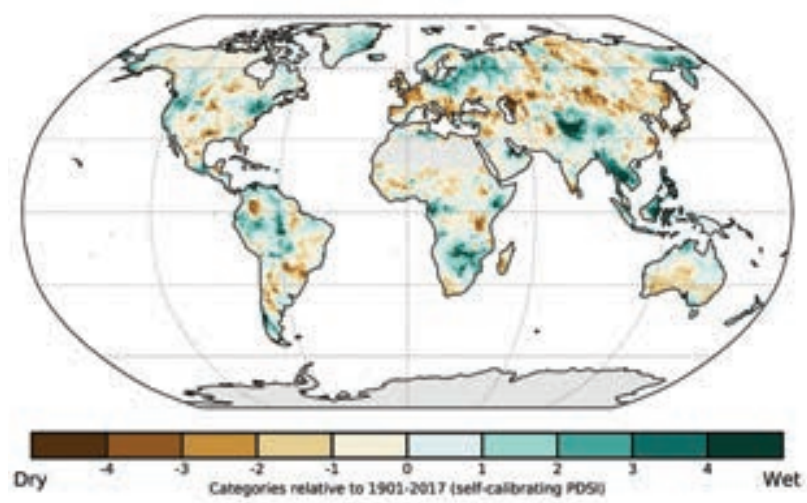

FIG. 2.32. Change in drought (mean scPDSI) from 2016 to 2017. Increases in drought severity are indicated by negative values (brown), decreases by positive values (green). No calculation is made where a drought index is meaningless (gray areas: ice sheets or deserts with approximately zero mean precipitation). affecting south-central Chile (Garreaud et al. 2017) continued for the eighth consecutive year, though the geographic extent of extreme drought decreased with a slight increase in winter rainfall. Notably, severe drought in the semiarid northeastern Brazil (Jiménez-Muñoz et al. 2016) continued in 2017 without much change in intensity and extent (Fig. 2.32). Moderate, or occasionally severe, drought was present across the Northern Hemisphere part of the South American continent (Plate 2.1s) though its intensity had eased compared with 2016 in most areas (Fig. 2.32).

Many coastal countries in Africa experienced drought in 2017, with the exception of some in East Africa (see Section 7e3). These droughts intensified compared with 2016 especially in southern Madagascar and the Western Cape of South Africa, the latter contributing to water supply restrictions in Cape Town in early 2018 (Le Page 2018). The partial easing of drought farther north, including in the Zambezi basin, is important given the increasing concentration of hydropower in the region that increases the risk of concurrent drought-related disruption to electricity production (Conway et al. 2017). Conditions were drier in 2017 than in 2016 in a band across Eurasia around $45^{\circ} \mathrm{N}$ (Fig. 2.32). This exacerbated drought in western and southern Europe, resulting in many impacts, including reduced agricultural yields and hydroelectric power production in the Balkans and Albania, and wildfire and hydrological impacts in Iberia.

Parts of the Middle East remained in drought, and particularly severe drought developed in the southwestern peninsula of India (especially Kerala) during 2017. Farther north in Asia, severe drought conditions were present in the Krasnoyarsk region of Russia, extending south to northern China. The severe drought in mainland Southeast Asia in 2016 was ended by much wetter conditions during 2017 (Plate 2.1s and Fig. 2.32). Much of Australia was drier than normal during 2017, with severe drought most notable in Tasmania.

10) Land evaporation-D. G. Miralles, B. Martens, H. E. Beck, A. J. Dolman, C. Jiménez, M. F. McCabe, and E. F. Wood

Evaporation, the return flux of water from terrestrial ecosystems to the atmosphere, modulates regional energy and water balances and affects precipitation, both locally and in remote locations. Estimating this variable in near real-time is important for both agricultural and hydrological management, while being able to monitor long-term trends enables the identification of climatological impacts 
on the global hydrosphere. Despite promising advances in the global sensing of evaporation from space (e.g., Mallick et al. 2016; McCabe et al. 2017b), and a potentially bright future as novel sensors are launched into space (McCabe et al. 2017a; Fisher et al. 2017), evaporation remains an elusive variable: in situ measurements are scarce and satellites can only sense it indirectly. As such, models that combine the satellite-observed environmental and climatic drivers of the flux are often applied to yield global evaporation estimates (Wang and Dickinson 2012). Ongoing efforts aim to reduce product latency and improve spatial resolution, which is essential for applications such as drought monitoring, seasonal extreme forecasting, or irrigation management (Ghilain et al. 2011; Anderson et al. 2011; Mu et al. 2013; McCabe et al. 2017a). The results shown here reflect recent simulations of the Global Land Evaporation Amsterdam Model (GLEAM; Miralles et al. 2011) version v3.2a by Martens et al. (2017). While GLEAM was not intentionally designed with an operational intent, the long-term record is updated to near real-time on an annual basis.

The geographical patterns of evaporation anomalies shown in Plate 2.1t resemble those from El Niño years (see Miralles et al. 2014), yet the ENSO condition in 2017 was neutral on average. Consequently, regional negative anomalies coincide with those in 2016: eastern South America, Amazonia, southern Africa, the Horn of Africa, and India (Plate 2.1t). In addition, other regions such as central-eastern Australia and Central America also experienced low values. A closer look at these patterns indicates that evaporation was below normal in most of the tropics during the second half of the year (Fig. 2.33). In

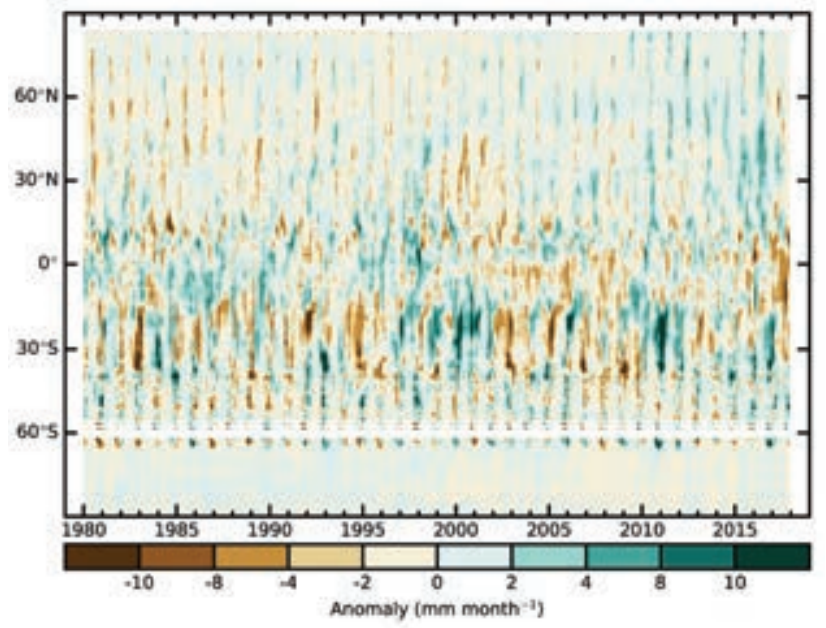

Fig. 2.33. Zonal mean terrestrial evaporation anomalies $\left(\mathrm{mm}\right.$ month $^{-1}$; relative to $\left.1980-2017\right)$. (Source: GLEAM.) wet tropics this is typically associated with negative anomalies of incoming radiation (due to cloudy conditions, for example), while in dry tropics it reflects an abnormally low supply of rainfall (Miralles et al. 2011). As such, the low evaporation in the semiarid eastern South America likely relates to the drought that started in 2011, intensified in 2012, and persisted into 2017 (Brito et al. 2018). These conditions were particularly intense in the Caatinga shrubland ecosystems of Brazil. In fact, the strong anomaly in evaporation, shown in Fig. 2.33 around $20^{\circ} \mathrm{S}$ in the second half of the year, possibly relates to the shortage in plant-available water in this region. Likewise, the negative anomaly in Amazonia, shown in Plate 2.1t, persisted throughout the year, reflecting the impact of the meteorological drought that started in 2015, and was driven by the strong El Niño (Jiménez-Muñoz et al. 2016). The legacy of such events on rainforest ecosystem functioning is known to extend over prolonged periods of time (Zemp et al. 2017).

The spatial patterns found in Africa also relate to anomalies in the supply of water to a large extent. Negative anomalies in the Sahel region and Horn of Africa can be attributed to below -average rainfall (Mpelasoka et al. 2018), particularly during the second half of the year. A low water supply also explains the negative anomaly in the Congo basin. While the Congo rainforest is thought to be primarily energy limited, recent studies have shown evidence of ecosystem water limitation (Zhou et al. 2014). Furthermore, the flux of interception loss, i.e., the vaporization of the rainfall captured by the leaves and branches of plants, constitutes a large fraction of the evaporation in the Congo region (Miralles et al. 2010). Conversely, the positive anomaly in the Kalahari Desert (Plate 2.1t) relates to above-average rainfall in January and February, which was followed by a positive anomaly in the atmospheric demand for water in March (Section 2f). Finally, in the absence of particularly strong anomalies in water supply in North America, the positive anomaly in evaporation over the U.S. likely relates to the abnormally high temperatures during the first months of 2017 (see Section 7b2).

Figure 2.34 shows the multiannual (1980-2017) variability in terrestrial evaporation derived from GLEAM v3.2a (Martens et al. 2017). A linear trend of approximately $0.3 \mathrm{~mm} \mathrm{yr}^{-1}(p=0.002)$ for the entire continental surfaces is obtained. While the year-toyear variability is mostly dictated by the variability in the Southern Hemisphere-and particularly affected by the signature of ENSO (Miralles et al. 2014) - the multidecadal trend detected by GLEAM relates almost exclusively to the dynamics of evaporation in the 


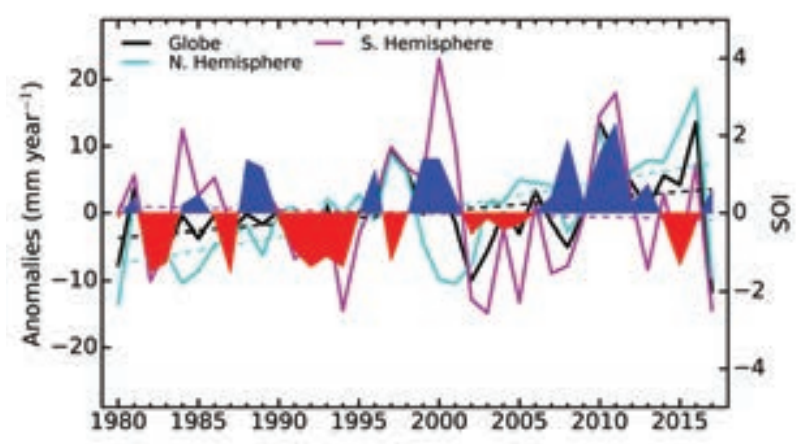

FIG. 2.34. Land evaporation anomaly ( $\mathrm{mm} \mathrm{yr}^{-1}$; $1980-$ 2017 base period) for the $\mathrm{NH}, \mathrm{SH}$, and the entire globe (blue, purple, and black solid lines, respectively). Linear trends in evaporation (dashed lines) and the SOI from NOAA (right axis, shaded area) are also shown. (Source: GLEAM.)

Northern Hemisphere. This trend is qualitatively and quantitatively in agreement with Clausius-Clapeyron expectations in a warming atmosphere (Miralles et al. 2014; Brutsaert 2017). The global average terrestrial evaporation in 2017 was slightly below this trend and close to the 1980-2016 mean (Fig. 2.34). Notwithstanding the novel insights made available from remote platforms, trends in satellite-based evaporation should be interpreted with care, and the weighted use of multiple retrieval approaches is usually recommended (Miralles et al. 2016; McCabe et al. 2016). Unfortunately, as of today, algorithms dedicated to estimating evaporation using satellite observations at global scales are mostly intended for research applications and are not regularly updated in nearreal time (Fisher et al. 2017).

\section{e. Atmospheric circulation}

I) Mean sea level pressure AND RELATED MODES OF VARIABILITY-R. Allan and C. K. Folland

Overviews of the most recent El Niño have been made in papers such as L'Heureux et al. (2017), but the protracted nature of the El Niño from 2014 to 2016 should also be noted (Allan and D'Arrigo 1999; Allan et al. 2018, manuscript submitted to Atmosphere). The climate system exhibited weak La Niña (positive SOI) to neutral conditions follow- ing the 2014-16 episode. ENSO, arguably the most globally impactful mode of variability, encompasses a family of events and episodes. Individually, these exhibit wide-ranging effects across the Indo-Pacific region, with teleconnections to higher latitudes in both hemispheres (Capotondi et. al. 2015; C. Wang et. al. 2017). The sea level pressure derived Southern Oscillation index (SOI; Allan et al. 1996; Kaplan 2011) was primarily positive (the phase typically associated with La Niña conditions) from mid-2016 through the end of 2017 (Fig. 2.35). Nevertheless, the immediate impacts of the 2014-16 El Niño episode have lingered in the eastern Australian region, where its influence was particularly profound (Allan and Folland 2017). This has taken the form of persistent above-average eastern Australian SST anomalies from the Coral Sea southwards via major extensions of the East Australian Current into the Tasman Sea region from 2014 through 2017 (Australian Bureau of Meteorology 2017; Oliver et al. 2017). Historically, periods of persistent drought (widespread flooding) in this region have been strongly amplified by protracted El Niño (La Niña) episodes (Murphy and Ribbe 2004; Allan et al. 2018, manuscript submitted to Atmosphere).

Mean sea level pressure (MSLP) can also be used to derive indices of many regional modes of variability that drive significant weather and climate events

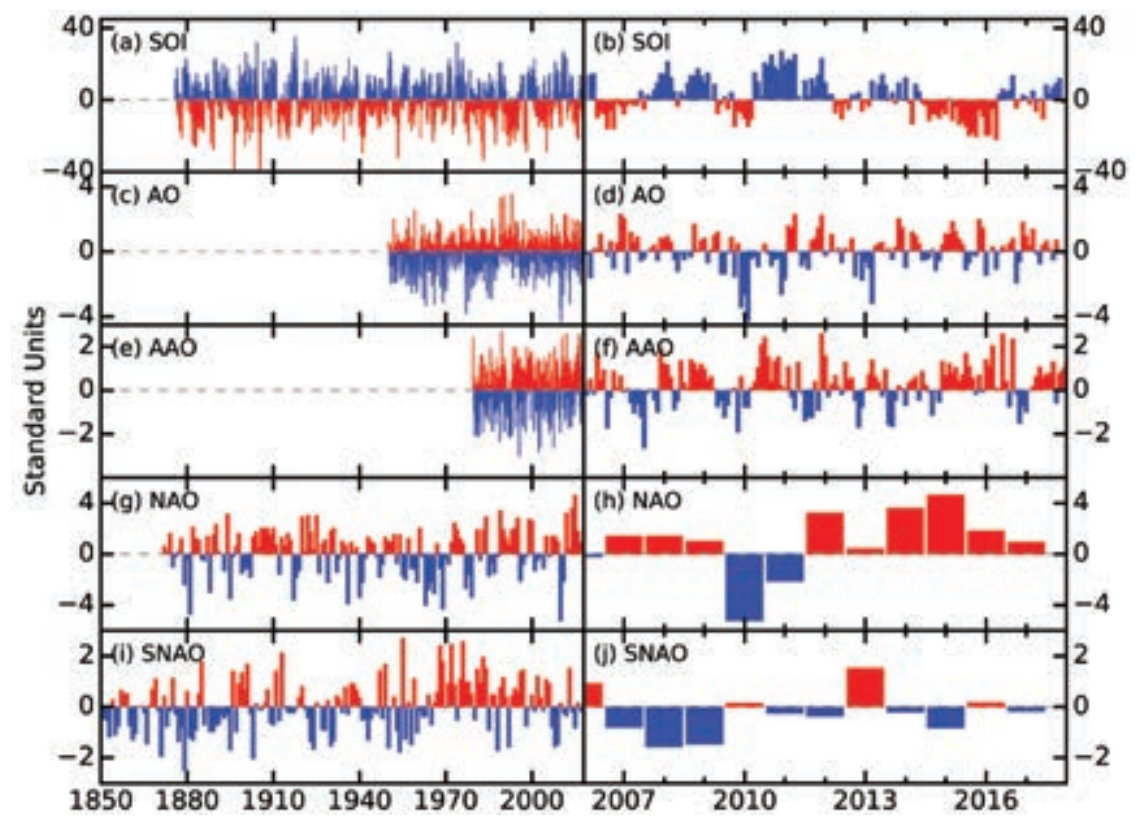

FIG. 2.35. Time series for modes of variability described using sea level pressure for the (left) complete period of record and (right) 2006-I7. (a),(b) SOI (provided by the Australian Bureau of Meteorology); (c),(d) AO (NCEP Climate Prediction Center); (e),(f) AAO (NCEP Climate Prediction Center); (g),(h) winter (Dec-Feb) NAO average (NCAR; presented for winter at the beginning of each year so winter $2017 / 18$ is not shown); (i),(j) summer (Jul-Aug) SNAO average (Folland et al. 2009). 
(a) $2015 / 16$

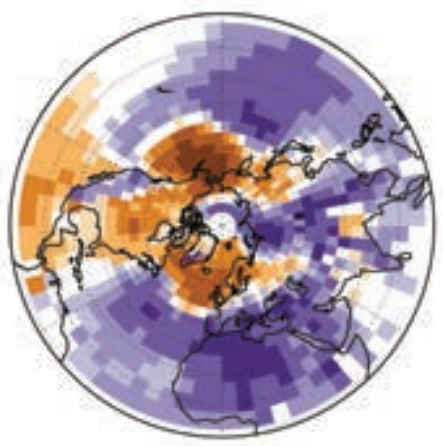

(b) $2016 / 17$

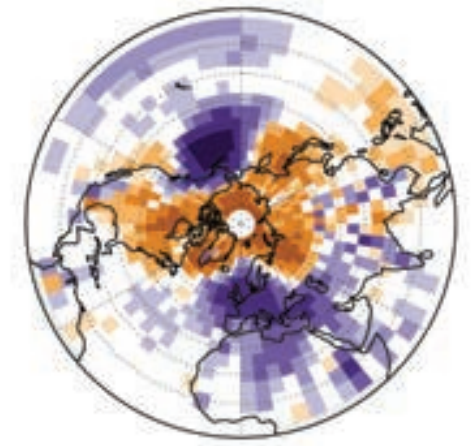

(c) $2017 / 18$
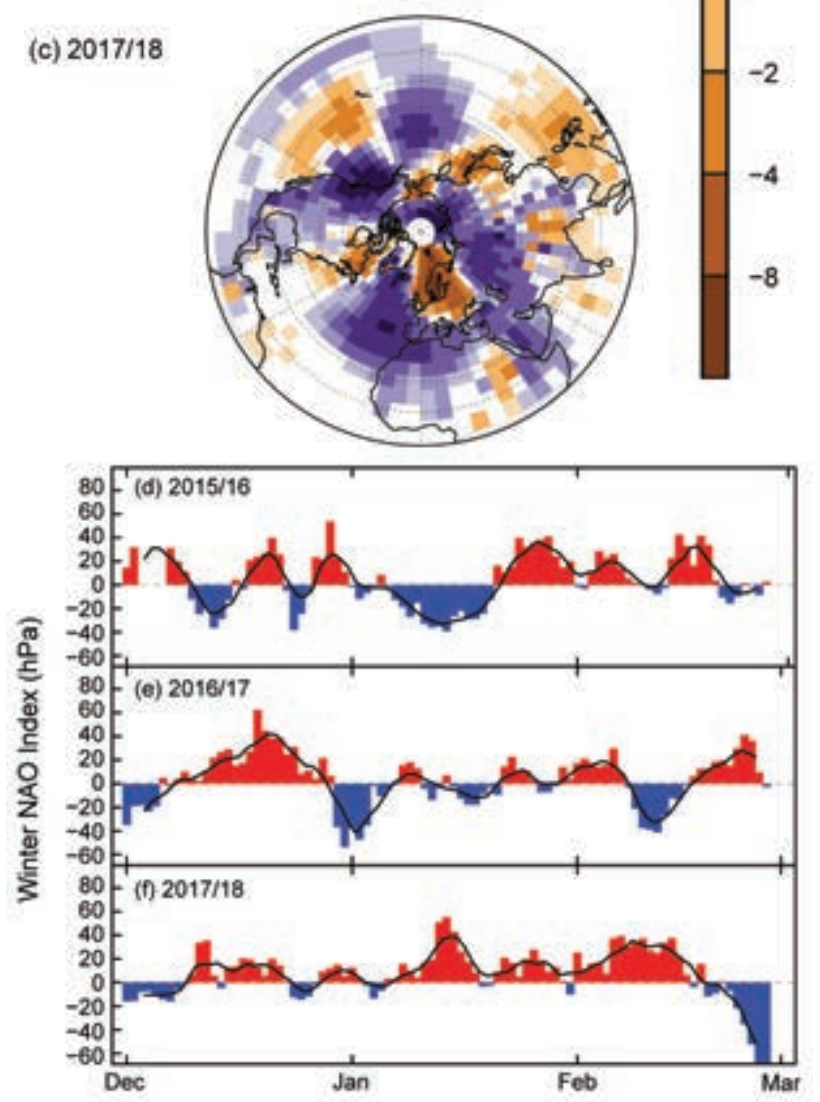

FIG. 2.36. Boreal winter sea level pressure anomalies (hPa; 198I-2010 base period) averaged over Dec-Feb for (a) $2015 / 16$, (b) $2016 / 17$, and (c) 2017/18. NAO daily time series (hPa) for winter (d) 2015/16, (e) 2016/17, and (f) 2017/18. The 5-day running mean is shown by the solid black line. The data are from HadSLP2r (Allan and Ansell 2006).
(Kaplan 2011): the Arctic Oscillation (AO); North Atlantic Oscillation (NAO); summer NAO (SNAO); and the Antarctic Oscillation (AAO) (Fig. 2.35). In the Northern Hemisphere, the last six winters have displayed broadly positive NAO conditions but a diverse range of circulation patterns. During the early winter of 2015/16 the NAO oscillated between phases, with a deep trough over the North Atlantic leading to an enhanced jet stream that directed a series of extratropical cyclones toward northern Ireland and Scotland-northern England (Fig. 2.36). By the mid-to-latter part of the 2015/16 winter the pattern had changed, with the NAO swinging from slightly negative in January 2016 to positive in February 2016 (Allan and Folland 2017). The 2016/17 boreal winter was marked by an increasingly positive NAO through mid-December 2016, temporarily negative NAO values around the start of 2017, and then a fluctuation between phases for the rest of January (Fig. 2.36; Allan and Folland 2017). During the 2017/18 boreal winter, the NAO has been mainly positive (Fig. 2.36). As a consequence, temperatures in Europe were mild to warm, and the region experienced its fifth warmest year on record, while Portugal in particular was strongly impacted, with its driest April to December period in its 87-year record (Section 2d9, Section 7f4). As in 2016/17, the Aleutian low was markedly weakened, leading to reduced rainfall and conditions conducive to major wildfires in the British Columbia region of Canada (Section 2h3; Figs. 2.36a-c; Section 7b1).

In 2017, the phase of the SNAO defined over July and August as in Folland et al. (2009) was on average slightly negative (Figs. 2.37a,b). As in 2016 (Allan and Folland 2017), there was a rather persistent anticyclonic anomaly over southern Greenland in both months, but this was markedly less intense and smaller than in 2016. This feature is normally associated with a negative SNAO. In fact, July (Fig. 2.37a) had a variable and overall negative SNAO as seen in the daily values (Fig. 2.37c). The most notable feature in summer 2017 was a mostly strong negative SNAO that lasted ten days from the end of July into early August. August overall showed a near-neutral SNAO despite the anticyclonic MSLP anomaly over southern Greenland (Fig. 2.37b) and the variable August daily SNAO series. The multidecadal tendency noted in Allan and Folland (2017) toward a more negative SNAO index since 1970 continued to slow. Thus, the average level of the SNAO index in the last five years is near the average observed over 1850-1960 but is considerably more negative than the positive 
(a) Jul

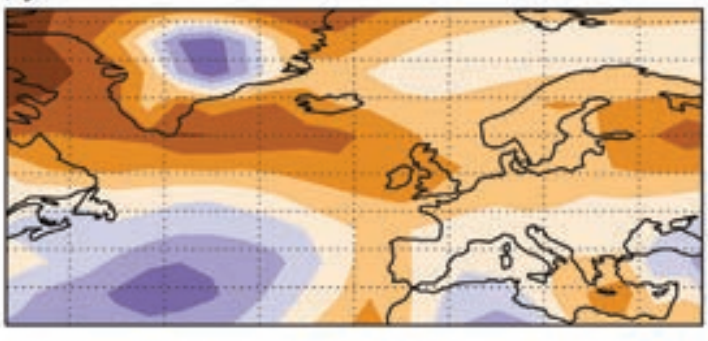

(b) Aug
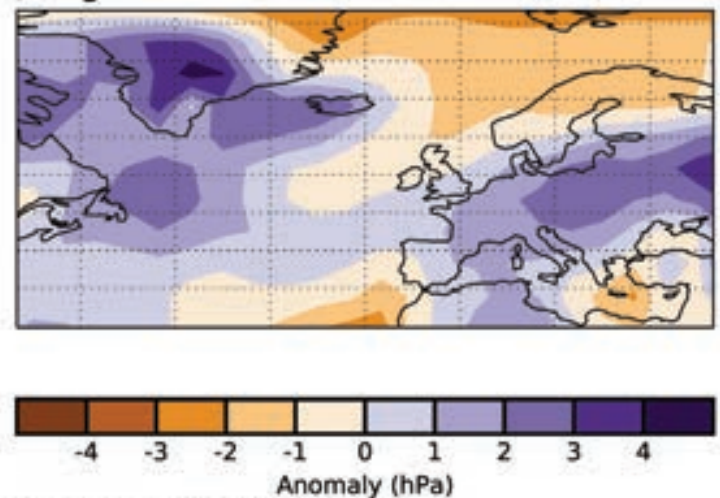

(c) Summer NAO Index

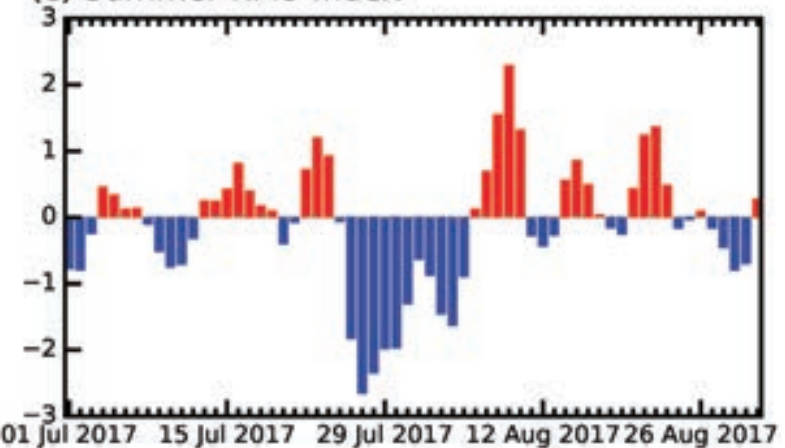

FIG. 2.37. MSLP anomalies (hPa; $1961-90$ base period) in (a) Jul and (b) Aug 2017 over the extratropical North Atlantic and Europe. (c) Daily SNAO index for Jul and Aug 2017, calculated from eigenvectors of the daily SNAO.

index averaged over the two decades 1966-1985. Linderholm and Folland (2017) provide more detail on recent multidecadal changes in the SNAO index.

In the Southern Hemisphere, the AAO has been predominantly in its positive phase since 2015/16 (Fig. 2.35). This favors reduced sea ice extent in the West Antarctic Peninsula (WAP) region, owing to enhanced westerly wind conditions (Stammerjohn et al. 2008). In the interplay between the protracted El Niño, which favors a weaker polar jet stream, and a positive AAO mode, with stronger westerly winds, the former appears to have dominated. With the cessation of the protracted El Niño episode in mid-2016 (Allan and Folland 2017; Allan et al. 2018, manuscript submitted to Atmosphere), and of a negative AAO (Fig. 2.35), there was a major reduction in the WAP sea ice margin centering on November 2016 and a slight recovery in extent through 2017 (see Section 6e) despite a return to positive AAO values (Fig. 2.35f; http://nsidc.org/data/seaice_index/).

2) Surface Winds - C. Azorin-Molina, R. J. H. Dunn, C. A. Mears, P. Berrisford, and T. R. McVicar

Over land, observations of globally averaged wind speed continued to "recover" (commencing in 2013; Dunn et al. 2016a; Azorin-Molina et al. 2017a) from the previous slowdown of winds (from $~ 1960$ s onwards; McVicar et al 2012), termed "stilling" by Roderick et al. (2007). Surface wind speed increased in 2017 (Fig. 2.38a), showing a global (excluding Australia) average wind speed anomaly of $+0.024 \mathrm{~m} \mathrm{~s}^{-1}$ with respect to the 1981-2010 climatology (Table 2.4). Regionally, this recent rebound was caused by positive anomalies for central $\left(+0.142 \mathrm{~m} \mathrm{~s}^{-1}\right)$ and East $\left(+0.108 \mathrm{~m} \mathrm{~s}^{-1}\right)$ Asia, with Europe $\left(+0.002 \mathrm{~m} \mathrm{~s}^{-1}\right)$ being very close to average. North America $\left(-0.068 \mathrm{~m} \mathrm{~s}^{-1}\right)$ showed a negative anomaly but less negative than its 2012 record lowest anomaly. In contrast, Australia

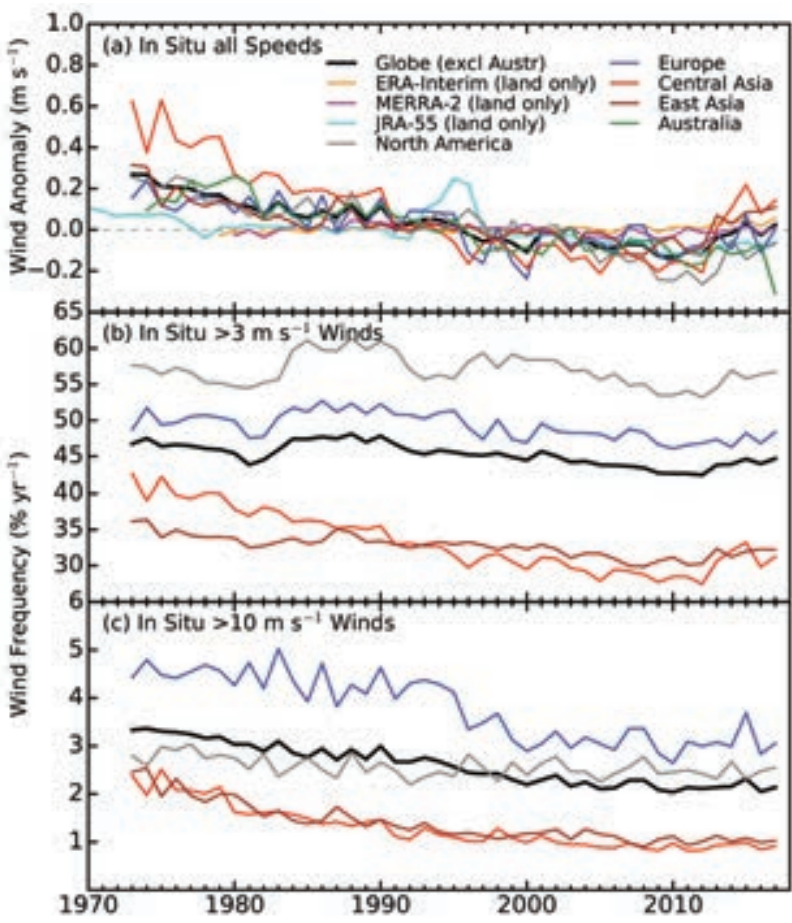

Fig. 2.38. Global (excluding Australia) and regional annual time series of land surface wind speed anomaly $\left(\mathrm{m} \mathrm{s}^{-1}\right.$; relative to $\left.198 \mathrm{I}-2010\right)$ using HadISD2 (19732017), an Australian dataset, and ERA-Interim (19792017), MERRA-2 (1980-2017) and JRA-55 (1970-2017). Occurrence frequencies (in \%) for wind speeds (b) $>3$ $\mathrm{m} \mathrm{s}^{-1}$ and (c) $>10 \mathrm{~m} \mathrm{~s}^{-1}$ do not include Australia. 


\begin{tabular}{|c|c|c|c|c|}
\hline Region & $\begin{array}{c}\text { Mean } \\
198 \mathrm{I}-2010 \\
\left(\mathrm{~m} \mathrm{~s}^{-1}\right)\end{array}$ & $\begin{array}{c}\text { Anomaly } \\
2017 \\
\left(\mathrm{~m} \mathrm{~s}^{-1}\right)\end{array}$ & $\begin{array}{l}\text { Trend } 1979-2017 \\
\left(\mathrm{~m} \mathrm{~s}^{-1} \text { decade }^{-1}\right) \text { and } \\
\text { 5th to } 95 \text { th percentile } \\
\text { confidence range }\end{array}$ & $\begin{array}{l}\text { Number of } \\
\text { Stations }\end{array}$ \\
\hline $\begin{array}{c}\text { Globe } \\
\text { (excluding } \\
\text { Australia) }\end{array}$ & 3.332 & +0.024 & $\begin{array}{c}-0.066 \\
(-0.074 \rightarrow-0.058)\end{array}$ & 2632 \\
\hline $\begin{array}{l}\text { North } \\
\text { America }\end{array}$ & 3.728 & -0.068 & $\begin{array}{c}-0.088 \\
(-0.099 \stackrel{\rightarrow}{\rightarrow}-0.076)\end{array}$ & 598 \\
\hline Europe & 3.662 & +0.002 & $\begin{array}{c}-0.057 \\
(-0.070 \stackrel{\rightarrow}{\rightarrow}-0.047)\end{array}$ & 788 \\
\hline $\begin{array}{l}\text { Central } \\
\text { Asia }\end{array}$ & 2.875 & +0.142 & $\begin{array}{c}-0.128 \\
(-0.144 \stackrel{-0.099)}{\rightarrow}\end{array}$ & 263 \\
\hline East Asia & 2.738 & +0.108 & $\begin{array}{c}-0.036 \\
(-0.045 \stackrel{-0.027)}{\rightarrow}\end{array}$ & 474 \\
\hline Australia & 2.091 & -0.311 & -0.092 & 28 \\
\hline
\end{tabular}

reanalyses to reproduce wind speed trends. This is shown in Fig. 2.38a, as the long-term variability of reanalyzed land surface winds is almost stable as opposed to the decline in the observations. The underestimation of the magnitude of reanalysis wind trends is mainly due to the shortcomings in the simulation of near-surface layer processes (e.g., McVicar et al. 2008; Pryor et al. 2009; Vautard et al. 2010).

The global land wind speed trend from observations was $-0.066 \mathrm{~m} \mathrm{~s}^{-1}$ decade $^{-1}$ for 1979-2017, which is slightly less negative than the 1979-2016 trends $\left(-0.311 \mathrm{~m} \mathrm{~s}^{-1}\right)$ had the lowest anomaly in its time series. Excluding the latter, the 2017 anomalies continue to support the reversal in the "stilling" detected over the last few years. This rebound of wind speeds has also been reported elsewhere (South Korea, Kim and Paik 2015; and Saudi Arabia, Azorin-Molina et al. 2018a). The recent strengthening in terrestrial wind speed is much clearer for the moderate $\left(>3 \mathrm{~m} \mathrm{~s}^{-1}\right)$ than the strong $\left(>10 \mathrm{~m} \mathrm{~s}^{-1}\right)$ winds (Figs. $\left.2.38 \mathrm{~b}, \mathrm{c}\right)$, as the occurrence of moderate winds has slightly increased after a steady slowdown since records began. The recovery of surface winds is not detected for those of strong intensity in 2017, which only showed a stabilization in frequency recently.

Two observational databases from anemometer records were chosen for evaluating the spatiotemporal variability of land-surface winds globally: (1) the HadISD2 (1973-2017; Dunn et al. 2012, 2016b) and (2) an Australian dataset (1979-2017; McVicar et al. 2008). As a result of unresolved differences for the wind run and wind speed data over Australia, this region is treated separately (see Dunn et al. 2016a). Both data sources were subject to quality control checks resulting in 2660 series for 1979-2017. Additionally, three reanalysis products (MERRA-2, 19802017; Gelaro et al. 2017; ERA-Interim, 1979-2017; Dee et al. 2011a; and JRA-55, 1970-2017; Kobayashi et al. 2015) were used to assess wind speed variability across land and ocean surfaces. A global reanalysis intercomparison (Torralba et al. 2017) has pointed out the large uncertainty in the ability of atmospheric

( $-0.070 \mathrm{~m} \mathrm{~s}^{-1}$ decade $^{-1}$; Azorin-Molina et al. 2017a). As shown in Table 2.4, the strongest 1979-2017 negative trends are in Central Asia $\left(-0.128 \mathrm{~m} \mathrm{~s}^{-1}\right.$ decade $\left.^{-1}\right)$ and North America $\left(-0.088 \mathrm{~m} \mathrm{~s}^{-1}\right.$ decade $\left.^{-1}\right)$, whereas the weakest ones are in East Asia $\left(-0.036 \mathrm{~m} \mathrm{~s}^{-1}\right.$ decade $\left.^{-1}\right)$ and Europe $\left(-0.057 \mathrm{~m} \mathrm{~s}^{-1}\right.$ decade $\left.^{-1}\right)$. For all these regions, the magnitude of observed trends is also less negative than Azorin-Molina et al. (2017a), except for Australia $\left(-0.092 \mathrm{~m} \mathrm{~s}^{-1}\right.$ decade $\left.^{-1}\right)$. Individual station trends (Fig. 2.39) are $64.9 \%$ negative from the HadISD2 dataset, and $96.4 \%$ negative for the Australian dataset. Even though a recent recovery of terrestrial surface wind speeds is detected, when considering the past four decades "stilling" remains widespread (McVicar et al. 2012).

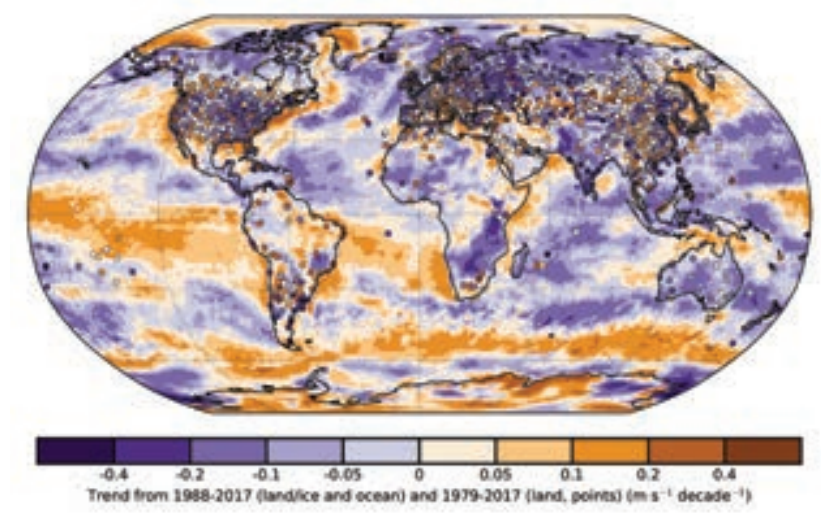

FIG. 2.39. Wind speed trends $\left(\mathrm{m} \mathrm{s}^{-1}\right.$ decade $\left.^{-1}\right)$ for the observational HadISD2 and Australian datasets (circles) over land for 1979-2017, and MERRA2 over land/ice and RSS over ocean for 1988-2017 (shaded areas). 


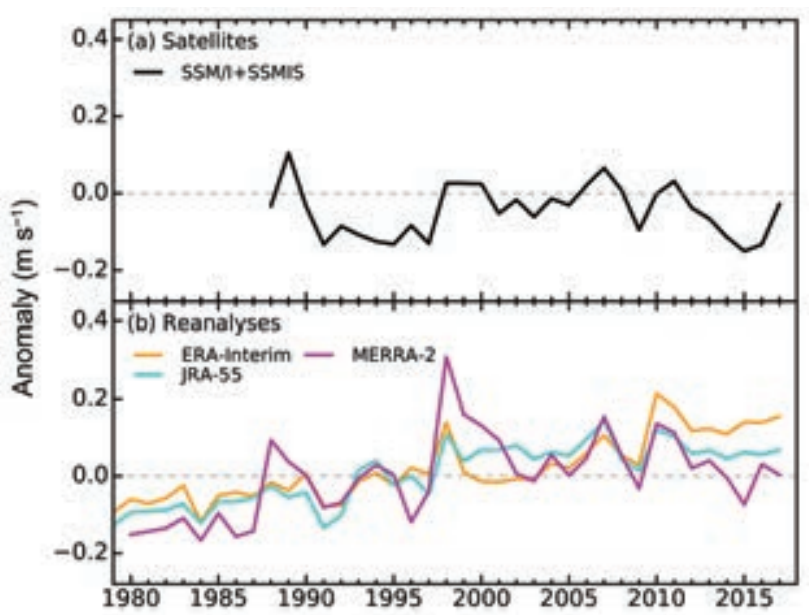

FIG. 2.40. Global average surface wind anomaly $\left(\mathrm{m} \mathrm{s}^{-1}\right.$; 198I-2010 base period) over ocean from (a) satellite radiometers and $(b)$ reanalyses.

Satellite-borne microwave radiometers and the three above-mentioned reanalysis products were chosen for assessing surface wind variability over oceans. During 2017, global wind speed anomalies for the satellite estimates (Fig. 2.40a) were close to zero, with reanalysis showing neutral to positive anomalies (Fig. 2.40b). In comparison to 2016, over ocean, globally averaged wind speed anomalies tended to be less negative (or even positive) for all products; in agreement with the observed recovery of terrestrial surface winds. The strongest spatial anomalies for 2017 (Plate 2.1v) corresponded to: (1) strong negative anomalies dominating in the Gulf of Alaska and for much of the Atlantic Ocean north of the equator, as well as in the southwest Pacific-Tasman Sea and western Indian Ocean; and (2) strong positive anomalies mostly observed over the South Pacific and South Atlantic Oceans and parts of the Southern and Arctic Oceans.

The limited knowledge about the causes behind the stilling phenomenon and the recent recovery of surface winds suggests the need for comprehensive attribution analyses of wind speed variability over land and ocean and at different altitudes (i.e., including high-elevation stations; Azorin-Molina et al. 2017c). In the last few years the scientific literature has attributed the stilling over land to three major drivers: (1) increase of surface roughness (Vautard et al. 2010; Bichet et al. 2012; Wever 2012; Wu et al. 2016); (2) large-scale atmospheric circulation changes (AzorinMolina et al. 2014, 2016); and (3) instrumental issues (Wan et al. 2010; Azorin-Molina et al. 2017b, 2018b). The attribution analysis of the recent recovery of surface winds is also complicated by interplaying factors, and future research should fill this knowledge gap.
3) UPPER AIR WINDS-L. Haimberger, M. Mayer, and V. Schenzinger

Figure 2.41 shows global (land + ocean) mean 850$\mathrm{hPa}$ wind speed anomalies from reanalyses and in situ upper air (TEMP and PILOT) observations, for comparison with surface wind speed anomalies in Section $2 \mathrm{e} 2$. There is a general tendency towards higher wind speeds at this level, at least in the reanalysis data, but only trends from ERA-Interim (Dee et al. 2011a) and MERRA2 (Gelaro et al. 2017) for 1979-2017 are statistically significant (95\% confidence). Trends are larger over the oceans, particularly in the Pacific trade wind region, and weaker over land. At higher levels (200-300 hPa), the global wind trends turn negative (not shown) but remain weak.

The annual mean 850-hPa wind speeds for 2017 are clearly above normal $\left(0.22 \mathrm{~m} \mathrm{~s}^{-1}\right.$ in ERA-Interim), consistent with the overall increasing trend at this level and also with the recovery of the surface winds from wind stilling noted in Section 2e2. They appear anomalously high particularly in the tropics, as can be seen from Plate $2.1 \mathrm{w}$, with stronger-than-normal easterlies over large regions. This result should be taken with care though, because Liu and Allan (2018) recently have detected problems with reanalysis winds.

Over land (not shown), the $850-\mathrm{hPa}$ trends from reanalyses are only weakly positive $\left(0.01 \mathrm{~m} \mathrm{~s}^{-1}\right.$ decade $^{-1}$ in ERA-Interim for the 1979-2017 period; the 2017 anomaly is $0.13 \mathrm{~m} \mathrm{~s}^{-1}$ ). They are still slightly more positive than the surface wind trends over land (see Section 2e2). The in situ upper air dataset (GRASP; Ramella Pralungo et al. 2014) has negative trends $\left(-0.03 \mathrm{~m} \mathrm{~s}^{-1}\right.$ decade $\left.^{-1}\right)$ in the period 1979-2016. The anomalies of this dataset in the most recent years were, however, also slightly positive, similar to the surface wind anomalies (see Section 2e2).

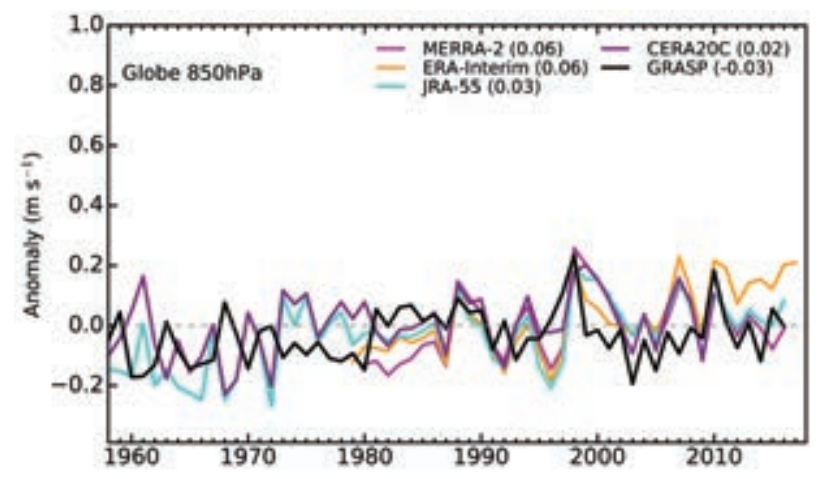

FIG. 2.4I. Annual anomalies of global mean wind speed ( $\mathrm{m} \mathrm{s}^{-1}$; base period 198I-2010) at $850 \mathrm{hPa}$ from four reanalyses and one observational dataset (GRASP; Ramella Pralungo et al. 2014). The numbers in brackets are linear trends in $\mathrm{m} \mathrm{s}^{-1}$ decade $^{-1}$; valid for 1979-2017. 
To date, there is no independent satellite-derived product for upper air winds. Atmospheric motion vectors from AVHRR have been reprocessed recently at EUMETSAT and are ready to be assimilated (Schulz et al. 2017); however no gridded product has been generated.

The 2017 Atlantic hurricane season (see Section 4f2) deserves special attention since it was exceptionally intense, particularly at peak time (mid-AugustSeptember). From an upper air circulation perspective, one cause that may have favored the observed large number of strong hurricanes is anomalously large upper-level divergence, a parameter whose

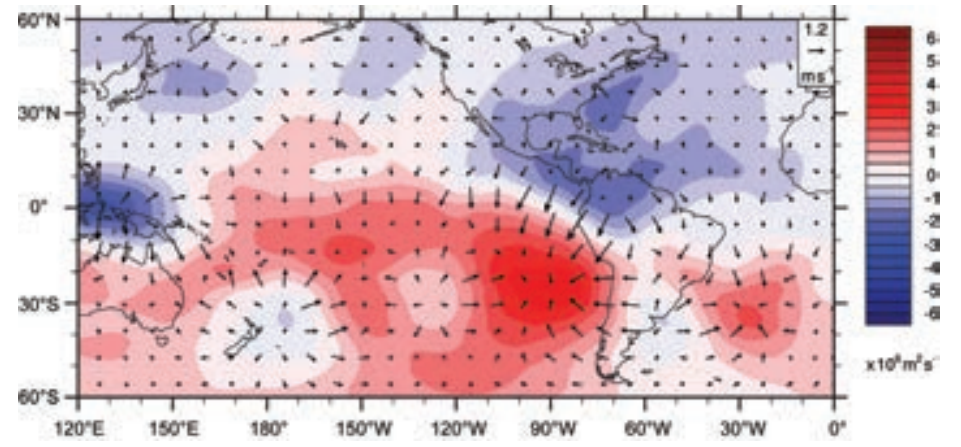

FIG. 2.42. Aug-Sep 2017 average of velocity potential anomaly ( $x$ $10^{6} \mathrm{~m}^{2} \mathrm{~s}^{-1}$ ) and divergent wind at $200 \mathrm{hPa}$ (vector arrows) compared to the 1979-2016 Aug-Sep climatology. Velocity potential anomaly minima indicate positive divergence anomalies. (Source: ERA-Interim.) importance has been stressed in previous State of the Climate reports. A second factor may be the abundance of strong tropical easterly wave disturbances that can amplify under favorable conditions (Dieng et al. 2017; Russell et al. 2017). Figure 2.42 shows that upper level divergence averaged over August and September was anomalously positive throughout the western Atlantic. Together with negative (positive) values over the eastern (western) tropical Pacific, this is consistent with weak La Niña conditions establishing at that time (Mayer et al. 2013). However, it is difficult to separate cause and effect for the anomaly in the upper air circulation over the western Atlantic, because the strong hurricanes themselves potentially contributed to the anomalies in that region.

Tropical wave activity was also high, as shown in the Hovmöller diagram [similar, for example, to Seo et al. (2008)] in Fig. 2.43 for the period 15 August-1 October, during which four major hurricanes were observed. In particular the standard deviation of meridional wind speed in the west central Atlantic was high compared with 2015, 2016, and the 1979-2017 climatology, which shows slowly decaying wave activity from the maximum near the West African coast toward the west. The strong waves in 2017 together with the anomalously high oceanic heat content (see Section 3c) likely fostered the quick formation of Irma, Jose, and Maria, which developed into major hurricanes already over the west central Atlantic. Hurricanes are visible in Fig. 2.43 as regions of extreme east-west wind gradients.

The quasi-biennial oscillation (QBO; see also Section 2b5) exhibited an unprecedented anomaly at the beginning of 2016. It was characterized by highly unusual and strong upward propagation of equatorial wind regimes, particularly between $10-\mathrm{hPa}$ and 40-hPa (Newman et al 2016; Dunkerton 2016). The

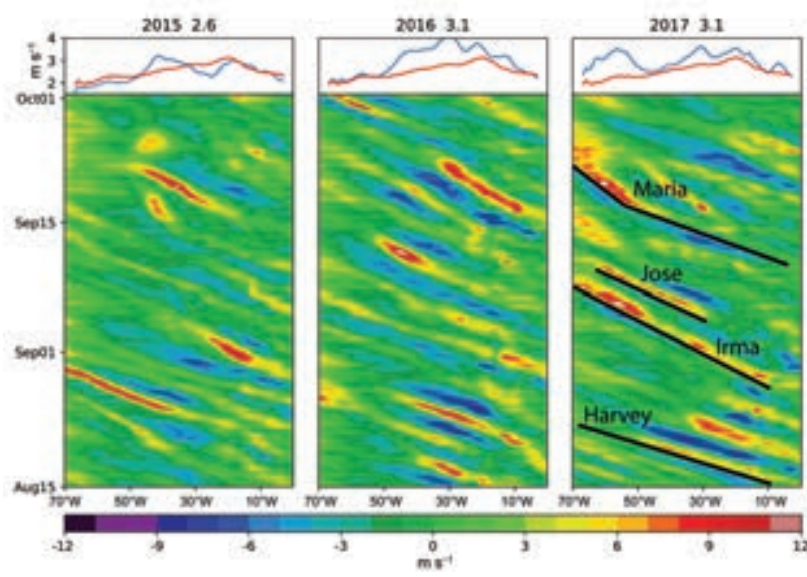

Fıg. 2.43. Hovmöller diagrams of $850-\mathrm{hPa}$ meridional wind $\left(\mathrm{m} \mathrm{s}^{-1}\right)$ averaged over $8^{\circ}-18^{\circ} \mathrm{N}$ (the region with strongest wave disturbances according to Dieng et al. 2017) for the peak hurricane season 15 Aug-I Oct between $70^{\circ} \mathrm{W}$ and $0^{\circ}$. 6-hourly ERA-Interim wind fields at $1^{\circ}$ resolution without any filter have been used. Upper panels show standard deviation of meridional wind $\left(\mathrm{m} \mathrm{s}^{-1}\right)$ as a function of longitude in individual years (blue) and for the 1979-2017 average (red). Selected waves that developed into hurricanes in $\mathbf{2 0 1 7}$ are marked with lines and named.

anomaly decayed in 2017 and the usual oscillation resumed with a relatively large, but not exceptional, amplitude (Online Fig. S2.16). However, the westerly wind regime at $20-\mathrm{hPa}$ lasted for 24 months, compared to the average duration of 13 months and the mean QBO period of 28 months (e.g., Schenzinger et al. 2017). A new analysis by Watanabe et al. (2018) points to interaction of extratropical Rossby waves with the mean equatorial flow as main reason for the anomaly. Comparison of this episode with results from historical CMIP climate model runs shows only one similar event in the model data (Osprey et al. 2016; see also Schenzinger 2016). 


\section{f. Earth radiation budget}

I) EARTH RADIATION BUDGET AT TOP-OF-ATMOSPHERET. Wong, D. P. Kratz, P. W. Stackhouse, Jr., P. Sawaengphokhai, A. C. Wilber, S. K. Gupta, and N. G. Loeb

The energetic state of the Earth-atmosphere system is defined by the balance of the incoming total solar irradiance (TSI) from the Sun with the reflected shortwave (RSW) and the outgoing longwave radiation (OLR) from Earth. This balance characterizes Earth's radiation budget (ERB) at the top of the atmosphere (TOA) and drives weather processes and climate forcings as well as climate feedbacks.

An analysis of all CERES ERB measurements (Table 2.5) shows that the 2017 global annual mean OLR remained approximately unchanged while the RSW decreased by $\sim 0.05 \mathrm{~W} \mathrm{~m}^{-2}$ relative to their corresponding values in 2016. Over the same timeframe, the global annual mean TSI declined by $\sim 0.10 \mathrm{~W} \mathrm{~m}^{-2}$. The sum of these components amounts to a small reduction of $\sim 0.05 \mathrm{~W} \mathrm{~m}^{-2}$ in the global annual mean total net radiation into the Earth climate system for 2017 as compared with 2016. Relative to the multiyear data average from 2001 to 2016, the 2017 global annual mean flux anomalies (Table 2.5 ) are $+0.50,-0.10$, -0.80 , and $+0.20 \mathrm{~W} \mathrm{~m}^{-2}$ for OLR, TSI, RSW, and total net flux, respectively. These changes are at or within the corresponding 2-sigma interannual variability (Table 2.5) for this period.

The global monthly mean anomaly time series of TOA fluxes (Fig. 2.44) reveals that the global monthly mean OLR anomaly stayed mostly positive throughout 2017. The OLR anomaly began 2017 with a value of $+0.9 \mathrm{~W} \mathrm{~m}^{-2}$, reached its maximum value of $+1.2 \mathrm{~W} \mathrm{~m}^{-2}$ in April, dropped to its minimum value of $-0.2 \mathrm{~W} \mathrm{~m}^{-2}$ in August, then oscillated around $+0.4 \mathrm{~W} \mathrm{~m}^{-2}$ for the rest of the year. The global monthly mean absorbed shortwave (TSI-RSW) anomaly also remained

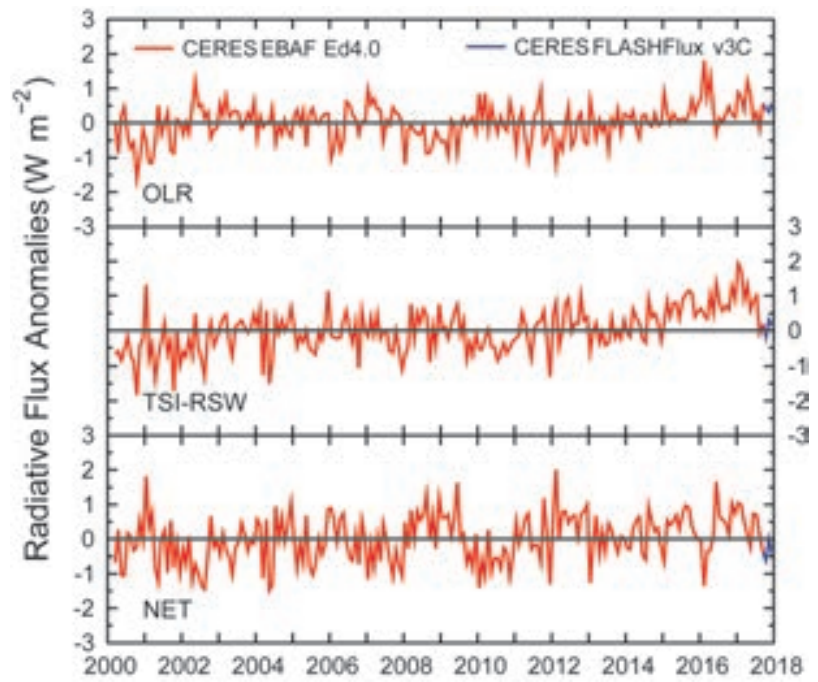

FIG. 2.44. Time series of global monthly mean deseasonalized anomalies $\left(\mathrm{W} \mathrm{m}^{-2}\right)$ of TOA Earth radiation budget for OLR (upper), absorbed shortwave (TSIRSW; middle), and total net (TSI-RSW-OLR; lower) from Mar 2000 to Dec 2017. Anomalies are relative to their calendar month climatology (200I-16). Time series shows the CERES EBAF Ed4.0 IDeg data (Mar 2000-Sep 2017) in red and the CERES FLASHFlux version 3C data (Oct-Dec 2017) in blue; see text for merging procedure

mostly positive during 2017, and the magnitudes of this anomaly were larger than the corresponding OLR anomaly. The absorbed shortwave anomaly started the year with a maximum value of +1.9 $\mathrm{W} \mathrm{m}{ }^{-2}$, decreased to a minimum value of $-0.2 \mathrm{~W} \mathrm{~m}^{-2}$ in October, then climbed back to a positive value at year end. For the year as a whole, the 2017 global annual mean absorbed shortwave anomaly is +0.7 $\mathrm{W} \mathrm{m} \mathrm{m}^{-2}$. The global monthly mean total net anomaly, which is calculated from absorbed shortwave anomaly minus OLR anomaly, began 2017 with a maximum

\begin{abstract}
TABLE 2.5. Global annual mean TOA radiative flux changes between 2016 and 2017 , the global annual mean radiative flux anomalies relative to their corresponding 200I-16 mean climatological values, and the 2-sigma interannual variabilities of the 200I-16 global annual mean fluxes (all units in $\mathrm{W} \mathrm{m}^{-2}$ ) for the outgoing longwave radiation (OLR), total solar irradiance (TSI), reflected shortwave (RSW) and total net fluxes. All flux values have been rounded to the nearest $0.05 \mathrm{~W} \mathrm{~m}^{-2}$.
\end{abstract}

\begin{tabular}{|c|c|c|c|}
\hline & $\begin{array}{c}\text { One Year Change } \\
\text { (2017 minus 2016) }\end{array}$ & $\begin{array}{c}\text { 2017 Anomaly } \\
\text { (Relative to Climatology) }\end{array}$ & $\begin{array}{c}\text { Interannual Variability } \\
\text { (2001 to 2016) }\end{array}$ \\
\hline OLR & 0.00 & +0.50 & \pm 0.60 \\
\hline TSI & -0.10 & -0.10 & \pm 0.15 \\
\hline RSW & -0.05 & -0.80 & \pm 0.80 \\
\hline Net & -0.05 & +0.20 & \pm 0.75 \\
\hline
\end{tabular}


value of $+1.0 \mathrm{~W} \mathrm{~m}^{-2}$, remained mostly positive for eight months, declined to mostly negative in the last four months of the year, and ended the year with a value of $-0.4 \mathrm{~W} \mathrm{~m}^{-2}$. The positive absorbed shortwave anomaly in 2017 dominated the negative effect of OLR anomaly and resulted in a slightly positive 2017 global annual mean total net anomaly of $+0.2 \mathrm{~W} \mathrm{~m}^{-2}$. Longterm trend analyses that include the last three months of the merged dataset are discouraged because of the natural fluctuation in ERB components, uncertainty from the data merging process, and potential for drift in the FLASHFlux product.

The TSI data used in this study are provided by the Total Irradiance Monitor aboard the Solar Radiation and Climate Experiment (SORCE) mission (Kopp and Lean 2011) and the Royal Meteorological Institute of Belgium composite dataset (Dewitte et al. 2004), both renormalized to the SORCE Version 15. The RSW and OLR data were obtained from the Clouds and the Earth's Radiant Energy System (CERES) mission (Wielicki et al. 1996, 1998) aboard Terra and Aqua.

The time series (Fig. 2.44) was constructed from the CERES EBAF (Energy Balanced And Filled) Ed4.0 product (Loeb et al. 2009, 2012, 2018) for March 2000 to September 2017 and from the CERES Fast Longwave and Shortwave Radiative Fluxes (FLASHFlux) version 3C product (Kratz et al. 2014), for October to December 2017. The normalization of the FLASHFlux data (Stackhouse et al. 2016) results in a 2-sigma monthly uncertainty of $\pm 0.43, \pm 0.08, \pm 0.20$ and \pm 0.55

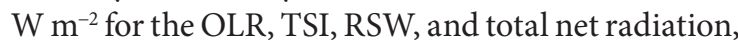
respectively.

\section{g. Atmospheric composition}

I) LONG-LIVED GREeNHOUSE GASES-E. J. Dlugokencky, B. D. Hall, S. A. Montzka, G. Dutton, J. Mühle, and J. W. Elkins

The three long-lived greenhouse gases (LLGHGs) with the largest contributions to climate forcing are, in decreasing order: carbon dioxide $\left(\mathrm{CO}_{2}\right)$, methane $\left(\mathrm{CH}_{4}\right)$, and nitrous oxide $\left(\mathrm{N}_{2} \mathrm{O}\right)$. Systematic measurements of $\mathrm{CO}_{2}$ began at Mauna Loa, Hawaii (MLO) in 1958 , when the atmospheric $\mathrm{CO}_{2}$ abundance was $\sim 315$ ppm (parts per million in dry air). In 2017, MLO annually averaged $\mathrm{CO}_{2}$ reached $406.5 \pm 0.1 \mathrm{ppm}$ (www .esrl.noaa.gov/gmd/ccgg/trends/; all uncertainties are $68 \%$ confidence intervals, unless noted otherwise), while preliminary globally averaged $\mathrm{CO}_{2}$ at Earth's surface was $405.0 \pm 0.1 \mathrm{ppm}$ (Fig. 2.45a, see www.esrl .noaa.gov/gmd/ccgg/trends/global.html).

The atmospheric history of $\mathrm{CO}_{2}$ prior to 1958 is determined from air extracted from ice in Greenland and Antarctica. From those measurements, it is known that the abundance of atmospheric $\mathrm{CO}_{2}$ was $\sim 278$ ppm in 1750 (Etheridge et al. 1996). Since then, $\sim 430 \mathrm{Pg} \mathrm{C}\left(1 \mathrm{Pg} \mathrm{C}=10^{15} \mathrm{~g} \mathrm{C}\right)$ were emitted as $\mathrm{CO}_{2}$ to the atmosphere from fossil fuel burning and cement production (Boden et al. 2017). Based on observations of atmospheric $\mathrm{CO}_{2}$ and $\mathrm{N}_{2} / \mathrm{O}_{2}$ (Manning and Keeling 2006) and increased carbon in the oceans (Sabine et al. 2004), most of the anthropogenic $\mathrm{CO}_{2}$ not remaining in the atmosphere was taken up by the oceans (Tans 2009). While the terrestrial biosphere is currently also a net sink for fossil fuel $\mathrm{CO}_{2}$, net emissions of $\mathrm{CO}_{2}$ to the atmosphere from land use change prior to $\sim 1940$ offset recent terrestrial uptake (Tans 2009). These mass balance considerations overwhelmingly suggest that the observed increase in atmospheric $\mathrm{CO}_{2}$ since 1750 is caused by combustion of fossil fuels. This conclusion is further supported by measured decreases in ${ }^{13} \mathrm{C} /{ }^{12} \mathrm{C}$ and ${ }^{14} \mathrm{C} /{ }^{12} \mathrm{C}$ of atmospheric $\mathrm{CO}_{2}$, and an increase in the north-south gradient of atmospheric $\mathrm{CO}_{2}$ abundance (Tans 2009).

The global growth rate of $\mathrm{CO}_{2}$ has risen from 0.6 $\pm 0.1 \mathrm{ppm} \mathrm{yr}^{-1}$ in the early 1960 s to an average of $2.3 \mathrm{ppm} \mathrm{yr}^{-1}$ during the past ten years, with interannual variability of $\pm 0.5 \mathrm{ppm} \mathrm{yr}^{-1}$ (1-sigma) (Fig. 2.45). The increase in global annual mean $\mathrm{CO}_{2}$ from 2016 to 2017 was $2.2 \pm 0.1 \mathrm{ppm}$. In the two years prior to this (2015 and 2016), atmospheric $\mathrm{CO}_{2}$ increased by $3.0 \mathrm{ppm}$ $\mathrm{yr}^{-1}$. The strong El Niño that peaked in late-2015 contributed to this strong $\mathrm{CO}_{2}$ increase (Betts et al. 2016).

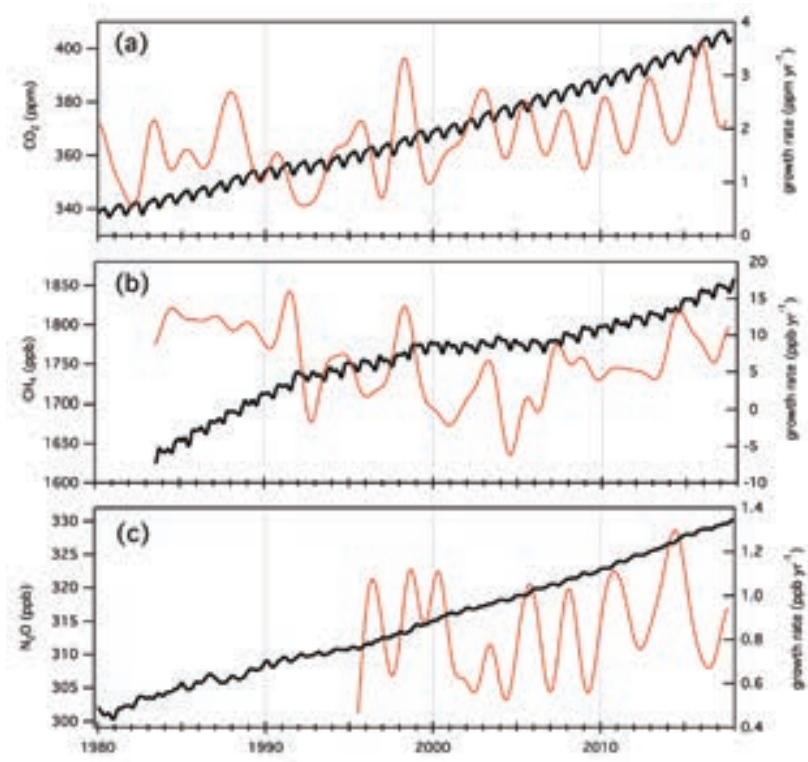

Fig. 2.45. Global mean surface mole fractions (in dry air) of (a) $\mathrm{CO}_{2}$ (ppm), (b) $\mathrm{CH}_{4}$ (ppb), and (c) $\mathrm{N}_{2} \mathrm{O}$ (ppb) derived from the NOAA sampling network. Growth rates are shown on the right axis. (Measurements were not sufficient to calculate instantaneous growth rates for $\mathrm{N}_{2} \mathrm{O}$ with reasonable certainty prior to 1995). 
The 2017 globally averaged methane mole fraction at Earth's surface was $1849.7 \pm 0.8 \mathrm{ppb}$ (Dlugokencky 2018). The increase in annual mean $\mathrm{CH}_{4}$ from 2016 to 2017 was $6.9 \pm 0.9 \mathrm{ppb}$, comparable to the average growth rate over the past 10 years $(+7.1 \pm 2.6 \mathrm{ppb}$ $\mathrm{yr}^{-1}$; the uncertainty is the standard deviation of annual increases). Since $1750, \mathrm{CH}_{4}$ has increased by $\sim 1128 \mathrm{ppb}$ from $722 \pm 15 \mathrm{ppb}$.

Atmospheric $\mathrm{CH}_{4}$ is influenced by a complex mix of sources and sinks, with emissions from both anthropogenic $(\sim 60 \%)$ and natural $(\sim 40 \%)$ sources (Fung et al. 1991). Its main loss process, atmospheric oxidation initiated by reaction with hydroxyl radical $(\mathrm{OH})$, is the largest term in the atmospheric $\mathrm{CH}_{4}$ budget of sources and sinks. Total global emissions of $\mathrm{CH}_{4}$ are well-constrained by the atmospheric measurements and an estimate of its lifetime (Dlugokencky et al. 2011), but the magnitude and trend in emissions from individual sources and trends in $\mathrm{CH}_{4}$ atmospheric lifetime are still highly uncertain. In the past three decades, the $\mathrm{CH}_{4}$ growth rate has undergone long- and short-term changes (red line in Fig. 2.45b). Analysis of these changes can be used to improve understanding of processes that emit and remove $\mathrm{CH}_{4}$, but so far, causes behind even large changes have not been unambiguously identified. Numerous publications address the increase in growth rate that started in 2007; measurements of $\mathrm{CH}_{4}$ abundance and its isotopic composition strongly suggest increased emissions from biogenic sources, both natural and anthropogenic (Nisbet et al. 2016; Schaefer et al. 2016; Schwietzke et al. 2016), rather than changes in fossil fuel-related emissions. Changes in other $\mathrm{CH}_{4}$ sources (e.g., Worden et al. 2017) and $\mathrm{CH}_{4}$ loss rate (Prather and Holmes 2017) have also been implicated, but because the problem is underconstrained by observations, all explanations are uncertain.

Nitrous oxide $\left(\mathrm{N}_{2} \mathrm{O}\right)$ is both a greenhouse gas and an ozone-depleting substance (Ravishankara et al. 2009). Sources include natural and agricultural soils as well as oceans. Anthropogenic activity is thought to contribute about one-third to total global emissions of $\sim 18 \mathrm{Tg} \mathrm{yr}^{-1}$ (Ciais et al. 2013). Except for a brief period in the 1940s, atmospheric $\mathrm{N}_{2} \mathrm{O}$ has been increasing steadily throughout the industrial era (MacFarling Meure et al. 2006). The mean global atmospheric $\mathrm{N}_{2} \mathrm{O}$ mole fraction in 2017 was $329.8 \pm 0.1 \mathrm{ppb}$, an increase of $0.9 \mathrm{ppb}$ from 2016 (Fig. 2.45c). This $0.9 \mathrm{ppb}$ annual change is similar to the average annual change over the last two decades $(0.85 \pm 0.17 \mathrm{ppb})$.

The NOAA Annual Greenhouse Gas Index (AGGI) (Fig. 2.46) summarizes trends in the combined direct radiative forcing by five major LLGHGs

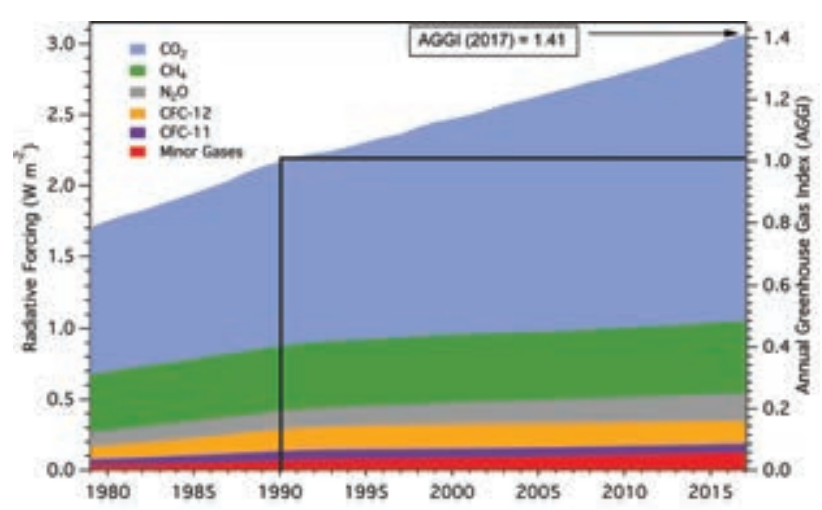

FIG. 2.46. Direct radiative forcing $\left(\mathrm{W} \mathrm{m}^{-2}\right)$ due to 5 major LLGHG and 15 minor gases (left axis) and the associated values of the AGGI (right axis).

$\left(\mathrm{CO}_{2}, \mathrm{CH}_{4}, \mathrm{~N}_{2} \mathrm{O}, \mathrm{CFC}-11\right.$, and CFC-12) and 15 minor gases (Hofmann et al. 2006; Table 2.6; Fig. 2.47; www .esrl.noaa.gov/gmd/aggi/). The AGGI represents the annual cumulative radiative forcing of these gases relative to the Kyoto Protocol baseline year of 1990 $\left(2.16 \mathrm{~W} \mathrm{~m}^{-2}\right)$. It does not include indirect radiative forcing (e.g., influences on ozone and water vapor). In 2017, $\mathrm{CO}_{2}$ contributed $2.01 \mathrm{~W} \mathrm{~m}^{-2}$ direct radiative forcing, or about $66 \%$ of the combined forcing of $3.06 \mathrm{~W} \mathrm{~m}^{-2}$ from LLGHGs. $\mathrm{CH}_{4}$ and $\mathrm{N}_{2} \mathrm{O}$ contributed $0.5 \mathrm{~W} \mathrm{~m}^{-2}(16 \%)$ and $0.2 \mathrm{~W} \mathrm{~m}^{-2}(6.5 \%)$ respectively, while the sum of halogenated gases, including CFCs, HCFCs, and HFCs, among others (Table 2.6), con-

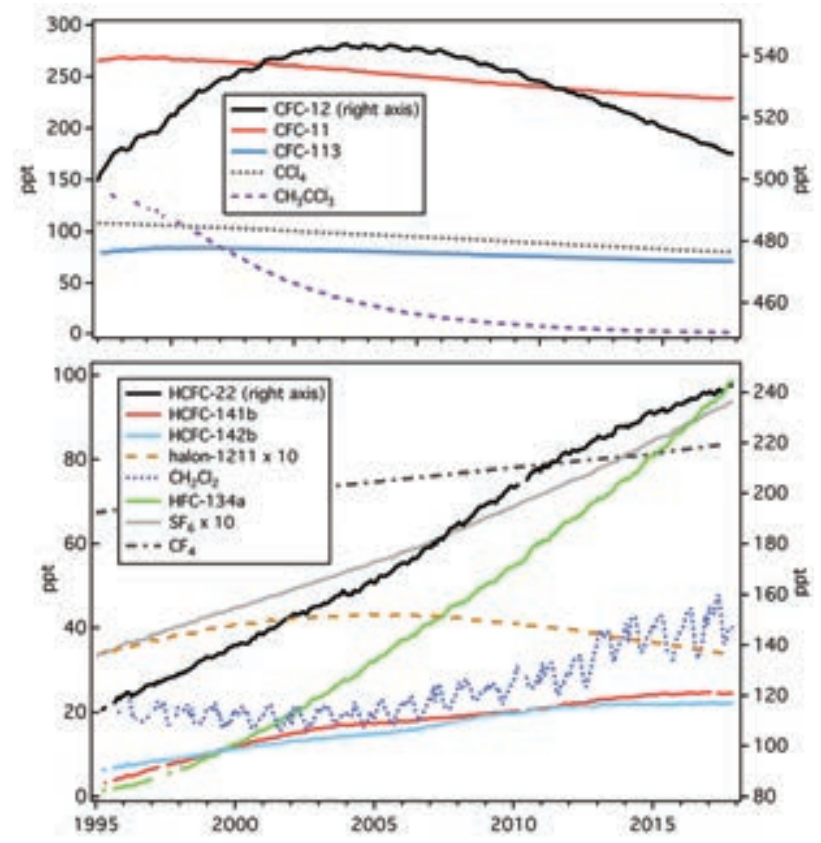

FIG. 2.47. Global mean mole fractions at Earth's surface (ppt, dry air) for several LLGHG, many of which also deplete stratospheric ozone. See Table 2.6 for the 2017 global mean mole fractions of these gases. 
TABLE 2.6. Summary table of long-lived greenhouse gases for $2017\left(\mathrm{CO}_{2}\right.$ mixing ratios are in ppm, $\mathrm{N}_{2} \mathrm{O}$ and $\mathrm{CH}_{4}$ in $\mathrm{ppb}$, and all others in ppt).

\begin{tabular}{|c|c|c|c|c|c|c|}
\hline $\begin{array}{l}\text { Industrial Designation } \\
\text { or Common Name }\end{array}$ & $\begin{array}{l}\text { Chemical } \\
\text { Formula }\end{array}$ & AGGI & ODGI & 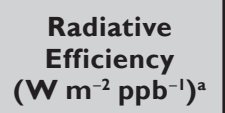 & $\begin{array}{c}\text { Mean Surface Mole } \\
2017 \text { Fraction } \\
\text { (change from prior year) }^{\mathrm{b}}\end{array}$ & $\begin{array}{l}\text { Lifetime } \\
\text { (years) }\end{array}$ \\
\hline Carbon Dioxide & $\mathrm{CO}_{2}$ & $\mathrm{Y}$ & $\mathrm{N}$ & $1.37 \times 10^{-5}$ & $405.0(2.2)^{c}$ & \\
\hline Methane & $\mathrm{CH}_{4}$ & $\mathrm{Y}$ & $\mathrm{N}$ & $3.63 \times 10^{-4}$ & $1849.7(6.9)^{c}$ & 9.1 \\
\hline Nitrous Oxide & $\mathrm{N}_{2} \mathrm{O}$ & $\bar{Y}$ & $\mathrm{~N}$ & $3.00 \times 10^{-3}$ & $329.8(0.9)^{\mathrm{c}, \mathrm{d}}$ & 123 \\
\hline \multicolumn{7}{|l|}{ Chlorofluorocarbons } \\
\hline CFC-II & $\mathrm{CCl}_{3} \mathrm{~F}$ & $\mathrm{Y}$ & $Y$ & 0.26 & $228.9(-0.8)^{\mathrm{c}, \mathrm{d}}$ & 52 \\
\hline CFC-12 & $\mathrm{CCl}_{2} \mathrm{~F}_{2}$ & $\mathrm{Y}$ & $\bar{Y}$ & 0.32 & $509.3(-2.9)^{c, d}$ & 102 \\
\hline CFC-II3 & $\mathrm{CCl}_{2} \mathrm{FCClF}_{2}$ & $\bar{Y}$ & $\bar{Y}$ & 0.30 & $70.9(-0.5)^{c}$ & 93 \\
\hline \multicolumn{7}{|c|}{ Hydrochlorofluorocarbons } \\
\hline HCFC-22 & $\mathrm{CHClF}_{2}$ & $\mathrm{Y}$ & $\mathrm{Y}$ & 0.21 & $240.8(3.3)$ & 11.9 \\
\hline HCFC-14Ib & $\mathrm{CH}_{3} \mathrm{CCl}_{2} \mathrm{~F}$ & $\mathrm{Y}$ & $\bar{Y}$ & 0.16 & $24.5(-0.4)$ & 9.4 \\
\hline HCFC-142b & $\mathrm{CH}_{3} \mathrm{CClF}_{2}$ & $\bar{Y}$ & $\bar{Y}$ & 0.19 & $22.1(0.2)$ & 18 \\
\hline \multicolumn{7}{|l|}{ Hydrofluorocarbons } \\
\hline HFC-I34a & $\mathrm{CH}_{2} \mathrm{FCF}_{3}$ & $\mathrm{Y}$ & $\mathrm{N}$ & 0.16 & $95.7(6.1)$ & 14 \\
\hline HFC-I52a & $\mathrm{CH}_{3} \mathrm{CHF}_{2}$ & $\mathrm{Y}$ & $\mathrm{N}$ & 0.10 & $6.8(0.2)$ & 1.6 \\
\hline HFC-I43a & $\mathrm{CH}_{3} \mathrm{CF}_{3}$ & $\mathrm{Y}$ & $\mathrm{N}$ & 0.16 & $20.6(1.6)$ & 51 \\
\hline HFC-I25 & $\mathrm{CHF}_{2} \mathrm{CF}_{3}$ & $\bar{Y}$ & $\mathrm{~N}$ & 0.23 & $22.8(2.7)$ & 31 \\
\hline HFC-32 & $\mathrm{CH}_{2} \mathrm{~F}_{2}$ & $\mathrm{~N}$ & $\mathrm{~N}$ & 0.11 & $13.0(1.8)$ & 5.4 \\
\hline HFC-23 & $\mathrm{CHF}_{3}$ & $\bar{Y}$ & $\mathrm{~N}$ & 0.18 & $29.9(1.0)$ & 228 \\
\hline HFC-365mfc & $\mathrm{CH}_{3} \mathrm{CF}_{2} \mathrm{CH}_{2} \mathrm{CF}_{3}$ & $\mathrm{~N}$ & $\mathrm{~N}$ & 0.22 & $0.93(0.05)$ & 8.7 \\
\hline HFC-227ea & $\mathrm{CF}_{3} \mathrm{CHFCF}_{3}$ & $\mathrm{~N}$ & $\mathrm{~N}$ & 0.26 & $1.29(0.12)$ & 36 \\
\hline \multicolumn{7}{|l|}{ Chlorocarbons } \\
\hline Methyl Chloroform & $\mathrm{CH}_{3} \mathrm{CCl}_{3}$ & $\bar{Y}$ & $Y$ & 0.07 & $2.2(-0.4)$ & 5.0 \\
\hline Carbon Tetrachloride & $\mathrm{CCl}_{4}$ & $\bar{Y}$ & $\bar{Y}$ & 0.17 & $80.2(-0.9)^{c, d}$ & 33 \\
\hline Methyl Chloride & $\mathrm{CH}_{3} \mathrm{Cl}$ & $\mathrm{N}$ & $Y$ & 0.01 & $547.3(-12.1)$ & 0.9 \\
\hline \multicolumn{7}{|l|}{ Bromocarbons } \\
\hline Methyl Bromide & $\mathrm{CH}_{3} \mathrm{Br}$ & $\mathrm{N}$ & $\mathrm{Y}$ & 0.004 & $6.6(-0.2)$ & 0.8 \\
\hline Halon I2II & $\mathrm{CBrClF}_{2}$ & $\mathrm{Y}$ & $Y$ & 0.29 & $3.43(-0.09)$ & 16 \\
\hline Halon I30I & $\mathrm{CBrF}_{3}$ & $\mathrm{Y}$ & $\mathrm{Y}$ & 0.30 & $3.26(0.00)$ & 72 \\
\hline \begin{tabular}{|l|l|} 
Halon 2402 \\
\end{tabular} & $\mathrm{CBrF}_{2} \mathrm{CBrF}_{2}$ & $\mathrm{Y}$ & $Y$ & 0.31 & $0.4(-0.0 \mathrm{I})$ & 28 \\
\hline \multicolumn{7}{|l|}{ Fully fluorinated species } \\
\hline Sulfur Hexafluoride & $\mathrm{SF}_{6}$ & $\mathrm{Y}$ & $\mathrm{N}$ & 0.57 & $9.26(0.34)$ & $>600$ \\
\hline PFC-14 & $\mathrm{CF}_{4}$ & $\mathrm{~N}$ & $\mathrm{~N}$ & 0.09 & $83.6(0.9)^{c}$ & $\sim 50000$ \\
\hline PFC-116 & $\mathrm{C}_{2} \mathrm{~F}_{6}$ & $\mathrm{~N}$ & $\mathrm{~N}$ & 0.25 & $4.66(0.10)^{c}$ & $\sim 10000$ \\
\hline
\end{tabular}

${ }^{a}$ Radiative efficiencies were taken from IPCC AR5 (Myhre et al. 2013). Steady-state lifetimes were taken from Myhre et al. (2013) $\left(\mathrm{CH}_{4}\right)$, Ray et al. (2017) $\left(\mathrm{SF}_{6}\right)$, Ko et al. (2013), Liang et al. (2016) $\left(\mathrm{CCl}_{4}\right)$, and Carpenter et al. (2014). For $\mathrm{CO}_{2}$, numerous removal processes complicate the derivation of a global lifetime.

${ }^{\mathrm{b}}$ Mole fractions are global, annual surface means for the indicated calendar year determined from the NOAA cooperative global air sampling network (Hofmann et al. 2006), except for PFC-14, PFC-116, and HFC-23, which were measured by AGAGE (Mühle et al., 2010; Miller et al., 2010). Changes indicated in brackets are the differences between the 2017 and 2016 means.

Preliminary estimate.

d Global mean estimates derived from multiple NOAA measurement programs (“Combined Dataset”). 
tributed $0.34 \mathrm{~W} \mathrm{~m}^{-2}$ (11\%). $\mathrm{CH}_{4}$-related production of tropospheric $\mathrm{O}_{3}$ and stratospheric $\mathrm{H}_{2} \mathrm{O}$ contributed $\sim 0.3 \mathrm{~W} \mathrm{~m}^{-2}$ indirect radiative forcing (Myhre et al. 2013). The combined direct forcing in 2017 represents a 41\% increase since 1990 (2017 AGGI = 1.41).

2) Ozone-depleting gases-B. D. Hall, S. A. Montzka, G. Dutton, B. R. Miller, and J. W. Elkins

Chlorine and bromine from CFCs, HCFCs, halons, and other ozone-depleting substances (ODS) are released in the stratosphere, causing ozone destruction. The emissions and atmospheric abundances of most ODS are declining as expected due to controls implemented in the Montreal Protocol and its Amendments (Carpenter et al. 2014). An exception is carbon tetrachloride, which has not decreased as expected for a number of years (Carpenter et al. 2014). Furthermore, it has recently been reported that the atmospheric abundance of CFC-11 has not declined as rapidly as expected, leading to concern that sustained increased emissions of CFC-11 would substantially delay the recovery of stratospheric ozone (Montzka et al. 2018). CFC-11 declined at a rate of 2.1 $\pm 0.3 \mathrm{ppt} \mathrm{yr}^{-1}$ from 2002 through 2011, but that rate slowed to $1.0 \pm 0.2 \mathrm{ppt} \mathrm{yr}^{-1}$ from mid-2015 to mid-2017 (Montzka et al. 2018). The observed changes in CFC11 are due to an increase in emissions, although some changes in atmospheric transport also contributed in some years. In addition, emissions and abundances of some short-lived chlorine-containing gases, which are not controlled by the Protocol, have increased recently and could delay ozone recovery if they were to continue to increase at similar rates in the future. For example, the atmospheric abundance of $\mathrm{CH}_{2} \mathrm{Cl}_{2}$ has approximately doubled over the past fifteen years (Fig. 2.47; Hossaini et al. 2017).

Equivalent effective stratospheric chlorine (EESC) is a measure of the ozone-depleting potential of the stratospheric halogen loading at a given time and place. As EESC declines, stratospheric ozone is showing signs of recovery (Kuttippurath and Nair 2017; Strahan and Douglass 2018; see Sections 2g4 and 6h). EESC is calculated from global average surface mole fractions of long-lived ozone-depleting gases and weighting factors that include surface-to-stratosphere transport times, mixing during transit, photolytic reactivity, and ozone-destruction efficiency (Montzka et al. 1996; Newman et al. 2007). Short-lived gases such as $\mathrm{CH}_{2} \mathrm{Cl}_{2}$ are not included in EESC. NOAA tracks changes in EESC with an Ozone-Depleting Gas Index (ODGI; Hofmann and Montzka 2009; www .esrl.noaa.gov/gmd/odgi/).
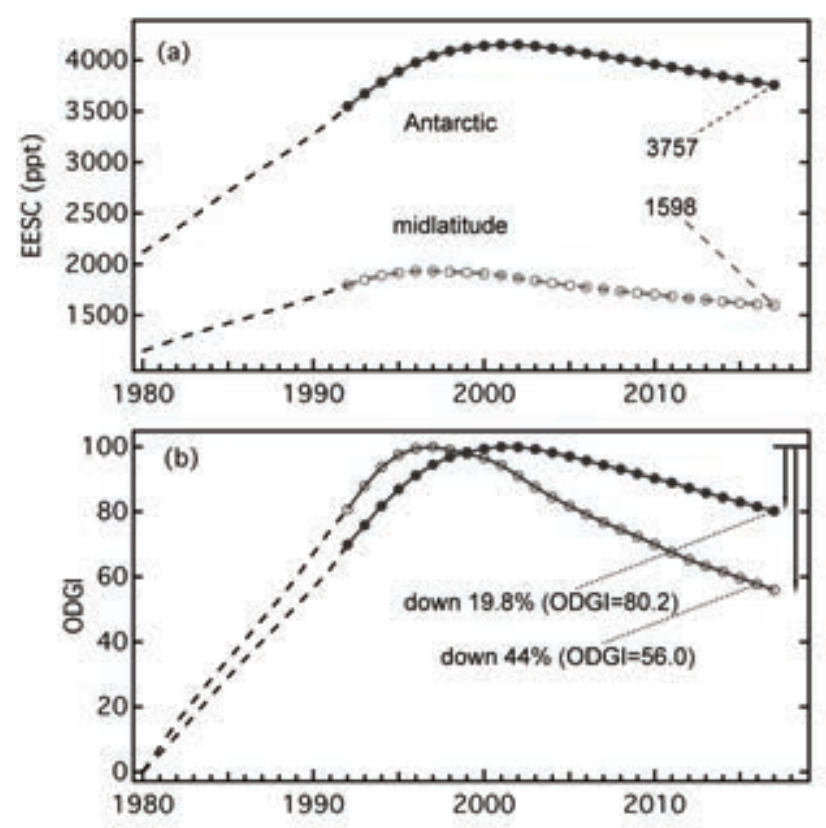

FIG. 2.48. (a) EESC (ppt) and (b) NOAA ODGI. The ODGI represents the relative mole fractions of reactive halogen in the midlatitude (open circles) and Antarctic stratosphere (closed circles) scaled such that ODGI = I00 at maximum EESC and zero in 1980. Both EESC and ODGI are derived from NOAA surface measurements of long-lived ODS (circles) or, for earlier years, WMO scenarios (dashed lines; N. Harris et al. 2014). The EESC and ODGI values from 1992 forward correspond to Jan of each year.

EESC and ODGI have been calculated since 1992 for two representative stratospheric regionsAntarctica and the midlatitudes-that differ in total available reactive halogen (Fig. 2.48). EESC is larger in the Antarctic stratosphere than in the midlatitudes because more ozone-reactive halogen is released during the longer transit time to the Antarctic from midlatitude surface-based source regions. ODGI values at the beginning of 2017 were approximately 80 and 56 for the Antarctic and midlatitudes, respectively. These represent 20\% (100 minus 80 ) and 44\% (100 minus 56) reductions from the peak values in EESC over Antarctica and the midlatitudes, respectively, toward the 1980 benchmark values.

3) Aerosols - S. Rémy, N. Bellouin, A. Benedetti, and 0 . Boucher

Atmospheric aerosols are a key component of air quality and are now recognized as a serious public health issue (WHO 2013). They also play an important role in the climate system, by scattering and absorbing short- and long-wave radiation, and by indirectly affecting the life cycle, optical properties, and precipitation activity of clouds. 
The Copernicus Atmosphere Monitoring Service (CAMS; http://atmosphere.copernicus.eu) runs a near real time (NRT) global analysis of aerosols and trace gases. The CAMS project also produced a reanalysis of global aerosols and trace gases that spanned 2003 to 2015 (Flemming et al. 2017) named the CAMS interim reanalysis (CAMSiRA). This reanalysis was extended to 2017.

Retrievals of aerosol optical depth (AOD) at $550 \mathrm{~nm}$ (Remer et al. 2005) from the MODIS instrument onboard NASA's Aqua and Terra (Collection 5) were used as observational constraints from 2003 to 2016. In 2017, MODIS Collection 6 (Sayer et al. 2014) was assimilated, which can lead to significant differences between 2017 and the previous years in CAMSiRA.

Aerosols are produced both by mechanical uplifting over ocean (marine aerosols) and dry areas (mineral dust) and by human activities (industries, traffic, domestic heating, agricultural burning, etc.). Generally, the variability of natural aerosols such as dust is large and has high seasonality. Anthropogenic aerosols are more localized but can have significant temporal variability as well. In CAMSiRA, the anthropogenic emissions of black carbon, organic matter, and sulfur dioxide were taken from the MACCity inventory (Granier et al. 2011). Open fire emissions were provided by the Global Fire Assimilation System (GFAS) inventory (Kaiser et al. 2012) that estimates fire emissions from MODIS observations of fire radiative power. These emissions are similar between the NRT analysis and the CAMSiRA. Dust and sea salt aerosol emissions are computed dynamically as a function of wind speed.

Time series of globally averaged total AOD during 2003-17 (Fig. 2.49) show strong seasonality, with yearly maxima in March-April and AugustSeptember driven mainly by dust episodes primarily in spring and summer in the Sahara, Middle East,

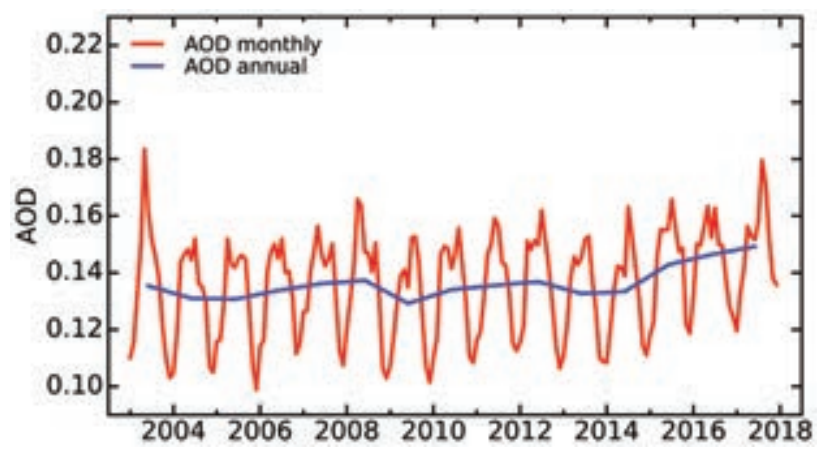

Fig. 2.49. Global average of total AOD at $550 \mathrm{~nm}$ averaged over monthly (red) and annual (blue) periods for 2003-17. and Taklimakan/Gobi deserts and seasonal biomass burning in Africa, South America, and Indonesia.

Overall, the 2017 anomalies of biomass burning aerosols are consistent with those of tropospheric ozone (Section 2g6), carbon monoxide (Section 2g7), and fires (Section 2h3). Seasonal burning was, in general, less severe than usual in 2017 in the main regions that are subject to large seasonal fires: Indonesia, the Amazon Basin, and parts of south equatorial Africa. Negative anomalies in 2016 and 2017 over Indonesia may be explained by meteorological conditions as well as the government policies regarding land use following the El Niño event of 2015 which contributed to severe drought and extreme fires in this region in 2015. Large but isolated biomass burning events in 2017 are associated with positive anomalies in Chile (January 2017), Siberia (June 2017), and western Canada-where British Columbia experienced the worst fires in its recent history during July-August 2017 (Plate 2.1ab, Section 7b).

Global maps of the 2003-17 average total AOD and statistically significant (95\% confidence) linear trends over the period are shown in Fig. 2.50. The highly polluted areas of eastern Asia and India remain prominent features in the total AOD map, as are the dust-producing regions of the Sahara, Arabia, the Middle East, and the Taklamakan and Gobi deserts (Fig. 2.50a). Large AOD values over equatorial Africa are caused by seasonal biomass burning. The linear trend highlights the long-term decrease in anthropogenic aerosols over the eastern U.S., Europe, Japan, and parts of southern China, while a significant increase occurred over most of the Indian subcontinent, possibly linked to increased industrial activity and, hence, increased emissions in the area. The area of decreasing trends in the southern Amazon Basin is associated with reduced deforestation there (Chen et al. 2013). The decreasing trends over the northern Sahara and western Mediterranean indicate lower frequencies or intensities of dust episodes in these regions or less transport; these were already present in 2016 so are not attributable to model changes. The positive trends over the Southern Ocean may be an artifact of the CAMS interim reanalysis in 2017 and 2016.

Radiative forcing resulting from aerosol-radiation (RFari) and aerosol-cloud interactions (RFaci) for the period 2008-17 is shown in Fig. 2.51, as estimated using the methods described in Bellouin et al. (2013) using CAMSiRA data. Negative radiative forcings imply a cooling effect of the aerosols on the climate. Due to a relatively large contribution of anthropogenic aerosols to total aerosol optical depth, 2017 has been a 

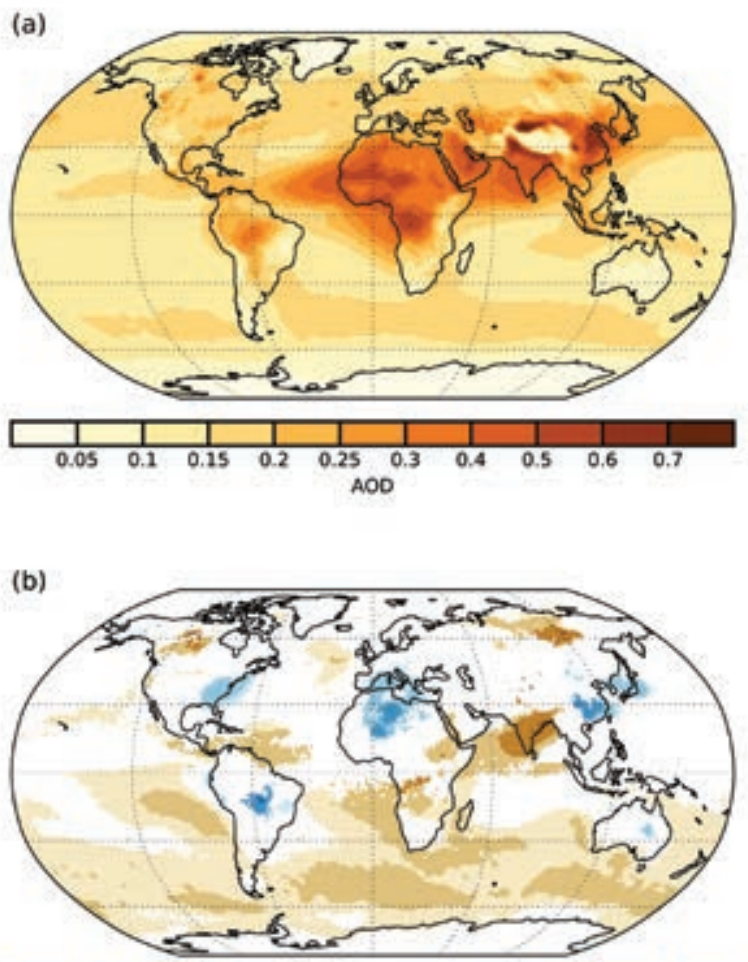

$\begin{array}{llllllllllllll}-0.05 & 0.01 & 0.005-0.002-0.001 & 0.001 & 0.002 & 0.005 & 0.01 & 0.05\end{array}$ AOD $\mathrm{yr}^{-1}$

Fig. 2.50. (a) Total 550-nm AOD averages for 2003-17. Note the regional differences, with much greater total AOD values over parts of northern Africa, the Arabian Peninsula, southern Asia, and eastern China. (b) Linear trends of total AOD (AOD $\mathrm{yr}^{-1}$ ) for 2003-17. Only trends that are statistically significant $(95 \%$ confidence) are shown.

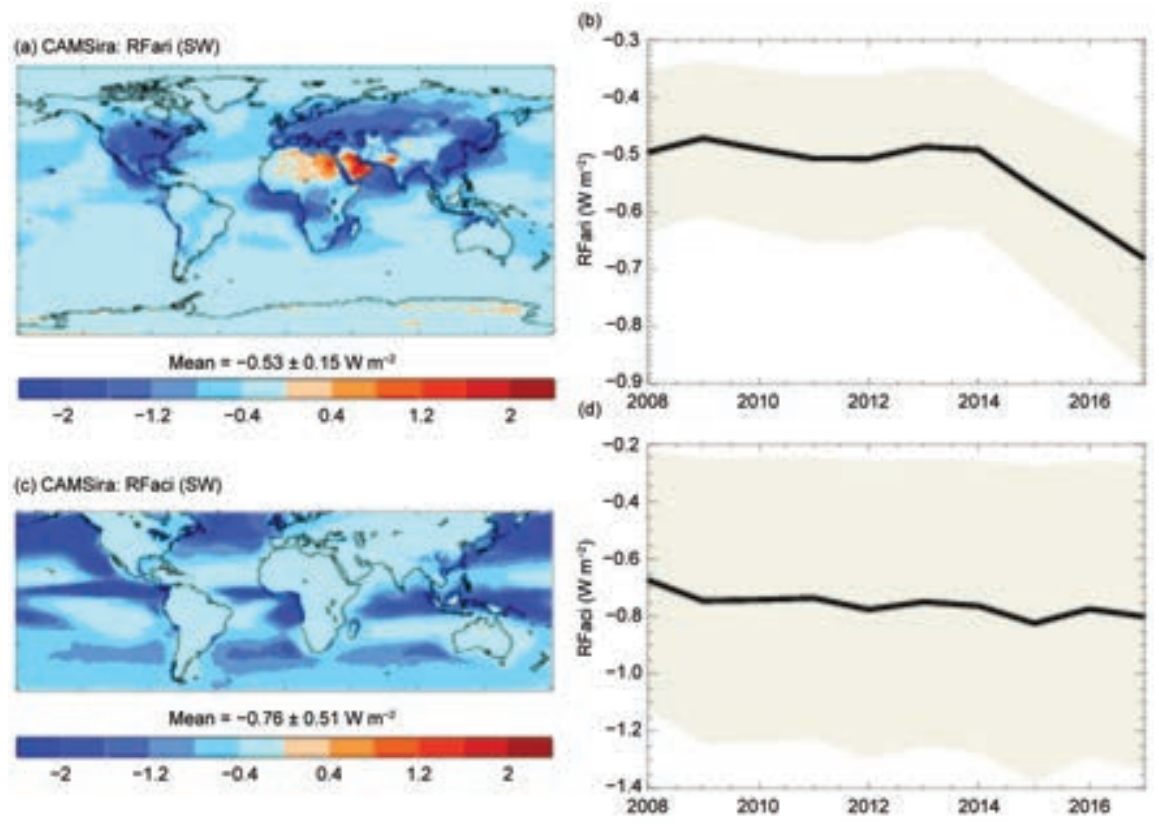

Fig. 2.5I. Radiative forcing $\left(\mathrm{W} \mathrm{m}^{-2}\right)$ in the $\mathrm{SW}$ spectrum resulting from (a) RFari and (c) RFaci from 2008-17. (b,d) The uncertainties of these estimates are shown in gray. strong year in terms of aerosol radiative forcing, with the third consecutive increase in RFari, estimated to be $-0.68 \mathrm{~W} \mathrm{~m}^{-2}$ in 2017 , stronger than the $-0.55 \mathrm{~W} \mathrm{~m}^{-2}$ estimated for 2015. The increase may be linked to increased biomass-burning aerosols in the tropics. Trends remain statistically fragile, however, because of large uncertainties in the estimates. Absorbing anthropogenic aerosols exert positive RFari over bright surfaces, like the African and Arabian deserts, as shown in the upper panel of Fig. 2.51. RFaci, estimated at $-0.8 \mathrm{~W} \mathrm{~m}^{-2}$ in 2017, was comparable to 2015 $\left(-0.82 \mathrm{~W} \mathrm{~m}^{-2}\right)$ and $2016\left(-0.77 \mathrm{~W} \mathrm{~m}^{-2}\right)$.

4) Stratospheric ozone-M. Weber, W. Steinbrecht, R. van $\operatorname{der}$ A, S. M. Frith, J. Anderson, M. Coldewey-Egbers, S. Davis, D. Degenstein, V. E. Fioletov, L. Froidevaux, D. Hubert, J. de Laat, C. S. Long, D. Loyola, V. Sofieva, K. Tourpali,

C. Roth, R. Wang, and J. D. Wild

Throughout nearly the entire Southern Hemisphere annual mean total column ozone levels in 2017 were above the mean from the 1998-2008 reference period (Plate 2.1y). In particular, the Antarctic region showed values that were more than 10 DU (Dobson units) above the long-term mean (see also October mean in Fig. 2.52e). The main cause was the weak polar vortex (stratospheric cyclone) observed in southern winter/spring resulting in below-average polar ozone losses and a rather small ozone hole in size and depth (see Section 6h). In the second half of 2017 the quasi-biennial oscillation (QBO) was in the east phase (easterly flow in the tropical lower stratosphere), which had a global impact on the stratospheric circulation. During the QBO east phase planetary waves are deflected toward the pole ( $\mathrm{SH}$ winter in 2017) and weaken the polar vortex (Baldwin et al. 2011). Associated with these planetary waves is an enhanced meridional or Brewer-Dobson circulation transporting more ozone into middle to high latitudes which, in addition to reduced polar losses, contributed to the overall $\mathrm{SH}$ increase (e.g., Salby 2008; Weber et al. 2011). In the Northern Hemisphere total ozone was generally near 


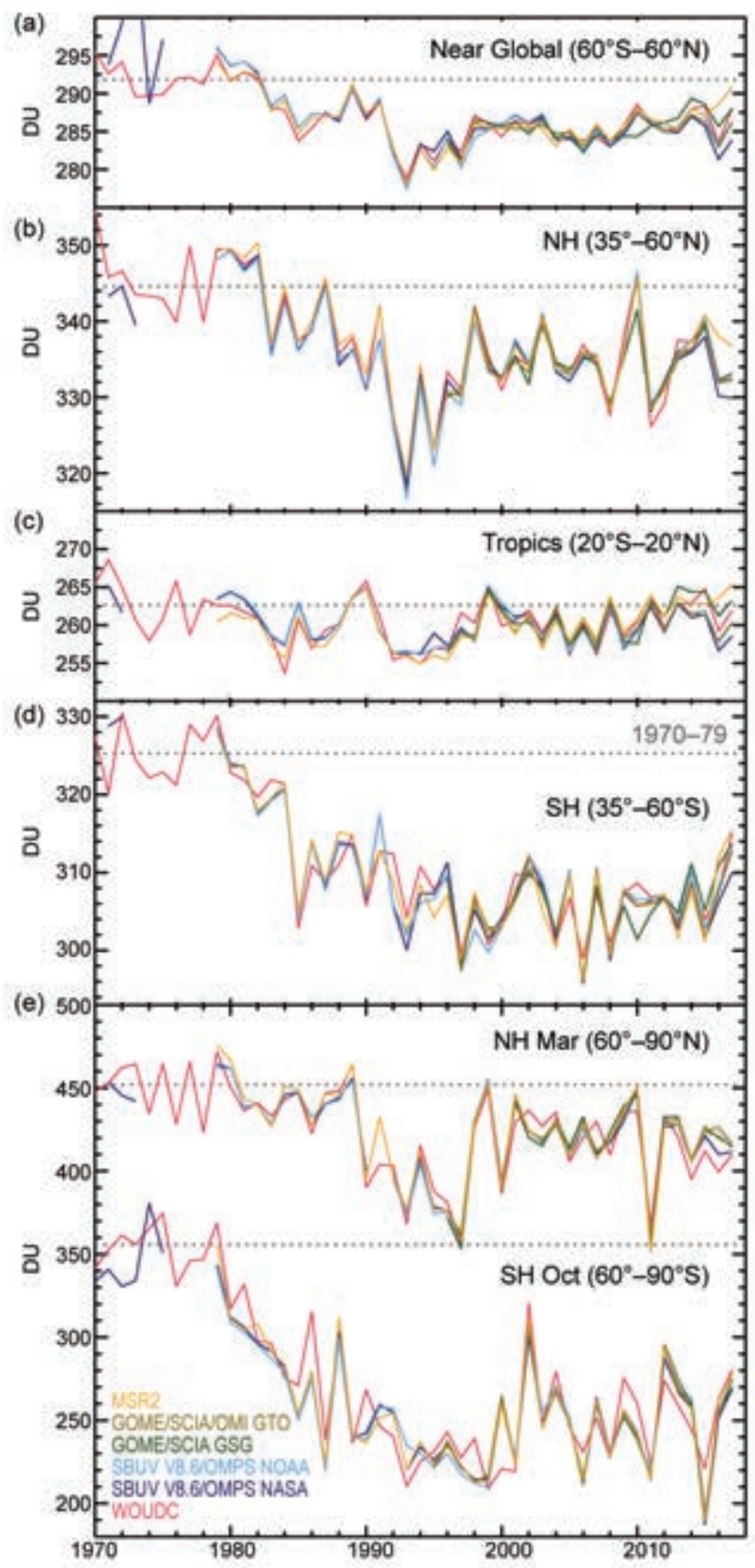

Fig. 2.52. Time series of annual mean total ozone (DU) in (a)-(d) four zonal bands, and (e) polar $\left(60^{\circ}-90^{\circ}\right)$ total ozone in Mar (NH; see also Section $\left.5 \mathrm{j}\right)$ and Oct (SH), the months when polar ozone losses usually are largest. Data are from WOUDC (World Ozone and Ultraviolet Radiation Data Centre) ground-based measurements combining Brewer, Dobson, SAOZ, and filter spectrometer data (Fioletov et al. 2002, 2008); the BUV/SBUV/SBUV2 V8.6/OMPS merged products from NASA (MOD V8.6, Frith et al. 2014, 2017) and NOAA (Wild and Long 2018, manuscript in preparation); the GOME/SCIAMACHY/GOME-2 products from University of Bremen (Weber et al. 20II; Weatherhead et al. 2017) and GTO from ESA/DLR (Coldewey-Egbers et al. 2015; Garane et al. 2018). MSR-2 assimilates nearly all ozone datasets after corrections with respect to the ground data (van der $A$ et al. 2015). All six datasets have been bias corrected by subtracting averages from the reference period 1998-2008 and adding the multiple data mean from the same period. The horizontal dotted gray lines in each panel show the average ozone level for 1970-79 calculated from the WOUDC data. All data from 2017 are preliminary. average in 2017 with some regions with slightly lower ozone (Plate 2.1y).

Figure 2.52 shows the annual mean total ozone time series from various merged datasets in the tropics, extratropics, and selected months in the polar regions as well as the near-global $\left(60^{\circ} \mathrm{N}-60^{\circ} \mathrm{S}\right)$ average. For all time series, the average ozone levels from the 1970s, a time when ozone losses due to ozone-depleting substances were still very small, are et 2018). The small increase in global total ozone works.

ODS currently decrease at about one-third of the absolute increasing rate before the 1990s, but the recent increase in total column ozone is in comparison smaller than expected from the ODS change. Model studies show that the predicted ozone evolution is consistent in most regions outside the tropics with ODS changes and observed stratospheric ozone and (1) 2017). The lack of observed ODSin climate models with stratospheric chemistry) may be due to a compensation by increases in tropospheric ozone that contribute to the total column (Shepherd et al. 2014). However, observed global tropospheric ozone trends from various studies are highly variable and often insignificant (Gaudel et al. 2018 and Figure 26 therein).

Ball et al. (2018) suggest, based on an analysis of satellite measurements, that a near-continuous, near-global $\left(<60^{\circ}\right.$ in both hemispheres) decline in lower stratospheric ozone since 1998 was compensated by observed upper stratospheric increases and tropospheric increases, resulting in rather small total ozone trends. A recent chemistry-transport model study by Chipperfield et al. (2018) shows that the observed 
lower stratospheric and total column ozone changes are mostly explained by variability in atmospheric dynamics and is not contradicting our current understanding of stratospheric ozone chemistry related to ODS changes as otherwise suggested by Ball et al. (2018). In the tropics a continuous decline in total ozone in the future is predicted by chemistry-climate models as climate change will enhance tropical upwelling and potentially thin ozone in the lowermost tropical stratosphere, thus increasing UV radiation in the equatorial region (WMO 2014; Chipperfield et al. 2017).

While the expected slow recovery of stratospheric ozone has not yet resulted in substantial increases of total column ozone, ozone in the upper stratosphere has been showing clearer signs of increase and recovery over the last 10 to 15 years (WMO 2014;

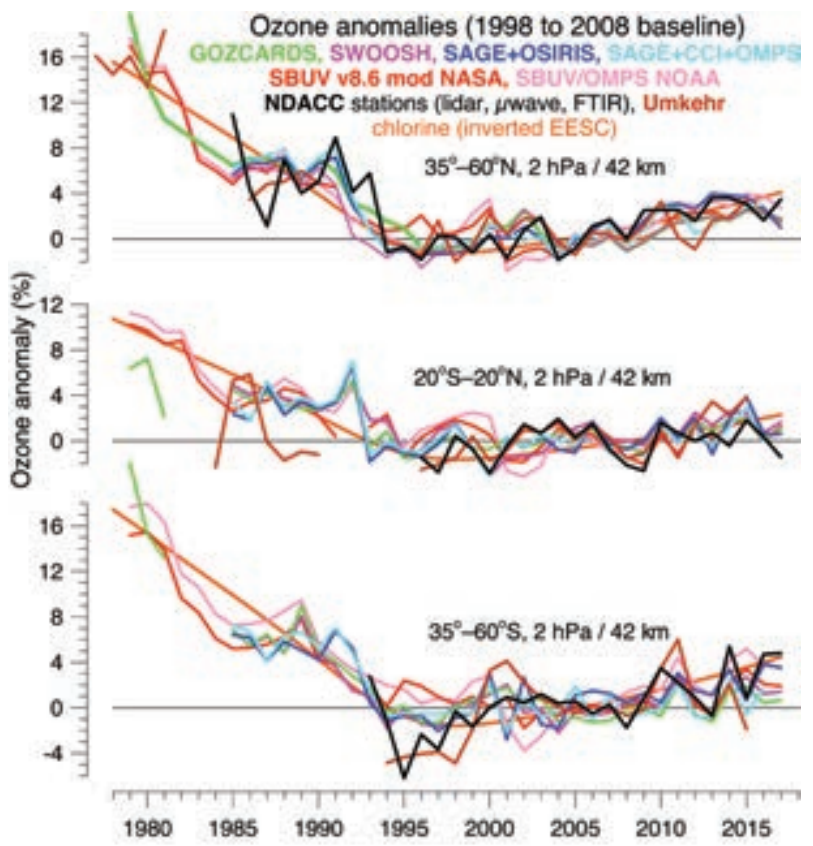

Fig. 2.53. Annual mean anomalies of ozone (\%; 19982008 baseline) in the upper stratosphere, near $42-\mathrm{km}$ altitude or 2-hPa pressure for three zonal bands: $35^{\circ}-60^{\circ} \mathrm{N}(\mathrm{NH}), 20^{\circ} \mathrm{N}-20^{\circ} \mathrm{S}$ (tropics), and $35^{\circ}-60^{\circ} \mathrm{S}$ (SH). Colored lines are for long-term records obtained by merging different limb (GOZCARDS, SWOOSH, SAGE+OSIRIS, SAGE+CCI+OMPS-LP) or nadir viewing (SBUV, OMPS-NP) satellite instruments. Black line is from merging ground-based ozone records at NDACC stations employing differential absorption lidars, microwave radiometers, and/or Fourier Transform InfraRed spectrometers (FTIRs). Gray line is for ground-based Umkehr measurements. See Steinbrecht et al. (20I7) for details on the various datasets. Orange line gives inverted EESC as a proxy for manmade ozone depletion. Ozone data for 2017 are not yet complete for all instruments and are still preliminary.
Steinbrecht et al. 2017). Figure 2.53 shows that since about 2000, ozone has generally been increasing in the upper stratosphere, ending the previous period of ozone decline. In 2017, ozone values in the upper stratosphere were below the EESC curve both in the tropical belt and at northern midlatitudes. This is somewhat surprising for the easterly phase of the QBO and may in part arise from the decadal
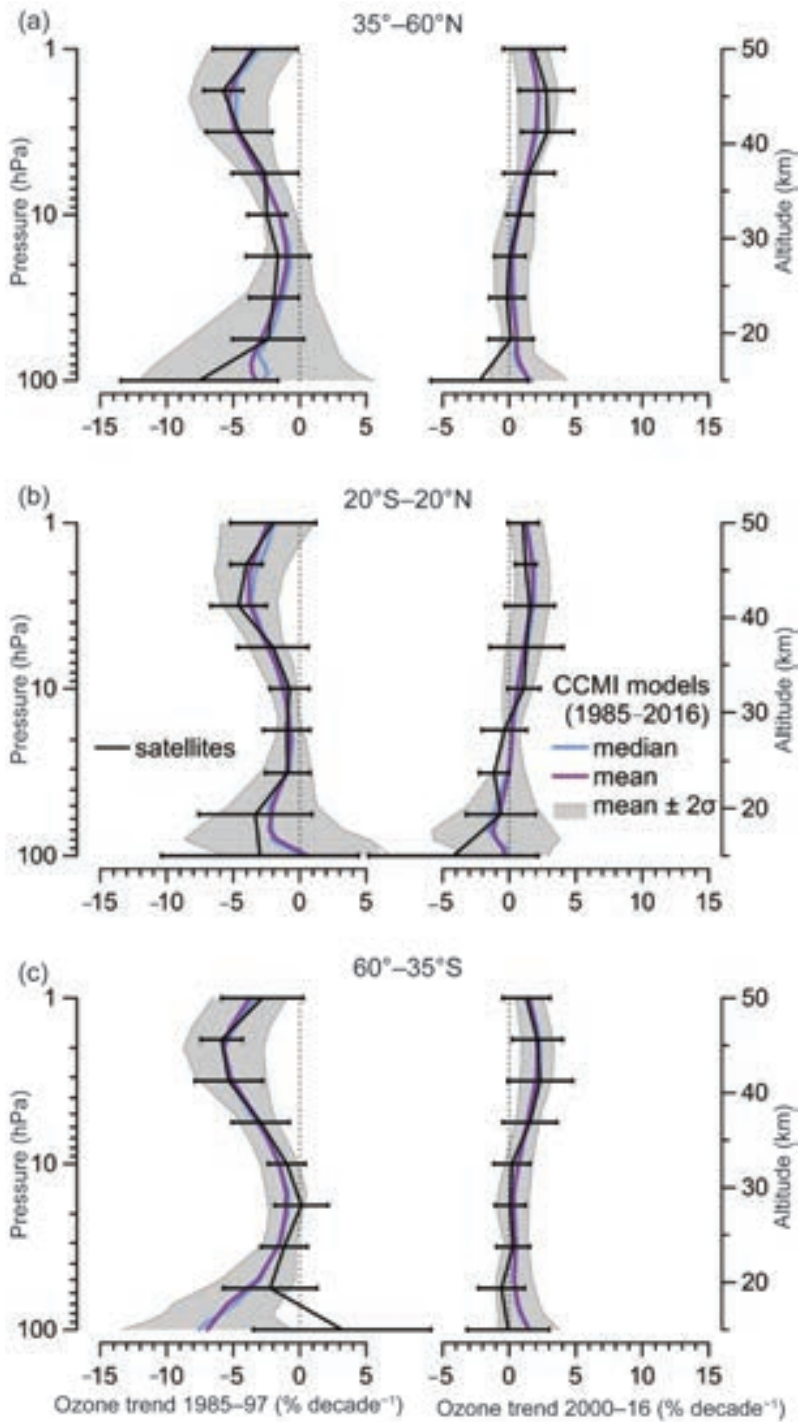

FIG. 2.54. Mean ozone trends in the upper atmosphere $\left(\%\right.$ decade $^{-1}$ ) prior to 1997 and after 2000 as derived from the CCMI REF-C2 models' simulation (median in blue and mean in purple) and satellite data (black line) in three zonal bands: (a) $35^{\circ}-60^{\circ} \mathrm{N}$ (NH), (b) $20^{\circ} \mathrm{N}-20^{\circ} \mathrm{S}$ (tropics), and (c) $35^{\circ}-60^{\circ} \mathrm{S}(\mathrm{SH})$. Mean trends were averaged from trends of individual model runs and various merged datasets shown in Fig. 2.53. The shading shows the $2 \sigma$ of the models' mean trend. Same type of multilinear regression analysis was used to determine the trends in models and observations. Adapted from LOTUS (2018, SPARC report under review). 
minimum of solar activity (e.g., Randel and Wu 1996; Newchurch et al. 2003; WMO 2014).

It is a challenge to accurately attribute observed stratospheric ozone changes, because changes due to recovery are expected to be small and thus potentially masked by long-term natural variability and measurement uncertainty. Substantial efforts, therefore, have gone into improving the available observational ozone profile records and into better ways to estimate ozone profile trends and their uncertainties (LOTUS 2018, SPARC report under review). Figure 2.54 shows the resulting updated trend profiles from observations and chemistry-climate models, both during the phase of ODS-driven ozone decline from the late 1970s to the late 1990s, and during the beginning recovery phase from 2000 to 2016. Observations are in generally good agreement with chemistry-climate model simulations.

As a result of the Montreal Protocol and its Amendments, ODS have been declining in the stratosphere since the late 1990s. The model simulations predict that ozone in the upper stratosphere should now increase by $2 \%-3 \%$ decade $^{-1}$, due to both declining ODS and stratospheric cooling, the latter caused by increasing greenhouse gases (WMO 2014). The right panels of Fig. 2.54 demonstrate that ozone increases are observed in the upper atmosphere after 2000 , although they are not statistically significant at all latitudes and altitudes. Nevertheless, the good agreement between model simulations and observations gives confidence that ozone trends in the upper stratosphere are well understood and that ozone in that region is on its continuing (slow) path towards recovery.

5) Stratospheric water vapor-S. M. Davis, K. H. Rosenlof, D. F. Hurst, H. B. Selkirk, and H. Vömel

Stratospheric water vapor (SWV) is a radiatively important gas that can also impact stratospheric ozone chemistry. The second consecutive year of dramatic changes in lower SWV occurred in 2017. Following 2016, during which the tropical mean $\left(15^{\circ} \mathrm{N}-15^{\circ} \mathrm{S}\right)$ water vapor anomaly in the lowermost stratosphere (at $82 \mathrm{hPa}$ ) dropped from a near record high in January $(+0.5 \mathrm{ppm}$, parts per million mole fraction, equivalent to $\mu \mathrm{mol} \mathrm{mol}^{-1}$ ) to a record low by December ( -1 ppm), 2017 anomalies increased to near record high values by midyear.

In January 2017 negative (dry) anomalies were observed in the tropics and subtropics, in stark contrast to the strong positive (wet) anomalies of June 2017. From January to June 2017, the tropical SWV anomaly in the lower stratosphere increased by 0.9 ppm (Figs. $2.55,2.56 \mathrm{c}, \mathrm{d}$ ), about $40 \%$ of the average seasonal cycle amplitude at $82 \mathrm{hPa}$ in the tropics and $140 \%$ of the climatological average difference between these two months. This steep increase in tropical lowermost SWV during the first half of 2017 and subsequent return to near-normal values by the end of the year were observed by both the Aura Microwave Limb Sounder (MLS) satellite instrument (Fig. 2.55) and balloon-borne frost point hygrometer soundings at tropical sites Hilo, Hawaii $\left(20^{\circ} \mathrm{N}\right)$, and San José, Costa Rica $\left(10^{\circ} \mathrm{N}\right)$ (Figs. $\left.2.56 \mathrm{c}, \mathrm{d}\right)$.

Variations in cold-point temperatures (CPTs) in the tropical tropopause layer (TTL) on annual and interannual timescales provide the dominant control on water vapor entering into the lowermost stratosphere in the tropics by freeze-drying tropospheric air during its slow ascent through the TTL. Thus, seasonal to interannual variability in tropical SWV around $82 \mathrm{hPa}$ is highly correlated with CPT variations. The dramatic swing in tropical lower SWV during 2017 is consistent with the substantial $2.5^{\circ} \mathrm{C}$ increase from November 2016 to May 2017 and subsequent $1.5^{\circ} \mathrm{C}$ decrease in tropical CPT anomalies over the remainder of 2017 (Fig. 2.56d).

Interannual variations in CPTs are partially related to interannual variability in the phases of ENSO
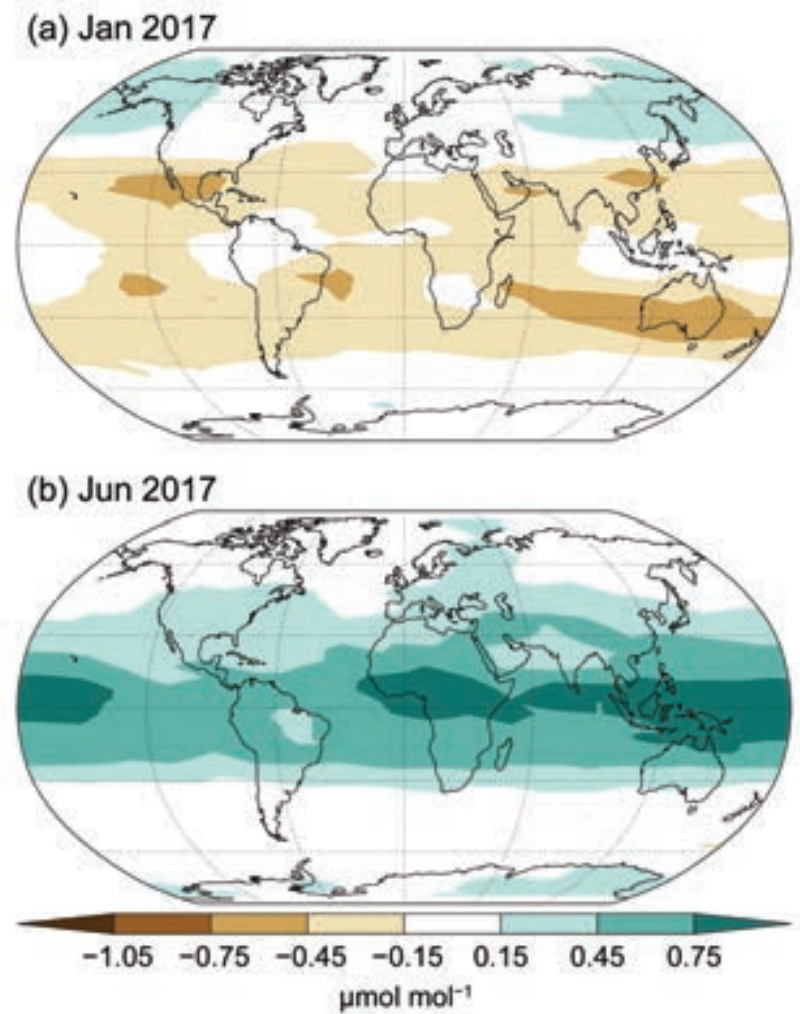

FIG. 2.55. Global stratospheric water vapor anomalies ( $\mu \mathrm{mol} \mathrm{mol}^{-1}$; 2004-17 base period) centered on $82 \mathrm{hPa}$ in (a) Jan and (b) Jun 2017 from the Aura MLS. 


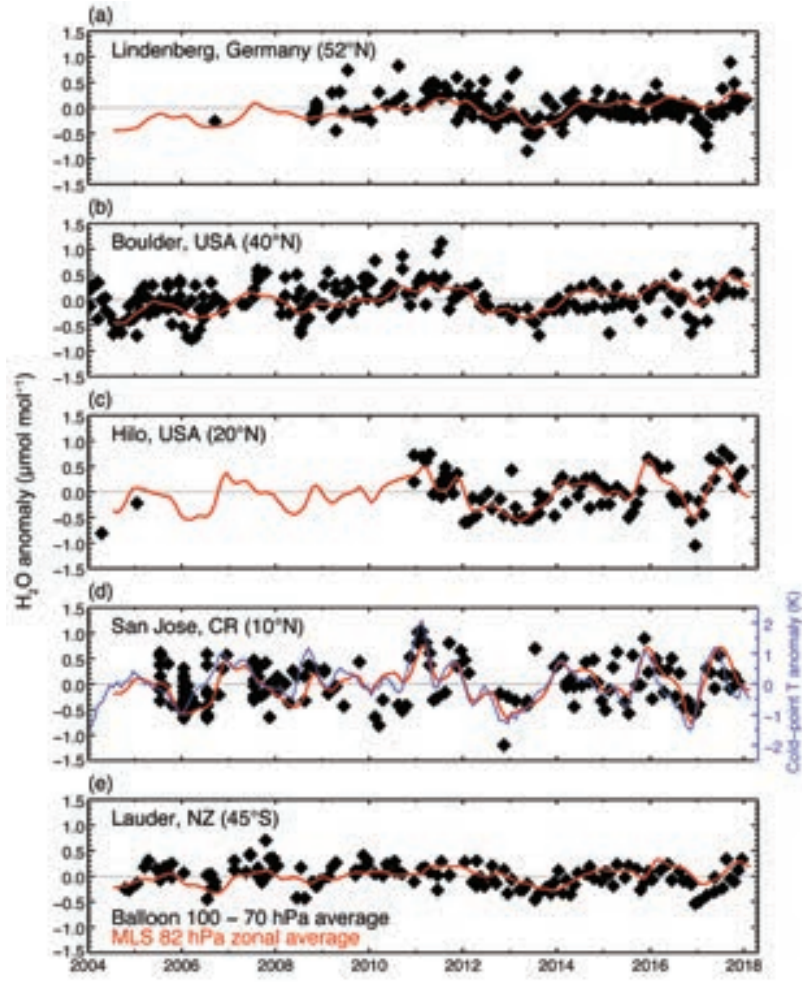

FIG. 2.56. Lower stratospheric water vapor anomalies $\left(\mu \mathrm{mol} \mathrm{mol}{ }^{-1}\right)$ over five balloon-borne frost point (FP) hygrometer stations. Each panel shows the lower stratospheric anomalies of individual FP soundings (black squares) and of monthly zonal averages of MLS retrievals at $82 \mathrm{hPa}$ in the $5^{\circ}$ latitude band containing the FP station (red lines). High-resolution FP vertical profile data were averaged between 70 and 100 $\mathrm{hPa}$ to emulate the MLS averaging kernel for $82 \mathrm{hPa}$. Each MLS monthly zonal mean was determined from 2000-3000 profiles. Anomalies for MLS and FP data are calculated relative to the 2004-17 period for sites except for Lindenberg (2009-17) and Hilo (20II-I7). Tropical CPT anomalies (K) based on the MERRA-2 reanalysis (d, blue curve), which were generally well correlated with the tropical lower SWV anomalies, are the driving force behind the variations in tropical SWV during 2017.

and the quasi-biennial oscillation (QBO) in tropical stratospheric winds (Dessler et al. 2014). During 2017, the QBO was in a westerly (warm) phase at $70 \mathrm{hPa}$, and ENSO was in a neutral state. It is possible that suppressed tropical upwelling due to the QBO westerly phase led to the warm CPT anomalies and positive (wet) SWV anomalies in the tropical lower stratosphere in the first half of 2017.

Water vapor entering the tropical lowermost stratosphere is transported vertically in a quasicoherent fashion, forming the well-known "tropical tape recorder" phenomenon (Fig. 2.57a; Mote et al. 1996). In the tropical middle stratosphere, the water vapor abundance is indicative of how much entered the stratosphere in the previous year and was subsequently transported upward. During late 2017, the tropical SWV anomalies at $30 \mathrm{hPa}$ were negative (dry), due to the anomalously cold CPTs and correspondingly dry water vapor anomalies that entered the stratosphere in the latter half of 2016 and beginning of 2017 .

In general, lowermost SWV anomalies propagate quasi-isentropically from the tropics to the middle latitudes of both hemispheres, as is demonstrated by the "C"-shaped contours in Fig. 2.57b. The early 2017 dry anomaly and the mid-2017 wet anomaly in tropical lower SWV can be seen a few months later in the middle latitudes of each hemisphere. These midlatitude anomalies are also observed by balloon measurements at Lindenberg, Germany $\left(52^{\circ} \mathrm{N}\right)$; Boulder, Colorado $\left(40^{\circ} \mathrm{N}\right)$; and Lauder, New Zealand $\left(45^{\circ} \mathrm{S}\right)$ (Fig. 2.56a,b,e).

SWV anomalies over Lauder, New Zealand (Fig. 2.56e) increased during most of 2017, consistent with the poleward transport of the strong wet anomalies in SWV present in the tropics during mid-2017. SWV in the Southern Hemisphere mid-
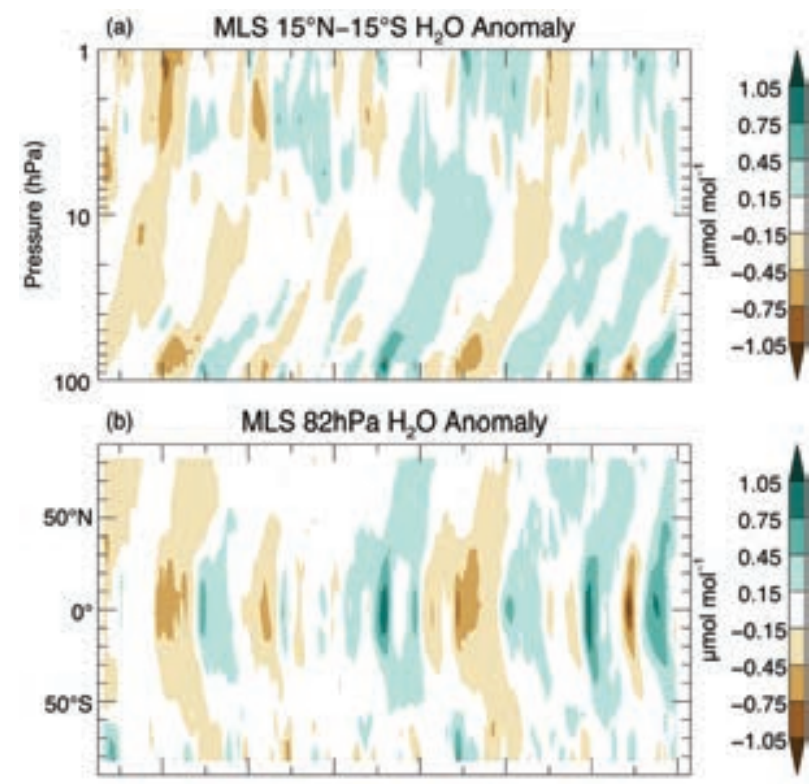

FIG. 2.57. (a) Time series of vertical profiles of tropical $\left(15^{\circ} \mathrm{S}-15^{\circ} \mathrm{N}\right)$ stratospheric water vapor anomalies $\left(\mu \mathrm{mol} \mathrm{mol}^{-1}\right)$ and (b) latitudinal distributions of SWV anomalies $\left(\mu \mathrm{mol} \mathrm{mol}{ }^{-1}\right)$ at $82 \mathrm{hPa}$. Both are based on Aura MLS data. Anomalies are differences from the mean 2004-17 water vapor mixing ratios for each month. In panel (b) propagation of tropical lower SWV anomalies to higher latitudes in both hemispheres as well as the influences of dehydrated air masses from the Antarctic polar vortex as they are transported towards the SH midlatitudes at the end of each year are clearly seen. 
latitudes can also be influenced by the springtime (October-November) northward transport of air masses that were dehydrated within the Antarctic vortex. The weak anomalies at high southern latitudes in late 2017 (Fig. 2.56b) indicate that the Antarctic dehydration in 2017 was not unusual. Therefore, the positive anomalies observed at Lauder in late 2017 are primarily attributed to the southward transport of the strong tropical wet anomalies.

6) Tropospheric Ozone- J. R. Ziemke and 0. R. Cooper Tropospheric ozone is a surface pollutant, a greenhouse gas, and the dominant source of the hydroxyl radical $(\mathrm{OH})$, which is the troposphere's primary oxidizing agent. Sources include transport from the stratosphere along with photochemical production from a number of precursor gases such as lightninggenerated $\mathrm{NO}_{\mathrm{x}}$, methane, biogenic hydrocarbons, and emissions generated from combustion of fossil fuels and biomass burning (e.g., Sauvage et al. 2007; Leung et al. 2007; Martin et al. 2007; Murray et al. 2013; Young et al. 2013; Monks et al. 2015; Zhang et al. 2016; Lin et al. 2017). Tropospheric ozone is highly variable from small (urban) to large (hemispheric) scales due to variations in dynamical transport and photochemical production (i.e., heterogeneity of precursor gas emissions and sunlight) and sinks including loss mechanisms such as through $\mathrm{HO}_{x}$ photochemistry and through surface deposition (IPCC 2014). Transport phenomena that drive large-scale variability include the El Niño-Southern Oscillation (e.g., Chandra et al. 1998, 2009; Sudo and Takahashi 2001; Doherty et al. 2006; Koumoutsaris et al. 2008) and the Madden-Julian Oscillation (e.g., Sun et al. 2014; Ziemke et al. 2015). Relatively short lifetimes for ozone and ozone precursors and short-term variability of transport including convection drives much of the variability of tropospheric ozone on short timescales including day-to-day changes. Variability from daily to interannual timescales adds challenges to quantifying decadal trends at hemispheric and global scales (e.g., Neu et al. 2014; M. Lin et al. 2014; Barnes et al. 2016).

The tropospheric ozone summary in the State of the Climate in 2012 was based on measurements by ground- and satellite-based instruments (Cooper and Ziemke 2013). Since then the reports have primarily relied on the Aura Ozone Monitoring Instrument/ Microwave Limb Sounder (OMI/MLS) satellite measurements (Ziemke et al. 2006, 2015) because of insufficient updates of global ground-based observations (Cooper and Ziemke 2014, 2015; Ziemke and Cooper 2016, 2017). The Tropospheric Ozone Assessment
Report (TOAR) further discusses the global ground network including update issues (Schultz et al. 2017; see Sidebar 2.2). The present update again relies mostly on OMI/MLS satellite data.

Plate $2.1 \mathrm{x}$ shows broad regions of positive anomalies (relative to the 2005-16 average) of up to $1.2 \mathrm{DU}$ (4\%) in tropospheric ozone columns for 2017 in the Northern Hemisphere lower midlatitudes and smaller anomalies of $\sim 1$ DU or less elsewhere. Hemispheric and global average tropospheric ozone burdens and their 95\% confidence level precision uncertainties for 2017 were $159 \pm 6 \mathrm{Tg}$ for $0^{\circ}-60^{\circ} \mathrm{N}, 147 \pm 8 \mathrm{Tg}$ for $0^{\circ}-60^{\circ} \mathrm{S}$, and $306 \pm 7 \mathrm{Tg}$ for $60^{\circ} \mathrm{N}-60^{\circ} \mathrm{S}$ (Fig. 2.58). Each of these 2017 averages represents an increase from previous years, continuing the long-term positive trend. Linear trends in hemispheric and global burdens from October 2004 through December 2017 in Fig. 2.58 all depict increases of $~ 0.6 \%$ to $0.7 \% \mathrm{yr}^{-1}$.

Figure 2.59 shows the spatial distribution of tropospheric ozone trends on a $5^{\circ} \times 5^{\circ}$ grid for October 2004 to December 2017. All trends with statistical significance depict increases, the strongest of which

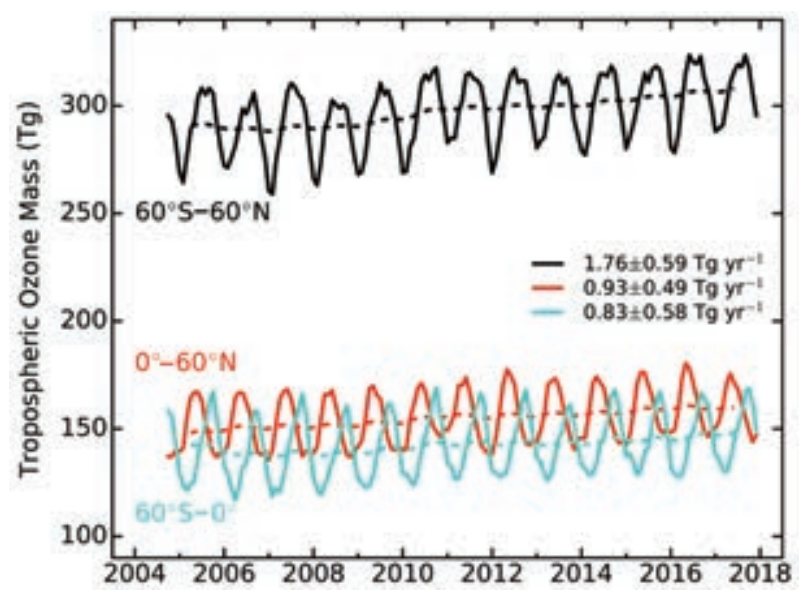

FIG. 2.58. Monthly averages of OMI/MLS tropospheric ozone burdens (Tg) from Oct 2004 through Dec 2017. Top curve (solid black line) shows $60^{\circ} \mathrm{S}-60^{\circ} \mathrm{N}$ monthly averages with 12-mo running means (dashed black line). Bottom two curves show monthly averages and running means for the NH (red) and SH (blue). Slopes of linear fits to the data are presented with their 2-sigma uncertainties. All three trends are statistically significant at the $95 \%$ confidence level. Prior to our analyses, the data were evaluated for potential offset and drift by comparison with globally distributed ozonesonde profiles and OMI convective cloud differential (CCD) measurements (Ziemke et al. 1997). A small drift of about +0.5 DU decade ${ }^{-1}$ was found and an appropriate correction was applied to the OMI/MLS data. OMI/MLS tropospheric ozone was also adjusted everywhere by $+2 \mathrm{DU}$ to correct for mean offset relative to the ozonesondes. 


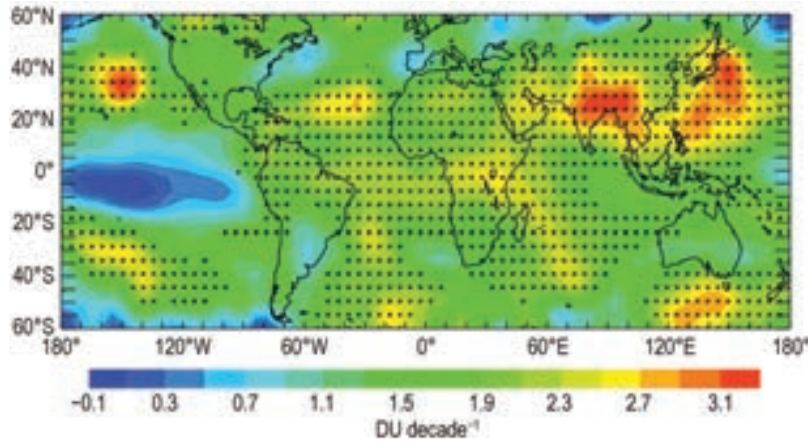

FIG. 2.59. Linear trends in OMI/MLS tropospheric column ozone ( $D U$ decade $^{-1}$ ) on a $5^{\circ} \times 5^{\circ}$ grid for Oct 2004-Dec 2017. Asterisks denote statistically significant trends at the $95 \%$ confidence level. Note that trends were calculated using a multivariate linear regression model (Ziemke et al. 1998, and references therein) that included a seasonal cycle fit and the Niño-3.4 index as an ENSO proxy; trend uncertainties included autoregressive adjustment via Weatherhead et al. (1998).

$\left[\sim+3.3 \mathrm{DU} \mathrm{decade}^{-1}\left(+1.05 \% \mathrm{yr}^{-1}\right)\right]$ are located above India, Southeast Asia, and extend eastward across the North Pacific Ocean. These upward trends are consistent with model estimates based on strengthening emissions of ozone precursors from Southeast, East, and South Asia, primarily due to fossil fuel combustion (Zhang et al. 2016; Lin et al. 2017). The model simulations indicate that ozone produced in these densely populated areas is transported eastward in the free troposphere over the North Pacific Ocean as suggested in Fig. 2.59. Positive trends are also found above the North Atlantic Ocean, the equatorial Africa and Atlantic/Indian Oceans regions, and the Southern Hemisphere extratropics.

As noted above, updating global surface ozone measurements annually is difficult because most ground stations do not provide quality-assured final data soon enough for the timing of this report. However, there are three remote monitoring sites with rapidly updated data: 1) the high-elevation Mauna Loa Observatory (MLO), Hawaii $\left(19.5^{\circ} \mathrm{N}, 155.6^{\circ} \mathrm{W}\right.$, 3397 m asl); 2) South Pole Observatory (SPO), Antarctica $\left(90^{\circ} \mathrm{S}, 59^{\circ} \mathrm{E} ; 2840 \mathrm{~m}\right.$ asl); and 3) Utqiagivik (Barrow), Alaska $\left(71.3^{\circ} \mathrm{N}, 156.6^{\circ} \mathrm{W} ; 11 \mathrm{~m}\right.$ asl). Continuous UV-based measurements of ozone began at MLO in September 1973, at SPO in January 1975, and at Barrow in March 1973. Reliable ozone observations based on the Regener automatic wetchemical method are also available at SPO for 1961-63 (Oltmans and Komhyr 1976), and at MLO for 1957-59 (Price and Pales 1963). These time series, the world's longest at remote locations, are reported in Fig. 2.60 as monthly medians, based on all 24 hours of the day at SPO and Barrow, but the MLO data are restricted to nighttime values when local winds are downslope, ensuring that the observations are representative of the lower free troposphere. The limited data at MLO and SPO from the 1950s and 1960s indicate that ozone levels at these remote high-elevation sites were similar during the mid-20th century despite being located in different hemispheres. Ozone at SPO has changed little since the 1960s with no significant trend. In

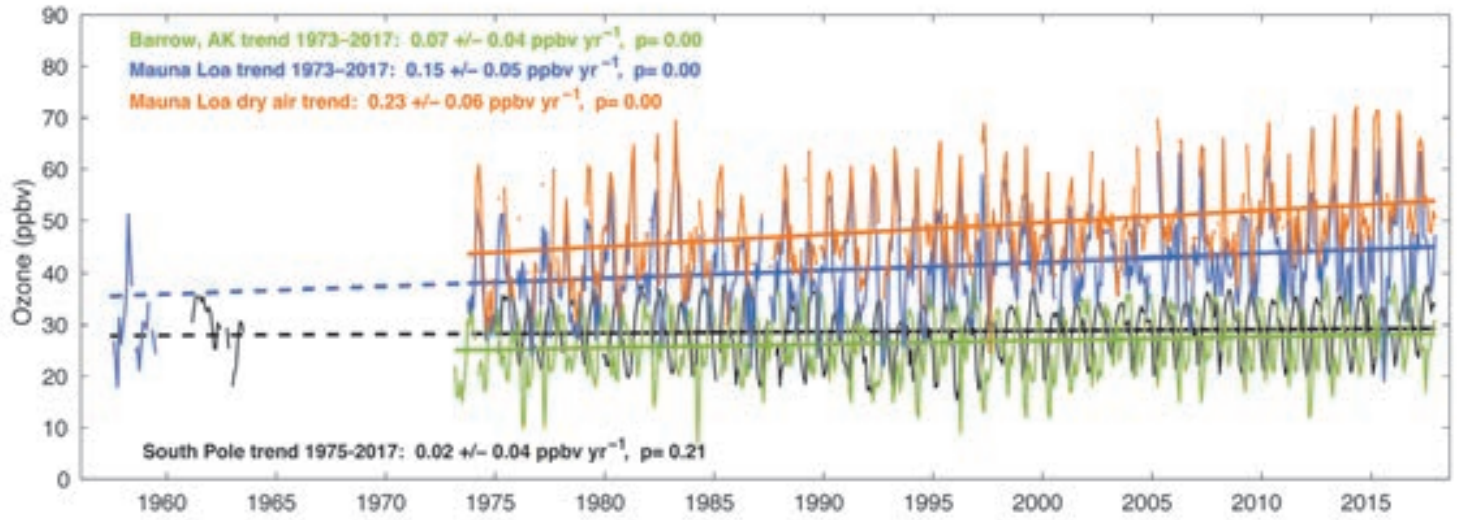

Fıg. 2.60. Monthly median surface ozone at Utqiagivik (Barrow), Alaska (Mar I973-Dec 20I7; green) and South Pole (Jan 1975-Dec 2017; black) using data from all hours of the day. Additional data from South Pole are shown for the early 1960s. Also shown are nighttime monthly median ozone values at the Mauna Loa Observatory (MLO) calculated with all available data for months with at least $\mathbf{5 0 \%}$ data availability, Sep 1973-Dec 2017 (blue), with early observations from the late I950s. Monthly median values associated with dry air masses (orange) at MLO are also included (dew point less than the climatological monthly 40 th percentile, and a sample size of at least 24 individual hourly nighttime observations). Trends (solid straight lines) are based on least-squares linear regression fit through the monthly values (1970s-2017), and reported with $95 \%$ confidence intervals and $p$-values. MLO and South Pole trend lines are extrapolated back in time to the late 1950s (dashed lines). 
Recognizing the need for a comprehensive tropospheric ozone survey and the challenges associated with gathering and processing ozone observations from thousands of sites worldwide, the International Global Atmospheric Chemistry (IGAC) Project developed the Tropospheric Ozone Assessment Report (TOAR): Global metrics for climate change, human health, and crop/ecosystem research, released in October 2017. Initiated in 2014, TOAR's mission is to provide the research community with an up-to-date scientific assessment of tropospheric ozone's global distribution and trends from the surface to the tropopause. TOAR's primary goals are: (I) produce the first tropospheric ozone assessment report based on all available surface observations, the peer-reviewed literature, and new analyses; and (2) generate easily accessible and documented ozone exposure metrics at thousands of measurement sites around the world. TOAR is an international collaborative effort with participation from over 230 scientists and air quality experts from 36 nations representing research on all seven continents.

Monitoring global trends of long-lived greenhouse gases such as carbon dioxide and methane is relatively straightforward as their spatial and temporal variability is limited and relatively few measurement sites are required to demonstrate globalscale changes. Quantification of global ozone trends is much more difficult due to ozone's short lifetime (days to weeks) and multiple sources and sinks that have heterogeneous spatial distributions and seasonal cycles. While over 5000 surface ozone monitoring sites are presently established worldwide, the TOAR database these ozone metrics are freely accessible for research on the global-scale impact of ozone on human health, crop/ecosystem productivity, and climate. All ozone data submitted to the database have undergone quality control procedures by the agencies or research groups that made the observations. The site locations are then cross-referenced with global gridded datasets of human population, satellitedetected tropospheric nitrogen dioxide $\left(\mathrm{NO}_{2}\right)$, a bottom-up $\mathrm{NO}_{x}$ emissions inventory, satellite-detected night-time lights of the world, and land cover so that all sites can be objectively queried to determine if they meet predetermined criteria for urban or rural classifications. The database is publicly available and the ozone metrics can be downloaded from: https://doi .pangaea.de/10.1594/PANGAEA.876108.

The particular ozone metrics available from the database were chosen for their relevance to research (Lefohn et al. 2018) related to human health (Fleming and Doherty et al. 2018), vegetation (Mills et al. 2018, manuscript submitted to Elementa), and climate (Gaudel et al. 2018). The metrics are also being used to evaluate global atmospheric chemistry models (Young et al. 2018), to assess long-term global ozone trends from the early 20th century to the present (Tarasick et al. 2018, manuscript submitted to Elementa), and to develop new statistical methods for quantifying regional ozone trends (Chang et al. 2017).

An illustration of the database's capabilities is provided in Fig. SB2.3 which shows the warm season (April-September in the Northern Hemisphere and October-March in the their distribution is uneven with high densities in North America, Europe, and East Asia, and few or no sites in South Asia, the Middle East, Central Asia, Africa, and South and Central America. Monitoring is also limited across the oceans and the polar regions. Another barrier to producing a global survey of surface ozone trends is the logistical problem of gathering the data from dozens of air quality agencies and research groups across many nations, all with different data formats.

To produce a wide range of ozone metrics at thousands of surface sites worldwide, TOAR built the world's largest database of surface hourly ozone observations (Schultz et al. 2017). Through

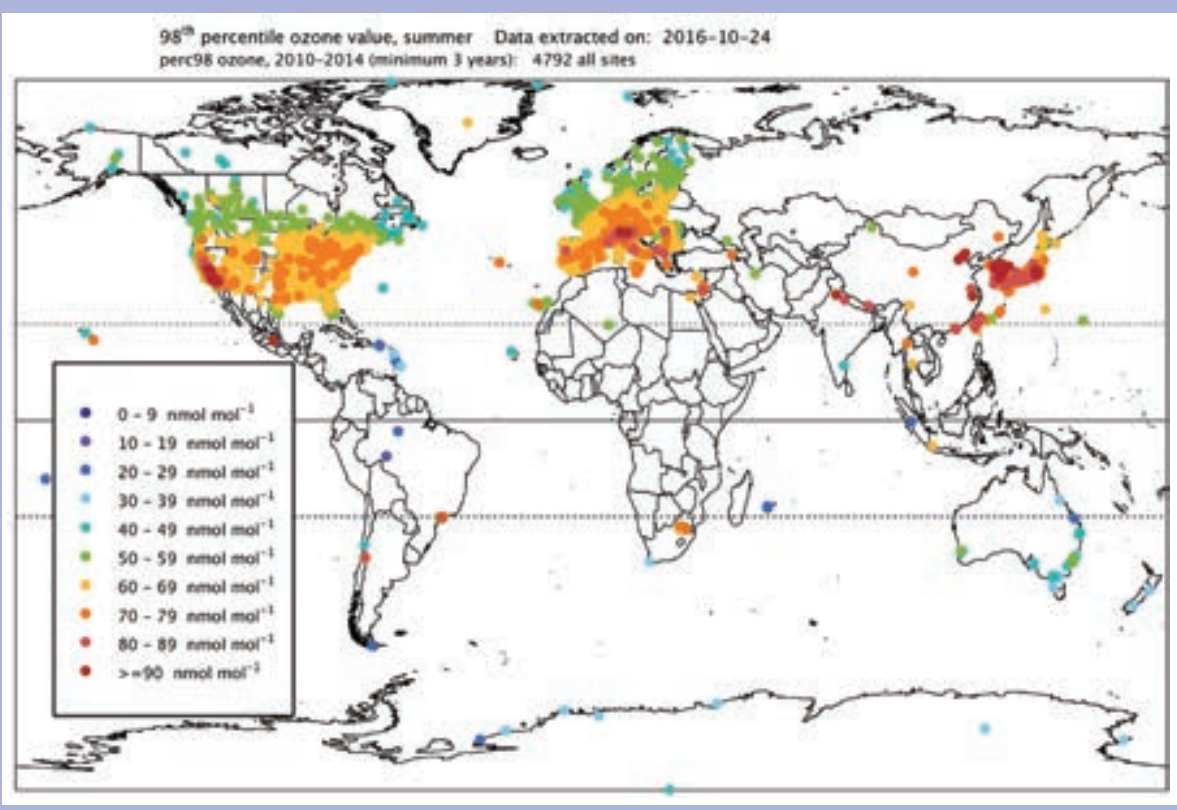

FIG. SB2.3. 98th percentile ozone (nmol mol-1 equivalent to $\mathrm{ppb})$ at all available (4792) surface sites for the 2010-14 warm season (Apr-Sep in the NH, and Oct-Mar in the SH). 
Southern Hemisphere) surface ozone 98th percentile value at all available stations, averaged across the period 2010-14. The data quickly reveal that the most extreme ozone events are found in Southern California, Mexico City, northern Italy, northern India, eastern China, South Korea, and Japan. Ozone monitoring is sparse in the Southern Hemisphere, but in general concentrations are much lower. Figure SB2.4 depicts the trends of the 98th percentile surface ozone at all available stations showing widespread decreases across North America and much of Europe in response to emission controls of ozone precursor gases (oxides of nitrogen, carbon monoxide, volatile organic compounds). In contrast, high ozone events increased in Hong Kong, South Korea, and parts of western Japan due to broad, regional scale ozone precursor emission increases.

Further information on TOAR can be found on the IGAC webpage: www.igacproject.org /activities/TOAR/

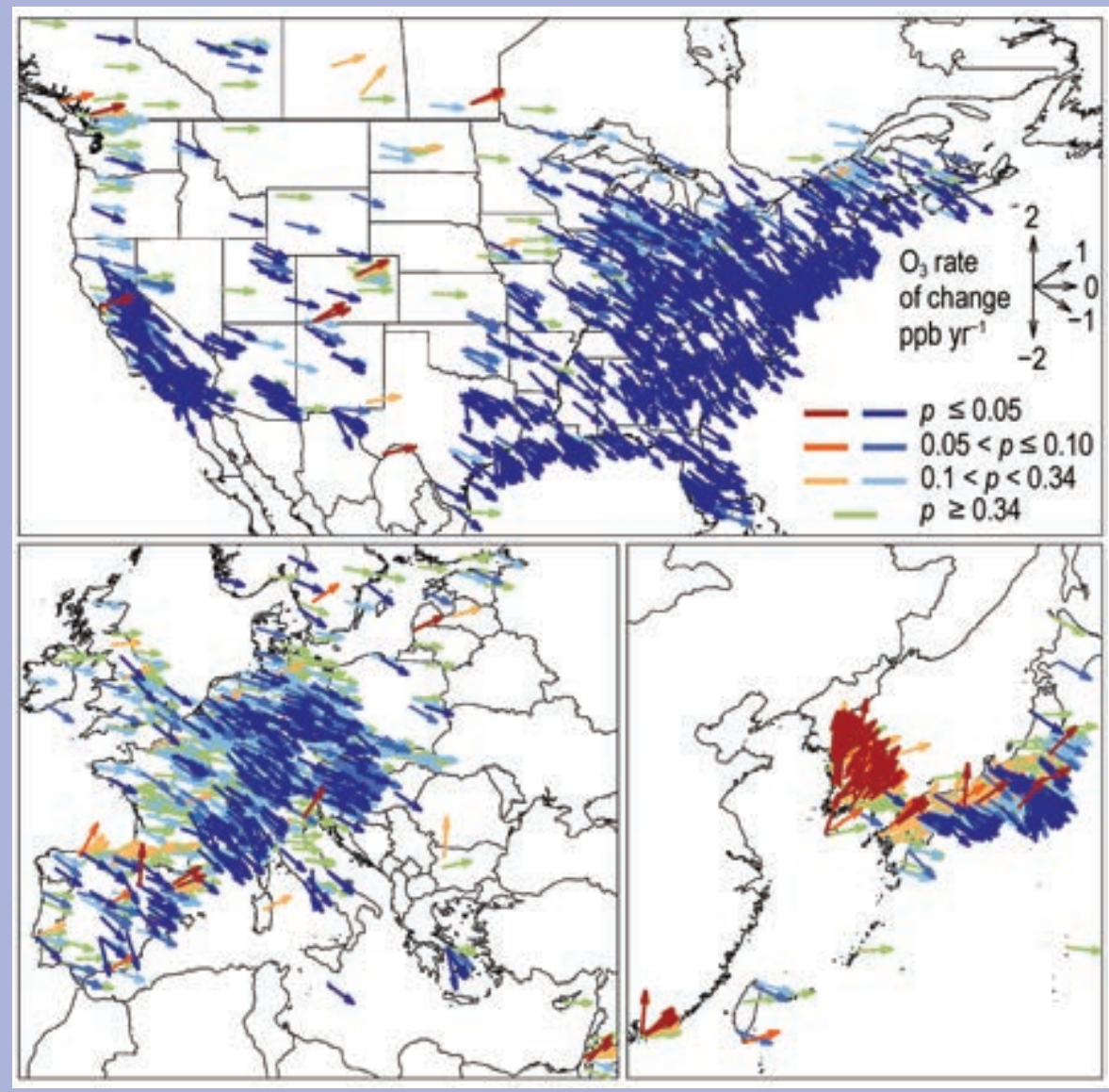

FIG. SB2.4. Trends of the $\mathrm{O}_{3}$ 98th percentile at the sites shown in Fig.SB 2.3, during 2000-14. Vector colors indicate the $p$-values on the linear trend for each site: blues indicate negative trends, oranges indicate positive trends, and green indicates weak or no trend; lower p-values have greater color saturation.

contrast, ozone at MLO has increased significantly at the rate of $0.15 \pm 0.05 \mathrm{nmol} \mathrm{mol}^{-1} \mathrm{yr}^{-1}$, resulting in an overall increase of $6.5 \mathrm{nmol} \mathrm{mol}^{-1}$ since 1973 , or $17 \%$. MLO experiences high interannual ozone variability due to its location in the transition region between tropical and extratropical air masses. The ozone trend in the dry air masses, which tend to originate at higher altitudes and latitudes to the west and northwest of MLO, while moist air masses tend to come from the east at lower latitudes and altitudes (Harris and Kahl 1990; Oltmans et al. 2006; M. Lin et al. 2014). Ozone observations at MLO were divided into dry $(<40$ th percentile) and moist ( $>60$ th percentile) air masses using observed dew point temperatures and a long-term climatology. The trend in the dry air masses is 50\% greater compared to the trend using all air masses (9.9 ppbv total increase since 1974, or 23\%), which im- plies that the site is influenced by ozone increases in upwind regions to the west and northwest, most likely Asia where limited in situ observations have shown general ozone increases over the past two decades at the surface (Cooper et al. 2014; Ma et al. 2016; Sun et al. 2016; Xu et al. 2016; T. Wang et al. 2017) and in the free troposphere (Zhang et al. 2016).

\section{7) Carbon monoxide-J. Flemming and A. Inness}

Carbon monoxide (CO) plays a significant role as a chemical precursor in determining the abundance of climate forcing gases like methane $\left(\mathrm{CH}_{4}\right)$, through hydroxyl radical $(\mathrm{OH})$ chemistry and tropospheric ozone (Hartmann et al. 2013). CO is therefore regarded as an indirect climate forcing agent. Sources of CO include incomplete fossil fuel and biomass combustion and in situ production via the oxidation 
of $\mathrm{CH}_{4}$ and other organic trace gases. Combustion and chemical in situ sources typically produce similar amounts of $\mathrm{CO}$ each year.

The Copernicus Atmosphere Monitoring Service (CAMS) produced a retrospective analysis of CO, aerosols, and ozone for the period $2003-15$ by assimilating satellite retrievals of atmospheric composition with the ECMWF model (Flemming et al. 2017). This dataset has been extended to the end of 2017 and is used here. Version 5 total column retrievals of $\mathrm{CO}$ from the MOPITT instrument (Deeter et al. 2013) were assimilated from January 2003 until the end of February 2017. From March 2017 onwards MOPITT version 7 data were used because the older version was discontinued. The anthropogenic emissions were taken from the MACCity inventory (Granier et al. 2011) that accounts for projected emission trends according to the representative concentration pathways (RCP) 8.5 scenario (Riahi et al. 2011). Biomass burning emissions were taken from the Global Fire Assimilation System (v1.2, Kaiser et al. 2012, also Section 2h3).

The global tropospheric CO concentrations have decreased by about $1 \% \mathrm{yr}^{-1}$ in the last decade according to studies based on MOPITT and other observations (Worden et al. 2013; Yin et al. 2015; Flemming et al. 2017; Gaubert et al. 2017). Model simulations (Flemming et al. 2017; Gaubert et al. 2017) result in weaker negative trends than the observation based estimates. This could point to an underestimation of anthropogenic emissions trends or to unaccounted chemical feedback in the $\mathrm{CO}-\mathrm{OH}-\mathrm{O}_{3}-\mathrm{CH}_{4}$ system of the models (Gaubert et al. 2017).

The time series of the global CO burden obtained from the CAMS interim reanalysis (Fig. 2.61) shows an average reduction from $410 \mathrm{Tg}$ in 2003 to $358 \mathrm{Tg}$ in 2017. This is equivalent to a linear trend of $-3.3 \mathrm{Tg} \mathrm{yr}^{-1}$ $\left(-0.8 \% \mathrm{yr}^{-1}\right)$ over the whole period. However, the global burden decreased more rapidly during 2008 than

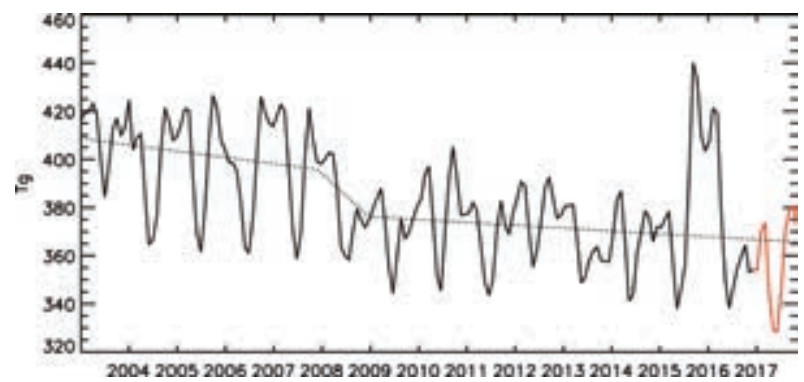

FIG. 2.6I. Time series (black solid line for 2003-16, red for 2017) of monthly global $\mathrm{CO}$ burdens ( $\mathrm{Tg}$ ) from the CAMS interim reanalysis and a piecewise linear trend (dotted line) for the periods 2003-07, 2008, and 2009-I7. in the periods before and after this year, and further investigation is necessary to determine the cause. The large increase in the global $\mathrm{CO}$ burden in the second half of 2015 and the first half of 2016 was caused by intensive biomass burning in Indonesia in October 2015 (Huijnen et al. 2016). A piecewise calculation of linear trends for the periods 2003-07, 2008, and 2009-17 revealed trends of $-3.0 \mathrm{Tg} \mathrm{yr}^{-1}\left(-0.7 \% \mathrm{yr}^{-1}\right)$, $-20.0 \mathrm{Tg} \mathrm{yr}^{-1}\left(-5.0 \% \mathrm{yr}^{-1}\right)$, and $-1.1 \mathrm{Tg} \mathrm{yr}^{-1}(-0.3 \%$ $\left.\mathrm{yr}^{-1}\right)$, respectively. This means that a much stronger reduction of the global CO burden occurred in 2008 and in the period 2003-07 than after 2009.

2017 was the year with the lowest CO burden in the CAMS interim reanalysis. The annual mean of 2017 was below the median of the annual means for the 2003-17 period almost everywhere, mostly in the range from 0 to $-10 \%$ (Fig. 2.62). This indicates that no regional biomass burning event in $2017 \mathrm{had}$ a global impact on annual regional burdens.

In general the relative decrease was more pronounced in the mid- and high latitudes of the Northern Hemisphere than in the Southern Hemisphere. The largest annual minima occurred over Indonesia, where the annual CO burden was up to $20 \%$ lower than the median values after the extreme fires of
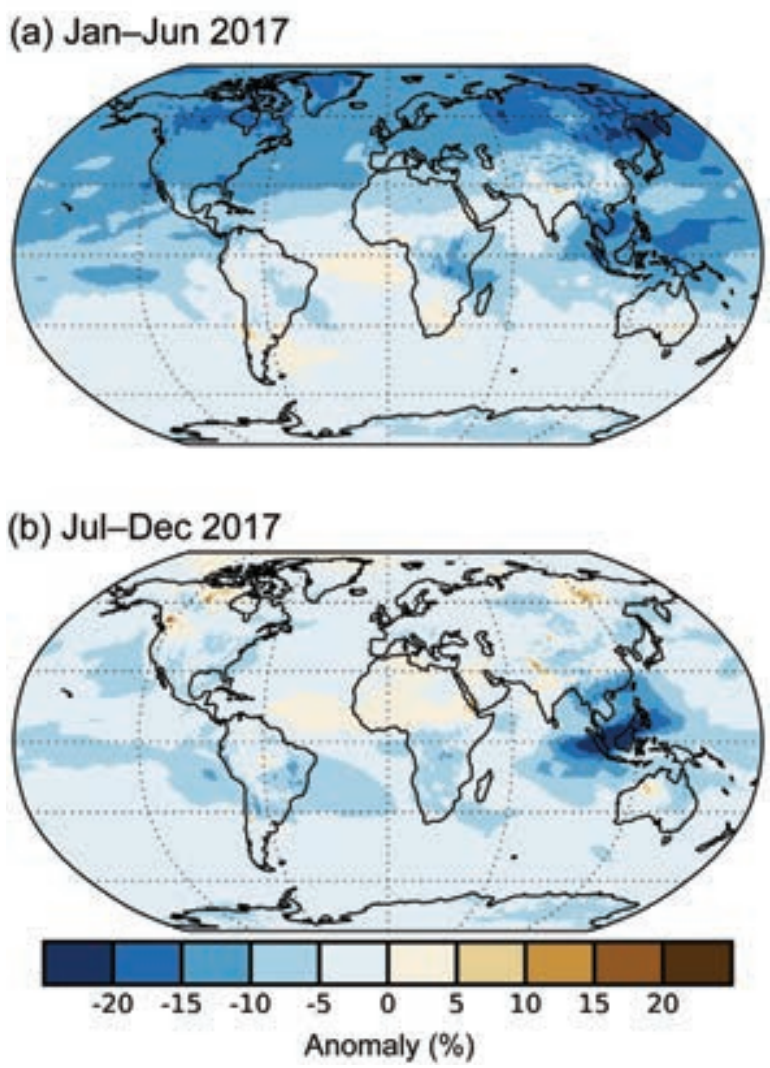

Fig. 2.62. Total column CO anomalies (\%) for (a) JanJun 2017 and (b) Jul-Dec 2017 with respect to 2003-17 median from the CAMS interim reanalysis. 
2015. Also, fire activity in Central Africa was overall lower than in previous years. The lower $\mathrm{CO}$ in the first half of 2017 (Fig. 2.62a) was the primary reason for the negative annual anomalies. Intensive fires in Chile in January had only a localized effect on the CO burden in the first quarter of 2017.

The more active fires occurred predominantly in the second half of 2017 (Fig. 2.62b; Section 2h3). Large boreal fires in Canada (British Columbia, The Northwest Territories) and Central Siberia increased the $\mathrm{CO}$ burden in the high northern latitudes in the third quarter of 2017 by over $10 \%$ and locally up to $20 \%$ with respect to the decadal median (not shown). In September and the final quarter of 2017, increased activity during the fire seasons in Brazil and in eastern and central Africa caused the $\mathrm{CO}$ burden to rise up to $10 \%$ over the long-term seasonal mean in the affected regions and in the adjacent outflow regions over the central Atlantic.

\section{h. Land surface properties}

I) Land surface albedo dynamics-B. Pinty and N. Gobron

The land surface albedo represents the fraction of solar radiation scattered backward by land surfaces. In the presence of vegetation, surface albedo results from complex nonlinear radiation transfer processes determining the amount of radiation that is scattered by the vegetation and its background, transmitted through the vegetation layer, or absorbed by the vegetation layer and its background (Pinty 2012).

The geographical distributions of normalized anomalies in visible and near-infrared surface albedo for 2017 calculated for a 2003-17 base period [for which two MODIS sensors are available (Schaaf et al. 2002)] are shown in Plate 2.1ac, ad, respectively. Note that MODIS collection 6 albedo products are used here. Mid- and high latitude regions of the Northern Hemisphere are characterized by both positive (blue) and negative (brown) anomalies mainly as a consequence of interannual variations in snow cover (see Section 2c1), amount, and duration in winter and spring seasons.

The positive anomalies especially in the visible range over the U.S. Northwest and High Plains, southwest and eastern Canada, Scandinavia, and northern Russia are probably associated with aboveaverage snow cover and extent in spring with the occurrence of snow storms in some of these regions. Below-average snow cover extent across most of Europe, Turkey, Iran, southern Russia, and in parts of the U.S. Northern Plains and Rockies extending into the southern Canadian Prairies may be responsible for the negative anomalies reaching (or locally exceeding) $-30 \%$ in the visible and about $-10 \%$ in the near-infrared domain. The fast decline of the snow cover extent and duration as early as February (Section 2c2) may be due to unusually warm and relatively dry conditions over western Europe from early spring to June (https://climate.copernicus.eu/resources /data-analysis/average-surface-air-temperature -analysis/monthly-maps/)

A few snow-free regions show positive anomalies, especially in the visible domain, in northeast Brazil, from southeast Somalia and Kenya to northern Tanzania, Anatolia, and Nigeria, and in some localized spots around the Caspian Sea. These are generally associated with less favorable vegetation growing conditions compared to previous years (Section 2h2), although contamination of the albedo retrievals by clouds and aerosol load (especially in intertropical regions) may also induce some artifacts. Many snow-free regions exhibit noticeable and spatially consistent negative anomalies, in particular in the visible domain, and especially pronounced (up to 30\%) across eastern China, Southeast Asia, parts of India, much of southern and central Africa, parts of Australia, and much of Argentina. Consistent warmer-than-usual conditions persisted over most of these regions, sometimes associated with below-normal precipitation. A significant fraction of these variations is attributable to vegetation dynamics (Pinty et al. 2011a,b) over these regions where vegetation is sensitive to stress from ambient conditions and, in particular, water availability. Although weaker in the near-infrared domain, these negative anomalies are, in some instances, spectrally correlated, for example, over India and northeast Brazil. The amplitude of these positive and negative anomalies often changes with seasons. The situation is thus globally analogous to 2016, with above-average temperatures and a few extreme precipitation and drought events (e.g., across southern Europe) occurring across the world.

Analysis of the zonally averaged albedo anomalies in the visible (Fig. 2.63a) and near-infrared (Fig. 2.63b) broadband spectral domains indicates large interannual variations related to the occurrence of snow events in winter and spring at mid- and high northern latitudes as well as to vegetation conditions during the spring and summer periods. Negative anomalies are noticeable between $20^{\circ}$ and $45^{\circ} \mathrm{S}$ in 2017, featuring a deviation from average conditions mainly over Latin America, southern Africa, and Australia. Consistent negative anomalies in the visible domain are discernible across midlatitude regions in the Northern Hemisphere in 2017. 

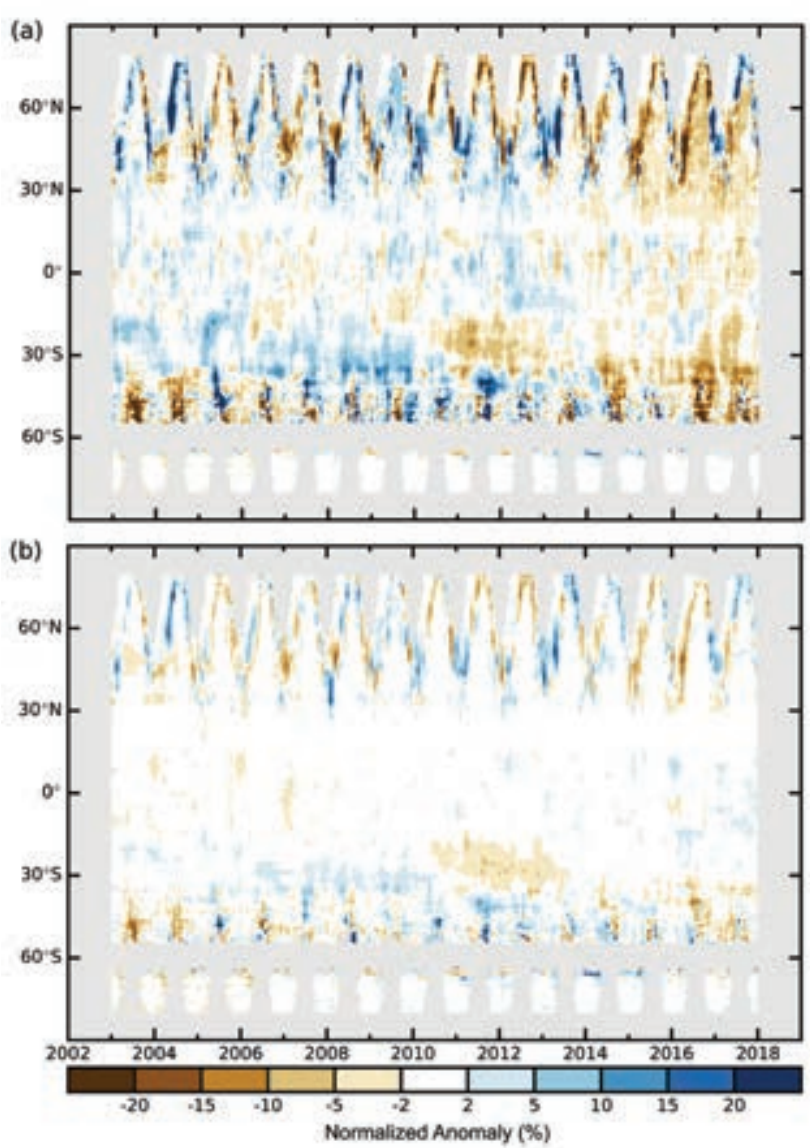

FIG. 2.63. Zonally averaged albedo anomalies (\%; 2003-I7 base period) in the (a) visible and (b) nearinfrared broadband.

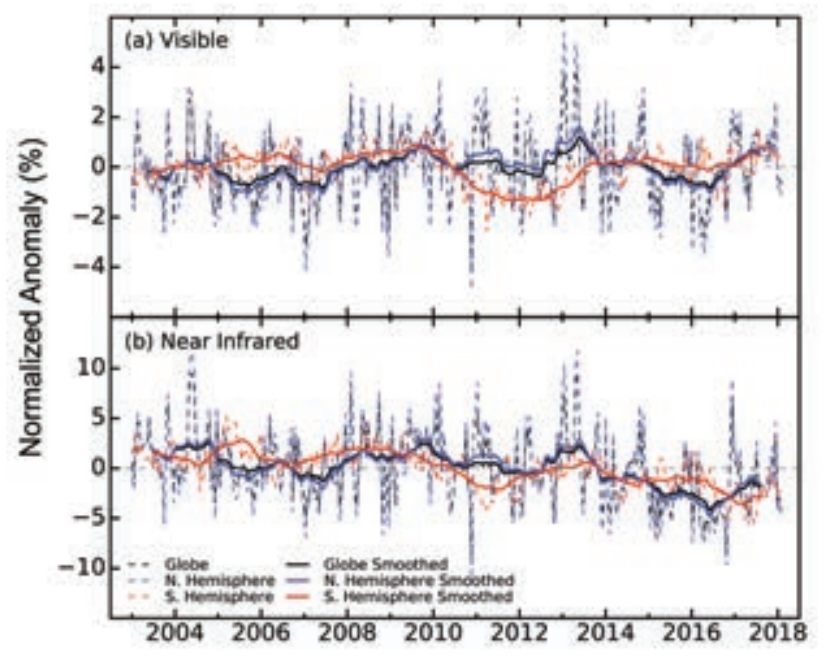

FIG. 2.64. Global albedo anomalies (\%; 2003-I7 base period) in the (a) visible and (b) near-infrared broadband.

The amplitude of the globally and hemispherically averaged normalized anomalies resulting from a 12 -month running mean (Fig. 2.64) is within $\pm 5 \%$ (3\%) in the visible (near-infrared) domain. The anomalies are not estimated over Antarctica ow- ing to missing data. The year 2017 is characterized by a trend of the negative anomalies toward average conditions in the visible domain that is driven by the dominant contributions from the Northern Hemisphere regions. These figures also indicate spectrally correlated multiannual variations during 2003-17 with positively biased values in the visible at the beginning of this period.

\section{2) Terrestrial Vegetation activity-N. Gobron}

Terrestrial photosynthesis activity is inferred from space on the basis of one land essential climate variable (ECV) as defined by GCOS (2016): the fraction of absorbed photosynthetically active radiation (FAPAR). The 2017 analysis has merged 20 years of global FAPAR products retrieved from three passive optical sensors at medium spatial scale from 1998 to 2017 (Gobron et. al. 2010; Pinty et al. 2011a,b; Gobron and Robustelli 2013). Note that Collection 6 MODIS albedo (Section 2h1) was used in this year's report.

Plate 2.1ae displays the annual FAPAR anomalies at global scale for which brown (blue) color indicates negative (positive) values. Large geographical variations in vegetated surface conditions were present at the global scale. Negative and positive anomalies indicate less and more photosynthetic activities in green live vegetation.

The most negative anomaly events (not favorable for vegetation) took place over eastern Brazil, Somalia, and Kenya followed by the weakest negative ones in the western part of Russia. The major positive events occurred in the eastern part of China and Botswana and the weakest appeared over Coahuila (northern state of Mexico), India, and the Rio Negro region in Argentina.

The strong negative FAPAR anomalies over eastern Brazil were mainly due to severe droughts occurring at the start of the year that impacted the annual results. Over Somalia the persistent precipitation deficit extended both the geographical area and its negative level in terrestrial activities, meaning that vegetation photosynthesis declined rapidly at the beginning of the year. The vegetation activities in northwestern Russia declined during spring, possibly due to heavy snow events. Terrestrial photosynthesis activities continued to proliferate over the eastern part of China as stronger positive FAPAR anomaly events were observed as both higher temperatures and heavy precipitation were favorable to vegetation growth in 2017. FAPAR anomalies were also positive in 2017 over Botswana as in 2014, meaning that after droughts in 2015-16, sufficient precipitation helped vegetation recover. 


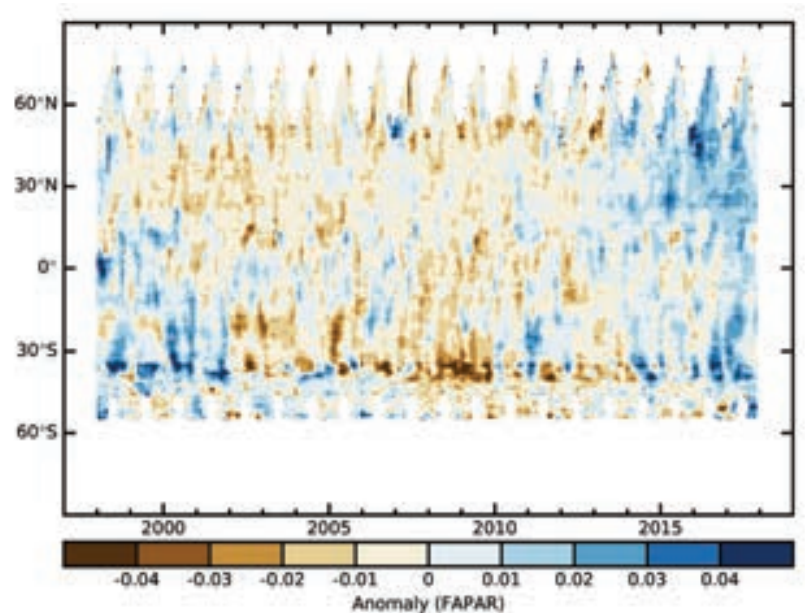

FIG. 2.65. Zonally averaged FAPAR anomalies from 1998-20I7.

Positive anomalies occurred also over smaller regions such as over Coahuila (Mexico) and the Rio Negro region in Argentina; these have occurred each year since 2015 and may correspond to high spring temperatures. Australia was found to have positive FAPAR anomalies over several local regions.

Figure 2.65 displays the longitudinal average anomalies from 1998 to 2017. Strong seasonal interhemispheric variations are depicted with mainly positive anomalies after 2014 over $20^{\circ} \mathrm{N}$ and negative anomalies from $2002-10$ in the south latitudes.

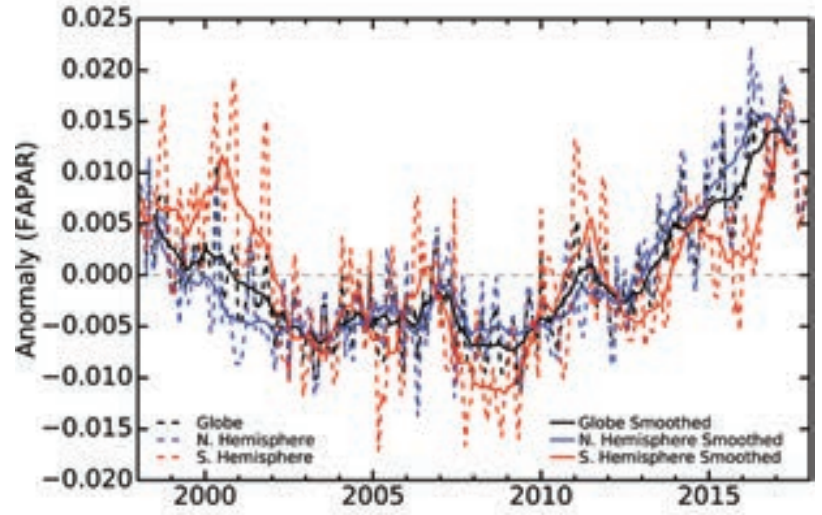

FIG. 2.66. Global, NH, and SH FAPAR anomalies from 1998-2017, plotted in black, blue, and red, respectively. Dotted lines denote each monthly period; solid lines indicate the 6-mo running averaged mean. (Sources: SeaWiFS, MERIS, and MODIS sensors.)

Spring 2017 revealed negative anomalies at higher latitudes $\left(\sim 60^{\circ} \mathrm{N}\right)$, as was the case in summer around $20^{\circ} \mathrm{N}$ and $20^{\circ} \mathrm{S}$. Around $30^{\circ} \mathrm{S}$ recurrent and strong positive anomalies have occurred since 2014, contradicting the strong negative anomalies from 2005-10.

As shown in Fig. 2.66, there was a strong reversal between anomalies over the Northern and Southern Hemispheres during the past 20 years. The FAPAR anomaly over the Southern Hemisphere in 2017 returned to a positive level (last evident in 2000) while it has continued to increase over the Northern Hemisphere since the 2008-10 minimum.

\section{SIDEBAR 2.3: PHENOLOGY OF TERRESTRIAL AND FRESHWATER}

PRIMARY PRODUCERS - D. L. HEMMING, R. ABERNETHY, C. ARMITAGE, K. BOLMGREN, R. MYNENI, T. PARK, A. D. RICHARDSON, T. RUTISHÄUSER, T. H. SPARKS, AND S. J. THACKERAY.

Phenology is the study of recurring events in nature and their relationships with climate. The word derives from the Greek phaíno "appear" and logos "reason”, emphasizing the focus on observing events and understanding why they occur (Demarée and Rutishauser 2009). Phenological recording has a history that dates back many centuries (Linnaeus 1753; Aono and Kazui 2008). More recently, advances in monitoring technologies have enabled automated and remotely sensed observations, complemented by increasing citizen science participation in monitoring efforts. Phenological information can also be derived from widespread environmental monitoring stations around the globe.

Phenological records clearly demonstrate the biological effects of year-to-year variability in climate, as well as longer-term trends associated with environmental change.
Shifts in the growing season, for example, are more tangible and more readily conveyed to the general public than seemingly small increases in mean annual temperature. Phenological monitoring thus plays an important role in understanding how our planet is changing.

Here, we describe just a fraction of the phenological information currently available, highlighting northern hemisphere records of phenology of primary producers across a range of spatial and temporal scales.

\section{Ground-based observations}

\section{Long-term phenology monitoring network,}

Germany: Deutscher Wetterdienst (DWD) maintains a dense national phenological observation network and database (www.dwd.de/phaenologie/). Plant phenological 
CONT. SIDEBAR 2.3: PHENOLOGY OF TERRESTRIAL AND FRESHWATER PRIMARY PRODUCERS-D. L. HEMMING, R. ABERNETHY, C. ARMITAGE, K. BOLMGREN, R. MYNENI, T. PARK, A. D. RICHARDSON, T. RUTISHÄUSER, T. H. SPARKS, AND S. J. THACKERAY.

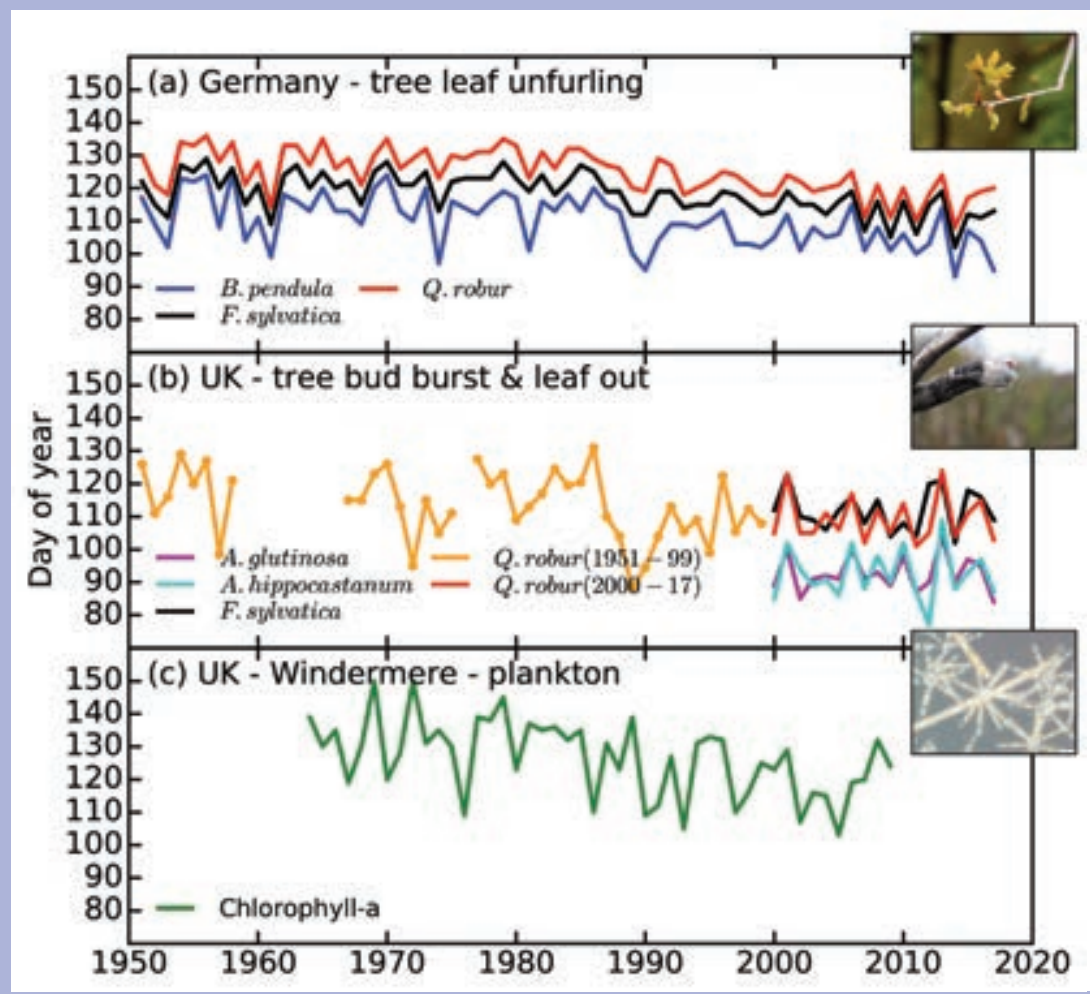

FIG.SB2.5. Time series of phenological changes in primary producers from records in Germany and UK, showing timing (by ordinal date) of (a) leaf unfolding of tree species in Germany from DWD national network: Pedunculate oak - Quercus robur L, (b) budburst of 4 common tree species in U.K. from Nature's Calendar: Alder - Alnus glutinosa L. Gaertn; horse chestnut - Aesculus hippocastinum L.; pedunculate oak; and beech - Fagus sylvatica L, and (c) long-term phenological changes in spring phytoplankton growth, indicated by the seasonal timing of maximum spring chlorophyll- $a$ concentrations. Original chlorophyll data collected from the north basin of Windermere by the Centre for Ecology \& Hydrology and the Freshwater Biological Association, U.K.

records dating to 1951 , some available since 1925, are openly accessible via the online archive (Kaspar et al. 2014). Currently, about 1100 observers contribute to the database, recording phenological events in cover crops, wild plants, and fruit trees. The data have many applications, including advice on current growing season for agricultural activities, pollen forecasts, and environmental change research. Figure SB2.5a highlights the record of leaf unfolding of pedunculate oak (Quercus robur L.), which has advanced by about 10 days over the last 50 years. This species is referred to as an "indicator species", and, due to its strong dependence on spring temperature, leaf unfolding is used to mark the beginning of "full spring".

Nature's Calendar, UK: Nature's Calendar is a coordinated national "citizen science" network of phe- nological observations, supported by the Woodland Trust (www . woodland trust.org.uk /visiting-woods/natures-calendar/). Currently, over 4000 members of the public contribute regular observations, and the database includes over 2.7 million records, dating from 1695. Early observations of "Indicators of Spring" were made from 1736 to 1797 by Robert Marsham in Norfolk and continued by his descendants until 1958 (Sparks and Lines 2008). In 1875 , a national network was launched by the (Royal) Meteorological Society, which ran until 1948, recording flowering, appearance of bird and insect species, and publishing unusual events and their climate relationships (Clark 1936). In 1998, the Centre for Ecology and Hydrology resurrected this network, and in 2000 , was joined by the Woodland Trust to promote phenology to a wider audience (Sparks et al. 1998; Sparks and Smithers 2002). Figure SB2.3b highlights the timing of budburst for four tree species in this record. As with other plant species, budburst is significantly related to spring average temperature (Online Fig. S2.21), with a $1^{\circ} \mathrm{C}$ rise in March or April temperature associated with earlier budburst of 3.5 to 4.8 days, depending on species and region (Abernethy et al. 2017).

Windermere, UK: Seasonal activity of primary producers is monitored in marine and freshwater environments. For example, at Windermere-England's largest lake-fortnightly measurements of chlorophyll-a concentrations, a proxy for primary producer biomass, have been recorded since the 1960s. These data show a long-term shift toward earlier spring algal blooms (Fig. 2.3c), which is correlated with both increasing spring water temperatures and changes in nutrient availability (Thackeray et al. 20I3). Hence, large-scale climatic drivers act alongside more localized lake-specific influences to bring about phenological changes in this system. 


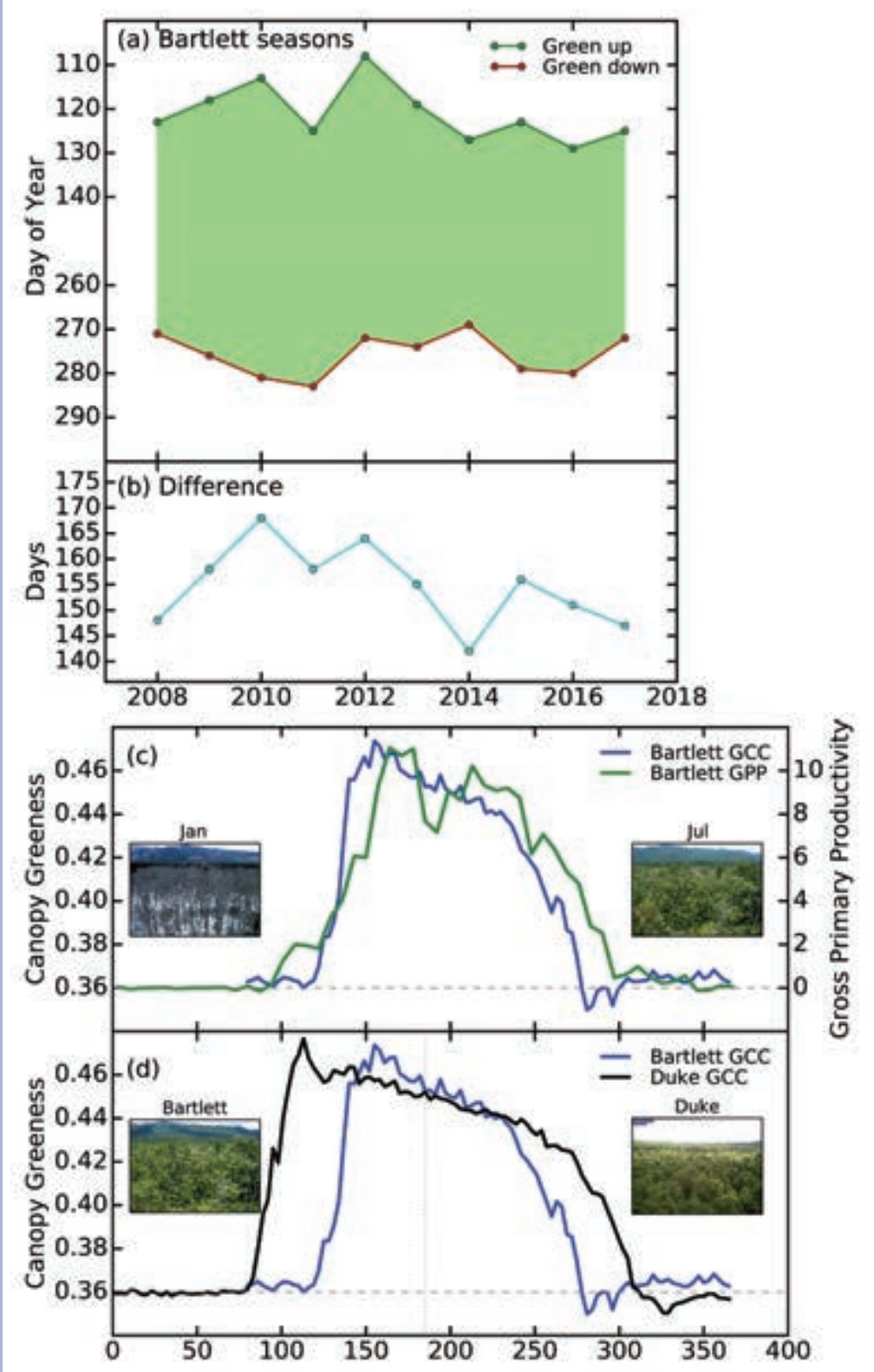

FIG. SB2.6. Phenocam records of canopy greenness (green chromatic coordinate, GCC) and GPP from two deciduous forest sites in the U.S.: Bartlett Experimental Forest, NH, and Duke Forest, NC, showing: (a) Time series of day of year of "Greenup", "Greendown" and (b) number of days of "Green canopy duration" at Bartlett, (c) comparison of seasonality of GCC and GPP (estimated from flux measurements) at Bartlett during 2017, and (d) seasonality in GCC between Bartlett (mean annual temperature $=6.6^{\circ} \mathrm{C}$ ) and a warmer site, Duke (mean annual temperature $=15^{\circ} \mathrm{C}$ ) during 2017 . Photos show both sites in Jul 2017.
Pan European Phenology (PEP) project: The PEP project promotes and facilitates phenological research, education and environmental monitoring across Europe. It maintains the Pan European Phenology (PEP) database (www.pep725.eu), which provides unrestricted data access for science and education. This currently includes 12 million records, with contributions since 1868 from 32 European partners for 46 growing stages and 265 plant species and cultivars (Templ et al. 2018).

\section{Remote sensing}

Remote sensing provides some of the clearest records of regional, hemispheric, and global phenological changes by linking radiance measurements to photosynthetic indicators of terrestrial and marine primary producers (Park et al. 2016; Sapiano et al. 2012).

Near-surface remote sensing: Digital camera networks observe "the rhythm of the seasons", from the tropics to the tundra. PhenoCam (http://phenocam.sr.unh.edu) is a collaborative network of over 400 cameras, most at research sites in the United States. Measures of canopy greenness (Richardson et al. 2018a) derived from camera imagery can be used to track vegetation activity and identify the start and end of season. At one temperate deciduous forest (Richardson et al. 2007), the 2017 growing season was markedly shorter than the decadal average because of late onset and early senescence (Fig. SB2.6a). At the same site, the seasonal cycle of canopy greenness follows that of gross primary productivity (GPP) estimated from eddy covariance measurements of $\mathrm{CO}_{2}$ fluxes, confirming the role of phenology in regulating ecosystem carbon fixation (Richardson et al. 2010; Fig. SB2.6c). The difference between this cooler forest and a warmer forest (Fig. SB2.6d) illustrates the role of climate in controlling phenology. These data can therefore help improve understanding of relationships between phenology, ecosystem processes, and environmental driv- 
CONT. SIDEBAR 2.3: PHENOLOGY OF TERRESTRIAL AND FRESHWATER PRIMARY PRODUCERS-D. L. HEMMING, R. ABERNETHY, C. ARMITAGE, K. BOLMGREN, R. MYNENI, T. PARK, A. D. RICHARDSON, T. RUTISHÄUSER, T. H. SPARKS, AND S. J. THACKERAY.

ers. Furthermore, phenocam data are valuable for ground truthing satellite observations, as they are continuous in time and require minimal correction or screening for atmospheric effects Richardson et al. 2018b).

Satellite remote sensing: Satellite-derived phenology indices provide useful regional to global-scale monitoring for phenology studies (Zhang et al. 2003). Figure SB2.7 highlights Northern Hemisphere land surface phenology indices during 2000-17, derived from radiance observations from the MODIS sensor. It shows a widespread and continued earlier startof-season ( - I.5 days) and later end-of-season $(+1.3$ days) over this period (Park et al. 2016). In 2017, the start-of-season reveals a dramatic spatial contrast between North America and Eurasia. Northeastern Europe and western Russia showed a striking delay (+6.0 days) associated with an anomalous spring cold spell $\left(-2.4^{\circ} \mathrm{C}\right)$, whereas North America showed a widespread earlier start-of-season ( -5.1 days), due to warmer than average spring temperatures $\left(+0.5^{\circ} \mathrm{C}\right)$. The end-of-season across Eurasia was generally later than average ( +2.3 days), but earlier ( -3.6 days) over southern European temperate zones.

Many phenological events provide clear indicators of the influence of climate on our environment and natural resources. Current observations apply diverse techniques for 2000-I7.

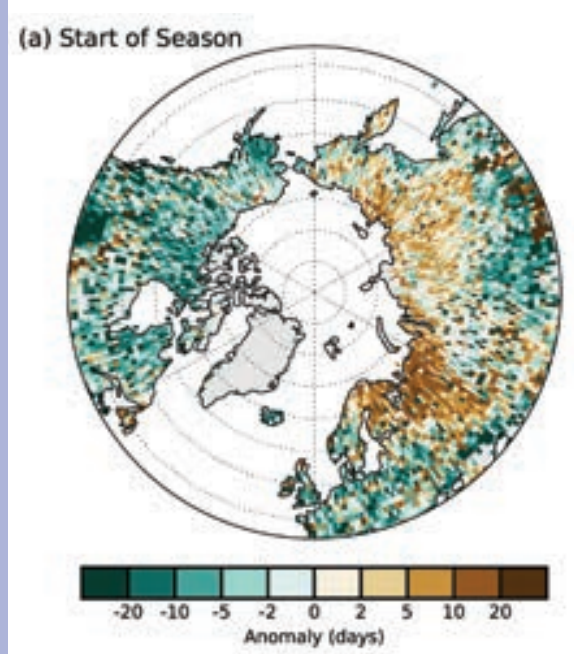

(b) End of Season
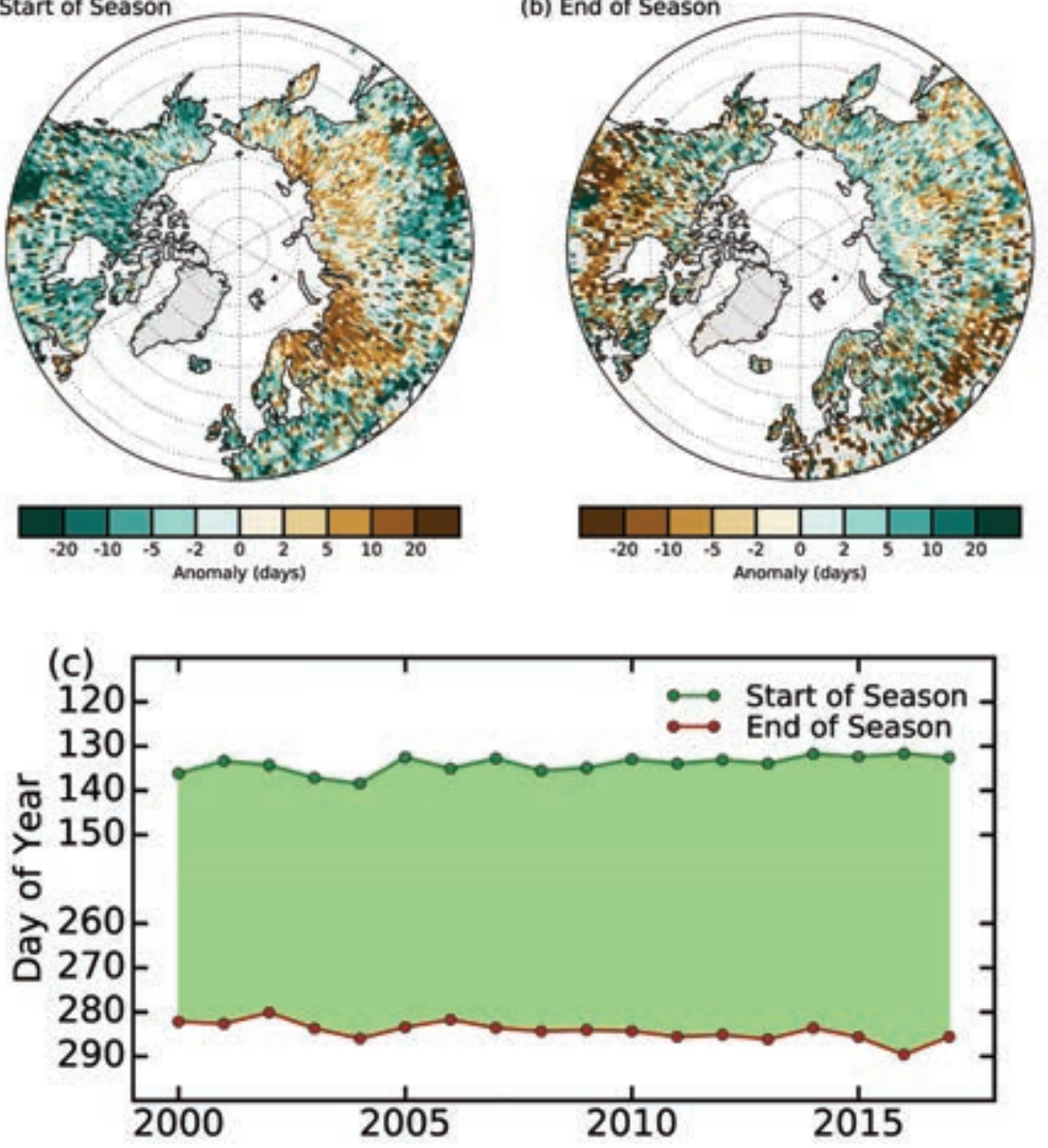

FIG. SB2.7. MODIS-derived NH $\left(>45^{\circ} \mathrm{N}\right)$ land surface phenology, showing 2017 anomaly (days), relative to 2000-17 average, for (a) start-of-season, (b) end-ofseason, and (c) hemispheric average day of year of the start and end of season

to monitor phenological changes across wide spatial scales-from global biomes to microscopic organisms. Furthermore, phenology records exist that span multiple decades, even centuries, and these provide valuable archives of long-term environmental change. There is now a fundamental need for integrated analyses of multiple phenology and climate observations to help understand, and prepare for, the future impacts of climate variability and change on environmental systems, and routine monitoring to capture important changes as they occur. 
3) BıomAsS BURNING-J. W. Kaiser and G. R. van der Werf

The first vegetation fires, a.k.a. biomass burning, occurred shortly after the first land plants evolved. They have since become an integral part of many natural and cultivated ecosystems and are largely modulated by climate. Conversely, fires are a major source of climate-forcing atmospheric aerosols and trace gases. Today, human activity also exerts a strong influence on fire occurrence through land cover change by providing a large number of ignitions and by active fire suppression. Fires have substantial interannual variability, which mostly originates from the boreal region and the tropical deforestation zone. The extent of vegetation fires is traditionally quantified in terms of burned area, which is around 500 million hectares worldwide each year (Giglio et al. 2013; Randerson et al. 2012).

Burned area and the thermal radiation released by active fires have been quantified on a global scale with satellites since the late 1990s. The Global Fire Emissions Database (GFED) estimates emissions since 1997 based on burned area and fuel consumption (van der Werf et al. 2017). Satellite-observed fire radiative power is used by the Global Fire Assimilation System (GFAS) to estimate emissions since 2003 and in near-real time (Kaiser et al. 2012). GFAS is calibrated to partly match GFED. Here, an updated GFAS version (Kaiser et al. 2017) is used; it resolves the subdaily variability and uses MODIS Collection 6 products (Giglio et al. 2016) for the entire time period. The absolute values have been homogenized with earlier GFAS and GFED versions by removing a global average bias of $-14 \%$. The combined use of GFAS (2003-17) and GFED (1997-2016) indicates that fire emissions were around $2 \mathrm{Pg} \mathrm{C} \mathrm{yr}^{-1}$ (Fig. 2.67).

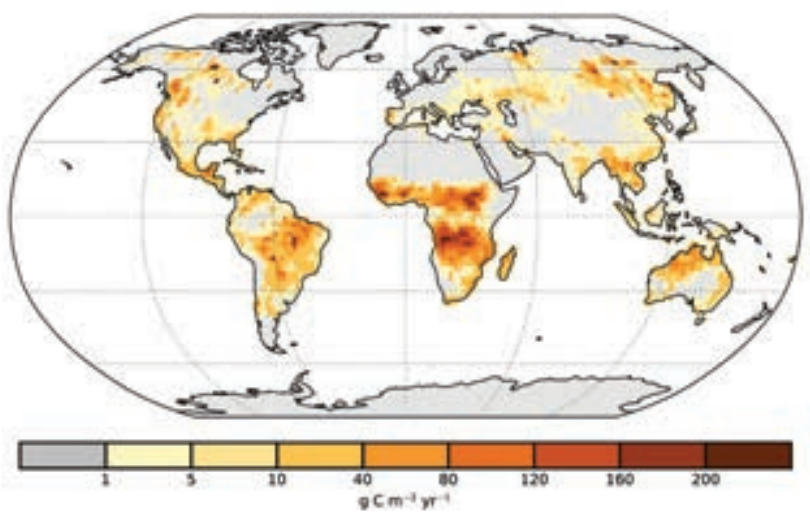

FIG. 2.67. Global map of fire activity in 2017 in terms of carbon consumption ( $\left.\mathrm{g} \mathrm{C} \mathrm{m}^{-2} \mathrm{yr}^{-1}\right)$. (GFASvl.4)
In 2017, low fire activity led to the lowest global pyrogenic emissions since at least 2003 and probably since the start of GFED in 1997. Emissions were 15\% below the 2003-16 average (Table 2.7; Plate 2.1af). The year with lowest emissions prior to 2017 was 2013; those two years were relatively close in magnitude, especially when considering the substantial uncertainty associated with these estimates. The negative regional anomalies were particularly pronounced in tropical Asia, where high rainfall rates, among other things, led to emissions that were only about $5 \%$ of those reached during the El Niño episode in 2015. Strong negative anomalies also occurred in Indochina and in southern Siberia.

Stronger-than-usual fire activity occurred in North America and Europe, with anomalies of $+36 \%$ and $+22 \%$, respectively. The time series for North America (Fig. 2.68) shows that four out of the last five fire seasons were exceptionally intense. European fire emissions were dominated by an unusually long burning season in Portugal and in Galicia in northwestern Spain.

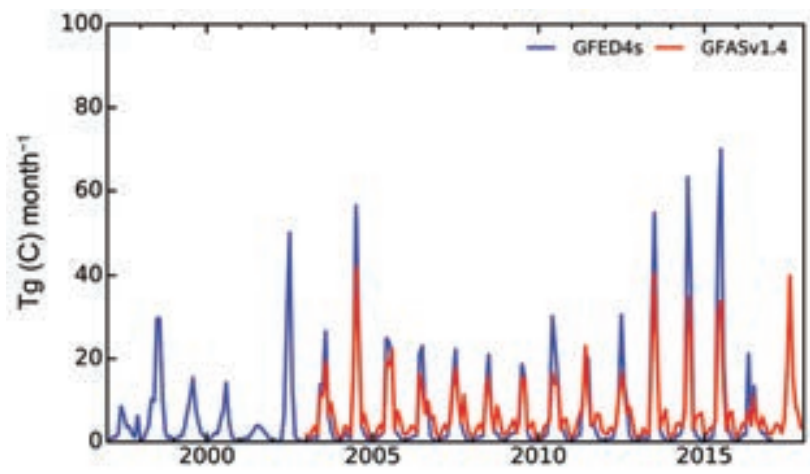

FIG. 2.68. Time series of fire activity during 1997-2017 in terms of carbon consumption ( $\mathrm{Tg}$ month $^{-1}$ ) for North America. 
Table 2.7. Annual continental-scale biomass burning budgets in terms of carbon emission

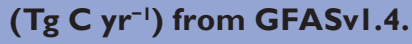

\begin{tabular}{|c|c|c|c|c|}
\hline & & $2003-16$ & \multicolumn{2}{|c|}{2017} \\
\hline Quantity in $\mathrm{Tg} C \mathrm{yr}^{-1}$ & & $\begin{array}{c}\text { Mean Value } \\
\text { (Range) }\end{array}$ & Value & $\begin{array}{c}\text { Anomaly } \\
(\%)\end{array}$ \\
\hline Global & & $\begin{array}{c}1973 \\
(1690-2272)\end{array}$ & 1683 & $-290(-15 \%)$ \\
\hline North America & $\begin{array}{c}30^{\circ}-75^{\circ} \mathrm{N} \\
170^{\circ}-30^{\circ} \mathrm{W}\end{array}$ & $\begin{array}{c}84 \\
(56-I 12)\end{array}$ & 113 & $+30(+36 \%)$ \\
\hline Central America & $\begin{array}{c}0^{\circ}-30^{\circ} \mathrm{N} \\
170^{\circ}-30^{\circ} \mathrm{W}\end{array}$ & $\begin{array}{c}85 \\
(65-122)\end{array}$ & 72 & $-12(-14 \%)$ \\
\hline SH America & $\begin{array}{c}0^{\circ}-60^{\circ} \mathrm{S} \\
170^{\circ}-30^{\circ} \mathrm{W}\end{array}$ & $\begin{array}{c}320 \\
(190-473)\end{array}$ & 285 & $-35(-11 \%)$ \\
\hline Europe and Mediterranean & $\begin{array}{c}30^{\circ}-75^{\circ} \mathrm{N} \\
30^{\circ} \mathrm{W}-60^{\circ} \mathrm{E}\end{array}$ & $\begin{array}{c}33 \\
(19-62)\end{array}$ & 41 & $+7(+22 \%)$ \\
\hline NH Africa & $\begin{array}{c}0^{\circ}-30^{\circ} \mathrm{N} \\
30^{\circ} \mathrm{W}-60^{\circ} \mathrm{E}\end{array}$ & $\begin{array}{c}404 \\
(353-453)\end{array}$ & 357 & $-47(-12 \%)$ \\
\hline SH Africa & $\begin{array}{c}0^{\circ}-35^{\circ} \mathrm{S} \\
30^{\circ} \mathrm{W}-60^{\circ} \mathrm{E}\end{array}$ & $\begin{array}{c}485 \\
(444-528)\end{array}$ & 457 & $-28(-6 \%)$ \\
\hline Northern Asia & $\begin{array}{c}30^{\circ}-75^{\circ} \mathrm{N} \\
60^{\circ} \mathrm{E}-170^{\circ} \mathrm{W}\end{array}$ & $\begin{array}{c}186 \\
(99-418)\end{array}$ & 139 & $-48(-26 \%)$ \\
\hline Southeast Asia & $\begin{array}{c}10^{\circ}-30^{\circ} \mathrm{N} \\
60^{\circ} \mathrm{E}-190^{\circ} \mathrm{E}\end{array}$ & $\begin{array}{c}122 \\
(101-150)\end{array}$ & 81 & $-4 I(-34 \%)$ \\
\hline Tropical Asia & $\begin{array}{l}10^{\circ} \mathrm{N}-10^{\circ} \mathrm{S} \\
60^{\circ}-170^{\circ} \mathrm{E}\end{array}$ & $\begin{array}{c}143 \\
(38-425)\end{array}$ & 23 & $-120(-84 \%)$ \\
\hline Australia & $\begin{array}{c}10^{\circ}-50^{\circ} \mathrm{S} \\
60^{\circ} \mathrm{E}-170^{\circ} \mathrm{W}\end{array}$ & $\begin{array}{c}112 \\
(47-219)\end{array}$ & 115 & $+3(+3 \%)$ \\
\hline
\end{tabular}




\section{GLOBAL OCEANS}

a. Overview-G. C. Johnson

The global oceans transport, store, and exchange with the atmosphere vast amounts of heat, water, carbon dioxide, and other constituents vital to climate. This chapter describes, with a focus on 2017 conditions, seasonal to interannual variability of sea surface temperature; ocean heat content; salinity; air-sea fluxes of heat, freshwater, and momentum; sea level; surface currents; the Atlantic meridional circulation; phytoplankton; and ocean inorganic carbon cycling. It also puts 2017 conditions in a longer-term context.

Neutral to weak La Niña conditions that held for much of 2016 recurred in 2017, so sea surface temperatures (SSTs), ocean heat content (OHC), and sea level continued to rise in the western tropical Pacific and fall in the eastern tropical Pacific. A zonal band of westward surface current anomaly north of and along the equator played a role in the redistribution of warm near-surface waters from east to west. Sea surface salinity (SSS) freshened in the west and became saltier in the east. In the eastern equatorial Pacific chlorophyll- $a$ and $\mathrm{CO}_{2}$ flux from ocean to atmosphere were both elevated. All these tropical Pacific variations were consistent with 2016 to 2017 tendencies in regional wind stress and freshwater flux. There was a prominent band of anomalously high SST, OHC, and sea level as well as low SSS across much of the North Pacific between about $5^{\circ}$ and $30^{\circ} \mathrm{N}$ in 2017. Effects included nuisance flooding in Hawaii.

Southeast of Greenland ${ }^{1}$ SST, OHC, SSS, and sea level all remained below average in 2017, as they have since 2014. Along the east coast of North America SSTs, OHC, and sea level were all anomalously high in 2017, as they have generally been since at least 2009 . In climate models this North Atlantic SST pattern is associated with a reduction in the Atlantic meridional overturning circulation.

In the Indian Ocean SST and SSS anomalies were both high in the west and below average in different parts of the east in 2017. Around the equator OHC fell in the west owing to a shoaling thermocline there. Anomalous eastward surface velocities around the equator in 2017 were likely associated with that shoaling thermocline and the high SSS anomalies there, with the latter owing partly to anomalous eastward advection of salty water. Sea level fell from 2016 to 2017 north of $\sim 10^{\circ} \mathrm{S}$ in the Indian Ocean and rose south of that latitude.

\footnotetext{
${ }^{1}$ Arctic and Nordic Seas SST and sea ice are discussed in Chapter 5.
}

Over the long term, as atmospheric $\mathrm{CO}_{2}$ concentrations have risen, the ocean has taken up more carbon and acidified. Also on the long term, the 1993-2017 trends in OHC and sea level reflect statistically significant warming and sea level rise, especially in the Southern Hemisphere. Near the Antarctic Circumpolar Current a warming trend is evident in the Indian Ocean and western Pacific sectors of the Southern Ocean, but a cooling trend is discernible in the central Pacific sector. ${ }^{2}$

While the global average SST for 2017 was slightly below the 2016 value, the long-term trend is upward. The last three years have been the three highest annual values observed and have been associated with widespread coral bleaching. Both global average sea level and the global integrals of $0-700 \mathrm{~m}$ and 0-2000 $\mathrm{m}$ OHC reached record highs in 2017. Global integrals of $\mathrm{OHC}$ and global averages of sea level exhibit substantially less variable upward trends than that for SST. In haiku form:

$$
\begin{gathered}
\text { Surface fluctuates, } \\
\text { ocean warms more steadily, } \\
\text { seas continue rise. }
\end{gathered}
$$

\section{b. Sea surface temperatures-B. Huang, J. Kennedy, Y. Xue, and H.-M. Zhang}

Global sea surface temperature (SST) and its changes are assessed mostly based on the Extended Reconstruction Sea-Surface Temperature version 5 (ERSSTv5; Huang et al. 2017) unless otherwise specified. The global integral of annually averaged SST anomaly (SSTA; relative to a 1981-2010 climatology) decreased slightly from a historic high of $0.40( \pm 0.06){ }^{\circ} \mathrm{C}$ in 2016 to $0.34( \pm 0.06){ }^{\circ} \mathrm{C}$ in 2017 , although these values are not statistically distinguishable. The $95 \%$ confidence levels are estimated from a 1000-member ensemble of ERSSTv4 (Huang et al. 2016a).

Annually averaged SSTA in 2017 exceeded $+0.5^{\circ} \mathrm{C}$ in the western tropical Pacific, subtropical North Pacific, western subtropical South Pacific, western tropical Indian Ocean, and eastern North Atlantic (Fig. 3.1a). SSTA values exceeded $+1^{\circ} \mathrm{C}$ adjacent to the Arctic (in the Nordic, Barents, Chukchi, and Bering Seas; see Section 5e for a full description of Arctic SSTs), the northwestern North Atlantic southeast of Cape Cod, around the Korean Peninsula, the central southern Indian Ocean, and South Atlantic near the coasts of Argentina and Uruguay. In contrast, SSTA was slightly colder than average in the Southern

\footnotetext{
${ }^{2}$ Southern Ocean conditions and sea ice are discussed in Chapter 6.
} 


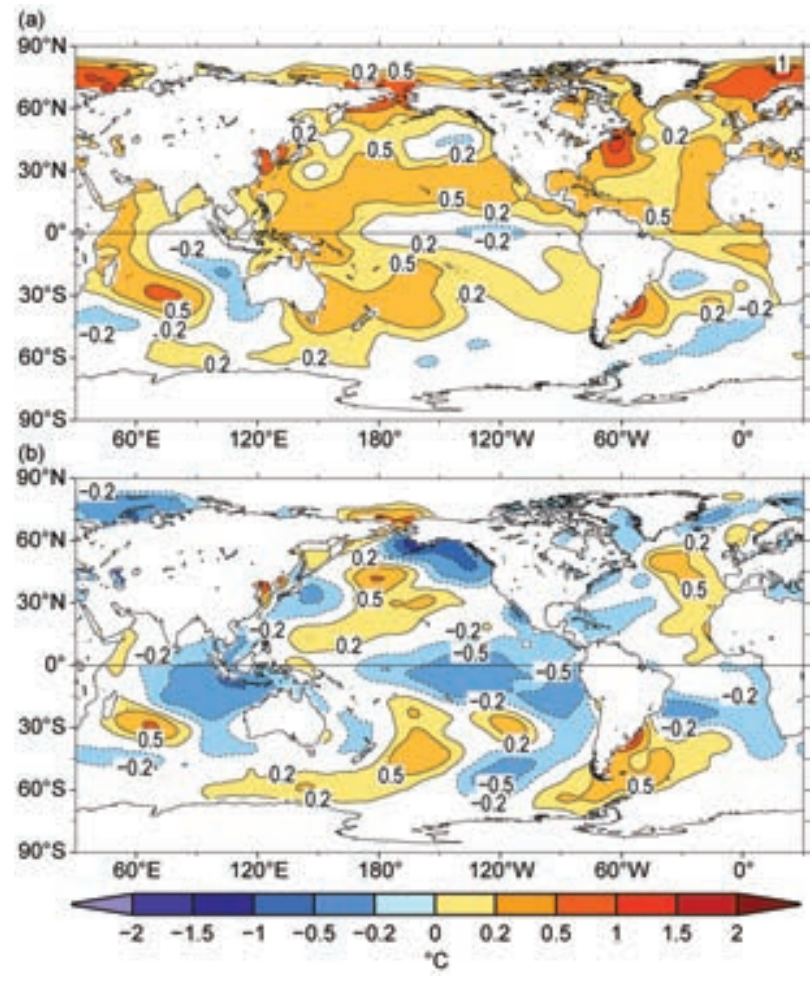

Fig. 3.I. (a) Annually averaged ERSSTv5 SSTA $\left({ }^{\circ} \mathrm{C}\right)$ for 2017 relative to a $198 \mathrm{I}-2010$ climatology and (b) difference of annually averaged SSTAs between 2017 and 2016 (2017-2016).

Hemisphere oceans, the central-eastern tropical Pacific, eastern North Pacific near $45^{\circ} \mathrm{N}$, southeastern tropical Indian Ocean, and Southern Ocean south of $40^{\circ} \mathrm{S}$ in $60^{\circ} \mathrm{W}-60^{\circ} \mathrm{E}$ and $180^{\circ}-120^{\circ} \mathrm{W}$.

In comparison with 2016, SST in 2017 was mostly cooler in the tropical/subtropical oceans while warming in the midlatitudes (Fig. 3.1b). Specifically, the $2017 \mathrm{SST}$ was $0.2^{\circ}-0.5^{\circ} \mathrm{C}$ higher than 2016 in the central-tosouthwestern North Pacific, central South Pacific, eastern North Atlantic, Chukchi Sea of the Arctic, western Indian Ocean, and Southern Ocean south of $40^{\circ} \mathrm{S}$. In contrast, SST was $0.5^{\circ}-1.0^{\circ} \mathrm{C}$ lower in the high-latitude North Pacific and $0.2^{\circ}-0.5^{\circ} \mathrm{C}$ lower in the central-eastern tropical Pacific, western subtropical North Pacific, western North Atlantic, Arctic in the Atlantic sector, subtropical South Atlantic, and eastern Indian Ocean.

Cooling SST in the tropical Pacific and Indian Oceans in 2017 in comparison with 2016 (Figs. 3.1a,b) resulted from a shift from the strong 2015/16 El Niño to a weak La Niña in late 2016, with neutral conditions during most of 2017 and La Niña recurring later in 2017 (Fig. 3.2d; Ashok et al. 2003; Huang et al. 2016b; Xue and Kumar 2017; L'Heureux et al. 2017). In the eastern tropical Pacific near Peru, negative SSTAs reached $-1 \sigma$ (standard deviation derived from ERSSTv5 over 1981-2010) below average in SON 2017 (Fig. 3.2d), while SSTAs were extraordinarily high $(+2 \sigma)$ in DJF and MAM (Figs. 3.2a,b). In the western tropical Pacific, high SSTAs $(+1$ to $+2 \sigma)$ persisted throughout the year (Fig. 3.2), extending to the subtropical North Pacific over $10^{\circ}-30^{\circ} \mathrm{N}$. In the Indian Ocean, the SSTA pattern of warm $(+1$ to $+2 \sigma)$ in the west and cold $(-1 \sigma)$ in the east was sustained throughout all of 2017. This SST pattern resulted in a positive phase of the Indian Ocean dipole (IOD; Saji et al. 1999) in 2017 (Fig. 3.2), while the IOD was negative in 2016. The positive IOD in 2017 did not correspond with the development of the La Niña (Meyers et al. 2007).

In the North Pacific near $45^{\circ} \mathrm{N}$, SST was $1 \sigma$ colder than average in DJF (Fig. 3.2a), cold SSTA weakened in MAM and JJA (Figs. 3.2b,c), and SSTA reached $+1 \sigma$ near the dateline in SON (Fig. 3.2d). The pattern of $+1 \sigma$ SSTA near the dateline and weaker $(<+1 \sigma)$ SSTA east of the dateline resulted in a negative phase of the Pacific decadal oscillation (PDO; Mantua and Hare 2002) in JJA and SON (Figs. 3.2c,d), consistent with the development of La Niña conditions in the tropical

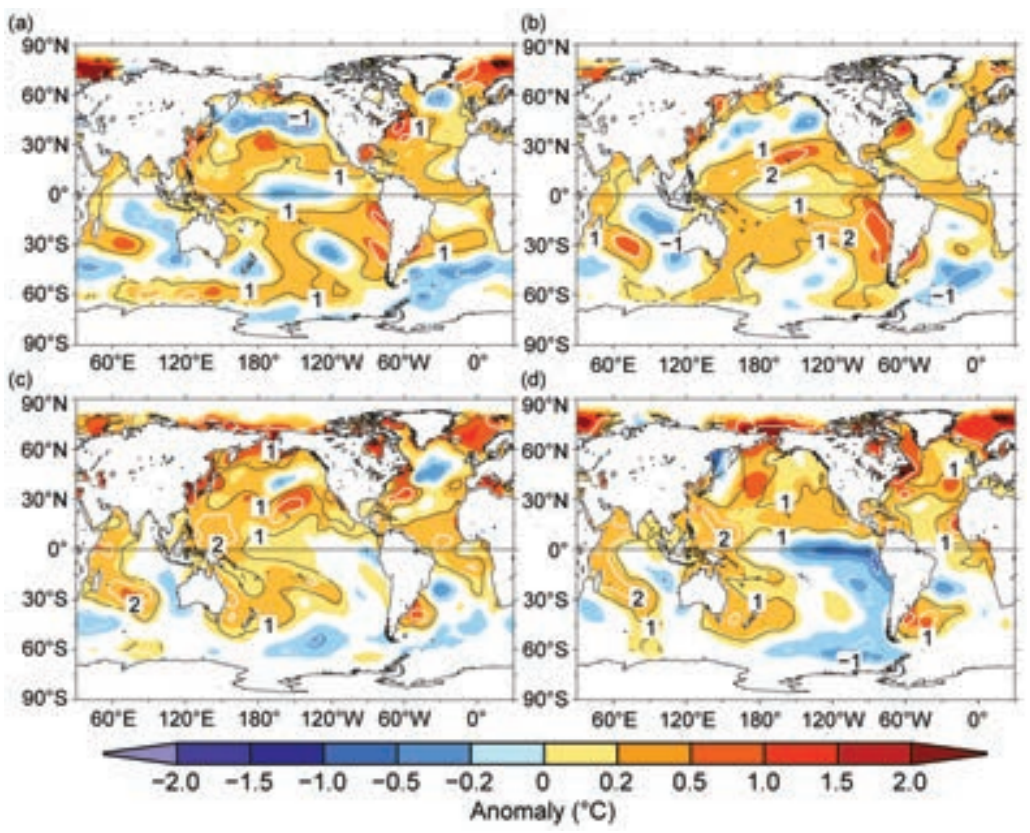

Fig. 3.2. Seasonally averaged SSTAs of ERSSTv5 ( ${ }^{\circ} \mathrm{C}$; colors) for (a) Dec 2016-Feb 2017, (b) Mar-May 2017, (c) Jun-Aug 2017, and (d) Sep-Nov 2017. Normalized seasonal mean SSTA based on seasonal mean std. dev. for 198I-2010 are indicated by contours of - I (dashed white), + I (solid black), and +2 (solid white). 
Pacific. In the subtropical South Pacific, the SSTA was +1 to $+2 \sigma$ in DJF and MAM (Figs. 3.2a,b). The warm SSTA sustained in the west in JJA and SON, but diminished in the east (Figs. 3.2c,d) due to the development of the La Niña.

SSTAs were +1 to $+2 \sigma$ in most of the Atlantic (Fig. 3.2). SSTA in the Chukchi Sea was near neutral in DJF and MAM, and warmed to $+2 \sigma$ in JJA and SON. SSTA south of Greenland was below normal in DJF, MAM, and JJA (de Jong and de Steur 2016) but above normal in SON. SSTA from $20^{\circ}-30^{\circ} \mathrm{S}$ was near neutral in DJF and MAM, and cooled in JJA and SON. Cold anomalies in the high-latitude Southern Ocean weakened from $-1 \sigma$ in DJF and MAM to near neutral in JJA and SON in the Atlantic sector (Figs. 3.2a,b), but strengthened from near neutral in DJF and MAM to $-1 \sigma$ in JJA and SON in the Pacific sector (Figs. 3.2c,d).

The long-term warming trend of globally averaged SST remained strong (Figs. 3.3a,b), although SST cooled slightly from 2016 to 2017. The linear trend of globally and annually averaged SSTA (for ERSSTv5) is $0.17( \pm 0.08){ }^{\circ} \mathrm{C}$ decade $^{-1}$ from 2000 to 2017 and $0.10( \pm 0.01){ }^{\circ} \mathrm{C}$ decade $^{-1}$ from 1950 to 2017 (Table 3.1), with 95\% confidence levels. The higher trend for 2000 to 2017 indicates a potential accelerating warming in the modern period. The 2000 to 2017 warming trend for ERSSTv5 is consistent with those reported by Karl et al. (2015) and Hausfather et al. (2017) using ERSSTv4 data.

Warming of the global oceans from 2000 to 2017 (Table 3.1) was fast in the North Pacific (Fig. 3.3d) and tropical Indian Ocean (Fig. 3.3e) compared with the other regions (Fig. 3.3). Warming of the global oceans from 1950 to 2017 (Table 3.1) was nominally faster in the tropical Indian Ocean, tropical Atlantic, and North Atlantic; and slower in the tropical Pacific, Southern Ocean, and North Pacific.

In addition to the long-term SST trend, short-term SST variations can be seen in all global ocean basins, although their am- plitude is typically smaller in the Southern Ocean. The variations associated with the Atlantic multidecadal oscillation (AMO; Wanner et al. 2001) in the North Atlantic can clearly be identified with warm periods during the 1930s-50s (not shown) and 1990s-2010s and a cold period during the 1960s-80s (Fig. 3.3f). From 2016 to 2017, annually averaged SSTA decreased in the Indian Ocean from $0.58^{\circ} \mathrm{C}$ to $0.35^{\circ} \mathrm{C}$ and decreased in the Pacific from $0.45^{\circ} \mathrm{C}$ to $0.39^{\circ} \mathrm{C}$. However, annually averaged SSTA increased slightly in the Atlantic from $0.42^{\circ} \mathrm{C}$ to $0.43^{\circ} \mathrm{C}$ due to strong warming in the eastern North Atlantic, and it increased slightly from $-0.11^{\circ} \mathrm{C}$ to $-0.08^{\circ} \mathrm{C}$ in the Southern Ocean south of $45^{\circ} \mathrm{S}$.

SSTs in ERSSTv5 are compared with those in the high-resolution satellite-based daily optimum
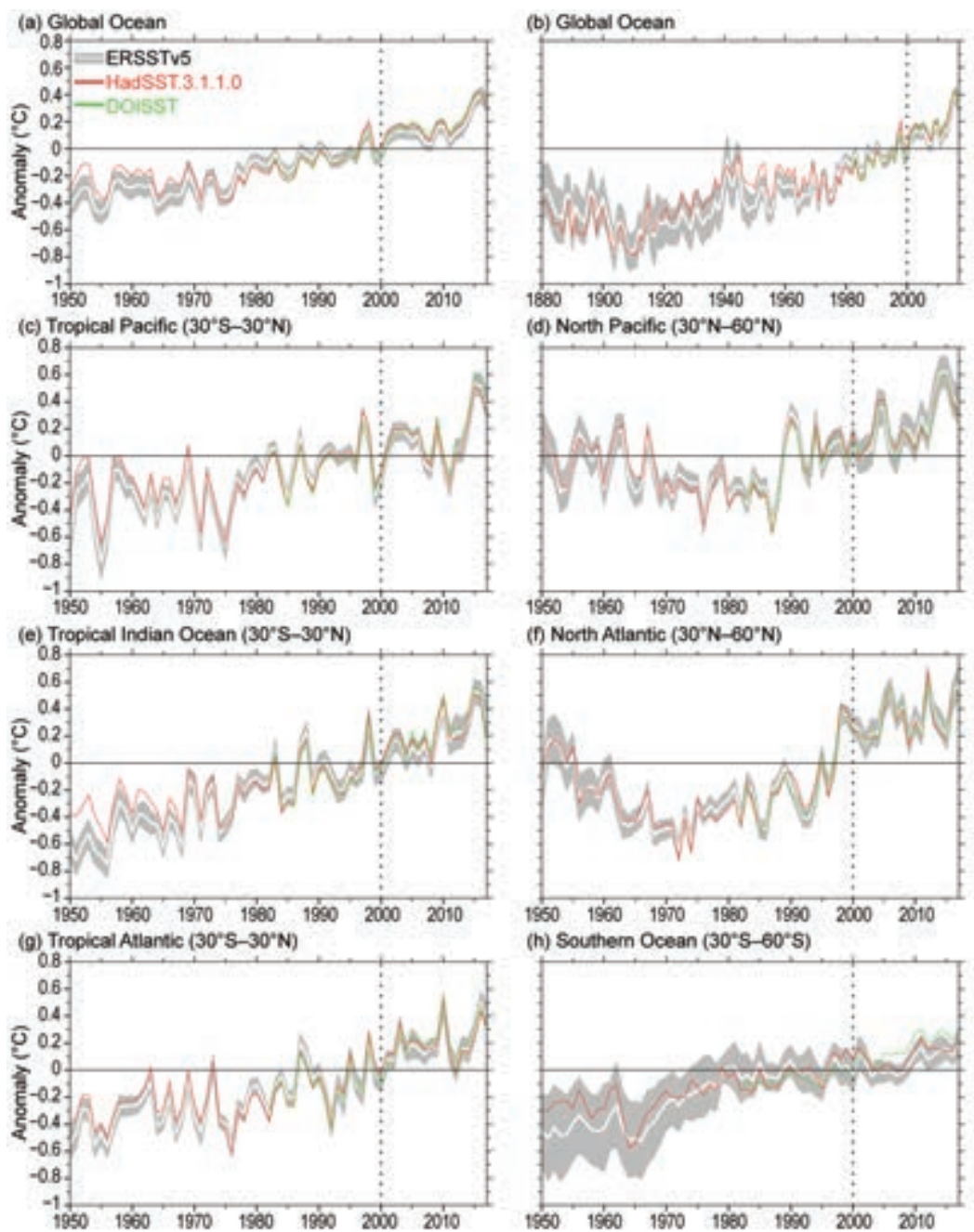
(d) North Pacific $\left(30^{\prime} \mathrm{N}-60^{\circ} \mathrm{N}\right)$

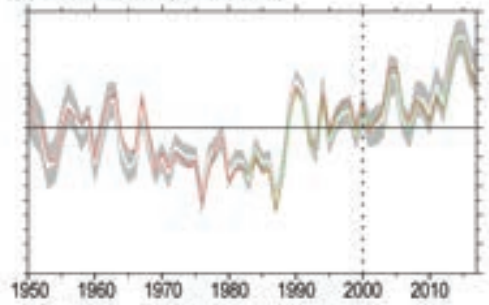
(f) North Atlantic (30 $\left.\mathrm{N}-60^{\circ} \mathrm{N}\right)$

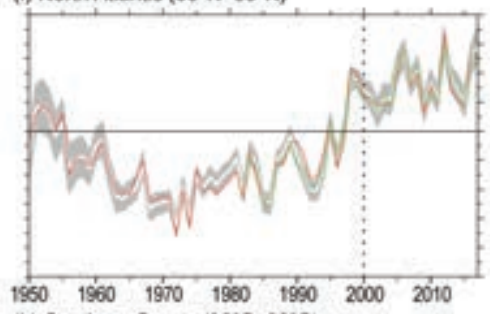
(h) Southem Ocean $\left(30^{\circ} \mathrm{s}-60^{\circ} \mathrm{s}\right)$

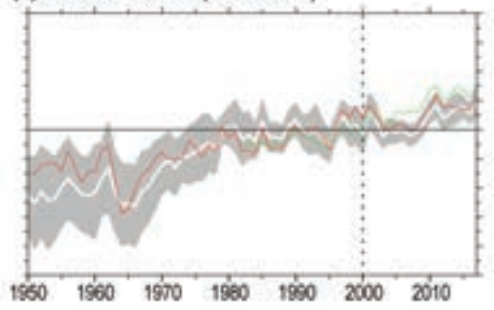

FIg. 3.3. Annually averaged SSTAs from ERSSTv5 (white line) with $2 \sigma$ std. dev. (gray shading) of ERSSTv4, DOISST (green line), and HadSST.3.I.I.0 (red line) from 1950 to 2017 except for (b). (a) global ocean, (b) global ocean from 1880 to 2017, (c) tropical Pacific, (d) North Pacific, (e) tropical Indian, (f) North Atlantic, (g) tropical Atlantic, and (h) Southern Oceans. The year 2000 is indicated by a vertical black dotted line. 
TABLE 3.I. Linear trends $\left({ }^{\circ} \mathrm{C}\right.$ decade ${ }^{-1}$ ) of annually averaged SSTAs from ERSSTV 5 except for global averaged SSTAs from HadSST3 and DOISST. The uncertainty at $95 \%$ confidence level are estimated by accounting for $A R(I)$ effect on the degrees of freedom of annually averaged SST series.

\begin{tabular}{|c|c|c|}
\hline & 2000-20I7 & I950-2017 \\
\hline HadSST.3.I.I.0, Global & $0.137 \pm 0.078$ & $0.083 \pm 0.017$ \\
\hline DOISST, Global & $0.180 \pm 0.067$ & $\mathrm{~N} / \mathrm{A}$ \\
\hline ERSSTv5, Global & $0.166 \pm 0.082$ & $0.099 \pm 0.011$ \\
\hline Tropical Pacific $\left(30^{\circ} \mathrm{S}-30^{\circ} \mathrm{N}\right)$ & $0.188 \pm 0.192$ & $0.100 \pm 0.024$ \\
\hline North Pacific $\left(30^{\circ}-60^{\circ} \mathrm{N}\right)$ & $0.268 \pm 0.135$ & $0.062 \pm 0.031$ \\
\hline Tropical Indian Ocean $\left(30^{\circ} \mathrm{S}-30^{\circ} \mathrm{N}\right)$ & $0.240 \pm 0.084$ & $0.143 \pm 0.016$ \\
\hline North Atlantic $\left(30^{\circ}-60^{\circ} \mathrm{N}\right)$ & $0.118 \pm 0.100$ & $0.102 \pm 0.042$ \\
\hline Tropical Atlantic $\left(30^{\circ} \mathrm{S}-30^{\circ} \mathrm{N}\right)$ & $0.158 \pm 0.104$ & $0.109 \pm 0.018$ \\
\hline Southern Ocean $\left(30^{\circ}-60^{\circ} \mathrm{S}\right)$ & $0.103 \pm 0.055$ & $0.097 \pm 0.014$ \\
\hline
\end{tabular}

slightly higher in DOISST from 2000 to 2017. These SSTA differences are mostly attributed to differences in ship-based observation bias corrections in different products (Huang et al. 2015; Kent et al. 2017).

c. Ocean heat contentG. C. Johnson, J. M. Lyman, T. Boyer, L. Cheng, C. M. Domingues, J. Gilson, M. Ishii, R. Killick, D. Monselesan, S. G. Purkey, and S. E. Wijffels Storage and transport of heat in the ocean are central to aspects of climate such as ENSO (Johnson and Birnbaum 2017), tropical cyclones (Goni et al. 2009), sea level rise (Section 3f), variations in the global average surface warming rate (Xie et al. 2016), melting of ice sheet outlet glaciers around

interpolation SST (DOISST; Reynolds et al. 2007), and U.K. Met Office Hadley Centre SST version 3 (HadSST.3.1.1.0; Kennedy et al. 2011a,b), which uses a different algorithm from ERSSTv5 to correct ship SST observation bias. ERSSTv5 is a monthly SST product on a $2^{\circ} \times 2^{\circ}$ horizontal grid from 1854 to present based on in situ observations only (Huang et al. 2017). It builds upon ERSSTv4 (Huang et al. 2015) with more ship and buoy observations and the added ingestion of near-surface Argo observations. Biases in ship-based measurements are corrected using more accurate buoy observations. ERSSTv 5 provides a better representation of spatial and temporal variations in high-latitude oceans and ENSO variability in the tropical Pacific than ERSSTv4. DOISST is a daily $0.25^{\circ} \times 0.25^{\circ} \mathrm{SST}$ product for the modern satellite era from September 1981 to present using both in situ and satellite observations. HadSST.3.1.1.0 is a monthly $5^{\circ} \times 5^{\circ}$ SST product from 1850 to present using in situ observations only. All datasets are averaged to monthly $2^{\circ} \times 2^{\circ}$ grids for comparison purposes.

Comparisons (Fig. 3.3) indicate that SSTA deviations of DOISST and HadSST.3.1.1.0 from ERSSTv5 are largely within $2 \sigma$ (gray shading in Fig. 3.3), as derived from a 1000 -member ensemble analysis of ERSSTv4 (Huang et al. 2016a) and centered on ERSSTv5 SSTA. However, SSTAs are slightly higher in the 1950s-70s and 1920s-30s in HadSST.3.1.1.0 than in ERSSTv5 (Fig. 3.3b). Additionally, SSTAs are slightly higher in the 2000s-10s in HadSST.3.1.1.0 and DOISST than in ERSSTv5, particularly in the Southern Ocean. Therefore, SST trends are slightly weaker in HadSST.3.1.1.0 for both 1950 to 2017 and 2000 to 2017 (Table 3.1). In contrast, SST trends are
Greenland (Castro de la Guardia et al. 2015) and Antarctica (Schmidtko et al. 2014), and coral bleaching (Sidebar 3.1). Ocean warming accounts for about 93\% of the total increase in Earth's energy storage from 1971 to 2010 (Rhein et al. 2013).

Maps of annual (Fig. 3.4) upper (0-700 m) ocean heat content anomaly (OHCA) relative to a 1993-2017 baseline mean are generated from a combination of in situ ocean temperature data and satellite altimetry data following Willis et al. (2004), but using Argo (Riser et al. 2016) data downloaded in January 2018. Near-global average seasonal temperature anomalies (Fig. 3.5) vs. pressure from Argo data (Roemmich and Gilson 2009, updated) since 2004 and in situ global estimates of OHCA (see Fig. 3.6) for three pressure layers from six different research groups (including those responsible for the 2000-6000-m estimate) are also discussed.

The 2017 minus 2016 tendency of $0-700-\mathrm{m}$ OHCA (Fig. 3.4b) shows increases in the western subtropical and tropical North Pacific, with strong bands extending east-southeastward from Papua New Guinea and east-northeastward from the Philippines. These bands are reminiscent of Rossby wave signatures, which propagate westward more quickly closer to the equator (Chelton and Schlax 1996). Decreases are observed in portions of the central South Pacific and eastern North Pacific, as well as in the eastern equatorial Pacific around the latitude of the ITCZ.

Throughout much of the Pacific, the 2017 upper OHCA is generally above the long-term average, with the most prominent below-average region in the central South Pacific (Fig. 3.4a). A prominent band of high $\mathrm{OHCA}$ from about $5^{\circ}$ to $30^{\circ} \mathrm{N}$ in 2017 
is associated with anomalously high sea level (see Fig. 3.16), with impacts that include nuisance flooding in Hawaii (Sidebar 3.2). The Bering Sea, the Sea of Okhotsk, and especially the Yellow Sea and the Sea of Japan all exhibited anomalously high OHCA values in 2017. The 2017 0-700-m OHCA anomalies (Fig. 3.4a) are slightly above the 1993-2017 average in the western tropical Pacific, and below that average in the eastern tropical Pacific on both sides of the
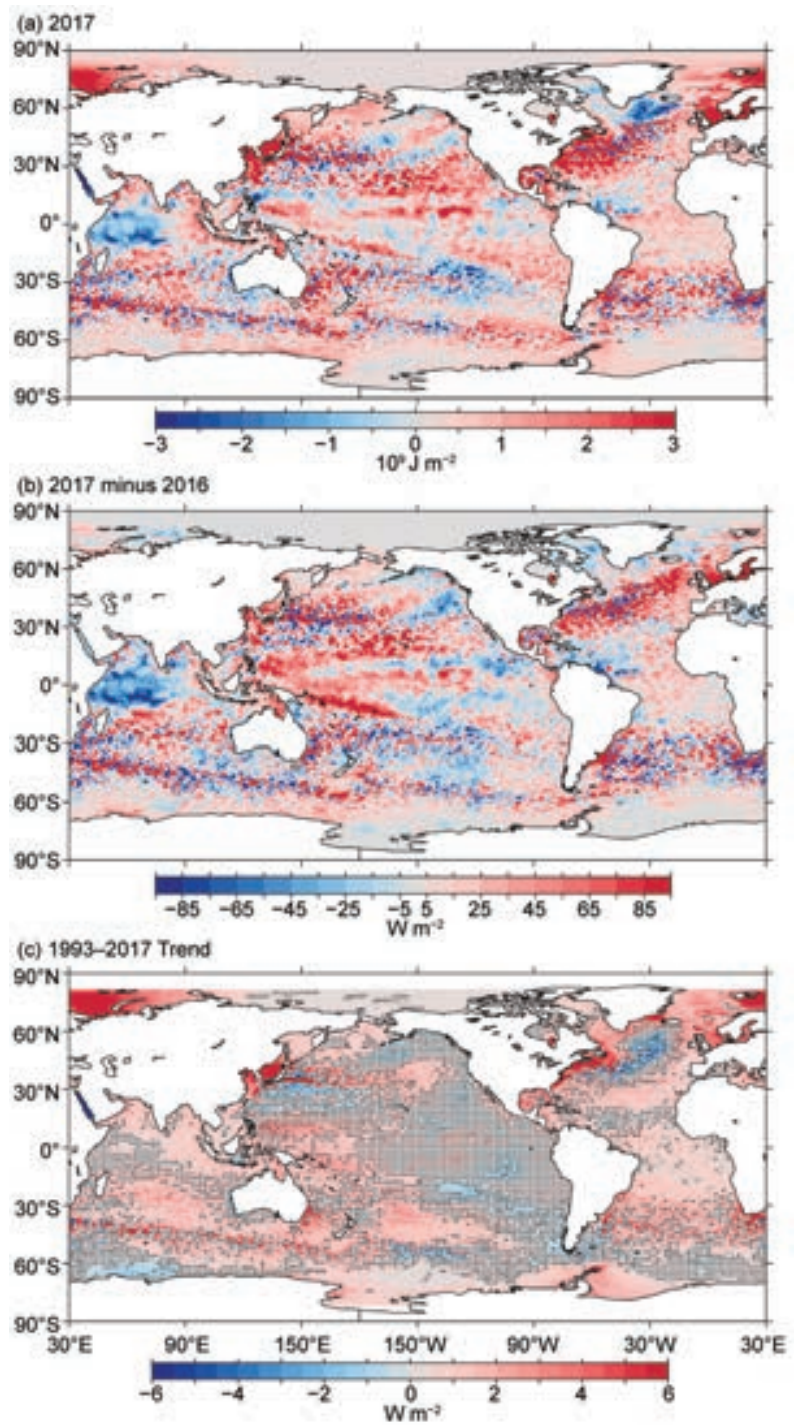

FIG. 3.4. (a) Combined satellite altimeter and in situ ocean temperature data estimate of upper $(0-700 \mathrm{~m})$ OHCA $\left(\times 10^{9} \mathrm{~J} \mathrm{~m}^{-2}\right)$ for 2017 analyzed following Willis et al. (2004), but using an Argo monthly climatology and displayed relative to the 1993-2017 baseline. (b) 2017 minus 2016 combined estimates of OHCA expressed as a local surface heat flux equivalent $\left(\mathrm{W} \mathrm{m}^{-2}\right)$. For (a) and (b) comparisons, note that $95 \mathrm{~W} \mathrm{~m}^{-2}$ applied over one year results in a $3 \times 10^{9} \mathrm{~J} \mathrm{~m}^{-2}$ change of OHCA. (c) Linear trend for 1993-2017 of the combined estimates of upper (0-700 $\mathrm{m})$ annual OHCA $\left(\mathrm{W} \mathrm{m}^{-2}\right)$. Areas with statistically insignificant trends are stippled. equator. This reverses a pattern that had held since 2014 (see previous State of the Climate reports) and is also reflected in sea level (see Fig. 3.16).

In the Indian Ocean, the 2017 minus 2016 tendency of 0-700-m OHCA (Fig. 3.4b) exhibited strong cooling in the western equatorial region. This cooling was caused by a shoaling of the thermocline, which had little expression in SST (see Fig. 3.1), but was reflected in a reduction in SSH (see Fig. 3.16b) and likely effected by anomalous eastward flow in 2017 around the equator (see Fig. 3.18a). Near-surface salinity also increased in the western Indian Ocean (see Figs. 3.7b and 3.10c) during 2017, so the SSH reductions may be larger than would be expected from the cooling alone. There was also some warming south of $10^{\circ} \mathrm{S}$ and in much of the eastern Indian Ocean along with a large tendency toward higher values in a zonal band around $40^{\circ} \mathrm{S}$ in the Indian sector of the Southern Ocean. Upper OHCA values for 2017 were above the 1993-2017 mean in much of the Indian Ocean (Fig. 3.4a), with the notable exception of the formation of a large patch of low values in the western equatorial region discussed above.

There was a 2017 minus 2016 tendency toward higher values of $0-700-\mathrm{m} \mathrm{OHCA} \mathrm{(Fig.} \mathrm{3.4b)} \mathrm{in} \mathrm{the}$ western subtropical and eastern subpolar North Atlantic, along with a slight increase throughout much of the tropics and a strong increase in a patch at about $35^{\circ} \mathrm{S}$ adjacent to South America. Weak decreases from 2016 to 2017 were apparent in the western tropical North Atlantic and in the subpolar region around Greenland. Much of the western North Atlantic from the Tropic of Capricorn to about $50^{\circ} \mathrm{N}$ had anomalously high upper OHCA values in 2017 (Fig. 3.4a), as did much of the Gulf of Mexico, the western Caribbean Sea, and the Greenland-IcelandNorwegian Seas. The warm conditions off the east coast of North America have generally been present since 2009 (see previous State of the Climate reports). The only large region in the entire Atlantic with 2017 values well below the 1993-2017 mean was south of Greenland, especially in the Irminger Sea; a pattern that has persisted since at least 2014.

Regions around all the subtropical western boundary current extensions: the Kuroshio and the East Australian Current in the Pacific, the Agulhas retroflection in the Indian Ocean, and the Gulf Stream and the Brazil Current in the Atlantic all displayed anomalously high upper OHCA in 2017 (Fig. 3.4a). A trend toward higher values is also statistically significant from 1993 to 2017 in all these boundary currents (Fig. 3.4c), consistent with previous analysis (Wu et al. 2012). 
Other large-scale statistically significant (Fig. 3.4c) regional patterns in the 1993-2017 local linear trends of upper OHCA reflect a warming trend in much of the Southern Hemisphere (Roemmich et al. 2015; Wijffels et al. 2016). In addition, there are significant positive trends in much of the tropical Atlantic and North Indian Oceans, as well as all of the marginal seas except the Red Sea. The strongest negative trends are found in the North Pacific south of the Kuroshio Extension and in the North Atlantic south

\section{SIDEBAR 3.I: UNPRECEDENTED THREE YEARS OF GLOBAL CORAL}

BLEACHING 20I4-I7-C. M. EAKIN, G. LIU, A. M. GOMEZ, J. L. DE LA COURI, S. F. HERON, W. J. SKIRVING, E. F. GEIGER, B. L. MARSH, K. V. TIRAK, AND A. E. STRONG

Continued ocean warming has taken a severe toll on tropical coral reefs worldwide as heat stress has caused repeated bleaching and disease outbreaks (Eakin et al. 2009). Bleaching occurs when stress to the coral-algal symbiosis causes corals to expel endosymbiotic algae and, if prolonged or particularly severe, can result in partial or complete coral mortality (Brown 1997). While many stressors can cause bleaching, "mass" coral bleaching (covering hundreds of kilometers or more) is primarily driven by prolonged anomalously warm ocean temperatures coupled with high subsurface light levels, exceeding corals' physiological tolerances. Heat stress causing mass coral bleaching can be monitored accurately by satellites (G. Liu et al. 2014, 20I7) and has increased in frequency and severity with a warming climate (Hughes et al. 2018).

Past mass bleaching events usually have been limited to El Niño years: the first in 1983 (Glynn 1990; Coffroth et al. 1990) was followed by the first recorded global event in 1998 and the second in 2010 (Heron et al. 2016b). The third global coral bleaching lasted three full years during 2014 to 2017 (NOAA 2017). This third global bleaching event was the longest, most widespread, and almost certainly most destructive on record. NOAA's Coral Reef Watch (CRW) defines global coral bleaching events as those with coral bleaching spanning hundreds of kilometers or more in all three ocean basins.

The third global bleaching event started in June 2014, when El Niño formation was expected but never fully materialized (Blunden and Arndt 20I5). CRW satellite monitoring first detected heat stress sufficient to cause coral bleaching (Alert Level I, defined in Fig. SB3.I) in Guam and the Commonwealth of the Northern Mariana Islands (CNMI; Heron et al. 2016a). An anomalously warm North Pacific Ocean brought severe heat stress to parts of the Northwestern Hawaiian Islands (Couch et al. 2017) and the Marshall Islands in the central Pacific (Fellenius 2014) and moderate stress to the main Hawaiian Islands (DAR 2014; Bahr et al. 2015). Teleconnected warming then brought heat stress to Florida (FRRP 20I5).

Despite El Niño formation being delayed until March (Blunden and Arndt 2016), 2015 followed the classic pattern

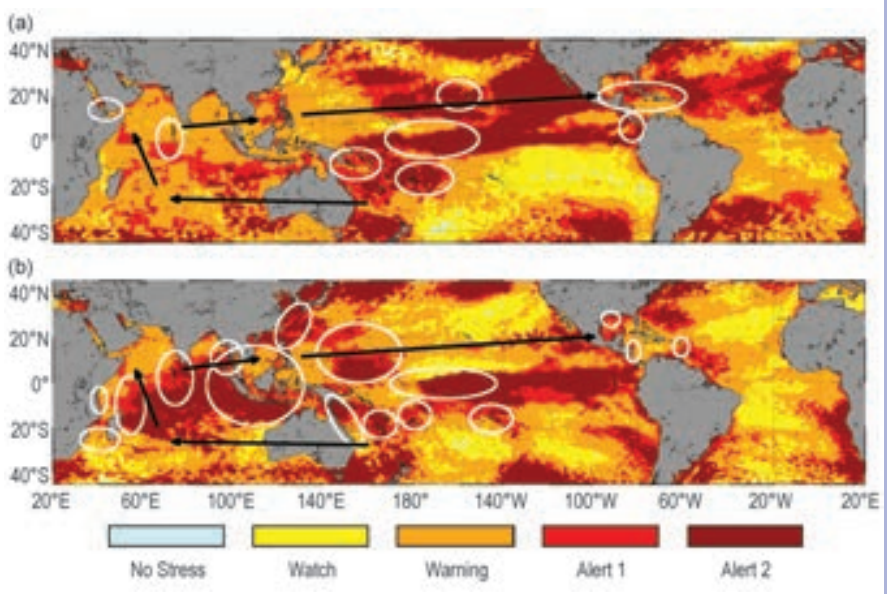

FIG. SB3.I. Evolution of and maximum heat stress for (a) 2015 and (b) 2016. Black lines show the annual pattern of heat stress from the South Pacific to the southern Indian Ocean, northern Indian Ocean and Southeast Asia, then to the Caribbean. Severe coral bleaching was reported from colleagues in all areas circled in white. CRW Bleaching Alert Area categories are defined as:

No Stress, HotSpot $\leq \mathbf{0}$;

Watch, $0<$ HotSpot $<$ I;

Warning, I $\leq$ HotSpot and $0<$ DHW $<$;

Alert I, I $\leq$ HotSpot and $4 \leq \mathrm{DHW}<8$, coral bleaching likely;

Alert 2, I $\leq$ HotSpot and $8 \leq$ DHW, widespread bleaching and significant coral mortality likely; where HotSpot is the positive SST anomaly compared to the maximum monthly mean climatology and DHW is the Degree Heating Week heat stress accumulated from 12 preceding weeks of HotSpot values (G. Liu et al. 20I4). Data from CRW's Daily Global 5-km Coral Bleaching Heat Stress Monitoring Product Suite v.3 (G. Liu et al. 2017).

and sequence of heat stress and bleaching (Fig. SB3.la) seen during the second year of an El Niño during prior global bleaching events (Hoegh-Guldberg 1999). Papua New Guinea and Fiji reported moderate heat stress and bleaching early in 2015 (Alert Level I; Fig. SB3. Ia); American Samoa reported its worst bleaching ever with widespread Alert Level 2 conditions. CRW documented moderate heat stress in the Indian Ocean, which spread to the Chagos Archipelago, Red Sea, and western Indonesia (Eakin et al. 2016). With the El Niño's onset, SST anomalies in the central and eastern tropical Pacific resulted 
of Greenland. The apparent warming and cooling trends adjacent to Antarctica are located in both in situ and altimeter data-sparse regions and may not be robust. A statistically significant warming trend in the western tropical Pacific that was quite strong in 1993-2013 but had disappeared for 1993-2016 (see previous State of the Climate reports) returned for 1993-2017, emphasizing the strong influence of El Niño and perhaps the PDO on sea level trends in that region (Merrifield et al. 2012), as well as the sen- in heat stress in the Line Islands at record levels (Fig. SB3.Ia). Hawaii saw its worst bleaching ever (Rosinski et al. 2017). Florida's reefs experienced a second consecutive mass bleaching (FRRP 2016), and bleaching was reported on reefs across the eastern and western Caribbean (Eakin et al. 2016). With widespread bleaching observed in the Indian, Pacific, and Atlantic basins, NOAA declared in October 2015 the third global coral bleaching event was underway (NOAA 20I5). By then, $41 \%$ of the world's coral reefs had experienced heat stress of $4^{\circ} \mathrm{C}$-weeks (as defined in the caption of Fig. SB3.Ia) or more, and almost all reefs had exceeded their normal warm-season temperatures.

With a strong El Niño in 2016, heat stress and bleaching returned to the Southern Hemisphere and followed the same global sequence as 2015 - the first time this occurred in backto-back years (Fig. SB3.Ib). Heat stress in 2016 was much more widespread and intense than in 2015, encompassing $51 \%$ of coral reefs globally. Even more important was the severity. Continuous El Niño-related heat stress in the central Pacific for over a year caused the highest heat stress values CRW had ever documented. More than $25^{\circ} \mathrm{C}$-weeks of heat stress in the Northern Line Islands killed $80 \%$ and bleached another $15 \%$ of corals in Kiritimati (Harvey 2016) and killed $98 \%$ of corals at Jarvis Island (Brainard et al. 2018). The first mass bleaching ( $85 \%$ bleached) of the northern and far-northern Great Barrier Reef (GBR; Hughes et al. 2017) killed 29\% of the GBR's shallowwater corals (GBRMPA 2018). Widespread heat stress brought bleaching to much of the western Indian Ocean (CORDIO-EA 2016), including 69\%-99\% of corals bleached and $50 \%$ dead in ever seen in the Flower Garden Banks, located in the Gulf of Mexico (Johnston et al. 2017). Later, bleaching returned to the Marshall Islands in the central Pacific (Eakin et al. 2017).

Some South Pacific bleaching was reported in early 2017: mild in Fiji and severe in Niue, Samoa, and American Samoa. A second year of bleaching struck the GBR; this first-ever consecutive bleaching there focused on the northern and central sectors, killing another $22 \%$ of the GBR's corals (Hughes and Kerry 2017). Heat stress was limited in the Indian Ocean with moderate bleaching in southwestern Madagascar (CORDIO-EA 2016) and mild bleaching elsewhere. With a lack of widespread, severe Indian Ocean bleaching, NOAA declared the global event over as of May 2017 (NOAA 2017). However, bleaching still continued, with Guam and the CNMI experiencing widespread heat stress again. This was Guam's worst documented bleaching and fourth widespread event in five years.

Lasting an unprecedented 36 months, the third global event brought mass bleaching-level heat stress (Alert I) to more than $75 \%$ of global reefs; nearly $30 \%$ also suffered mortalitylevel stress (Alert 2; Fig. SB3.2). More than half of affected reef areas were impacted at least twice. This global event has punctuated the recent acceleration of mass bleaching. Occurring at an average rate of once every 25-30 years in the 1980 s, mass bleaching now returns about every six years and is expected to further accelerate as the oceans continue to warm (Hughes et al. 2018). Severe bleaching is now occurring more quickly than reefs can recover, with severe downstream consequences to ecosystems and people. the Seychelles (SIF 20I7). CRW's forecasts of mass bleaching led Thailand to close many coral reef sites to diving (Agence FrancePresse 2016). In the boreal summer, over $90 \%$ bleaching and $70 \%$ mortality were observed on Japan's largest reef (Harvey 2017); widespread bleaching also hit Guam again. Heat stress in the western Atlantic caused extensive bleaching in the western Caribbean and the worst bleaching ing Product Suite v.3 (G. Liu et al. 2017).

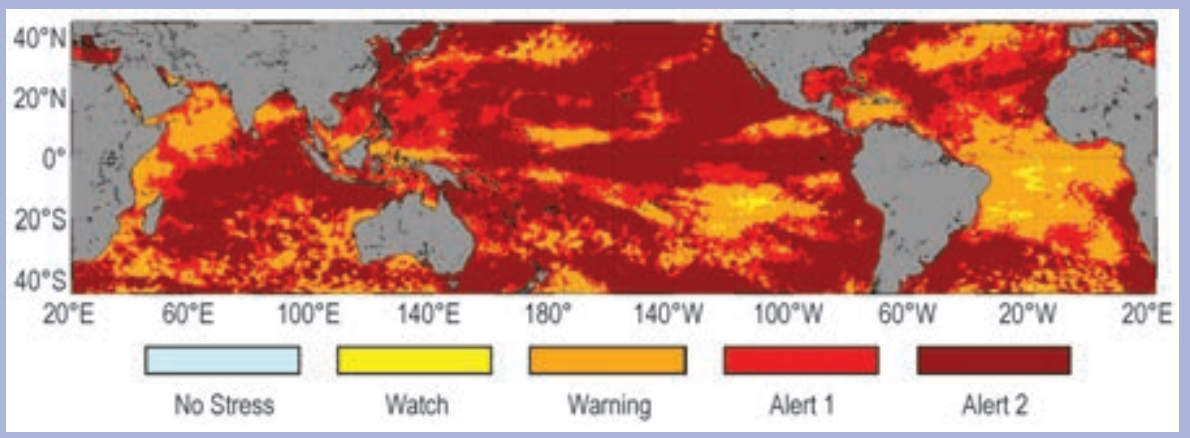

FIg. SB3.2. NOAA CRW Maximum Bleaching Alert Area map for Jun 2014-May 2017. Data from CRW's Daily Global 5-km Coral Bleaching Heat Stress Monitor- 
sitivity of trends in relatively short records to choices of end points.

Near-global average monthly (smoothed to seasonal time-scale) temperature anomalies (Fig. 3.5a) reflect both a long-term warming trend (Fig. 3.5b, orange line) and ENSO redistributing heat (e.g., Roemmich and Gilson 2011) from the upper $100 \mathrm{dbar}$ to a roughly 300 -dbar thick layer just below. Lower temperature values are evident in the upper $100 \mathrm{dbar}$ and higher values from 100 to 400 dbar during La Niña (e.g., 2008/09), and vice versa during El Niño (e.g., 2015/16). Since the peak of El Niño near the start of 2016, mean temperatures in the upper $100 \mathrm{dbar}$ declined, but throughout 2017 they still remained above the long-term average. Negative anomalies from 150 to $400 \mathrm{dbar}$ peaking around the start of 2016 also abated, such that the entire water column from 0 to 2000 dbar was warmer in 2017 than the 2004-17 average. The overall warming trend (Fig. 3.5b, orange line) from 2004 to 2017 exceeds $0.19^{\circ} \mathrm{C}$ decade $^{-1}$ near the surface, declining to less than $0.03^{\circ} \mathrm{C}$ decade ${ }^{-1}$ be-

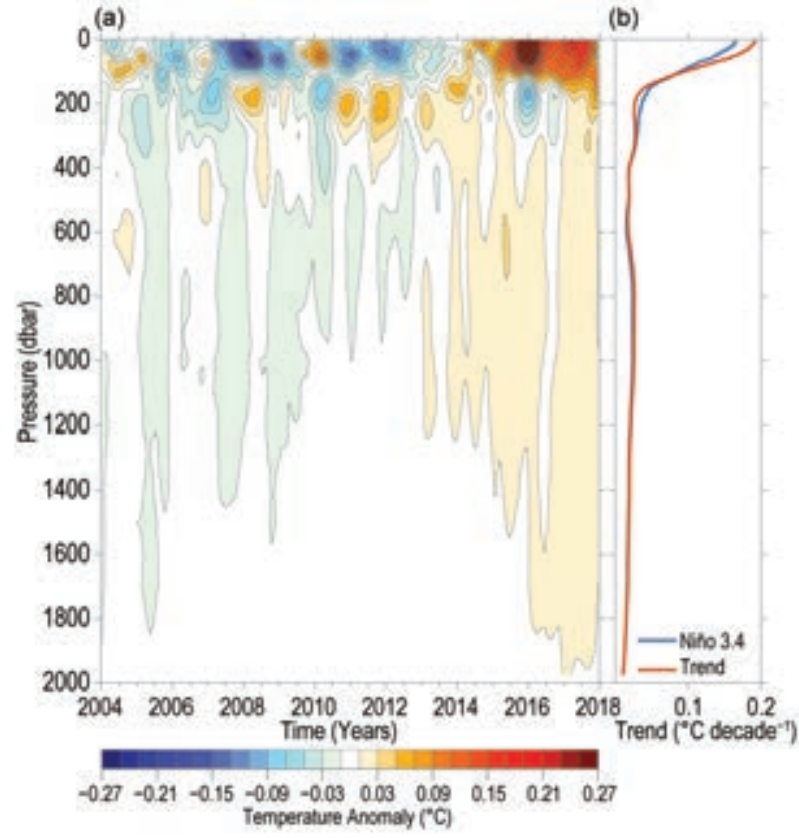

Fig. 3.5. (a) Near-global $\left(65^{\circ} \mathrm{S}-80^{\circ} \mathrm{N}\right.$, excluding continental shelves, the Indonesian seas, the Sea of Okhostk, the Caribbean Sea, and the Gulf of Mexico) integrals of monthly ocean temperature anomalies ${ }^{\circ} \mathrm{C}$; updated from Roemmich and Gilson (2009)] relative to record-length average monthly values, smoothed with a 5-month Hanning filter and contoured at odd $0.02^{\circ} \mathrm{C}$ intervals (see colorbar) vs. pressure and time. (b) Linear trend of temperature anomalies over time for the length of the record in (a) plotted vs. pressure in ${ }^{\circ} \mathrm{C}$ decade $^{-1}$ (orange line), and trend with a Niño-3.4 regression removed (blue line) following Johnson and Birnbaum (2017). low $180 \mathrm{dbar}$ and about $0.01^{\circ} \mathrm{C}$ decade $\mathrm{e}^{-1}$ by $2000 \mathrm{dbar}$. Removing a linear regression against the Niño-3.4 index (e.g., Johnson and Birnbaum 2017) results in a decadal warming trend (Fig. 3.5b, blue line) that is somewhat less than the simple linear trend near the surface and slightly larger from about 100 to $400 \mathrm{dbar}$.

The analysis is extended back in time from the Argo period (which started in the early 2000s) to 1993, and deeper, using sparser, and more heterogeneous, historical data collected mostly from ships (e.g., Abraham et al. 2013). Six different estimates of glob-
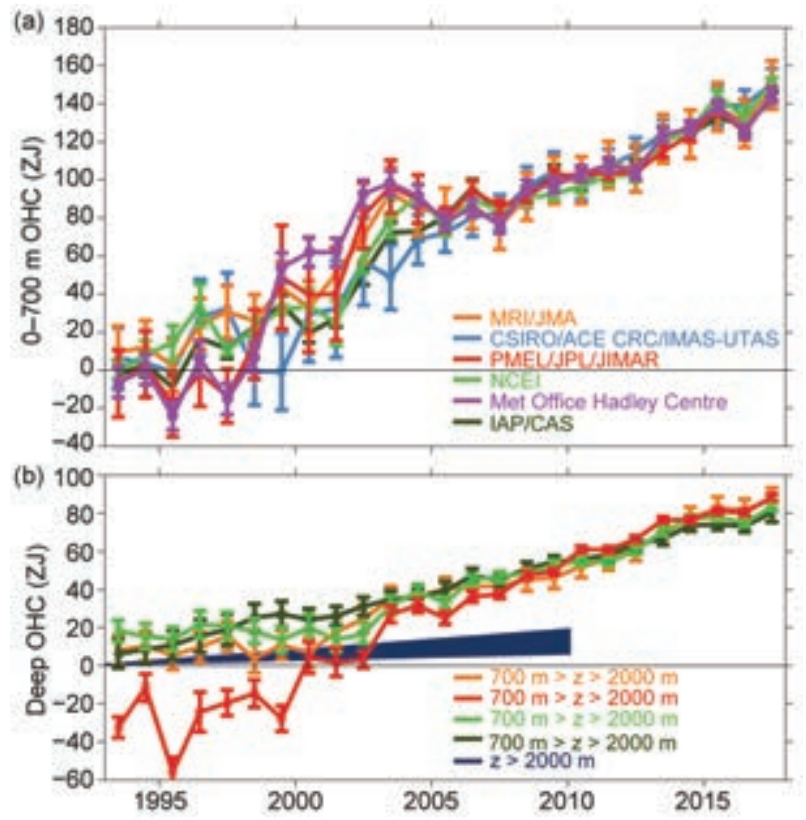

Fig. 3.6. (a) Annual average global integrals of in situ estimates of upper $(0-700 \mathrm{~m})$ OHCA $\left(\mathrm{ZJ} ; \mathrm{I} \mathrm{ZJ}=10^{21} \mathrm{~J}\right)$ for 1993-2017 with standard errors of the mean. The MRI/JMA estimate is an update of Ishii et al. (20I7). The CSIROIACE CRC/IMAS-UTAS estimate is an update of Domingues et al. (2008). The PMEL/JPL/ JIMAR estimate is an update and refinement of Lyman and Johnson (2014). The NCEI estimate follows Levitus et al. (2012). The Met Office Hadley Centre estimate is computed from gridded monthly temperature anomalies (relative to 1950-2016) following Palmer et al. (2007). The IAP/CAS estimate is described in Cheng et al. (2017). See Johnson et al. (2014) for details on uncertainties, methods, and datasets. For comparison, all estimates have been individually offset (vertically on the plot), first to their individual 2005-17 means (the best sampled time period), and then to their collective 1993 mean. (b) Annual average global integrals of in situ estimates of intermediate (700-2000 m) OHCA for 1993-2017 with standard errors of the mean, and a long-term trend with one standard error uncertainty shown from 1992-2010 for deep and abyssal $(z>2000$ m) OHCA following Purkey and Johnson (2010) but updated using all repeat hydrographic section data available from https://cchdo.ucsd.edu/ as of Jan 2018. 
ally integrated in situ 0-700-m OHCA (Fig. 3.6a) all reveal a large increase since 1993, with 2017 being a record high value. A similar pattern is apparent from 700 to $2000 \mathrm{~m}$ (Fig. 3.6b). While the trend in globally integrated ocean heat content is modulated by El Niño and is slowed or even reversed after El Niño peaks (Johnson and Birnbaum 2017), it, like globally averaged sea level (see Fig. 3.15a), exhibits a much steadier increase than globally averaged surface temperatures (see Fig. 3.3a). Globally integrated OHCA values vary more both from year-to-year for individual years and from estimate-to-estimate in any given year prior to the achievement of a near-global Argo array around 2005. Causes of differences among estimates are discussed in Johnson et al. (2015).

The rate of heat gain from linear trends fit to each of the six global integral estimates of 0-700 m OHCA from 1993 through 2017 (Fig. 3.6a) range from 0.36 $( \pm 0.06)$ to $0.40( \pm 0.18) \mathrm{W} \mathrm{m}^{-2}$ applied over the surface area of Earth (Table 3.2). Linear trends from 700 to $2000 \mathrm{~m}$ over the same time period range from 0.19 $( \pm 0.07)$ to $0.35( \pm 0.03) \mathrm{W} \mathrm{m}^{-2}$. Trends in the $0-700-\mathrm{m}$ layer all agree within uncertainties, and all but one of the four trends in the 700-2000-m layer do as well. For that layer the PMEL/JPL/JIMAR trend is larger than the others because it assumes the average anomaly in sampled regions applies globally (Lyman and Johnson 2014). For 2000-6000 m, the linear trend is $0.04( \pm 0.04) \mathrm{W} \mathrm{m}^{-2}$ from 1992 to 2010 . Summing the three layers (with their slightly different time periods), the full-depth ocean heat gain rate ranges from 0.59 to $0.79 \mathrm{~W} \mathrm{~m}^{-2}$.

\begin{tabular}{|c|c|c|c|}
\hline \multirow[t]{2}{*}{ Research group } & \multicolumn{3}{|c|}{$\begin{array}{l}\text { Global ocean heat content trends } \\
\left(\mathrm{W} \mathrm{m}^{-2}\right) \text { for three depth ranges }\end{array}$} \\
\hline & $0-700 \mathrm{~m}$ & $700-2000 \mathrm{~m}$ & $2000-6000 \mathrm{~m}$ \\
\hline MRI/JMA & $0.36 \pm 0.06$ & $0.22 \pm 0.06$ & - \\
\hline IRO/ACE/CRC/IMAS/UTAS & $0.40 \pm 0.07$ & - & - \\
\hline PMEL/JPL/JIMAR & $0.40 \pm 0.16$ & $0.35 \pm 0.03$ & - \\
\hline NCEI & $0.38 \pm 0.07$ & $0.19 \pm 0.07$ & - \\
\hline Met Office Hadley Centre & $0.40 \pm 0.18$ & - & - \\
\hline ICCES & $0.40 \pm 0.06$ & $0.19 \pm 0.01$ & - \\
\hline Purkey and Johnson update & - & - & $0.04 \pm 0.04$ \\
\hline
\end{tabular}

d. Salinity-G. C. Johnson, J. Reagan, J. M. Lyman, T. Boyer, C. Schmid, and R. Locarnini

I) INTRODUCTION-G. C. Johnson and J. Reagan

The ocean plays a large role in the global hydrological cycle, with the vast majority of evaporation and precipitation occurring over the oceans (e.g., Schanze et al. 2010). Ocean freshwater storage and transport, and variations thereof, are reflected in salinity patterns and their variations (e.g., Yu 2011). Where evaporation exceeds precipitation, such as in the subtropics, relatively salty surface waters are found. In contrast, where precipitation (and river run off) is greater than evaporation, such as under the ITCZs and in subpolar regions, fresher waters are present. In high latitudes, sea ice formation, advection, and melt also influences SSS (e.g., Petty et al. 2014). Subsurface ocean salinity patterns reflect the surface formation regions of water masses (e.g., Skliris et al. 2014), with fresher tropical waters overlying saltier subtropical waters, which in turn overlay fresher subpolar waters. Below these water masses lie the saltier North Atlantic Deep Water and below that the fresher Antarctic Bottom Water (Johnson 2008). North Atlantic Deep Water temperature and salinity vary over decades (e.g., Yashayaev and Loder 2016), whereas Antarctic Bottom Waters have been freshening in recent decades (e.g., Purkey and Johnson 2013). Salinity changes impact sea level changes (e.g., Durack et al. 2014) as well as the thermohaline circulation (e.g., W. Liu et al. 2017) and have been used to quantify changes in the hydrological cycle (e.g., Skliris et al. 2014).

To investigate interannual changes of subsurface salinity, all available salinity profile data are quality controlled following Boyer et al. (2013) and then used to derive $1^{\circ}$ monthly mean gridded salinity anomalies relative to a longterm monthly mean for years 1955-2012 [World Ocean Atlas 2013 version 2 (WOA13v2); Zweng et al. 2013] at standard depths from the surface to $2000 \mathrm{~m}$ (Boyer et al. 2013). In recent years, the largest source of salinity profiles is the profiling floats of the Argo program (Riser et al. 2016). These data are a mix of real-time (preliminary) and delayed-mode (scientific quality controlled) 
observations. Hence, the estimates presented here could change after all data have been subjected to scientific quality control. The SSS analysis relies on Argo data downloaded in January 2018, with annual maps generated following Johnson and Lyman (2012) as well as monthly maps of bulk (as opposed to skin) SSS data from BASS (Xie et al. 2014). BASS blends in situ SSS data with data from the Aquarius (Le Vine et al. 2014; mission ended in June 2015), SMOS (Soil Moisture and Ocean Salinity; Font et al. 2013), and recently SMAP (Soil Moisture Active Passive; Fore et al. 2016) satellite missions. BASS maps can be biased fresh around land (including islands) and at high latitudes. Despite the larger uncertainties of satellite data relative to Argo data, their higher spatial and temporal sampling allows higher spatial and temporal resolution maps than are possible using in situ data alone at present. Salinity is measured as a dimensionless quantity and reported on the 1978 Practical Salinity Scale, or PSS-78 (Fofonoff and Lewis 1979).

2) Sea surface Salinity-G. C. Johnson and J. M. Lyman

Sea surface salinity anomalies outside of the tropics are fairly persistent, so 2017 SSS anomalies (Fig. 3.7a, colors) include some extratropical large-scale patterns that largely held from 2004 to 2016 (previous State of the Climate reports). Regions around the subtropical salinity maxima are generally salty with respect to WOA13v2, except in the North Pacific, where the salinity maximum is anomalously fresh in 2017. There are fresh anomalies relative to WOA13v2 in much of the high-latitude, low-salinity regions, primarily in portions of the subpolar gyres of the North Pacific and North Atlantic, and to a lesser extent around the Southern Ocean. These multiyear patterns are consistent with an increase in the hydrological cycle (e.g., more evaporation in drier locations and more precipitation in rainy areas) over the ocean, as expected in a warming climate (Rhein et al. 2013). A similar assertion could be made for some of the extratropical 2005-17 trends discussed below.

Tropical sea surface salinity changes from 2016 to 2017 (Fig. 3.7b, colors) are anti-correlated with 2016 to 2017 tendencies in precipitation minus evaporation $(P-E$; see Fig. 3.12b). The freshening in the offequatorial western tropical Pacific and salinification around the equator in the west and under the ITCZ in the east are all well anti-correlated with $P-E$ tendencies, and associated with the transition from an El Niño that peaked around early 2016 to the neutral or weak La Niña conditions since then. A prominent example of the role of advection by anomalous ocean currents (see Fig. 3.18) in the 2016 to 2017 SSS tenden- cies is the increase in salinity in the equatorial Indian Ocean. This increase is associated with anomalous eastward currents, consistent with anomalous advection in the presence of mean SSS that decreases from west to east. Other prominent large-scale SSS changes from 2016 to 2017 include freshening in the northeast Pacific, the western tropical Atlantic, and around the equator across much of the Atlantic (Fig. 3.7b).
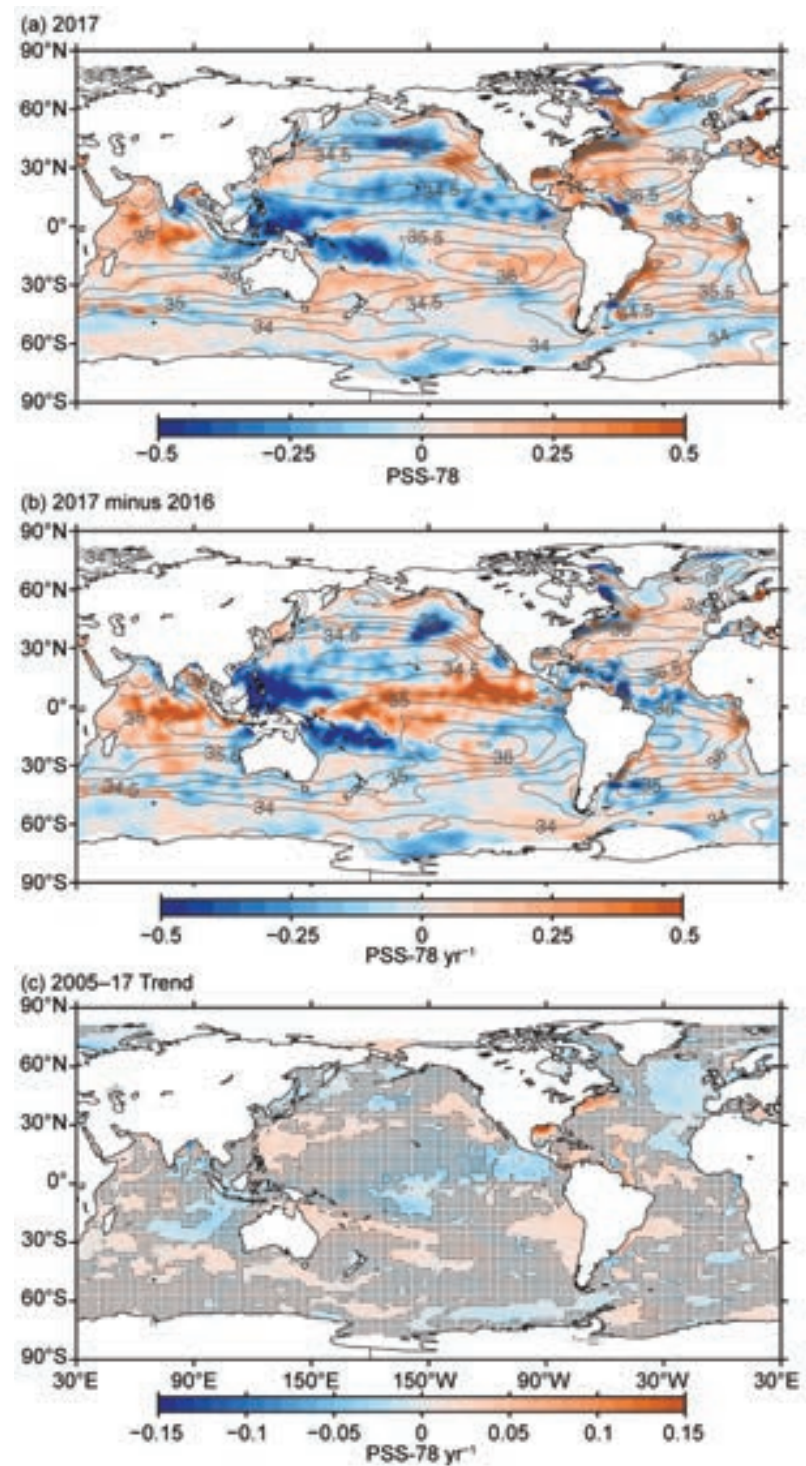

FIG. 3.7. (a) Map of the 2017 annual surface salinity anomaly (colors, PSS-78) with respect to monthly climatological 1955-20I2 salinity fields from WOAI3v2 [yearly average (gray contours at $\mathbf{0 . 5}$ intervals), PSS78]. (b) Difference of 2017 and 2016 surface salinity maps (colors, PSS-78 yr $^{-1}$ ). White ocean areas are too data-poor (retaining $<80 \%$ of a large-scale signal) to map. (c) Map of local linear trends estimated from annual surface salinity anomalies for 2005-I7 (colors, PSS-78 $\left.\mathrm{yr}^{-1}\right)$. Areas with statistically insignificant trends are stippled. All maps are made using Argo data. 
(a)

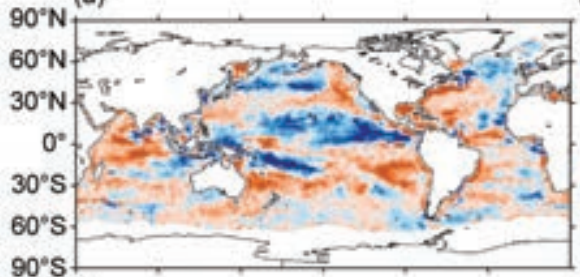

90 's (c) (d)

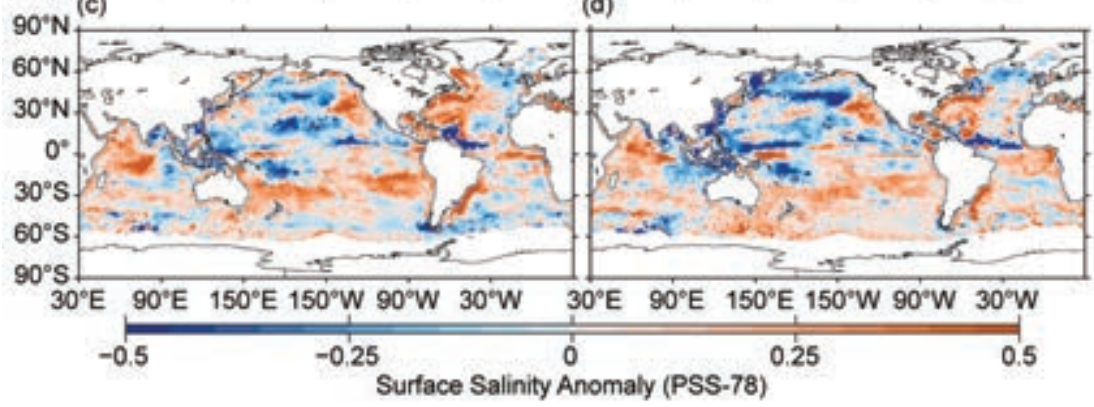

FIG. 3.8. Seasonal maps of SSS anomalies (colors) from monthly blended maps of satellite and in situ salinity data (BASS; Xie et al. 2014) relative to monthly climatological 1955-2012 salinity fields from WOAI3v2 for (a) Dec-Feb 2016/17, (b) Mar-May 2017, (c) Jun-Aug 2017, and (d) Sep-Nov 2017. Areas with maximum monthly errors exceeding 10 PSS-78 are left white.
North Pacific, as well as patches in the Pacific and Atlantic sectors of the Southern Ocean. In the tropics, they include the central Pacific, at the eastern edge of the western fresh pool, and in the warm fresh pool of the northeastern equatorial Pacific. There are also freshening trends in the already fresh Bay of Bengal, and a large patch west of Indonesia and Australia that has been present since at least 2009 (see previous State of the Climate reports). The regions to the northwest of the Gulf Stream and in the northern Gulf of Mexico are also trending strongly saltier, as well as warmer (Section 3c).

3) SUbSURFACE SALINITY-J. Reagan, T. Boyer, C. Schmid, and R. Locarnini

For the first time in the past decade, nearly all 2017 Atlantic Ocean basin-average monthly salinity anomalies were positive from 0 to $1500 \mathrm{~m}$ (Fig. 3.9a). The year 2017 continued the same Atlantic salinity anomaly pattern that has been evident since 2008 with strong positive $(>0.05)$ near-surface salinity anomalies that weaken with depth $(\sim 0.005$ at 700 m) (Fig. 3.9a). Salinity increased at nearly all depths within 0-1500 m from 2016 to 2017 (Fig. 3.9b) with the highest increase between 100 and $125 \mathrm{~m}(\sim 0.017)$.

The 2017 Pacific Ocean basin-average salinity anomalies continued the same pattern that began in mid-2014 with fresh anomalies from 0 to $75 \mathrm{~m}$, salty anomalies from 100 to $200 \mathrm{~m}$, and fresh anomalies from 200 to $600 \mathrm{~m}$ (Fig. 3.9c). This marks the third straight year (2015-17) in which the upper $75 \mathrm{~m}$ of the Pacific Ocean has been fresher than the long-term average. Previously, this layer had been saltier than the long-term average for five straight years (2009-13; Fig. 3.9c). These basin-average multiyear near-surface salinity shifts may be related to in-phase transitions of both ENSO and the PDO and their associated precipitation (Lau and Yang 2002) and equatorial wind stress/Ekman upwelling changes (Wang et al. 2015). From 2016 to 2017 the upper $125 \mathrm{~m}$ of the Pacific became fresher ( $\max$ of $\sim-0.018$ at $0 \mathrm{~m}$ ), while the $150-400-m$ layer became saltier ( $\max$ of $\sim 0.013$ at 200 m; Fig. 3.9d).

From mid-2016 through 2017 the upper $200 \mathrm{~m}$ of the Indian Ocean became very salty $(>0.05$ near the surface) when compared to the long-term mean 


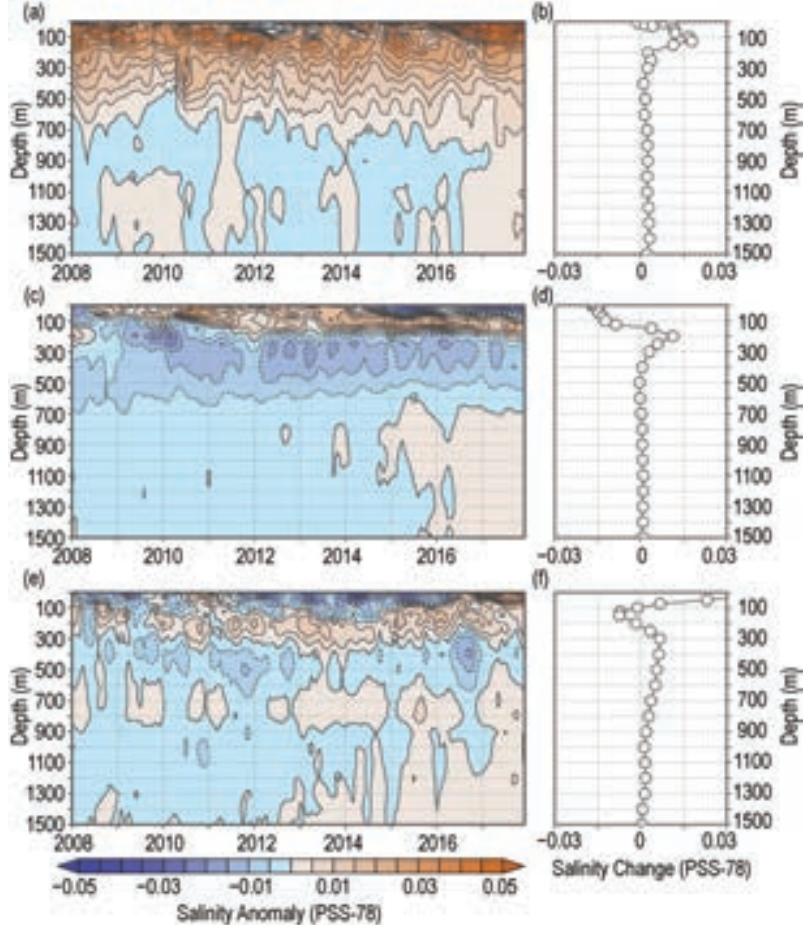

FIG. 3.9. Average monthly salinity anomalies (PSS-78) relative to the long-term WOA13v2 monthly salinity climatology for years 1955-20I2 (Zweng et al. 2013) from 0 to $1500 \mathrm{~m}$ for the (a) Atlantic for 2008-17 and (b) the change from 2016 to 2017; (c) Pacific for 2008-17 and (d) the change from 2016 to 2017; (e) Indian for 2008-17 and (f) the change from 2016 to 2017. Data were smoothed using a 3 -month running mean.

(Fig. 3.9e). Much of the surface of the Indian Ocean experienced salty anomalies (Fig. 3.7a) that were not driven directly by changes in $P-E$ (see Fig. 3.12a) but were due to anomalous ocean currents (see Fig. 3.18a and Section 3d2). Unsurprisingly, there was a large ( $\sim 0.05$ at $0 \mathrm{~m}$; Fig. $3.9 \mathrm{f})$ salinification of the nearsurface from 0 to $100 \mathrm{~m}$ between 2016 and 2017, with freshening from 100 to $200 \mathrm{~m}$, and salinification from 200 to $1000 \mathrm{~m}$ (Fig. 3.9f).

Most of the large $(>|0.09|)$ zonally averaged salinity changes from 2016 to 2017 in the Atlantic occurred in the North Atlantic (Fig. 3.10a). There was freshening in the upper $50 \mathrm{~m}$ from $0^{\circ}$ to $20^{\circ} \mathrm{N}$, with maximum freshening $(<-0.12)$ at $\sim 10 \mathrm{~m}$ depth. This is in contrast to the salinification that was observed in this region between 2015 and 2016 (see Fig. 3.10a in Reagan et al. 2017). The freshwater discharge from the Amazon and Orinoco Rivers are likely the source of this freshening (Figs. 3.7b and 3.8a-d) with a stronger 2017 North Brazil Current (when compared to 2016) from March through August (see Figs. 3.19b,c) helping advect the freshwater river discharge farther to the north and northwest. Increased $P-E$ (see Fig. 3.12a) over the Atlantic ITCZ may have also played a role in the freshening over this area. North of this freshening, there was salinification $(>0.03)$ between 2016 and 2017 from $20^{\circ}$ to $52^{\circ} \mathrm{N}$, which expanded and deepened from the surface to $100 \mathrm{~m}$ at $20^{\circ} \mathrm{N}$ to $400 \mathrm{~m}$ at $50^{\circ} \mathrm{N}$ with maximum salinification $(>0.09)$ occurring at $50 \mathrm{~m}$ at $47.5^{\circ} \mathrm{N}$.

The zonally averaged Pacific salinity changes from 2016 to 2017 are primarily concentrated in the upper $150 \mathrm{~m}$ (Fig. 3.10b). Near-surface $(0-50 \mathrm{~m})$ freshening $(<-0.03)$ at $22^{\circ} \mathrm{S}$ extends equatorward and deepens to $150 \mathrm{~m}$ at $8^{\circ} \mathrm{S}$ with maximum freshening $(<-0.12)$ at the surface near $15^{\circ} \mathrm{S}$. This is a reversal of the salinification that took place from 2015 to 2016 in this area, and it is likely due to the transition from the strong El Niño in early 2016 to the neutral and weak La Niña conditions that dominated 2017 and its associated precipitation tendencies from 2016 to
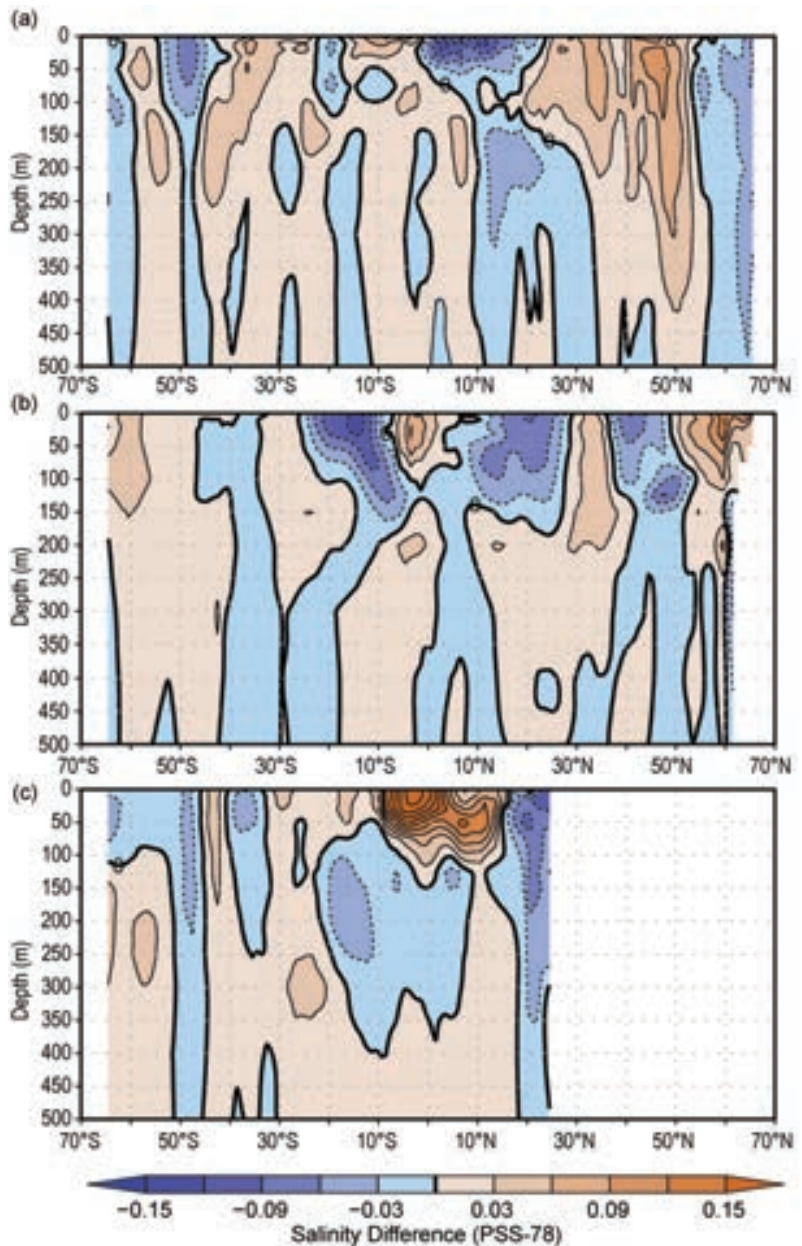

Fig. 3.10. Difference between the 2017 and 2016 zonal average monthly salinity anomalies (PSS-78) relative to the long-term WOAI3v2 monthly salinity climatology for 1955-2012 (Zweng et al. 2013) from 0 to $500 \mathrm{~m}$ for the (a) Atlantic, (b) Pacific, and (c) Indian Ocean basins. Contours are multiples of \pm 0.03 with a bold 0 contour. 
2017 (see Fig. 3.12d). Near the equator, salinity increased between 2016 and 2017, likely due to the aforementioned ENSO transition and upwelling of higher salinity water caused by increased zonal wind stress from 2016 to 2017 (see Fig. 3.13b). Farther north there was freshening $(<-0.03)$ from $10^{\circ}$ to $27^{\circ} \mathrm{N}$ reaching a depth of $\sim 140 \mathrm{~m}$ and freshening $(<-0.03)$ between $38^{\circ}$ and $50^{\circ} \mathrm{N}$ from 0 to $150 \mathrm{~m}$. Finally, there was salinification (> 0.03 ) between $50^{\circ}$ and $60^{\circ} \mathrm{N}$ in the upper $100 \mathrm{~m}$.

The largest changes in zonally averaged salinity between 2016 and 2017 in the Indian Ocean occurred in the upper $100 \mathrm{~m}$ between $10^{\circ} \mathrm{S}$ and $15^{\circ} \mathrm{N}$ (Fig. 3.10c). In this region, there was broad-scale salinification $(>0.03)$ with large increases in salinity $(>0.20)$ in the upper $50 \mathrm{~m}$ between $10^{\circ} \mathrm{S}$ and the equator. As was discussed previously in this section, this salinification was primarily due to the advection of salty water via 2017 anomalous ocean currents (see Fig. 3.18a). Freshening (a)
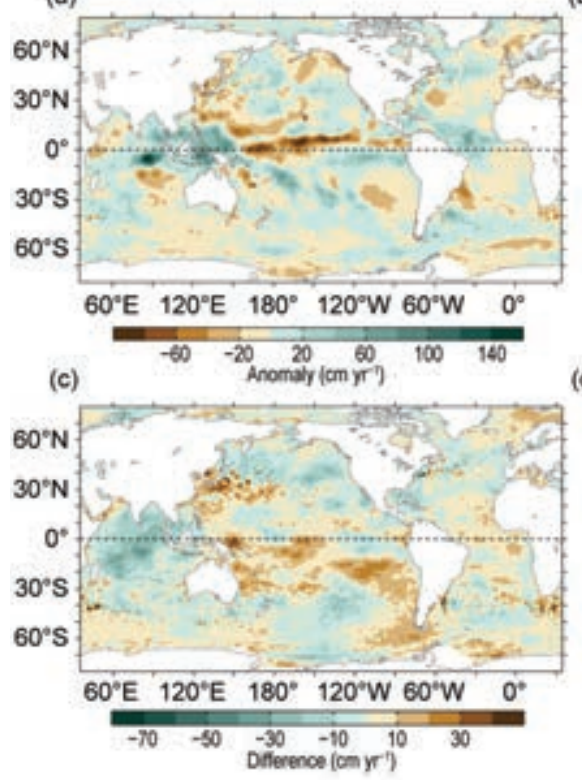

(b)
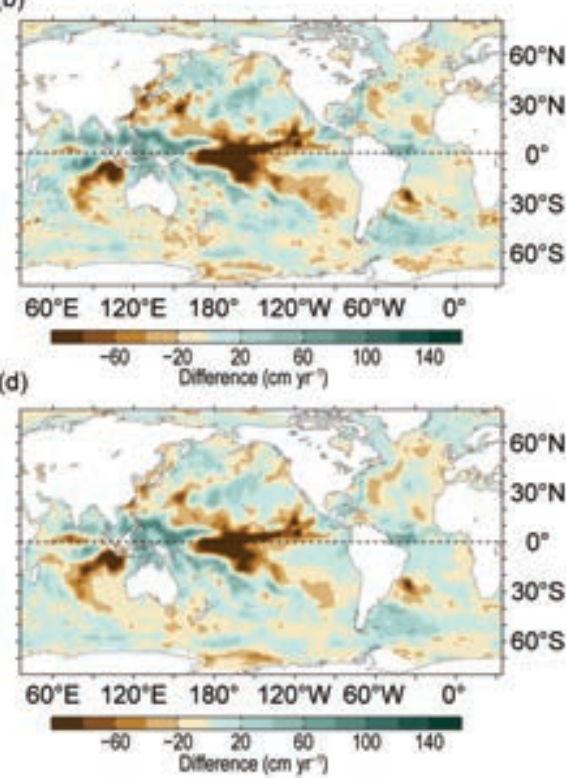

Fig. 3.I2. (a) Surface freshwater $(P-E)$ flux anomalies $\left(\mathrm{cm} \mathrm{yr}^{-1}\right)$ for 2017 relative to a 1988-2014 climatology. 2017 minus 2016 tendencies for (b) P-E, (c) evaporation $(E)$, and $(d)$ precipitation $(P)$. Green colors denote anomalous ocean moisture gain and browns denote loss, consistent with the reversal of the color scheme in (c). $P$ is computed from the GPCP version 2.3 product, and $E$ from OAFlux-HR satellite-based analysis.
$(<-0.03)$ from 2016 to 2017 from $17^{\circ}$ to $24^{\circ} \mathrm{N}$ extends down to $350 \mathrm{~m}$ and is primarily caused by the nearcoast freshening along India's west coast (Fig. 3.7b).

e. Global ocean heat, freshwater, and momentum fluxes-L. Yu, X. Jin, S. Kato, N. G. Loeb, P. W. Stackhouse, R. A. Weller, and A. C. Wilber

The ocean and the atmosphere communicate via interfacial exchanges of heat, freshwater, and momentum. These air-sea fluxes are the primary mechanisms for keeping the global climate system nearly balanced with the incoming insolation at Earth's surface. Most of the shortwave radiation (SW) absorbed by the ocean's surface is vented into the atmosphere by three processes: longwave radiation (LW), turbulent heat loss by evaporation (latent heat flux, or LH), and conduction (sensible heat flux, or SH). The residual heat is stored in the ocean and transported by ocean circulation, forced primarily by the momentum transferred to 
(a)

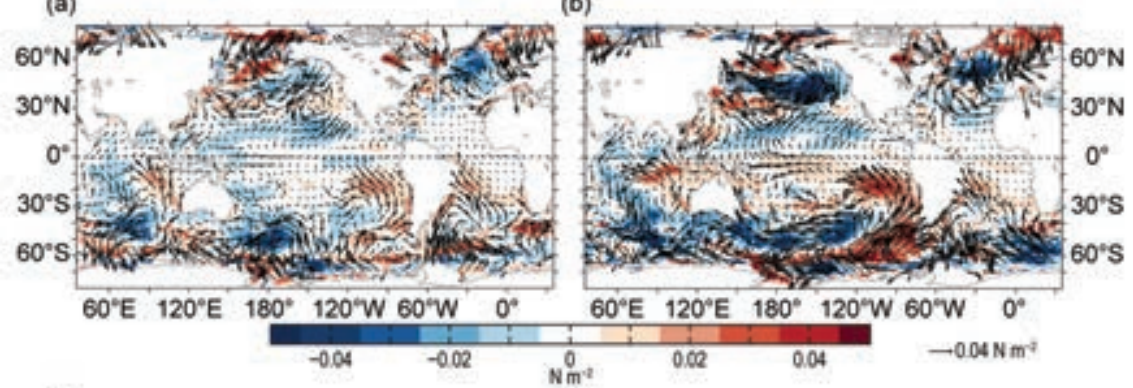

(c)

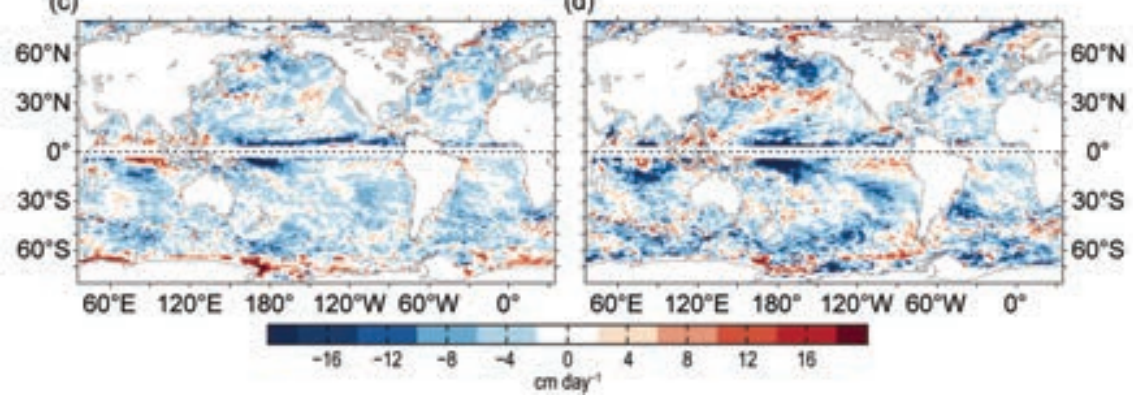

FIG. 3.13. (a) Wind stress magnitude (colors) and vector anomalies $\left(\mathbf{N ~ m}^{-2}\right)$ for 2017 relative to a 1988-2014 climatology, (b) 2017 minus 2016 differences in wind stress, (c) Ekman vertical velocity $\left(W_{E K} ; \mathrm{cm} \mathrm{day}^{-1}\right)$ anomalies for 2017 relative to a 1988-2014 climatology, and (d) 2017 minus 2016 differences in $W_{E K}$. In (c) and (d), positive values denote upwelling favorable differences, and values are not presented within $\pm 3^{\circ}$ of the equator. Winds are computed from the OAFlux-HR satellite-based vector wind analysis.

the ocean by wind stress. Evaporation connects heat and moisture transfers, and the latter, together with precipitation, determines the local surface freshwater flux. Identifying changes in the air-sea fluxes is essential in deciphering observed changes in ocean circulation and its transport of heat and salt from the tropics to the poles.

Air-sea heat flux, freshwater flux, and wind stress in 2017 and their relationships with ocean surface variables are examined here. The net surface heat flux, $Q_{\text {net, }}$ is the sum of four terms: $\mathrm{SW}+\mathrm{LW}+\mathrm{LH}$ $+\mathrm{SH}$. The net surface freshwater flux into the ocean (neglecting riverine and glacial fluxes from land) is simply precipitation $(P)$ minus evaporation $(E)$, or the $P-E$ flux. Wind stress is computed from satellite wind retrievals using the bulk parameterization of Edson et al. (2013). The production of the global maps of $\mathrm{Q}_{\text {net }}$ (Fig. 3.11), $P-E$ (Fig. 3.12), and wind stress (Fig. 3.13) and the long-term perspective of the change of the forcing functions (Fig. 3.14) integrate multigroup efforts. Ocean-surface $\mathrm{LH}, \mathrm{SH}, E$, and wind stress are from the Objectively Analyzed air-sea Fluxes (OAFlux; http://oaflux.whoi.edu) project's newly developed satellite-derived, high-resolution (hereafter OAFluxHR) products (Yu and Jin 2012, 2014, 2018). Surface SW and LW radiative fluxes are from the Clouds and the Earth's Radiant Energy Systems (CERES) Fast Long- wave And Shortwave Radiative Fluxes (FLASHFlux; https: //ceres.larc.nasa.gov/products .php?product $=$ FLASHFlux) Ed3A product (Stackhouse et al. 2006). Global $P$ is from the Global Precipitation Climatology Project (GPCP; http: //gpcp.umd.edu) version 2.3 products (Adler et al. 2003). The CERES Energy Balanced and Filled (EBAF) surface SW and LW version 4.0 products (http://ceres.larc.nasa.gov; Loeb et al. 2018) are used in the time series analysis.

\section{I) Surface heat fluXes}

The dominant feature in the $2017 \mathrm{Q}_{\text {net }}$ anomalies (Fig. 3.11a) is the broad-scale ocean heat gain anomalies (positive $\mathrm{Q}_{\text {net }}$ ) generally exceeding $10 \mathrm{~W} \mathrm{~m}^{-2}$ in the tropical Pacific and Indian Oceans. The anomaly pattern in the equatorial Pacific is associated with La Niñas at the end of both 2016 and 2017 bracketing neutral conditions in between, so the central and eastern tropical Pacific were cooler than normal both at the beginning and end of 2017. Convection was located more in the far western Pacific and less in the central Pacific, and SSTA was lower in the equatorial central and eastern Pacific (see Fig. 3.1a). The 2017 minus 2016 net downward radiation $(\mathrm{SW}+\mathrm{LW})$ differences (Fig. 3.11c) were positive (ocean heat gain) in the central Pacific and negative in the far west. The maximum SW+LW differences were centered near the dateline and extended both to the east along the ITCZ location and to the southeast into the South Pacific. This difference pattern is consistent with the $P$ difference pattern (Fig. 3.12d), showing that SW+LW increased in area of reduced ITCZ rainfall and, conversely, SW+LW reduced in area of increased ITCZ rainfall.

The ocean turbulent heat loss $(\mathrm{LH}+\mathrm{SH})$ tendencies from 2016 to 2017 increased (positive anomalies, blue colors) in the equatorial and southeast tropical Pacific (Fig. 3.11d). The enhanced turbulent heat loss tendencies were related primarily to the strengthening tendencies of the southeast trade winds from 2016 to 2017 (Fig. 3.13b). Winds facilitate the efficiency of evaporation; stronger winds usually generate stron- 


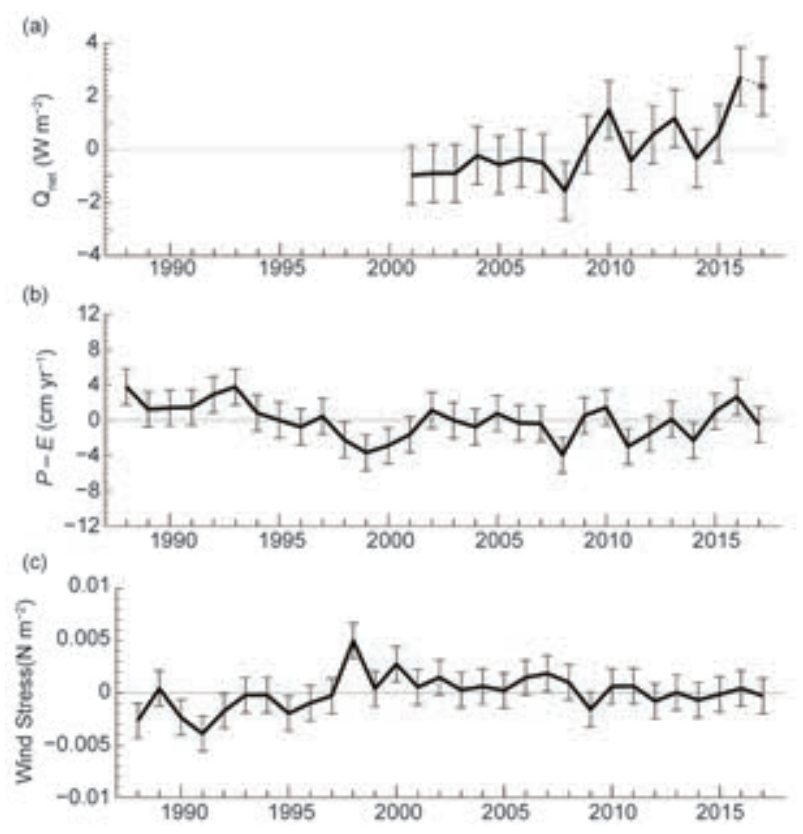

FIG. 3.I4. Annual-mean time series of global average anomalies of (a) net surface heat flux $\left(Q_{\text {net }} ; W^{-2}\right)$ from the combination of CERES EBAF4.0 SW+LW and OAFlux-HR LH+SH, relative to 2000-14. The $2017 Q_{\text {net }}$ (denoted by star) is estimated from FLASHFlux and OAFlux-HR. (b) net freshwater flux (P-E; cm yr-1) from the combination of GPCP P and OAFlux-HR E, and (c) wind stress magnitude $\left(\mathrm{N} \mathrm{m}^{-2}\right)$ from OAFlux-HR. Both $P-E$ and wind stress magnitude anomalies are relative to 1988-2014. Gray error bars denote one std. dev. of annual-mean variability.

ger latent heat loss. In the South Pacific, $\mathrm{LH}+\mathrm{SH}$ tendencies increased in places where wind speeds strengthened and vice versa. On the other hand, wind is not the only factor controlling $\mathrm{LH}+\mathrm{SH}$. The pronounced basin-wide reduction of $\mathrm{LH}+\mathrm{SH}$ in the tropical Indian Ocean was governed by the basinwide surface cooling tendencies (see Fig. 3.1b). The surface cooling was also responsible for the reduction of the $\mathrm{LH}+\mathrm{SH}$ tendencies $\left(\right.$ by $\sim 10 \mathrm{~W} \mathrm{~m}^{-2}$ ) in the North Pacific between $30^{\circ}$ and $60^{\circ} \mathrm{N}$.

Except for the equatorial Pacific, the 2016 to 2017 $\mathrm{Q}_{\text {net }}$ tendencies were predominantly determined by LH+SH tendencies. During 2017, the ocean gained more heat in the tropical Indian Ocean, the equatorial Pacific, and the extratropical Pacific and Atlantic between $30^{\circ}$ and $60^{\circ}$ north and south, while the ocean lost heat in the western Pacific, the south and southeast Pacific, and the subpolar North Atlantic. Net heat loss tendencies south of $60^{\circ} \mathrm{S}$ may be influenced by sea ice edge effect on flux estimates.

\section{2) Surface freshWATER fluXes}

The $2017 P-E$ anomaly pattern is characterized by a reduction of net freshwater input in the central and eastern Pacific and an increase in the Indo-Pacific warm pool (Fig. 3.12a-d). This pattern is primarily in response to the far westward location of tropical convection in association with La Niñas at the ends of both 2016 and 2017. The 2016 to 2017 ITCZ rainfall tendencies (Fig. 3.12d) were reduced considerably in the central equatorial Pacific, with major deficit tendencies (brown) of $1 \mathrm{~m}$ and greater centered near the dateline, stretching both eastward and southeastward. At the same time, the far western Pacific and the eastern equatorial Indian Ocean received more rainfall (green) in 2017 than 2016. The pattern reflects the enhanced regional deep convection associated with La Niña. The central tropical Pacific along the ITCZ had a net freshwater deficit by about $0.5 \mathrm{~m}$ and the Indo-Pacific warm pool region had a freshwater gain by about $0.3 \mathrm{~m}$ relative to climatology (Fig. 3.12a).

The tropical Indian Ocean in 2017 experienced a basin-wide reduction in evaporation, leading to less moisture loss from the region, or equivalently, more freshwater gain (Fig. 3.12c). There were widespread sea surface cooling tendencies, which appear to be a leading factor causing the reduced $E$ tendencies. Wind may contribute too, as the cooling was also accompanied by weakened surface winds in the western Indian Ocean. Away from the Indian Ocean, however, $E$ tendencies were governed mostly by wind tendencies. For instance, the enhanced $E$ tendencies in the tropical and South Pacific were associated with enhanced wind tendencies, and the weakened $E$ tendencies in the North Pacific were associated with weakened wind tendencies. A similar correlation pattern is also observed in the Atlantic basin from $45^{\circ} \mathrm{S}$ to $75^{\circ} \mathrm{N}$. The increase of $E$ in the tropical and subpolar North Atlantic and the reduction of $E$ in both the north and south subtropical basins were primarily the work of wind.

\section{3) WIND STRESS}

The 2017 wind stress anomalies were most pronounced in the extratropical regions (Figs. 3.13a,b). Large negative anomalies were generally associated with the weakening of westerly winds in the midlatitude North Pacific $\left(30^{\circ}-50^{\circ} \mathrm{N}\right)$, the subpolar North Atlantic, and along the Antarctic Circumpolar Current in the Southern Ocean $\left(30^{\circ}-60^{\circ} \mathrm{S}\right)$. In the equatorial region, enhanced deep convection associated with La Niña conditions strengthened the surface branch of the Walker circulation (Rasmusson and Carpenter 1982) from 2016 to 2017, with stronger easterly anomalies in the central equatorial Pacific. Meanwhile, there was a strengthening of the southeast trade winds in the South Pacific and a weakening 
of the northeast trade winds in the North Pacific from 2016 to 2017.

Winds vary considerably in space. These spatial variations of winds cause divergence and convergence of the Ekman transport, leading to a vertical velocity, denoted by Ekman pumping (downward) or suction (upward) velocity $W_{E K}$, at the base of the Ekman layer. Computation of $W_{E K}$ follows the equation: $W_{E K}=1 / \rho \nabla \times(\tau / f)$, where $\rho$ is the density and $f$ the Coriolis force. The 2016 to $2017 W_{E K}$ tendencies (Fig. 3.13d) reveal stronger downwelling (negative) anomalies in the vicinity of the ITCZ location $\left(3^{\circ}-\right.$ $5^{\circ} \mathrm{N}$ ) and stronger upwelling (positive) anomalies in the eastern equatorial Indian Ocean. Outside of the tropical region, the weakened westerly band in the midlatitude North Pacific induced a band of upwelling anomalies (positive) to its south and a band of downwelling anomalies (negative) to its north. In the North Atlantic, $W_{E K}$ anomalies were characterized by a tripole pattern, with positive upwelling anomalies at midlatitudes $\left(40^{\circ}-60^{\circ} \mathrm{N}\right)$ and negative downwelling anomalies at subpolar latitudes (poleward $60^{\circ} \mathrm{N}$ ) as well as the subtropical latitudes $\left(5^{\circ}-30^{\circ} \mathrm{N}\right)$. Negative downwelling anomalies dominated the ocean basins in the Southern Hemisphere (Fig. 3.13d).

\section{4) LONG-TERM PERSPECTIVE}

Annual-mean time series of $\mathrm{Q}_{\text {net }}, P-E$, and wind stress anomalies averaged over the global ice-free oceans (Figs. 3.14a-c) provide a decadal perspective on the ocean surface forcing functions in 2017. The $Q_{\text {net }}$ time series from 2001 to 2016 were constructed from the CERES EBAF4.0 surface radiation and OAFlux-HR turbulent heat fluxes, and the $\mathrm{Q}_{\text {net }}$ in 2017 was diagnosed from FLASHFlux and OAFluxHR. $Q_{\text {net }}$ forcing functions were down slightly in 2017.

Recalling that the ocean has absorbed heat at an average rate of about $0.7 \mathrm{~W} \mathrm{~m}^{-2}$ from 1993 through 2017 (see Section 3c), the time series of $Q_{\text {net }}$ anomalies indicate that the heat budget over the global ocean displays contrasting patterns before and after 2008 . $\mathrm{Q}_{\text {net }}$ was relatively constant from 2001 to 2007, but after a sharp increase from 2008 to 2010, $Q_{\text {net }}$ became more volatile on interannual time scales. The time series of $P-E$ anomalies and wind stress anomalies are about 30 years long, starting from 1988 when Special Sensor Microwave Imager observations became available. Over the 30-year period, $P-E$ experienced a slight decrease during the 1990s but had no obvious trend in the 2000s. The $P-E$ dip in 2008 coincided well with that of $\mathrm{Q}_{\text {net }}$, suggesting a coherence between $P-E$ and $\mathrm{Q}_{\text {net }}$ over the global ocean. A strengthening of the global winds in the 1990s is observed, followed by a period of no trend in the 2000s. The time series showed also a dip in 2009, lagging behind $\mathrm{Q}_{\text {net }}$ and $P-E$ by one year, and the mean level of the global winds was slightly lower thereafter.

\section{f. Sea level variability and change-P. R. Thompson,}

M. A. Merrifield, E. Leuliette, W. Sweet, D. P. Chambers, B. D. Hamlington, S. Jevrejeva, J. J. Marra, G. T. Mitchum, R. S. Nerem, and M. J. Widlansky

Global mean sea level (GMSL) during 2017 became the highest annual average in the satellite altimetry record (1993-present), rising to $77 \mathrm{~mm}$ above the 1993 average (Fig. 3.15a). This marks the sixth consecutive year (and 22nd out of the last 24) that GMSL increased relative to the previous year. The new high reflects the ongoing multidecadal trend in GMSL during the satellite altimetry era, $3.1( \pm 0.2) \mathrm{mm} \mathrm{yr}^{-1}$ (Fig. 3.15a), which continues unabated despite relaxing to neutral to weak La Niña conditions following the 2015/16 El Niño (see Section $4 b$ ).

An early section of the GMSL time series from satellite altimetry (1993-99) was updated during 2017 to reflect a reevaluation of an algorithm designed to detect drift in the altimeter measurements due to thermal or other changes in the internal hardware of the instrument (Beckley et al. 2017). Applying this correction lowers the global mean rate of change over the altimeter record by $0.3 \mathrm{~mm} \mathrm{yr}^{-1}$ and increases quadratic acceleration (i.e., two times the quadratic coefficient in a second-order polynomial fit) to 0.1 $( \pm 0.04) \mathrm{mm} \mathrm{yr}^{-2}$. When effects of the Pinatubo volcanic eruption and ENSO are subtracted from GMSL variability, the estimated climate-change-driven acceleration in GMSL over the altimeter record is 0.084 $( \pm 0.025) \mathrm{mm} \mathrm{yr}^{-2}$ (Nerem et al. 2018).

Variations in GMSL (Fig. 3.15a) result from changes in both the mass and density of the global ocean (Leuliette and Willis 2011; Chambers et al. 2017). From 2005 to present, increasing global ocean mass observed by the NASA Gravity Recovery and Climate Experiment (GRACE) accounted for approximately two thirds of the GMSL trend, $2.5( \pm 0.4) \mathrm{mm} \mathrm{yr}^{-1}$. The positive trend in ocean mass primarily resulted from melting of glaciers and ice sheets (see Sections $2 \mathrm{c}, 5 \mathrm{e}$, and $5 \mathrm{f}$ ), but these contributions from land ice were partially offset by increased hydrological storage of fresh water on land, accounting for $-0.7( \pm 0.2) \mathrm{mm} \mathrm{yr}^{-1}$ (Reager et al. 2016) of sea level change. Steric (i.e., density-related) sea level rise of $1.3( \pm 0.2) \mathrm{mm} \mathrm{yr}^{-1}$, as observed by the Argo profiling float array, is mostly owing to ocean warming and accounts for the balance of the GMSL trend since 2005. 
(a)

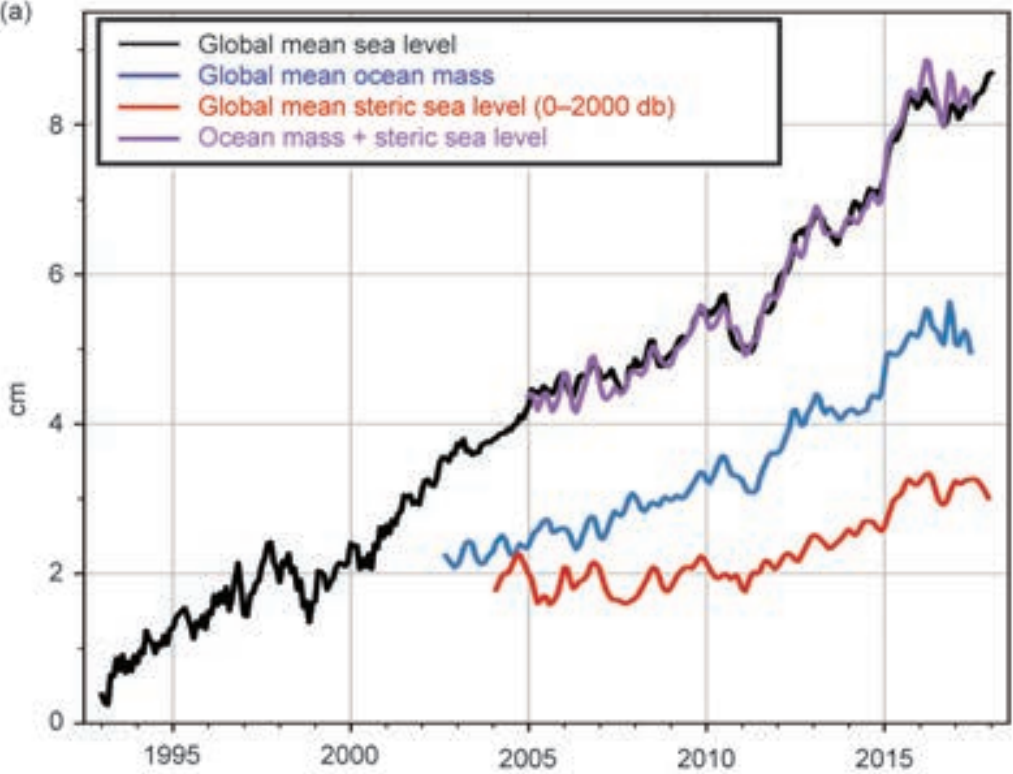

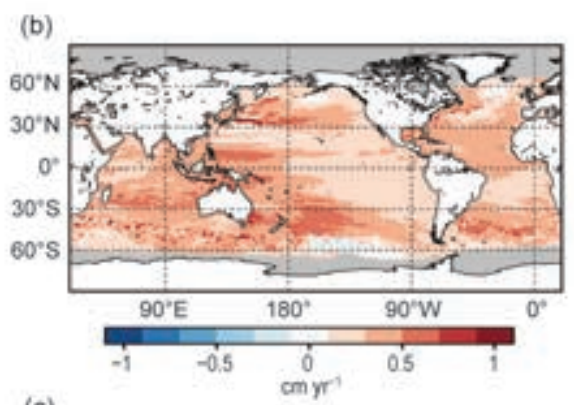

(c)

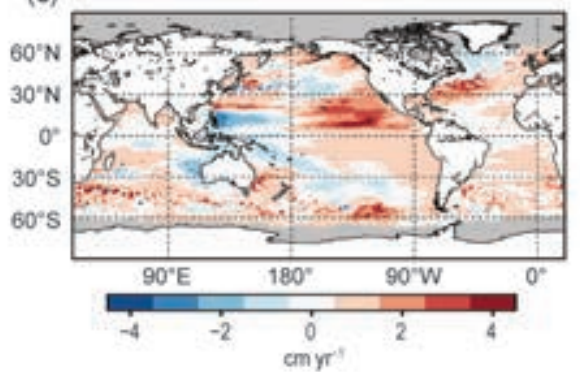

FIG. 3.I5. (a) Monthly averaged global mean sea level (cm; black line) observed by satellite altimeters (1993-20I7) from the NOAA Laboratory for Satellite Altimetry relative to the start of the altimeter time series in late 1992. Monthly averaged global ocean mass (blue line; 2003-Aug 2017) from GRACE. Monthly averaged global mean steric sea level (red line; 2004-I7) from the Argo profiling float array. Mass plus steric (purple line). All

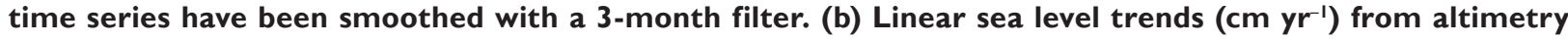
during 1993-2017. (c) Linear sea level trends (cm $\left.\mathrm{yr}^{-1}\right)$ from altimetry during 20I2-I7.

GMSL from altimetry observations increased from 2016 to 2017 by $0.9 \mathrm{~mm}$ (Fig. 3.15a). A majority of this moderate increase resulted from warming of the upper $400 \mathrm{~m}$ of the global ocean (see Fig. 3.5) and a $0.6 \mathrm{~mm}$ increase in global mean steric sea level observed by Argo (Fig. 3.15a). Unfortunately, the mass contribution to the year-over-year increase cannot be directly ascertained due to failure of an accelerometer on board one of the GRACE satellites, which resulted in only five months of valid GRACE observations during 2017 (January and March-June). Global ocean mass averaged over these five months of data (after removing the mean seasonal variability) decreased relative to the 2016 average equivalent to $4.8( \pm 2.4) \mathrm{mm}$ in sea level change, where the uncertainty represents one standard error accounting for the different number of data points in the 2016 and 2017 averages and the substantial monthly uncertainties in the 2017 data (Fig. 3.15a). Closing the sea level budget requires a small $(\sim 0.3 \mathrm{~mm})$ sea level equivalent for year-over-year increase in global ocean mass. Thus we can infer an approximate increase in global ocean mass equal to roughly $5 \mathrm{~mm}$ of sea level rise over the second half of 2017 to recover mass lost from the ocean early in the year.

Regional sea level trends can differ substantially from the global mean trend, but as the altimetry record has grown in length-capturing complete cycles of decadal oscillations in the process-the long-term trend map has become more uniform (Fig. 3.15b). During the altimetry era, rates of sea level change in the Indian Ocean and western tropical Pacific (3 to $7 \mathrm{~mm} \mathrm{yr}^{-1}$ ) generally exceed the global average rate while rates in the eastern Pacific ( 1 to $3 \mathrm{~mm} \mathrm{yr}^{-1}$ ) are below the global mean. East-west trend differences across the Pacific result from fluctuations in trade winds, which strengthened during a multidecadal trend toward the La Niña-like phase of the PDO during the first 15-20 years of the satellite record (e.g., Merrifield 2011). More recently, a trend toward El Niño-like conditions during 2012-17 resulted in a reversal of the Pacific zonal trend pattern (Hamlington et al. 2016) with a majority of the eastern Pacific experiencing rates of sea level rise greater than $10 \mathrm{~mm} \mathrm{yr}^{-1}$ (Fig. 3.15c). Over the same period, positive sea level trends in the North Atlantic subtropical gyre opposed negative sea level trends in the subpolar gyre (Fig. 3.15c). The recent North Atlantic trends suggest increasing gyre strength, which is coincident with a positive trend in the North Atlantic Oscillation (NAO). The tendency toward a positive NAO state in recent years represents a reversal of decadal trends in the Atlantic observed in leading modes of wind-stress curl over the basin throughout the 1990s and 2000s (Häkkinen et al. 2013). 


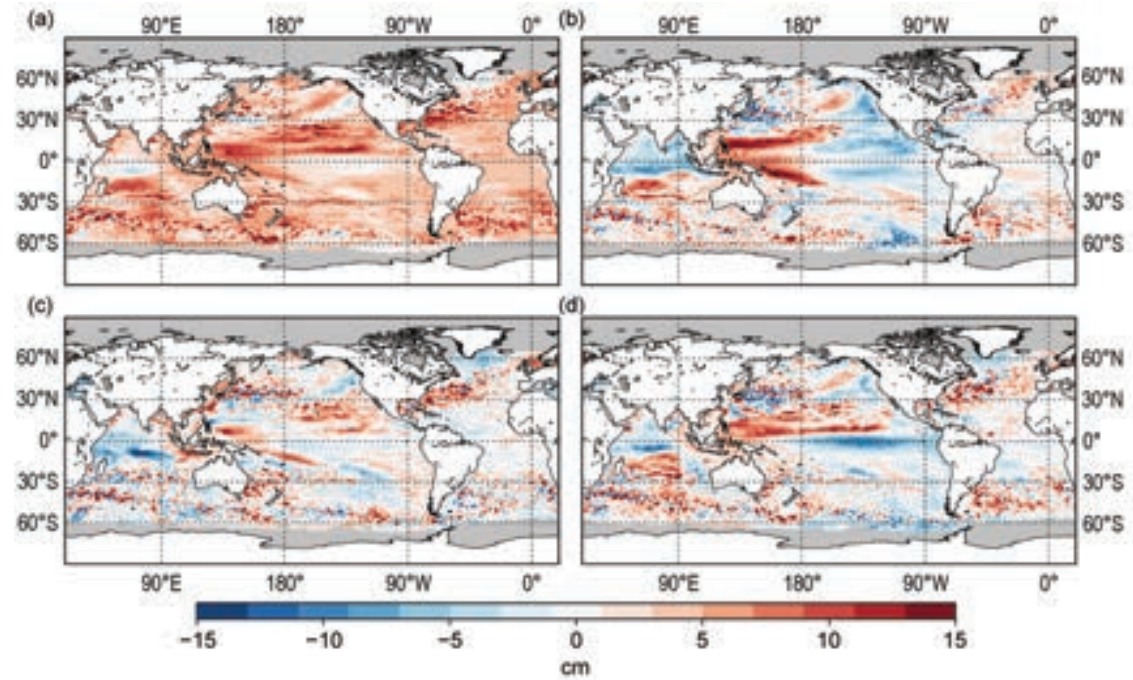

FIG. 3.16. (a) Annual average sea level anomaly during 2017 relative to the average sea level at each location during 1993-2017. (b) Average 2017 sea level anomaly minus 2016. (c) Average sea level anomaly during Dec 2016Feb 2017 (DJF) relative to the DJF average during 1993-20I7. (d) Same as (c), but for Sep-Nov 2017. GMSL was subtracted from (c) and (d) to emphasize regional, non-secular change. Altimetry data were obtained from the gridded, multimission product maintained by the Copernicus Marine and Environment Monitoring Service (CMEMS).

Positive annual sea level anomalies spanned most of the global ocean during 2017 (Fig. 3.16a), which primarily reflects the global mean trend relative to the 1993-2017 climatology. The change in annual mean sea level from 2016 to 2017 (Fig. 3.16b; similar to $\mathrm{OHC}$, see Fig. 3.4b) shows an increase in the western tropical Pacific and decrease in the eastern tropical Pacific. This zonal pattern is consistent with the continuation of ENSO-neutral to weak La Niña conditions during most of 2017 in contrast to 2016, which began in a strong El Niño state. Despite decreased trade wind strength over the North Pacific from 2016 to 2017 (see Fig. 3.13b), sea level increased in the western North Pacific due in part to downwelling (i.e., positive sea level) oceanic Rossby waves propagating east to west across the basin during the year (Figs. 3.16c,d). These propagating anomalies were likely reinforced by a tendency toward downwelling Ekman pumping anomalies at low latitudes north of the equator (see Fig. 3.13d). A similar tendency toward downwelling Ekman pumping occurred south of the equator, which likely accounts for the increase in sea level in the western South Pacific.

Tendencies in the Indian Ocean show decreased sea level from 2016 to 2017 across the equatorial and north Indian Ocean (ENIO) while sea levels increased in the south Indian Ocean subtropical gyre region (Fig. 3.16b). The Indian Ocean tendencies are most likely linked to an increase in trade wind strength south of the equator (see Fig. 3.13d) and are consistent with the tendency toward enhanced westward geostrophic surface currents in the region of the Indian Ocean South Equatorial Current (see Fig. 3.18b). Increasing trades in the region create more negative wind-stress curl near the equator, which in turn enhances subtropical and cross-equatorial overturning cells (e.g., Miyama et al. 2003) that can lead to near-uniform variability in sea level across the ENIO (Thompson et al. 2016).

Ongoing trends and yearto-year changes in sea level impact coastal communities by increasing the magnitude and frequency of positive sea level extremes that cause flooding and erosion. In many areas, coastal infrastructure is currently exposed to nuisance-level (i.e., minorimpact) flooding when water levels exceed a threshold defined by the top $1 \%$ of observed daily maxima from a global network of tide gauges (Sweet et al. 2014). These thresholds vary geographically (Fig. 3.17a) but are typically around $0.5 \mathrm{~m}$ above mean higher high water (MHHW) - the average of observed daily maxima-and are expected to be exceeded 3-4 times per year. Most locations along the U.S. East Coast experienced greater-than-expected numbers of exceedances during 2017 (Fig. 3.17b), due in part to mean sea level trends in the region that exceed the global mean rate at multiple time scales (Figs. 3.15b,c). The number of events over most of the U.S. East Coast in 2017 decreased relative to 2016 (Fig. 3.17c), however, as mean sea levels decreased year-over-year in the western North Atlantic (Fig. 3.16b). Year-over-year increases in threshold exceedances occurred across the tropical North Pacific and along the western coast of South America (Fig. 3.17c). The increase in the North Pacific, including Hawaii (see Sidebar 3.2), is at least partially related to the positive sea level anomalies propagating across the region during 2017 (Figs. 3.16c,d). In contrast, increased exceedances along the western coast of South America cannot be readily attributed to mean sea level change, as neither trends nor annual sea level anomalies are anomalous in the region. 

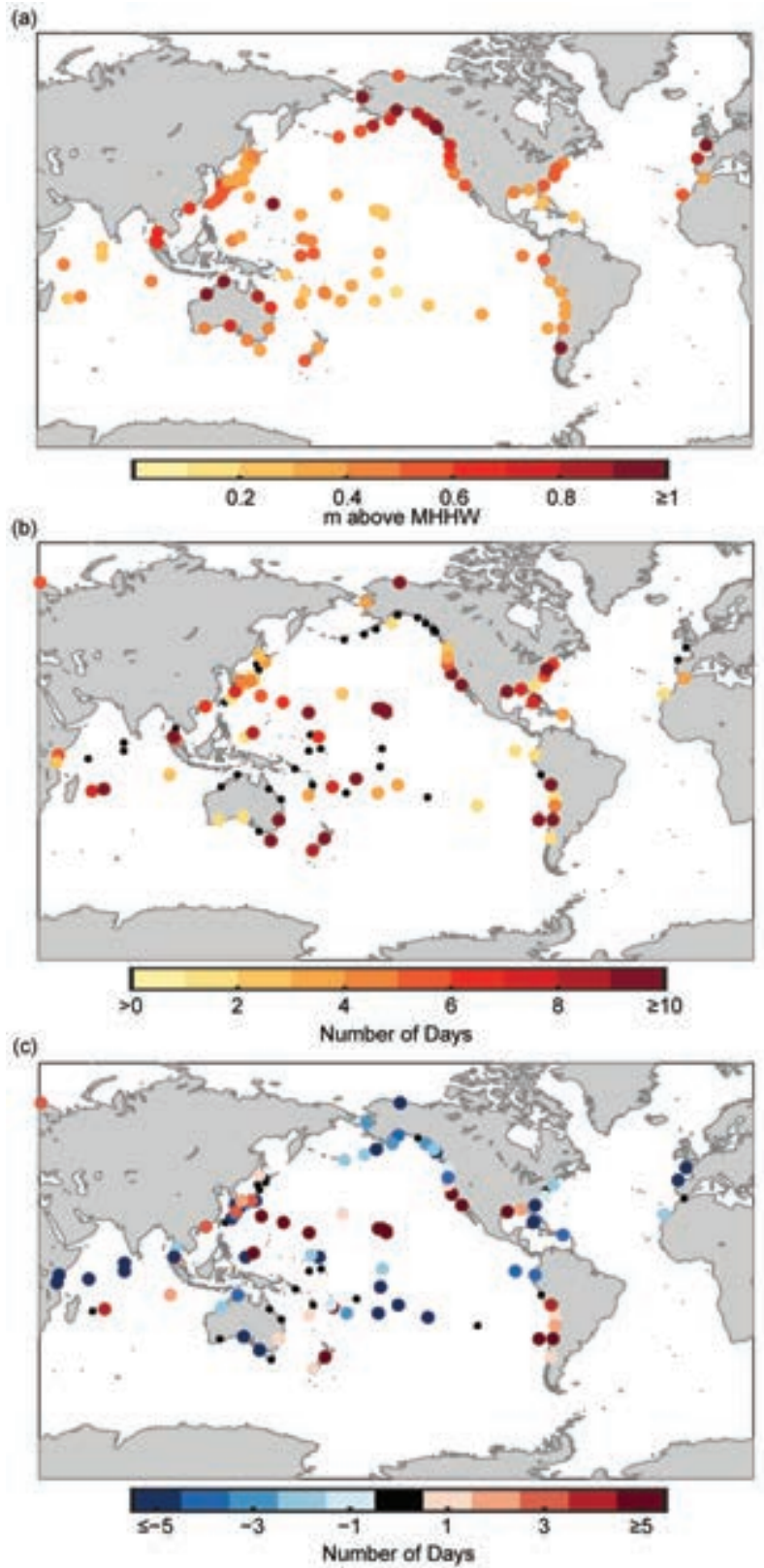

FIG. 3.I7. (a) Nuisance-level flooding thresholds defined by the level of the top $I \%$ of observed daily maxima during 1998-2016 from tide gauge records. Units are in meters above mean higher high water (MHHW) calculated over 1998-2016. (b) Number of daily maximum water levels during 2017 above the thresholds in (a). Small, black circles in (b) and (c) indicate a value of zero. (c) Same as in (b), but for 2017 minus 2016. Daily maximum water levels were calculated from hourly tide gauge observations obtained from the University of Hawaii Sea Level Center Fast Delivery database. Only records with at least $80 \%$ completeness during 1996-2016 and $80 \%$ completeness during 2017 were analyzed. g. Surface currents - R. Lumpkin, G. Goni, and K. Dohan

This section describes ocean surface current changes, transports derived from ocean surface currents, and features such as rings inferred from surface currents. Surface currents are obtained from in situ (global array of drogued drifters and moorings) and satellite (altimetry, wind stress, and SST) observations. Transports are derived from a combination of sea height anomaly (from altimetry) and climatological hydrography. See the State of the Climate in 2011 report for details of these calculations. Zonal surface current anomalies are calculated with respect to a 1992-2007 climatology and are discussed below for individual ocean basins.

\section{I) Pacific Ocean}

In 2017, the Pacific basin exhibited annual mean zonal westward current anomalies of $5-20 \mathrm{~cm} \mathrm{~s}^{-1}$ at $1^{\circ}-7^{\circ} \mathrm{N}$ across much of the basin (Fig. 3.18a), with peak values of $20 \mathrm{~cm} \mathrm{~s}^{-1}$ at $6^{\circ} \mathrm{N}, 125^{\circ}-145^{\circ} \mathrm{W}$. This anomaly had two proximate causes: a northward shift of the North Equatorial Countercurrent (NECC), normally centered on $7^{\circ} \mathrm{N}$ but in 2017 on $8^{\circ} \mathrm{N}$; and a strengthened northern South Equatorial Current (nSEC) at $2^{\circ} \mathrm{N}$, which is $50 \mathrm{~cm} \mathrm{~s}^{-1}$ westward in the annual climatology but averaged $60 \mathrm{~cm} \mathrm{~s}^{-1}$ in

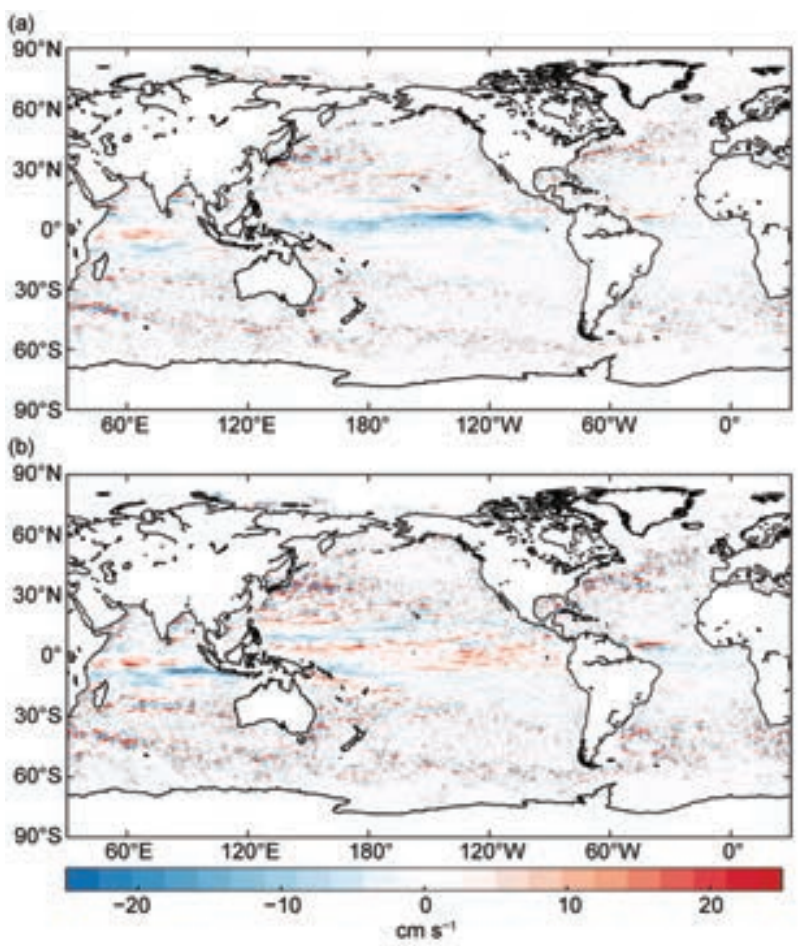

Fig. 3.18. Annually averaged geostrophic zonal surface current anomalies ( $\mathrm{cm} \mathrm{s}^{-1}$ ) for (a) 2017 relative to a 1992-2007 climatology and (b) 2017 minus 2016 zonal currents $\left(\mathrm{cm} \mathrm{s}^{-1}\right)$ derived from a synthesis of drifters, altimetry, and winds. 

AND P. R. THOMPSON

The Hawaiian Islands experienced record-high sea levels during 2017 (Fig. SB3.3; also see Fig. 3.17b), which caused nuisance flooding in vulnerable coastal communities and exacerbated beach erosion, especially around times of highest tides. During April and May, tide gauges throughout the main

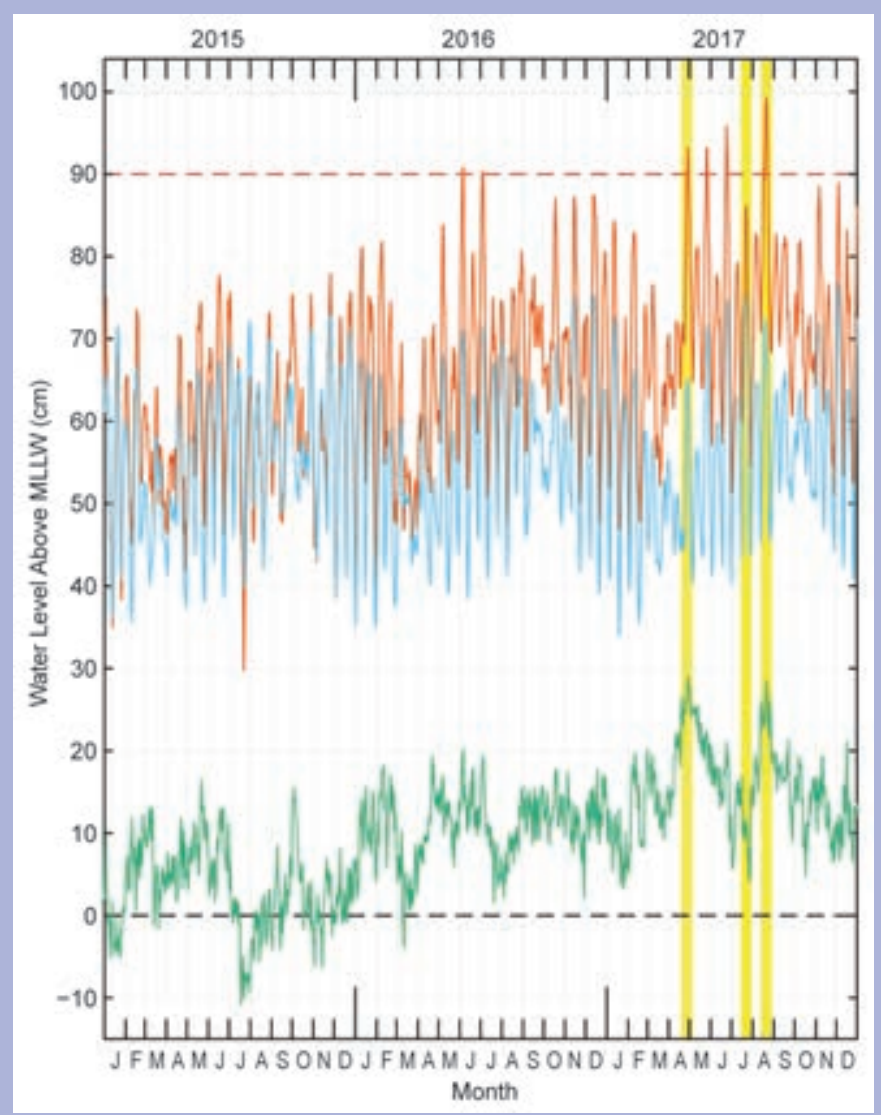

FIG. SB3.3. Daily maximum hourly sea levels $(\mathrm{cm})$ for Honolulu, HI. Tide predictions (blue) are based on harmonic analysis of the Honolulu Harbor sea level recorded during the NTDE (1983-200I). Predictions and observations (orange) are with respect to the MLLW datum. Residuals between the observed sea levels and the tide prediction are

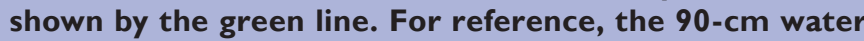
level is shown (dashed horizontal line), which is a threshold for coastal impacts near Honolulu.
Hawaiian Islands recorded water levels that were $20-30 \mathrm{~cm}$ above the astronomical tidal predictions (levels expected based only on the Earth-Moon-Sun's gravitational pull upon the ocean). On 21 August 2017, the tide gauge in Honolulu Harbor observed the highest hourly water level, $99 \mathrm{~cm}$ above mean lower low water (MLLW), since records began in 1905. In addition to this new maximum, the gauge registered an unprecedented number of high-water events. In the II2-year record, sea level in Honolulu Harbor exceeded $90 \mathrm{~cm}$ above MLLW-the approximate level of nuisance flooding-on just 40 days; 15 of those days occurred during 2017. The highest observed water levels generally occurred under clear skies with wind and rain playing little to no role in the flooding impacts.

The repeated flooding events on fair-weather days during 2017 generated substantial scientific and media interest. Near-real-time analyses of tide gauge observations and satellite-based altimetry measurements of sea surface heights around Hawaii allowed the above-normal sea levels to be broken down into five primary contributions: I) long-term sea level rise, 2) seasonally high astronomical tides, 3) oceanic planetary waves, 4) oceanic mesoscale eddies, and 5) an inverse-barometer effect of low atmospheric pressure on the ocean. This combination of processes contributing to high sea levels in Hawaii has become known as Nu'a Kai, which means "piled ocean" in the Hawaiian language and helps to convey the sense of multiple components of sea level variability stacking together to produce tangible impacts at the coast.

Any one component of Nu'a Kai would not have caused extreme high sea levels on its own. Long-term sea level rise relative to the National Tidal Datum Epoch (NTDE; 1983200I), on which tidal datums are based, is approximately $4 \mathrm{~cm}$ near Hawaii. However, sea level rose during the 20 th century more than $12 \mathrm{~cm}$ prior to the current NTDE, and none of the 2017 events would have reached nuisanceflood levels without this long-term trend. Large-scale (>500 km in zonal width) anomalies raised background sea level around the Hawaiian Islands during most of 2017 (see Figs. $3.16 \mathrm{c}, \mathrm{d}$ ), including 13 and $16 \mathrm{~cm}$ above normal during
2017. Because 2016 on average had similar westward anomalies over a broader area, the 2017 minus 2016 tendencies (Fig. 3.18b) do not show this feature but instead exhibit narrow bands of eastward anomaly differences. The northward shift of the NECC also produced eastward anomalies of $\sim 10 \mathrm{~cm} \mathrm{~s}^{-1}$ at $8^{\circ}-12^{\circ} \mathrm{N}$. On the equator, eastward anomalies of $10-15 \mathrm{~cm} \mathrm{~s}^{-1}$ were at $0^{\circ}-1^{\circ} \mathrm{S}$, associated with the presence of a $\sim 10 \mathrm{~cm} \mathrm{~s}^{-1}$ equatorial surface countercurrent not present in the 1992-2007 climatology.

From the start of 2017, all of the major anomalies present in the annual average anomaly map were 
the highest water level events of April and August, respectively (highlighted in Fig. SB3.3). These anomalies were associated with an oceanic Rossby (planetary) wave, which propagated slowly westward across the tropical North Pacific over the past year. In addition, a series of energetic mesoscale eddies impinged on Hawaii, either elevating or lowering sea levels depending on whether they were anti-cyclonic or cyclonic. Anti-cyclonic eddies near Honolulu during flood events in April and August raised sea levels by 10 and $5 \mathrm{~cm}$, respectively (Fig. SB3.4). Low atmospheric pressure made additional, nonnegligible contributions to Nu'a Kai via the inverse-barometer effect during April and August, increasing water levels by an additional 4 and $2 \mathrm{~cm}$. In total, the sum of all non-tidal components of the highest levels during April and August was close to $30 \mathrm{~cm}$ above MLLW, but the relative contributions of each component differed in each case.

The coastal impacts of the non-tidal contributions to Nu'a Kai described above (e.g., overwash and erosion of the famed Waikiki Beach) occurred during seasonally large astronomical high tides, which contributed another 7 and $16 \mathrm{~cm}$ above the average tidal range in April and August, respectively. Astronomical tides are a necessary component of Nu'a Kai, but the highest sea levels of 2017 did not occur during the month with the highest high tides of the summer (July; Fig. SB3.3). During the highest tides of July, a cyclonic eddy near Honolulu lowered sea level by $6 \mathrm{~cm}$ (Fig. SB3.4), which cancelled much of the large-scale contribution to Nu'a Kai (the inverse-barometer effect was negligible). As a result, at no time during July did the Honolulu tide gauge record water levels above $90 \mathrm{~cm}$ and no significant coastal impacts occurred, unlike during April and August when astronomical tide cycles were less extreme.

There is a pressing need to understand the causes and implications of the unprecedented number of high sea level events across Hawaii during 2017, because increasing global mean sea level rise will increase the frequency of such periods of coastal flooding in the future (see Fig. 3.15a). Whereas the magnitude of each component of Nu'a Kai can be reasonably well-quantified in hindsight, a number of questions remain concerning the forcing, duration, and probability of reoccurrence. Most importantly, the largest non-tidal components of $\mathrm{Nu}$ 'a Kai are oceanic Rossby waves and mesoscale eddies. Eddies can be difficult to predict, which makes it challenging for those affected by Nu'a Kai to prepare for the events. Researchers at the University of Hawaii are working toward high sea level forecast products, which will be improved by more complete dynamical understanding. By the end of 2017 , Honolulu sea level anomalies decreased relative to earlier in the year, but levels remained above normal.

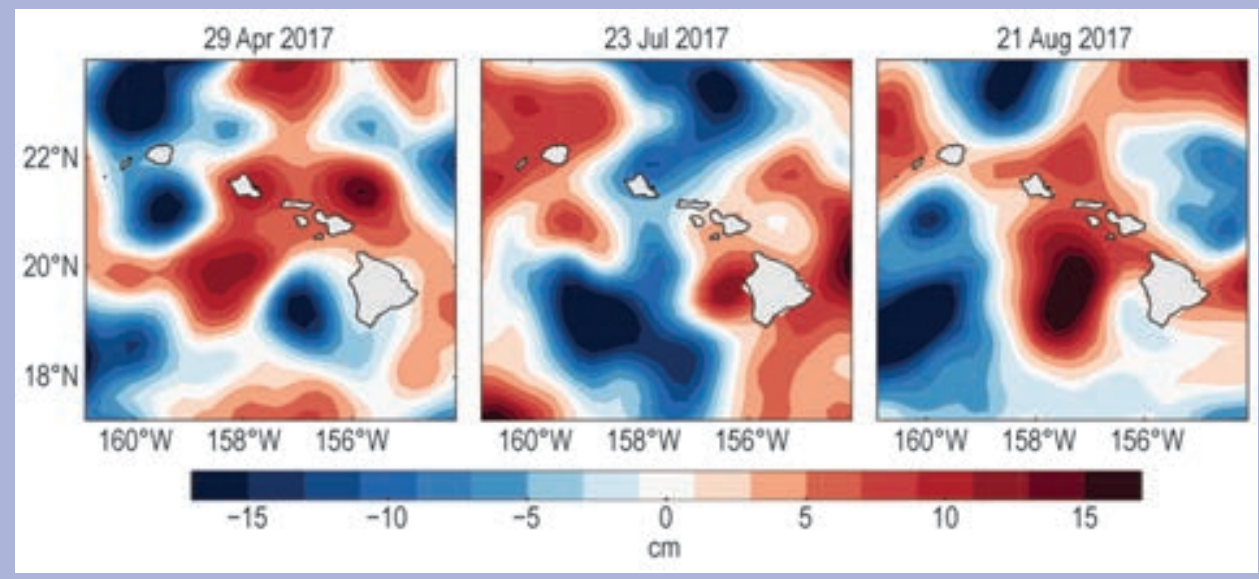

FIG. SB3.4. Daily mean sea surface height anomalies $(\mathrm{cm})$ from satellite altimetry (CMEMSIAVISO). The spatial mean has been removed over the domain of each map to highlight mesoscale structure.

already established. The evolution of these features through the year (Fig. 3.19) was as follows:

Eastward anomalies of $20-33 \mathrm{~cm} \mathrm{~s}^{-1}$ were present in the central and eastern equatorial Pacific in January 2017 , with peak values at $0^{\circ}-1^{\circ} \mathrm{S}, 115^{\circ}-155^{\circ} \mathrm{W}$, associated with the anomalous surface equatorial countercurrent. These anomalies intensified in February to maximum values of $40 \mathrm{~cm} \mathrm{~s}^{-1}$ and persisted through March. While the countercurrent did not weaken significantly in April, anomalies were weaker because the climatological flow reverses to eastward at these latitudes in April. This situation was 
(a)

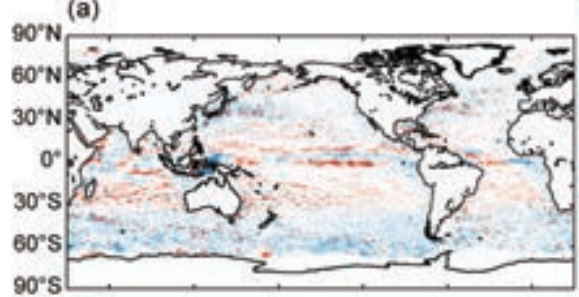

(c)

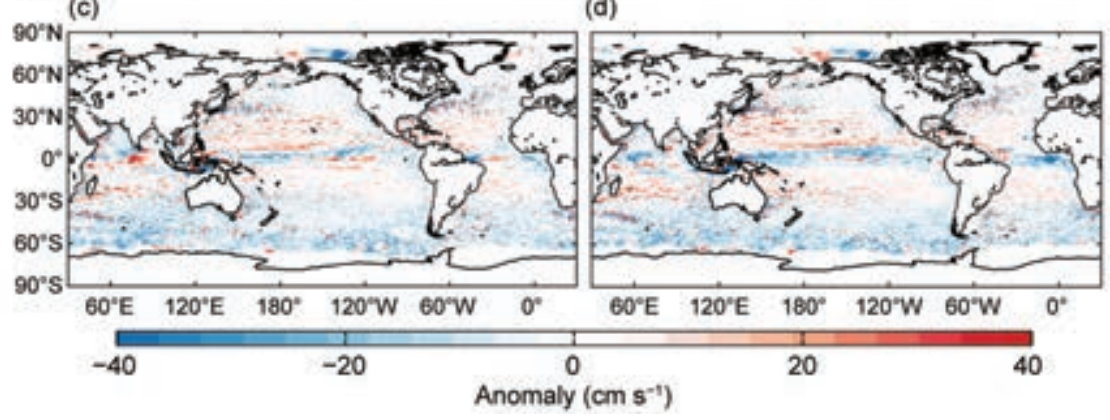

FIG. 3.19. Seasonally averaged zonal geostrophic surface current anomalies $\left(\mathrm{cm} \mathrm{s}^{-1}\right)$ with respect to a 1992-2007 seasonal climatology, for (a) Dec 2016Feb 2017, (b) Mar-May 2017, (c) Jun-Aug 2017, and (d) Sep-Nov 2017. (b)

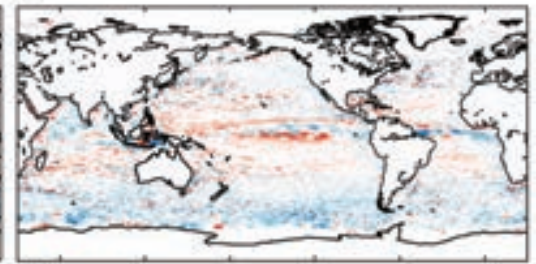

(d)

Kuroshio has remained close to its climatological latitude. These shifts reflect a decadal stable/unstable oscillation of the Kuroshio jet (Qiu and Chen 2005), which shifts to the north when it intensifies and becomes stable, thus lowering eddy kinetic energy (EKE). Averaged in the downstream Kuroshio jet region $32^{\circ}-38^{\circ} \mathrm{N}$ $141^{\circ}-153^{\circ} \mathrm{E}$, (Qiu and Chen 2005) EKE was low in 1994/95, elevated in 1999-2001, low in $2002 / 03$, reached a peak in 2005 , and then decreased from 2009 to 2015. Since 2015, EKE has remained relatively steady (at interannual time scales) and somewhat lower than the 1993-2017 average in

maintained through June. In July, when the climatological equatorial current reverses again to westward, the flow was near zero (an eastward anomaly of $5-10 \mathrm{~cm} \mathrm{~s}^{-1}$ ). By August, the equatorial current was westward (no longer a countercurrent) and remained close to climatology for the remainder of the year.

The northward shift of the NECC was already present in January 2017. By March, core speeds of the NECC were a maximum of $25-30 \mathrm{~cm} \mathrm{~s}^{-1}$ at $8^{\circ} \mathrm{N}$, compared to $20 \mathrm{~cm} \mathrm{~s}^{-1}$ at $7^{\circ} \mathrm{N}$ in the March climatology. Eastward velocity associated with the NECC extended north to $11^{\circ} \mathrm{N}$, compared to $9.5^{\circ} \mathrm{N}$ in climatology. Anomalies with respect to the April climatology were dramatic, as the NECC maintained its intensity through the month when it weakens in climatology. However, the NECC then rapidly weakened, becoming anomalously weak (westward anomalies of $\sim 5 \mathrm{~cm} \mathrm{~s}^{-1}$ ) in May. For the remainder of the year, the NECC was close to its climatological strength, with a core latitude also matching climatology in June-August and a shift to the north with respect to climatology in September-December.

In all months of 2017, the northern branch of the SEC was faster to the west than in climatology, with little seasonal variation in the magnitude of this anomaly as the current followed typical seasonal variations, weakening from March to May and strengthening from June to October.

As noted in earlier State of the Climate reports (e.g., Dohan et al. 2015), the Kuroshio was shifted anomalously northward in 2010-14, although this shift diminished during 2014. During 2015 through 2017, the the downstream Kuroshio jet region, while exhibiting intra-annual variations such as a short-lived increase in mid-2016. During 2017, EKE in the region averaged $0.10 \mathrm{~m}^{2} \mathrm{~s}^{-2}$ compared to the 1993-2017 average of $0.18 \mathrm{~m}^{2} \mathrm{~s}^{-2}$.

Changes in the equatorial Pacific current system that advect surface waters across the basin result in anomalies in the SST fields. The behavior of the surface current anomalies in this region is an indicator of upcoming SST anomalies with surface current anomaly behavior leading SST anomalies by several months. This leading nature can be seen in the first

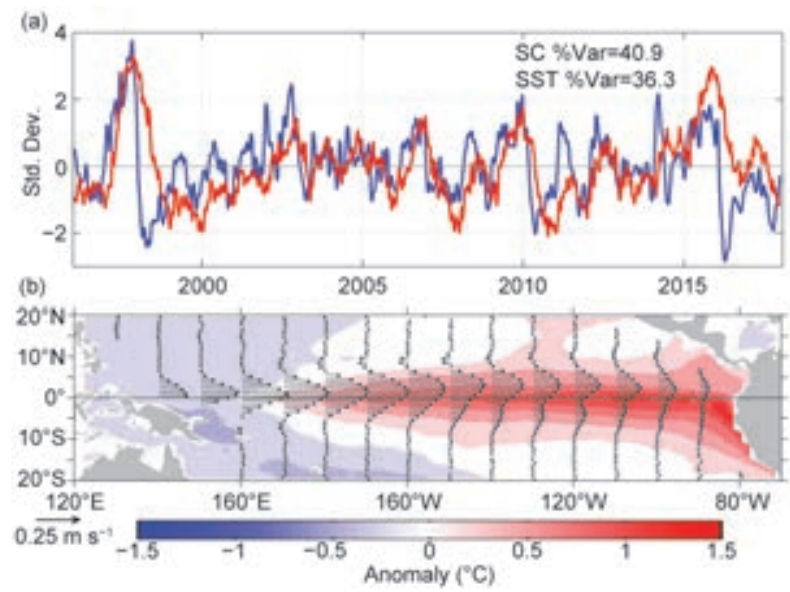

FIG. 3.20. Principal EOF of surface current (SC; $\left.\mathrm{m} \mathrm{s}^{-1}\right)$ and of SST anomaly $\left({ }^{\circ} \mathrm{C}\right)$ variations in the tropical Pacific from the OSCAR model (Bonjean and Lagerloef 2002; www.esr.org/enso_index.html). (a) Amplitude time series of the EOFs normalized by their respective std. dev. (b) Spatial structures of the EOFs. 
principal empirical orthogonal function (EOF) of surface current (SC) anomaly and separately the first EOF of SST anomaly in the tropical Pacific basin (Fig. 3.20). The maximum correlation between SC and SST anomalies is $\mathrm{R}=0.65$ for 1993-2017, with SC leading SST anomalies by 76 days. The year 2017 began with a continued lessening of the dramatic negative SC anomalies of 2016, approaching zero values in January. Although the EOF amplitude for SC anomalies was negative throughout 2017, this lessening coincided with an increase in positive SST anomalies, with a maximum SST EOF amplitude in March of 0.9 standard deviations. As the year progressed the SC EOF amplitude decreased to a minimum of -1.9 standard deviations in October. The SST EOF followed this trend with a steady decrease after the peak in March to a minimum of -1.2 standard deviations in December. The year ended with SC anomalies again approaching zero.

\section{2) INDIAN OCEAN}

The annually averaged near-equatorial current in the Indian Ocean basin is eastward, reflecting the dominance of the Southwest Monsoon Current in the annual average. During 2017, the mean current near the equator had peak values of $33-35 \mathrm{~cm} \mathrm{~s}^{-1}$, somewhat elevated from its climatological average

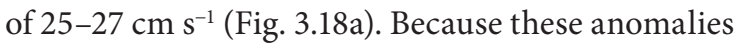
were much stronger in 2017 than in 2016, the 2017 minus 2016 tendencies (Fig. 3.18b) are negative on the equator. An examination of the month-by-month development of these anomalies reveal that they reflect a much stronger-than-average Southwest Monsoon Current during July-October 2017. Maximum eastward anomalies of $30-35 \mathrm{~cm} \mathrm{~s}^{-1}$ were observed at $1^{\circ}-2^{\circ} \mathrm{S}, 65^{\circ}-85^{\circ} \mathrm{E}$, in August.

\section{3) Atlantic Ocean}

Annual mean anomalies in the Atlantic Ocean (Fig. 3.18a) indicate an $\sim 15 \mathrm{~cm} \mathrm{~s}^{-1}$ strengthening of the eastward NECC at $5^{\circ}-6^{\circ} \mathrm{N}, 33^{\circ}-50^{\circ} \mathrm{W}$ and a $20-25 \mathrm{~cm} \mathrm{~s}^{-1}$ strengthening of the westward nSEC at $0^{\circ}-1^{\circ} \mathrm{N}, 25^{\circ} \mathrm{W}-0^{\circ}$. The year began with the NECC anomaly established but with an anomalously weak (by 5-10 $\mathrm{cm} \mathrm{s}^{-1}$ ) nSEC (Fig. 3.19). In February, strengthening of the nSEC had developed east of $24^{\circ} \mathrm{W}$ and spanned the basin in March. These anomalies weakened through April and May, and in June-August the nSEC was close to climatology. Westward anomalies again developed in the nSEC in September and persisted through November. In December, the nSEC was close to its climatological December strength.
The changes in transport and location of several key surface currents and mesoscale rings associated with them in the Atlantic Ocean basin are continuously monitored using satellite altimetry observations (www.aoml.noaa.gov/phod/altimetry/cvar/index .php). During 2017, the number of rings shed by the Agulhas and North Brazil Currents, which are partly indicative of Indian-Atlantic and South-North Atlantic water mass exchanges, respectively, remained within their mean 1993-2017 values. The altimetryderived transports of the Agulhas, Malvinas, Brazil, North Brazil, and Florida Currents did not exhibit 2017 variations beyond one standard deviation from their mean 1993-2017 values. In the southwest Atlantic Ocean, the separation of the Brazil Current from the continental shelf break (located at $37.6^{\circ} \mathrm{S}$ in the mean) reveals the intrusion of subtropical waters into the subpolar region. Since 1993, this current has separated farther to the south from the continental shelf break by $3^{\circ}$ latitude (c.f., Lumpkin and Garzoli 2011; Goni et al. 2011). Compared to its mean value in 2016, the separation moved to the south by about $2^{\circ}$ latitude (see www.aoml.noaa.gov/phod/altimetry /cvar/mal/BM_ts.php), the largest southward shift in the altimeter time period 1993-present.

\section{h. Meridional overturning and oceanic heat transport circulation observations in the North Atlantic Ocean- M. 0. Baringer, J. Willis, D. A. Smeed, B. Moat, S. Dong, W. R. Hobbs, D. Rayner, W. E. Johns, G. Gonil, M. Lankhorst, and U. Send}

The Atlantic meridional overturning circulation (AMOC) and the Atlantic meridional heat transport (AMHT) carry warm near-surface water northward, provide heat to the atmosphere at northern latitudes, and carry colder deep water southward. Buckley and Marshall (2016) present a summary of the dynamical forcing mechanisms of the AMOC and AMHT and the role they play in regulating climate variability around the Atlantic sector. Owing to the large amounts of heat, carbon, and fresh water transported by the AMOC, climate models suggest accurate estimation of its rate of change is critical to understanding and predicting our changing climate (e.g., W. Liu et al. 2017; Rahmstorf et al. 2015). Even on short time scales the AMOC/AMHT can impact climate (e.g., Duchez et al. 2016). These recognitions have led to the implementation of enhanced observing systems of the strength of the AMOC in the subpolar North Atlantic (Lozier et al. 2017) and the subtropical South Atlantic (Ansorge et al. 2014). These new observing systems will eventually provide a more complete spatial picture of the state of the AMOC. 
In general, estimating the AMOC/AMHT amounts to summing ocean-spanning measurements of the velocity/heat transport horizontally and vertically over the full water column. As all relevant time and space scales cannot be simultaneously measured, all the current AMOC/AMHT time series estimates include trade-offs between one quantity and another and can have errors and biases that are dependent on observing system design (e.g., Sinha et al. 2018). The systems described herein include the AMOC/ AMHT observing systems at $41^{\circ} \mathrm{N}, 26^{\circ} \mathrm{N}$, and $16^{\circ} \mathrm{N}$ and $\mathrm{AMHT}$ at $41^{\circ} \mathrm{N}, 26^{\circ} \mathrm{N}$, and $35^{\circ} \mathrm{S}$, which represent the most complete, longest time AMOC/AMHT series currently available.

Studies have shown that density anomalies along the western boundary in particular are essential predictors of the strength of the AMOC (e.g., Le Bras et al. 2017; Yashayaev and Loder 2016), and subpolar density anomalies precede those in the subtropical gyre by $8-10$ years; hence, observing systems that measure western boundary variability are particularly essential. The Florida Current (FC; as the Gulf Stream is called at $26^{\circ} \mathrm{N}$ ) observing system is one such example that can provide a longer time perspective of possible AMOC variations (e.g., Frajka-Williams 2015). Providing data since 1982, this is the longest open ocean transport time series (Fig. 3.21). Additionally, FC and AMOC transport variations at all time scales are inversely linked to sea level variations along the east coast (e.g., Domingues et al. 2016). The median FC transport from the full record $(1982-2017)$ is $31.9( \pm 0.25) \mathrm{Sv}$ (one standard error of the mean assuming a 20-day integral time scale) with a small downward trend of $-0.29( \pm 0.23) S_{\text {Sv }}$ decade $^{-1}$ (errors estimating 95\% significance as above). The 2017 median FC transport was $32.3( \pm 1.6) \mathrm{Sv}$, slightly above the long-term average and the 2016 annual average. Daily FC transports compared to those of all previous years (Fig. 3.21a) indicate that 2017, unlike previous years, had few unusual transport anomalies (extremes defined as outside the 95\% confidence limits for daily values). During 2017 there were no high transport events and the only low transport anomaly that was sustained for more than a day occurred during 10-11 December 2017 (averaging $23.6 \mathrm{~Sv}$ ). The FC lagged by 8 years has its maximum positive correlation with the NAO (Fig. 3.21b). The FC lagged by 5 years has its maximum negative correlation with the Atlantic multidecadal oscillation (AMO). It continues to be inversely correlated with the difference between observed and astronomically predicted sea level at the Lake Worth tide gauge station (Fig 3.21a, significant at over the $99 \%$ significance level, correlation coefficient -0.57 and $28 \%$ of variance explained).

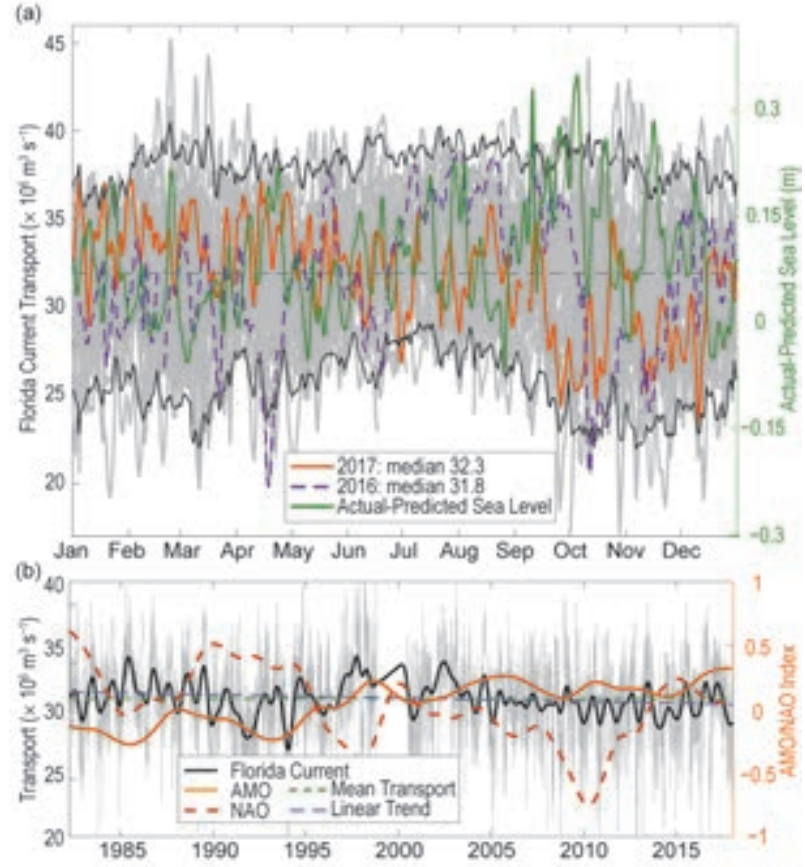

FIG. 3.2I. (a) Daily estimates of FC transport $\left(\times 10^{6} \mathrm{~m}^{3} \mathrm{~s}^{-1}\right)$ during 2017 (orange solid line), 2016 (dashed purple line), and 1982-2015 (light gray lines) with $95 \%$ confidence interval of daily transport values computed from all years (black solid line) and the longterm mean (dashed black line). Actual sea level minus predicted sea level at the Lake Worth tide gauge station (dark green line). (b) Daily estimates of FC transport $\left(\times 10^{6} \mathrm{~m}^{3} \mathrm{~s}^{-1}\right)$ for the full time series record (light gray), smoothed using a I2-month second-order Butterworth filter (heavy black line), mean transport for the full record (dashed black line), and linear trend from 1982 through 2017 (dashed blue line). Two-year low-passed AMO (orange line) and NAO (red dashed line) indices are also shown.

The FC time series contributes to the estimate of the AMOC at $26^{\circ} \mathrm{N}$ (Figs. 3.22, 3.23), where the AMOC is measured with full-water column moorings that span the full basin and include direct transport measurements in the boundary currents as part of the large RAPID-MOC/MOCHA/WBTS $26^{\circ} \mathrm{N}$ mooring array (Smeed et al. 2017). The data from these moorings are collected every 18 months, with AMOC data presented in this section extending from April 2004 to February 2017. In the latest update, adding data from October 2015 through February 2017, the AMOC has increased slightly with average AMOC of $17.2 \mathrm{~Sv}$ in 2016 and $17 \mathrm{~Sv}$ in part of 2017. This seeming stabilization of the downward trend in the AMOC has resulted in a statistically insignificant downward trend estimate of $-1.99( \pm 2.01) \mathrm{Sv}$ decade $^{-1}$, half the $-5.3 \mathrm{~Sv}$ decade ${ }^{-1}$ trend first noted in Smeed et al. (2014). This trend is entirely due to the in- 


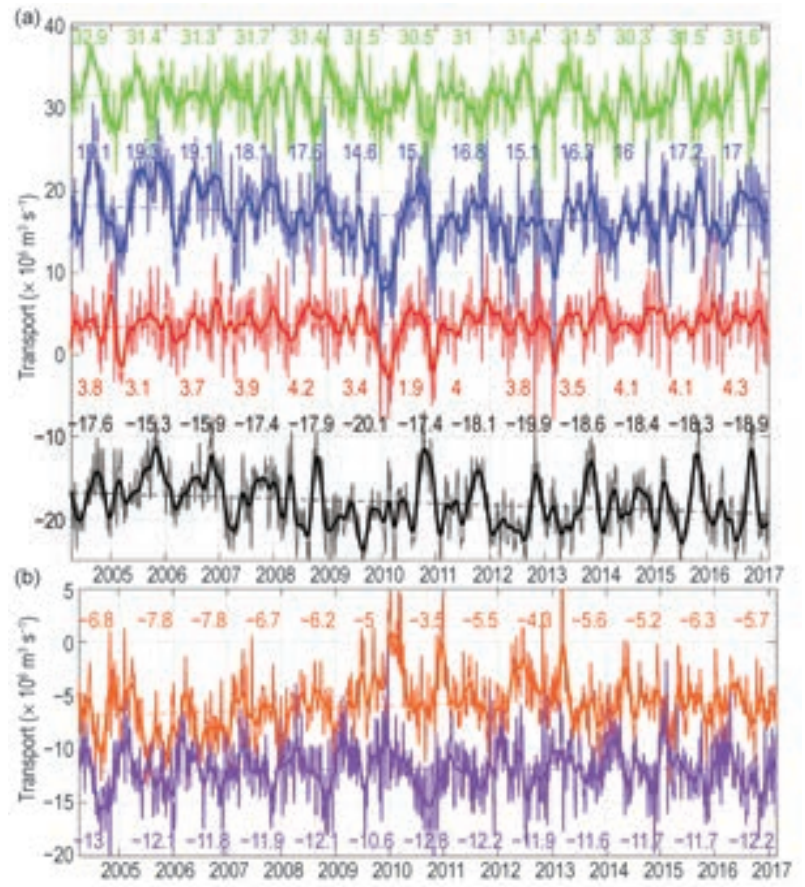

Fig. 3.22. (a) Daily estimates of the volume transport $\left(\times 10^{6} \mathrm{~m}^{3} \mathrm{~s}^{-1}\right)$ of the meridional overturning circulation (blue line) and its components, the FC (green line), wind-driven Ekman transport (red line), and the geostrophic interior (black line), as measured by the UK National Environmental Research Council (NERC) Rapid Climate Change Program (RAPID-WATCH), the National Science Foundation's Meridional Overturning and Heat transport Array proposal, and the NOAA Western Boundary Time Series project (WBTS). The volume transports have a 10 -day low-pass filter applied to the daily values and the annual median transports for each year are shown in the associated color text (Sv). (b) The deepest part of the MOC can be divided into upper deep water (1000-3000 m; orange) and lower deep water (3000-5000 m; purple) transports $\left(\times 10^{6} \mathrm{~m}^{3} \mathrm{~s}^{-1}\right)$.

crease in the southward near-surface interior flow of $-2.05( \pm 1.35)$ Sv decade ${ }^{-1}$ (Fig. 3.22, black dashed line), while the decrease in FC transport balances the increase in Ekman transport. The decrease in the AMOC at this latitude can be explained by the decreased export, $1.65( \pm 1.07) \mathrm{Sv}$ decade $^{-1}$, of upper North Atlantic Deep Water in the $1-3 \mathrm{~km}$ depth range, while the lowest layer remains fairly stable. Changepoint analysis shows that the AMOC time series trend is not linear but rather consists of a significant break or jump in the time series in 2008 (Smeed et al. 2018), and the baseline shift toward decreased AMOC was concurrent with changes of a southward shifting Gulf Stream and large-scale changes of sea surface temperature, sea surface height, and heat content.

AMOC estimates are also provided at $41^{\circ} \mathrm{N}$, where a combination of profiling Argo floats (that measure ocean temperature and salinity for the upper $2000 \mathrm{~m}$ on broad spatial scales, as well as velocity at $1000 \mathrm{~m}$ ) and altimetry-derived surface velocity (Willis 2010; Hobbs and Willis 2012) are used to estimate the AMOC (Fig. 3.23) and AMHT (not shown). This time series has been updated since last year's report (Baringer et al. 2017), extending from January 2002 to October 2017. Near $16^{\circ} \mathrm{N}$, the AMOC is estimated using a mooring array of inverted echo sounders, current meters, and dynamic height moorings (Send et al. 2011) that measure the flow below $1000 \mathrm{~m}$ (the southward flowing part of the AMOC "conveyor belt"); hence, the AMOC estimate at this latitude (Fig. 3.23) is a negative number (southward deep flow) to distinguish these observations from the full water column systems. These data have not been updated since last year's report and remain from February 2000 to September 2016. At $35^{\circ} \mathrm{S}$ in the South Atlantic, the AMOC and AMHT are estimated

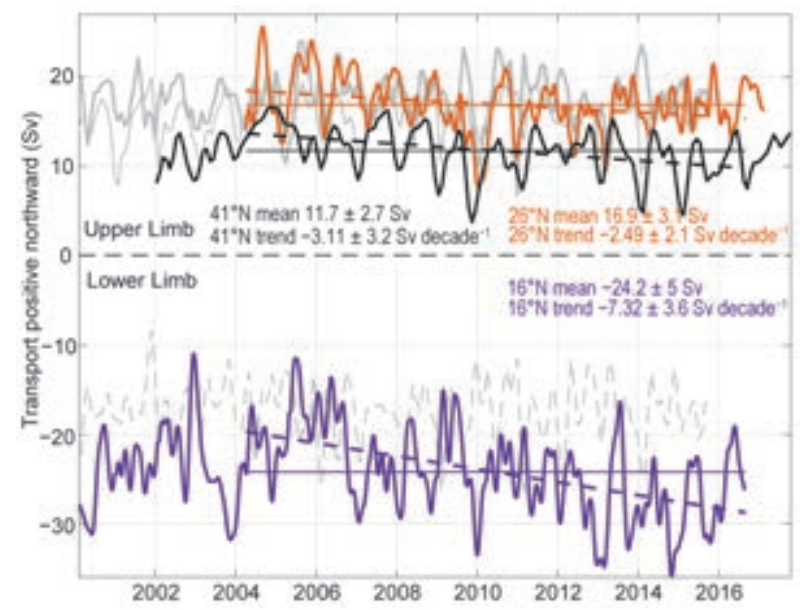

FIG. 3.23. Estimates of AMOC transports ( $\mathrm{S} \mathrm{Sv}=\times 10^{6} \mathrm{~m}^{3} \mathrm{~s}^{-1}$ ) from the Argo/Altimetry estimate at $41^{\circ} \mathrm{N}$ (black; Willis 20I0), the RAPID-MOC/ MOCHA/WBTS $26^{\circ} \mathrm{N}$ array (orange; Smeed et al. 2017), and the German/NOAA MOVE array at $16^{\circ} \mathrm{N}$ (purple; Send et al. 20II) shown vs. year. All time series have a 3-month second-order Butterworth low-pass filter applied. Horizontal lines are mean transports during similar time periods as listed in the corresponding text. Dashed lines are trends for each series over the time period with data available for all three series (Apr 2004 through Aug 2016). For MOVE data, the net zonal and vertical integral of the deep circulation represents the lower limb of the AMOC (with a negative sign indicating southward flow), and hence a stronger negative (southward) flow represents an increase in the AMOC amplitude. Light gray lines show ECCO2-derived transports (Menemenlis et al. 2008): (top) thin gray is the $41^{\circ} \mathrm{N}$ transport, thick gray is the $26^{\circ} \mathrm{N}$ transport, (bottom) the negative meridional overturning circulation in the model shown for ease of comparison with the $16^{\circ} \mathrm{N}$ data. 
using a combination of high-density (closely spaced) expendable bathythermograph (XBT) and broaderscale Argo profiling float data (Dong et al. 2014, not shown; www.aoml.noaa.gov/phod/soto/mht/ax18 /report.php). These data are collected and analyzed in near-real time, with values spanning July 2002 to September 2017.

Similar to $26^{\circ} \mathrm{N}$, at $41^{\circ} \mathrm{N}$ the AMOC and AMHT are decreasing less rapidly (Fig. 3.23), changing to $-0.08( \pm 2.7) \mathrm{Sv}_{\mathrm{decade}}{ }^{-1}$ and $-0.03( \pm 0.04) \mathrm{PW}$ decade $^{-1}$ as compared with $-1.2( \pm 3.0) \mathrm{Sv}$ decade $^{-1}$ and $-0.09( \pm 0.21) \mathrm{PW}$ decade $^{-1}$ reported last year. Farther south, the MOC/MHT trends are positive, but decreasing in the past three years as the annual means at $16^{\circ} \mathrm{N}$ increased from $-29.2 \mathrm{~Sv}$ in 2014 to $-27.8 \mathrm{~Sv}$ in 2015 to -23.8 in 2016 . This recent reduction in southward flow has led to a reduced estimate of the long-term trend of the AMOC from February 2000 to September 2016 at $16^{\circ} \mathrm{N}$ to be $+3.4( \pm 2.4) \mathrm{Sv}_{\text {decade }}{ }^{-1}$. While the $35^{\circ} \mathrm{S}$ AMOC transport estimate has remained fairly constant for the last three years (median AMOC of about $20 \mathrm{~Sv}$ ), during 2017 it was dominated by the Ekman component whereas in previous years it had been dominated by the geostrophic component. The variability at all latitudes in the Atlantic is not well correlated and, therefore, data from more than one latitude are needed to describe the state of the ocean.

i. Global ocean phytoplankton-B. A. Franz, E. M. Karaköylül, D. A. Siegel, and T. K. Westberry

Marine phytoplankton contribute roughly half the net primary production (NPP) on Earth, fixing atmospheric $\mathrm{CO}_{2}$ into food that fuels global ocean ecosystems and drives biogeochemical cycles (e.g., Field et al. 1998; Falkowski et al. 1998). Phytoplankton growth is dependent on availability of light and nutrients (e.g., iron, nitrogen, phosphorous) in the upper ocean euphotic zone, which in turn is influenced by physical factors such as ocean temperature (e.g., Behrenfeld et al. 2006). SeaWiFS (McClain 2009) and MODIS (Esaias et al. 1998) are satellite ocean color sensors that provide observations of sufficient frequency and geographic coverage to globally monitor changes in the near-surface concentration of the phytoplankton pigment chlorophyll- $a$ (Chla; $\mathrm{mg} \mathrm{m}^{-3}$ ), which serves as a proxy for phytoplankton abundance. Here, global Chla distributions for 2017 are evaluated within the context of the 20 -year continuous record provided through the combined observations of SeaWiFS (1997-2010) and MODIS on Aqua (MODISA, 2002-present). All Chla data used in this analysis correspond to NASA process-

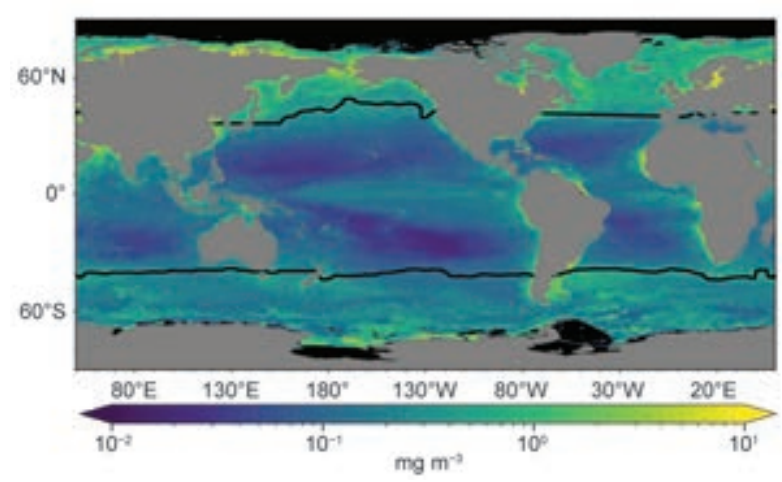

Fig. 3.24. Annual mean Chla distribution $\mathrm{mg} \mathrm{m}^{-3} \mathrm{de}-$ rived from MODIS on Aqua for 2017. Also shown is the location of the mean $15^{\circ} \mathrm{C}$ SST isotherm (black lines) delineating the boundary of the PSO. Chla data are from NASA Reprocessing version 2018.0. Data are averaged into geo-referenced equal area bins of approximately $4.6 \times 4.6 \mathrm{~km}^{2}$ and mapped to an equirectangular projection centered at $150^{\circ} \mathrm{W}$.

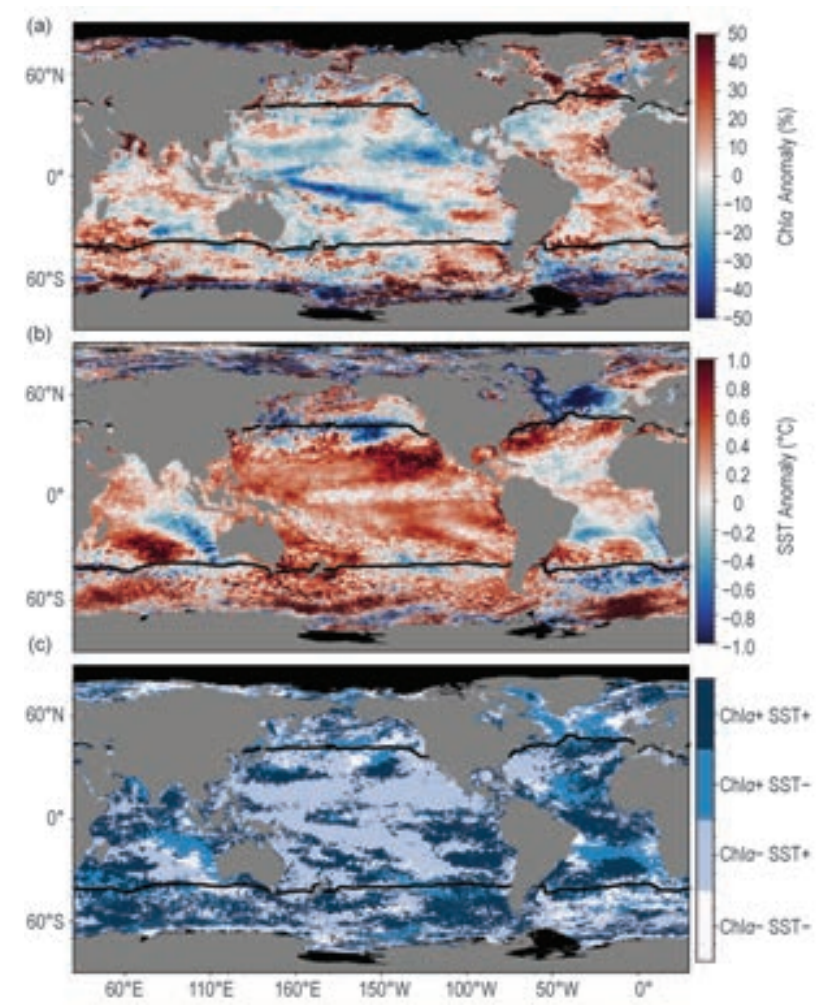

FIG. 3.25. Spatial distribution of average monthly (a) MODISA Chla anomalies and (b) SST anomalies where monthly differences were derived relative to the MODISA 9-year climatological record (2003-II). Chla is expressed as \% difference from climatology, while SST is shown as an absolute difference $\left({ }^{\circ} \mathrm{C}\right)$. (c) identifies relationships between the sign of SST and Chla anomalies from panels (a) and (b), with colors differentiating sign pairs and missing data masked in black. Also shown in each panel is the location of the mean $15^{\circ} \mathrm{C} \mathrm{SST}$ isotherm (black lines) delineating the PSO. 
ing version R2018.0 (https://oceancolor.gsfc.nasa.gov /reprocessing/), which utilizes common algorithms and calibration methods to maximize consistency in the multi-mission satellite record.

The spatial distribution of MODISA annual mean Chla for 2017 (Fig. 3.24) is consistent with the well-established, physically driven distribution of nutrients (Siegel et al. 2013) and surface mixed-layer light conditions (Behrenfeld et al. 2016). Chla values during 2017 ranged over three orders of magnitude, from $<0.02 \mathrm{mg} \mathrm{m}^{-3}$ in the central ocean gyres to $>20 \mathrm{mg} \mathrm{m}^{-3}$ in nutrient-rich coastal and subpolar waters. To assess changes in this distribution during 2017, mean values for MODISA Chla in each month of the year were subtracted from monthly climatological means for MODISA (2003-11). These monthly fields were then averaged to produce the global chlorophyll anomaly map for 2017 (Fig. 3.25a). Identical calculations were performed on MODISA sea surface temperature $\left({ }^{\circ} \mathrm{C}\right)$ data to produce an equivalent SST annual mean anomaly (Fig. 3.25b), used to illustrate the relationships between Chla and SST anomalies (Fig. 3.25c). Here the permanently stratified ocean (PSO) is defined as the region where annual average surface temperatures are $>15^{\circ} \mathrm{C}$ (black lines in Figs. 3.24 and 3.25) and is characterized by surface mixed layers that are typically low in nutrients and shallower than the nutricline (Behrenfeld et al. 2006).

Consistent with the establishment of weak La Niña conditions through much of 2017, Chla concentrations along the equatorial Pacific were neutral to slightly elevated $(<10 \%)$ above the climatological mean (Fig. 3.25a), reflecting the return of cooler, more nutrient-rich waters conducive to phytoplankton growth. Chla concentrations throughout much of the tropical Pacific, however, were generally diminished relative to climatological values (10\%-30\%) and inversely related to SST anomalies (gray areas above and below the equator in Fig. 3.25c). Annual mean SST anomalies (Fig. 3.25b) generally coincide with surface mixed layer depth (MLD) anomalies in the PSO, with warmer temperatures associated with shallower mixing, such that phytoplankton spend more time near the ocean's surface and thus have higher daily sunlight exposures than deeper mixing populations. Phytoplankton respond to this increased light by de- creasing their cellular chlorophyll levels (Behrenfeld et al. 2016). A secondary consequence of decreased MLD is a decrease in the vertical transport of nutrients to the surface layer, but coupling between the MLD and nutricline depths throughout much of the PSO is known to be weak (Lozier et al. 2011). Modestly depressed Chla concentrations (<10\%) were also observed throughout the Sargasso Sea and in the Mediterranean in 2017. Strongly elevated Chla concentrations were observed in the northern reaches of the North Atlantic (>30\%), with weaker increases observed throughout much of the South Atlantic and Indian Ocean regions. Within the boundaries of the PSO, an inverse relationship was generally observed between Chl $a$ and SST anomalies (light blue and gray colors in Fig. 3.25c), with some notable exceptions of positive correlations between Chl $a$ and SST anomalies in the South Atlantic and southwestern Pacific (dark blue colors in Fig. 3.25c). In regions outside the PSO, no clear relationship was observed between Chl $a$ and SST anomalies (Fig. 3.25c), consistent with previous studies (e.g., Behrenfeld et al. 2006; Franz et al. 2017).

Over the 20-year time series of spatially integrated monthly mean Chla values for the PSO (Fig. 3.26a) mean concentrations varied by $\sim 20 \%\left( \pm 0.03 \mathrm{mg} \mathrm{m}^{-3}\right)$ around a long-term average of $\sim 0.14 \mathrm{mg} \mathrm{m}^{-3}$. This variability includes significant seasonal cycles in

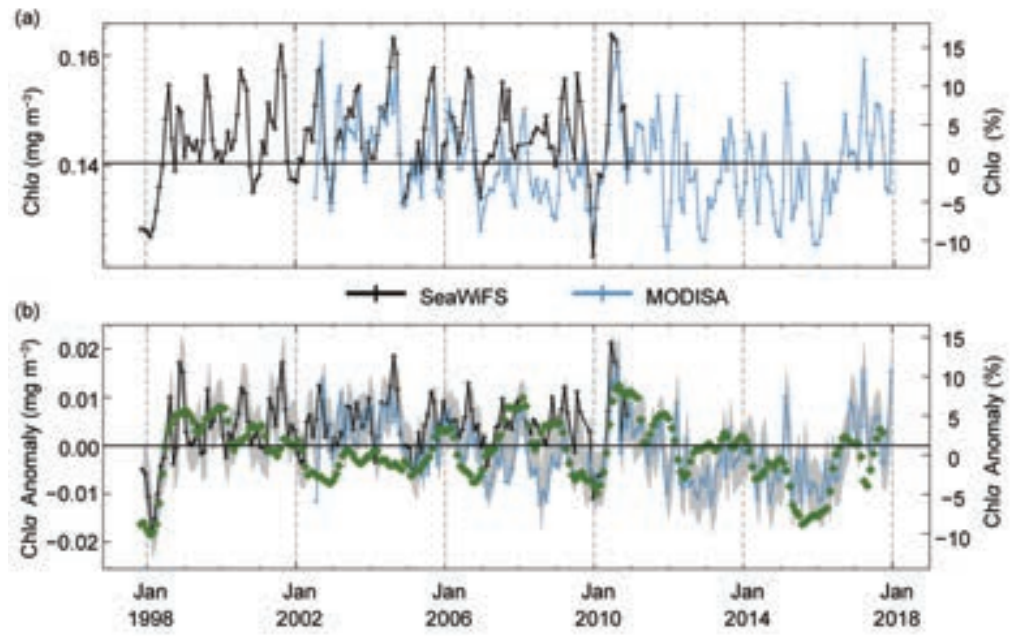

FIG. 3.26. 1998-20I7, multimission record of Chla averaged over the PSO for SeaWiFS (black) and MODISA (blue). (a) Independent record from each mission, with horizontal black line indicating the multimission mean Chla concentration for the region $\left(\mathrm{mg} \mathrm{m}^{-3}\right)$. (b) Monthly anomaly (\%) for SeaWiFS and MODISA after subtraction of the 9-year MODISA monthly climatological mean (2003-II) from each mission record. The gray region in (b) shows the averaged difference between SeaWiFS and MODISA over the common mission lifetime. Green diamonds show the MEI, inverted and scaled to match the range of the Chla anomalies. 
Chla distributions and responses to climatic events. The time series also demonstrates the high level of consistency between the overlapping periods of the SeaWiFS and MODISA missions, lending confidence to interpretation of the multimission record.

Chla monthly anomalies within the PSO (Fig. 3.26b) show variations of $\pm 15 \%\left( \pm 0.02 \mathrm{mg} \mathrm{m}^{-3}\right)$ over the multimission time series. For 2017, these anomalies were relatively constant and slightly elevated $\left(+0.005 \mathrm{mg} \mathrm{m}^{-3}\right.$, on average) relative to the long-term mean, consistent with the weak La Niña conditions as discussed previously. The link between ENSO variability and mean Chla response in the PSO is demonstrated by the correspondence of anomaly trends with the multivariate ENSO index (MEI; Wolter and Timlin 1998; Fig. 3.26b, green diamonds, presented in the inverse to illustrate the covariation). From 1997 through 2017, monthly anomalies in Chla concentration within the PSO continue to track large-scale climate oscillations as captured by the MEI (Fig. 3.26b), with some notable deviations in the 2002-06 period.

Variability and trends in Chla reflect both adjustments in phytoplankton biomass and physiology (or health). Both of these properties are mechanistically linked to physical properties of the upper ocean, as well as ecological relationships between phytoplankton and their zooplankton predators. Unraveling the diversity and covariation of factors that influence Chla concentrations is essential for correctly interpreting the implications of Chla anomalies on ocean biogeochemistry and food webs. For example, inverse relationships between Chla and SST can emerge from changes in either mixed-layer light levels or vertical nutrient flux, but these two mechanisms have opposite implications on phytoplankton NPP (Behrenfeld et al. 2016). An additional complication is that measured changes in ocean color often contain a contribution from colored dissolved organic matter (Siegel et al. 2005) that can be mistakenly attributed to changes in Chla (Siegel et al. 2013). Thus, while the satellite record of ocean color continues to provide critical insights on global processes, ongoing effort and new approaches are needed to fully understand the story these data are telling regarding relationships between climate and marine ecosystems.

j. Global ocean carbon cycle-R. A. Feely, R. Wanninkhof, B. R. Carter, P. Landschützer, A. Sutton, and J. A. Triñanes

As a consequence of humankind's collective release of $\mathrm{CO}_{2}$ emissions into the atmosphere from fossil fuel burning, cement production, and land use changes over the last 250 years, referred to as Anthropogenic
$\mathrm{CO}_{2}\left(\mathrm{C}_{\text {anth }}\right)$, the atmospheric $\mathrm{CO}_{2}$ has risen from preindustrial levels of about $278 \mathrm{ppm}$ (parts per million) to about $405 \mathrm{ppm}$ (see Section 2g1). The atmospheric concentration of $\mathrm{CO}_{2}$ is now higher than has been observed on Earth for at least the last 800000 years (Lüthi et al. 2008). As discussed in previous State of the Climate reports, the global ocean is a major sink for $\mathrm{C}_{\mathrm{anth}}$. Here the discussion is updated to include recent estimates of that sink. Over the last decade the global ocean has continued to take up a substantial fraction of the anthropogenic carbon $\left(\mathrm{C}_{\text {anth }}\right)$ emissions and therefore is a major mediator of global climate change. Of the $10.7( \pm 0.9) \mathrm{Pg} \mathrm{C} \mathrm{yr}^{-1} \mathrm{C}_{\text {anth }}$ released during the period 2007-16, about $2.4( \pm 0.5) \mathrm{Pg} \mathrm{C} \mathrm{yr}^{-1}(26 \%)$ accumulated in the ocean, $3.0( \pm 0.8) \mathrm{Pg} \mathrm{C} \mathrm{yr}^{-1}(30 \%)$ accumulated on land, and $4.7( \pm 0.1) \mathrm{Pg} \mathrm{C} \mathrm{yr}^{-1}(43 \%)$ remained in the atmosphere with an imbalance of $0.6 \mathrm{Pg} \mathrm{C} \mathrm{yr}^{-1}$ (Le Quéré et al. 2018). This decadal ocean carbon uptake estimate is a consensus view based on a combination of measured decadal inventory changes, models, and global air-sea $\mathrm{CO}_{2}$ flux estimates based on surface ocean partial pressure of $\mathrm{CO}_{2}\left(p \mathrm{CO}_{2}\right)$ measurements. Using ocean general circulation models that include biogeochemical parameterizations (OBGCMs) and inverse models that are validated with observations-based air-sea exchange fluxes and basin-scale ocean inventories, Le Quéré et al. (2018) have demonstrated that the oceanic anthropogenic carbon sink has grown from $1.0( \pm 0.5) \mathrm{Pg} \mathrm{C} \mathrm{yr}^{-1}$ in the decade of the 1960s to $2.6( \pm 0.5) \mathrm{Pg} \mathrm{C} \mathrm{yr}^{-1}$ in 2016 . Air-sea $\mathrm{CO}_{2}$ flux studies reported here indicate an ocean uptake of $\mathrm{C}_{\text {anth }}$ of $2.6 \mathrm{Pg} \mathrm{C} \mathrm{yr}^{-1}$ for 2017.

\section{I) Air-sea carbon dioxide fluXes}

Ocean uptake of $\mathrm{C}_{\text {anth }}$ can be estimated from the net air-sea $\mathrm{CO}_{2}$ flux derived from the bulk flux formula with air-sea differences in $\mathrm{CO}_{2}$ partial pressure $\left(\Delta p \mathrm{CO}_{2}\right)$ and gas transfer coefficients as input. $\mathrm{A}$ steady contribution of carbon from riverine runoff, originating from organic and inorganic detritus from land, estimated at $0.45 \mathrm{Pg} \mathrm{C} \mathrm{yr}^{-1}$ (Jacobson et al. 2007) is included to obtain the $\mathrm{C}_{\text {anth }}$ uptake by the ocean. The data sources for $p \mathrm{CO}_{2}$ are annual updates of surface water $p \mathrm{CO}_{2}$ observations from the Surface Ocean $\mathrm{CO}_{2}$ Atlas (SOCAT) composed of mooring and shipbased observations (Bakker et al. 2016) and the LDEO database with ship-based observations (Takahashi et al. 2018). The increased observations and improved mapping techniques such as neural network methods and self-organizing maps (Landschützer et al. 2013, 2014; Rödenbeck et al. 2015) provide global $p \mathrm{CO}_{2}$ fields on a $1^{\circ}$ latitude $\times 1^{\circ}$ longitude grid at monthly time scales annually. This allows investigation of 
variability on subannual to decadal time scales. The $\Delta p \mathrm{CO}_{2}$ and a parameterization of the gas transfer with wind described in Wanninkhof (2014) are used to calculate the air-sea $\mathrm{CO}_{2}$ fluxes.

The monthly $2017 \Delta p \mathrm{CO}_{2}$ maps are based on an observation-based neural network approach of Landschützer et al. $(2013,2014)$. The 2017 values are projections based on surface temperature, sea surface salinity, climatological mixed-layer depth, satellite chlorophyll- $\alpha$, atmospheric $\mathrm{CO}_{2}$, and the neural network for $p \mathrm{CO}_{2 \mathrm{w}}$ developed from the data from the previous decade. Moreover, winds from 2016 are used. A comparison of the 2016 air-sea estimate using wind speeds from 2015, as presented in last year's State of the Climate report, and the 2016 global flux using measured $2016 p \mathrm{CO}_{2 \mathrm{w}}$ and 2016 winds show agreement on a global scale to within $0.1 \mathrm{Pg} \mathrm{C} \mathrm{yr}^{-1}$. Changes in winds over time have a small effect on global air-sea $\mathrm{CO}_{2}$ fluxes (Wanninkhof and Triñanes 2017). The $C_{\text {anth }}$ fluxes from 1982 to 2017 suggests a decreasing ocean sink in the first part of the record and a strong increase from 2001 onward that continued into 2017 (Fig. 3.27). The amplitude of seasonal variability is large $(\approx 1 \mathrm{Pg} C)$ compared to the long-term trend with minimum uptake in the June-September timeframe. The $\mathrm{C}_{\text {anth }}$ air-sea flux of $2.6 \mathrm{Pg} \mathrm{C} \mathrm{yr}^{-1}$ in 2017 is $36 \%$ above the $2005-15$ average of $1.9( \pm 0.5) \mathrm{Pg} \mathrm{C} \mathrm{yr}^{-1}$.

The average fluxes in 2017 (Fig. 3.28a) show the characteristic pattern of effluxes in the tropical regions and uptake at higher latitudes. The region with largest efflux is the equatorial Pacific. Localized hotspots of upwelling include the Arabian Sea, off

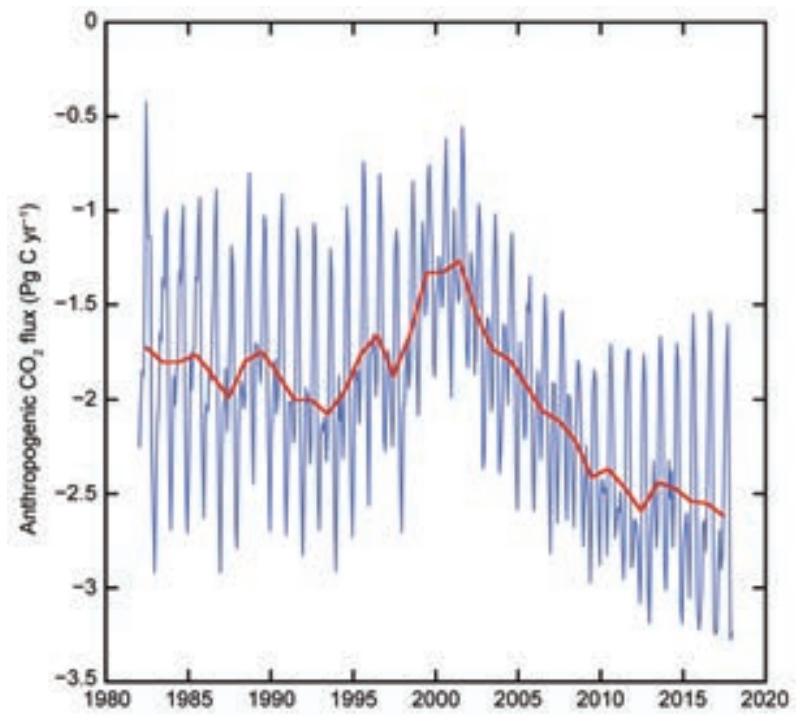

FIG. 3.27. Global annual (red line) and monthly (blue line) $\mathrm{C}_{\text {anth }}$ fluxes $\left(\mathrm{Pg} \mathrm{C} \mathrm{yr}^{-1}\right)$ for 1982 to 2017 . Negative values indicate $\mathrm{CO}_{2}$ uptake by the ocean. the coast of Mauritania, and the Peruvian upwelling system. Large sinks are observed poleward of the subtropical fronts, and the frontal position determines the location of the maximum that is farther south in the Pacific sector of the Southern Ocean compared to the other basins.

In the Northern Hemisphere, there is a significant asymmetry in the sub-Arctic gyre with the North Atlantic being a large sink while the North Pacific is a source of $\mathrm{CO}_{2}$. Ocean carbon uptake anomalies (Fig. 3.28b) in 2017 relative to a 1995-2015 average are attributed to the increasing ocean $\mathrm{CO}_{2}$ uptake with time (Fig. 3.27) and to variations in large-scale climate modes. The air-sea flux trend since 2000 is $-0.8 \mathrm{Pg} \mathrm{C}$ decade $^{-1}$, which leads to predominantly negative flux anomalies (greater ocean uptake). Despite this strong trend there are several regions
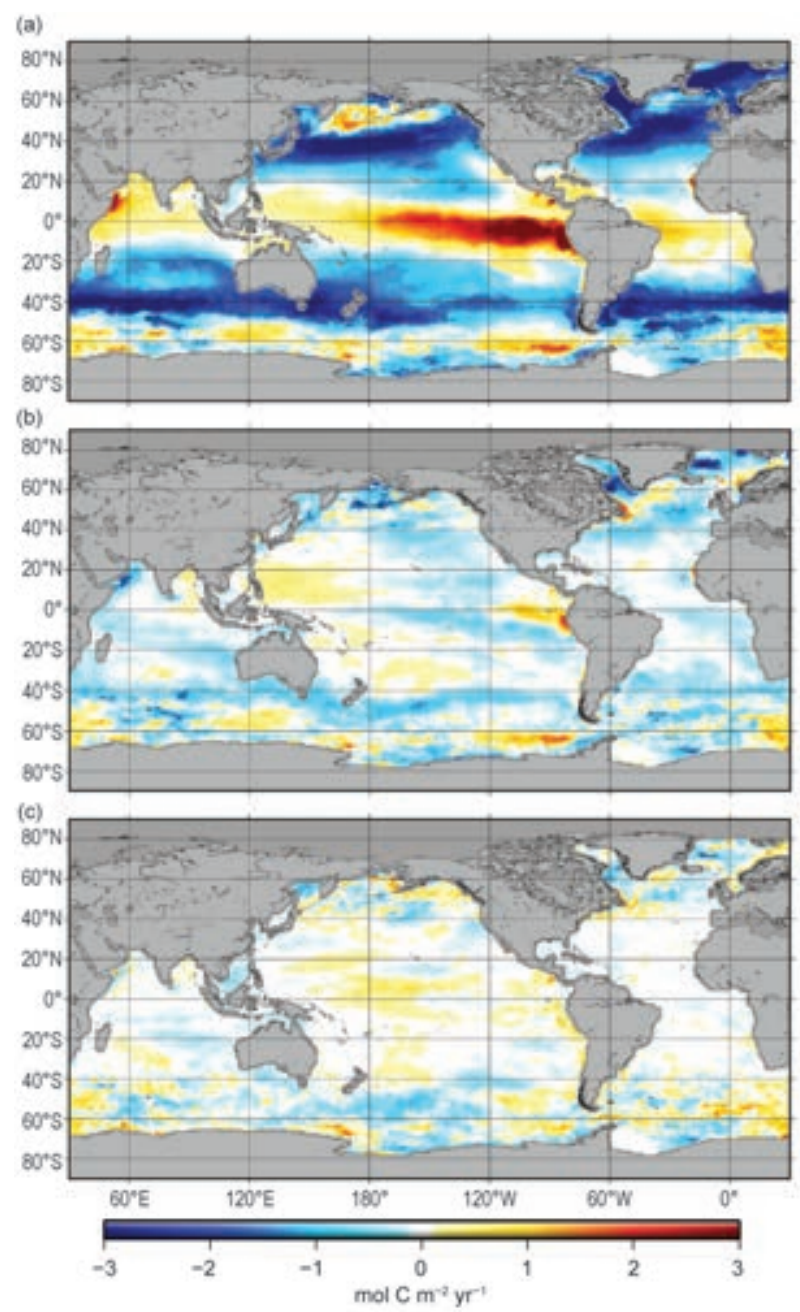

Fig. 3.28. Global map of (a) net air-sea $\mathrm{CO}_{2}$ fluxes for 2017, (b) net air-sea $\mathrm{CO}_{2}$ flux anomalies for 2017 relative to a 1995-20I5 average, and (c) net air-sea $\mathrm{CO}_{2}$ flux anomalies for 2017 minus 2016 values following the method of Landschützer et al. (20l3), all in mol C m $\mathrm{m}^{-2} \mathrm{yr}^{-1}$. 
showing positive anomalies for 2017, notably the eastern equatorial and western tropical Pacific. The increased effluxes in the eastern equatorial Pacific are related to a predominant positive sign of the ENSO index and the associated switch from the 2015/16 El Niño to the weak La Niñas at the ends of 2016 and 2017. Weaker effluxes in the western tropical Pacific are related to strongly positive PDO values over the past three years that have persisted into the first half of 2017 and associated warmer SSTs.

The differences between the air-sea $\mathrm{CO}_{2}$ fluxes in 2017 compared to 2016 (Fig. 3.28c) are relatively small. The increase in $\mathrm{CO}_{2}$ effluxes in the western tropical Pacific from 2016 to 2017 is associated with anomalously warm temperatures in this region in 2017. The Southern Ocean (south of $40^{\circ} \mathrm{S}$ ) shows a bimodal pattern with increasing fluxes in the Pacific and decreasing fluxes in the Atlantic for 2017 compared to 2016. This broadly corresponds to the temperature anomalies in this region, with greater uptake in 2017 associated with warmer temperatures attributed to less upwelling of cold high- $\mathrm{CO}_{2}$ waters in the western and central Pacific sector of the Southern Ocean and overall colder patterns in the eastern Pacific, Indian, and Atlantic sectors of the Southern Ocean associated with increased ventilation and associated effluxes. The alternating patterns of stronger and weaker uptake in the Southern Ocean are in accord with an asymmetric distribution of the atmospheric pressure systems moving around the Southern Ocean associated with the Antarctic Circumpolar Wave (Landschützer et al. 2015).

Many of the $p \mathrm{CO}_{2}$ and flux anomalies can be attributed to variations in large-scale climate modes and associated physical anomalies, notably temperature, but the causality is often complex. For example, the behavior of $p \mathrm{CO}_{2}$ with respect to temperature includes competing processes: thermodynamics dictate decreasing $p \mathrm{CO}_{2}$ with decreasing SST, but waters originating from the deep with a cold temperature signal will have a high $p \mathrm{CO}_{2}$. Moreover, the drawdown of $p \mathrm{CO}_{2}$ due to biology is often associated with increasing temperature, but this depends on region and season.

The strong trend of increasing $\mathrm{CO}_{2}$ uptake since 2002 has continued through 2017 with an increase of $0.1 \mathrm{Pg} \mathrm{C}$ above the 2016 estimate. This increase is well within the uncertainty of the estimate, but it is within the overall expectation that the ocean will remain an increasing sink as long as atmospheric $\mathrm{CO}_{2}$ levels continue to rise. The sequestration of $\mathrm{CO}_{2}$ by the ocean partially mitigates the atmospheric $\mathrm{CO}_{2}$ rise but it comes at a cost of increased acidification of surface and subsurface waters.

\section{2) OCEan ACIDIFICATION}

To date, the global oceans have absorbed approximately $150( \pm 20) \mathrm{Gt} C$ of the total anthropogenic carbon dioxide emissions (Le Quéré et al. 2018). This uptake has caused an increase of ocean acidity in a process referred to as anthropogenic ocean acidification (OA). Models indicate that over the last two-anda-half centuries, the $\mathrm{pH}$ in open-ocean surface waters has decreased by about 0.11 units, equivalent to about a 29\% increase in the hydrogen ion $(\mathrm{H}+)$ concentration (Gattuso et al. 2015). This absorption of anthropogenic carbon is beneficial in slowing the rise of atmospheric carbon dioxide. However, the ocean's uptake of carbon dioxide is having negative impacts on ocean chemistry and biology. Time series measurements, hydrographic surveys, and modeling studies have revealed that the changes in seawater chemistry resulting from the absorption of $\mathrm{CO}_{2}$ are lowering seawater $\mathrm{pH}$. For example, the time series data at Ocean Station ALOHA shows an average $\mathrm{pH}$ decrease of approximately 0.02 units decade $^{-1}$ in the northeast Pacific (Fig. 3.29).

The long-term trend at Ocean Station ALOHA shows an increasing rate of increase of $p \mathrm{CO}_{2}$ of $2.0( \pm 0.1) \mu a \mathrm{a} \mathrm{yr}^{-1}$ (Fig. 3.29a) while $\mathrm{pH}$ of ocean surface waters has already decreased by about $0.0016 \mathrm{yr}^{-1}$, with no apparent long-term change in annual $\mathrm{CO}_{2}$ influx (Fig. 3.29b; Sutton et al. 2017). The increase in surface ocean $\mathrm{CO}_{2}$ over recent decades is consistent with the atmospheric increase within the statistical limits of the measurements.

\section{3) Carbon inventories}

The Global Ocean Ship-based Hydrographic Investigations Program (GO-SHIP) is providing new information about the uptake and storage of carbon within the ocean interior by determining the change in measured dissolved inorganic carbon (DIC) and $\mathrm{C}_{\text {anth }}$ concentrations between decadal cruise reoccupations. During the 2017/18 timeframe, a new set of measurements, including DIC, were finalized along the P18 line extending from San Diego south to Antarctica and collected along the P06 line extending from Australia east to Chile. A synthesis of estimates of $\mathrm{C}_{\text {anth }}$ storage along these sections and other recently measured Pacific sections is currently underway. While results are preliminary, the dominant signal is a clear and continuous increase in $\mathrm{C}_{\text {anth }}$ storage, especially in the least-dense and most well-ventilated shallower parts of the ocean (Fig. 3.30a). This $\mathrm{C}_{\text {anth }}$ storage is increasing ocean acidity, decreasing ocean 


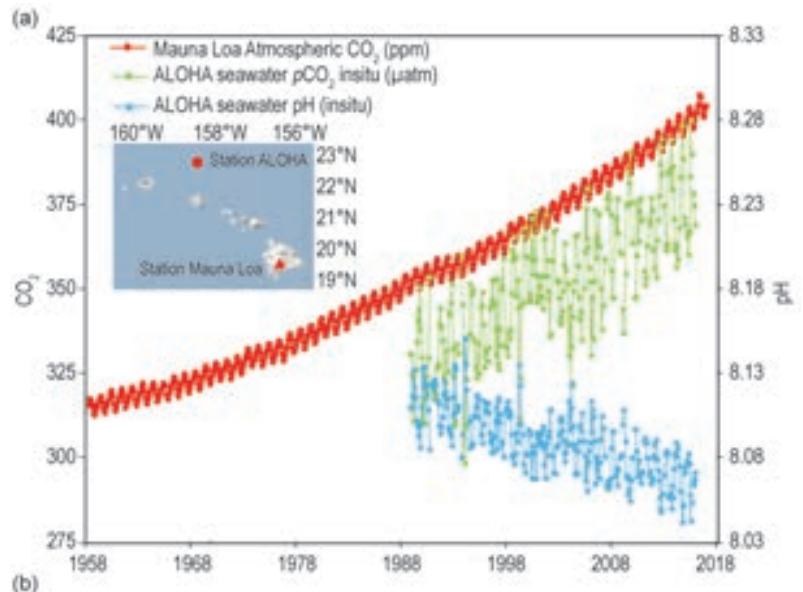

(b)

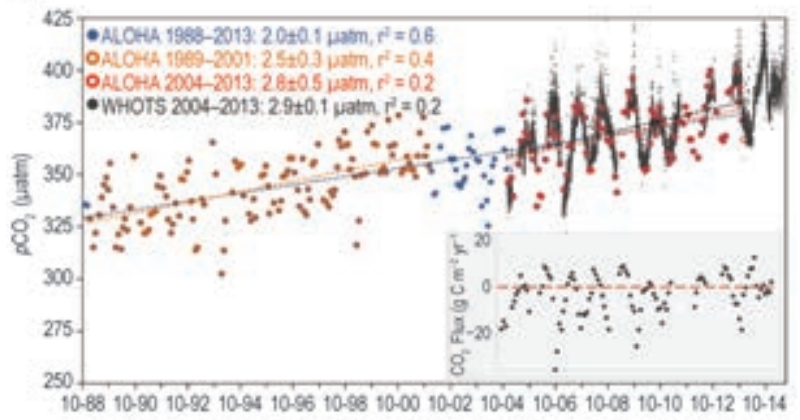

FIG. 3.29. (a) Time series of atmospheric $\mathrm{CO}_{2}$ at Mauna

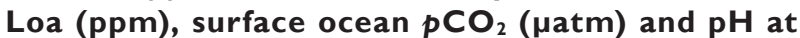
Ocean Station ALOHA in the subtropical North Pacific Ocean. Mauna Loa data: (ftp://aftp.cmdl.noaa .gov/products/trends/co2/co2_mm_mlo.txt); HOTS IALOHA data: University of Hawaii (http://hahana .soest.hawaii.edu/hot/products/HOT_surface_CO2 .txt). (b) Surface ocean $\mathrm{pCO}_{2}$ ( $\left.\mu \mathrm{atm}\right)$ and rates of change from Station ALOHA 1988-20I3 (blue), 1989-200I (orange), 2004-I3 (red), and the adjacent WHOTS buoy 2004-I3 (black) and (shaded inset) $\mathrm{CO}_{2}$ flux ( $\left.\mathrm{g} \mathrm{C} \mathrm{m}^{-2} \mathrm{yr}^{-1}\right)$ from WHOTS buoy observations 2004-I5 (after Sutton et al. 2017).

$\mathrm{pH}$ (Fig. 3.30b), and decreasing carbonate mineral saturation states. For this comparison, anthropogenic $\mathrm{CO}_{2}$ storage rates-estimated from decadal measurements using methods described by Carter et al. (2017) - are used directly and, in some regions, extrapolated in time to estimate patterns of $\mathrm{C}_{\text {anth }}$ storage since 1994. These storages are added to the 1994 global $C_{\text {anth }}$ climatology of Sabine et al. (2004) as gridded by Key et al. (2004).

As also found in recent studies in the Atlantic (Woosley et al. 2016) and Pacific (Carter et al. 2017), these preliminary results suggest that Pacific storage rates have been increasing since $\sim 2005$ despite the tendency of water with more $\mathrm{CO}_{2}$ to absorb smaller fractions of atmospheric $\mathrm{C}_{\text {anth }}$ increases (due to the decreasing buffering capacity of seawater). The observed storage increases are attributable to continued rapid atmospheric $\mathrm{CO}_{2}$ growth and changes in mixing and ventilation within the ocean interior. The largest storages per unit area are found in high-latitude deep water formation regions such as the North Atlantic (Woosley et al. 2016), though the majority of the $\mathrm{C}_{\text {anth }}$ inventory is stored in the subtropics due to the vast size of that region. Upwelling regions near the equator, in the North Pacific, and in the Southern Ocean south of the Antarctic Circumpolar Current have lower decadal storages per unit area (e.g., the dark colors on the lower right Section in Fig. 3.30a). In these regions, upwelling of deep waters that have been isolated from the atmosphere for all or some of the industrial era displace the better-ventilated, higher $\mathrm{C}_{\text {anth }}$ intermediate depth waters. A preliminary estimate of the decadal changes suggests that the Pacific basin stored 8.2 Pg C between 1995 and 2005 and $9.8 \mathrm{Pg} \mathrm{C}$ between 2005 and 2015 .

Ocean acidification, or the impact of $\mathrm{C}_{\text {anth }}$ on $\mathrm{pH}$, has a similar global pattern to the net $\mathrm{C}_{\text {anth }}$ storage, though the $\mathrm{pH}$ decrease is amplified in seawater with

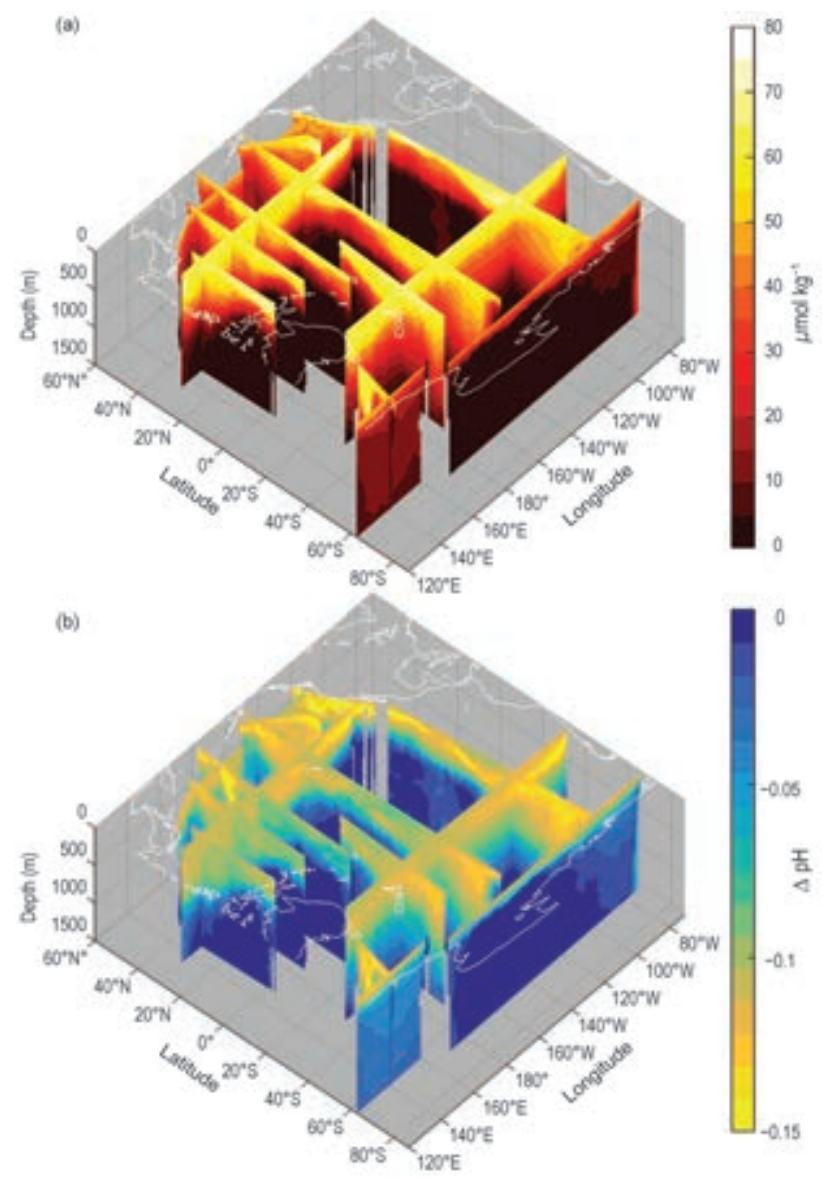

FIG. 3.30. Preliminary estimates of (a) anthropogenic carbon $\left(C_{\text {anth }} ; \mu \mathrm{mol} \mathbf{~ k g}^{-1}\right)$ along hydrographic sections in the Pacific interpolated (or extrapolated) in time to the year 2015 and (b) the net impact of this $\mathrm{C}_{\text {anth }}$ on $\mathrm{pH}$. 
naturally high accumulated DIC from respiration by marine organisms. Such waters have a reduced buffer capacity due to their naturally high carbon concentrations, so the ongoing $\mathrm{C}_{\text {anth }}$ storage has an enhanced impact on acidification. This effect can be seen in the nearly global subsurface $\Delta \mathrm{pH}$ magnitude maximum, which is especially notable off the US West Coast where unusually high-DIC waters upwell near the surface (Fig. 3.30b). 
4. THE TROPICS - H. J. Diamond and C. J. Schreck, Eds.

a. Overview-H. J. Diamond and C. J. Schreck

The Tropics in 2017 were dominated by neutral El Niño-Southern Oscillation (ENSO) conditions during most of the year, with the onset of La Niña conditions occurring during boreal autumn. Although the year began ENSO-neutral, it initially featured cooler-than-average sea surface temperatures (SSTs) in the central and east-central equatorial Pacific, along with lingering La Niña impacts in the atmospheric circulation. These conditions followed the abrupt end of a weak and short-lived La Niña during 2016, which lasted from the July-September season until late December.

Equatorial Pacific SST anomalies warmed considerably during the first several months of 2017 and by late boreal spring and early summer, the anomalies were just shy of reaching El Niño thresholds for two consecutive, overlapping seasons of April-June and May-July. Thereafter, SSTs cooled through the remainder of the year and exceeded La Niña thresholds during September-November and October-December.

For the global tropics, land and ocean surfaces combined (measured between $20^{\circ} \mathrm{S}$ and $20^{\circ} \mathrm{N}$ ), the 2017 annual average temperature was $0.31^{\circ} \mathrm{C}$ above the 1981-2010 average. This makes 2017 the third warmest year for the tropics since records began in 1880 , behind only $2016\left(+0.55^{\circ} \mathrm{C}\right)$ and $2015\left(+0.53^{\circ} \mathrm{C}\right)$. Precipitation over land for the same latitudes was above the 1981-2010 average for three major datasets (GHCN, GPCC, GPCP), with anomalies ranging from 45 to $125 \mathrm{~mm}$ above average. The dataset analyzed for tropical rainfall over the oceans (GPCP; Adler et al. 2003) measured tropical precipitation $14 \mathrm{~mm}$ above the 1981-2010 average.

Globally, 85 named tropical storms (TS) were observed during the 2017 Northern Hemisphere storm season and the 2016/17 Southern Hemisphere storm season, as documented in the International Best Tracks Archive for Climate Stewardship (IBTrACS; Knapp et al. 2010). Overall, this number was slightly more than the 1981-2010 global average of 82 TSs. By comparison, Diamond and Schreck (2017) reported 93 named storms for 2016, although that number decreased to 85 after reanalysis. In terms of accumulated cyclone energy (ACE; Bell et al. 2000), the North Atlantic basin had an ACE of about $241 \%$ of its 1981-2010 median value and was the only basin that featured an above-normal season. For the North Atlantic, this was the fourth most active season since at least 1950 and the seventh most active season in the historical record (since 1854). The western North
Pacific, South Indian, and Australian basins were all particularly quiet, each having about half their median ACE.

Three tropical cyclones (TCs) reached the SaffirSimpson scale category 5 intensity level-two in the North Atlantic and one in the western North Pacific basins. This number was less than half of the eight category 5 storms recorded in 2015 (Diamond and Schreck 2016), and was one fewer than the four recorded in 2016 (Diamond and Schreck 2017).

The editors of this chapter would like to insert two personal notes recognizing the passing of two giants in the field of tropical meteorology.

Charles J. Neumann passed away on 14 November 2017, at the age of 92 . Upon graduation from MIT in 1946, Charlie volunteered as a weather officer in the Navy's first airborne typhoon reconnaissance unit in the Pacific. Later, as head of research and development at the National Hurricane Center, he developed techniques for statistical tropical cyclone track forecasting, error and risk analysis, and the compilation of a complete set of historical Atlantic hurricane tracks and intensities dating from the 1800s. These data were prototypes for the modern day best track datasets upon which so much of our science relies. Charlie was known for his friendliness and for his generosity in readily sharing data and his expertise, and he was the recipient of numerous national and international awards. Please visit www .hurricanecenterlive.com/charles-newman.html for more information.

Professor Tiruvalam Natarajan Krishnamurti ("Krish" to all who knew and worked with him) passed away on 7 February 2018, at the age of 86 . He was Professor Emeritus and Lawton Distinguished Professor of Meteorology at Florida State University's (FSU) Department of Earth, Ocean, and Atmospheric Science. Krish, along with Bill Gray, is considered one of the fathers of modern tropical meteorology. For more than a half-century, Krish was a pioneer in tropical meteorology and numerical weather prediction, including high-resolution forecasting of hurricane tracks, landfall, and intensities; short- and long-range monsoon prediction; and interseasonal and interannual variability of the tropical atmosphere. Krish was the recipient of the highest awards given by both the American Meteorological Society and the World Meteorological Organization.

Both Charlie and Krish will be greatly missed by all who knew and worked with them, as well as for all that they accomplished to advance the science of tropical meteorology. 
b. ENSO and the tropical Pacific-M. L'Heureux, G. Bell, and M. S. Halpert

The El Niño-Southern Oscillation (ENSO) is a coupled ocean-atmosphere climate phenomenon over the tropical Pacific Ocean, with opposite phases called El Niño and La Niña. For historical purposes, NOAA's Climate Prediction Center (CPC) classifies and assesses the strength and duration of El Niño and La Niña using the Oceanic Niño index (ONI, shown for the last half of 2016 and all of 2017 in Fig. 4.1). The ONI is the 3-month (seasonal) running average of SST anomalies in the Niño-3.4 region $\left(5^{\circ} \mathrm{N}-5^{\circ} \mathrm{S}\right.$, $170^{\circ}-120^{\circ} \mathrm{W}$ ) calculated as the departure from the $1986-2015$ base period. ENSO is classified as El Niño (La Niña) when the $\mathrm{ONI}$ is at or greater than $+0.5^{\circ} \mathrm{C}$ (at or less than $-0.5^{\circ} \mathrm{C}$ ) for at least five consecutive, overlapping seasons.

The ONI shows 2017 was ENSO-neutral during most of the year, with the onset of La Niña conditions occurring during boreal autumn. ENSO-neutral conditions at the start of 2017 followed the abrupt end of a short-lived, weak La Niña in 2016. That event lasted from July-September (JAS) until late December 2016 (Bell et al. 2017a).

Although officially ENSO-neutral, 2017 started off cooler relative to average, as reflected by a December-February (DJF) 2016/17 ONI value of $-0.3^{\circ} \mathrm{C}$. Also, La Niña's atmospheric impacts lingered into 2017. However, the equatorial Pacific continued to warm, and by late boreal spring and early summer the ONI increased to $+0.4^{\circ} \mathrm{C}$ (just shy of El Niño thresholds) for two consecutive, overlapping seasons of April-June (AMJ) and May-July (MJJ). Thereafter, the ONI decreased through the remainder of the year,

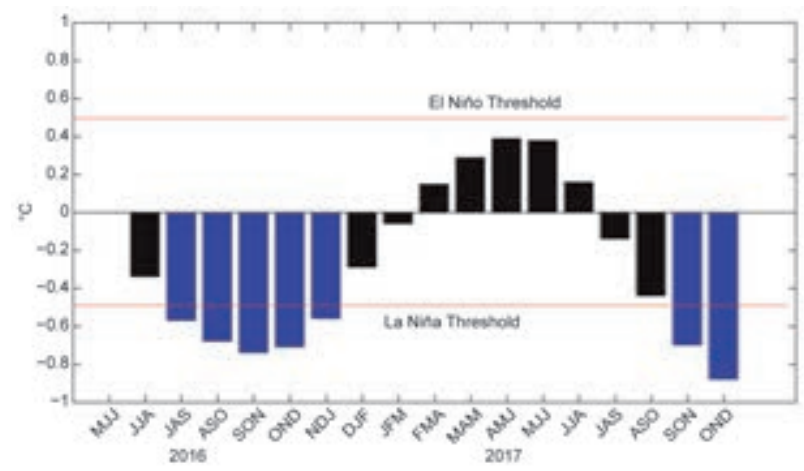

FIG. 4.I. Time series of the ONI $\left({ }^{\circ} \mathrm{C}\right)$ during the last half of 2016 and all of 2017. Overlapping, 3-month seasons are labeled on the $x$-axis. Values less than $-0.5^{\circ} \mathrm{C}$ are shaded blue, indicating La Niña conditions. ONI values are derived from the ERSSTv5 dataset and are based on departures from the 1986-2015 monthly means. (Huang et al. 2017). exceeding thresholds for La Niña during SeptemberNovember $\left(\mathrm{SON} ;-0.7^{\circ} \mathrm{C}\right)$ and October-December $\left(\mathrm{OND} ;-0.9^{\circ} \mathrm{C}\right)$.

\section{I) OCEANIC CONDITIONS}

Figures $4.2 \mathrm{~b}$,h further illustrate that 2017 was bookended by below-average SSTs in the east-central equatorial Pacific Ocean. Yet it was only in the last season (SON 2017) that La Niña appeared, as the negative SST anomalies expanded and strengthened from the international dateline to coastal South America (Figs. 4.2g,h). In contrast, the rest of the year was more clearly ENSO-neutral, with near-average SSTs evident across much of the central and eastern Pacific Ocean (and above-average SSTs persisting in the western Pacific Ocean; Figs. 4.2c-f). The primary exception to this pattern occurred near coastal South America during DJF and March-May (MAM, Fig. 4.2d) 2017, when above-average SSTs emerged and became quite intense. This warming is indicative of a so-called "coastal El Niño" (Takahashi and Martínez 2017; see Sidebar 7.2). During FebruaryApril 2017 the SST anomalies exceeded $+2.5^{\circ} \mathrm{C}$ and were accompanied by damaging rainfall and flooding in Peru (L'Heureux 2017; Di Liberto 2017).

Consistent with the overall equatorial SST evolution, subsurface temperatures east of the dateline were generally near average most of the year (Fig. 4.3), with a broad stretch of negative anomalies becoming evident with the onset of La Niña (Fig. 4.3d). West of the dateline, the positive SST anomalies evident for much of the year were accompanied by higher subsurface temperatures and a deeper-than-average oceanic thermocline. However, these positive subsurface anomalies weakened as the year went on, and the thermocline began to shoal in the eastern Pacific in association with a developing La Niña.

\section{2) AtMOSPHERIC CIRCULATION: TROPICS AND SUBTROPICS}

Consistent with the average to below-average SSTs in the east-central equatorial Pacific, atmospheric anomalies during both DJF 2016/17 and SON 2017 were La Niña-like (Figs. 4.4, 4.5). Tropical convection (as measured by outgoing longwave radiation) was enhanced over Indonesia and suppressed over the central Pacific Ocean during these two seasons (Figs. 4.4a,d; 4.5a,d), with some evidence for weak La Niña impacts lingering into MAM 2017 (Figs. 4.4b, 4.5b). Correspondingly, the low-level $(850-\mathrm{hPa})$ wind anomalies over the western and central tropical Pacific were easterly in both periods, which indicated a strengthening of the trade winds (Figs. 4.4a,b,d). 
(a) Dec-Feb 2016/17

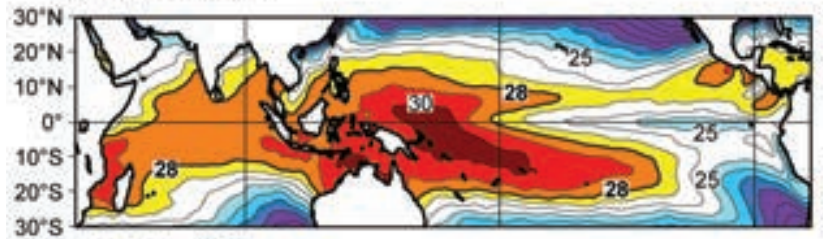

(c) Mar-May 2017
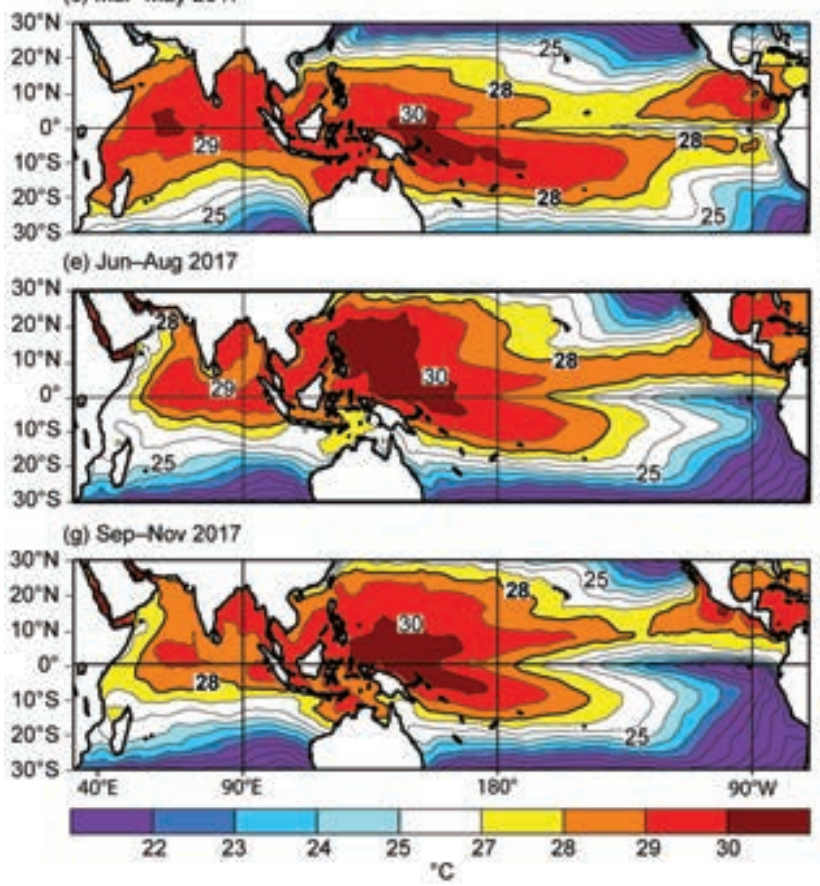

(b) Dec-Feb 2016/17

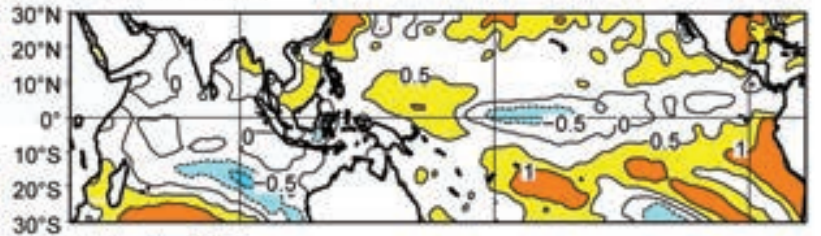

(d) Mar-May 2017

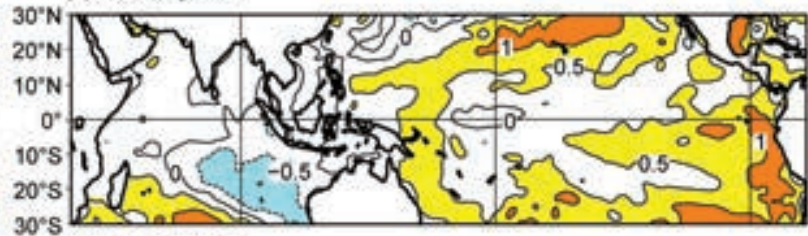

(f) Jun-Aug 2017

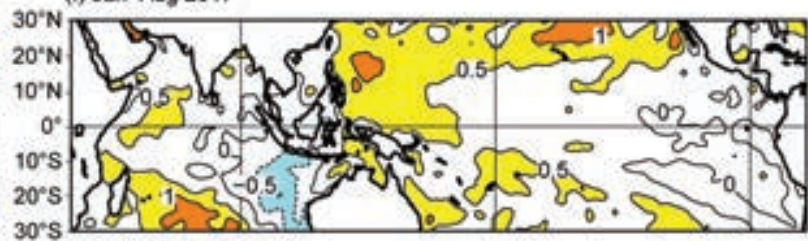

(h) Sep-Nor 2017

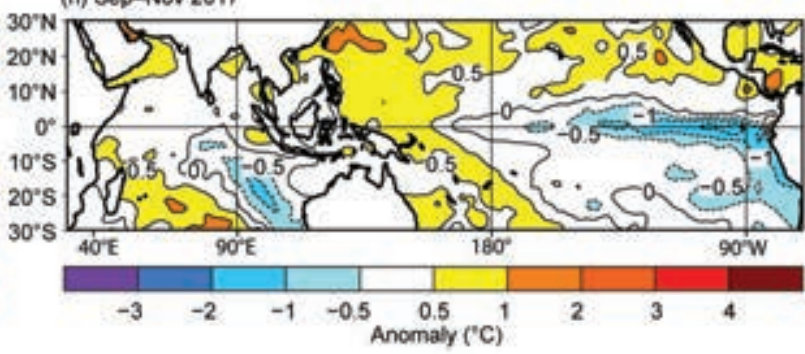

FIG. 4.2. Seasonal SST (left) and anomaly (right) for (a),(b) DJF 2016/17; (c),(d) MAM 2017; (e),(f) JJA 2017; and (g),(h) SON 2017. Contour interval for seasonal SST is $1^{\circ} \mathrm{C}$. For anomalous SST, contour interval is $0.5^{\circ} \mathrm{C}$ for anomalies between $\pm I^{\circ} \mathrm{C}$, and $I^{\circ} \mathrm{C}$ for anomalies $> \pm I^{\circ} \mathrm{C}$. Anomalies are departures from the $198 \mathrm{I}-20 \mathrm{I} 0$ seasonal adjusted OI climatology (Reynolds et al. 2002).

(a) Dec-Feb 2016/17

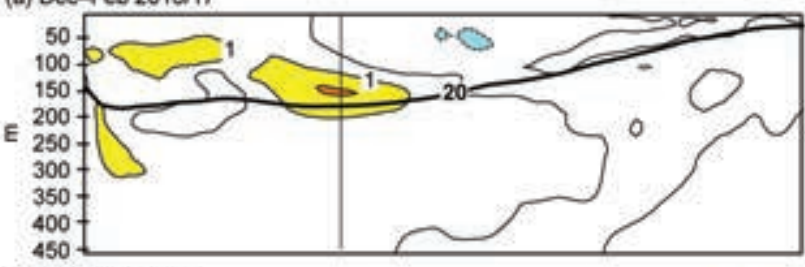

(b) Mar-May 2017

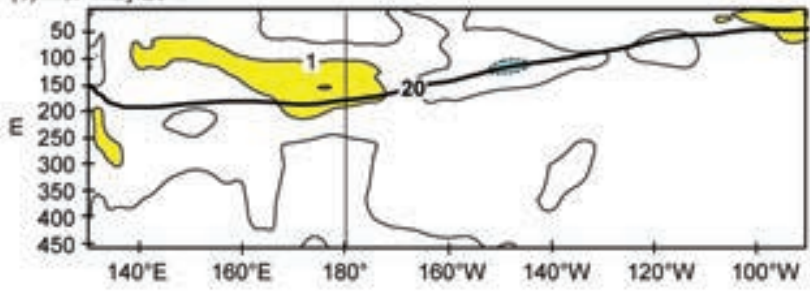

(c) Jun-Aug 2017

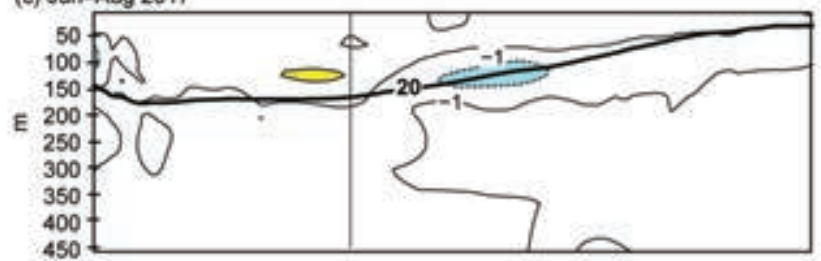

(d) Sep-Nov 2017

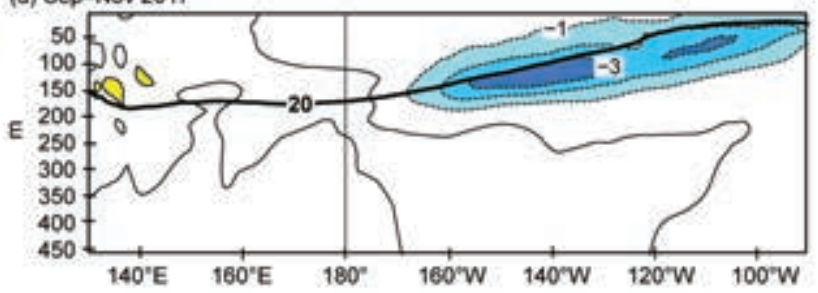

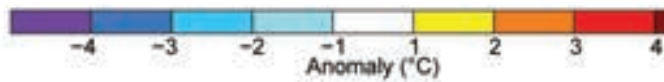

Fig. 4.3. Equatorial depth-longitude section of Pacific Ocean temperature anomalies $\left({ }^{\circ} \mathrm{C}\right)$ averaged between $5^{\circ} \mathrm{N}$ and $5^{\circ} \mathrm{S}$ during (a) DJF 2016/17, (b) MAM 2017, (c) JJA 2017, and (d) SON 2017. The $20^{\circ} \mathrm{C}$ isotherm (thick solid line) approximates the center of the oceanic thermocline. The data are derived from an analysis system that assimilates oceanic observations into an oceanic general circulation model (Behringer et al. 1998). Anomalies are departures from the 198I-2010 monthly means. 


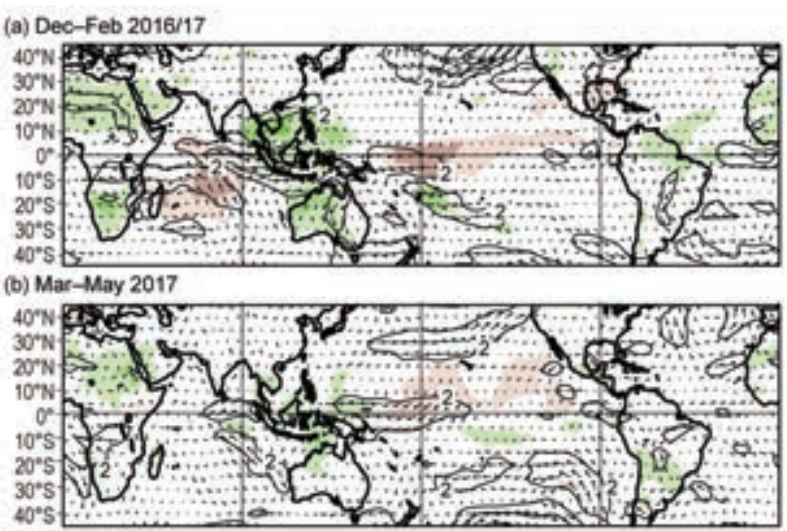

(c) Jun-Aug 2017

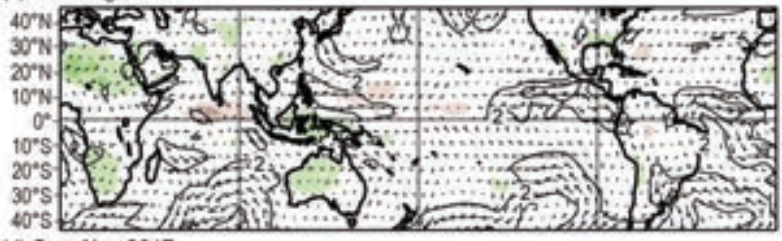

(d) Sep-Nov 2017

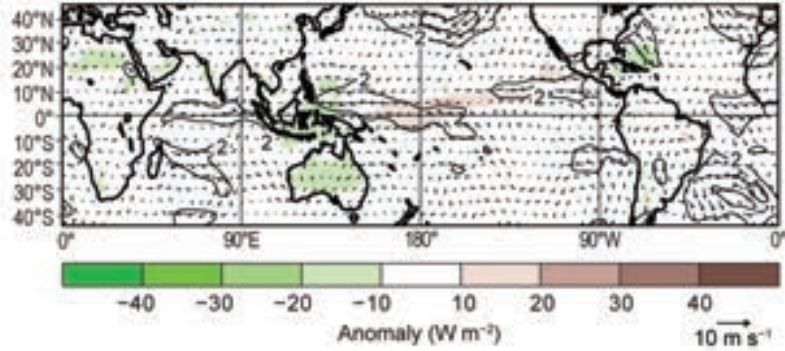

Fig. 4.4. Anomalous $850-\mathrm{hPa}$ wind vectors and speed (contour interval is $2 \mathrm{~m} \mathrm{~s}^{-1}$ ) and anomalous OLR (shaded, $\mathrm{W} \mathrm{m}^{-2}$ ) during (a) DJF 2016/17, (b) MAM 2017, (c) JJA 20I7, and (d) SON 20I7. Reference wind vector is below right of color bar. Anomalies are departures from the I98I-2010 monthly means.

The associated upper-level (200-hPa) winds over the central tropical Pacific in both hemispheres indicated enhanced mid-Pacific troughs flanking the region of suppressed convection near the dateline (Figs. 4.5a,d). The resulting anomalous cross-equatorial flow near the dateline, flowing from the Southern Hemisphere tropics into the Northern Hemisphere, was especially prominent during DJF (Fig. 4.5a). However, the upper-level winds were anomalously westerly over the central tropical Pacific only during SON 2017, which indicates that the broader, overturning Pacific Walker circulation was enhanced only late in the year (Fig. 4.5d).

In the Northern Hemisphere, a La Niña-like anomalous $500-\mathrm{hPa}$ height anomaly pattern was evident both early (DJF) and late (SON) in the year (see Online Figs. S4.1 and S4.2). In particular, both periods featured an anomalous ridge over the North Pacific Ocean in association with a retracted East
Asian jet stream. Downstream of the ridge, anomalous troughing occurred over western Canada while an anomalous ridge was apparent over the southern contiguous United States. This teleconnection pattern, with three centers of action over the PacificNorth American region, is indicative of La Niña-like forcing from the tropical Pacific.

C. Tropical intraseasonal activity - S. Baxter, C. Schreck, and G. D. Bell

In the atmosphere, tropical intraseasonal variability was prominent throughout the year, alternating between constructive and destructive interference with the background low-frequency state. Two aspects of this intraseasonal variability are the MaddenJulian Oscillation (MJO; Madden and Julian 1971, 1972, 1994; Zhang 2005), and convectively coupled equatorial waves which include equatorial Rossby waves and atmospheric Kelvin waves (Wheeler and

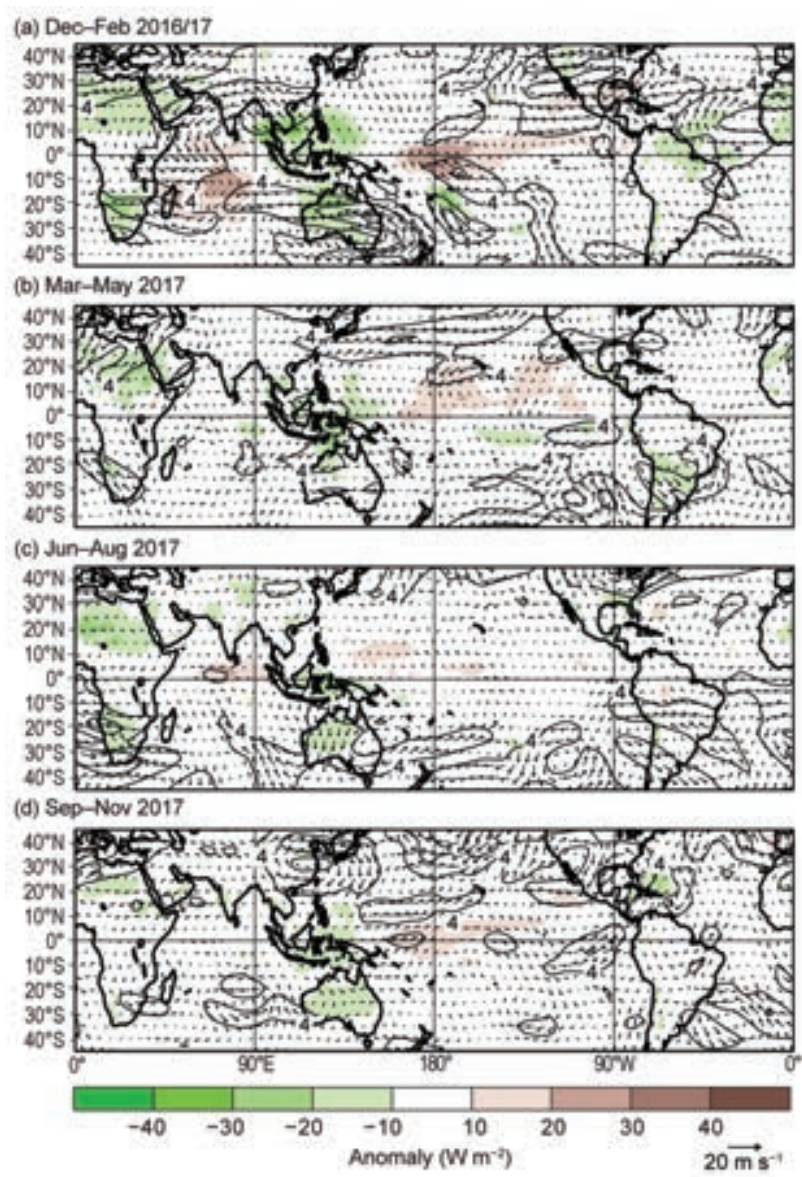

FIG. 4.5. Anomalous 200-hPa wind vectors and speed (contour interval is $4 \mathrm{~m} \mathrm{~s}^{-1}$ ) and anomalous OLR (shaded, W m ${ }^{-2}$ ) during (a) DJF 2016/17, (b) MAM 2017, (c) JJA 20I7, and (d) SON 2017. Reference wind vector is below right of color bar. Anomalies are departures from the $1981-2010$ period monthly means. 


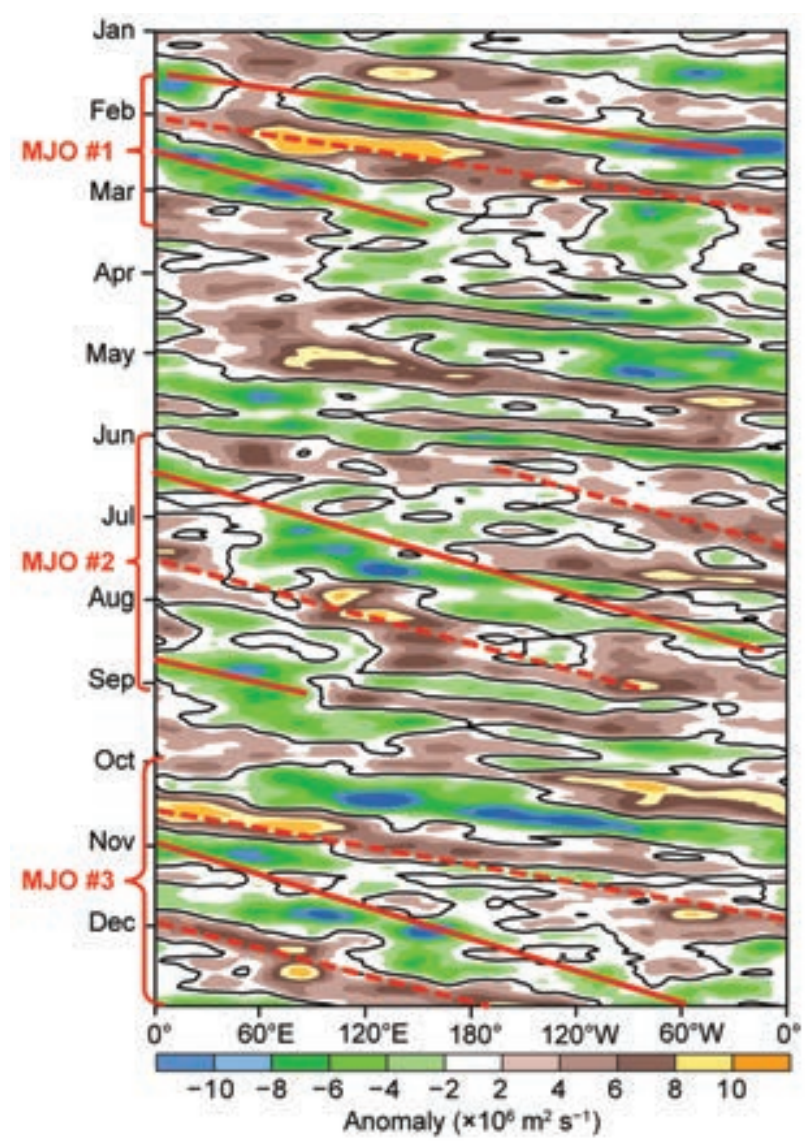

FIG. 4.6. Time-longitude section for 2017 of 5-day running anomalous $200-\mathrm{hPa}$ velocity potential $\left(\times 10^{6} \mathrm{~m}^{2} \mathrm{~s}^{-1}\right)$ averaged for $5^{\circ} \mathrm{N}-5^{\circ} \mathrm{S}$, from NCEP-NCAR reanlysis (Kalnay et al. 1996). For each day, the period mean is removed prior to plotting. Green (brown) shading highlights likely areas of anomalous divergence and rising motion (convergence and sinking motion). Red lines and labels highlight the periods when the MJO was most active; solid (dashed) lines indicate the MJO enhanced (suppressed) phase. Anomalies are departures from the 198I-2010 base period daily means.

Kiladis 1999; Kiladis et al. 2009). There were three distinct periods of MJO activity during 2017 spanning a total of eight months (Fig. 4.6). Between the first two active MJO periods, intraseasonal variability reflected atmospheric Kelvin waves (Fig. 4.7) and tropical cyclone activity. Between the latter two active MJO periods, intraseasonal variability largely reflected the evolution to La Niña.

The MJO is a leading intraseasonal climate mode of tropical convective variability. Its convective anomalies often have a similar spatial scale to ENSO but differ in that they exhibit a distinct eastward propagation and generally traverse the globe in 30-60 days. The MJO affects weather patterns around the globe (Zhang 2013), including monsoons (Krishnamurti

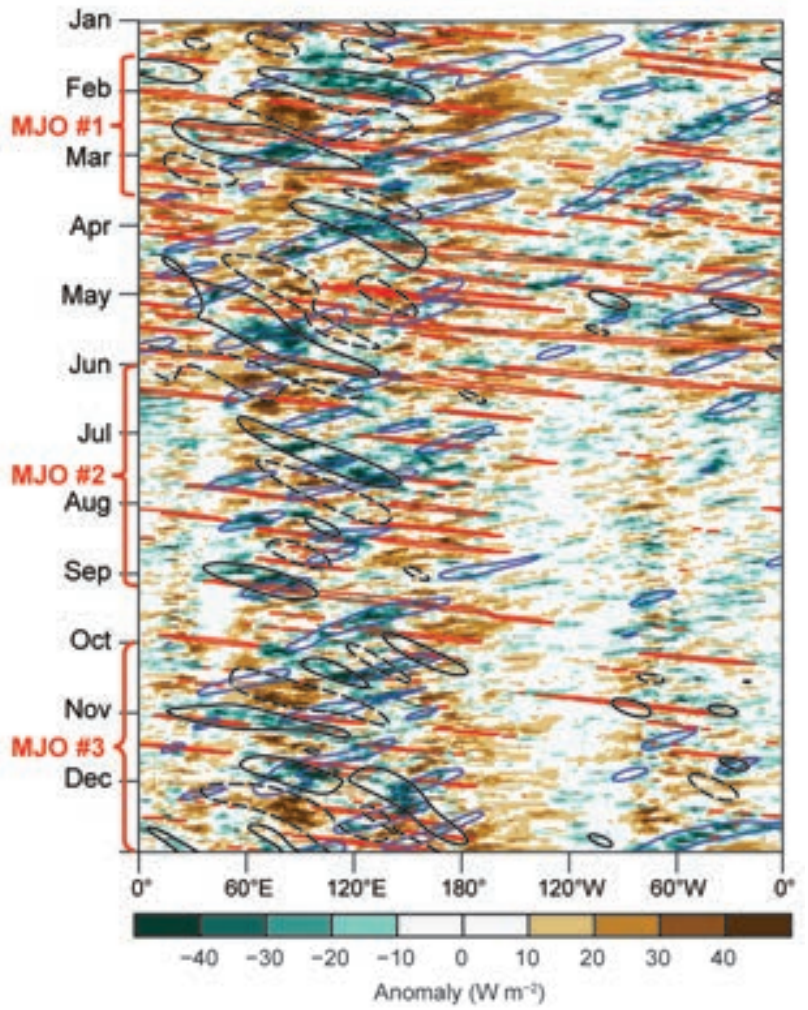

Fig. 4.7. Time-longitude section for 2017 of anomalous OLR $\left(\mathrm{W} \mathrm{m}^{-2}\right)$ averaged for $10^{\circ} \mathrm{N}-10^{\circ} \mathrm{S}$ (Lee 2014). Negative anomalies indicate enhanced convection and positive anomalies indicate suppressed convection. Contours identify anomalies filtered for the MJO (black), atmospheric Kelvin waves (red), and Rossby waves (blue). Red labels highlight the main MJO episodes. Contours are drawn at $\pm 12 \mathrm{~W} \mathrm{~m}^{-2}$, with the enhanced (suppressed) convective phase of these phenomena indicated by solid (dashed) contours. Anomalies are departures from the 198I-2010 base period.

and Subrahmanyam 1982; Lau and Waliser 2012), tropical cyclones (Mo 2000; Frank and Roundy 2006; Camargo et al. 2009; Schreck et al. 2012), and extratropical circulations (Knutson and Weickmann 1987; Kiladis and Weickmann 1992; Mo and Kousky 1993; Kousky and Kayano 1994; Kayano and Kousky 1999; Cassou 2008; Lin et al. 2009; Riddle et al. 2013; Schreck et al. 2013; Baxter et al. 2014). The MJO is often episodic, with periods of moderate or strong activity sometimes followed by little or no activity. The MJO tends to be most active during ENSOneutral and weak ENSO periods. The MJO is often absent during strong El Niño events (Hendon et al. 1999; Zhang and Gottschalck 2002; Zhang 2005), though the strong El Niño winter of 2015/16 exhibited unusually strong MJO activity (Baxter et al. 2017).

Common metrics for identifying the MJO include time-longitude plots of anomalous $200-\mathrm{hPa}$ 
(a)

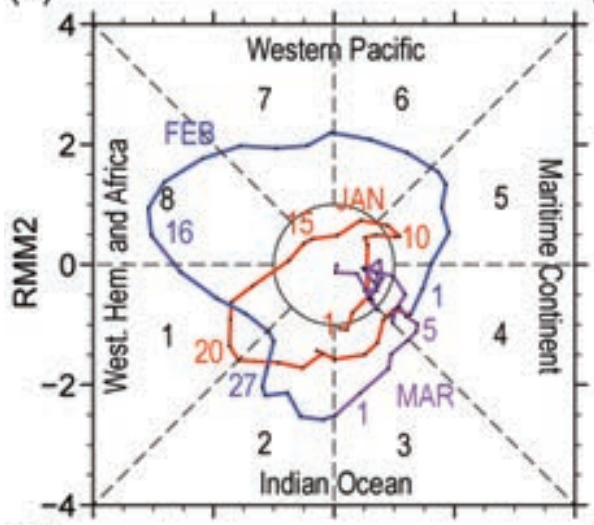

(b)

(c)

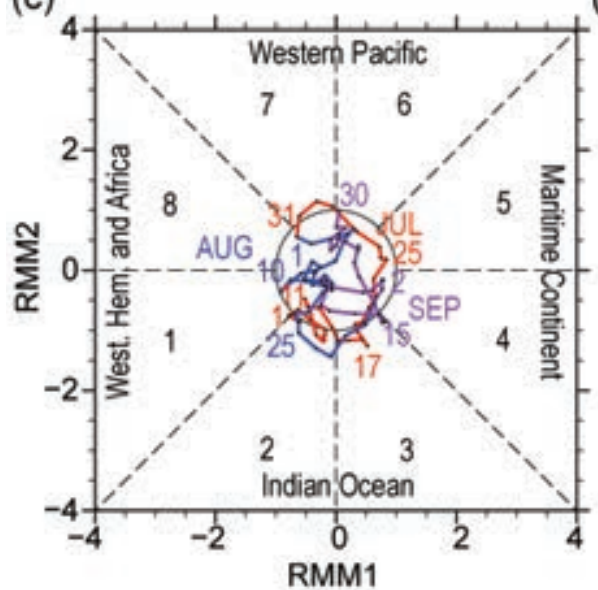

(d)

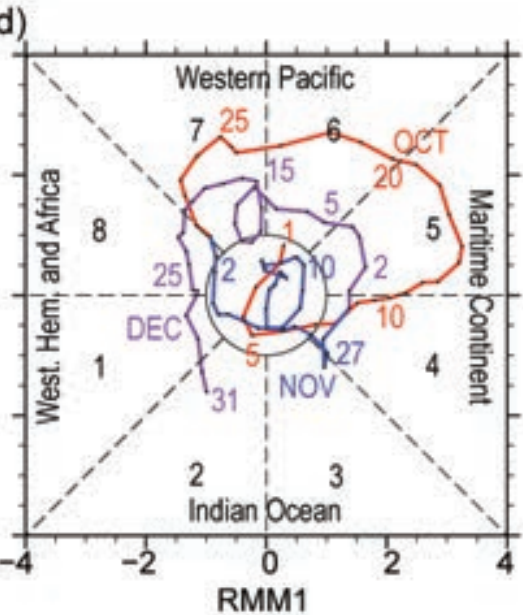

Fig. 4.8. Wheeler-Hendon (2004) Real-time Multivariate MJO (RMM) index during 2017 for (a) Jan-Mar, (b) Apr-Jun, (c) Jul-Sep, and (d) Oct-Dec. Each point represents the MJO amplitude and location on a given day, and the connecting lines illustrate its propagation. Amplitude is indicated by distance from the origin, with points inside the circle representing weak or no MJO. The eight phases around the origin identify the region experiencing enhanced convection, and counter-clockwise movement reflects eastward propagation.

velocity potential (Fig. 4.6) and anomalous outgoing longwave radiation (OLR; Fig. 4.7), as well as the Wheeler-Hendon (2004) Real-time Multivariate MJO (RMM) index (Fig. 4.8). In the time-longitude plots, the MJO exhibits eastward propagation from upper left to lower right. In the RMM, the MJO propagation and intensity are seen as large, counterclockwise circles around the origin. When considered together, these diagnostics point to three main MJO episodes during 2017. MJO \#1 was a strong episode that began in January and continued into March. MJO \#2 was a weak but long-lived signal that began in June and lasted into early September. MJO \#3 featured strong MJO activity that began in October and continued through the end of the year.

MJO \#1 featured a zonal wave-1 pattern of strong convective anomalies with a periodicity of $30-35$ days (Figs. 4.6, 4.8a), which is on the fast end of phase speeds for $\mathrm{MJO}$ events. The plot of anomalous velocity potential (Fig. 4.6) shows that the MJO circumnavigated the globe almost twice during this period, and the RMM index (Fig. 4.8a) indicates that the event was strongest in February. The episode ended in March when the convective anomalies became dominated by westward-moving Rossby waves (Fig. 4.7, blue contours). This period was followed during April and May by a series of fast propagating atmospheric Kelvin waves (Fig. 4.7, red contours).

Impacts from $\mathrm{MJO} \# 1$ included distinct periods with westerly and easterly zonal wind anomalies over the western Pacific, including a significant westerly wind burst (labeled WWB) and a significant easterly trade wind surge (labeled TWS) event (Fig. 4.9a). These conditions produced alternating downwelling and upwelling equatorial oceanic Kelvin waves, the last of which was a downwelling wave whose anomalous warming reached the west coast of South America in early June (Fig. 4.9b).

In the extratropics, MJO \#1 may have had impacts over the North Pacific and North America. The 500-hPa height anomalies (not shown) featured an extratropical wave train that terminated in an anomalous ridge over the contiguous United States, a pattern associated with the MJO as it traverses the Maritime Continent (Schreck et al. 2013; Baxter et al. 2014). In the second half of February and early March, however, there was little evidence of an MJO extratropical response over North America.

MJO \#2 occurred during June-August, and its wave-1 signal circumnavigated the globe about 1.5 times (Fig. 4.6). The MJO's periodicity during this episode was about 60 days, which is on the slower side of the MJO phase speed envelope. This episode terminated when the anomalous convective pattern 

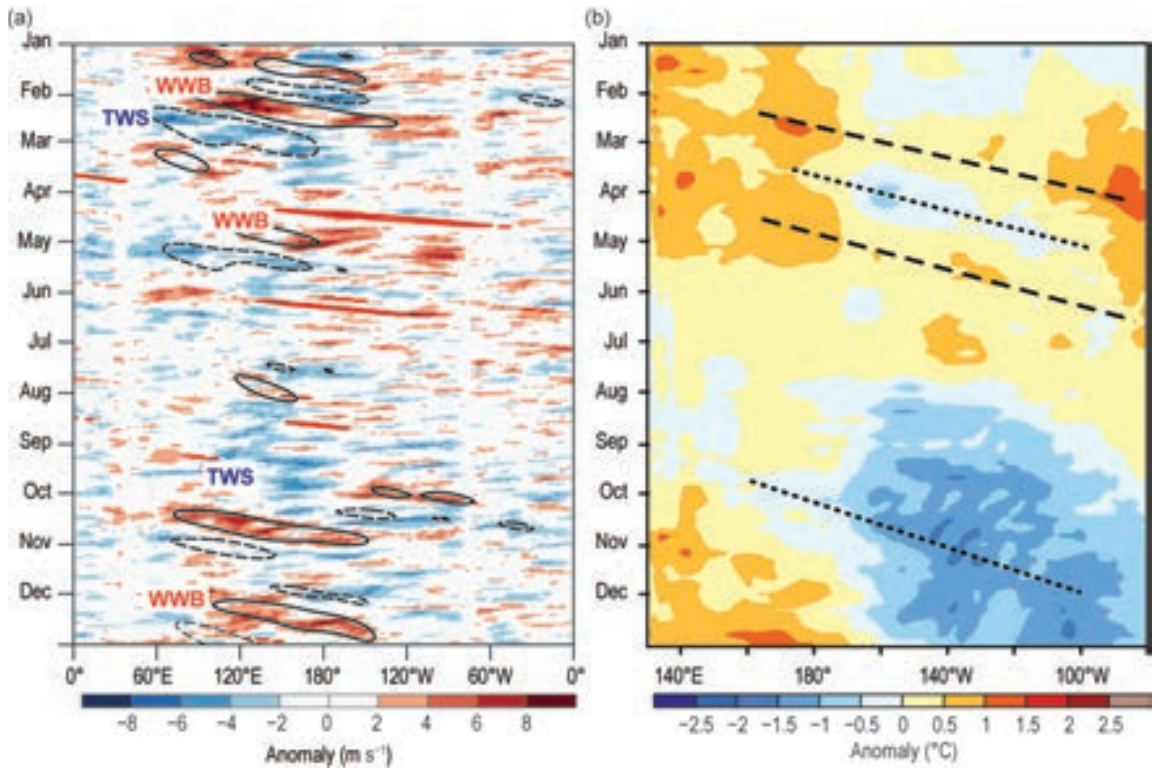

La Niña conditions which typically favor late-season Atlantic hurricane activity (Klotzbach et al. 2017). Second, the MJO's strong WWB west of the dateline in December (Fig. 4.9a) triggered a downwelling equatorial oceanic Kelvin wave that led to warming of the upper ocean by late December (Fig. 4.9b). Third, this MJO likely played a role in modulating the relative strength and position of anomalous upper-level ridging over the North Pacific and, in turn, supporting cold air outbreaks over east-central North America during late December 2017 and early January 2018 (L’Heureux 2018).

Within the equatorial Pacific Ocean itself, two key aspects of intraseasonal variability during 2017 were likely not related to the MJO. The first

became more dominated by tropical cyclone activity and two high-amplitude atmospheric Kelvin waves (Fig. 4.7). The RMM index indicates that $\mathrm{MJO} \# 2$ was quite weak (Fig. 4.8c). Consequently, its impacts were also weak and limited, with no associated equatorial oceanic Kelvin wave activity and only weak linkages to Northern Hemisphere TC activity. This MJO may have played a role in enhancing the eastern North Pacific TC activity during July and in suppressing that basin's TC activity during August (see Section 4f3).

MJO \#3 was a period of strong MJO activity that began during October and persisted through the end of the year, making nearly two passes around the globe. The average periodicity was about 45 days, but the propagation slowed with time: the first MJO circumnavigation of the globe took about 30 days, while the second took almost twice that (Fig. 4.6).

This episode had several notable impacts. First, it was in phases 5-7 during most of October (Fig. 4.8d), which are generally less favorable phases for Atlantic hurricane activity. Therefore, it may have played a role in the October activity being closer to climatology after a record-breaking September, despite was the rapid development during August, and the subsequent persistence, of negative upper-ocean heat content anomalies across the eastern half of the Pacific basin. This evolution reflected the developing La Niña. The second was additional strengthening of those negative anomalies from mid-September to mid-November in response to an upwelling equatorial oceanic Kelvin wave. This upwelling wave was associated with a trade wind surge event in September over the far western Pacific (Fig. 4.9a).

\section{d. Intertropical convergence zones}

I) PACIFIC—A. B. Mullan

Tropical Pacific rainfall patterns are dominated by two convergence zones, the intertropical convergence zone (ITCZ) and the South Pacific convergence zone (SPCZ), both of which are strongly influenced by ENSO and longer time-scale variations (Schneider et al. 2014; Vincent 1994; Folland et al. 2002). Figure 4.10 summarizes the convergence zone behavior for 2017 using rainfall patterns rather than cloudiness, and it allows comparison of the 2017 seasonal variation against the longer-term 1998-2016 


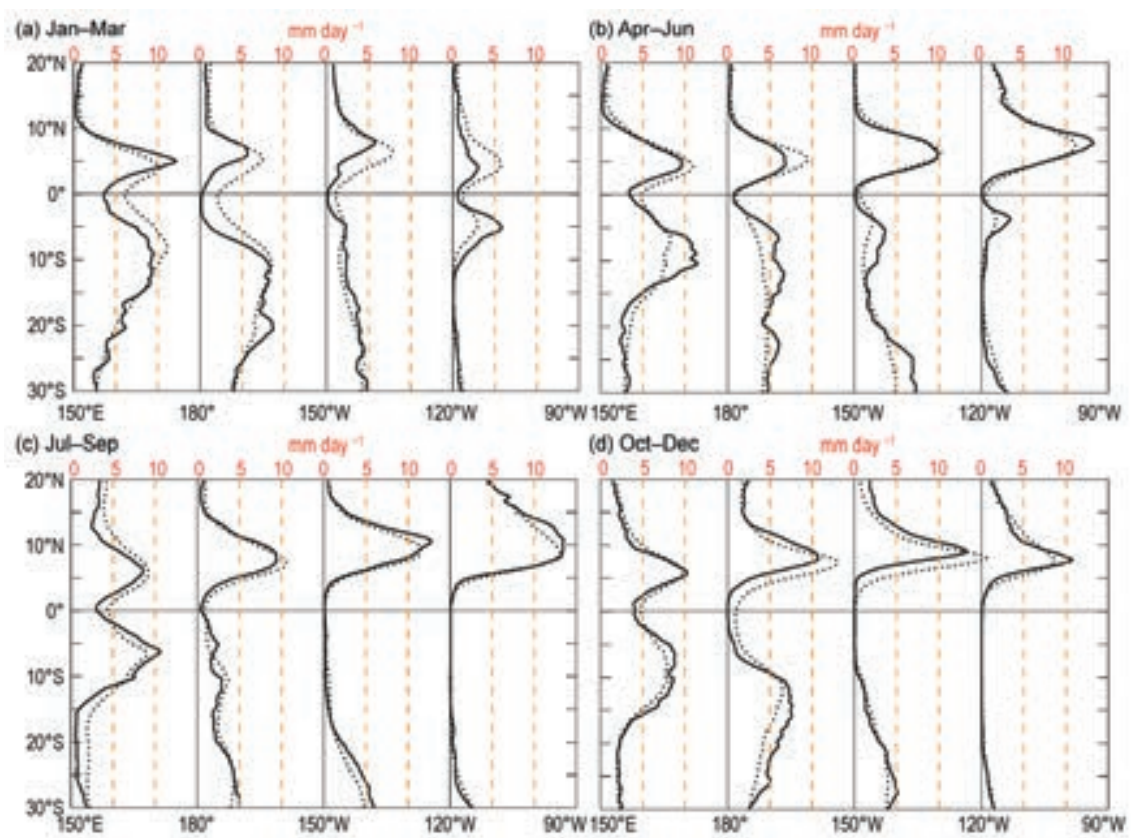

FIG. 4.I0. Rainfall rate ( $\mathrm{mm} \mathrm{day}^{-1}$ ) from CMORPH analysis during 2017 for (a) Jan-Mar, (b) Apr-Jun, (c) Jul-Sep, and (d) Oct-Dec. The separate panels for 3-month periods show the 2017 rainfall cross-section between $20^{\circ} \mathrm{N}$ and $30^{\circ} \mathrm{S}$ (solid line) and the 1998-2016 climatology (dotted line), separately for four $30^{\circ}$ sectors from $150^{\circ} \mathrm{E}-180^{\circ}$ to $120^{\circ}-90^{\circ} \mathrm{W}$.

climatology. Rainfall transects over $20^{\circ} \mathrm{N}$ to $30^{\circ} \mathrm{S}$ are presented for each quarter of the year, averaged across successive 30 -degree longitude bands, starting in the western Pacific at $150^{\circ} \mathrm{E}-180^{\circ}$. The rainfall is estimated from satellite microwave and infrared data using NOAA's CPC morphing technique (CMORPH; Joyce et al. 2004) and is available at $0.25^{\circ}$ resolution.

The ITCZ lies between $5^{\circ}$ and $10^{\circ} \mathrm{N}$ and is most active during August-December, when it lies at its northernmost position and displays more of an eastnortheasterly tilt. The SPCZ extends diagonally from around the Solomon Islands $\left(10^{\circ} \mathrm{S}, 160^{\circ} \mathrm{E}\right)$ to near $30^{\circ} \mathrm{S}, 140^{\circ} \mathrm{W}$, and is most active during NovemberApril. As described in Section 4b, 2016 ended with the demise of a weak La Niña and neutral conditions prevailed for most of 2017, with the eventual emergence of another weak La Niña in October. In the first quarter of 2017 (Fig. 4.10a), both the ITCZ and the SPCZ were poleward of their normal positions, likely due to persistence of the weak La Niña conditions of the previous year (Mullan 2017). Thus, island groups close to the equator (e.g., Kiribati and Tokelau) experienced continued dry conditions (www.niwa .co.nz/climate/icu). Conversely, many islands within the Federated States of Micronesia were far enough north of the equator to experience wetter conditions due to the displaced ITCZ (www.weather.gov/peac /update). Please refer to Section 7 h2 for more details.

Figure 4.10a also shows that, except west of the dateline, the ITCZ was much weaker than normal across the North Pacific. Figure 4.11 gives an alternative view of the much drier-than-normal conditions that prevailed across most of the tropical Pacific during JanuaryMarch. The other unusual feature of the convergence zones in this quarter, apparent in Fig. 4.10a, is what is commonly referred to as the double ITCZ in the far eastern tropical Pacific. The southern branch of the ITCZ is seen during February through April but only in ENSO-neutral or La Niña years. The southern ITCZ was prominent during these months in 2017 (Fig. 4.11) and was one of the strongest since the beginning of the Tropical Rainfall Measuring Mission (TRMM) satellite era [equivalent to 2009, not shown; TRMM has since been replaced by the Global Precipitation Measurement (GPM) satellite in 2014 (Hou et al. 2014)].

The tropical Pacific remained in a neutral ENSO state through April-June and July-September, often with weak but conflicting ENSO signals in the atmosphere and ocean. For example, conditions at the end of June indicated a negative Southern Oscillation index (i.e., leaning towards El Niño), but large-scale rainfall and convection anomalies showed more intense-than-normal convection and

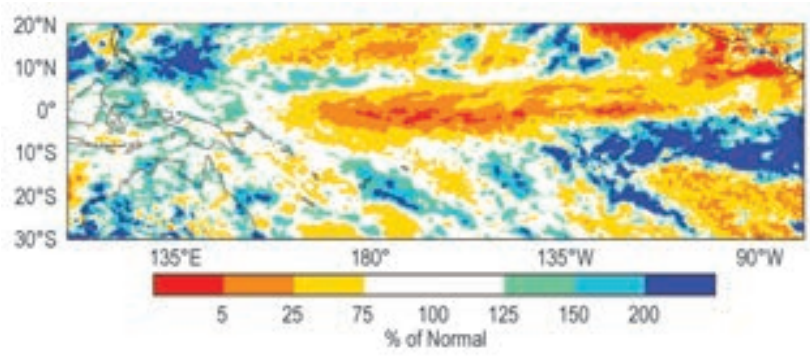

FIG. 4.II. CMORPH rainfall anomalies over the tropical Pacific for Jan-Mar 2017, as a percentage of the 1998-2016 average. The white areas indicate anomalies within $25 \%$ of normal. 


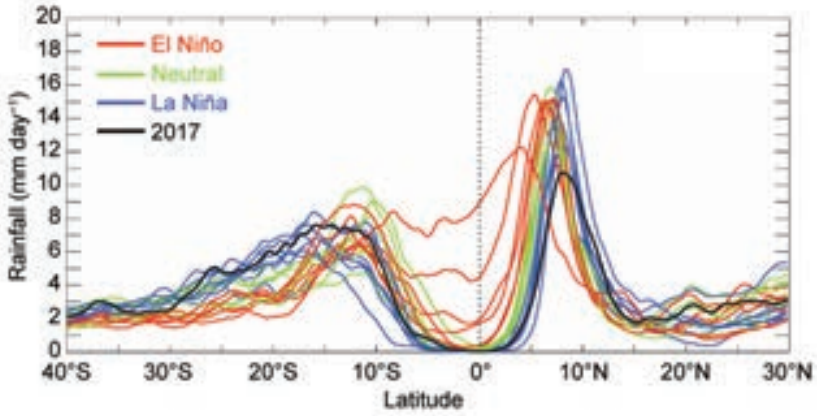

FIG. 4.I2. CMORPH rainfall rate $\left(\mathrm{mm} \mathrm{day}^{-1}\right)$ for OctDec, for each year 1998 to 2017, averaged over the longitude sector $180^{\circ}-150^{\circ} \mathrm{W}$. The cross-sections are color-coded according to NOAA's ONI, except for 2017 (a La Niña period) shown in black.

rainfall over large parts of Indonesia, indicative of a La Niña pattern. In general, the ITCZ and SPCZ were near their climatological positions and intensities during this 6-month period, although the SPCZ was somewhat more active than usual at about $10^{\circ} \mathrm{S}$ during April-June (Fig. 4.10b). Associated with this enhanced convection, SSTs were $0.5^{\circ}-1.0^{\circ} \mathrm{C}$ above normal throughout the central and western subtropical South Pacific (see Fig. 4.2d).

In September, the tropical Pacific edged closer to La Niña conditions, with anomalous cooling in the eastern and central tropical Pacific, an increase in the Southern Oscillation index, and more enhanced easterly trade winds in the central and western equatorial Pacific. During the last quarter of 2017, La Niña conditions became more consistent across both atmospheric and oceanic features. The ITCZ and SPCZ remained at their climatological locations west of the dateline; on average, however, both were displaced poleward of their normal positions to the east of the dateline (Fig. 4.10d).

In the central north Pacific $\left(180^{\circ}-120^{\circ} \mathrm{W}\right)$, rainfall was well below normal from the equator to the latitude where the ITCZ rainfall peaked (about $8^{\circ}-9^{\circ} \mathrm{N}$ as depicted in Fig. $4.10 \mathrm{~d}$ ). In the $180^{\circ}-150^{\circ} \mathrm{W}$ sector, the latitude of peak rainfall matched well with previous La Niña events, but the intensity was the lowest since the beginning of the TRMM satellite record. Figure 4.12 shows the south-north rainfall transect of Fig. 4.10d, except that every year from 1998 is shown, color-coded according to NOAA's Oceanic Niño index. October-December 2017, classified as a La Niña quarter, is highlighted separately in black. Although rainfall north of the equator was unusually weak for a La Niña, conditions along the equator and southwards followed the expected La Niña behavior. Islands near the equator (e.g., Nauru and all the Kiri- bati groups) thus continued the dry conditions they had experienced since the weak La Niña at the end of 2016. In the Southern Hemisphere during OctoberDecember, the SPCZ matched well with past La Niña periods with respect to both intensity and latitudinal location (Fig. 4.12).

\section{2) Atlantic-A. B. Pezza and C. A. S. Coelho}

The Atlantic ITCZ is a well-organized convective band that oscillates approximately between $5^{\circ}-12^{\circ} \mathrm{N}$ during July-November and $5^{\circ} \mathrm{N}-5^{\circ} \mathrm{S}$ during JanuaryMay (Waliser and Gautier 1993; Nobre and Shukla 1996). Equatorial atmospheric Kelvin waves can modulate the ITCZ intraseasonal variability (Guo et al. 2014). ENSO and the southern annular mode (SAM) also influence the ITCZ on the interannual time scale (Münnich and Neelin 2005). The SAM is typically positive during La Niña events, and it was generally so in 2017 (from April onwards) when the equatorial Pacific started to anomalously cool from ENSO neutral (Fig. 4.13a) to a La Niña state (Fig. 4.13b). The SAM is the primary pattern of climate variability in the Southern Hemisphere (Marshall 2003; Thompson et al. 2011), influencing latitudinal rainfall
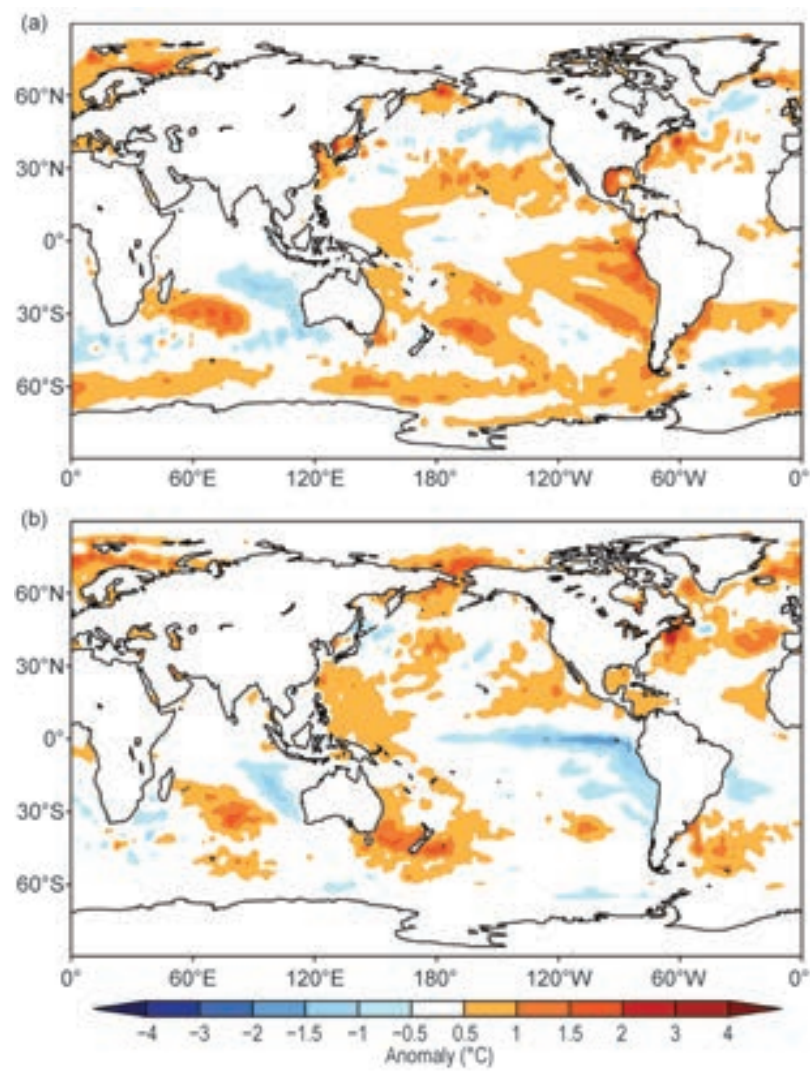

FIG. 4.I3. Spatial distribution global SST anomalies ( ${ }^{\circ}$ C; Reynolds et al. 2002) for (a) Jan-Apr and (b) Sep-Dec 2017. 
distribution and temperatures from the subtropics to Antarctica. The station-based index of the SAM is based on the zonal pressure difference between the latitudes of $40^{\circ} \mathrm{S}$ and $65^{\circ} \mathrm{S}$. As such, the SAM index measures a "see-saw" of atmospheric mass between the middle and high latitudes of the Southern Hemisphere (Marshall 2003). A positive SAM value can be indicative of a number of things; for instance, a positive SAM coupled with La Niña conditions may lead to increased extratropical cyclone transition of tropical cyclones across or toward New Zealand (Diamond and Renwick 2015).
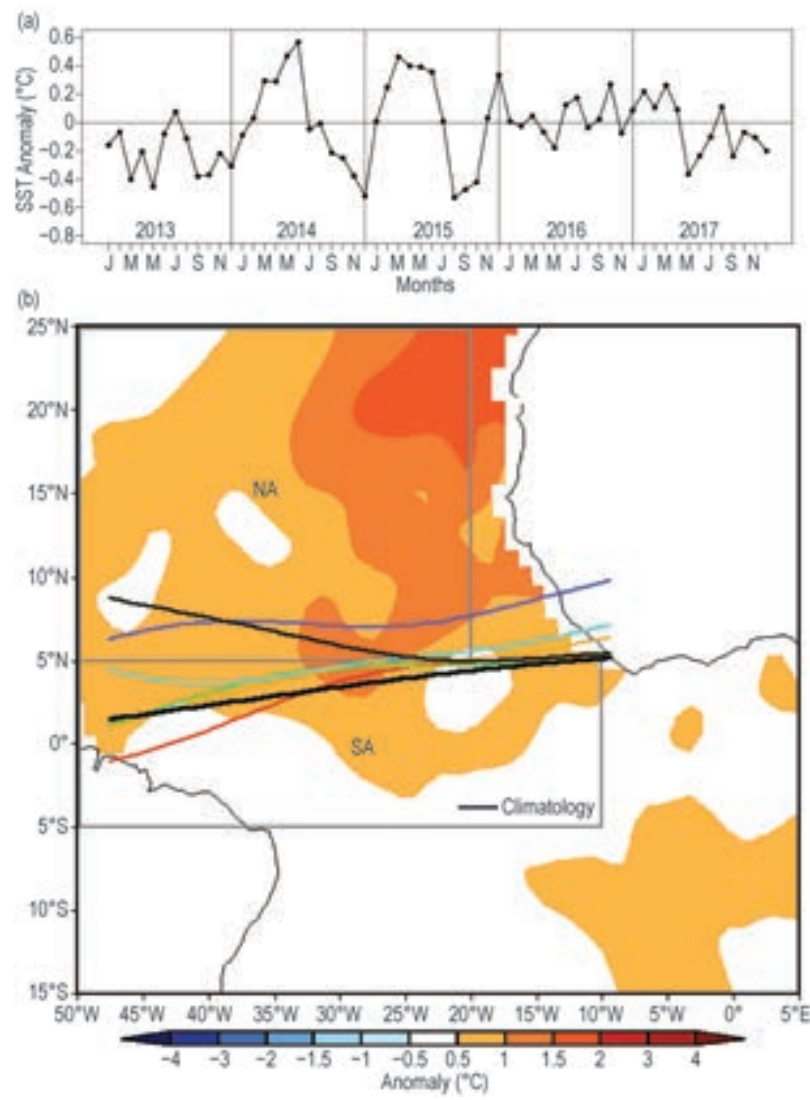

FIG. 4.I4. (a) Monthly OISST (Smith et al. 2008) anomaly time series averaged over the South American sector (SA region, $5^{\circ} \mathrm{S}-5^{\circ} \mathrm{N}, 10^{\circ}-50^{\circ} \mathrm{W}$ ) minus the SST anomaly time series averaged over the North Atlantic sector (NA region, $5^{\circ}-25^{\circ} \mathrm{N}, 20^{\circ}-50^{\circ} \mathrm{W}$ ) for 2013-17, forming the Atlantic index. Positive phase of the index indicates favorable conditions for enhanced Atlantic ITCZ activity. (b) Atlantic ITCZ position inferred from OLR (Liebmann and Smith 1996) during May 2017. Colored thin lines indicate the approximate position for the six pentads of the month. Black thick line indicates the Atlantic ITCZ climatological position for May. The SST anomalies $\left({ }^{\circ} \mathrm{C}\right)$ for May 2017 based on the 1982-2016 climatology are shaded. The two boxes indicate the areas used for the calculation of the Atlantic index in (a).
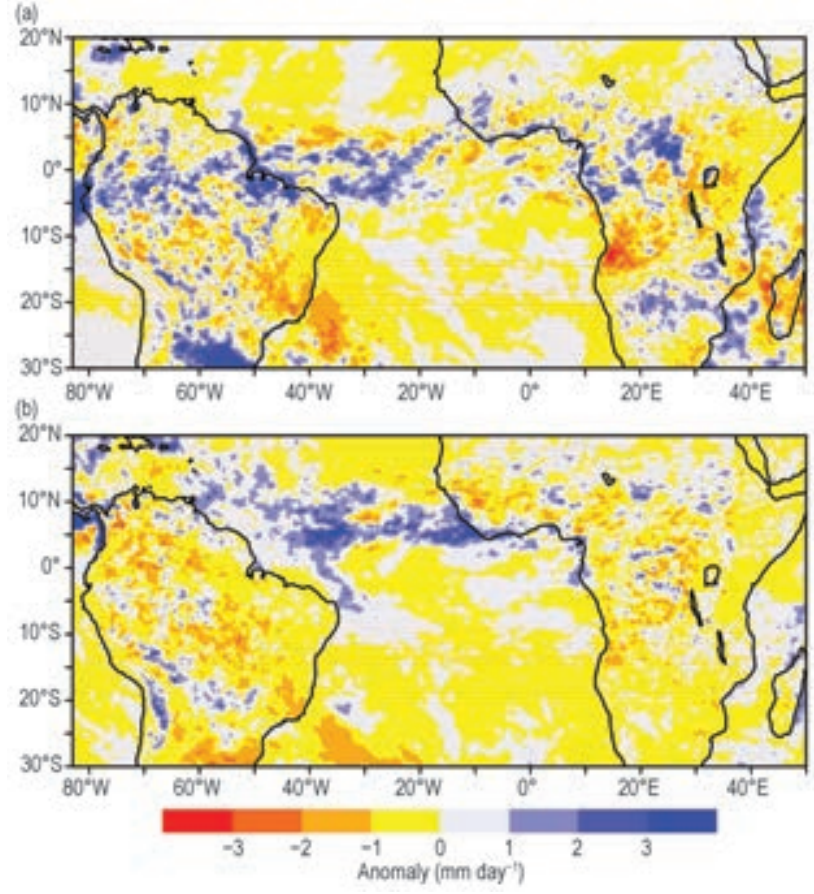

FIG. 4.15. Observed 2017 precipitation anomalies (mm day ${ }^{-1}$ ) for tropical and subtropical South America during (a) Jan-May and (b) Jun-Dec. Anomalies calculated based on the 1998-2016 climatology derived from CMORPH (Joyce et al. 2004).

While in principle this reversal toward the cool ENSO phase would tend to favor the Atlantic ITCZ moving south, in reality the change occurred too late in the ITCZ's southern migration season in order to have a positive effect on the rainy season in northeastern Brazil, even though overall the ITCZ was very active over the ocean. For the most part an enhanced South Atlantic anticyclone, increased trade winds, and relatively warmer waters north of the equator prevailed. This was accompanied by a mostly negative South American sector (SA) index, although not so pronounced as in some previous years (Fig. 4.14a). The SA index, as defined in Fig. 4.14, is given by the SST south of the equator minus the SST north of the equator over key areas of ITCZ influence. The ITCZ tends to shift toward the warmer side of this gradient. Indeed, it was generally north of its climatological position for most of 2017, especially in May when it is typically at its southernmost location (Fig. 4.14b).

As discussed above, the overall convection was active over the ocean, and although northeastern Brazil remained dry, the eastern Amazon region (Para state) had above-normal precipitation during the wet season (Fig. 4.15a). The ITCZ remained active for the remainder of the year, mostly over the ocean, as La Niña developed (Fig. 4.15b). 


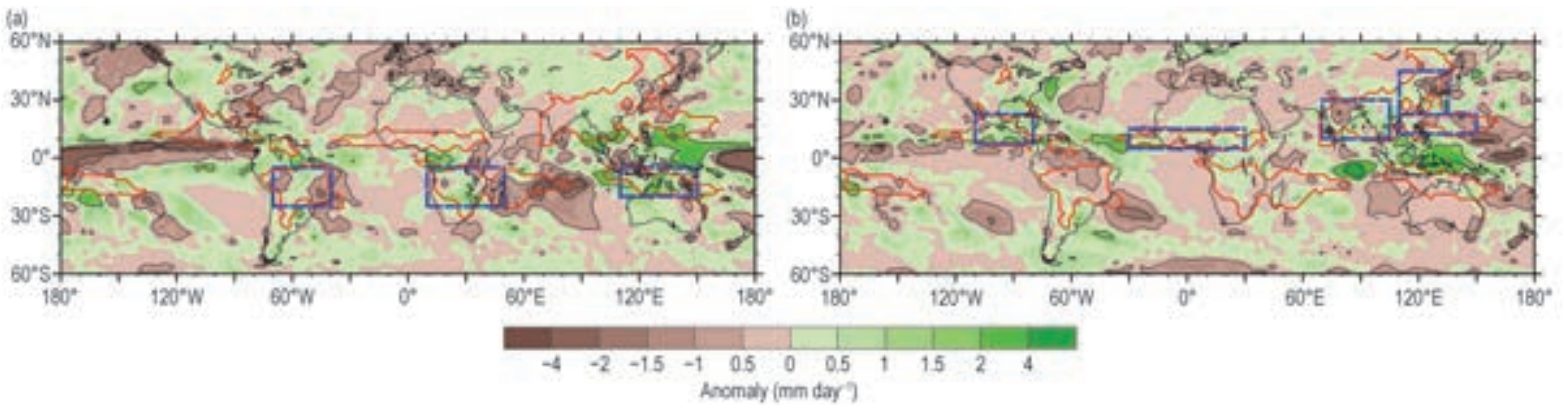

FIG. 4.I6. Precipitation anomalies $\left(\mathrm{mm} \mathrm{day}^{-1}\right)$ averaged for (a) northern winter season: Nov $2016-\mathrm{Apr} 2017$ and (b) northern summer: May-Oct 20I7. The red lines outline the global monsoon precipitation domain defined by (a) annual range (local summer minus winter) precipitation exceeding $\mathbf{3 0 0}$ mm and (b) summer mean precipitation $>55 \%$ of the total annual precipitation amount (Wang and Ding 2008). Here the local summer denotes May-Sep for the NH and Nov-Mar for the SH. Precipitation indices for each regional monsoon are defined by the areal mean precipitation in the corresponding rectangular regions (dashed blue boxes), which are highly correlated with the precipitation averaged over the corresponding real regional monsoon domains (see Table 4.I). Rainfall data were taken from the Global Precipitation Climatology Project (GPCP; Huffman et al. 2009). Note that the threshold of $300 \mathrm{~mm}$ excludes a small latitudinal band of the monsoon in the Sahel.

e. Global monsoon summary-B. Wang

The global monsoon (GM) is the dominant mode of annual variations of tropicalsubtropical precipitation and circulation (Wang and Ding 2008) and thus a defining feature of seasonality and a major mode of variability of Earth's climate system. Figure 4.16 summarizes the monsoon rainfall anomalies for both the SH summer monsoon (SHSM) from November 2016 to April 2017 and the NH summer monsoon (NHSM) from May to October 2017.

Global land monsoon precipitation is strongly influenced by the status of ENSO, especially the land areas of Asia, Australia, northern Africa, and Central America (Wang et al. 2012). As documented in Fig. 4.1 for this year, the equatorial Pacific SSTs evolved from a weak La Niña from NDJ to a neutral state, then toward another weak La Niña during SON. Figure 4.16 indicates that the monsoon precipita-

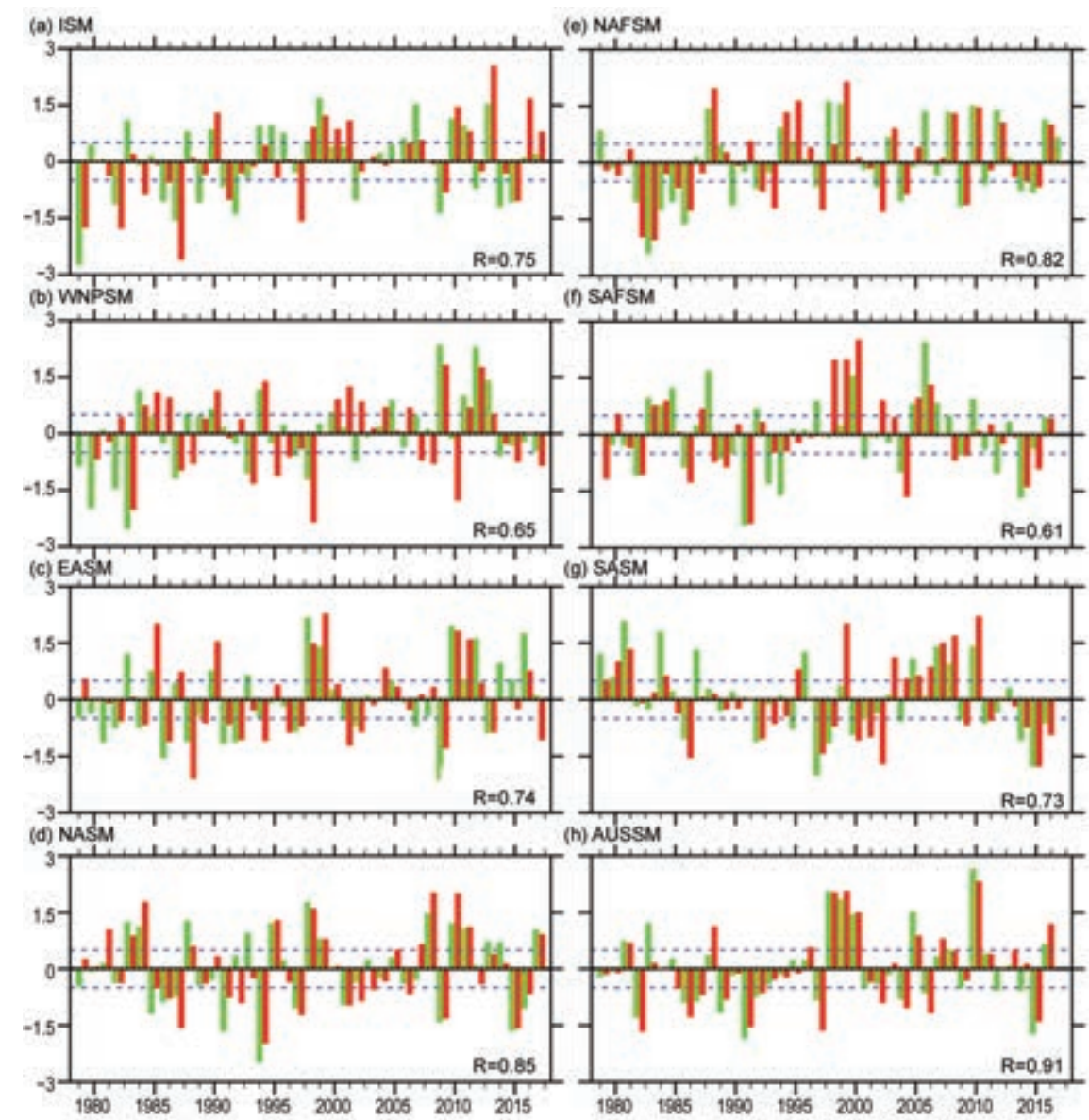

Fig. 4.17. Normalized summer mean precipitation (green) and circulation (red) indices in each of eight regional monsoon regions (see Table 4.I). Indices are normalized by their corresponding std. dev. Numbers shown in the corner of each panel denote the correlation coefficient between seasonal mean precipitation and circulation indices. Dashed lines indicate std. dev. of \pm 0.5 . Here the summer denotes May-Oct for the NH and Nov-Apr for the SH. [Source: GPCP for precipitation; Upper air indices as described in Yim et al. (2014).] 
TABLE 4.I. (Modified from Yim et al. 20I3). Definition of the regional summer monsoon circulation indices and their correlation coefficients (CCs) with the corresponding regional summer monsoon precipitation indices for the period 1979-2015. All circulation indices are defined by meridional shear of zonal winds at $850 \mathrm{hPa}$ which measures the intensity (relative vorticity) of the monsoon troughs at $850 \mathrm{hPa}$ except the northern African (NAF) and East Asian (EA). The NAF monsoon circulation index is defined by the westerly monsoon strength: $\mathrm{U} 850\left(0^{\circ}-15^{\circ} \mathrm{N}, 60^{\circ}-10^{\circ} \mathrm{W}\right)$ and the EASM circulation index is defined by the meridional wind strength: V850 $\left(20^{\circ}-40^{\circ} \mathrm{N}, 120^{\circ}-140^{\circ} \mathrm{E}\right)$ which reflects the east-west thermal contrast between the Asian continent and western North Pacific. The precipitation indices are defined by the areal mean precipitation over the blue box regions shown in Fig. 4.18. The correlation coefficients were computed using monthly time series (148 summer months) [Jun-Sep (JJAS) in NH (1979-2015) and Dec-Mar (DJFM) in SH (1979/80-2015/16]. The bolded numbers represent significance at $99 \%$ confidence level.

\begin{tabular}{|c|c|c|}
\hline Region & Circulation Index Definition & CC \\
\hline Indian (ISM) & $\begin{array}{l}\text { U850 }\left(5^{\circ}-15^{\circ} \mathrm{N}, 40^{\circ}-80^{\circ} \mathrm{E}\right) \text { minus } \\
\text { U850 }\left(25^{\circ}-35^{\circ} \mathrm{N}, 70^{\circ}-90^{\circ} \mathrm{E}\right)\end{array}$ & 0.71 \\
\hline Western North Pacific (WNPSM) & $\begin{array}{l}\text { U850 }\left(5^{\circ}-15^{\circ} \mathrm{N}, 100^{\circ}-130^{\circ} \mathrm{E}\right) \text { minus } \\
\text { U850 }\left(20^{\circ}-35^{\circ} \mathrm{N}, 110^{\circ}-140^{\circ} \mathrm{E}\right)\end{array}$ & 0.78 \\
\hline East Asian (EASM) & $\operatorname{V850}\left(20^{\circ}-40^{\circ} \mathrm{N}, 120^{\circ}-140^{\circ} \mathrm{E}\right)$ & 0.73 \\
\hline North American (NASM) & $\begin{array}{l}\text { U850 }\left(5^{\circ}-15^{\circ} \mathrm{N}, 130^{\circ}-100^{\circ} \mathrm{W}\right) \text { minus } \\
\text { U850 }\left(20^{\circ}-30^{\circ} \mathrm{N}, 110^{\circ}-80^{\circ} \mathrm{W}\right)\end{array}$ & 0.84 \\
\hline Northern African (NAFSM) & U850 $\left(0-15^{\circ} \mathrm{N}, 60^{\circ}-10^{\circ} \mathrm{W}\right)$ & 0.72 \\
\hline South American (SASM) & $\begin{array}{l}\text { U850 }\left(5^{\circ}-20^{\circ} \mathrm{S}, 70^{\circ}-40^{\circ} \mathrm{W}\right) \text { minus } \\
\text { U850 }\left(20^{\circ}-35^{\circ} \mathrm{S}, 70^{\circ}-40^{\circ} \mathrm{W}\right)\end{array}$ & 0.77 \\
\hline Southern African (SAFSM) & $\begin{array}{l}\text { U850 }\left(0^{\circ}-15^{\circ} \mathrm{S}, 10^{\circ}-40^{\circ} \mathrm{E}\right) \text { minus } \\
\quad \text { U850 }\left(10^{\circ}-25^{\circ} \mathrm{S}, 40^{\circ}-70^{\circ} \mathrm{E}\right)\end{array}$ & 0.55 \\
\hline Australian (AUSSM) & $\begin{array}{l}\text { U850 }\left(0^{\circ}-15^{\circ} \mathrm{S}, 90^{\circ}-130^{\circ} \mathrm{E}\right) \text { minus } \\
\text { U850 }\left(20^{\circ}-30^{\circ} \mathrm{S}, 100^{\circ}-140^{\circ} \mathrm{E}\right)\end{array}$ & 0.89 \\
\hline
\end{tabular}

tion anomalies are generally in normal states with a few individual regions slightly positive, consistent with the near-neutral ENSO SST anomalies. Figure 4.17 shows the time series of the monsoon precipitation and low-level circulation indices for each regional monsoon. Note that the precipitation indices represent the total amount of precipitation over both land and ocean. The definitions of circulation indices for each monsoon region are shown in Table 4.1. The precipitation and circulation indices together represent the strength of each regional monsoon system.

During the SH summer (November 2016-April 2017), global precipitation exhibited a pattern consistent with the decay of a weak La Niña (averaged $\mathrm{ONI}=-0.2$ ): suppressed precipitation over the Pacific ITCZ and southern Indian Ocean convergence zone, and increased precipitation over the Maritime Continent and adjacent regions (Fig. 4.16a). As a result, the Australian summer monsoon region received slightly more precipitation than normal, and the strength of the corresponding circulation was also above normal (Fig. 4.17h). The southern African summer monsoon precipitation and circulation were near normal (Fig. 4.17f), while the South American monsoon shows slightly below-average intensity in both precipitation and circulation (Fig. $4.17 \mathrm{~g}$ ). Overall, the SH summer monsoon during November 2016 to April 2017 was normal.

During the NH summer (May-October) of 2017, ENSO was neutral (average $\mathrm{ONI}=0.0$ ) and global precipitation also tended to be near normal, as did overall $\mathrm{NH}$ summer monsoon precipitation (Fig. 4.16b). On regional scales, the summer precipitation over India, East Asia, and western North Pacific were all near normal (Figs. $4.17 \mathrm{a}-\mathrm{c}$ ), while precipitation was above normal over the North American monsoon region and slightly above normal over the northern African monsoon region (Figs. $4.17 \mathrm{~d}$,e).

\section{f. Tropical Cyclones}

I) OVerview-H. J. Diamond and C. J. Schreck

The IBTrACS dataset comprises historical TC best-track data from numerous sources around the globe, including all of the WMO Regional Specialized 


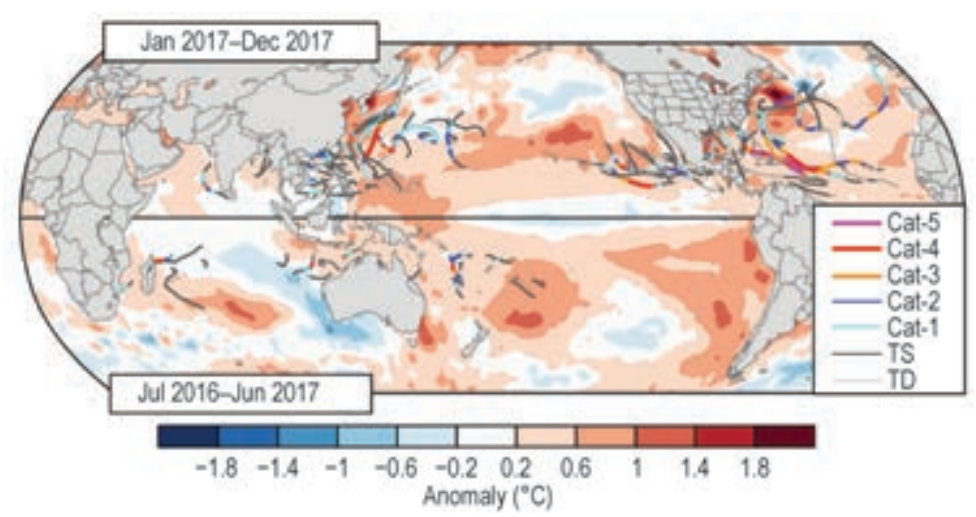

FIG. 4.I8. Global summary of TC tracks overlaid on the associated OISST anomalies ( ${ }^{\circ} \mathrm{C}$ ) for the 2017 season relative to $1982-2010$.

2017) and is slightly above the 1981-2010 average of 82 (Schreck et al. 2014). The 2017 season also featured 41 hurricanes/ typhoons/cyclones (HTC; wind speeds $\geq 64 \mathrm{kt}$ or $33 \mathrm{~m} \mathrm{~s}^{-1}$ ), which is below the 1981-2010 average of 46 HTCs (Schreck et al. 2014). Twenty storms reached major HTC status during the 2017 season (wind speeds $\geq 96 \mathrm{kt}$ or $49 \mathrm{~m} \mathrm{~s}^{-1}$ ), which is near the long-term average of 21 and is six fewer than the post-analysis 26 HTCs recorded in 2016 (Diamond and Schreck 2017).

In Sections 4f2-4f8, the 2017 seasonal activity is described and compared to the historical record for each of the seven

Meteorological Centers (RSMC; Knapp et al. 2010). IBTrACS represents the most complete compilation of global TC data. From these data, Schreck et al. (2014) compiled climatological values of TC activity for each basin for 1981-2010 using both the WMO RSMCs and the Joint Typhoon Warning Center (JTWC). These values are referenced in each subsection.

The tallying of the global TC numbers is challenging and involves more than simply adding up basin totals, because some storms cross TC basin boundaries, some TC basins overlap, and multiple agencies are involved in tracking and categorizing TCs. Compiling the activity using preliminary IBTrACS data over all seven TC basins (Fig. 4.18), the 2017 season (2016/17 in the Southern Hemisphere) had 85 named storms (wind speeds $\geq 34 \mathrm{kt}$ or $17 \mathrm{~m} \mathrm{~s}^{-1}$ ). This number matches the post-analysis 2016 total (Diamond and Schreck
WMO-defined hurricane basins. For simplicity, all counts are broken down by the United States' SaffirSimpson scale. The overall picture of global TCs during 2017 is shown in Fig. 4.18 and actual counts by category are documented in Table 4.2 .

The North Atlantic hurricane season was above normal in both storm numbers and intensity (Section $4 \mathrm{f} 2$ ). In fact, it was the only basin globally that featured above-normal accumulated cyclone energy (ACE). The central and eastern North Pacific hurricane season was well below normal for number of storms (Section 4f3). The western North Pacific had less than half of its normal annual ACE, and the Southern Hemisphere had one of its quietest TC seasons on record, particularly with respect to ACE (Sections 4f6-8).

Globally, only three storms during the year reached Saffir-Simpson category 5 strength (wind

\begin{tabular}{|c|c|c|c|c|c|c|}
\hline TABLE 4.2. Global tropical cyclone counts by basin in 2017. \\
\hline Basin & TDs & TSs & HTCs & $\begin{array}{c}\text { Major } \\
\text { HTCs }\end{array}$ & SS Cat 5 & $\begin{array}{c}\text { ACE } \\
\left(\times \mathbf{~ I 0 ~}^{4} \mathbf{~ t}^{2}\right)\end{array}$ \\
\hline North Atlantic & 18 & 17 & 10 & 6 & 2 & 225 \\
\hline Eastern North Pacific & 20 & 18 & 9 & 4 & 0 & 97 \\
\hline Western North Pacific & 35 & 26 & 12 & 4 & 1 & 150 \\
\hline North Indian & 4 & 4 & 2 & 1 & 0 & 15 \\
\hline South Indian & 5 & 5 & 2 & 1 & 0 & 28 \\
\hline Australian Region & 8 & 8 & 3 & 3 & 0 & 30 \\
\hline Southwest Pacific & 7 & 7 & 3 & 1 & 0 & 35 \\
\hline Totals & $\mathbf{9 8}$ & $\mathbf{8 5}$ & $\mathbf{4 1}$ & $\mathbf{2 0}$ & $\mathbf{3}$ & $\mathbf{5 8 0}$ \\
\hline
\end{tabular}


speeds $\geq 137 \mathrm{kt}$ or $70.5 \mathrm{~m} \mathrm{~s}^{-1}$ ), which is one less than in 2016 and five fewer than in 2015. The three 2017 storms were Hurricanes Irma and Maria in the North Atlantic and Super Typhoon Noru in the western North Pacific. Sidebars 4.1 and 4.3 detail the records set and devastating local impacts of Irma and Maria, respectively.

Several other Saffir-Simpson category 3 and 4 intensity level systems during 2017 also had major impacts, including: (1) Hurricane Harvey in the North Atlantic, (2) Typhoons Tembin and Hato in the western North Pacific, and (3) Tropical Cyclone Debbie in the Australian basin. Also noteworthy was the development of Tropical Cyclone Donna in the southwest Pacific basin in early May 2017, a date which is outside of the formal TC season for that basin. Donna became the most intense TC recorded in that basin during the month of May.

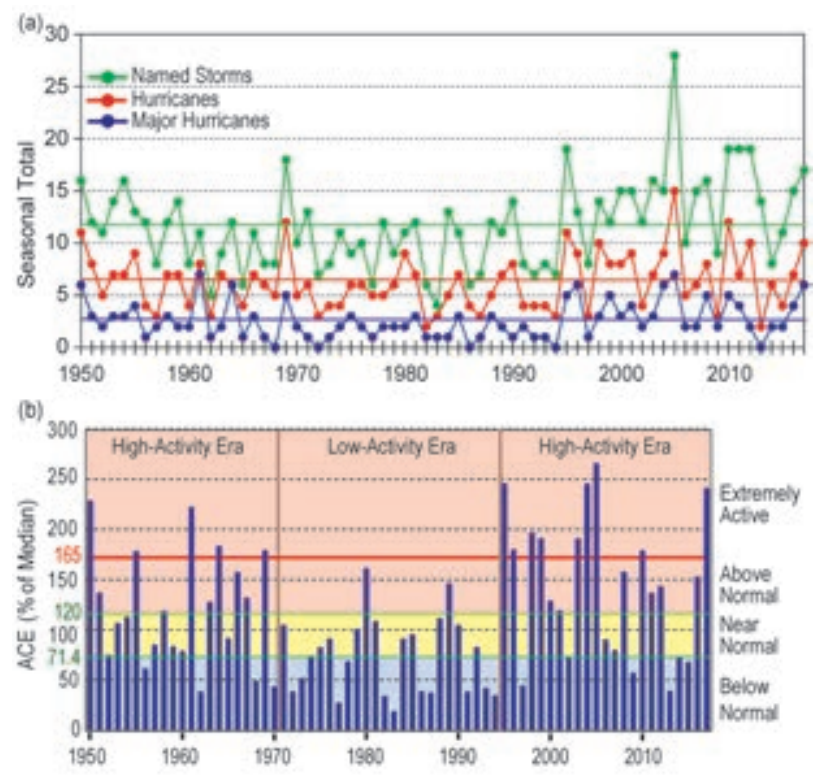

Fig. 4.19. Seasonal Atlantic hurricane activity during 1950-2017 based on HURDAT2 (Landsea and Franklin 2013). (a) Number of named storms (green), hurricanes (red), and major hurricanes (blue), with I98I-2010 seasonal means shown by solid colored lines. (b) ACE index expressed as percent of the 198I-2010 median value. ACE is calculated by summing the squares of the 6-hourly maximum sustained surface wind speed (knots) for all periods while the storm is at least tropical storm strength. Red, yellow, and blue shadings correspond to NOAA's classifications for above-, near-, and below-normal seasons, respectively ( $w w w$ .cpc.ncep.noaa.gov/products/outlooks/background _information.shtml). The thick red horizontal line at $165 \%$ ACE value denotes the threshold for an extremely active season. Vertical brown lines separate high- and low-activity eras.
2) Atlantic basin-G. D. Bell, E. S. Blake, C. W. Landsea,

S. B. Goldenberg, and R. J. Pasch

(i) 2017 Seasonal activity

The 2017 Atlantic hurricane season produced 17 named storms, of which 10 became hurricanes and 6 of those became major hurricanes (Fig. 4.19a). The HURDAT2 30-year (1981-2010) seasonal averages are 11.8 tropical (named) storms, 6.4 hurricanes, and 2.7 major hurricanes (Landsea and Franklin 2013).

The 2017 seasonal ACE value (Bell et al. 2000) was about $241 \%$ of the 1981-2010 median (92.4 $\times$ $10^{4} \mathrm{kt}^{2}$; Fig. 4.19b). This value is well above NOAA's thresholds for an above-normal season (120\%) and an extremely active season (165\%), www.cpc.ncep .noaa.gov/products/outlooks/background _information.shtml.

This ACE value makes 2017 the most active season since 2005, and the first extremely active season since 2010. It also makes 2017 the fourth most activeseason since at least 1950 and the seventh most active season in the historical record (since 1854). However, it should be noted that reliable basin-wide records for exact season-to-season comparisons with ACE began in the mid-1970s with the advent of the geostationary satellite era (Landsea et al. 2006).

The occurrence of above-normal and extremely active seasons shows a strong multidecadal signal. The 2017 season is the 15 th above-normal season and the 9th extremely active season since the current high-activity era for Atlantic hurricanes began in 1995. The previous Atlantic high-activity era (1950-70) also featured numerous above-normal and extremely active seasons. In stark contrast, the intervening low-activity era of 1971-94 featured only two above-normal seasons, and none were extremely active (Goldenberg et al. 2001).

\section{(ii) Storm formation regions, tracks, and landfalls}

A main delineator between above-normal and below-normal Atlantic hurricane seasons is the number of hurricanes and major hurricanes that develop from storms that are named while in the main development region (MDR, green boxed region in Fig. 4.21a) spanning the tropical Atlantic Ocean and Caribbean Sea between $9.5^{\circ}$ and $21.5^{\circ} \mathrm{N}$ (Goldenberg and Shapiro 1996; Goldenberg et al. 2001; Bell and Chelliah 2006). When activity is high in the MDR, overall seasonal TC activity and ACE are also high. The vast majority of storms which form within the MDR do so during the peak months (August-October, ASO) of the season. This peaked climatology is why seasonal hurricane predictions are essentially based on predictions for ASO of the atmospheric and 
oceanic conditions within the MDR (Goldenberg and Shapiro 1996; Klotzbach et al. 2017).

During 2017, seven of the ten Atlantic hurricanes and five of the six major hurricanes first became named storms during ASO in the MDR. For the season as a whole, MDR-originating storms produced an ACE of 212\% of the 1981-2010 median and accounted for $86 \%$ of the total season's ACE. The strongest and longest-lived MDR storm of the season was Major Hurricane Irma, which developed in late August and by itself produced an ACE value of $77.5 \%$ of the 1981-2010 median. Only one storm in the satellite record since 1966 (Major Hurricane Ivan in 2004) produced a larger ACE.

Extremely active seasons have a higher frequency of landfalling tropical storms, hurricanes, and major hurricanes. During 2017, there were 13 separate storm landfalls for the basin as a whole. This count reflects ten distinct named storms, of which six formed in the MDR. These six MDR storms include all three landfalling major hurricanes and two of the three (excluding Nate which formed in the extratropics) landfalling non-major hurricanes.

Six named storms struck the United States during 2017, including three catastrophic major hurricanes (Harvey in Texas, Irma in Florida, and Maria in Puerto Rico and the U.S. Virgin Islands), one nonmajor hurricane (Nate in Louisiana/ Mississippi), and two tropical storms (Cindy in Texas and Emily in Florida). Harvey was the first continental U.S. landfalling major hurricane since Wilma struck Florida in October 2005.

From a historical perspective, $86 \%$ (12 of 14 seasons) of extremely active seasons during 1950-2017 featured at least two continental U.S. landfalling hurricanes (Fig. 4.20a). This rate far exceeds the 50\% rate (7 of 14 seasons) for above-normal seasons that were not extremely active and is almost triple the rate (30\%, 6 of 20 seasons) for near-normal seasons. Only $5 \%$ ( 1 of 20 seasons) of the below-normal seasons since 1950 produced multiple continental U.S. landfalling hurricanes. Similarly, 71\% (10 of 14 seasons) of extremely active seasons since 1950 featured at least one major hurricane landfall in the continental U.S (Fig. 4.20b). This is more than double the $31 \%$ rate (17 of 54 seasons) of landfalling major hurricanes for all other seasons combined. Interestingly, about $20 \%$ of below-normal seasons have had a continental U.S. landfalling major hurricane.

The entire region around the Caribbean Sea also typically sees an increased number of hurricane landfalls during extremely active seasons. During 2017, eight named storms struck the region. These included two catastrophic major hurricanes (Irma and Maria), two non-major hurricanes (Franklin and Katia in eastern Mexico), and four tropical storms (Bret in Trinidad and Venezuela; Harvey in Barbados and St. Vincent; Nate in Central America; and Philippe in Cuba).

\section{(iii) Atlantic sea surface temperatures}

SSTs were above average during ASO 2017 across the MDR, the Gulf of Mexico, and much of the extratropical North Atlantic (Fig. 4.21a). The areaaveraged SST anomaly within the MDR was $+0.54^{\circ} \mathrm{C}$ (Fig. 4.21b). The area-averaged SST anomaly within the Caribbean Sea, a subregion of the MDR, was $+0.60^{\circ} \mathrm{C}$. This departure for the Caribbean Sea was the second highest since 1950 and followed the record warmth of ASO 2016 (Fig. 4.21c).

Historically, when assessing links between Atlantic SSTs and hurricane season strength, it is important to consider their common relationships to largerscale climate patterns. Two key climate patterns are the Atlantic multidecadal oscillation (AMO; Enfield and Mestas-Nuñez 1999; Goldenberg et al. 2001; Bell and Chelliah 2006; Bell et al. 2011, 2012) and ENSO (Gray 1984; Tang and Neelin 2004; Bell and Chelliah 2006). These SST-based phenomena strongly control large-scale atmospheric conditions (such as vertical wind shear, trade winds, moisture, atmospheric sta-

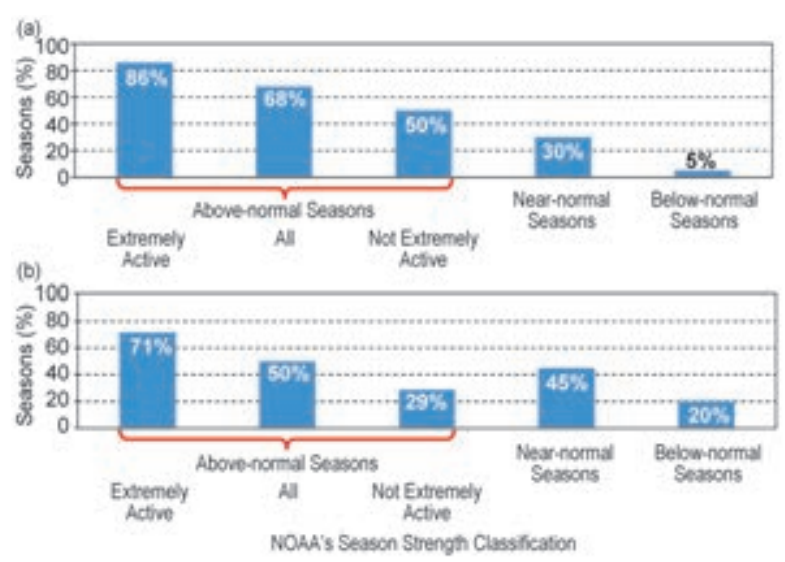

FIG. 4.20. Continental U.S. landfalling hurricane frequencies during 1950-2017 for each of NOAA's season types. (a) Percent of specified season type with at least two U.S. hurricane landfalls, and (b) percent of specified season type with one or more U.S. major hurricane landfall. Above-normal seasons include those labeled "Extremely Active" and "Above Normal Not Extremely Active." Season classifications are shown in www.cpc.ncep.noaa.gov/products/outlooks /background_information.shtml. Landfall data is based on HURDAT2 (Landsea and Franklin 2013). 
bility, etc.) across the MDR, thereby influencing the strength of the hurricane season.

The AMO predisposes the ocean-atmosphere system to be either more or less conducive to Atlantic hurricane activity for periods of 25-40 years at a time. One measure of the AMO is the standardized time series of the detrended Kaplan AMO index (www .esrl.noaa.gov/psd/data/correlation/amon.us.long .data). For ASO 2017, that index was +1.51 standard deviation (std. dev.), indicating the positive (i.e., warm) phase of the AMO. The standardized 7-year running mean (using ASO seasons only) of the detrended Kaplan AMO index for ASO 2017 was +1.75 std. dev. (Fig. 4.22a). Historically, the warm AMO is associated with the Atlantic high activity eras of 1950-70 and 1995-present. Conversely, the Atlantic low activity eras of 1900-20 and 1971-94 were associated with the negative (i.e., cool) phase of the AMO.
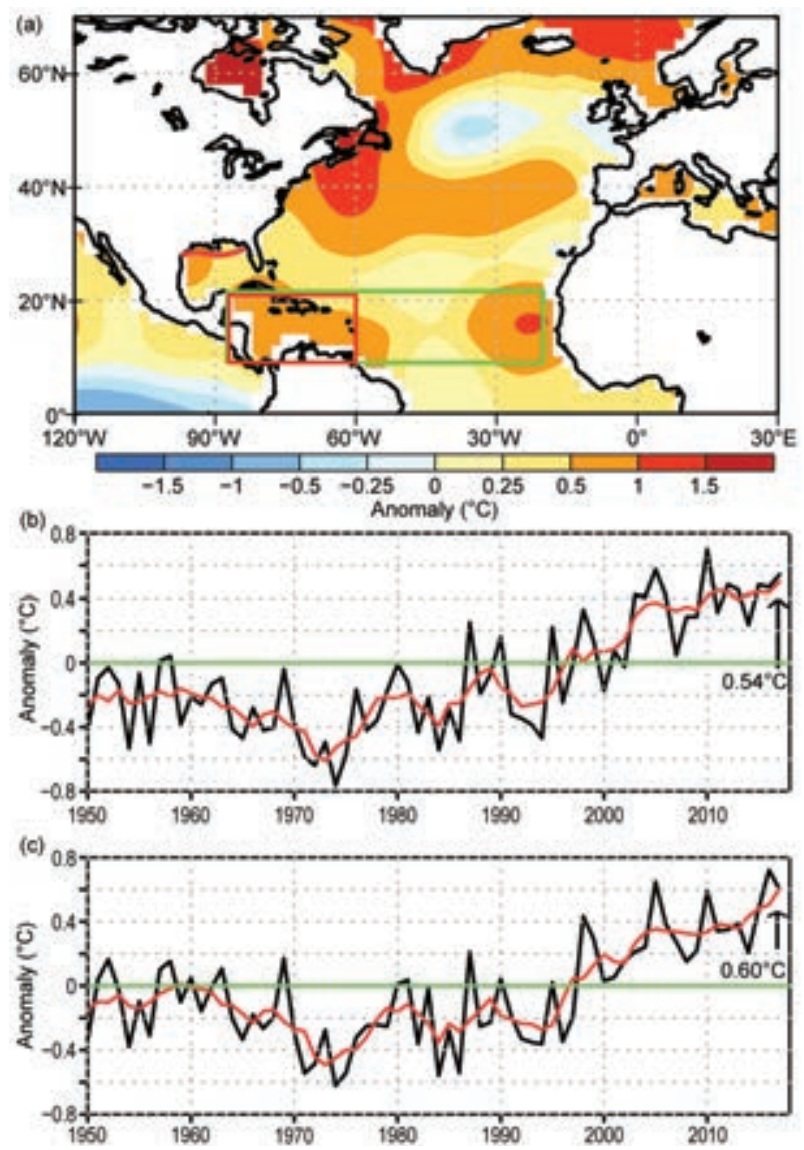

FIG. 4.2I. (a) ASO $2017 \mathrm{SST}$ anomalies $\left({ }^{\circ} \mathrm{C}\right)$. (b),(c) Time series of ASO area-averaged SST anomalies $\left({ }^{\circ} \mathrm{C}\right)$ in (b) the MDR [green box in (a)] and (c) the Caribbean Sea [red box in (a) spanning $60^{\circ}-87.5^{\circ} \mathrm{W}$ and $10^{\circ}-21.5^{\circ} \mathrm{N}$ ]. Red lines in (b) and (c) show a 5-pt. running mean of each time series. Data source is ERSSTv4 (Huang et al. 2015). Anomalies are departures from the 198I-2010 monthly means.
Another complementary measure of the AMO is the standardized 5-year running mean of the difference between the area-averaged SST departure in the MDR and that of the global tropics (Fig. 4.22b, based on Vecchi and Soden 2007). The warm AMO during ASO 2017 featured an anomalously warm MDR compared to the remainder of the global tropics $\left(0.36^{\circ} \mathrm{C}\right.$ higher), a relationship seen throughout the historical record for active seasons. These observations, combined with the seasonal ACE time series (Fig. 4.19b), suggest that continuation during 2017 of the current Atlantic high-activity era was associated with the ongoing warm phase of the AMO.

Another ocean-atmosphere related factor for the 2017 Atlantic hurricane season was the development of La Niña in October (see Section 4b). La Niña is conducive to a more active Atlantic hurricane season because it reduces the vertical wind shear and decreases the atmospheric stability in the western MDR (Gray 1984; Tang and Neelin 2004). Cool neutral ENSO conditions prevailed during the other two peak months of the season (August and September).

\section{(iv) Atmospheric conditions}

The atmospheric conditions within the MDR during ASO 2017 reflected an inter-related set of anomalies which are typical of other extremely active seasons (Landsea et al. 1998; Bell et al. 1999, 2000, 2004, 2006, 2009, 2011, 2012, 2014, 2015, 2016; Goldenberg et al. 2001; Bell and Chelliah 2006; Kossin
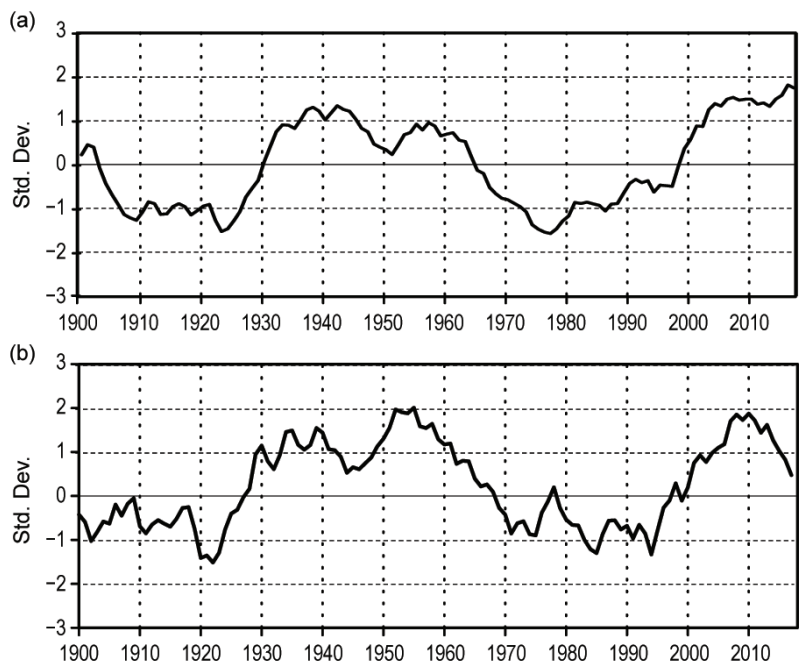

FIG. 4.22. SST time series for 1900-2017 based on ERSSTv4 (Huang et al. 2015). (a) Standardized (std. dev.) 7-yr running mean of the detrended Kaplan AMO index based on the ASO season only. (b) Standardized (std. dev.) 7-yr running mean of the difference between ASO area-averaged SST anomalies in the MDR and those for the entire global tropics $\left(20^{\circ} \mathrm{N}-20^{\circ} \mathrm{S}\right)$. 
and Vimont 2007). Historically, the combination of a warm AMO and La Niña yields the most spatially extensive set of atmospheric conditions that are conducive for Atlantic hurricane activity, while the combination of El Niño and the cool AMO yields the least conducive conditions (Bell and Chelliah 2006).

In the lower atmosphere, the conducive conditions during ASO 2017 included below-average heights/ sea-level pressure (blue shading, Fig. 4.23a) across the MDR, along with weaker trade winds (i.e., westerly anomalies) extending from the eastern tropical North Pacific across the southern MDR to Africa. These westerly anomalies extended up to $700-\mathrm{hPa}$, the approximate level of the African easterly jet (AEJ), and were associated with a deep layer of anomalous cyclonic relative vorticity across the entire MDR (Fig. 4.23b). As noted by Bell et al. (2011), the increased cyclonic shear along the equatorward flank of the AEJ helps the easterly waves within the MDR to be better maintained and also provides an inherent cyclonic rotation to their embedded convective cells.

In the upper atmosphere at $200-\mathrm{hPa}$, the circulation during ASO 2017 featured an extensive and persistent ridge of high pressure across the western half of the MDR and the western North Atlantic (Fig. 4.23c). This pattern was accompanied by an eastward displacement of the tropical upper tropospheric trough (TUTT) from the western MDR to the central MDR and central North Atlantic. Consistent with this pattern, the upper-level westerly winds were weaker than average (indicated by easterly anomalies) in the western MDR along the southern flank of the anomalous ridge. The resulting vertical wind shear (Fig. 4.24a) was also weaker than average across the central and western MDR as well as in the vicinity of the Bahamas (Fig. 4.24b).

As a result, weak vertical wind shear $\left(<10 \mathrm{~m} \mathrm{~s}^{-1}\right)$ extended across the entire MDR from Africa to Central America, as well as northward over the western North Atlantic (Fig. 4.24a). Also, the associated steering current (Fig. 4.24a, vectors) allowed African easterly waves and named storms to track farther westward into the region of anomalously weak vertical wind shear and exceptionally warm SSTs. These conditions greatly increased the number and strength of the TCs within the MDR, as well as the number of landfalling hurricanes.

The exceptionally strong and persistent ridge over the western Atlantic was a crucial aspect of the 2017 Atlantic hurricane season. Although La Niña technically developed in October, a La Niña-like pattern of tropical convection was already present in September. The rapid response in the upper-level atmospheric
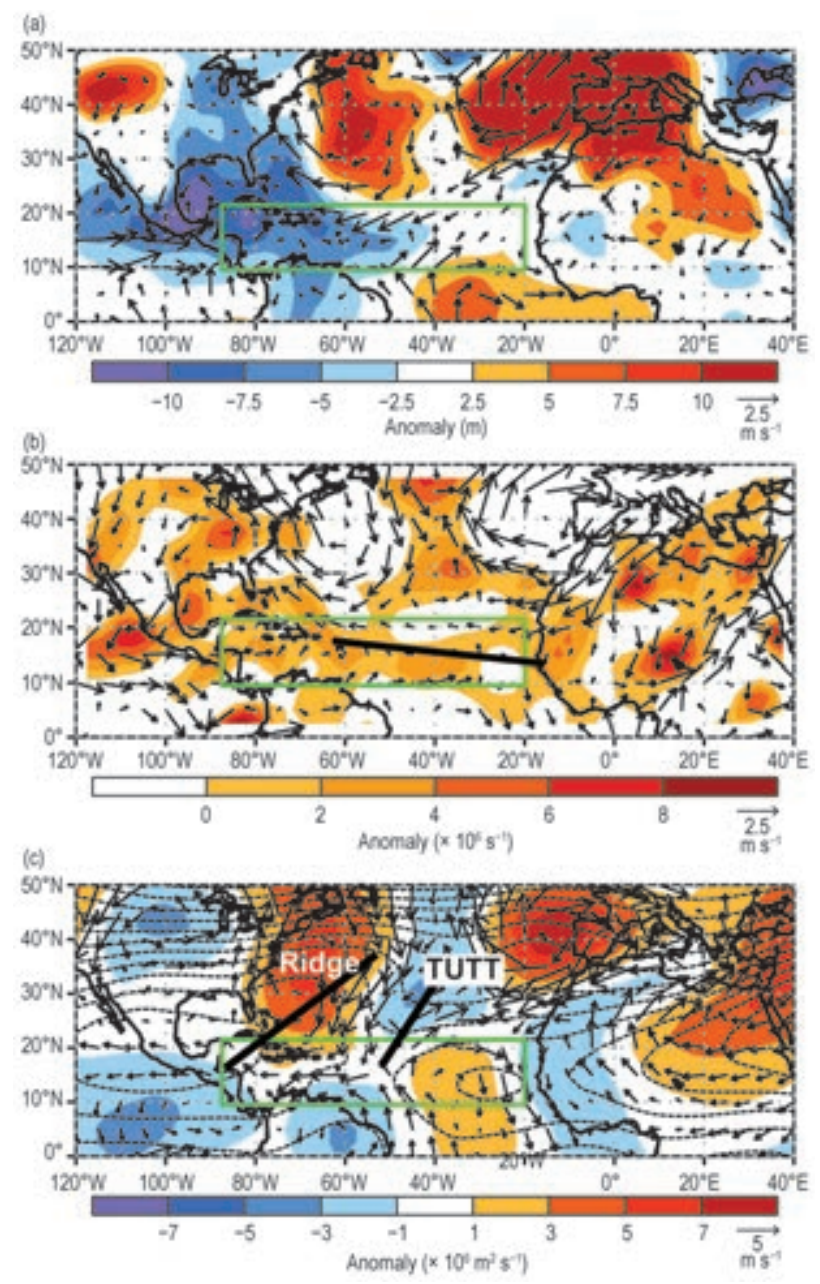

FIG. 4.23. ASO 20I7: (a) anomalous I000-hPa heights (shaded; $\mathrm{m}$ ); (b) anomalous $700-\mathrm{hPa}$ cyclonic relative vorticity (shaded; $\times 10^{6} \mathrm{~s}^{-1}$ ); (c) 200-hPa total streamfunction (contours, interval: $5 \times 10^{6} \mathrm{~m}^{2} \mathrm{~s}^{-1}$ ) and anomalies (shaded), from NCEP-NCAR reanalysis (Kalnay et al. 1996). The corresponding anomalous wind vectors $\left(\mathrm{m} \mathrm{s}^{-1}\right)$ are shown in each panel. In (b), the thick solid line indicates the axis of the mean African easterly jet which was hand-drawn based on total seasonal wind speeds (not shown). In (c) the upper-level ridge and TUTT discussed in the text are labeled and denoted by thick black lines. Vector scales are below right of color bar. Green box denotes the MDR. Anomalies are departures from the 198I-2010 means.

circulation to the developing La Niña likely helped maintain that ridge during October-November [a period when two hurricanes (including Major Hurricane Ophelia) and two tropical storms formed] and may have contributed to the September conditions as well.

A pronounced ridge such as this was last seen in association with the record strong 2005 Atlantic hurricane season (Bell et al. 2006). Therefore, while 

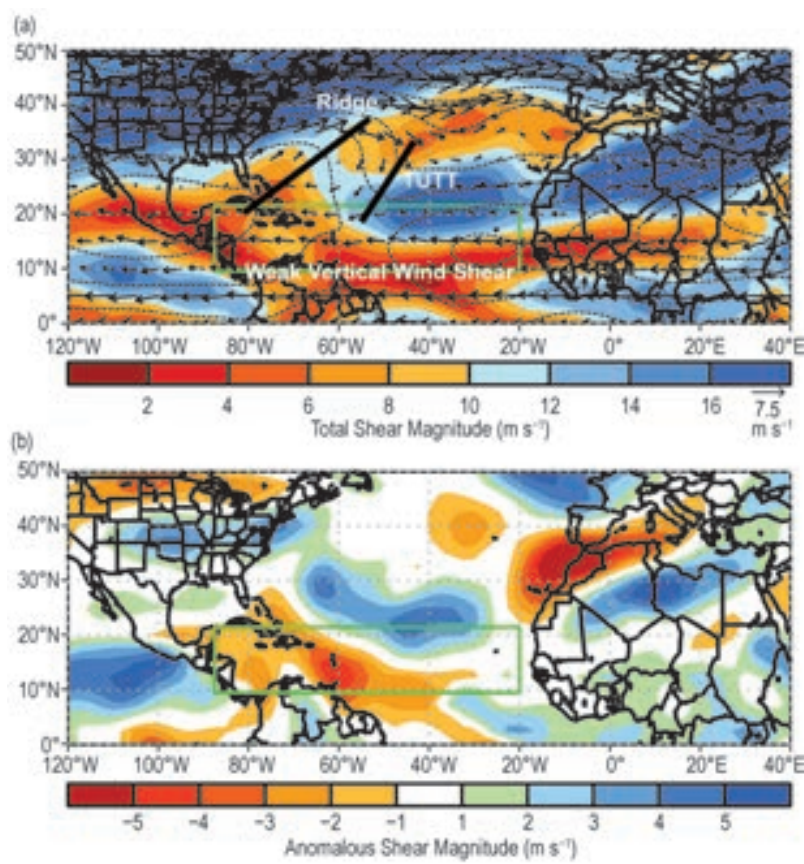

FIG. 4.24. ASO 20I7: 200-850 hPa vertical wind shear magnitude (shaded; $\mathrm{m} \mathrm{s}^{-1}$ ) (a) total and (b) anomalies. Overlaid in (a) are the total $200-\mathrm{hPa}$ streamfunction field (contours, interval: $5 \times 10^{6} \mathrm{~m}^{2} \mathrm{~s}^{-1}$ ) and the 200-850 $\mathrm{hPa}$ layer mean wind vectors $\left(\mathrm{m} \mathrm{s}^{-1}\right)$ representing the steering current. The upper-level ridge and TUTT discussed in the text are labeled and denoted by thick black lines. Vector scale is below right of color bar. Green box denotes the MDR. Data is from NCEPNCAR reanalysis (Kalnay et al. 1996). Anomalies are departures from the 1981-2010 means on total seasonal wind speeds (not shown). In (c) the upper-level ridge and TUTT discussed in the text are labeled and denoted by thick black lines. Vector scales are below right of color bar. Green box denotes the MDR. Anomalies are departures from the 1981-2010 means.

the warm AMO and La Niña set the stage for an extremely active 2017 Atlantic hurricane season, these combined climate factors alone do not likely account for the combined magnitude and duration of the western Atlantic ridge, which is seen less frequently.

3) Eastern North Pacific and Central North PACIFIC BASINS-M. C. Kruk and C. J. Schreck

(i) Seasonal activity

The eastern North Pacific (ENP) basin is officially split into two separate regions for the issuance of warnings and advisories by NOAA's National Weather Service. NOA A's National Hurricane Center in Miami, Florida, is responsible for issuing warnings in the eastern part of the basin (ENP) that extends from the Pacific Coast of North America to $140^{\circ} \mathrm{W}$, while NOAA's Central Pacific Hurricane Center in
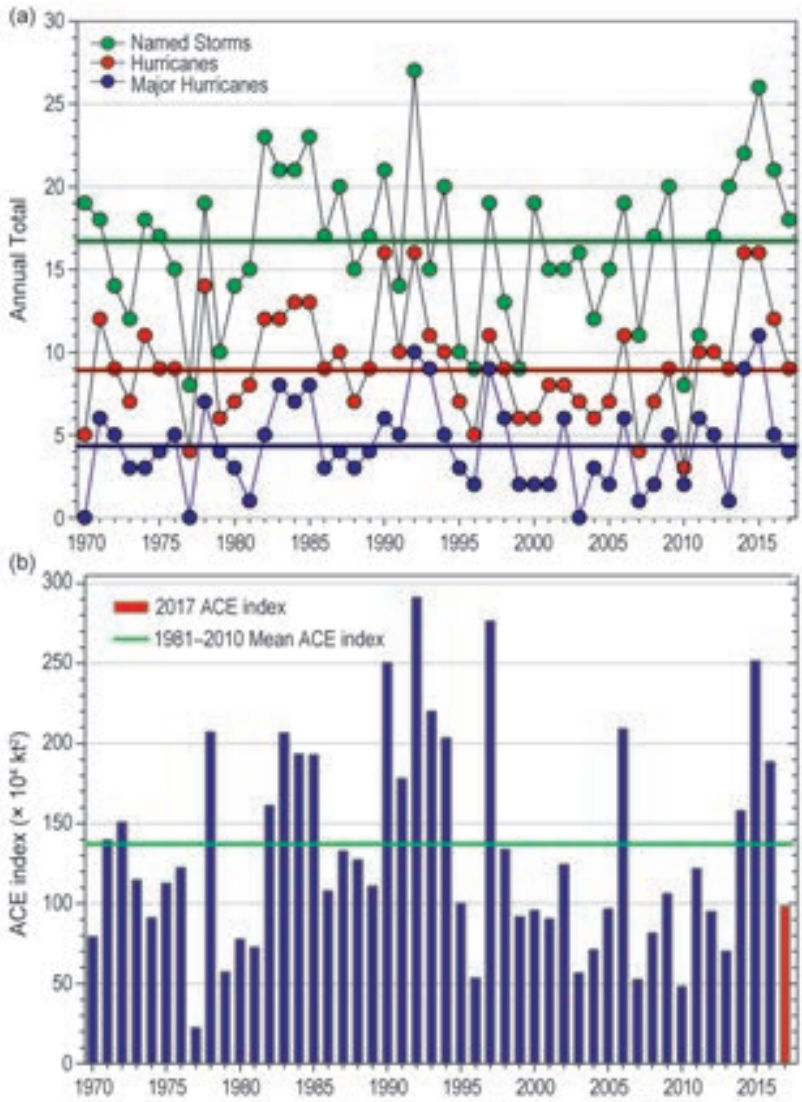

FIG. 4.25. Seasonal TC statistics for the full ENPICNP basin over the period 1970-2017: (a) number of named storms, hurricanes, and major hurricanes and (b) the ACE index $\left(\times 10^{4} \mathrm{kt}^{2}\right)$ with the 2017 seasonal total highlighted in red. Horizontal lines denote the corresponding 1981-2010 base period means for each parameter.

Honolulu, Hawaii, is responsible for issuing warnings in the central North Pacific (CNP) region between $140^{\circ} \mathrm{W}$ and the dateline. This section summarizes the TC activity in both warning areas using combined statistics, along with information specifically addressing the observed activity and impacts in the CNP region.

The ENP/CNP hurricane season officially spans from 15 May to 30 November. Hurricane and tropical storm activity in the eastern area of the basin typically peaks in September, while in the CNP TC activity normally reaches its seasonal peak in August (Blake et al. 2009). During the 2017 season, a total of 18 named storms formed in the combined ENP/CNP basin (Fig. 4.25a). This total includes 9 hurricanes, 4 of which were major hurricanes. The 1981-2010 IBTrACS seasonal averages for the basin are 16.5 named storms, 8.5 hurricanes, and 4.0 major hurricanes (Schreck et al. 2014).

The 2017 seasonal ACE index was $98.5 \times 10^{4} \mathrm{kt}^{2}$ (Fig. 4.25b), which is below the 1981-2010 mean of 


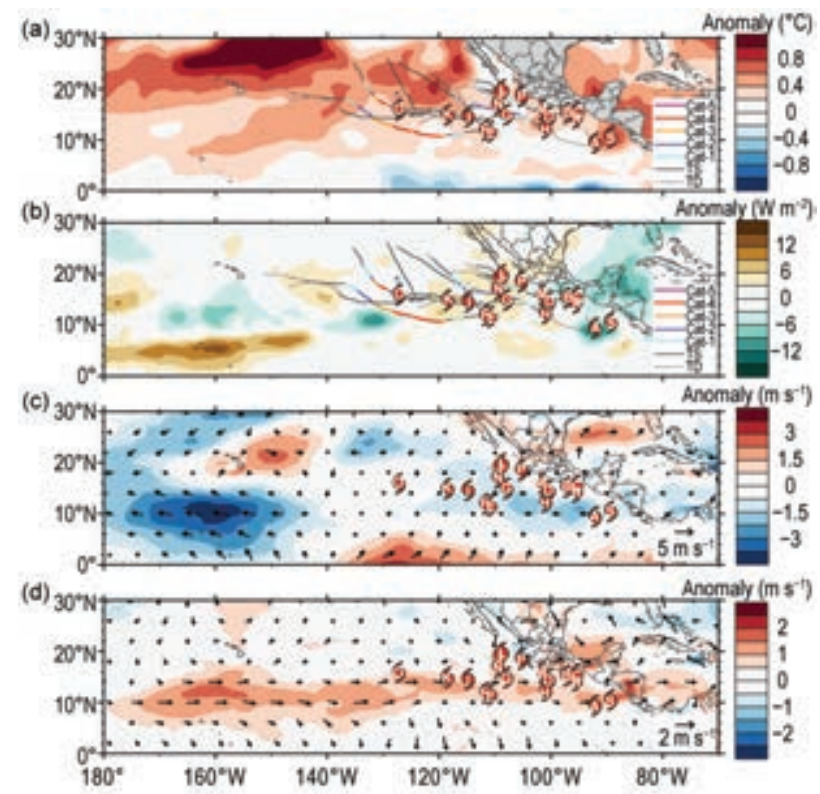

FIG. 4.26. May-Nov 2017 anomaly maps of (a) SST $\left({ }^{\circ} \mathrm{C}\right.$; Banzon and Reynolds 2013), (b) OLR (W m ${ }^{-2}$; Lee 20I4), (c) 200-850-hPa vertical wind shear ( $\mathrm{m} \mathrm{s}^{-1}$; vectors) and scalar (shading) anomalies, and (d) 850-hPa winds ( $\mathrm{m} \mathrm{s}^{-1}$; vectors) and zonal wind (shading) anomalies. Anomalies are relative to the annual cycle from I98I2010 , except for SST which is relative to 1982-2010 due to data availability. Hurricane symbols with letters denote where each ENP TC attained tropical storm intensity. Wind data obtained from CFSR (Saha et al. 2014).

$132.0 \times 10^{4} \mathrm{kt}^{2}$ (Bell et al. 2000; Bell and Chelliah 2006; Schreck et al. 2014). The CNP basin only had one storm in 2017: The remnants of Major Hurricane Fernanda moved from the ENP to the CNP as a weak tropical storm before dissipating around $146^{\circ} \mathrm{W}$. The long-term 1981-2010 IBTrACS mean in the CNP basin is 4.7 storms making the 2017 season much below average.

\section{(ii) Environmental influences on the 2017 season}

Figure 4.26 shows the mean environmental conditions that the ENP and CNP TCs experienced in 2017. The borderline weak La Niña is indicated by the cool SST anomalies along the equatorial eastern Pacific and warm anomalies to the north (Fig. 4.26a). Much of the TC activity was concentrated along the Mexican coast, which is not unusual during La Niña years (Collins and Mason 2000; Fu et al. 2017). The SST anomalies were slightly above normal in that region. Mixing from the storms themselves may have played a role in tempering those anomalies (Hart et al. 2007), but the OLR anomalies (Fig. 4.26b) were also near-normal and suggest weaker-than-normal convection in the region. Weak easterly vertical

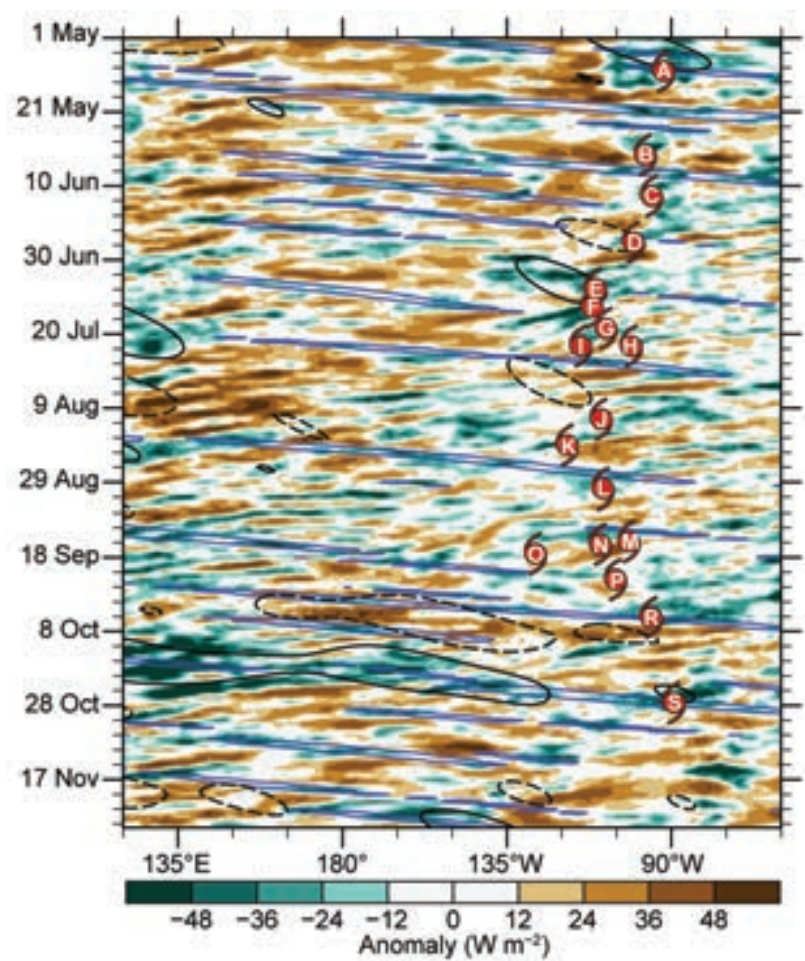

FIG. 4.27. Longitude-time Hovmöller of OLR (W m ${ }^{-2}$; Lee 2014 ) averaged $5^{\circ}-15^{\circ} \mathrm{N}$. Unfiltered anomalies from a daily climatology are shaded. Negative anomalies (green) indicate enhanced convection. Anomalies filtered for Kelvin waves are contoured in blue at $-10 \mathrm{~W} \mathrm{~m}^{-2}$ and MJO-filtered anomalies in black at $\pm 10 \mathrm{~W} \mathrm{~m} \mathrm{~m}^{-2}$. Hurricane symbols and letters indicate genesis of ENP TCs.

shear anomalies, on the other hand, did favor the TC activity (Fig. 4.26c). Similarly, a narrow swath of $850-\mathrm{hPa}$ westerly anomalies along $10^{\circ}-15^{\circ} \mathrm{N}$ would have provided enhanced cyclonic vorticity, wave accumulation, and/or barotropic energy conversion (Maloney and Hartmann 2001; Aiyyer and Molinari 2008; Rydbeck and Maloney 2014).

ENP TC activity is strongly influenced by the MJO (Maloney and Hartmann 2001; Aiyyer and Molinari 2008; Slade and Maloney 2013), and recent studies have found a greater role for convectively coupled Kelvin waves in modulating tropical cyclogenesis (Schreck and Molinari 2011; Ventrice et al. 2012a,b; Schreck 2015, 2016). Figure 4.27 uses OLR to examine the intraseasonal evolution of convection during the 2017 ENP hurricane season. Following Kiladis et al. $(2005,2009)$, the black contours identify the MJOfiltered anomalies and the blue contours identify the Kelvin waves. Easterly waves are also apparent in the unfiltered anomalies (shading) as westward moving features, such as those leading up to Tropical Storms Jova and Selma. 
A weak MJO event in early July likely contributed to an active month that included five named storms, including Major Hurricanes Eugene and Fernanda. The subsequent dry phase of the MJO provided the longest break (21 days) between named storm formations from June through September. MJO activity appeared to play less of a role in the remainder of the season. However, Kelvin waves probably enhanced conditions for at least three tropical storms: Lidia, Ramon, and Selma.

\section{(iii) TC impacts}

During the 2017 season, five named storms made landfall along the western coast of Mexico or Baja California, while the one storm in the CNP region did not make landfall in Hawaii. The long-term annual average number of landfalling storms on the western coast of Mexico is 1.8 (Raga et al. 2013); thus this year was exceptional, in part due to the number of storms forming so close to the coast (Fig. 4.26).

Tropical Storm Beatriz (31 May-2 June) was the first storm to make landfall in 2017 along the Mexican coast, followed closely by Tropical Storm Calvin (11-13 June). Both storms brought torrential rainfall and landslides to the Oaxaca and Guerraro areas of coastal Mexico. Beatriz produced localized rainfall of up to $380 \mathrm{~mm}$, and five people were killed when mudslides washed away their homes and vehicles. Additional rainfall from Calvin, while not as extreme as Beatriz, exacerbated relief efforts and compounded the already saturated soils leading to further landslides and mudslides.

Tropical Storm Lidia (31 August-03 September) tracked northwest along the entire Baja Peninsula. While maximum sustained winds were $55 \mathrm{kt}$ $\left(29 \mathrm{~m} \mathrm{~s}^{-1}\right)$, the storm weakened dramatically as it crossed over the mountainous terrain of the Baja Peninsula. The biggest impact from Lidia was heavy rainfall, up to $300 \mathrm{~mm}$ in San Jose Del Cabo, resulting in numerous flooded streets and the cancellation of several dozen flights from Mexico City International Airport. In the city of Cuautitlán Izcalli, located in the central state of Mexico, roughly 300 people were evacuated after the nearby El Ángulo dam collapsed, and in Ecatepec de Morelos a nearby canal overflowed, filling many homes with sewage. The wind field from Lidia made a close approach to southern California in the United States, where gusty winds were reported along area beaches.

Hurricane Max (13-15 September) made landfall in areas of the Mexican coastline already plagued by tropical storms earlier in the season. Max briefly intensified to hurricane strength about 12 hours prior to landfall, with maximum sustained winds of $75 \mathrm{kt}$ $\left(39 \mathrm{~m} \mathrm{~s}^{-1}\right)$. The city of Guerraro, flooded by Beatriz and Calvin, was also affected by torrential rains from Max. Two people died as rapidly rising rivers swept away their residence. Meanwhile over the ocean, large waves and swell, with peak wave heights of 3-5 m, sunk six boats before they could return to port.

Tropical Storm Selma (27-28 October) was the final storm of the 2017 season, and the first storm on record to make landfall in El Salvador. When combined with a cold front moving through Honduras, rainfall was widespread across the region, resulting in the overtopping of at least a dozen local rivers.

\section{4) Western North Pacific basin—S. J. Camargo \\ (i) Introduction}

The TC season in the western North Pacific (WNP) was below normal by most measures of TC activity considered. According to the $\mathrm{JTWC}^{1}$, the 2017 season had 26 named storms (which is the median). These included 12 typhoons (bottom quartile is $\leq 14)$ two of which reached super-typhoon (130 kt, $65 \mathrm{~m} \mathrm{~s}^{-1}$ ) status (bottom quartile is $\leq 2$ ). In Fig. 4.28a, the number of each category per season is shown for the period 1945-2017. While the number of tropical storms matched the climatological median, the number of typhoons and supertyphoons was below normal. Only $46 \%$ of tropical storms became typhoons (bottom quartile is $\leq 57 \%$ ). Further, the percentage of typhoons reaching supertyphoon intensity (17\%) was below normal (median is $24 \%$ ).

The JMA total for 2017 was 27 named storms (above the median of 26; Fig. 4.28b). Guchol was considered a tropical storm by JMA but only a tropical depression by JTWC. Saola was considered a severe tropical storm by JMA and a typhoon by JTWC ${ }^{2}$. The Philippine Atmospheric, Geophysical, and As-

${ }^{1}$ The TC data used here are from the Joint Typhoon Warning Center (JTWC) western North Pacific best-track dataset for the 1945-2017 period and from the JTWC preliminary operational data for 2017. Climatology is defined using the period 1981-2010, with exception of landfall statistics, where 1951-2010 was used. The best-track data from the RSMCTokyo, Japan Meteorological Agency was used in Fig. 4.28b. All other figures and statistics were obtained using JTWC TC data. All statistics are based on the climatological distribution (CLD), unless specifically stated that is based on the historical record.

${ }^{2}$ It is well known that there are systematic differences between the JMA and the JTWC datasets, which have been extensively documented in the literature (e.g., Wu et al. 2006; Nakazawa and Hoshino 2009; Song et al. 2010; Ying et al. 2011; Yu et al. 2012; Knapp et al. 2013; Schreck et al. 2014). 
(a)

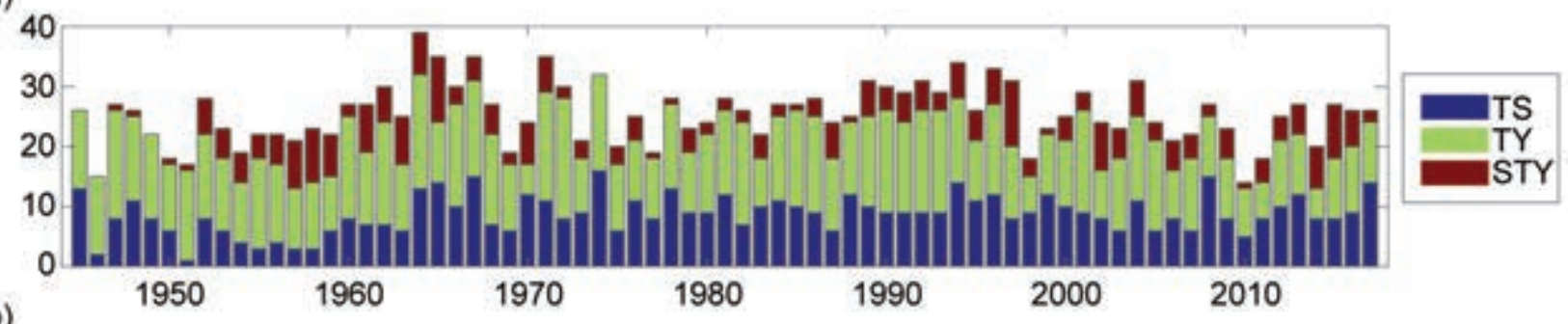

(b)

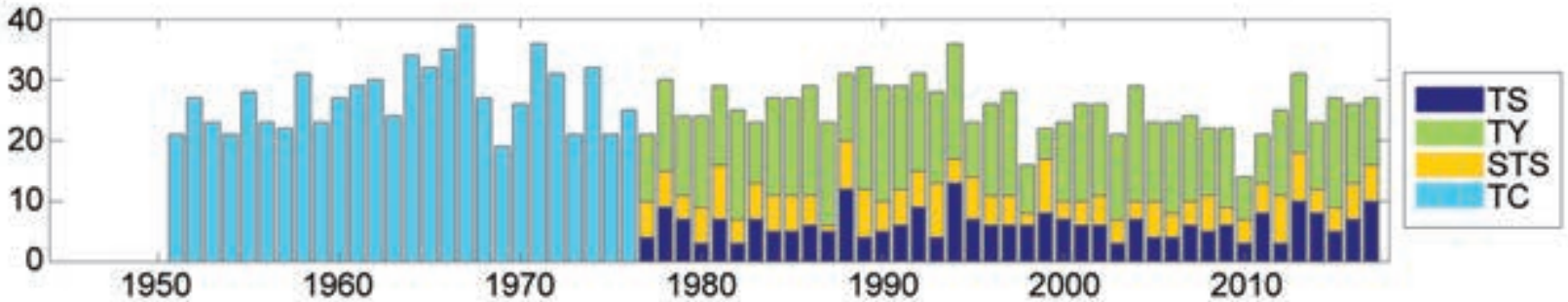

(c)
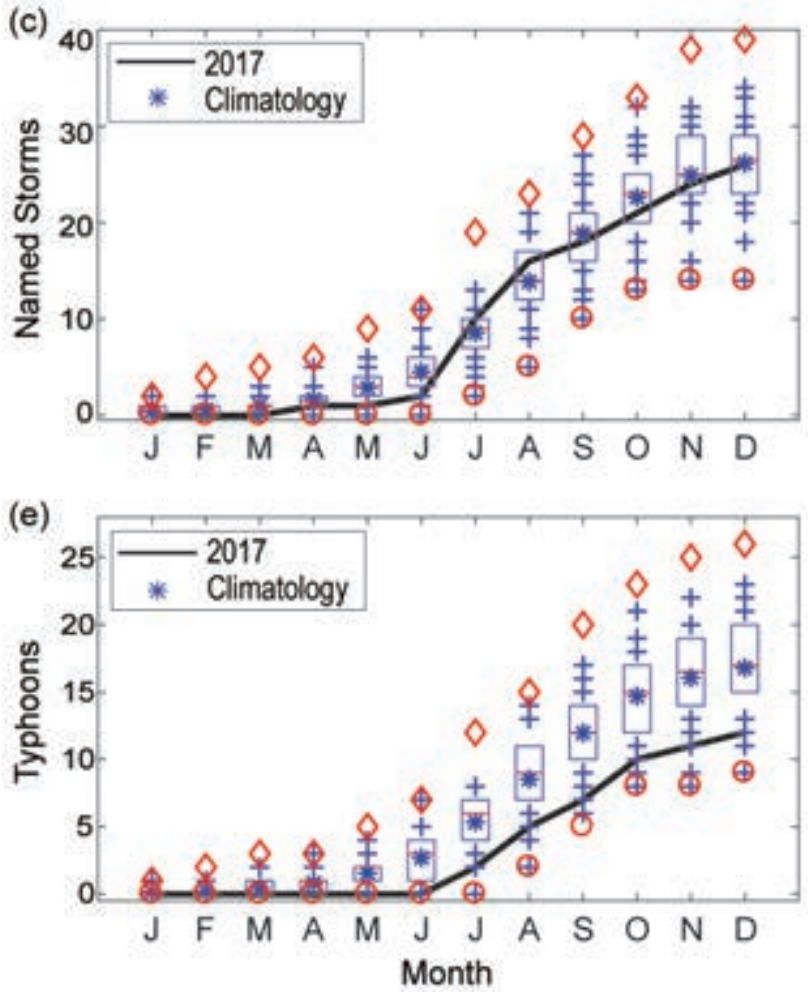

(d)

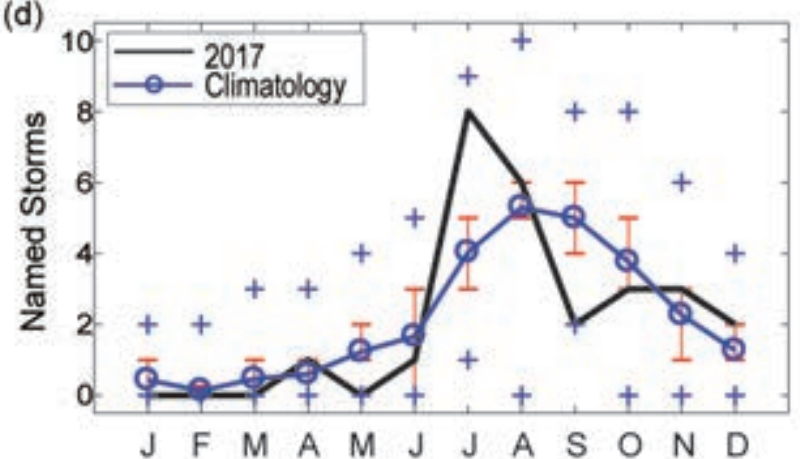

(f)

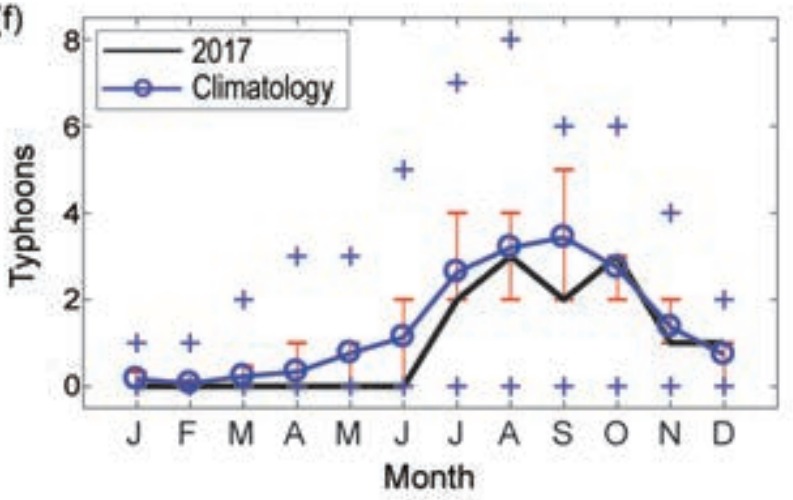

FIG. 4.28. (a) Number of tropical storms (TS), typhoons (TY), and supertyphoons (STY) per year in the western North Pacific (WNP) for the period 1945-2017 based on the JTWC best-track dataset. (b) Number of tropical cyclones (TC; all storms which reach TS intensity or higher) from 195I to 1976; number of TSs, severe tropical storms (STS) and TY from 1977 to 2017 based on the JMA best-track dataset. Panels (c) and (e) show the cumulative number of tropical cyclones with TS intensity or higher (named storms) and number of TYs, per month in the WNP in 2017 (black line), and climatology (198I-2010) as box plots [interquartile range: box; median: red line; mean: blue asterisk; values in the top or bottom quartile: blue crosses; high (low) records in the 1945-2016 period: red diamonds (circles)]. Panels (d) and (f) show the number of NSs and TYs respectively, per month in 2017 (black line) and the climatological mean (blue line), the blue plus signs denote the maximum and minimum monthly historical records and the red error bars show the climatological interquartile range for each month (in the case of no error bars, the upper and/or lower percentiles coincide with the median. [Sources: 1945-2017 JTWC best-track dataset, 2017 JTWC preliminary operational track data for panels (a) and (c)-(f). 195I-2017 RSMCenter-Tokyo, JMA best-track dataset for panel (b).] 
tronomical Services Administration named all 22 TCs that entered its area of responsibility, including Tropical Depression Bising (February) which was considered a tropical depression by JMA but was not tracked by JTWC. Only $41 \%$ of the storms reached typhoon intensity (bottom quartile is $\leq 50 \%$ ).

\section{(ii) Seasonal activity}

The season had a slow start, with the first named tropical storm not developing until April (Muifa). No TCs formed in May and only one tropical storm (Merbok) formed in June. In contrast, July was an active month with 8 TCs (top quartile is 5) forming: Tropical Storms Nanmandol, Talas, Sonca, Kulap, Roke, and Haitang; Typhoon Nesat; and Supertyphoon Noru. The two typhoons for July 2017 ranked among the bottom quartile. Four TCs were simultaneously active in the WNP during 21-23 July, 3 with TS strength on 22 and 23 July. August was also an active month with 6 named storms (top quartile is $\geq 6$ ): 3 tropical storms (Nalgae, Pakhar, and Mawar) and 3 typhoons (Banyan, Hato, Sanvu), each matching the median for that month. Only 4 TCs (bottom quartile is $\leq 4$ ) formed in September: Tropical Depressions Guchol, 22W, and Typhoons Talim and Doksuri, with only two storms reaching tropical storm or typhoon intensity, which is in the bottom quartile for both distributions ( $\leq 4$ and $\leq 2.5$, respectively). The TC activity increased somewhat in October, with three typhoons (Khanun, Lan, and Saola), in the bottom quartile for named storms $(\leq 3)$ but matching the median for typhoons. Lan was the second storm of the season to reach supertyphoon intensity in the season. In November there were 2 tropical storms (Haiku and Kirogi) and 1 typhoon (Damrey), which ranked in the top quartile for named storms $(\geq 3)$ but in the bottom quartile for typhoons $(\leq 1)$. The 2017 typhoon season concluded with two December TCs: Tropical Storm Kai-Tak and Typhoon Tembin, each in the top quartile for their respective categories.

The early season (January-June) totals (2 tropical storms and no typhoons) were in the bottom quartile of all storm counts ( $\leq 3$ and $\leq 1$, respectively). In contrast, the peak season (July-October) had 19 named storms (median is 17) and 10 typhoons (median is 12). The late season (November and December) total of 5 named storms and 2 typhoons was in the top quartile for named storms $(\geq 4)$ and equal to the median for typhoons. The overall character of the season was a normal number of TCs, but a low number attaining typhoon intensity, with the greatest TC activity concentrated from July to August.

\section{(iii) Environmental conditions}

During the peak and latter part of the season, the tropical Pacific SST transitioned from neutral to weak La Niña conditions. The mean genesis location in 2017 was at latitude $15.8^{\circ} \mathrm{N}$, longitude $129.9^{\circ} \mathrm{E}$, which was a shift northwestward from the climatological mean of latitude $13.2^{\circ} \mathrm{N}$, longitude $141.6^{\circ} \mathrm{E}$ (standard deviation $1.9^{\circ}$ latitude and $5.6^{\circ}$ longitude. This northwestward shift is typical during La Niña years (e.g., Chia and Ropelewski 2002; Camargo et al. 2007). The mean track position of $19.5^{\circ} \mathrm{N}, 133.7^{\circ} \mathrm{E}$ was also northwestward relative to the WNP climatological mean of $17.3^{\circ} \mathrm{N}, 136.6^{\circ} \mathrm{E}$ (standard deviations of $1.4^{\circ}$ latitude and $4.7^{\circ}$ longitude). Therefore, these shifts were consistent with a La Niña event.

Also consistent with a weak La Niña, the total ACE in 2017 was below normal (Camargo and Sobel 2005), in the bottom quartile, and the eighth lowest value
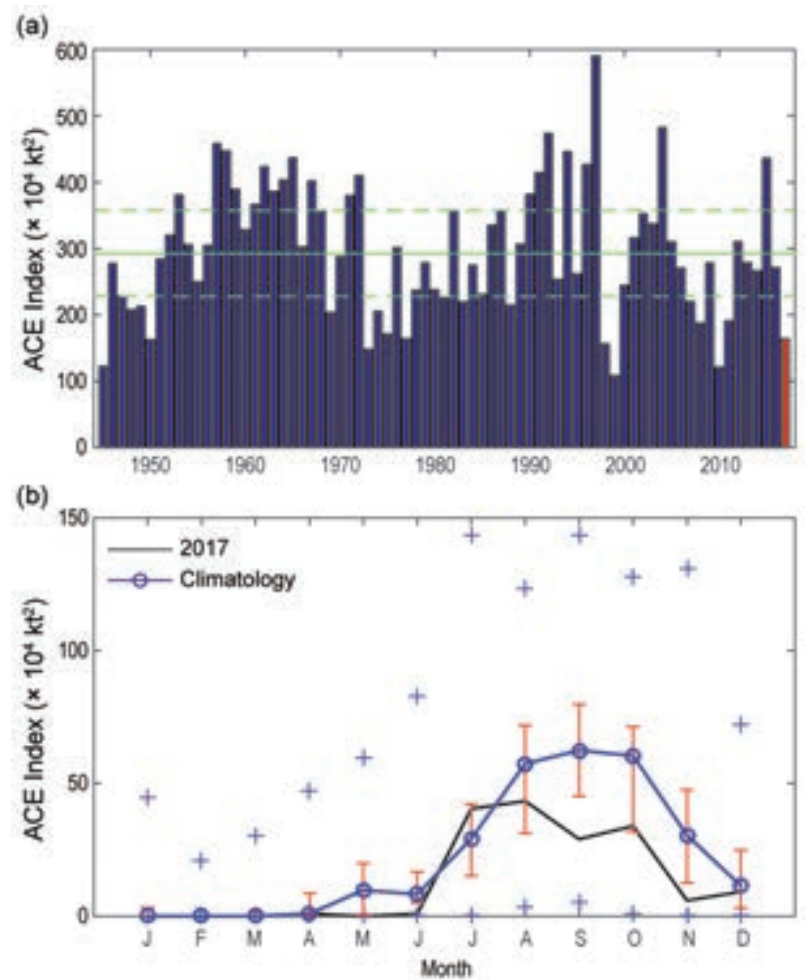

FIG. 4.29. (a) ACE index per year in the western North Pacific for 1945-2017. The solid green line indicates the median for the climatology (198I-2010), and the dashed lines show the climatological 25th and 75th percentiles. (b) ACE index per month in 2017 (black line) and the median during 1981-2010 (blue line), the red error bars indicate the 25 th and 75 th percentiles. In case of no error bars, the upper and/or lower percentiles coincide with the median. The blue "+" signs denote the maximum and minimum values during the 1945-2016. (Source 1945-2016 JTWC best-track dataset, 2017 JTWC preliminary operational track data.) 
(a)
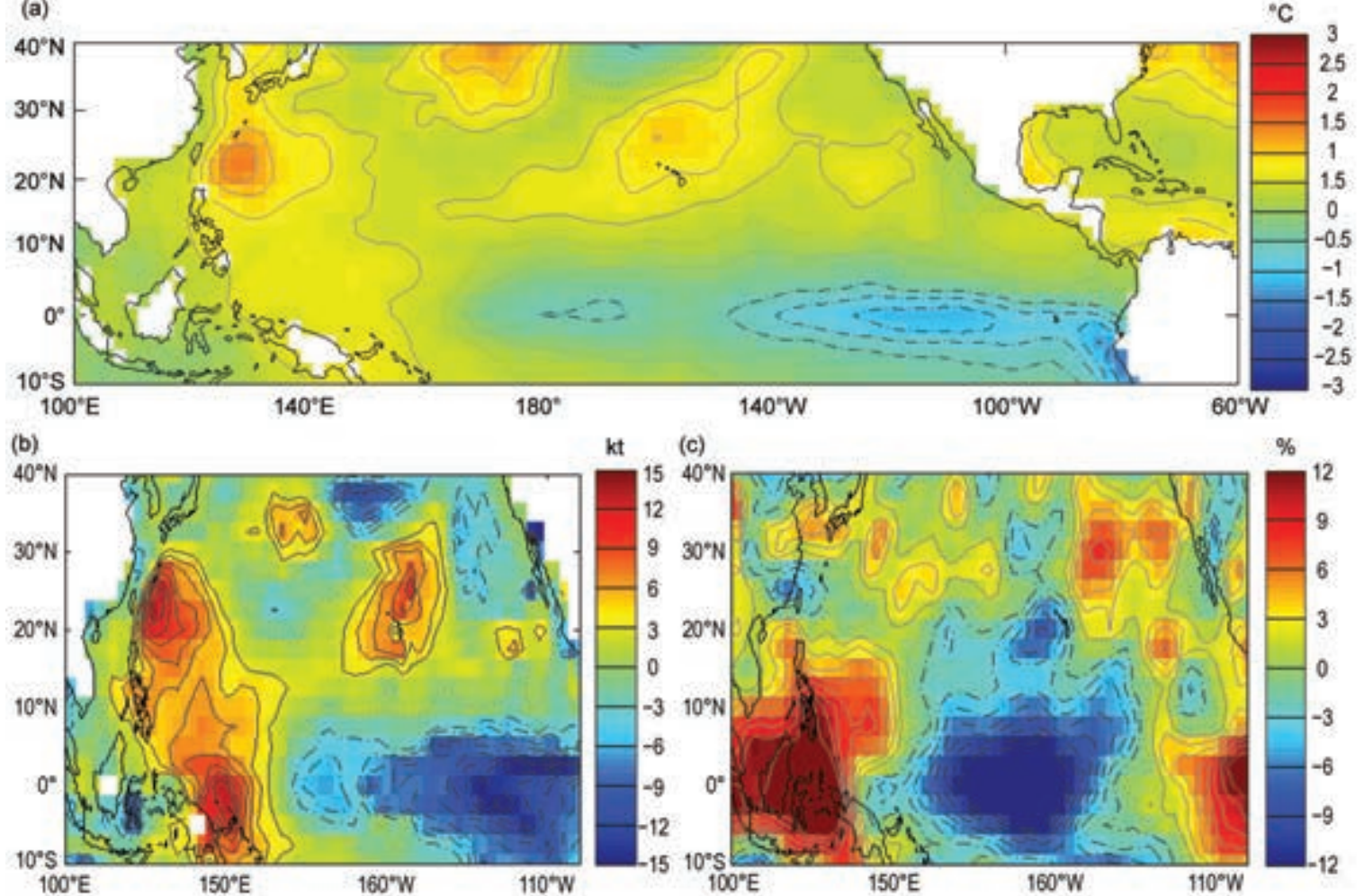

kt (c)
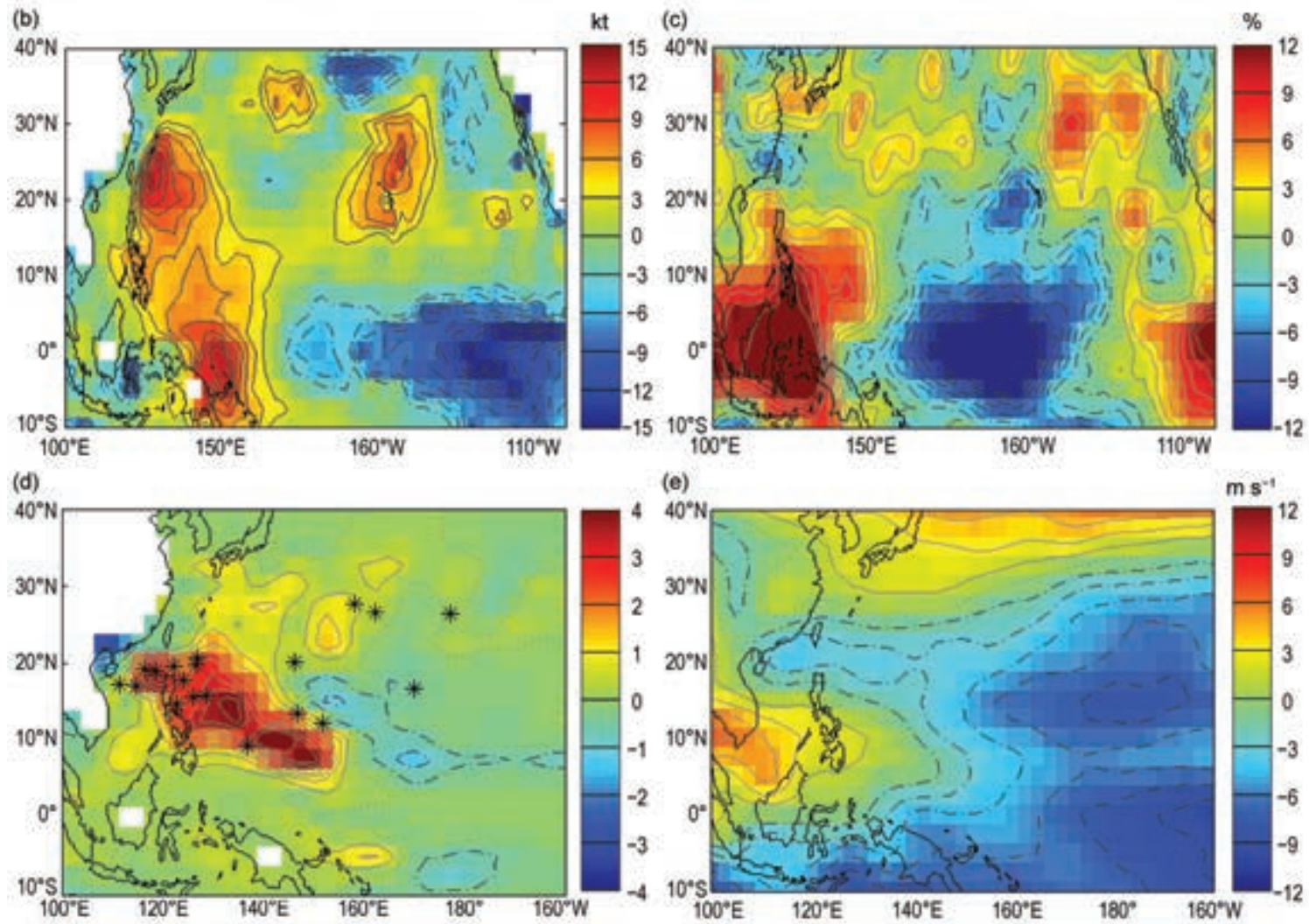

(e)

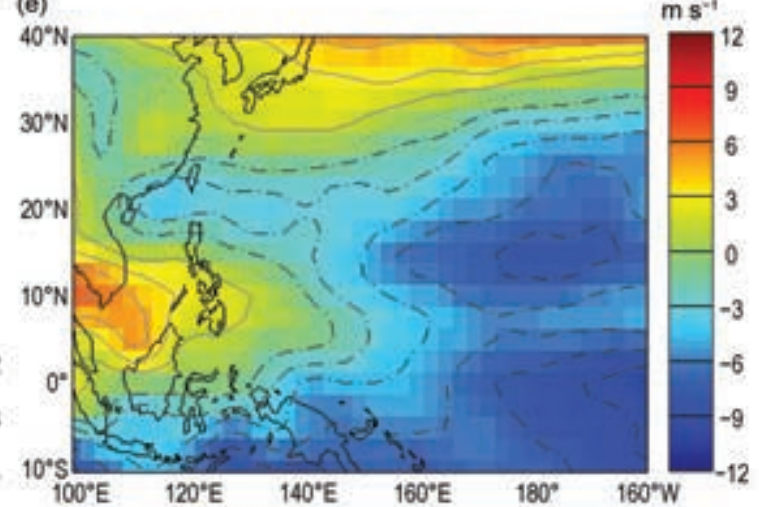

FIG. 4.30. (a) SST anomalies ( ${ }^{\circ} \mathrm{C}$ ) for Jul-Oct (JASO) 20I7. (b) PI anomalies (kt) in JASO 20I7. (c) Relative humidity 600-hPa relative humidity anomalies (\%) in JASO 2017. (d) GPI anomalies in JASO 20I7. First positions of storms in JASO 2017 are marked with an asterisk. (e) Zonal winds in JASO 2017 (positive contours are shown in solid lines, negative contours in dash dotted lines and the zero contour in a dotted line) [Source: atmospheric variables: NCEP/NCAR Reanalysis data (Kalnay et al. 1996); SST (Smith et al. 2008).]

of seasonal ACE in the historical record (Fig. 4.29a). The only months when ACE was not below the median were April and July; January-March, May, June, September, and November all had ACE values in their respective bottom quartiles. The bulk of the seasonal ACE occurred in July and August (Fig. 4.29b), with those months contributing $25 \%$ and $26 \%$ of the total ACE respectively, followed by October (21\%). The ACE values in September and November were the 9th and 11th lowest for those months in the historical record.
Only 3 typhoons in 2017 were in the top quartile for ACE per storm: Supertyphoons Noru and Lan, and Typhoon Talim, contributing $26.6 \%, 13.4 \%$, and $10.8 \%$ of the seasonal ACE, respectively. Combined, they accounted for just over half of the seasonal ACE. The only storm in the top decile was Supertyphoon Noru. It should be noted that Noru contributed to the ACE values for both July and August, as it was active from 20 July to 9 August.

There were 85 days with named storms. From these active days, 36 had typhoons and 6 had major 
typhoons (categories 3-5), all in the bottom quartiles. The percentage of days during the season with typhoons and major typhoons were $28.6 \%$ and $4.8 \%$, respectively in the bottom quartile of their distributions ( $\leq 33 \%$ and $\leq 10 \%$, respectively). The percentage of major typhoons days is the sixth lowest in the historical record (two of those happened in 1945 and 1948, when the data reliability was much lower). The median lifetime of the 2017 season for named storms and typhoons was 4.5 and 5.6 days, respectively, both in the bottom quartile ( $\leq 6.3$ and $\leq 7.8$ days). The longest living storm was Supertyphoon Noru, which lasted 19.5 days (20 July-9 August), which places it in the 98th percentile for all WNP named storms since 1945. Tropical Storm Kai-Tak (10.8 days) was the only other WNP named storm in 2017 in the top quartile ( $\geq 10.5$ days). All other storms in 2017 had lifetimes at or below the median. The occurrence of short-lived storms this season is typical of La Niña years (Camargo and Sobel 2015) and related to the northwest shift of TC activity.

Including tropical depressions, 26 storms made landfall ${ }^{3}$ in 2017, ranking in the 95th percentile compared with the 1951-2010 climatology. Of these, 11 made landfall as tropical depressions (second highest in the historical record), 7 as tropical storms (median is 6), 8 as typhoons (top quartile is $\geq 7$ ), and none as major typhoons (bottom quartile is $\leq 1$ ). Vietnam was hit by 9 storms this season, including Typhoon Damrey, which was the strongest typhoon to make landfall in south-central Vietnam in 16 years, and Typhoon Doksuri which affected the northern and central Vietnam provinces. The median number of landfalls in Vietnam per year is 4.5; 9 landfalls (at any intensity) is in the 90th percentile of the climatological distribution of landfalls there.

Figure 4.30 shows the environmental conditions associated with the typhoon activity in 2017. The main feature is the borderline weak La Niña with below-normal SST anomalies in the eastern and central Pacific during July-October (JASO; Fig. 4.30a) and slightly above normal SST in the WNP. This SST pattern is reflected in other environmental fields, as can be seen in potential intensity (PI; Emanuel 1988; Fig. 4.30b), 600-hPa relative humidity (Fig. 4.30c), and genesis potential index (GPI; Emanuel and Nolan

\footnotetext{
${ }^{3}$ Landfall is defined when the storm track is over land and the previous location was over ocean. In order not to miss landfall over small islands, first the tracks were interpolated from 6-hourly to 15 minute intervals before determining if the storm track was over land or ocean using a high-resolution land mask.
}

2004; Camargo et al. 2007; Fig. 4.30d) anomalies, which were positive in the western part of the basin and negative in the eastern part, typical of La Niña years. The GPI anomalies had a maximum near and east of the Philippines, in the region of high occurrence of TC formation. The maximum extent of the monsoon trough, as defined by the zonal wind (Fig. 4.30e) maximum extension, was confined to the area west of $130^{\circ} \mathrm{E}$, consistent with the westward shift of the genesis location in 2017.

\section{(iv) TC impacts}

Many storms had significant social and economic impacts in 2017. Typhoon Tembin, known as Vinta in the Philippines, struck the Philippine province of Mindanao in late December, causing 200 deaths with 172 missing, making it the deadliest WNP TC of 2017. Tembin hit the Philippines less than one week after Tropical Storm Kai-Tak (named Urduja in the Philippines) made landfall causing 160 deaths and leaving 163 missing $^{4}$. The costliest typhoon in the season was Typhoon Hato, with damages totaling almost \$7 billion U.S. dollars, impacting Macau and Hong Kong, as well as several provinces along the Pearl River, where storm surge caused major flooding in various provinces of mainland China. Hato was the strongest typhoon to hit Macau and Hong Kong in 50 years.

\section{5) North Indian OCEAN Basin-M. C. Kruk}

The North Indian Ocean (NIO) TC season typically extends from April to December, with two peaks in activity: during May-June and again in November, when the monsoon trough is positioned over tropical waters in the basin. TCs in the NIO basin normally develop over the Arabian Sea and Bay of Bengal between $8^{\circ}$ and $15^{\circ} \mathrm{N}$. These systems are usually short-lived, relatively weak, and often quickly move into the Indian subcontinent (Gray 1968; Schreck et al. 2014).

According to the JTWC, the 2017 TC season produced three tropical storms, one cyclone, and no major cyclones (Fig. 4.31a). The 1981-2010 IBTrACS seasonal averages for the basin are 3.9 tropical storms, $1.4 \mathrm{cy}$ clones, and 0.6 major cyclones (Schreck et al. 2014). The seasonal ACE index was $15.8 \times 10^{4} \mathrm{kt}^{2}$, which is near the 1981-2010 mean of $16.3 \times 10^{4} \mathrm{kt}^{2}$ (Fig. 4.31b). Typically, there is enhanced TC activity, especially in the Bay of Bengal, during the cool phase of ENSO (Singh et al. 2000). While this season was not yet a fully-developed La Niña, two storms developed in the Bay of Bengal and

\footnotetext{
${ }^{4}$ Casualty statistics are from the ReliefWeb site; for Tembin see https://reliefweb.int/disaster/tc-2017-000182-phl and for Kai-Tak, see https://reliefweb.int/disaster/tc-2017-000180-phl.
} 

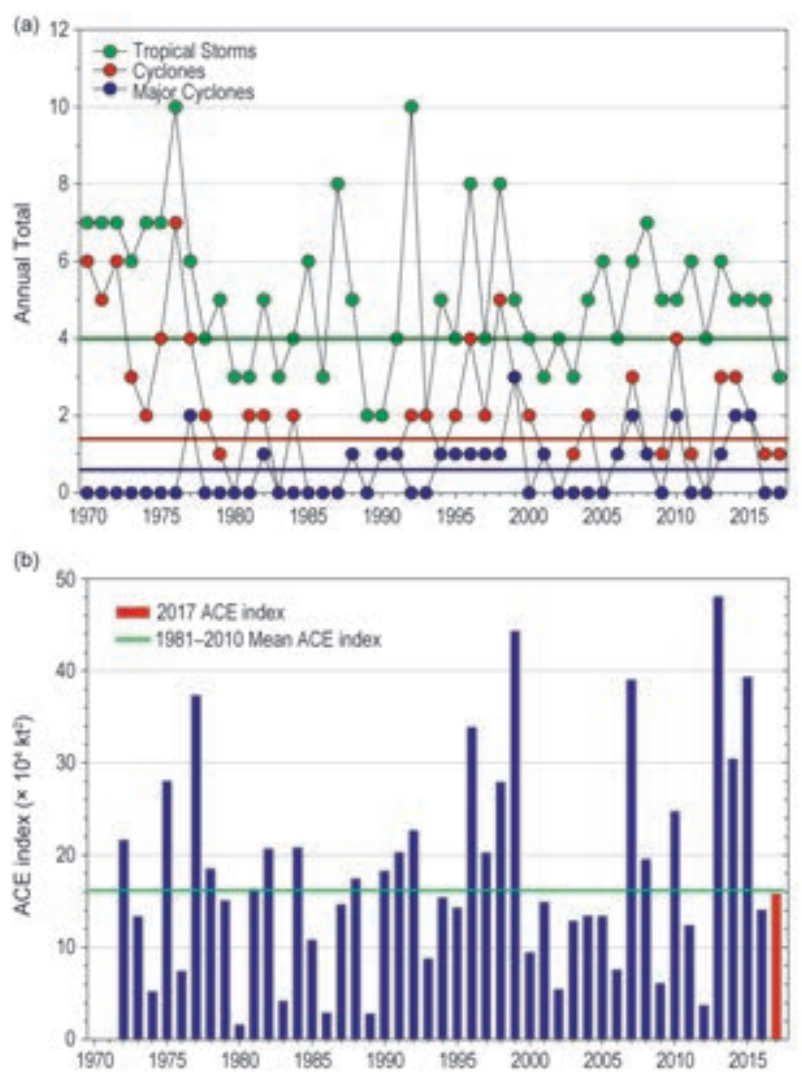

Fig. 4.3I. Annual TC statistics for the NIO for 1970-2017: (a) number of tropical storms, cyclones, and major cyclones and (b) estimated annual ACE index (in $\mathrm{kt}^{2} \times 10^{4}$ ) for all TCs at least tropical storm strength or greater intensity (Bell et al. 2000). The 1981-2010 means (horizontal lines) are included in both (a) and (b).

only one system, Tropical Storm Four (9 December), developed in the Arabian Sea.

The second named storm of the season was Cyclone Mora (27-30 May), which had maximum sustained winds of $65 \mathrm{kt}\left(33 \mathrm{~m} \mathrm{~s}^{-1}\right)$ and a minimum central pressure of $978 \mathrm{hPa}$. The cyclone caused dramatic impacts across Sri Lanka, the Andaman Islands, and Bangladesh due to widespread flooding rains and significant storm surge. At landfall, the storm surge was a stunning $3 \mathrm{~m}$ above astronomical high tide, resulting in an inland penetration of saltwater nearly $20 \mathrm{~km}$. The government of Bangladesh estimated 52000 homes were destroyed by the storm which displaced an estimated 260000 people. In Sri Lanka, Cyclone Mora exacerbated ongoing flooding from an active period of the southwest monsoon, resulting in numerous floods and landslides, killing more than 200 people and displacing 630000 more.

The most intense storm in the basin was Cyclone Ockhi late in the season, from 29 November to
6 December, with maximum sustained winds of $90 \mathrm{kt}$ $\left(45 \mathrm{~m} \mathrm{~s}^{-1}\right)$ and a minimum central pressure of $976 \mathrm{hPa}$. The storm originated over Sri Lanka and moved west-northwest into the Arabian Sea and then turned northeast where it was affected by a cold continental airmass which led to its quick demise west of the Gujarat coastline. However, the storm again plagued areas of Sri Lanka with additional rainfall and galeforce winds. The strong winds forced the diversion of flights to Mattala and closed schools. Farther west across the Maldives, two cargo boats were capsized by the cyclone, with more than a dozen other boating incidents reported during the height of the storm. As the storm turned northeast back toward India, it generated large ocean swells which led to substantial erosion along the west-facing Mumbai beaches. In addition, the cyclone-generated waves deposited over $80000 \mathrm{~kg}$ of trash and debris on the Mumbai beaches following $125 \mathrm{~mm}$ of rainfall.

6) SOUTH INDIAN OCEAN BASIN-M. C. Kruk and C. Schreck

The South Indian Ocean (SIO) basin extends south of the equator from the African coastline to $90^{\circ} \mathrm{E}$, with most cyclones developing south of $10^{\circ} \mathrm{S}$. The SIO TC season extends from July to June encompassing equal portions of two calendar years (the 2017 season includes storms from July to December 2016 and from January to June 2017). Peak activity typically occurs during December-April when the ITCZ is located in the Southern Hemisphere and migrating toward the equator. Historically, the vast majority of landfalling cyclones in the SIO affect Madagascar, Mozambique, and the Mascarene Islands, including Mauritius and Réunion Island. The Regional Specialized Meteorological Centre (RSMC) on La Réunion serves as the official monitoring agency for TC activity within the basin.

The 2016/17 SIO storm season was below average with five named storms, of which two were cyclones and one was a major cyclone (Fig. 4.32a). The 1981-2010 IBTrACS seasonal median averages are eight tropical storms, four cyclones, and one major cyclone (Schreck et al. 2014). The 2016/17 seasonal ACE index was $30.8 \times 10^{4} \mathrm{kt}^{2}$, which is about one-third of the 1981-2010 average of $91.5 \times 10^{4} \mathrm{kt}^{2}$ (Fig. 4.32b), and the lowest since the 2010/11 season. SSTs and 850 -hPa winds were both near normal in 2016/17 (Figs. 4.33a,d). The quiet season likely relates more to changes in the upper-level circulation. Positive OLR anomalies across the eastern portion of the basin suggested a broad area of unfavorable subsidence (Fig. 4.33b). The western half of the basin, on the other hand, experienced westerly vertical shear anomalies 
in excess of $4.5 \mathrm{~m} \mathrm{~s}^{-1}$, which would have precluded significant activity there.

During the 2016/17 season, the strongest storm was Cyclone Enawo (3-10 March), which reached category 4 equivalent with peak sustained winds of $125 \mathrm{kt}\left(64 \mathrm{~m} \mathrm{~s}^{-1}\right)$ and an estimated minimum central pressure of $932 \mathrm{hPa}$. The storm was the strongest to strike Madagascar since Gafilo in 2004. Enawo initially developed near the center of the basin out of the monsoon trough and gradually strengthened as it headed southwest towards Madagascar. The intense cyclone attained its maximum intensity just prior to landfall on 7 March before impacting the towns of Sambava and Antalaha. According to advisories from the RSMC La Réunion, storm surge was estimated to be 3-4 $\mathrm{m}$ across these areas, which ultimately led to swamped rice fields, displaced residents, and an estimated 81 fatalities due to the storm.
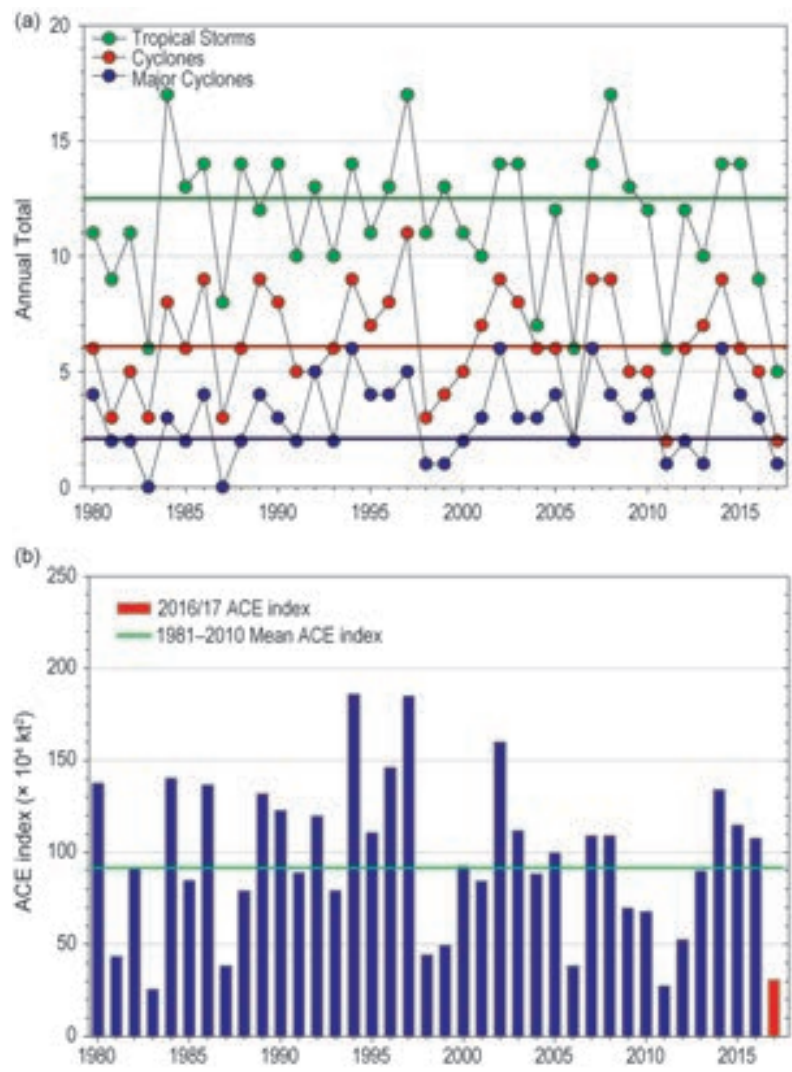

FIG. 4.32. Annual TC statistics for the SIO for 19802017: (a) number of tropical storms, cyclones, and major cyclones and (b) estimated annual ACE index (in $\mathbf{k t}^{2} \times 10^{4}$ ) for all TCs at least tropical storm strength or greater intensity (Bell et al. 2000). The 198I-20I0 means (horizontal lines) are included in both (a) and (b). Note that ACE is estimated due to lack of consistent 6-h sustained winds for each storm.

\section{7) Australian basin-B. C. Trewin}

(i) Seasonal activity

The 2016/17 TC season was near normal in the broader Australian basin (areas south of the equator and between $90^{\circ}$ and $160^{\circ} \mathrm{E}^{5}$, which includes the Australian, Papua New Guinean, and Indonesian

${ }^{5}$ The Australian Bureau of Meteorology's warning area overlaps both the southern Indian Ocean and southwest Pacific.
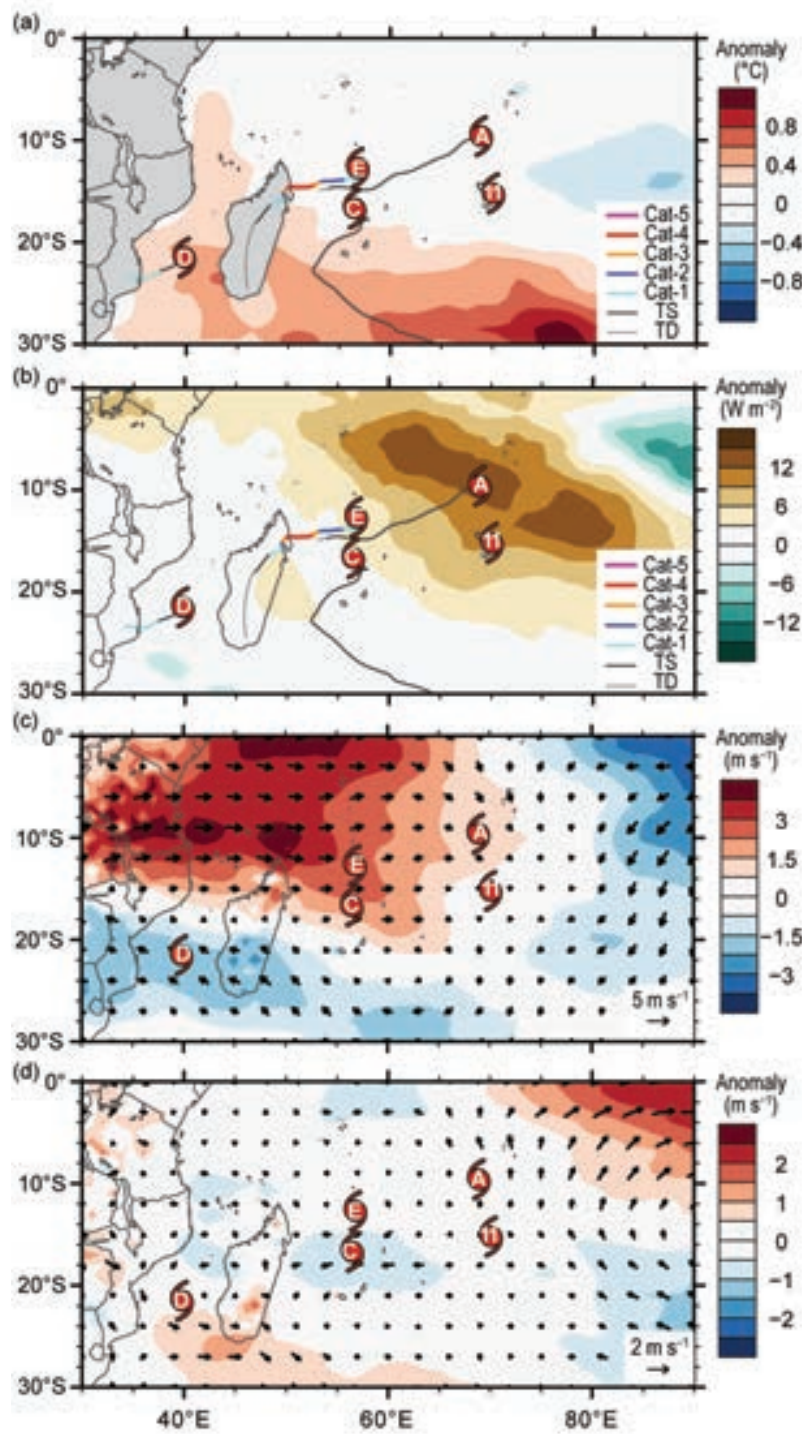

Fig. 4.33. Jul 2016-Jun 2017 anomaly maps of (a) SST ( ${ }^{\circ} \mathrm{C}$; Banzon and Reynolds 2013), (b) OLR ( $\mathrm{W} \mathrm{m}^{-2}$; Lee 2014), (c) 200-850-hPa zonal wind shear ( $\mathrm{m} \mathrm{s}^{-1}$; vectors) and scalar (shading) anomalies, and (d) 850-hPa winds ( $\mathrm{m} \mathrm{s}^{-1}$; vectors) and zonal wind (shading) anomalies. Anomalies are relative to the annual cycle from 1981 2010 , except for SST which is relative to $1982-2010$ due to data availability. Letter symbols denote where each SIO TC first attained tropical storm intensity. Wind data obtained from CFSR (Saha et al. 20I4). 
areas of responsibility), despite a late start, with only one cyclone before mid-February. The season produced nine TCs (Fig. 4.34), near the 1983/84-2010/11 average $^{6}$ of 10.8, and consistent with neutral to cool ENSO conditions. The 1981-2010 IBTrACS seasonal averages for the basin are 9.9 named storms, 7.5 TCs, and 4.0 major TCs. All references to TC category in this section use the Australian Bureau of Meteorology TC intensity scale.

There were six TCs in the western sector ${ }^{7}$ of the Australian region during 2016/17, three in the northern sector, and one in the eastern sector ${ }^{8}$. Three systems made landfall in Australia as tropical cyclones, two in Western Australia and one in Queensland, while two others made landfall after weakening below tropical cyclone intensity. The first landfall of the season did not occur until 6 March, the latest first landfall since comprehensive satellite records began in 1970 .

\section{(ii) Landfalling and other significant TCs}

The most significant cyclone of the season was Debbie, which affected eastern Australia in late March. Debbie formed as a tropical disturbance south of Papua New Guinea and initially moved south, reaching cyclone intensity on 24 March near $17^{\circ} \mathrm{S}$, $152^{\circ} \mathrm{E}$, before turning southwest and intensifying. It reached its peak intensity of category 4 while just off the Queensland coast at 0000 UTC on 28 March, with maximum 10 -minute sustained winds of $95 \mathrm{kt}$ $\left(49 \mathrm{~m} \mathrm{~s}^{-1}\right)$. It later made landfall at 0240 UTC (1240 local time) just north of Airlie Beach, by which time it had weakened slightly to a category 3 storm with maximum sustained winds of $80 \mathrm{kt}\left(41 \mathrm{~m} \mathrm{~s}^{-1}\right)$. Debbie then moved southwest into inland Queensland, weakening below cyclone intensity by 1600 UTC. The remnant low then took a south to southeast track through Queensland, passing back out to sea near Brisbane late on 30 March. A wind gust of $142 \mathrm{kt}$ $\left(73 \mathrm{~m} \mathrm{~s}^{-1}\right)$, the strongest measured gust on record in Queensland, was observed at the elevated Hamilton Island Airport site on $28 \mathrm{March}$, and $89 \mathrm{kt}\left(46 \mathrm{~m} \mathrm{~s}^{-1}\right)$ at Proserpine. There was extremely heavy rainfall near landfall, as well as from the remnant low; totals

${ }^{6}$ Averages are taken from 1983/84 onwards as that is the start of consistent satellite coverage of the region.

${ }^{7}$ The western sector covers areas between $90^{\circ}$ and $125^{\circ} \mathrm{E}$. The eastern sector covers areas east of the eastern Australian coast to $160^{\circ} \mathrm{E}$, as well as the eastern half of the Gulf of Carpentaria. The northern sector covers areas from $125^{\circ} \mathrm{E}$ east to the western half of the Gulf of Carpentaria.

${ }^{8}$ Frances passed through both the western and northern sectors.
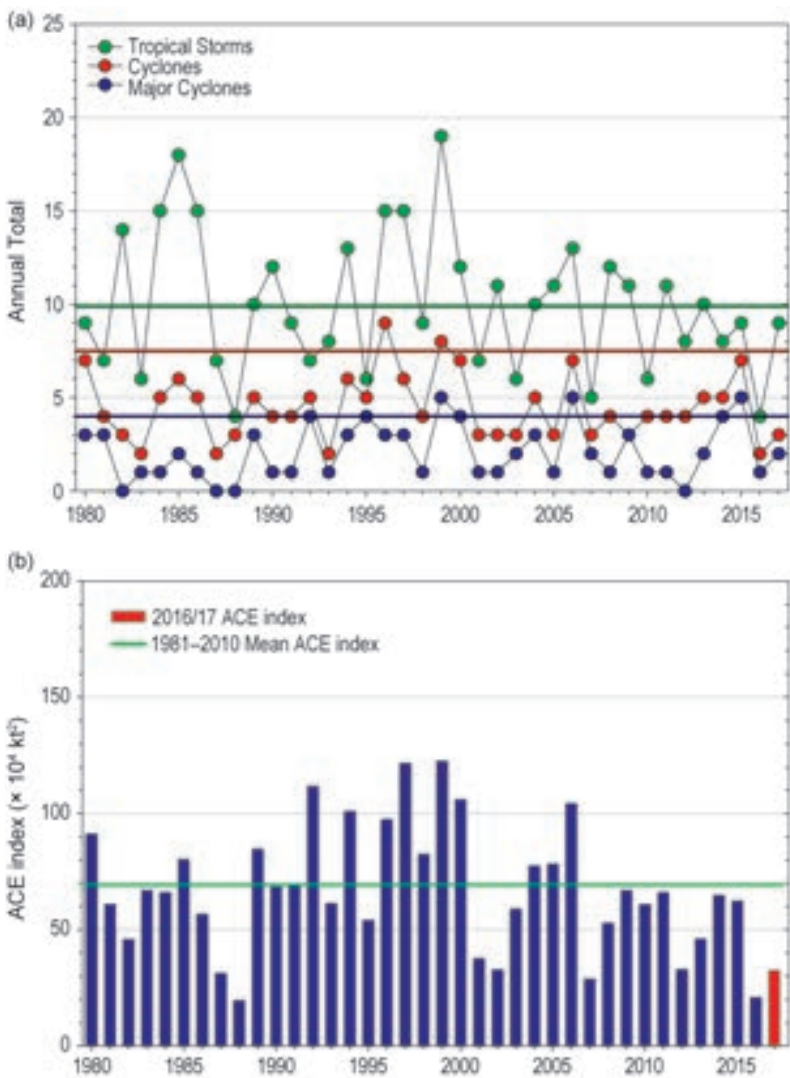

Fig. 4.34. Annual TC statistics for the Australian basin for 1980-2017: (a) number of tropical storms, cyclones, and major cyclones and (b) estimated annual ACE index (in $\left.\mathrm{kt}^{2} \times 10^{4}\right)$ for all TCs at least tropical storm strength or greater intensity (Bell et al. 2000). The 198I-2010 means (horizontal lines) are included in both (a) and (b). Note that ACE is estimated due to lack of consistent 6-h sustained winds for each storm.

near landfall included $635 \mathrm{~mm}$ in 24 hours at Mount Jukes and $986 \mathrm{~mm}$ in 48 hours at Clarke Range on 28-29 March, while near the Queensland-New South Wales border, 24-hour totals on 31 March included $602 \mathrm{~mm}$ at Upper Springbrook, $507 \mathrm{~mm}$ at Chillingham, and $478 \mathrm{~mm}$ at Boat Harbour. A 2.6-m storm surge ( $0.9 \mathrm{~m}$ above highest astronomical tide) was observed at Laguna Quays, north of Mackay.

Debbie caused extensive wind damage in the Whitsunday region on the mainland and on offshore islands, including Airlie Beach, Proserpine, Bowen, Hamilton, and Daydream Islands, and inland to Collinsville. There was also severe flooding both in the region near landfall, including the fifth highest height on record for the Fitzroy River at Rockhampton and in the Logan, Albert, and Tweed catchments near the Queensland-New South Wales border. Moisture from the remnant low also contributed to major flooding in parts of the North Island of New Zealand 
on 4-5 April, including the inundation of large parts of the town of Edgecumbe where a stopbank of the Rangitaiki River was breached on 6 April. In total, three direct deaths and several indirect deaths were attributed to Debbie, while insured losses for Debbie in Australia, according to the Insurance Council of Australia, were assessed at $\$ 1.565$ billion AUS dollars ( $\$ 1.207$ billion U.S. dollars), the second-largest (inflation-adjusted) insurance loss on record for an Australian tropical cyclone (after Cyclone Tracy in 1974). An additional \$91.5 million NZ dollars (\$66.7 million U.S. dollars) of insured damages happened in New Zealand from Debbie's extratropical remnants.

Blanche formed as a tropical low within a trough over the Arafura Sea on 2 March. It began to strengthen on the 3 rd and moved southwest on the 4 th while strengthening, crossing over the Tiwi Islands (northwest of Darwin) early on 5 March. Continuing to move southwest over the Timor Sea, it reached tropical cyclone intensity at 1200 UTC on the 5th, when approximately $200 \mathrm{~km}$ west of Darwin. It strengthened further to category 2 while moving southwest, with peak 10 -minute sustained wind speeds of $55 \mathrm{kt}\left(28 \mathrm{~m} \mathrm{~s}^{-1}\right)$, before making landfall at that intensity at 0300 UTC on 6 March, on the northeast Kimberley coast of Western Australia between Kalumburu and Wyndham. Point Fawcett, on the Tiwi Islands, received $384 \mathrm{~mm}$ of rain in the 24 hours prior to 0900 local time on 5 March, its wettest day on record, while in the Kimberley, the highest recorded 48-hour rainfall was $207 \mathrm{~mm}$ at Me No Savvy, between Fitzroy Crossing and Halls Creek. Tropical cyclone warnings were issued for Darwin but no major impacts occurred there.

The third landfall of the season occurred on 23 March, at 0500 UTC just west of Port Hedland. The original low formed on 19 March north of the Kimberley coast, before moving west and then southwest and intensifying shortly before landfall. The cyclone was not named operationally but was analyzed as a category 2 system based on post-analysis [maximum sustained winds $50 \mathrm{kt}\left(26 \mathrm{~m} \mathrm{~s}^{-1}\right)$ ] on the basis of observed surface winds, including a gust of $61 \mathrm{kt}(32 \mathrm{~m}$ $\mathrm{s}^{-1}$ ) at a beacon offshore from Port Hedland. There was minor wind damage in the Port Hedland area and significant river rises in the Pilbara coastal rivers, De Grey River, and Fortescue River. Minor to major flooding occurred at some locations in the De Grey catchment. Port Hedland received $268 \mathrm{~mm}$ of rain during 22-24 March.

Yvette, in late December, and Alfred, in midFebruary, were both cyclones that weakened below cyclone intensity before making landfall near Broome in Western Australia and the Northern Territory/ Queensland border, respectively. Alfred peaked offshore as a category 2 and Yvette as a category 1. Moisture from Yvette combined with a separate tropical low to bring heavy rains through a large area of central and southern Australia in the final days of December. Walungurru, near the Northern Territory/ Western Australia border, received $287 \mathrm{~mm}$ of rain during 25-26 December, while Adelaide $(61.2 \mathrm{~mm}$ on 28th) had its third wettest December day on record. There was significant flash flooding in parts of metropolitan Melbourne. Record high dewpoints and precipitable water levels were observed at numerous sites in South Australia and Victoria. Alfred brought some flooding and minor wind damage, and $862 \mathrm{~mm}$ of rain was recorded from 18 to 22 February at Sweers Island.

The most intense Australian tropical cyclone of the season was Ernie. This storm formed as a tropical low on 4 April near $10^{\circ} \mathrm{S}, 115^{\circ} \mathrm{E}$, well north of Western Australia. Ernie reached tropical cyclone intensity late on 6 April near $14^{\circ} \mathrm{S}, 111^{\circ} \mathrm{E}$, and then intensified exceptionally rapidly, reaching category 5 intensity within 24 hours. It reached its peak intensity (maximum sustained winds $115 \mathrm{kt}\left(62 \mathrm{~m} \mathrm{~s}^{-1}\right)$ at $1200 \mathrm{UTC}$ on 7 April near $16^{\circ} \mathrm{S}, 111^{\circ} \mathrm{E}$, before turning west-southwest and weakening, dropping below tropical cyclone intensity on 10 April. The other major cyclone of the season was Frances, which reached category 3 intensity on 28-29 April, with maximum sustained winds of $70 \mathrm{kt}\left(36 \mathrm{~m} \mathrm{~s}^{-1}\right)$, as it tracked westsouthwest through the Timor Sea between Timor and the Australian mainland. Neither Ernie nor Frances approached any land areas, although heavy rain associated with Frances did affect the Tiwi Islands.

8) Southwest Pacific basin —P. R. Pearce, A. M. Lorrey, and H. J. Diamond

(i) Seasonal activity

The 2016/17 season in the southwest Pacific officially began in November 2016, but the first named storm did not occur until February 2017, despite numerous tropical depressions during the early part of the season. Storm track data for November 2016April 2017 was gathered from the Fiji Meteorological Service, Australian Bureau of Meteorology, and New Zealand MetService, Ltd. The southwest Pacific basin as defined by Diamond et al. (2012) $\left(135^{\circ} \mathrm{E}-\right.$ $120^{\circ} \mathrm{W}$ ) had six tropical cyclones, including three major tropical cyclones (based on the Australian TC intensity scale). As noted in Section 4f1, Fig. 4.35 shows the standardized TC distribution based on the basin spanning the area from $160^{\circ} \mathrm{E}-120^{\circ} \mathrm{W}$ to avoid 

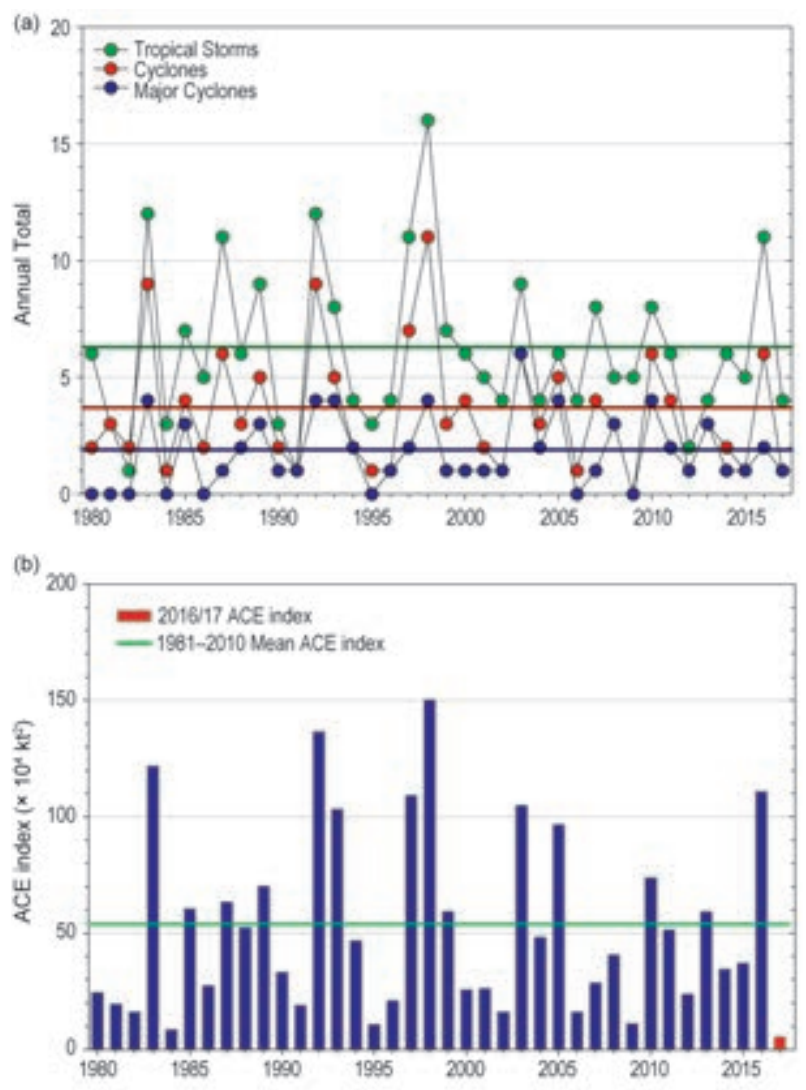

Fig. 4.35. Annual TC statistics for the southwest Pacific for 1980-2017: (a) number of tropical storms, cyclones, and major cyclones and (b) estimated annual ACE index (in $\mathrm{kt}^{2} \times 10^{4}$; Bell et al. 2000). The 1981-2010 means (horizontal lines) are included in both (a) and (b). Note that ACE is estimated due to lack of consistent 6-h sustained winds for each storm.

overlaps with the Australian basin that could result in double counting of storms. However, it is important to use the definition of the southwest Pacific basin of Diamond et al. (2012) as that is how annual TC outlooks are produced and disseminated. All references to TC category in this section use the Australian TC intensity scale.

The 1981-2010 Southwest Pacific Enhanced Archive of Tropical Cyclones (SPEArTC) indicates a seasonal average of 10.4 named tropical cyclones and 4.3 major tropical cyclones. Therefore, the 2016/17 TC season had less-than-normal activity. The first storm (Tropical Cyclone Alfred) developed as a tropical disturbance in the Gulf of Carpentaria in mid-February. The season concluded in mid-May with Tropical Cyclone Ella affecting Wallis and Futuna and Samoa. The ratio of major TCs relative to the total number of named TCs in 2016/17 was 50\%, down from 63\% during the previous season. Tropical Cyclone Donna, which caused significant damage in northern
Vanuatu and the Solomon Islands in May, was the strongest TC to form outside the official southwest Pacific TC season (which ended on 30 April 2017) on record per the SPEArTC dataset (Diamond et al 2012).

\section{(ii) Landfalling and other significant TCs}

Tropical Cyclone Alfred developed as a tropical low on 16 February in the southern Gulf of Carpentaria. The low gradually intensified into a category 1 TC on 20 February and remained at TC strength before weakening approximately 24 hours later. Alfred was the first tropical cyclone to make landfall in Australia's Northern Territory since 2015. Alfred's peak 10-minute wind speed was $46 \mathrm{kt}\left(24 \mathrm{~m} \mathrm{~s}^{-1}\right)$ and its lowest central pressure was $994 \mathrm{hPa}$.

Tropical Cyclone Bart was a short-lived cyclone which lasted from 19 to 22 February, forming south of Samoa and traveling southeast to the south of the southern Cook Islands. Bart reached category 1 status, where peak 10-minute sustained wind speeds were $40 \mathrm{kt}\left(21 \mathrm{~m} \mathrm{~s}^{-1}\right)$ and minimum central pressures reached $994 \mathrm{hPa}$.

Tropical Cyclone Cook was named on 8 April after forming northeast of Vanuatu. Some trees were felled and power was cut to some residents in Port Vila, Vanuatu. Cook brought heavy rain and destructive winds to parts of New Caledonia, where one fatality was reported. Cook also caused wind damage to trees and infrastructure in parts of New Zealand's North Island, one week after ex-Tropical Cyclone Debbie caused major flooding in the same area. Cook achieved category 3 status with 10-minute sustained winds of $84 \mathrm{kt}\left(43 \mathrm{~m} \mathrm{~s}^{-1}\right)$ and a minimum central pressure of $961 \mathrm{hPa}$.

Tropical Cyclone Donna formed to the north of Vanuatu on 1 May, which is just past the traditional end of the season (30 April). It achieved named storm status on 3 May, and late on 4 May it began to show a clear eye and was upgraded to a category 3 tropical cyclone. On 6 May, Donna was upgraded to category 4 status. It weakened to a category 3 storm later on 6 May but then strengthened again to category 4 status the next day before being upgraded to category 5 status on 8 May. Donna's peak 10-minute sustained wind speed reached $111 \mathrm{kt}\left(57 \mathrm{~m} \mathrm{~s}^{-1}\right)$ and its lowest minimum central pressure was $935 \mathrm{hPa}$. As a result, Donna became the strongest out-of-season TC on record for May in the southwest Pacific. Donna degraded quickly to tropical low strength on 10 May. The storm caused significant damage in Vanuatu. Entire villages across the Torres Islands in Torba Province were forced to seek shelter from the storm in caves. Throughout the province, many buildings 
were destroyed or severely damaged. On the island of Efate, heavy rainfall led to flooding of low-lying areas. Structures collapsed in Port Vila because they were undermined during flash floods. Across the northern half of Vanuatu, crops sustained significant damage and communications were severed with the rest of the country. In the Temotu Province of the Solomon Islands, Donna caused two fatalities. In New Zealand, Donna's remnants produced heavy rain over much of the North Island and the west coast of the South Island on 11-12 May.

The season concluded with Tropical Cyclone Ella, which formed southwest of American Samoa on 9 May. Just three hours later, the system intensified into a category $1 \mathrm{TC}$, and it reached category 2 status on 10 May. Its peak 10-minute sustained wind speed was $59 \mathrm{kt}\left(31 \mathrm{~m} \mathrm{~s}^{-1}\right)$ with a minimum central pressure of $977 \mathrm{hPa}$.

g. Tropical cyclone heat potential-G. J. Goni, J. A. Knaff, I.-I. Lin, and R. Domingues

This section summarizes the changes in upper ocean thermal conditions within the seven tropical cyclone (TC) basins (see Table 4.1), using tropical cyclone heat potential (TCHP; Goni and Trinanes 2003) as the main parameter. The assessment presented here focuses on the vertically-integrated upper ocean temperature conditions during the TC season of each ocean basin with respect to the long-term mean and to values observed during the previous year. TCHP is defined as the excess heat content contained in the water column between the sea surface and the depth of the $26^{\circ} \mathrm{C}$ isotherm. This parameter has been linked to TC intensity changes (Shay et al. 2000; Mainelli et al 2008; Lin et al. 2014) with TCHP values above $50 \mathrm{~kJ} \mathrm{~cm}^{-2}$ providing the necessary ocean conditions for Atlantic hurricane intensification when favorable atmospheric conditions are present. The magnitude of the TCHP has been identified as modulating the effective SST under a TC during air-sea coupling due to latent and sensible heat fluxes (Mainelli et al. 2008; Lin et al. 2013). In addition, improved temporal and spatial sampling of the ocean has been shown to lead to the correct representation of the upper ocean density field (Domingues et al. 2015), which in turn led to reducing the error in hurricane intensification forecasts within operational numerical models (Dong et al. 2017). Fields of TCHP show high spatial and temporal variability associated mainly with oceanic mesoscale features, year-to-year variability (e.g., ENSO), or long-term decadal variability. The assessment of this variability on various timescales can be accomplished using a combination of satellite altimetry and in situ observations (Goni et al. 1996; Lin et al. 2008; Goni and Knaff 2009; Pun et al. 2013).

To assess year-to-year variations in TCHP, two fields are presented. First, Fig. 4.36 presents TCHP anomalies (departures from the 1993-2016 mean values) for the primary months of TC activity in each hemisphere: June-November in the Northern Hemisphere, and November 2016-April 2017 in the Southern Hemisphere. TCHP anomalies generally show large variability within and among the TC basins. Figure 4.37 shows the differences of TCHP between this season (2017) and last year (2016).

Most basins exhibited positive TCHP anomalies in 2017 (Fig. 4.36), except for a small region just east of $60^{\circ} \mathrm{E}$ in the southwest Indian basin. Above-average TCHP in most basins provided anomalously favorable ocean conditions for the intensification of TCs. In the tropical Atlantic basin, TCHP values observed in 2017 were approximately $10 \%$ larger than the longterm mean, consistent with the above-normal activity there. Meanwhile, the western North Pacific (WNP) basin had below-normal activity despite TCHP values being over $30 \%$ larger than the mean conditions. This is explained because the number of TCs in the WNP during a season is more closely related to atmospheric dynamics (Lin and Chan 2015) than to upper ocean conditions.

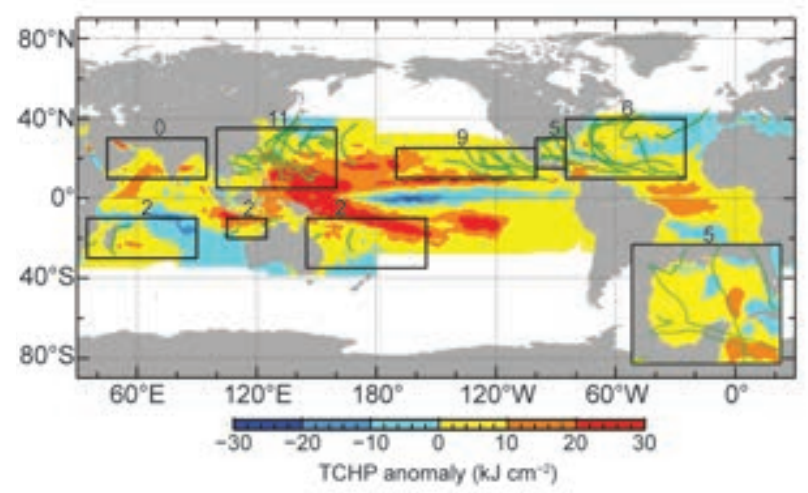

FIG. 4.36. Global anomalies of TCHP $\left(\mathrm{kJ} \mathrm{cm}^{-2}\right)$ corresponding to 2017 computed as described in the text. Boxes indicate the seven regions where TCs occur: from left to right, southwest Indian, north Indian, west North Pacific, southeast Indian, South Pacific, East Pacific, and North Atlantic (shown as Gulf of Mexico and tropical Atlantic separately). Green lines indicate the trajectories of all tropical cyclones reaching at least Saffir-Simpson category I during Nov 2016-Apr 2017 in the SH and Jun-Nov 2017 in the NH. The numbers above each box correspond to the number of category I and above cyclones that traveled within each box. Gulf of Mexico conditions during Jun-Nov 2017 are shown in the inset in the lower right corner. 


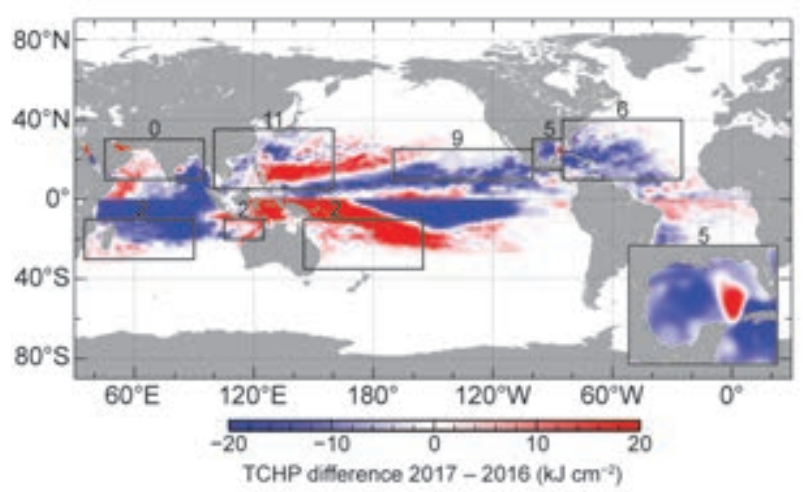

Fig. 4.37. TCHP differences $\left(\mathrm{kJ} \mathrm{cm}^{-2}\right)$ between 2017 and 2016.

In the Gulf of Mexico, TCHP anomalies ranged between -10 and $20 \mathrm{~kJ} \mathrm{~cm}^{-2}$ with the spatial distribution largely determined by the mesoscale field, such as the extension of the Loop Current, and cold cyclonic features. In the eastern Gulf of Mexico, prominent intrusion of the Loop Current caused TCHP values in 2017 to be $50 \%$ larger than the mean; a noticeable change with respect to conditions in 2016, which was characterized by a small intrusion of the Loop Current. The TCHP in the western Gulf of Mexico once again exhibited positive anomalies, with values approximately $30 \%$ larger than the long-term mean. Compared to 2016, TC activity increased in the Gulf of Mexico in 2017 with a total of five TCs including the rapidly intensifying category 4 Hurricane Harvey.

In the eastern North Pacific (ENP) basin, TCHP values were $10-20 \mathrm{~kJ} \mathrm{~cm}^{-2}$ above the long-term mean associated with a continued positive phase of the Pacific decadal oscillation (Zhang et al. 1997). Anomalies observed in 2017, however, were not so large as the values observed in 2016. This change is largely due to the ENSO conditions described in Section $4 \mathrm{~b}$. As a consequence, average TC activity was observed in the ENP, with nine hurricanes in 2017 (Fig. 4.36).

The TCHP in the WNP basin is also closely modulated by ENSO variability (Lin et al. 2014; Zheng et al. 2015). For example, from the 1990s to 2013 the WNP experienced a long-term decadal surface and subsurface warming associated with more prevalent La Niña-like conditions (Pun et al. 2013; England et al. 2014; Lin and Chan 2015). With the ENSO conditions during 2014/15, however, this warming trend stopped, but it recovered again in 2016. In 2017, further warming of the WNP basin and TCHP anomalies as large as $40 \mathrm{~kJ} \mathrm{~cm}^{-2}$ were observed, which is approximately $30 \%$ larger than the long-term mean for the region. However, the overall TC activity over the WNP basin was not so active as in 2016 due to less favorable atmospheric dynamic conditions (Lin and Chan 2015; Section 4f4).

For each basin, the differences in the TCHP values between this season and 2016 (Fig. 4.37) indicate that three of the seven active TC basins exhibited a decrease in TCHP values, namely the: (1) South Indian Ocean, (2) eastern North Pacific Ocean, and (3) North Atlantic Ocean basins. It is likely that lower TCHP values in the south Indian Ocean played a role in suppressing TC activity in 2016/17, which observed only one major TC during the season. However, despite showing a moderate decrease in TCHP with respect to 2016, above-normal TC activity in terms of category 4 and 5 storms was observed in the tropical Atlantic and Gulf of Mexico, with the development of six major Atlantic hurricanes. Intense hurricane activity in the Atlantic during the last season likely benefited from above-normal TCHP in the tropical Atlantic and Gulf of Mexico (Fig. 4.36) combined with favorable atmospheric conditions associated with a cool neutral ENSO state, which is known for decreasing vertical wind shear and trade wind intensity, supporting TC development and intensification (Gray 1984). In addition, atmospheric conditions in the tropical Atlantic, as described in Section 4f2, favored the development of intense TC activity (Bell et al. 2017b). Hurricanes Irma and Maria, for example, had sustained winds that reached $160 \mathrm{kt}\left(67 \mathrm{~m} \mathrm{~s}^{-1}\right)$ and $150 \mathrm{kt}\left(72 \mathrm{~m} \mathrm{~s}^{-1}\right)$, respectively. Both storms were well observed by reconnaissance aircraft equipped with stepped frequency microwave radiometers that provide accurate estimates of surface wind speeds (Uhlhorn and Black 2003).

An increase in TCHP values with respect to the previous season was recorded in the North Indian Ocean (Arabian Sea), southeast Indian Ocean, southwest Pacific, and WNP ocean basins. The largest changes with respect to the previous season were observed in the south Indian Ocean basin, and in the WNP north of $10^{\circ} \mathrm{N}$, with differences above -20 and $20 \mathrm{~kJ} \mathrm{~cm}^{-2}$ respectively. Super Typhoon Noru was the fifth named storm to develop during the season and experienced rapid intensification from tropical storm into a category $5 \mathrm{TC}$ as it moved from an area of low TCHP $\left(\sim 40 \mathrm{~kJ} \mathrm{~cm}^{-2}\right)$ into an area with TCHP values of $\sim 80 \mathrm{~kJ} \mathrm{~cm}^{-2}$.

Ocean conditions of four of the six major hurricanes (Harvey, Irma, Jose, and Maria) of the Atlantic basin are described here. Data from the ocean observing system, including observations from underwater gliders that were deployed to collect data in support of operational hurricane intensity forecasts, are presented here (Fig. 4.38). These observations were 


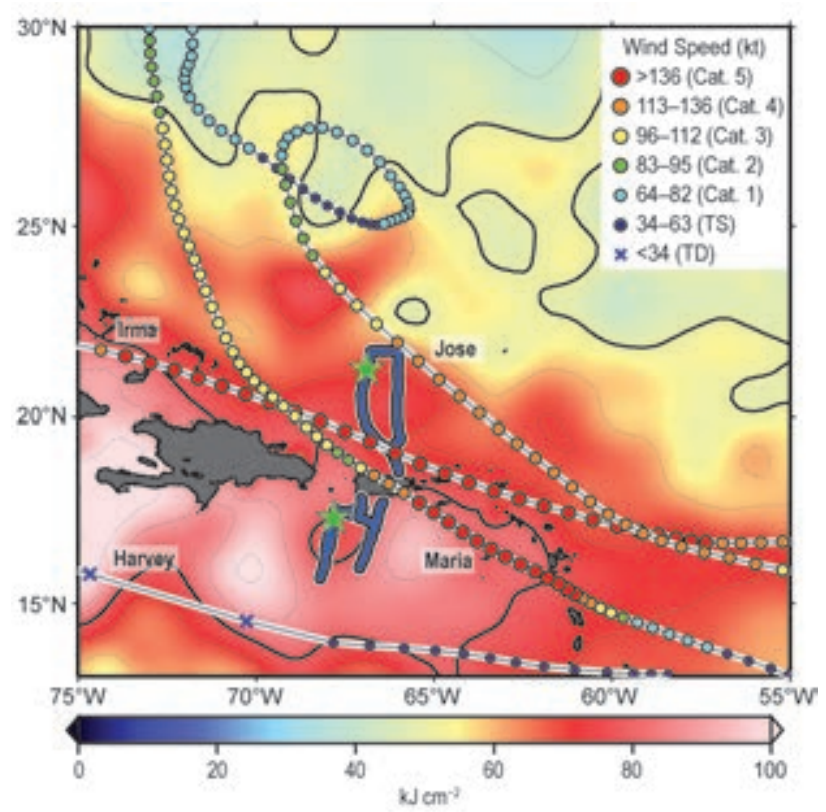

Fig. 4.38. Tracks of major Atlantic hurricanes that traveled over the Caribbean Sea and tropical North Atlantic Ocean during the 2017 hurricane season. Blue lines indicate the location of some of the underwater gliders, which were parked in fixed locations (green stars) during the passage of the major hurricanes. Background colors show values of TCHP averaged for Aug 2017, with thin contours every $10 \mathrm{~kJ} \mathrm{~cm}^{-2}$, and thick contours indicate $50 \mathrm{~kJ} \mathrm{~cm}^{-2}$ and $80 \mathrm{~kJ} \mathrm{~cm}$, respectively.

collected because a better representation of the upper ocean temperature and salinity conditions has been shown to reduce the error in Atlantic hurricane intensity forecasts within the NOAA experimental HYCOM-HWRF operational model (Dong et al. 2017). Ocean conditions before, during, and after the passage of these hurricanes were continuously monitored by some of these gliders.

Hurricane Harvey traveled through the Caribbean Sea south of Puerto Rico on 20 August, where the upper ocean exhibited TCHP values higher than $80 \mathrm{~kJ} \mathrm{~cm}^{-2}$. In this area, underwater glider data showed that a relatively shallow mixed layer favored cooling of the upper ocean, which together with the moderate wind shear contributed to its lack of intensification in that region. Once it reached the Gulf of Mexico, Hurricane Harvey intensified from a tropical depression into a category 4 hurricane with $115 \mathrm{kt}\left(51 \mathrm{~m} \mathrm{~s}^{-1}\right)$ winds in a period of less than 48 hours as it traveled over positive TCHP anomalies in the western Gulf of Mexico. Harvey produced the largest amount of rain on record in the continental United States, which caused extensive flooding in the Houston, Texas, metropolitan area (see Sidebar

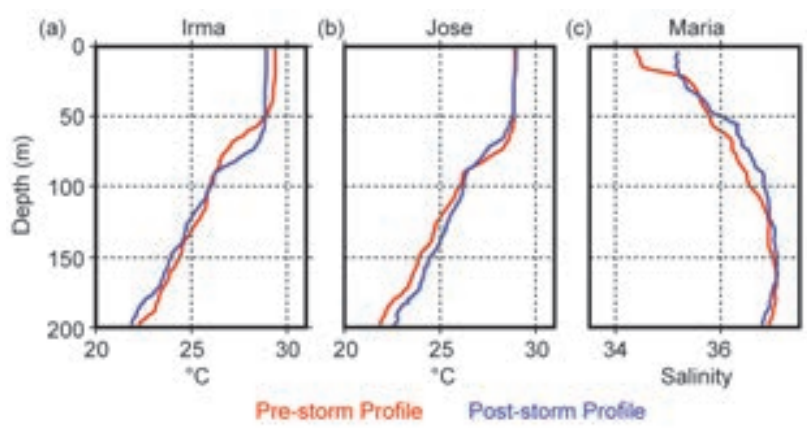

Fig. 4.39. (a), (b) Temperature $\left({ }^{\circ} \mathrm{C}\right)$ and (c) salinity profiles sampled by underwater gliders before and after the passage of three major North Atlantic hurricanes (Irma, Jose, and Maria) in 2017.

4.3 for detailed information about the precipitation associated with Harvey).

Hurricane Irma, the strongest TC globally in 2017, reached its maximum intensity of $160 \mathrm{kt}\left(82 \mathrm{~m} \mathrm{~s}^{-1}\right)$ on 6 September while traveling over waters north of Puerto Rico and Hispaniola that had TCHP values higher than $70 \mathrm{~kJ} \mathrm{~cm}^{-2}$. Underwater glider data showed that the upper ocean conditions exhibited low salinity values at the surface, partially suppressing upper ocean mixing with colder underlying waters, similar to what happened with Hurricane Gonzalo in 2014 (Domingues et al. 2015; Dong et al. 2017), but opposite to the conditions experienced during Hurricane Harvey. Glider observations also revealed that the upper $50 \mathrm{~m}$ of the ocean cooled by approximately $1^{\circ} \mathrm{C}$ (Fig. 4.39a) as a result of storm-induced mixing.

Hurricane Jose was the third strongest Atlantic hurricane in 2017 and was the seventh longest-lived Atlantic named storm in the satellite era (since 1966). While Jose was off Puerto Rico, $2^{\circ}-3^{\circ}$ latitude to the north of where Irma traveled, its trajectory coincided at a time with the cold wake left behind by the passage of Hurricane Irma. Therefore, Jose experienced a relatively cooler and well mixed upper ocean as observed by underwater glider data (Fig. 4.39b). These cooler ocean conditions may have partly contributed to its weakening from a category 4 hurricane to category 3 during this time.

Hurricane Maria traveled through the eastern Caribbean Sea and later through the same approximate area as Irma transited the tropical North Atlantic, On 20 September, after entering the Caribbean Sea following a landfall in Dominica, Maria peaked in intensity with maximum sustained winds of $150 \mathrm{kt}$ $\left(77 \mathrm{~m} \mathrm{~s}^{-1}\right)$ and a minimum pressure of $908 \mathrm{hPa}$, making Maria the tenth-most intense Atlantic hurricane on record. When Maria's path was close to the gliders in the Caribbean Sea, these ocean observations 
revealed the existence of a very stable barrier layer of approximately $30-\mathrm{m}$ depth (Fig. $4.39 \mathrm{c}$ ) providing ocean conditions conducive for intensification. Maria made landfall in Puerto Rico on 20 September as an intense category 4 hurricane. Interaction with land further weakened the hurricane, though it regained some strength as it traveled over waters with TCHP values of $\sim 70 \mathrm{~kJ} \mathrm{~cm}^{-2}$ north of Hispaniola (Fig. 4.38). As it traveled farther to the north it encountered lower TCHP which helped to contribute to Maria's weakening to a tropical storm on 28 September.

In summary, 2017 was characterized by higherthan-normal values of TCHP by $10 \%-30 \%$ over most TC basins. Overall, TCHP anomalies observed in 2017 were not so large as anomalies observed in 2016, which likely contributed to both fewer overall TCs as well as fewer category 5 TCs globally. Ocean observations during 2017 indicated that upper ocean conditions may have favored the intensification of major TCs, but atmospheric conditions (especially in the western North Pacific) were likely not as conducive for strong TCs.

\section{h. Indian Ocean dipole-J.-J. Luo}

The Indian Ocean dipole (IOD), referring to the anomalous SST gradient between the western and eastern equatorial Indian Ocean, is a major internal climate mode in the tropical Indian Ocean (IO). It often starts to grow during boreal summer, peaks in September-November, and ends rapidly in December in association with the reversal of monsoonal winds along the west coast of Sumatra (Saji et al. 1999). The IOD displays a strong asymmetry with the magnitude of the positive IOD being much larger than that of the negative IOD (e.g., Hong et al. 2008). Correspondingly, air-sea coupling strength and predictability of the positive IOD are usually strong and high, respectively, compared to those of the negative IOD (Luo et al. 2007).

Following a negative IOD event in 2016 (Luo 2017), a positive IOD event developed during April-August 2017, despite the occurrence of neutral ENSO conditions during this time (Fig. 4.40). This positive IOD event was quite weak and uncoupled. The positive west-minus-east zonal SST gradient did not bring anomalous easterlies along the equatorial IO during April-August (Fig. 4.40b). Moreover, while the cold SST anomalies in the eastern IO and warm anomalies in the western IO formed a positive dipole SST pattern during April-August, local rainfall anomalies did not follow the SST anomalies. Instead, positive rainfall anomalies occurred in the eastern IO, while drier conditions occurred in the western IO (Fig. 4.40a).
Following the strong El Niño event of 2015/16, back-to-back La Niña events occurred in late 2016 and late 2017 (Figs. 4.1, 4.40c). In addition, a negative IOD started in May 2016 and persisted until January 2017 (Fig. 4.40b). Correspondingly, during December 2016-February 2017, basin-wide cold SST anomalies appeared in the tropical IO, and warm SST anomalies were observed around Indonesia (Fig. 4.41a). Consistently dry conditions occurred in the western-central IO with wet conditions in the eastern IO to the Maritime Continent. Westerly anomalies were present in the central-eastern equatorial IO that helped deepen the thermocline in the east and generate warm upper ocean temperature in that region (Figs. 4.41a, 4.42a). Cyclonic wind anomalies in the southeastern IO, which often happen following
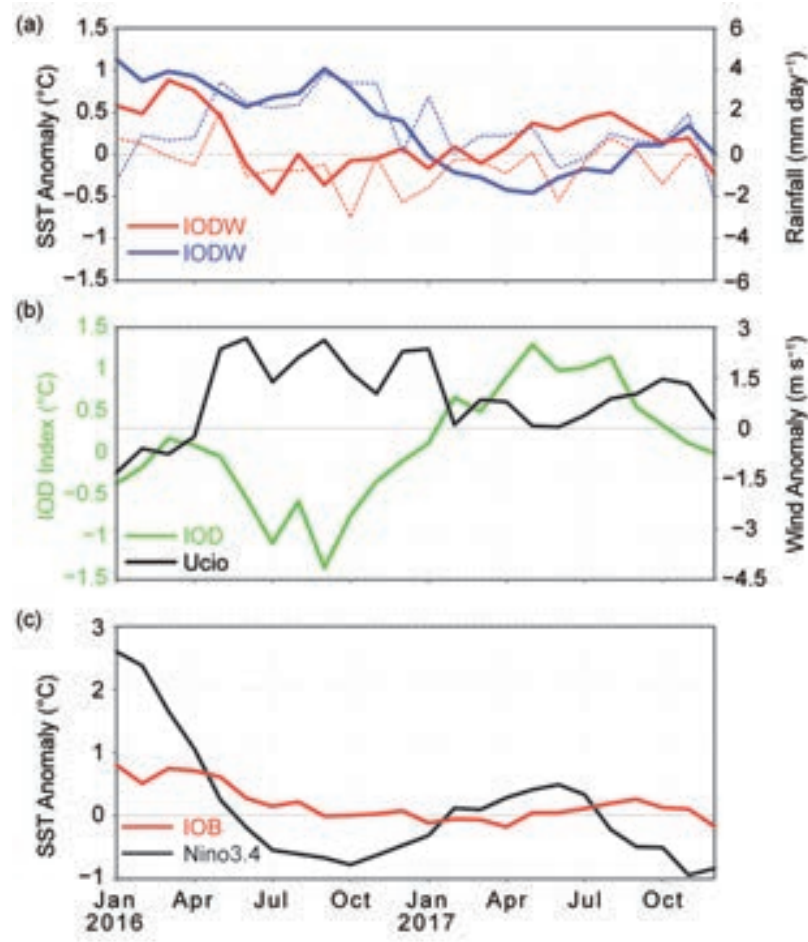

FIG. 4.40. (a) Monthly anomalies of SST ( ${ }^{\circ} \mathrm{C}$; solid lines) and precipitation ( $\mathrm{mm} \mathrm{day}{ }^{-1}$; dashed lines) in the eastern pole (IODE; $10^{\circ} \mathrm{S}-0^{\circ}, 90^{\circ}-110^{\circ} \mathrm{E}$; blue lines) and the western pole (IODW; $10^{\circ} \mathrm{S}-10^{\circ} \mathrm{N}, 50^{\circ}-70^{\circ} \mathrm{E}$; red lines) of the IOD. (b) As in (a), but for the IOD index (measured by the SST difference between IODW and IODE, green line) and surface zonal wind anomaly $\left(\mathrm{m} \mathrm{s}^{-1}\right)$ in the central equatorial 10 (Ucio; $5^{\circ} \mathrm{S}-5^{\circ} \mathrm{N}, 70^{\circ}-90^{\circ} \mathrm{E}$; black line). (c) As in (a), but for the SST anomalies in the Niño-3.4 region ( $5^{\circ} \mathrm{S}-5^{\circ} \mathrm{N}, 190^{\circ}-240^{\circ} \mathrm{E}$; black line) and the tropical 10 (IOB; $20^{\circ} \mathrm{S}-10^{\circ} \mathrm{N}, 40^{\circ}-120^{\circ} \mathrm{E}$; red line). Anomalies are relative to the 1982-2017 base period. [Sources: NOAA OISST (Reynolds et al. 2002); monthly GPCP precipitation analysis (available at http://precip.gsfc.nasa.gov/); and JRA-55 atmospheric reanalysis (Ebita et al. 20II).] 
La Niña and/or a negative IOD (Behera et al. 2006; Luo et al. 2010), tend to upwell the local thermocline and drive westward-propagating cold Rossby waves. During December 2016-February 2017, cold upper-300-m mean temperature anomalies occurred along $10^{\circ} \mathrm{S}$ and in the western IO, reminiscent of the Rossby wave activities (Fig. 4.42a). Meanwhile, the cold Rossby waves and anomalous southerlies in the southeastern IO favor the occurrence of cold SST anomalies there (Figs. 4.41a,b).

During January-July, La Niña dissipated rapidly and warm anomalies appeared in the central-eastern equatorial Pacific (Fig. 4.40c). However, the wet condition continued in the eastern IO-Maritime Continent while the western IO remained dry (Fig. 4.41b). The persistent wet condition around Indonesia is consistent with a strong increasing SST trend there.

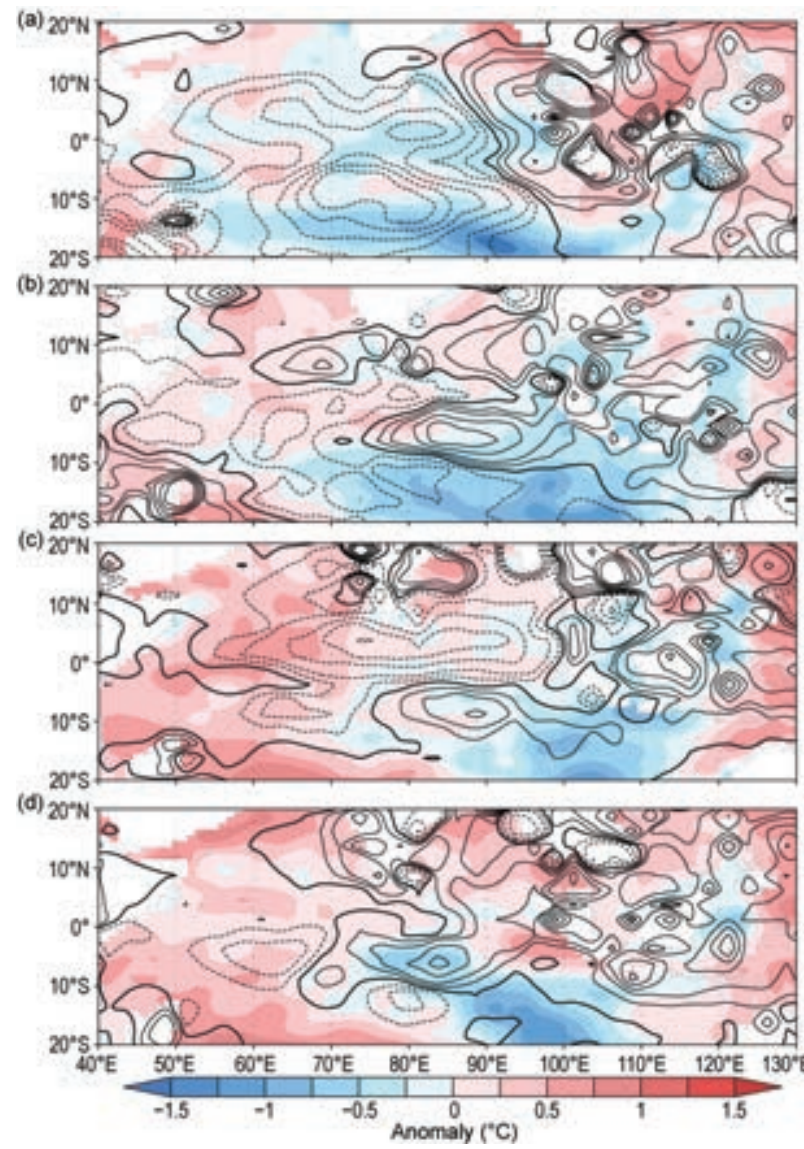

FIG. 4.4I. SST ( ${ }^{\circ} \mathrm{C}$; colors) and precipitation (contoured at: $0, \pm 0.5, \pm \mathrm{I}, \pm 2, \pm 3, \pm 4$, and $\pm 5 \mathrm{~mm} \mathrm{day}^{-1}$ ). Solid/ dashed lines denote positive/negative values, and thick solid lines indicate the zero contour) anomalies during (a) Dec 2016-Feb 2017, (b) Mar-May 2017, (c) Jun-Aug 2017, and (d) Sep-Nov 2017. Anomalies were calculated relative to 1982-2017. [Sources: NOAA OISST (Reynolds et al. 2002) and monthly GPCP precipitation analysis (available at http://precip.gsfc.nasa.gov/).]
Moreover, the corresponding westerly anomalies in the central-eastern equatorial IO did not generate warm upper ocean temperature anomalies in the east, probably owing to the arrival of eastward-propagating equatorial cold Kelvin waves. The cold subsurface anomalies helped generate cold SST anomalies along the west coast of Sumatra (Fig. 4.41b), which may have prevented the development of a negative IOD. Meanwhile, SSTs in the western IO increased during March-August (Fig. 4.41b,c), partly due to less cloud cover (i.e., dry condition) and strong increasing SST trend in that region. Thus, a positive dipole SST pattern formed. However, the persistent wet condition around Indonesia tends to induce westerly anomalies in the eastern IO, which prevents the occurrence of a positive air-sea feedback to intensify the positive dipole SST pattern. During September-November, in association with the development of the second
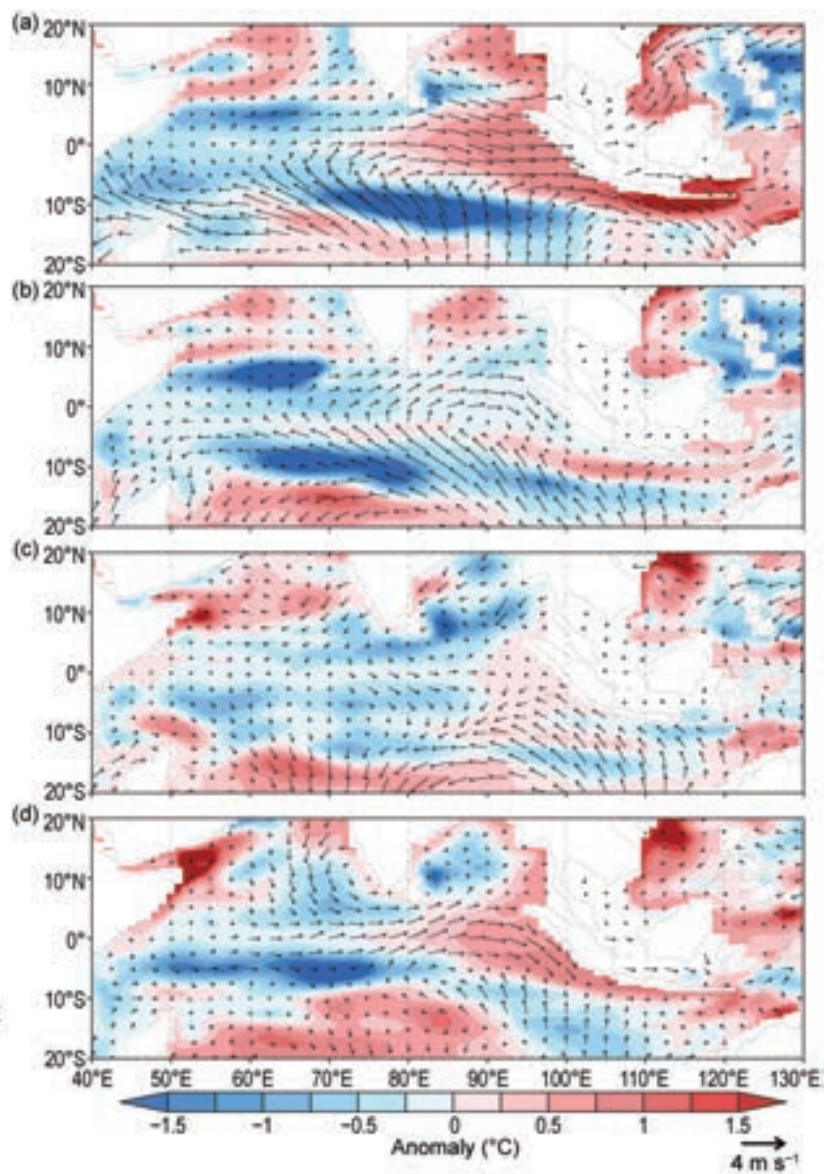

FIG. 4.42. Upper 300-m mean ocean temperature ( ${ }^{\circ} \mathrm{C}$; colored scale) and surface wind $\left(\mathrm{m} \mathrm{s}^{-1}\right)$ anomalies during (a) Dec 2016-Feb 2017, (b) Mar-May 2017, (c) Jun-Aug 2017, and (d) Sep-Nov 20I7. [Sources: NCEP ocean reanalysis (available at $w w w . c p c . n c e p . n o a a . g o v$ /products/GODAS/) and JRA-55 atmospheric reanalysis (Ebita et al. 20II).] 
La Niña event, a negative IOD signal with westerly anomalies in the central IO became apparent.

In summary, the positive IOD event in 2017 was weak and uncoupled. It did not appear to exert significant impacts on the climate in surrounding areas. Since the negative IOD in 2016 does not appear to be driven by the corresponding weak La Niña (Lim and Hendon 2017), the positive dipole SST pattern in 2017 may be largely caused by the internal mechanisms in the IO that are responsible for the biennial character of the IOD (Behera et al. 2006). Cold subsurface tem- perature anomalies in the southern IO, which were induced by the 2016 negative IOD, may have provided an important precursor for the occurrence of the cold SST anomalies in the eastern IO in 2017. However, the annually persistent anomalous westerlies in the IO, associated with the persistent wet condition around Indonesia, suppressed the positive air-sea interaction during the positive IOD event in 2017 and may have led to the occurrence of a weak uncoupled positive dipole SST event in April-August 2017. 


\section{SIDEBAR 4.I: HURRICANE IRMA: REWRITING THE RECORD BOOKS-P. J. KLOTZBACH}

Hurricane Irma generated the highest ACE values (Bell et al. 2000) of any Atlantic hurricane during the extremely active 2017 season. Irma developed from a tropical wave in the eastern Atlantic, reaching tropical storm status on 30 August. Over the next several days, Irma intensified into a major hurricane in an environment of anomalously weak vertical wind shear and anomalously high SSTs.

On 5 September, Irma reached category 5 intensity as it bore down on the northern Leeward Islands. Over the next several days, Irma devastated many islands in the eastern and central Caribbean, then went on to make landfall in Cuba before making two landfalls in Florida. It finally weakened to a tropical depression early on 12 September near the Georgia/Alabama border. In this sidebar, several of Hurricane Irma's most notable meteorological records are highlighted. All statistics for Irma listed in this sidebar are from the formal National Hurricane Center report on Hurricane Irma (Cangialosi et al. 2018). Historical statistics are calculated from the HURDAT2 database, which provides six-hourly estimates of historical Atlantic tropical cyclone wind speeds, pressures, and locations since 185I (Landsea and Franklin 2013).

Irma began to set records as it approached the northern Leeward Islands. It intensified into a I55-kt (80- $\left.\mathrm{m} \mathrm{s}^{-1}\right)$ category 5 hurricane late on 5 September, making it the strongest Atlantic hurricane outside of the Gulf of Mexico and Caribbean on record. Irma also shattered the old record for strongest hurricane to impact the northern Leeward Islands (defined as $15^{\circ}-19^{\circ} \mathrm{N}, 65^{\circ}-60^{\circ} \mathrm{W}$ ), breaking the old record of $140 \mathrm{kt}\left(72 \mathrm{~m} \mathrm{~s}^{-1}\right)$ set by the Lake Okeechobee Hurricane of 1928 and Hurricane David (1979). Irma brought devastation to Barbuda (Fig. SB4.I), Anguilla, and portions of the U.S. and British Virgin Islands and then passed north of Puerto Rico. During its track across the Caribbean, Irma made four category 5 landfalls at: Barbuda, St. Martin, Virgin Gorda (British Virgin Islands), and Little Inagua (Bahamas).

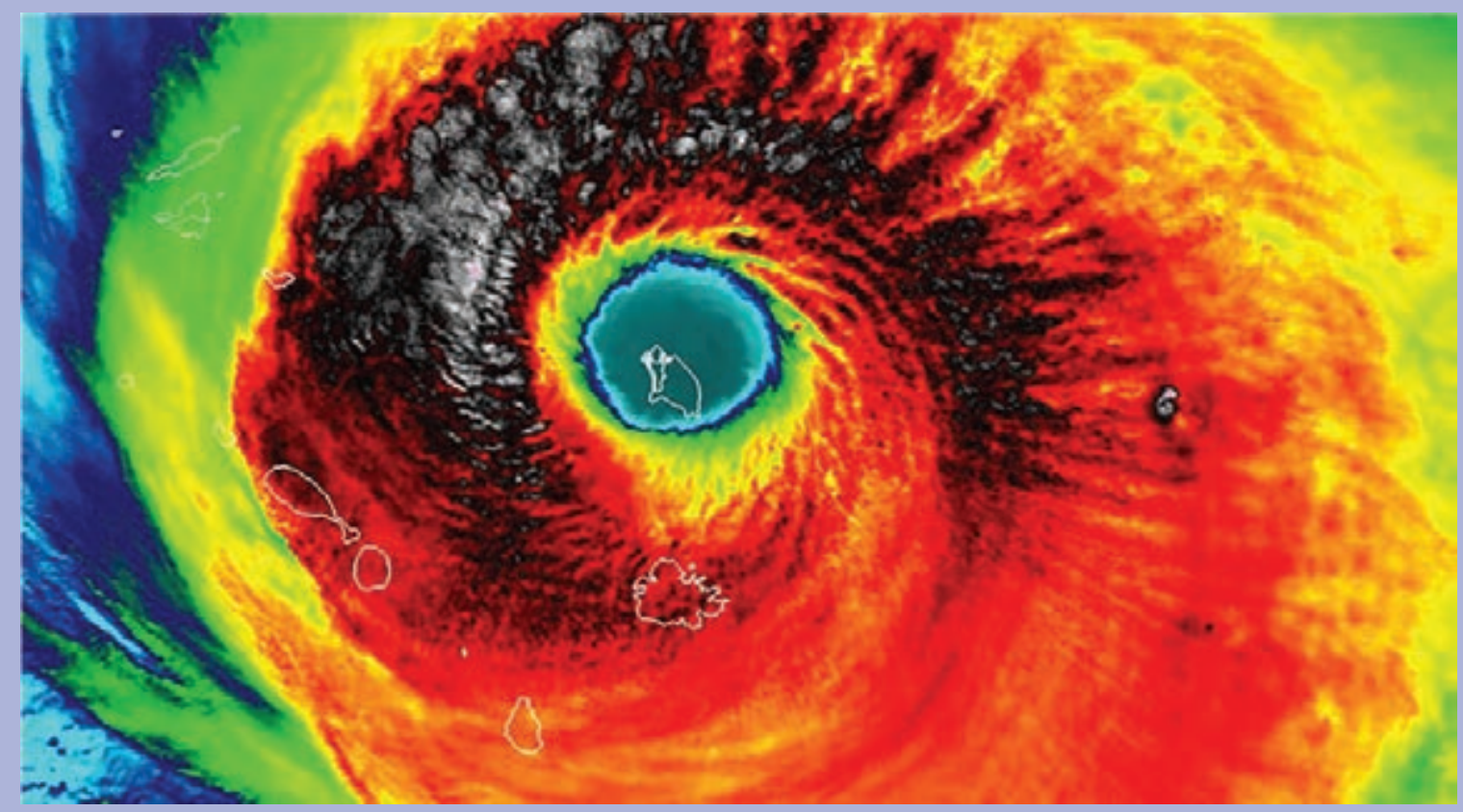

FIG. SB4.I. GOES-16 infrared satellite image of Hurricane Irma as it made landfall over Barbuda at 0600 UTC on 6 Sep 2017. 
Despite weakening slightly as it tracked across the Caribbean, Irma maintained its category 5 intensity for 2.75 consecutive days - the longest contiguous period that an Atlantic hurricane has spent at category 5 intensity in the satellite era (since 1966). It became the first category 5 hurricane to make landfall in the Bahamas since Hurricane Andrew in 1992. Irma briefly weakened to category 4 strength but then re-intensified to category 5 before making landfall in Cuba on 9 September (Fig. SB4.2). The last category 5 hurricane to hit Cuba was the Cuba Hurricane of 1924.

Land interaction with Cuba caused Irma to weaken to a category 3 hurricane, but it then re-intensified to category 4 over the warm waters of the Florida Straits before mak- ing landfall near Cudjoe Key, Florida (Fig. SB4.2). Irma's landfall pressure in the Florida Keys of 931 hPa tied with Hurricane Carla (196I) for the tenth lowest on record for a continental U.S. landfalling hurricane. This also marked the first time on record that two category 4 hurricanes (Harvey and Irma) made landfall in the continental U.S. in the same calendar year. Irma made a second landfall near Marco Island as a category 3 hurricane. At the time of its second landfall, Irma had maximum winds of $100 \mathrm{kt}$ $\left(51 \mathrm{~m} \mathrm{~s}^{-1}\right)$ and a central pressure of $936 \mathrm{hPa}$ - the exact same maximum sustained winds and $4 \mathrm{hPa}$ lower central pressure than Hurricane Wilma had when it made landfall in virtually the exact same location in 2005.

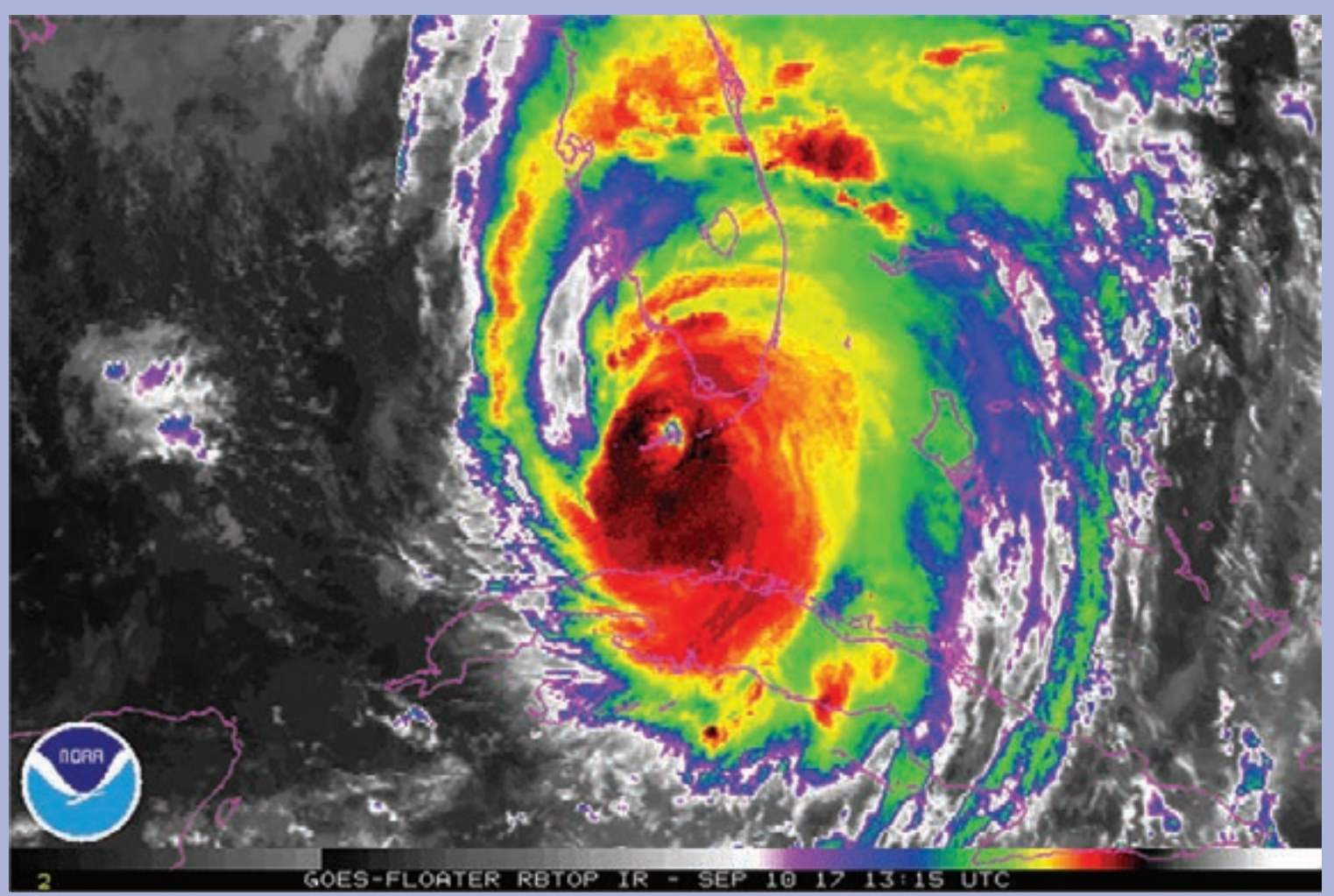

FIG. SB4.2. GOES-I6 infrared satellite image of Hurricane Irma making landfall near Cudjoe Key on I3I5 UTC on 10 Sep 2017. 


\section{SIDEBAR 4.2: THE NEW GOES-R SERIES: MUCH IMPROVED "GLASSES" TO VIEW THE TROPICS-C. S. VELDEN}

NOAA's Geostationary Operational Environmental Satellites (GOES) have historically been one of the principle tools utilized by tropical analysis and forecast centers to monitor hurricane activity. NOAA's National Hurricane Center (NHC), Central Pacific Hurricane Center (CPHC), and Satellite Analysis Branch (SAB), as well as the Department of Defense Joint Typhoon Warning Center (JTWC), employ GOES data and derived products for critical analysis of storm intensity and motion. Over the years, algorithms have been developed to estimate hurricane intensity from GOES imagery. The new GOES-R series (-R/S/T/U which become -16/17/18/19 when operational) includes an advanced imager with improved spatiotemporal and spectral resolution that will enable better assessment of hurricane structure and intensity. The first of this series, GOES-16, was operated in experimental mode for much of 2017 near $90^{\circ} \mathrm{W}$. It was declared operational by NOAA in December 2017 and positioned at $75^{\circ} \mathrm{W}$ to cover the Atlantic hurricane belt.
What are the implications of improved hurricane intensity analyses and forecasts?

The primary mission at $\mathrm{NHC/CPHC}$ is to save lives, mitigate property loss, and improve economic recovery efficiency by issuing the best possible watches and warnings of approaching hazardous tropical weather conditions. The 2017 Atlantic hurricane season was historic, with notable landfalling Hurricanes Harvey, Irma, and Maria. These storms were powerful examples of devastating disasters that could have been even worse if not for the accurate and timely track forecasts and warnings issued by the NHC. While hurricane track forecasts have generally improved, less progress has been made with intensity forecasts, which has prompted the NHC to elevate this issue to its top priority for the tropical meteorology research community. While gains clearly have been made, the losses due to the hurricanes in 2017 show that work remains to be done to fully address the goals set by the NHC.

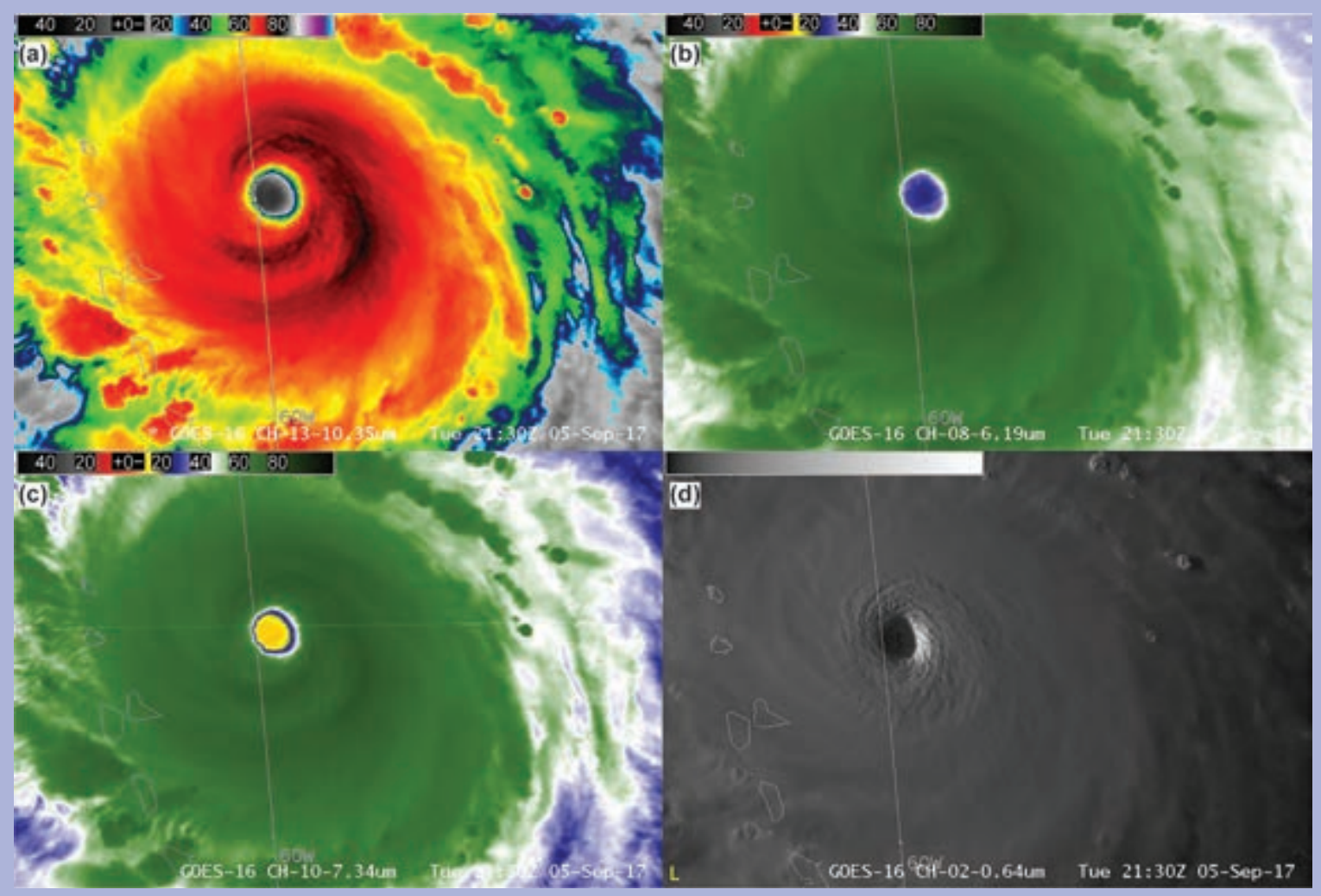

FIG. SB4.3. Multispectral GOES-16 imagery: (a) infrared window $(10.3 \mu \mathrm{m})(\mathrm{b})$ and (c) water vapor (6.19 $\mu \mathrm{m}$, upper right, $7.34 \mu \mathrm{m}$, respectively,) and (d) visible (0.64 $\mathrm{mm}$ ), at 2I30 UTC on 5 Sep 2017 during Hurricane Irma. 
In addition to operational aspects of hurricane intensity estimation, climate analyses depend heavily on the fidelity of the estimates. Trends in hurricane intensity (along with frequency, duration, and landfalls) may be linked to climate change, and these records are intrinsically dependent on satellite analyses. The GOES, along with counterparts around the world (e.g., Meteosat and Himawari), have been the backbone of the satellite-based observing system since the late 1970s.

How will the GOES-R series address hurricane intensity?

The most common use of satellite imagery to estimate tropical cyclone intensity is via the Dvorak technique (DT; Dvorak 1984), which employs recognizable patterns in enhanced infrared and/or visible satellite imagery to quantitatively estimate the intensity of a tropical system. Indications of continued development and/or weakening can also be found in the cloud features. Trained satellite analysts identify the cloud pattern types, and along with a series of standardized technique rules, a fairly accurate intensity analysis can be made. An objective offshoot of the DT is the advanced Dvorak technique, or ADT (Olander and Velden 2007). The ADT follows some of the same procedures and rules as the DT, but it is completely computer-based and includes many enhancements to the DT.
Both the DT and ADT will benefit from the improved attributes of the GOES-R series imager. The superior sensor performance and higher spatiotemporal resolution provide an improved ability to characterize storm cloud patterns and detect features such as emerging eyes. For example, Fig. SB4.3 shows the sharp contrast of the warm eye and cold eyewall in Hurricane Irma. This information translates into more confident DT/ADT intensity estimate analyses, which can be used in conjunction with data from the GOES-R series Geostationary Lightning Mapper (GLM) instrument. The GLM on GOES-16 is the first operational lightning mapper flown in geostationary orbit and maps total lightning (in-cloud and cloud-toground) continuously over the Americas and adjacent ocean regions. Data from GLM will inform forecasters about changes in lightning activity in the eyewall and rain bands of hurricanes, which can be used as an indicator of intensity changes, especially rapid intensification (DeMaria 2012; Xu and Wang 2018; Stevenson et al. 2018). Improved hurricane intensity analyses from the GOES-R series should result in better intensity forecasts and also benefit the fidelity of the climate record. 


\section{SIDEBAR 4.3: HURRICANE HARVEY: THE HALLMARK STORM OF A BUSY AND WET 2017 HURRICANE SEASON FOR THE UNITED STATES-D. M. ROTH AND J. W. NIELSEN-GAMMON}

The 2017 tropical cyclone season was busy for the United States, with nine Atlantic, Caribbean, and Gulf of Mexico systems affecting the nation. Harvey, originally a tropical storm over the western tropical Atlantic and eastern Caribbean Sea, traversed the Yucatán Peninsula, then redeveloped in the Bay of Campeche. It made landfall on the evening of 25 August five miles east of Rockport, as the first category 4 or stronger storm to make landfall in Texas since Carla in 1961. Its 3-m storm surge resulted in 15000 homes destroyed and another 25000 damaged. Remarkably, there were no deaths caused by storm surge or wind damage during landfall (Blake and Zelinsky 2018), perhaps attributable to $\mathrm{NHC}$ issuance of storm surge watches and warnings made operational in early 2017.

Harvey's impact, and memory of the storm, however, will be associated with its historic inland rainfall and associated flooding. It is the wettest known tropical cyclone to impact the United States, on a number of time and spatial scales.

After landfall, positioned near a col in the steering flow, Harvey's forward motion slowed to a virtual halt about $100 \mathrm{~km}$ inland. Harvey quickly weakened to tropical storm strength but maintained this status over land. It eventually moved southeast, moving out over the Gulf of Mexico during the morning of 28 August. Still a tropical storm, Harvey curved northeastward and made another landfall in southwest Louisiana early on 30 August. The storm then accelerated northeastward and weakened as it neared the Ohio River Valley.

At the station scale, daily rainfall totals exceeding $254 \mathrm{~mm}$ occurred on five successive days as the storm wandered across the area. The highest Harvey storm total precipitation presently recognized by the National Weather Service is $1538.7 \mathrm{~mm}$ at an automated gauge one mile southwest of Nederland, Texas. This far exceeds the previous known tropical cyclone record of $1320.8 \mathrm{~mm}$. For the same gauge, the three-day total of $1338.1 \mathrm{~mm}$ appears to exceed any previously measured U.S. value for any type of event. Rainfall at Jack Brooks Regional Airport near Nederland shattered records for wettest day ( $661 \mathrm{~mm}$ vs. $324 \mathrm{~mm})$, August (1390 mm vs. $438 \mathrm{~mm}$ ), month (1390 mm vs. $578 \mathrm{~mm}$ ), and summer (1814 mm vs. $804 \mathrm{~mm}$ ). Houston Intercontinental Airport recorded its wettest I-6 days, August, month, and year on record. Houston's monthly total doubled the previous record associated with Tropical Storm Allison in June 200I.

Area-averaged totals appear to far exceed any previously measured in the United States. The

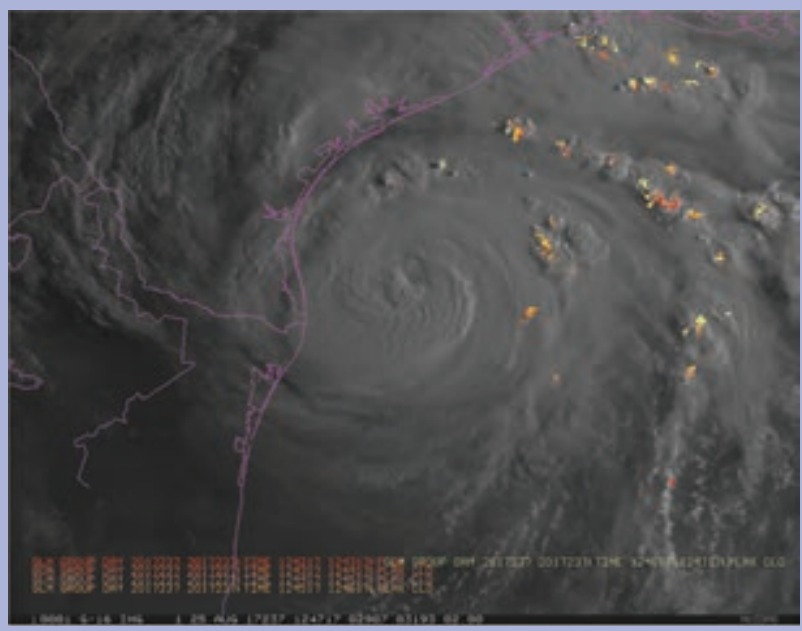

FIG. SB4.4. GOES-I6 ABI Band I $(0.47 \mu \mathrm{m})$ and colorcoded GLM parallax-corrected observations of lightning groups in the $\mathbf{5}$ minutes prior to the nominal time of the ABI image (red: oldest; yellow: latest), 1247 UTC on 25 Aug 2017, just prior to the rapid intensification of Hurricane Harvey.

average of $838 \mathrm{~mm}$ falling across Harris County-roughly two-thirds its typical annual rainfall—represents over a trillion gallons of water.

Several factors contributed to Harvey's extensive rainfall footprint and extreme volume across southeast Texas. It spent nearly 60 hours inland at tropical storm or greater intensity, the longest such duration over Texas. The cyclone moved slowly, with a continuous fetch of warm, humid Gulf air. It was large in size, based on its radius of tropical storm force winds and radius of outermost closed isobar (ROCl). During its overland time in

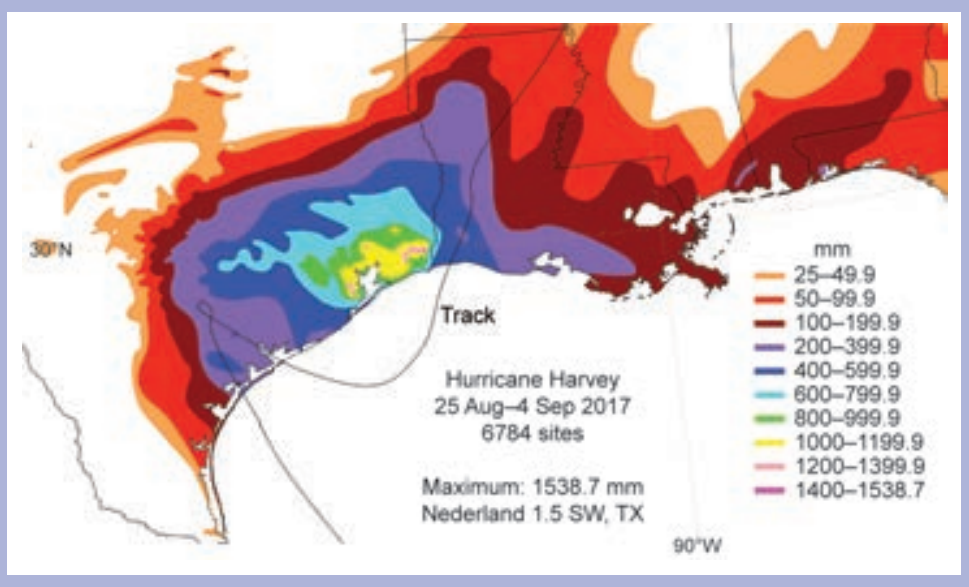

FIG. SB4.5. Observed rainfall totals in association with Harvey and its remnants. (Source: Weather Prediction Center, NOAA.) 
Texas, it interacted with a weak frontal boundary that provided some additional focus for convection (Blake and Zelinsky 2018). Additionally, the area of heaviest rain pivoted from the storm's northeast to northwest quadrants prior to its landfall in Louisiana, generally keeping the storm's heaviest rains over southeast Texas during that time.

The magnitude of its rainfall was captured well by numerical weather prediction guidance. NOAA's Weather Prediction Center forecasts indicated $600+\mathrm{mm}$ areal average amounts by 24 August, and areal average amounts of $1000+\mathrm{mm}$ by 25 August.

The annual exceedance, or recurrence interval, for rainfall of this magnitude in southeast Texas was less than $0.1 \%$ in any given year (per the current NOAA Atlas 14), or less frequent than once in 1000 years. Harvey's rainfall totals have been included in the preliminary version of NOAA Atlas 14 Version II for Texas (2018, manuscript under review).

Several studies have already examined Harvey's rainfall in the context of climate change. For example, van Oldenborgh et al. (2017) found that trends in three-day rainfall totals along the north-

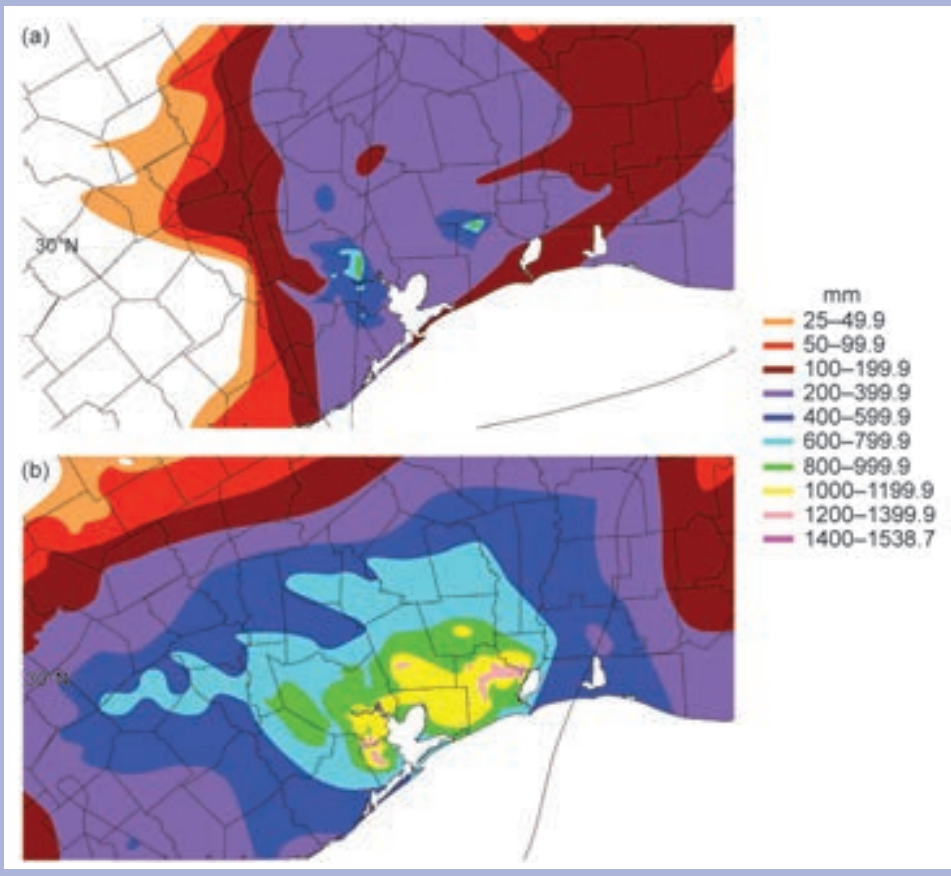

FIG. SB4.6. Tropical Storm Allison (200I) versus Hurricane Harvey (2017) rainfall $(\mathrm{mm})$ in southeast Texas (images use the same color scale).

ern Gulf Coast accounted for an increased chance of Harveylike rainfall occurring within the region in any given year, from roughly I in 27000 to I in 9000 , with similar trends found in forced climate simulations.

For portions of southeast Texas, Harvey became the flood of record. Lake Conroe exceeded its previous record maximum lake level, set in October 1994, by $18.3 \mathrm{~cm}$. Major and record flooding occurred in the bayous of Houston and along rivers from the Colorado to the Sabine. The entire town of Port Arthur was submerged.

Prior to Harvey, water crossing between the basins of the Sabine/Calcasieu Rivers, the Neches/Sabine Rivers, and, more unusually, between those of the San Bernard and Colorado Rivers had been observed. However, the magnitude and duration of basin crossovers during Harvey is unique in hydrologic records.

West of Houston, two flood control reservoirs, normally dry, rapidly filled. Many residents discovered their homes were built within a reservoir footprint, though beyond the reservoir's 100 -year floodplain. Reservoir operators faced a difficult challenge: flooding was unavoidable, but the release rates from the reservoirs would determine how much flooding would occur within, versus below, the reservoirs. Retaining

too much water within the reservoirs would also increase the risk of uncontrolled releases or even dam failure (Brust 2017).

The unprecedented flooding presented numerous challenges for disaster response. At Houston, familiar with localized flooding, the simultaneous inundation of watersheds throughout the metropolitan area exhausted the capacity of first responders to conduct water rescues. Public officials called on the public to help with evacuation. Hundreds responded with boats, jet skis, and even monster trucks (Sullivan 2017; Collier 2017). Rising floodwaters caused primary and backup water supply systems in Beaumont to fail. Several months later, some residents of southeast Texas were still required to boil water for drinking (Gstalter 2017). Aid for Beaumont, virtually inaccessible by land from Texas, arrived from Louisiana.

Of the 68 fatalities directly caused by Harvey, 65 were due to freshwater flooding. About 35 additional deaths are indirectly attributable to Harvey. An estimated 300000 structures were flooded, nearly half of those in Harris County. Up to 500000 vehicles were also flooded. Total direct damages from Harvey are estimated by NOAA at approximately $\$ 125$ billion U.S. dollars, making Harvey the second-costliest United States tropical cyclone in inflation-adjusted dollars, behind Hurricane Katrina (Blake and Zelinsky 2018). 
5. THE ARCTIC-J. Richter-Menge, M. 0. Jeffries, and E. Osborne, Eds.

a. Introduction-E. Osborne, J. Richter-Menge, and M. 0. Jeffries Annual average Arctic air temperatures (above $60^{\circ} \mathrm{N}$ ) in 2017 continued to increase at twice the rate of the rest of the world, with the annual average surface air temperature second highest (2016 ranked first) since the year 1900. Extreme warm conditions were particularly prevalent in Alaska at the end of 2017 when the atmospheric circulation drove warm southern air masses into the Pacific Arctic region.

The same wind pattern, along with high sea surface temperatures, slowed the southward advance of the sea ice edge, leading to a month-long delay in autumn freeze up in the Chukchi Sea and Bering Strait regions of the Pacific Arctic, setting another new record for the satellite era (1978-present). Earlier in the year, on 7 March, the Arctic sea ice winter maximum extent measured by satellite was the lowest on record (since 1979), covering $8 \%$ less area than the 1981-2010 mean. The 2017 sea ice minimum on 13 September was the eighth lowest on record and covered 25\% less area than the long-term mean. Ten of the lowest September sea ice minimum extents have been recorded in the last eleven years. Continued loss of thick multiyear ice (evidenced by $<1 \%$ multiyear ice present in March 2017 relative to $16 \%$ in 1985) also contributes a positive feedback to ice loss, as the majority of today's sea ice is thin first-year ice prone to breakup and melt.

As summer sea ice extents continue to shrink back, seasonal buildup of upper ocean heat in ice-free regions is increasing. In August 2017, sea surface temperature (SST) records were broken for the Chukchi Sea, with some regions as warm as $+11^{\circ} \mathrm{C}$, or $3^{\circ}$ to $4^{\circ} \mathrm{C}$ warmer than the long-term mean (1982-present). Most other boundary regions and marginal seas, which are typically ice free during summer months, also had anomalously warm SSTs in 2017. As in winter 2016/17, the delayed freeze up in the Pacific Arctic in late 2017 extended the exposure of the upper ocean in the Chukchi Sea to the sun's heat. Mean SSTs from 1982-present show statistically significant warming trends over much of the Arctic.

After a rapid start to the Greenland ice sheet melt season in early April, moderate to below-average melt persisted for much of the remainder of the season. As a result, summertime area-averaged albedo for the entire Greenland ice sheet was the third highest value since 2000. Glaciers and ice caps outside of Greenland continue to show declining trends in cumulative mass balance. Long-term terrestrial snow cover estimates show dramatic declines in the
Arctic since 2005. In 2017, snow cover extent was again below the 1981-2010 average across the North American Arctic, driven by earlier snow melt across the Canadian Arctic.

Terrestrial permafrost, a critical component of the Arctic landscape, supports much of the built infrastructure in the region (e.g., buildings, highways, airstrips, pipelines) and continues to experience notable change. Climate variables, such as atmospheric temperature, rain events, and snow depths, are driving higher permafrost temperature and increasing active layer thickness (surface soil layer that thaws and refreezes seasonally). In 2017, five of six permafrost observatories on the North Slope of Alaska reported record warm permafrost temperatures. In the same region, tundra greening, or an increase in above-ground vegetation, has been linked to changes in the permafrost active layer thickness, the warming Arctic climate, the extended growing season, and even reductions in sea ice cover. Over the 35-year observational time series, tundra greenness has increased throughout the majority of the circumpolar Arctic, most notably on the North Slope of Alaska, Canadian low Arctic tundra, and eastern Siberia. Another phenomenon, tundra browning, is emerging in the relatively sparse regions of western Alaska, the Canadian Archipelago high Arctic, and northwestern Siberia and may be attributed to winter warming events and perhaps even insect outbreaks. The Arctic tundra is also impacted by wildland fires, which are increasing as a result of warming climate conditions. While 2017 was an average wildfire season in Alaska (652 904 acres burned), significantly warmer and drier conditions in the Upper Yukon zone of northeast Alaska resulted in high fire danger for much of the season and accounted for more than half of the acres burned in the United States.

High above the Arctic, atmospheric ozone concentrations in winter 2016/17 were unremarkable and well above previous record minima in 2010/11 and 2015/16. UV radiation, which depends on atmospheric ozone concentrations and other factors, varied in time and space across the Arctic.

While observational time series are central to monitoring Arctic change, paleoclimate reconstructions based on fossil records can help scientists place the rates and magnitudes of modern change into a long-term, geological context. Arctic paleoceanographic records indicate that the magnitude and sustained rate of declining sea ice trend observed in the modern era is unprecedented in any existing high resolution paleoclimate sea ice reconstruction for at least the last 1450 years. Similarly, according 
to paleoclimate studies, today's abnormally warm Arctic air and sea surface temperatures have not been observed in the last 2000 years. Indigenous knowledge gathered by Arctic Peoples over many millennia is another means to holistically understand Arctic change beyond instrumental records. Coproduction of knowledge can bring together knowledge systems of scientists and indigenous knowledge-holders to develop suitable sustainability and adaptation practices to address issues arising from the changing Arctic system (see Sidebar 5.2).

b. Surface air temperature-J. Overland, E. Hanna, I. Hanssen-Bauer, S.-J. Kim, J. E. Walsh, M. Wang, U. S. Bhatt, and R. L. Thoman

Arctic surface air temperature is an indicator of both regional and global climate change. Although natural variability contributes to year-to-year and regional differences in air temperature, the magnitude of the long-term temperature trend across the entire Arctic is an indicator of global climate change and the impact of increasing greenhouse gas concentrations (Overland 2009; Notz and Stroeve 2016).

After a warm Arctic-wide autumn 2016, early 2017 had notable short-term, regional temperature anomalies in response to a highly variable jet stream. Spring and summer 2017 had near-average air temperatures relative to the 1981-2010 climatology. The spring and summer conditions were reminiscent of those occurring before the long-term, above-average temperature increases began in the 1990s. Rather than higher sea level pressure extending over much of the Arctic, as observed in many recent years, weak low pressures were seen in 2017-a return to a wind forcing typical from a decade ago. The atmospheric forcing in spring and summer 2017 is consistent with a year when some Arctic indicators ran counter to the recent long-term trend over the previous decade. For example, Eurasian spring snow extent was above average for the first time in over a decade (see Section 5i).

At $+1.6^{\circ} \mathrm{C}$, the mean annual 2017 surface air temperature (SAT) anomaly for land stations north of $60^{\circ} \mathrm{N}$ is the second highest value (after 2016) in the record starting in 1900 (Fig. 5.1). Despite near-average temperatures during spring and summer months, extreme heat during autumn and winter, particularly over the Chukchi Sea and extending northward to the pole, contributed to near-record breaking warm conditions in 2017 (Fig. 5.2). Currently, the Arctic is warming at more than twice the rate of lower latitudes.

The greater rate of Arctic temperature increase, compared to the global increase, is referred to as

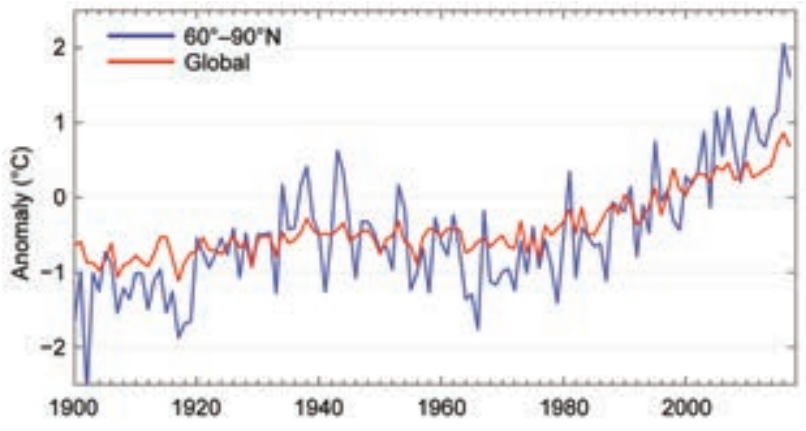

Fig. 5.I. Arctic (land stations north of $60^{\circ} \mathrm{N}$ ) and global mean annual land surface air temperature (SAT) anomalies ( ${ }^{\circ} \mathrm{C}, 198 \mathrm{I}-2010$ base period) for 1900-2017. Note that there were few stations in the Arctic, particularly in northern Canada, before 1940. (Source: CRUTEM4 dataset.)

Arctic amplification. Mechanisms for Arctic amplification include: reduced summer albedo due to losses of sea ice and snow cover; the increase of total water vapor content in the Arctic atmosphere; a summer decrease and winter increase in total cloudiness (Makshtas et al. 2011); the additional heat generated by newly sea ice-free ocean areas that are maintained later into the autumn (Serreze and Barry 2011); and the lower rate of heat loss to space in the Arctic,
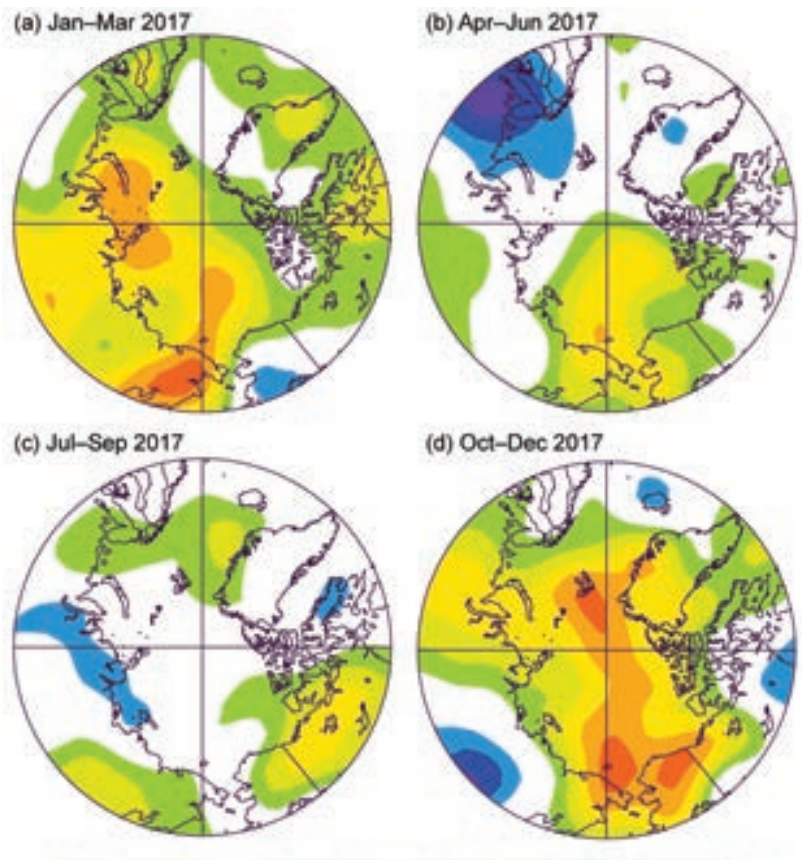

(d) Oct-Dec 2017

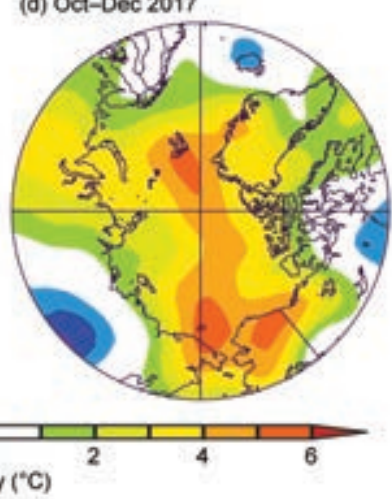

FIG. 5.2. Seasonal anomaly patterns for near-surface air temperatures $\left({ }^{\circ} \mathrm{C}, 1981-2010\right.$ base period) for 2017 in (a) JFM, (b) AMJ, (c) JAS, and (d) OND. Temperatures are from slightly above the surface layer $(925 \mathrm{mb})$ to emphasize large spatial patterns rather than local features. (Source: NOAA/ESRL.) 
relative to the subtropics, due to lower mean surface temperatures in the Arctic (Pithan and Mauritsen 2014). Recent reductions in air pollution in Europe are reducing the relative rate of Arctic warming due to decreased downward longwave radiation, countering other mechanisms that contribute to Arctic amplification (Acosta Navarro et al. 2016).

Seasonal air temperature variations in 2017 are divided into winter (January-March, JFM), spring (April-June, AMJ), summer (July-September, JAS), and autumn (October-December, OND; Fig. 5.2). These seasonal SAT divisions are chosen to coincide with the seasonal cycles of key Arctic variables. For example, the summer sea ice minimum occurs in September, and autumn cooling continues through December.

On a seasonal basis, winter was unremarkable in terms of major features (Fig. 5.2a). However, there were notable short-term, regional temperature anomalies in response to highly variable jet stream shapes. For instance, Iceland experienced a record high maximum temperature of $19.1^{\circ} \mathrm{C}$ in February, exceeding the previous February (1998) record of $18.1^{\circ} \mathrm{C}$ by a full degree (Trausti Jonsson, Icelandic Met Office, 2017, personal communication). March 2017 had major warmth across Siberia (Fig. 5.3) including eastern Asia.

Spring showed some positive temperature anomalies in the East Siberian Sea (Fig. 5.2b), a continuation

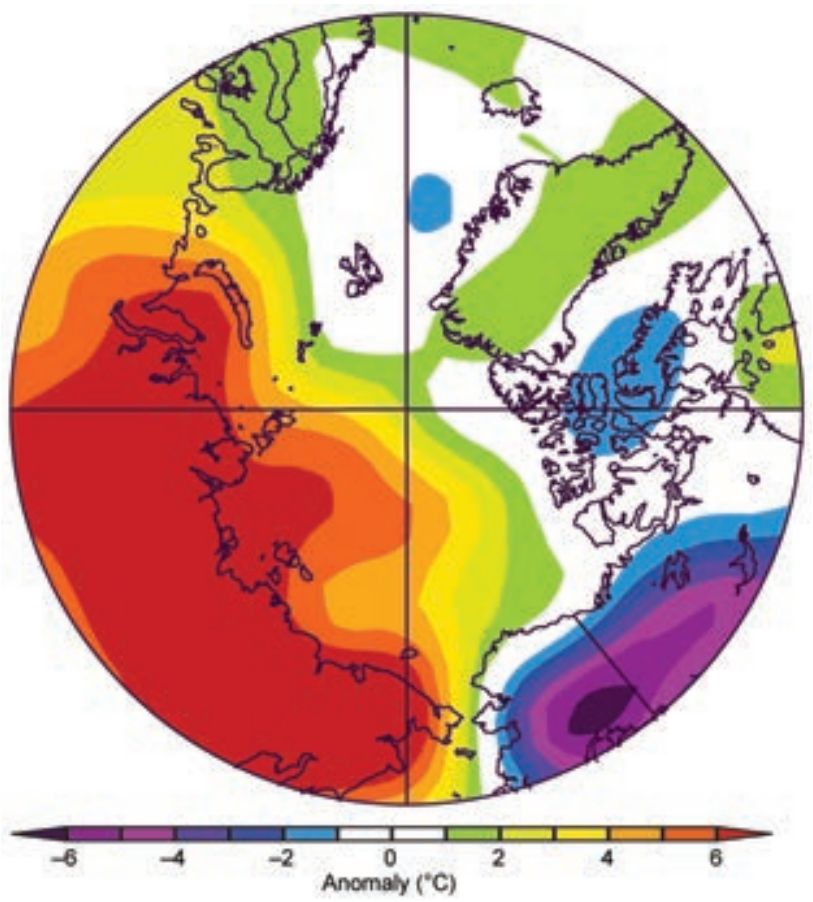

Fig. 5.3. Arctic Mar 2017 air temperature anomalies ( $\left.{ }^{\circ} \mathrm{C}\right)$. of a warm feature observed in March. This regional warming supported early sea ice loss in the Chukchi Sea (see Section 5d). May saw anomalous high pressure extend between Greenland and Norway, with relatively warm but unexceptional temperatures over Greenland.

Similar to summer 2016, neutral temperature anomalies occurred across the central Arctic in summer 2017 (Fig. 5.2c), in contrast to the warm conditions observed during much of the previous decade. The summer 2017 conditions did not support continued overall extreme summer sea ice loss (see Section 5d). Mean coastal Greenland temperatures were near climatological levels, in contrast to some summers in the recent decade.

Alaska/northwestern Canada was the only region with above-average summer surface air temperatures. Several locations in the interior of Alaska had the warmest calendar month of record in July. On a more local and short-term basis, many stations in the north and east of Iceland reported record high temperatures for September.

Summer sea level pressure was characterized by negative anomalies in the central Arctic (Fig. 5.4). This pattern prevented extra heat in the midlatitudes from penetrating into the central Arctic. Such added heat from outside the Arctic is associated with low sea ice summers (Parkinson and Comiso 2013). This sea level pressure pattern was accompanied by cloud

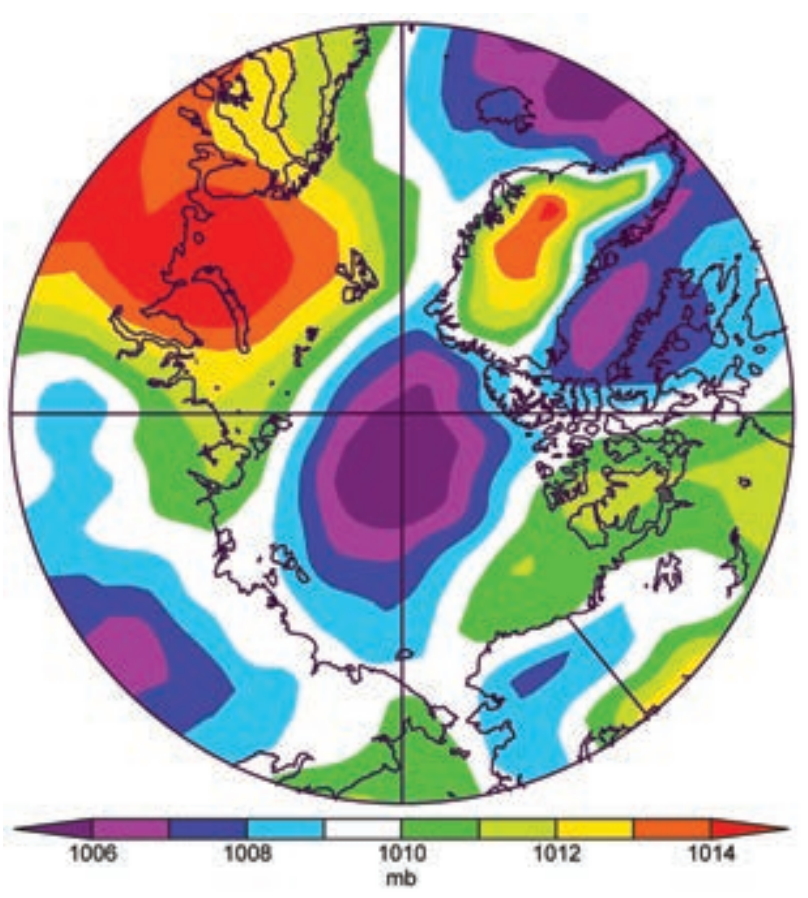

FIG. 5.4. Arctic mean sea level pressure field (hPa) for summer 2017. 
cover that limited the solar heating of the lower atmosphere in the central Arctic.

A broad swath of extreme warm temperature anomalies $\left(>+4^{\circ} \mathrm{C}\right)$ stretched across the central Arctic in autumn (Fig. 5.2d). The warmest temperature extremes, north of the Bering Strait and north of Svalbard, were due to heat stored in the upper Arctic Ocean (see Section 5c) and to advection of warm air from the south (generated from the Pacific and Atlantic Oceans).

December 2017 had extreme warm temperatures in Alaska and cold temperatures in the central and eastern U.S., with incidences of snow as far south as Mississippi (Fig. 5.5a). This temperature pattern is associated with large north-south meanders of the tropospheric jet stream (Fig. 5.5b). Because the extratropical mid-troposphere wind direction approximately follows the contour direction of geopotential heights, Fig. 5.5b shows warm winds from the southwest extending into Alaska and cold air moving southeast from Canada in December. Warm air is less dense and supports rising geopotential heights. Thus,
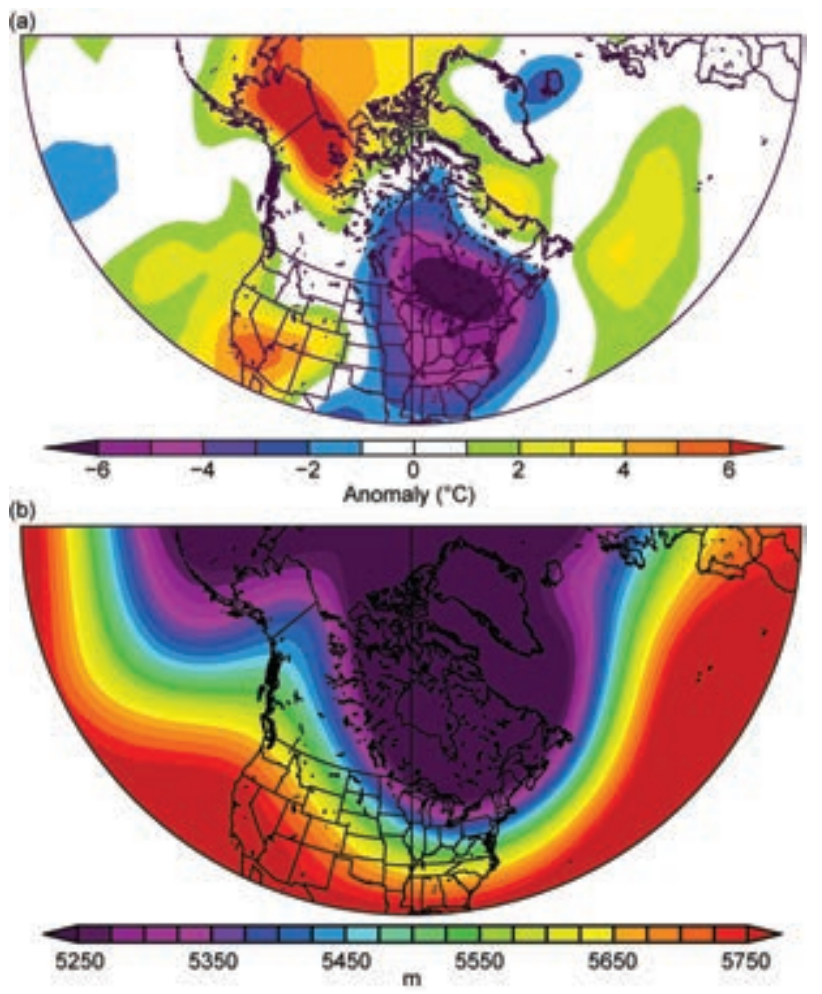

Fig. 5.5. Dec 2017 fields show the cause of warm temperatures in Alaska and simultaneous cold temperatures in the central and southern U.S. (a) 925-hPa air temperature anomalies $\left({ }^{\circ} \mathrm{C}\right.$ ) and (b) corresponding $\mathbf{5 0 0}-\mathrm{hPa}$ geopotential height field $(\mathrm{m})$, showing the strong wave tropospheric jet stream pattern extending north into Alaska and south into eastern North America. warm temperatures over Alaska can help maintain the persistence of this North American weather pattern. Contributing to the relatively warm temperatures in Alaska in autumn was the delayed freeze-up of sea ice in Alaskan waters. Freeze-up lasted well into December and set a new record for the satellite era beginning in 1978 (see Section 5d).

\section{Sea surface temperature-M.-L. Timmermans, C. Ladd, and K. Wood}

Summer sea surface temperatures (SST) in the Arctic Ocean are determined mainly by absorption of solar radiation into the surface layer. In the Barents and Chukchi Seas, there is an additional contribution from advection of warm water from the North Atlantic and North Pacific Oceans, respectively. Solar warming of the ocean surface layer is influenced by the distribution of sea ice (with more solar warming in ice-free regions), cloud cover, water color, and upper-ocean stratification. River influxes influence the latter two, as well as provide an additional source of warm water. SSTs are an essential indicator of the role of the ice-albedo feedback mechanism in any given melt season; as the area of sea ice cover decreases, more incoming solar radiation is absorbed by the ocean and the warmer ocean in turn melts more sea ice.

SST data presented here are from the NOAA Optimum Interpolation (OI) SST Version 2 product (OISSTv2), which is a blend of in situ and satellite measurements (Reynolds et al. 2002, 2007). Compared to in situ temperature measurements, the OISSTv2 product showed average correlations of about $80 \%$, with an overall cold SST bias of $-0.02^{\circ} \mathrm{C}$ (Stroh et al. 2015).

August SSTs provide the most appropriate representation of Arctic Ocean summer SSTs because they are not affected by the cooling and subsequent sea ice growth that typically takes place in the latter half of September. Mean SSTs in August 2017 in ice-free regions ranged from $\sim 0^{\circ} \mathrm{C}$ in some regions to as high as $11^{\circ} \mathrm{C}$ in the Chukchi and Barents Seas (Fig. 5.6a). Compared to the 1982-2010 August mean (note the monthly SST record begins in December 1981), most boundary regions and marginal seas had anomalously high SSTs in August 2017 (Fig. 5.6b). Particularly high anomalies (around $3^{\circ}-4^{\circ} \mathrm{C}$ above the 1982-2010 average) were observed in the Beaufort, Chukchi, and southern Barents Seas. SSTs in the boundary regions and marginal seas, which are mostly ice free in August, are linked to the timing of local sea ice retreat, which facilitates the direct solar heating of the exposed surface waters. 

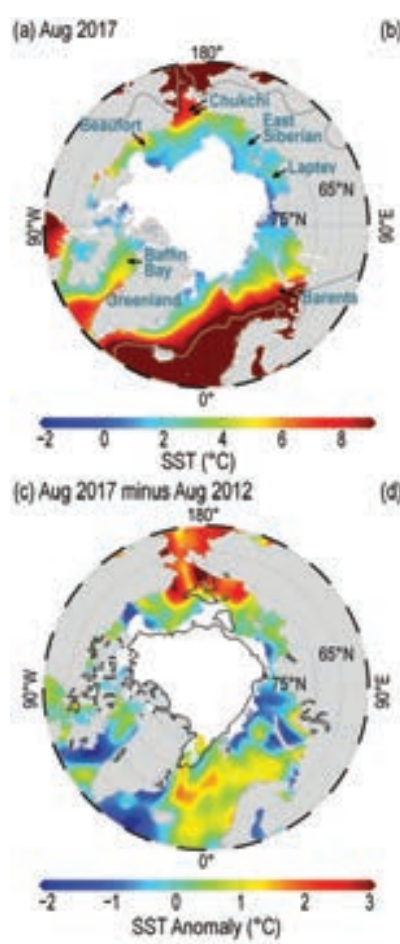

(ब) Linear Trend 1982-2017

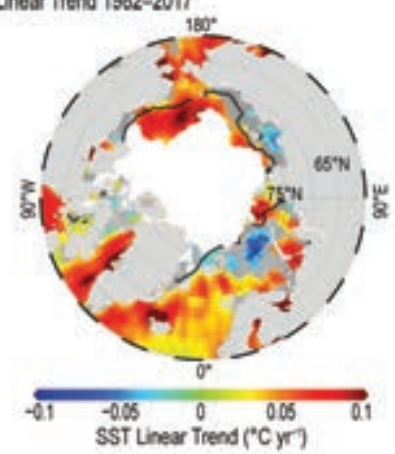

FIG. 5.6. (a) Mean SST $\left({ }^{\circ} \mathrm{C}\right.$ ) in Aug 2017. White shading is the Aug 2017 mean sea ice extent (shown in each panel) and gray contours indicate the $10^{\circ} \mathrm{C} \mathrm{SST}$ isotherm. (b) SST anomalies ( ${ }^{\circ} \mathrm{C}$ ) in Aug 2017 relative to the Aug 1982-2010 mean (dotted black contour indicates zero anomaly). Black line indicates the median ice edge for Aug 1982-2010. (c) SST anomalies ( ${ }^{\circ} \mathrm{C}$ ) in Aug 2017 relative to Aug 2012. Black line indicates the median ice edge for Aug 2012. (d) Linear SST trend

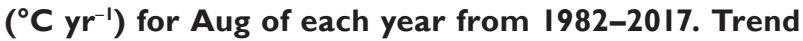
is only shown for values that are significant at the $\mathbf{9 5 \%}$ confidence interval; the region is gray otherwise. Black line indicates the median ice edge for Aug 1982-20I0. (Sources: SST data are from the NOAA OISSTr2; sea ice extent and ice-edge data are from NSIDC Sea Ice Index, Version 3, Fetterer et al. 2017.)

In August, regions off the west and east coasts of Greenland and in the southern Barents Sea were markedly cooler (by up to $3^{\circ} \mathrm{C}$ ) than in August 2016 (see Timmermans 2017). It is notable also that compared to August 2012 (the summer of lowest minimum sea ice extent in the satellite record, 1979-present), August 2017 SSTs in the Chukchi Sea region were up to $3^{\circ} \mathrm{C}$ higher (Fig. 5.6c). This illustrates the significant interannual and spatial variability in summer SSTs. Cooler SSTs in August 2012 (compared to August 2017) in the Chukchi Sea were related to the persistence of sea ice in that particular region (even while the main ice pack retreated) and a strong cyclonic storm in the region that brought cool conditions late in the summer season (see Timmermans et al. 2013).

Mean August SSTs from 1982 to 2017 show statistically significant linear warming trends over much of the Arctic Ocean (Fig. 5.6d); the cooling trends in the Laptev and northern Barents Seas are notable exceptions. Warming trends coincide with declining trends in summer sea ice extent (including late-season freeze-up and early melt, e.g., Parkinson 2014; see section 5d), increased solar absorption (e.g., Pinker et al. 2014), release of stored ocean heat (e.g., Timmermans 2015), and milder air temperatures (see Section 5b). Mean August SSTs for the entire Chukchi Sea region exhibit a statistically significant warming trend of about $+0.7^{\circ} \mathrm{C}$ decade ${ }^{-1}$, based on a linear fit.

\section{d. Sea ice cover-D. Perovich, W. Meier, M. Tschudi, S. Farrell, S. Hendricks, S. Gerland, C. Haas, T. Krumpen, C. Polashenski, R. Ricker, and M. Webster \\ I) SEA ICE EXTENT}

Arctic sea ice (1) acts as a barrier between the underlying ocean and the atmosphere, (2) limits the amount of absorbed solar energy due to its high albedo, (3) provides a habitat for biological activity, and (4) limits human access to the Arctic Ocean and adjacent seas. The extent of the Arctic sea ice cover varies substantially over the course of a year, with the end-of-winter ice cover generally two to three times as large as at the end of summer. The months of March and September are of particular interest because they are the months when the sea ice typically reaches its maximum and minimum extents, respectively. Figure 5.7 shows the monthly average Arctic sea ice extents in March 2017 and September 2017, measured by satellite-based passive microwave instruments.

Sea ice extent is the total area covered by at least $15 \%$ concentration of sea ice. Based on data from the
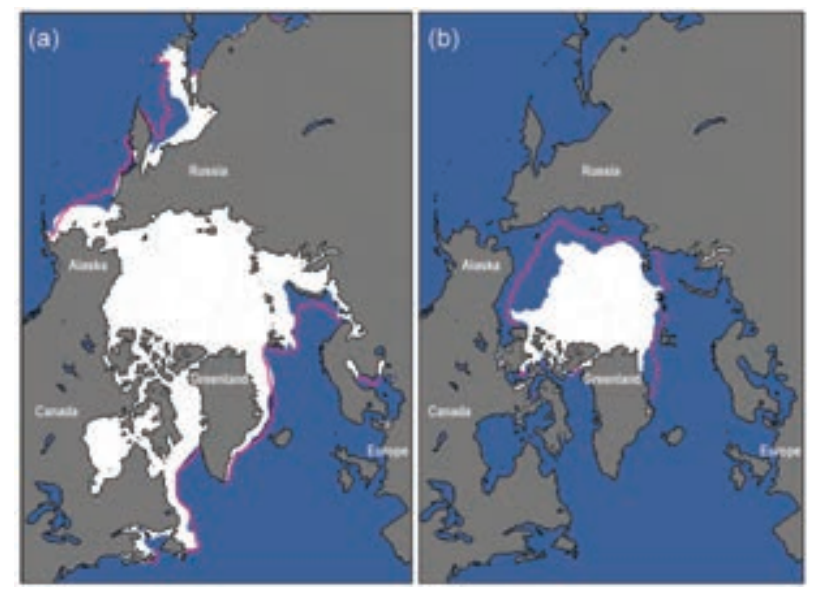

FIG. 5.7. Average monthly sea ice extent in (a) Mar (left) and (b) Sep (right) 2017 illustrate the respective winter maximum and summer minimum extents. The magenta line indicates the median ice extents in Mar and Sep, respectively, for the period 198I-2010. Maps are from NSIDC at https://nsidc.org/data/seaice_index (Fetterer et al. 2017). 
National Snow and Ice Data Center (NSIDC) sea ice index (Fetterer et al. 2017), the sea ice cover reached a maximum extent of 14.42 million $\mathrm{km}^{2}$ on 7 March, which was $8 \%$ below the 1981-2010 average. This is the lowest maximum value ever observed in the satellite record.

On 13 September, the sea ice extent reached a summer minimum value of 4.64 million $\mathrm{km}^{2}$. This is the eighth lowest extent in the satellite record. While the 2017 minimum extent represents a modest increase from the 2016 minimum, it was $25 \%$ less than the 1981-2010 average minimum ice extent. The 10 lowest September extents have occurred in the last 11 years (Parkinson and DiGirolamo 2016).

In 2017, sea ice extent showed decreasing trends in all months and virtually all regions, except for the Bering Sea during winter (Meier et al. 2014). The September (typical Arctic sea ice minimum) monthly average trend for the entire Arctic Ocean is now $-13.2 \%$ decade $^{-1}$ relative to the $1981-2010$ average (Fig. 5.8). Trends are smaller during March (typical Arctic sea ice maximum), at $-2.7 \%$ decade $^{-1}$, but the decrease is statistically significant. Both the September and March trends are significant at the 99\% confidence level.

Freeze-up in the Chukchi Sea was extremely slow, and the sea ice extent in the region at the beginning of December 2017 was the lowest in the satellite record. It was not until the end of December that the region was substantially frozen over, a month later than normal. Upper ocean heat accumulated during the summer, through the absorption of solar radiation, likely slowed ice growth in the Chukchi

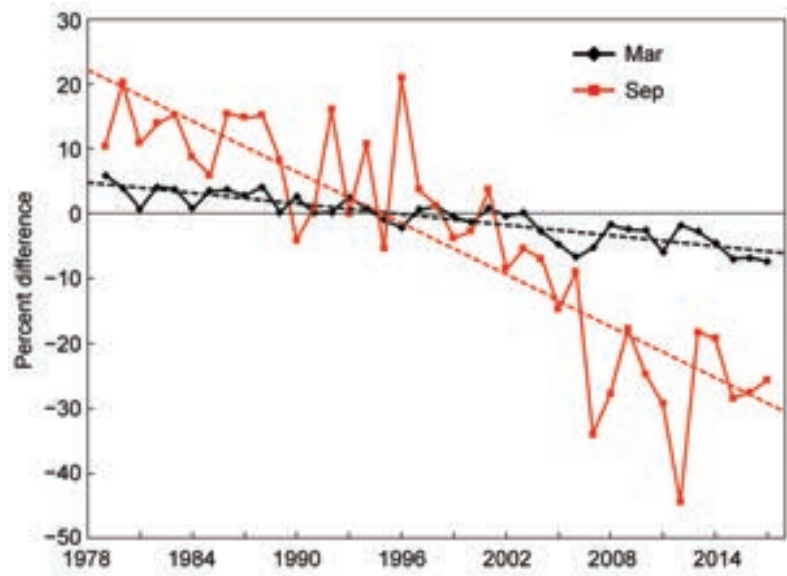

FIG. 5.8. Time series of sea ice extent anomalies (\%) in Mar (the month of maximum ice extent) and Sep (the month of minimum ice extent). Anomaly value for each year is the percent difference in ice extent relative to the 198I-2010 mean. The black and red dashed lines are least squares linear regression lines. region (see Section 5c). Anomalous southerly winds during October-December also played a significant role by advecting warm air and ocean waters into the region through the Bering Strait (see Section 5b) and preventing southward advancement of the ice edge.

\section{2) Age OF THE ICE}

The age of sea ice is another key descriptor of the state of the sea ice cover. Compared to younger ice, older ice tends to be thicker, stronger, and more resilient to changes in atmospheric and oceanic forcing (i.e., changes in atmospheric circulation patterns and ocean heat). The age of the ice is measured using satellite observations and drifting buoy records to track ice parcels over several years (Tschudi et al. 2010; Maslanik et al. 2011). This method has been used to provide a record of the age of the ice since 1985 (Tschudi et al. 2015, 2016).

Very old ice ( $>4$ years old) continues to be a diminishingly small fraction of the Arctic ice pack in March (Fig. 5.9). The extent of the oldest ice has declined from 2.54 million $\mathrm{km}^{2}$ in March 1985 (representing $16 \%$ of the total ice pack) to 0.13 million $\mathrm{km}^{2}$ in March 2017 ( $0.9 \%$ of the total ice pack). The distribution of ice age in March 2017 was similar to that of March 2016, although there was a decrease in the fractional coverage of the oldest ice, from 1.2\% in March 2016 to $0.9 \%$ in March 2017. First-year ice dominates the winter sea ice cover, comprising $79 \%$ of the ice cover

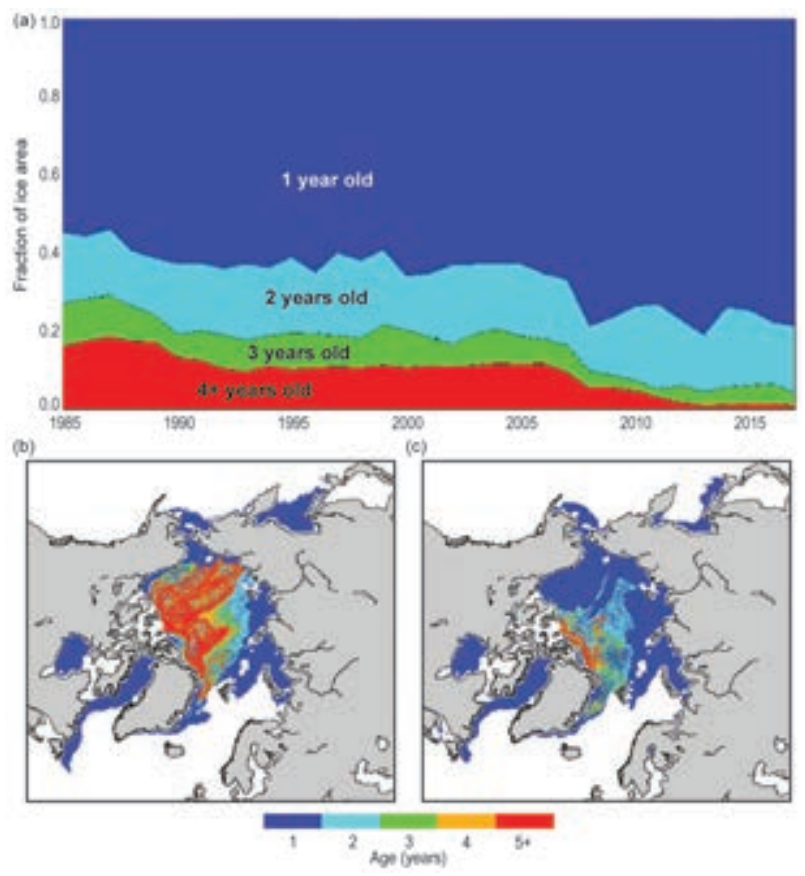

FIG. 5.9. (a) Arctic sea ice age coverage by year, expressed as the fraction of the total ice area, 1985-2017. Sea ice age coverage maps for (b) Mar 1985 and (c) Mar 2017. 
in March 2017, compared to $55 \%$ in the 1980s. The thinner, younger ice is more mobile and susceptible to mechanical wind forcing, and it is vulnerable to complete melting in the summer and contributes to the observed decrease in summer sea ice extents by enabling more heat to be absorbed by the upper ocean.

\section{3) Sea ICE THICKNESS AND SNOW DEPTH}

Satellite remote sensing and regular airborne survey programs continued to record changes in Arctic sea ice thickness and volume. These survey programs derive ice thickness and volume by observing the freeboard of the ice cover, which is the distance between the surface of the ocean and the top of the ice. During this past year the ESA CryoSat-2 radar altimeter mission completed its seventh year of operation, providing sea ice thickness estimates between October and April (Laxon et al. 2013). The CryoSat-2 freeboard measurements expand the data record of satellite and submarine-based observations that document the decline in sea ice thickness since 1958 (Kwok and Rothrock 2009; Lindsay and Schweiger 2015).

In spring 2017, CryoSat-2 products from the Alfred Wegener Institute indicated a spatially variable pattern of ice thickness (Fig. 5.10a), which is typical. The April 2017 thickness anomaly, compared to the period 2011-16 (Fig. 5.10b), shows below-average thicknesses in the multiyear ice region north of the Queen Elizabeth Islands of the Canadian Arctic Archipelago, the Chukchi Sea, and the shelf regions of the East Siberian Sea. Above-average thicknesses were observed in the Beaufort Sea and the eastern part of the central Arctic Ocean.

Sea ice volume estimates were generated from Cryosat-2 observations for 2011-17 for the months of October through April. Results for the central Arctic Ocean show a decline from 2011 to 2013, an increase in 2014, followed by a steady decline from 2014 to 2017. The April 2017 sea ice volume (13.19 $\pm 1.15 \times$ $\left.10^{3} \mathrm{~km}^{3}\right)$ ranks as the third lowest spring volume after April $2012\left(13.14 \pm 1.27 \times 10^{3} \mathrm{~km}^{3}\right)$ and $2013(12.56 \pm$ $\left.1.21 \times 10^{3} \mathrm{~km}^{3}\right)$ in the CryoSat-2 data record (2011-17). The difference between the three lowest volume estimates lies within the observational uncertainties of the instrument. For more information regarding instrument uncertainty see Ricker et al. (2014).

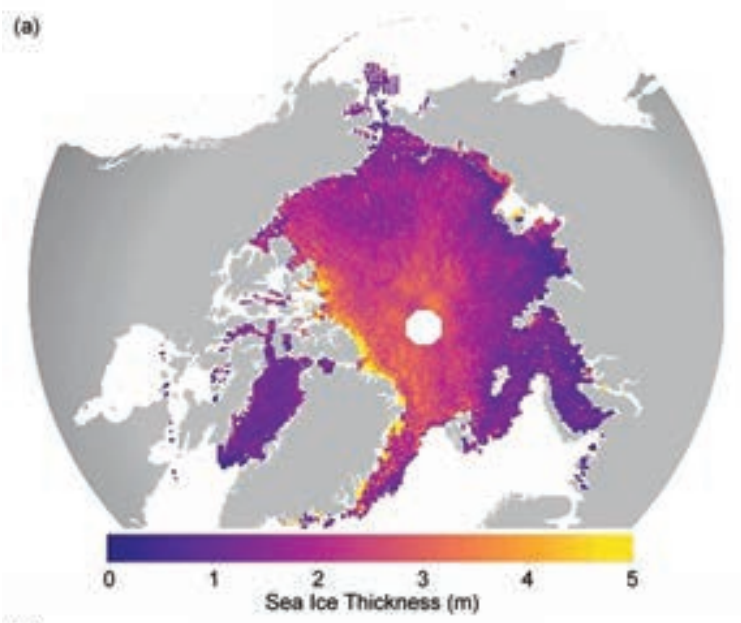

(b)

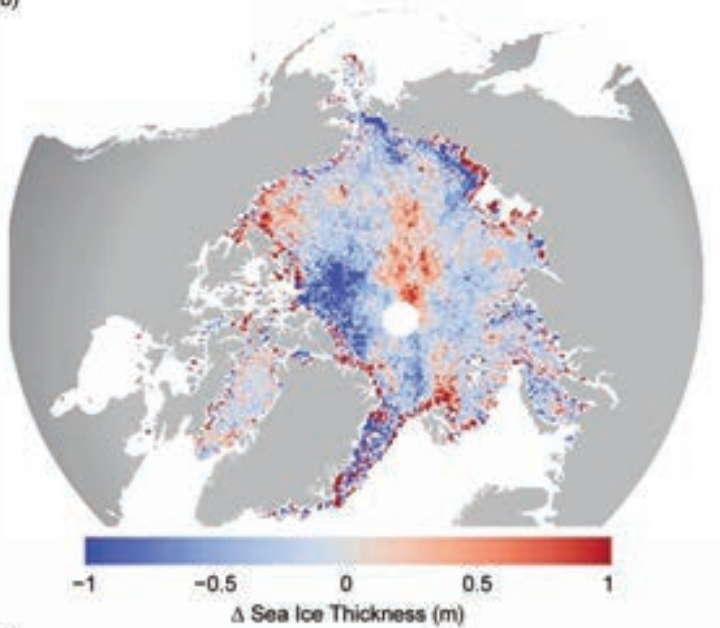

(c)

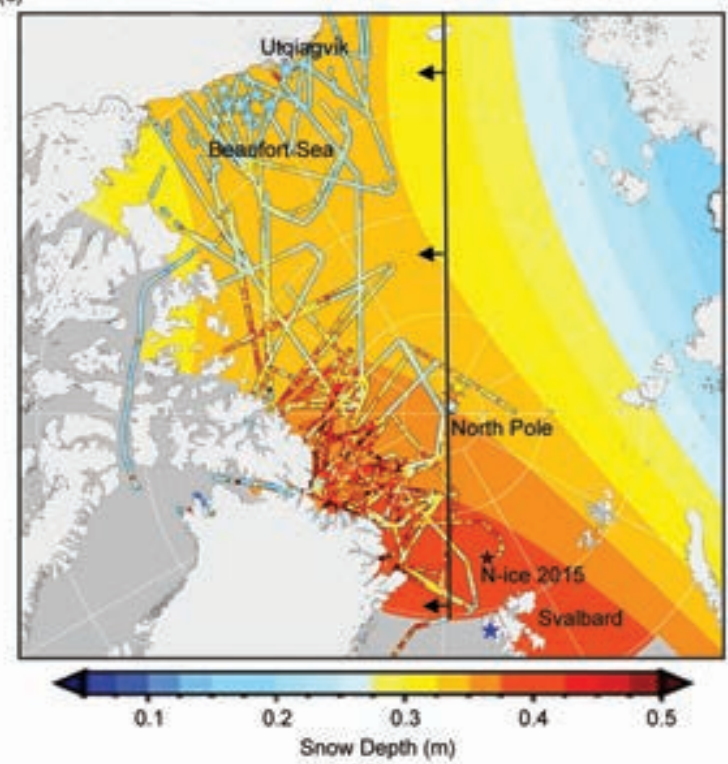

Fig. 5.10. Apr 2017 (a) sea ice thickness (m) derived from CryoSat-2 radar altimeter data and (b) sea ice thickness anomaly (m; base period 20Il-16). (c) Snow depth (m) on Arctic sea ice at the end of winter, prior to melt onset; recent in situ measurements (stars), made in 2015 and 2017, and airborne observations (multiple airborne survey lines), made in Mar and May in 2009-12 and 2014-15, are overlaid on the long term mean snow depth for the months of Mar and Apr (adapted from Warren et al. 1999). Black line and arrows in (c) designate the western Arctic. 


\title{
SIDEBAR 5.I: PALEOCLIMATE RECORDS: PROVIDING CONTEXT AND UNDERSTANDING OF CURRENT ARCTIC CHANGE-
}

\author{
E. OSBORNE, T. CRONIN, AND J. FARMER
}

At present, the Arctic Ocean is experiencing changes in ocean surface temperature and sea ice extent that are unprecedented in the era of satellite observations, which extend from the 1980s to the present (see Sections 5c,d). To provide context for current changes, scientists turn to paleoclimate records to document and study anthropogenic influence and natural decadal and multidecadal climate variability in the Arctic system. Paleoceanographic records extend limited Arctic instrumental measurements back in time and are central to improving our understanding of climate dynamics and the predictive capability of climate models. By comparing paleoceanographic records with modern observations, scientists can place the rates and magnitudes of modern Arctic change in the context of those inferred from the geological record.

Over geological time, paleoceanographic reconstructions using, for instance, marine sediment cores indicate that the Arctic has experienced huge sea ice fluctuations. These fluctuations range from nearly completely ice-free to totally ice-covered conditions. The appearance of ice- rafted debris and sea ice-dependent diatoms in Arctic marine sediments indicate that the first Arctic sea ice formed approximately 47 million years ago (St. John 2008; Stickley et al. 2009; Fig. SB5.I), coincident with an interval of declining atmospheric carbon dioxide $\left(\mathrm{CO}_{2}\right)$ concentration, global climate cooling, and expansion of Earth's cryosphere during the middle Eocene. The development of year-round (i.e., perennial) sea ice in the central Arctic Ocean, similar to conditions that exist today, is evident in sediment records as early as 14-18 million years ago (Darby 2008). These records suggest that transitions in sea ice cover occur over many millennia and often vary in concert with the waxing and waning of circum-Arctic land ice sheets, ice shelves, and long-term fluctuations in ocean and atmosphere temperatures and atmospheric $\mathrm{CO}_{2}$ concentrations (Stein et al. 2012; Jakobsson et al. 2014).

Over shorter time scales, shallow sediment records from Arctic Ocean continental shelves allow more detailed, higherresolution (hundreds of years resolution) reconstructions of sea ice history extending through the Holocene (II 700 years ago to present), the most recent interglacial period.

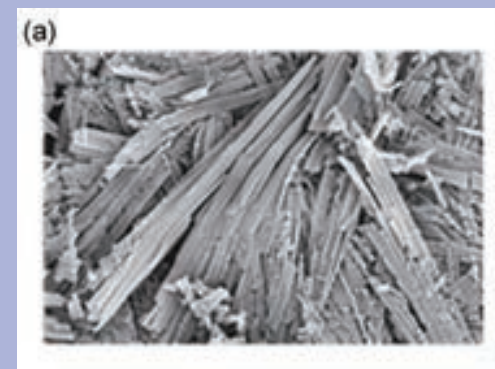

(b)

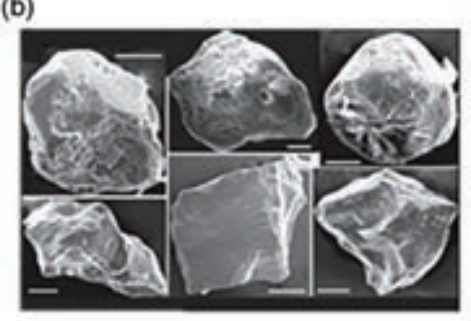

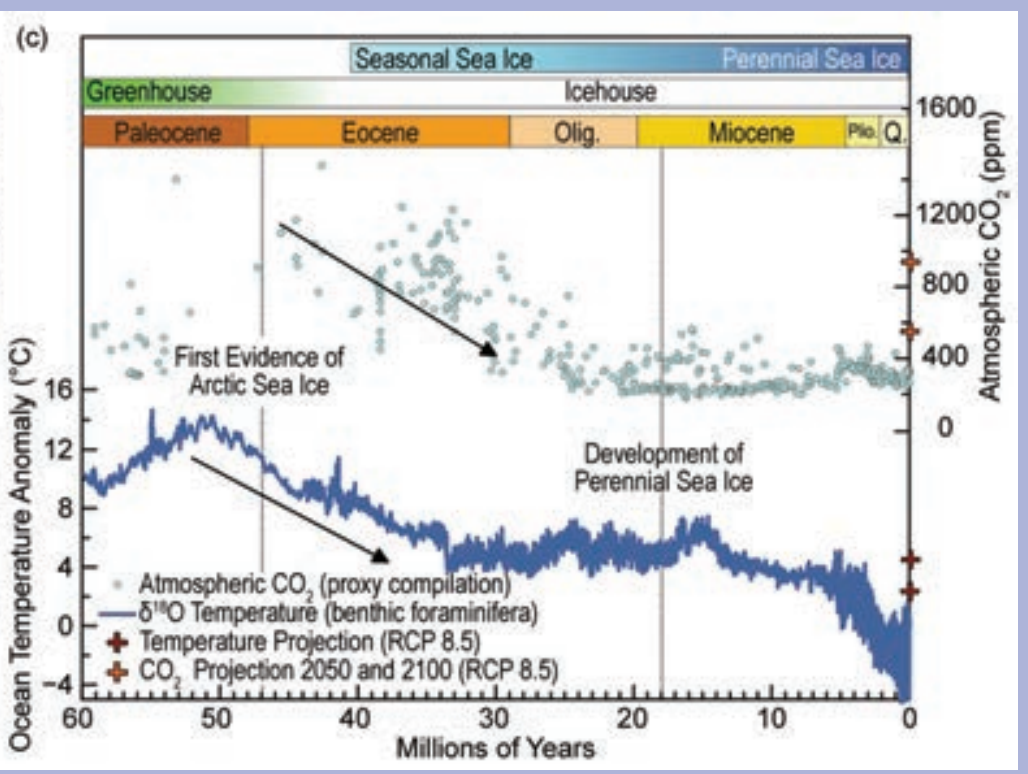

FIG. SB5.I. The oldest known paleoclimate evidence of sea ice in the Arctic are (a) fossilized remains of sea ice dwelling diatoms (Synedropsis spp.) and (b) ice rafted debris that date back to 47 million years ago (Stickley et al. 2009). (c) Global compilation of paleoclimate records indicates that cooling ocean temperatures $\left({ }^{\circ} \mathrm{C}\right)$ and declining atmospheric $\mathrm{CO}_{2}$ (ppm) coincide with major NH sea ice development (data: Beerling and Royer 20 I I; Zhang et al. 2013; Anagnostou et al. 2016). Global ocean temperature anomalies are determined by millions of stable oxygen isotopic measurements of fossilized calcite benthic foraminifera shells. Arrows indicate cooling temperature and declining $\mathrm{CO}_{2}$ concentrations through the greenhouse to icehouse transition. Red and orange "+" on the right $y$-axis indicate the CMIP5 multimodel mean projected temperature and atmospheric $\mathrm{CO}_{2}$, respectively, in the year 2050 and 2100. 
A notable feature of these records is an early Holocene sea ice minimum, corresponding to a thermal maximum (warm) period from II 000 to 5000 years ago, when the Arctic may have been warmer and had less summertime sea ice than today (Kaufman et al. 2004). However, it is not clear that the Arctic was ice-free at any point during the Holocene (Polyak et al. 2010). High-resolution paleo-sea ice records from the western Arctic in the Chukchi and East Siberian Seas indicate that sea ice concentrations increased through the Holocene in concert with decreasing summer solar insolation (sunlight). Sea ice extent in this region also varied in response to the volume of Pacific water delivered via the Bering Strait into the Arctic Basin (Stein et al. 2017; Polyak et al. 2016). Records from the Fram Strait (Müller et al. 2012), Laptev Sea (Hörner et al. 2016), and Canadian Arctic Archipelago (Vare et al. 2009) also indicate a similar long-term expansion of sea ice and suggest sea ice extent in these regions is modulated by the varying influx of warm Atlantic water into the Arctic Basin (e.g., Werner et al. 2013). Taken together, available records support a circumArctic sea ice expansion during the late Holocene.

A notably high-resolution summer sea ice history ( $<5$-year resolution) has been established for the last 1450 years using a network of terrestrial records (tree ring, lake sediment, and ice core records) located around the margins of the Arctic Ocean (Kinnard et al. 20II). Results summarized in Fig. SB5.2 indicate a pronounced decline in summer sea ice extent beginning in the 20 th century, with exceptionally low ice extent recorded since the mid-1990s, consistent with the satellite record (see Section $5 d$ ). While several episodes of reduced and expanded sea ice extent occur in association with climate anomalies such as the Medieval Climate Warm Period (AD 800-1300) and the Little Ice Age (AD 1450-1850), the magnitude and pace of the modern decline in sea ice is outside of the range of natural variability and unprecedented in the I450-year reconstruction (Kinnard et al. 20II). A radiocarbon-dated driftwood record of the Ellesmere ice shelf in the Canadian High Arctic, the oldest landfast ice in the Northern Hemisphere, also demonstrates a substantial reduction in ice extents over the 20th century (England et al. 2017). A supporting sediment record indicates that inflowing Atlantic water in Fram Strait has warmed by $2^{\circ} \mathrm{C}$ since 1900 , driving break up and melt of sea ice (Spielhagen et al. 20II). Complementary mooring and satellite observations show the "Atlantification" of the eastern Arctic due to enhanced inflow of warm saline water through Fram Strait (Nilsen et al. 2016) and nutrient-rich Pacific water via the Bering has increased by more than $50 \%$

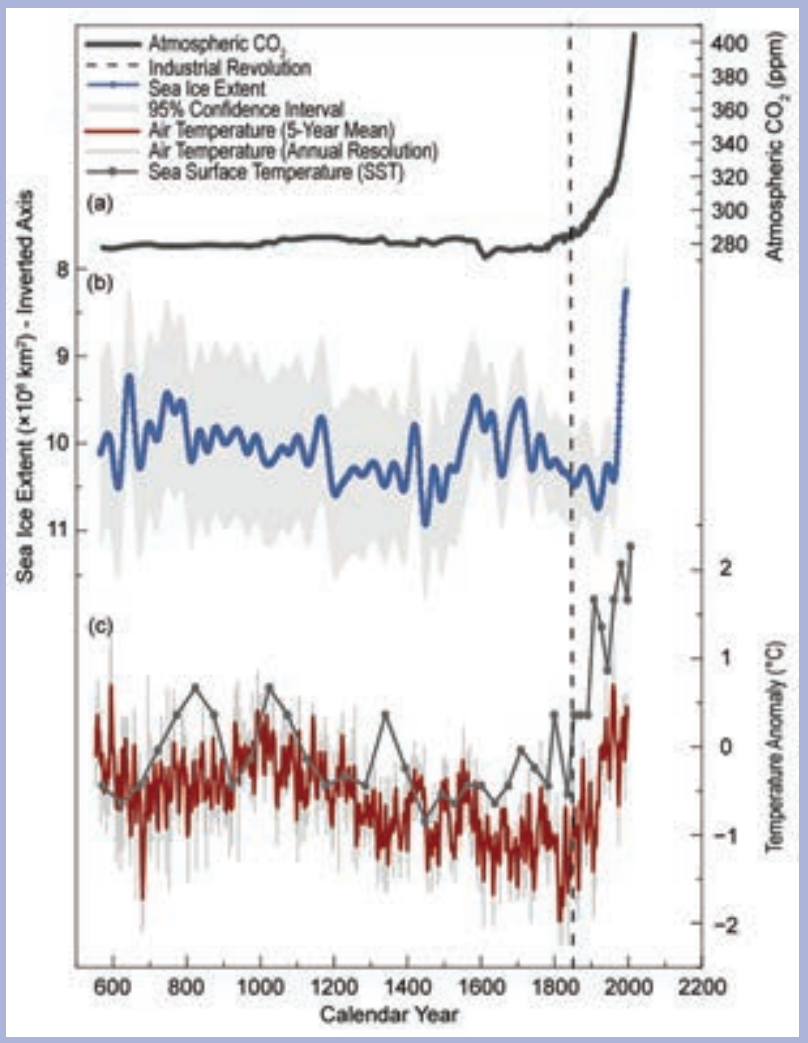

FIG. SB5.2. (a) Atmospheric $\mathrm{CO}_{2}$ concentrations (ppm), (b) paleoclimate reconstructions of summer Arctic sea ice extent ( $\mathrm{km}^{2}$; Kinnard et al. 20II), and (c) annual atmospheric temperature anomalies ( ${ }^{\circ} \mathrm{C}$; McKay and Kaufman 2014) and sea surface temperature anomalies ( ${ }^{\circ} \mathrm{C}$; Spielhagen et al. 20II) spanning the last $\mathbf{5 0 0}$ years. Atmospheric (red solid line: 5-yr mean and light gray: annual mean) and upper-ocean (dark gray with circles indicating individual data points) temperature anomalies are plotted together to show respective temperature trends. Vertical dashed line indicates the onset of the Industrial Revolution. Atmospheric $\mathrm{CO}_{2}$ concentrations [shown in (a)] are from the Law Dome ice core record (Etheridge et al. 1996, 1998) and modern observations from the Mauna Loa observatory [Dr. Pieter Tans, NOAA/ESRL (www.esrl.noaa.gov/gmd /ccgg/trends/), and Dr. Ralph Keeling, Scripps Institution of Oceanography (www.scrippsco2.ucsd.edu/)].

(Woodgate et al. 20I2), further driving sea ice melt and warming seas. Similar high-resolution proxy records from Arctic regions also indicate that the modern rate of increasing annual surface air temperatures has not been observed over at least the last 2000 years (McKay and Kaufman 2014). Scientists conclude that broad-scale sea ice variations recorded in the paleo 


\section{CONT. SIDEBAR 5.I: PALEOCLIMATE RECORDS: PROVIDING CONTEXT}

AND UNDERSTANDING OF CURRENT ARCTIC CHANGE-

\section{E. OSBORNE, T. CRONIN, AND J. FARMER}

record were predominantly driven by changes in basinscale atmospheric circulation patterns, fluctuations in air temperature and strength of incoming solar radiation, and changes in the inflow of warm water via Pacific and Atlantic inflows (Polyak et al. 2010).

There is general consensus that ice-free Arctic summers are likely before the end of the 2 Ist century (e.g., Stroeve et al. 2007; Massonnet et al. 2012), while some climate model projections suggest ice-free Arctic summers as early as 2030 (Wang and Overland 2009). Paleoclimate

Snow plays several critical roles in the growth and melt of Arctic sea ice. These roles include insulating the ocean from the atmosphere, dampening heat fluxes, reducing sea ice growth, reflecting more than $80 \%$ of the incoming sunlight, delaying ice melt, and contributing to melt pond formation (Granskog et al. 2017). Prior to the 1990s, observations of snow on Arctic sea ice were limited to in situ measurements. Warren et al. (1999) compiled many of these observations into a long-term record. New approaches to measure snow depth have since emerged, including improved instruments for in situ and autonomous observations and remote sensing. Field observations from recent years underscore significant regional and interannual variability in snow on Arctic sea ice. Figure 5.10c shows the historical snow depth record, plus a compilation of airborne snow depth measurements collected between March and May in 2009-12 and 2014-15, and in situ measurements made in 2015 and 2017. The recent mean snow depths range from 0.05 to $0.55 \mathrm{~m}$. Compared to the record published by Warren et al. (1999) there has been an overall decrease in snow depths of $37 \% \pm 29 \%$ in most of the western Arctic (aka North American Arctic) at the end of winter (Fig. 5.10c). The trend in the mean anomalies is $-0.27 \mathrm{~cm} \mathrm{yr}^{-1}$ with $99 \%$ significance. This decrease is potentially associated with later sea ice formation and thus later onset of snow accumulation in the previous autumn (Webster et al. 2014; Kurtz and Farrell 2011; Blanchard-Wrigglesworth et al. 2015).

e. Greenland ice sheet-M. Tedesco, J. E. Box, J. Cappelen, R. S. Fausto, X. Fettweis, K. Hansen, M. S. Khan, S. Luthcke, T. Mote, I. Sasgen, C. J. P. P. Smeets, D. van As, R. S. W. van de Wal, and I. Velicogna

The Greenland ice sheet (GrIS) plays a crucial role in the climatological, hydrological, and ecological studies and observational time series attribute the decline in sea ice extent and thickness over the last decade to both enhanced greenhouse warming and natural climate variability. While understanding the interplay of these factors is critical for future projections of Arctic sea ice and ecosystems, most observational time series records cover only a few decades. This highlights the need for additional paleoceanographic reconstructions across multiple spatial and temporal domains to better understand the drivers and implications of present and future Arctic Ocean change.

cycles at regional and global scales. The high albedo of the ice sheet contributes to a modulation of the amount of solar energy absorbed by Earth, and the location and topography of the ice sheet affects atmospheric circulation. The GrIS is also a major contributor to current and projected sea level rise, through surface runoff and iceberg calving. The summer of 2017 over the Greenland ice sheet was characterized by below-average (1981-2010) melt extent and aboveaverage surface albedo, with the net ablation being below the 2008-17 average at many test sites but still above the average for the 1961-90 reference period when the ice sheet was in steady equilibrium. Overall, total mass loss in 2017 was close to the average of the years 2003-16.

\section{I) Surface melting}

Estimates of melt extent across the GrIS are obtained from brightness temperatures measured by the Special Sensor Microwave Imager/Sounder (SSMIS) passive microwave radiometer (e.g., Mote 2007; Tedesco et al. 2013). These estimates point to a rapid start of the melting season in 2017, similar to 2016, with melt extent in early April reaching an area once typical of early June (Fig. 5.11a). From mid-June through mid-July 2017, however, melt extent was persistently below the 1981-2010 average. The spatial extent of melt for summer 2017 (June-August, JJA) was above average on 15 of 93 days (16\%) and reached its maximum extent of $32.9 \%$ of the ice sheet area on 26 July. The maximum extent of surface melt in 2017 was lower than the average maximum extent of $39.8 \%$ for the period $1981-2010$ and was the lowest maximum extent since 1996. There was regional variability in the characteristics of the summer melt. Most of the western and northeast ice sheet margins had more days than average with melt (relative to 
1981-2010), while the southeast margin had fewer days than average. The magnitude and evolution of surface melt in 2017 were consistent with the state of the dominant atmospheric circulation pattern, as defined by the Arctic Oscillation and North Atlantic Oscillation, both of which were strongly positive (Tedesco et al. 2017).
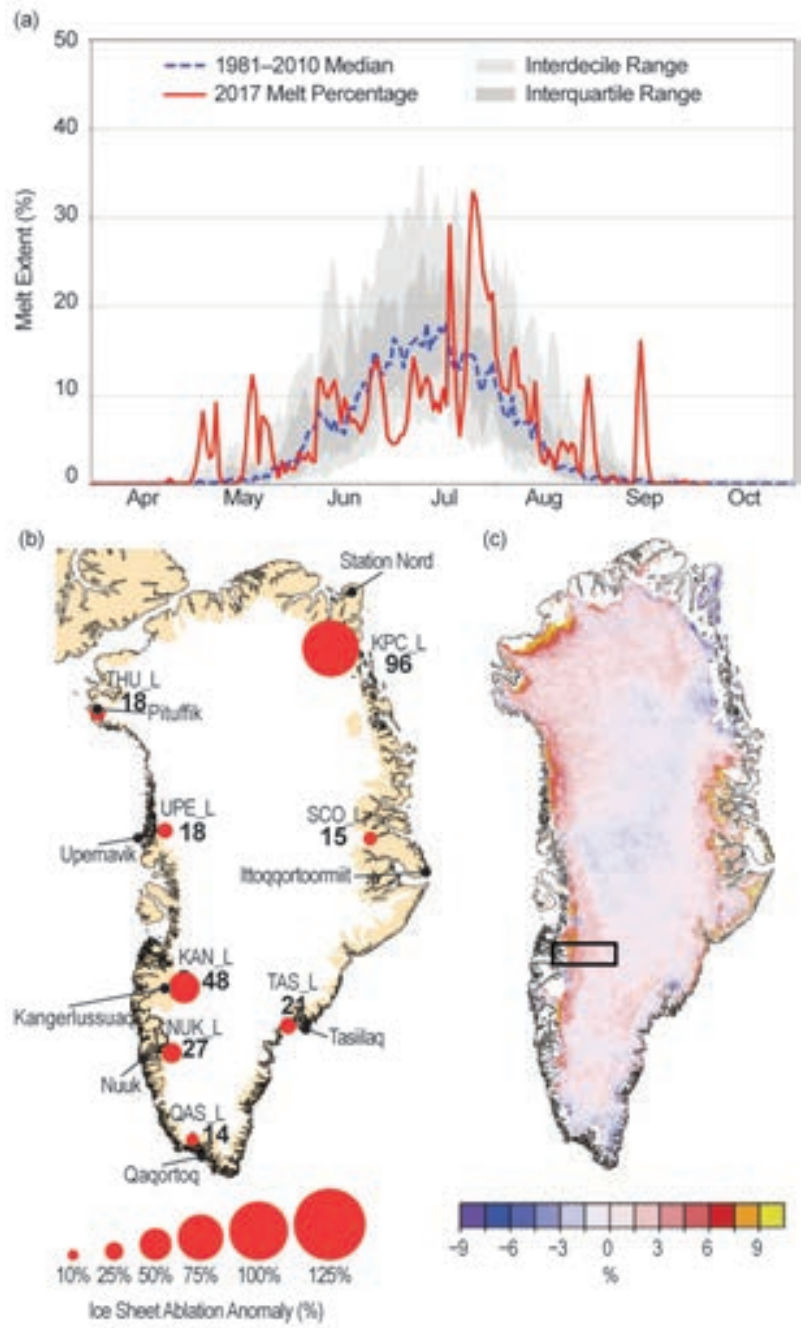

(c)
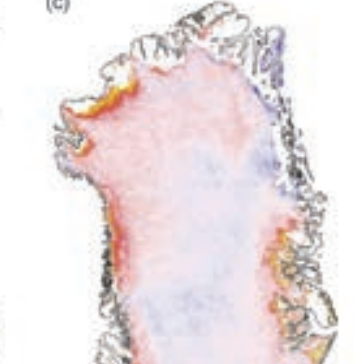

FIG. 5.II. (a) Spatial extent of melt, derived from the satellite product, as a percentage of the ice sheet area during 2017 (red line) and the 1981-2010 mean spatial extent of melt (dashed blue line). Light and dark gray areas represent the interdecile and interquartile ranges, respectively. (b) 2017 ablation anomalies (\% of average, relative to 196I-90) at lower PROMICE (Programme for monitoring of the Greenland ice sheet weather station sites in the Greenland ice sheet) ablation area, using historical coastal temperature records. (c) Distribution of albedo anomalies (\%, 2000-09 reference period) for summer 2017 , derived from MODIS. Area within the rectangle in (c) indicates the location of the K-transect.

\section{2) Surface mass balance}

Consistent with the low-to-moderate surface melting described above, the August 2016-August 2017 surface mass balance (SMB) year along the K-transect at $67^{\circ} \mathrm{N}$ in west Greenland (Fig. 5.11b; van de Wal et al. 2012) was characterized by moderate mass loss over the ablation region (Tedesco et al. 2017). The SMB along the transect line, which has been continuously monitored for 28 years, was approximately one standard deviation below the 1990-2017 mean. The equilibrium line altitude (defined as the elevation at which mass losses balance mass gain, i.e., $\mathrm{SMB}=$ 0) in 2017 was around 1490 meters, which is $40 \mathrm{~m}$ below the 28-year mean. The mass balance gradient was $3.4 \mathrm{~mm}$ w.e. (water equivalent) $\mathrm{m}^{-1} \mathrm{yr}^{-1}$, which is about $6 \%$ lower than the average (Tedesco et al. 2017).

Due to the relatively low summer temperatures, net ice ablation averaged over the PROMICE sites (Fig. 5.11b), distributed around Greenland in the ablation zone, was about $20 \%$ (or 0.6 standard deviations) lower in 2017 than compared to the 2008-17 average. The largest ablation anomaly values, more than one standard deviation below average, occurred at the southwest and northwest margins. The largest absolute ablation of $5.5 \mathrm{~m}$ of ice was measured at the southern tip of the ice sheet. More details can be found in Tedesco et al. (2017). While the surface mass balance observations indicate that surface melt was relatively moderate in 2017, compared to that observed in the last decade, it was still higher than observed prior to 1990 . When referencing the values to the 1961-90 climatological standard period (Van As et al. 2016), all eight low-elevation PROMICE station sites experienced above-average ablation anomalies in 2017 (Fig. 5.11b). However, only three stations were beyond the estimated uncertainty: KPC_L (+96\% $\pm 49 \%)$, SCO_L $(+15 \% \pm 14 \%)$ and KAN_L $(+48 \%$ $\pm 35 \%)$.

\section{3) Albedo}

The area-averaged albedo (the fraction of incident solar radiation reflected by a surface) for the entire Greenland ice sheet for summer 2017 was $80.9 \%$, as determined using data from the Moderate Resolution Imaging Spectroradiometer (MODIS; after Box et al. 2017; Fig. 5.11c). This is the third highest summer albedo value, after those of 2000 and 2013, during the 2000-17 MODIS period. Positive albedo anomalies are consistent with reduced melting in 2017 and snowfall events during the summer. The highest 2017 summer albedo anomalies occurred along the western margins of the ice sheet (Tedesco et al. 2017). 


\section{4) Total mass balance}

GRACE satellite gravity estimates obtained following Velicogna et al. (2014), Sasgen et al. (2012), and Luthcke et al. (2013) and available since 2002, indicate that between April 2016 and April 2017 (the most recent 12-month period of reliable data) there was a net ice mass loss of $276 \pm 47$ Gt (gigatonnes; Fig. 5.12). This is 144\% greater than the April 2015-April 2016 mass loss (191 $\pm 28 \mathrm{Gt})$ and close to the average Aprilto-April mass loss (255 $\pm 7 \mathrm{Gt}$ ) for 2003-17 (Sasgen et al. 2012). The updated trends of total ice mass loss for the 15-year GRACE period are $264 \mathrm{Gt} \mathrm{yr}^{-1}$ (Velicogna et al. 2014) and $270 \mathrm{Gt} \mathrm{yr}^{-1}$ (Sasgen et al. 2012); the different values reflect the slightly different computational approaches adopted in the two studies. The GRACE mission came to an expected end in October 2017. No further data will be available from this important source. It is anticipated that gravity measurements from space will resume and ice mass estimates will be possible again when the GRACE follow-on mission is launched. At the time of writing, the expected launch window is in spring 2018.

\section{5) Marine-terminating GlaCiers}

Marine-terminating glaciers are the outlets by which the Greenland ice sheet discharges ice mass to the ocean. Glacier area measurements from LANDSAT and ASTER, available since 1999 (Box and Hansen 2015) for 45 of the widest and fastestflowing marine-terminating glaciers, reveal a pattern of continued relative stability since 2012/13 (Fig. 5.13).

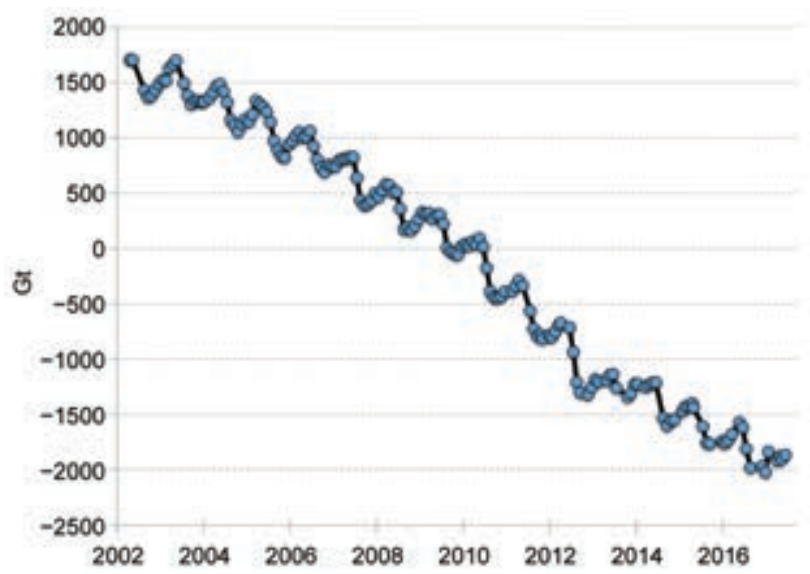

Fig. 5.I2. Change in the total mass (Gt) of the Greenland ice sheet between Apr 2002 and Jun 2017, estimated from GRACE measurements. (Due to the decommissioning of the GRACE satellite, no data are available after Jun 2017.) Data are based on an unweighted average of JPL RL05, GFZ RL05, and CSR RL05 solutions, which reduce noise in the GRACE data for 2017 (Sasgen et al. 2012).

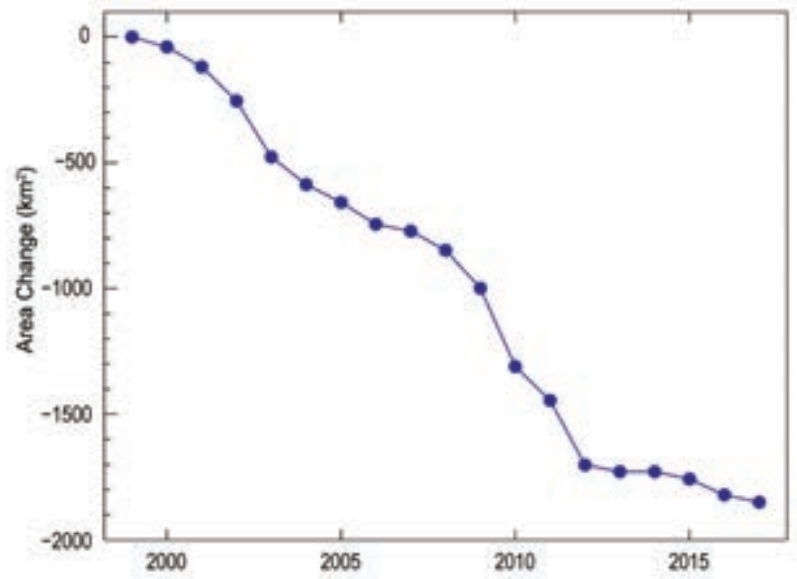

FIG. 5.I3. Glacier area change $\left(\mathrm{km}^{2}\right)$ from LANDSAT and ASTER imagery available since 1999 for 45 of the widest and fastest-flowing marine-terminating glaciers (after Box and Hansen 20I5).

Among the surveyed glaciers, 22 retreated, 10 were stable, and 13 advanced. Overall, the annual net area change of the 45 glaciers at the end of the 2017 melt season, which started in June and ended in September, was $-102.8 \mathrm{~km}^{2}$. This is $\sim 80 \%$ of the 18 -year survey period average of $-126.6 \mathrm{~km}^{2}$ year ${ }^{-1}$. The largest area losses were in eastern Greenland, where the Helheim and Kangerdlugssauq glaciers lost, respectively, $11.6 \mathrm{~km}^{2}$ and $9.9 \mathrm{~km}^{2}$ in area. The largest advance was observed at Petermann glacier, northwest Greenland, where the area increased by $11.5 \mathrm{~km}^{2}$.

\section{6) Surface AIR temperatures}

Measurements at 20 weather stations of the Danish Meteorological Institute (Cappelen et al. 2018; Table 5.1) indicate widespread above or near-average air temperatures for 2017, relative to the period 19812010. The exception was during spring 2017 (MarchMay, MAM) in coastal northeast Greenland and the start of July in western Greenland, when many sites experienced relatively cool temperatures. Looking in more detail, during winter 2016/17 (DecemberFebruary, DJF) a new seasonal record high was set in Aputiteeq, located in eastern Greenland. February in Aputiteeq was particularly warm, with a new monthly record set. At Kap Morris Jesup, along the northern coast, the winter season was the second warmest (only exceeded in 2011), with December 2016 matching the record warmth of December 2009. April 2017 was generally colder than average at many sites, compared to April 2016 when record breaking high temperatures were recorded. In autumn (SeptemberNovember, SON) some individual months were record setting at Danmarkshavn, Daneborg, and Ittoqqortoormiit. At Danmarkshavn, Daneborg, and 
TABLE 5.I. Seasonal and annual surface air temperature anomalies $\left({ }^{\circ} \mathrm{C}\right)$ relative to the $198 \mathrm{I}-2010$ average at 20 Danish Meteorological Institute weather stations in Greenland, where observations have been made for a minimum of 30 years. Seasons are winter (DJF 2016/17); spring (MAM 2017); summer (JJA 2017); autumn (SON 2017). Highlighted cell indicates a new seasonal record. The year that observations began is given, together with the station name, geographic coordinates, and elevation.

\begin{tabular}{|c|c|c|c|c|c|c|}
\hline \multicolumn{2}{|c|}{$\begin{array}{l}\text { Station Name, Start Year; } \\
\text { Latitude, Longitude, Elevation }\end{array}$} & $\begin{array}{c}\text { Jan-Dec } \\
2017 \\
\end{array}$ & $\begin{array}{c}\text { DJF } \\
2016 / 17 \\
\end{array}$ & $\begin{array}{l}\text { MAM } \\
2017\end{array}$ & $\begin{array}{l}\text { JJA } \\
2017\end{array}$ & $\begin{array}{l}\text { SON } \\
2017 \\
\end{array}$ \\
\hline \multirow{3}{*}{$\begin{array}{l}\text { Pituffik/Thule AFB } \\
1948 ; \\
76.5^{\circ} \mathrm{N}, 68.8^{\circ} \mathrm{W}, \\
77 \text { m a.s.l. }\end{array}$} & Anomaly $\left({ }^{\circ} \mathrm{C}\right)$ & 1.1 & 0.5 & 0.2 & 0.2 & 1.4 \\
\hline & Max Year & 2010 & 1986 & 1953 & 1957 & 2010 \\
\hline & Min Year & 1992 & 1949 & 1992 & 1996 & 1964 \\
\hline \multirow{3}{*}{$\begin{array}{l}\text { Upernavik } \\
1873 ; \\
72.8^{\circ} \mathrm{N}, 56.1^{\circ} \mathrm{W}, \\
126 \mathrm{~m} \text { a.s. } \\
\end{array}$} & Anomaly $\left({ }^{\circ} \mathrm{C}\right)$ & 1.2 & 0.7 & 1.4 & 0.0 & 0.7 \\
\hline & Max Year & 2010 & 1947 & 1932 & 2012 & 2010 \\
\hline & Min Year & 1887 & 1983 & 1896 & 1873 & 1917 \\
\hline \multirow{3}{*}{$\begin{array}{l}\text { Aasiaat } \\
1958 ; \\
68.7^{\circ} \mathrm{N}, 52.8^{\circ} \mathrm{W}, \\
43 \mathrm{~m} \text { a.s.l. } \\
\end{array}$} & Anomaly $\left({ }^{\circ} \mathrm{C}\right)$ & 0.9 & 0.8 & 0.6 & 0.3 & 0.8 \\
\hline & Max Year & 2010 & 2010 & 2016 & 2012 & 2010 \\
\hline & Min Year & 1983 & 1984 & 1993 & 1972 & 1986 \\
\hline \multirow{3}{*}{$\begin{array}{l}\text { Ilulissat } \\
1807 ; \\
69.2^{\circ} \mathrm{N}, 51.1^{\circ} \mathrm{W}, \\
29 \mathrm{~m} \text { a.s.l. }\end{array}$} & Anomaly $\left({ }^{\circ} \mathrm{C}\right)$ & 0.4 & 0.1 & 0.1 & -0.5 & 0.5 \\
\hline & Max Year & 2010 & 1929 & 1847 & 1960 & 2010 \\
\hline & Min Year & 1863 & 1863 & 1813 & 1863 & 1837 \\
\hline \multirow{3}{*}{$\begin{array}{l}\text { Kangerlussuaq } \\
1949 ; \\
67^{\circ} \mathrm{N}, 50.7^{\circ} \mathrm{W}, \\
50 \mathrm{~m} \text { a.s.l. }\end{array}$} & Anomaly $\left({ }^{\circ} \mathrm{C}\right)$ & 0.6 & -0.7 & -0.4 & 0.3 & 0.7 \\
\hline & Max Year & 2010 & 1986 & 2016 & 1960 & 2010 \\
\hline & Min Year & 1984 & 1983 & 1993 & 1983 & 1982 \\
\hline \multirow{3}{*}{$\begin{array}{l}\text { Sisimiut } \\
1961 ; \\
70^{\circ} \mathrm{N}, 53.7^{\circ} \mathrm{W}, \\
10 \mathrm{~m} \text { a.s.l. } \\
\end{array}$} & Anomaly $\left({ }^{\circ} \mathrm{C}\right)$ & 1.2 & 1.2 & 0.6 & 0.4 & 1.2 \\
\hline & Max Year & 2010 & 2010 & 2010 & 2012 & 2010 \\
\hline & Min Year & 1984 & 1984 & 1983 & 1972 & 1982 \\
\hline \multirow{3}{*}{$\begin{array}{l}\text { Nuuk } \\
1784 ; \\
64.2^{\circ} \mathrm{N}, 51.7^{\circ} \mathrm{W}, \\
80 \mathrm{~m} \text { a.s.l. }\end{array}$} & Anomaly $\left({ }^{\circ} \mathrm{C}\right)$ & 0.6 & 0.6 & 0.1 & 0.2 & 0.6 \\
\hline & Max Year & 2010 & 2010 & 1932 & 2012 & 2010 \\
\hline & Min Year & 1818 & 1818 & 1802 & 1819 & 1811 \\
\hline \multirow{3}{*}{$\begin{array}{l}\text { Paamiut } \\
1958 \\
62^{\circ} \mathrm{N}, 49.7^{\circ} \mathrm{W}, \\
36 \mathrm{~m} \text { a.s.l. }\end{array}$} & Anomaly $\left({ }^{\circ} \mathrm{C}\right)$ & 0.9 & 1.3 & -0.2 & 0.0 & 1.0 \\
\hline & Max Year & 2010 & 2010 & 2005 & 2010 & 2010 \\
\hline & Min Year & 1984 & 1984 & 1993 & 1969 & 1982 \\
\hline \multirow{3}{*}{$\begin{array}{l}\text { Ivittuut/Narsarsuaq } \\
1873 ; \\
61.2^{\circ} \mathrm{N}, 45.4^{\circ} \mathrm{W}, \\
27 \mathrm{~m} \text { a.s.l. }\end{array}$} & Anomaly $\left({ }^{\circ} \mathrm{C}\right)$ & 1.4 & 1.4 & 1.3 & 0.2 & 0.9 \\
\hline & Max Year & 2010 & 2010 & 2010 & 2016 & 2010 \\
\hline & Min Year & 1884 & 1984 & 1989 & 1873 & 1874 \\
\hline \multirow{3}{*}{$\begin{array}{l}\text { Qaqortoq } \\
1807 ; \\
60.7^{\circ} \mathrm{N}, 46.1^{\circ} \mathrm{W}, \\
32 \mathrm{~m} \text { a.s.l. }\end{array}$} & Anomaly $\left({ }^{\circ} \mathrm{C}\right)$ & 0.7 & 1.0 & 0.3 & -0.1 & 0.7 \\
\hline & Max Year & 2010 & 2010 & 1932 & 1929 & 2010 \\
\hline & Min Year & 1884 & 1863 & 1811 & 1811 & 1874 \\
\hline \multirow{3}{*}{$\begin{array}{l}\text { Kap Morris Jesup } \\
1980 ; \\
83.7^{\circ} \mathrm{N}, 33.4^{\circ} \mathrm{W}, \\
4 \mathrm{~m} \text { a.s.I. }\end{array}$} & Anomaly $\left({ }^{\circ} \mathrm{C}\right)$ & 1.5 & 5.2 & 0.8 & 0.4 & -0.4 \\
\hline & Max Year & 2011 & 2011 & 2014 & 1995 & 2016 \\
\hline & Min Year & 1985 & 1988 & 1985 & 1997 & 1990 \\
\hline
\end{tabular}




\begin{tabular}{|c|c|c|c|c|c|c|}
\hline \multicolumn{2}{|c|}{$\begin{array}{l}\text { Station Name, Start Year; } \\
\text { Latitude, Longitude, Elevation }\end{array}$} & $\begin{array}{c}\text { Jan-Dec } \\
2017\end{array}$ & $\begin{array}{c}\text { DJF } \\
2016 / 17\end{array}$ & $\begin{array}{l}\text { MAM } \\
2017\end{array}$ & $\begin{array}{l}\text { JJA } \\
2017\end{array}$ & $\begin{array}{l}\text { SON } \\
2017\end{array}$ \\
\hline \multirow{3}{*}{$\begin{array}{l}\text { Station Nord } \\
1961 ; \\
81.6^{\circ} \mathrm{N}, 16.7^{\circ} \mathrm{W}, \\
36 \mathrm{~m} \text { a.s.l. }\end{array}$} & Anomaly $\left({ }^{\circ} \mathrm{C}\right)$ & 1.0 & 2.7 & -1.8 & 0.4 & 2.2 \\
\hline & Max Year & 2016 & 2011 & 2006 & 2003 & 2016 \\
\hline & Min Year & 1968 & 1967 & 1961 & 1970 & 1989 \\
\hline \multirow{3}{*}{$\begin{array}{l}\text { Danmarkshavn } \\
1949 ; \\
76.8^{\circ} \mathrm{N}, 18.7^{\circ} \mathrm{W}, \\
\text { I m a.s.l. }\end{array}$} & Anomaly $\left({ }^{\circ} \mathrm{C}\right)$ & I.I & 0.6 & -2.1 & 1.0 & 4.4 \\
\hline & Max Year & 2016 & 2005 & 1976 & 2016 & 2016 \\
\hline & Min Year & 1983 & 1967 & 1966 & 1955 & 1971 \\
\hline \multirow{3}{*}{$\begin{array}{l}\text { Daneborg } \\
1958 \text {; } \\
74.3^{\circ} \mathrm{N}, 20^{\circ} \mathrm{W} 2, \\
44 \mathrm{~m} \text { a.s.l. . }\end{array}$} & Anomaly $\left({ }^{\circ} \mathrm{C}\right)$ & 0.5 & -0.3 & -3.1 & 0.1 & 4.8 \\
\hline & Max Year & 2016 & 2005 & 1996 & 2016 & 2016 \\
\hline & Min Year & 1968 & 1975 & 1961 & 1985 & 1971 \\
\hline \multirow{3}{*}{$\begin{array}{l}\text { Ittoqqortoormiit } \\
1949 ; \\
70.5^{\circ} \mathrm{N}, 22^{\circ} \mathrm{W}, \\
70 \mathrm{~m} \text { a.s.l. }\end{array}$} & Anomaly $\left({ }^{\circ} \mathrm{C}\right)$ & 1.0 & 2.5 & -0.9 & 0.2 & 3.6 \\
\hline & Max Year & 2016 & 2014 & 1996 & 2016 & 2016 \\
\hline & Min Year & 1951 & 1966 & 1956 & 1955 & 1951 \\
\hline \multirow{3}{*}{$\begin{array}{l}\text { Aputiteeq } \\
1958 ; \\
67.8^{\circ} \mathrm{N}, 32.3^{\circ} \mathrm{W}, \\
13 \mathrm{~m} \text { a.s.l. }\end{array}$} & Anomaly $\left({ }^{\circ} \mathrm{C}\right)$ & 1.6 & 4.4 & 1.4 & -0.2 & 2.2 \\
\hline & Max Year & 2016 & 2017 & 1974 & 2016 & 2016 \\
\hline & Min Year & 1973 & 1969 & 1969 & 1967 & 1973 \\
\hline \multirow{3}{*}{$\begin{array}{l}\text { Tasiilaq } \\
1895 ; \\
65.6^{\circ} \mathrm{N}, 37.6^{\circ} \mathrm{W}, \\
53 \mathrm{~m} \text { a.s.l. }\end{array}$} & Anomaly $\left({ }^{\circ} \mathrm{C}\right)$ & 1.2 & 2.3 & 1.3 & 0.2 & 1.6 \\
\hline & Max Year & 2016 & 1929 & 1929 & 2016 & 1941 \\
\hline & Min Year & 1899 & 1918 & 1899 & 1983 & 1917 \\
\hline \multirow{3}{*}{$\begin{array}{l}\text { Ikermiuarsuk } \\
1958 ; \\
61.9^{\circ} \mathrm{N}, 42^{\circ} \mathrm{W}, \\
39 \mathrm{~m} \text { a.s.l. }\end{array}$} & Anomaly $\left({ }^{\circ} \mathrm{C}\right)$ & - & - & - & -0.1 & 1.1 \\
\hline & Max Year & 2003 & 2011 & 1999 & 1961 & 2010 \\
\hline & Min Year & 1983 & 1976 & 1967 & 1983 & 1969 \\
\hline \multirow{3}{*}{$\begin{array}{l}\text { Prins Chr. Sund } \\
1958 ; \\
60.1^{\circ} \mathrm{N}, 42.2^{\circ} \mathrm{W}, \\
88 \mathrm{~m} \text { a.s.l. }\end{array}$} & Anomaly $\left({ }^{\circ} \mathrm{C}\right)$ & 0.5 & 0.6 & 0.2 & -0.2 & 1.3 \\
\hline & Max Year & 2010 & 2010 & 2005 & 2010 & 2010 \\
\hline & Min Year & 1993 & 1993 & 1989 & 1970 & 1982 \\
\hline \multirow{3}{*}{$\begin{array}{l}\text { Summit } \\
\text { 1991; } \\
72.6^{\circ} \mathrm{N}, 38.5^{\circ} \mathrm{W}, \\
3202 \mathrm{~m} \text { a.s.l. }\end{array}$} & Anomaly $\left({ }^{\circ} \mathrm{C}\right)$ & 0.6 & 1.4 & 0.6 & -0.6 & 2.7 \\
\hline & Max Year & 2010 & 2010 & 2016 & 2012 & 2002 \\
\hline & Min Year & 1992 & 1993 & 1992 & 1992 & 2009 \\
\hline
\end{tabular}

Aputiteeq the autumn season was second warmest, exceeded only by 2016 .

At Summit, the highest elevation of the GrIS, winter 2016/17 was the fourth warmest, with February 2017 second warmest after February 2005. May was the second warmest since 1991, after May 2010. A new July record-breaking low temperature of $-33.0^{\circ} \mathrm{C}$ was measured at Summit on 4 July. On 28 July, a new record high July temperature of $1.9^{\circ} \mathrm{C}$ was measured at Summit. f. Glaciers and ice caps outside Greenland-M. Sharp, B. Wouters, G. Wolken, L. M. Andreassen, D. Burgess, L. Copland, J. Kohler, S. O'Neel, M. S. Pelto, L. Thomson, and T. Thorsteinsson The Arctic is the world's third most heavily glaciated region, after Antarctica and Greenland. Though the total mass of glaciers and ice caps in the region is significantly less than that of the Antarctic and Greenland ice sheets, ice loss from Arctic glaciers and ice caps has become a significant contributor to current global sea level rise as a result of recent summer warming (Gardner et al. 2011, 2013; Jacob et al. 2012; Millan et al. 2017). 
The state of glaciers, ice caps, and ice sheets is often described by their mass balance. The annual climatic mass balance of a glacier $\left(\mathrm{B}_{\text {clim }}\right)$ is defined as the difference between the annual snow accumulation on the glacier and the annual mass loss by surface melting and runoff. For the purposes of calculation, a "mass balance year" is usually taken as the period between the ends of successive summer melt seasons. Variations in the mass of most monitored Arctic glaciers and ice caps are controlled largely by changes in their climatic mass balance. However, those glaciers that terminate in the ocean [e.g., Devon Ice Cap NW (Arctic Canada), and Hansbreen and Kongsvegen (Svalbard); Table 5.2; Fig. 5.14] or in lakes can also lose mass by melting below the waterline. However, this mass balance term is rarely routinely measured.

Here, $B_{\text {clim }}$ measurements made in 2015-16 and 2016-17 at individual glaciers monitored across the Arctic region are reported (Table 5.2; Fig. 5.141). All $\mathrm{B}_{\text {clim }}$ data are from the World Glacier Monitoring Service (WGMS 2018). Positive (negative) annual $B_{\text {clim }}$ values indicate that a glacier gained (lost) mass over the course of the mass balance year that includes a winter accumulation season, when snow deposition typically exceeds meltwater runoff (positive mass balance), followed by a summer ablation season, when the opposite is the case (negative mass balance). The timing and duration of the accumulation and ablation seasons vary from region to region and from year to year, but in most cases, net accumulation occurs from late autumn to late spring, and net ablation from late spring to late autumn. At the time of writing, estimates for the 2016-17 mass balance year were available for only 16 glaciers [two in Alaska, nine in Iceland (nine measurement locations at seven glaciers), three in Svalbard, and two in Norway] of the 27 that are regularly monitored (Fig. 5.14). So that a complete cycle of results can be reported, $\mathrm{B}_{\text {clim }}$ measurements for the 2015-16 mass balance year are also reported.

Relative to the long-term (1985-2015) mean $\mathrm{B}_{\text {clim }}$ values, 20 of the 24 values reported for 2015-16 were more negative than the mean, and four were more positive. Five of the 18 annual net balances reported for 2016-17 were more negative than the 1985-2015 mean, and 13 were more positive. The mix of positive and negative anomalies in $2016-17$ contrasts

\footnotetext{
${ }^{1}$ Table 5.2 lists 25 glaciers and ice caps by name while Fig. 5.14 shows the location of 27 sites where $B_{\text {clim }}$ is measured. The difference in numbers is accounted for by Hofsjökull, Iceland, where $B_{\text {clim }}$ is measured at three different sites on a single ice cap (no. 9 in Table 5.2).
}

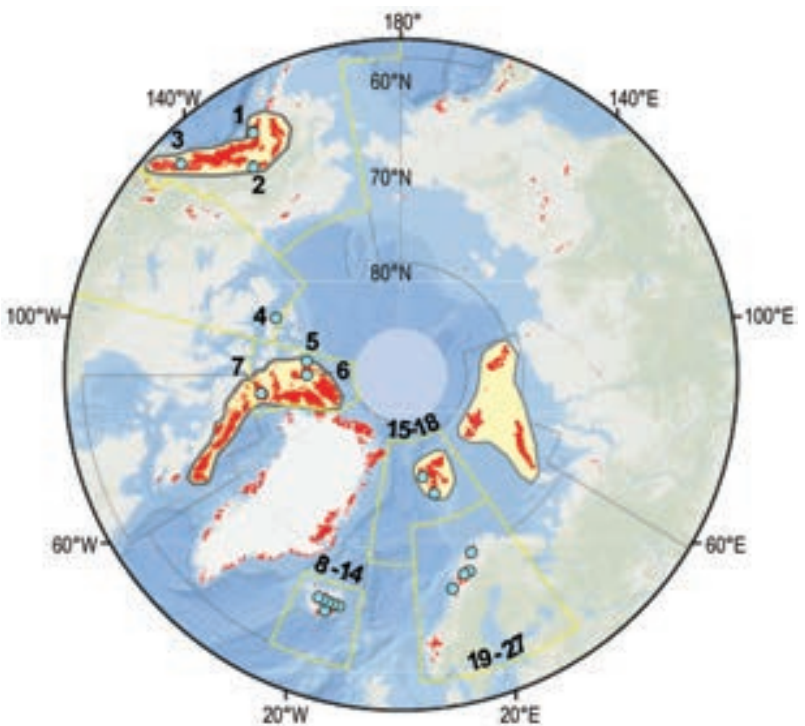

FIG. 5. I4. Locations of the 27 sites on 25 Arctic glaciers and ice caps (black circles) that have long-term observations of annual climatic mass balance $\left(B_{\text {clim }}\right)$. Areas outlined in yellow are the Randolph Glacier Inventory (RGI) regions of the Arctic (Pfeffer et al. 20I4). Some individual glaciers are too close for identification and can be identified by the numbers shown at the edge of the RGI region. They can also be referenced in Table 5.2. Red shading indicates glaciers and ice caps, including ice caps in Greenland outside the ice sheet.

with the tendency for predominantly negative mass balance anomalies over the past decade. However, the long-term tendency of the cumulative $B_{\text {clim }}$ since the mid-1990s continues to be toward more negative cumulative balances in all five regions (Fig. 5.15), indicating continuing mass loss. With the exception of Svalbard (where there has been no obvious recent acceleration of mass loss rates; Fig. 5.15), rapid mass loss across the five regions typically began during the 1990s.

New data on the length of the summer melt season at Wolverine and Gulkana glaciers in Alaska (Fig. 5.16) show that since measurements began in 1966 the summer melt season has increased by about 18 days (14\%) at Wolverine Glacier, located in a maritime climate, and 24 days (24\%) at Gulkana Glacier, located in a more continental climate. These data suggest that increases in summer melt played a significant role in generating more negative annual mass balances in this region.

$\mathrm{B}_{\text {clim }}$ measurements for the 2015-16 mass balance year are from 24 glaciers: three in Alaska, four in Arctic Canada, nine in Iceland, four in Svalbard, two in northern Norway, and two in northern Sweden (Table 5.2). All these glaciers had a negative annual $\mathrm{B}_{\text {clim }}$ in 2015-16. At Austre Broggerbreen and Midtre 
TABLE 5.2. Measured $B_{\text {clim }}$ climatic mass balance of 25 glaciers in Alaska (3), Arctic Canada (4), Iceland (7), Svalbard (4), and Northern Scandinavia (7) for 2015/16 and 2016/17, together with the 1985-2015 mean and standard deviation for each glacier [(Hofsjökull (Iceland) is treated as a single glacier, although measurements are made in three different sectors of this ice cap)]. (* Indicates one or more years of data missing from the record). Negative (positive) values for $\mathbf{B}_{\text {clim }}$ indicate mass loss (gain). Data are from the World Glacier Monitoring Service (WGMS 2018), with updates for Alaska from S. O'Neel and M. Pelto, White Glacier from L. Thomson, Svalbard from J. Kohler, and mainland Norway (Engabreen and Langfjordjokulen) from L. M. Andreassen. Numbers in column I refer to the glaciers located in Fig. 5.14. Results for 2016/17 may be based on measurements made before the end of the melt season and may be subject to revision.

\begin{tabular}{|c|c|c|c|c|c|}
\hline Region & $\begin{array}{c}\text { Glacier } \\
\text { (record length, years) }\end{array}$ & $\begin{array}{c}\text { B }_{\text {clim }} \text { Mean } \\
\left(\mathrm{kg} \mathrm{m}^{-2} \mathrm{yr}^{-1}\right) \\
(1985-2015)\end{array}$ & $\begin{array}{c}\text { B }_{\text {clim }} \text { Std. dev. } \\
\left(\mathrm{kg} \mathrm{m}^{-2} \mathrm{yr}^{-1}\right) \\
1985-2015\end{array}$ & $\begin{array}{c}B_{\text {clim }} \\
\left(\mathrm{kg} \mathrm{m}^{-2} \mathrm{yr}^{-1}\right) \\
2015-16\end{array}$ & $\begin{array}{c}B_{\text {clim }} \\
\left(\mathrm{kg} \mathrm{m}^{-2} \mathrm{yr}^{-1}\right) \\
2016-17\end{array}$ \\
\hline \multicolumn{6}{|l|}{ Alaska } \\
\hline 1 & Wolverine (52) & -603 & 1016 & -400 & -1160 \\
\hline 3 & Lemon Creek (65) & -640 & 798 & -1200 & -1480 \\
\hline 2 & Gulkana (52) & -778 & 721 & -1400 & - \\
\hline \multicolumn{6}{|c|}{ Arctic Canada } \\
\hline 7 & $\begin{array}{l}\text { Devon Ice Cap (NW) } \\
(56)\end{array}$ & -204 & 205 & -483 & - \\
\hline 5 & Meighen Ice Cap (55) & -26 & 397 & -775 & - \\
\hline 4 & $\begin{array}{l}\text { Melville South Ice Cap } \\
\text { (52) }\end{array}$ & -418 & 477 & -792 & - \\
\hline 6 & White (54) & -308 & 316 & -268 & - \\
\hline \multicolumn{6}{|l|}{ Iceland } \\
\hline 8 & Langjökull S. Dome (19) & $-1288^{*}$ & 855 & -1677 & - \\
\hline 9 & Hofsjökull E (25) & $-545^{*}$ & 871 & -1120 & -650 \\
\hline 9 & Hofsjökull N (26) & $-565^{*}$ & 754 & -830 & -490 \\
\hline 9 & Hofsjökull SW (25) & $-802 *$ & 1017 & -450 & 80 \\
\hline 10 & Köldukvislarjökull (22) & $-475^{*}$ & 738 & -642 & - \\
\hline II & Tungnaarjökull (24) & $-1128 *$ & 830 & 196 & - \\
\hline 12 & Dyngjujökull (18) & $-146 *$ & 806 & M & - \\
\hline 13 & Brúarjökull (23) & $-258^{*}$ & 683 & -342 & - \\
\hline 14 & Eyjabakkajökull (24) & $-709 *$ & 839 & -930 & - \\
\hline \multicolumn{6}{|l|}{ Svalbard } \\
\hline 17 & Midre Lovenbreen (49) & -379 & 330 & -1200 & -420 \\
\hline 16 & Austre Broggerbreen (50) & -486 & 363 & -1450 & -530 \\
\hline 15 & Kongsvegen (3I) & $-114 *$ & 360 & -320 & 40 \\
\hline 18 & Hansbreen (28) & $-397 *$ & 474 & -1078 & - \\
\hline
\end{tabular}

Lovenbreen in Svalbard, $\mathrm{B}_{\text {clim }}$ was the most negative ever recorded. This is attributed to relatively low snow accumulation in winter 2015-16 and high summer melt in 2016, especially in the record warm and rainy month of July. Of the 18 glaciers with measurements for both 2015-16 and 2016-17, 16 (two in Arctic Canada, all nine in Iceland, three in Svalbard, and two in northern Scandinavia) had a more positive annual $B_{\text {clim }}$ in 2016-17 than in the previous year, while two (both in Alaska) had a more negative annual $B_{\text {clim }}$ than in the previous year. In Svalbard, the positive mass balance on Kongsvegen in 2016-17 is linked to above-average winter snowfall, which delayed the onset of ice melt in summer 2017. 


\begin{tabular}{|c|c|c|c|c|c|}
\hline \multicolumn{6}{|c|}{ TABLE 5.2. (CONT.) } \\
\hline Region & $\begin{array}{c}\text { Glacier } \\
\text { (record length, years) }\end{array}$ & $\begin{array}{l}B_{\text {clim Mean }} \\
\left(\mathrm{kg} \mathrm{m}^{-2} \mathrm{yr}^{-1}\right) \\
(1985-2015)\end{array}$ & $\begin{array}{c}\text { B }_{\text {clim }} \text { Std. dev. } \\
\left(\mathrm{kg} \mathrm{m}^{-2} \mathrm{yr}^{-1}\right) \\
1985-2015\end{array}$ & $\begin{array}{c}B_{\text {clim }} \\
\left(\mathrm{kg} \mathrm{m}^{-2} \mathrm{yr}^{-1}\right) \\
2015-16\end{array}$ & $\begin{array}{c}B_{\text {clim }} \\
\left(\mathrm{kg} \mathrm{m}^{-2} \mathrm{yr}^{-1}\right) \\
2016-17\end{array}$ \\
\hline \multicolumn{6}{|c|}{ Northern Scandinavia } \\
\hline 19 & Engabreen (48) & -127 & 1024 & -230 & -1250 \\
\hline 20 & Langfjordjokulen (27) & $-948 *$ & 737 & -1660 & -270 \\
\hline 21 & Marmaglaciaren (24) & $-460 *$ & 550 & -370 & - \\
\hline 22 & Rabots Glaciar (3I) & $-465^{*}$ & 659 & - & - \\
\hline 23 & Riukojetna (26) & $-592 *$ & 785 & - & - \\
\hline 24 & Storglaciaren (7I) & -153 & 760 & -240 & - \\
\hline 25 & Tarfalaglaciaren (19) & $-198 *$ & 1118 & - & - \\
\hline
\end{tabular}

Although some of the 2016-17 mass balance measurements are provisional, 12 of the reporting glaciers (two in Alaska, one in Arctic Canada, six in Iceland, two in Svalbard, and one in northern Scandinavia) had negative annual balances, and six (Meighen Ice Cap, Canada; Hofsjokull SW, Brúarjökull, and Dyngjujökull, Iceland; Kongsvegen, Svalbard; and Engabreen, Norway) had positive balances (Table 5.2).

Estimates of regional scale ice mass changes since 2011 can be derived from CryoSat-2 radar altimetry, which measures glacier surface elevation (Wouters

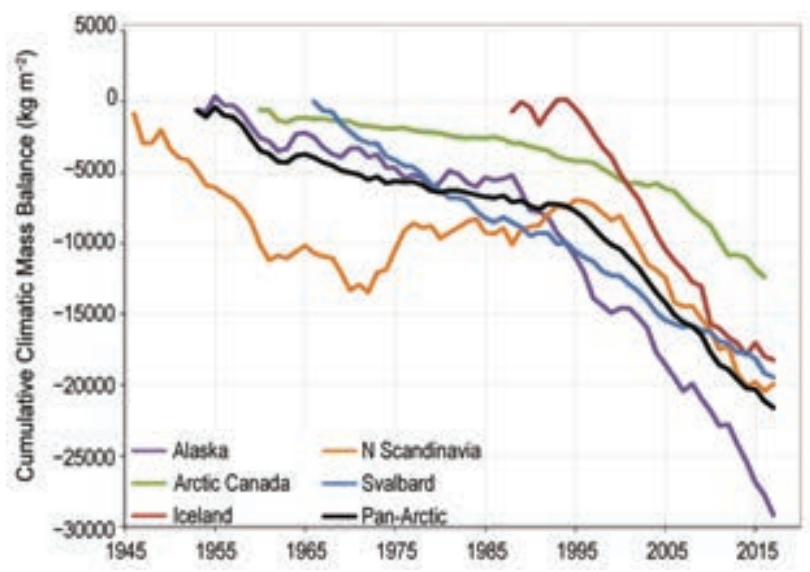

FIG. 5.15. Cumulative climatic mass balance $\left(\mathbf{B}_{\text {clim }}\right.$ in $\mathrm{kg} \mathrm{m}^{-2}$ ) for glaciers and ice caps in five regions of the Arctic, and for all monitored glaciers and ice caps (PanArctic). Average annual climatic balances for each region are calculated for each year using the measured annual mass balances for all monitored glaciers in the region which are then summed over the period of record to produce the cumulative $B_{\text {clim. Note that the }}$ monitoring periods vary between regions and that the number and identity of glaciers monitored in a region may vary between years. et al. 2015). This approach provides regional mass change estimates for Iceland, Svalbard, the Russian Arctic, and the Canadian Arctic (Fig. 5.17). CryoSat-2 estimates for the period 2011-17 identify the Canadian Arctic as the most important of these four regional sources of glacier mass loss (7-year mean:

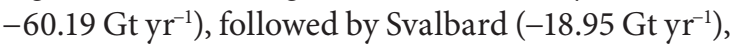
the Russian Arctic (-13.46 $\left.\mathrm{Gt} \mathrm{yr}^{-1}\right)$, and Iceland $\left(-2.36 \mathrm{Gt} \mathrm{yr}^{-1}\right)$. Estimates for Alaska and northern Scandinavia are not available.

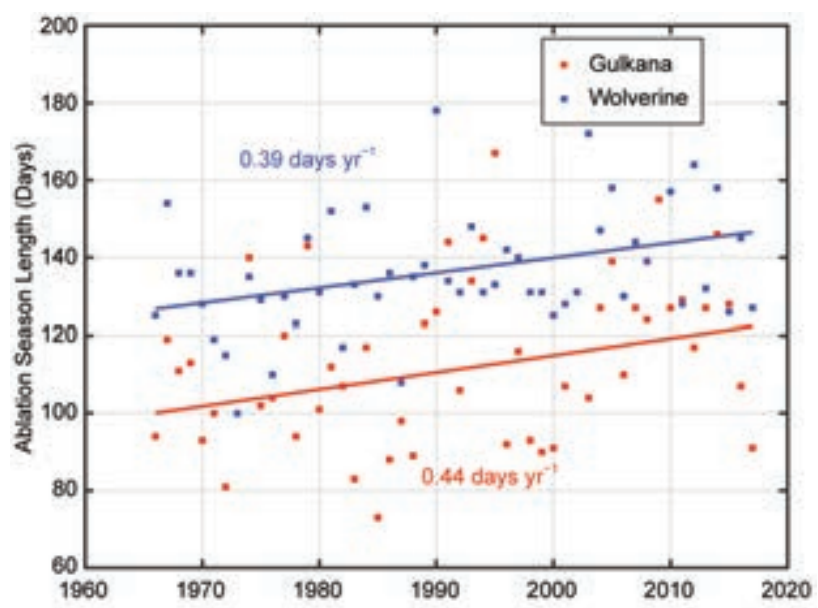

FIG. 5.16. Length (days) of the annual ablation season at Gulkana (red) and Wolverine (blue) glaciers, Alaska, showing the mean rate of change (days $\mathrm{yr}^{-1}$ ) over the 1966-2017 observation period at each site. Coefficients of determination $\left(r^{2}\right)$ determined by least squares linear regression are 0.133 for Wolverine Glacier $(p=0.008)$ and 0.08 for Gulkana Glaciers $(p=0.04)$. (Source: S. O'Neel, USGS.) 


\section{SIDEBAR 5.2: INDIGENOUS KNOWLEDGE AND THE COPRODUCTION OF KNOWLEDGE PROCESS: CREATING A HOLISTIC UNDERSTANDING OF ARCTIC CHANGE-C. BEHE}

\section{AND R. DANIEL}

Rapid changes occurring within the Arctic heighten the need to understand the many causes of the changes and their cumulative impacts. Most importantly, to better understand Arctic change a holistic view is needed that can only be achieved by bringing together multiple knowledge systems and scientific disciplines. This includes Arctic Indigenous Peoples and their knowledge.

Arctic Indigenous Peoples have been an integral part of the Arctic ecosystem from time immemorial and have acquired and built upon a unique knowledge system-an indigenous knowledge-shaped by that environment. It is a systematic way of thinking, which is applied to phenomena across biological, physical, cultural, and spiritual systems. It includes insights based on evidence acquired through direct and long-term experiences and extensive and multigenerational observations, lessons, and skills.

Indigenous knowledge has developed over millennia and is still developing in a living process, including knowledge acquired today and in the future, and it is passed on from generation to generation (Inuit Circumpolar Council-Alaska 2016). Indigenous knowledge stresses the importance of understanding interconnecting systems, that is, ecological, physical, cultural, and social systems, the relationship between those components, and the need to understand cumulative impacts (Inuit Circumpolar Council-Alaska 20I5). This world view and way of understanding will aid in gaining a holistic understanding of the Arctic and the changes that are occurring there.

To gain a truly holistic understanding of the changing Arctic, it is necessary to bring together indigenous knowledge and science through a coproduction of knowledge process. Such a process offers opportunities to bring together different knowledge systems to develop adaptation policies and practices for sustainability, and to address biodiversity conservation and ecosystem-based management in a changing Arctic.

The coproduction of knowledge process brings together indigenous knowledge holders and scientists to work in partnership from the inception of a project, for example, identification of research questions and hypotheses, through analysis and output. Equity is a cornerstone of the process, ensuring fairness and the opportunity to engage in all aspects of a project. All participants have a fair and equal chance of succeeding. The coproduction of knowledge process requires culturally appropriate methodologies in data collection and analyses to be agreed upon by all knowledge holders.

Successful coproduction of knowledge fosters an environment of trust and respect, works toward empowerment and capacity building, and recognizes indigenous knowledge sovereignty; it is important to recognize the sovereign rights of indigenous peoples, including those related to their own knowledge. This includes indigenous peoples fully understanding the risks and opportunities of participating in a research project, having authority over how data and information are shared, and the right to not participate in a research project. The principles of free, prior, and informed consent are critical to the coproduction of knowledge process (UN General Assembly 2007).

Successful coproduction of knowledge is built upon long-term partnerships. A good first step is an understanding of the lay of the land in indigenous homelands. Just as scientists understand the importance of networks in their research, so indigenous peoples also live in complex social and governance systems, allowing the opportunity to leverage existing indigenous networks, institutions, and organizations. It is important to understand partnership building from an indigenous perspective and to know that partnership and participation are not synonymous. Clear, transparent, culturally appropriate terms of reference are recommended to ensure there are no misunderstandings and to help with relationship building.

Indigenous knowledge and modern science have different approaches, methodologies, analyses, and validation processes. The coproduction of knowledge process requires respect for each knowledge system and avoiding translation of one knowledge system into the other, that is, trusting an indigenous knowledge holder's ability to analyze their own information and respect that each person at the table comes with the credentials needed to be there. While some credentials are built from academic degrees and publications, others come from holding and demonstrating a body of knowledge through a lifetime of hunting, fishing, gathering, or being an elder.

Many Arctic science projects have aimed to build partnerships with indigenous communities, but few have used a true coproduction of knowledge process that brings together indigenous knowledge holders and scientists equitably from the inception of the project. An exemplar that demonstrates the process is the Ikaagivik 
Sikukuun (Ice Bridges) project in Kotzebue in northwest Alaska (Mahoney et al. 2017). This four-year (2017-20) project, which aims to understand fundamental processes underlying the mechanisms and impacts of changing coastal sea ice, first brought together indigenous knowledge holders with scientists from different disciplines to develop the research focus and questions, decide on a methodology, and then agree on a plan for implementing the project together. Indigenous knowledge will also inform the synthesis and dissemination of the results of the project.

The success of a coproduction of knowledge process must be defined by both the indigenous knowledge holders and scientists involved in a project. Experts from both knowledge systems must agree that a coproduction of knowledge occurred and it will hold all of the basic elements presented here. These include recognizing and working toward equity through building capacity, empowering indigenous partners, fostering an environment for trust and respect, building a collaborative process that involves multiple steps and continuous evaluation and which is defined by all those involved in a project, and respecting indigenous knowledge sovereignty.

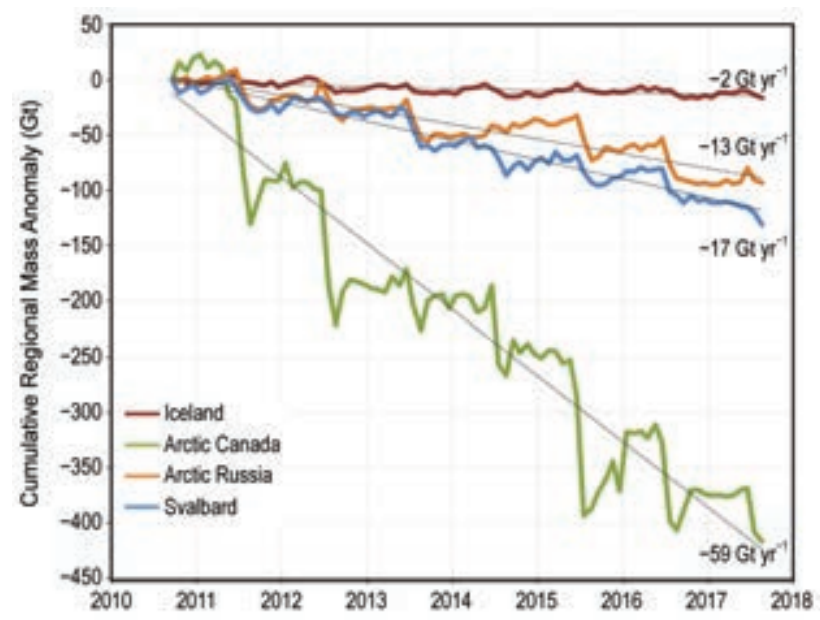

FIG. 5.17. Cumulative regional glacier mass anomalies (in, Gt) for Iceland, Arctic Canada, Arctic Russia, and Svalbard, derived using data from CryoSat2 radar altimetry (20II-17) (B. Wouters, Utrecht University). Cumulative mass anomalies in each region are defined relative to the glacier mass measured in the region at the start of the measurement period. Trend lines and

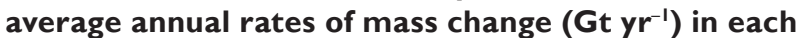
region are shown. Annual cycles in the accumulation and removal of mass are evident in each region. g. Terrestrial permafrost-V. E. Romanovsky, S. L. Smith, K. Isaksen, N. I. Shiklomanov, D. A. Streletskiy, A. L. Kholodov, H. H. Christiansen, D. S. Drozdov, G. V. Malkova, and S. S. Marchenko

Permafrost is an important component of the Arctic landscape, influencing hydrological systems and ecosystems, and presenting challenges for built infrastructure, for example, buildings, roads, railways, airports, and pipelines. Permafrost temperature and active layer thickness (ALT) are key indicators of changes in permafrost conditions. Permafrost is defined as earth materials (e.g., soil, rock) that exist at or below $0^{\circ} \mathrm{C}$ continuously for at least two consecutive

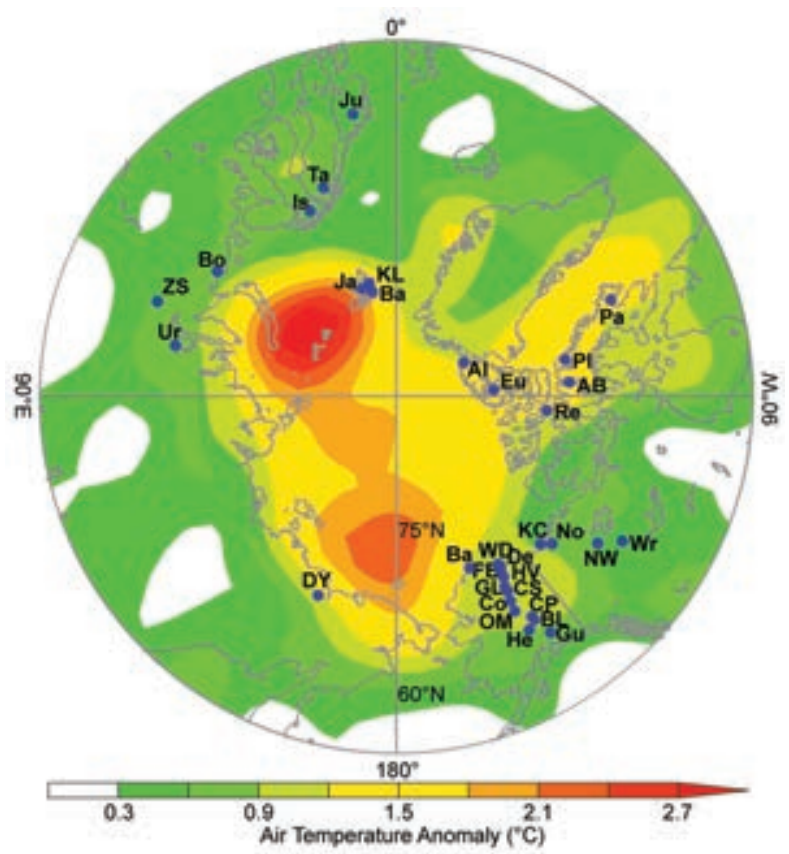

Fig. 5.18. Location of the permafrost temperature monitoring sites shown in Fig. $\mathbf{5 . 1 9}$ superimposed on average surface air temperature anomalies $\left({ }^{\circ} \mathrm{C}\right)$ during 2000-16 (with respect to the 198I-2010 mean) from the NCEP-reanalysis (Kalnay et al. 1996). Data provided by the NOAA/ESRL Physical Sciences Division (www.esrl.noaa.gov/psd). Sites shown in Fig. 5.19 for (a) Barrow (Ba), West Dock (WD), KC-07 (KC), Duvany Yar (DY), Deadhorse (De), Franklin Bluffs (FB), Galbraith Lake (GL), Happy Valley (HV), Norris Ck (No); (b) College Peat (CP), Old Man (OM), Chandalar Shelf (CS), Birch Lake (BL), Coldfoot (Co), Norman Wells (NW), Wrigley I and 2 (Wr), Healy (He), Gulkana (Gu); (c) Eureka EUK4 (Eu), Alert BHI, BH2, and BH5 (AI), Resolute (Re), Arctic Bay (AB), Pond Inlet (PI), Pangnirtung (Pa); (d) Janssonhaugen (Ja), Bayelva (Ba), Kapp Linne I (KL), Urengoy \# I5-06 and \# I510 (Ur), Juvvasshøe (Ju), Tarfalaryggen (Ta), Polar Ural (ZS), Bolvansky \#56, \#59, and \#65 (Bo), Iskoras Is-B-2 (Is). Information about these sites is available at http: //gtnpdatabase.org/, http://perma-frost.gi.alaska.edu /sites_map, and www2.gwu.edu/ calm/data/data-links .html. 
years. The active layer is the seasonally thawed layer above the permafrost. Permafrost temperatures, at a depth where seasonal temperature variations are negligible, are powerful indicators of long-term change. On the other hand, the active layer responds to shorter term fluctuations in climate and is especially sensitive to changes in summer air temperature and precipitation. Warming and thawing of permafrost in the Arctic are reported here.

Changes up to 2017 (most recent data available) in mean annual permafrost temperatures and ALT are summarized for a number of sites throughout the Arctic (Fig. 5.18). Recent long-term changes in permafrost temperature are driven mostly by air temperature trends (Romanovsky et al. 2015). Other important influences on permafrost temperature, such as snow depth and density, vegetation characteristics, and soil moisture, can affect the observed permafrost temperature trends at the local scale. In general, the increase in permafrost temperatures observed since the 1980s is more significant in the higher latitudes where the largest increase in air temperature is observed (Fig. 5.18).

I) Permafrost temperaTURES

Temperatures in the cold continuous permafrost of northern Alaska, Northwest Territories (Canada), and northeastern East Siberia continue to rise (Fig. 5.19a). In 2017 on the North Slope of Alaska, record high temperatures at 20-m depth occurred at all permafrost observatories (Barrow, West Dock, Franklin Bluffs, Happy Valley, and Deadhorse; Fig. 5.19a) with the exception of Galbraith Lake. The permafrost temperature increase $\left(+0.1^{\circ}\right.$ to $+0.2^{\circ} \mathrm{C}$ ) between 2016 and
2017 was substantial and comparable to the highest rate of warming observed in this region, which occurred during 1995-2000 (Fig. 5.19a). Since 2000, permafrost temperature increase at $20-\mathrm{m}$ depth in this region has ranged from $0.21^{\circ}$ to $0.66^{\circ} \mathrm{C}$ decade $^{-1}$ (Fig. 5.19a; Table 5.3).

In Interior Alaska, following the slight cooling of 2007-13, permafrost temperatures increased and were higher in 2017 than in 2016 at all sites (Coldfoot, Old Man, College Peat, Birch Lake, Gulkana, and Healy in Fig. 5.19b). The largest changes, at Birch Lake and Old Man, were associated with new record highs in 2017 for the entire 33-year measurement period (Fig. 5.19b; Table 5.3).
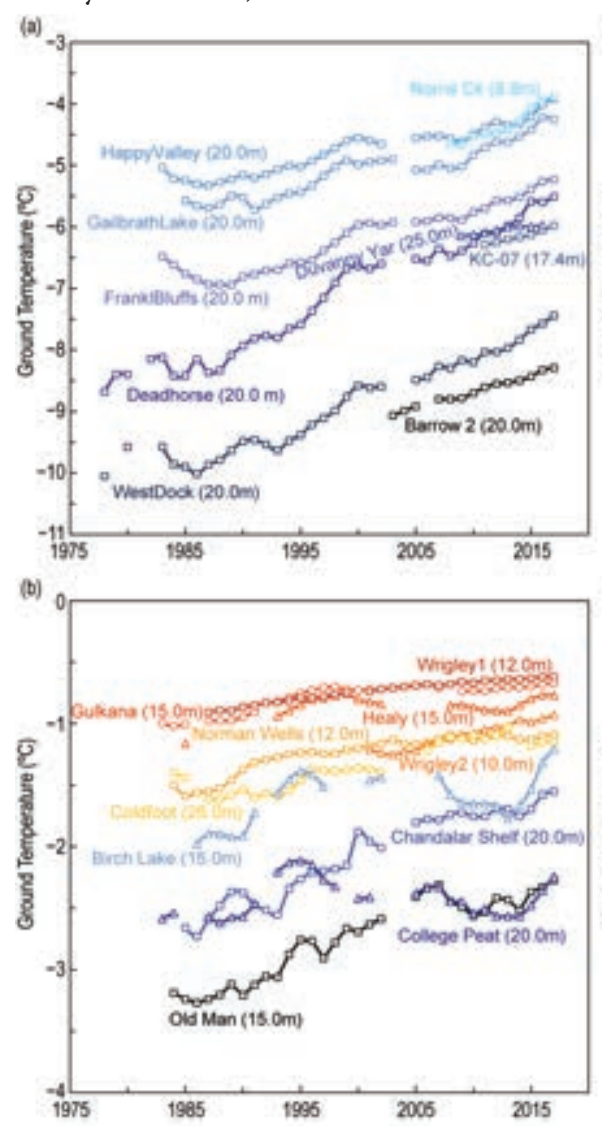

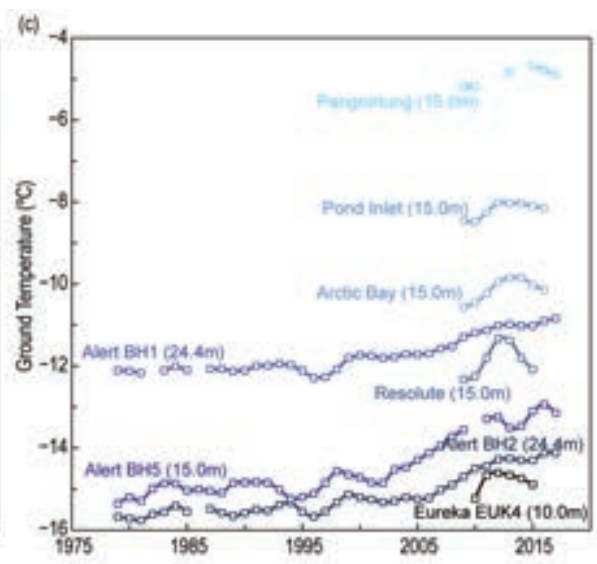

(d)

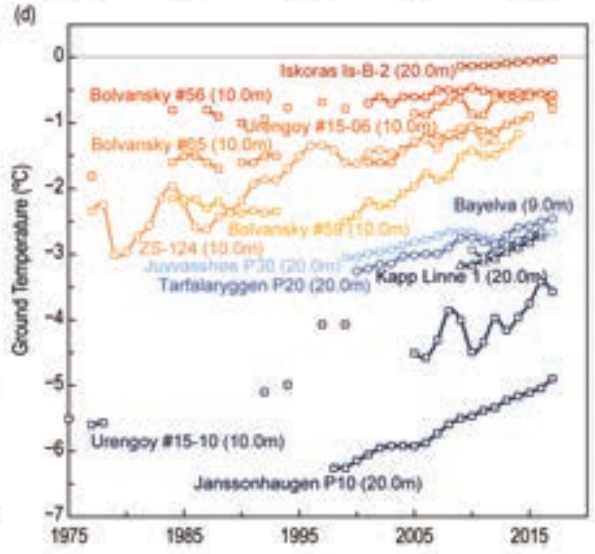

Fig. 5.19. Time series of mean annual ground temperature $\left({ }^{\circ} \mathrm{C}\right)$ at depths of 9 to $26 \mathrm{~m}$ below the surface at selected measurement sites that fall roughly into priority regions of the Adaptation Actions for a Changing Arctic Project (AMAP 2015): (a) cold continuous permafrost of northern Alaska, Northwest Territories (Canada), and NE East Siberia; (b) discontinuous permafrost in Interior Alaska and northwestern Canada; (c) cold continuous permafrost of eastern and High Arctic Canada (Baffin Davis Strait); and (d) continuous to discontinuous permafrost in Scandinavia, Svalbard, and Russia/Siberia (Barents region). Temperatures are measured at or near the depth of zero annual amplitude where the seasonal variations of ground temperature are negligible. Note that the temperature scales are different in each graph. Data are updated from Christiansen et al. 2010; Romanovksy et al. 2017; Smith et al. 2015, 2017; Ednie and Smith 2015; Boike et al. 2018. 
TABLE 5.3. Change in mean annual ground temperature $\left({ }^{\circ} \mathrm{C}\right.$ decade $\left.{ }^{-1}\right)$ for sites shown in Fig. 5.19. For sites where measurements began prior to 2000 , the rate for the entire available record is provided as well as the rate for the period after $\mathbf{2 0 0 0}$. The names of the stations with record high temperatures in 2017 are shown in red. Note that some records only began after 2007, as shown in Fig. 5.19.

\begin{tabular}{|c|c|c|c|}
\hline Region & Sites & Entire Record & Since 2000 \\
\hline Alaskan Arctic plain & $\begin{array}{l}\text { West Dock (WD), Deadhorse (De), } \\
\text { Franklin Bluffs (FB), Barrow (Ba) }\end{array}$ & +0.36 to +0.8 & +0.44 to +0.65 \\
\hline $\begin{array}{l}\text { Northern foothills of the } \\
\text { Brooks Range, Alaska }\end{array}$ & Happy Valley (HV), Galbraith Lake (GL) & +0.3 to +0.42 & +0.34 to +0.47 \\
\hline $\begin{array}{l}\text { Southern foothills of the } \\
\text { Brooks Range, Alaska }\end{array}$ & $\begin{array}{l}\text { Coldfoot (Co), Chandalar Shelf (CS), } \\
\text { Old Man (OM) }\end{array}$ & +0.08 to +0.35 & +0.14 to +0.25 \\
\hline Interior Alaska & $\begin{array}{l}\text { College Peat (CP), Birch Lake (BL), } \\
\text { Gulkana (Gu), Healy }(\mathrm{He})\end{array}$ & +0.07 to +0.22 & +0.03 to +0.1 \\
\hline Central Mackenzie Valley & Norman Wells (NW), Wrigley (Wr) & Up to +0.1 & $<+0.1$ to +0.2 \\
\hline Northern Mackenzie Valley & Norris Ck (No), KC-07(KC) & - & +0.5 to +0.9 \\
\hline Baffin Island & $\begin{array}{l}\text { Pangnirtung }(\mathrm{Pa}) \text {, Pond Inlet }(\mathrm{PI}) \text {, } \\
\text { Arctic Bay }(\mathrm{AB})\end{array}$ & - & +0.5 to +0.7 \\
\hline High Canadian Arctic & Resolute (Re), Eureka (Eu) & - & +0.4 to +0.7 \\
\hline High Canadian Arctic & $\begin{array}{l}\text { Alert }(\mathrm{Al}) \text { at } 15 \mathrm{~m} \\
24 \mathrm{~m}\end{array}$ & $\begin{array}{l}+0.5 \\
+0.3 \text { to }+0.4\end{array}$ & $\begin{array}{l}+1.2 \\
+0.7 \text { to }+0.9\end{array}$ \\
\hline North of East Siberia & Duvany Yar (DY) & - & +0.3 \\
\hline North of West Siberia & $\begin{array}{l}\text { Urengoy } 15-06 \text { and } \\
15-10 \text { (Ur) }\end{array}$ & +0.31 to +0.47 & +0.1 to +0.19 \\
\hline Russian European North & $\begin{array}{l}\text { Bolvansky 56, 59, and } 65 \text { (Bo), } \\
\text { Polar Ural (ZS-I24) }\end{array}$ & +0.18 to +0.46 & +0.1 to +0.83 \\
\hline Svalbard & $\begin{array}{l}\text { Janssonhaugen }(\mathrm{Ja}) \text {, Bayelva }(\mathrm{Ba}) \\
\text { Kapp Linne I (KL) }\end{array}$ & +0.7 & +0.6 to +0.7 \\
\hline Northern Scandinavia & Tarfalarggen (Ta), Iskoras Is-B-2 (Is) & - & +0.1 to +0.4 \\
\hline Southern Norway & Juvvasshøe (Ju) & +0.2 & +0.2 \\
\hline
\end{tabular}

In northwestern Canada, the temperature of permafrost in the central Mackenzie Valley (Norman Wells and Wrigley in Fig. 5.19b; Table 5.3) has generally increased since the mid-1980s (Smith et al. 2017). Although less warming has been observed since 2000, permafrost temperatures in 2017 at these sites were the highest recorded. Greater recent warming has been observed in the colder permafrost of the northern Mackenzie region (Norris Ck, KC-07 in Fig. 5.19a and Table 5.3; Smith et al. 2017), with the highest temperatures during the observation period occurring in 2016/17.
In northeastern Canada, the 2016/17 mean permafrost temperatures in the upper $25 \mathrm{~m}$ of the ground at Alert, northernmost Ellesmere Island in the high Arctic, were among the highest recorded since 1978 (Fig. 5.19c). Although permafrost at Alert has generally warmed since 1978, permafrost temperatures have increased at a higher rate since 2000 (Table 5.3; Smith et al. 2015), consistent with air temperature trends (Fig. 5.18). There has been little change at Alert since 2010 (Fig. 5.19c), which coincides with a period of lower mean annual air temperatures. At other sites in the Queen Elizabeth Islands (Resolute and Eureka) and on Baffin Island (Pangnirtung, Pond Inlet, and 
Arctic Bay), permafrost temperature measurements since 2008, at 10- to $15-\mathrm{m}$ depth, indicate an overall warming (Fig. 5.19c; Table 5.3). A decrease in permafrost temperature since 2012 appears to be associated with lower mean annual air temperatures over the last few years in the region.

Increases in permafrost temperature over the last 30-35 years in northern Russia have been similar to those in northern Alaska and the Canadian high Arctic (Drozdov et al. 2015). In the Russian European North and western Siberian Arctic, temperatures at $10-\mathrm{m}$ depth have increased by $\sim 0.4^{\circ}$ to $0.6^{\circ} \mathrm{C}$ decade $^{-1}$ since the late 1980s at colder permafrost sites (Fig. 5.19d, sites Bolvansky \#59, Urengoy \#15-06 and $\# 15-10)$ and increased less in warmer permafrost sites (Table 5.3; Fig. 5.19d, sites Bolvansky \#56 and Urengoy \#15-06; Drozdov et al. 2015). In these regions, there are differences in permafrost temperature (cold vs. warm) because surface conditions such as vegetation, surface wetness, and soil moisture vary according to landscape types, while climatic conditions are largely independent of surface condition and landscape.

In the Nordic region, where the temperature at $20-\mathrm{m}$ depth has increased between $0.1^{\circ}$ and $0.7^{\circ} \mathrm{C}$ decade $^{-1}$ (Fig. 5.19d; Table 5.3) since 2000, warming and thawing of permafrost have been observed recently (Christiansen et al. 2010; Isaksen et al. 2011; Farbrot et al. 2013). Lower rates of warming occur where permafrost temperatures are close to $0^{\circ} \mathrm{C}$ and latent heat effects related to melting ground ice are important. Greater warming occurred in colder permafrost on Svalbard and in northern Scandinavia (Table 5.3). In the discontinuous permafrost zone of southern Norway, permafrost warmed between 2015 and 2017, following a period of cooling between 2011 and 2014 (Fig. 5.19d).

\section{2) ACTIVE LAYER tHICKNESS}

In 2017, standardized, mechanical probing of ALT was conducted at 76 Circumpolar Active-Layer Monitoring (CALM) program sites in Alaska and Russia. Each site consists of a spatial grid varying from 1 ha to $1 \mathrm{~km}^{2}$ in size and is representative of the regional landscape (Shiklomanov et al. 2012). Additional active-layer observations, derived from thaw tubes (Duchesne et al. 2015), are available from 25 Canadian sites located in the Mackenzie Valley, northwestern Canada.

The average ALT in 2017 for 20 North Slope of Alaska sites was $0.52 \mathrm{~m}$, which is $0.06 \mathrm{~m}$ (or $+12 \%$ ) higher than the 1996-2005 mean and is one of the highest in the 22-year data record. Previous maxima occurred in 1998, 2013, and 2016 (Fig. 5.20). The interior of Alaska is characterized by a pronounced ALT increase over the last 22 years (Fig. 5.20). However, after reaching the 22-year maximum of $0.77 \mathrm{~m}$ in 2016, the 2017 ALT decreased by $10 \%$ to $0.69 \mathrm{~m}$.

Records from the sites with thaw tubes in the Mackenzie Valley indicate that there has been a general increase in ALT in this region since 2008
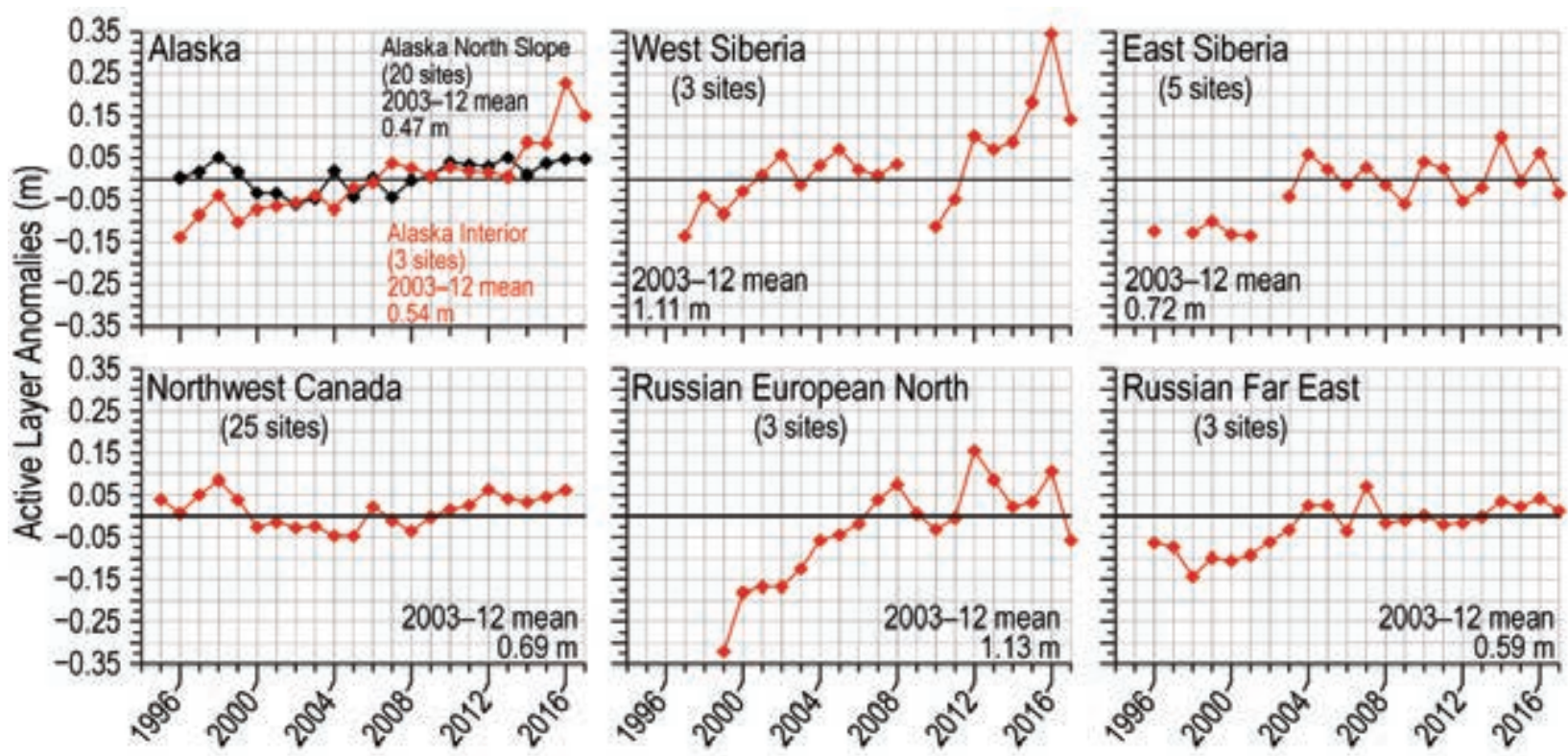

FIG. 5.20. Long-term annual active-layer thickness change (m) in six different Arctic regions for 2017 as observed by the CALM program relative to the 2003-12 mean. Positive (negative) anomaly values indicate the active layer was thicker (thinner) than average. Thaw depth observations from the end of the thawing season were used. Only sites with at least $\mathbf{2 0}$ years of continuous thaw depth observations are shown. 
(Fig. 5.20; Duchesne et al. 2015; Smith et al. 2017). ALT in 2016 (most recently available data) was on average $0.06 \mathrm{~m}$ greater than the 2003-12 mean, similar to the previous peak value in 2012 .

A decrease in ALT from 2016 to 2017 was reported for all Russian regions. In West Siberia, the average 2017 ALT was $1.25 \mathrm{~m}$, which is $0.2 \mathrm{~m}$ (or $14 \%$ ) smaller than the 20-year maximum observed in 2016. In the Russian European North, the 2017 ALT was $1.08 \mathrm{~m}$ compared to $1.24 \mathrm{~m}$ in 2016. A 2017 ALT of $0.69 \mathrm{~m}$ was reported for East Siberia, which is $0.1 \mathrm{~m}$ smaller than the regional average 2016 ALT value. The smallest decrease was reported in the Russian Far East (Chukotka), where the ALT in 2017 was $0.03 \mathrm{~m}$ (or 5\%) less than that reported in 2016.

In the Nordic region, active layer records (19992017) indicate a general ALT increase of 0.10 to $0.30 \mathrm{~m}$ since 1999 . The particularly warm summer of 2014 in the Nordic region contributed to the thickest active layer measured so far at some places.

h. Tundra greenness-H. Epstein, U. Bhatt, M. Raynolds, D. Walker, J. Pinzon, C. J. Tucker, B. C. Forbes, T. Horstkotte, M. Macias-Fauria, A. Martin, G. Phoenix, J. Bjerke, H. Tømmervik, P. Fauchald, H. Vickers, R. Myneni, T. Park, and C. Dickerson

Vegetation in the Arctic tundra has been responding to environmental changes over the course of the last several decades, with the tendency being an increase in the amount of above-ground vegetation, that is, "greening" (Bhatt et al. 2010). These vegetation changes vary spatially throughout the circumpolar Arctic in both direction and magnitude, and they are not always consistent over time. This suggests complex interactions among the atmosphere, ground (soils and permafrost), vegetation, and animals of the Arctic system. Changes in tundra vegetation can have important effects on permafrost, hydrology, carbon and nutrient cycling, and the surface energy balance (e.g., Frost et al. 2017; Kępski et al. 2017), as well as the diversity, abundance, and distribution of both wild and domesticated herbivores (e.g., Fauchald et al. 2017; Horstkotte et al. 2017). We continue to evaluate the state of the circumpolar Arctic vegetation, to improve our understanding of these complex interactions and their impacts on the Arctic system and beyond.

The reported controls on tundra greening are numerous and varied. They include increases in summer, spring, and winter temperatures and increases in growing season length (Bhatt et al. 2017; Fauchald et al. 2017; Horstkotte et al. 2017; Myers-Smith et al. 2018; Vickers et al. 2016), in part controlled by reductions in Arctic Ocean sea ice cover (Bhatt et al.
2017; Macias-Fauria et al. 2017; see Section 5d). Other controls on tundra greening include increases in snow water equivalent (see Section $5 \mathrm{i}$ ) and soil moisture, increases in active layer depth (see Section 5g), changes in the patterns of herbivore activity, and even a reduction in the human use of the land (Fauchald et al. 2017; Horstkotte et al. 2017; Martin et al. 2017; Westergaard-Nielsen et al. 2017).

Using Earth-observing satellites with subdaily return intervals, Arctic tundra vegetation has been continuously monitored since 1982 . Here, data are reported from the Global Inventory Modeling and Mapping Studies (GIMMS) 3g V1 dataset, based largely on the AVHRR sensors aboard NOAA satellites (Pinzon and Tucker 2014). At the time of writing, the GIMMS3g V1 dataset was only available through 2016. The GIMMS product (at $1 / 12^{\circ}$ resolution for this report) is a biweekly, maximum-value composited dataset of the normalized difference vegetation index (NDVI). NDVI is highly correlated with aboveground vegetation (e.g., Raynolds et al. 2012), or "greenness," of the Arctic tundra. Two metrics based on the NDVI are used: MaxNDVI and TI-NDVI. MaxNDVI is the peak NDVI for the year (growing season) and is related to yearly maximum aboveground vegetation biomass. TI (time-integrated) NDVI is the sum of the biweekly NDVI values for the growing season and is correlated with the total above-ground vegetation productivity.

Examining the overall trend in tundra greenness for the now 35-year record (1982-2016), it is apparent that the MaxNDVI and the TI-NDVI have increased throughout most of the circumpolar Arctic tundra (Fig. 5.21). Regions with some of the greatest increases in tundra greenness are the North Slope of Alaska, the low Arctic (southern tundra subzones) of the Canadian tundra, and eastern Siberia. However, tundra greenness has declined (i.e., the tundra has been "browning") on the Yukon-Kuskokwim Delta of western Alaska, in the high Arctic of the Canadian Archipelago, and in northwestern Siberia. Regions of greening and browning, measured by NDVI increases and decreases, respectively, tend to be consistent between MaxNDVI and TI-NDVI.

Following 2-3 years of successive declines prior to and including 2014, the NDVI or greenness of Arctic tundra increased in 2015 and 2016 for both indices (MaxNDVI and TI-NDVI) and both continents (North America and Eurasia), exhibiting substantial recovery from the previous years of "browning." (Fig. 5.22). One exception was the TI-NDVI for North America, which continued to decrease in 2015. MaxNDVI and TI-NDVI for the entire Arctic 
increased $6.0 \%$ and $9.3 \%$, respectively, between 2015 and 2016. MaxNDVI in North America increased by 6.3\% compared to 5.4\% in Eurasia. The first substantial annual increase in TI-NDVI for North America since 2010 occurred in 2016, potentially due to the high growing season temperatures that year.

All NDVI values for 2016 were greater than their respective mean values for the 35-year record. MaxNDVI values ranked second, third, and first for the Arctic, Eurasian Arctic, and North American Arctic, respectively. TI-NDVI values ranked first, first, and second for the Arctic, Eurasian Arctic,
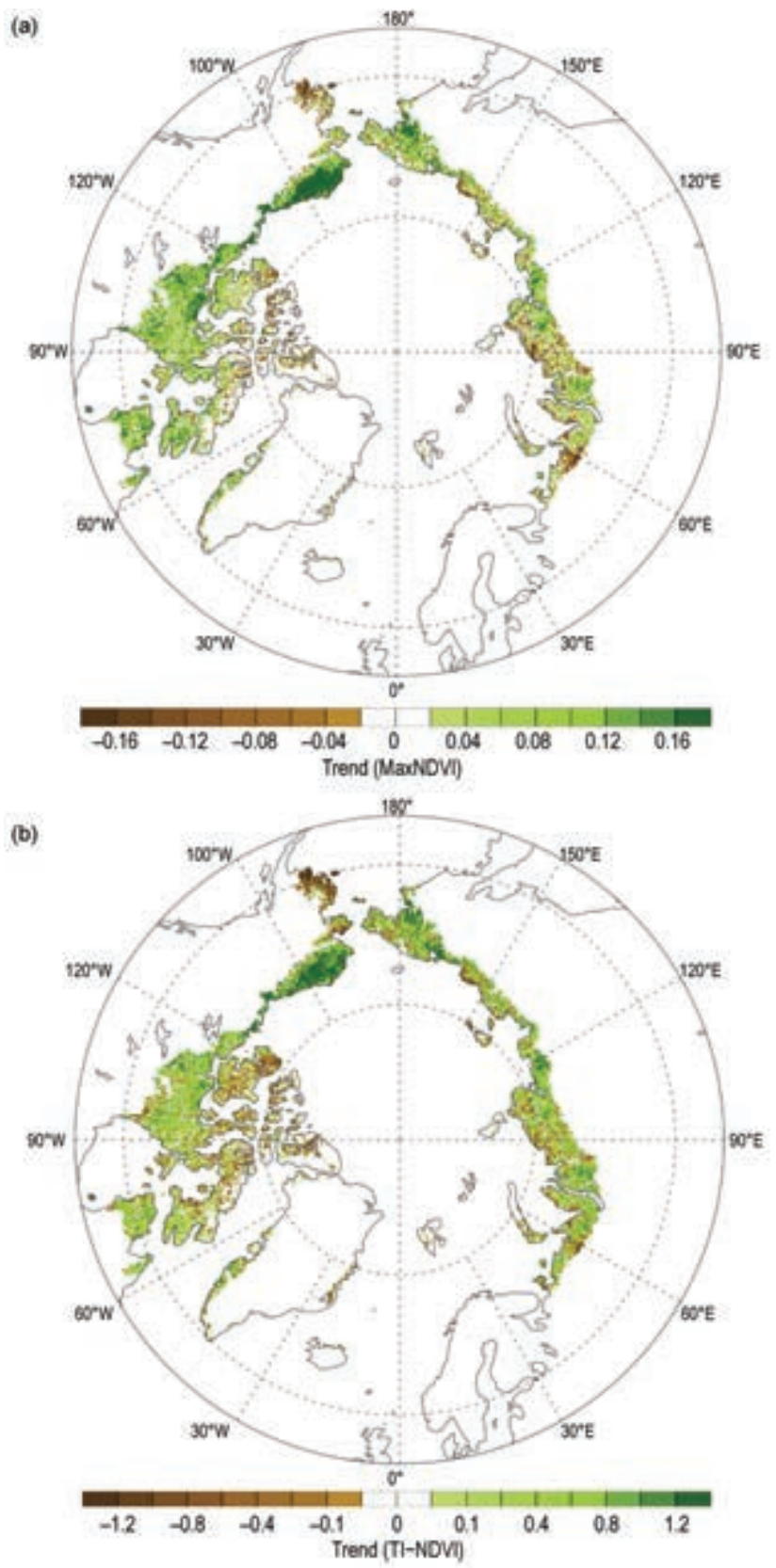

FIG. 5.2I. (a) Magnitude of the trend in (a) MaxNDVI and (b) TI-NDVI for 1982-2016 and North American Arctic, respectively. Based on remotely-sensed land surface temperatures (LST) from the same sensors as those providing the NDVI values, the summer warmth index (SWI: sum of mean monthly temperatures $>0^{\circ} \mathrm{C}$ ) for the Arctic as a whole and for the Eurasian Arctic was greater in 2016 than in any other year of the satellite record (since 1982). For the North American Arctic, the 2016 SWI was the second highest on record (very close to the highest value in 1994).

Even though the past two years have seen large increases in tundra NDVI, there are still regions of the Arctic that have experienced browning over the length of the satellite record. There have also been substantial periods of tundra browning even within a general greening trend. While research on tundra browning is still relatively sparse, there has recently been greater attention given to this phenomenon. Bjerke et al. (2017) report on extensive vegetation dieback in northern Norway (including Svalbard) in 2014 and 2015. They attributed this dieback largely to
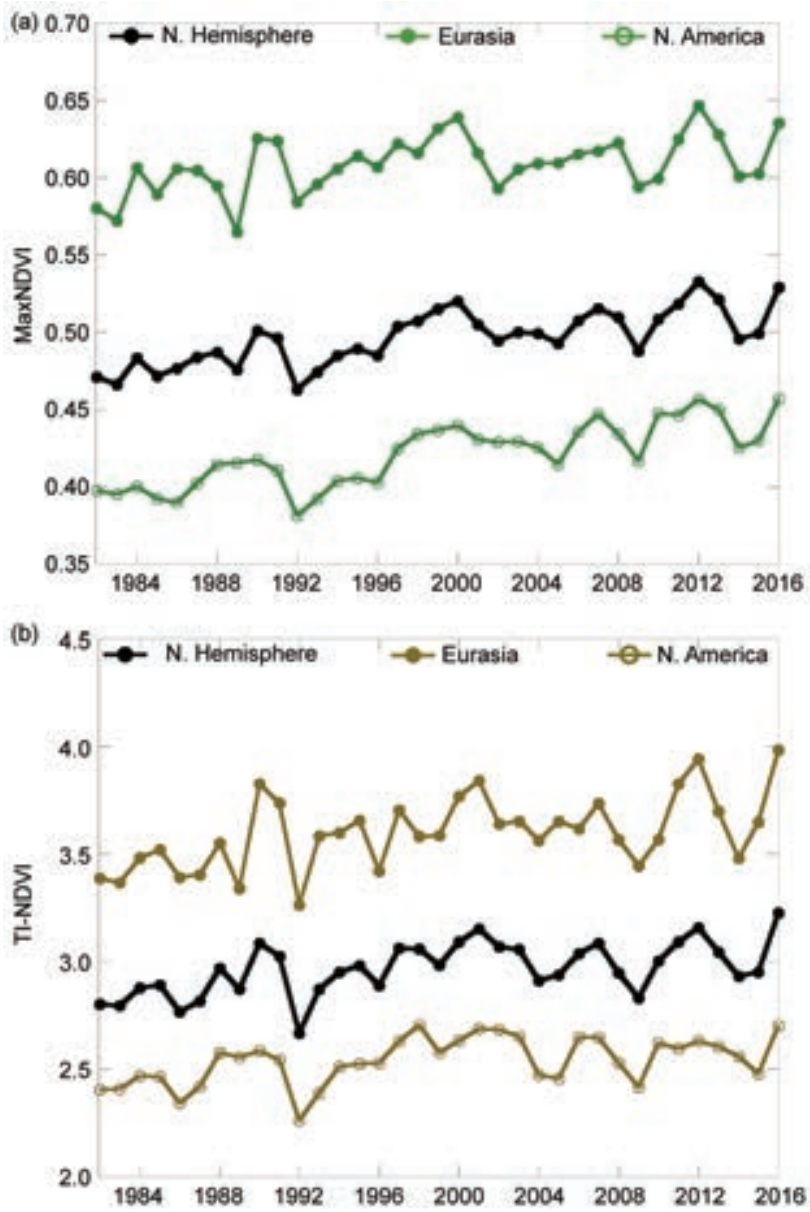

FIG. 5.22. (a) MaxNDVI and (b) TI-NDVI for Eurasia (top), the Arctic as a whole (middle), and North America (bottom) for 1982-2016. 


\section{SIDEBAR 5.3: WILDLAND FIRE IN BOREAL AND ARCTIC NORTH}

\section{AMERICA-A. YORK, U. BHATT, R. THOMAN, AND R. ZIEL}

Despite the low temperatures and short growing seasons of northern ecosystems, wildland fire is the dominant ecological disturbance in the boreal forest, the world's largest terrestrial biome. Wildland fire also affects adjacent tundra regions. This sidebar, with a focus on the 2017 Alaska fire season, addresses the history and variability of fire disturbance in Alaska (US) and Northwest Territories (Canada), outlines how short-term weather conditions (temperature, precipitation, convection, and wind) influence area burned, and discusses projections for future tendencies in fire susceptibility.

Beyond immediate threats to lives and property, fire impacts include compromised human health and limited visibility due to smoke. Fire disturbance affects terrestrial ecosystems at multiple scales, including carbon release through combustion (Kasischke et al. 2000). About $35 \%$ of global soil carbon is stored in tundra and boreal ecosystems (Scharlemann et al. 2014) that are potentially vulnerable to fire disturbance (Turetsky et al. 2015). Other impacts include interactions with vegetation succession (Mann et al. 2012; Johnstone et al. 2010), biogeochemical cycles (Bond-Lamberty et al. 2007), energy balance (Rogers et al. 2015), and hydrology (He. Liu et al. 2005). Combustion of the insulating surface organic layer can destabilize underlying permafrost. Because permafrost impedes drainage and ice-rich permafrost settles upon thawing (thermokarst), accelerating degradation of the permafrost may have large consequences for northern ecosystems (Jorgenson et al. 2010; Jones et al. 2015).

Weather is a dominant control of fire activity on a year-to-year basis. Over the longer term, high-latitude fire regimes appear to be responding rapidly to environmental changes associated with the warming climate. Although highly variable, area burned has increased since the 1960s in much of boreal North America (Kasischke and Turetsky 2006; Gillett et al. 2004). Over that time, both the number and size of individual fire events has increased, contributing to more frequent large fire years in northwestern North America
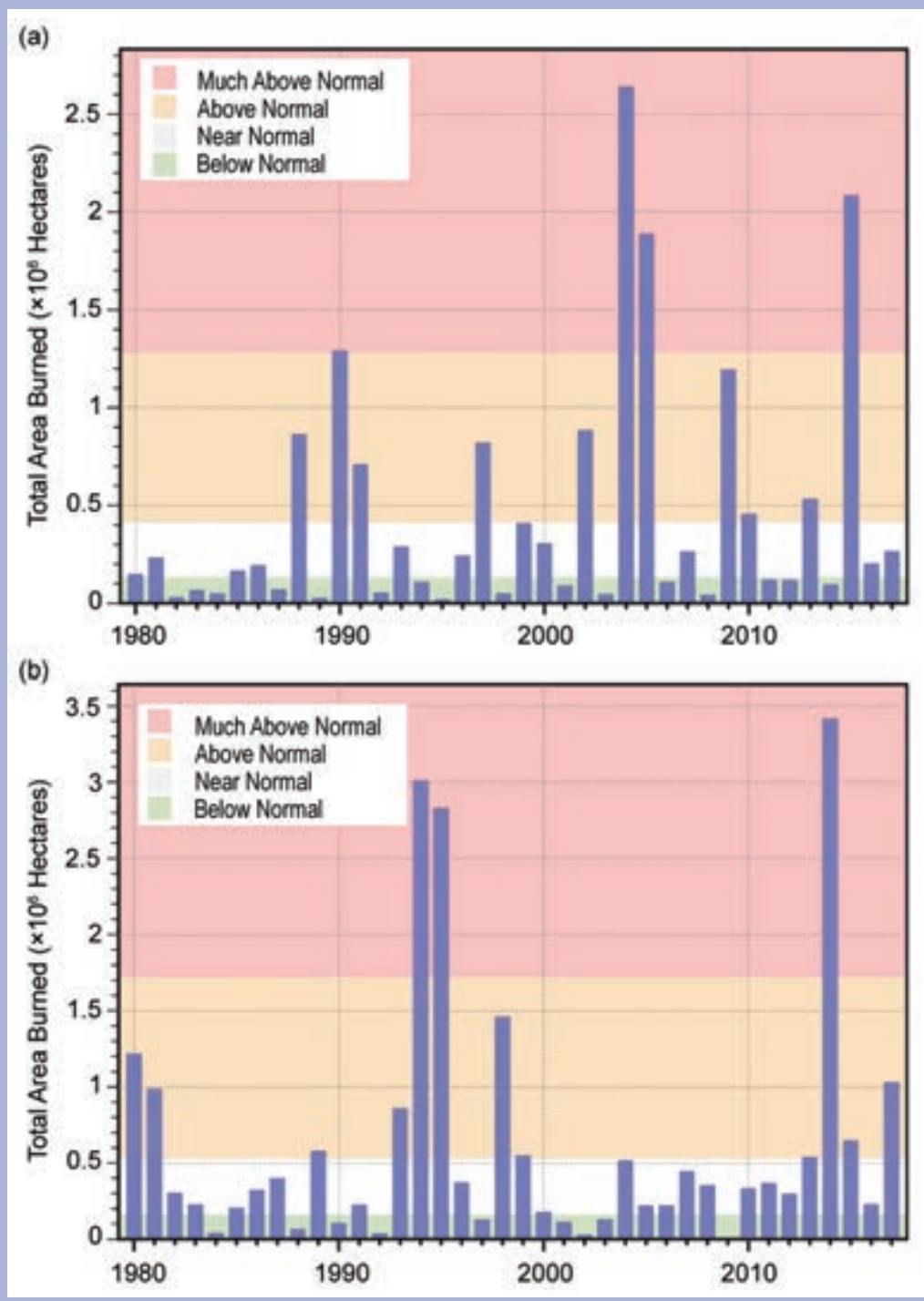

FIG. SB5.3. Annual area burned (ha) each year since 1980 in (a) Alaska and (b) Northwest Territories (Canada), including both boreal and tundra regions. Note that high fire years are not coincident in these subregions, indicating the importance of local weather and other conditions (e.g., fuels, ignition). Category definitions used here are from the fitted log-normal distribution to the observed 1980-2017 area burned; below normal is the $0-33$ rd percentiles, near normal is the $33 \mathrm{rd}-66$ th percentiles, above normal is the $66 \mathrm{th}-90$ th percentiles, much above is greater than the 90 th percentile.

(Kasischke and Turetsky 2006). Figure SB5.3 shows area burned each year since 1980 in Alaska and Northwest Territories, including both boreal and tundra regions.

Although highly variable, high-latitude fire seasons generally begin and end earlier than in more temperate areas 
(Fig. SB5.4). Depending on weather, fire danger can increase as soon as areas are snow-free in April and May; season-ending rains typically fall in July or August, but their absence can extend the season into September, as in the record years of 2004 (2.67 million ha) and 2005 ( 1.88 million ha) in Alaska. Recent large fire seasons in high latitudes include 2014 in Northwest Territories (Fig. SB5.3), where 385 fires burned 3.4 million ha, and 2015 in Alaska (Fig. SB5.3), where 766 fires burned 2 million ha-the latter was more than half the total area burned in the entire United States (NWT 20I5; AICC 20I5). Northern communities threatened or damaged by recent wildfires include Fort McMurray, located in the boreal forest in Alberta, Canada, where 88000 people were evacuated and 2400 structures were destroyed in May 2016 (Kochtubajda et al. 2017). The 2007 Anaktuvuk River Fire is the largest (104000 ha) and longestburning (almost 3 months) fire known to have occurred on the North Slope of Alaska and initiated widespread thermokarst development (Jones et al. 2015).

Most area burned in northern ecosystems occurs during sporadic periods of high fire activity. Half of the area burned in Alaska from 2002 to 2010 was consumed over just 36 days (Barrett et al. 2016). Recent analyses have identified a temperature threshold in Alaska with a much greater likelihood of fire occurrence within a 30 -year period at locations where mean July temperatures exceed $13.4^{\circ} \mathrm{C}$ (Young et al. 2017). Large fire events require the confluence of warm and dry weather conditions with a source of ignition (often lightning from convective thunderstorms) and fuels that can carry fire. High latitude ecosystems are characterized by unique fuels, in particular, fast-drying beds of mosses, lichens, and accumulated organic material (duff) that underlie resinous shrubs and dense, highly flammable conifers. These understory fuels dry rapidly during periods of warm, dry weather and the long day lengths of June and July. Consequently, extended drought is not required to increase fire danger to extreme levels.

Historically, lightning is responsible for the majority of the acreage burned in high latitudes, as lightning-ignited fires occur in more remote locations and thus are subject to lower levels of suppression than human-started incidents. Veraverbeke et al. (2017) showed that lightning ignitions have increased in boreal
North America since 1975 and were a major contributor in the extreme 2014 Northwest Territories and 2015 Alaska fire seasons. In addition, Partain et al. (2016) found that humaninduced climate change-manifested as a combination of high surface air temperatures, low relative humidity, and low precipitation-increased the likelihood of the extremely dry fuel conditions seen in Alaska in 2015 by $34 \%-60 \%$.

The snow-free season has increased by approximately 5 days decade ${ }^{-1}$ in Alaska since 1979 (Liston and Hiemstra 20II). In response, in 2006 Alaska's fire management agencies shifted the statutory start of fire season ahead by a month, from I May to I April, to better prepare for early season events. In addition to adapting to long-term trends, managers in Alaska and Canada must track day-to-day variability in threats to dispersed populations with limited resources. Managers in both regions use the Canadian fire weather in$\operatorname{dex}(\mathrm{FWI})$ system on a daily basis to estimate the spatial and temporal distribution of wildfire potential from observed and forecast weather conditions (Lawson and Armitage 2008). Among the FWI indices, the buildup index (BUI), based on cumulative scoring of daily temperature, relative humidity, and precipitation, represents seasonal variability in fuel availability and flammability (Fig. SB5.4). A BUI threshold of 80 has been identified as a critical indicator of fire growth potential in Alaska (Ziel et al. 2015). 
In 2017, the typical area burned in Alaska (26422I ha; Fig. SB5.3) was reflected in a fairly normal BUI across the boreal region that essentially paralleled the climatological average (Fig. SB5.4). However, the impact of a "normal" season can fall disproportionately on specific areas in a landscape this large. In 2017, while there were no significant peaks in the BUI, local conditions in the Upper Yukon zone in northeast Alaska were significantly warmer and drier. Consistent with the Upper Yukon BUI trend (Fig. SB5.4), the fire season was extended and fairly severe in that large region of the state, with periods of high fire danger ( $B U I$ 280) from mid-June to mid-August near and north of the Arctic Circle. More than 160000 ha $(63 \%$ of the 2017 Alaska total) burned in the Upper Yukon area during this period.
Under a range of climate change scenarios, analyses using multiple approaches project significant increases (up to four-fold) in area burned in high latitude ecosystems by the end of the 2 Ist century (French et al. 20I5; Young et al. 2017; Yue et al. 2015, and references therein). In addition, annual lightning frequency is projected to increase by $12 \%$ $\pm 5 \%$ per ${ }^{\circ} \mathrm{C}$ of warming in the contiguous United States (Romps et al. 2014) and may increase correspondingly in high latitudes. Because specific fire events depend on multiple interacting factors, the resulting changes in high latitude fire regimes will vary greatly over space and time, but all evidence indicates that northern ecosystems will become increasingly susceptible to burning. changes in winter weather, specifically reductions in snow cover areal extent due to winter warming events, which left the ground exposed to subsequent freezing and desiccation (Vikhamar-Schuler et al. 2016). Insect outbreaks were identified as a secondary contributor to vegetation mortality (Bjerke et al. 2017).

i. Terrestrial snow cover in the Arctic-C. Derksen, R. Brown, L. Mudryk, K. Luojus, and S. Helfrich

Satellite-derived estimates of snow cover extent (SCE) over Arctic land areas date back to 1967 and have revealed dramatic reductions since 2005. These changes are important to the Arctic system because spring snow cover over land areas significantly influences the surface energy budget (snow is highly reflective of incoming solar energy), ground thermal regime (snow is an effective insulator of the underlying soil), and hydrological processes (the snowpack stores water in solid form for many months before spring melt). Changes in snow cover also have the potential to impact fauna living above, in, and under the snowpack, vegetation, biogeochemical activity, and exchanges of carbon dioxide and other trace gases (Brown et al. 2017).

Spring (April-June) SCE anomalies for the Arctic (land areas north of $60^{\circ} \mathrm{N}$ ) were regionally computed for North America and Eurasia using the NOAA snow chart climate data record, which extends from 1967 to present (maintained at Rutgers University; Estilow et al. 2015; http://climate.rutgers.edu/snowcover/; Fig. 5.23). For the first time in over a decade, 2017 Eurasian Arctic spring SCE was above average relative to the 1981-2010 reference period. April and May SCE anomalies were positive, including the second highest May SCE over the period of satellite observations. These are the first positive SCE anomalies observed in May over the Eurasian Arctic since 2005; June SCE anomalies were positive across the Eurasian Arctic for the first time since 2004. SCE anomalies over the North American Arctic were negative all spring but did not approach the series of record-breaking low SCE values observed in recent years.

Snow cover duration (SCD) departures were calculated from the NOAA Interactive Multisensor Snow and Ice Mapping System (IMS; Helfrich et al. 2007) product to identify differences in the onset of snow cover in fall and melt of snow cover in spring relative to a 1998-2010 reference period. While there was evidence of earlier snow cover onset over much of midlatitude Eurasia in autumn 2016 (consistent with cold surface air temperature anomalies), Arctic land areas (with the exception of Alaska) had near-normal snow onset timing (Fig. 5.24a). Later-than-normal snow melt onset across Eurasia (Fig. 5.24b), also reflected in the positive SCE anomalies (Fig. 5.23), was consistent with colder-than-normal surface air temperatures across this region (especially in May and June). Spring snow melt across the Canadian Arc- 

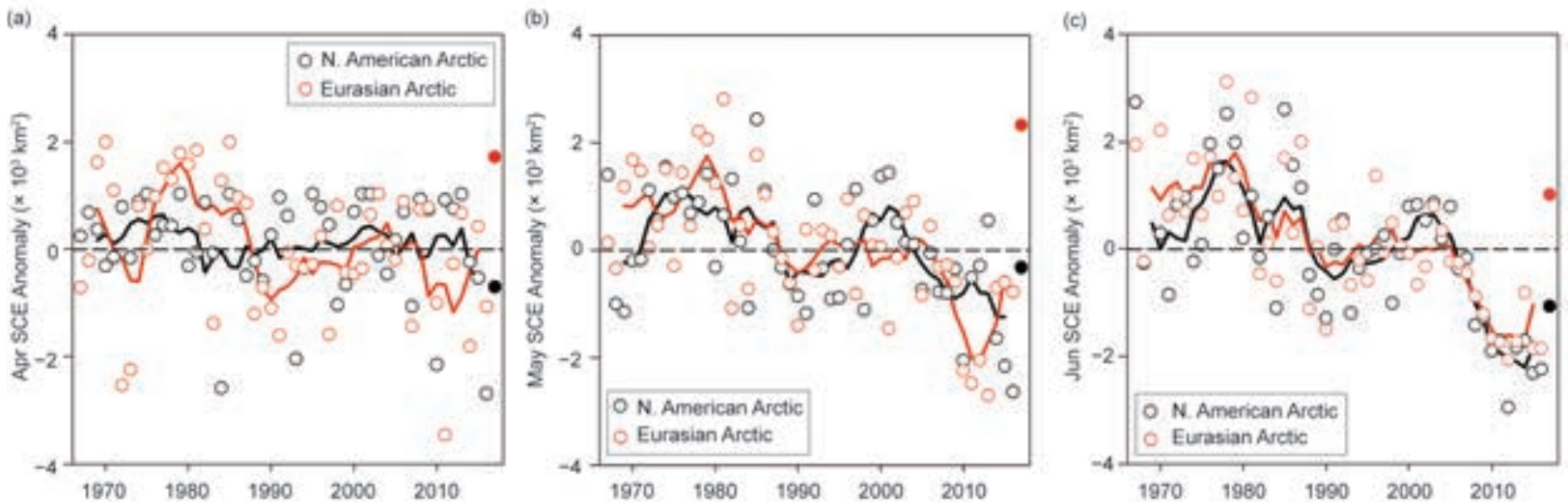

Fig. 5.23. (a) Monthly SCE anomaly $\left(\times 10^{3} \mathrm{~km}^{2}\right)$ for Arctic land areas $\left(>60^{\circ} \mathrm{N}\right)$ from the NOAA snow chart CDR for (a) Apr, (b) May, and (c) Jun from 1967 to 2017. Anomalies are relative to the average for $1981-2010$ and standardized (each observation is differenced from the mean and divided by the standard deviation and is thus unitless). Solid black and red lines depict 5-yr running means for North America and Eurasia, respectively. Solid symbols denote anomalies for 2017.
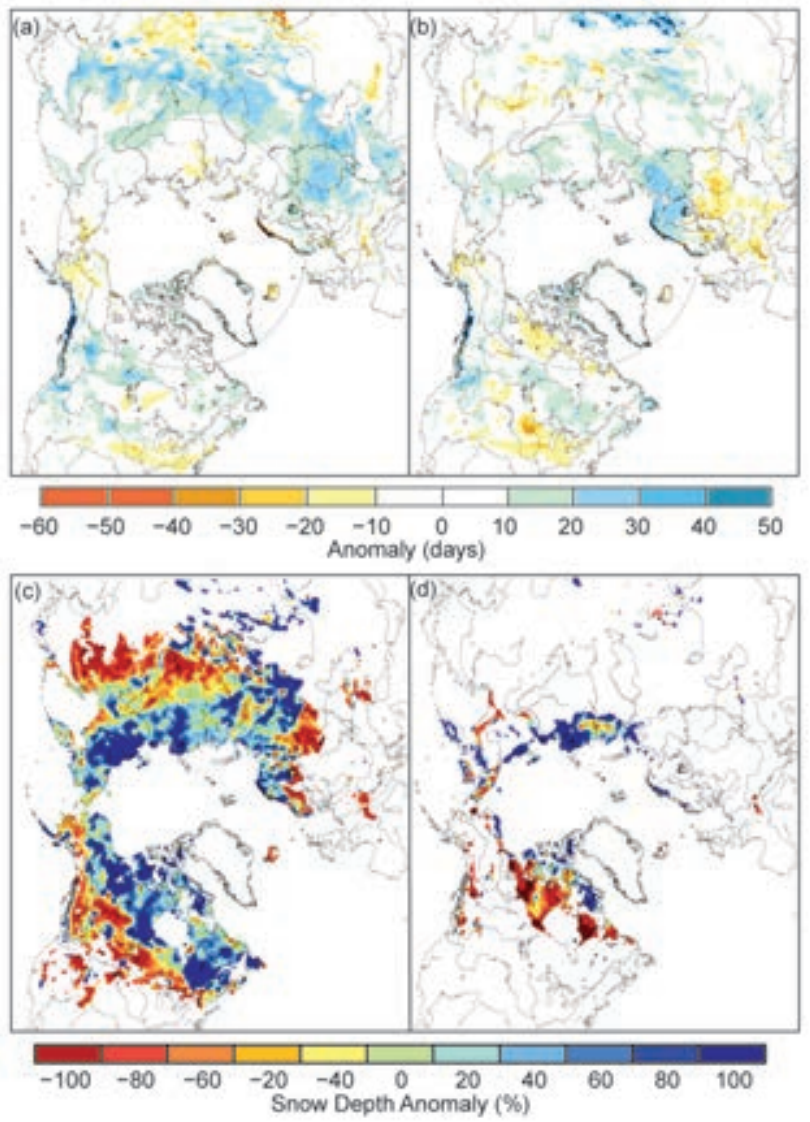

FIG. 5.24. SCD anomalies (\%) from the NOAA daily IMS snow cover product (Helfrich et al. 2007; relative to 1998-2010 base period because of the shorter available time series but higher spatial resolution IMS data). IMS data record for the (a) 2016 autumn season and (b) 2017 spring season. Snow depth anomaly (\% of 1999-2010 average) from the CMC snow depth analysis for (c) Apr and (d) Jun 2017. tic was slightly earlier than normal, coincident with warmer-than-average surface temperatures in May and June. Snow depth anomalies derived from the Canadian Meteorological Centre daily gridded global snow depth analysis (Brasnett 1999) showed predominantly positive anomalies over high latitude regions of Siberia and North America in April (Fig. 5.24c) and mainly negative anomalies outside the Arctic. By late spring (June), the anomalies exhibited contrasting continental patterns, with Eurasia characterized by extensive positive snow depth anomalies, while the North American Arctic was dominated by negative snow depth anomalies (Fig. 5.24d), consistent with the region of earlier snow melt (Fig. 5.24b).

Four independent products were integrated to generate a multidataset snow water equivalent (SWE; the amount of water stored in solid form as snow) anomaly time series (1980-2017) for April (typically the month of maximum SWE across the Arctic; Fig. 5.25). The datasets were derived from: (1) modern atmospheric reanalysis (the Modern-Era Retrospective Analysis for Research and Applications version 2; Reichle et al. 2017); (2) reconstructed SWE driven by ERA-Interim meteorology described by Brown et al. (2003); (3) the physical snowpack model Crocus driven by ERA-Interim meteorology (Brun et al. 2013); and (4) the European Space Agency GlobSnow product derived through a combination of satellite passive microwave measurements and climate station observations (Takala et al. 2011). While there is a high degree of interannual variability in the multidataset SWE anomalies, they predominantly show a negative trend since 2000 (Fig. 5.25). North American Arctic SWE was again negative in 2017 while Eurasian SWE anomalies were positive, indicating a deeper-than- 


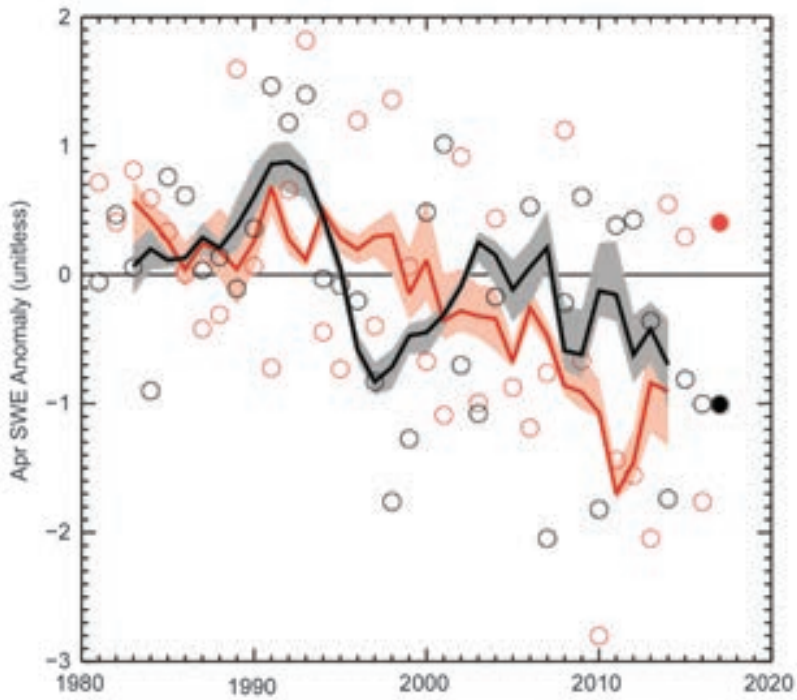

FIG. 5.25. Mean Apr SWE anomalies for Arctic land areas calculated from four independent products for North American (black) and Eurasian (red) sectors of the Arctic. Anomalies are relative to the average for 198I-20I0 and standardized (each observation is differenced from the mean and divided by the std. dev. and is thus unitless). Solid black and red lines depict 5-yr running means for North America and Eurasia, respectively, and shading indicates the interdataset anomaly spread ( \pm I std. dev.). Solid symbols denote anomalies for 2017.

average snowpack in early spring was a precursor to the above-average snow extent that followed later in the season.

Despite the long-term decline in Arctic spring SCE driven by increasing temperature trends, negative snow anomalies are not consistently observed in every season (nor in all regions). Off-trend anomalies, such as those observed in the Eurasian Arctic in 2017, are driven by natural variability in atmospheric circulation patterns which drive regional temperature and precipitation anomalies. The rebound in Eurasian SCE during May and June 2017 was consistent with winter and spring season circulation patterns which generally favored colder surface temperatures, enhanced precipitation, and above-average snow accumulation across northern Eurasia.

j. Ozone and UV radiation-G. H. Bernhard, V. E. Fioletov, J.-U. GrooB, I. Lalongo, B. Johnsen, K. Lakkala, G. L. Manney, and R. Müller

This report emphasizes the November 2016 to April 2017 period because chemically-induced loss of polar ozone occurs predominantly during winter and spring (WMO 2014). Chemical processes that drive ozone depletion are initiated at temperatures below about $195 \mathrm{~K}\left(-78^{\circ} \mathrm{C}\right)$ in the lower stratosphere (altitude of approximately 15 to $25 \mathrm{~km}$ ), which lead to the formation of polar stratospheric clouds (PSCs). These clouds act as a catalyst to transform inactive forms of chlorine-containing substances (e.g., $\mathrm{HCl}$ and $\mathrm{ClONO}_{2}$ ) to active, ozone-destroying chlorine species (e.g., $\mathrm{ClO}$ ).

Temperatures in the Arctic stratosphere between late November and late December 2016 were about $5^{\circ} \mathrm{C}$ higher than the average temperature of the observational record (1979-2015); temperatures in late November 2016 were near the highest values on record for this period. Temperatures dropped below the threshold for the formation of PSCs only in late December. (The onset of PSC formation is typically in early December with the earliest onsets observed in mid-November.) Temperatures remained low enough to sustain PSCs through mid-February 2017. Starting in late December, modest chlorine activation was measured by the Aura Microwave Limb Sounder (MLS). From late January to mid-February 2017, active chlorine $(\mathrm{ClO})$ concentrations were, on average, $45 \%$ higher than the mean concentration calculated from the MLS data record (2005-16) because stratospheric temperatures during this period were about $4^{\circ} \mathrm{C}$ below average. Ozone decreases via destruction by activated chlorine started in late January and continued through mid-March 2017. After mid-March, chlorine was deactivated and chemical ozone destruction ceased.

Between December 2016 and mid-January 2017, ozone mixing ratios (a measure of ozone concentrations) were close to the upper limit of values from the observational record (2004-17) (Fig. 5.26). At the end of January, mixing ratios started to decline and fell below average in March and April 2017. However, in

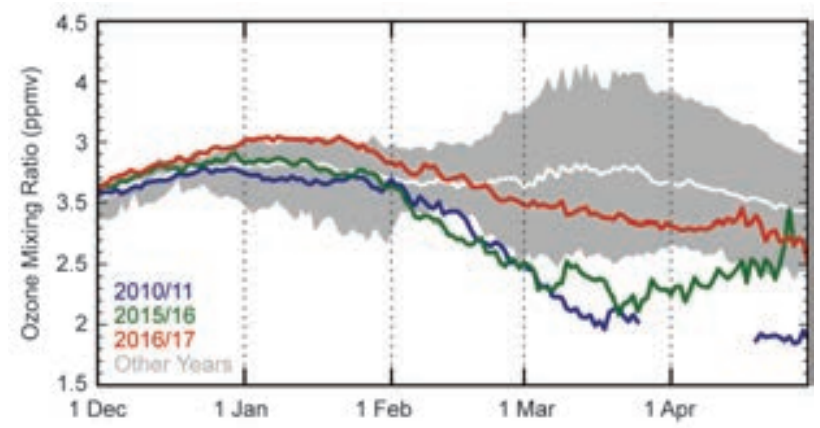

FIG. 5.26. Average ozone mixing ratios (ppmv) measured by Aura MLS at an altitude of $\sim 18 \mathrm{~km}$ for the area bounded by the polar vortex. Data from 2016/17 (red), 2015/16 (green), and 2010/1I (blue) are compared with the average (solid white) and minimum/maximum range (gray shading) from 2004/05 to 2014/I5, excluding 2010/II. Gaps in the record for $2010 / \mathrm{II}$ are due to missing data. 
comparison to 2010/11 and 2015/16 (the years with the largest chemical ozone loss in the observational record), mixing ratios in 2016/17 remained well above values observed in those record years.

The evolution of the Arctic total ozone column (TOC; i.e., ozone amounts integrated from the surface to the top of the atmosphere) is used here to compare 2017 measurements to the observational record (1979-2016). Specifically, March TOC is evaluated because chemically induced Arctic ozone loss is typically largest in this month (WMO 2014). The minimum Arctic daily TOC measured by satellites in March 2017 was 345 Dobson units (DU), which was $7.7 \%$ (29 DU) below the average of the observational record (374 DU) and 5.4\% (20 DU) below the 2005-16 average when MLS data are also available (Fig. 5.27).

Spatial deviations of monthly average TOCs from historical (2005-16) averages (Figs. 5.28a,b) were estimated with measurements from the Ozone Monitoring Instrument (OMI), which is co-located with MLS on the Aura satellite. Average TOCs for March 2017 were up to $15 \%$ higher over the Norwegian Sea, Greenland, and northern Canada, and up to $20 \%$ lower over northern Siberia relative to the long-term average (Fig. 5.28a). This spatial pattern is similar to a recently described Eurasia-North America dipole mode for the month of February, consisting of a shift to negative ozone anomalies over Eurasia and positive anomalies over North America (Zhang et al. 2018). Monthly average TOCs for April 2017, the month when the polar vortex (the low-temperature cyclone in which most of the springtime chemical destruction

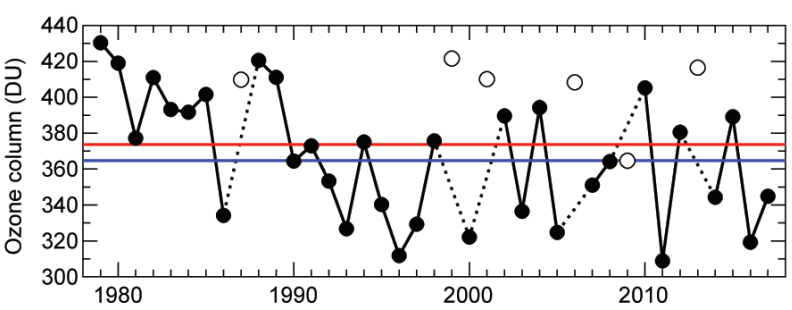

Fig. 5.27. Area-averaged minimum total ozone column (DU) for Mar that are calculated poleward of $63^{\circ}$ equivalent latitude (Butchart and Remsberg 1986). Open circles represent years in which the polar vortex broke up before Mar, resulting in relatively high values due to mixing with lower latitude air masses and a lack of significant chemical ozone depletion. Red and blue lines indicate the average TOC for 1979-2016 and 2005-16, respectively. Data are adapted from Müller et al. (2008) and WMO (20|4), updated using ERA-Interim reanalysis data (Dee et al. $201 \mathrm{la}$ ). Ozone data from 1979-2012 are based on the combined total column ozone database version 3.0 produced by Bodeker Scientific ( $w w w . b o d e k e r s c i e n t i f i c . c o m / d a t a$ Itotal-column-ozone). Data for 2013-17 are from OMI. of ozone occurs) broke up and air from high and midlatitudes started to mix, departed by less than $\pm 10 \%$ from the historical average, and ozone anomalies for May through November 2017 were unremarkable.

UV radiation is quantified with the UV index (UVI), which is a measure of the ability of UV radiation to cause erythema (sunburn) in human skin (WHO 2002). In addition to its dependence on TOC, the UVI depends on the sun angle, cloud cover, and surface albedo (Weatherhead et al. 2005). In the Arctic, the UVI scale ranges from 0 to about 7, with sites closest to the North Pole having the smallest peak radiation and UVI values $<4$ all year. UVI values $\leq 5$ indicate low to moderate risk of erythema (WHO 2002). UVI anomalies are assessed using satellite instruments (OMI) and ground-based measurements, with the former providing the better spatial coverage and the latter providing greater regional accuracy (Bernhard et al. 2015). Figures 5.28c,d quantify the spatial differences in monthly average noontime UVIs from historical (2005-16) averages and are based on OMI measurements. Figures 5.28c,d also indicate anomalies calculated from groundbased measurements at ten research stations located throughout the Arctic and Scandinavia.

Compared to the historical mean, average noontime UVIs for March 2017 were larger by up to 25\% over northern Siberia and smaller by up to $20 \%$ over Greenland and the Davis Strait (Fig. 5.28c). Areas with high UVIs roughly match areas with low TOCs and vice versa, but UVI anomalies have a larger spatial variability because of their added dependence on cloud cover. While relative UVI anomalies can be high, absolute anomalies remained below 1 UVI unit because solar elevations in March in the Arctic remain low. Anomalies derived from OMI and ground-based measurements agree to within $\pm 7 \%$. Anomalies for April 2017 differed by less than $\pm 15 \%$ from the historical average (not shown), except at the western coast of Alaska and the Bering Strait, where OMI measured anomalies of up to $50 \%$.

Ground-based UV measurements at all sites varied within historical bounds from July to November. However, UVIs at Alert, Eureka, and Resolute in northernmost Canada and at Summit, Greenland, were unusually high between 15 May and 15 June despite only small negative TOC anomalies (Fig. 5.28b). At Alert, Resolute, and Summit, positive UVI anomalies of between $5 \%$ and $10 \%$ measured at the ground were in good $( \pm 3 \%)$ agreement with the satellite data. At Eureka, heavy snowfall in mid-May led to high surface albedo and high UVIs until midJune. Measurements from the ground indicated a 
(a) Mar

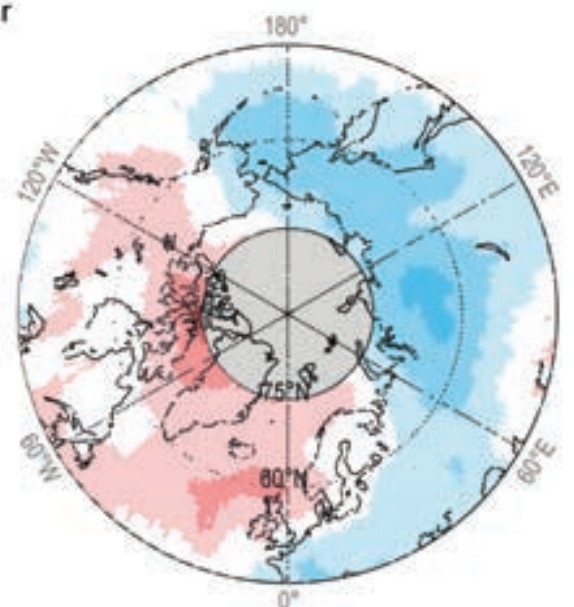

(b) 15 May-15 Jun

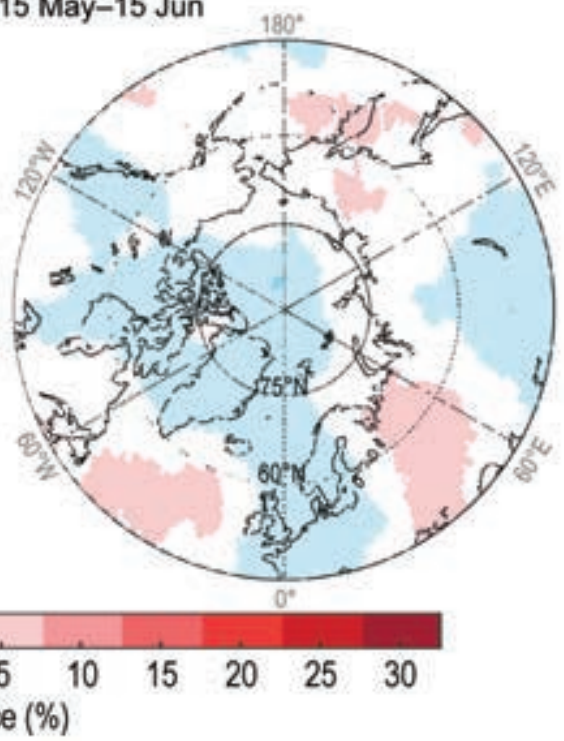

(c) Mar

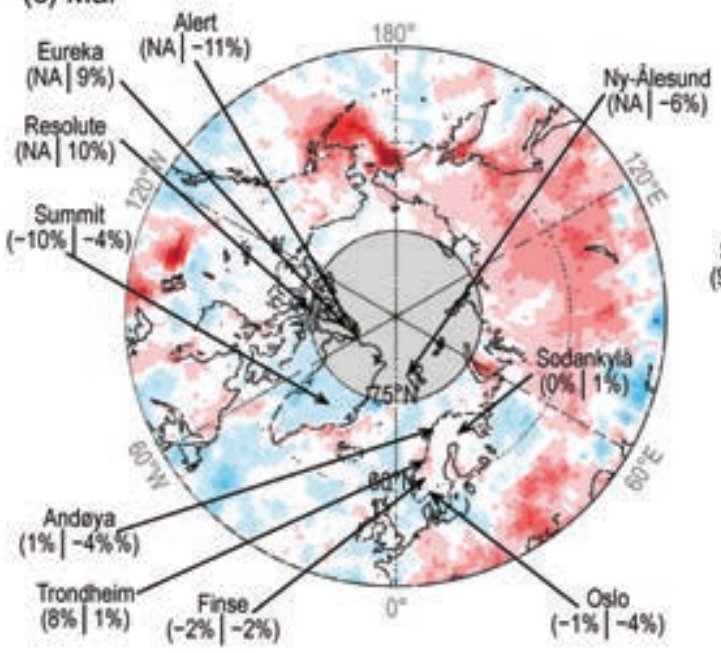

(d) 15 May-15 Jun

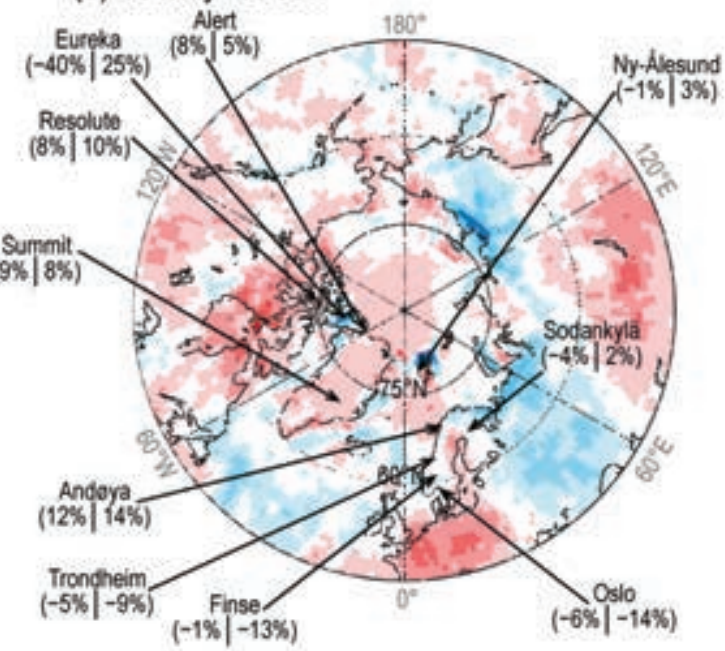

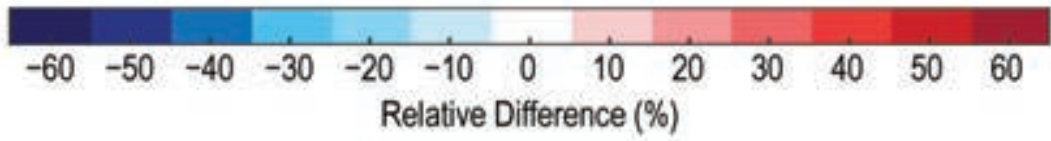

FIG. 5.28. (a) Anomalies of TOC (\%) and (c) noontime UVI (\%) for Mar 20I7. (b) and (d) as in (a) and (c) but for 15 May-15 Jun. Anomalies are relative to 2005-16 averages. Maps are based on OMTO3 Level 3 total ozone product (Bhartia and Wellemeyer 2002). (c) and (d) also compare UVI anomalies from OMI (first value in parenthesis) with ground-based measurements at 10 locations (second value presented). Gray shading indicates areas where no OMI data are available.

positive UVI anomaly of $25 \%$, while OMI reported a negative anomaly of $-40 \%$. This large inconsistency can be attributed to systematic errors in the OMI dataset, which are caused by a mismatch of the actual high surface albedo and the albedo climatology (Tanskanen et al. 2003) used by the OMI UV algorithm. Because of this mismatch, the high reflectivity observed from space due to snow was misinterpreted as cloud cover, resulting in erroneously low UVIs reported by OMI. The relatively large difference (12\%) of UVI anomalies derived from OMI and groundbased measurements at Finse, Norway, for the same period can be attributed to snow cover disappearing 20 days earlier in 2017 compared with the average snow disappearance date for 2005-16 (Fig. 5.28d). Differences between satellite and ground-based measurements at Eureka and Finse illustrate that UV estimates from space require verification with ground-based measurements, in particular during months when snowmelt occurs. 


\section{ANTARCTICA-T. Scambos and S. Stammerjohn}

a. Overview-T. Scambos and S. Stammerjohn Eds.

Last year we reported on an unusual Antarctic climate and sea ice anomaly that developed during late winter-early spring 2016 (Stammerjohn and Scambos 2017; see also Schlosser et al. 2018; Stuecker et al. 2017). This anomaly pattern coincided with record-breaking negative southern annular mode (SAM) index values. Antarctic-wide climate anomalies, including weakened westerly winds, high continental surface pressures and temperatures, and the lowest spring sea ice extent on record, stood in stark contrast not only to the beginning of 2016, but also to the previous four record-breaking high sea ice years (2012-15). This unusual climate anomaly pattern continued until late summer 2017 (February-March), after which SAM index values slowly shifted towards positive for the remainder of the year (except for a short-lived reversal in October). Sea ice extent remained low for most of 2017, as discussed in Section 6e.

In general, 2017 was notable for its strong regional climate anomalies. An anticyclone pattern in January in the South Pacific abruptly shifted to an intense cyclonic anomaly in late summer-autumn (February-May). A strong zonal wave-three pattern then emerged in winter (June-September). Sea ice extent remained below average for the entirety of 2017, with record lows persisting for the first four months, followed by the re-emergence of the Maud Rise polynya in the Weddell Sea in mid-September. The year 2017 was also distinguished by the second smallest Antarctic ozone hole observed since 1988. (Note: throughout the chapter, anomalies and standard deviations are with respect to the 1981-2010 climatological mean, unless otherwise specified.)

Additional highlights for 2017:

- In association with the strong cyclonic pattern in the South Pacific during February-May, anomalously warm near-surface atmosphere conditions persisted over much of West Antarctica, including over the ocean areas from the Ross Sea to the Bellings-hausen Sea. Record maximum surface temperatures were observed at several western Peninsula stations in March and on the Ross Ice Shelf in May, along with anomalously warm summer-autumn SSTs, shallower ocean mixed layers, and delays in the autumn ice edge advance over the West Antarctic ocean sector. The seasonal melt extent and melt index over the continent were the second highest since 2005, mostly due to strong positive anomalies of air temperature over most of the West Antarctic coast. In contrast, the East Antarctic Plateau recorded record low mean temperatures in March. Over the coast and adjacent ocean, conditions were near average.

- In contrast to autumn, winter ushered in anomalously low surface pressures and temperatures over the continent, and a pronounced zonal wave-three pattern existed over midlatitudes from June to September. However, by spring much of the continent experienced near-average pressures and slightly above-average temperatures from October to December, with an East Antarctic station setting a record high temperature in October. Exceptions were a record low continental surface pressure recorded for November on the West Antarctic Ice Sheet and a low-pressure anomaly centered over the northwestern Weddell Sea $\left(\sim 60^{\circ} \mathrm{S}\right.$ and $\left.\sim 40^{\circ} \mathrm{W}\right)$, which contributed to anomalously warm surface conditions over the central-eastern Weddell Sea $\left(\sim 30^{\circ} \mathrm{W}\right.$ to $\left.\sim 30^{\circ} \mathrm{E}\right)$. The latter was coincident with the Maud Rise polynya, which expanded and persisted into early December.

- The brief appearance of the Maud Rise polynya in 2016 and its greater presence in 2017 is significant, as it appears to announce a revival of deep ocean convection in the eastern Weddell Sea (see Sidebar 6.1).

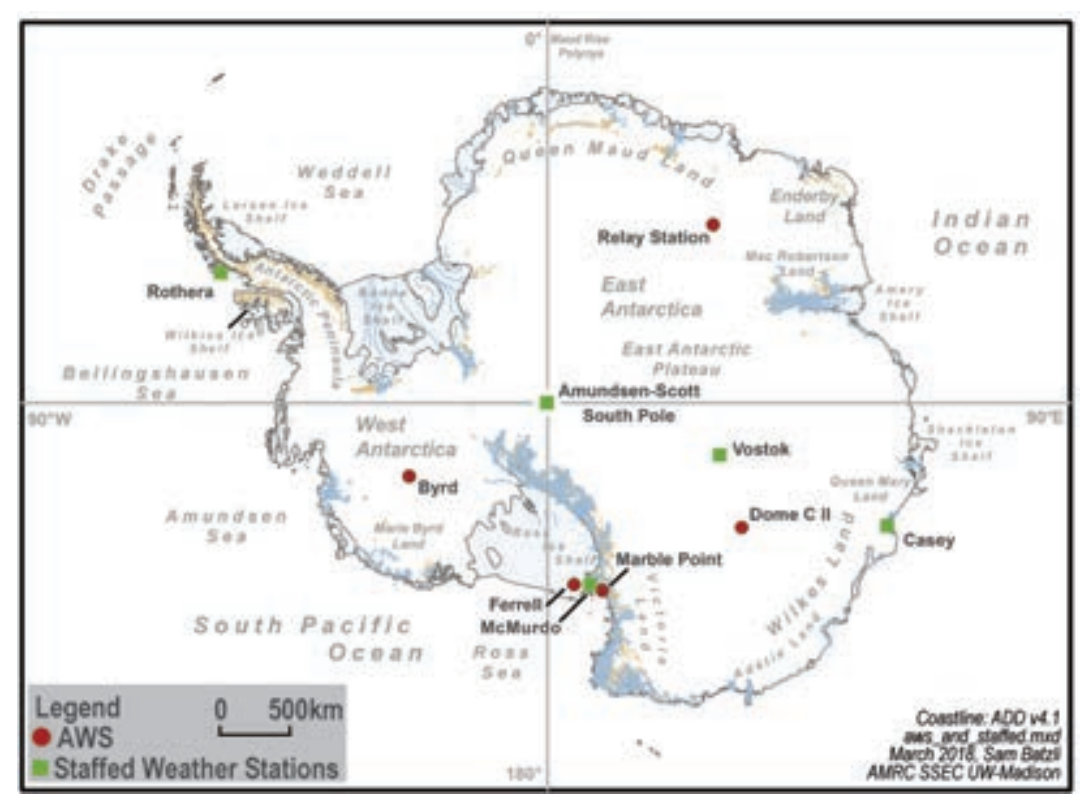

Fig. 6.I. Map of stations and other regions discussed in the chapter. 
- The mid-depth Southern Ocean ( 500-1500 m) continued to warm at rates up to $0.02^{\circ} \mathrm{C} \mathrm{yr}^{-1}$ while the surface ocean continued to cool

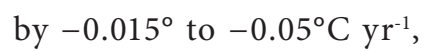
freshen, and acidify.

The state of Antarctica's climate, weather, ice, ocean, and ozone in 2017 are presented below. Place names used throughout this chapter are provided in Fig. 6.1.

b. Atmospheric circulation and surface observationsK. R. Clem, S. Barreira, R. L. Fogt, S. Colwell, C. Costanza, L. M. Keller, and M. A. Lazzara.

Atmospheric circulation patterns are the main drivers of all other aspects of this climate summary, affecting sea ice, precipitation, weather records, and even ozone loss. Moreover, long-term changes in climate are impacting ocean circulation (e.g., Schneider et al. 2012) and surface melt patterns (e.g., van den Broeke 2005) and thereby affecting the ice mass balance of the Antarctic ice sheet.

For this detailed analysis of the atmospheric circulation and temperature and pressure anomalies, the European Centre for Medium-Range Weather Forecasts interim reanalysis (ERA-Interim) is utilized as it is shown to be the most reliable representation of Antarctic tropospheric pressure and temperature among all modern global reanalyses (Bracegirdle and Marshall 2012). Figure 6.2 shows the monthly geopotential height (Fig. 6.2a) and temperature (Fig. 6.2b) anomalies averaged over the polar cap $\left(60^{\circ}-90^{\circ} \mathrm{S}\right)$ and the monthly circumpolar zonal wind (Fig. 6.2c) anomalies averaged over $50^{\circ}-70^{\circ} \mathrm{S}$. Anomalies are contoured and the standard deviation level is indicated by colored (a) 2017 Polar-Cap $\left(60^{\circ}-90^{\circ} \mathrm{S}\right)$ Averaged Geopotential Height Anomalies (m)

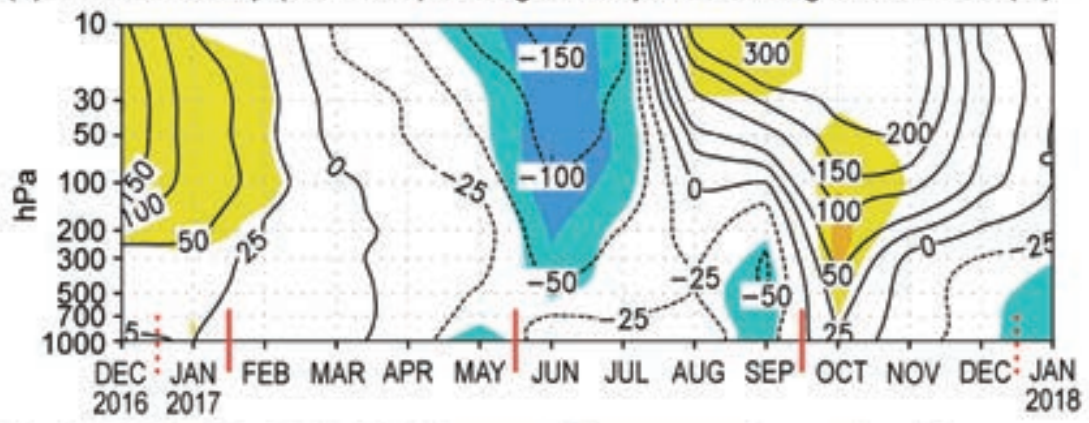

(b) 2017 Polar-Cap $\left(60^{\circ}-90^{\circ} \mathrm{S}\right)$ Averaged Temperature Anomalies $\left({ }^{\circ} \mathrm{C}\right)$

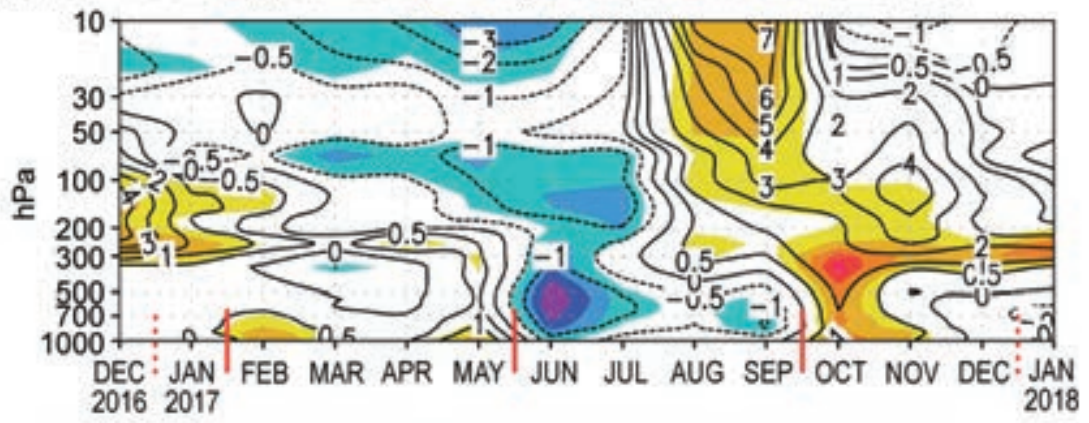

(c) 2017 Circumpolar $\left(50^{\circ}-70^{\circ} \mathrm{S}\right)$ Averaged Zonal Wind Anomalies $\left(\mathrm{m} \mathrm{s}^{-1}\right)$

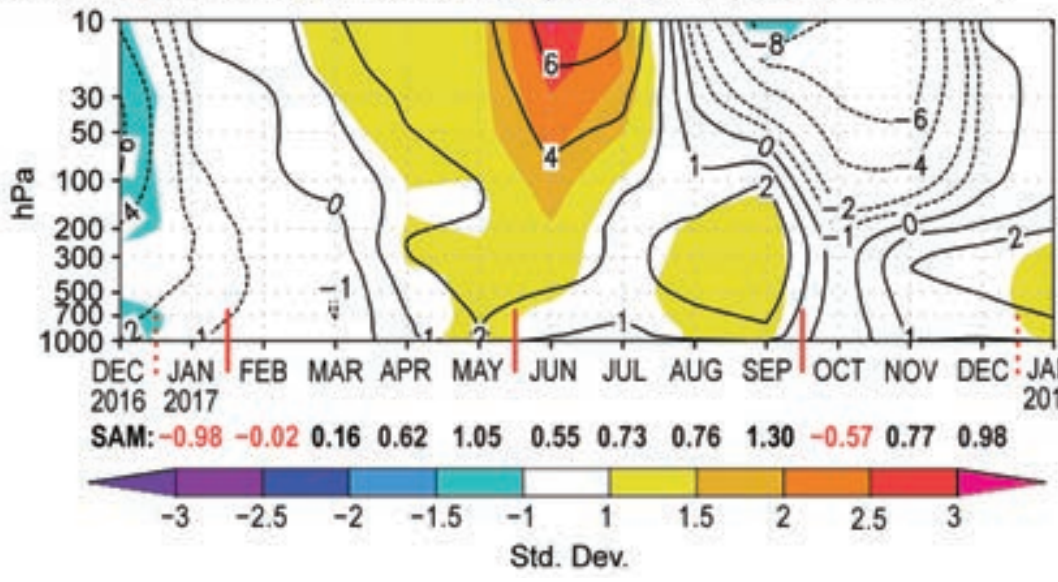

Fig. 6.2. Area-averaged (weighted by cosine of latitude) monthly anomalies over the southern polar region in 2017 relative to 198I-2010: (a) polar cap $\left(60^{\circ}-90^{\circ} \mathrm{S}\right)$ averaged geopotential height anomalies (contour interval is $50 \mathrm{~m}$ up to $\pm 200 \mathrm{~m}$ with additional contour at $\pm 25 \mathrm{~m}$, and $100 \mathrm{~m}$ contour interval after $\pm 200 \mathrm{~m}$ ); (b) polar cap averaged temperature anomalies (contour interval is $1^{\circ} \mathrm{C}$ with additional contour at $\pm 0.5^{\circ} \mathrm{C}$ ); (c) circumpolar $\left(50^{\circ}-70^{\circ} \mathrm{S}\right)$ averaged zonal wind anomalies (contour interval is $2 \mathrm{~m} \mathrm{~s}^{-1}$ with additional contour at $\pm \mid \mathrm{m} \mathrm{s}^{-1}$ ). Shading depicts std. dev. of monthly anomalies from the 198I-20I0 climatological average as indicated by color bar at bottom. (Source: ERA-Interim reanalysis.) Red vertical bars indicate the four climate periods used for compositing in Fig. 6.3; the dashed lines near Dec 2016 and Dec 2017 indicate circulation anomalies wrapping around the calendar year. Values from the NOAA CPC Antarctic Oscillation index (herein referred to as the SAM index) are shown below (c) in black (positive values) and red (negative values).

shading. The year was grouped into four periods characterized by relatively consistent climatic fea- 
tures: January, February-May, June-September, and October-December. These periods are indicated by vertical red bars at the bottom of each panel in Fig. 6.2. Anomalies for the four groups from their respective group climatological mean are shown in Fig. 6.3, with surface pressure anomalies shown on the left and 2-m temperature anomalies shown on the right. Monthly temperature and pressure anomalies during 2017 are also displayed in Fig. 6.4 for three staffed stations (Amundsen-Scott, Casey, and Rothera) and three automatic weather stations (AWS; Byrd, Dome C II, and Ferrell) to examine the monthly variability and extreme events for the surface conditions across the continent.

January 2017 was distinct from the rest of the year with positive pressure anomalies over the continent and primarily negative pressure anomalies between $40^{\circ}$ and $60^{\circ} \mathrm{S}$ (Fig. 6.3a) and slightly weaker-thanaverage circumpolar westerlies throughout the troposphere and lower stratosphere (Fig. 6.2c). The January circulation pattern is consistent with the negative phase of the southern annular mode (SAM) which continued from late 2016 [the SAM index from NOAA's Climate Prediction Center (CPC) in January was -0.98], and it marks the transition of the late 2016 circulation to opposite sign anomalies in autumn 2017. At the surface, a strong high pressure anomaly was present over the South Pacific poleward to the Amundsen Sea, which through altered temperature advection and sea ice conditions produced negative temperature anomalies of $\sim 1^{\circ} \mathrm{C}$ across the Antarctic Peninsula (Figs. 6.3a,b). These features weakened after January, and from February through May they were replaced by an anomalously deep Amundsen Sea Low centered over the northwest Amundsen Sea into the South Pacific (Fig. 6.3c; 6-9 hPa and 2-3 standard deviations below average). The anomalous cyclonic circulation, in conjunction with an anticyclone anomaly in the northwest Weddell Sea, produced well-above-average temperatures across much of West Antarctica during late summer and autumn spanning the western Antarctic Peninsula, Amundsen Sea Embayment, Marie Byrd Land, and Ross Ice Shelf (Fig. $6.3 \mathrm{~d} ; 2^{\circ}-5^{\circ} \mathrm{C}$ and $>3$ standard deviations above average). Temperatures at the Byrd AWS in central West Antarctica were $2^{\circ}-5^{\circ} \mathrm{C}$ above average during February-May, and record maximum monthly mean temperatures were observed on the Antarctic Peninsula in March at both Marambio $\left(-2^{\circ} \mathrm{C}\right)$ and Rothera $\left(1.2^{\circ} \mathrm{C}\right.$; Fig. $\left.6.4 \mathrm{c}\right)$; Dome C II AWS, on the East Antarctic plateau, reported record low monthly mean temperatures in March $\left(-57.1^{\circ} \mathrm{C}\right.$, Fig. 6.4e), nearly $5^{\circ} \mathrm{C}$ below average.
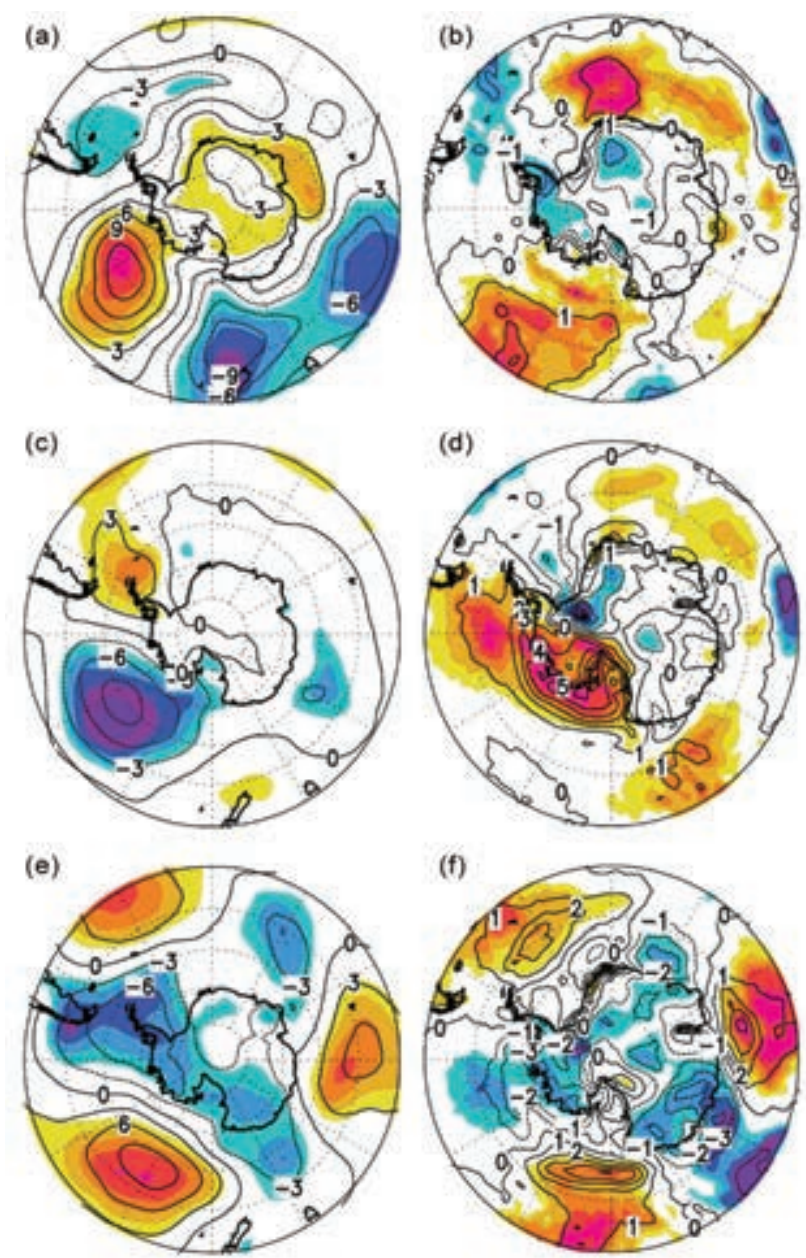

(g)

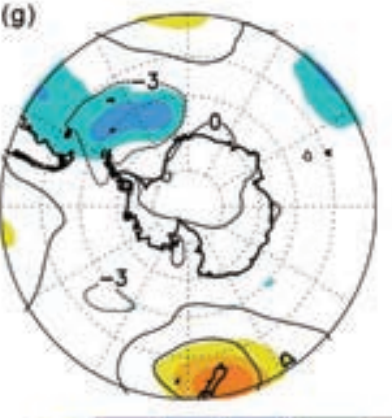

(h)

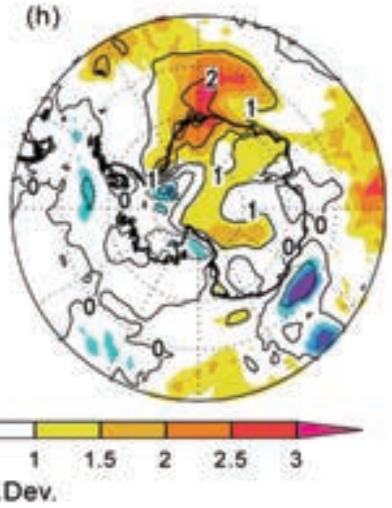

FIG. 6.3. (left) Surface pressure anomalies and (right) 2-m temperature anomalies relative to each group's 198I-2010 climatological average for (a) and (b) Jan 2017; (c) and (d) Feb-May 2017; (e) and (f) Jun-Sep 20I7; and (g) and (h) Oct-Dec 20l7. Contour interval for surface pressure anomalies is $3 \mathrm{hPa}$ and $I^{\circ} \mathrm{C}$ for 2-m temperature anomalies. Shading depicts std. dev. of anomalies relative to the $1981-2010$ average of each group. (Source: ERA-Interim reanalysis.) 
(a)

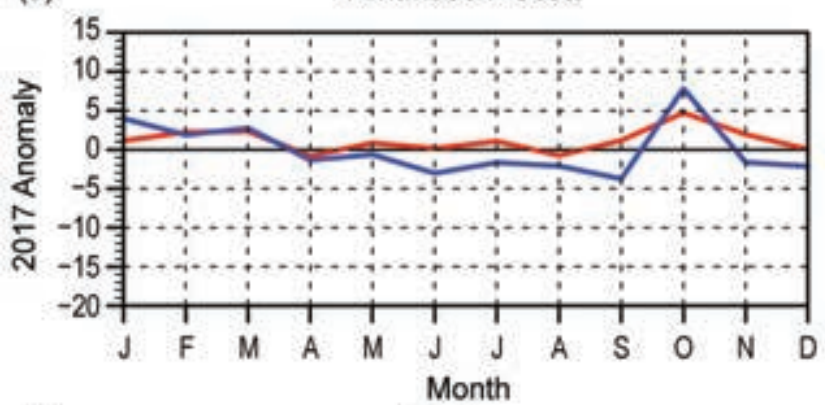

(c)

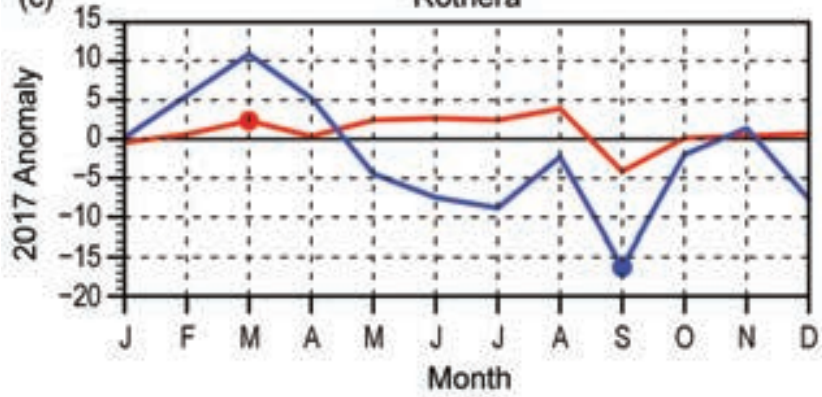

(e)

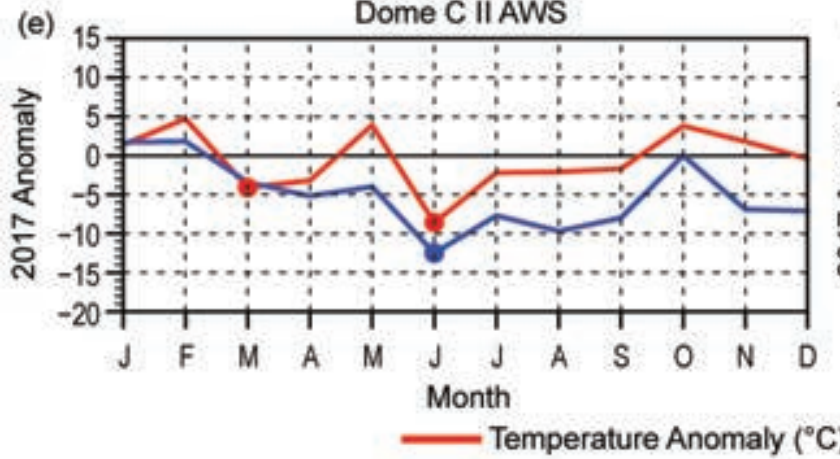

(b)

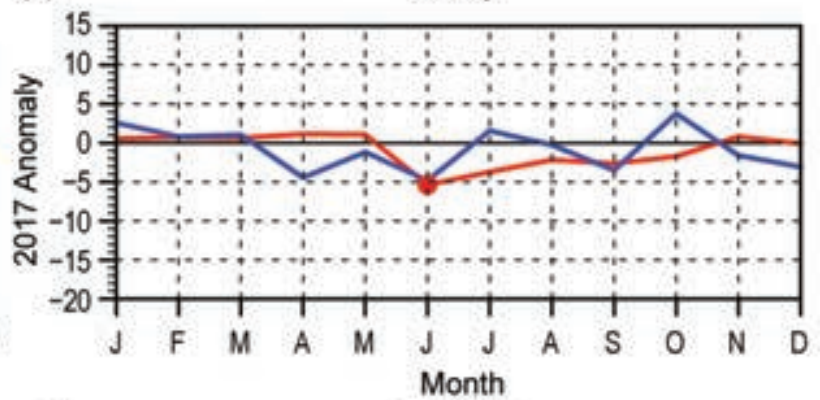

(d)

Byrd AWS

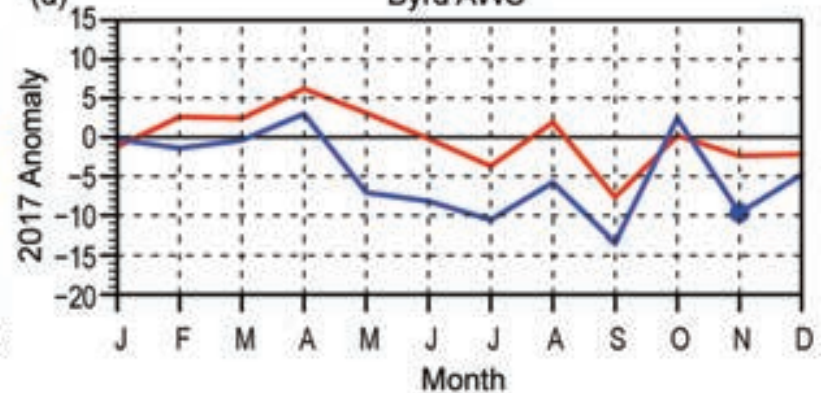

Ferrell AWS

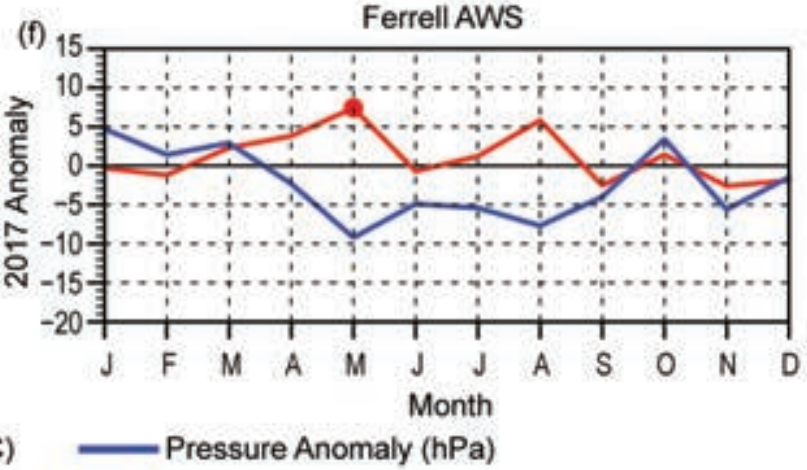

FIG. 6.4. Monthly Antarctic climate anomalies during 2017 at six representative stations [three staffed (a)-(c), and three automatic (d)-(f)]. Anomalies for temperature $\left({ }^{\circ} \mathrm{C}\right)$ are shown in red and MSLP/surface pressure $(\mathrm{hPa})$ in blue are shown, with filled circles denoting record anomalies for a given month at each station in 20I7. All anomalies are based on differences from the monthly 198I-2010 averages. Observational data start in 1957 for Amundsen-Scott, 1959 for Casey, 1976 for Rothera, 1980 for Byrd AWS, and I98I Dome C II and Ferrell AWS.

During April (not shown), negative pressure anomalies developed over Wilkes Land and Queen Maud Land, and the associated northerly flow was an important contributor to the late advance of sea ice in the western Ross and eastern Weddell Seas; these cyclonic circulation anomalies were part of a larger shift in the Antarctic circulation as captured to some extent in the polar-cap-averaged geopotential height (Fig. 6.2a) and circumpolar zonal wind anomalies (Fig. 6.2c), both of which changed sign in April and intensified in May. At Casey Station, located in Wilkes Land in coastal East Antarctica, pressure anomalies were the lowest in April, consistent with this circulation shift. On the eastern side of this low pressure system, the northerly flow increased temperatures across the Ross Ice Shelf, and Ferrell AWS reported a record monthly mean maximum temperature for May of $-23.1^{\circ} \mathrm{C}, 7.4^{\circ} \mathrm{C}$ warmer than the climatological average (Fig. 6.4f).

During the winter months (June-September), a pronounced zonal wave-three pattern developed, characterized by three anomalous ridges along $50^{\circ} \mathrm{S}$ centered at $90^{\circ} \mathrm{E}, 150^{\circ} \mathrm{W}$, and $30^{\circ} \mathrm{W}$ and a deep low pressure anomaly over the Antarctic Peninsula (Fig. 6.3e). Temperatures were generally below average across the continent, especially on the eastern side of the midlatitude ridges/western side of the troughs, where southerly flow produced cool conditions. Colder-than-average winter temperatures were also observed throughout the troposphere and 
stratosphere, accompanied by negative geopotential height anomalies and stronger-than-average circumpolar westerlies in winter (Fig. 6.2); the stratospheric vortex exhibited the greatest positive anomalies of 4-6 $\mathrm{m} \mathrm{s}^{-1}$ above average during June. East Antarctica experienced its most negative temperature anomalies during 2017 in June $\left(2^{\circ}-6^{\circ} \mathrm{C}\right.$ below average), with Casey (Fig. 6.4b) and Dome C II AWS (Fig. 6.4e) both setting record low monthly mean temperatures in June $\left(-19.4^{\circ} \mathrm{C}\right.$ and $-57.1^{\circ} \mathrm{C}$, respectively). West Antarctica saw its strongest cold anomalies during July $\left(2^{\circ}-4^{\circ} \mathrm{C}\right.$ below average $)$ and September $\left(4^{\circ}-8^{\circ} \mathrm{C}\right.$ below average; see Byrd AWS temperature anomalies in Fig. 6.4d). The colder-than-average temperatures in September were partially due to the low pressure anomaly over the Antarctic Peninsula, reflected in the record negative monthly mean pressure of $971.3 \mathrm{hPa}$ at Rothera (Fig 6.4c), more than $16 \mathrm{hPa}$ below the climatological average.

A positive temperature/geopotential height anomaly developed in the stratosphere during September and propagated downward into the lower troposphere during October (Fig. 6.2). Positive pressure and temperature anomalies developed at the surface across much of the continent in October, reflected in the observations at Amundsen Scott in Fig. 6.4a; the strongest positive surface air temperature anomalies during October (not shown) were over interior portions of East Antarctica along the Transantarctic Mountains reaching $2^{\circ}-4^{\circ} \mathrm{C}(>3$ standard deviations) above average, and Vostok Station in the central East Antarctic plateau set a record high monthly mean temperature in October of $-51.1^{\circ} \mathrm{C}, 1.7^{\circ} \mathrm{C}$ higher than the previous record set in 2015. Averaged over the October-December period (Figs. 6.3g,h), the strongest positive temperature anomalies were over Queen Maud Land, while the rest of the continent experienced near-average to slightly-above-average temperatures and near-average pressure to close out 2017; exceptions include the Ross Ice Shelf where below-average temperatures were observed during November due to enhanced southerly flow from the development of an anomalous cyclone in the South Pacific that was consistent with the late austral spring La Niña conditions (see Section $4 \mathrm{~b}$ ) and a record monthly mean low surface pressure value at the Byrd AWS in November (787.7 hPa).

There were several record high monthly-mean wind speeds recorded at various AWS during the year. Ferrell had record high wind speeds in May $\left(9.7 \mathrm{~m} \mathrm{~s}^{-1}\right)$, July $\left(9.5 \mathrm{~m} \mathrm{~s}^{-1}\right)$, and August $\left(10.6 \mathrm{~m} \mathrm{~s}^{-1}\right)$ and Marble Point had a record high wind speed in March $\left(5.7 \mathrm{~m} \mathrm{~s}^{-1}\right)$. Byrd had a record high wind speed in May $\left(10.6 \mathrm{~m} \mathrm{~s}^{-1}\right)$, and Dome C II had a record in October $\left(5.4 \mathrm{~m} \mathrm{~s}^{-1}\right)$. Relay Station tied its record low wind speed in November $\left(5.5 \mathrm{~m} \mathrm{~s}^{-1}\right)$. The record high wind speeds reflect the incidence of lower than normal pressure for much of the year (Figs. 6.3, 6.4).

\section{c. Net precipitation $(P-E)-D$. H. Bromwich and S.-H. Wang}

Precipitation minus evaporation/sublimation $(P-E)$ closely approximates the surface mass balance over Antarctica (e.g., Bromwich et al. 2011; Lenaerts and van den Broeke 2012), except for near-coastal areas where wind-driven transport of snow and meltwater runoff can become significant factors. Precipitation variability is the dominant term for $P-E$ changes at regional and larger scales over the Antarctic continent. Precipitation and evaporation fields from the Japanese 55-year reanalysis (JRA55; Kobayashi et al. 2015) were examined to assess Antarctic net precipitation $(P-E)$ behavior for 2017. JRA-55, the second generation of JRA, has incorporated many improvements compared to its predecessor JRA-25 (Onogi et al. 2007; Bromwich et al. 2007). The JRA-55 is used here because of these improvements and its low latency, rather than ERA-Interim used elsewhere. Because of the highly uneven distribution of $P-E$ characteristics (from large Peninsula and coastal West Antarctica values $>1000 \mathrm{~mm} \mathrm{yr}^{-1}$ to very low values $<50 \mathrm{~mm} \mathrm{yr}^{-1}$ in the high interior), only annual $P-E$ changes are shown in Fig. 6.5.

Figure 6.5 shows the JRA-55 2017 and 2016 annual anomalies of $P-E$ (Figs. 6.5a,b) and mean sea level pressure (MSLP; Figs. 6.5c,d) departures from the 1981-2010 average. In general, annual $P-E$ anomalies over the high interior of the continent were small (within $\pm 50 \mathrm{~mm} \mathrm{yr}^{-1}$ ), and larger anomalies were observed along the coast, consistent with the low and high net precipitation accumulation in these regions. From JRA-55, the 2016 positive anomalies located along the coast between Queen Maud Land and Mac Robertson Land (between $5^{\circ} \mathrm{W}$ and $60^{\circ} \mathrm{E}$ ) became weak negative anomalies in 2017, most pronounced near $60^{\circ} \mathrm{E}$. The weak negative anomalies over the American Highland (between $70^{\circ}$ and $90^{\circ} \mathrm{E}$ ) in 2016 became strongly positive in 2017. Both Queen Mary Land and Wilkes Land (between $90^{\circ}$ and $125^{\circ} \mathrm{E}$ ) remained strongly negative. The strong positive anomalies over Adélie Land and Victoria Land (between $125^{\circ}$ and $175^{\circ} \mathrm{E}$ ) became near-zero in 2017. The positive anomaly over the eastern Ross Ice Shelf in 2016 evolved into a larger positive anomaly that extended into interior Antarctica in 2017. The largest positive anomalies that were located over the Bellingshausen Sea and the southern Antarctic 
(a) $45^{\circ} \mathrm{W} \quad 30^{\circ} \mathrm{W} \quad 15^{\circ} \mathrm{W} \quad 0^{\circ} \quad 15^{\circ} \mathrm{W} \quad 30^{\circ} \mathrm{E} \quad 45^{\circ} \mathrm{E}$
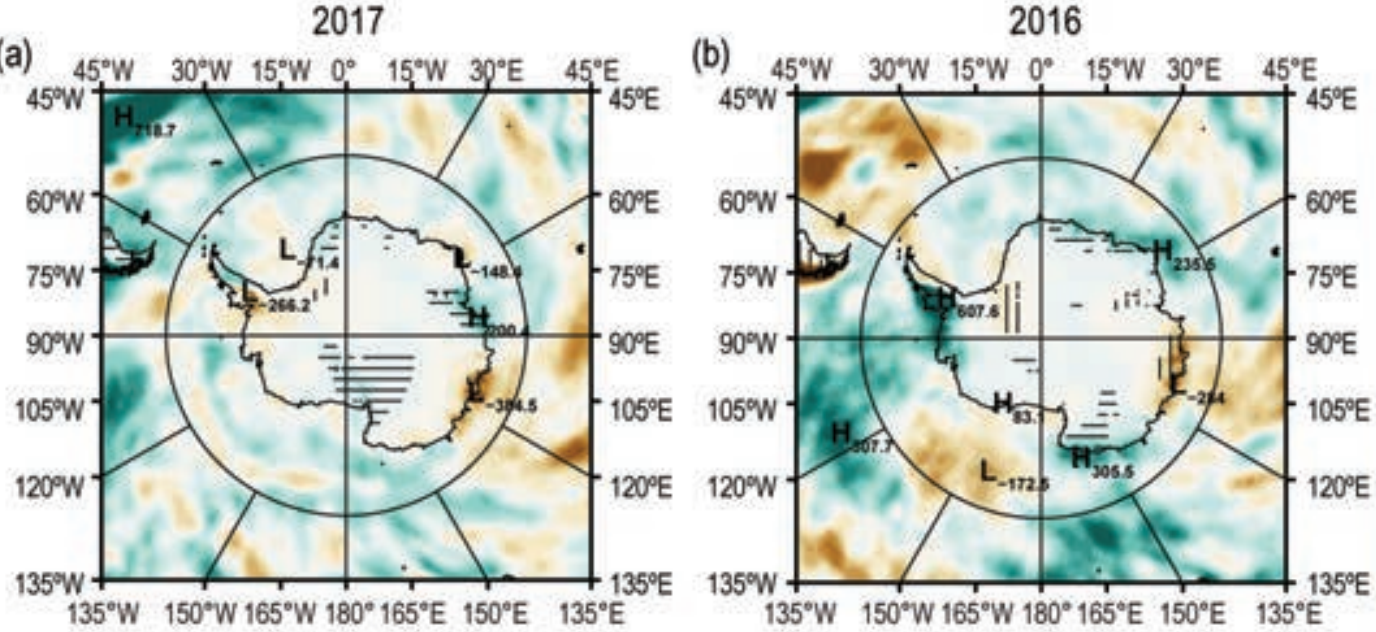

Anomaly

(c)

(c) $45^{\circ} \mathrm{W} \quad 30^{\circ} \mathrm{W} \quad 15^{\circ} \mathrm{W} \quad 0^{\circ} \quad 15^{\circ} \mathrm{W} \quad 30^{\circ} \mathrm{E} \quad 45^{\circ} \mathrm{E}$

(d) $45^{\circ} \mathrm{W} \quad 30^{\circ} \mathrm{W} \quad 15^{\circ} \mathrm{W} \quad 0^{\circ} \quad 15^{\circ} \mathrm{W} \quad 30^{\circ} \mathrm{E} \quad 45^{\circ} \mathrm{E}$

Anomaly

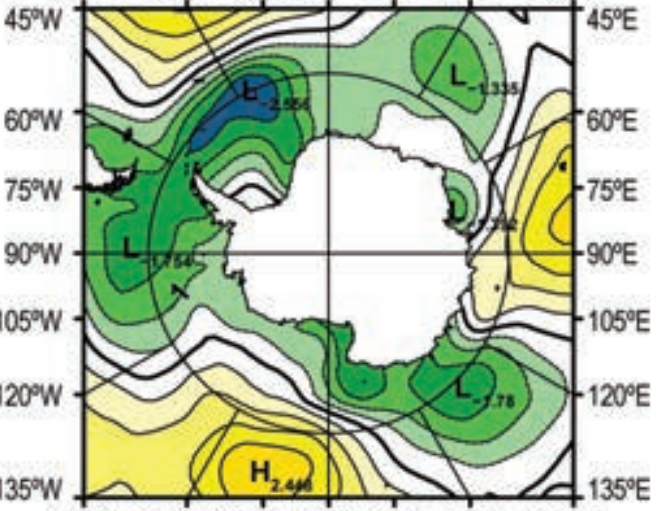

$135^{\circ} \mathrm{W} 150^{\circ} \mathrm{W} 165^{\circ} \mathrm{W} 180^{\circ} 165^{\circ} \mathrm{E} 150^{\circ} \mathrm{E} \quad 135^{\circ} \mathrm{E}$

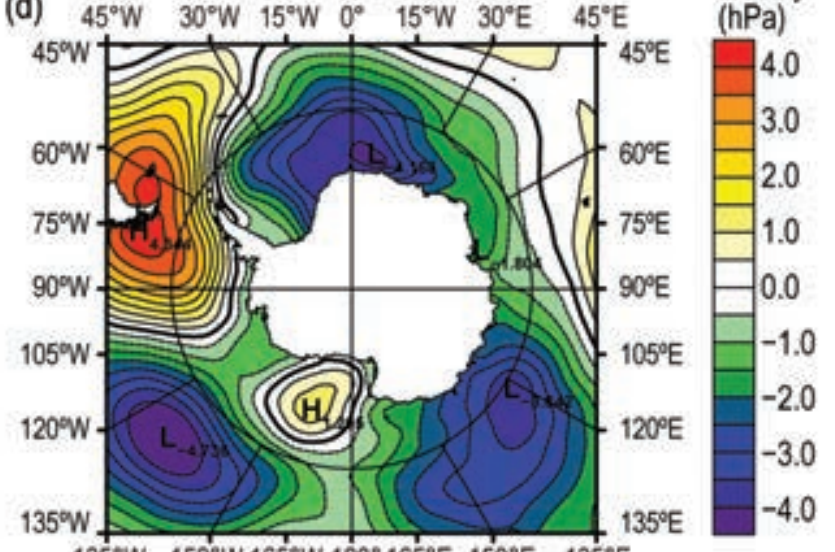

$135^{\circ} \mathrm{W} \quad 150^{\circ} \mathrm{W} 165^{\circ} \mathrm{W} 180^{\circ} 165^{\circ} \mathrm{E} 150^{\circ} \mathrm{E} \quad 135^{\circ} \mathrm{E}$

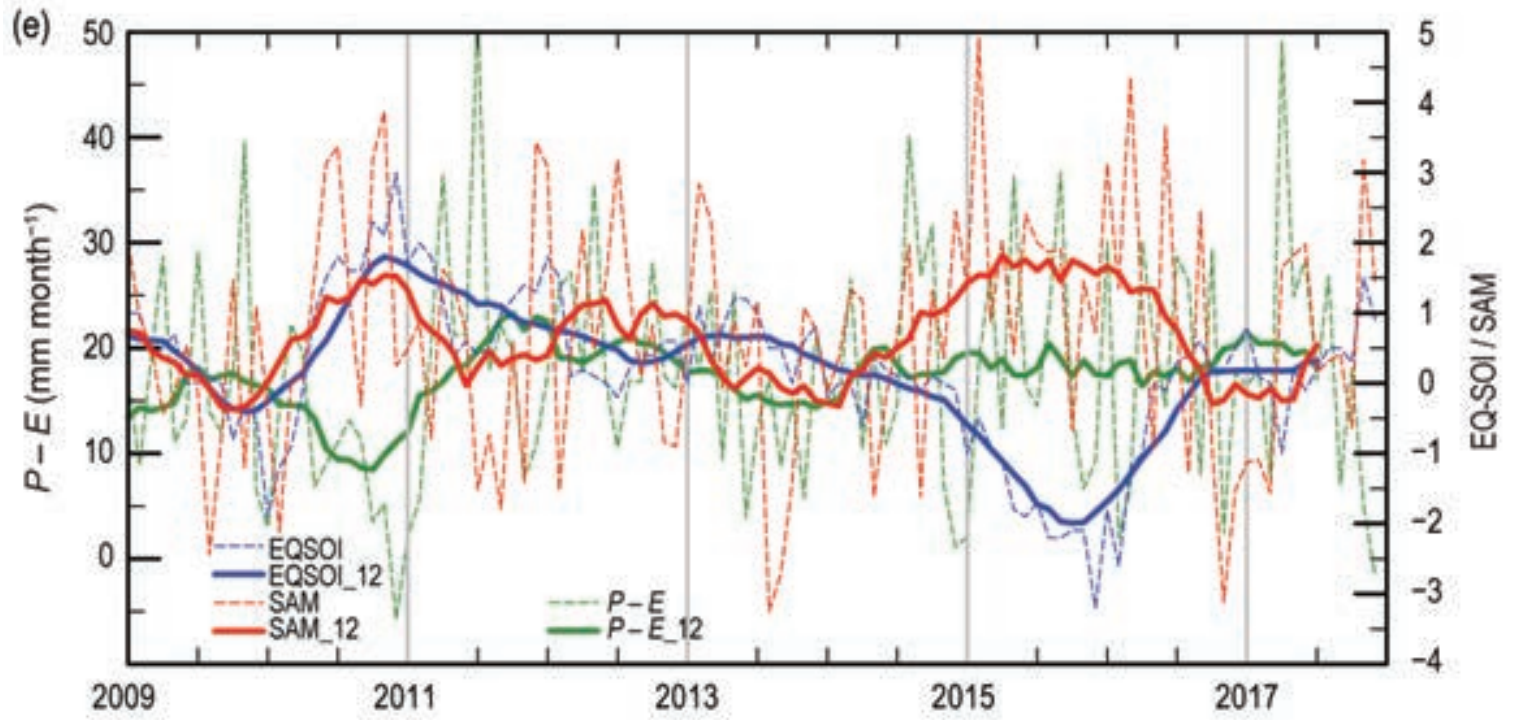

Fig. 6.5. (a-d) Annual precipitation minus evaporation ( $P-E)$ and MSLP anomalies: (a) $2017 P-E$ anomaly $(\mathrm{mm})$; (b) $2016 P-E$ anomaly $(\mathrm{mm})$. Antarctic regions with $> \pm 30 \%$ departure from the reference mean are hatched; vertical denotes negative anomaly and horizontal is positive. (c) $2017 \mathrm{MSLP}$ anomaly (hPa); and (d) $2016 \mathrm{MSLP}$ anomaly $(\mathrm{hPa})$. All anomalies are calculated with respect to the 198I-20I0 means. (e) Monthly total P-E (mm; dashed green) for part of West Antarctica bounded by $75^{\circ}-90^{\circ} \mathrm{S}, 120^{\circ} \mathrm{W}-180^{\circ}$, along with index trends for EQ-SOI (dashed blue, from NOAA CPC) and SAM (dashed red, from Marshall 2003). Centered annual running means are plotted as solid lines. 
Peninsula (between $110^{\circ}$ and $70^{\circ} \mathrm{W}$ ) in 2016 became the second largest negative anomalies in 2017. Similar to 2016, the two sides of the Antarctic Peninsula had opposite anomalies but with a reversal of signs in 2017: positive in the east, negative to the west. The Ronne Ice Shelf anomalies remained negative but were weaker during 2017.

These annual $P-E$ anomaly features are generally consistent with the mean annual atmospheric circulation implied by the MSLP anomalies (Figs. 6.5c,d). In 2017 (Fig. 6.5c), the MSLP annual anomalies surrounding Antarctica were less regionalized and were weaker than in 2016 (Fig. 6.5d) with strong seasonal variation during 2017 (e.g., Fig. 6.3). The largest positive anomaly center in 2016 over the Drake Passage $\left(\sim 75^{\circ} \mathrm{W}\right)$ became the largest negative anomaly in 2017 and extended into the Weddell Sea as the seasons progressed through the year, with a peak in September-November (SON; e.g., Figs. 6.3 e,g). The observed negative anomaly centers over the South Pacific $\left(160^{\circ} \sim 110^{\circ} \mathrm{W}\right)$ and Indian Ocean $\left(105^{\circ} \sim 165^{\circ} \mathrm{E}\right)$ strengthened in the first half of 2017 (e.g., Figs. 6.3a,c). Both anomalies expanded and changed to positive values that covered nearly two-thirds of the Southern Ocean (between $15^{\circ} \mathrm{E}$ and $90^{\circ} \mathrm{W}$ ) later in the year (SON; e.g., Fig. 6.3e). These seasonal MSLP changes resulted in negative-positive-negative anomaly centers along the East Antarctic coast in the Southern Ocean (Figs. 6.3e, 6.5c). Two secondary negative MSLP anomaly centers located over coastal Ross Sea (between $165^{\circ} \mathrm{E}$ and $160^{\circ} \mathrm{W}$ ) and the Amery Ice Shelf $\left(\sim 65^{\circ} \mathrm{E}\right)$ produced stronger onshore wind flows and resulted in greater than $30 \%$ higher $P-E$ in the interior of the Antarctic continent (Fig. 6.5a). By contrast, two negative $P-E$ anomalies $\left(\sim 120^{\circ} \mathrm{E}\right.$ and $\sim 80^{\circ} \mathrm{W}$; Fig. $6.5 \mathrm{a})$ were associated with strong offshore flow in 2017 (Fig. 6.5c).

Earlier studies (e.g., Cullather et al. 1998) show that almost half of the moisture transport into interior Antarctica occurs in the West Antarctic sector. Antarctic moisture transport has large interannual variability, often associated with variations of ENSO (e.g., Bromwich et al. 2004) and the southern annular mode (SAM; e.g., Fogt et al. 2011). Figure 6.5e shows the time series, with 12-month running means, of monthly total $P-E$ over Marie Byrd Land-Ross Ice Shelf $\left(75^{\circ}-90^{\circ} \mathrm{S}, 120^{\circ} \mathrm{W}-180^{\circ}\right)$ and the monthly equatorial Southern Oscillation index (EQ-SOI) and SAM indices. The NOAA CPC EQ-SOI is a standardized sea level pressure difference centered on the equator between the east Pacific $\left(5^{\circ} \mathrm{N}-5^{\circ} \mathrm{S}, 80^{\circ}-130^{\circ} \mathrm{W}\right)$ and Indonesia (the west Pacific; $5^{\circ} \mathrm{N}-5^{\circ} \mathrm{S}, 90^{\circ}-140^{\circ} \mathrm{E}$ ) and is negative during warm events. In comparison to the conventional station-based SOI, EQ-SOI is less susceptible to weather noise and better captures the equatorial trade wind events (see www.climate.gov /news-features/blogs/enso/why-are-there-so-manyenso-indexes-instead-just-one).

The EQ-SOI and SAM were in phase (same sign) but have opposite behavior to $P-E$ in most months from 2010 to mid-2011 (Fig. 6.5e). From then on, EQ-SOI and SAM were out of phase (opposite sign) through early 2016. Both EQ-SOI and SAM were offsetting factors modulating precipitation, resulting in little overall change of $P-E$. From late 2016 to early 2017, the MSLP anomalies over the Ross Sea shifted from positive (December-February) to negative (March-May; e.g., Figs. 6.3a,c). A combination of a weak La Niña pattern and a negative SAM resulted in higher $P-E$ amounts in this region during early 2017. As the seasons progressed into late 2017, both ENSO and SAM indices strengthened and became in phase with each other. $P-E$ began to show signs of a large decrease in late 2017.

\section{d. Seasonal melt extent and duration-L. Wang and H. Liu}

Surface melt contributes to accelerated iceberg calving, hence the retreat of ice margins and continental ice mass loss (Scambos et al. 2013; Rignot et al. 2004). The intensity, duration, and spatial extent of surface melt (Tedesco et al. 2013) contribute directly to the enlargement of ice crevasses (Scambos et al. 2000), accelerated glacier ice flow (Zwally et al. 2002), and disintegration of buttressing ice tongues and ice shelves (van den Broeke 2005; Massom et al. 2018).

Surface melt on the Antarctic continent during the 2016/17 austral summer season was estimated from daily passive microwave brightness temperature data at the $19 \mathrm{GHz}$ frequency acquired by the Special Sensor Microwave Imager/Sounder (SSM/IS) onboard the Defense Meteorological Satellite Program (DMSP) F17 satellite in the ascending passes. The data were preprocessed and provided by the U.S. National Snow and Ice Data Center (NSIDC) at level-3 EASE-Grid format (Armstrong et al. 1994) and were analyzed using a wavelet transform-based edge detection method (Ho. Liu et al. 2005). The algorithm delineates each melt event in the time series by tracking its onset and end dates, with the onset day of the first melt event being the start day of the melt season (Fig. 6.6a) and the end day of the last melt event being the end day of the melt season (Fig. 6.6b). The melt duration is then the total number of melting days per pixel during the defined melt season (excluding any refreezing events that may have occurred during this period; Fig. 6.6c). The melt extent and melt index are metrics useful for 




FIG. 6.6. Estimated surface melt for the $2016 / 17$ austral summer: (a) melt start day, (b) melt end day, (c) melt duration (days), and (d) melt duration anomalies (days).

quantifying the interannual variability in surface melt (Zwally and Fiegles 1994; Liu et al. 2006). Melt extent $\left(\mathrm{km}^{2}\right)$ is the total area that experienced surface melt for at least one day during the melt season. Melt index (day. $\mathrm{km}^{2}$ ) is the sum of the duration (days) of the melt pixels in the study area that describes the strength of melt as the accumulative melt days in a year. The anomaly map (Fig. 6.6d) was created by referencing to the mean melt duration computed over the 1981-2010 period (see also Fig. 3 in Liu et al. 2006).

Figure 6.6a shows that the earliest melt events occurred on the Wilkins Ice Shelf during the austral summer of 2016/17. The early melt area also extended to the tip of the Antarctic Peninsula. Some late but short melt events occurred on the Ross Ice Shelf. The melt events on the Wilkins Ice Shelf extended to late March 2017 (Fig. 6.6b). Figure 6.6c shows the melt duration in the austral summer of 2016/17 (Fig. 6.6c). Areas with intensive melt ( $>45$ day duration in orange-red) were the Larsen, Wilkins, and Shackleton ice shelves, and some coastal areas of Wilkes Land and Queen Maud Land. The Shackleton Ice Shelf had an abnormal prolonged melt season this year, which could have been related to the higher-than-average temperature in November and record-breaking low monthly mean pressure recorded at the nearby Casey Station (Keller et al. 2017). Areas with moderate intensity of melt (16-45 day duration in green-yellow) included coastal Queen Maud Land and the Amery Ice Shelf; short-term melt ( $<16$ day duration in blues) 


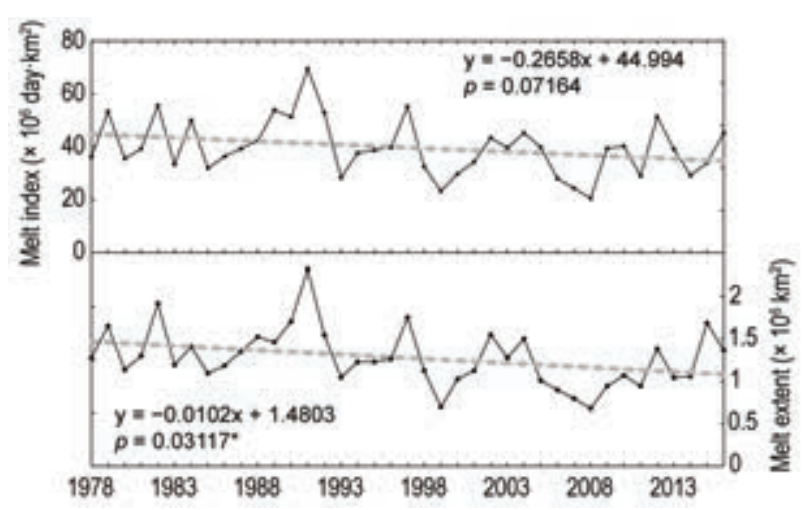

FIG. 6.7. (a) Melt index ( $\left.\times 10^{6} \mathrm{day} \cdot \mathrm{km}^{2}\right)$ from $1978 / 79$ to 2016/17, showing a negative trend (265 800 day $\mathrm{km}^{2} \mathrm{yr}^{-1}$, not significant at $95 \%$ ). (b) Melt extent ( $\left.\times 10^{6} \mathrm{~km}^{2}\right)$ from $1978 / 79$ to $2016 / 17$, showing a negative trend $\left(10200 \mathrm{~km}^{2} \mathrm{yr}^{-1}, p<0.05 \%\right)$. The year on the $\mathrm{x}$-axis corresponds to the start of the austral summer melt season, that is, 2008 corresponds to summer 2008/09.

occurred on the Ross Ice Shelf and small portions of coastal Queen Maud Land. Almost half of the Ross Ice Shelf experienced melt, albeit briefly, in the summer of 2016/17. Compared to the previous year, melt on the Ross Ice Shelf was less extensive. Overall, the 2016/17 melt season was slightly longer than the historical average (Fig. 6.6d), indicating an above-average melt year for Antarctica.

Figure 6.7a shows a non-significant $(p>0.05)$ negative trend (265 800 day. $\left.\mathrm{km}^{2} \mathrm{yr}^{-1}\right)$ in melt index since 1978, highlighted by the record low melt season observed during austral summer 2008/09. The trend lines were fit using a linear regression between the melt indices and year number. Before adding 2017 to the regression, the negative trend in melt index was significant $(p<0.05$; Wang and Liu 2017). The marked increase in melt index for 2017 was due to the intensive melt (> 90 days) on the Wilkins Ice Shelf. The negative trend of the melt extent, however, remained significant ( $p<0.05$; Fig. 6.7b), because half of the Ross Ice Shelf did not melt (Fig. 6.6c) as it did in 2016, which reduced the 2017 melt extent as compared to 2016 (Fig. 6.7b). Nonetheless, both the melt extent and melt index were the second highest since 2005. The negative trends are consistent with previous reports (Liu et al. 2006; Tedesco 2009; Tedesco et al.2009).

e. Sea ice extent, concentration, and seasonalityP. Reid, S. Stammerjohn, R. A. Massom, J. L. Lieser, S. Barreira, and T. Scambos

Antarctic sea ice performs important roles in the climate system through the formation of dense oxygen rich Antarctic Bottom Water (Johnson 2008) and modulating fluxes across the ocean/atmosphere interface within the high southern latitudes (Bourassa et al. 2013). It also acts as a buffer for ice shelves against ocean processes (Williams and Squire 2007; Massom et al. 2018).

Net sea ice extent (SIE; the area enclosed by the ice edge consisting of a range in sea ice concentration) and sea ice area (SIA; the actual area covered by sea ice) were well below the 1981-2010 average for all of 2017 (Fig. 6.8b). Following the record low seasonal sea ice cover in November and December 2016 (Reid et al. 2017; Stuecker et al. 2017; Turner et al. 2017; Schlosser et al. 2018), the first four months of 2017 also had record low net SIE, followed by sporadic periods of record low SIE into September. Overall, 130 days of record low SIE occurred during 2017, with 57 individual days of record low SIA between January and early October. The month of February 2017 recorded the lowest monthly mean SIE on record (Schlosser et al. 2018). Other records in 2017 included the lowest observed daily value of SIE in the continuous satellite record (since 1978) on 1 March 2017 of $2.1 \times 10^{6} \mathrm{~km}^{2}$ (not shown; previous lowest was $2.3 \times 10^{6} \mathrm{~km}^{2}$ on 27 February 1997). The annual daily maximum was also later than previously observed, on 9 October (previous latest maximum was 3 October 1988). Record low sea ice cover during $2016 / 17$ is in contrast to the long-term (1979-2016) positive trend in net SIE (Turner and Comiso 2017), as discussed further below.

Regionally, early 2017 (January through midApril) sea ice coverage followed on from the predominantly low net sea ice coverage in late 2016 . However, high concentrations of sea ice were observed along much of the coast of East Antarctica $\left(\sim 80^{\circ}-160^{\circ} \mathrm{E}\right)$ and in parts of the Weddell Sea $\left(\sim 30^{\circ}-60^{\circ} \mathrm{W}\right)$, for example (Fig. 6.8c). Synoptically, in late 2016 and January 2017, winds around East Antarctica and the Weddell Sea were anomalously easterly, causing an initial southward compaction of the sea ice via Ekman transport while largely retaining the sea ice extent in these regions during the summer season (Figs. 6.8a,c). Consequently, sea ice advanced early across much of East Antarctica. Elsewhere around the coast in early 2017, sea ice coverage was either non-existent or well below average (e.g., Fig. 6.8c). Ocean SSTs around Antarctica through early 2017 were anomalously high (e.g., Fig. 6.8c; Section 6f) and coincident with regions of suppressed ice formation, particularly in the Ross, Bellingshausen, and Amundsen Seas and the eastern Weddell Sea. The suppressed ice formation led to considerably later ice edge advance in these regions, by as much as 50 days later in most of the Amundsen 

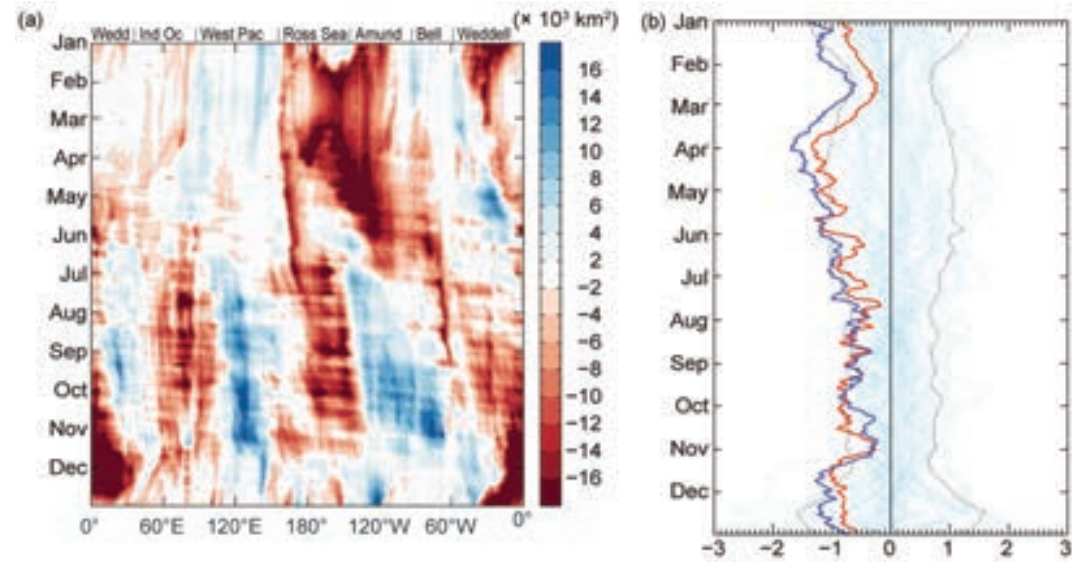

(c)

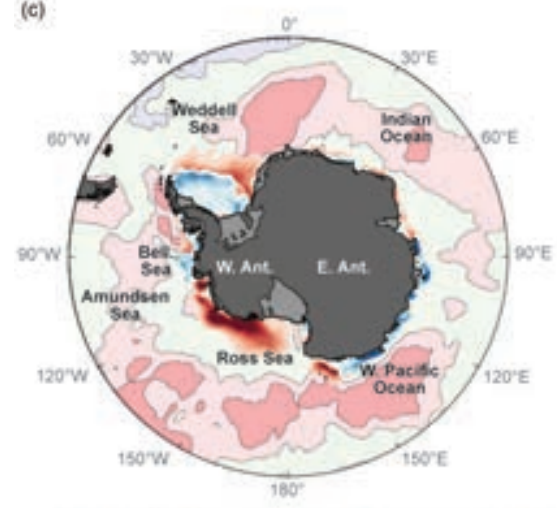

(d)

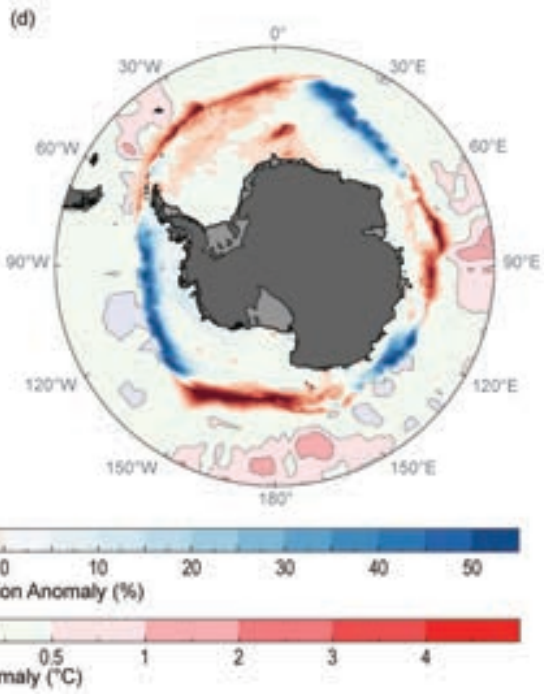

FIG. 6.8. (a) Hovmöller plot of daily SH sea ice extent anomalies for 2017 $\left(\times 10^{3} \mathrm{~km}^{2}\right.$ per degree of longitude; from the 198I-2010 mean); (b) net sea ice extent anomaly (blue) and sea ice area anomaly (red) (from 198I-2010 mean); thin blue lines represent the historical daily values of extent for 1979-2015, while the thin black lines represents \pm 2 std. dev. of extent. (c) and (d) sea ice concentration anomaly (\%) and SST anomaly $\left({ }^{\circ} \mathrm{C}\right.$; Reynolds et al. 2002; Smith et al. 2008) for (c) Feb. and (d) Sep. 2017. Based on satellite passive-microwave ice concentration data [Cavalieri et al. 1996, updated yearly, for climatology; and Maslanik and Stroeve (1999) for the 2017 sea ice concentrations].

Sea, as reflected in the negative duration anomaly in this region (Fig. 6.9a).

The atmospheric circulation pattern changed during April with deep low pressure systems developing north of the Weddell Sea $\left(\sim 30^{\circ} \mathrm{W}\right)$, Wilkes Land $\left(\sim 125^{\circ} \mathrm{E}\right)$, and well north of the Amundsen Sea $\left(\sim 100^{\circ} \mathrm{W}\right.$; see Section $\left.6 \mathrm{~b}\right)$. This pattern enhanced ice coverage predominantly within the western Weddell Sea while continuing to suppress extent in the Bellingshausen, Amundsen, and Ross Seas through warm air advection and higher-than-normal SSTs. A zonal wave-two atmospheric pattern developed in May (not shown), with synoptic lows centered in the eastern Ross Sea $\left(\sim 140^{\circ} \mathrm{W}\right)$ and north of the Amery
Ice Shelf $\left(\sim 70^{\circ} \mathrm{E}\right)$, promoting sea ice advance (albeit later than normal) in the Ross $\left(\sim 120^{\circ} \mathrm{W}-\right.$ $\left.180^{\circ}\right)$ and Weddell $\left(\sim 10^{\circ}-30^{\circ} \mathrm{W}\right)$ Seas. Through May and into early June, SIE continued to be above average across much of East Antarctica but below average in the western Ross, Amundsen, and Bellingshausen Seas and across the eastern Weddell Sea and Indian Ocean sectors $\left(\sim 10^{\circ} \mathrm{W}-80^{\circ} \mathrm{E}\right)$.

During mid-June, a stationary wave-three atmospheric pattern began to develop (Section $6 \mathrm{~b}$ ), with broad low-pressure centers to the north of the Bellingshausen Sea $\left(\sim 80^{\circ} \mathrm{W}\right)$, East Antarctica $\left(\sim 140^{\circ} \mathrm{E}\right)$, and Dronning Maud Land $\left(\sim 40^{\circ} \mathrm{E}\right)$ that broadly correspond to the SIE anomalies (Fig. 6.8a). This pattern increased southerly cold air outflow in the eastern Ross Sea, far eastern Weddell Sea, and north of Wilkes Land $\left(\sim 120^{\circ} \mathrm{E}\right)$, increasing ice coverage and contributing to a positive anomaly in SIE in these regions (Fig. 6.8a). Conversely, intervening warm air advection and higher SSTs associated with this zonal wave-three pattern were observed in the western Weddell and Ross Seas and to the north of the Amery Ice Shelf $\left(\sim 60^{\circ}-100^{\circ} \mathrm{E}\right)$, suppressing ice expansion and producing a negative SIE anomaly (Fig. 6.8a). Interestingly, while the atmospheric zonal wave-three pattern subsided during September, the zonal wave-three pattern within both the patterns of SIE and SST anomalies persisted through early November (Figs. 6.8a,d). It was during this period (September onwards; e.g., Fig. 6.8d) that, again similar to 2016 (Mazloff et al. 2017; Reid et al. 2017), the Maud Rise polynya opened up (see Sidebar 6.1).

Early November saw another change in the circumpolar atmospheric circulation pattern, with the development of a deep Amundsen Sea low pressure system and an associated zonal wave-three pattern. The change in atmospheric circulation influenced 


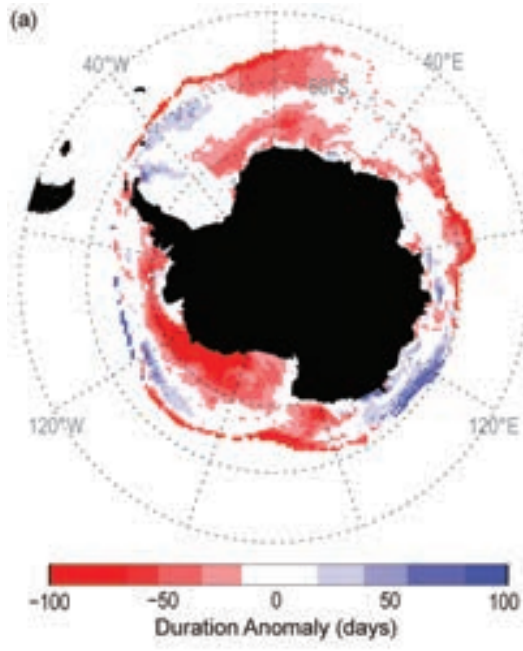

(b)

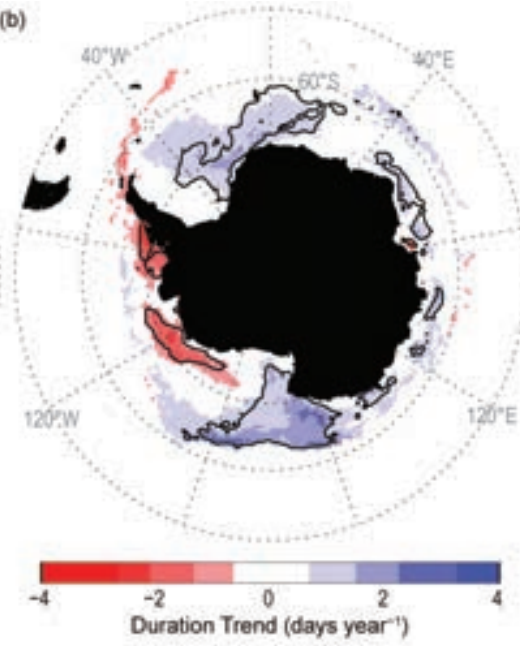

Fig. 6.9. Maps showing (a) duration anomaly for the $2016 / 17$ sea ice season in days and (b) duration trend for 1979/80-2016/17 in days $\mathrm{yr}^{-1}$. The black contour in (b) delineates those trends with significance at the $p<0.0$ I significance level.

the regional rate of ice retreat, particularly in the Bellingshausen-Amundsen $\left(60^{\circ}-120^{\circ} \mathrm{W}\right)$ and Weddell $\left(30^{\circ} \mathrm{W}-30^{\circ} \mathrm{E}\right)$ Seas where slower and faster retreat occurred, respectively (Fig. 6.8a).

These austral springtime sea ice distribution changes are consistent with the influence of the relatively weak La Niña developing within the tropical Pacific in early November 2017 (see Section 4b), which changed the position of the higher-latitude southern jet streams and hence the cyclonicity around the Antarctic continental edge (Yuan 2004; Stammerjohn et al. 2008). Thus, SIE towards the end of the year and within the Weddell Sea was, in some areas, more than six standard deviations below average. Elsewhere, SIE was close to average, although small pockets of greater-than-average SIE existed within the Amundsen Sea and western Pacific sector $\left(\sim 110^{\circ}-150^{\circ} \mathrm{E}\right)$ associated with wind-driven compaction of the sea ice cover and lower-than-normal SSTs near these regions.

The long-term trend for Antarctic sea ice is regionally and seasonally variable: increased SIE and longer seasonal duration within the Ross and Weddell Seas, and decreased SIE and shorter duration in the Bellingshausen-Amundsen Seas (e.g., Fig. 6.9b for sea ice duration trends over 1979/80-2016/17; see Comiso et al. 2017 for sea ice extent trends). For SIE these changes are largest during January-May (Hobbs et al. 2016). Apart from some areas of the Amundsen Sea, the regional pattern of sea ice coverage during 2017, described above, was in contrast to this long-term trend (Fig. 6.9a), particularly in much of the Ross
Sea and the Weddell Sea through the end of March.

f. Southern Ocean-S. Swart, K. Johnson, M. R. Mazloff, A. Meijers, M. P. Meredith, L. Newman, and J.-B. Sallée

In the climate system, the Southern Ocean is disproportionately important when it comes to its storage of heat and carbon. Modification of the upper Southern Ocean could have significant implications for the rate and magnitude of air-sea fluxes (of heat and carbon) and for the ventilation of the ocean interior, thereby altering the effects of climate warming on the ocean system as a whole. Here, we evaluate the state of the Southern Ocean in 2017 by first assessing the upper ocean as the interface between the atmosphere and ocean interior. We then discuss the changes in intermediate to deep water masses, which are critical pathways to moving heat and carbon to the ocean interior where it will (in general) remain for decades to centuries. Lastly, we report on the status of ocean acidification in the Southern Ocean using newly available biogeochemical observations.

\section{I) UPPER OCEAN}

By utilizing all available 2017 hydrographic profiles (40 816 from Argo floats and 11916 from tagged seals), anomalies of mixed layer depth (MLD) and mixed layer (ML) temperature and salinity (Figs. 6.10a-c) were computed from the climatological (2000-2010) seasonal cycle (see Pellichero et al. 2017). During 2017, the most significant observation is the shallower MLDs (negative anomalies) occurring in the Pacific sector, particularly within the Antarctic Circumpolar Current (ACC), where MLDs are more than $100 \mathrm{~m}$ shallower than the climatology. Meanwhile, the Atlantic and Indian sectors are characterized by mixed MLD anomalies.

In contrast to anomalies reported for 2015 and 2016 (Sallée et al. 2016; Mazloff et al. 2017), a markedly warmer ML (Fig. 6.10b) was observed throughout most of the Southern Ocean in 2017, except for the northern subantarctic region of the Atlantic sector. In further contrast, positive Southern Ocean ML temperature anomalies in 2015 were juxtaposed against negative anomalies to the north, indicating a north-south dipole separated by the ACC (Sallée et al. 2016), while in 
(a)

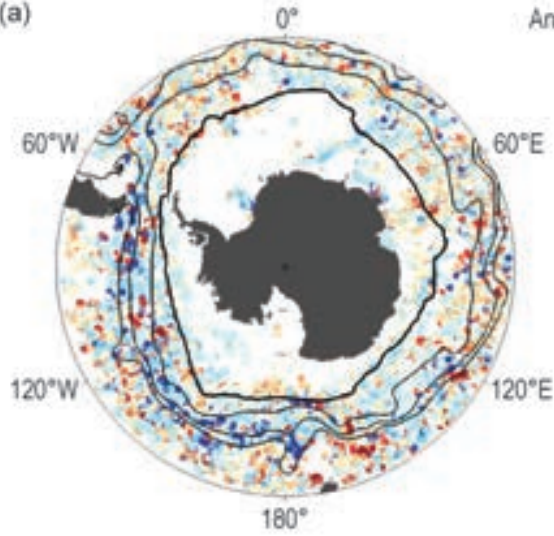

(c)

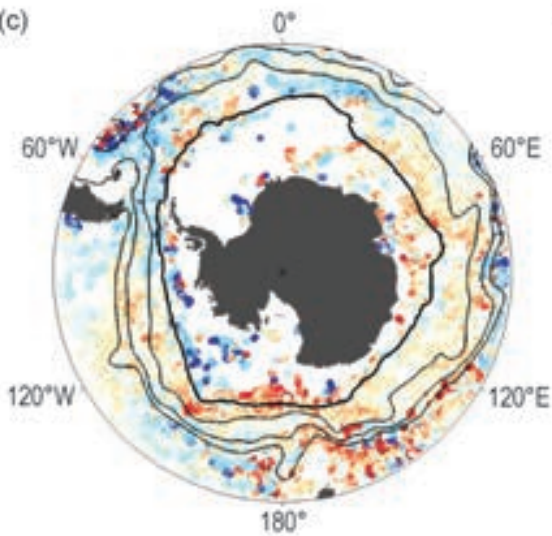

(e)
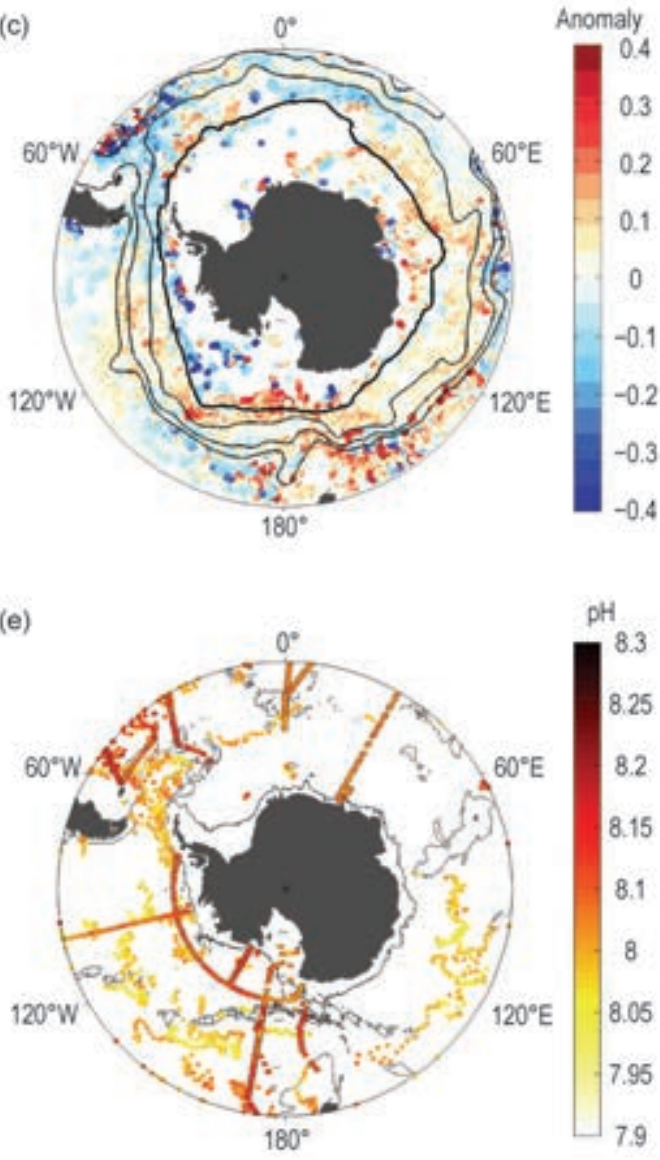

(b)
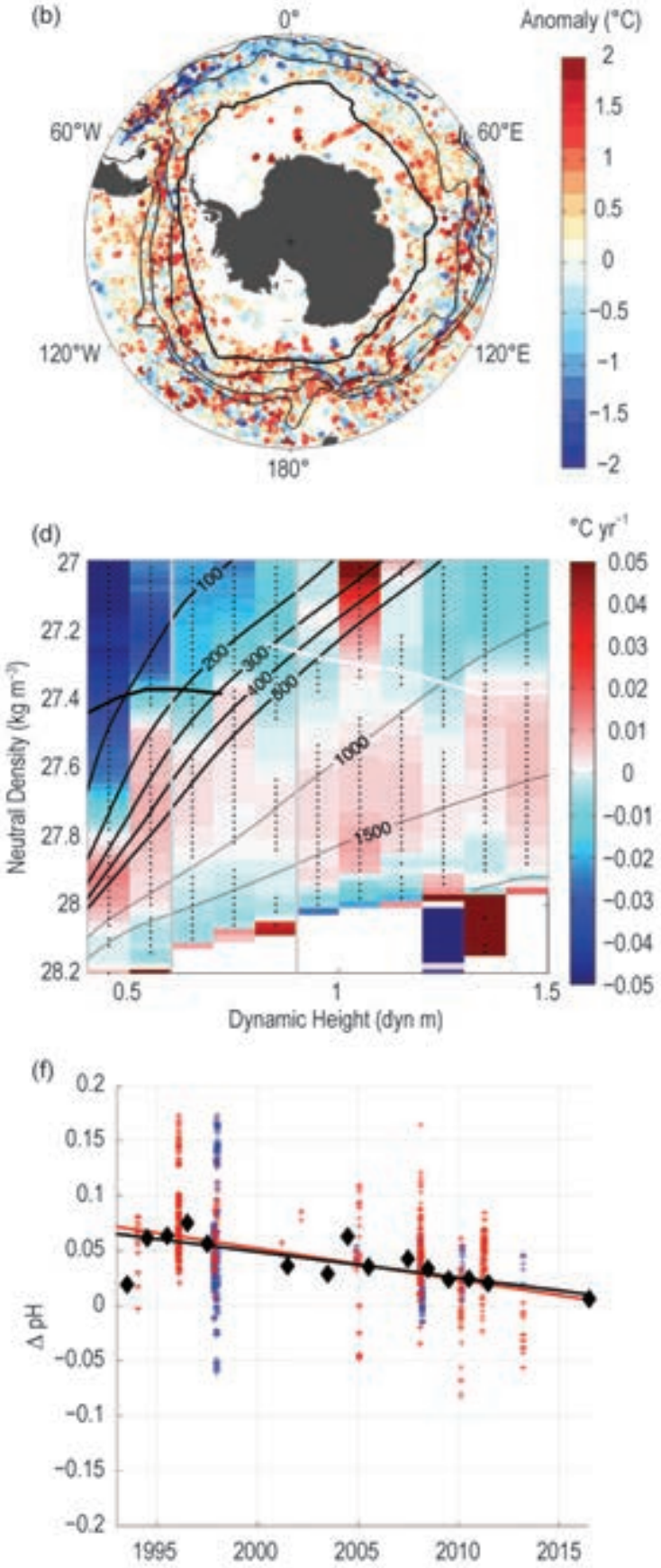

Fig. 6.10. (a) Mixed layer depth anomaly (m) in 2017 from the climatological seasonal cycle. The thin black contours represent the main ACC fronts from north to south: northern Subantarctic Front (SAF), main SAF, Polar Front (PF). The thick black contour is the Sep. climatological sea ice extent. (b) Same as (a) but for mixed layer temperature $\left({ }^{\circ} \mathrm{C}\right)$. (c) Same as (a) but for mixed layer absolute salinity. (d) Circumpolar average trend in potential temperature (in ${ }^{\circ} \mathrm{C}_{\mathrm{yr}^{-1}}$ ) from Argo float data (seasonal cycle removed), oriented along constant dynamic height and isopycnal surfaces. The thick solid black contour is the T-min layer and the white contour is the S-min layer. Constant pressure surfaces are indicated. Vertical lines indicate the position of the PF (left) and SAF (right). Dots indicate trends in potential temperature significant at the $95 \%$ level. (e) Observed upper 30-m pH (black outlined colored dots) from the GLODAPv2 database (Key et al. 2015) spanning 1992-2013 and the SOCCOM pH observations in 2017 (colored dots without outlines). The $3000-\mathrm{m}$ bathymetry contour is shown in black. (f) Changes in pH via two different methods: black diamonds are annual averaged GLODAPv2 comparisons (1992-2013) to all SOCCOM float data (2014-17), while red/blue pluses denote the discrete GLODAPv2 comparisons to only 2017 float data and all other float data, respectively (based on criteria explained in the text). The black and red lines are the linear fit to the respective color markers. 
2016, ML temperature anomalies defined a quadrupole delimited by ocean basins (Mazloff et al. 2017).

In 2017 warmer ML temperatures north of the mean September ice edge (thick black contour in Figs. 6.10a-c) generally coincided with shallower MLDs (negative anomalies; Fig. 6.10a) and increased ocean stratification (not shown). However, deeper MLDs (positive anomalies) appearing in the Indian sector of the Southern Ocean (centered on $60^{\circ} \mathrm{E}$ near the mean September ice edge) coincided with anomalously saline mixed layers (Fig. 6.10c) and reduced ocean stratification (not shown). South of the ACC (and mean September ice edge) there are fewer observations, but overall the data suggest a negative MLD anomaly (shallower) in the West Antarctic sector together with strongly negative ML salinity (fresher) and positive (higher) ML temperature anomalies. These fresher MLs may be linked with a long-term increase in wind-driven transport of freshwater northward (Haumann et al. 2016) and/or increased sea ice melt in summer (February) 2017 (Section $6 \mathrm{e})$. From the Maud Rise region $\left(3^{\circ} \mathrm{E}\right)$ towards East Antarctica positive ML salinity anomalies (Fig. 6.10c) were observed, which resulted in weak stratification. These changes may be linked to the anomalously low sea ice conditions experienced in the eastern Weddell Sea (Section 6e) together with the recent re-emergence of the Maud Rise polynya and its associated impacts on the upper ocean via enhanced air-sea exchanges and ventilation of warmer, saltier interior water masses (see Sidebar 6.1).

\section{2) INTERMEDIATE OCEAN}

Significant thermohaline changes are occurring below the surface layers of the Southern Ocean. Due to the slow time scales of these changes (unlike the more temporally sensitive surface mixed layer properties just described), it is more appropriate to discuss multi-year changes (2002-16). The gravest empirical mode (GEM; see methods in Meijers et al. 2011; Swart et al. 2010), a highly effective method to reconstruct subsurface property fields from sea surface height, is used to map thermal changes at intermediate depths (thermocline depth to $2000 \mathrm{~m}$ ). The GEM uses a current inventory of all Argo float profiles (2002 to 2016) to derive circumpolar-averaged potential temperature trends approximately oriented along stream-following dynamic height contours, here shown on constant isopycnal surfaces (Fig. 6.10d). Such a coordinate choice removes aliasing and trends due to frontal movements and vertical heave.

Overall, there was a consistent warming of up to $0.02^{\circ} \mathrm{C} \mathrm{yr}^{-1}$ (Fig. 6.10d) and salinification (not shown: $\left.27.6-28 \mathrm{~kg} \mathrm{~m}^{-3}\right)$ of the densest Antarctic Intermediate Water (AAIW) and Circumpolar Deep Water (CDW) throughout the Southern Ocean over 2002-16. This may be related to changes in westerly winds (due to long-term increases in the SAM; Böning et al. 2008). Lying above these depths, two fairly distinct negative trends were observed, one north of the Polar Front ( $>0.8$ dyn $\mathrm{m}$ ), which indicates cooling of the upper AAIW and Subantarctic Mode Water (SAMW; $\left.-0.01^{\circ} \mathrm{C} \mathrm{yr}^{-1}\right)$, and the other south of the Polar Front, which indicates relatively strong cooling and freshening of winter and surface water (e.g., Haumann et al. 2016) ranging from $-0.015^{\circ}$ to $-0.05^{\circ} \mathrm{C}_{\mathrm{yr}^{-1}}$. The cooling of SAMW in the northern ACC does not contradict the general warming trend observed beyond the northern ACC, as this may be related to increased volume and hence heat content of SAMW and AAIW predominantly caused by wind-driven changes, namely increased wind stress curl (Gao et al. 2018).

\section{3) Biogeochemical status: Continued ocean ACIDIFICATION}

The new Southern Ocean Carbon and Climate Observations and Modeling project (SOCCOM) array currently has 105 active profiling floats, allowing a characterization of ocean $\mathrm{pH}$ variability at shorter time scales and higher spatial resolution. Ocean $\mathrm{pH}$ is decreasing as anthropogenic $\mathrm{CO}_{2}$ enters the ocean and forms carbonic acid (causing ocean acidification). Ocean acidification challenges the viability of organisms producing $\mathrm{CaCO}_{3}$ shells and has fundamental impacts on the ocean carbon cycle.

Observed $\mathrm{pH}$ in the upper $30 \mathrm{~m}$ from the GLODAPv2 database (1992-2013 observations as black outlined colored dots in Fig. 6.10e; Key et al. 2015; Olsen et al. 2016) is compared to SOCCOM pH observations in 2017 (colored dots without black outlines). It is qualitatively apparent that the GLODAPv2 estimates have higher $\mathrm{pH}$. Two methods were used to quantify these differences. For the first method, all upper 150-m GLODAPv2 observations from 1992 to 2013 were used, and float observations (from 2014 to 2017) that were within $20-\mathrm{km}$ and 5-m depth of the GLODAPv2 observations were identified. Differences in $\mathrm{pH}$ between GLODAPv2 and float observations were determined and bin-averaged for each year of GLODAPv2 observations (black diamonds in Fig. 6.10f); any year with less than five matches was eliminated. (The additional data point for 2016 shows the mean offset between float $\mathrm{pH}$ and hydrocast $\mathrm{pH}$, the latter acquired during float deployments; Johnson et al. 2017). A second method identified all 


\section{SIDEBAR 6.I: RETURN OF THE MAUD RISE POLYNYA: CLIMATE LITMUS OR SEA ICE ANOMALY? —S. SWART, E. C. CAMPBELL, C. H. HEUZÉ, K. JOHNSON,}

J. L. LIESER, R. MASSOM, M. MAZLOFF, M. MEREDITH, P. REID, J.B. SALLÉE, AND S. STAMMERJOHN

The Maud Rise polynya is a persistent area of open water within the sea ice cover of the Southern Ocean, which overlies an area of elevated topography called Maud Rise $\left(66^{\circ} \mathrm{S}, 3^{\circ} \mathrm{E}\right)$ located in the eastern sector of the Weddell Sea (Fig. SB6.la). It is termed a "Weddell polynya" if it grows and migrates westward into the central Weddell Sea. This larger sized polynya was first observed in satellite data in 1974 and recurred for each of the two subsequent austral winters (Zwally and Gloersen 1977; Carsey 1980). Its large size, $2300000 \mathrm{~km}^{2}$, meant that it could contribute strongly to the transfer of heat from the ocean to the atmosphere in winter and, hence, instigate dense water production and the renewal of deep ocean waters in the Weddell Sea (Gordon 1978). The amount of deep water formed via this route was estimated at I-3 Sverdrups (Martinson et al. 1981). The 1974-76 polynya may have been responsible for up to $34 \%$ of observed warming of the deep Southern Ocean (Zanowski et al. 20I5). Smaller features, perhaps associated with topographically driven upwelling of warm waters, have been observed subsequently (Comiso and Gordon 1987), but a large polynya had not re-appeared until recently and unexpectedly during austral winters 2016 and 2017.

Following the Maud Rise polynya development in 2016 (Mazloff et al. 2017), mid-September 2017 saw the opening of a longer lived and larger polynya over the same region. The 2017 polynya grew quickly but its size remained quite static at approximately $50000 \mathrm{~km}^{2}$ until 3 November, after which it more than tripled in size over a period of a week. The sudden expansion is possibly the result of a considerable change in atmospheric circulation due to the development of a La Niña in early November (Section 6e), combined with an anomalously earlier spring ice edge retreat (see Section 6e). The polynya continued to expand over the following month (Fig. SB6.Ib) and reached its maximum size of $295000 \mathrm{~km}^{2}$ (larger than New Zealand) on 2 December 2017 before coalescing with the open ocean. Overall, it contributed to a significantly large negative anomaly in sea ice concentration (see Section 6e).

Two under-ice biogeochemical profiling floats from the Southern Ocean Carbon and Climate Observations and Modeling (SOCCOM) project were present at Maud Rise before, during, and after the 2016 and 2017 polynyas. Both floats surfaced and transmitted data within the 2017 polynya (Fig. SB6.Ib). These data show the appearance of cold and fresh subsurface anomalies in late 2016 (extending from $\sim 100$ to $300 \mathrm{~m}$ depth in Figs. SB6.2a,b), indicating that deep ventilation may have occurred during the brief 2016 polynya. This modified subsurface water mass persisted into 2017 and was punctuated in October and November by warm and salty intrusions indicative of deep
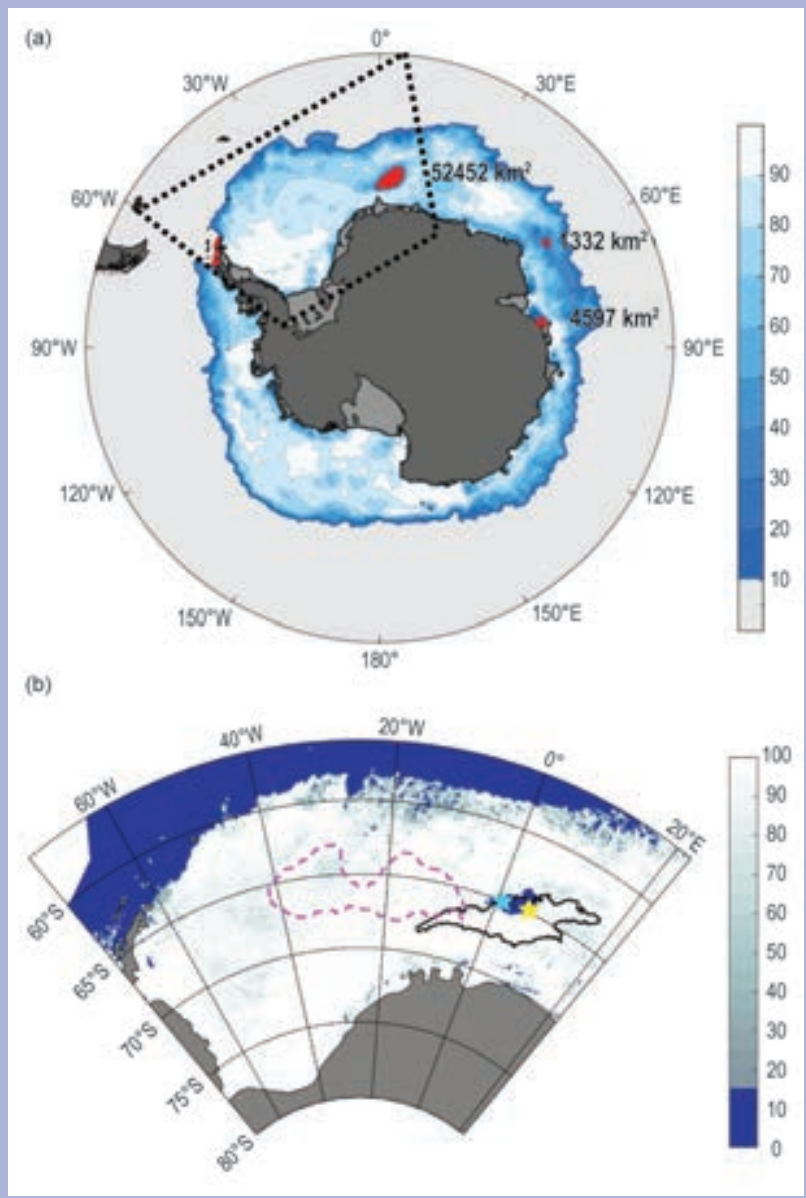

FIG. SB6.I. (a) Circumpolar map of AMSR2 sea ice concentration (in \%) on 8 Nov 2017, with the red shading marking polynya locations, including the largestthe Maud Rise polynya. (b) Location of the polynya on 14 Oct 2017 from AMSR2 sea ice concentration (Spreen et al. 2008). The black line represents the polynya size on 29 Nov 2017, at its largest extent just prior to coalescing with the open ocean. The yellow and cyan stars represent the location of the SOCCOM floats 590447I and 5904468, respectively. The magenta contour shows a 20 -yr mean location of the polynya as depicted in the MPI-ESM-LR model.

mixing during the 2017 polynya event. Additionally, enhanced biogeochemical responses to the polynya's presence were observed with approximately a 2-month earlier (September 2017) increase in chlorophyll fluorescence (phytoplankton) and $\mathrm{pH}$ (Figs. SB6.2c,d) compared to the two previous years, which were ice covered. Hydrographic measurements collected near Maud Rise during two research expeditions on the R/V S.A. 


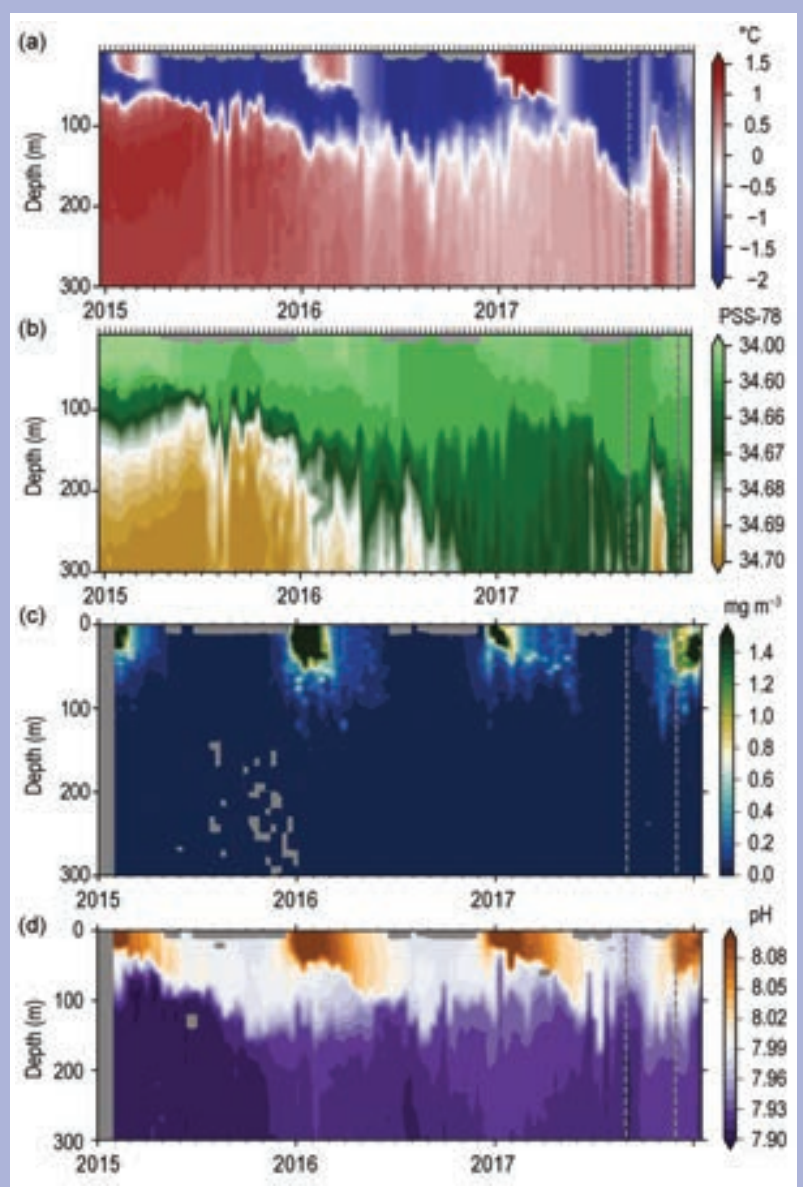

FIG. SB6.2. Sections of (a) potential temperature $\left({ }^{\circ} \mathrm{C}\right)$, (b) salinity (PSS-78) from SOCCOM float 590447I, (c) chlorophyll-a $\left(\mathrm{mg} \mathrm{m}^{-3}\right)$, and (d) $\mathrm{pH}$ from SOCCOM float

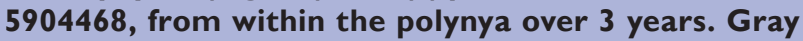
dashed lines represent the start and end dates of the 2017 polynya. Gray shading indicates absence of data.

Agulhas II and R/V Polarstern in December 2017 and January 2018 , respectively, when fully processed and analyzed, may lend additional insights regarding the ocean impacts from the 2016 and 2017 polynyas.

The research community continues to speculate on the causes of the 2017 polynya and whether it is related to the 2016 event. It is possible that the 2017 polynya was caused by persistent subsurface ocean conditions that were initiated during the 2016 polynya, and/or it was caused by preconditioning that resulted from anomalous sea ice divergence occurring late spring 2016 (Schlosser et al. 2018). Preconditioning mechanisms may include a build-up of subsurface heat (Martin et al. 2013), a precipitation deficit caused by prolonged negative SAM
(Gordon et al. 2007), and/or reduced sea ice concentration and upper-ocean instability from upwelling of warm and salty waters on the flanks of Maud Rise (Gordon and Huber 1995; Lindsay et al. 2004; de Steur et al. 2007; Cheon et al. 2014, 2015). Triggering mechanisms remain less clear but may include transient eddies or other topography-mean flow interactions associated with Maud Rise (Holland 200I) or small positive salinity anomalies at the surface caused by anomalous wind and/or sea ice conditions (Cheon et al. 2014; Heuzé et al. 2015; Kjellsson et al. 2015). A prolonged period of strong westerly winds (coincident with positive SAM) might also explain the 2016 and 2017 openings that may have responded to the wind-induced Ekman transport and associated upwelling of warmer water (Cheon et al. 2014; Ferreira et al. 20I5). In the lead-up to the 2016 and 2017 polynyas, the SAM index was indeed strongly positive with three of its ten highest monthly values since 1957 recorded in 2015 and 2016, including the largest value in February 2015-coinciding with the annual sea ice minimum. It is quite possible that strong winds and an associated enhanced Weddell Gyre were the catalyst for these polynya events. A contributing mechanism during both years may be anomalously warm waters advecting south from the Indian and western Atlantic sectors of the Southern Ocean. More research is needed to better understand the respective roles of large-scale modes (SAM) versus regional circulation anomalies, in addition to needing more highly resolved data in space and time (e.g., Schlosser et al. 2018).

Global coupled models generally exhibit a greater frequency of Maud Rise polynya occurrence compared to observations (e.g., Heuzé et al. 2013; Fig. SB6.Ib) and have thus been a valuable source of information regarding their causes and occurrences. Models suggest a preconditioning is needed by the slow accumulation of subsurface heat over several decades (Martin et al. 2013; Dufour et al. 2017), heat that would be lost after years of the polynya remaining open, possibly explaining why polynyas on the scale of the 1974-76 event have not been seen in 40 years. Alternatively, models also suggest that increased freshening at the ocean surface, caused by increased ice sheet/iceberg melt for example, may increase stratification and reduce the frequency of polynya formation (Kjellsson et al. 2015). The extent to which such models robustly reproduce the real ocean is largely unknown due to the comparatively short observational record, but such results highlight the need to better understand this intermittent but important mode of deep ocean ventilation. 
float observations in the upper $30 \mathrm{~m}$ at intervals of 5 days, $5-\mathrm{m}$ depth, $3^{\circ}$ latitude, and $10^{\circ}$ longitude of the GLODAPv2 1992-2013 observations (Fig. 6.10f, red and blue pluses for 2017 and 2014-16 float data comparisons, respectively).

The two estimates reveal consistent trends (determined by least-squares fit) in $\mathrm{pH}$, hence ocean acidification. The first approach resulted in an acidification rate of $-0.0023 \mathrm{yr}^{-1}$; for the second method the rate was $-0.0025 \mathrm{yr}^{-1}$ and $-0.0028 \mathrm{yr}^{-1}$ for the 2014-16 and 2017 float data comparisons, respectively, implying either the 2017 floats sampled lower $\mathrm{pH}$ (than was sampled in 2014 to 2016) or the 2017 floats captured different spatial variability. These results are nevertheless consistent with previous observations based on individual hydrographic lines (Rios et al. 2015; Williams et al. 2015) or based on predictions from coupled models. Faster acidification rates in the Southern Ocean compared to the global average $\left(\sim-0.0017\right.$ year $\left.^{-1}\right)$ expected due to low carbonate ion concentrations in the Southern Ocean (McNeil and Matear 2008; Orr et al. 2005). Nonetheless, there is considerable spatial and temporal variability in surface ocean $\mathrm{pH}$, both in observed and as predicted with coupled climate models (Russell et al. 2018), but as the float record expands and lengthens, both the assessment and prediction of the spatial and temporal variability in acidification rates will improve.

\section{g. 2017 Antarctic ozone hole-N. Kramarova,}

P. A. Newman, E. R. Nash, S. E. Strahan, C. S. Long, B. Johnson, M. L. Santee, I. Petropavlovskikh, G. O. Braathen, and L. Coy

Severe ozone depletion in the Antarctic stratosphere has been observed every austral spring since the early 1980s (WMO 2014) and is caused by heterogeneous chemical reactions with human-made chlorine- and bromine-containing compounds. As much as $98 \%$ of the ozone in the lower stratosphere around $70 \mathrm{hPa}$ is destroyed in September-October. As a result of regulations set in place by the Montreal Protocol and its amendments, levels of chlorine from ozone depleting substances have gradually declined, and springtime Antarctic ozone is beginning to show signs of recovery (WMO 2014).

The 2017 Antarctic ozone hole was the second smallest since 1988, with an area of 17.4 million $\mathrm{km}^{2}$ (or 6.7 million $\mathrm{mi}^{2}$ ) averaged from 7 September to 13 October, the period of greatest ozone depletion. The ozone hole area is defined as the area with total column ozone values less than 220 Dobson units (DU). Figure 6.11d displays the daily areal coverage of the ozone hole for 2017 (black curve). The area started expanding at the beginning of August, with a dip due to stratospheric warming in mid-August. It increased until another stratospheric warming stopped the expansion in mid-September, reaching a 19.6 million $\mathrm{km}^{2}$ peak on 11 September, and then declined slowly into October and disappeared on 19 November. The warmings prevented the hole from

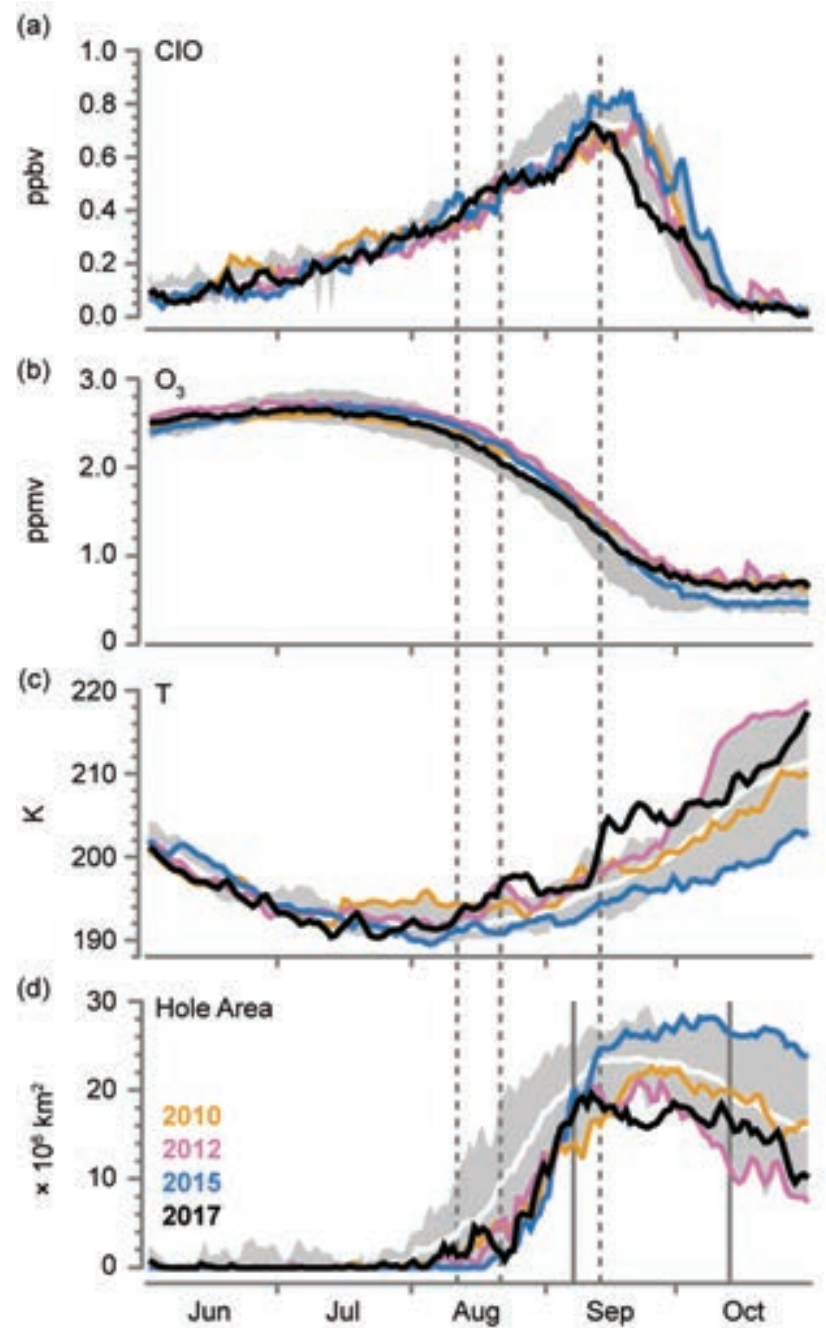

FIG. 6.II. Antarctic vortex-averaged concentrations of: (a) $\mathrm{ClO}$ and (b) ozone from Aura MLS (updated from Manney et al. 20II). These MLS averages are made inside the polar vortex on the $440-\mathrm{K}$ isentropic surface $(\sim 18 \mathrm{~km}$ or $65 \mathrm{hPa})$. (c) Temperature on the $440-\mathrm{K}$ isentropic surface over Antarctica $\left(60^{\circ}-90^{\circ} \mathrm{S}\right)$ from MERRA-2 (Gelaro et al. 2017). (d) Ozone hole area based on Ozone Monitoring Instrument (OMI) and Ozone Mapping and Profiler Suite (OMPS) satellite observations. Four years are shown: 2010 (orange), 2012 (pink), 2015 (blue), and 2017 (black). The white line shows the daily average and the gray shading shows the daily ranges for 2005-16. The vertical solid lines indicate the averaging period for Fig. 6.13, while the vertical dashed lines indicate the dates of maximum wave forcing for the stratospheric warming events in 2017. 
(a)

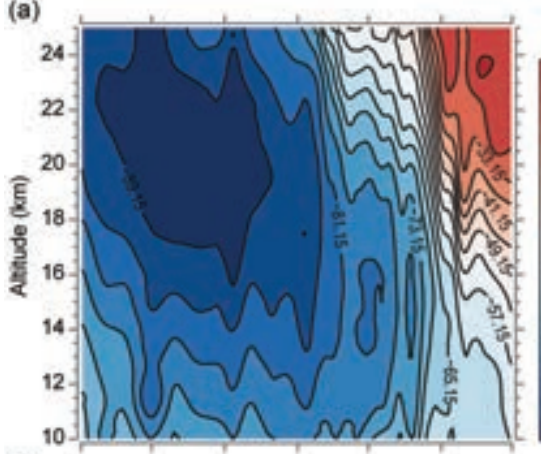

(c)

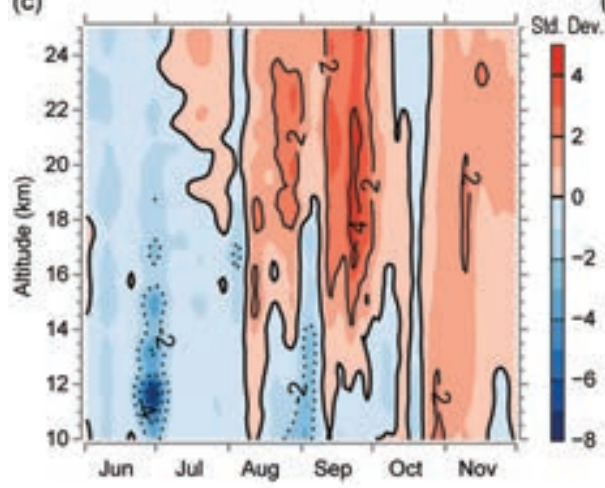

(b)

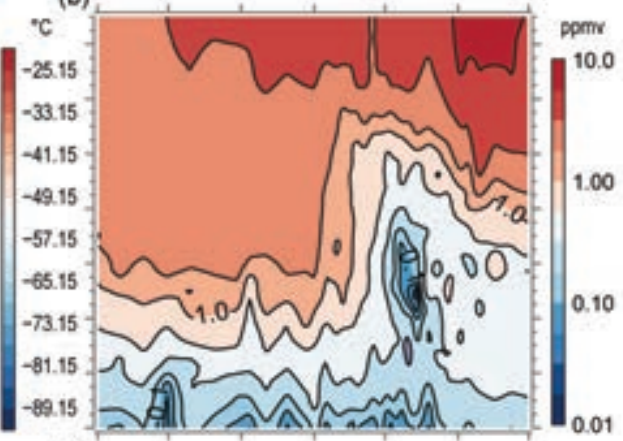

(d)

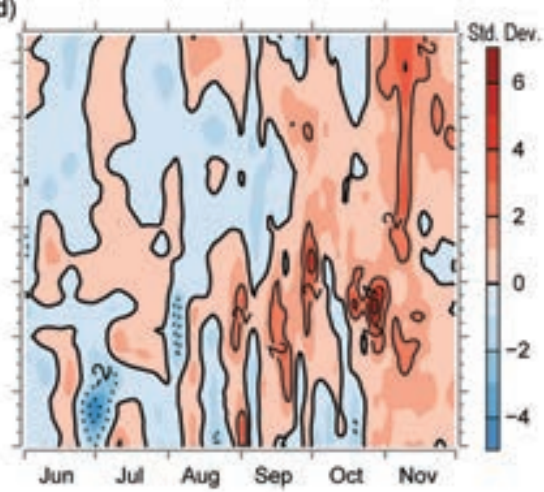

FIG. 6.12. Altitude vs. time cross sections from balloon observations at South Pole station in 2017 for: (a) temperature profiles $\left({ }^{\circ} \mathrm{C}\right),(\mathrm{b})$ ozone profiles (ppmv), and anomalies from the 2005-16 average normalized by std. dev. of (c) temperature and (d) ozone.

growing further, accounting for the low average area compared to previous years.

The extent of the seasonal ozone depletion over Antarctica is controlled by the total inorganic chlorine and meteorological conditions in the lower stratosphere. Colder temperatures facilitate formation of the polar stratospheric clouds (PSC) and transformation of inorganic chlorine to active chlorine that eventually lead to ozone loss. There were two key planetary wave events in the lower stratosphere that slowed ozone depletion (and thus the areal expansion of the ozone hole). The first occurred between 11 and 21 August, and the second on 13 September. These disturbed the polar vortex and warmed the lower Antarctic stratosphere (Fig. 6.11c). Satellite observations acquired by the NASA Aura Microwave Limb Sounder (MLS) show that ClO (chlorine monoxide) levels rose until the 13 September planetary wave event and then rapidly declined (Fig. 6.11a, black curve), stalling this year's ozone depletion (Fig. 6.11b). The seasonal evolution of the stratospheric ozone concentration, ozone hole area, $\mathrm{ClO}$, and temperature in 2017 is similar to those in 2010 and 2012-two other years with unusually strong wave activity that resulted in higher-than-average stratospheric temperatures and smaller-than-average ozone holes.

In July 2010, a wave event warmed the stratosphere, followed by little wave activity until a mild event early in September of that year. The 2010 ozone hole slowed its areal growth but continued to develop in a normal manner with reduced values. In 2012, the development of the ozone hole proceeded as in 2017, but large wave events happened in late September into October. In contrast to these active years, 2015 was a year with little planetary wave activity and consistently lower-than-average temperatures throughout the austral winter and spring. Consequently, 2015 had severe Antarctic ozone depletion and a larger ozone hole area.

Balloon ozone and temperature observations at South Pole station (Fig. 6.12) revealed the record high temperatures in the stratosphere above $\sim 15 \mathrm{~km}$ in August and September, soon after the wave events. These temperatures were 2-4 standard deviations higher than the average seasonal values derived from the balloon observations over the period 2005-16 (Fig. 6.12c). The aboveaverage stratospheric temperatures over the South Pole led to weak ozone depletion this year (Fig. 6.12d). Even though the ozone values dropped below 0.1 ppm in October between 12 and $18 \mathrm{~km}$ (Fig. 6.12b), the anomalies show that compared to previous years, ozone concentrations were 3-6 standard deviations above the mean, consistent with smaller ozone loss.

The weaker 2017 ozone depletion has further strengthened the long-term downward trend seen in the annual ozone hole area since the early 2000s (Fig. 6.13). Since 1988, the only ozone hole smaller than the 2017 hole was observed in 2002, when the only major stratospheric warming on record rapidly warmed the polar vortex in late September and drastically limited ozone depletion. The 2017 wave events noted above, while strong, were still smaller in amplitude than those in 2002. Moreover, the 2017 wave events occurred earlier in September, stalling the typical seasonal evolution of ozone depletion. 
Because of that, the maximum daily area in 2017 (the top of the vertical gray bars in Fig. 6.13) was the smallest since 1988 , at 19.6 million $\mathrm{km}^{2}$.

MLS observations for 2004-16 show that inorganic chlorine $\left(\mathrm{Cl}_{\mathrm{y}}\right)$ levels in the Antarctic lower stratospheric vortex have declined on average

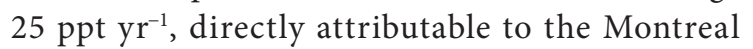
Protocol and its amendments (Strahan et al. 2014; Strahan and Douglass 2017). Year-to-year meteorological variability can cause dynamically driven multiyear $\mathrm{Cl}_{\mathrm{y}}$ increases in the Antarctic, as occurred from 2013 to 2017, in spite of the overall downward trend in stratospheric chlorine loading. Year-to-year $\mathrm{Cl}_{\mathrm{y}}$ variations and large temperature variability in late September and October complicate the attribution of the decline in hole area (Fig. 6.13) to declining chlorine levels. The appearance of a downward areal trend in the last decade is mostly driven by higher spring temperatures in the lower stratosphere. In Fig. 6.13, ozone holes in the last two decades with September Antarctic lower stratospheric temperatures one standard deviation below the average are highlighted in blue. It is apparent that these cold years produce ozone hole areas with similar size and show no clear trend in area. Depletions in recent years are consistent with current knowledge of the photochemical destruction driven by chlorine and bromine compounds and stratospheric temperatures and circulation.

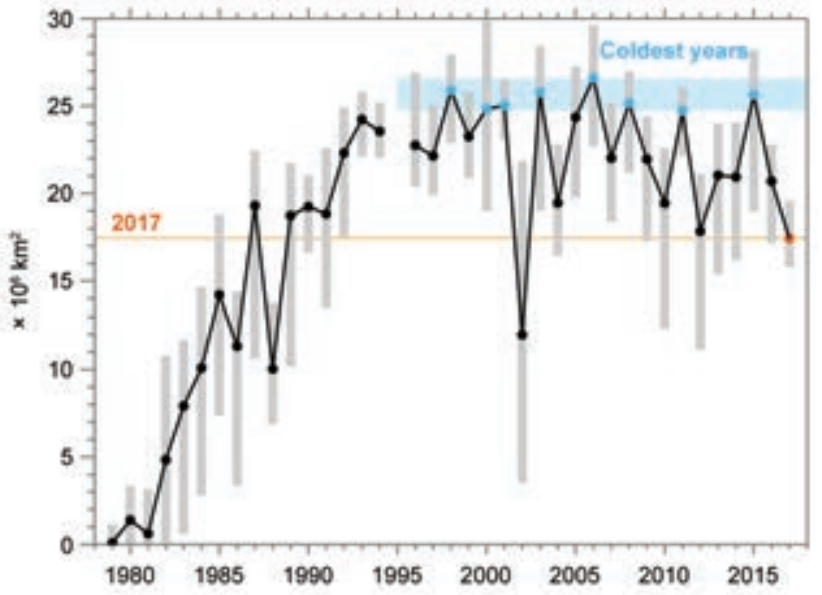

Fig. 6.13. Average Antarctic ozone hole area calculated between 7 Sep and 13 Oct (dots), along with the range of daily values over this period (gray vertical bars). The value for 2017 is highlighted (orange dot and horizontal line). The years with significantly cold temperatures since 1995 are highlighted (blue dots) and the horizontal blue band indicates the range of the associated ozone hole areas. Data for 1979-92 are from Total Ozone Mapping Spectrometer (TOMS) Nimbus-7; 1993-94 are from TOMS Meteor-3; 1996-2004 are from; 200515 are from Aura OMI; and 2015-17 are from Suomi National Polar-orbiting Partnership (SNPP) Ozone Mapping and Profiler Suite (OMPS). There were no satellite total ozone observations for 1995. 
7. REGIONAL CLIMATES-P. Bissolli, C. Ganter, T. Li, A. Mekonnen, and A. Sánchez-Lugo, Eds.

\section{a. Overview}

This chapter provides summaries of the 2017 temperature and precipitation conditions across seven broad regions: North America, Central America and the Caribbean, South America, Africa, Europe, Asia, and Oceania. In most cases, summaries of notable weather events are also included. Local scientists provided the annual summary for their respective regions and, unless otherwise noted, the source of the data used is typically the agency affiliated with the authors. Please note that different nations, even within the same section, may use unique periods to define their normals. Section introductions will typically define the prevailing practices for that section, and exceptions will be noted within the text. In a similar way, many contributing authors use languages other than English as their primary professional language. To minimize additional loss of fidelity through reinterpretation after translation, editors have been conservative and careful to preserve the voice of the author. In some cases, this may result in abrupt transitions in style from section to section.

\section{b. North America}

This section is divided into three subsections: Canada, the United States, and Mexico. All anomalies are with respect to the 1981-2010 base period, unless otherwise noted.

Much of North America had warmer-than-average conditions during 2017. The annual temperatures for each country were among the 10 warmest years for their respective records, with Mexico having its warmest year on record. Precipitation varied greatly across the continent, with the United States and Mexico recording near-average national precipitation totals. Annual precipitation across Canada was mostly near to below average, with only parts of the east experiencing above-average conditions. Warm, dry conditions across the west contributed to the development of one of the earliest and largest fires ever recorded in Canada. Over the course of the year, the U.S. experienced 16 weather and climate events that each caused over $\$ 1$ billion (U.S. dollars), tying with 2011 as the highest number since records began in 1980.

I) Canada-L. A. Vincent, R. Whitewood, D. Phillips, and V. Isaac

In Canada, 2017 was characterized by higherthan-average winter mean temperatures from the Yukon to Atlantic Canada, followed by spring, sum-

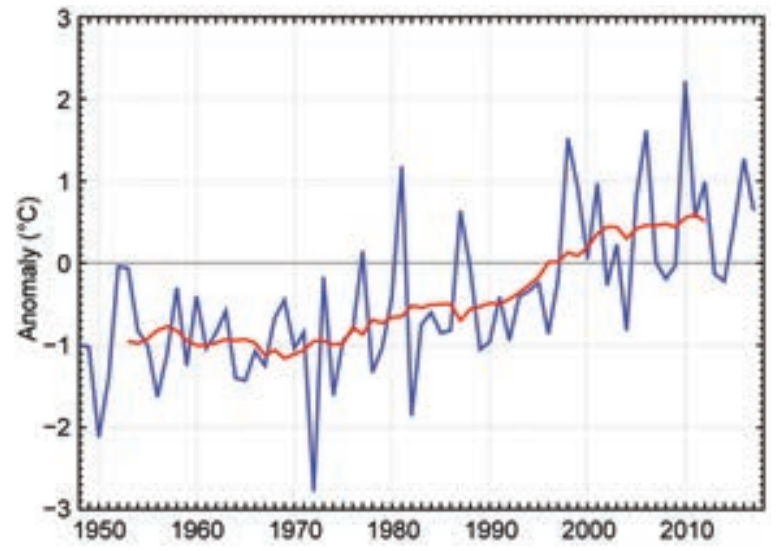

FIG. 7.I. Annual average temperature anomalies $\left({ }^{\circ} \mathrm{C}\right.$; 198I-2010 base period) in Canada for 1948-2017. Red line is the II-year running mean. (Source: Environment and Climate Change Canada.)

mer, and autumn mean temperatures near or below average across the country. Precipitation measured at 28 available stations indicates wetter-than-average spring conditions across the country and drier-thanaverage summer conditions mainly in southern British Columbia.

\section{(i) Temperature}

The annual average temperature in 2017 for Canada was $0.7^{\circ} \mathrm{C}$ above the $1981-2010$ national average, its tenth warmest year since nationwide records began in 1948 (Fig. 7.1). Four of the ten warmest years have occurred during the last decade, with 2010 being the record warmest $\left(+2.2^{\circ} \mathrm{C}\right)$. The national annual average temperature has increased by $1.8^{\circ} \mathrm{C}$ over the past 70 years. Spatially, annual departures above $+2.0^{\circ} \mathrm{C}$ were recorded in the north (Fig. 7.2a), which resulted in two provinces/territories reporting annual average temperatures among their ten highest: Northwest Territories (fifth highest) and Nunavut (seventh highest).

Seasonally, winter (December-February) 2016/17 was $1.8^{\circ} \mathrm{C}$ above average-the seventh warmest winter on record. The national winter average temperature has increased by $3.4^{\circ} \mathrm{C}$ over the past 70 years. Winter anomalies above $+3.0^{\circ} \mathrm{C}$ were recorded from the northwest to the Atlantic coast, and five provinces/ territories had winter average temperatures among their ten highest: Northwest Territories (third highest), Nunavut (fourth highest), Ontario (fifth highest), Manitoba (sixth highest), and Saskatchewan (ninth highest). During the spring (March-May), near- to below-average temperatures were recorded from the Pacific to the Atlantic coast across southern Canada while above-average temperatures were observed in the north. The nationally averaged temperature for 
(a)
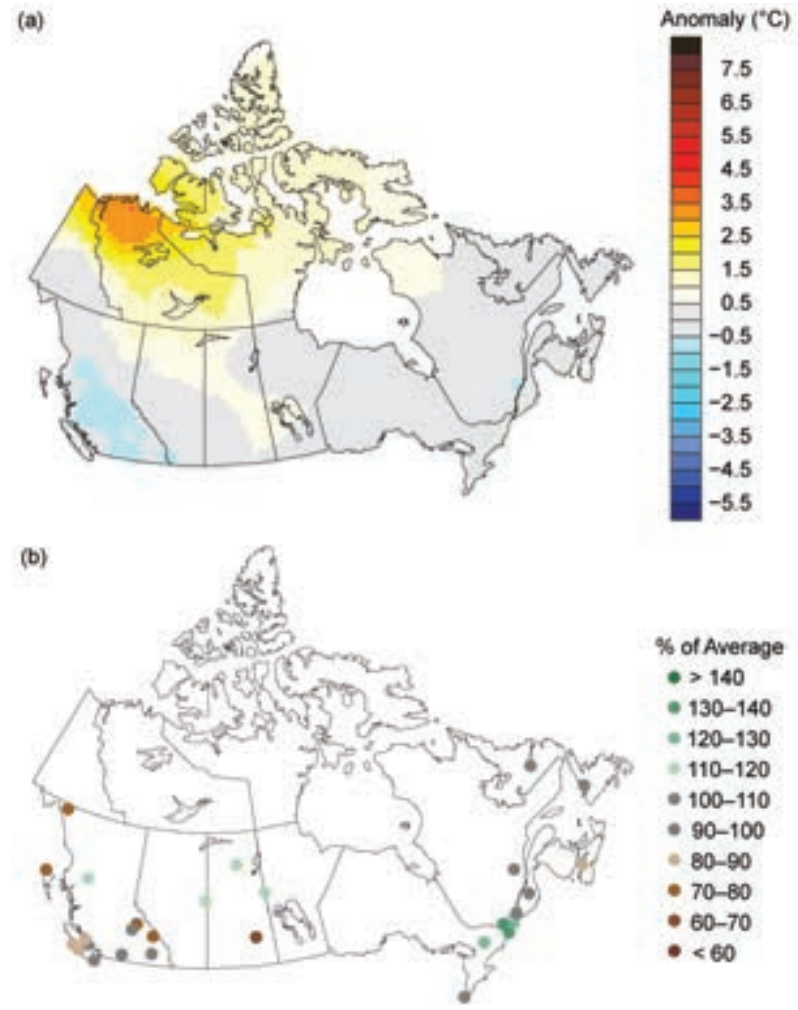

Fig. 7.2. Annual (a) average temperature anomalies ( ${ }^{\circ} \mathrm{C}$ ) and (b) total precipitation (\% of average) in Canada for 2017. Base period: 198I-20I0. (Source: Environment and Climate Change Canada.)

spring 2017 was $0.3^{\circ} \mathrm{C}$ below the 1981-2010 average and the 27 th highest in the 70 -year record. The national spring temperature has increased by $1.7^{\circ} \mathrm{C}$ over the past 70 years. None of the provinces/territories experienced an average spring temperature that ranked among their ten highest or lowest on record (since 1948).

Summer (June-August) was $0.4^{\circ} \mathrm{C}$ above average and the 13th warmest since 1948. Most of the Yukon, Northwest Territories, and southern Nunavut experienced summer anomalies greater than $+1.0^{\circ} \mathrm{C}$; Northwest Territories and Yukon reported their seventh and eighth warmest summer on record, respectively. Summer temperatures were below average for the regions extending from southern Manitoba to the Atlantic provinces, and were near average for the remainder of the country. The national summer temperature has increased by $1.5^{\circ} \mathrm{C}$ over the past 70 years. Autumn (September-November) was $0.6^{\circ} \mathrm{C}$ above average and the 19th highest since 1948. Above-average temperatures were experienced in the north and in the eastern provinces, from eastern Ontario to Atlantic Canada, which resulted in two Maritimes provinces, New Brunswick and Nova Scotia, each having their third warmest autumn since 1948. Near- or below- average temperatures were experienced in the western provinces, from southern Yukon to western Ontario. The national autumn temperature has increased by $1.7^{\circ} \mathrm{C}$ over the past 70 years. December 2017 was $2.0^{\circ} \mathrm{C}$ above average with most of the north experiencing above-average conditions, while Ontario and southern Quebec had below-average temperatures.

\section{(ii) Precipitation}

Over the past decade, precipitation monitoring technology has evolved and Environment and Climate Change Canada and its partners implemented a transition from manual observations to using automatic precipitation gauges. Extensive data integration is required to link the current precipitation observations to the long-term historical manual observations. While this data reconciliation due to changing monitoring technology and methods is in progress, this report presents the analysis based on only 28 stations which have sufficient precipitation observations from similar instrumentation over the period 1981-2017; most of these stations are located in the southern regions of the country.

Annual precipitation was near to below average across western Canada, with near to above-average precipitation across eastern Canada (Fig. 7.2b). Seasonally, drier-than-average conditions were experienced at several stations located in the western provinces during the winter 2016/17 and summer 2017; wetter-than-average conditions were observed at most stations across the country during the spring 2017; near-average conditions were found at most stations otherwise.

\section{(iii) Notable events and impacts}

In 2017, the southern British Columbia interior experienced its longest and most severe wildfire season in the province's history. After a wet spring, the region had its driest summer on record. One of the earliest and largest fires ever recorded in Canada burned west of Kamloops in the Ashcroft-Cache Creek-Clinton area. The towns of Ashcroft, Kamloops, and Kelowna each received less than $10 \mathrm{~mm}$ of total precipitation during the entire summer. A province-wide state of emergency, the first in 15 years and the province's longest one, began on 7 July and lasted until 15 September. In total, the British Columbia Wildfire Service reported 1265 fires that destroyed 1.2 million hectares of timber, bush, and grassland, exceeding the previous record for burned land by $30 \%$. Total firefighting costs exceeded half a billion Canadian dollars and insured property losses reached close to $\$ 130$ million Canadian dollars (\$103 million U.S. 
dollars). This memorable season follows the equally memorable extreme Fort McMurray wildfire in May 2016 in neighboring Alberta province (Kochtubajda et al. 2017).

In May, eastern Ontario and southern Quebec each experienced one of their worst spring flooding events on record. Several rivers exceeded the maximum amount of water released in the past and overflowed from Gananoque to Gaspésie. In Montréal, April rainfall totaled $156.2 \mathrm{~mm}$-its second wettest April in 147 years. Both Ottawa and Montréal had their wettest spring on record-with $400 \mathrm{~mm}$ or more at each location (records date back to the 1870s). Spring flooding forced 4000 people to evacuate their homes from the Ottawa region to near Quebec City. Many towns and cities declared states of emergency, including Gatineau, Laval, and Montréal. According to the Insurance Bureau of Canada, spring flooding in April and May resulted in 15750 claims and \$223 million Canadian dollars ( $\$ 177$ million U.S. dollars) in property damages. In total, more than 5000 residences were flooded, 550 roads were washed or swept away by floods or landslides, and — tragically—on 6 May, two people were swept away by the swollen Sainte-Anne River in the Gaspé region.

2) United States-J. Crouch, A. Smith, C. Fenimore, and R. R. Heim Jr.

The annual average temperature in 2017 for the contiguous United States (CONUS) was $12.5^{\circ} \mathrm{C}$ or $1.0^{\circ} \mathrm{C}$ above the $1981-2010$ average - its third warmest year since records began in $1895,0.2^{\circ} \mathrm{C}$ cooler than 2016 and $0.4^{\circ} \mathrm{C}$ cooler than 2012 (Fig. 7.3). The annual CONUS temperature over the 123-year period of record is increasing at an average rate of $0.1^{\circ} \mathrm{C}$

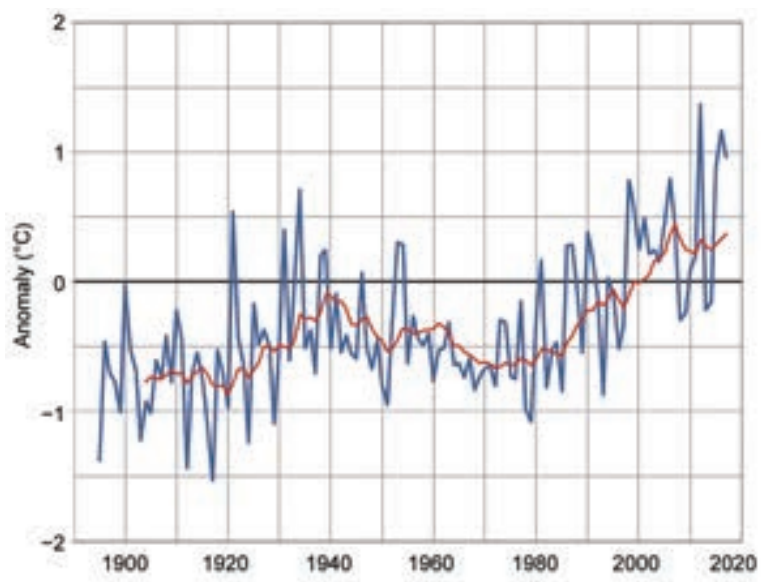

FIG. 7.3. Annual mean temperature anomalies $\left({ }^{\circ} \mathrm{C}\right.$; 198I-2010 base period) for the contiguous United States for 1895-2017. Red line is the 10-year running mean. (Source: NOAA/NCEI.) decade $^{-1}$, with the trend increasing since 1970 to $0.3^{\circ} \mathrm{C}$ decade $^{-1}$. The nationally averaged precipitation total during 2017 was $104 \%$ of average, the 20th wettest year in the historical record. The annual CONUS precipitation total is increasing at an average rate of $4.3 \mathrm{~mm} \mathrm{decade} \mathrm{m}^{-1}$. Outside the CONUS, Alaska had its seventh warmest year $\left(+1.2^{\circ} \mathrm{C}\right.$ departure $)$ since statewide records began in 1925, and near-median precipitation (104\% of average). Complete U.S. temperature and precipitation maps are available at www.ncdc.noaa.gov/cag/.

\section{(i) Temperature}

For the CONUS, ten months in 2017 were warmer than their respective 1981-2010 average. Every state, except Washington, had a warmer-than-average annual temperature (Fig. 7.4a). Arizona, Georgia, New Mexico, North Carolina, and South Carolina were each record warm.
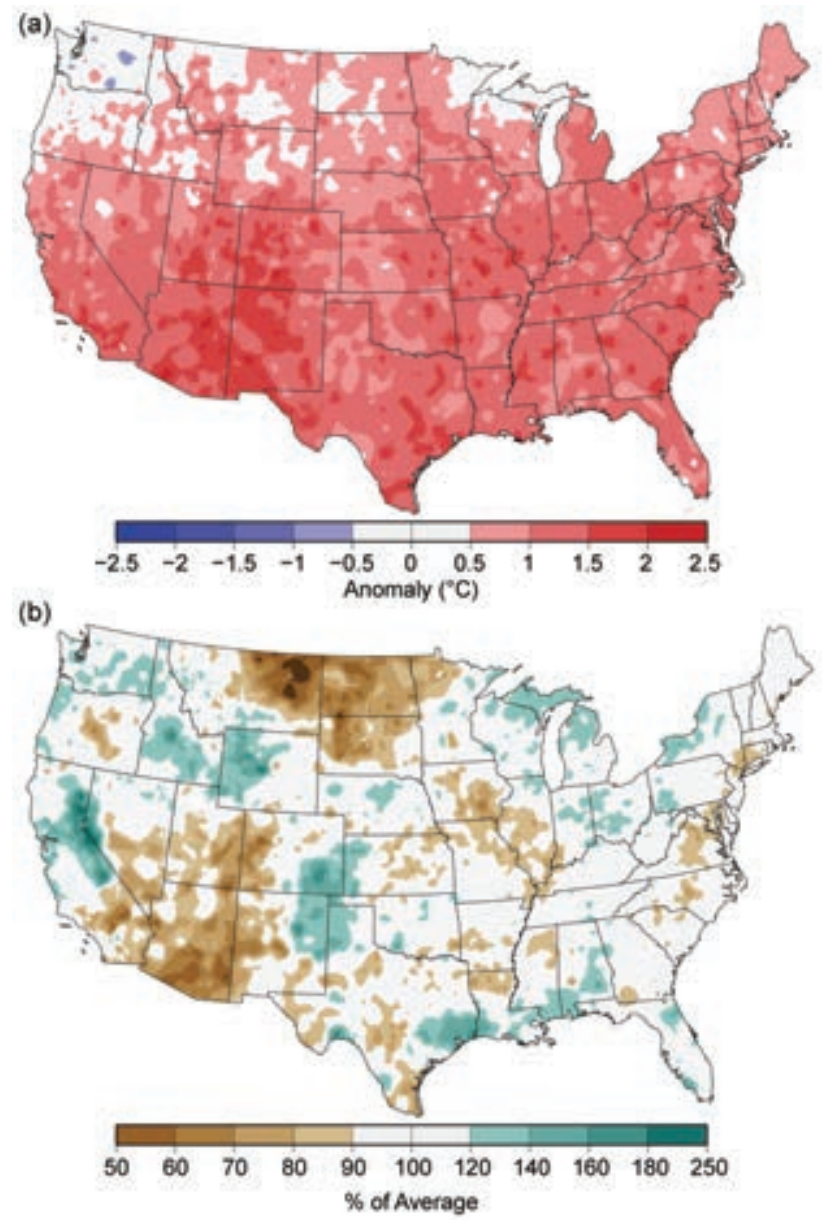

FIG. 7.4. Annual (a) average temperature anomalies ( ${ }^{\circ} \mathrm{C}$ ) and (b) total precipitation (\% of average) in the contiguous United States for 2017. Base period: I98I2010. (Source: NOAA/NCEI.) 
The winter (December-February) 2016/17 CONUS temperature was sixth highest at $1.3^{\circ} \mathrm{C}$ above average, driven largely by the second warmest February on record. The Rockies to the East Coast were warmer than average, while the Northwest was cooler than average. The CONUS spring (MarchMay) temperature was $0.9^{\circ} \mathrm{C}$ above average, its eighth warmest spring on record. Above-average temperatures spanned the nation with near-average conditions in the Northwest and Northeast. The summer (June-August) CONUS temperature was $0.4^{\circ} \mathrm{C}$ above average, its 15 th warmest summer on record. Above-average conditions were observed in the West and along parts of the East Coast. California and Nevada experienced a record-warm summer. The south-central CONUS was cooler than average. The autumn (September-November) temperature was $0.9^{\circ} \mathrm{C}$ above average, the tenth warmest such period on record for the CONUS. Record warmth occurred in parts of the Southwest and Northeast. December 2017 was $0.6^{\circ} \mathrm{C}$ above average with the first half of the month having record and near-record warmth across much of the nation and a significant cold wave impacting the East the last week of the month.

\section{(ii) Precipitation}

Locations across the West, Great Plains, Great Lakes, Deep South, Midwest, and Northeast had a wetter-than-average year in 2017, while areas of the Northern Rockies and Plains were drier than average (Fig. 7.4b). Six states had annual precipitation totals above their 90th percentile, including Michigan, which was record wet, while only North Dakota was below its 10th percentile. Areas of the West, particularly California, experienced significant drought relief in early 2017, with a multiyear drought nearly eradicated due to the heavy winter precipitation. However, the wet winter allowed vegetation to flourish, creating an abundance of fuels for wildfires during the subsequent dry season. In the Northern Plains, a dry spring and summer set the stage for a rapidly expanding and intensifying drought. The year began and ended with about one-quarter of the contiguous U.S. in drought.

The CONUS winter precipitation was $120 \%$ of average, its wettest since 1997/98 and ninth wettest on record. Above-average winter precipitation occurred across the West and parts of the Northern Plains and Midwest. Nevada and Wyoming each had their wettest winter. Spring 2017 was tenth wettest for the CONUS, with $119 \%$ of average precipitation. Above-average precipitation occurred across the Northwest, Central Plains, Midwest, Northeast, and Mid-Atlantic. A record-breaking flood event impacted the mid-Mississippi Valley in late April. The Northern Plains were drier than average with drought conditions developing by the end of the season. Summer precipitation for the CONUS was $112 \%$ of average, its 13th wettest on record. Above-average precipitation fell across the Southeast, Great Lakes, and Northeast. In August, Hurricane Harvey brought record rainfall to parts of Louisiana and Texas (see Sidebar 4.3 for more details). Below-average precipitation fell across the Northwest, Northern Rockies, and Plains. For autumn, the CONUS precipitation total was $94 \%$ of average, which is near the median value. Above-average precipitation fell across the Northwest, Northern Rockies, Midwest, and Northeast. Above-average precipitation also fell in Florida where Hurricane Irma made landfall in September (see Sidebar 4.1 for more details). Below-average autumn precipitation occurred across parts of the Southwest, Southern Plains, and Lower Mississippi Valley. Arkansas had its driest autumn on record. By the end of the season, drought covered much of the southern CONUS. December 2017 was the 11th driest on record for the CONUS and driest since 1989 with $68 \%$ of average precipitation. Drier-than-average conditions stretched from coast to coast with nearly one-third of the CONUS having precipitation totals below the 10th percentile.

\section{(iii) Notable events and impacts}

There were 16 weather and climate events with losses exceeding $\$ 1$ billion (U.S. dollars) each across the United States (Fig. 7.5) in 2017, including three tropical cyclones, eight severe storms, two inland floods, a crop freeze, drought, and wildfires. The 2017 total tied with 2011 as highest annual number of U.S. billion-dollar disasters (adjusted for inflation) since records began in 1980. Cumulatively, these events led to 362 fatalities and caused $\$ 306$ billion U.S. dollars in total, direct costs-a new U.S. annual cost record. The previous costliest year for the U.S. was 2005 with losses of $\$ 215$ billion. One of the more noteworthy events included the western wildfire season, with total costs of $\$ 18$ billion, tripling the previous U.S. annual wildfire cost record set in 1991. Overall, wildfires burned over 4.0 million hectares across the United States during 2017, which is well above the 2000-10 average of 2.7 million hectares. Hurricane Harvey had total costs of $\$ 125$ billion, second only to Hurricane Katrina in the 38-year period of record for billion-dollar disasters. Hurricanes María and Irma had total costs of $\$ 90$ billion and $\$ 50$ billion, respectively. Hurricane María now ranks as the third 


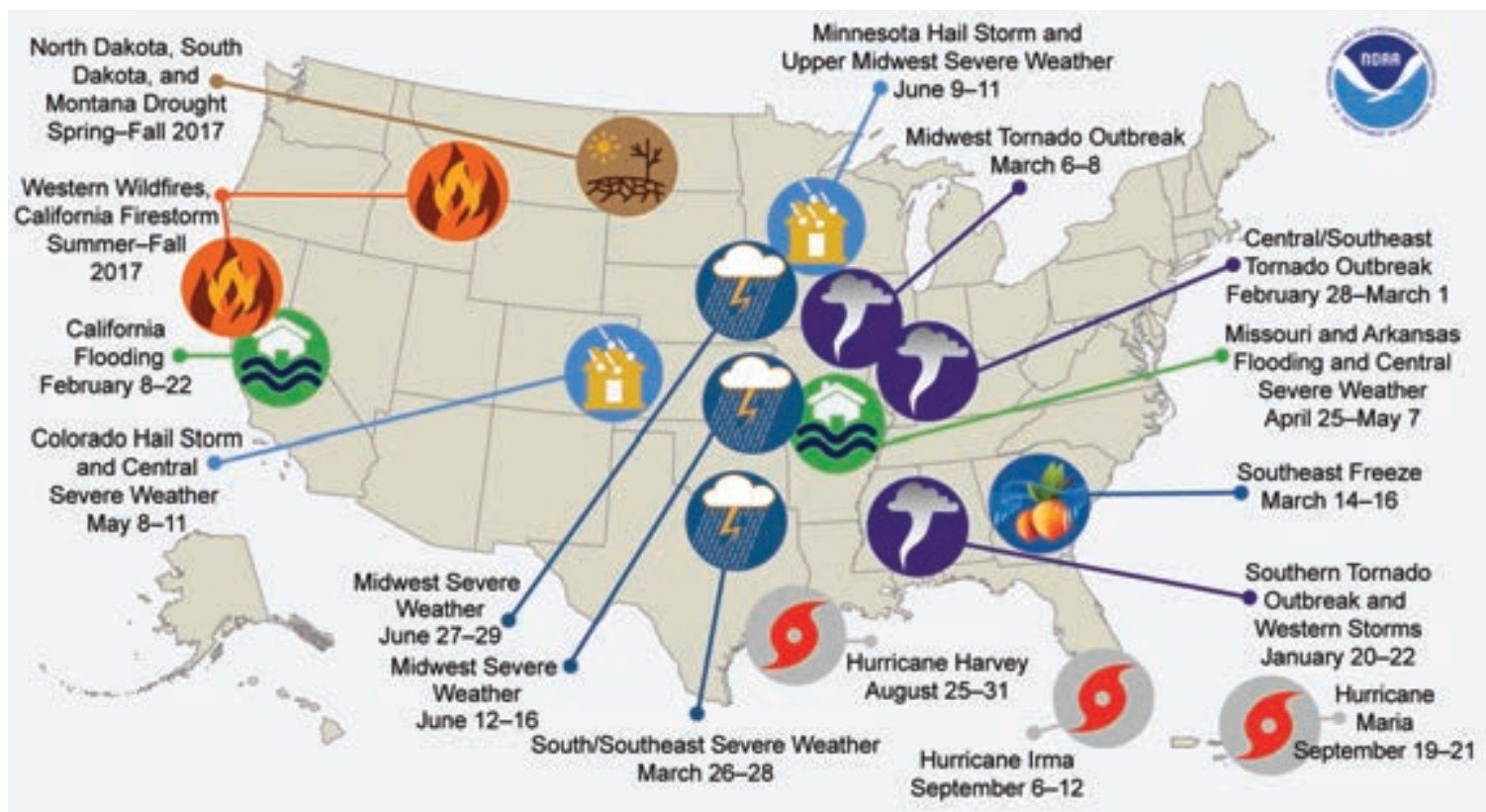

FIG. 7.5. Map depicting date, approximate location, and type of the 16 weather and climate disasters in the U.S. in 2017 with losses exceeding \$I billion U.S. dollars. (Source: NOAA/NCEI.)

costliest weather and climate disaster on record for the nation, and Irma ranks as the fifth costliest.

Tornado activity during 2017 was above average for the first time since 2011 with 1400 tornadoes confirmed, compared to the 1991-2010 annual average of approximately 1250 . There were 34 tornado-related fatalities, well below the 30-year average of 110 .

\section{3) MeXico-R. Pascual Ramírez and A. Albanil}

The 2017 mean temperature for Mexico was the highest since national temperature records began in 1971, marking the fourth consecutive year that a new national annual temperature has been tied or broken. Precipitation during 2017 varied greatly across the country; however, the 2017 national precipitation total was near average at $99.4 \%$ of normal.

\section{(i) Temperature}

The 2017 mean temperature for Mexico was the highest since national temperature records began in 1971 at $22.6^{\circ} \mathrm{C}$, or $1.6^{\circ} \mathrm{C}$ above its $1981-2010$ average. This surpassed the previous record set in 2016 by $0.2^{\circ} \mathrm{C}$ and 2014 and 2015 by $0.5^{\circ} \mathrm{C}$, which at the time had been reported as the warmest years on record (Fig. 7.6). The year 2017 also marks the 14th consecutive year with an above-average annual temperature. The national daily mean, maximum, and minimum temperatures were close to two standard deviations above average during much of January-October (Fig. 7.7), resulting in above-average monthly tem-

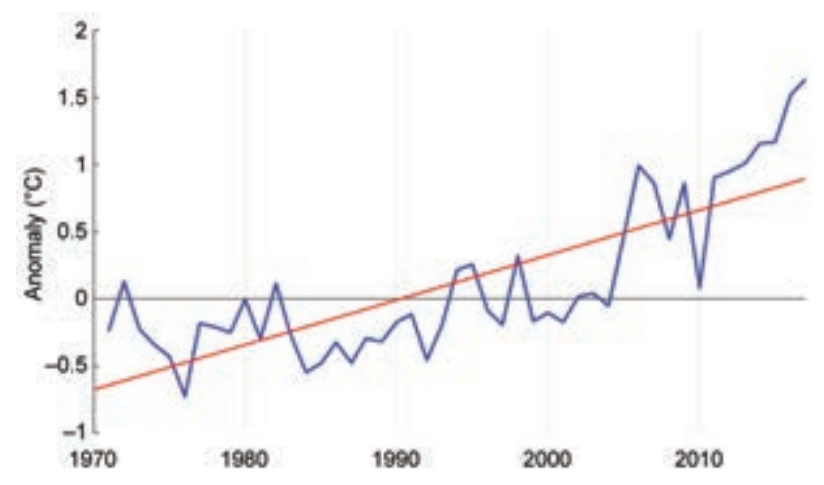

Fig. 7.6. Annual mean temperature anomalies $\left({ }^{\circ} \mathrm{C}\right.$; 198I-2010 base period) for Mexico for 197I-2017. The red line represents the linear trend over this period. (Source: Meteorological Service of Mexico.)

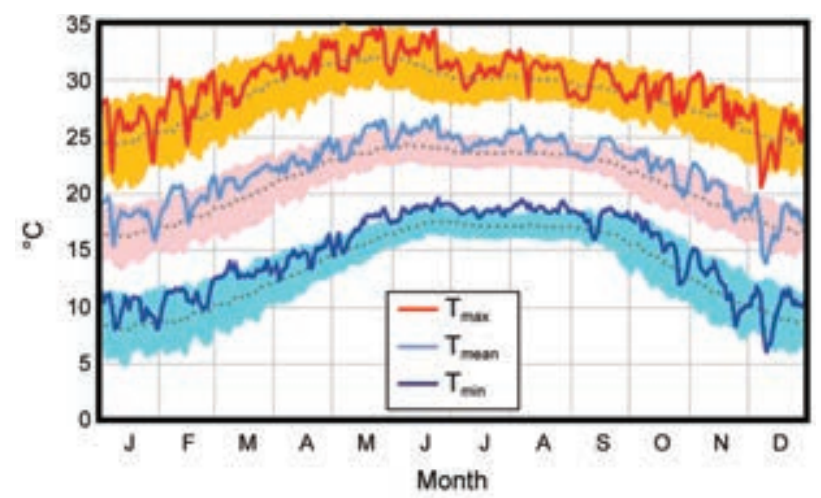

FIG. 7.7. Nationwide daily temperatures $\left({ }^{\circ} \mathrm{C}\right.$; $198 \mathrm{I}-2010$ base period) for Mexico in 2017. Shaded areas represent the \pm 2 std dev. Solid lines represent daily values for the three temperature parameters and dotted lines are the climatology. (Source: National Meteorological Service of Mexico.) 


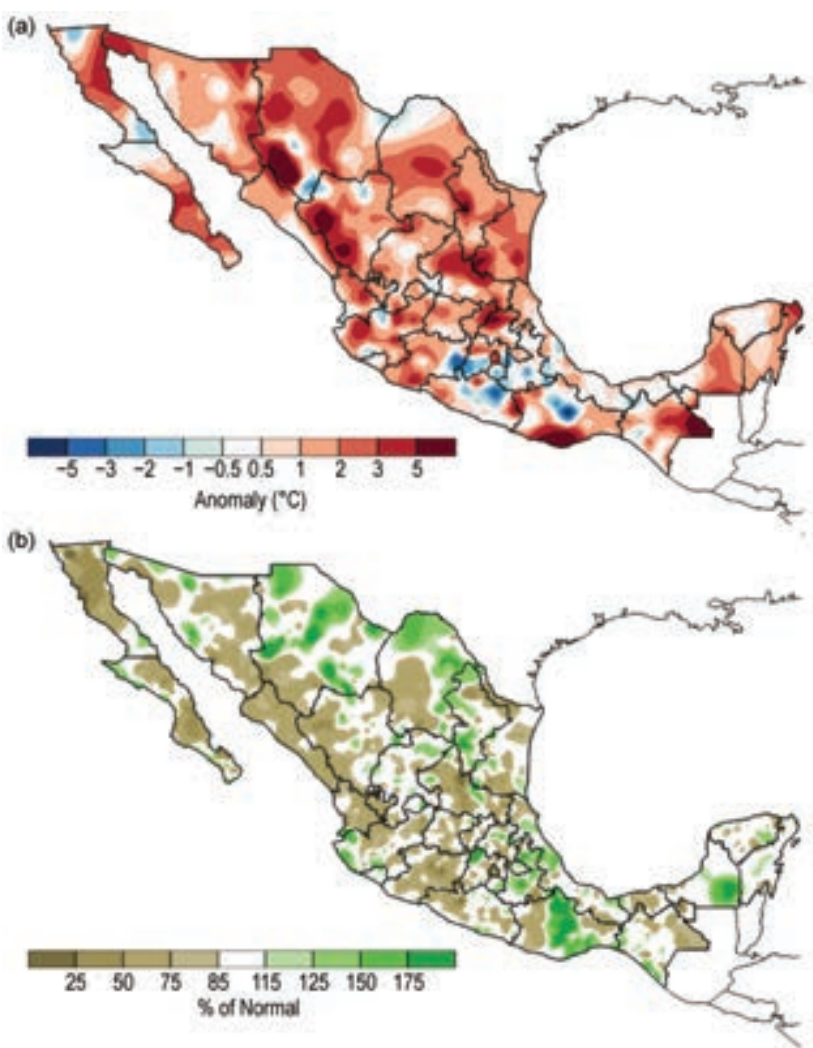

FIG. 7.8. 2017 annual (a) mean temperature anomalies ( $\left.{ }^{\circ} \mathrm{C}\right)$ over Mexico and (b) precipitation anomalies (\% of normal;). Base period: 198I-2010. (Source: National Meteorological Service of Mexico.)

peratures for 2017. March, June, and November were each warmest on record for their respective months.

Temperatures were above average across most of the country, with small areas in the middle of the country experiencing cooler-than-average conditions (Fig. 7.8a). Eight of Mexico's 31 states reported their warmest year on record. With the exception of Quintana Roo, located in the south, the remaining record-setting states are located across the northern half of Mexico (Durango, Sinaloa, Nuevo León, Jalisco, Hidalgo, San Luis Potosí, and Tamaulipas).

\section{(ii) Precipitation}

Rainfall anomalies varied across Mexico, with above-average conditions in northern Chihuahua and Coahuila, coastal Jalisco, northern Puebla and Veracruz, some areas of Oaxaca, and most of the Yucatan Peninsula. The rest of the country had below-average conditions, with the most notable precipitation deficit of $50 \%$ of normal precipitation in Sonora, Sinaloa, and a portion in the central-west (Fig. 7.8b).

Climatologically, September is typically the wettest month of the year, contributing about $18.4 \%$ of the annual total rainfall. September 2017 provided
$21.7 \%$ of the annual rainfall. During the month, four tropical cyclones (Tropical Storms Lidia and Pilar from the Pacific; Hurricane Max in the Pacific; and Hurricane Katia in the Gulf of Mexico) impacted the nation with heavy rain. Three of those four tropical cyclones made landfall, while Pilar stayed off shore, along Mexico's Pacific coastline. The last time four cyclones came close to or made landfall in Mexico was in September 1974. Four is the highest number of cyclones to come close to or make landfall in Mexico for any month, according to available hurricane data since 1949.

March is typically the driest month of the year, providing only $1.8 \%$ of the annual rainfall; however, February was the driest month of 2017, contributing only $1.6 \%$ to the annual rainfall total.

Northwestern Mexico typically receives nearly $60 \%$ of its total annual rainfall during the four-month period of June-September. However, in 2017, precipitation associated with the monsoon and Tropical Storm Lidia caused the region to receive $60 \%-68 \%$ of its annual rainfall total in just one week.

\section{(iii) Notable events and impacts}

Ten tropical cyclones affected Mexico in 2017, five fewer than the 1971-2012 average of fifteen. Six tropical cyclones were near land or made landfall from the Pacific basin, and four from the Caribbean basin/ Gulf of Mexico. The Pacific number was fewer than the average of ten, and the Caribbean/Gulf of Mexico number was near the average of five.

Of note, Caribbean Hurricane Franklin (Category 1 on the Saffir-Simpson scale) produced the year's highest 24-hour precipitation total for Mexico when $404 \mathrm{~mm}$ fell in Veracruz upon landfall on 9 August. This value ranks among the top 20 highest daily precipitation totals recorded in the country, according to the Mexican National Meteorological Service.

Drought conditions, which commenced during spring (March-May) 2016, continued to affect southern Mexico in 2017, in particular the Isthmus of Tehuantepec in Oaxaca. Drought conditions deteriorated during the first five months of 2017 due to the warmer- and drier-than-average conditions affecting the area. However, heavy precipitation associated with Tropical Storms Beatriz and Calvin, which made landfall in the affected area, helped ameliorate the long-term drought. These two storms impacted the same area within two weeks of each other (1 June and 12 June, respectively), producing much-needed precipitation and relief for the agriculture sector, but causing damage to infrastructure, such as damaged roads and bridges due to landslides. Drought also af- 
fected southern Sinaloa, in northwest Mexico, causing agricultural and livestock losses, and a shortage of drinking water in more than 400 rural communities.

Several heat waves affected eastern Mexico, notably the Huastecas (an area that encompasses the states of San Luis Potosi, Hidalgo, and Veracruz) from 26-30 April and again from 5-8 June. During both heat waves, the maximum temperature reached $50^{\circ} \mathrm{C}$, breaking the previous record of $49^{\circ} \mathrm{C}$ in Huejutla, Hidalgo, set in April 2013. These heat waves were produced by a broad high pressure system located over northeastern Mexico, inhibiting cloudiness and thus increasing temperature. Another major heat wave affected the municipality of Aldama, Chihuahua, during 11-20 June. c. Central America and the Caribbean

I) Central America-J. A. Amador, H. G. Hidalgo, E. J. Alfaro, B. Calderón, and N. Mora

For this region, nine stations from five countries were analyzed (Fig. 7.9). Stations on the Caribbean slope are: Philip Goldson International Airport, Belize; Puerto Barrios, Guatemala; Puerto Lempira, Honduras; and Puerto Limón, Costa Rica. Stations located on the Pacific slope are: Tocumen International Airport and David, Panamá; Liberia, Costa Rica; Choluteca, Honduras; and Puerto San José, Guatemala. The station distribution covers the relevant precipitation regimes located on the Caribbean and Pacific slopes of Central America (Magaña et al. 1999). Precipitation and temperature records for the stations analyzed were provided by Central American

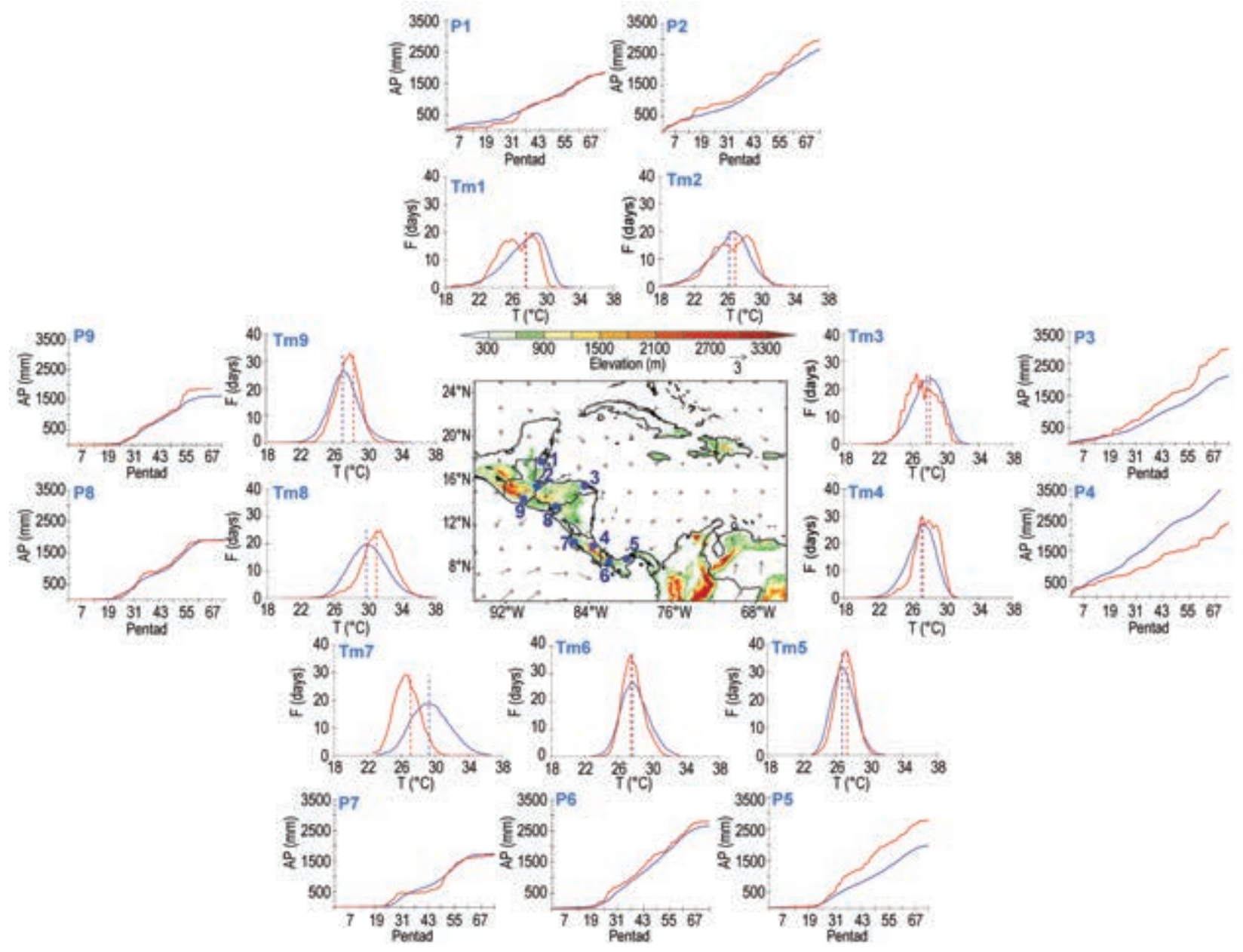

Fig. 7.9. Mean surface temperature $\left(\mathrm{Tm}\right.$; $\left.{ }^{\circ} \mathrm{C}\right)$ frequency (F; days) and accumulated pentad precipitation (AP; $\mathrm{mm}$ ) time series are shown for nine stations (blue dots) in Central America: (I) Philip Goldson International Airport, Belize; (2) Puerto Barrios, Guatemala; (3) Puerto Lempira, Honduras; (4) Puerto Limón, Costa Rica; (5) Tocumen International Airport, Panamá; (6) David, Panamá; (7) Liberia, Costa Rica; (8) Choluteca, Honduras; and (9) Puerto San José, Guatemala. The blue solid line represents the 198I-2010 average values and the red solid line shows 2017 values. Vertical dashed lines show the mean temperature for 2017 (red) and the 198I-2010 period (blue). Vectors indicate July wind anomalies at $925 \mathrm{hPa}$ (198I-2010 base period). Shading depicts regional elevation $(m)$. (Sources: NOAA/NCEI and CA-NWS.) 
National Weather Services (CA-NWS) or by NOAA. Anomalies are reported using a 1981-2010 base period and were calculated using CA-NWS data. The methodologies used for all variables can be found in Amador et al. (2011).

\section{(i) Temperature}

The mean temperature $(\mathrm{Tm})$ frequency distribution for the climatology and for 2017 for all stations is shown in Fig. 7.9. Five stations on the Caribbean slope and northern Central America (Tm2, Tm3, Tm5, Tm8, and Tm9) had a higher annual mean temperatures than the base period. The largest annual mean temperature occurred at Puerto San José and Choluteca ( $\operatorname{Tm} 8$ and $\operatorname{Tm} 9$, respectively), which were about $1.0^{\circ} \mathrm{C}$ above normal. Three stations ( $\mathrm{Tm} 1, \mathrm{Tm} 4$, and Tm6) had a mean annual temperature similar to the reference period, and the Liberia Station ( $\mathrm{Tm} 7)$ mean annual temperature was colder by $2.0^{\circ} \mathrm{C}$. On the Caribbean side, three stations ( $\mathrm{Tm} 1, \mathrm{Tm} 2$, and $\operatorname{Tm} 3$ ) depicted a bi-modal temperature distribution during 2017.

\section{(ii) Precipitation}

The accumulated pentad precipitation ( $\mathrm{P} ; \mathrm{mm}$ ) time series for the nine stations in Central America are presented in Fig. 7.9. Puerto San José (P9) was close to normal until pentad 55, when storms produced above-average conditions that continued through pentad 59, followed by a sparse rain period that lasted for over 2 months. This was sufficient to yield above-normal precipitation accumulations at the end of the year. Choluteca (P8) was generally near-normal all year but had a light mid-summer drought from pentad 35 to 41. Liberia (P7) started with significantly above-average conditions during the first part of its rainy season, then experienced a deep midsummer drought (Magaña et al. 1999) and a near-normal second part of the rainy season that resulted in near-normal annual accumulations. During most of the year, David (P6) recorded slightly-aboveaverage conditions, while Puerto Barrios (P2) and Tocumen (P5) were wetter than normal during most of the year, and extremely wet from pentad 32, with values that surpassed the normal average at the 95\% confidence level. Belize (P1) had considerable rainfall deficit until pentad 35, after which it recuperated due to wetter-than-average conditions and remained normal until the end of the year. Lempira (P3) recorded conditions during most of the year that were significantly higher than normal at the $95 \%$ confidence level, while Puerto Limón (P4) was the only station that had below-average conditions during 2017. Low-level circulations in the region showed a slightly strongerthan-average Caribbean low-level jet (Amador 1998) during summer (July vectors in Fig. 7.9), a condition usually associated with wetter (drier and more intense mid-summer drought) conditions in the Caribbean (Pacific) slope of Central America.

\section{(iii) Notable events and impacts}

Tropical storms were very active in the Caribbean basin $\left(6^{\circ}-24^{\circ} \mathrm{N}, 92^{\circ}-60^{\circ} \mathrm{W}\right)$ during 2017 . There were eight named storms: five tropical storms (Bret, Franklin, Harvey, Nate, and Phillipe) and three major hurricanes (Irma, José, and María). Tropical Storm Nate made landfall in Nicaragua and crossed Honduras on 5-6 October. Nate induced indirect cyclonic circulations (Peña and Douglas 2002) over the isthmus, impacting the Pacific slope of Costa Rica. According to the Costa Rica National Emergency Commission (CNE, its Spanish acronym), Nate caused more than $\$ 540$ million U.S. dollars in damages, the highest amount in the country's documented history of natural disasters since 1996. This information is based on a CNE study (Hidalgo 2017) of economic loses including Tropical Storms Alma (2008) and Nate (2017) and Hurricanes Cesar (1996), Mitch (1998), Tomas (2010), and Otto (2016). As with Tropical Depression 12-E in 2011 (Amador et al. 2012), the relative position of Nate with respect to highly vulnerable areas in Central America is as important as tropical storm intensity. Tropical Storm Selma developed in the eastern tropical Pacific and affected Central America during 27-28 October. Selma made landfall in El Salvador on 28 October, marking the first time on record a tropical storm made landfall in El Salvador. For additional information on regional impacts from hydrometeorological events during the year, please refer to Online Table 7.1.

2) Caribbean-T. S. Stephenson, M. A. Taylor, A. R. Trotman, C. J. Van Meerbeeck, V. Marcellin, K. Kerr, J. D. Campbell, J. M. Spence, G. Tamar, M. Hernández Sosa, and K. Stephenson

\section{(i) Temperature}

Normal to above-normal annual mean temperatures were recorded across the Caribbean in 2017 (Fig. 7.10a). Some locations in the northern Caribbean (including southern Cuba and Bahamas) experienced below-normal surface temperatures during January-June. In the latter half of the year, above-normal surface temperatures $\left(+0.2^{\circ}\right.$ to $\left.+1.0^{\circ} \mathrm{C}\right)$ were spread across the entire region.

Trinidad reported its tenth warmest annual mean temperature $\left(28.0^{\circ} \mathrm{C}\right)$ since records began in 

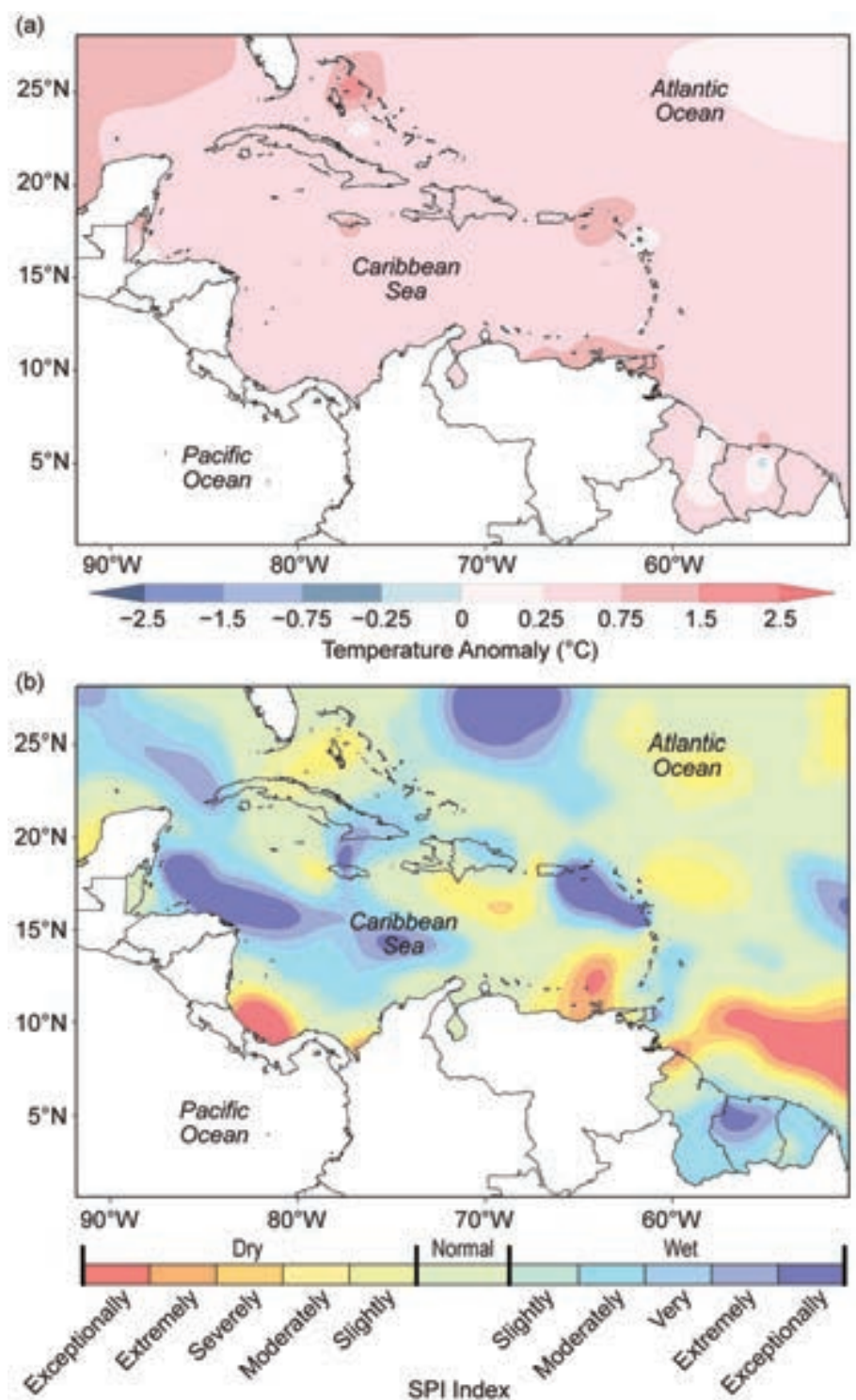

Fig. 7.10. (a) 2017 Annual mean temperature anomalies $\left({ }^{\circ} \mathrm{C}\right.$; 198I-2010 base period) and (b) 2017 annual rainfall pattern as characterized using the standardized precipitation index across the Caribbean. [Source: Caribbean Climate Outlook Forum (CariCOF) and NCEP/NCAR Reanalysis Data. Prepared by the Caribbean Institute for Meteorology and Hydrology (CIMH).]

\begin{tabular}{|c|c|c|c|c|}
\hline Country & $\begin{array}{l}\text { Station } \\
\text { Name/ } \\
\text { Location }\end{array}$ & $\begin{array}{l}\text { Start Year of } \\
\text { Records }\end{array}$ & $\begin{array}{l}\text { Max temp } \\
\left({ }^{\circ} \mathrm{C}\right)\end{array}$ & 2017 Rank \\
\hline Aruba & Bea & 1985 & 32.1 & 9 \\
\hline Bahamas & Freeport & 1971 & 29.0 & 5 \\
\hline Bahamas & LPIA & 1971 & 30.1 & 3 \\
\hline Belize & Airport & 1971 & 30.5 & 8 \\
\hline Jamaica & Sangster & 1973 & 32.0 & 4 \\
\hline Jamaica & Worthy Park & 1973 & 30.8 & 2 \\
\hline Martinique & Lamentin & 1971 & 30.7 & 4 \\
\hline Trinidad & Piarco & 1946 & 32.4 & 7 \\
\hline
\end{tabular}

1946; second highest mean maximum temperature in August $\left(33.6^{\circ} \mathrm{C}\right)$, which tied with August 2015 and 2016; and highest daily maximum temperature for August $\left(35.8^{\circ} \mathrm{C}\right)$ set on 23 August. San Juan, Puerto Rico, had its third warmest mean temperature in both February $\left(26.4^{\circ} \mathrm{C}\right)$ and September $\left(29.2^{\circ} \mathrm{C}\right)$ since records began in 1898. Grenada had its highest May mean maximum temperature on record as temperatures soared to $31.1^{\circ} \mathrm{C}$ in Point Salines. Several locations across the $\mathrm{Ca}-$ ribbean had annual maximum temperatures among their nine highest on record (Table 7.1).

\section{(ii) Precipitation}

The year brought normal to above-normal annual rainfall totals to much of the Caribbean (Fig. 7.10b). This was observed in association with above-normal annual and seasonal Caribbean SSTs (Chen and Taylor 2002; Taylor et al. 2002; Spence et al. 2004). During the first quarter of the year, most islands experienced predominantly near-normal conditions. However, some islands-including Tobago, Aruba, Curacao, Dominica, parts of Puerto Rico, Dominican Republic, and Jamaica-observed abovenormal rainfall, while severely dry conditions were observed in some areas of Puerto Rico. For the April-June period, apart from Tobago where moderately dry conditions were recorded in some areas, rainfall over the islands of the eastern Caribbean was normal to above normal. Mixed conditions were observed over the northern islands. Notably, extremely wet conditions were observed in central regions of Jamaica.

Above-normal rainfall dominated much of the Caribbean between July and September. This was likely related to the passage of a number of storms through the region, including Hurricanes Irma (see Sidebar 4.1), Jose, and María (see Sidebar 7.1), and favorable atmospheric and oceanic conditions in the region enabled by a La Niña event in the Pacific Ocean. Barbados, Dominica, Guadeloupe, St. Kitts, northern Dominican Republic, and eastern Cuba were extremely wet. In contrast, western areas of Jamaica were extremely dry. During the final three months 
of the year, mixed rainfall conditions were experienced across the region. Parts of Trinidad and Tobago and central Jamaica experienced very wet conditions, while parts of Martinique and Guadeloupe were severely dry.

Two locations (Cave Valley, Jamaica, and Sainte Marie, Martinique) each observed their wettest year using records available since 1971, with $2961.2 \mathrm{~mm}$ and $2923.0 \mathrm{~mm}$ of precipitation, respectively. Port-au-Prince (Haiti) recorded its driest year (588.3 mm) using records available since 1971. Cyril E. King Airport in St. Thomas had its second wettest March (148.1 mm). Jamaica experienced its seventh heaviest mean rainfall across the island in March $(248.0 \mathrm{~mm})$ using records available since 1881. San Juan International Airport, Puerto Rico, recorded its wettest September ( $401.1 \mathrm{~mm}$ ) since records began in 1898. Christiansted, Henry E. Rohlsen Airport, U.S. Virgin Islands, experienced its wettest March $(162.6 \mathrm{~mm})$ and second wettest September $(282.4 \mathrm{~mm})$ since records commenced in 1951. The September extreme anomalies were observed in relation to the passage of Hurricanes Irma and María.

\section{(iii) Notable events and impacts}

Category 5 Hurricane Irma severely impacted the Caribbean during 5-8 September. Some of the impacts of Irma on the islands included: 14 deaths and over 50000 residents without electrical power in the Turks and Caicos; one death and total destruction in Barbuda; several deaths reported in St. Martin; one death and severe damage in Anguilla; damage to property in St. Kitts; five deaths and extensive damage in the U.S. Virgin Islands; four deaths and severe impacts in the British Virgin Islands; major power outages over eastern Puerto Rico; more than 2000 homes damaged in the Dominican Republic; and flooding in some northern coastal areas in Cuba. See Sidebars 4.1 and 7.1 for more detailed information about Irma.

\section{SIDEBAR 7.I: IMPACTS FROM HURRICANES IRMA AND MARIA IN THE CARIBBEAN-0. MARTINEZ-SÁNCHEZ}

September 2017 featured the passage of two major hurricanes across the Caribbean: Irma and María. Both hurricanes caused extensive to catastrophic damages across the eastern and northeastern Caribbean islands, where buildings, roads, homes, and the electrical grids were left in ruins.

Hurricane Irma had sustained winds of $160 \mathrm{kt}\left(82 \mathrm{~m} \mathrm{~s}^{-1}\right)$ with higher wind gusts, torrential rain, and destructive storm surge just as it made landfall on the islands of Barbuda, Saint Martin, and the British Virgin Islands (BVI). Reports indicated that at least $95 \%$ of Barbuda's infrastructure was damaged or destroyed. The catastrophic damage that occurred in Barbuda forced a mandatory evacuation of the entire island, with residents brought to the island of Antigua. In the aftermath of Irma, $22.5 \%$ of the population in Tortola (BVI) was displaced. Even though the center of Irma passed just north of St. Thomas and St. John (U.S. Virgin Islands; USVI), wind gusts greater than $117 \mathrm{kt}\left(60 \mathrm{~m} \mathrm{~s}^{-1}\right)$ were reported as the southern eyewall clipped the USVI, causing catastrophic damage and five confirmed deaths. Hurricane Irma delivered the first powerful punch to the electrical grid, structures, and roads across the northern USVI and eastern Puerto Rico.

Two weeks later, Hurricane María made landfall in Dominica as a category 5 storm. María maintained category 5 strength as it continued its path towards the USVI and Puerto Rico (Fig. SB7.I). María made landfall on the southeastern coast of Puerto Rico as a category 4 hurricane with sustained winds of $134 \mathrm{kt}\left(69 \mathrm{~m} \mathrm{~s}^{-1}\right)$. Unfortunately, most wind sensors were

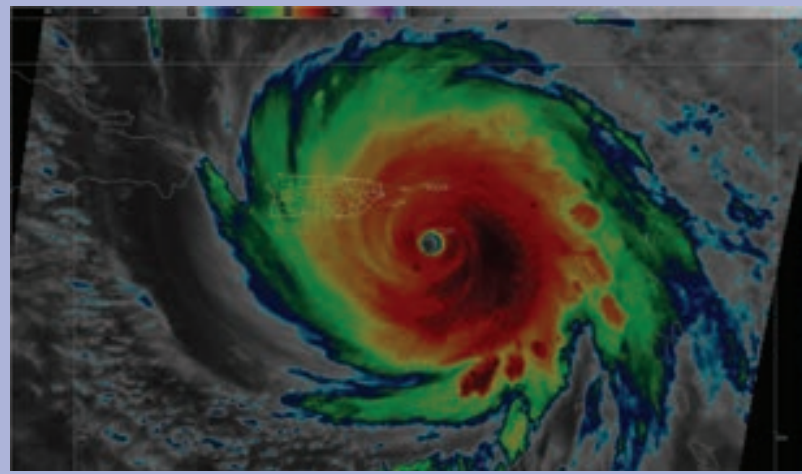

FIG. SB7.I. Satellite image of the center of Hurricane Maria located southeast of St. Croix, USVI on 20 September 2017. (Source: NOAA/NWS.)

damaged by María before making landfall, resulting in no landbased wind observations that would record the maximum winds affecting the island. María's strong winds also destroyed the FAA-NWS radar, which was designed to endure maximum sustained winds of $116 \mathrm{kt}\left(60 \mathrm{~m} \mathrm{~s}^{-1}\right)$. Although the lack of observations was an issue for the post-hurricane assessment, there is no doubt that María was much more severe than Irma as the center moved west-northwestward from southeastern Puerto Rico through the interior and into the northwestern sections of the island. Most trees were defoliated, and many were either broken or uprooted. Citizens reported the ground and their houses shaking, and most were amazed by the force of the 
Hurricane María made landfall in Dominica as a Saffir-Simpson category 5 intensity level storm on 18 September and struck southeastern Puerto Rico at category 4 intensity on 20 September (see Sidebar 7.1). In Dominica approximately 15 deaths were associated with María, with an additional 20 persons missing. The hurricane destroyed much of the island's infrastructure, removed vegetation, cut off communication and access to the island, and resulted in food and water shortages. Approximately $80 \%$ of agriculture crops were ruined in Puerto Rico and the power grid was destroyed, leaving 3.4 million residents without electricity.

Remarkably Hurricanes Irma, Jose (which peaked as a top end category 4), and María traversed the region over a two-week period. Largely as a result of these three hurricanes, the accumulated cyclone energy (ACE) index (Bell et al. 2000; see also Section $4 \mathrm{f} 2$ for an explanation of ACE) for September 2017 was $175 \times 10^{4} \mathrm{kt}^{2}$-the highest value for any month for the Atlantic basin since 1851 .

Multiple extreme rainfall events were observed in Jamaica throughout the year. A surface to upper-level trough over the western Caribbean resulted in heavy rain over parts of Jamaica during 13-15 May, causing major flooding and landslides. Impacts include destroyed bridges, multiple damaged roads, and stranded communities. (Clarendon was the worst affected parish; flooding was also observed in nine other parishes.) On 8-10 September, a trough induced by Hurricane Irma across the western Caribbean resulted in heavy thundershowers and flooding over the eastern and central parishes. An accompanying lightning strike on the Jamaica Civil Aviation Authority facility in Kingston on 8 September resulted in damage to radar and communication equipment, resulting in the shutdown of Jamaica's airspace for more than 24 hours and for 12-hour periods on 10-11 September. unprecedented strong winds. While most structures across the island are built of concrete and are generally strong enough to withstand strong winds, countless homes and buildings suffered some type of structural damage. Nearly all commercial signs, traffic lights, and roads signs were destroyed. All communications-cellphones and landlines, radio, and television-were largely disrupted; an estimated $95 \%$ of the cell towers were out of service in Puerto Rico. The electrical grid was also destroyed, causing $100 \%$ of the island to lose electric power. The damage to the electrical grid was so extensive that 5 months later $25 \%$ of residents in Puerto Rico were still without power.

The flash flooding due to Hurricane María's extreme heavy rainfall was catastrophic. The 48-hour rainfall accumulations were generally between 380 and $500 \mathrm{~mm}$ with isolated higher amounts. As a result, 30 rivers reached major flood stage, with 13 of those at or above record-flood stage. Numerous bridges were destroyed by the strong currents, isolating many rural communities. The La Plata River, across north central and northeastern Puerto Rico, flooded its entire alluvial valley, including the municipality of Toa Baja where hundreds of families had to be rescued from their rooftops in Barrios Ingenio and Levittown. Across northwestern Puerto Rico, excessive runoff moving across the dam at the Guajataca Lake compromised the stability of the dam, resulting in communities along the Guajataca River below the dam being displaced due to the risk of dam failure. The excessive rainfall also resulted in widespread landslides across the Island, making thousands of roads impassable, especially across the mountainous areas of Puerto Rico. The blocked roads disrupted the ability of rescue workers to distribute food, water, medical supplies, and fuel for stranded communities. The damage was so bad that $<8 \%$ of roads were open and usable a month following María's passage over Puerto Rico. Damage due to beach erosion and coastal flooding was also observed along the shorelines, particularly across western Puerto Rico, where waves destroyed dozens of houses. Storm surge observations across the local islands ranged from 2-3 meters with wave heights greater than 6 meters. Winds, waves, and the storm surge across eastern Puerto Rico sank more than 300 boats.

María was the strongest hurricane to impact Puerto Rico since 1928, when Hurricane San Felipe II (also known as Hurricane Okeechobee) made landfall over the island as a category 5 . The official death toll for María stands at 64 , although many believe the number is much higher. The catastrophic damage caused thousands of Puerto Ricans to move to the U.S. mainland after the storm. NOAA's National Centers for Environmental Information (NCEI), in consultation with the National Hurricane Center (NHC), classified Hurricane María as the third costliest U.S. tropical cyclone on record, with $\$ 90$ billion U.S. dollars in damages across Puerto Rico and the U.S. Virgin Islands (www.nhc.noaa.gov/news UpdatedCostliest.pdf). 


\section{d. South America}

Warmer-than-normal conditions engulfed much of South America during 2017, with anomalies $+1.0^{\circ} \mathrm{C}$ or higher. However, below-normal minimum temperatures were observed across Suriname, French Guiana, a small area in northern Colombia, and across parts of southern Brazil. During 2017, wetterthan-normal conditions prevailed over much of the region, with the largest positive anomalies across the coast of Peru. Drier-than-normal conditions persisted across northeastern Brazil and across parts of southern South America.

Anomalies in this section are all with respect to the 1981-2010 average, unless otherwise noted.

I) Northern South America-R. Martínez, L. López, D. Marín, S. Mitro, R. Hernández, E. Zambrano, and J. Nieto

The northern South America region includes Ecuador, Colombia, Venezuela, Guyana, Suriname, and French Guiana.

\section{(i) Temperature}

Most of northern South America had abovenormal temperatures during 2017. Colombia, Ecuador, Suriname, and Venezuela had annual maximum temperatures that were $0.5^{\circ}-1.5^{\circ} \mathrm{C}$ above normal and, in some isolated areas, greater than $+2.0^{\circ} \mathrm{C}$. Below-normal maximum temperatures for 2017 were limited to small areas across northern South America (Fig. 7.11a). Most of northern South America also experienced above-normal annual minimum temperatures that were $+1.5^{\circ} \mathrm{C}$ or more, although Suriname, French Guiana, and a small area in northern Colombia observed below-normal minimum temperatures during 2017 (Fig. 7.11b).
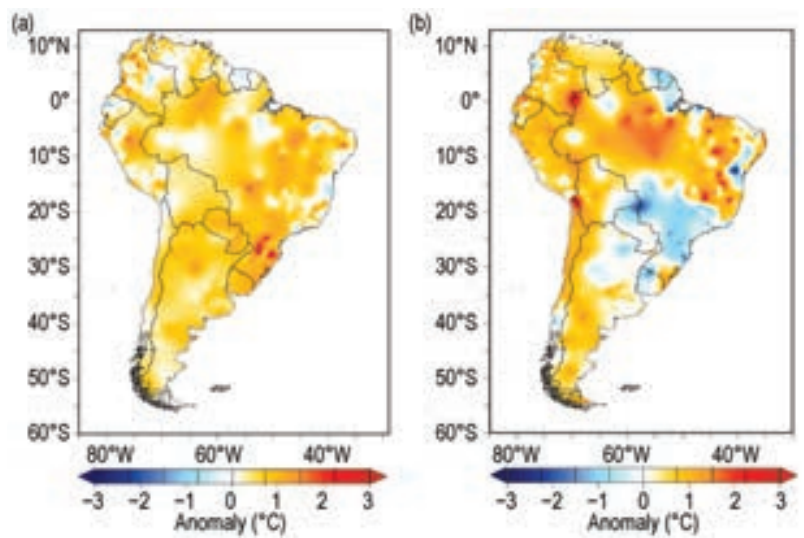

FIG. 7.II. Annual anomalies of 2017 (a) maximum and (b) minimum temperature $\left({ }^{\circ} \mathrm{C}\right.$; $198 \mathrm{I}-2010$ base period). (Source: Data from the NMHSs of Argentina, Colombia, Chile, Brazil, Ecuador, Paraguay, Peru, Suriname, and Venezuela; processed by CIIFEN, 2018.)
During 2017, August had the highest positive maximum and minimum temperature anomalies $\left(+2^{\circ} \mathrm{C}\right)$ across the region.

Cooler-than-normal conditions were limited to Colombia and Venezuela during January and March. However, on 8 February, Bogota, Colombia, set a new maximum temperature of $25.1^{\circ} \mathrm{C}$, surpassing the previous record of $24.9^{\circ} \mathrm{C}$ set in 1995 .

\section{(ii) Precipitation}

Most of northern South America had abovenormal precipitation during 2017 (Fig. 7.12). During January-March 2017, the presence of the coastal El Niño caused above-normal precipitation in the coastal region of Ecuador and southern Colombia (Fig. 7.13). The extreme rainfall events triggered deadly landslides (see Notable events and impacts section). These locations received 150-300 mm (180\%-230\%) of their normal precipitation from January to March.

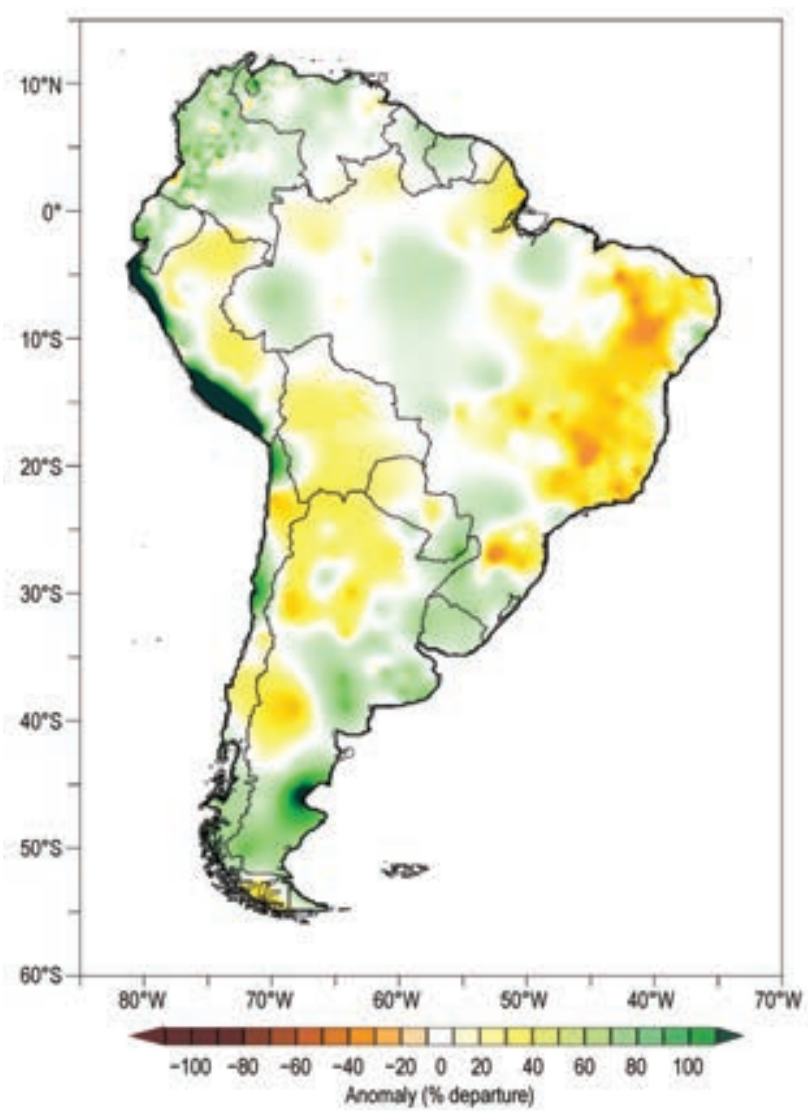

FIg. 7.12. Annual anomalies of 2017 precipitation (\%; 198I-2010 base period). (Source: Data from the NMHSs of Argentina, Colombia, Chile, Brazil, Ecuador, Paraguay, Peru, Suriname, and Venezuela; processed by CIIFEN, 2018.) 


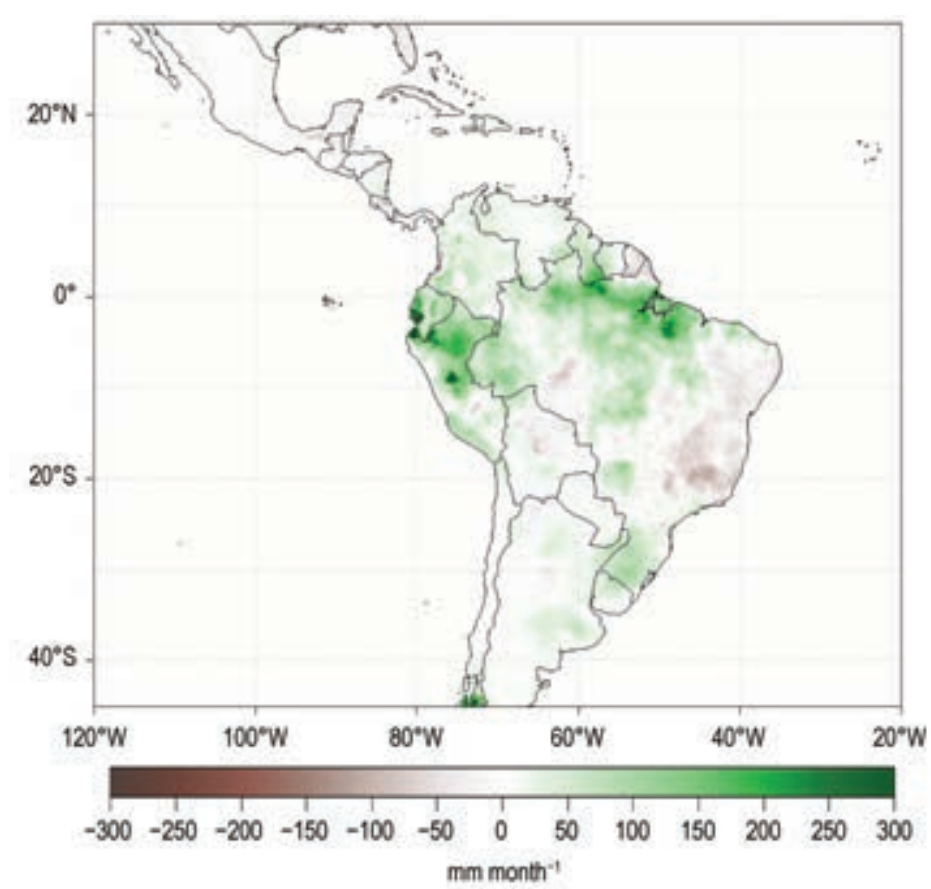

FIG. 7.I3. Precipitation anomalies (mm month ${ }^{-1}$; $1981-2010$ base period) during Jan-Mar 2017. (Source: UCSB CHIRPS v2; processed by CIIFEN, 20I8.)

\section{(iii) Notable events and impacts}

During the first quarter of 2017, regional climate was highly influenced by sea surface temperature warming of the coastal El Niño (Sidebar 7.2). The sudden warming in the eastern equatorial Pacific was different from the typical development of El Niño events. Although its impacts in the Andean countries varied, the most significant effects of the intense and quick coastal El Niño were mainly associated with extreme precipitation events and subsequent flooding and landslides.

From January to April, rainfall exceeded normal conditions in a large part of the coastal region of Ecuador and most of Colombia, Suriname, and Venezuela. Heavy rain during February-April produced floods in Ecuador, which were responsible for more than two dozen fatalities and over 127000 people affected in the provinces of Guayas and Manabi. Some locations set new precipitation records during March. In Mocoa, Colombia, extreme rainfall $(130 \mathrm{~mm}$ in 3 hours) in late March fell in areas that were already saturated by heavy rain earlier in the month, causing flash floods and a landslide that killed more than 250 people and left over 300 people injured. During March-May, devastating floods affected the departments of Antioquia, Cundinamarca, and Choco in Colombia.

In Venezuela, above-normal precipitation fell during August-September, triggering the most devastat- ing floods in more than a decade in the states of Bolívar and Delta Amacuro. The 5-day accumulated rainfall of $120 \mathrm{~mm}$ at the end of August caused flash floods and a landslide in Río Mercedes (State of Aragua), affecting hundreds of people and causing four fatalities.

2) Central South America-J. A. Marengo, J. C. Espinoza, L. M. Alves, J. Ronchail, J. Báez, K. Takahashi, and W. Lavado-Casimiro

The central South America region includes Brazil, Peru, Paraguay, and Bolivia.

\section{(i) Temperature}

The first half of 2017 was characterized by extreme high temperatures $\left(2^{\circ}-3^{\circ} \mathrm{C}\right.$ above normal) in Bolivia, Paraguay, northern Peru, and southern Brazil. Warmer-than-normal conditions continued to affect the region from June through September, with temperatures ranging from $1^{\circ}$ to $3^{\circ} \mathrm{C}$ above normal over Bolivia, Paraguay, and northeastern Brazil. Near-normal temperatures were recorded across the region during October-December.

Several cold episodes occurred from April through July. The passage of a cold front on 20 June brought cold temperatures to the southern half of Brazil, with some regions recording minimum temperatures $<0^{\circ} \mathrm{C}$. São Joaquim and Bom Jesus (located in the state of Río Grande do Sul; climatologies of $5.9^{\circ} \mathrm{C}$ and $8.0^{\circ} \mathrm{C}$, respectively) reported minimum temperatures as low as $-3^{\circ} \mathrm{C}$ and $-2.6^{\circ} \mathrm{C}$, respectively. A polar air intrusion during 17-19 July (see Notable events and impacts section) brought cooler-thannormal conditions to parts of southern and eastern Brazil and in western Amazonia, resulting in monthly minimum temperatures $1^{\circ}-3^{\circ} \mathrm{C}$ below normal.

\section{(ii) Precipitation}

The first half of 2017 was characterized by belownormal precipitation in Bolivia and west-central and northeastern Brazil. Above-normal precipitation was observed in northwestern Amazonia, southern Brazil, and along the northern Peruvian coast during the second half of the year.

The dry conditions observed in 2016 in Bolivia and northeastern Brazil (Marengo et al. 2017) persisted through 2017. Most of central South America east of the Andes experienced below-normal rainfall (100-150 mm month ${ }^{-1}$; Fig. 7.14) from January through April, with only weak episodes of the South Atlantic convergence zone (SACZ) - a summertime circulation pattern associated with rainfall in the 

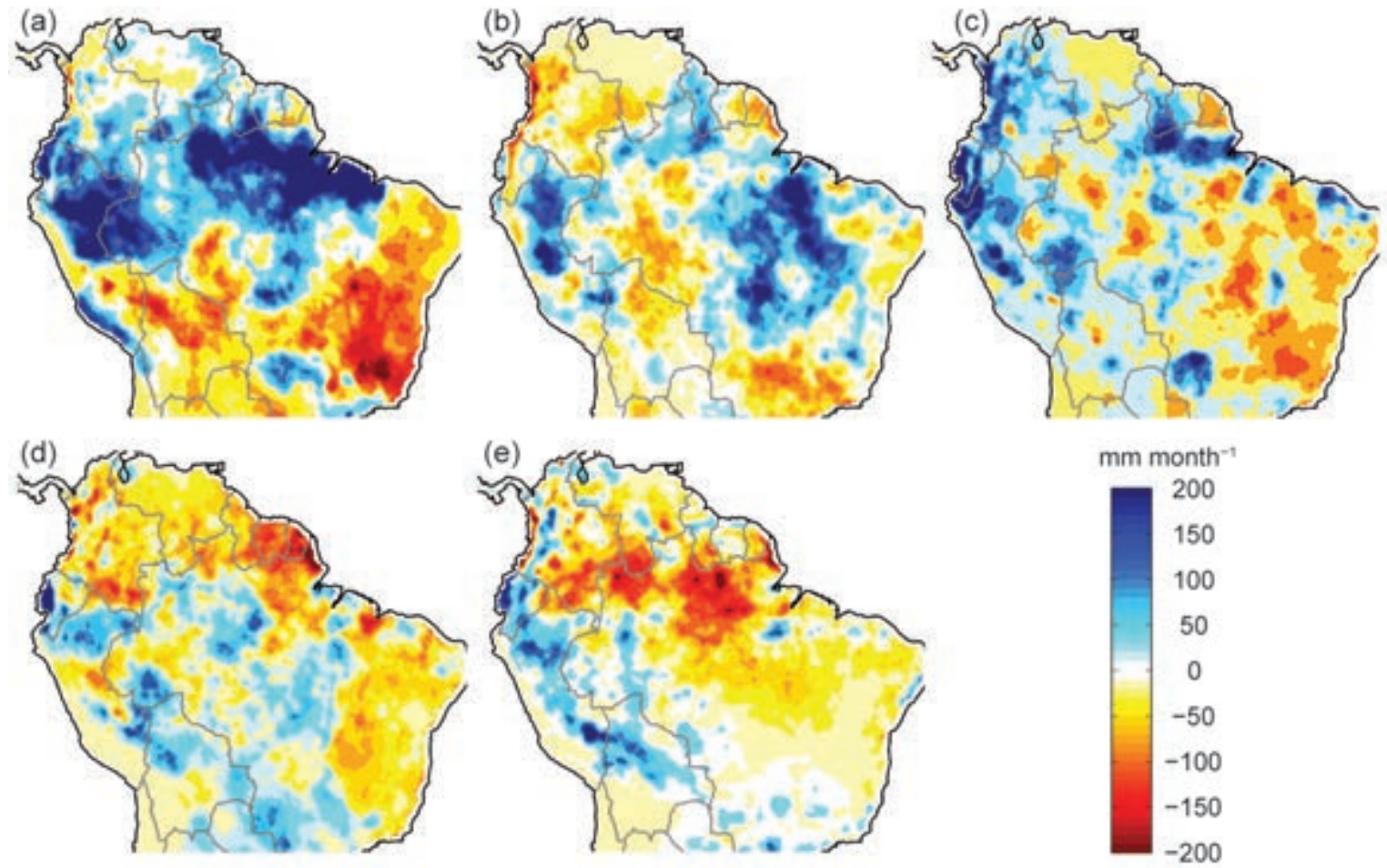

FIG. 7.I4. Monthly rainfall anomalies ( $\mathrm{mm}$ month $^{-1}$; $198 \mathrm{I}-2010$ base period) for Jan-May 20I7. [Source: Climate Hazards group Infrared Precipitation with Stations (CHIRPS) dataset.]

region. The extreme dry conditions were ideal for the development of wildfires. According to the Brazilian National Institute for Space Research, the total number of wildfires for the Amazon region in 2017 was 272000 , the highest number since records began in 1999, which burned over 986000 hectares. In December, a SACZ episode caused heavy rainfall over southeastern Brazil, Paraguay, and Bolivia, resulting in high river levels for Amazonas-Solimões and Negro River basins. Floods affected the cities of Trinidad and Santa Cruz de la Sierra (Bolivia), as well as soybean crops and livestock in the lowlands of Bolivia.

\section{(iii) Notable events and impacts}

Heavy rains that fell in Peru during January-May (Fig. 7.14) were triggered by the coastal El Niño present in the eastern tropical Pacific Ocean (see Sidebar 7.2). Torrential rainfall triggered flash floods and landslides that affected over 625000 people in the regions of Tumbes, Piura, Lambayeque, La Libertad, Ancash, Ica, and Arequipa and claimed nearly 100 lives. Losses include 242 bridges, $13227 \mathrm{~km}$ of rural and main roads (1.5\% of the national road system), $45335 \mathrm{~km}$ of agricultural irrigation channels, and 60400 ha of crops. In the suburbs of Lima, landslides ("huaycos") destroyed houses, and the highway between Lima and the Andean cities was inaccessible for several days.

The January 2017 precipitation total for the city of São Paulo was $453.8 \mathrm{~mm}, 179 \%$ of normal for the month, and its wettest January since 2011. The copious rain prompted flash floods in several locations across the city.

In the city of Maceio, located on the coast in the state of Alagoas in northeast Brazil, a state of emergency was declared due to torrential rains that produced landslides and flash flooding on 27 May, killing three people. By 29 May, over 8400 families were affected, and more than 16500 people were left homeless. Total rainfall in May 2017 was $742.4 \mathrm{~mm}$ (more than twice the monthly normal of $344.7 \mathrm{~mm}$ ), with $169.6 \mathrm{~mm}$ recorded on the $27 \mathrm{th}$.

During the first two weeks of June, well-abovenormal rainfall was observed in the eastern portion of the state of Santa Catarina (southern Brazil) due to the passage of a cold front. Torrential rains affected more than 28800 people and, in some districts, a state of emergency was declared due to floods. The same cold front caused heavy rainfall and flash floods in Rio de Janeiro, and the total rainfall measured on 20 June was almost $247 \mathrm{~mm}$ (June climatology is $461.8 \mathrm{~mm}$ ). This event affected public transportation in the city and flooded some neighborhoods. 


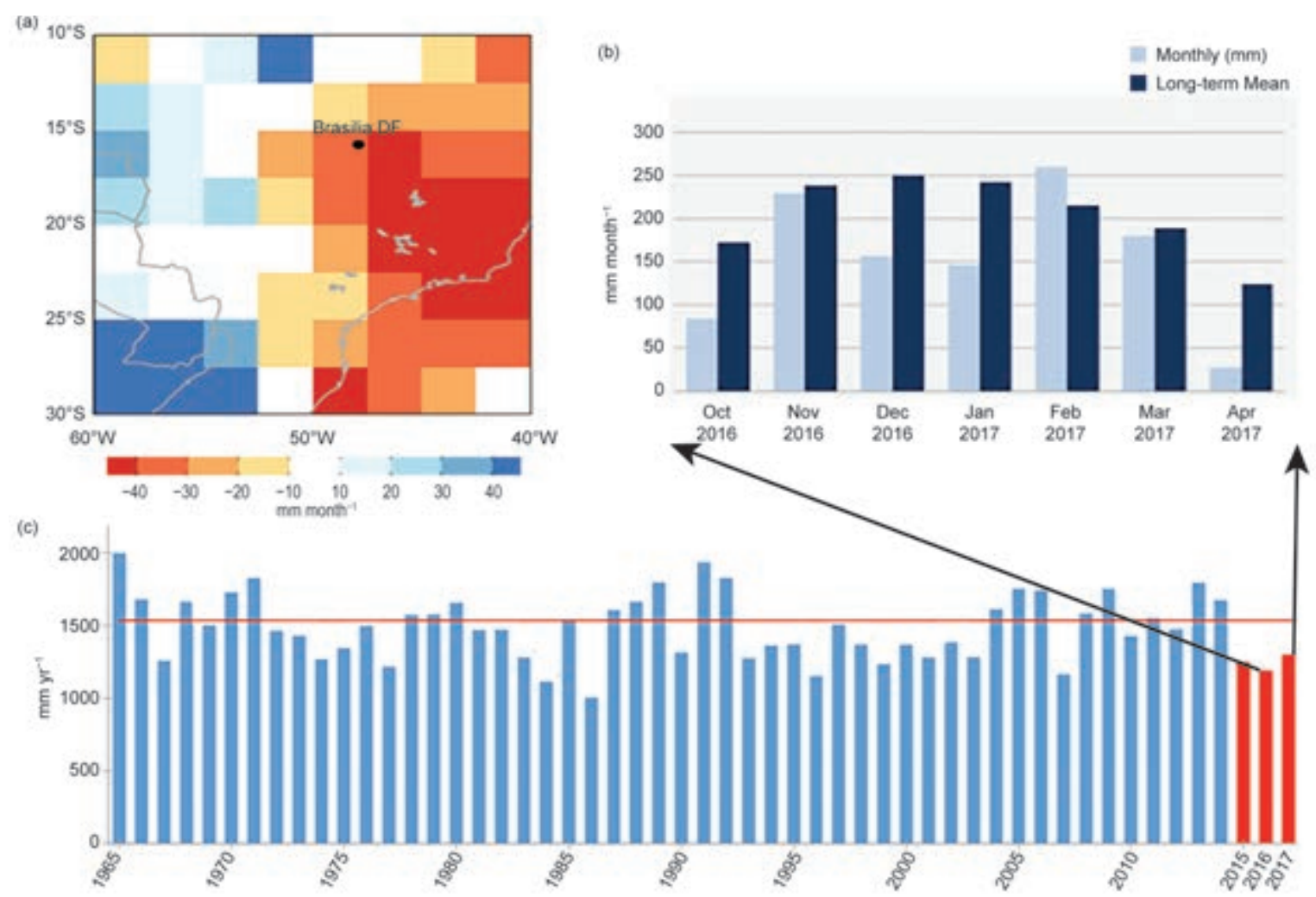

FIG. 7.I5. (a) Rainfall anomalies in west-central Brazil during Jan-Apr 2017; the city of Brasilia is marked with a black dot; (b) Monthly rainfall $(\mathrm{mm})$ in Brasilia from Oct 2016 to Apr 2017; 2017 monthly totals are depicted in light blue, while the 198I-2010 normals are in dark blue; (c) Time series of annual rainfall $(\mathrm{mm})$ from 1965 to 2017 ; normal annual value is depicted with a red line. (Source: GPCP and INMET.)

West-central Brazil, particularly Brasilia (Distrito Federal), has been affected by dry conditions since 2015. The drought conditions, which continued into 2017, were the worst in the last 57 years. In April 2017, Brasilia received only $20 \%$ of its normal April precipitation, which is $125 \mathrm{~mm}$; in fact, during the peak of the rainy season (October 2016-April 2017), only February had above-normal monthly rainfall (Fig. 7.15). This prompted a state of emergency and mandatory water restrictions.

The most intense cold episode during austral winter 2017 occurred during 17-19 July. A polar air mass affected the Andes, bringing cooler-thannormal conditions to the western Amazonia regions of Brazil, Peru, and Bolivia. On 17 July, minimum temperatures as low as $10^{\circ} \mathrm{C}$ were recorded in the Bolivian Amazon and in Puerto Maldonado, Peru (July climatology of $18^{\circ} \mathrm{C}$ ), while on 18 July the western Brazilian Amazon saw temperatures drop to $7.2^{\circ} \mathrm{C}$ in Campo Verde (located in the state of Mato Grosso; climatology of $21.2^{\circ} \mathrm{C}$ ), $11.3^{\circ} \mathrm{C}$ in Epitaciolândia (located in the state of Acre; climatology of $19.0^{\circ} \mathrm{C}$ ), and $11.1^{\circ} \mathrm{C}$ in Guajará-Mirim (located in the state of Rondonia; climatology of $20.0^{\circ} \mathrm{C}$ ). In the city of São
Paulo, the maximum temperature was $8^{\circ} \mathrm{C}$ (climatology of $11.7^{\circ} \mathrm{C}$ ) on $18 \mathrm{July}$, and one person died due to exposure to the cold temperatures. From mid-July to mid-August, a cold front in Peru produced temperatures as low as $-20^{\circ} \mathrm{C}$ at 4000 meters above sea level (the record-coldest value is $-25^{\circ} \mathrm{C}$ set on 6 July 1968 at Macusani station in Puno region), and snow fell in the Andes of Peru and Altiplano.

3) Southern South America一-J. L. Stella and L. S. Aldeco This region includes Argentina, Chile, and Uruguay.

\section{(i) Temperature}

Above-normal temperatures were observed across southern South America (SSA) during 2017, with annual mean temperatures $0.5^{\circ}-1.5^{\circ} \mathrm{C}$ above normal. The national mean temperature anomaly for Argentina and Uruguay was $+0.68^{\circ} \mathrm{C}$ and $+1.0^{\circ} \mathrm{C}$, respectively, placing 2017 as the warmest year on record since 1961 for both countries. The five warmest years on record for Argentina have all occurred since 2012 (Fig. 7.16). The mean temperature anomaly by decade since the 1960s (Fig. 7.17) shows an increase 


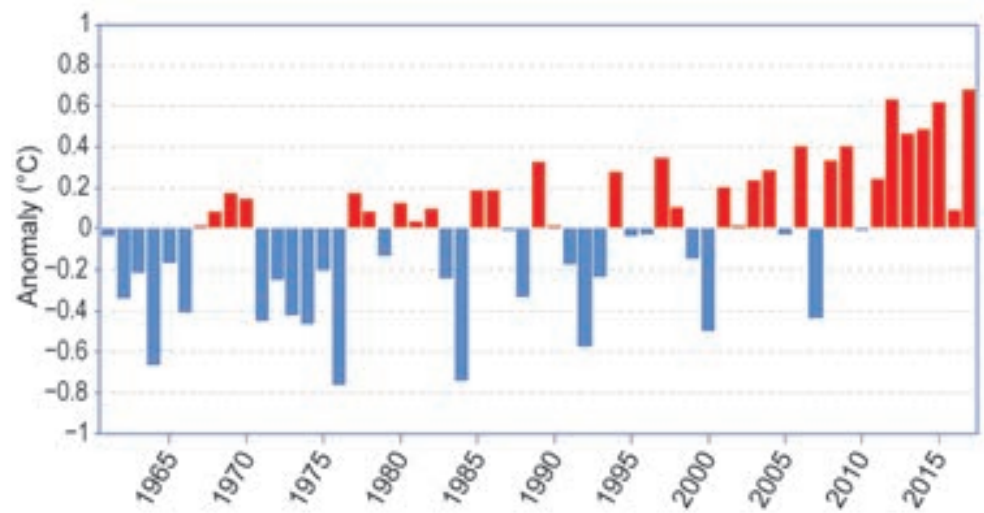

Fig. 7.16. Annual mean temperature anomalies $\left({ }^{\circ} \mathrm{C}\right.$; $198 \mathrm{I}-2010$ base period) for Argentina for 196I-2017. (Source: Argentina's National Meteorological Service.)

across central and northern Argentina during 2001-2010 and a significant rise across the country as a whole during the decade to date (2011-2017).

Summer (December-February) 2016/17 was particularly warm over most of SSA, with mean temperatures $1^{\circ}-2^{\circ} \mathrm{C}$ above normal. Chile had its second warmest summer since 1964. At the end of the season, a heat wave affected a large area in central Argentina. The maximum duration of extreme heat, defined here as minimum and maximum temperatures surpassing the 90th percentile, ranged between five and eight days, and for some locations these conditions extended into the beginning of March, resulting in one of the latest heat waves recorded in that area.
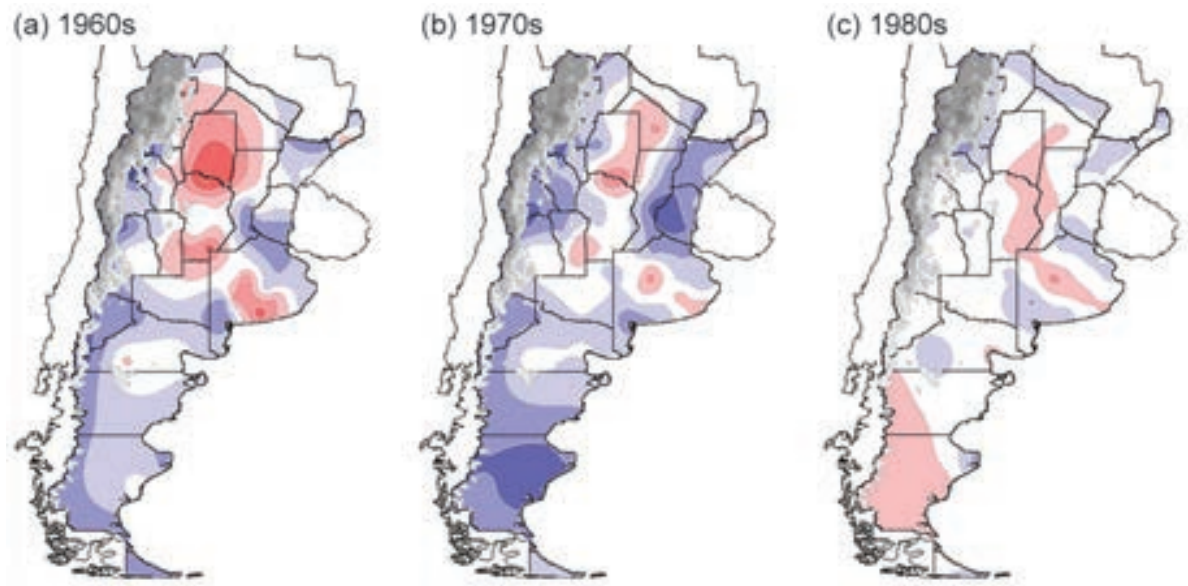

(d) $1990 \mathrm{~s}$

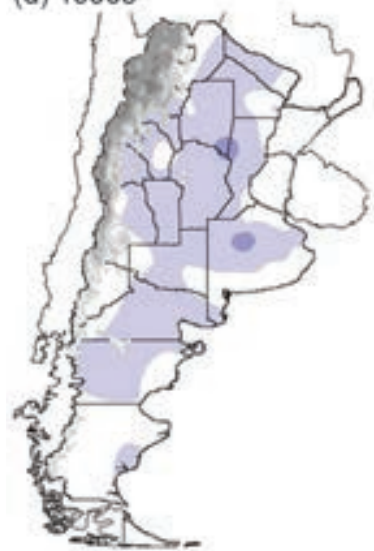

(e) $2000 \mathrm{~s}$

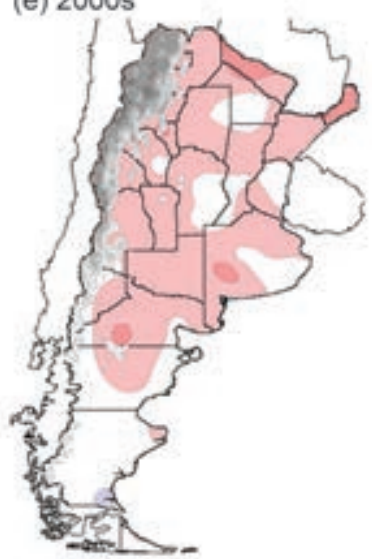

(f) $2010 \mathrm{~s}$

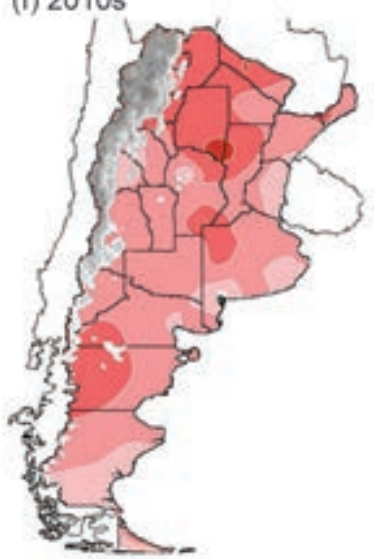

Below-normal maximum temperatures and above-normal minimum temperatures during austral autumn (March-May) resulted in near-normal mean temperatures across much of SSA $\left( \pm 0.5^{\circ} \mathrm{C}\right)$.

Winter (June-August) 2017 was extremely warm over much of the region, with temperatures $1^{\circ}-3^{\circ} \mathrm{C}$ above normal across the eastern and northern parts of SSA. This was the warmest winter on record for Uruguay and second warmest for Argentina in their 46-year records. Several individual locations in eastern Argentina reported their warmest winter on record. A new national maximum temperature record was set on 17 June when the temperature soared to $40^{\circ} \mathrm{C}$ at Tinogasta (northwestern Ar-

FIG. 7.I7. Decadal mean temperature anomalies $\left({ }^{\circ} \mathrm{C}\right.$; $198 \mathrm{I}-2010$ base period) across gentina), marking the Argentina from the 1960s through 2017. (Source: Argentina's National Meteoro- first time on record the logical Service.) 
temperature reached $40^{\circ} \mathrm{C}$ between May and July. Meanwhile, a few cold outbreaks during June and July also impacted the region. Bariloche (northwestern Patagonia, Argentina) broke its absolute minimum temperature record when temperatures dropped to $-25.4^{\circ} \mathrm{C}$ on 16 July. The previous record was $-21.1^{\circ} \mathrm{C}$ set on 30 June 1963. These cold spells also caused heavy snowfalls over southern Argentina and Chile and broke several minimum temperature records across Uruguay during June and July.

Spring (September-November) was characterized by below-normal temperatures. The cooling in the Pacific Ocean during spring contributed to the change in temperature pattern across SSA.

\section{(ii) Precipitation}

Much of eastern and southern SSA had abovenormal annual rainfall during 2017. The most significant precipitation totals were observed in central Argentina, Uruguay, eastern Patagonia, and southern Chile (between $40^{\circ}$ and $50^{\circ} \mathrm{S}$ ). Conversely, central Chile and northwestern Patagonia $\left(32^{\circ}-42^{\circ} \mathrm{S}\right)$ had below-normal rainfall during 2017. The estimated annual precipitation anomaly for Argentina was $109.8 \%$ of normal, the fourth consecutive year with abovenormal rainfall after a long dry period (2003-13). At Isla de Pascua, Chile, 2017 was the second driest year on record since 1950.

The beginning of 2017 was particularly dry in central Argentina and central Chile, causing severe drought that contributed to the development of wildfires in both countries. Meanwhile, northeastern Argentina and Uruguay had above-normal rainfall during summer 2016/17. This pattern intensified and extended to central Argentina during autumn and winter. Intense precipitation affected central and northeastern Argentina and Uruguay, triggering floods in large parts of the region. One of the most extreme precipitation events occurred in Comodoro Rivadavia, a city located in eastern Patagonia (see Notable events and impacts section). Heavy precipitation events also occurred in April 2017, affecting northern, eastern, and southern Uruguay, with several locations recording new daily precipitation records. The copious rainfall triggered floods and caused road interruptions.
During May, intense daily rainfall $(>100 \mathrm{~mm})$ affected the Coquimbo region in central Chile; it was considered the most extreme event since the 1950s. La Serena, also in central Chile, received $200 \%$ of its normal precipitation for the month.

As La Niña conditions emerged in October, the precipitation pattern across SSA changed abruptly. Most of the SSA region had below-normal rainfall, particularly during October and November, with 50-150 mm below-normal precipitation reported in northern Argentina and 25-50 mm below normal in central Patagonia of Chile and Argentina.

\section{(iii) Notable events and impacts}

During January, an extraordinary heat wave affected central Chile and Argentina. The Chilean cities of Antofagasta and Curicó recorded the most prolonged warm periods with extreme high temperatures for 14 and 17 days, respectively. The temperature at Santiago de Chile rose to $37.4^{\circ} \mathrm{C}$, the highest value recorded in the 104 -year record. The locations of Chillán $\left(41.5^{\circ} \mathrm{C}\right)$, Los Angeles $\left(42.2^{\circ} \mathrm{C}\right)$, and Curicó $\left(37.3^{\circ} \mathrm{C}\right)$ also broke their maximum temperature records. In Argentina, the temperature reached $43.4^{\circ} \mathrm{C}$ on 27 January at Puerto Madryn, the highest temperature ever recorded so far south $\left(43^{\circ} \mathrm{S}\right)$ anywhere in the world.

Drought, combined with high temperatures, triggered devastating forest fires in large areas of central and southern Chile in January. More than 600000 hectares were burned, with thousands of people affected. Central Argentina had a similar situation with forest fires affecting La Pampa province, leading to more than 1 million hectares burned and cattle and crops losses.

On 30 March, Comodoro Rivadavia reported an impressive daily rainfall amount of $232.4 \mathrm{~mm}$, close to the city's annual normal precipitation total. The heavy rain produced severe flash floods that affected the region. A few days later, the city was impacted once again by heavy rainfall (more than $60 \mathrm{~mm}$ in a few hours), leaving most of the city destroyed.

On 15 July, Santiago, Chile's capital, experienced its heaviest snowfall since 1922, with $3-10 \mathrm{~cm}$ of snow. Meanwhile, the same synoptic system produced $40 \mathrm{~cm}$ of snow over the city of Bariloche, Argentinaits heaviest snowfall in 20 years. 
The original concept of El Niño consisted of anomalously high sea surface temperature and heavy rainfall along the arid northern coast of Peru (Carranza I891; Carrillo 1893). The concept evolved into the EI Niño-Southern Oscillation (ENSO; Bjerknes 1969), although the original El Niño and the Southern Oscillation do not necessarily have the same variability (Deser and Wallace 1987), and the strong EI Niño episode in early 1925 coincided with cold-to-neutral ENSO conditions (Takahashi and Martínez 2017). To distinguish the near-coastal El Niño from the warm ENSO phase, Peru operationally defines the "coastal El Niño" based on the seasonal Niño I+2 SST anomaly (ENFEN 2012; L'Heureux et al. 2017). While recent attention has been brought to the concept of ENSO diversity (e.g., "central Pacific" vs "eastern Pacific" events; Capotondi et al. 2015), the coastal EI Niño represents another facet of ENSO that requires further study in terms of its mechanisms and predictability.

A strong coastal El Niño developed off the coast of Peru from January to April 2017 (ENFEN 2017; WMO 2017a,b; Takahashi and Martínez 2017; Ramírez and Briones 2017; Garreaud 2018). The changes were dramatic within the cool coastal upwelling region, as daily SST at Puerto Chicama $\left(7.8^{\circ} \mathrm{S}\right.$, $79.1^{\circ} \mathrm{W}$ ) increased abruptly from $\sim 17^{\circ} \mathrm{C}$ by mid-January to a peak of $26.9^{\circ} \mathrm{C}$ in early February (ENFEN 2017). The mean maximum/minimum air temperature anomalies along the coast ranged between $+1.0^{\circ} \mathrm{C}$ and $+2.3^{\circ} \mathrm{C}$ across the north, central, and southern regions during February-March.

Convective precipitation is activated in the eastern Pacific when SST exceeds a threshold of $\sim 26^{\circ}-27^{\circ} \mathrm{C}$ (Takahashi and Dewitte 2016; Jauregui and Takahashi 2017). With SST well in excess of $27^{\circ} \mathrm{C}$, the southern ITCZ branch (Huaman and Takahashi 2016; Fig. SB7.2a) was very strong between February and March 2017 and extended into the South American continent (Fig. SB7.2b). The coastal city of Piura $\left(5.2^{\circ} \mathrm{S}, 80.6^{\circ} \mathrm{W}\right)$, located at the core of the ITCZ extension, had a FebruaryMarch precipitation total of $723 \mathrm{~mm}$, which is nearly seven times its normal amount of $106 \mathrm{~mm}$. The largest precipitation anomalies were observed at low and medium elevations on the western slope of the Andes, triggering several floods and mudslides along the Peruvian coast. Mean January-March 2017 river discharge was around $250 \%$ of normal in the Santa $\left(9.01^{\circ} \mathrm{S}\right.$, $\left.77.76^{\circ} \mathrm{W}\right)$, Rímac $\left(11.77^{\circ} \mathrm{S}, 76.46^{\circ} \mathrm{W}\right)$, and Cañete $\left(12.77^{\circ} \mathrm{S}\right.$, $\left.75.83^{\circ} \mathrm{W}\right)$ River basins.

Impacts along the coast were severe. In the northern regions, a total of 50927 houses were damaged with close to I. 2 million people affected by flooding, and over 76000 ha of crops were damaged. As is common with El Niño, this event affected marine resources, primarily the anchovies (Niquen and Bouchon 2004; Niquen et al. 1999), resulting in decreased fat content and early spawning as a reproductive strategy (IMARPE 2017). The estimated growth of the Peruvian gross domestic product in 2017 was $1.3 \%$ lower than expected (BCRP 2017).

The coastal El Niño appears to have been initiated by westerly anomalies in the equatorial far-eastern Pacific in January, the largest for that month since 1981, with a northerly component near the coast (Fig. SB7.3a). At upper levels, the Bolivian high (Lenters and Cook 1996) was located west of its normal position, and a subtropical ridge spread from the Northern Hemisphere, resulting in easterly anomalies and divergence favorable for convection over northwestern Peru (Kousky and Kayano 1994; Vuille et al. 2000). The MaddenJulian oscillation (MJO) had its highest amplitudes in the second half of January and was dominated by the MJO phases I to 3, which feature westerly anomalies in this region, according to the Real-time Multivariate MJO index (RMM; Wheeler and Hendon 2004; see Section 4c). The northerly component was probably associated with the negative mean sea

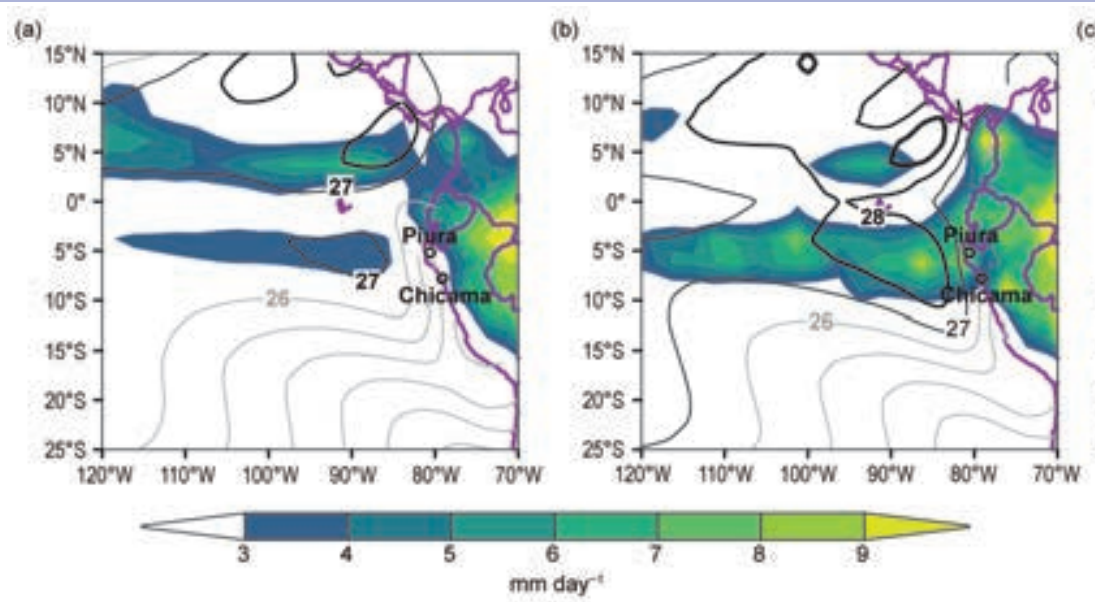

FIG. SB7.2. Feb-Mar SST (contours, interval I ${ }^{\circ} \mathrm{C}$ ) and rainfall (shading, $\left.\mathrm{mm}^{-1 a y}{ }^{-1}\right):($ a) $1981-2010$ climatology, (b) 2017 observations, and (c) 2017 anomalies (contour interval: $0.25^{\circ} \mathrm{C}$ ). (Sources: SST: ERSST v5; rainfall: CMAP.) 
level pressure anomalies in the southeast Pacific (Fig. SB7.3a). The latter could have been associated with Rossby-wave teleconnections from the western Pacific (Garreaud 2018), but the SLP anomalies also extended zonally uniformly across the subtropical South Pacific (Fig. SB7.3a), consistent with the negative phase of Antarctic Oscillation (Mo 2000a), while the subtropical anomalies closer to the coast of South America were probably partly a response to preexisting positive SST anomalies in that region.

In early February, rainfall in the southern ITCZ became active, and the subsequent growth and maintenance of the event was consistent with the ocean-atmosphere mechanisms proposed for the 1925 coastal El Niño (Takahashi and Martínez 2017), that is, positive feedback between surface warming to the south of the equator, enhanced southern branch of the ITCZ, and reinforced near-equatorial northerly surface wind anomalies (Figs. SB7.3b,c; e.g., $X i e$ and Philander 1994). The strong coastal ocean warming off northern Peru $\left(>+2^{\circ} \mathrm{C}\right)$ was limited to a shallow layer of about $30 \mathrm{~m}$ until the end of February, consistent with local surface forcing (Garreaud 2018). This, jointly with the smaller regional basin scale, explains the much faster timescale of this event (Takahashi and Martínez 2017). The termination of the event in April (Fig. SB7.3d) was also abrupt, as the insolation-driven seasonal sea surface cooling (Takahashi 2005) deactivated the southern branch of the ITCZ, shutting down the feedback mechanism. We should note that toward the end of March, the subsurface warming off northern Peru became deeper (down to $180 \mathrm{~m}$; ENFEN 2017) and persisted until May, probably associated with local ocean-atmospheric

Bjerknes feedback (Takahashi and Martínez 2017; Dewitte and Takahashi 2017), although warm ENSO conditions did not materialize (L'Heureux et al. 2017; also see Section 4b), similar to 1925 .

The knowledge of the basic mechanism of the 1925 coastal El Niño guided the official Peruvian forecasts in CMAP.)
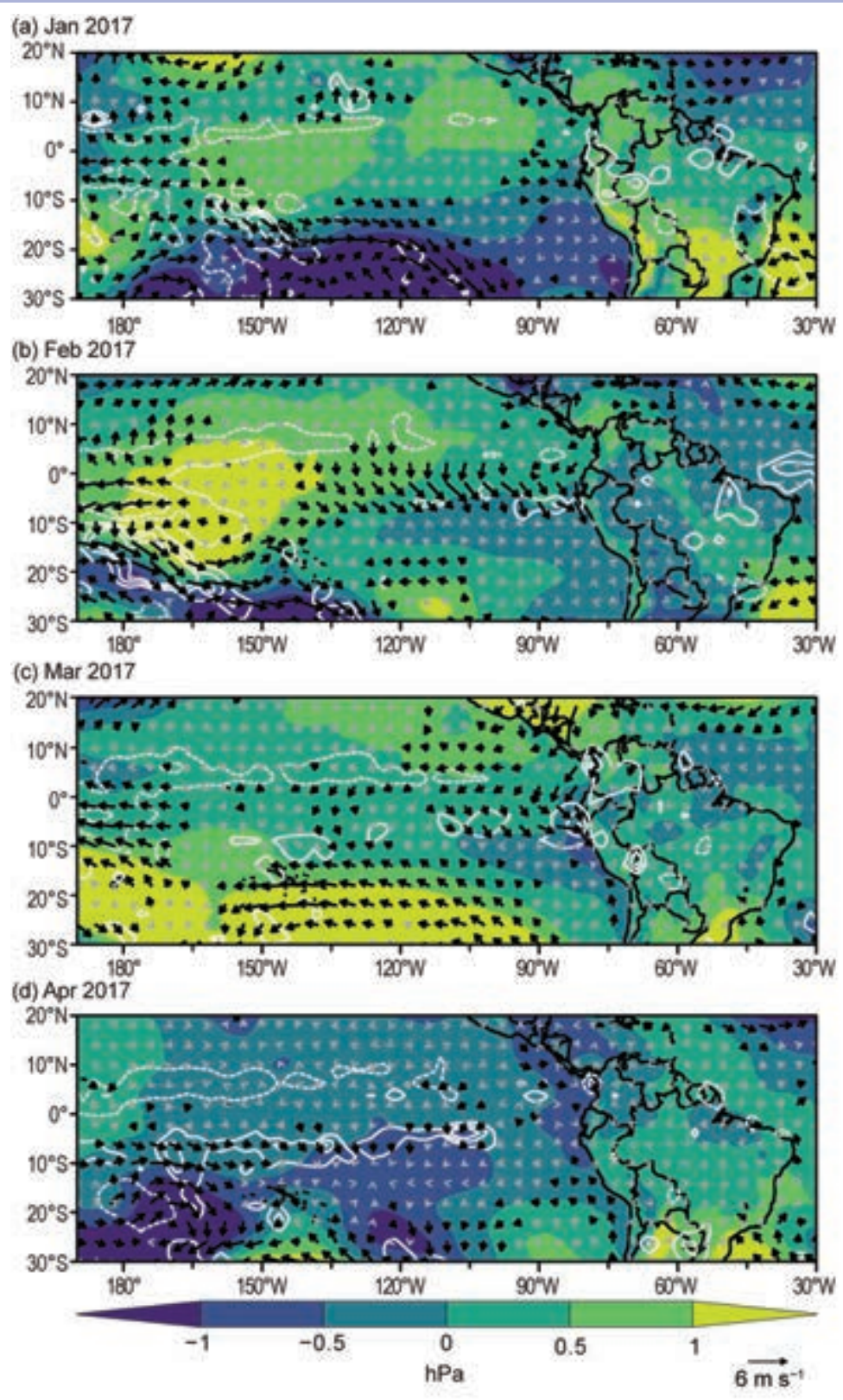

FIG. SB7.3. Mean sea level pressure (shading, hPa), $10-\mathrm{m}$ wind (vectors, $\mathrm{m} \mathrm{s}^{-1}$; >I $\mathrm{m} \mathrm{s}^{-1}$ in black), and precipitation [contours: $3 \mathrm{~mm}$ day , solid (dashed) contours represent positive (negative) anomalies. Zero not shown]. (Sources: MSLP and wind: ERA-interim; precipitation:

2017 , but only once the event started in late January, since international climate models provided little indication that such an event would occur (ENFEN 2017). Extending the lead time and accuracy of the prediction of coastal El Niño events is a critical challenge for Peru and requires increased understanding and improved models for this region. 


\section{e. Africa}

In 2017, most of Africa experienced above-normal air temperatures, with slightly lower-than-normal temperatures in a few areas of West and southern Africa (Fig. 7.18). For the continent as a whole (except for a few areas in southern Africa and in the deep Sahara, stretching between Niger and Libya), 2017 was above normal by about $0.3^{\circ}-1.8^{\circ} \mathrm{C}$. Annual mean rainfall was above normal over boreal summer rainfall areas in West, central, and parts of East Africa. Below-normal rainfall was recorded in equatorial and southern Africa between $10^{\circ}$ and $20^{\circ} \mathrm{S}$ (Fig. 7.19).

Extreme events like heavy rainfall and flooding were reported in many parts of the region. These reports include heavy downpours in February and December 2017 in Morocco and during August and September in Nigeria, The Gambia, and Niger. Tropical cyclone events in the Mozambique Channel affected Mozambique and Zimbabwe. An additional tropical cyclone over the southern Indian Ocean affected Réunion Island and Madagascar.

This report was compiled using observational records from the meteorological and hydrological services of Morocco, Egypt, Nigeria, Ethiopia, South

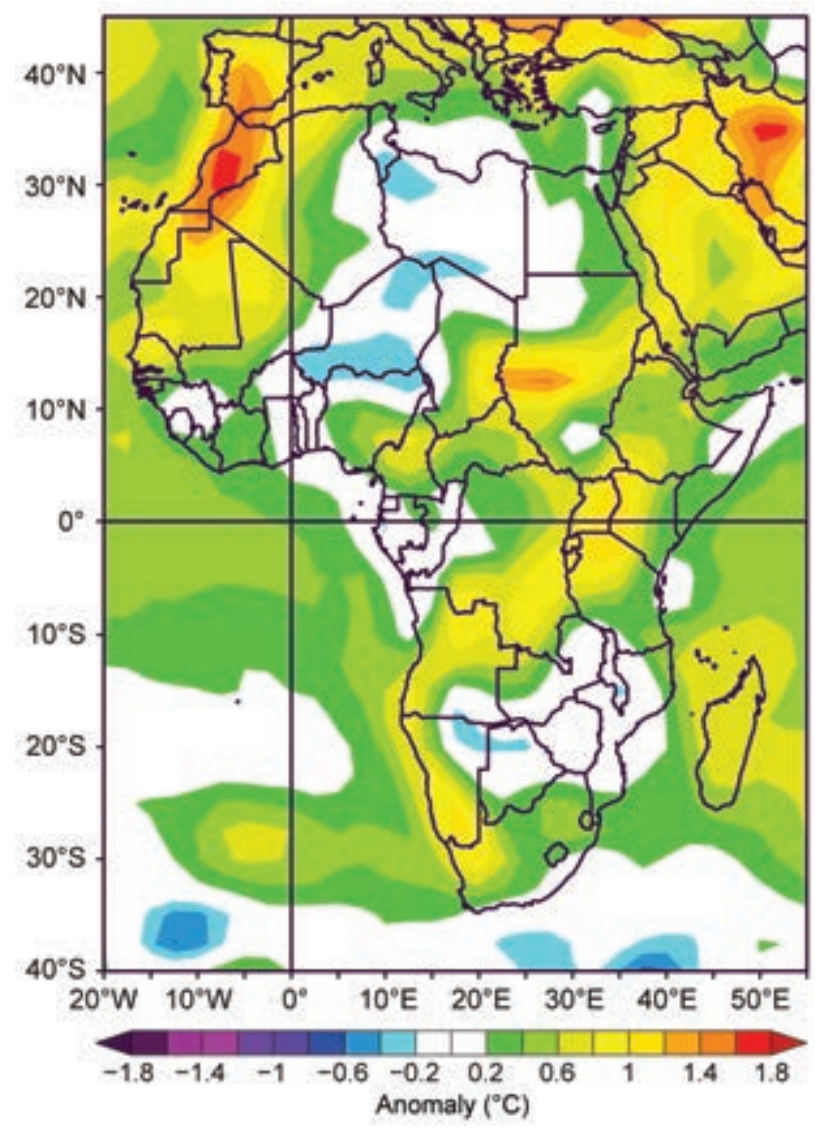

Fig. 7.18. Annual 2017 mean temperature anomalies ( ${ }^{\circ} \mathrm{C}$; 198I-20I0 base period) over Africa. (Source: NOAA/NCEP.)

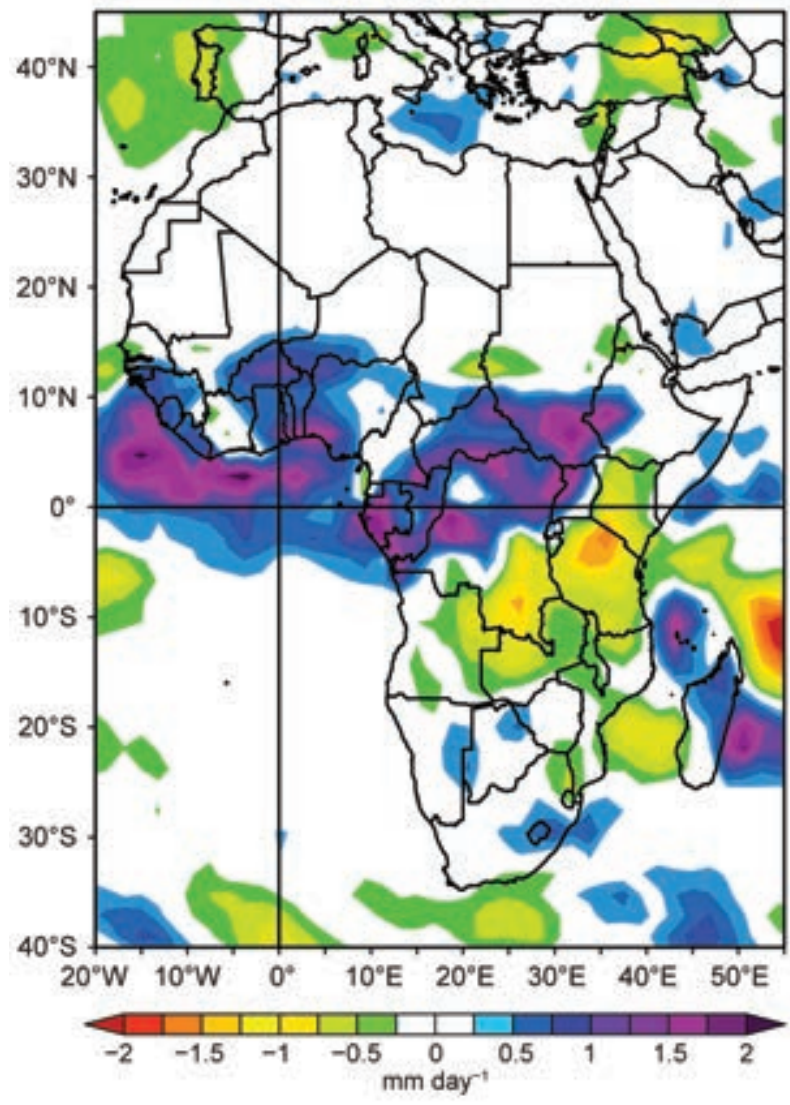

Fig. 7.19. Annual 2017 rainfall anomalies $\left(\mathrm{mm}\right.$ day $^{-1}$; 198|-2010 base period) over Africa. (Source: NOAA/ NCEP.)

Africa and the southern Indian Ocean Island countries of Madagascar, Seychelles, Mayotte (France), La Réunion (France), Mauritius, and Rodrigues (Mauritius). Reanalysis data from NCEP/NCAR and the ECMWF and rainfall from version 2 of Climate Hazards Group Infrared Precipitation with Stations data (CHIRPS) were also used. Precipitation fields from reanalyses are problematic, but unfortunately observations from many African nations are not available. fatalities and flooding hazards are as reported in news outlets. The climatological base period used is 1981-2010.

I) North Africa一K. Kabidi, A. Sayouri, M. ElKharrim, and A. E. Mostafa

Countries considered in this section include Morocco, Mauritania, Algeria, Tunisia, Libya, and Egypt.

In 2017, the region was marked by unusually high temperatures, below-normal rainfall, and extreme events including heavy rainfall and flooding that caused loss of life and property damage. In Morocco, extreme events were pronounced during February and December. 


\section{(i) Temperature}

Temperatures in 2017 were above normal over most of the region. However, January was cooler than normal over most of North Africa (Fig. 7.20a). Minimum temperatures of about $3^{\circ} \mathrm{C}$ below normal were observed over the mountains and southern parts of Morocco. Mean temperatures of about $2^{\circ}-3^{\circ} \mathrm{C}$ below average were also observed over most of Algeria, southern Tunisia, and western parts of Libya in January (Fig. 7.20a). January-February mean temperatures were also below normal over southern parts

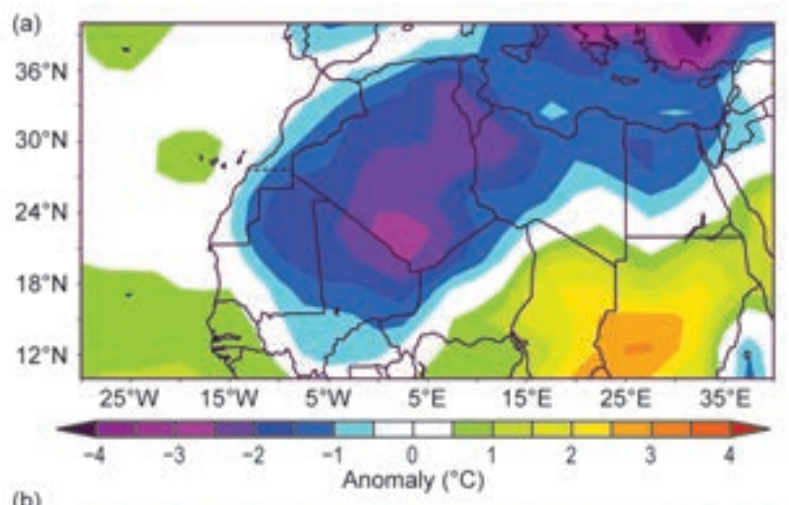

(b)
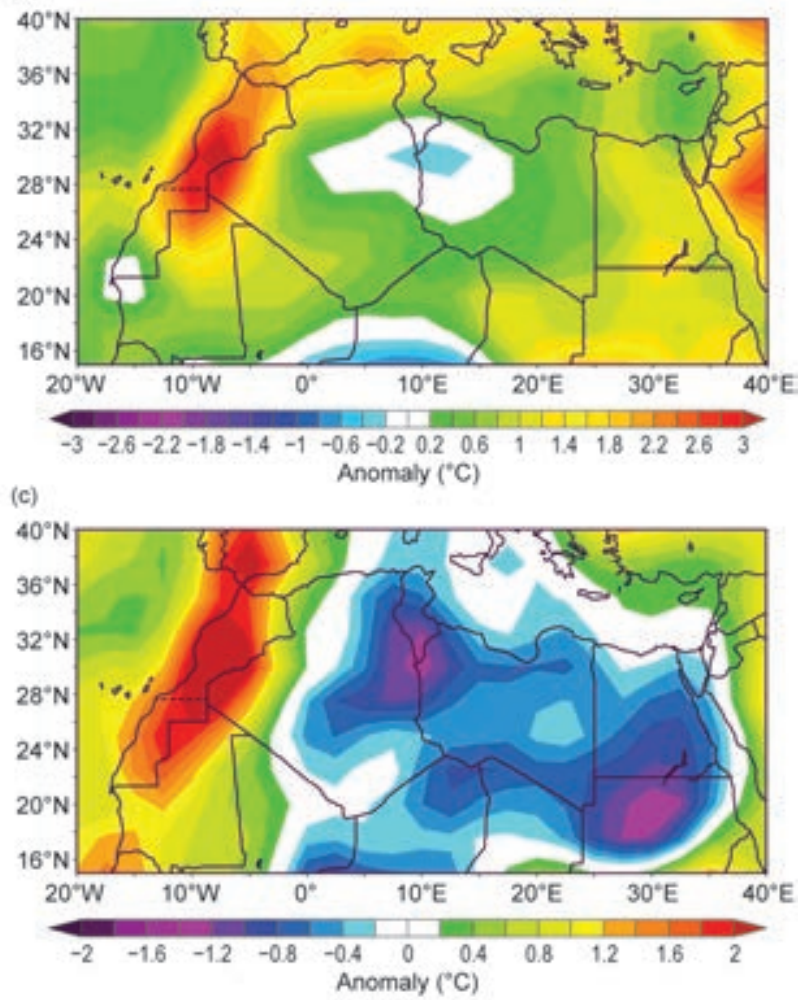

Fig. 7.20. (a) Northern Africa 2017 surface air temperature anomalies $\left({ }^{\circ} \mathrm{C}\right.$; $198 \mathrm{I}-2010$ base period) for Jan. (b) Northern Africa 2017 surface air temperature anomalies ( ${ }^{\circ} \mathrm{C}$; 198I-2010 base period) for Jun-Aug. (c) Northern Africa 2017 surface air temperature anomalies ( ${ }^{\circ} \mathrm{C}$; $198 \mathrm{I}-2010$ base period) for Sep-Nov. (Source: NOAA/NCEP.) of Morocco, northern and northwestern Mauritania, extreme southern Algeria, and over Libya and Egypt. Extreme minimum air temperatures of $0.2^{\circ} \mathrm{C}$ at El-Arish (northern Egypt) on 10 January and $1.3^{\circ} \mathrm{C}$ at Asyut (Upper Egypt) on 10 February were recorded.

Minimum and maximum temperatures over Morocco were among the highest in the period of record starting in 1901 . The mean annual temperature anomaly was $0.65^{\circ} \mathrm{C}$ above normal (exceeding the value recorded in 2016 by $+0.2^{\circ} \mathrm{C}$ ), with anomalies of $+0.6^{\circ} \mathrm{C}$ for the annual maximum temperature and $+0.7^{\circ} \mathrm{C}$ for the annual minimum temperature. The largest monthly mean temperature anomalies of about $3.7^{\circ} \mathrm{C}$ were recorded in May and October in Morocco.

Summer temperatures were above normal over most of the region and up to $3^{\circ} \mathrm{C}$ above normal over most of Morocco (Fig. 7.20b). Autumn (SeptemberNovember) temperatures were above normal over Morocco, with anomalies exceeding $2^{\circ} \mathrm{C}$ over central regions, and in Algeria. Eastern Algeria, southern Tunisia, and most of Libya and Egypt were colder than normal (Fig. 7.20c).

\section{(ii) Precipitation}

Annual precipitation over Morocco was $61 \%$ of normal. Morocco received $40 \%$ less precipitation in 2017 than 2016. Moroccan precipitation was characterized by strong spatial and temporal variability. About $13 \%$ of normal precipitation was recorded in the south at Smara (Saharan region), while close to normal rainfall ( $~ 89 \%$ of normal) was received in the north at Rabat. About half (46\%) of the annual precipitation was received in February and December 2017.

January-February precipitation over the region was largely below average due to a prevailing anticyclonic circulation that settled over North Africa's Atlantic coast and western Europe. However, heavy rainfall was recorded in Morocco on 22-24 February (Fig. 7.21). Heavy rainfall events were observed at many places, including $91 \mathrm{~mm}$ in 24 hours at Agadir in southwest Morocco. Above-normal rainfall was observed over northern Algeria in February. Heavy rainfall was also reported from Egypt in January.

The spring season (December-March) was generally characterized by rainfall deficits over most of the region. In Morocco, the seasonal precipitation was $47 \%$ of normal. Seasonal totals of $60 \%-80 \%$ of normal were recorded along the northern coastal areas of Algeria. Some eastern and southern Moroccan stations received less than half of their normal precipitation, with some recording zero precipitation. Spring precipitation was below normal, especially in 


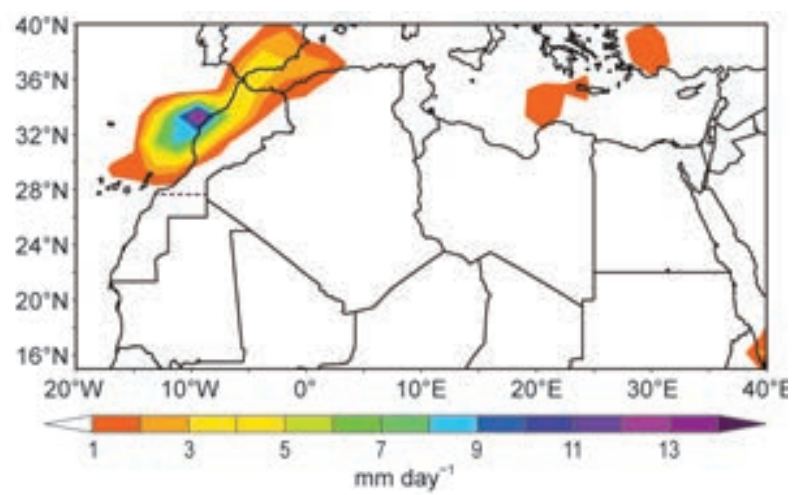

Fıg. 7.2I. Northern Africa 2017 rainfall rate anomalies (mm day ${ }^{-1}$; 198I-20I0 base period) over 2I-24 Feb. (Source: NOAA/NCEP.)

northern and east-central Algeria. In Algeria, Skikda received no precipitation, and Annaba received only $11 \%$ of its normal March rainfall. Alexandria received a record rainfall of $50 \mathrm{~mm}$ in 24 hours on 21 April, the highest 24-hour rainfall in Egypt during 2017.

Precipitation during summer (June-September) was generally below normal over the entire region; however, convective events in August produced monthly rainfall that was $192 \%$ of normal in Morocco. Al Hoceima observed $44.8 \mathrm{~mm}$, an order of magnitude greater than its normal $4 \mathrm{~mm}$. In Algeria, summer rainfall was highly variable, with deficits across the northern part of the country. Western coastal stations observed amounts on the order of $40 \%-85 \%$ of normal. Stations in the plains and inland basins of Algeria received just 10\%-40\% of normal, while Saïda (in the northwest) received $166 \%$ (66\% above normal) of normal precipitation. Farther south, at Saharan Atlas stations of Algeria, the seasonal totals varied, from $20 \%-60 \%$ of normal near El Bayadh and Mechria, to $125 \%-150 \%$ of normal at AinSefra and Naâma.

In contrast to summer, precipitation during autumn was $38 \%$ of normal in Morocco. However, precipitation for November was above normal over northern Tunisia, leading to flooding on 10-11 November at Gabès, killing 5 people and causing more than 117 evacuations.

\section{(iii) Notable events and impacts}

Flooding in both February and December 2017 caused loss of life and damage to property in Morocco. Cold spells, ranging from $0.3^{\circ}$ to $7.0^{\circ} \mathrm{C}$ below normal, were reported in January and December in Morocco. An all-time heavy rainfall of $119.2 \mathrm{~mm}$ was recorded on 23 February at Rabat, Morocco.

Extended heat waves occurred over the region during May and June with maximum temperatures exceeding $40^{\circ} \mathrm{C}$. These were associated with eastern continental winds and caused significant forest fires, especially in Morocco and Algeria. About 325 forest fires were reported in Morocco, causing the destruction of about 2056 hectares of forested land.

2) West Africa一S. Hagos, I. A. ljampy, F. Sima, S. D. Francis and $Z$. Feng

In this section, West Africa refers to the region between $17.5^{\circ} \mathrm{W}$ (eastern Atlantic coast) and $\sim 15^{\circ} \mathrm{E}$ (the western border of Chad), and from $5^{\circ} \mathrm{N}$ (near the Guinean coast) to $20^{\circ} \mathrm{N}$. It is typically divided into two climatically distinct subregions; the semiarid Sahel region (north of about $12^{\circ} \mathrm{N}$ ) and the relatively wet Coast of Guinea region to the south. The rainy period over the region is associated with the latitudinal movement of the convective zone referred to as the West African monsoon which typically occurs during June through September.

\section{(i) Temperature}

The annual mean temperature over western parts of West Africa was higher than average, with much of the region about $0.5^{\circ} \mathrm{C}$ above normal (Fig. 7.18). During September (Fig. 7.22), much warmer-thanaverage conditions $-\sim 0.5^{\circ} \mathrm{C}$ above normal-were reported with record-warm conditions over Ghana, Ivory Coast, Burkina Faso, and southern Nigeria. There was, however, significant regional variability. For example, daily temperatures $>40^{\circ} \mathrm{C}$ were recorded between January and June in parts of Nigeria, especially over its northern states. The highest daily temperatures of April, March, and May were $45.3^{\circ}$, $44.2^{\circ}$, and $44^{\circ} \mathrm{C}$, recorded at Maiduguri, Yelwa, and Nguru, respectively. Other cities, such as Sokoto

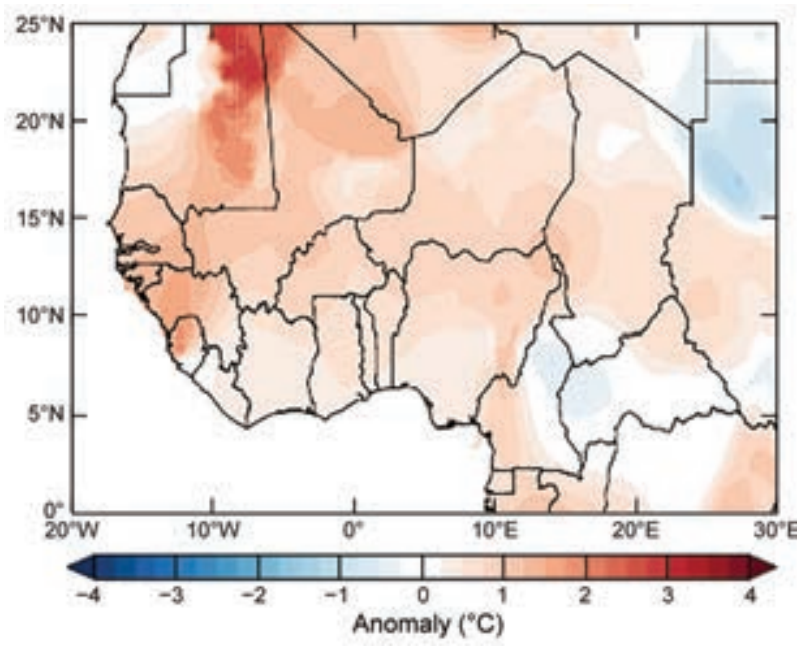

Fig. 7.22. Temperature anomalies $\left({ }^{\circ} \mathrm{C} ; 198 I-2010\right.$ base period) for West Africa for Sep 2017. (Source: NOAA/ NCEP.) 
and Yola, also recorded daily high temperatures of $43.0^{\circ}$ and $43.5^{\circ} \mathrm{C}$, respectively. The Gambia also experienced warmer-than-normal conditions during 2017. The annual mean maximum temperature over the country was $35.6^{\circ} \mathrm{C}$, about $4.5^{\circ} \mathrm{C}$ above normal. Daily maximum temperatures exceeded $40^{\circ} \mathrm{C}$ in some places, such as the $47.7^{\circ} \mathrm{C}$ recorded at Kaur, in the Central River region of The Gambia.

\section{(ii) Precipitation}

Rainfall totals for June to September (JJAS), during which the West African monsoon provides much of the annual precipitation, are presented in Fig. 7.23. During JJAS, the northern Sahel was wetter, and coastal regions were drier, than normal. This was consistent with above-normal SSTs over the northern tropical Atlantic early in the season. Earlyseason monsoon precipitation over the Sahel region, particularly northern Nigeria and southern Niger, was observed. Later in the season, the southern and central tropical Atlantic was warmer, and relatively
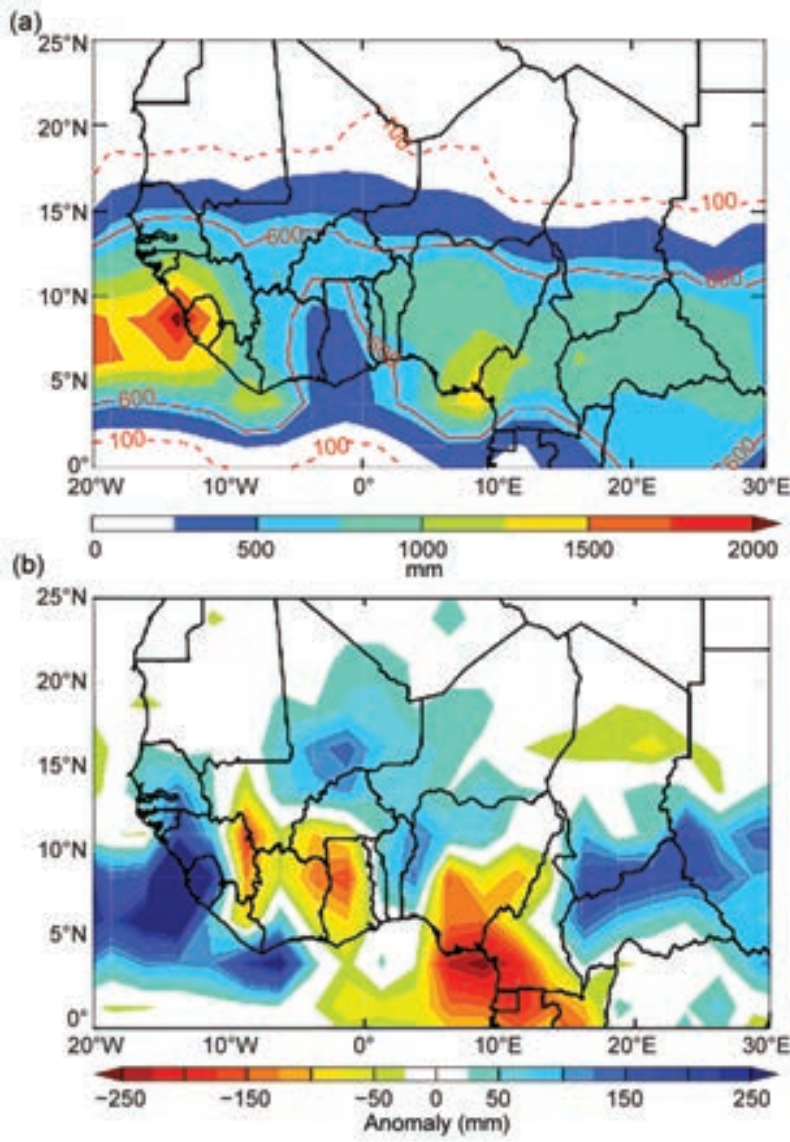

Fıg. 7.23. Jun-Sep 2017 precipitation $(\mathrm{mm})$ for West Africa: (a) total accumulation; $100-\mathrm{mm}$ isohets (red dashed line), $600-\mathrm{mm}$ isohyets (red solid line). (b) Departure from 198I-20I0 climatology. (Source: NOAA/NCEP.) drier conditions dominated much of the region, with significant regional variability. According to the Nigerian Meteorological Agency, most of the country recorded normal rainfall conditions, while the cities in central and northwestern Nigeria recorded belownormal rainfall. The Gambia experienced early onset and cessation of the rains, but overall seasonal rainfall was near normal. However, the timing of rainfall had an uneven distribution, with prolonged dry spells and flooding, leading to crop failure in some parts of the country. Most of the rain during the 2017 season was in July-September, with the highest amounts of $130.8 \mathrm{~mm}$ recorded in August at Jenoi in the lower river region of The Gambia.

\section{(iii) Notable events and impacts}

On 6 July, flooding and wind storms occurred at Jarra Bureng and Jasobo, in The Gambia's Lower River region, destroying hundreds of homes and farms, and affecting 20000 individuals; wells and latrines were also affected. The event lasted for 4 hours. The event affected 94 households and 857 people across 5 communities. On 12 July, a wind storm at Kerewan, North Bank region, caused one casualty and affected 222 households. A wind storm claimed two lives the same day in The Gambia's West Coast region.

In Nigeria, heavy rain during August and September caused the Niger and Benue Rivers to overflow, causing flooding in the Benue and Kogi States. In Benue State, it was reported that 100000 people were displaced by flooding, 12 local governments within the state were affected, and around 4000 homes damaged. No fatalities were reported. Flooding in Kogi State came just days after thousands of people were displaced by floods in Benue. The Kogi flood displaced over 10000 people. The worst affected area was the state capital, Lokoja, which lies at the confluence of the two rivers. Other affected areas included Ibaji, Igalamela-Odolu, Ajaokuta, Bassa, and Koton-Karfe. A bridge at Tatabu village along Mokwa-Jebba road, in the Kwara State, collapsed after a heavy rainfall. The road is the major link between the northern and southern parts of the country; motorists were advised to use alternative routes. The popular Ahmadu Bello way in Victoria Island, Lagos State, was temporarily closed on 7 September by the Lagos State Police Command due to flooding.

On 27 August, several hours of rainfall caused floods in Churchill Town, Bakoteh, and Ebou town in The Gambia's west coast region, and Tabanani and Sare Molo in its Central River region. Two lives were lost, more than a thousand homes were damaged, and about 4000 people were displaced. 
On 12 and 29 August, flooding at Kuntaur Niani, in the Central River region, caused significant internal displacements, damage to public and private properties, including a bridge, and submerging of farmlands. There were five fatalities and around 8000 people affected.

In Niger, heavy rain on 26 August caused flooding in the capital city of Niamey and surrounding areas; around $100 \mathrm{~mm}$ of rain fell in Niamey. The UN Office for the Coordination of Humanitarian Affairs (UNOCHA) reported that two people had died and four were injured. According to Niger's government, 219 houses were destroyed and over 1000 people were left homeless in Gabagoura and other villages around Niamey.

(a) DJF

3) Eastern AfricaG. Mengistu Tsidu

Eastern Africa, also known as the Greater Horn of Africa (GHA), is a region comprised of South Sudan, Sudan Republic, Ethiopia, Somalia, Eritrea, Kenya, Uganda, Rwanda, Burundi, and Tanzania. Despite its location across the equator, the region has a relatively cool climate due to its generally high altitude. Some parts of the region are also characterized by bimodal seasonal rainfalls. In general, the GHA experienced above-average temperatures in 2017.

\section{(i) Temperature}

The December 2016-February 2017 (DJF) mean temperature was below normal to normal over central Kenya, the Ethiopian highlands, eastern Ethiopia, much of northern Somalia, and the northwestern Sudan Republic (Fig. 7.24a). Abovenormal anomalies, up to $+3^{\circ} \mathrm{C}$, were observed over the rest of the GHA. During MAM, the GHA remained warmer than normal, except for the northern Ethiopian highlands, northwestern Sudan Republic, part of central Kenya, north-central and southwestern Tanzania which had normal to below-normal temperatures (Fig.

(c) JJA 7.24b). During June-August (JJA), above-normal temperatures covered large parts of GHA, extending to the Ethiopian highlands and northwestern Sudan Republic (Fig. 7.24c). However, South Sudan and western Ethiopia enjoyed near-normal temperatures during this season. During September-November (SON), cold anomalies of up to $-2^{\circ} \mathrm{C}$ prevailed over the northern half of Sudan Republic, southwestern Ethiopia, and adjoining South Sudan and northern Uganda, extending across western Kenya towards northern Tanzania (Fig. 7.24d). The rest of the GHA region experienced above-normal mean temperatures.

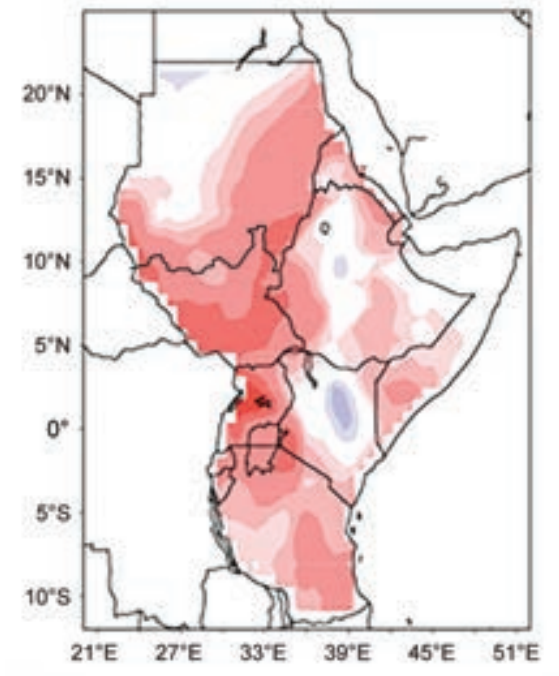

(b) MAM
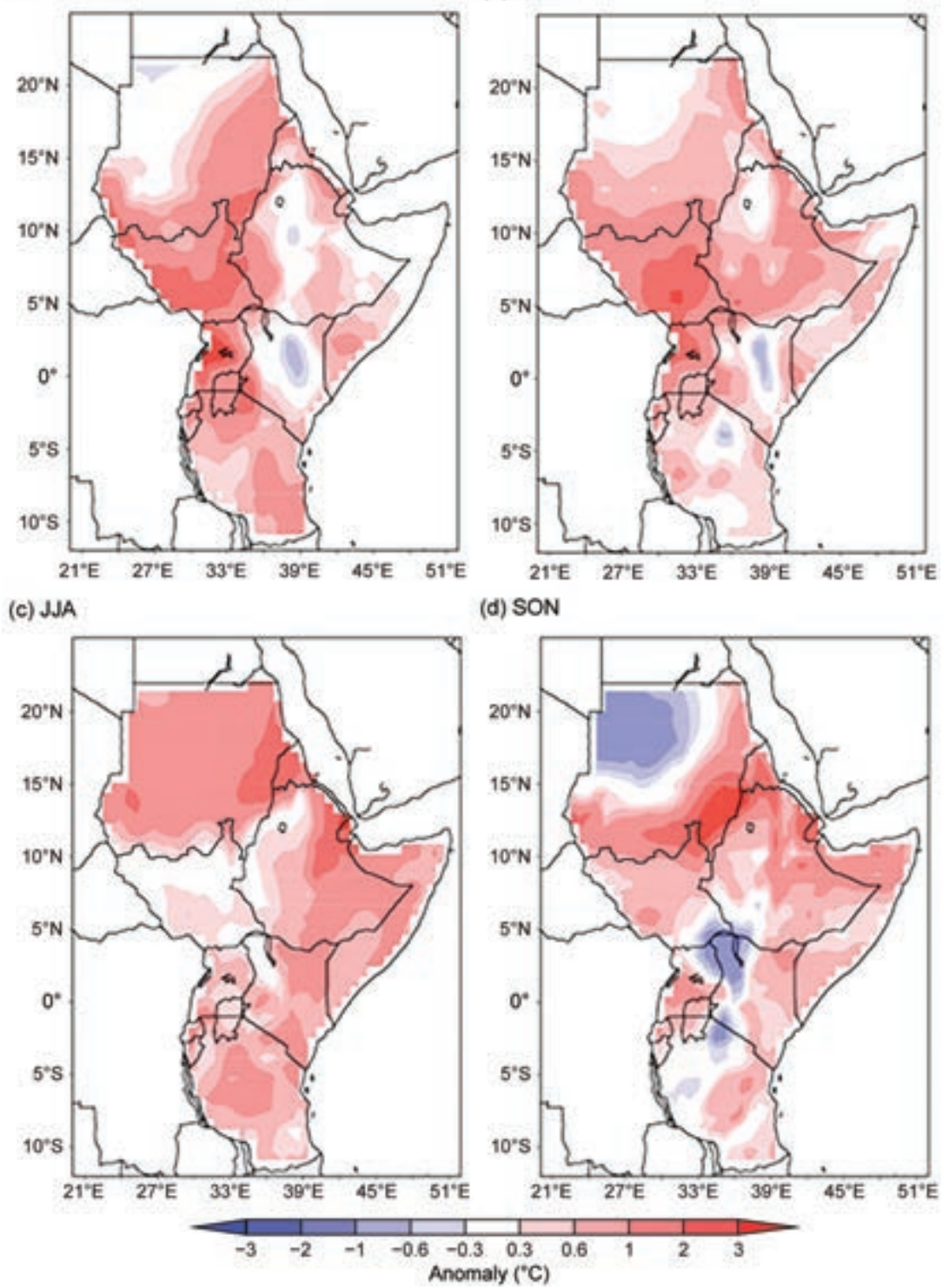

FIG. 7.24. Eastern Africa seasonally averaged mean temperature anomalies ( ${ }^{\circ} \mathrm{C}$; 198I-2010 base period) for (a) DJF 20I6/17 and (b) MAM, (c) JJA, and (d) SON 2017 (Source: ERA-Interim.) 


\section{(ii) Precipitation}

The northern half of Uganda, northwestern and northeastern Kenya, and adjacent western Somalia received normal to above-average rainfall, whereas southern Uganda, most of Kenya, Tanzania, Burundi, and Rwanda received $50 \%-90 \%$ of the base period mean during DJF (Fig. 7.25a). Some isolated pockets in Tanzania and Kenya received less than half of their normal DJF rainfall. Rainfall during MAM was below normal over southern Ethiopia and adjacent southern Somalia, all of Kenya, northern Uganda, and most of Tanzania (Fig. 7.25b). Southeastern Tanzania, in particular areas along the coast, received above-normal rainfall during MAM. Ethiopia, with the exception of
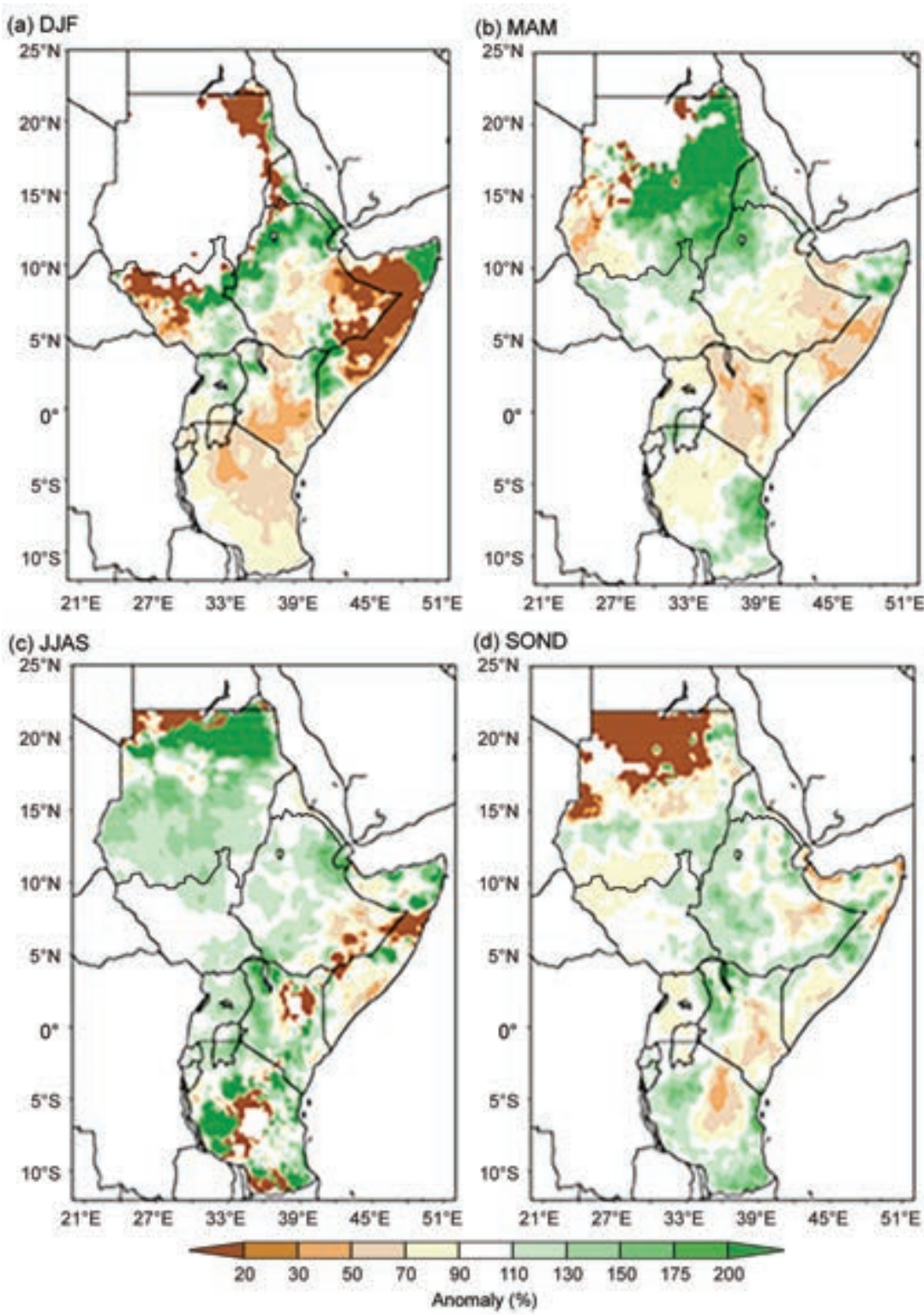

FIg. 7.25. Eastern Africa seasonal total rainfall anomalies (\% of normal; 198I-2010 base period) for (a) DJF 2016/17 and (b) MAM, (c) JJAS, and (d) SOND 2017 (Source: CHIRPS.) its southeastern lowlands, South Sudan, and southern Sudan Republic receive their main rainfall during JJAS. Normal to above-average rainfall, ranging from $110 \%$ to $200 \%$ of the seasonal mean, dominated the region in 2017, including unseasonal rain over the southern half of GHA (Fig. 7.25c). Dry conditions prevailed over most of Kenya, central Tanzania, and coastal Somalia during SOND, which is the climatological rainy season in this area (Fig. 7.25d).

\section{(iii) Notable events and impacts}

Heavy rainfall recorded in most parts of the region throughout the 2017 rainy seasons caused flooding. For example, eastern Kenya and Tanzania had steady torrential rain in May. As a result, Mombasa recorded $235 \mathrm{~mm}$ on 9 May, which led to flash flooding. According to news outlets, at least nine people perished. There were also heavy rains in mid-May, with a number of stations in western and central Ethiopia recording $49 \mathrm{~mm}$ and above (e.g., Gore: $59.9 \mathrm{~mm}$; Jimma: $53 \mathrm{~mm}$; Addis Ababa Bole: $49 \mathrm{~mm}$ ). The subsequent flooding led to a death in the Gambella region of Ethiopia on 18 May. JJAS rainfall was also notably heavy over Sudan and Ethiopia. Resulting floods affected more than 53000 people in the Gambella and Oromia regions during August and September, according to a UNICEF humanitarian report.

4) Southern AfricaG. Mengistu Tsidu, A. C. Kruger, and C. McBride

Southern Africa comprises the Republic of South Africa, Angola, Botswana, Zimbabwe, Namibia, Malawi, Zambia, Lesotho, Swaziland, and Mozambique. The rainfall assessment is based on rainfall from CHIRPS, and in situ observations from South Africa.

\section{(i) Temperature}

Above-normal temperatures prevailed across Angola, northeastern Zimbabwe, western Namibia, western South Africa, 
(a) DJF

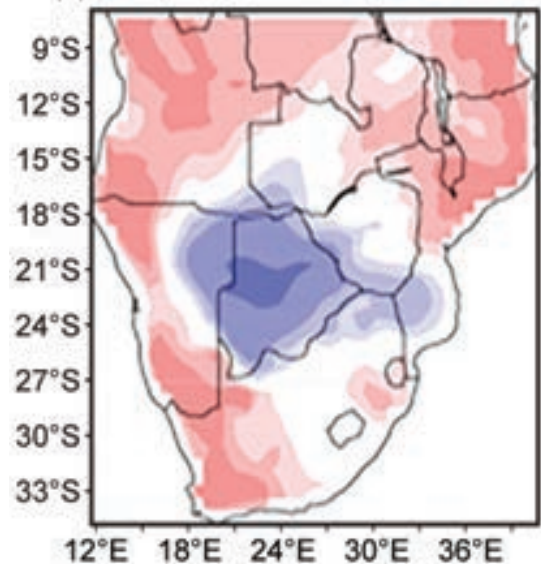

(c) JJA

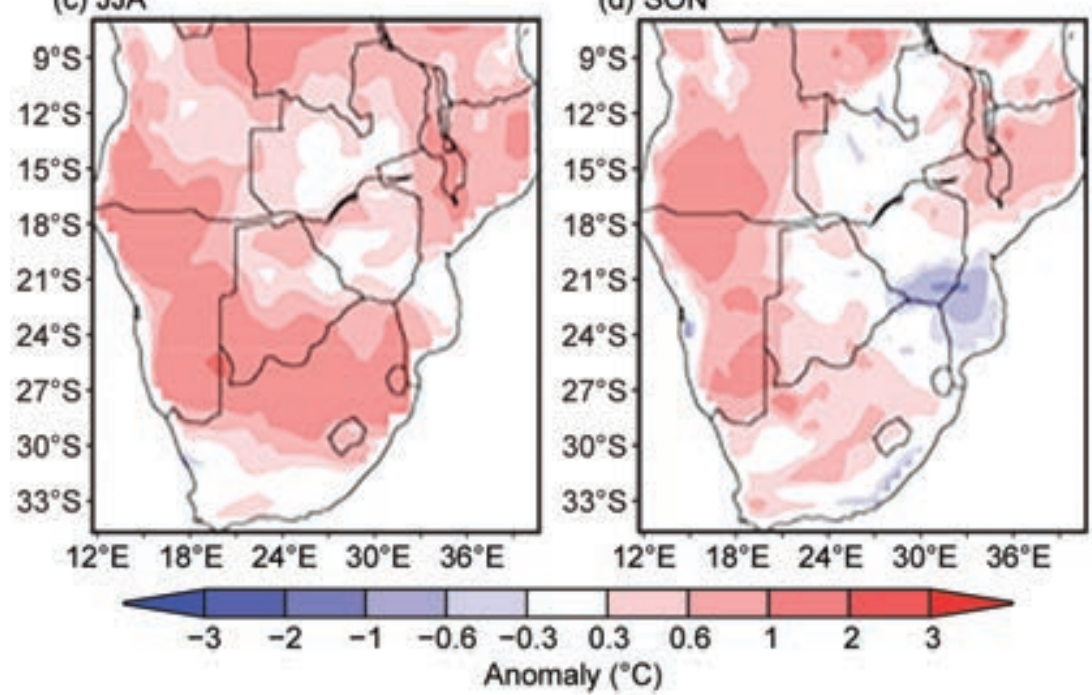

Fig. 7.26. Southern Africa seasonally averaged mean temperature anomalies ( ${ }^{\circ} \mathrm{C}$; 198I-2010 base period) for (a) DJF 2016/17, (b) MAM, (c) JJA, and (d) SON 2017 (Source: ERA-Interim.)

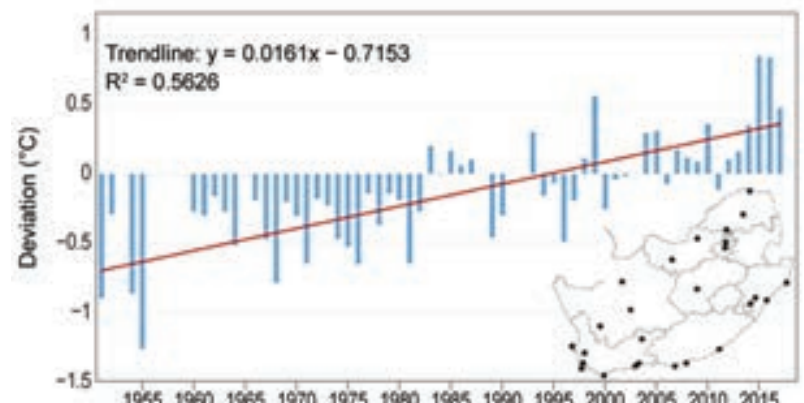

Fig. 7.27. Annual mean temperature anomalies $\left({ }^{\circ} \mathrm{C}\right.$; 198 I-2010 base period) of 26 climate stations in South Africa, as indicated on inset map, for 195I-2017. Red line represents the linear trend. (Source: South African Weather Service.)

and Mozambique from December 2016 to February 2017. In contrast, northeastern Namibia, all of Botswana, Southern Zimbabwe, Zambia, southern
Mozambique, and northeastern South Africa remained lower than normal (Fig. 7.26a). Normal to below-normal mean temperatures expanded to include much of Zimbabwe in MAM (Fig. 7.26b). During JJA, warm conditions dominated across the region, with the exceptions of isolated pockets in Botswana, Zimbabwe, Zambia, Mozambique, and southern strips of South Africa, where normal mean temperature conditions were observed (Fig. 7.26c). However, during SON, southern Mozambique and adjoining areas in Zambia experienced temperature anomalies exceeding $-1{ }^{\circ} \mathrm{C}$, with normal mean temperature prevailing over most of Zimbabwe, Zambia, northern Botswana, northeastern South Africa, and Swaziland. The rest of the region remained moderately warmer than normal (Fig. 7.26d). For the year as a whole, warmer-than-normal conditions throughout 2017 prevailed across the southern part of the region (spatial representation not shown), as evident from the annual mean temperature anomalies of 26 climate stations in South Africa, which averaged $0.48^{\circ} \mathrm{C}$ above average (Fig. 7.27).

\section{(ii) Precipitation}

Above-normal rainfall, exceeding $150 \%$ of average, was observed over Botswana and adjoining eastern Namibia, eastern Angola, Zimbabwe, Zambia, western Mozambique, and most of South Africa from December 2016 to February 2017. However, most of Angola, western Namibia, western South Africa, and eastern Mozambique experienced below-normal rainfall (Fig. 7.28a). Wet conditions persisted through MAM only over central parts of the region, namely northern Botswana, northern Namibia, Zambia, Mozambique, and southern Zimbabwe. Below-normal conditions-as low as $20 \%$ of normal-prevailed over the rest of the region (Fig. 7.28b). The JJA period is typically dry over the region. Compared to this 
(a) DJF

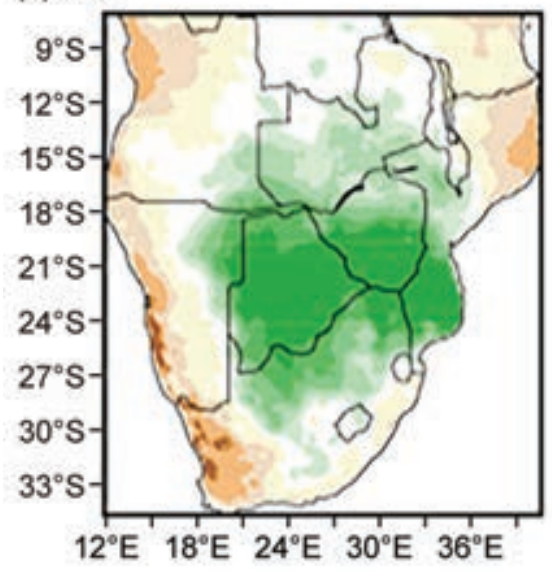

(c) JJA

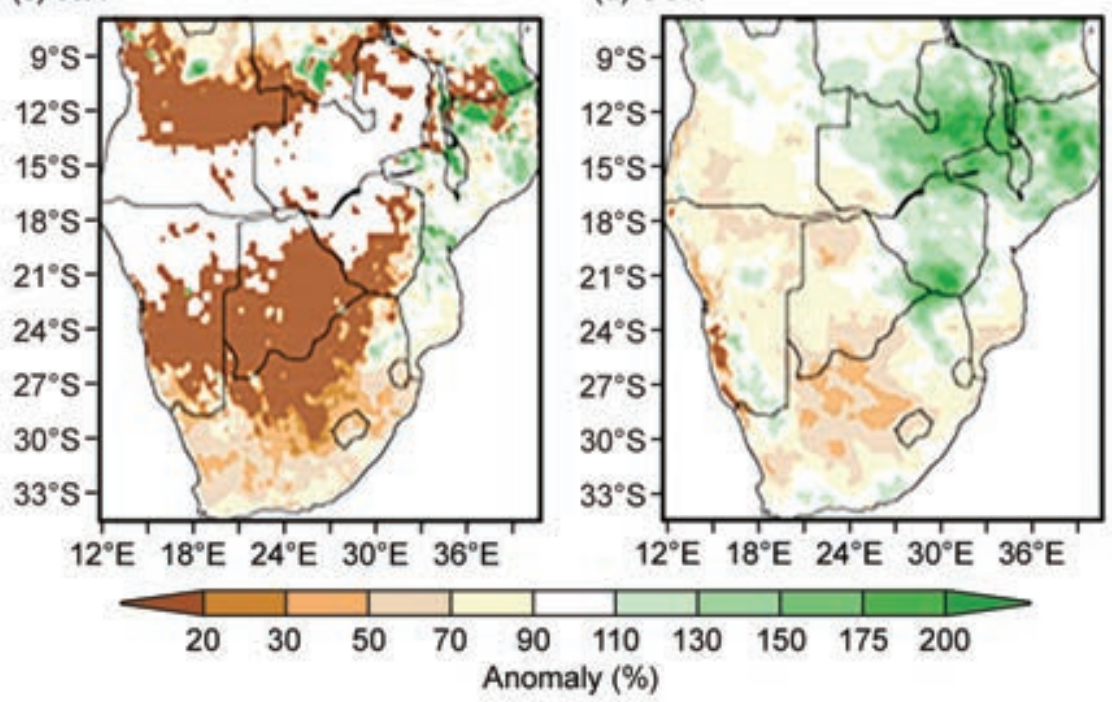

Fig. 7.28. Southern Africa seasonal total rainfall anomalies (\% of normal; 198I-2010 base period) for (a) DJF 2016/17 and (b) MAM, (c) JAS, and (d) SON 2017 (Source: CHIRPS.)

baseline, most of Mozambique received above-normal rainfall (Fig. 7.28c), whereas the rest of the region remained drier than normal. The wet conditions in Mozambique in JJA expanded to Zimbabwe, Zambia, and isolated areas in the northeastern part of South Africa by SON (Fig. 7.28d).

Analysis of annual total gauge rainfall over South Africa confirms that large parts of the country received near-normal rainfall. The most notable exception was the region including the largest part of the Western Cape and the western parts of the Northern Cape, which received less than $75 \%$ of its normal annual precipitation (figure not shown). The western Northern Cape was especially dry with station averages indicating less than half of normal rainfall, in agreement with the analysis of seasonal rainfall from CHIRPS. 2017 was the driest year over the last three-year period in the southwestern Cape fected the region. since at least 1951. A Standardized Precipitation Index (SPI) analysis of South Africa (not shown) indicates that almost the whole Western Cape Province, including the adjacent areas of the northern and eastern Cape Provinces, experienced what can be described as moderate to extreme drought conditions over an extended period of time, (i.e., longer than two years). In addition, an analysis of Cape Town in particular shows that the only other comparable dry period was around 1973/74, with a probability of occurrence lower than 3\%.

(iii) Notable events and impacts

Tropical cyclones impacted the region during early February. Cyclone Carlos was active from 3-10 February. On 13 February, Cyclone Dineo formed in the Mozambique Channel and made landfall in southern Mozambique on 15 February. The cyclone subsequently tracked westwards, leaving significant flood-related damage in southern Mozambique and southern Zimbabwe. The impact of Dineo was also felt as far west as Bo-

tswana, where daily rainfall of $70 \mathrm{~mm}$ was observed at Kgomokitswa on 19 February and $136 \mathrm{~mm}$ at Lobatse on 20 February. These amounts accounted for $70 \%$ and $66 \%$, respectively, of the total February rainfall at each station. As a result, the Gaborone dam filled up due to the intense rains, marking an abrupt end to the multiyear hydrological droughts that have af-

Other notable but localized events during early summer includes stormy weather over South Africa. In October, a cut-off low system moving southeastward from northwestern South Africa triggered large thunderstorms, especially over western Gauteng province, with several tornado sightings. A subsequent statement by the South African Weather Service reported that severe thunderstorms with heavy downpours, strong damaging winds, and large hail hit parts of eastern North-West, Gauteng, eastern Free 
State, KwaZulu-Natal, Mpumalanga, and Limpopo provinces on 9 and 10 October. Areas that were most affected were Mogale City, the city of Johannesburg, and Ekurhuleni Metropolitan municipalities. There were two sightings of tornadoes in Ruimsig (adjacent to Roodepoort and Krugersdorp) and Eloff, near Delmas (Mpumalanga), which caused extensive damage to property. Elsewhere in the Free State, a tornado was observed near Bethulie. Golf ball- to tennis ballsized hail was also reported near Krugersdorp. The system moved rapidly east, affecting KwaZulu-Natal from 10 October, with severe urban flooding and high winds resulting in loss of life. In 24 hours, Durban recorded $108 \mathrm{~mm}$ of rain, where $65 \mathrm{~mm}$ fell in less than an hour. Similarly, Virginia in KwaZulu-Natal received $142 \mathrm{~mm}$ of rain, where $89 \mathrm{~mm}$ occurred within an hour. Maximum sustained wind speeds of 75 and $78 \mathrm{~km} \mathrm{~h}^{-1}$ were reported in Durban and King Shaka airport to the north, respectively.

5) Western Indian Ocean Island countriesG. Jumaux, C. L. Rakotoarimalala, M. Belmont, and K. R. Dhurmea

This region consists of several island countries: Madagascar, Seychelles, Mayotte (France), La Réunion (France), Mauritius, and Rodrigues (Mauritius).

Overall, the 2017 mean temperature for the region was well above normal, while precipitation was mixed across the region. It was the warmest year on record in the Mascarenes archipelago (Réunion, Mauritius, Rodrigues) because of strong SST anomalies in this

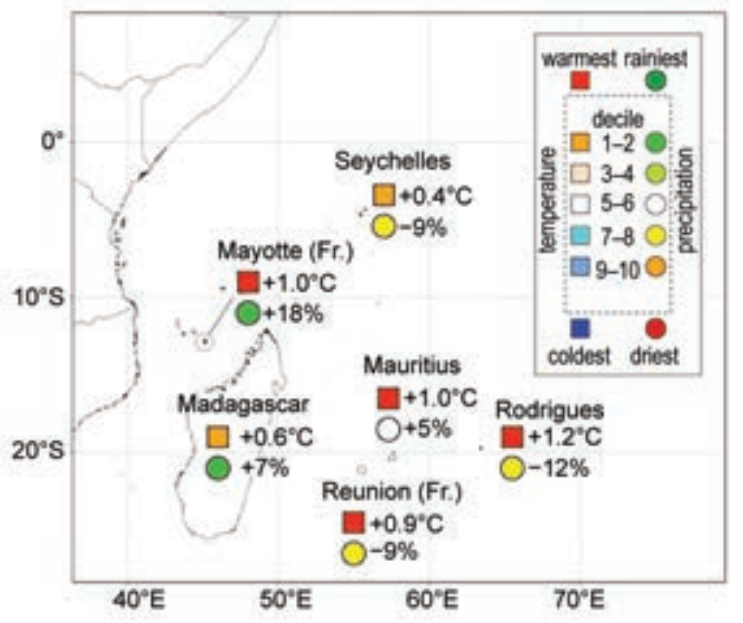

Fig. 7.29. Mean annual temperature anomalies $\left({ }^{\circ} \mathrm{C}\right.$; squares), annual rainfall anomalies (\% of average; circles), and their respective deciles for the western Indian Ocean islands countries in 2017. (Sources: Météo France; and Meteorological Services of Madagascar, Seychelles, and Mauritius.) region. Figure 7.29 shows temperature and rainfall anomalies for selected areas.

\section{(i) Temperature}

In Madagascar, the annual mean temperature, based on fifteen stations, in 2017 was $24.1^{\circ} \mathrm{C}$; the annual anomaly was $+0.6^{\circ} \mathrm{C}$. It was the fifth warmest year on record since 1978 . June recorded the highest monthly anomaly, around $+1.4^{\circ} \mathrm{C}$. The highest maximum temperature was observed in Antsohihy on 10 October $\left(37.7^{\circ} \mathrm{C}\right)$, and the lowest minimum temperature $\left(2.0^{\circ} \mathrm{C}\right)$ was recorded three times in Antsirabe: on 13, 15, and 19 July.

At Seychelles International Airport, monthly mean maximum temperatures were slightly below normal during the first four months of 2017. Abovenormal temperatures prevailed from June through November. The annual mean maximum temperature was $30.3^{\circ} \mathrm{C}$ and ranks as the seventh highest since records began in 1972. (The warmest year on record is 2009 with an annual mean of $30.6^{\circ} \mathrm{C}$.) The 2017 extreme daily maximum temperature was $33.7^{\circ} \mathrm{C}$ on 22 April. Monthly mean daily minimum temperature departures from the long-term means varied from $+0.3^{\circ}$ to $+1.2^{\circ} \mathrm{C}$. The extreme daily minimum temperature for 2017 was $21.6^{\circ} \mathrm{C}$, recorded on 6 July. Finally, the annual mean temperature was $+0.4^{\circ} \mathrm{C}$ above normal, ranking as the fourth highest since 1972. The highest monthly temperature deviation occurred during October $\left(+1.2^{\circ} \mathrm{C}\right)$.

For Mayotte Island, 2017 was the warmest year since records began in 1961, with an annual mean temperature anomaly of $+1.0^{\circ} \mathrm{C}$ at Pamandzi Airport. Temperatures during January and February were slightly above normal. From March to December temperatures were well above the reference base period, often more than $+1.2^{\circ} \mathrm{C}$ from June to November.

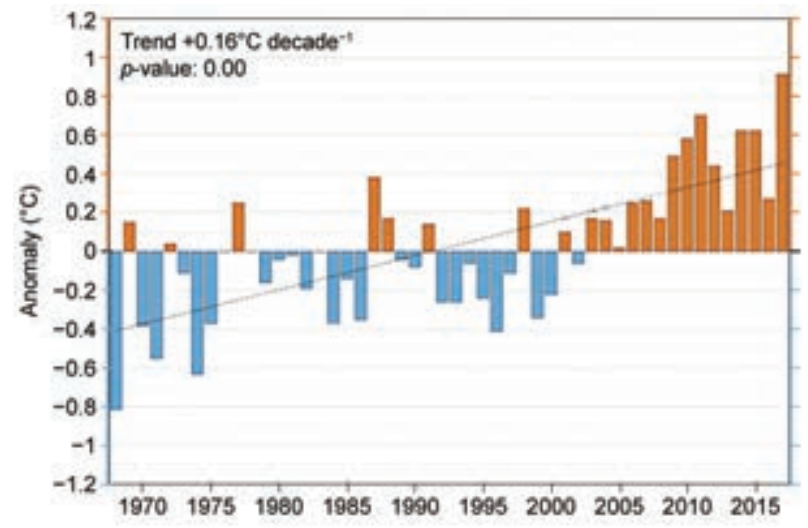

Fig. 7.30. Annual mean temperature anomalies $\left({ }^{\circ} \mathrm{C}\right.$; 198 I-2010 base period) for Réunion Island, I968-20I7. (Source: Météo-France.) 
For Réunion Island, the annual mean temperature, based on three stations, was $+0.9^{\circ} \mathrm{C}$ above normal in 2017, ranking as the highest since 1968, far exceeding the previous record of $+0.7^{\circ} \mathrm{C}$ in 2011 (Fig. 7.30). Temperatures during January and February, the warmest months of the year climatologically, were slightly above normal. From March to December they were well above the reference base period, often by more than $+1.0^{\circ} \mathrm{C}$.

Over the island of Mauritius, the annual mean maximum temperature anomaly based on two stations was $+0.6^{\circ} \mathrm{C}$, and the annual mean minimum temperature anomaly was $+1.5^{\circ} \mathrm{C}$, indicating a greater departure during nighttime. July and August were among the warmest on record since 1951. The annual mean temperature anomaly over the island was $+1.0^{\circ} \mathrm{C}$. This makes 2017 the warmest on record since 1951. Similar observations were made at Rodrigues (Pointe Canon) with an annual mean temperature anomaly of $+1.2^{\circ} \mathrm{C}$.

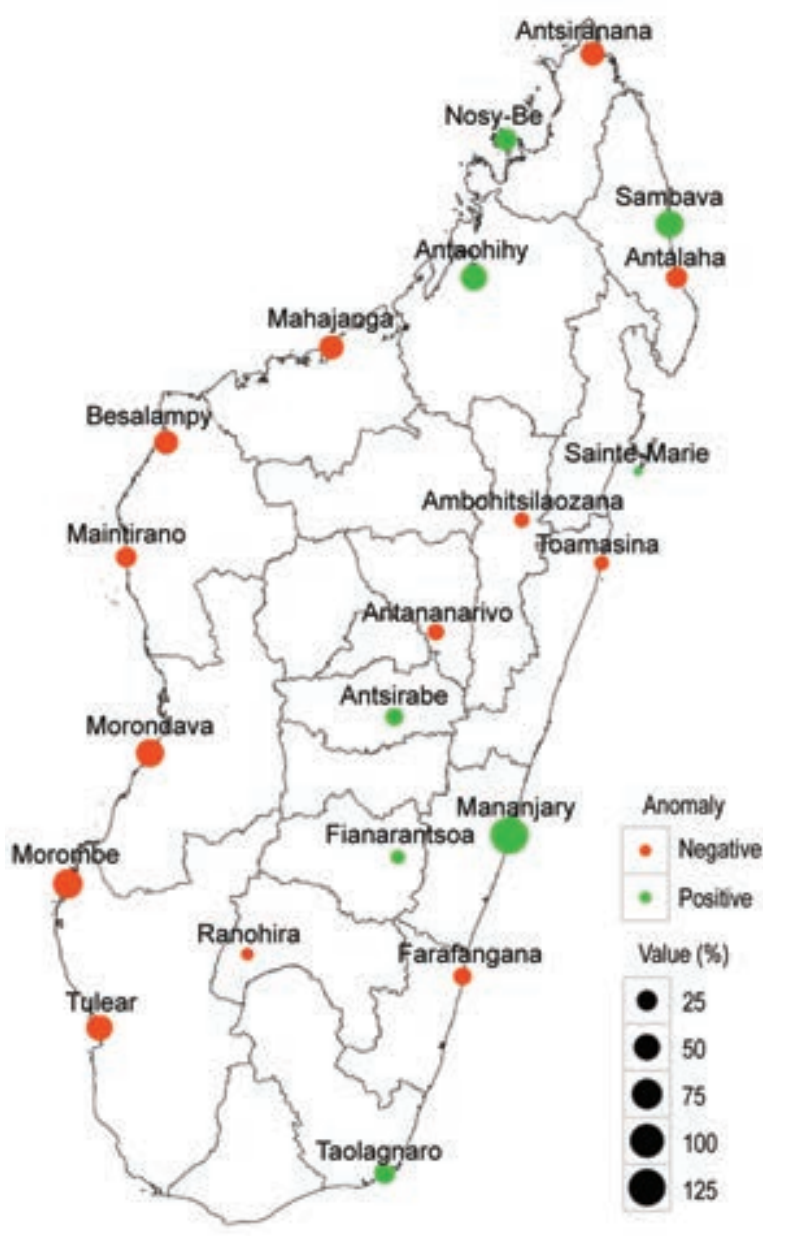

Fig. 7.3I. Annual total precipitation anomalies (\% of average; 198I-2010 base period) for Madagascar in 2017. (Source: Madagascar Meteorological Services.)

\section{(ii) Precipitation}

For Madagascar, annual precipitation, based on 21 stations, was $107 \%$ of normal in 2017 . It was the sixth wettest year on record since 1978. Nine months were above normal, with November the relative wettest at $175 \%$ of normal for the month. More stations in western Madagascar were below normal than in the eastern part (Fig. 7.31). The highest percent of normal (233\%) was recorded at Mananjary and the lowest at Morombe (30\%). The highest accumulated precipitation within a 24-hr period in 2017 was $215.4 \mathrm{~mm}$ recorded in Sambava on 7 March, the eighth wettest day there since 1961.

For Seychelles, five months recorded higher-thannormal rainfall during 2017. The second half of the year was dominated by persistent negative anomalies that impacted the amount of rain received at the beginning of the rainy season. The outer islands were worst affected during that period. (The rainy season usually starts mid-October and ends midApril.) The total rainfall amount recorded for the year is $2146.2 \mathrm{~mm}$, which is $91 \%$ of the long-term mean, ranking as 18th driest since records began in 1972. The total number of rain days was 195 , which is slightly below normal.

For Mayotte Island, the annual rainfall amount based on two stations was $118 \%$ of average, ranking eighth wettest since 1961. January, May, and October were drier than normal, whereas February, April, and December were among the rainiest on record.

For Réunion Island, the annual rainfall based on 34 stations was $91 \%$ of the long-term mean, ranking 18th driest since 1969. January was the second driest on record, associated with a late rainy season onset in early February. Total precipitation during the rainy season (January-April) was only $76 \%$ of average, ranking ninth driest. During May to November, typically the driest months of the year, the rainfall amount was $133 \%$ of average, ranking fifth rainiest. At Plaine des Fougères, $215 \mathrm{~mm}$ of rain fell fell in three hours on 29 August, which is very unusual during this season.

The year started very dry both at Mauritius and Rodrigues (Fig. 7.32). Dry conditions persisted over Rodrigues until March. May, usually a dry transition month, was very wet on both islands; it was the seventh wettest on record for both Mauritius and Rodrigues. Heavy rainfall and widespread flooding affected both islands. Winter months (May-October) yielded a positive rainfall anomaly over Mauritius. December 2017 was the second driest in Mauritius since 2010 and second driest in Rodrigues (Pointe Canon) since 2003. The total annual rainfall over Mauritius amounted to 


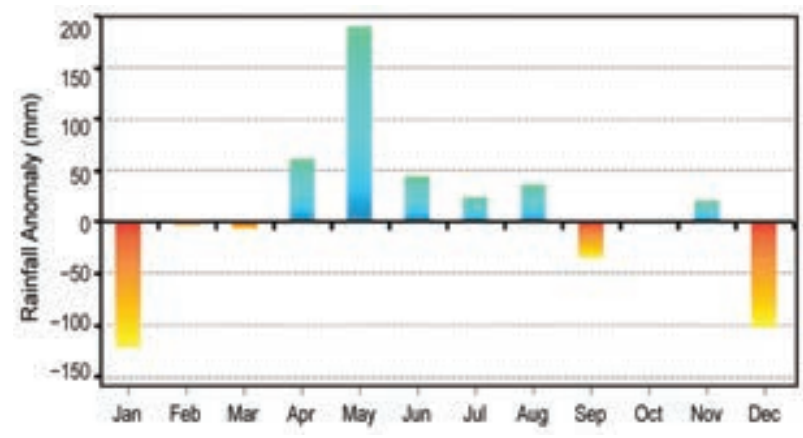

FIG. 7.32. Mean monthly total precipitation anomalies (mm; 198I-2010 base period) over Mauritius in 2017 (Source: Mauritius Meteorological Services.)

$2110 \mathrm{~mm}$ (105\% of average). The total annual rainfall amounted to $968 \mathrm{~mm}$ at Rodrigues (88\% of average).

\section{(iii) Notable events and impacts}

Tropical cyclone Carlos passed $130 \mathrm{~km}$ off the western coast of Réunion Island on 7 February. A maximum wind gust of $37 \mathrm{~m} \mathrm{~s}^{-1}$ was recorded at Bellecombe, and $934 \mathrm{~mm}$ of rain was recorded at Grand-Ilet within a 72-hr period. The agricultural sector sustained losses up to 4.9 million U.S. dollars.

In Madagascar, March 2017 was marked by Cyclone Enawo which formed in the Indian Ocean. It tracked across the island from 7 to 9 March, producing three-day precipitation totals of $224 \mathrm{~mm}$ at Sambava, $210 \mathrm{~mm}$ at Antsohihy, $184 \mathrm{~mm}$ at Antananarivo, $159 \mathrm{~mm}$ at Fianarantsoa, $291 \mathrm{~mm}$ at Mananjary, and $178 \mathrm{~mm}$ at Taolagnaro which were, respectively, $82 \%, 86 \%, 112 \%, 113 \%, 81 \%$, and $101 \%$ of the normal monthly precipitation for March at each location. Enawo led to 81 fatalities, injured 250 people, and caused significant flooding. Eastern Madagascar was the most affected.

f. Europe and the Middle East-P. Bissolli, M. Demircan, J. J. Kennedy, M. Lakatos, M. McCarthy, C. Morice, S. Pastor Saavedra, M. R. Pons, C. Rodriguez Camino, B. Rösner, S. Sensoy, S. Spillane, K. Trachte, and G. van der Schrier

For this section, 1961-90 is used as the base period for temperature, and 1981-2010 is used as the base period for precipitation, as described in Figs. 7.33-7.37, unless otherwise specified. European countries conform to different standards applied by their individual national weather services, and their specific base periods are noted throughout the subsections as needed. All seasons mentioned in this section refer to the Northern Hemisphere. More detailed information can be found in the Monthly and Annual Bulletin on the Climate in RA VI - European and the Middle East, provided by WMO RA VI Regional
Climate Centre on Climate Monitoring (RCC-CM; www.dwd.de/rcc-cm). Anomaly information has been taken from Figs. 7.34-7.37 when national reports are not available.

\section{I) OVERVIEW}

Based on the CRUTEM4 dataset (Jones et al. 2012) dating to 1851 , Europe $\left(35^{\circ}-75^{\circ} \mathrm{N}, 10^{\circ} \mathrm{W}-30^{\circ} \mathrm{E}\right)$ observed its fifth warmest year on record with an anomaly of $+1.3^{\circ} \mathrm{C}$; its five warmest years have all occurred since 2011 (Fig. 7.33). NOAA data (not shown) also ranks Europe as fifth warmest for 2017.

Local temperature anomalies varied mostly between $+1^{\circ}$ and $+2^{\circ} \mathrm{C}$ and were homogeneously distributed across Europe, with local areas in the Ukraine and central Spain above $+2^{\circ} \mathrm{C}$ (Fig. 7.34).

While large parts of Europe had near-normal precipitation for the year on average, some regions like northeastern Germany, northern Poland, and western Russia recorded above-normal precipitation totals up to $167 \%$. This contrasted with $60 \%-80 \%$ of normal precipitation on the Iberian Peninsula, in southern France, and Italy. Especially noteworthy is the Middle East, with $20 \%-60 \%$ of normal precipitation (Fig. 7.35).

Winter 2016/17 was exceptionally mild over Scandinavia with temperature anomalies reaching more than $+4^{\circ} \mathrm{C}$, whereas the southern Balkan states, Greece, and Turkey recorded widespread below-average temperature anomalies down to $-2^{\circ} \mathrm{C}$ (Fig. 7.36a). The 500-hPa heights featured above-average heights which allows for an anomalous southwesterly flow of mild marine air masses into northern Europe (dotted in Fig. 7.36a). In particular, January was a cold month over much of central and southeastern Europe. With respect to precipitation, winter in Europe was dry

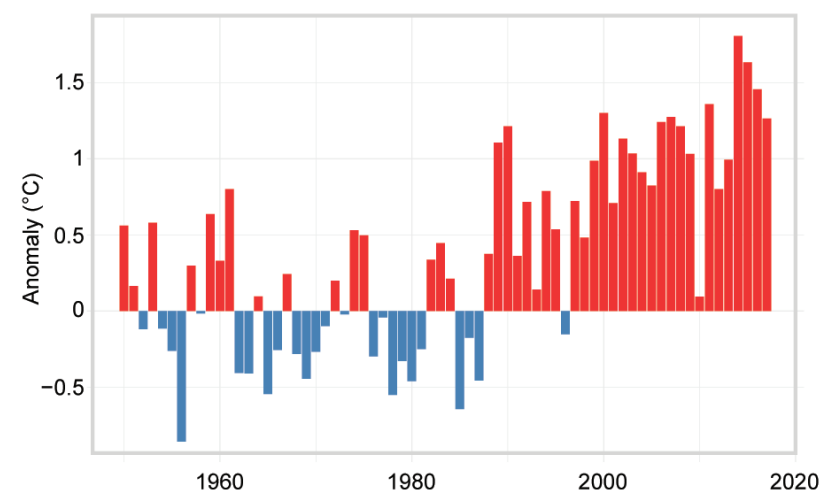

FIG. 7.33. Annual average land surface air temperature anomaly for Europe $\left(35^{\circ} \mathrm{N}-75^{\circ} \mathrm{N}, 10^{\circ} \mathrm{W}-30^{\circ} \mathrm{E}\right)$ relative to the 196I-90 base period. [Source: CRUTEM4 dataset (Jones et al. 20I2.)] 


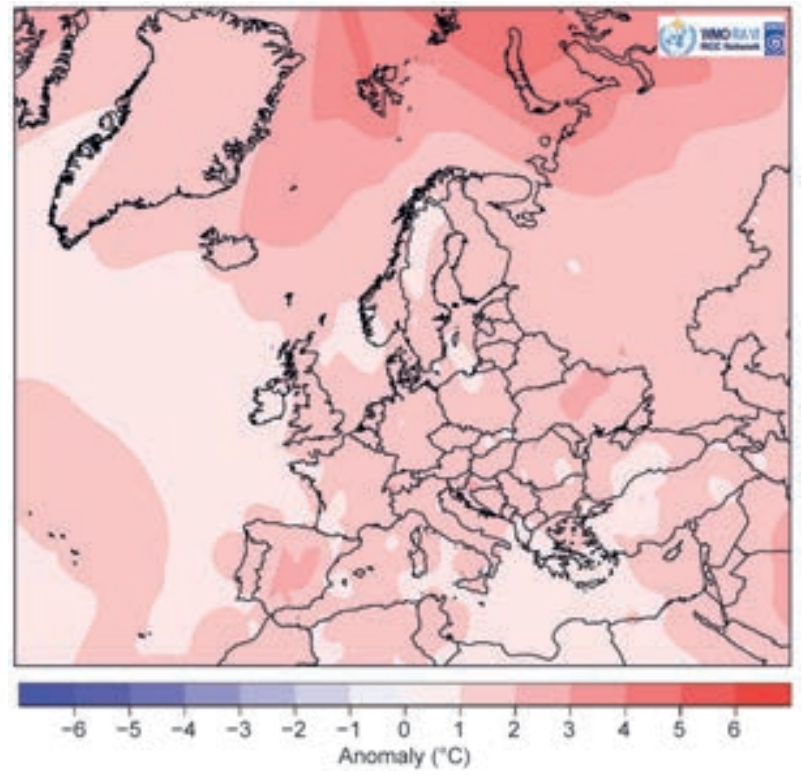

FIG. 7.34. Annual mean air temperature anomalies $\left({ }^{\circ} \mathrm{C}\right.$, 1961-90 base period) in 2017. (Source: DWD.)

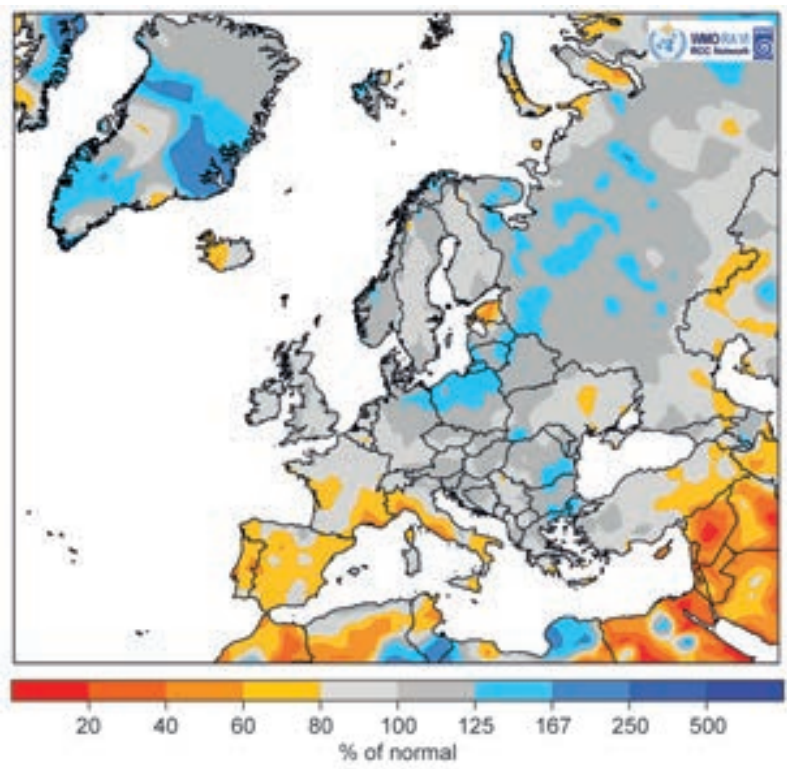

FIG. 7.35. European precipitation totals (\% of $1981-2010$ average) for 2017 . (Source: DWD.) (a) D.JF

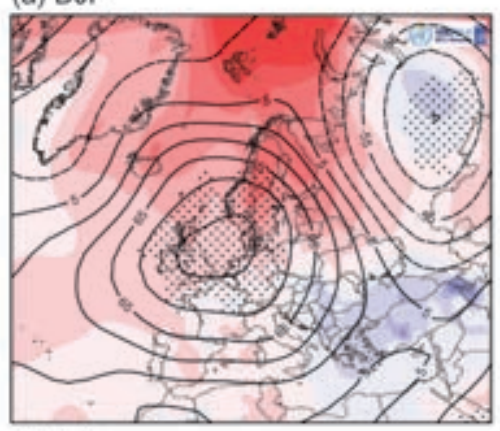

(c) JJA
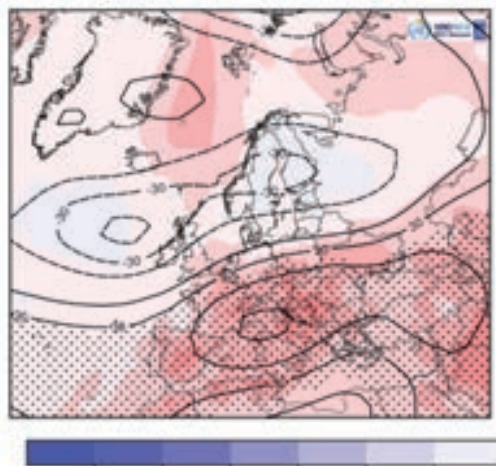

- (b) MAM

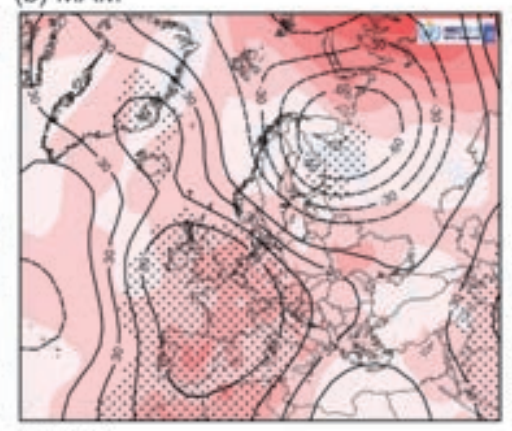

(d) SON

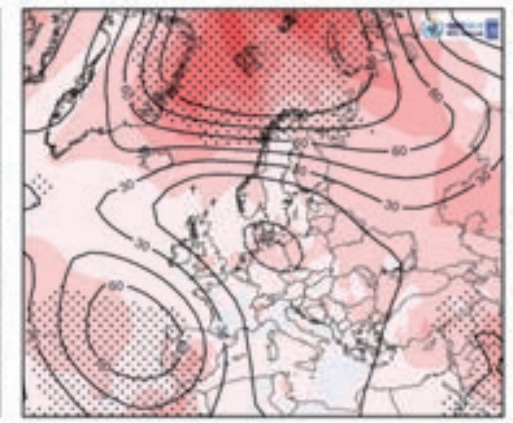

Anomaly $\left({ }^{\circ} \mathrm{C}\right)$

FIG. 7.36. Seasonal anomalies (196I-90 base period) of 500-hPa geopotential height (contour, gpm) and air temperature (shading, $\left.{ }^{\circ} \mathrm{C}\right)$ using data from the NCEP/NCAR reanalysis and DWD, respectively, for (a) DJF 2016/17, (b) MAM 2017, (c) JJA 2017, and (d) SON 2017. Dotted areas indicate regions where $500-\mathrm{hPa}$ geopotential is higher (lower) than the 95th percentile (5th percentile) of the 1961-90 distribution, while hatched areas represent the corresponding thresholds but for air temperature.

with values ranging mostly from $40 \%$ to $60 \%$ of normal, except for the Norwegian coast, which was wet with some locations exceeding $167 \%$ of normal (Fig. 7.37a). This was a consequence of both the strong Icelandic low and Azores high $(\mathrm{NAO}+1.22)$, favoring westerly flows inducing a mild and wet winter in northern Europe and dry winter conditions over the more southern parts.

In spring, along with above-average $500-\mathrm{hPa}$ heights situated over central Europe (dotted in Fig. 7.36b), abovenormal temperatures were measured all over Europe, up to $+4^{\circ} \mathrm{C}$ in Spain. However, an unusually warm March was followed by a cold late April, and severe late frosts led to agricultural losses across many European countries. April and May temperatures were well below normal in northwest Russia and northern Scandinavia, contributing to the highest May snow cover extent in this area since 1985. While eastern Europe, except for central Ukraine, showed normal to slightly above-normal spring precipitation totals, most of the Iberian Peninsula, Italy, and the Benelux countries continued to be drier than normal. 
(a) DJF

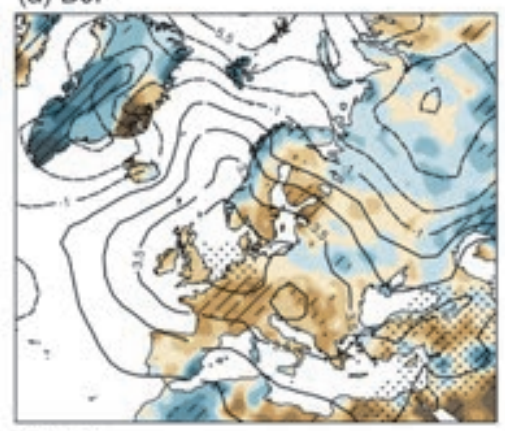

(c) JJA
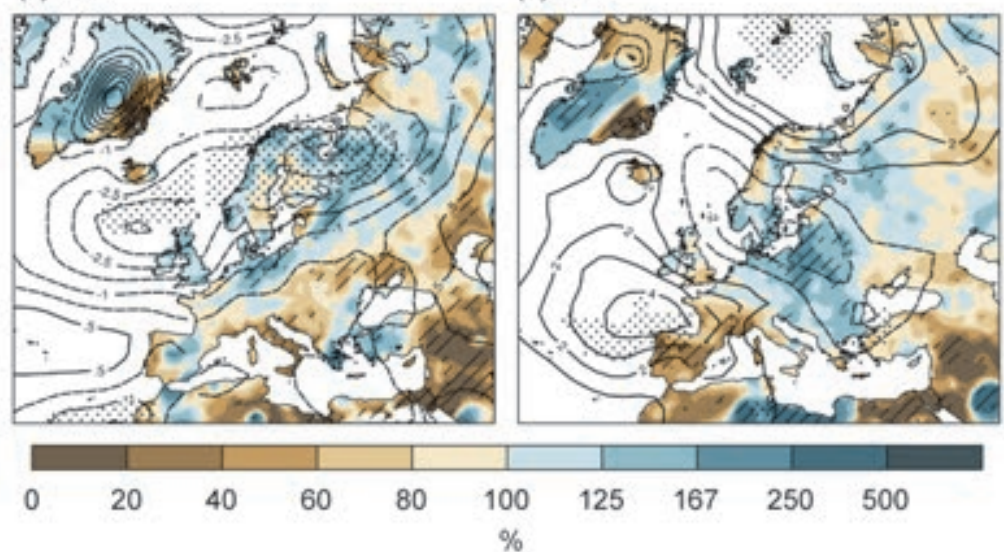

FIG. 7.37. Seasonal anomalies for 2017 (198I-2010 base period) of sea level pressure (hPa) from NCAR/NCEP reanalysis (contours) for (a) DJF 2016/17, (b) MAM 2017, (c) JJA 2017, and (d) SON 2017. Colored shading represents the percentage of seasonal mean precipitation for 2017 compared with the 198I-2010 mean from the monthly Global Precipitation Climatology Centre (Schneider et al. 2015) dataset. Dotted areas indicate regions where SLP is larger (lower) than the 95th percentile (5th percentile) of the 198I-2010 distribution, while hatched areas represent the corresponding thresholds but for precipitation. quent cyclonic situations, autumn was characterized by some severe storms accompanied by extreme wind velocities and heavy precipitation leading to widespread severe damage to infrastructure and floods in northeastern Germany, Poland, Slovakia, and the Czech Republic. Therefore, eastern Europe received precipitation up to $250 \%$ of normal, while on the Iberian Peninsula precipitation totals were mostly well below $60 \%$ of the normal.

With temperature anomalies reaching $+4^{\circ} \mathrm{C}$ or more and abovenormal precipitation of at least $125 \%$, the year ended very mild and wet for northeastern Europe, while temperature anomalies of around $-1^{\circ} \mathrm{C}$ and below-normal precipitation of locally less than $40 \%$ in the Mediterranean region brought a rather cold and dry December.

\section{2) Central and western Europe}

This region includes Ireland, the United Kingdom (UK), the Netherlands, Belgium, Luxembourg, France, Germany, Switzerland, Austria, Poland, Czech Republic, Slovakia, and Hungary.

\section{(i) Temperature}

Overall, western and central Eu-
With a similar circulation pattern featuring the development of a high pressure bridge during the summer months, temperatures in central Europe continued to be high, with anomalies of up to $+5^{\circ} \mathrm{C}$ measured in Italy and the Balkan states (former Yugoslavia). Characteristically for this blocking pattern situation, summer in Italy and the Balkan states was dry, with precipitation totals as low as $20 \%$ of normal while northern Europe, western Russia, Greece, and western Turkey recorded aboveaverage precipitation totals of up to $250 \%$ under the influence of the surrounding lows. Italy in particular experienced a massive heat wave with recordbreaking temperatures and extreme drought.

During autumn, temperatures in central Europe remained near-normal, while eastern Europe experienced above-normal temperature anomalies of up to $+2^{\circ} \mathrm{C}$. The Iberian Peninsula was under the influence of above-average 500-hPa height anomalies, which led to temperatures up to $+3^{\circ} \mathrm{C}$ above normal. Due to fre- rope were warmer than normal for 2017, with many countries reporting a year ranking among their ten warmest [UK $+0.7^{\circ} \mathrm{C}$ (fifth; since 1910), Switzerland $+0.8^{\circ} \mathrm{C}$ (sixth; since 1864), Austria $+0.8^{\circ} \mathrm{C}$ (eighth; since 1767), France $+0.8^{\circ} \mathrm{C}$ (fifth; since 1900); reference period is 1981-2010 for all four].

Winter 2016/17 was mostly mild or around normal. In February, several storms in southwestern Europe brought warm air masses to central Europe, leading to exceptionally high temperatures, with France reporting its warmest February and several stations in Switzerland observing record-breaking daily maximum temperatures in their more than 100 -year measurement series.

This warm episode continued in March, with many new monthly records set in France, Austria, Belgium, and Germany. For the first time in station history (since 1837), a monthly mean temperature of $9.0^{\circ} \mathrm{C}$ was measured in $\mathrm{Graz}, 3.7^{\circ} \mathrm{C}$ above the 1981-2010 normal. In Vienna, the high value of 
March monthly means (in 1990) was surpassed by $+0.1^{\circ} \mathrm{C}$. Similarly, in France, record-high monthly mean temperatures of $10.1^{\circ} \mathrm{C}$ and $10.9^{\circ} \mathrm{C}$ were measured at the stations in Dunkerque and Le Mans, respectively. In Germany, at the station Kitzingen, a maximum temperature of $25.6^{\circ} \mathrm{C}$ was measured on $30 \mathrm{March}$, a temperature not generally observed so early in the year. At Swiss stations La Chaux-de-Fonds and Meiringen, records of $+4.0^{\circ} \mathrm{C}$ and $+4.1^{\circ} \mathrm{C}$ above their 1981-2010 March normal were reached. After a late-night frost episode in many countries (e.g., Germany, Switzerland, Austria, United Kingdom, the Netherlands) during the second half of April, a low pressure system northwest of Ireland in May led to the advection of warm dry air from Africa, leading to many more daily maximum temperature records in France $\left(35.1^{\circ} \mathrm{C}\right.$ at station Biscarrosse), the United Kingdom $\left(29.4^{\circ} \mathrm{C}\right.$ at station Lossiemouth), the Netherlands $\left(33.5^{\circ} \mathrm{C}\right.$ at station Volkel), and Austria $\left(35.0^{\circ} \mathrm{C}\right.$ at station Horn).

Summer was characterized by exceptional heat, when high pressure conditions dominated. June was the warmest month since 1901 in the Netherlands (together with 1976) as well as the second warmest month in Austria (251 year series), France (after June 2003), and Switzerland (after June 2003). In Belgium, June 2017 was also one of the warmest, close to the record of June 2003. In August, subtropical warm air reached as far north as Bavaria and Baden-Württemberg (southern Germany), leading to new records in those regions. The station in Emmendingen-Mundigen, Germany, experienced 11 consecutive hot days (daily maximum temperature equal or above $30^{\circ} \mathrm{C}$ ), and the Czech Republic had daily maximum temperatures as high as $38.3^{\circ} \mathrm{C}$. In Figari (Corsica, France), a record high temperature of $42.7^{\circ} \mathrm{C}$ was reached. In July and August, Hungary reported a record 27 days of heat wave conditions and Budapest experienced a record-breaking 34 tropical nights (minimum temperature $\geq 20^{\circ} \mathrm{C}$; Klein Tank et al. 2009) in the series since 1901.

In autumn, anticyclonic conditions prevailed over western Europe, which on average made western and central Europe slightly warmer than normal (around $+1^{\circ} \mathrm{C}$ ) with some exceptions like Austria, where temperature anomalies were below average by $1.5^{\circ} \mathrm{C}$ in September as well as in France where, although the mean monthly temperature anomaly was $+0.9^{\circ} \mathrm{C}$, locally daily maximum temperature anomalies (19812010 base period) of $-5^{\circ} \mathrm{C}$ were measured. Switzerland reported a September monthly mean anomaly of $-1.6^{\circ} \mathrm{C}$ below its $1981-2010$ average. In contrast, autumn in the Netherlands was among its ten warm- est, with October $\left(+2.6^{\circ} \mathrm{C}\right.$ anomaly; $1981-2010$ base period) fourth warmest since 1901. On 7 November, a station in Freiburg (Germany) recorded $23.2^{\circ} \mathrm{C}$, its highest daily maximum temperature for November. The year ended with close to or moderately abovenormal temperatures for the United Kingdom and northern France and as much as $+2^{\circ}$ to $+4^{\circ} \mathrm{C}$ above normal east of Germany, while Switzerland, particularly the south, and the Mediterranean coast of France were colder than normal in December.

\section{(ii) Precipitation}

Most of central Europe recorded near- to abovenormal precipitation-up to $167 \%$ in northeastern Germany and northern Poland; however, France, had slightly below-normal precipitation and even experienced exceptional drought in the region ProvenceAlpes-Côte d'Azur, with an average deficit of less than $60 \%$ of normal between May and November, the lowest cumulative rainfall since 1959.

In winter 2016/17, central Europe was much drier than normal with $20 \%-80 \%$ of normal precipitation; except for Poland, which had above-normal precipitation of around $125 \%$. Regionally, Switzerland recorded its driest winter for the last $45-55$ years. In the mountains in the canton of Ticino, an unprecedented $14 \mathrm{~cm}$ average of snow depth was the lowest value since the beginning of measurements.

In spring, western Europe continued to be drier than normal on average, with eastern France, the Benelux countries, and western Germany having a precipitation deficit as low as $40 \%-60 \%$ of normal; conversely, parts of Poland locally received up to $167 \%$ of normal. In March, a deep low pressure system over the United Kingdom triggered a foehn storm in the northern Alps, bringing up to $100 \mathrm{~mm}$ of precipitation within three days in the southern Alps. Austria and Switzerland reported intense snowfall in late April, with $35 \mathrm{~cm}$ accumulation within two days in St. Gallen (Switzerland).

Frequent Atlantic cyclones during the summer brought above-normal precipitation to most of the northern region. Northern Germany and northern Poland received as much as $250 \%$ of normal. Often accompanied by thunderstorms, the cyclones brought heavy rainfall that led to flooding and widespread traffic impact. Highest daily total records were broken, for example, at station Berlin-Tegel where $197 \mathrm{~mm}$ on 29 June was measured (previous record was below $90 \mathrm{~mm}$ ). Station Shannon Airport (Ireland) reported its wettest July in its 71 year record with $133.6 \mathrm{~mm}$ (203\% of normal). 
In autumn, southern France, under the influence of above-normal 500-Pa heights centered over the Iberian Peninsula, experienced a rain deficit as low as $20 \%$ in the Mediterranean region, while eastern Europe received up to $250 \%$ of normal precipitation due to several low pressure systems. At the end of the year, precipitation was distributed unevenly, but with above-normal precipitation for most of central Europe (exceptions are the coast of southern France, eastern Germany, and the border region of Poland and the Czech Republic, which received belownormal precipitation).

\section{(iii) Notable events and impacts}

A severe storm affected France on 6-7 March, with peak gusts reaching $54 \mathrm{~m} \mathrm{~s}^{-1}$ in Brittany.

On 18-19 May, thunderstorms over Germany (low "Dankmar"), accompanied by hail and heavy rainfall of more than $36.3 \mathrm{~mm}$ (Bad Bibra) within 1 hour, led to flooding in several cities.

Local intense rainstorms occurred in France during 29-31 May, with 24-hr totals often exceeding $20 \mathrm{~mm}$ : $53.9 \mathrm{~mm}$ in Genouillax, $58.9 \mathrm{~mm}$ in Muret, $72.1 \mathrm{~mm}$ in Castelnau-Magnoac, and $80 \mathrm{~mm}$ in Chateauponsac. During the same period, in Switzerland a violent storm with heavy rain and hail the size of golf balls was reported at the station in Thun; the storm brought the highest daily precipitation amount $(59.6 \mathrm{~mm})$ there since the start of measurements in 1875 .

In summer, severe hailstorms impacted western and central Europe. Perhaps the most remarkable was cyclone Zlatan, which developed over England on 19 July. Moving eastward, it affected the eastern half of France, Switzerland, Austria, Germany, the Czech Republic, and Poland with heavy rain and hail causing damage, especially in Germany (North RhineWestphalia, Station Cologne measured $48.8 \mathrm{~mm} \mathrm{~h}^{-1}$ and gusts of $26 \mathrm{~m} \mathrm{~s}^{-1}$ ) with closed roads and traffic delays. The airport in Cologne was closed for 90 minutes.

In Austria, between 4 and 6 August, intense precipitation in Lungau (state of Salzburg) and Obersteiermark (state of Styria) led to several landslides, causing an estimated damage of more than 20 million Euros (\$25 million U.S. dollars) to the local road network.

In October, three storms (ex-Hurricane Ophelia, Storm Brian, and Storm Herwart), with extreme wind speeds of $40 \mathrm{~m} \mathrm{~s}^{-1}$ or more, brought much damage to the United Kingdom, Ireland, Germany, the Netherlands, France, Austria, Czech Republic, Poland, and Slovakia, with falling trees killing at least seven people in Germany and three in the UK, as well as road and railway blockings affecting traffic for days during clean up. During Ophelia, an individual wave height record of $26.1 \mathrm{~m}$ was set at the Kinsale gas platform off the Cork coast (Ireland).

Several storms affected central Europe from 17 to 18 November, with wind gusts of more than $48 \mathrm{~m} \mathrm{~s}^{-1}$, impacting traffic and causing major damage to trees and buildings.

\section{3) The Nordic and the Baltic Countries}

This region includes the Nordic countries Iceland, Norway, Denmark, Sweden, and Finland, and the Baltic countries Estonia, Latvia, and Lithuania

\section{(i) Temperature}

Temperatures across the Nordic and Baltic area in 2017 were mostly higher than normal, between $+1^{\circ}$ and $+2^{\circ} \mathrm{C}$. Estonia, Finland, and Denmark had positive anomalies of $+1.5^{\circ},+1.3^{\circ}$ and $+1.2^{\circ} \mathrm{C}$, respectively.

Winter 2016/17 was exceptionally mild due to the influence of above-average $500-\mathrm{hPa}$ heights (Fig. 7.36a), with $+2^{\circ} \mathrm{C}$ anomalies in the south and up to $+5^{\circ} \mathrm{C}$ in northern Sweden and Finland. Denmark recorded its fifth and fourth highest daily minimum and maximum temperatures in December, respectively, since 1953. During long-lasting foehn winds in January, a daily mean temperature of $13.8^{\circ} \mathrm{C}$ was measured at station Sunndalsøra (Norway) on 25 January, which was the highest daily mean temperature ever recorded in January by a weather station in Norway and is a value commonly measured around the beginning of July. During February, 12 stations in Norway observed new daily maximum temperature records as well as extreme anomalies at the Arctic station of Svalbard Lufthavn, with a monthly mean temperature of $+9.3^{\circ} \mathrm{C}$.

On 26 March, under the influence of southwesterly flows, daily maximum temperatures of $20^{\circ} \mathrm{C}$ or more were measured at stations Akershus, Oslo, Hedmark, Buskerud, and Telemark in Norway, the first known occurrence of such high temperatures in March. In May, the northeastern part of the North suffered from a cold wave which led to several record below-average anomalies in Latvia (e.g., station Rezekne $-4.7^{\circ} \mathrm{C}$, Mersrags $-6.1^{\circ} \mathrm{C}$ ). Finland was also affected, with anomalies between $-1^{\circ}$ and $-3^{\circ} \mathrm{C}$ for May across the whole country. Temperatures for Lithuania in May also were slightly below normal, and frost days were even recorded. In contrast, a new record high maximum temperature of $31.8^{\circ} \mathrm{C}$ was measured at Sigdal - Nedre Eggedal (Buskerud) in Norway on 27 May.

Under the influence of below-average $500-\mathrm{hPa}$ anomalies, summer in the Baltic States on average had slightly below-normal temperatures with anomalies 
ranging from $-0.5^{\circ}$ to $-2.5^{\circ} \mathrm{C}$ in the east of Finland. Lithuania observed an unusually cold July $\left(-1.4^{\circ} \mathrm{C}\right)$, while the rest of the summer was closer to average. Overall, the summer was rather cold without any hot spells, which was apparent in the maximum temperatures; for example, Sweden, with a daily maximum temperature of only $28.0^{\circ} \mathrm{C}$, had its coolest summer since 1922.

During autumn, temperatures were higher than normal in all Nordic and Baltic countries, with around $+1^{\circ} \mathrm{C}$ anomaly. The entire north was under the influence of above-average 500 -hPa height anomalies, which also led to a new record high sea level air pressure of $1044.1 \mathrm{hPa}$ at Lycksele and Åsele in northern Sweden. November and December were especially mild. It was the warmest autumn in Denmark since 1984, with a new maximum temperature record of $17.1^{\circ} \mathrm{C}$ on 2 November at Kjevik (Kristiansand, Vest-Agder, Norway), as well as at station Yngør Lighthouse (Tvedestrand, Norway) with a reading of $14.4^{\circ} \mathrm{C}$. With temperatures up to $+5^{\circ} \mathrm{C}$ above normal in eastern Finland and between $+1^{\circ} \mathrm{C}$ and $+4^{\circ} \mathrm{C}$ for most of the Baltic States, 2017 ended rather warm.

\section{(ii) Precipitation}

Except for Iceland and most regions of the northern Baltic States, annual precipitation totals were around normal to above normal. Norway experienced its sixth wettest year since records began in 1900 .

During winter 2016/17, all Baltic states and most Nordic countries had a precipitation deficit; only Norway received a surplus of up to $167 \%$ of normal, with northern Norway having its wettest winter on record but only the 15th wettest for the country as a whole. This deficit continued in spring, especially in May, with Lithuania observing only $24 \%$ of its normal precipitation and Latvia having its sixth driest May, with a nationally-averaged total of $21.4 \mathrm{~mm}$.

Summer in northern parts of the Baltic was drier than normal; however, Lithuania, Denmark, and Norway received above-normal precipitation. Lithuania reported a wet summer, particularly notable for July (almost $150 \%$ of normal), due in part to several severe storms with heavy rainfall. Norway, with $130 \%$ of normal precipitation, recorded its third wettest summer since 1900 .

Prevailing westerlies in autumn brought well above-normal precipitation to the Nordic and southern Baltic states. Lithuania and Latvia each reported a record (since 1961) wet season with up to $176 \%$ and $135 \%$ of normal precipitation. Latvia, with a seasonal total of $313.5 \mathrm{~mm}$, reported its second wettest autumn in the last 94 years (for some stations even the wet- test). At the end of 2017, precipitation totals continued to be above normal for almost all of the Nordic and Baltic States.

\section{(iii) Notable events and impacts}

On 12 August, widespread thunderstorms left 50000 households without power in southern Finland.

At the end of September, following heavy precipitation and warmth, major damage was caused by floods and landslides in southeastern and eastern Iceland.

In Lithuania, three microscale extreme heavy rain events were observed in summer. On 12 July, precipitation totals exceeded $80 \mathrm{~mm}$ in 12 hours.

Between 22 and 24 November, Storm Ylva caused wind gusts as high as $47.5 \mathrm{~m} \mathrm{~s}^{-1}$ at station NarvikFagernesfjellet (Nordland) in Norway. Another storm, "Birk", brought heavy precipitation to Hordaland and Rogaland counties, with a maximum daily precipitation total of $127.5 \mathrm{~mm}$ at Gullfjellet (highest mountain in Bergen, Hordaland) measured on 23 December.

\section{4) Iberian Peninsula}

This region includes Spain and Portugal. Anomalies refer to a reference period of 1981-2010 for Spain and 1971-2000 for Portugal.

\section{(i) Temperature}

Temperatures for 2017 on the Iberian Peninsula were well above normal, by $+1^{\circ}$ to $+3^{\circ} \mathrm{C}$ in central Spain. Portugal recorded its second warmest year on record with $+1.1^{\circ} \mathrm{C}$ anomaly compared to the 1971-2000 average and a new average annual maximum record temperature of $22.82^{\circ} \mathrm{C},+2.32^{\circ} \mathrm{C}$ above normal, since records began in 1931 . With an anomaly of $+1.1^{\circ} \mathrm{C}$, Spain recorded its warmest year since its series began in 1965, exceeding the previous record of 2011,2014 , and 2015 by $+0.2^{\circ} \mathrm{C}$. More than thirty individual stations in Spain (almost one-third of all principal stations) surpassed their annual mean temperature records in 2017.

During winter 2016/17, January had below-average anomalies of around $-0.5^{\circ} \mathrm{C}$. This situation was associated with an inflow of cold air from the north caused by a high pressure system located above the Canaries ranging as far north as Iceland and a low pressure system ranging from Scandinavia to the Mediterranean. Some stations in Portugal measured exceptionally low daily minimum air temperatures and, on 19 January, some even recorded absolute daily minimum records. February, in contrast, was 
clearly warmer than average, with anomalies as high as $+1.6^{\circ} \mathrm{C}$ in Spain.

Above-normal 500-hPa height anomalies situated over central Europe led to an extremely warm spring, with anomalies of $+1.7^{\circ} \mathrm{C}$, making 2017 the warmest spring since 1965 in Spain, exceeding the previous record of 2011 by $0.1^{\circ} \mathrm{C}$. In Portugal, April was the fifth and May the third warmest month since the record began in 1931. Additionally, the highest and second highest average maximum temperatures, respectively, since 1931 were measured for each of these months.

The warmth continued into summer, with Spain observing its second hottest since 1965 , at $+1.6^{\circ} \mathrm{C}$ above normal, behind only 2003 . June was particularly warm, with a monthly anomaly of $+3.0^{\circ} \mathrm{C}$. During 12-16 July, the highest daily maximum temperatures of that summer were observed: $46.9^{\circ} \mathrm{C}$ at Córdoba Airport, $45.7^{\circ} \mathrm{C}$ at Granada Airport, and $45.4^{\circ} \mathrm{C}$ at Badajoz Airport. Eight stations in the southern half of the peninsula observed their highest maximum absolute temperature of any summer month. With a mean temperature of $22.70^{\circ} \mathrm{C}$, summer in Portugal was $+1.43^{\circ} \mathrm{C}$ warmer than the $1971-2000$ normal, its ninth warmest summer since 1931.

While the autumn anomaly for Spain was only $+0.8^{\circ} \mathrm{C}$ above normal, October was the warmest since $1965\left(+2.6^{\circ} \mathrm{C}\right)$. Although it was only the fifth warmest autumn (with respect to mean temperatures) for Portugal since 2000 , the average maximum temperature was $24.40^{\circ} \mathrm{C}\left(+2.93^{\circ} \mathrm{C}\right.$ above normal), which is the highest value since 1931 . With slightly below-average temperature anomalies of $-0.4^{\circ} \mathrm{C}$ in December, the year ended cold for the Iberian Peninsula.

\section{(ii) Precipitation}

Overall, the Iberian Peninsula was very dry in 2017 and was characterized by intensive drought. It was the second driest year since the beginning of the series in 1965 for Spain and third driest for Portugal since 1931.

The winter season 2016/17 was drier than normal, with $69 \%$ of normal precipitation for Portugal. In Spain, a dry January (23\% of normal) was followed by a wetter-than-normal February (136\% of normal). Some regions, including the southern half of Galicia, west Castilla-León, south Navarra, and extensive areas of La Rioja, Central System, Pyrenees, Huesca, and Huelva provinces, as well as the eastern Canary Islands, had above-normal rainfall of $175 \%$.

For Spain, spring began with a wet March but the seasonal average showed a precipitation deficit of about $75 \%$ of normal for both Spain and Portugal. While summer in Portugal was its seventh driest since 1931 with an average of $23 \mathrm{~mm}$ corresponding to $40 \%$ of normal, summer in Spain was slightly wetter than normal (107\% of normal). Notably, much of the precipitation can be attributed to storms during which new daily maximum precipitation total records were measured.

Autumn was dominated by above-normal $500-\mathrm{hPa}$ height anomalies centered above the Iberian Peninsula. As a result, both Spain and Portugal recorded below-average precipitation totals, making 2017 the driest autumn on record in Spain and second driest autumn since 1931 for Portugal (only 35\% of normal precipitation). September was the driest such month of the last 87 years in mainland Portugal, with an average precipitation of $2 \mathrm{~mm}$ ( $5 \%$ of the normal). In many places, no precipitation was measured at all. It was followed by the driest October of the last 20 years in Portugal. By the end of October, 25\% of Portugal suffered from severe and $75 \%$ from extreme drought. This extended period of drought led to widespread wildfires in Portugal, with new records in the size of area burned. December marked the ninth consecutive month with below-normal precipitation for Portugal.

\section{(iii) Notable events and impacts}

A heat wave lasting 17-18 days in the northern and central regions of Portugal and 11-12 days in the remainder of the country occurred between 7 and 24 June.

During summer, high temperatures and severe precipitation deficits in Portugal enhanced extensive wildfires (> $1000 \mathrm{ha}$ ), with more than 60 fatalities; the fires were so large they were visible from space.

Due to ex-Hurricane Ophelia, strong winds prevented the extinguishing of fires in Portugal and Spain (9-21 October). At least 41 people were killed in wildfires across the region. Additionally, ashes from the fires were transported as far as the UK, where yellow skies and a red sun were reported, and Switzerland, where ashes were detected at air monitoring sites in Payerne and on Jungfraujoch (3580 m a.s.1.). According to the Portuguese Institute for Nature Conservation and Forests, burned areas exceeded 440000 ha, a new record. Central regions of mainland Portugal were the most affected by very large fires (> $1000 \mathrm{ha}$ ) during several periods: 16-21 June, 16-18 July, 23-26 July, 9-19 August, 23-27 August, 5-9 September, and 12-15 October. During these periods, the associated meteorological conditions were extremely favorable to fire propagation and adverse to fire combat; fire weather index values were higher than the 90th percentile in the majority of the regions. 


\section{5) Mediterranean, Italy, and Balkan States}

This region includes Italy, Malta, Slovenia, Croatia, Serbia, Montenegro, Bosnia and Herzegovina, Albania, Republic of North Macedonia, Greece, Bulgaria, and Turkey. Balkan States include North Macedonia and Bulgaria unless otherwise specified.

\section{(i) Temperature}

The Mediterranean and the Balkan states showed average anomalies of mostly between $+1^{\circ}$ and $+2^{\circ} \mathrm{C}$ in 2017. Based on station Zagreb-Grič, Croatia had its sixth warmest year in the series from 1862. With an anomaly of $+1.2^{\circ} \mathrm{C}$, Bulgaria experienced its warmest year on record since 1980 .

Winter 2016/17 was dominated by an unusually cold January due to a low pressure system centered over southeastern Europe leading to an inflow of cold air masses from Siberia. In Greece, monthly minimum and maximum temperatures were $3^{\circ}$ to $5^{\circ} \mathrm{C}$ below the 1971-2000 normal. Slovenia reported its coldest January of the last 30 years. In west Bulgaria, minimum daily temperatures were close to the records of the last 50 years, with $-26^{\circ} \mathrm{C}$ in Kyustendil and $-27^{\circ} \mathrm{C}$ in Pernik $\left(-1.2^{\circ} \mathrm{C}\right.$ below normal for the whole winter). Serbia observed its fourth coldest January since its record began in 1951. Turkey reported a negative January anomaly of $-1.5^{\circ} \mathrm{C}$ below its 1981-2010 normal.

In spring, due to prevailing southerly flows, temperatures in Italy, Greece, and the other countries of the Balkan Peninsula were above normal with anomalies around $+1^{\circ} \mathrm{C}$. Although anomalies showed only a slightly warmer-than-normal spring, events like the heat wave that occurred between 12 and 13 May in the central and southern parts of Greece led to a new daily maximum temperature record of $40.6^{\circ} \mathrm{C}$ at the station Argos.

A prolonged anticyclonic situation over the northern Adriatic Sea contributed to a very warm summer for Italy and the Balkan states, with anomalies around $+3^{\circ}$ to $+5^{\circ} \mathrm{C}$. Several heat waves contributed to these high anomalies during all three summer months. Some stations in Italy measured new alltime records in early August, for example, $41^{\circ} \mathrm{C}$ in Pescara. Slovenia reported its second warmest summer, surpassed only by 2003. Serbia also reported its second warmest summer; July and August proved to be extraordinarily warm. Several stations in Serbia observed their third highest August temperature, although on average across the country, it was seventh highest. A record-breaking number of days with temperatures above $38^{\circ} \mathrm{C}$ and new all-time records for the number of tropical nights were set at several stations in Serbia. Croatia categorized its summer as extremely warm, with above-average anomalies between $+2.7^{\circ}$ and $+4.5^{\circ} \mathrm{C}$. During heat wave events, Bulgaria measured extreme maximum temperatures of $42.5^{\circ} \mathrm{C}$ in Sandanski and $43.6^{\circ} \mathrm{C}$ in Ruse. Macedonia experienced unusually long-lasting periods of warm weather, with anomalies exceeding $+5^{\circ} \mathrm{C}$ in mid-June. Turkey set a new all-time high temperature record of $45.4^{\circ} \mathrm{C}$ in Antalya on 1 July.

Anomalies were up to $+2^{\circ} \mathrm{C}$ in eastern Turkey in autumn. Temperatures mostly fluctuated around normal, and no major extremes were reported. The year ended warmer than normal for the region (except parts of Italy, Malta, southern Greece) due to prevailing southerly flows over southeastern Europe in December.

\section{(ii) Precipitation}

Especially for Italy, 2017 was drier than normal. For most Balkan states, precipitation totals were near-normal but often irregularly distributed in both time and space. For example, while overall Serbia was near-normal, the station in Zrenjanin recorded its driest year since its record began in 1925. Similarly, Croatia was slightly wetter than normal for the year but the wider area of the town Split was extremely dry.

Winter 2016/17 was drier than normal, with precipitation of around $60 \%$ of normal for the Balkan states and most of Italy. Nevertheless, in January, due to the cold Siberian air masses crossing the warmer Aegean Sea, high amounts of snowfall were observed in Greece and North Macedonia with adverse impacts on transportation. Turkey reported a winter precipitation deficit of $19.5 \%$.

With the exception of Italy and southern Greece, spring was near to slightly wetter than normal overall. In May, several extreme precipitation events were measured during low pressure situations over Greece and Bulgaria. Thunderstorms accompanied by cyclone "Victor" led to flooding and hail that destroyed crops. During 17-18 May, 230 mm of rain was measured at station Sitta in Greece, while $139 \mathrm{~mm}$ fell in twelve hours at station Semprona at the end of the month.

Throughout the summer, several cut-off lows were centered south of Greece and supplied Greece and western Turkey with well above-normal precipitation (up to $250 \%$ of the seasonal normal), including heavy rainfall and hailstorms, sometimes leading to flooding; conversely, Italy and the Balkan states, under the influence of high pressure, experienced a drier-than-normal season. The summer for the Emilia-Romagna region in northern Italy was its 
third hottest since 1961; warm temperatures, combined with dryness, aggravated drought conditions. At the end of August, the drought in Italy reached its maximum intensity. Serbia reported a dry to very dry summer, and Malta had its driest July since 1951 ( $56 \%$ of normal precipitation). Autumn in the Balkan states was wetter than normal, especially in Bulgaria with precipitation up to $167 \%$ of normal. In October, Bulgaria's average precipitation was 2.5-3 times the normal. Conversely, Italy and most of Turkey suffered from precipitation deficits and drought. The year ended drier than normal for southern Turkey and southern Italy, while most of the Balkan states received above-normal precipitation.

\section{(iii) Notable events and impacts}

In Bulgaria, for the first time in the past 60 years, the coastal waters of the Black Sea were frozen-an occurrence observed only three times since the beginning of the 20th century.

On 21-22 April, a severe frost event in Slovenia caused catastrophic damage to crops.

In Greece, extensive and long-lasting snowfall during several days in January caused severe traffic problems, trapping hundreds of vehicles, disturbing public transport in Thessaloniki, and suspending flights. After serious power failures, the Aegean islands of Skopelos, Alonnisos, and Evia declared a state of emergency.

A severe hailstorm during 7-9 May caused heavy damage in the agricultural areas in northern Greece. At the beginning of June, Bulgaria was hit by a series of severe thunderstorms accompanied by heavy rainfall and hail causing floods and damage to crops. Further local storms with hail were reported in Slovenia and Italy with hourly precipitation totals reaching as high as $46.5 \mathrm{~mm}$ in Salsomaggiore (Italy). At station Vojsko in Slovenia, on 6 June, a new 24-hr daily precipitation record of $200 \mathrm{~mm}$ was set. Two intense hailstorms were registered on 7 and 14 June in North of Macedonia.

On 3 July, northwestern and north-central Bulgaria reported severe convective storms accompanied by strong winds and extreme hail, with stones measuring up to $8 \mathrm{~cm}$ diameter in Mezdra and Levski.

During the first half of July, an intense heat wave hit Croatia, drying out the plant cover, which led to the outbreak of a wildfire on 17 July near Split. Approximately 4300 ha of forest, brush, olive groves, and vineyards were burned. With a $40-\mathrm{km}$ long fire front at its maximum, it was one of the biggest wildfires in Croatian history.
Turkey recorded a severe hailstorm on 27 July, with hailstones up to $9 \mathrm{~cm}$ in diameter observed in Istanbul.

In Naples, Italy, a heavy thunderstorm on 5 September brought hail up to $11.5 \mathrm{~cm}$ in diameter and weights up to $350 \mathrm{~g}$, injuring several people and animals, as well as causing damage to vehicles, houses, trees, and crops.

The slow-moving cyclone "Quasimodo", approaching Italy from the Ligurian Sea, reached the city of Livorno on 9 September, with heavy precipitation causing flooding and damage, along with six fatalities. After passing over Toscana and the city of Pisa, the cyclone reached the Balkans. The Adriatic coast and the islands of the Adriatic Sea received more than $500 \mathrm{~mm}$ precipitation, causing floods in Croatia that damaged houses and cars. A total of 135 million Euros (around 160 million US dollars) in damages in the aftermath of the flood was estimated just for the Croatian county Zadar.

Very heavy precipitation on 1 December led to extensive flooding and landslides in Greece. Between 8 and 12 December, an exceptional meteorological event occurred in Italy with intense rain at some locations (more than $300 \mathrm{~mm}$ in 48 hours). At Cabanne, Genoa province (Italy), an overall total of $507.0 \mathrm{~mm}$ was measured. Strong winds as high as $49.5 \mathrm{~m} \mathrm{~s}^{-1}$ were measured at Loiano.

\section{6) EASTERn EuROPE}

This region includes the European part of Russia, Belarus, Ukraine, Moldova, and Romania.

\section{(i) Temperature}

For most of European Russia and Belarus, 2017 was warmer than average, with anomalies of $+1.45^{\circ}$ and $+1.7^{\circ} \mathrm{C}$, respectively. Moldova and Romania recorded slightly lower positive anomalies of $+1.2^{\circ} \mathrm{C}$ (normal 1961-1990) and $+0.7^{\circ} \mathrm{C}$ (normal 1981-2010), respectively. Ukraine reported its third hottest year since the beginning of observations in 1961 with an anomaly of $+1.8^{\circ} \mathrm{C}$.

The winter season 2016/17 on average was warm for European Russia, Belarus, and Ukraine. Anomalies were below average only in January, when a cold spell in the Volga region dropped temperatures to as low as $-40^{\circ} \mathrm{C}$ and several absolute minimum temperatures were exceeded in the cities of Arkhangelsk, Kotlas, Naryan-Mar, Kirov, and Tver. Similarly, Romania and Moldova reported severe cold during this time, with the latter measuring temperatures of $8^{\circ}-10^{\circ} \mathrm{C}$ below normal. Winter in Moldova, overall, 
was slightly colder than normal, with an anomaly of $-0.6^{\circ} \mathrm{C}$ (1961-90 normal) for the season.

At the beginning of spring, under the influence of a cyclone located over northwest Europe, new high temperature records in Moscow and St. Petersburg, as well as abnormal warmth at the Arctic coast, were reported. During the second half of March, temperature records in Smolensk, Tambov, Cheboksary, and other Russian cities were measured and, overall, the seasonal weather was climatologically ahead by a month. A nation-wide heat wave hit Romania in March, with a monthly temperature $+3.4^{\circ} \mathrm{C}$ above its $1961-2010$ normal. At the station in Baisoara, the absolute monthly maximum temperature for March was exceeded. Moldova also reported an abnormally warm March. Then, in late April a wintry spell resulted in additional-this time minimum-temperature records in the area, as low as $-15^{\circ} \mathrm{C}$ in Smolensk (Russia). The season ended with a cold May, which brought additional minimum temperature records. Nevertheless, overall, spring was warmer than normal for Moldova, Belarus, and the Ukraine. With a monthly mean air temperature of $10.9^{\circ} \mathrm{C}$, Moscow (Russia) experienced its coldest May of the 21st century.

Even with a late frost event on 4 June (temperatures down to $-1^{\circ} \mathrm{C}$ ) in the Ukraine, overall, summer for the Ukraine, Moldova, and Romania was warmer than normal, with widespread anomalies up to $+2^{\circ} \mathrm{C}$ above normal. In contrast, the northern part of European Russia was colder than average; a new daily low temperature record of $7.8^{\circ} \mathrm{C}$ was set in Moscow on 15 June, with observations dating to 1949.

Autumn was warmer than normal for Russia, Ukraine, Belarus, and Moldova, while temperatures in Romania were near-normal. During the second half of September and November, anomalies of up to $+2^{\circ} \mathrm{C}$ were observed, while the rest of the season mostly remained close to normal. The year ended with an exceptionally warm December-especially notable in European Russia where anomalies exceeded $+6^{\circ} \mathrm{C}$; anomalies for Belarus, Ukraine, and Moldova, ranging between $+3^{\circ}$ and $+5^{\circ} \mathrm{C}$, were also quite high, and only the southern part of Romania showed anomalies below $+3^{\circ} \mathrm{C}$.

\section{(ii) Precipitation}

Precipitation totals were near- to slightly above normal in eastern Europe with the exception of Ukraine, which reported precipitation $60 \%-70 \%$ of normal in the south and central regions and nearnormal for the rest of the country. Russia and Belarus on average had slightly above-average totals of $115 \%$ and $121 \%$, respectively. Nevertheless, it was the second wettest year on record for European Russia.

During winter 2016/17, only Romania, Moldova, and isolated spots in Russia showed below-average precipitation of around $60 \%$ of normal; the rest of the area was near-normal or slightly above.

Spring was rather wet for Moldova, where some places during April observed values of $85-128 \mathrm{~mm}$, corresponding to $230 \%-350 \%$ of normal precipitation, for the first time in the period of record dating back at least 80 years. Most areas of Russia also reported a precipitation surplus (of up to $167 \%$ and locally even more) while Belarus was near-normal. The exception to the wet spring was the central region of Ukraine where deficits of $60 \%$ of normal were measured.

During summer, this deficit extended over all of Ukraine, with $60 \%$ of the agricultural area affected by drought. Belarus reported a dry June but, overall, summer precipitation was near- or slightly above normal. Most regions of European Russia, other than the south, which received $3 \%-25 \%$ of normal monthly precipitation in August, had near-normal precipitation or even a surplus (up to $167 \%$ in the northwest). After heavy rain events accompanied by hail and strong winds caused major damage in June and July, Moldova experienced a precipitation deficit in August where locally severe drought was reported.

With prevailing anticyclonic conditions in September, autumn began with a large precipitation deficit (mostly below $60 \%$ of normal) for the south of European Russia as well as for eastern Ukraine. October was the wettest month of the year for the eastern countries (Moldova, Belarus, and Romania). At the end of the season, only eastern Ukraine, southern parts of European Russia, and the Ural region suffered from precipitation deficits. December was wet throughout eastern Europe.

\section{(iii) Notable events and impacts}

On 20 April, the Kirov region (Russia) reported exceptionally heavy snowfalls and freezing rain, leading to power failures due to damage to transmission lines for 44 settlements and to extensive damage to forests and agriculture.

In April, Moldova reported extreme weather conditions, with rain, snow, and sleet depositing on wires and trees, as well as strong wind and frost with disastrous consequences for the country's economy. Likewise, reports were made in the Ukraine of unusually high numbers of frost days that damaged fruits, vegetables, and other crops. 
A severe thunderstorm ("Falk") hit Moscow (Russia) and the surrounding area on 30 May. For the first time since the beginning of instrumental observations in Moscow for more than 100 years, wind gusts of $30 \mathrm{~m} \mathrm{~s}^{-1}$ were recorded, resulting in structural damage to buildings. Also in Moscow, 11 people were killed and 70 injured on 29 July during a storm where wind gusts reached $29 \mathrm{~m} \mathrm{~s}^{-1}$.

Heavy precipitation of $100-120 \mathrm{~mm}$ within a $24-\mathrm{hr}$ period in the region of Bucharest (Romania) caused flooding in July.

\section{7) Middle East}

This region includes Israel, Cyprus, Jordan, Lebanon, Syria, West Kazakhstan, Armenia, Georgia, and Azerbaijan.

\section{(i) Temperature}

In the Middle East, temperatures in 2017 were above normal by $+1^{\circ}$ to $+2^{\circ} \mathrm{C}$. Israel reported its fourth warmest year among the last 67 years.

The year began on a cold note, however. Winter 2016/17 temperatures on average were below normal. January and February showed negative anomalies down to $-2^{\circ} \mathrm{C}$ for some regions in Georgia, Armenia, Israel, and Jordan. Israel reported its coolest February daily minimum temperatures since 1999 .

Spring had slightly above-normal temperatures, with anomalies around $+1^{\circ} \mathrm{C}$. In May, unusually high temperatures above $40^{\circ} \mathrm{C}$ were measured in Israel as a result of Sharav (heat wave) events, which brought warm sandy air from the Sinai Peninsula.

The Middle East experienced a hot summer, with anomalies of up to $4^{\circ} \mathrm{C}$ above normal. Multiple heat waves in July were responsible for extreme temperatures in Cyprus, Jordan, and Israel, which tied with 2012 as the warmest July in Israel since the beginning of records, with average daily temperatures $+2^{\circ}$ to $+2.5^{\circ} \mathrm{C}$ above normal.

On average, autumn also was warmer than normal, between $+1^{\circ}$ and $+2^{\circ} \mathrm{C}$. The year ended with well above-normal temperatures in December, with some stations in Israel ranking as high as second warmest since the beginning of measurements.

\section{(ii) Precipitation}

With regard to precipitation in the Middle East, 2017 was characterized by widespread deficits of $20 \%-40 \%$ of normal and even less for some regions. Israel reported its third lowest annual precipitation total; only 1959 and 1999 had less rainfall. Regionally, it was the driest year on record in the coastal plain of Israel.
During winter 2016/17, precipitation was unevenly distributed, but, except for most parts of the South Caucasus which received slightly above-normal precipitation, totals were below normal, with extreme deficits in some regions. Northeast Israel reported less than 15\% of its normal monthly average in February, which was the driest February since 1958 for this area.

Spring continued to be dry, with totals between $20 \%$ and $70 \%$ of normal for Cyprus, Jordan, Lebanon, and Israel. Georgia and some parts of Azerbaijan and western Armenia received above-normal precipitation. Summer was extremely dry, with no precipitation at all for widespread regions in Lebanon, northern Syria, and Israel.

While autumn was also dry for the region around the Mediterranean, locally heavy precipitation events provided surpluses of up to $250 \%$ of the monthly normal (e.g., the Karmel Region in Israel), sometimes resulting in flooding. Georgia received near-normal precipitation amounts, with Armenia and Azerbaijan above normal (up to $167 \%$ ).

The year ended dry for the Middle East countries on the Mediterranean and near-normal for Georgia, Armenia, and Azerbaijan.

\section{(iii) Notable events and impacts}

Three men died after being swept away by strong easterly winds of 14-18 $\mathrm{m} \mathrm{s}^{-1}$ accompanied by gusts of $22-25 \mathrm{~m} \mathrm{~s}^{-1}$ in northern Israel on 12 April. One day later, at the station Neot Smadar in the southern Negev, heavy rainfall of $27 \mathrm{~mm}$, of which $10 \mathrm{~mm}$ fell within only 5 minutes, was measured, resulting in flooding and the closing of two main routes to Eilat.

On 18 May, severe sandstorms were advected to southern Israel from the Sinai Peninsula, where they were created by downdraft winds related to welldeveloped clouds. These Haboob-type sandstorms are uncommon in Israel. As a result, the Eilat Airport was closed for several hours.

On 16 October, a heavy rainfall event in Nahariyya (northwest coast of Israel) brought more than $70 \mathrm{~mm}$ of precipitation within two hours. During the morning hours of 30 October more than $50 \mathrm{~mm}$ within one hour were measured in Haifa. Both events were followed by flooding and subsequent road closures.

\section{g. Asia}

Throughout this section the base periods used vary by region. The current standard is the 1981-2010 average for both temperature and precipitation, but earlier base periods are still in use in several countries. All seasons mentioned in this section refer to those of the Northern Hemisphere, with winter 
referring to December 2016-February 2017, unless otherwise noted.

I) Overview - T. Li, Z. Zhu, P. Zhang, T. C. Lee, Y. Mochizuki, S.-E. Lee, L. Oyunjargal, and B. Timbal

Annual mean surface air temperatures during (January-December) 2017 were above normal across most of Asia and much above normal (anomalies $>1.5^{\circ} \mathrm{C}$ ) in Siberia (Fig. 7.38). Annual precipitation amounts were above normal from western China to northeastern India, from the western part of the Indochina Peninsula to the central part of the Malay Peninsula, in the Maritime Continent, and from the western part of eastern Siberia to western Siberia, and they were below normal in the eastern part of eastern Siberia, from the Korean Peninsula across northeastern China to Mongolia, and in central Asia (Fig. 7.39).

Though annual mean temperature anomalies were virtually all positive, they evolved quite differently season by season (Fig. 7.40). In winter (Fig. 7.40a), negative temperature anomalies appeared over western Siberia, associated with a large-scale tropospheric barotropic negative geopotential height anomaly (Figs. 7.41a and 7.42a). In spring, cold anomalies appeared over southwestern China and the Indochina Peninsula (Fig. 7.40c), corresponding to positive rainfall anomalies in the region (Fig. 7.40d). In summer, negative temperature anomalies dominated over the northern part of central to eastern Siberia. Autumn was marked by negative temperature anomalies from central Siberia to Japan. Seasonal precipitation amounts were persistently above normal in the western part of the Tibetan Plateau from winter to summer and in Southeast Asia throughout the year, but they were below normal in northeastern China and Korean Peninsula from spring to autumn.

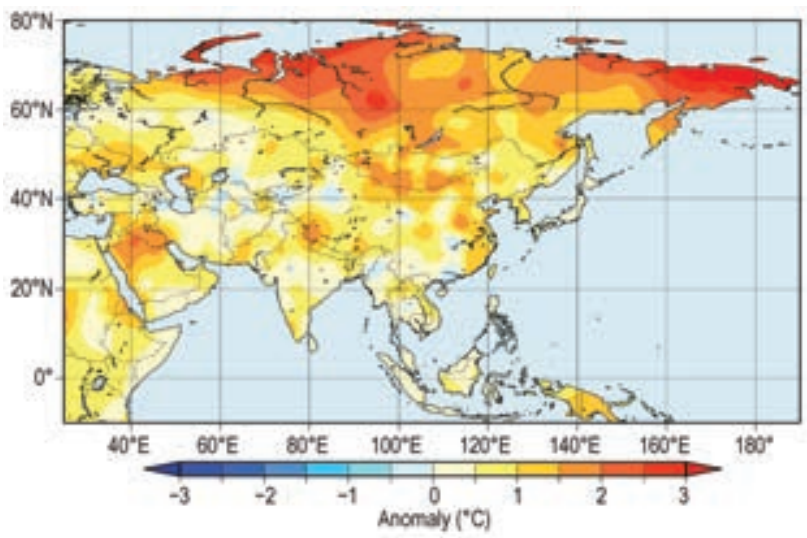

Fig. 7.38. Annual mean surface temperature anomalies $\left({ }^{\circ} \mathrm{C}\right.$; 198I-2010 base period) over Asia in 2017. (Source: Japan Meteorological Agency.)
In winter, enhanced convection appeared over the Maritime Continent and the South China Sea (Fig. 7.41a); to its north, positive anomalies of 500-hPa geopotential height and 850-hPa temperature (Fig. 7.42a) were observed over East Asia. In spring, anticyclonic circulation anomalies straddled the equator over the western Pacific in the lower troposphere (Fig. 7.41b). In summer, convective activity was suppressed to the east of the Philippines, and the western North Pacific subtropical high was shifted westward (Fig. 7.41c). In autumn, anticyclonic (cyclonic) circulation anomalies straddled the equatorial western Pacific (Indian) Ocean in the lower troposphere (Fig. 7.41d).

In terms of the summer monsoon in 2017, East Asian summer monsoon rainfall was weaker than normal, while Indian summer monsoon rainfall was near normal. Intraseasonal variability of convective activity was clearly evident in the monsoon regions.

2) RussiA-0. N. Bulygina, N. N. Korshunova, M. Yu. Bardin, and S. G. Davletshin

This review for Russia and its individual regions, along with estimates of abnormal climate features, are obtained from hydrometeorological observations taken at the Roshydromet Observation Network. Unless otherwise noted, anomalies are relative to a 1961-90 period, and national rankings reflect an 82year (1936-2017) period of record.

\section{(i) Temperature}

The year 2017 in Russia was warm: the mean annual national air temperature was $2.02^{\circ} \mathrm{C}$ above normal (Fig. 7.43). This is the fourth highest such temperature on record. Positive annual mean air temperature anomalies were observed in all regions of Russia. The largest anomalies occurred over Asian Russia (east of the Urals, approximately $60^{\circ} \mathrm{E}$ ); the annual tem-

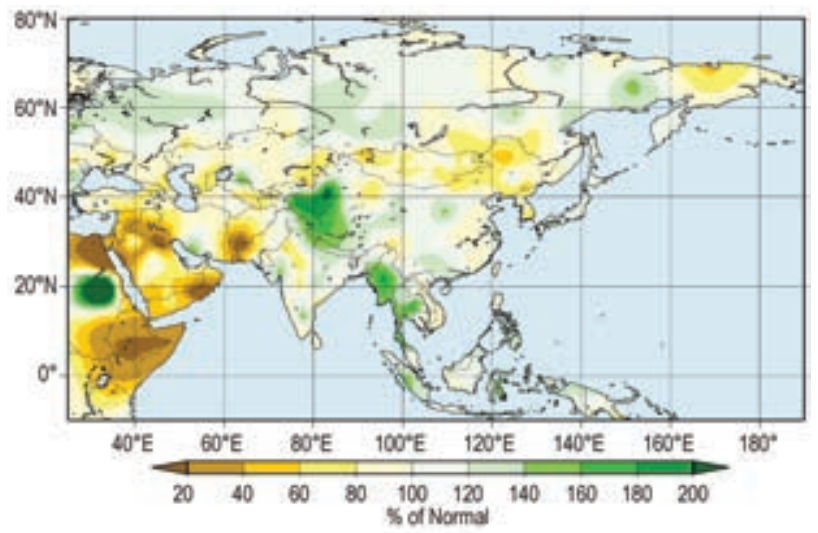

FIG. 7.39. Annual precipitation (\% of normal; I98I-20I0 base period) over Asia in 2017. (Source: Japan Meteorological Agency.) 
(a) DJF

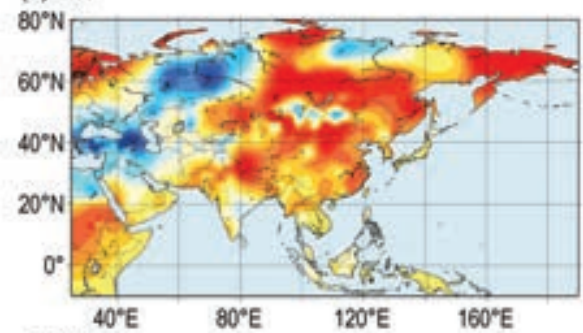

(c) MAM
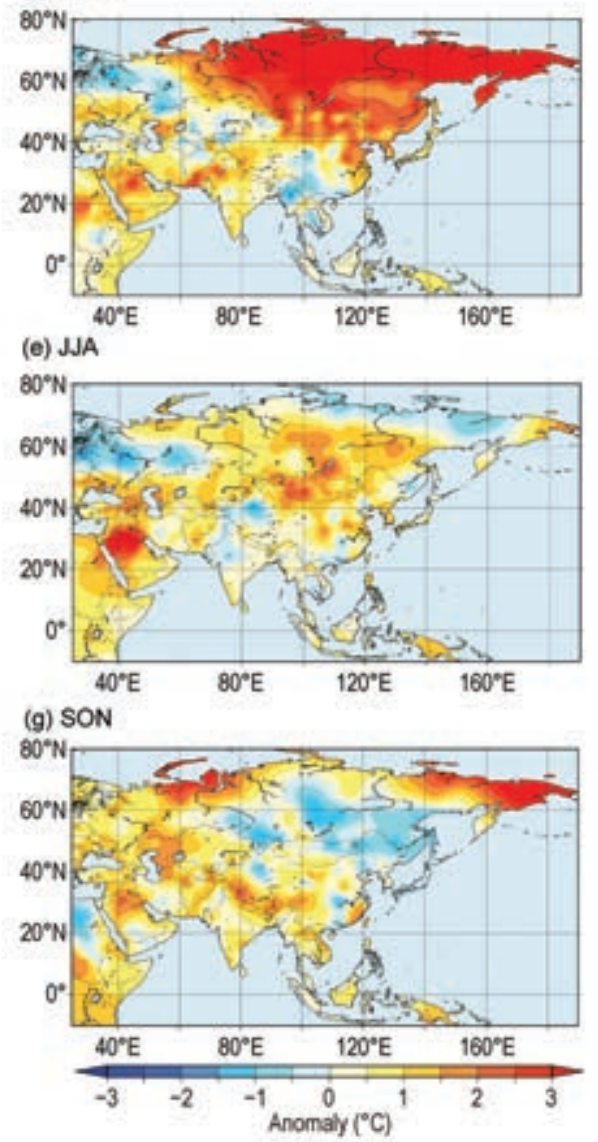

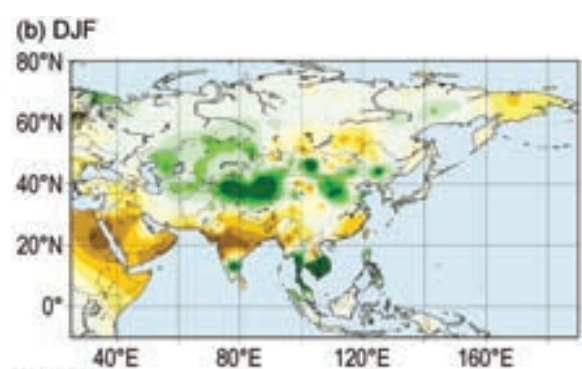

(d) MAM

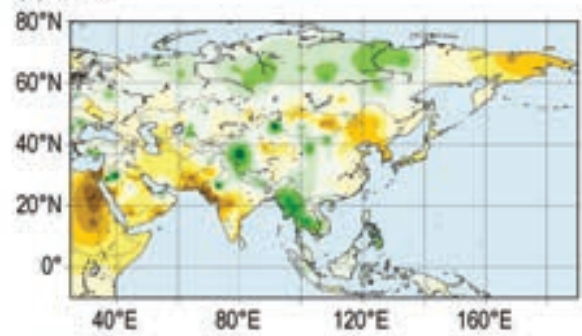

(f) JJA

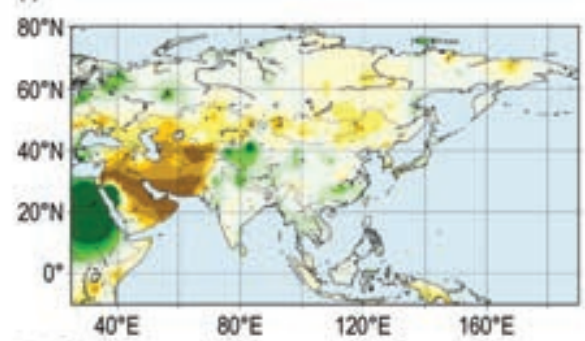

(h) SON

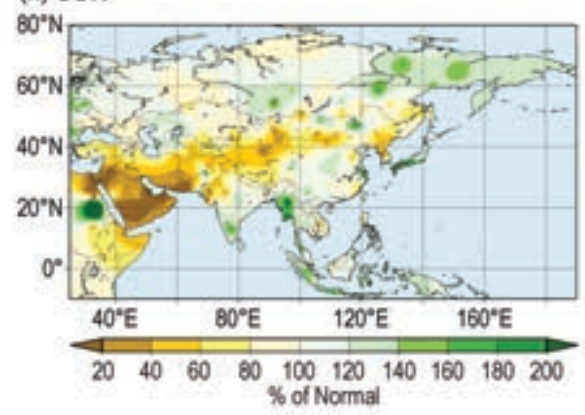

FIG. 7.40. Seasonal mean surface temperature anomalies ( ${ }^{\circ} \mathrm{C}$, left column) and seasonal precipitation (\% of normal, right column) over Asia in 2017 for (a), (b) winter; (c), (d) spring; (e), (f) summer; and (g), (h) autumn. All relative to I98I-20I0. (Source: Japan Meteorological Agency)

perature averaged over this region was $2.27^{\circ} \mathrm{C}$ above normal, the highest such value on record.

For Russia as a whole, winter was moderately warm, with the mean winter temperature $2.05^{\circ} \mathrm{C}$ above normal (14th warmest on record).

Spring 2017 was warm, with an average seasonal mean air temperature anomaly of $+2.82^{\circ} \mathrm{C}$; it was the fourth warmest spring since 1936 . However, the temperature averaged over Asian Russia was recordbreaking at $3.69^{\circ} \mathrm{C}$ above normal, while European Russia was only slightly warmer than normal $\left(+0.65^{\circ} \mathrm{C}\right.$ anomaly; the 27th warmest value of the record) with an unusually cold May, especially compared to recent

decades. March was exceptionally warm (see Fig. 7.44), ranked warmest on record, both for Asian Russia $\left(+6.79^{\circ} \mathrm{C}\right.$ anomaly) and the whole of Russia $\left(+6.03^{\circ} \mathrm{C}\right.$ anomaly). Monthly temperature extremes exceeding the 95th percentile were observed at virtually all stations in Asian Russia north of $60^{\circ} \mathrm{N}$. North Atlantic cyclones brought warm, wet air in the northern regions as far east as Yakutia. Monthly March anomalies in Yamal-Nenets and Taymyrsky DolganoNenetsky Autonomous Districts exceeded $13^{\circ} \mathrm{C}$. At many stations monthly temperatures exceeded previous records. In Tiksi, Nar'jan-Mar, abovenormal daily temperatures were observed almost throughout the entire month, with even minimum daily temperatures above the normal daily maximum (Fig. 7.44). On 21 March a daily minimum temperature above the climatological maximum daily temperature was recorded in Tiksi. European Russia was cooler than its Asian counterpart $\left(+4.14^{\circ} \mathrm{C}\right.$ anomaly; third highest), but extremes above the 95th percentile were observed at most stations in the central and northeastern parts of this region.

Summer 2017 was warm in Asian Russia, with a seasonal air temperature anomaly of $+1.37^{\circ} \mathrm{C}$, the sixth highest since 1936. In European Russia summer was much colder (only $+0.46^{\circ} \mathrm{C}$, rank 39th, which is close to the median value in the series) but not unusual, even against the background of the last two decades. June was the coldest summer month, 
(a) D.JF
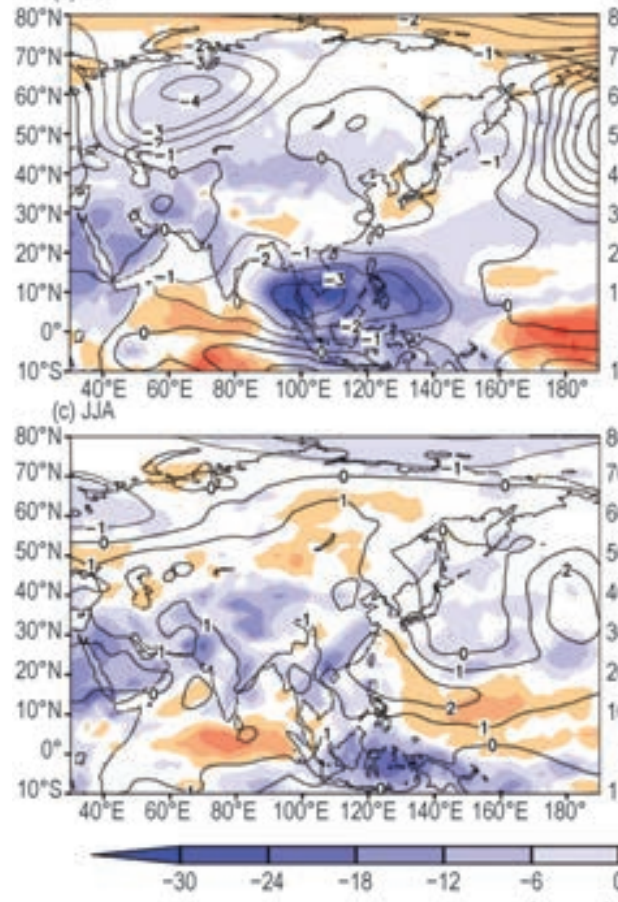

Anomaly $\left(\mathrm{W} \mathrm{m}^{-2}\right)$

FIG. 7.4I. Seasonal mean anomalies of $850-\mathrm{hPa}$ stream function (contour, I $x$ $10^{6} \mathrm{~m}^{2} \mathrm{~s}^{-1}$ ) using data from the JRA-55 reanalysis and OLR (shading, $\mathrm{W} \mathrm{m}^{-2}$ ) using data originally provided by NOAA in 2017 for (a) winter, (b) spring, (c) summer, and (d) autumn. Base period: 198I-2010. (Source: Japan Meteorological Agency.)

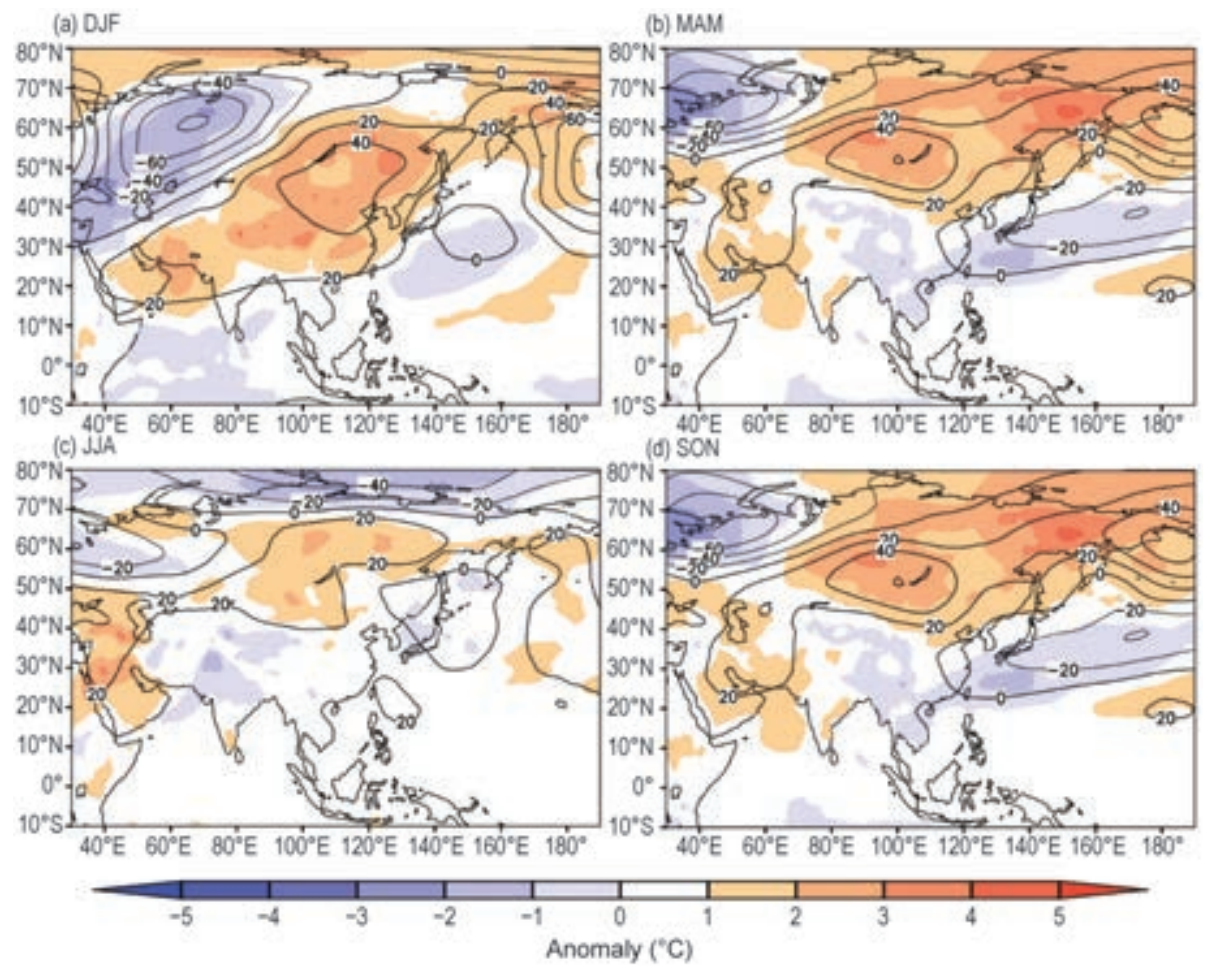

FIG. 7.42. Seasonal mean anomalies of $500-\mathrm{hPa}$ geopotential height (contour, gpm) and 850-hPa temperature (shading, ${ }^{\circ} \mathrm{C}$ ) in 2017 for (a) winter, (b) spring, (c) summer, and (d) autumn, using data from the JRA-55 reanalysis. Base period: 1981-2010. (Source: Japan Meteorological Agency.) especially in European Russia, where it ranked as the eighth coldest June on record, with an anomaly of $-1.44^{\circ} \mathrm{C}$. In contrast, August was exceptionally warm, with the second highest anomaly on record of $+1.61^{\circ} \mathrm{C}$ over Asian Russia and the fourth highest $\left(+1.81^{\circ} \mathrm{C}\right)$ for Russia as a whole.

Autumn was temperate across Russia, with a seasonal anomaly of $+1.12^{\circ} \mathrm{C}$. December 2017 was very warm in European Russia, with an anomaly of $+4.81^{\circ} \mathrm{C}$ (third warmest). Combined with warmth in Asian Russia $\left(+2.35^{\circ} \mathrm{C}\right)$, Russia as a whole was $3.05^{\circ} \mathrm{C}$ warmer than average, the eighth warmest December on record. The location of the Siberian anticyclone remained stable throughout the month. This enabled advection of warm subtropical air along its western periphery and the formation of large positive temperature anomalies in European Russia and western Siberia. The largest anomalies $\left(>+10^{\circ} \mathrm{C}\right)$ were observed in the Yamal-Nenets Autonomous District. A large anomaly observed in the northern Yakutia and Chukotka persisted from November through the end of the year. At many stations monthly temperatures in December exceeded the 95th percentile. On 24, 25, and 27 December temperatures 

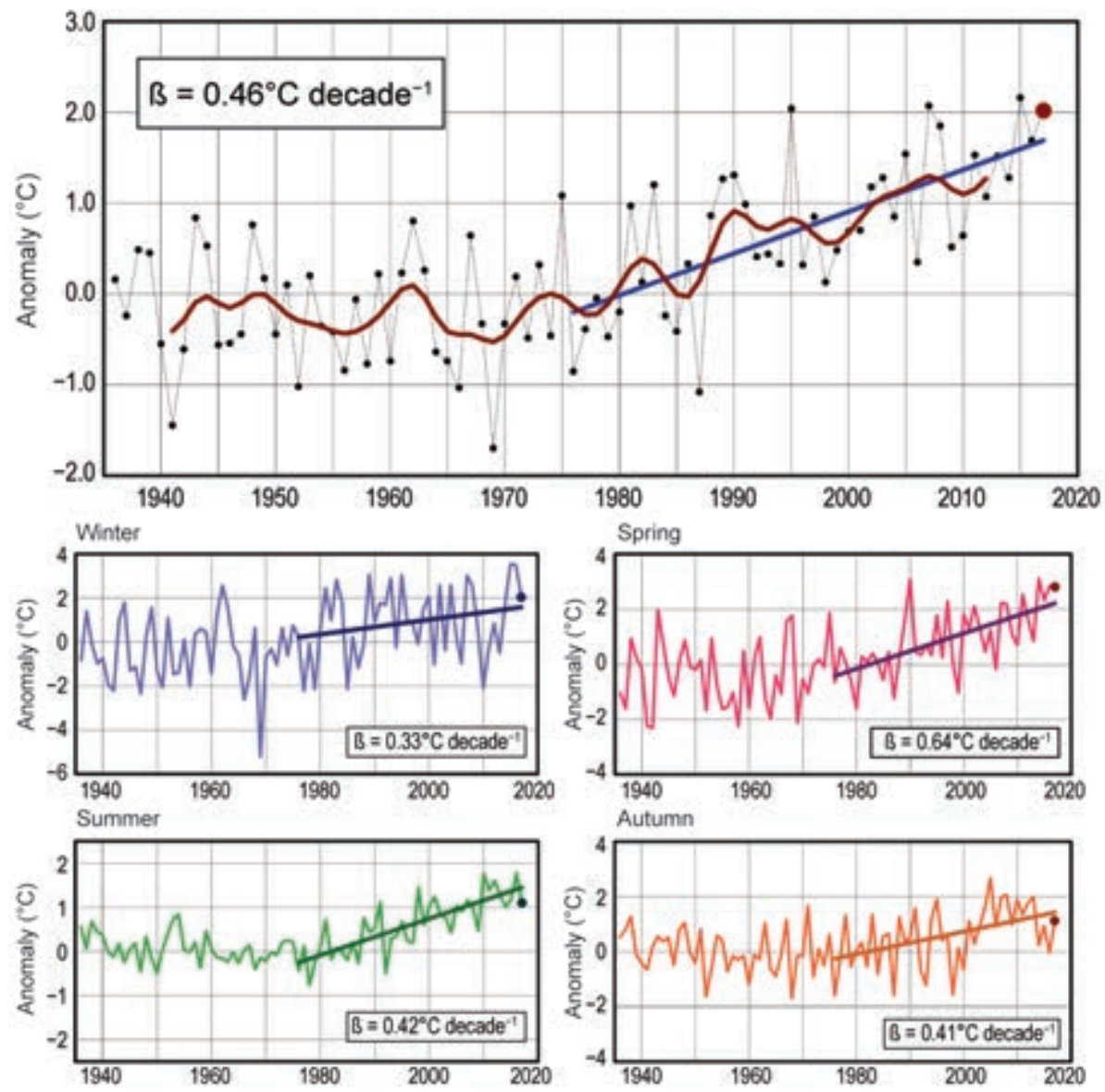

Fig. 7.43. Mean annual and seasonal temperature anomalies ( ${ }^{\circ} \mathrm{C}$; base period 196I-90) averaged over Russia, 1936-2017. The smoothed annual mean time series ( $\mathrm{II}$-point binomial filter) is shown as a red bold line. Linear trend B $\left({ }^{\circ} \mathrm{C}\right.$ decade $^{-1}$ ) is calculated for the period 1976-2017.

above the previous daily maximum were recorded at Mys Uelen, and the December mean temperature there exceeded $-5^{\circ} \mathrm{C}$ for the first time on record.

\section{(ii) Precipitation}

In 2017, Russia as a whole received above-normal precipitation, $111 \%$ of its $1961-90$ normal. This is the second wettest year on record, after 2013, which had $112 \%$ of normal precipitation (Fig. 7.45). European Russia was relatively wetter (115\%, second wettest) than Asian Russia (109\%, fifth wettest).

Winter precipitation was $110 \%$ of normal, which ranks 15th wettest. Spring in Russia had $119 \%$ of normal precipitation, which ranks fourth wettest. The wettest months of 2017 were April in European Russia (137\% of normal) and May in the Asian part (125\% of normal).

Although summer precipitation in Russia as a whole was near normal (107\%), European Russia received much-above-normal precipitation in June and July (135\% and 129\% respectively, both ranked second), while August was drier ( $87 \%$ of normal). Autumn precipitation for the whole of Russia was moderate (108\%), with a dry October in the Asian part (87\%).

Precipitation in December 2017 was much above normal with $124 \%$ of normal precipitation, the third wettest on record. This was especially so in European Russia $(128 \%$, tied for second wettest).

\section{(iii) Notable events and impacts}

On 8-9 March, an extremely severe snowstorm raged in the eastern Chukotka Autonomous Area, with wind gusts attaining $36 \mathrm{~m} \mathrm{~s}^{-1}$ and visibility as low as $0.5 \mathrm{~m}$. Schools were closed; traffic and local flights stopped.

On 28 April, strong winds $\left(25 \mathrm{~m} \mathrm{~s}^{-1}\right)$ in the Eravninsk region of Buryatia increased the number of wild fires. These burned 21 buildings (including 17 homes). Property damage was estimated to exceed 7.5 million rubles (\$130 000 U.S. dollars).

On 3 May, severe forest fires were recorded in the Irkutsk Region and the Krasnoyarsk Territory resulting in the introduction of a federal emergency regime. In the Krasnoyarsk Territory alone, the fire destroyed about 130 houses, leaving more than 500 people homeless. In the Strelka settlement, where the Yenisei and Angara rivers merge, streets were burnt away. Two citizens of Kansk were killed.

On 29 May, a squall wind event in Moscow, with gusts as strong as $29 \mathrm{~m} \mathrm{~s}^{-1}$, caused the largest number of victims on record for such an event: officially, 11 people were killed. According to the TASS Agency, referring to a source in emergency services, 105 people were admitted to hospitals. Within just a few minutes, the winds felled thousands of trees, damaged many cars and the roofs of 30 houses, and stopped the operation of above-ground subway and commuter trains. 


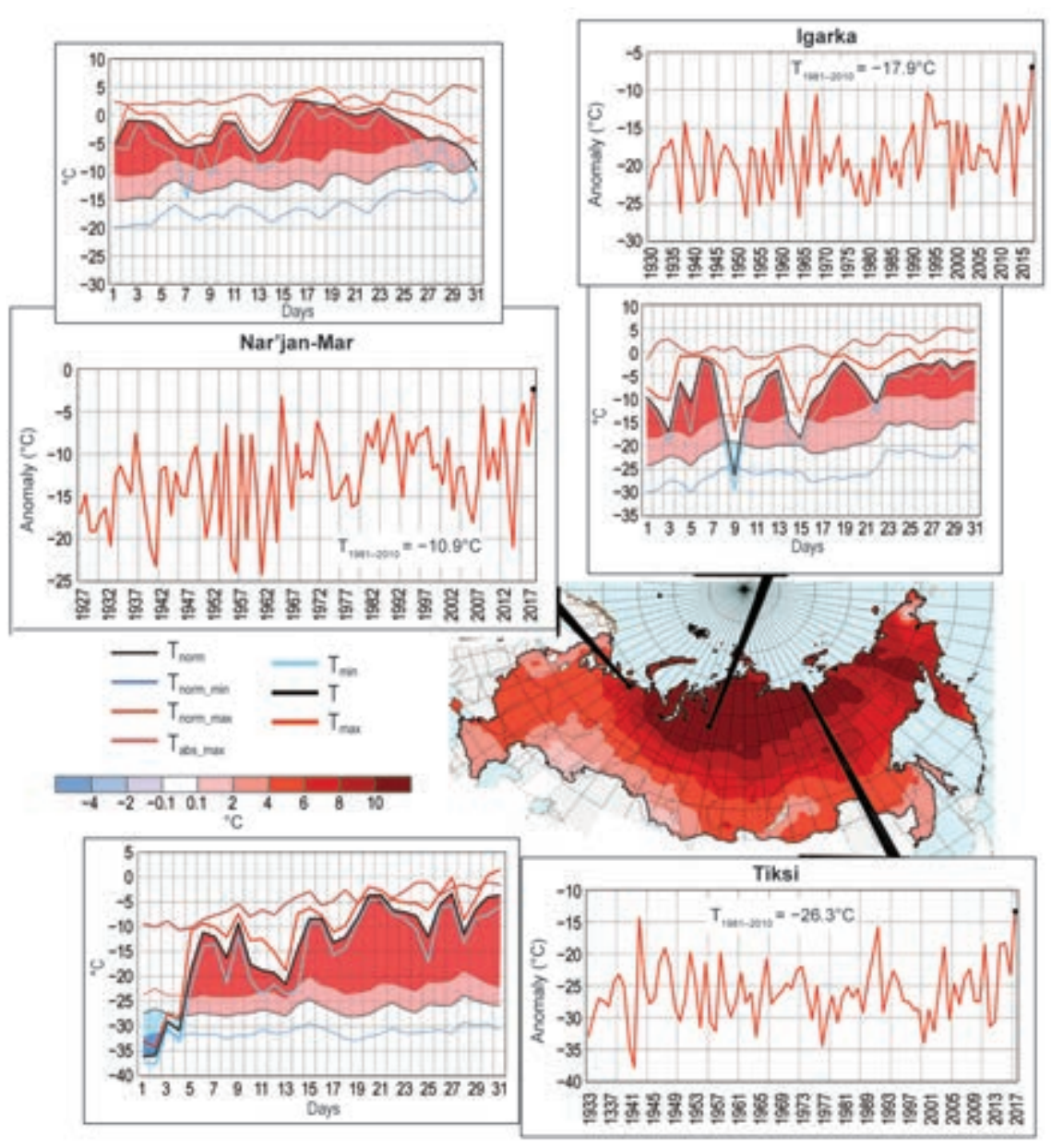

FIG. 7.44. Air temperature anomalies $\left({ }^{\circ} \mathrm{C}\right.$, shaded) in Mar 20I7. Insets show the series of mean monthly (from the beginning of the record to 2017) and mean daily air temperatures $\left({ }^{\circ} \mathrm{C}\right)$ in Mar 2017 at meteorological stations Igarka, Tiksi, Nar'jan-Mar. Plots of daily temperature show observed daily mean (black curve), minimum (blue) and maximum (red) temperatures along with their climatological normals and absolute maximum temperature; the area between daily mean values above normal and the normal daily mean curve is shaded pink, and where values are above normal daily maximum the shading is red.

On 30 June-1 July, a heavy thundershower (65 $\mathrm{mm})$, accompanied by hail as large as $3-8 \mathrm{~cm}$, and strong winds occurred in Moscow. Railroad beds in the Moscow Central Circle and motor roads were inundated, 1200 trees fell, and the roofs of nearly 100 houses and nearly 100 cars were damaged. Two people were killed.

Heavy rains (50$250 \mathrm{~mm}$ ) in the southwestern Maritime Territory on 6-7 August caused flooding in Ussuriisk on 7-8 August. Parked cars were submerged, ground floors of houses were inundated, and bus services and commuter trains were canceled. On 20-21 August, heavy rain $(113 \mathrm{~mm})$ in Krasnoyarsk lasted for more than 24 hours, flooding 40 homes and 43 road sections. In addition, 67 power transforming substations were inundated and cut off from personnel.

On 1 September, in the upper reaches of the Adyl$\mathrm{Su}$ River in the North Caucasus a dam failure

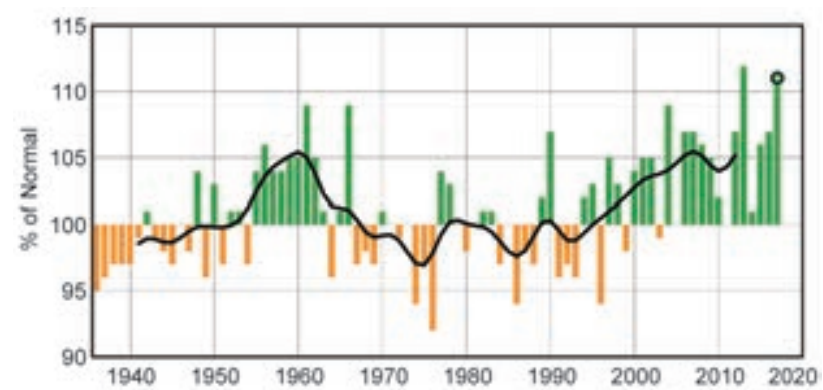

FIG. 7.45. Annual precipitation (\% of normal; 196I-90 base period) averaged over Russia for 1936-2017. The smoothed time series (II-point binomial filter) is shown as a bold line. occurred, resulting in a water discharge of $400000 \mathrm{~m}^{3}$ that transformed into a mud flow downstream. A 325-mm gas pipeline was damaged, and a federal highway was blocked. Three people were killed.

3) East and Southeast Asia_-P. Zhang, T. C. Lee, Y. Mochizuki, S.-E. Lee, L. Oyunjargal, and B. Timbal

Countries considered in this section include: China, Hong Kong (China), Japan, Korea, Mongolia, and Singapore. Unless otherwise noted, anomalies refer to a normal period of 1981-2010. 


\section{(i) Temperature}

Annual mean temperatures across East and Southeast Asia are visible in Fig. 7.38. The annual mean air temperature in 2017 for China was $0.84^{\circ} \mathrm{C}$ above normal $\left(9.55^{\circ} \mathrm{C}\right)$ - the third warmest year since records began in 1951, behind 2015 and 2007. All seasons were warm throughout the year, especially winter, with the highest anomaly in the historical record of $2.0^{\circ} \mathrm{C}$ above normal. Hong Kong had an annual mean temperature of $23.9^{\circ} \mathrm{C}, 0.6^{\circ} \mathrm{C}$ above normal and the third highest since records began in 1884 .

Annual mean temperatures were near normal in many regions of Japan and were significantly above normal in the Okinawa/Amami region. The 2017 annual average temperature over South Korea was $13.1^{\circ} \mathrm{C}$, which is $0.6^{\circ} \mathrm{C}$ above normal, making 2017 the seventh warmest year since national records began in 1973. The annual mean temperature over Mongolia for 2017 was $1.9^{\circ} \mathrm{C}, 1.4^{\circ} \mathrm{C}$ above normal, which is the second highest annual value since 1961 . The highest anomaly for Mongolia was April, with a mean temperature anomaly of $2.9^{\circ} \mathrm{C}$ above normal, representing the third warmest April since 1961. The lowest anomaly for Mongolia occurred in October when the mean temperature anomaly was $1.1^{\circ} \mathrm{C}$, $-0.3^{\circ} \mathrm{C}$ below normal.

In South Korea, May temperatures have significantly increased since the start of the record in 1973. The temperature averaged over South Korea in May 2017 was $18.7^{\circ} \mathrm{C}, 1.5^{\circ} \mathrm{C}$ above normal. This marks the fourth consecutive year of a new record high May temperature.

After two successive record warm years in 2015 and 2016, the mean annual temperature of Singapore $\left(27.7^{\circ} \mathrm{C}\right)$ returned closer to the long-term climatological average. This was $0.2^{\circ} \mathrm{C}$ warmer than normal and tied as the 12th warmest year on record since 1929; however, it is Singapore's warmest year on record not influenced by an El Niño event.

\section{(ii) Precipitation}

Figure 7.39 shows 2017 annual precipitation as a percentage of normal over East Asia. The annual mean precipitation in China was $641.3 \mathrm{~mm}, 101.8 \%$ of normal. Seasonal precipitation was $93 \%$ of normal in winter and $108 \%$ of normal in summer. Spring and autumn were near normal. Regionally, annual total precipitation was above normal in northwest China (115\% of normal), South China (105\%), the middle and lower reaches of the Yangtze River (104\%), north China (104\%), and near normal in southwest China, but below normal in northeast China (90\%). The annual total precipitation over river basins was above normal in the Yellow River (111\%), the Yangtze River (105\%), the Pearl River (105\%), and the Huaihe River (104\%) but below normal in the Liaohe (84\%), Songhua River (95\%), and Haihe River basins (98\%). The annual total rainfall in Hong Kong was $2572.1 \mathrm{~mm}$ (107\% of normal).

In Japan, annual precipitation amounts were above normal on the Sea of Japan side of northern and eastern Japan, and on the Pacific side of western Japan, and they were below normal in Japan's Okinawa/ Amami region. Annual total precipitation over South Korea was $967.7 \mathrm{~mm}, 74 \%$ of normal $(1307.7 \mathrm{~mm})$, and the fifth lowest total since 1973. Annual precipitation over Mongolia was $173.4 \mathrm{~mm}, 86.3 \%$ of normal. Although annual total precipitation was near normal, the majority of the growing season, especially May, June, and July, were dry $(57.1 \%-66.1 \%)$, causing drought conditions over $75 \%$ of the whole territory. Relative to normal, March was the wettest month (225\%) while July was the driest (57.1\%). January precipitation was near normal, with snow cover extent covering more than $70 \%$ of the total area. At the end of the year, snow covered almost $50 \%$ of the area and snow depth was $6-45 \mathrm{~cm}$ which caused difficulties for livestock pasturing.

In Singapore, there was a mixture of above- and below-normal rainfall for the individual months in 2017. Overall, the annual total rainfall was approximately $94 \%$ of the normal of $2165.9 \mathrm{~mm}$.

In 2017, the overall activity of the East Asian summer monsoon was near normal with some area to area differences in the region. Intraseasonal variability of the East Asian summer monsoon was clearly seen during the season. For example, convective activity over and around the Philippines was enhanced from late June to mid-July and was suppressed from late July to mid-August.

\section{(iii) Notable events and impacts}

Eight typhoons landed in China, the same number as 2016, and near the average of 7.2. However, the impact period was longer than normal, with the first typhoon, Merbok, landing in Shenzhen, Guangdong, on 12 June, 13 days earlier than normal, and the last typhoon, Khanun, landing in Zhanjiang, Guangdong, on 16 October, 10 days later than normal. Typhoon impacts varied strongly by time and region. For instance, Typhoons Nesat and Haitang landed successively on the coast of Fuqing city in Fujian Province during 30-31 July, and four typhoons hit the Grand Bay Area of Guangdong-Hong Kong-Macao in June, July, August, and October. As Tropical Cyclone Hato headed toward Hong Kong, the subsidence effect 
ahead of its circulation brought oppressive heat to the territory on 22 August as the temperature at the Hong Kong Observatory soared to an all-time high of $36.6^{\circ} \mathrm{C}$. Stormy weather with hurricane-force winds battered the city during the passage of Hato on the following morning. With Hato's approach coinciding with the astronomical high tide, its storm surge resulted in serious sea water flooding and damage in many low-lying areas in Hong Kong.

In 2017, meteorological disasters caused by rainstorms and floods in China were prominent and brought major losses, especially in southern China. Rainstorms occurred often and frequently in succession. Eleven days of persistent heavy rainfall occurred over southern China from 22 June to 2 July, associated with a rain belt across the provinces of Hunan, Jiangxi, Guizhou, and Guangxi, where local accumulations exceeded $500 \mathrm{~mm}$. During summer, the high temperature events hit China earlier in northern areas but were more intense in southern areas, which resulted in a record number of days with high temperatures (daily maximum temperature $\geq 35^{\circ} \mathrm{C}$ ) since the beginning of the record in 1961 . On 21 July, the maximum temperature at Xujiahui, in central Shanghai, was $40.9^{\circ} \mathrm{C}$, setting a record for its 145 -year period of observation (since 1873). In the west during mid-July, 53 high temperatures were recorded, which tied or broke records in counties (or cities) in Xinjiang, Gansu, Inner Mongolia, Shaanxi (44.7 ${ }^{\circ} \mathrm{C}$ in Xunyang), Ningxia, and Shanxi.

South Korea experienced above-normal temperatures and slightly below-normal rainfall during summer. The summer mean temperature over South Korea was $24.5^{\circ} \mathrm{C}$, which was $+0.9^{\circ} \mathrm{C}$ above normal. In particular, extreme temperatures were observed from late-June through late-July. During this period, South Korea was strongly influenced by the western North Pacific subtropical high that extended more to the northwest compared to its normal position brought hot, moist air by the southwesterlies along its flank. The summer rainfall $(609.7 \mathrm{~mm})$ over South Korea was $84 \%$ of normal $(723.2 \mathrm{~mm})$. The ratios of monthly rainfall amount to the normal value in June, July, and August were 38\%, 103\%, and 88\%, respectively. The 2017 Changma (early summer rainy period) started on 24 June and ended on 29 July. The Changma rainfall total was below normal $(291.7 \mathrm{~mm}$; normal: $356.1 \mathrm{~mm}$ ). The 2017 Changma was notable for the following: 1 ) onset and retreat were later than normal; 2) heavy rainfall events were concentrated on the central part of the Korean Peninsula; and 3) large spatial differences of rainfall between the southern and central regions of South Korea were observed.
In northern Japan, on 5-6 July, record-breaking heavy rain associated with the active Baiu front fell in Kyushu region, with $129.5 \mathrm{~mm} \mathrm{~h}^{-1}$ and $545.5 \mathrm{~mm}(24-\mathrm{h})^{-1}$ observed at Asakura in Fukuoka prefecture. The heavy rain caused serious damage, including landslides and river overflows. In Okinawa/ Amami, monthly mean temperatures were record high in August $\left(+1.4^{\circ} \mathrm{C}\right.$ above normal) and recordtying (since 1946) high in September $\left(+1.3^{\circ} \mathrm{C}\right.$ above normal) due to a stronger-than-normal subtropical high over south of Japan. In western Japan, the monthly precipitation total was record high, at 333\% of normal for October.

In Mongolia, a total of 76 extreme weather events were observed, including episodes of heavy snow and flash flooding. Together, these events caused about $\$ 1.9$ million (U.S. dollars) in economic loss.

4) South AsiA-A. K. Srivastava, J. V. Revadekar, and M. Rajeevan

Countries in this section include: Bangladesh, India, Pakistan, and Sri Lanka. Climate anomalies are relative to the 1981-2010 normal.

\section{(i) Temperature}

In general, South Asia witnessed significantly above-normal temperatures in 2017. The annual mean land surface air temperature averaged over India was $0.50^{\circ} \mathrm{C}$ above the $1981-2010$ average, ranking 2017 as the fourth warmest year on record since nationwide records commenced in 1901 (Fig. 7.46). India's seasonal mean temperatures were above normal for all four seasons. The country-averaged seasonal mean temperatures during the post monsoon season (October-December, with an anomaly of $+0.67^{\circ} \mathrm{C}$,

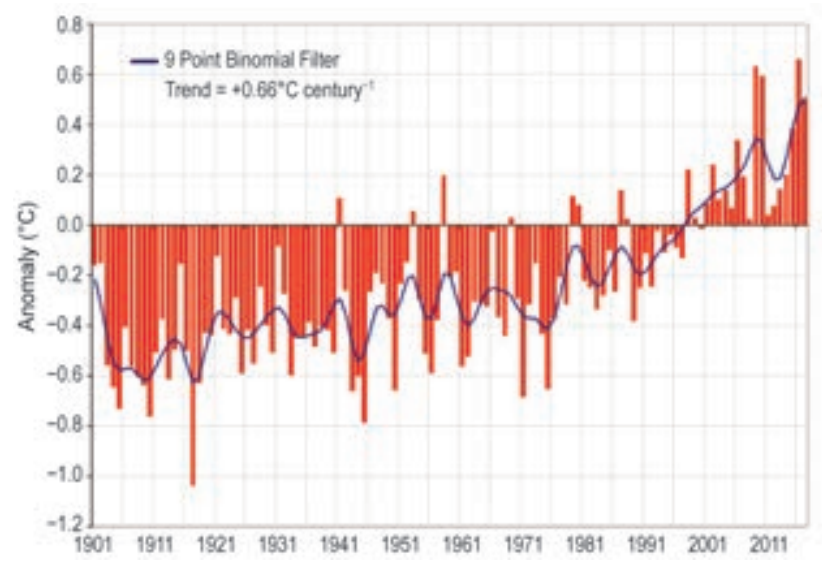

Fig. 7.46. Annual mean temperature anomalies $\left({ }^{\circ} \mathrm{C}\right.$; 198I-2010 base period) averaged over India for 190I2017. The smoothed time series (9-point binomial filter) is shown as a continuous blue line. 
the third highest since 1901) and the winter season (January-February, anomaly $+0.61^{\circ} \mathrm{C}$, fourth highest ever since 1901) mainly accounted for the abovenormal temperature for the year.

\section{(ii) Precipitation}

The summer monsoon season (June-September) typically contributes about $75 \%$ of annual precipitation over South Asia. The summer monsoon set in over Kerala (southern parts of peninsular India) on 30 May, 2 days prior to its climatological normal date (1 June) and covered the entire country on 19 July (4 days later than its normal date, 15 July).

For India, the long-term average (LTA) value of the summer monsoon rainfall, calculated using all data from 1951 to 2000 , is $890 \mathrm{~mm}$. The standard deviation of Indian summer monsoon rainfall (ISMR) is around $10 \%$ of the LTA value. However, over smaller regions natural variability of the monsoon is large (standard deviation around 19\%). In view of the above, an ISMR exceeding $110 \%$ of the LTA in a year is termed as excess rainfall, while an ISMR that is less than $90 \%$ of the LTA in a year is termed as deficient rainfall.

During 2017, the ISMR averaged over the country as a whole was $95 \%$ of its LTA and was characterized by significant spatial and temporal variability (Fig. 7.47).
The homogeneous region of South Peninsula received normal rainfall (100\% of LTA). The homogeneous regions of central India and east-northeast India received $94 \%$ and $96 \%$ of LTA of the seasonal rainfall, respectively. Northwest India received below-normal rainfall ( $90 \%$ of monsoon season LTA). On monthly scales, rainfall for the country as a whole was normal during June (104\% of its LTA value) and July (102\%). It was below normal during August (87\%) and September (88\%). During the monsoon season, out of 36 meteorological subdivisions, five subdivisions (West Rajasthan; Saurashtra \& Kutch; Nagaland, Manipur, Mizoram \& Tripura; Rayalaseema; and Tamil Nadu \& Pondicherry) received excess rainfall, 25 received normal rainfall, and the remaining six subdivisions (four subdivisions from the northwest region and two subdivisions from central India) received deficient rainfall. Figure 7.48 shows the standardized rainfall anomaly over the core monsoon region on a daily scale during the season. There was significant intraseasonal rainfall variability with marked active and break spells.

During the winter season (January-February), season, rainfall over the country was normal ( $95 \%$ of LTA); it was normal (98\% of LTA) during the pre-monsoon season (March-May), while it was below normal (a) Actual

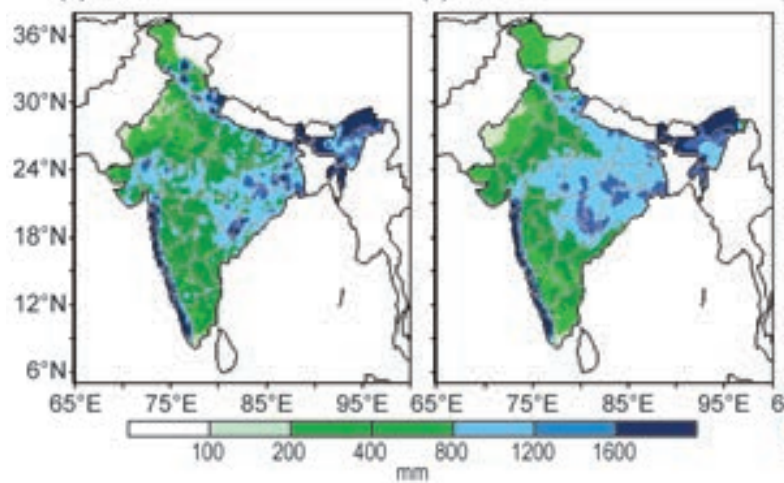

(c) Anomaly

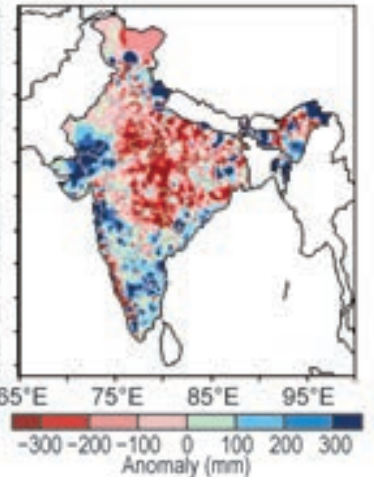

FIG. 7.47. Spatial distribution of monsoon seasonal (Jun-Sep) rainfall over India in 2017. (a) Actual, (b) normal, and (c) anomalies are in $\mathrm{mm}$.

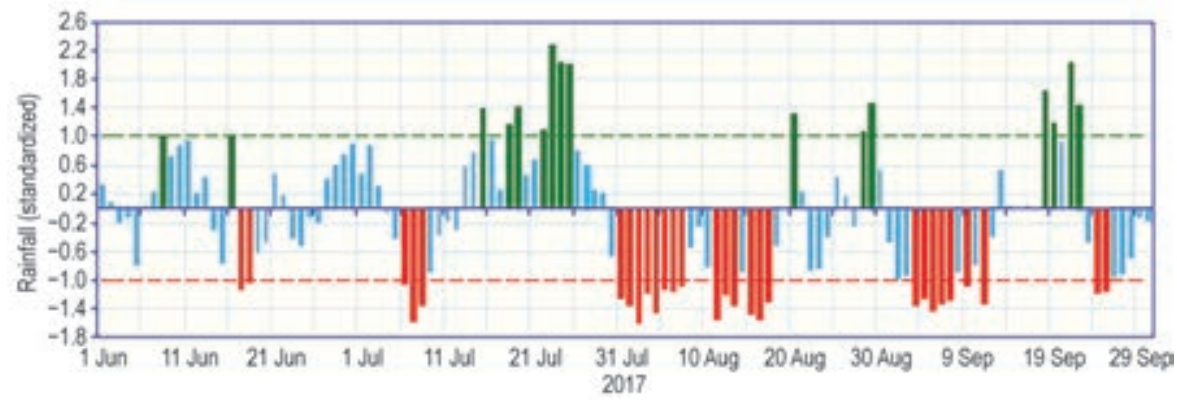

FIG. 7.48. Daily standardized rainfall time series averaged over the core monsoon zone of India (I Jun-30 Sep 2017). during the post-monsoon season (October-December, $89 \%$ of LTA). The northeast monsoon (NEM) normally sets in over southern peninsular India during October and over Sri Lan$\mathrm{ka}$ in late November. The NEM contributes $30 \%$ to $50 \%$ of the annual rainfall over southern peninsular India and Sri Lanka as a whole. The 2017 NEM set in over southern peninsular India on 27 October, and the seasonal rainfall over south peninsular India was below normal ( $86 \%$ of LTA value). Moderate La Niña conditions prevailed during the season, which could be one of the reasons for the below-normal performance of the NEM.

Pakistan, at the western edge of the pluvial region of the south Asian monsoon, 
receives $60 \%-70 \%$ of its annual rainfall during the summer monsoon season (July-September). The summer monsoon sets in over northeastern parts of Pakistan around 1 July with a standard deviation of five days. In 2017, summer monsoon rainfall over Pakistan was below normal (77.5\% of its LTA value). Pakistan observed below-normal rains during all three months from July to September (79.6\%, 74.3\%, and $82.7 \%$ of its LTA values). Rainfall was below normal in all the provinces of Pakistan. Southern parts of Pakistan (especially the southwest) received largely deficient rainfall. Other areas, including central Pakistan, received normal rainfall during the monsoon season. Bangladesh received normal rainfall during the 2017 summer monsoon season.

Sri Lanka received normal rainfall during its summer monsoon season (May-September). Northeast monsoon rainfall activity over the island nation, during October-December 2017, was also normal.

\section{(iii) Notable events and impacts}

During 2017, three cyclonic storms (one each in April, May, and November) formed over the north Indian Ocean. The first storm, Maarutha, formed over the east central Bay of Bengal on 15 April. However, it moved northeastward away from the Indian region and crossed the Myanmar coast on 16 April. Though the system did not cause significant weather over the mainland of India, it caused light to moderate rain over the Andaman and Nicobar islands during its formative stage.

The second severe storm, Mora, formed over the Bay of Bengal during 28-31 May. It made landfall over the Bangladesh coast on 30 May and dissipated over the northeastern parts of the country on 31 May. This system caused moderate to heavy rain over many parts of the northeastern region of India after making landfall.

The last severe storm, Ockhi, (29 November-5 December) formed over south Bay of Bengal and moved to the Arabian Sea. The storm, while moving across southern parts of India, caused severe damages in Kerala, Tamil Nadu, and Lakshadweep. The storm also claimed the lives of many fishermen (18 from Tamil Nadu and 74 from Kerala). Ockhi ultimately recurved and moved towards the south Gujarat coast.

Heavy rain and flood-related incidents during the monsoon season claimed around 800 lives from different parts of India (see Table 7.2 for 24-hr rainfall records over India). Around 150 people reportedly died in the state of Assam from 13 June to 11 September in two spells of floods. More than a hundred people were reported dead in Uttar Pradesh due to heavy rain and floods of the Ghaghara, Gomati, and Rapti

TABLE 7.2. Record rainfall (24hr) during the 2017 monsoon season in India.

\begin{tabular}{|c|c|c|c|c|c|c|}
\hline S. No. & Station & $\begin{array}{c}\text { Rainfall } \\
\text { During Past } 24 \\
\text { Hrs. (mm) }\end{array}$ & Date & $\begin{array}{c}\text { Previous } \\
\text { record } \\
(\mathrm{mm}) \\
\end{array}$ & $\begin{array}{l}\text { Date of } \\
\text { record }\end{array}$ & $\begin{array}{l}\text { Year of } \\
\text { record }\end{array}$ \\
\hline & & & Jun 2017 & & & \\
\hline 1 & Karnal & 140.4 & 28 & 80 & 30 & 1994 \\
\hline 2 & Baderwah & 56 & 30 & 55.8 & 2 & 2004 \\
\hline \multirow[t]{2}{*}{3} & Katra & 147.9 & 30 & 90.2 & 30 & 2000 \\
\hline & & & Jul 2017 & & & \\
\hline 1 & Ranchi AP & 205.8 & 26 & 178.8 & 23 & 1958 \\
\hline 2 & Bhagalpur & 173.6 & 2 & 154.6 & 27 & 2009 \\
\hline 3 & Raisen & 208.9 & 28 & 188.4 & 22 & 1973 \\
\hline \multirow[t]{2}{*}{4} & Jagdalpur & 191.4 & 19 & 180.8 & 7 & 1934 \\
\hline & & & Aug 2017 & & & \\
\hline 1 & Jalpaiguri & 295.2 & 12 & 264.2 & 10 & 1987 \\
\hline 2 & Osmanabad & 151.0 & 20 & 149.8 & 22 & 2010 \\
\hline 3 & Adirampattinam & 128.4 & 9 & 97.9 & 29 & 2007 \\
\hline 4 & Thanjavur & 110 & 10 & 105 & 30 & 2016 \\
\hline \multirow[t]{2}{*}{5} & Thanjavur & 105 & 30 & 99.0 & 7 & 1982 \\
\hline & & & Sep 2017 & & & \\
\hline 1 & Harnai & 373.6 & 19 & 308.6 & 23 & 1949 \\
\hline 2 & Pamban & 113.5 & 9 & 108.5 & 27 & 1901 \\
\hline 3 & Tuticorin & 63 & 1 & 58.3 & 6 & 1979 \\
\hline 4 & Uthagamandalam & 81.6 & 3 & 65.3 & 29 & 1951 \\
\hline 5 & Mysore & 137 & 27 & 129.3 & II & 1940 \\
\hline
\end{tabular}


Rivers during 4-10 September. About 120 deaths were reported from the western industrial state Gujarat during the month of July and 107 from Bihar during 13-23 August. On 13 August, 46 deaths were reported due to massive landslides at Kotrupi on the MandiPathankot National Highway near Jogindernagar in Himachal Pradesh (India). Similarly, 15 people died in Papum Pare, Arunachal Pradesh on 11 July due to a landslide.

Heat wave conditions prevailed mainly over peninsular parts of India during the second fortnight of May, which claimed the lives of about 100 people in the state of Telangana. However, the loss of lives in 2017 was much less than in the previous years due to timely heat wave warnings and heat wave action plans initiated by government. In April 2017, Larkana, a city in the southern province of Sindh of Pakistan, experienced a record maximum temperature of $51.0^{\circ} \mathrm{C}$ on 20 April. On 28 May, Turbat, in western Pakistan, recorded a temperature of $53.5^{\circ} \mathrm{C}$, tying the all-time highest temperature recorded in Moen Jo Daro, Pakistan, on 26 May 2010.

In August, Bangladesh suffered one of its worst floods in the past four decades, which affected approximately one-third of the country, primarily in the northern, northeastern, and central regions. Rangpur district in the northeast experienced a month's worth of rain-360 mm-in just two days (11-12 August). Around 140 deaths from the floods were reported, over fifty thousand people were displaced, and approximately six million were affected.

Fifteen districts of Sri Lanka were affected by severe floods during the last ten days of May. Parts of Sri Lanka received 300-500 $\mathrm{mm}$ of heavy monsoon rain in a 24 -hour period around 25 May, resulting in widespread flooding. The highest recorded rainfall was $533 \mathrm{~mm}$ in Kukuleganga. Galle, a coastal city, received $223 \mathrm{~mm}$ and Ratnapura experienced $453 \mathrm{~mm}$ of rainfall during 27-30 May, leading to severe inland flooding. Around 150 people were killed and around 450000 were affected.

\section{5) SOUtHWEST AsIA-M. Khoshkam and A. Kazemi}

This subsection covers only Iran. Turkey is incorporated in the Europe subsection, $7 \mathrm{f}$. Climate anomalies are relative to a $1996-2015$ base period.

\section{(i) Temperature}

In general, the year was warmer than average for Iran. The mean annual air temperature was $0.5^{\circ}-1.5^{\circ} \mathrm{C}$ above the 20 -year average. Spring and autumn temperatures were above average for the entire country, while the winter and summer seasons experienced regional patterns of above- and belowaverage temperatures. There is a sharp contrast between the pattern of temperature anomalies in winter and summer. Northwestern Iran experienced a colder-than-average winter season but a warmerthan-average summer season.

\section{(ii) Precipitation}

In 2017, Iran was drier than normal for the year as a whole, receiving $205 \mathrm{~mm}$ precipitation, with totals of $117.4,53.1,6.2$, and $28.4 \mathrm{~mm}$ for winter, spring, summer, and autumn, respectively. The country experienced drier-than-normal conditions in spring, summer, and autumn. The only relatively wet season was winter; however, several provinces, especially in southwestern, northwestern, and parts of central Iran, observed precipitation deficits of up to $50 \%$ of normal during winter. The winter seasonal rainfall largely occurred during the second half of the season. MODIS snow data indicate that snow coverage over the country was greatest in February and declined in March. Snow coverage was observed in December 2017, the first month of winter 2017/18.

According to spatial analysis of the standardized precipitation index (SPI), areas with mild to severe drought conditions were encountered especially in the northwest, west, and southwest in winter, the northwest, east, and northeast in the spring, and the northwest and northern parts in the summer. The SPI is a tool that was developed primarily for defining and monitoring drought. Mathematically, it is based on the cumulative probability of a given rainfall event occurring at a station. According to this indicator, most regions of the country were in mild to very severe drought during autumn. The central and eastern areas were in extreme drought conditions during autumn.

\section{(iii) Notable events and impacts}

A maximum temperature of $53.7^{\circ} \mathrm{C}$ was observed in Ahvaz in summer. In spring, an extreme warm temperature of $51.7^{\circ} \mathrm{C}$ was recorded in Sistan and Balochestan. While the entire country experienced dry conditions during 2017, an extreme rainfall event, with $264 \mathrm{~mm}$ in 24 hours, was observed in summer at Station Lahijan. Table 7.3 lists measured extreme events in each season over Iran. The frequency and duration of dust storms in 2017 became higher in some parts of the country, especially in the southwest and southeast during winter and spring. 


\begin{tabular}{|c|c|c|c|}
\hline \multicolumn{4}{|c|}{$\begin{array}{c}\text { TABLE 7.3. Measured values of } \mathbf{2 0 I 7} \text { record temperatures and 24-hr precipitation in Iran. Location } \\
\text { includes station (province). }\end{array}$} \\
\hline Season & $\begin{array}{c}\text { Minimum } \\
\text { temperature }\left({ }^{\circ} \mathrm{C}\right)\end{array}$ & $\begin{array}{c}\text { Maximum } \\
\text { temperature }\left({ }^{\circ} \mathrm{C}\right)\end{array}$ & $\begin{array}{c}\text { Maximum 24-hr } \\
\text { precipitation (mm) }\end{array}$ \\
\hline Winter & -30 Hezar Kanian (Kordestan) & $\begin{array}{c}37 \text { Rask } \\
\text { (Sistan and Balochestan) }\end{array}$ & $\begin{array}{c}\text { 164.6 Jem } \\
\text { (Bushehr) }\end{array}$ \\
\hline Spring & -8.6 Zarineh Obatoo (Kordestan) & $\begin{array}{c}51.7 \text { Rask } \\
\text { (Sistan and Balochestan) }\end{array}$ & $\begin{array}{c}99.7 \text { Ghir Kazeroun } \\
\text { (Fars) }\end{array}$ \\
\hline Summer & $\begin{array}{c}0.8 \text { Ardebil } \\
\text { (Ardebil) }\end{array}$ & $\begin{array}{c}53.7 \text { Ahvaz } \\
\text { (Khozestan) }\end{array}$ & $\begin{array}{c}\text { 264 Lahijan } \\
\text { (Gilan) }\end{array}$ \\
\hline Autumn & 45.2 Abadan (Khozestan) & -20.2 Khayerabad (Zanjan) & $\begin{array}{c}200.1 \text { Ramsar } \\
\text { (Gilan) }\end{array}$ \\
\hline
\end{tabular}

\section{SIDEBAR 7.3: ABNORMAL WEST CHINA AUTUMN RAINFALL IN 2017 AND PERSISTENCE OF THE PACIFIC-JAPAN PATTERN IN AUGUST 20I7-Z. ZHU, T. LI, AND H. TOGAWA}

Climatologically, a precipitation peak over West China $\left(27^{\circ}-35^{\circ} \mathrm{N}, 105^{\circ}-114^{\circ} \mathrm{E}\right)$ during September and October is referred to as West China Autumn Rainfall (WCAR). It is the final stage of the rainy season in mainland China. WCAR can have severe impacts on agricultural production-including the harvesting and sowing of winter crops-and reservoir levels. Due to the fragile ecological environment of West China, above-normal WCAR often results in landslides and debris flows, which threaten lives and economic development in the region.

WCAR in 2017 was $170 \%$ of normal (Fig. SB7.4a), the second highest total since records began in 1979 (Fig. SB7.4b). The event greatly affected 6 million people over seven Chinese provinces. Over 480000 hectares of crops were damaged, and the total economic loss was over $\$ 20$ billion (U.S. dollars).

In the lower troposphere during September and October 2017, an anticyclonic anomaly at $850 \mathrm{hPa}$ covered a large domain of southern China, with southwesterly anomalies at its western flank. Another anticyclonic anomaly (high pressure system) existed to the north of the anticyclonic anomaly. These two south-north anticyclonic anomalies led to a horizontal trough over West China. The southwesterly anomalies in the southern portions of the trough transported moisture from the northern Indian Ocean and South China Sea
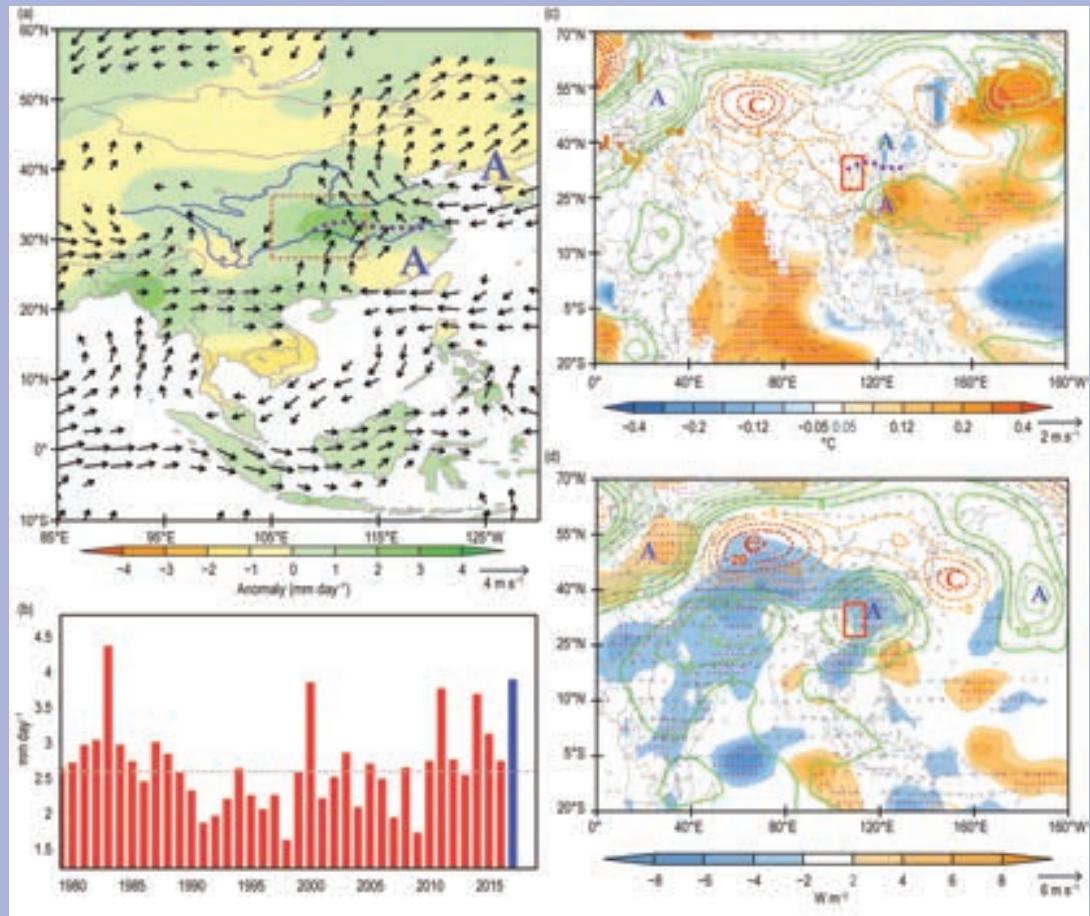

FIG. SB7.4. (a) Precipitation (shading; $\mathrm{mm} \mathrm{day}^{-1}$ ) and $850-\mathrm{hPa}$ wind (vector; $\mathrm{m} \mathrm{s}^{-1}$ ) anomalies in Sep and Oct 2017. Only winds with speeds >I $\mathrm{m} \mathrm{s}^{-1}$ are shown. (b) Year-to-year time series of the WCAR (red bars; $\mathrm{mm}$ day $^{-1}$ ). 2017 is blue bar. Gray dashed line is the $1981-2010$ climatological mean. (c) Wind (vectors; $\mathrm{m} \mathrm{s}^{-1}$ ), geopotential height (contours; gpm) at $850-\mathrm{hPa}$, and SST $\left({ }^{\circ} \mathrm{C}\right)$ fields regressed onto the WCAR index. (d) as in (c) but for 200-hPa wind, geopotential height, and OLR ( $\left.\mathrm{W} \mathrm{m}^{-2}\right)$ fields. Only winds significant at the $95 \%$ confidence level are shown, and the SST and OLR significant at $\mathbf{9 5 \%}$ confidence level are marked by red dots. "A (C)" denotes the anticyclonic (cyclonic) anomaly. Red box indicates the key region of WCAR, dashed purple line marks the horizontal trough. 
CONT. SIDEBAR 7.3: ABNORMAL WEST CHINA AUTUMN RAINFALL IN 2017 AND PERSISTENCE OF THE PACIFIC-JAPAN PATTERN IN AUGUST 2017-l. ZHU, T. LI, AND H. TOGAWA

The unusualness of the rainy season was the result of the combination of various atmospheric patterns. Typically, the enhanced WCAR is associated with positive tropical Indian Ocean SST anomalies (Fig. SB7.4c). Positive tropical Indian Ocean SST anomalies could induce a Kelvin wave response in terms of easterly anomalies in the lower troposphere. The Kelvin wave easterlies generated anticyclonic shear and resulted in anticyclonic anomalies over the western North Pacific, leading to anomalous moisture transport as seen in the 2017 event. Divergence at $200 \mathrm{hPa}$ (Fig. SB7.4d was predominant over West China and appeared to be part of the circumglobal wave train over midlatitudes. Divergence aloft and convergence (associated with the horizontal trough) at lower levels over the region provided a favorable dynamical condition to the enhanced rainfall in the region.

From early to mid-August, convective activity was particularly inactive over and around the Philippines. During the same period, the North Pacific subtropical high (NPSH) did not extend to mainland Japan as usual but shifted southward from its normal position, corresponding to the Pacific-Japan (PJ) pattern (Nitta 1987; Kosaka and Nakamura 2010; Fig. SB7.5a), with suppressed convective activity over and around the Philippines. Furthermore, the Tibetan high in the upper troposphere extended southward to cover Okinawa/Amami. Meanwhile, the Okhotsk high, which brought cool wet northeasterly flows to the Pacific side of northern and eastern Japan, had persisted since late July. The persistence of the Okhotsk high was presumed to be mainly due to blocking-high development over the Sea of Okhotsk, in association with the meandering westerly jet stream over northern Eurasia (Fig. SB7.5b).

Corresponding to the PJ pattern with suppressed convective activity over and around the Philippines, this anomalous atmospheric circulation in the lower troposphere brought longer-than-normal sunshine durations, adiabatic heating associated with stronger-than-normal subsidence, and westerly warm air inflow over Okinawa/Aamami. These factors contributed to significantly warm conditions over Okinawa/ Amami, and monthly mean temperature over Okinawa/Amami in August 2017 was the highest on record for August since 1946. A southward extension of the Tibetan high presumably contributed to the warm condition over the area. At the same time, the low-level anticyclonic circulation anomalies brought considerable moisture to the middle and lower Yangtze River basin where above-normal precipitation was observed. Meanwhile, due to both the Okhotsk high and the PJ pattern, the Pacific side of northern and eastern Japan experienced significantly below-normal sunshine duration.

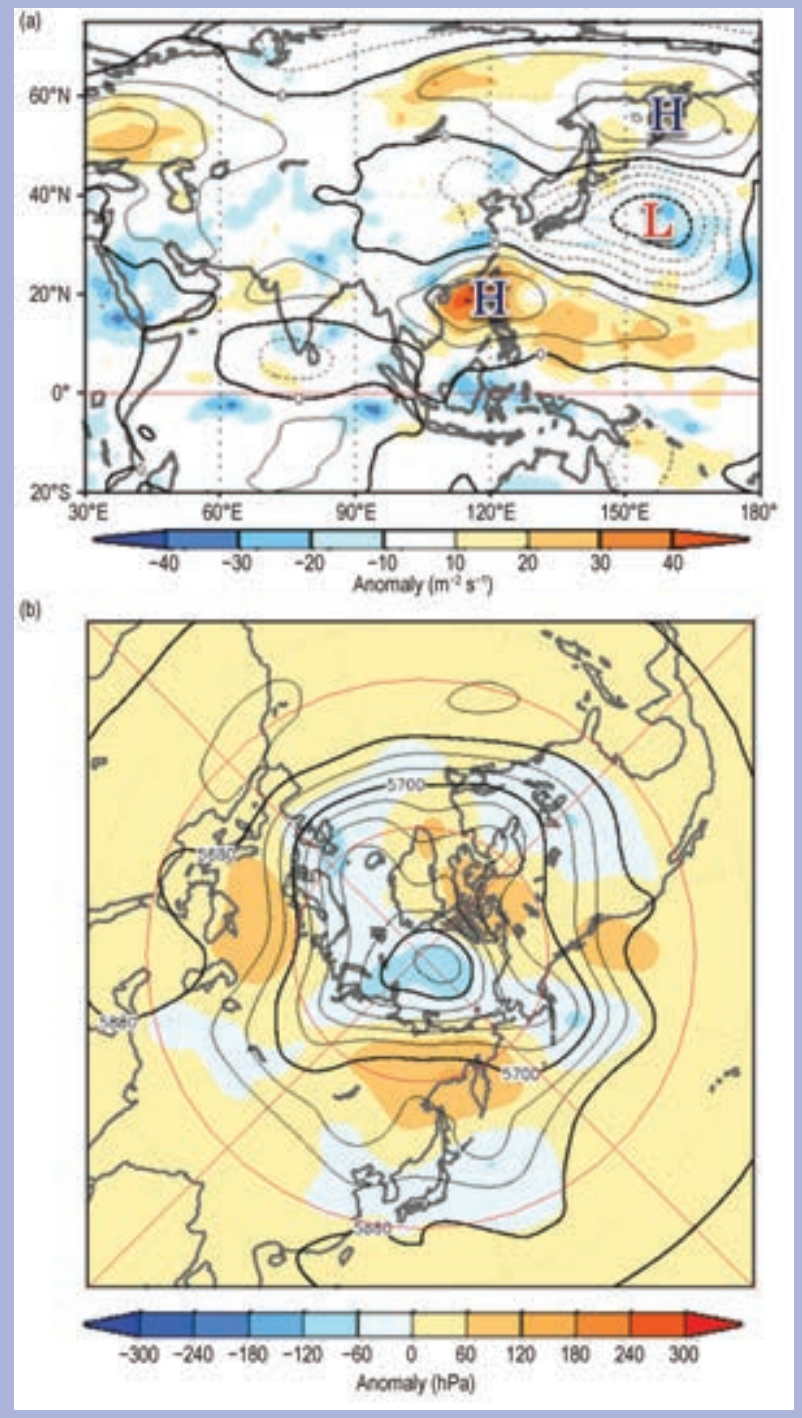

FIG. SB7.5. (a) Stream function anomalies at $850-\mathrm{hPa}$ (contours) and OLR anomalies $\left(\mathrm{m}^{2} \mathrm{~s}^{-1}\right.$; color shadings) averaged over I-20 Aug 2017. Thick and thin contours are intervals of $10 \times 10^{6}$ and $2.5 \times 10^{6} \mathrm{~m}^{2} \mathrm{~s}^{-1}$, respectively. For the $\mathrm{NH}$, solid and dashed lines indicate anticyclonic and cyclonic circulation anomalies, respectively. For the SH, vice versa. (b) $500-\mathrm{hPa}$ height anomaly in the NH averaged over I-20 Aug 2017. Contours show $500-\mathrm{hPa}$ height at intervals of $60 \mathrm{~m}$. Shading indicates anomalies. Base period is $198 \mathrm{I}-2010$.

The condition of enhanced NPSH over the south of Japan persisted from August to October. It is considered to have been caused by active convection over the Maritime Continent due to positive SST anomalies in the western tropical Pacific, which were related to the development of weak La Niña conditions in the eastern equatorial Pacific (see Fig. 3.2). 


\section{h. Oceania}

I) OVERVIEW-C. Ganter

The climate of Oceania experienced a neutral ENSO state for most of 2017, which then transitioned to weak La Niña conditions late in the year. The Indian Ocean dipole (IOD) was neutral during its typical active period (May-November), while several countries were influenced by a positive southern annular mode during the austral winter. Persistent strong stationary high pressure systems in the Tasman Sea during November and December contributed to warmer weather across southeast Australia and New Zealand, and they also warmed surface waters of the Tasman Sea, causing a notable marine heatwave which persisted into 2018 (see Sidebar 7.4).

\section{2) Northwest Pacific and Micronesia—M. A. Lander} and C. P. Guard

This assessment covers the area from the international dateline west to $130^{\circ} \mathrm{E}$, between the equator and $20^{\circ} \mathrm{N}$. It includes the U.S.-affiliated Islands of Micronesia but excludes the western islands of Kiribati and nearby northeastern islands of Indonesia. Temperature and precipitation anomalies in this section are relative to a 1981-2010 period.

Weather conditions across Micronesia during 2017 were mostly unremarkable. Annual rainfall was near to above average at most locations, and tropical cyclone activity was much lower than average. The western North Pacific summer monsoon system was displaced to the west and north of Micronesia, accompanying a similar westward and northward displacement of the basin's tropical cyclones. These patterns of rainfall, wind, and typhoon distribution were typical for an ongoing La Niña. The regional oceanic response to La Niña climate conditions (e.g., increased trade wind strength) was sustained higherthan-average mean sea level.

\section{(i) Temperature}

Temperatures across Micronesia in 2017 were mostly above average. The warmth was persistent, with above-average readings occurring during most or all the months of the year. Only Yap Island and Pohnpei Island reported moderate negative temperature departures for any of the time periods summarized in Table 7.4. Saipan reported extraordinary warmth with daytime highs $3.42^{\circ} \mathrm{C}$ above average during the second half of the year. The reason for Saipan's excessive warmth (with many records set for highest daily maximum and highest minimum temperatures) is uncertain. The 6-month minimum and maximum temperatures for selected locations across Micronesia are summarized in Table 7.4.

\section{(ii) Precipitation}

Annual rainfall totals during 2017 were mostly higher than average throughout Micronesia, with below-average seasonal and annual rainfall amounts restricted to the northern Mariana Islands (Rota, Tinian, and Saipan), a few of the northern atolls of Chuuk State, and the northern atolls of the Republic of the Marshall Islands (RMI). The 6-month and annual rainfall values for selected locations across Micronesia are summarized in Table 7.4.

\section{(iii) Notable events and impacts}

Late in December 2016, and again in October 2017, a landfalling waterspout caused damage on an atoll of Micronesia. In the former case, a large and intense waterspout swept across Falalop (one of the islets of the Ulithi Atoll). Eyewitnesses described a surge of high wind that blasted across the islet, filling the air with lofted debris that appeared to be rotating.

The Ulithi waterspout/tornado occurred in association with deep convection in a near-core rainband of Tropical Storm Nock-ten. As reported in the 23 January 2017 issue of the Khaselehlia Press:

"On December 22, 2016, a water spout turned tornado ripped through the island, tearing apart over 20 newly repaired homes and cook houses along its path. "It sounded like a jet was flying low over the island. Luckily, we had been warned that Typhoon Nock-ten could be headed in our direction so we were prepared for a potential disaster. If we hadn't received warning about Nock-ten, this tornado would have claimed lives on Falalop," said local resident Jon Rumal Jr.”...

It was not officially verified that this event was a tornado, but eyewitness accounts are convincing.

The next incident of a landfalling waterspout occurred on 14 October when waterspouts were observed at Nomwin Atoll in the Hall Islands of Chuuk State. One of the waterspouts went ashore on Nomwin where "it was strong enough to topple banana trees, and weak infrastructure houses were down and damaged" as reported to the Chuuk Weather Service Office. A boat was found capsized in Nomwin waters on 15 October. It is thought by islanders that the boat was capsized by a waterspout. The Nomwin incident of waterspout formation occurred in association with a large area of heavy convective showers comprising the monsoon 
TABLE 7.4. Temperature $\left({ }^{\circ} \mathrm{C}\right)$ and rainfall $(\mathrm{mm})$ anomalies for selected Micronesia locations during $20 \mathrm{I7.}$ Average (AVG) values are for the 198I-2010 base period. Latitudes and longitudes are approximate. "Kapinga" stands for Kapingamarangi Atoll in Pohnpei State, Federated States of Micronesia. Shading of the boxes indicates: red for above-average temperature and blue for below average; green for above-average rainfall and yellow for below average.

\begin{tabular}{|c|c|c|c|c|c|c|c|c|c|c|}
\hline \multirow[t]{2}{*}{ Location } & \multicolumn{2}{|c|}{$\begin{array}{l}\text { Max Temp } \\
\text { Min Temp }\end{array}$} & \multicolumn{8}{|c|}{ Rainfall (mm) } \\
\hline & Jan-Jun & Jul-Dec & Jan-Jun & Jan-Jun & Jan-Jun & Jul-Dec & Jul-Dec & Jul-Dec & Jan-Dec & Jan-Dec \\
\hline & ${ }^{\circ} \mathrm{C}$ & ${ }^{\circ} \mathrm{C}$ & AVG & 2017 & $\%$ & AVG & 2017 & $\%$ & 2017 & $\%$ \\
\hline $\begin{array}{c}\text { Saipan, } \\
15^{\circ} \mathrm{N}, 146^{\circ} \mathrm{E}\end{array}$ & $\begin{array}{l}+2.63 \\
+1.60 \\
\end{array}$ & $\begin{array}{l}+3.42 \\
+2.61 \\
\end{array}$ & 449.1 & 534.2 & 118.9 & 1322.8 & 861.3 & 65.1 & 1395.5 & 78.8 \\
\hline $\begin{array}{c}\text { Guam, } 13^{\circ} \mathrm{N}, \\
145^{\circ} \mathrm{E}\end{array}$ & $\begin{array}{l}+0.70 \\
+0.82 \\
\end{array}$ & $\begin{array}{l}+0.80 \\
+0.64 \\
\end{array}$ & 691.6 & 900.9 & 130.3 & 1788.4 & 1561.6 & 87.5 & 2462.5 & 99.4 \\
\hline \multirow{2}{*}{$\begin{array}{c}\text { Yap, } \\
9^{\circ} \mathrm{N}, 138^{\circ} \mathrm{E} \\
\end{array}$} & -0.70 & -0.43 & \multirow{2}{*}{1169.7} & \multirow{2}{*}{1548.4} & \multirow{2}{*}{132.4} & \multirow{2}{*}{1902.0} & \multirow{2}{*}{1985.0} & \multirow{2}{*}{104.4} & \multirow{2}{*}{3533.4} & \multirow{2}{*}{115.0} \\
\hline & +0.08 & +0.01 & & & & & & & & \\
\hline $\begin{array}{c}\text { Palau, } \\
7^{\circ} \mathrm{N}, 134^{\circ} \mathrm{E} \\
\end{array}$ & $\begin{array}{l}+0.77 \\
+0.18 \\
\end{array}$ & $\begin{array}{l}+0.97 \\
+0.20 \\
\end{array}$ & 1717.6 & 2037.8 & 118.6 & 2032.5 & 2452.4 & 120.7 & 4490.2 & 119.7 \\
\hline $\begin{array}{c}\text { Chuuk, } \\
7^{\circ} \mathrm{N}, 152^{\circ} \mathrm{E}\end{array}$ & $\begin{array}{l}+0.51 \\
+1.28 \\
\end{array}$ & $\begin{array}{l}+1.10 \\
+1.31 \\
\end{array}$ & 1584.2 & 1544.3 & 97.6 & I833.| & 1923.8 & 104.9 & 3468.1 & 101.5 \\
\hline \multirow{2}{*}{$\begin{array}{l}\text { Pohnpel, } \\
7^{\circ} \mathrm{N}, 158^{\circ} \mathrm{E}\end{array}$} & -0.54 & -0.54 & \multirow{2}{*}{2266.4} & \multirow{2}{*}{2613.7} & \multirow{2}{*}{115.3} & \multirow{2}{*}{2336.5} & \multirow{2}{*}{2231.1} & \multirow{2}{*}{95.5} & \multirow{2}{*}{4844.8} & \multirow{2}{*}{105.3} \\
\hline & +1.81 & +1.92 & & & & & & & & \\
\hline $\begin{array}{l}\text { Kapinga, } \\
I^{\circ} \mathrm{N}, 155^{\circ} \mathrm{E}\end{array}$ & - & - & 1750.8 & 2406.9 & 137.5 & 1510.5 & 1855.0 & 122.8 & 4261.9 & 130.7 \\
\hline \multirow{2}{*}{$\begin{array}{c}\text { Kosrae, } \\
5^{\circ} \mathrm{N}, 163^{\circ} \mathrm{E}\end{array}$} & +0.09 & -0.04 & \multirow{2}{*}{2567.9} & \multirow{2}{*}{3062.5} & \multirow{2}{*}{119.3} & \multirow{2}{*}{2342.9} & \multirow{2}{*}{2782.1} & \multirow{2}{*}{118.7} & \multirow{2}{*}{5844.5} & \multirow{2}{*}{119.0} \\
\hline & +2.03 & +2.39 & & & & & & & & \\
\hline $\begin{array}{c}\text { Majuro, } \\
7^{\circ} \mathrm{N}, 171^{\circ} \mathrm{E} \\
\end{array}$ & $\begin{array}{l}+0.07 \\
+0.81 \\
\end{array}$ & $\begin{array}{l}+0.09 \\
+0.65 \\
\end{array}$ & 1368.3 & 1739.1 & 127.1 & 1868.2 & 2414.3 & 129.2 & 4153.4 & 128.3 \\
\hline $\begin{array}{l}\text { Kwajalein, } \\
9^{\circ} \mathrm{N}, 168^{\circ} \mathrm{E}\end{array}$ & $\begin{array}{l}+0.98 \\
+0.53 \\
\end{array}$ & $\begin{array}{l}+0.65 \\
+0.65 \\
\end{array}$ & 801.4 & 891.8 & 112.1 & I579.| & 1503.6 & 95.2 & 2395.5 & 100.9 \\
\hline
\end{tabular}

depression that would become Tropical Storm Lan two days later.

The sea level across Micronesia exhibits large fluctuations related to ENSO. During the 2015 El Niño, the sea level dramatically fell across the region. During 2016, with the demise of El Niño, the sea level began a dramatic climb to become $6-8 \mathrm{~cm}$ above average by the end of the year. The sea level remained well above average throughout Micronesia for all of 2017, as La Niña became established in the second half of the year. Interannual variations of sea level across Micronesia are almost entirely a result of forcing by the Pacific trade wind system (blue line in Fig. 7.49). Fortunately, due to a general lack of high surf and swell, the high sea levels

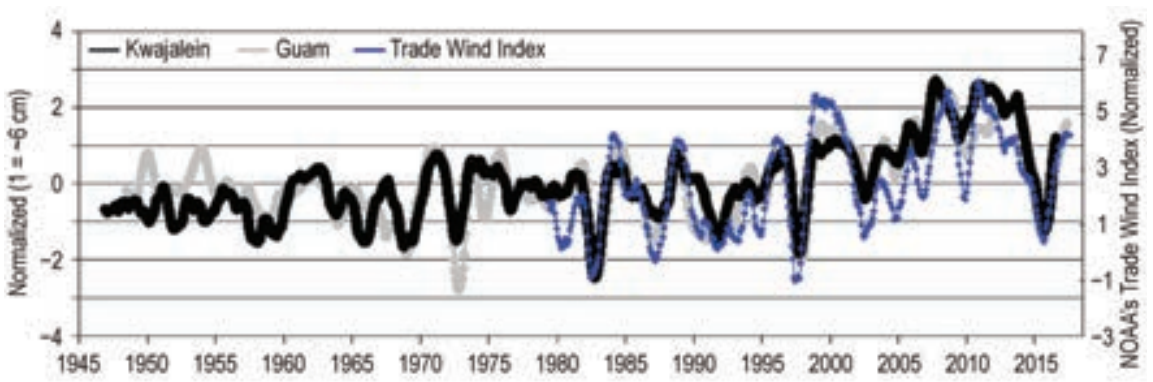

Fıg. 7.49. Time series of sea level at Guam (gray line) and Kwajalein (black line) since 1945. Blue line is a time series of NOAA's trade wind index for the region. Note the rapid rise in all times series at the end of the 1990s through the mid-2000s coinciding with La Niña, and also the sharp minima during strong EI Niño events (e.g., 1983, 1997, and 2015). There is a sharp rise of sea level in 2016 that remained high during 2017. A 12-month moving average has been applied to the raw monthly values of each time series. 
Low rainfall from late 2016 through September 2017 resulted in drought emergencies in most of the atolls in the northern RMI. Loss of potable water sources required the emergency shipment of bottled water, reverse osmosis systems, emergency food supplies, and public health and hygiene assistance. During this period the Guam Weather Forecast Office issued 18 bi-monthly specially tailored drought information statements for the RMI Government and U.S. State Department relief agencies.

\section{3) Southwest Pacific-A. Peltier}

Countries considered in this section include: American Samoa, the Cook Islands, Fiji, French Polynesia, Kiribati, Nauru, New Caledonia, Niue, Papua New Guinea (PNG), Samoa, the Solomon Islands, Tokelau, Tonga, Tuvalu, Vanuatu, and Wallis and Futuna. Air temperature and precipitation anomalies are relative to a 1981-2010 period unless otherwise indicated.

\section{(i) Temperature}

The southwest Pacific experienced warmer-thanaverage conditions throughout most of 2017. The only exceptions were islands close to the equator such as Nauru and Kiribati, where near or below-average temperatures were observed, as ENSO-neutral conditions prevailed for most of the year (Fig. 7.50).

The year started with exceptionally warm conditions across the region. In January, monthly anomalies exceeded two standard deviations over a wide area east of the dateline encompassing Tuvalu, Tonga, Wallis and Futuna, Samoa, American Samoa, and the Cook Islands. This resulted in the second highest monthly anomaly of $+0.96^{\circ} \mathrm{C}$, behind the record set in December $1998\left(+0.99^{\circ} \mathrm{C}\right)$ for the temperature anomaly averaged over the southwest Pacific area $25^{\circ}-10^{\circ} \mathrm{S}$ and $156^{\circ} \mathrm{E}-226^{\circ} \mathrm{E}$ (Fig. 7.51).

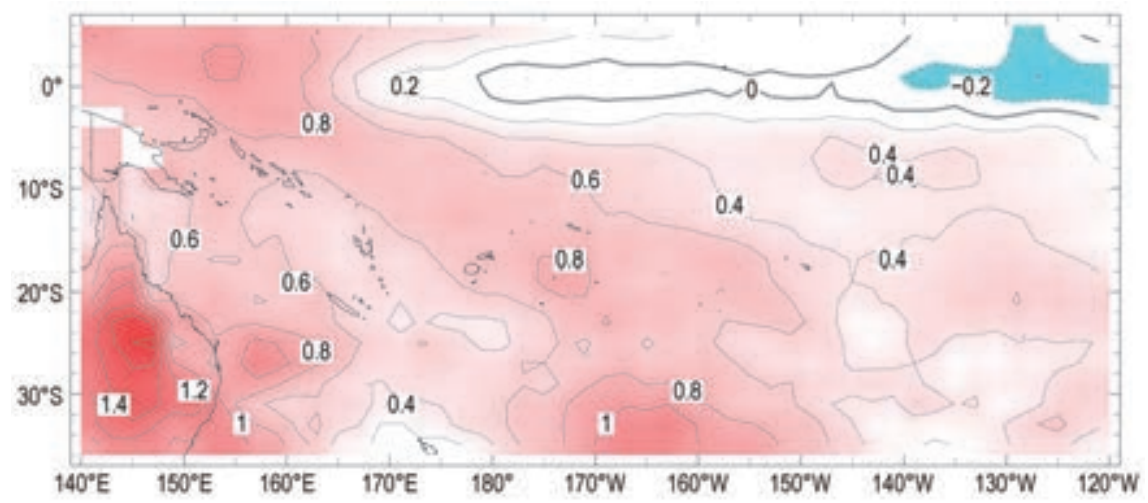

FIG. 7.50. Annual average surface air temperature anomalies $\left({ }^{\circ} \mathrm{C}, 1981-2010\right.$ base period; Source: NOAA NCEP CPC CAMS.)

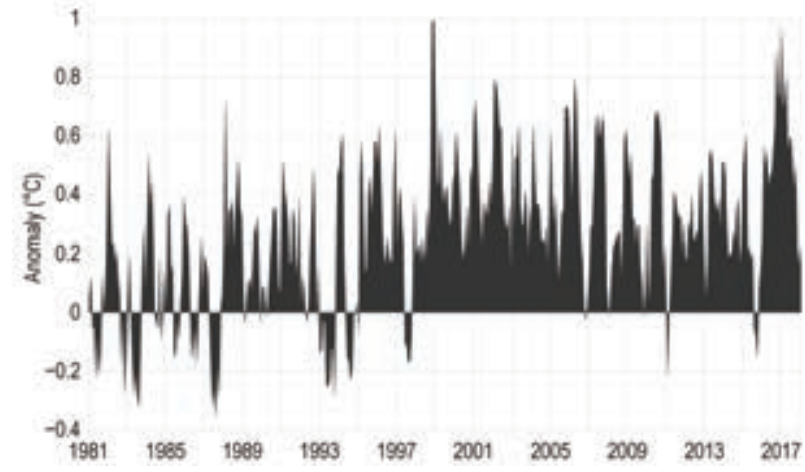

FIG. 7.5I. Monthly average surface air temperature anomalies ( ${ }^{\circ} \mathrm{C}, 198 \mathrm{I}-2010$ base period) for the entire southwest Pacific area $\left(25^{\circ}-10^{\circ} \mathrm{S}\right.$ and $\left.156^{\circ}-226^{\circ} \mathrm{E}\right)$ from 1981-2017. (Source: NOAA NCEP CPC CAMS.)

Apart from the equatorial area, which was average to below average, the region experienced relatively large positive temperature anomalies until April. While steadily declining in magnitude, temperature anomalies remained positive until the end of the austral winter. In October, surface temperature anomalies leaned toward negative values over French Polynesia and the Cook Islands. By the end of December, near to below-average temperatures covered most of the Pacific island countries east of the dateline.

\section{(ii) Precipitation}

In Nauru and the Kiribati Gilbert Islands, which are located near the equator west of the dateline, drier-than-average conditions prevailed during the first half of 2017, as cloudiness was reduced in both the intertropical convergence zone and the northwestern sector of the southern Pacific convergence zone (SPCZ). After two months of respite in July and August with above-average precipitation, relatively dry weather conditions resumed during the last four months of the year with ENSO trending towards La Niña. Precipitation totals for 2017 were as low as 50\% of average in Nauru and the Gilbert Islands. These dry conditions in 2017 were an extension of a drought event that began during the second half of 2016.

Farther south, the transition from a neutral ENSO state to a weak La Niña resulted in a rainfall pattern close to normal across most of the South Pacific from January to October. Yet, two notable 


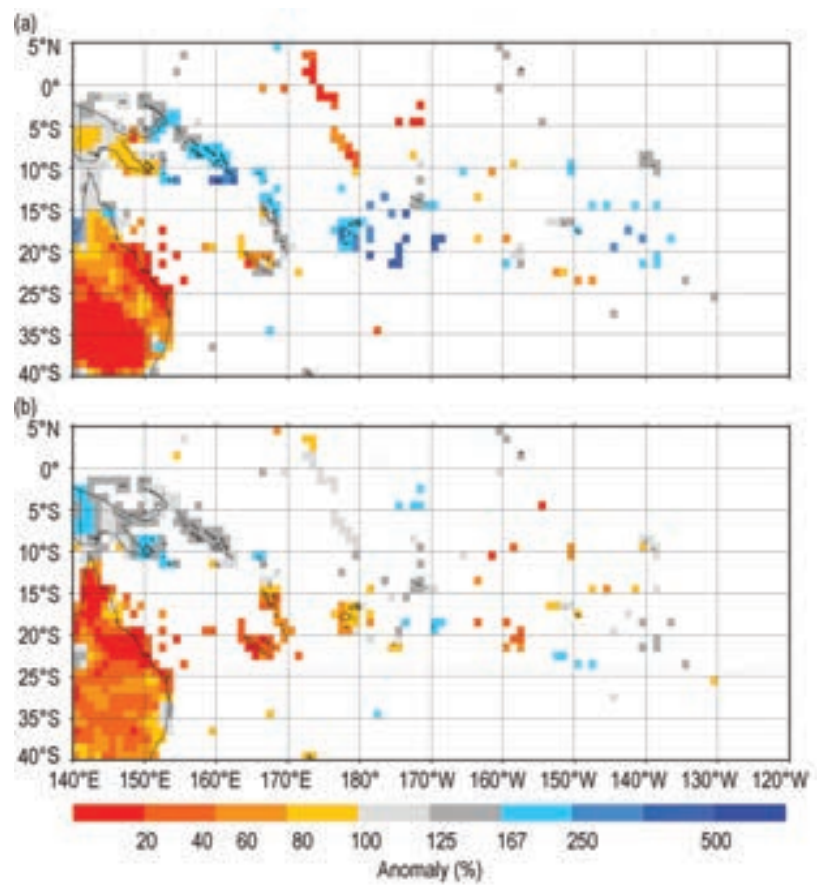

FIG. 7.52. Precipitation anomalies (\% of normal wrt 195I-2000): (a) Feb 20I7, (b) Jun-Aug 2017. (Source: GPCC Monitoring Product version 5.)

periods stood out. The first of these saw the SPCZ become remarkably enhanced in early February in response to an active Madden-Julian oscillation (MJO) phase over the western equatorial Pacific. This resulted in well above-average February rainfall over many Pacific nations (Fig. 7.52a): the Solomon Islands (170\% of average), Fiji (160\%), Wallis and Futuna (190\%), Tonga (250\%), and Niue (350\%). The second notable period saw relatively dry conditions prevail between June and September west of the dateline, resulting in precipitation as low as $60 \%$ of average in Fiji, $40 \%$ in Vanuatu, and 30\% in New Caledonia for the austral winter season (Fig. 7.52b). As oceanic indicators leaned towards La Niña in the tropical Pacific, cloudiness patterns across the region also showed a clear La Niña signal. In November and December, the SPCZ was slightly enhanced and displaced towards the southwest. This resulted in above-average rainfall across the Solomon Islands, Vanuatu, Fiji, Tonga, and Niue.

\section{(iii) Notable events and impacts}

On 7 February, a trough over the Solomon Islands and a slow-moving tropical low pressure system located in the Coral Sea caused heavy rain in and around Honiara, the capital city, situated on the northwestern coast of Guadalcanal. The rainfall total for that day was $208 \mathrm{~mm}$, the sixth highest since records began in 1949 (Source: Global Historical Climate Network Daily). The heavy downpour triggered flash flooding in the city. Major roads were submerged and flooding was reported in the main hospital and in many residences. All of the Guadalcanal plains were covered with water, and farmers who supply vegetables to Honiara lost around $70 \%-80 \%$ of their production.

New Caledonia experienced its driest winter on record. Cold fronts that usually bring precipitation to the island passed farther south than usual from mid-June to mid-July as a consequence of a positive southern annular mode. While the southern annular mode returned to neutral by August and frontal systems returned to their near-average position, most frontal systems rapidly dissipated while approaching New Caledonia. In Noumea, the capital city, the winter precipitation total was $33 \%$ of normal, the lowest on record (since 1951). Spring (SON) is usually the driest season in New Caledonia, and 2017 was no exception. The rain showers in early December ended the longest sequence of daily rainfall totaling $5 \mathrm{~mm}$ or less: 139 days for Noumea. As a result, New Caledonia experienced agricultural and hydrological droughts in the second half of 2017. The main consequences were restrictions on drinking water and fires that destroyed vast areas of vegetation, including primary forests, despite a territory-wide fire ban.

\section{4) Australia—S. Tobin and S. J. Jacobs}

The base period for this section is 1981-2010. Nationwide monthly average temperatures are based on the ACORN-SAT dataset (Trewin 2013), which extends to 1911. The rainfall and daily temperatures are based on the AWAP dataset (Jones et al. 2009), which extends to 1910 .

\section{(i) Temperature}

The 2017 annual mean temperature for Australia was $0.64^{\circ} \mathrm{C}$ above the $1981-2010$ average, its third warmest year on record. The decade ending 2017 was $0.30^{\circ} \mathrm{C}$ higher than average and the warmest 10 -year period in Australian records.

Australian mean maximum temperatures (Fig. 7.53) were $0.97^{\circ} \mathrm{C}$ above average, the second highest on record. Mean minimum temperatures (Fig. 7.54) were $0.31^{\circ} \mathrm{C}$ above average, the 11th highest on record.

Annual mean temperatures were above average for almost all of Australia and record high for much of the southern half of Queensland, northwestern New South Wales, and an area on the central coast of New South Wales between Sydney and Port Macquarie.

Maxima were above average for nearly all of Australia and in the highest $10 \%$ of observations for nearly all of eastern Australia, South Australia, and most of the Northern Territory. Maxima were the highest on 


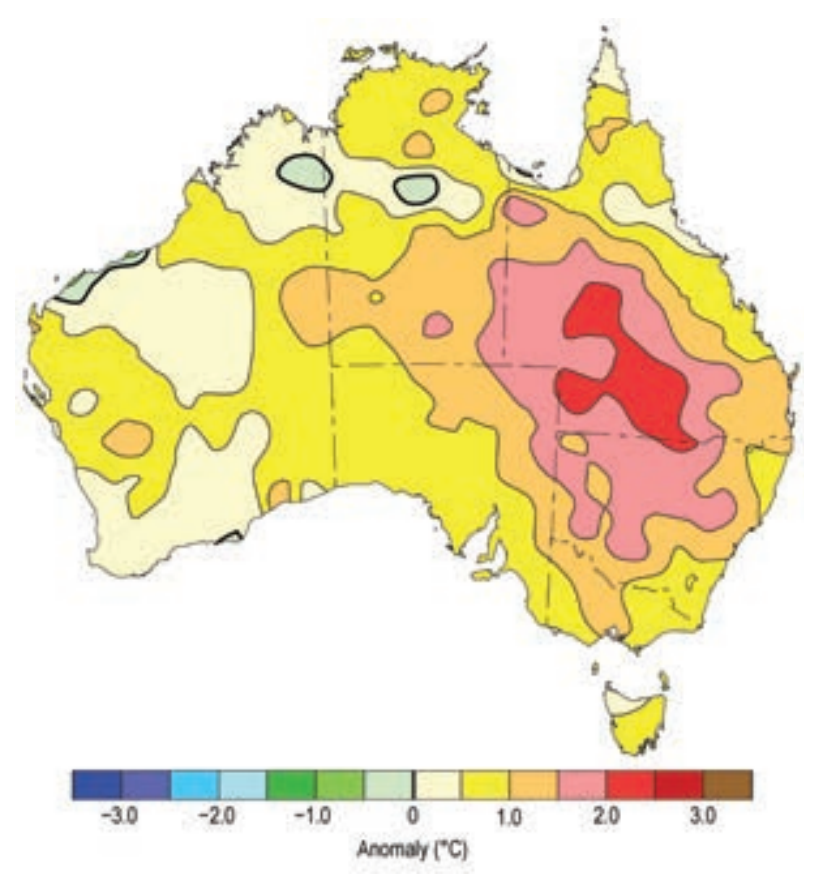

FIG. 7.53. Maximum temperature anomalies $\left({ }^{\circ} \mathrm{C}\right)$ for Australia, averaged over 2017, relative to a $1981-2010$ base period. (Source: Australia Bureau of Meteorology.)

record for much of the southern half of Queensland and some parts of northern New South Wales.

Minima were in the highest $10 \%$ of observations for much of Queensland, northern and eastern New South Wales, southwest Victoria, parts of coastal South Australia, western Tasmania, and parts of the Top End in the Northern Territory. Minima were highest on record for an area of southwest Queensland. Minima were above average for much of the rest of Australia but cooler than average for an area of inland northwestern Australia spanning the border between Western Australia and the Northern Territory.

Persistent warmth was featured throughout 2017. Daytime temperatures were especially warm, with monthly mean maxima ranking among the ten warmest on record for March, each month from May to September, and December.

January to March was much warmer than average for eastern Australia, while above-average rainfall kept days cooler than average in the northwest. Clear skies associated with a persistent strong high pressure ridge across the country contributed to warm, sunny days and cooler-than-average nights during late autumn and winter. June nights were much cooler than average for much of the southern mainland. Southeast Australia experienced cooler-than-average nights for a longer period, extending into September.

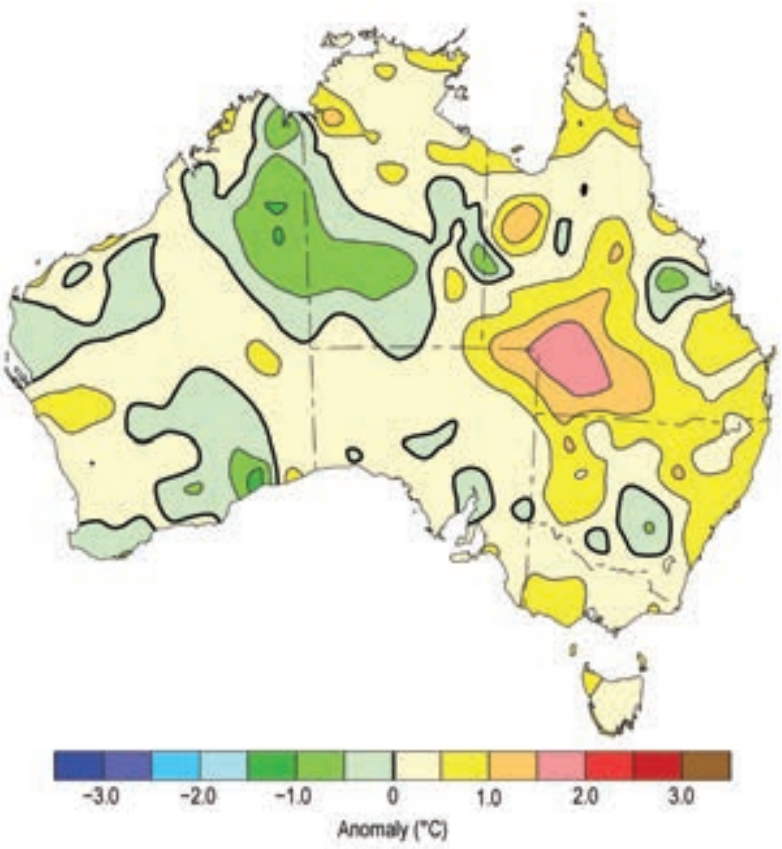

Fıg. 7.54. Minimum temperature anomalies $\left({ }^{\circ} \mathrm{C}\right)$ for Australia, averaged over 2017 , relative to a 198I-20I0 base period. (Source: Australia Bureau of Meteorology.)

In contrast, daytime temperatures during July were particularly warm, with maxima highest on record for much of northern Australia. Exceptional warmth was present during September-December, largely associated with blocking highs over the Tasman Sea and particularly affecting eastern Australia (see Notable events and impacts and Sidebar 7.4).

These prolonged warm spells on land also affected the surrounding oceans. For the Tasman Sea region, October, November, and December were each warmest on record for their respective months. This occurred without a southward extension of the warm East Australian Current and in the absence of El Niño-both of which contributed to exceptional sea surface temperatures (SSTs) in the region during the first half of 2016.

Annual SSTs for the Australian region were the eighth highest on record, based on ERSSTv5 data. Above-average annual SSTs have been observed each year from 1995 to 2017 (inclusive), with a range of negative effects on the marine environment. Prolonged high SSTs led to significant coral bleaching on the Great Barrier Reef during early 2017, following record bleaching during summer 2015/16. This is the first time mass bleaching events have occurred in consecutive years and in the absence of El Niño (see Sidebar 3.1 for more details). 


\section{(ii) Precipitation}

2017 was a year of contrasts for rainfall, with a wet start, a dry middle, and a wet end. Averaged across Australia, rainfall for 2017 was 504 mm, 4\% above the 1981-2010 average, the 30th wettest in the 118-year record. Annual rainfall was above average for the southeast, interior, and far north of Western Australia, for most of the Northern Territory, and for the west of South Australia. Large parts of Western Australia had annual rainfall in the highest $10 \%$ of their records (Fig. 7.55). Rainfall was below average for most of inland Queensland, most of New South Wales, eastern to central Victoria, all of Tasmania, and pockets of the west coast of Western Australia.

January and February rainfall was above average across the western half of Australia, while February rainfall was below average for large parts of eastern Australia.

In March, heavy rainfall events in New South Wales and Victoria, and Severe Tropical Cyclone Debbie in Queensland and northern New South Wales, brought above-average monthly rainfall along the east coast.

From April to September rainfall was generally below average, particularly over southeastern Australia. A positive southern annular mode (SAM) and strong subtropical ridge contributed to below-average winter rainfall by shifting the belt of westerly winds southward, resulting in fewer rain-bearing low

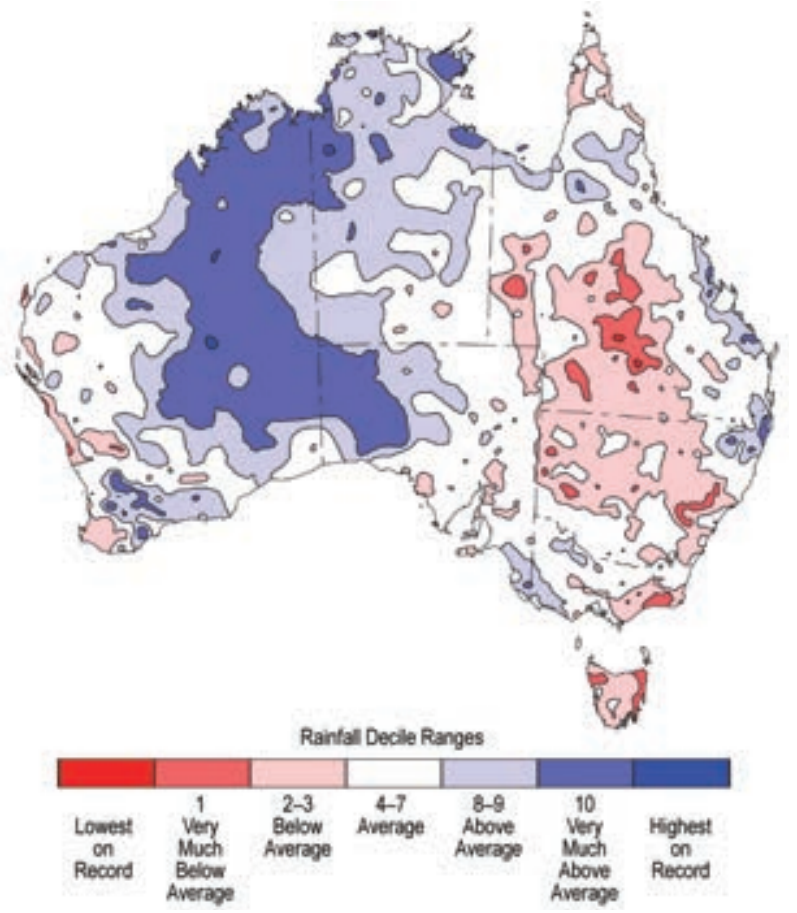

FIG. 7.55. Rainfall deciles for Australia for 2017, based on the 1900-2017 distribution. (Source: Australia Bureau of Meteorology.) pressure systems and cold fronts crossing southern Australia. A climate change signal has been identified in the observed increase in the strength of the subtropical ridge and reduction of cool season rainfall in southern Australia over recent decades (Timbal and Drosdowsky 2012).

June was the second driest on record nationally, and the driest on record for southeastern Australia as a whole (land area south of $33^{\circ} \mathrm{S}$, and east of $135^{\circ} \mathrm{E}$ ), while September was the driest on record for the Murray-Darling Basin.

October rainfall was above average for much of Australia, with flooding on the east coast of Queensland around Bundaberg and Tully. For Queensland, it was the third wettest October on record. November rainfall was generally average to above average, and while December was drier than average for Queensland and the Northern Territory, heavy rainfall events in southeast Australia and Tropical Cyclone Hilda in Western Australia resulted in above-average monthly rainfall across large areas.

The main natural climate drivers for AustraliaENSO and the IOD-were in a neutral phase for most of the year. However, cooler-than-average waters to Australia's west and warmer-than-average waters to the east of Africa to the south of the IOD regions created a strong temperature gradient across the Indian Ocean during the year, exerting a drying influence on Australia.

\section{(iii) Notable events and impacts}

Exceptional warmth affected large parts of eastern Australia from late December 2016 into February 2017. Records were set in southeastern Australia and southern Queensland for consecutive warm days or nights, or for total number of warm days or nights during January. Five separate locations in Queensland broke previous state records for hottest February day on the 12 th.

The McArthur Forest Fire Danger Index (FFDI) reached catastrophic levels across much of New South Wales on 12 February. A fire in the Warrumbungle Shire destroyed most of the small township of Uarbry.

Slow-moving tropical lows brought heavy rain over much of northern and western Australia between late January and early February. Cumulative rainfall resulted in flooding in the Kimberley and in parts of southwest Western Australia, the latter of which typically has low summer rainfall.

Flooding affected large areas of the east coast during March, resulting from thunderstorms in New South Wales around mid-month, thunderstorms in Victoria on 20 and 21 March, and Severe Tropical 
Cyclone Debbie at the end of the month. Debbie caused flooding and widespread wind damage in Queensland and northeastern New South Wales, with flooding continuing into April in some rivers.

An exceptional period of warm weather during the last week of September saw many records for high temperatures or early season warmth set in eastern Australia (see Sidebar 7.4).

In early October, heavy rainfall associated with surface and upper-level troughs affected southeastern Queensland and northeastern New South Wales, with flooding around Bundaberg. Further heavy rain midmonth affected the same region, as well as areas of Queensland's tropical coast, with flooding around Tully.

After a cool and frosty start to November an extended period of very warm weather affected Victoria and Tasmania, driven by long-lived blocking highs over the Tasman Sea during both November and December (see also Sidebar 7.4). November monthly mean temperatures were the highest on record for Tasmania and second highest for Victoria. Warmth was more widespread in December, affecting all states and the Northern Territory. These high pressure systems also contributed to record high sea surface temperatures for Bass Strait and the Tasman Sea as clear skies allowed more solar radiation absorption, and light winds limited mixing of surface waters.

An influx of tropical moisture between 1 and 3 December brought two to three times the monthly average rainfall to parts of northern Victoria and southern New South Wales. Flooding resulted in central to northeastern Victoria, with some flash flooding around Melbourne.

For further detail on these and other significant events please see Monthly Weather Reviews, Special Climate Statements, and the Annual Climate Statement-all available from www.bom.gov.au /climate/current/.

\section{5) New Zealand-B. E. Noll}

In the following discussion, the base period is 1981-2010, unless otherwise noted. The nationwide average temperature is based upon the National Institute of Water and Atmospheric Research (NIWA) seven-station temperature series that began in 1909 (see www.niwa.co.nz/our-science/climate /information-and-resources/nz-temp-record /seven-station-series-temperature-data). All statistics are based on data available as of 9 January 2018.

\section{(i) Temperature}

According to NIWA's seven-station temperature series, 2017 was New Zealand's fifth warmest year since records began in 1909 . The nationwide average temperature for 2017 was $13.15^{\circ} \mathrm{C}, 0.54^{\circ} \mathrm{C}$ above the annual average. Annual mean temperatures were near average (within $0.5^{\circ} \mathrm{C}$ of the annual average) or above average $\left(0.51^{\circ}-1.20^{\circ} \mathrm{C}\right.$ above the annual average) throughout the country (Fig. 7.56a). Only January observed a below-average nationwide temperature $\left(0.7^{\circ} \mathrm{C}\right.$ below average). The three months in 2017 with the largest national temperature anomalies were December $\left(+2.4^{\circ} \mathrm{C}\right)$, August $\left(+1.3^{\circ} \mathrm{C}\right)$, and November $\left(+1 \cdot 1^{\circ} \mathrm{C}\right)$. These marked New Zealand's second warmest December, third warmest August, and sixth warmest November on record. The warmth seen in November and December were likely influenced by synoptic patterns which also contributed to the exceptional warmth also experienced across southeast
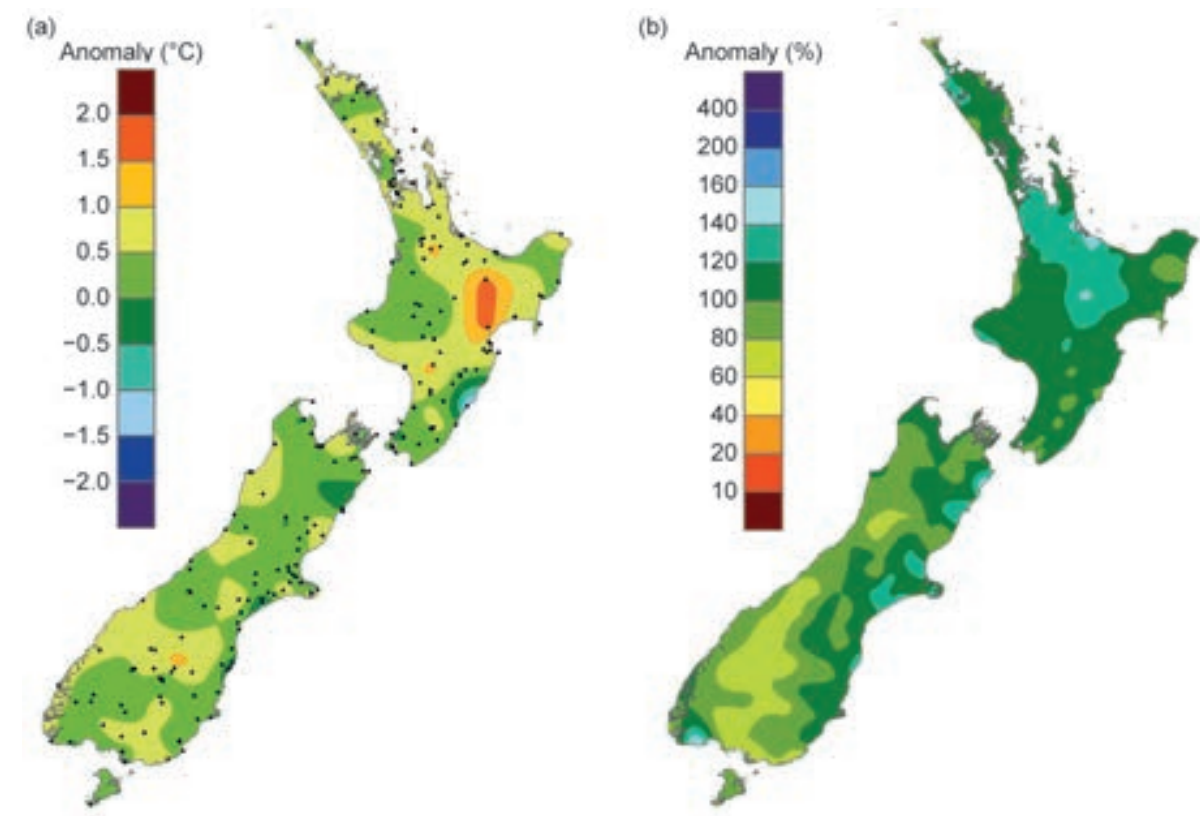

FIG. 7.56. 2017 annual (a) mean temperature anomaly $\left({ }^{\circ} \mathrm{C}\right)$ and (b) total rainfall (\%), relative to $1981-2010$. (Source: NIWA.) 
Australia and the Tasman Sea (see Sidebar 7.4). The highest recorded air temperature for 2017 was $35.5^{\circ} \mathrm{C}$, at Wairoa (Hawke's Bay) and Ashburton (Canterbury) on 6 February (see Fig. 7.57 for localities). The lowest recorded air temperature for 2017 (excluding high altitude alpine sites) was $-14.6^{\circ} \mathrm{C}$, observed at Lake Tekapo (Canterbury) on 29 July.

\section{(ii) Precipitation}

Annual rainfall totals for 2017 were above average (120\%-149\% of the annual average) in Auckland, Waikato, Bay of Plenty, coastal Canterbury, and north coastal Otago (Fig. 7.56b). On the other hand, rainfall was below average $(50 \%-79 \%$ of the annual average) across much of Southland and interior Otago. Elsewhere, 2017 annual rainfall totals were near average (within $20 \%$ of the annual average). Five locations observed near-record high annual rainfall totals while three locations observed record or nearrecord low rainfall totals.

Of the regularly reporting rainfall gauges, the wettest location in 2017 was Cropp River, in the Hokitika River catchment (West Coast, South Island, $975 \mathrm{~m}$ above sea level), with an annual rainfall total of $8662 \mathrm{~mm}$ (76\% of the long-term average). The driest of the regularly reporting rainfall sites in 2017 was Clyde (Central Otago), which recorded $278 \mathrm{~mm}$ of rainfall $(67 \%$ of the long-term average). Milford Sound (Southland) experienced the highest one-day rainfall total in 2017: 309 mm on 31 January.

(iii) Notable events and impacts

Figure 7.57 provides a schematic of notable events. By the end of 2017, parts of eleven of New Zealand's sixteen geographical regions had experienced meteorological drought following a dry November and December. These regions included Northland, Auck- land, Waikato, Taranaki, Manawatu-Whanganui, Wellington-Wairarapa, Hawke's Bay, Marlborough, Tasman, the West Coast, and Southland. In December, the Ministry for Primary Industries classified the drought as a medium-scale adverse event in Taranaki, western parts of the Manawatu-Whanganui region, and around Wellington. The drought conditions occurred following a wet start to the year, which featured significant rain impacts, especially across the North Island. These included two ex-tropical cyclones (Cook and Debbie), which affected the country during April, following a heavy rainstorm between 7 and 12 March. The impact from ex-Tropical Cyclone Debbie (4 April) led to several one-day rainfall records for the month of April across the Bay of Plenty, which contributed to severe flooding in parts of the region, and was particularly notable for the town of Edgecumbe.

Oamaru (Otago) had its second wettest year on record ( $813 \mathrm{~mm}$ of rain). On 21 July, $161 \mathrm{~mm}$ of rain fell, leading to flooding and making it the wettest day in the town since records began in 1950; thereafter, Oamaru recorded just $163 \mathrm{~mm}$ during the remainder of the year (August-December 2017).

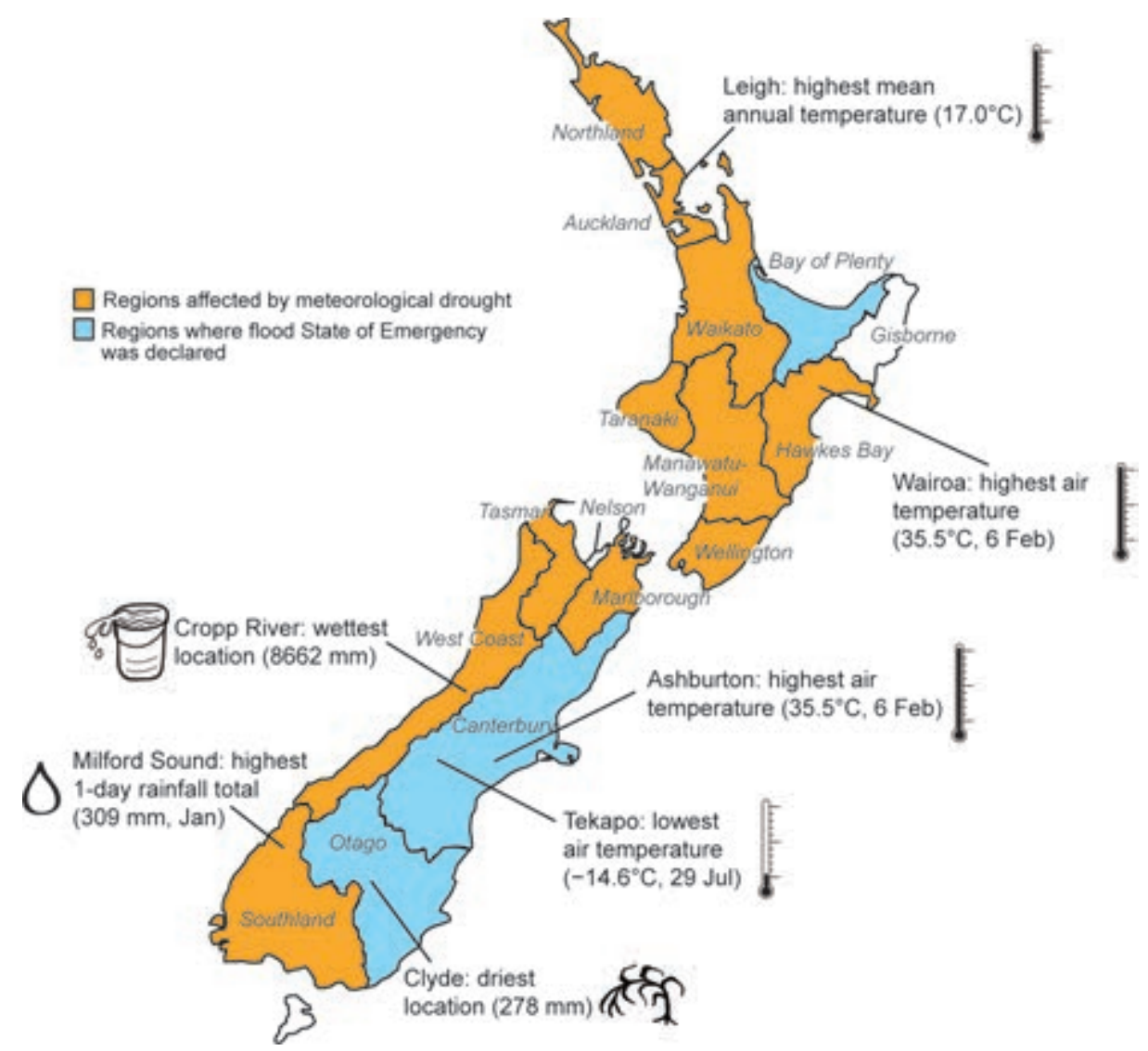

Fig. 7.57. Notable weather events and climate extremes for New Zealand in 2017. (Source: NIWA.) 


\section{SIDEBAR 7.4: SUMMER ARRIVES EARLY IN AUSTRALIA AS THE AUSTRAL SPRING BREAKS RECORDS-S. TOBIN}

\section{AND S. J. JACOBS}

Two significant heat events occurred during the Australian spring of 2017. The first event in September broke temperature records across eastern Australia while the second broke duration records in Victoria and Tasmania.

A high pressure system moved over New South Wales on 20 September. As a result, large parts of eastern and northern Australia had sunny, cloud-free days. With low rainfall through September and below-average soil moisture, these sunny days led to rapid heating of the land surface and overlying air in Central Australia, Queensland, and New South Wales.

By 22 September, the high pressure system became slow moving over the northern Tasman Sea while a low pressure system developed to the south of Australia. The two weather systems directed hot, dry air from the desert interior into eastern Australia, causing unprecedented hot September weather. The 22nd was Australia's warmest September day since national area-averaged

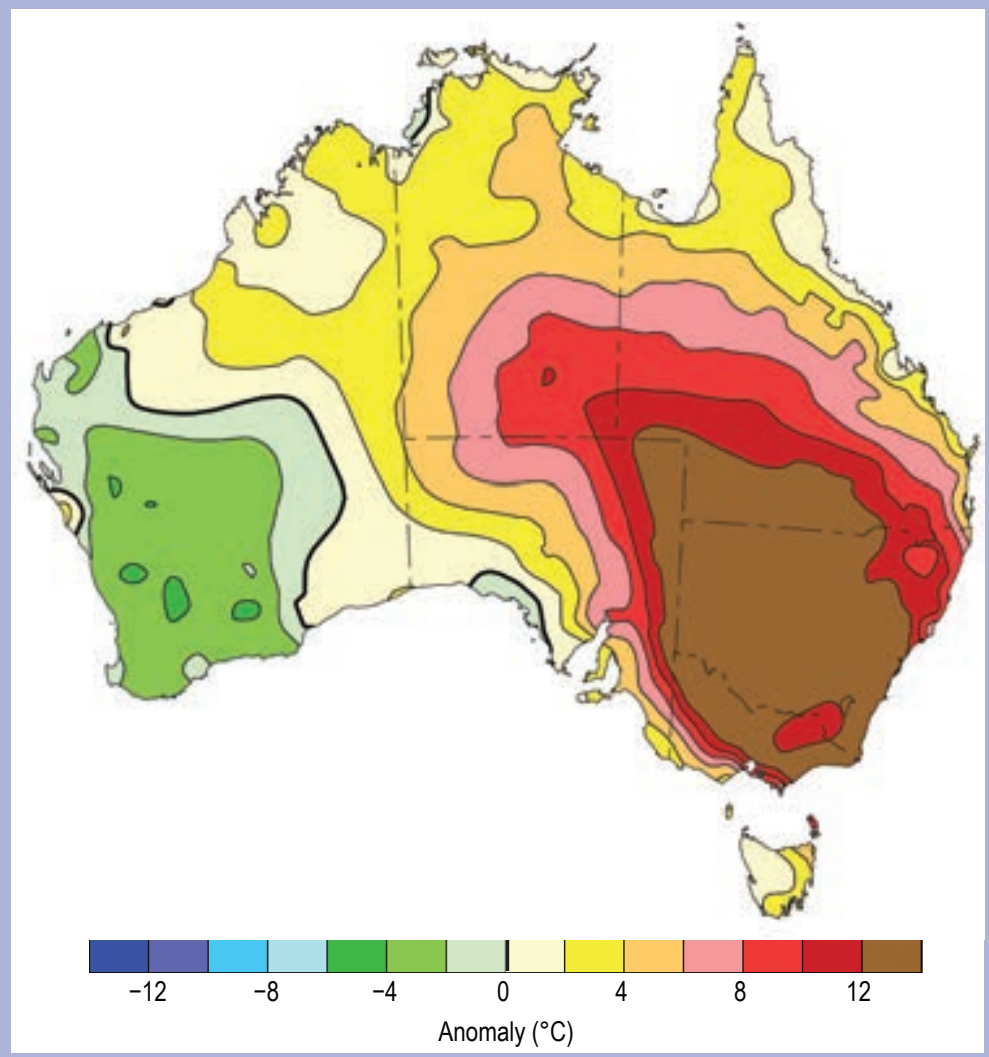

FIG. SB7.6. Maximum temperature difference $\left({ }^{\circ} \mathrm{C}\right)$ from the $1981-2010$ average for 23 Sep 2017. (Source: Australia Bureau of Meteorology.)

analyses commenced in 1911 , although the highest local temperatures were observed on the $23 \mathrm{rd}$. Maximum temperatures were more than $12^{\circ} \mathrm{C}$ above the $1981-2010$ average across much of the mainland southeast on the 23rd (Fig. SB7.6). A number of sites in New South Wales reached $40^{\circ} \mathrm{C}$, the first such occurrences in the state during September, while in Victoria, Mildura set a state record for September reaching $37.7^{\circ} \mathrm{C}$.

A new high pressure system crossed the southeast into the Tasman Sea between the 26th and 27th, bringing renewed heat to eastern Australia. During this period some New South Wales sites broke the records they had set only days earlier, while in Queensland, Birdsville reached $42.8^{\circ} \mathrm{C}$ on the 27 th, setting a new state record for September. By 29 September more than $20 \%$ of Australia (by area) had recorded its hottest September day on record.
The heat returned in mid-to-late November when the southeastern states of Victoria and Tasmania experienced an unusually long run of warm days and nights. A long-lived blocking high was again responsible for the high temperatures, but this time the center was over the southern Tasman Sea, directing the hot, dry air into southern states from Central Australia.

The extended warm spell lasted from 10 November until the start of December when a strong trough accompanied by heavy rain crossed the states. This heat wave was notable for its duration rather than its intensity, with many records set for consecutive days with maximum or minimum temperatures above thresholds and only a few records set for individual days. Events of this duration are unusual in spring when weather systems are normally more mobile than in late summer and autumn. 
During this event Melbourne experienced six consecutive days with maxima of at least $30^{\circ} \mathrm{C}$ and nine consecutive days of at least $28^{\circ} \mathrm{C}$ - the latter breaking the previous record of six days set in 2009. Melbourne also experienced 14 consecutive nights above $15^{\circ} \mathrm{C}$, solidly surpassing the previous spring record of nine days in 2009. A warm spell of this length had not occurred in Melbourne before midsummer (January) in at least the 108-year record.

In Tasmania, the length of the late spring warm spell was unprecedented for any time of year, particularly in the south and west. Many locations set November records for consecutive days above $25^{\circ} \mathrm{C}$. Strahan, on the west coast, had 18 consecutive days (from 13 to 30 November) of maximum temperatures $21^{\circ} \mathrm{C}$ or above, including seven consecutive days of $27^{\circ} \mathrm{C}$ or above, both records for any time of year. Hobart's six consecutive days of $25^{\circ} \mathrm{C}$ or above equaled the record for any time of year, while its five consecutive nights above $15^{\circ} \mathrm{C}$ was a November record.

The prolonged heat event also caused a marine heatwave to form around Tasmania due to the clear skies and light winds associated with the blocking high over the Tasman Sea. The surface waters increased to $3^{\circ} \mathrm{C}$ above the 1971-2000 November average and ranked among the highest values on record in that region. The marine heatwave persisted into the austral summer with November, December, and January 2018 monthly sea surface temperatures highest on record for large areas around Tasmania and extending to the western coast of New Zealand (Fig. SB7.7).

For further details on both events, see Special Climate Statement 62 and 63: www.bom.gov.au/climate/current /statements/scs62.pdf and www.bom.gov.au/climate/cur
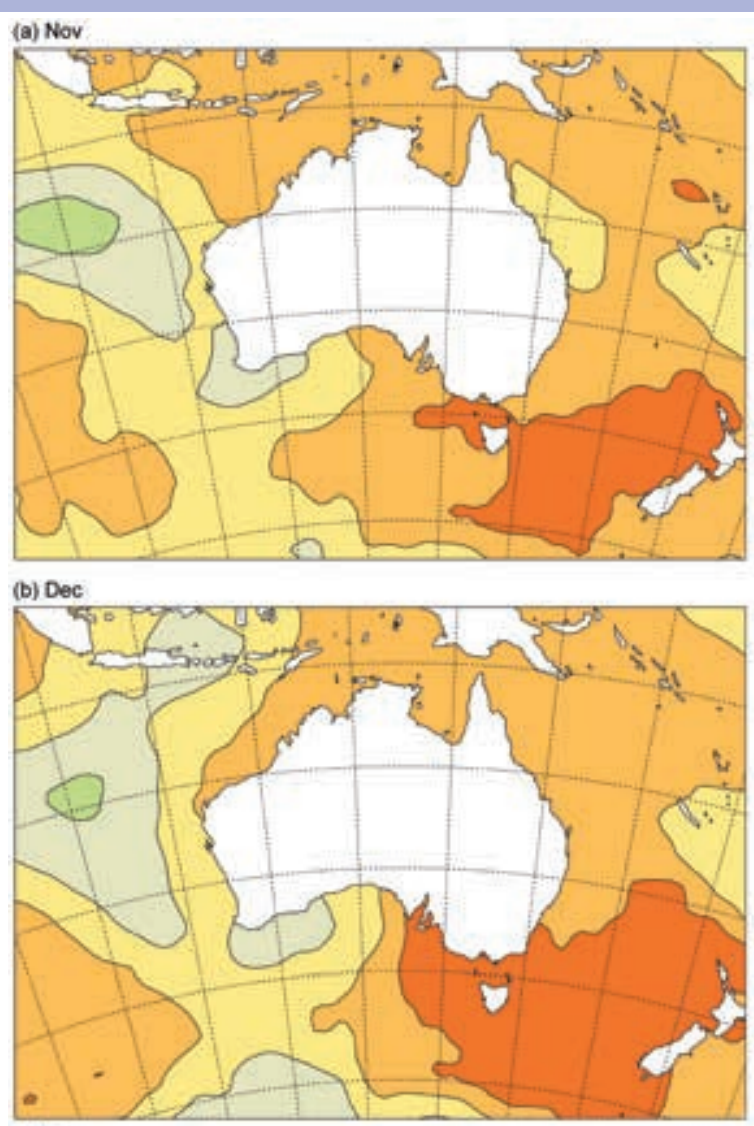

(c) Jan
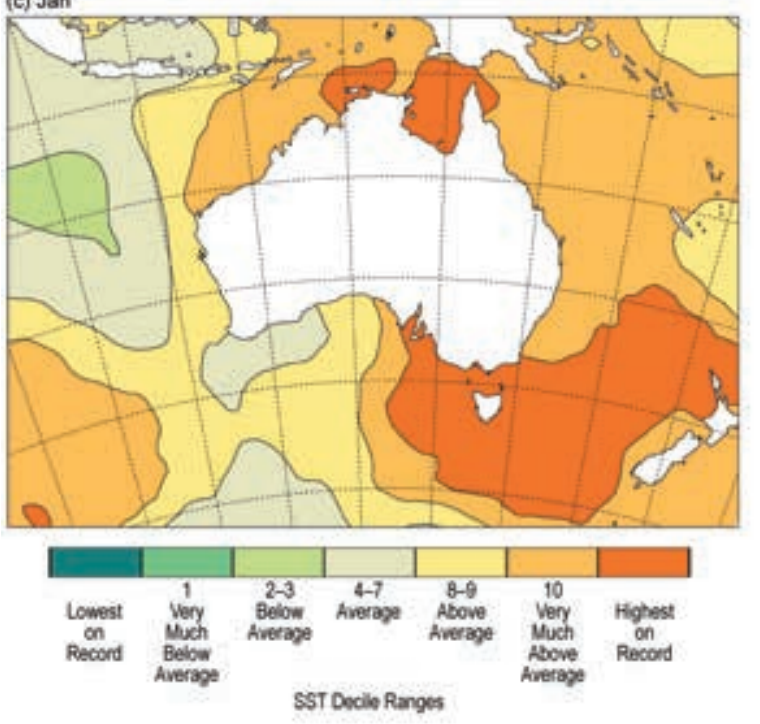

FIG. SB7.7. SST deciles for (a) Nov and (b) Dec 2017 and (c) Jan 2018, based on the 1900-2017 distribution using the NOAA ERSST v5 dataset. (Source: Australia Bureau of Meteorology.) 
APPENDIX I: RELEVANT DATASETS AND SOURCES

\begin{tabular}{|c|c|c|c|}
\hline $\begin{array}{l}\text { General Variable or } \\
\text { Phenomenon }\end{array}$ & $\begin{array}{l}\text { Specific Dataset or } \\
\text { Variable }\end{array}$ & Source & Section \\
\hline Aerosols & CAMS Reanalysis & https://atmosphere.copernicus.eu/ & $2 g 3$ \\
\hline \multirow{3}{*}{ Air-sea fluxes } & $\begin{array}{l}\text { CERES Energy Balanced and } \\
\text { Filled }\end{array}$ & https://ceres.larc.nasa.gov/ & $3 \mathrm{el}$ \\
\hline & CERES FLASHflux & $\begin{array}{l}\text { https://eosweb.larc.nasa.gov/project/ceres/ebaf } \\
\text { _surface_table }\end{array}$ & $3 e l, 3 e 4$ \\
\hline & $\begin{array}{l}\text { Woods Hole Oceanographic } \\
\text { Institute OAFlux }\end{array}$ & http://oaflux.whoi.edu & $\begin{array}{l}3 e l, 3 e 3 \\
3 e 4\end{array}$ \\
\hline Albedo & MODIS & http://ladsweb.nascom.nasa.gov & $2 \mathrm{hl}, 5 \mathrm{e} 3$ \\
\hline \multirow{3}{*}{$\begin{array}{l}\text { Biomass, Greenness } \\
\text { or Burning }\end{array}$} & GFAS vI.4 & ftp://ftp.mpic.de/GFAS/scl7 & $2 \mathrm{~h} 3$ \\
\hline & GFEDv4 & $\begin{array}{l}\text { https://daac.ornl.gov/VEGETATION/guides/fire } \\
\text { _emissions_v4.html }\end{array}$ & $2 \mathrm{~h} 3$ \\
\hline & MODIS NDVI & https://ecocast.arc.nasa.gov/data/pub/gimms/ & $5 \mathrm{~h}$ \\
\hline \multirow{10}{*}{ Clouds, Cloudiness } & Aqua MODIS C6 & $\begin{array}{l}\text { https://ladsweb.modaps.eosdis.nasa.gov/api/vI } \\
\text { /productPage/product=MYD06_L2 }\end{array}$ & $2 \mathrm{~d} 5$ \\
\hline & CALIPSO & $\begin{array}{l}\text { https://eosweb.larc.nasa.gov/project/calipso } \\
\text { /calipso_table }\end{array}$ & $2 \mathrm{~d} 5$ \\
\hline & CERES MODIS & $\begin{array}{l}\text { https://ceres.larc.nasa.gov/science_information } \\
\text {.php?page=ModisCloudRetr }\end{array}$ & $2 \mathrm{~d} 5$ \\
\hline & CLARA-A2 & $\begin{array}{l}\text { https://climatedataguide.ucar.edu/climate-data } \\
\text { /clara-al-cloud-properties-surface-albedo-and } \\
\text {-surface-radiation-products-based-avhrr }\end{array}$ & $2 \mathrm{~d} 5$ \\
\hline & CLOUD_CCl & www.esa-cloud-cci.org & $2 \mathrm{~d} 5$ \\
\hline & HIRS & www.ssec.wisc.edu/ donw/PAGE/CLIMATE.HTM & $2 \mathrm{~d} 5$ \\
\hline & MISR & https://I0dup05.larc.nasa.gov/L3Web/ & $2 \mathrm{~d} 5$ \\
\hline & PATMOS-x/AVHRR & $\begin{array}{l}\text { www.ncdc.noaa.gov/cdr/atmospheric/avhrr-cloud } \\
\text {-properties-patmos-x }\end{array}$ & $2 \mathrm{~d} 5$ \\
\hline & PATMOS-x/MODIS C6 & http://ladsweb.nascom.nasa.gov & $2 \mathrm{~d} 5$ \\
\hline & SatCORPS & No public archive & $2 \mathrm{~d} 5$ \\
\hline $\begin{array}{c}\text { Coral Bleaching Heat } \\
\text { Stress }\end{array}$ & Coral Reef Watch & https://coralreefwatch.noaa.gov/product $/ 5 \mathrm{~km} / \mathrm{v3} . \mathrm{I} /$ & SB3.I \\
\hline \multirow{2}{*}{ Drought } & scPSDI & https://crudata.uea.ac.uk/cru/data/drought/ & $2 d 9$ \\
\hline & CRU TS 3.26 & https://crudata.uea.ac.uk/cru/data/hrg/ & $2 \mathrm{~d} 9$ \\
\hline $\begin{array}{l}\text { Evaporation, } \\
\text { Interception, } \\
\text { Transpiration, } \\
\text { Sublimation }\end{array}$ & GLEAM & www.gleam.eu/ & $2 \mathrm{dIO}$ \\
\hline \multirow{3}{*}{ FAPAR } & MERIS & http://earth.esa.int/level3/meris-level3/ & $2 \mathrm{~h} 2$ \\
\hline & MODIS-TIP & http://ladsweb.nascom.nasa.gov/ & $2 \mathrm{~h} 2$ \\
\hline & SeaWiFS v 2010.0 & http://fapar.jrc.ec.europa.eu/ & $2 \mathrm{~h} 2$ \\
\hline \multirow{2}{*}{ Geopotential Height } & ERA-Interim & $\begin{array}{l}\text { www.ecmwf.int/en/research/climate-reanalysis } \\
\text { /era-interim }\end{array}$ & $6 b$ \\
\hline & $\begin{array}{l}\text { NCEP/NCAR Reanalysis I: } \\
\text { Pressure }\end{array}$ & $\begin{array}{l}\text { www.esrl.noaa.gov/psd/data/gridded/data.ncep } \\
\text {.reanalysis.pressure.html }\end{array}$ & $4 f 2,5 b$ \\
\hline
\end{tabular}




\begin{tabular}{|c|c|c|c|}
\hline $\begin{array}{l}\text { General Variable or } \\
\text { Phenomenon }\end{array}$ & $\begin{array}{l}\text { Specific Dataset or } \\
\text { Variable }\end{array}$ & Source & Section \\
\hline \multirow{4}{*}{$\begin{array}{l}\text { Glacier Mass or } \\
\text { Volume }\end{array}$} & Cryosat-2 & $\begin{array}{l}\text { https://earth.esa.int/web/guest/missions/esa } \\
\text {-operational-eo-missions/cryosat }\end{array}$ & $5 f$ \\
\hline & $\begin{array}{l}\text { Norwegian Water } \\
\text { Resources and Energy } \\
\text { Directorate }\end{array}$ & http://glacier.nve.no/Glacier/viewer/Cl/en/nve & $5 f$ \\
\hline & $\begin{array}{l}\text { Randolph Glacier Inventory } \\
\text { v3.2 }\end{array}$ & www.glims.org/RGI/ & $5 f$ \\
\hline & $\begin{array}{l}\text { World Glacier Monitoring } \\
\text { Service }\end{array}$ & https://wgms.ch/latest-glacier-mass-balance-data/ & $2 c 3,5 f$ \\
\hline $\begin{array}{c}\text { Groundwater and } \\
\text { terrestrial water } \\
\text { storage }\end{array}$ & GRACE & https://gracefo.jpl.nasa.gov/data/grace-data/ & $2 \mathrm{~d} 7$ \\
\hline \multirow{8}{*}{$\begin{array}{l}\text { Humidity, [Near] } \\
\text { Surface }\end{array}$} & Dai & by email to adai@ucar.edu & $2 \mathrm{dl}$ \\
\hline & ERA-Interim & $\begin{array}{l}\text { www.ecmwf.int/en/forecasts/datasets/archive } \\
\text {-datasets/reanalysis-datasets/era-interim }\end{array}$ & $2 \mathrm{dl}$ \\
\hline & HadCRUH & www.metoffice.gov.uk/hadobs/hadcruh & $2 \mathrm{dl}$ \\
\hline & HadISDH & www.metoffice.gov.uk/hadobs/hadisdh & $2 \mathrm{dl}$ \\
\hline & HOAPS & $\begin{array}{l}\text { https://doi.org/I0.5676/EUM_SAF_CM/HOAPS } \\
\text { /V00I }\end{array}$ & $2 \mathrm{dl}$ \\
\hline & $\begin{array}{l}\text { JRA-55 Atmospheric } \\
\text { Reanalysis }\end{array}$ & http://jra.kishou.go.jp/JRA-55/index_en.html & $2 \mathrm{dl}$ \\
\hline & MERRA-2 & https://gmao.gsfc.nasa.gov/reanalysis/MERRA-2/ & $2 \mathrm{dl}$ \\
\hline & NOCS 2.0 & $\begin{array}{l}\text { http://artefacts.ceda.ac.uk/badc_datadocs/nocs } \\
\text { _flux/nocs_flux.html }\end{array}$ & $2 \mathrm{dl}$ \\
\hline \multirow{3}{*}{$\begin{array}{l}\text { Humidity, Upper } \\
\text { Atmosphere }\end{array}$} & HIRS & $\begin{array}{l}\text { www.ncdc.noaa.gov/cdr/fundamental/hirs-ch } 12 \\
\text {-brightness-temperature }\end{array}$ & $2 \mathrm{~d} 3$ \\
\hline & NCEP/NCAR Reanalysis & $\begin{array}{l}\text { www.esrl.noaa.gov/psd/data/gridded/data.ncep } \\
\text {.reanalysis.html }\end{array}$ & $4 f 4$ \\
\hline & UTH & by email to Viju.John@eumetsat.int & $2 \mathrm{~d} 3$ \\
\hline \multirow{3}{*}{$\begin{array}{l}\text { Ice Sheet } \\
\text { Characteristics }\end{array}$} & DMSP-SSMIS & http://nsidc.org/data/nsidc-0032 & $5 e l, 6 d$ \\
\hline & GRACE & $\begin{array}{l}\text { http://podaac.jpl.nasa.gov/datasetlist?ids=Platform } \\
\text { \&values=GRACE }\end{array}$ & $5 e 4$ \\
\hline & PROMICE (Greenland) & www.promice.dk/home.html & $5 \mathrm{e} 2$ \\
\hline \multirow{10}{*}{ Lake Temperature } & $\begin{array}{l}\text { Advanced Along-Track } \\
\text { Scanning Radiometer } \\
\text { (AATSR) }\end{array}$ & $\begin{array}{l}\text { https://earth.esa.int/web/guest/missions/esa } \\
\text {-operational-eo-missions/envisat/instruments/aatsr }\end{array}$ & $5 \mathrm{e} 2$ \\
\hline & ATSR & $\begin{array}{l}\text { https://earth.esa.int/web/guest/missions/esa } \\
\text {-operational-eo-missions/ers/instruments/atsr }\end{array}$ & $5 e 2$ \\
\hline & AVHRR & https://Ita.cr.usgs.gov/AVHRR & $5 \mathrm{e} 2$ \\
\hline & Globolakes & www.globolakes.ac.uk & $2 \mathrm{~b} 2$ \\
\hline & Lake Vättern (Sweden) & Vättern Water Protection Association & $2 \mathrm{~b} 2$ \\
\hline & Lake Zurich (Switzerland) & $\begin{array}{l}\text { City of Zurich Water Supply and Amt für Abfall, } \\
\text { Wasser, Energie und Luft of the Canton of Zurich }\end{array}$ & $2 \mathrm{~b} 2$ \\
\hline & Mondsee (Austria) & http://hydro.ooe.gv.at/\#Startseite & $2 b 2$ \\
\hline & Neusiedler See (Austria) & $\begin{array}{l}\text { http://wasser.bgld.gv.at/hydrographie/online } \\
\text {-daten.html }\end{array}$ & $2 b 2$ \\
\hline & Polish Lakes & www.imgw.pl & $2 \mathrm{~b} 2$ \\
\hline & Wörther See (Austria) & $\begin{array}{l}\text { https://info.ktn.gv.at/asp/hydro/daten/hydroportal } \\
\text { /see_wt.asp }\end{array}$ & $2 \mathrm{~b} 2$ \\
\hline
\end{tabular}




\begin{tabular}{|c|c|c|c|}
\hline $\begin{array}{l}\text { General Variable or } \\
\text { Phenomenon }\end{array}$ & $\begin{array}{l}\text { Specific Dataset or } \\
\text { Variable }\end{array}$ & Source & Section \\
\hline \multirow{13}{*}{ Modes of Variability } & Arctic Oscillation (AO) & $\begin{array}{l}\text { www.cpc.ncep.noaa.gov/products/precip/CWlink } \\
\text { /daily_ao_index/teleconnections.shtml }\end{array}$ & $2 \mathrm{el}$ \\
\hline & $\begin{array}{l}\text { Madden-Julian Oscillation } \\
\text { (MJO) - Real-time } \\
\text { Multivariate MJO }\end{array}$ & $\begin{array}{l}\text { www.bom.gov.au/climate/mjo/graphics } \\
\text { /rmm.74toRealtime.txt }\end{array}$ & $4 c$ \\
\hline & $\begin{array}{l}\text { Multivariate ENSO index } \\
\text { (MEI) }\end{array}$ & www.esrl.noaa.gov/psd/enso/mei/ & $2 b 4,3 i$ \\
\hline & Niño3.4 (detrended) & $\begin{array}{l}\text { www.cpc.ncep.noaa.gov/products/analysis } \\
\text { _monitoring/ensostuff/detrend.nino34.ascii.txt }\end{array}$ & $3 c$ \\
\hline & $\begin{array}{l}\text { North Atlantic Oscillation } \\
(\mathrm{NAO})\end{array}$ & $\begin{array}{l}\text { https://climatedataguide.ucar.edu/climate-data } \\
\text { /hurrell-north-atlantic-oscillation-nao-index } \\
\text {-station-based }\end{array}$ & $2 \mathrm{el}$ \\
\hline & $\begin{array}{l}\text { North Atlantic Oscillation - } \\
\text { Summer (SNAO) }\end{array}$ & by request from Folland & $2 \mathrm{el}$ \\
\hline & Oceanic Niño Index (ONI) & $\begin{array}{l}\text { www.cpc.ncep.noaa.gov/products/analysis } \\
\text { _monitoring/ensostuff/ensoyears.shtml }\end{array}$ & $2 d 6,4 b$ \\
\hline & $\begin{array}{l}\text { Pacific Decadal Oscillation } \\
\text { (PDO) }\end{array}$ & www.cpc.ncep.noaa.gov/products/GODAS/ & $2 \mathrm{~d} 6$ \\
\hline & $\begin{array}{l}\text { Quasi-biennial Oscillation } \\
\text { (QBO) }\end{array}$ & multiple inputs & $2 \mathrm{~b} 5$ \\
\hline & $\begin{array}{l}\text { Southern Annular Mode } \\
\text { (SAM) }\end{array}$ & www.antarctica.ac.uk/met/gjma/sam.html & $6 c$ \\
\hline & $\begin{array}{l}\text { Southern Annular Mode } \\
\text { (SAM, AAO) }\end{array}$ & $\begin{array}{l}\text { www.cpc.ncep.noaa.gov/products/precip/CWlink } \\
\text { /daily_ao_index/aao/aao.shtml }\end{array}$ & $2 \mathrm{el}, 6 \mathrm{~b}$ \\
\hline & $\begin{array}{l}\text { Southern Oscillation Index } \\
\text { (SOI) }\end{array}$ & $\begin{array}{l}\text { ftp://ftp.bom.gov.au/anon/home/ncc/www/sco/soi } \\
\text { /soiplaintext.html }\end{array}$ & $2 \mathrm{el}$ \\
\hline & $\begin{array}{l}\text { Southern Oscillation Index } \\
\text { (EQ-SOI) }\end{array}$ & www.cpc.ncep.noaa.gov/data/indices & $6 c$ \\
\hline \multirow{6}{*}{ Ocean Carbon } & $\mathrm{pCO} 2$ & www.socat.info & $3 \mathrm{jl}$ \\
\hline & pCO2 & $\begin{array}{l}\text { http://hahana.soest.hawaii.edu/hot/products/HOT } \\
\text { _surface_CO2.txt }\end{array}$ & $3 \mathrm{j} 2$ \\
\hline & $\mathrm{pH}$ & $\begin{array}{l}\text { http://hahana.soest.hawaii.edu/hot/products/HOT } \\
\text { _surface_CO2.txt }\end{array}$ & $3 \mathrm{j} 2$ \\
\hline & $\begin{array}{l}\text { Global Ocean Ship-Based } \\
\text { Hydrographic Investigations } \\
\text { Program }\end{array}$ & www.go-ship.org & $3 \mathrm{j} 3$ \\
\hline & GLODAPv2 & https://odv.awi.de/data/ocean/glodap-v2-bottle-data/ & $6 f$ \\
\hline & SOCCOM & https://soccom.princeton.edu/content/float-data & 6f, SB6.I \\
\hline \multirow{3}{*}{ Ocean Circulation } & $\begin{array}{l}\text { Atlantic Meridional } \\
\text { Overturning Circulation }\end{array}$ & www.rapid.ac.uk/rapidmoc/rapid_data/datadl.php & $3 \mathrm{~h}$ \\
\hline & MOVE & www.oceansites.org/data/ & $3 \mathrm{~h}$ \\
\hline & XBT Data & www.aoml.noaa.gov/phod/hdenxbt/index.php & $3 \mathrm{~h}$ \\
\hline \multirow{5}{*}{ Ocean Heat Content } & $\begin{array}{l}\text { CSIRO/ACE CRC/IMAS- } \\
\text { UTAS estimate }\end{array}$ & $\begin{array}{l}\text { www.cmar.csiro.au/sealevel/thermal_expansion } \\
\text { _ocean_heat_timeseries.html }\end{array}$ & $3 c$ \\
\hline & IAP/CAS & $\begin{array}{l}\text { https://climatedataguide.ucar.edu/climate-data } \\
\text { locean-temperature-analysis-and-heat-content } \\
\text {-estimate-institute-atmospheric-physics }\end{array}$ & $3 c$ \\
\hline & PMEL/JPL/JIMAR & http://oceans.pmel.noaa.gov & $3 c$ \\
\hline & MRI/JMA & $\begin{array}{l}\text { www.data.jma.go.jp/gmd/kaiyou/english/ohc/ohc } \\
\text { _global_en.html }\end{array}$ & $3 c$ \\
\hline & NCEP Ocean Reanalysis & $\begin{array}{l}\text { http://apdrc.soest.hawaii.edu/datadoc/godas } \\
\text { _pentad.php }\end{array}$ & $4 \mathrm{~h}$ \\
\hline
\end{tabular}




\begin{tabular}{|c|c|c|c|}
\hline $\begin{array}{c}\text { General Variable or } \\
\text { Phenomenon }\end{array}$ & $\begin{array}{c}\text { Specific Dataset or } \\
\text { Variable } \\
\end{array}$ & Source & Section \\
\hline \multirow{2}{*}{$\begin{array}{l}\text { Ocean Heat Content } \\
\text { (continued) }\end{array}$} & NCEI & www.nodc.noaa.gov/OC5/3M_HEAT_CONTENT/ & $3 c$ \\
\hline & UK Met Office EN4.0.2 & $\begin{array}{l}\text { www.metoffice.gov.uk/hadobs/en4/download } \\
\text {-en4-0-2-109.html }\end{array}$ & $3 c$ \\
\hline Ocean Mass & $\begin{array}{l}\text { NASA Gravity Recovery and } \\
\text { Climate Experiment }\end{array}$ & $\begin{array}{l}\text { https://grace.jpl.nasa.gov/data/get-data/monthly } \\
\text {-mass-grids-ocean/ }\end{array}$ & $3 f$ \\
\hline \multirow{5}{*}{ Ocean Salinity } & Aquarius V3.0 & http://podaac.jpl.nasa.gov/aquarius & $3 \mathrm{dl}$ \\
\hline & Argo & www.argo.ucsd.edu, http://argo.jcommops.org & $3 c, 3 \mathrm{dl}, 6 \mathrm{f}$ \\
\hline & $\begin{array}{l}\text { Blended Analysis for Surface } \\
\text { Salinity }\end{array}$ & ftp://ftp.cpc.ncep.noaa.gov/precip/BASS & $3 \mathrm{dl}, 3 \mathrm{~d} 2$ \\
\hline & $\begin{array}{l}\text { CARICOOS Underwater } \\
\text { Gliders }\end{array}$ & www.aoml.noaa.gov/phod/goos/gliders/index.php & $4 \mathrm{~h}$ \\
\hline & World Ocean Atlas 2013 & www.nodc.noaa.gov/OC5/woal3/ & $3 \mathrm{dl}, 3 \mathrm{~d} 2$ \\
\hline \multirow{2}{*}{$\begin{array}{l}\text { Outgoing Longwave } \\
\text { Radiation }\end{array}$} & CERES FLASHFlux Project & http://flashflux.larc.nasa.gov & $3 \mathrm{el}, 3 \mathrm{e} 4$ \\
\hline & Daily OLR & $\begin{array}{l}\text { www.ncdc.noaa.gov/cdr/atmospheric/outgoing } \\
\text {-longwave-radiation-daily }\end{array}$ & $\begin{array}{l}4 \mathrm{~b} 2,4 \mathrm{c} \\
4 \mathrm{f3}, 4 \mathrm{f6}\end{array}$ \\
\hline \multirow{14}{*}{$\begin{array}{l}\text { Ozone, Total Column } \\
\text { and Stratospheric }\end{array}$} & Bodeker Scientific & $\begin{array}{l}\text { www.bodekerscientific.com/data/total-column } \\
\text {-ozone }\end{array}$ & $5 j$ \\
\hline & CCMI REFC2 & www2.acom.ucar.edu/gcm/ccmi-output & $2 g 4$ \\
\hline & $\begin{array}{l}\text { GOME/SCIAMACHYI } \\
\text { GOME2 (GSG) Merged } \\
\text { Total Ozone }\end{array}$ & www.iup.uni-bremen.de/gome/wfdoas/ & $2 g 4$ \\
\hline & $\begin{array}{l}\text { GOME/SCIAMACHY/ } \\
\text { GOME2 (GTO) Merged } \\
\text { Total Ozone }\end{array}$ & www.esa-ozone-cci.org & $2 g 4$ \\
\hline & GOZCARDS ozone profiles & https://gozcards.jpl.nasa.gov/info.php & $2 g 4$ \\
\hline & Aura OMI/MLS & $\begin{array}{l}\text { https://disc.sci.gsfc.nasa.gov/Aura/data-holdings } \\
\text { /MLS } \\
\text { ftp://toms.gsfc.nasa.gov/pub/omi/data/ozone/ } \\
\text { (for years 2013-2017) } \\
\text { https://disc.gsfc.nasa.gov/datasets/OMTO3d_003 } \\
\text { /summary } \\
\text { https://disc.gsfc.nasa.gov/datasets/OMUVBd_003 } \\
\text { /summary }\end{array}$ & $5 \mathrm{j}, 6 \mathrm{~g}$ \\
\hline & $\begin{array}{l}\text { Multi Sensor Reanalysis } \\
\text { (MSR-2) of total ozone }\end{array}$ & www.temis.nl & $2 g 4$ \\
\hline & $\begin{array}{l}\text { NASA BUV/SBUV v8.6 } \\
\text { (MOD v8.6) Merged Ozone }\end{array}$ & http://acdb-ext.gsfc.nasa.gov/Data_services/merged & $2 g 4$ \\
\hline & $\begin{array}{l}\text { NOAA BUV/SBUV v8.6 } \\
\text { (MOD v8.6) Merged Ozone }\end{array}$ & ftp://ftp.cpc.ncep.noaa.gov/SBUV_CDR & $2 g 4$ \\
\hline & $\begin{array}{l}\text { Ozone Mapping \& Profiler } \\
\text { Suite (OMPS) }\end{array}$ & https://ozoneaq.gsfc.nasa.gov/omps/ & $6 g$ \\
\hline & Ozonesonde & www.esrl.noaa.gov/gmd/dv/spo_oz & $6 \mathrm{~g}$ \\
\hline & SAGE II/OSIRIS & dataset linked to Bourassa et al. (2014) & $2 g 4$ \\
\hline & SWOOSH & www.esrl.noaa.gov/csd/groups/csd8/swoosh/ & $2 g 4$ \\
\hline & $\begin{array}{l}\text { WOUDC Ground-based } \\
\text { Ozone }\end{array}$ & $\begin{array}{l}\text { https://woudc.org/archive/Projects-Campaigns } \\
\text { /ZonalMeans/ }\end{array}$ & $2 g 4$ \\
\hline \multirow{3}{*}{ Ozone, Tropospheric } & Aura OMI/MLS & $\begin{array}{l}\text { http://acd-ext.gsfc.nasa.gov/Data_services/cloud } \\
\text { _slice/new_data.html }\end{array}$ & $2 g 6$ \\
\hline & NOAA Observatory Data & ftp://aftp.cmdl.noaa.gov/data/ozwv/SurfaceOzone/ & $2 g 6$ \\
\hline & $\begin{array}{l}\text { Tropospheric Ozone } \\
\text { Assessment Report }\end{array}$ & https://doi.pangaea.de/I0.1594/PANGAEA.876108 & SB2.3 \\
\hline
\end{tabular}




\begin{tabular}{|c|c|c|c|}
\hline $\begin{array}{c}\text { General Variable or } \\
\text { Phenomenon }\end{array}$ & $\begin{array}{l}\text { Specific Dataset or } \\
\text { Variable }\end{array}$ & Source & Section \\
\hline \multirow{7}{*}{ Permafrost } & Active Layer Thickness & www2.gwu.edu/ calm/ & $5 g 2$ \\
\hline & $\begin{array}{l}\text { Global Terrestrial Network } \\
\text { for Permafrost (GTN-P) }\end{array}$ & http://gtnp.arcticportal.org & $2 \mathrm{cl}$ \\
\hline & Permafrost Temperature & http://permafrost.gi.alaska.edu/sites_map & $5 g l$ \\
\hline & $\begin{array}{l}\text { Permafrost Temperature at } \\
\text { French sites }\end{array}$ & permafrance.osug.fr & $2 \mathrm{cl}$ \\
\hline & $\begin{array}{l}\text { Permafrost Temperature at } \\
\text { Norwegian sites }\end{array}$ & $\begin{array}{l}\text { www.tspnorway.com } \\
\text { www.met.no }\end{array}$ & $2 \mathrm{cl}, 5 \mathrm{gl}$ \\
\hline & $\begin{array}{l}\text { Permafrost Temperature at } \\
\text { Swedish sites }\end{array}$ & https://bolin.su.se/ & $5 g l$ \\
\hline & $\begin{array}{l}\text { Permafrost Temperature at } \\
\text { Swiss sites }\end{array}$ & www.permos.ch & $2 \mathrm{cl}$ \\
\hline \multirow{3}{*}{$\begin{array}{l}\text { Phytoplankton, } \\
\text { Ocean Color }\end{array}$} & MODIS-Aqua R2018.0 & http://oceancolor.gsfc.nasa.gov/cms/reprocessing/ & $3 i$ \\
\hline & SeaWiFS R2018.0 & http://oceancolor.gsfc.nasa.gov/cms/reprocessing/ & $3 i$ \\
\hline & VIIRS R20I8.0 & http://oceancolor.gsfc.nasa.gov/cms/reprocessing/ & $3 i$ \\
\hline \multirow{5}{*}{ Precipitation } & CMORPH & $\begin{array}{l}\text { www.cpc.ncep.noaa.gov/products/janowiak } \\
\text { /cmorph_description.html }\end{array}$ & $4 \mathrm{dI}, 4 \mathrm{~d} 2$ \\
\hline & $\mathrm{GHCN}$ & $\begin{array}{l}\text { www.ncdc.noaa.gov/temp-and-precip/ghcn-gridded } \\
\text {-products/precipitation }\end{array}$ & $2 \mathrm{~d} 4$ \\
\hline & GHCNDEX & www.climdex.org/datasets.html & SB2.I \\
\hline & GPCP v2.3 & http://precip.gsfc.nasa.gov & $\begin{array}{l}2 \mathrm{~d} 4,4 \mathrm{e}, \\
4 \mathrm{~h}\end{array}$ \\
\hline & GPCC & www.dwd.de/EN/ourservices/gpcc/gpcc.html & $\begin{array}{l}2 \mathrm{~d} 4 \\
\text { SB2.I }\end{array}$ \\
\hline \multirow{2}{*}{$\begin{array}{l}\text { Precipitation (net), } \\
\text { Freshwater Flux }\end{array}$} & $\begin{array}{l}\text { JRA-55 Atmospheric } \\
\text { Reanalysis }\end{array}$ & http://jra.kishou.go.jp/JRA-55/index_en.html & $6 c$ \\
\hline & GPCPv23, OAFlux & http://precip.gsfc.nasa.gov, http://oaflux.whoi.edu & $3 e 2,3 e 4$ \\
\hline \multirow{6}{*}{$\begin{array}{l}\text { Pressure, Sea Level } \\
\text { or Near-Surface }\end{array}$} & $\begin{array}{l}\text { Antarctic Meteorological } \\
\text { Research Center (AMRC) } \\
\text { AWS }\end{array}$ & http://amrc.ssec.wisc.edu/data & $6 \mathrm{~b}$ \\
\hline & ERA-Interim & $\begin{array}{l}\text { www.ecmwf.int/en/research/climate-reanalysis } \\
\text { lera-interim }\end{array}$ & $6 b$ \\
\hline & HadSLP2r & www.metoffice.gov.uk/hadobs/hadslp2/ & $2 \mathrm{el}$ \\
\hline & $\begin{array}{l}\text { JRA-55 Atmospheric } \\
\text { Reanalysis }\end{array}$ & http://jra.kishou.go.jp/JRA-55/index_en.html & $6 c$ \\
\hline & NCEP/NCAR Reanalysis & $\begin{array}{l}\text { www.esrl.noaa.gov/psd/data/gridded/data.ncep } \\
\text {.reanalysis.html }\end{array}$ & $5 b$ \\
\hline & READER & https://legacy.bas.ac.uk/met/READER/ & $6 c$ \\
\hline River Discharge & ELSE & No public archive & $2 \mathrm{~d} 6$ \\
\hline Sea Ice Age & EASE-Grid v3 & http://nsidc.org/data/nsidc-06II/ & $5 \mathrm{~d} 2$ \\
\hline \multirow{4}{*}{$\begin{array}{c}\text { Sea lce } \\
\text { Concentration }\end{array}$} & AMSR2 Daily & https://seaice.uni-bremen.de & SB6.I \\
\hline & $\begin{array}{l}\text { Near-Real-Time DMSP } \\
\text { SSM/I-SSMIS Daily Polar } \\
\text { Gridded }\end{array}$ & http://nsidc.org/data/nsidc-008I.html & $6 e$ \\
\hline & $\begin{array}{l}\text { Nimbus-7 SMMR and DMSP } \\
\text { SSM/I (Bootstrap) }\end{array}$ & http://nsidc.org/data/nsidc-0079.html & $6 e$ \\
\hline & $\begin{array}{l}\text { Nimbus-7 SMMR and DMST } \\
\text { SSM/I (NasaTeam) }\end{array}$ & http://nsidc.org/data/NSIDC-005I & $6 e$ \\
\hline Sea Ice Extent & $\begin{array}{l}\text { Nimbus-7 SMMR and DMSP } \\
\text { SSM/I (Bootstrap) }\end{array}$ & http://nsidc.org/data/seaice_index/ & $5 c, 5 \mathrm{dl}$ \\
\hline
\end{tabular}




\begin{tabular}{|c|c|c|c|}
\hline $\begin{array}{l}\text { General Variable or } \\
\text { Phenomenon }\end{array}$ & $\begin{array}{l}\text { Specific Dataset or } \\
\text { Variable }\end{array}$ & Source & Section \\
\hline \multirow{2}{*}{$\begin{array}{l}\text { Sea Ice Freeboard/ } \\
\text { Thickness }\end{array}$} & ESA CryoSat-2 & http://data.meereisportal.de/ & $5 \mathrm{~d} 3$ \\
\hline & TIFAX & $\begin{array}{l}\text { https://epic.awi.de/45409/I/CampaignReport } \\
\text { _TIFAX2017.pdf }\end{array}$ & $5 \mathrm{~d} 3$ \\
\hline \multirow{4}{*}{$\begin{array}{l}\text { Sea Level/Sea } \\
\text { Surface Height }\end{array}$} & NOAA/NESDIS/STAR & $\begin{array}{l}\text { www.star.nesdis.noaa.gov/sod/lsa/SeaLevelRise } \\
\text { /LSA_SLR_timeseries.php }\end{array}$ & $3 f$ \\
\hline & $\begin{array}{l}\text { Ssalto/Duacs Multimission } \\
\text { Altimeter Products }\end{array}$ & $\begin{array}{l}\text { http://marine.copernicus.eu/services } \\
\text {-portfolio/access-to-products/?option=com } \\
\text { ccsw\&view=details\&product_id=SEALEVEL_GLO } \\
\text { _PHY_L4_NRT_OBSERVATIONS_008_046 }\end{array}$ & $3 f, S B 3.2$ \\
\hline & Tide Gauge & http://uhslc.soest.hawaii.edu/ & $3 f$ \\
\hline & Tide Gauge & $\begin{array}{l}\text { https://tidesandcurrents.noaa.gov/ } \\
\text { noaatidepredictions/NOAATidesFacade } \\
\text {.jsp?Stationid }=8722670\end{array}$ & $3 \mathrm{~h}$ \\
\hline \multirow{6}{*}{$\begin{array}{l}\text { Sea Surface } \\
\text { Temperature }\end{array}$} & ERSSTv4 & $\begin{array}{l}\text { www.ncdc.noaa.gov/data-access/marineocean-data } \\
\text { lextended-reconstructed-sea-surface-temperature } \\
\text {-ersst-v4 }\end{array}$ & $4 f 2,4 f 4$ \\
\hline & ERSST v5 & https://doi.org//0.7289/V5T72FNM & $3 b$ \\
\hline & HadSST3 & www.metoffice.gov.uk/hadobs/hadsst3 & $2 \mathrm{bl}, 3 \mathrm{~b}$ \\
\hline & $\begin{array}{l}\text { NOAA Optimum } \\
\text { Interpolation SST (OISST) } \\
\text { v2 }\end{array}$ & $\begin{array}{l}\text { http://apdrc.soest.hawaii.edu/dods/public_data } \\
\text { /NOAA_SST/OISST/monthly }\end{array}$ & $4 f$ \\
\hline & $\begin{array}{l}\text { NOAA Optimum } \\
\text { Interpolation SST (OISST) } \\
\text { v2 }\end{array}$ & $\begin{array}{l}\text { www.ncei.noaa.gov/data/sea-surface-temperature } \\
\text {-optimum-interpolation/access/ }\end{array}$ & $\begin{array}{l}3 \mathrm{~b}, 4 \mathrm{bl}, \\
4 \mathrm{~d} 2,4 \mathrm{fl} \\
4 \mathrm{f3}, 4 \mathrm{fb} \\
4 \mathrm{~h}, 6 \mathrm{e}\end{array}$ \\
\hline & $\begin{array}{l}\text { NOAA Optimum } \\
\text { Interpolation SST (OISST) } \\
\text { v2 }\end{array}$ & http://nsidc.org/data/g02135 & $5 c$ \\
\hline \multirow{3}{*}{$\begin{array}{l}\text { Sea Subsurface } \\
\text { Temperature }\end{array}$} & Argo & $\begin{array}{l}\text { http://sio-argo.ucsd.edu/RG_Climatology.html, } \\
\text { ttp://argo.jcommops.org }\end{array}$ & $3 c, 6 f$ \\
\hline & $\begin{array}{l}\text { CARICOOS Underwater } \\
\text { Gliders }\end{array}$ & www.aoml.noaa.gov/phod/goos/gliders/index.php & $4 \mathrm{~h}$ \\
\hline & NCEP Ocean Reanalysis & www.cpc.ncep.noaa.gov/products/GODAS/ & $\begin{array}{l}4 \mathrm{bl}, 4 \mathrm{c}, \\
4 \mathrm{~h}\end{array}$ \\
\hline \multirow{3}{*}{ Snow Cover } & $\begin{array}{l}\text { NOAA Interactive Multi- } \\
\text { sensor Snow and Ice } \\
\text { Mapping System (Snow } \\
\text { Cover Duration) } \\
\end{array}$ & www.natice.noaa.gov/ims/index.html & $5 i$ \\
\hline & $\begin{array}{l}\text { NOAA Snow Chart Data } \\
\text { Record (Snow Cover Extent) }\end{array}$ & www.snowcover.org & $2 c 2,5 i$ \\
\hline & $\begin{array}{l}\text { NH Snow Water Equivalent } \\
\text { Ensemble }\end{array}$ & http://nsidc.org/data/NSIDC-0668 & $5 i$ \\
\hline \multirow{4}{*}{ Snow Depth } & $\begin{array}{l}\text { Canadian Meteorological } \\
\text { Centre Snow Depth Analysis }\end{array}$ & & $5 i$ \\
\hline & IceBridge Flights & ftp://ftp.star.nesdis.noaa.gov/pub/socd/lsa/ & $5 \mathrm{~d} 3$ \\
\hline & in situ snow stakes & $\begin{array}{l}\text { https://data.npolar.no/dataset/3099ea95-c3cd-4a8b } \\
\text {-af5d-73750e46d79| }\end{array}$ & $5 \mathrm{~d} 3$ \\
\hline & Magnaprobe & $\begin{array}{l}\text { https://data.npolar.no/dataset/3d72756d-788b-4c49 } \\
\text {-b0cc-8a345c091020 }\end{array}$ & $5 \mathrm{~d} 3$ \\
\hline Soil Moisture & ESA CCI SM & www.esa-soilmoisture-cci.org/index.php & $2 \mathrm{~d} 8$ \\
\hline
\end{tabular}




\begin{tabular}{|c|c|c|c|}
\hline $\begin{array}{l}\text { General Variable or } \\
\text { Phenomenon }\end{array}$ & $\begin{array}{l}\text { Specific Dataset or } \\
\text { Variable }\end{array}$ & Source & Section \\
\hline \multirow{5}{*}{ Surface Current } & $\begin{array}{l}\text { Brazil-Malvina Region } \\
\text { Confluence Region }\end{array}$ & $\begin{array}{l}\text { www.aoml.noaa.gov/phod/altimetry/cvar/mal } \\
\text { /BM_anm.php }\end{array}$ & $3 g$ \\
\hline & $\begin{array}{l}\text { Long Term Time Series of } \\
\text { Surface Currents: Agulhas } \\
\text { Current }\end{array}$ & www.aoml.noaa.gov/phod/altimetry/cvar/agu/ & $3 g$ \\
\hline & $\begin{array}{l}\text { Long Term Time Series of } \\
\text { Surface Currents: North } \\
\text { Brazil Current }\end{array}$ & www.aoml.noaa.gov/phod/altimetry/cvar/nbc & $3 g$ \\
\hline & $\begin{array}{l}\text { Ocean Surface Current } \\
\text { Analysis - Real time } \\
\text { (OSCAR) }\end{array}$ & www.oscar.noaa.gov & $3 g$ \\
\hline & Yucatan Current & $\begin{array}{l}\text { www.aoml.noaa.gov/phod/altimetry/cvar/yuc } \\
\text { /transport.php }\end{array}$ & $3 g$ \\
\hline \multirow{13}{*}{$\begin{array}{l}\text { Temperature, [Near] } \\
\text { Surface }\end{array}$} & $\begin{array}{l}\text { Antarctic Meteorological } \\
\text { Research Center (AMRC) } \\
\text { AWS }\end{array}$ & http://amrc.ssec.wisc.edu/data & $6 b$ \\
\hline & CRUTEM4 & $\begin{array}{l}\text { www.metoffice.gov.uk/hadobs/crutem4 } \\
\text { http://ww.cru.uea.ac.uk/cru/data/temperature }\end{array}$ & $2 \mathrm{bl}, 5 \mathrm{~b}$ \\
\hline & $\begin{array}{l}\text { Danish Meteorological } \\
\text { Institute }\end{array}$ & $\begin{array}{l}\text { http://research.dmi.dk/research/research-topics } \\
\text { /climate/ }\end{array}$ & $5 e 6$ \\
\hline & ERA-Interim & $\begin{array}{l}\text { www.ecmwf.int/en/forecasts/datasets/archive } \\
\text {-datasets/reanalysis-datasets/era-interim }\end{array}$ & $2 \mathrm{bl}, 6 \mathrm{~b}$ \\
\hline & GHCNDEX & www.climdex.org/datasets.html & $2 \mathrm{~b} 3$ \\
\hline & $\begin{array}{l}\text { HadCRUT4 Global } \\
\text { Temperature }\end{array}$ & www.metoffice.gov.uk/hadobs/hadcrut4/ & $2 \mathrm{bl}$ \\
\hline & JMA Global Temperature & $\begin{array}{l}\text { https://ds.data.jma.go.jp/tcc/tcc/products/gwp/temp } \\
\text { /map/download.html }\end{array}$ & $2 \mathrm{bl}$ \\
\hline & $\begin{array}{l}\text { JRA-55 Atmospheric } \\
\text { Reanalysis }\end{array}$ & http://jra.kishou.go.jp/JRA-55/index_en.html & $2 \mathrm{bl}$ \\
\hline & MERRA-2 & http://gmao.gsfc.nasa.gov/reanalysis/MERRA-2/ & $2 \mathrm{bl}$ \\
\hline & $\begin{array}{l}\text { NASA/GISS Global } \\
\text { Temperature }\end{array}$ & https://data.giss.nasa.gov/gistemp/ & $2 \mathrm{bl}, 2 \mathrm{~b} 2$ \\
\hline & NCEP/NCAR Reanalysis & $\begin{array}{l}\text { www.esrl.noaa.gov/psd/data/gridded/data.ncep } \\
\text {.reanalysis.html }\end{array}$ & $5 b$ \\
\hline & NOAAGlobalTemp & $\begin{array}{l}\text { www.ncdc.noaa.gov/data-access/marineocean-data } \\
\text { /noaa-global-surface-temperature-noaaglobaltemp }\end{array}$ & $2 \mathrm{bl}$ \\
\hline & READER & https://legacy.bas.ac.uk/met/READER/ & $6 c$ \\
\hline
\end{tabular}




\begin{tabular}{|c|c|c|c|}
\hline $\begin{array}{l}\text { General Variable or } \\
\text { Phenomenon }\end{array}$ & $\begin{array}{l}\text { Specific Dataset or } \\
\text { Variable }\end{array}$ & Source & Section \\
\hline \multirow{13}{*}{$\begin{array}{l}\text { Temperature, Upper } \\
\text { Atmosphere }\end{array}$} & CMIP5 & https://esgf-node.IInl.gov/search/cmip5/ & $2 \mathrm{~b} 5$ \\
\hline & ERA-Interim & $\begin{array}{l}\text { www.ecmwf.int/en/research/climate-reanalysis } \\
\text { /era-interim }\end{array}$ & $\begin{array}{l}2 b 4,2 b 5, \\
6 b\end{array}$ \\
\hline & $\begin{array}{l}\text { JRA-55 Atmospheric } \\
\text { Reanalysis }\end{array}$ & http://jra.kishou.go.jp/JRA-55/index_en.html & $2 b 4,2 b 5$ \\
\hline & MERRA-2 & http://gmao.gsfc.nasa.gov/reanalysis/MERRA-2/ & $\begin{array}{l}2 \mathrm{~b} 4,2 \mathrm{~b} 5 \\
2 \mathrm{~g} 5\end{array}$ \\
\hline & RAOBCORE, RICH & www.univie.ac.at/theoret-met/research/raobcore & $2 \mathrm{~b} 4,2 \mathrm{~b} 5$ \\
\hline & RATPAC A2 & $\begin{array}{l}\text { www.ncdc.noaa.gov/data-access/weather-balloon } \\
\text { /radiosonde-atmospheric-temperature-products } \\
\text {-accessing-climate/ratpac-a }\end{array}$ & $2 b 4,2 b 5$ \\
\hline & RSS & www.remss.com & $2 b 4,2 b 5$ \\
\hline & NCEP/NCAR Reanalysis & $\begin{array}{l}\text { www.esrl.noaa.gov/psd/data/gridded/data.ncep } \\
\text {.reanalysis.html }\end{array}$ & $5 b$ \\
\hline & NOAA/NESDIS/STAR & www.star.nesdis.noaa.gov/smcd/emb/mscat/ & $2 \mathrm{~b} 5$ \\
\hline & Ozonesonde & www.esrl.noaa.gov/gmd/dv/spo_oz & $6 g$ \\
\hline & SSU-3 & & $2 \mathrm{~b} 5$ \\
\hline & UAH MSU & http://vortex.nsstc.uah.edu/public/msu & $2 b 4,2 b 5$ \\
\hline & $\begin{array}{l}\text { University of New South } \\
\text { Wales }\end{array}$ & $\begin{array}{l}\text { http://web.science.unsw.edu.au/ stevensherwood } \\
\text { /radproj/index.html }\end{array}$ & $2 b 4,2 b 5$ \\
\hline \multirow{2}{*}{$\begin{array}{l}\text { TOA Earth Radiation } \\
\text { Budget }\end{array}$} & CERES FLASHFlux & $\begin{array}{l}\text { https://ceres-tool.larc.nasa.gov/ord-tool/jsp } \\
\text { /EBAF4Selection.jsp }\end{array}$ & $2 \mathrm{fl}$ \\
\hline & CERES EBAF Ed 4.0 & $\begin{array}{l}\text { https://ceres-tool.larc.nasa.gov/ord-tool/jsp } \\
\text { /EBAF4Selection.jsp }\end{array}$ & $2 \mathrm{fl}$ \\
\hline Total Solar Irradiance & SORCE/TIM & http://science.nasa.gov/missions/sorce/ & $2 \mathrm{fl}$ \\
\hline \multirow{12}{*}{ Trace Gases } & $\begin{array}{l}\text { Atmospheric Greenhouse } \\
\text { Gas Index (AGGI) }\end{array}$ & www.esrl.noaa.gov/gmd/aggi & $2 g l$ \\
\hline & Carbon Dioxide (CO2) & www.esrl.noaa.gov/gmd/dv/iadv & $2 g I$ \\
\hline & Carbon Dioxide (CO2) & $\begin{array}{l}\text { ftp://aftp.cmdl.noaa.gov/products/trends/co2/co2 } \\
\text { _mm_mlo.txt }\end{array}$ & $3 \mathrm{j} 2$ \\
\hline & Carbon Monoxide (CO) & https://atmosphere.copernicus.eu/ & $2 \mathrm{~g} 7$ \\
\hline & $\begin{array}{l}\text { Chlorine Monoxide }(\mathrm{ClO}) \text { - } \\
\text { Aura MLS }\end{array}$ & http://mls.jpl.nasa.gov/products/clo_product.php & $6 g$ \\
\hline & $\begin{array}{l}\text { Halocarbons (CFCs, HFCs, } \\
\text { HCFCs) }\end{array}$ & www.esrl.noaa.gov/gmd/hats/data.html & $2 g I$ \\
\hline & $\begin{array}{l}\text { Hydrogen Chloride }(\mathrm{HCl}) \text { - } \\
\text { Aura MLS }\end{array}$ & $\begin{array}{l}\text { http://disc.sci.gsfc.nasa.gov/datacollection/ML2HCL } \\
\text { _V004.html }\end{array}$ & $2 g l$ \\
\hline & Methane & www.esrl.noaa.gov/gmd/dv/iadv & $2 \mathrm{gl}$ \\
\hline & Nitrous Oxide & www.esrl.noaa.gov/gmd/hats/combined/N2O.html & $2 g I$ \\
\hline & $\begin{array}{l}\text { Ozone-Depleting Gas Index } \\
\text { (ODGI) }\end{array}$ & www.esrl.noaa.gov/gmd/odgi & $2 g 2$ \\
\hline & Perfluorocarbons & http://agage.eas.gatech.edu & $2 \mathrm{gl}$ \\
\hline & Sulfur Hexafluoride & www.esrl.noaa.gov/gmd/hats/combined/SF6.html & $2 g I$ \\
\hline
\end{tabular}




\begin{tabular}{|c|c|c|c|}
\hline $\begin{array}{l}\text { General Variable or } \\
\text { Phenomenon }\end{array}$ & $\begin{array}{l}\text { Specific Dataset or } \\
\text { Variable }\end{array}$ & Source & Section \\
\hline \multirow{5}{*}{$\begin{array}{l}\text { Tropical Cyclone } \\
\text { Data }\end{array}$} & HURDAT2 & www.aoml.noaa.gov/hrd/hurdat/Data_Storm.html & $4 \mathrm{f} 2$ \\
\hline & $\begin{array}{l}\text { International Best Track } \\
\text { Archive for Climate } \\
\text { Stewardship (IBTrACS) }\end{array}$ & www.ncdc.noaa.gov/ibtracs/ & $\begin{array}{l}4 f I, 4 f 3 \\
4 f 6,4 f 7\end{array}$ \\
\hline & $\begin{array}{l}\text { JTWC Best-track Dataset } \\
\text { (20II preliminary) }\end{array}$ & $\begin{array}{l}\text { www.usno.navy.mil/NOOC/nmfc-ph/RSS/jtwc } \\
\text { /best_tracks }\end{array}$ & $4 f 4,4 f 5$ \\
\hline & $\begin{array}{l}\text { RSMC-Tokyo, JMA best- } \\
\text { track data }\end{array}$ & $\begin{array}{l}\text { www.jma.go.jp/jma/jma-eng/jma-center/rsmc-hp } \\
\text {-pub-eg/besttrack.html }\end{array}$ & $4 \mathrm{f} 4$ \\
\hline & $\begin{array}{l}\text { Southwest Pacific Enhanced } \\
\text { Archive of Tropical Cyclones } \\
\text { (SPEArTC) }\end{array}$ & http://apdrc.soest.hawaii.edu/projects/speartc & $4 f 8$ \\
\hline \multirow{4}{*}{ UV Radation Data } & Canadian sites & $\begin{array}{l}\text { ftp://exp-studies.tor.ec.gc.ca/pub/uvdata } \\
\text { /Preliminary/MSC }\end{array}$ & $5 j$ \\
\hline & Greenland site & http://uv.biospherical.com/Version2/data.asp & $5 j$ \\
\hline & Finnish sites & $\begin{array}{l}\text { http://litdb.fmi.fi/soundingst_uvradiation.php, } \\
\text { http://uv.fmi.fi/uvdb/ }\end{array}$ & $5 j$ \\
\hline & Norwegian sites & https://github.com/uvnrpa/Minute_Data & $5 j$ \\
\hline \multirow{3}{*}{$\begin{array}{l}\text { Water Vapor, } \\
\text { Stratosphere }\end{array}$} & $\begin{array}{l}\text { Frost Point Hygrometer } \\
\text { Data (Boulder, Hilo, Lauder) }\end{array}$ & ftp://aftp.cmdl.noaa.gov/data/ozwv/WaterVapor & $2 g 5$ \\
\hline & $\begin{array}{l}\text { Frost Point Hygrometer } \\
\text { Data (San Jose) }\end{array}$ & http://physics.valpo.edu/ozone/ticosonde.html & $2 \mathrm{~g} 5$ \\
\hline & $\begin{array}{l}\text { NASA Aura Microwave Limb } \\
\text { Sounder }\end{array}$ & https://mls.jpl.nasa.gov/products/h2o_product.php & $2 g 5$ \\
\hline \multirow{6}{*}{$\begin{array}{l}\text { Water Vapor, Total } \\
\text { Column }\end{array}$} & COSMIC GPS-RO & $\begin{array}{l}\text { http://cdaac-www.cosmic.ucar.edu/cdaac/products } \\
\text {.html }\end{array}$ & $2 \mathrm{~d} 2$ \\
\hline & ERA-Interim & $\begin{array}{l}\text { www.ecmwf.int/en/research/climate-reanalysis } \\
\text { lera-interim }\end{array}$ & $2 \mathrm{~d} 2$ \\
\hline & $\begin{array}{l}\text { GNSS Ground-Based Total } \\
\text { Column Water Vapor }\end{array}$ & https://rda.ucar.edu/datasets/ds721.I/ & $2 \mathrm{~d} 2$ \\
\hline & $\begin{array}{l}\text { JRA-55 Atmospheric } \\
\text { Reanalysis }\end{array}$ & http://jra.kishou.go.jp/JRA-55/index_en.html & $2 \mathrm{~d} 2$ \\
\hline & MERRA-2 & http://gmao.gsfc.nasa.gov/reanalysis/MERRA-2/ & $2 \mathrm{~d} 2$ \\
\hline & $\begin{array}{l}\text { RSS SSM/I -AMSR-E Ocean } \\
\text { Total Column Water Vapor }\end{array}$ & www.remss.com & $2 \mathrm{~d} 2$ \\
\hline \multirow{6}{*}{ Wind, [Near] Surface } & Australian (McVicar) & http://doi.org//0.4225/08/56A8549IDDED2 & $2 \mathrm{e} 2$ \\
\hline & ERA-Interim & $\begin{array}{l}\text { www.ecmwf.int/en/research/climate-reanalysis } \\
\text { /era-interim }\end{array}$ & $2 \mathrm{e} 2$ \\
\hline & HadISD2 & www.metoffice.gov.uk/hadobs/hadisd/ & $2 e 2$ \\
\hline & $\begin{array}{l}\text { JRA-55 Atmospheric } \\
\text { Reanalysis }\end{array}$ & http://jra.kishou.go.jp/JRA-55/index_en.html & $2 \mathrm{e} 2,4 \mathrm{~h}$ \\
\hline & MERRA-2 & http://gmao.gsfc.nasa.gov/reanalysis/MERRA-2/ & $2 e 2$ \\
\hline & RSS SSM/I Ocean Winds & www.remss.com/measurements/wind & $2 e 2$ \\
\hline
\end{tabular}




\begin{tabular}{|c|c|c|c|}
\hline $\begin{array}{l}\text { General Variable or } \\
\text { Phenomenon }\end{array}$ & $\begin{array}{l}\text { Specific Dataset or } \\
\text { Variable }\end{array}$ & Source & Section \\
\hline \multirow{7}{*}{$\begin{array}{l}\text { Wind, Upper } \\
\text { Atmosphere }\end{array}$} & CERA-20C & $\begin{array}{l}\text { www.ecmwf.int/en/forecasts/datasets/archive } \\
\text {-datasets/reanalysis-datasets/cera-20c }\end{array}$ & $2 e 3$ \\
\hline & $\begin{array}{l}\text { Climate Forecast System } \\
\text { Reanalysis }\end{array}$ & $\begin{array}{l}\text { www.ncdc.noaa.gov/data-access/model-data } \\
\text { /model-datasets/climate-forecast-system-version2 } \\
\text {-cfsv2 }\end{array}$ & $\begin{array}{l}4 c, 4 f 3, \\
4 f 6\end{array}$ \\
\hline & ERA-Interim & $\begin{array}{l}\text { www.ecmwf.int/en/research/climate-reanalysis } \\
\text { /era-interim }\end{array}$ & $\begin{array}{l}2 e 3,6 b \\
4 e\end{array}$ \\
\hline & GRASP & https://doi.pangaea.de/I0.I594/PANGAEA.8236I7 & $2 \mathrm{e} 3$ \\
\hline & $\begin{array}{l}\text { JRA-55 Atmospheric } \\
\text { Reanalysis }\end{array}$ & http://jra.kishou.go.jp/JRA-55/index_en.html & $2 \mathrm{e} 3,4 \mathrm{~h}$ \\
\hline & MERRA-2 & http://gmao.gsfc.nasa.gov/reanalysis/MERRA-2/ & $2 \mathrm{e} 3$ \\
\hline & NCEP/NCAR Reanalysis & $\begin{array}{l}\text { www.esrl.noaa.gov/psd/data/gridded/data.ncep } \\
\text {.reanalysis.html }\end{array}$ & $\begin{array}{l}4 b 2,4 c \\
4 f 2,4 f 4 \\
5 g\end{array}$ \\
\hline
\end{tabular}




\section{ACKNOWLEDGMENTS}

In addition to the specific acknowledgments below readers are directed to Appendix 1: Relevant Datasets and Sources for information on specific data and products availability and relevant climate variables or phenomena.

The editors thank the AMS Journals editorial staff, in particular Andrea Herbst, and the NCEI graphics team for facilitating the construction of the report, and executing the countless number of technical edits needed. We also express our gratitude to Dr. Rick Rosen, who again served as the AMS special editor for this report. His handling of the reviews was thoughtful and timely. We also thank NOAA's Rotational Assignments Program and the Raleigh, NC National Weather Service Forecast Office for bringing Gail Hartfield to the document this year; her fresh set of eyes and professional perspective were quite valuable.

\section{Chapter 2}

Editors:

- The chapter editors thank David Parker, John Kennedy, and Elizabeth Good for providing details and comprehensive internal reviews of this chapter. The editors also thank Paul Berrisford (ECMWF), Mike Bosilovich (NASA), and Shinya Kobayashi (JMA) for timely provision of reanalysis data used herein. Robert Dunn, Kate Willett, Colin Morice, and Rob Allan were supported by the Joint UK BEIS/Defra Met Office Hadley Centre Climate Programme (GA01101).

Section $2 b 2$ (Lake Surface Temperature):

- RIW was funded by EUSTACE (EU Surface Temperature for All Corners of Earth) which received funding from the European Union's Horizon 2020 Programme for Research and Innovation, under Grant Agreement no 640171. Satellite data processed under UK Natural Environment Research Council project Globolakes (grant reference NE/J023345/2). This work was partly supported by Russian Ministry of Education and Science (project \#6.1387.2017), by the grants of Russian Science Foundation MA - 17-14-01063 and of the Lake Baikal Foundation for support of applied ecological studies (https://baikalfoundation .ru/project/tochka-1/). SGS and SW funded by the Tahoe Regional Planning Agency. Lake surface water temperatures in Poland were provided by the Institute of Meteorology and Water Management in Warsaw.
Section $2 b 3$ (Temperature Extremes):

- SEPK is supported by ARC grant number FT170100106.

Section 265 (Lower Stratospheric Temperature):

- Work performed by Stephen Po-Chedley at LLNL was performed under the auspices of the U.S. Department of Energy under Contract DE-AC5207NA27344 and under LDRD 18-ERD-054.

Section 2d6 (River Discharge):

- Hyungjun Kim was supported by the Japan Society for the Promotion of Science KAKENHI (16H06291) for this contribution.

\section{Section $2 d 7$ (Terrestrial Water Storage):}

- This research was supported by grants from NASA's GRACE and GRACE-FO Science Team. GRACE land data processing is supported by the NASA MEaSUREs Program.

Section $2 d 8$ (Soil Moisture):

- The ESA CCI SM datasets and the authors were supported by ESA's Climate Change Initiative for Soil Moisture (Contract No. 4000104814/11/INB and 4000112226/14/I-NB) and the European Union's FP7 EartH2Observe "Global Earth Observation for Integrated Water Resource Assessment" project (grant agreement number 331 603608). We would also like to thank support from the Copernicus Climate Change Service implemented by ECMWF.

\section{Section $2 d 9$ (Soil Moisture):}

- Tim Osborn received funding from UK NERC (NE/P006809/1). Jonathan Barichivich received funding from (CR)2 Chile (CONICYT /FONDAP/15110009). Ian Harris received funding from UK National Centre for Atmospheric Science (NCAS).

\section{Section $2 g$ (Atmospheric Composition):}

- Historical ozone observations from the 1950s at Mauna Loa Observatory and from the 1960s at South Pole were digitized by Samuel J. Oltmans, NOAA, retired. The authors would like to acknowledge a NASA Upper Atmosphere Composition grant for support that helps sustain the frost point hygrometer soundings at Boulder, Lauder and Hilo. Henry Selkirk and Holger Vömel would like to acknowledge support from the NASA 
Upper Atmosphere Composition Observations program. The CAMS interim Reanalysis has been produced by the Copernicus Atmosphere Monitoring Services (CAMS). The European Centre for Medium-Range Weather Forecast (ECMWF) runs CAMS on behalf of the European Commissions. Antje Inness and Johannes Flemming are funded by CAMS. Melanie Coldewey-Egbers, Daan Hubert, Diego Loyola, Victoria Sofieva, and Mark Weber are grateful to ESA's Climate Change Initiative Ozone project and to the EU Copernicus Climate Change Service 312a Lot4 Ozone project for supporting the generation and extension of the GTO-ECV total ozone and SAGE-CCI-OMPS data records. Stacey M. Frith is supported by the NASA Long Term Measurement of Ozone program WBS 479717. Lucien Froidevaux's contribution, with the assistance of Ryan Fuller, was performed at the Jet Propulsion Laboratory, California Institute of Technology, under contract with NASA. Daan Hubert acknowledges the partial support by the EU/ERC Horizon 2020 project GAIA-CLIM.

Section 2 h2 (Vegetation Dynamics):

- The authors would like to thank the SeaWiFS Project (Code 970.2) and the Goddard Earth Sciences Data and Information Services Center/ Distributed Active Archive Center (Code 902) at the Goddard Space Flight Center, Greenbelt, MD 20771, for the production and distribution of these data, respectively. These activities are sponsored by NASA's Earth Science Enterprise.

\section{Section 2 h3 (Biomass Burning):}

- The GFASv1.4 dataset was provided the by GFASCLIM project, which is funded by the German Bundesministerium für Wirtschaft und Energie (BMWi FKZ 50EE1543), and the Copernicus CAMS_44 project.

Sidebar 2SB.1 (Extreme Precipitation):

- NCAR is sponsored by the National Science Foundation.

Sidebar 2SB.2 (Phenology):

- The authors thank reviewers, T. Rutishäuser (Swiss Academies of Arts and Science, Berne, Switzerland) and T. Sparks (Coventry University, Coventry, UK), for their internal review.

\section{Chapter 3}

- The editor thanks NOAA/PMEL's Sandra Bigley for her invaluable work in assembling and copy editing Chapter 3.

Sidebar 3.1 (Coral bleaching):

- NOAA Coral Reef Watch work is supported primarily by the NOAA Coral Reef Conservation Program and the NOAA National Environmental Satellite, Data, and Information Service's Center for Satellite Applications and Research. The scientific results and conclusions, as well as any views or opinions expressed herein, are those of the author(s) and do not necessarily reflect the views of NOAA or the U.S. Department of Commerce.

Section 3e (Global ocean heat, freshwater, and momentum fluxes):

- The GPCP SG combined precipitation data were developed and computed at the NASA/Goddard Space Flight Center's Mesoscale Atmospheric Processes Laboratory-Atmospheres as a contribution to the GEWEX Global Precipitation Climatology Project.

\section{Section $3 h$ (AMOC and AMHT):}

- Data from the RAPID-WATCH MOC monitoring project are funded by the Natural Environment Research Council.

- MOVE contributions were made under award NA15OAR4320071 from the Climate Observations Division, National Oceanic and Atmospheric Administration, U.S. Department of Commerce. Previously, MOVE was funded by the German Bundesministerium für Bildung und Forschung (Grants 03F0246A and 03F0377B).

- The Florida Current cable and section data are funded by the DOC-NOAA Climate Program Office - Ocean Observing and Monitoring Division.

- The XBT data are funded by the NOAA Office of Climate Observations.

- Argo data are collected and made freely available by the International Argo Program and the national programs that contribute to it; the Argo Program is part of the Global Ocean Observing System. 


\section{Chapter 4}

The editors would like extend their thanks and appreciation to Joe Pelissier, the retired Meteorologistin-Charge of the NOAA/NWS Weather Forecast Office in Greenville-Spartanburg, SC, for his inputs regarding the passing of his good friend and colleague Charlie Neumann. Carl Schreck was supported by NOAA through the Cooperative Institute for Climate and Satellites - North Carolina under Cooperative Agreement NA14NES432003.

\section{Chapter 5}

Editor Team:

- Martin Jeffries thanks the Office of Naval Research (Code 32) for supporting his role as Associate Editor of the State of the Climate Report and co-editor of the Arctic section. Jackie Richter-Menge acknowledges that this publication is the result in part of research sponsored by the Cooperative Institute for Alaska Research with funds from the National Oceanic and Atmospheric Administration under cooperative agreement NA13OAR4320056 with the University of Alaska. Emily Osborne acknowledges the NOAA Arctic Research Program for supporting her role as coeditor of the State of the Climate Report Arctic section and coauthor of the paleoclimate sidebar.

\section{Section 5e (Greenland):}

- Marco Tedesco would like to acknowledge the NASA Cryosphere Program (NNX17AH04G, NNX16AH38G), the NASA IDS program (NNX14AD98G) and the Office of Polar Programs at the National Science Foundation (OPP 1643187, PLR-1603331). PROMICE stations are funded by the Danish Energy Agency. KAN stations are funded by SKB. IS acknowledges funding by the Helmholtz Climate Initiative REKLIM (Regional Climate Change), a joint research project of the Helmholtz Association of German Research Centres (HGF) and the German Research Foundation through grant SA 1734/4-1. The Netherlands Polar Programme (NPP) of the NWO (Netherlands Institute for Scientific Research) is acknowledged for the K-transect support.

\section{Section $5 g$ (Terrestrial permafrost):}

- Vladimir Romanovsky and coauthors acknowledge the support of the State of Alaska, the National Science Foundation (grants PLR-0856864 and PLR-1304271 to the University of Alaska Fairbanks; PLR-1002119 and PLR-1304555 to the
George Washington University), Natural Resources Canada and the Norwegian Meteorological Institute. Support was also provided by the Russian Science Foundation (project RNF 16-17-00102) and by the government of the Russian Federation.

\section{Section $5 j$ (Ozone and UV radiation):}

- G. Bernhard and coauthors acknowledge the U.S. National Science Foundation for supporting UV measurements at Barrow and Summit, a Research Council of Norway Centres of Excellence award (Project 223268/F50) to the Norwegian Radiation Protection Authority, and the Academy of Finland for supporting UV measurements through the FARPOCC, SAARA, and ILMA pilot projects. We also acknowledge Tove Svendby from the Norwegian Institute for Air Research and Arne Dahlback from the University of Oslo for overseeing UV measurements at Oslo, Andøya and Ny-Ålesund, and thank Juha M. Karhu, Tomi Karppinen and Markku Ahponen from the Finnish Meteorological Institute for operating the Brewer UV spectroradiometer at Sodankylä.

\section{Chapter 6}

The editors wish to acknowledge and thank the authors for their timely contributions, with additional special thanks to the internal and external reviewers and Document Editors for their thoughtful and constructive comments. The editors also wish to thank Dr. Sam Batzli of the Space Science and Engineering Center at the University of Wisconsin-Madison for his generation of the map in Figure 6.1.

- Ted Scambos was supported under NASA grant NNX16AN60G and NSF PLR 1565576, and thanks the National Snow and Ice Data Center.

- Sharon Stammerjohn was supported under NSF PLR 1440435; she also thanks the Institute of Arctic and Alpine Research and the National Snow and Ice Data Center, both at the University of Colorado Boulder, for institutional and data support.

- Linda Keller and Matthew Lazzara were supported by the Automatic Weather Station Program, National Science Foundation, PLR-1543305.

- Sebastiaan Swart was supported by a Wallenberg Academy Fellowship (WAF 2015.0186). 
- The work of Rob Massom, Phil Reid, Jan Lieser, and Steve Rintoul was supported by the Australian Government's Cooperative Research Centre program through the Antarctic Climate \& Ecosystems CRC, and contributes to AAS Project 4116. PR was also supported through the Bureau of Meteorology.

- Australian Research Council's Special Research Initiative for Antarctic Gateway Partnership (Project ID SR140300001).

- Jean-Baptiste Sallée was supported by the European Research Council (ERC) under the European Union>s Horizon 2020 research and innovation program (Grant Agreement no 637770); Mike Meredith received funding from the Natural Environment Research Council via award NE/ N018095/1.

- Work at the Jet Propulsion Laboratory, California Institute of Technology, was done under contract with the National Aeronautics and Space Administration (NASA). Work at NASA GSFC is supported through NASA's Atmospheric Composition Modeling and Analysis Program.

\section{Chapter 7}

The editors acknowledge and thank the numerous national meteorological and hydrological services for collecting and providing data for this report. Data centers like NCEP/NCAR, ECMWF-ERA, and CHIRPS are also acknowledged for making their data freely available.

Acknowledgments for specific regions are as follows:

Africa:

The editor expresses particular thanks to the following national meteorology and hydrology services for their contributions to our report:

- North Africa: National Meteorological and Hydrological Services of Morocco and Egypt

- West Africa: National Meteorological and Hydrological Services of The Gambia and Nigeria

- East Africa: National Meteorological Agency of Ethiopia

- South Africa: National Meteorological Services of South Africa

- Indian Ocean: Meteorological and Hydrological Services of Seychelles, Comoros, Mayotte, La Reunion, Mauritius, and Rodriguez.

\section{Europe:}

Valuable climate information was provided by $\mathrm{Na}-$ tional Meteorological and Hydrological Services (NMHSs) of the WMO RA VI Region, either by direct submission to the authors or via the web.

Asia:

The Editor wishes to thank all the authors for their timely contributions, and the internal and external reviewers and document editors for their thoughtful and constructive comments. The following grants (China National Key R\&D Program 2017YFA0603802 and 2015CB453201, NSFC grant 41630423, NSF grant AGS-1643297) are acknowledged. 


\section{ACRONYMS AND ABBREVIATIONS}

\begin{tabular}{|c|c|c|c|}
\hline BASS: & $\begin{array}{l}\text { Blended Analysis of Surface Salinity } \\
\text { (NOAA) }\end{array}$ & MLO: & $\begin{array}{l}\text { Mauna Loa Observatory (Hawaii, } \\
\text { US) }\end{array}$ \\
\hline \multirow{3}{*}{$\begin{array}{l}\text { CCI: } \\
\text { CERES: }\end{array}$} & Climate Change Initiative & MRI/JMA: & Meteorological Research Institute/ \\
\hline & Clouds and the Earth's Radiant & & Japan Meteorological Agency \\
\hline & Energy Systems & NASA: & National Aeronautics and Space \\
\hline \multirow[t]{2}{*}{ CFSR: } & Climate Forecast System Reanalysis & & Administration (US) \\
\hline & $(\mathrm{NCEP})$ & NCAR: & National Center for Atmospheric \\
\hline \multirow[t]{2}{*}{ CIIFEN: } & Centro Internacional para la & & Research (US) \\
\hline & $\begin{array}{l}\text { Investigación del Fenómeno El Niño } \\
\text { (Ecuador) }\end{array}$ & NCEI: & $\begin{array}{l}\text { National Centers for Environmental } \\
\text { Information (NOAA) }\end{array}$ \\
\hline CMAP: & $\begin{array}{l}\text { CPC Merged Analysis of } \\
\text { Precipitation }\end{array}$ & NCEP: & $\begin{array}{l}\text { National Centers for Environmental } \\
\text { Prediction (NOAA) }\end{array}$ \\
\hline \multirow[t]{2}{*}{ CMEMS: } & Copernicus Marine and & NOAA: & National Oceanic and Atmospheric \\
\hline & Environment Monitoring Service & & Administration (US) \\
\hline \multirow{9}{*}{$\begin{array}{l}\text { CPC: } \\
\text { CSIRO/ACE C }\end{array}$} & Climate Prediction Center (NOAA) & NSIDC: & National Snow and Ice Data Center \\
\hline & IMAS-UTAS: & & (US) \\
\hline & (Australia) Commonwealth & OLR: & outgoing longwave radiation \\
\hline & Scientific and Industrial Research & PMEL/JPL/ & :(US) \\
\hline & Organisation & & Pacific Marine Environmental \\
\hline & Antarctic Climate \& Ecosystems & & Laboratory/Jet Propulsion \\
\hline & Cooperative Research Centre & & Laboratory/ \\
\hline & Institute for Marine and Antarctic & & Joint Institute for Marine and \\
\hline & Studies - University of Tasmania & & Atmospheric Research \\
\hline \multirow{2}{*}{$\begin{array}{l}\text { DWD: } \\
\text { ECV: }\end{array}$} & Deutscher Wetterdienst & \multicolumn{2}{|c|}{ RAPID-MOC/MOCHA/WBTS: (International, } \\
\hline & Essential Climate Variable & & UK-led) \\
\hline ESA: & European Space Agency & & RAPID Climate Change Programme- \\
\hline \multirow[t]{2}{*}{ ESRL: } & Earth System Research Laboratory & & Meridional Overturning Circulation \\
\hline & (NOAA) & & Meridional Overturning Circulation \\
\hline \multirow[t]{2}{*}{ FLASHFlux: } & Fast Longwave And Shortwave & & and Heatflux Array \\
\hline & Radiative Fluxes & & Western Boundary Time Series \\
\hline \multirow[t]{3}{*}{ GO-SHIP: } & Global Ocean Ship-based & RSW: & reflected shortwave \\
\hline & Hydrographic Investigations & TOA: & top of atmosphere \\
\hline & Program & TRMM: & Tropical Rainfall Measuring Mission \\
\hline \multirow[t]{2}{*}{ GODAS: } & Global Ocean Data Assimilation & TSI: & total solar irradiance \\
\hline & System & WOA: & World Ocean Atlas \\
\hline \multirow[t]{2}{*}{ GPCP: } & Global Precipitation Climatology & & \\
\hline & Project & Addit & acronyms and abbrevia- \\
\hline \multirow[t]{2}{*}{ GRACE: } & Gravity Recovery and Climate & tions cal & found at this AMS website \\
\hline & Experiment & www.ame & rg/ams/index.cfm/publications \\
\hline INMET: & $\begin{array}{l}\text { Instituto Nacional de Meteorologia } \\
\text { (Brazil) }\end{array}$ & $\begin{array}{l}\text { /authors/jo } \\
\text {-componer }\end{array}$ & $\begin{array}{l}\text { and-bams-authors/and-manuscript } \\
\text {-of-acronyms-and-abbreviations/ }\end{array}$ \\
\hline
\end{tabular}




\section{REFERENCES}

Abernethy, R., J. Garforth, D. Hemming, M. Kendon, M. McCarthy, and T. Sparks, 2017: State of the UK Climate 2016: Phenology supplement. 39 pp., www.metoffice.gov.uk /binaries/content/assets/mohippo/pdf/uk-climate/state -of-the-uk-climate/mo-phenology-supplement-v4.pdf.

Abraham, J. P., and Coauthors, 2013: A review of global ocean temperature observations: Implications for ocean heat content estimates and climate change. Rev. Geophys., 51, 450-483, http://doi.org/10.1002/rog.20022.

Ackerman, S. A., R. E. Holz, R. Frey, E. W. Eloranta, B. C. Maddux, and M. McGill, 2008: Cloud detection with MODIS. Part II: Validation. J. Atmos. Oceanic Technol., 25, 1073-1086, http://doi.org/10.1175/2007jtecha1053.1.

Acosta Navarro, J. C., and Coauthors, 2016: Amplification of Arctic warming by past air pollution reductions in Europe. Nat. Geosci., 9, 277-281, http://doi.org/10.1038 /ngeo2673.

Adler, R. F., and Coauthors, 2003: The version-2 Global Precipitation Climatology Project (GPCP) monthly precipitation analysis (1979-present). J. Hydrometeor., 4, 1147-1167, http://doi.org/10.1175/1525-7541(2003)004<1147:tvgpcp $>2.0 . c 0 ; 2$.

Agence France-Presse, 2016: Thailand closes dive sites over coral bleaching crisis. The Guardian, May 26. www.theguardian.com/environment/2016/may/26 /thailand-closes-dive-sites-over-coral-bleaching-crisis.

AICC Predictive Services, 2015: Alaska Fire Numbers 2015. 38 pp., https://fire.ak.blm.gov/content/aicc/stats /Alaska\%20Fire\%20Numbers.pdf.

Aiyyer, A., and J. Molinari, 2008: MJO and tropical cyclogenesis in the Gulf of Mexico and eastern Pacific: Case study and idealized numerical modeling. J. Atmos. Sci., 65, 2691-2704, http://doi.org/10.1175/2007jas2348.1.

Alexander, L. V., and Coauthors, 2006: Global observed changes in daily climate extremes of temperature and precipitation. J. Geophys. Res., 111, D05109, http://doi.org/10.1029/2005JD006290.

Allan, R. J., and R. D. D'Arrigo, 1999: 'Persistent' ENSO sequences: How unusual was the 1990 1995 El Niño? The Holocene, 9, 101-118, http://doi .org/10.1191/095968399669125102.

— historical gridded mean sea level pressure dataset (HadSLP2): 1850-2004. J. Climate, 19, 5816-5842, http://doi .org/10.1175/jcli3937.1.

— - and C. K. Folland, 2017: Mean sea level pressure and related modes of variability [in "State of the Climate in 2016”]. Bull. Amer. Meteor. Soc., 98 (8), S35-S37, http://doi.org/10.1175/2017BAMSStateoftheClimate.1.
— J. J. A. Lindesay, and D. E. Parker, 1996: El Niño Southern Oscillation and Climatic Variability. CSIRO Publications, $405 \mathrm{pp}$.

Amador, J. A., 1998: A climatic feature of the tropical Americas: The trade wind easterly jet. Top. Meteor. Oceanogr., 5, 91-102, http://doi.org/10.1196/annals.1446.012.

—, E.J. Alfaro, H.G. Hidalgo, and B. Calderón, 2011: Central America [in "State of the Climate in 2010"]. Bull. Amer. Meteor. Soc., 92 (6), S182-S183, http://doi .org/10.1175/1520-0477-92.6.s1.

—, H. G. Hidalgo, E. J. Alfaro, B. Calderón, N. P. Mora, and I. L. Rivera, 2012: Central America [in "State of the Climate in 2011"]. Bull. Amer. Meteor. Soc., 93 (7), S169-S170, http://doi.org/10.1175/2012BAMSStateoftheClimate.1.

An, R., and Coauthors, 2016: Validation of the ESA CCI soil moisture product in China. Int. J. Appl. Earth Obs. Geoinf., 48, 28-36, http://doi.org/10.1016/j.jag.2015.09.009.

Anagnostou, E., and Coauthors, 2016: Changing atmospheric $\mathrm{CO}_{2}$ concentration was the primary driver of early Cenozoic climate. Nature, 533, 380-384, http://doi.org/10.1038 /nature17423.

Anderson, M. C., and Coauthors, 2011: Mapping daily evapotranspiration at field to continental scales using geostationary and polar orbiting satellite imagery. $\mathrm{Hy}$ drol. Earth Syst. Sci., 15, 223-239, http://doi.org/10.5194 /hess-15-223-2011.

Ansorge, I. J., and Coauthors, 2014: Basin-wide oceanographic array bridges the South Atlantic. Eos, Trans. Amer. Geophys. Union, 95, 53-54, http://doi.org/10.1002/2014EO060001.

Aono, Y., and K. Kazui, 2008: Phenological data series of cherry tree flowering in Kyoto, Japan, and its application to reconstruction of springtime temperatures since the 9th century. Int. J. Climatol., 28, 905-914, http://doi.org/10.1002/joc.1594.

Aquila, V., W. H. Swartz, D. W. Waugh, P. R. Colarco, S. Pawson, L. M. Polvani, and R. S. Stolarski, 2016: Isolating the roles of different forcing agents in global stratospheric temperature changes using model integrations with incrementally added single forcings. J. Geophys. Res. Atmos., 121, 8067-8082, http://doi.org/10.1002/2015JD023841.

Armstrong, R., K. Knowles, M. J. Brodzik, and M. A. Hardman, 1994, updated 2016: DMSP SSM/I-SSMIS Pathfinder Daily EASE-Grid Brightness Temperatures. Version 2. National Snow and Ice Data Center, http://doi .org/10.5067/3EX2U1DV3434. Accessed February 2018.

Arnone, E., D. Pumo, F. Viola, L. V. Noto, and G. La Loggia, 2013: Rainfall statistics changes in Sicily. Hydrol. Earth Syst. Sci., 17, 2449-2458, http://doi.org/10.5194 /hess-17-2449-2013. 
Ashok, K., Z. Guan, and T. Yamagata, 2003: A look at the relationship between the ENSO and the Indian Ocean dipole. J. Meteor. Soc. Japan, 81, 41-56, http://doi.org/10.2151 /jmsj.81.41.

Australian Bureau of Meteorology, 2017: Annual climate statement 2017. Bureau of Meteorology Australia. www.bom.gov.au/climate/current/annual/aus/.

Azorin-Molina, C., and Coauthors, 2014: Homogenization and assessment of observed near-surface wind speed trends over Spain and Portugal, 1961-2011. J. Climate, 27, 3692-3712, http://doi.org/10.1175/jcli-d-13-00652.1.

— J.-A. Guijarro, T. R. McVicar, S. M. Vicente-Serrano, D. Chen, S. Jerez, and F. Espírito-Santo, 2016: Trends of daily peak wind gusts in Spain and Portugal, 1961-2014. J. Geophys. Res. Atmos., 121, 1059-1078, http://doi .org/10.1002/2015JD024485.

—, S. M. Vicente-Serrano, T. R. McVicar, J. Revuelto, S. Jerez, and J.-I. López-Moreno, 2017a: Assessing the impact of measurement time interval when calculating wind speed means and trends under the stilling phenomenon. Int. J. Climatol., 37, 480-492, http://doi.org/10.1002/ joc. 4720 .

—, R. J. H. Dunn, C. A. Mears, P. Berrisford, and T. R. McVicar, 2017b: Surface winds [in "State of the Climate in 2016”]. Bull. Amer. Meteor. Soc., 98 (8), S37-S39, http://doi.org/10.1175/2017BAMSStateoftheClimate.1.

- - and Coauthors, 2017c: Wind speed variability over the Canary Islands, 1948-2014: Focusing on trend differences at the land-ocean interface and below-above the tradewind inversion layer. Climate Dyn., http://doi.org/10.1007 /s00382-017-3861-0.

—, S. Rehman, J. A. Guijarro, T. R. McVicar, L. Minola, D. Chen, and S. M. Vicente-Serrano, 2018a: Recent trends in wind speed across Saudi Arabia, 1978-2013: A break in the stilling. Int. J. Climatol., 38 (S1), e966-e984, http://doi.org/10.1002/joc.5423.

—, J. Asin, T. R. McVicar, L. Minola, J. I. Lopez-Moreno, S. M. Vicente-Serrano, and D. Chen, 2018b: Evaluating anemometer drift: A statistical approach to correct biases in wind speed measurement. Atmos. Res., 203, 175-188, http://doi.org/10.1016/j.atmosres.2017.12.010.

Bahr, K. D., P. L. Jokiel, and K. S. Rodgers, 2015: The 2014 coral bleaching and freshwater flood events in Kāne'ohe Bay, Hawai'i. PeerJ, 3, e1136, http://doi.org/10.7717 /peerj.1136.

Bakker, D. C. E., and Coauthors, 2016: A multi-decade record of high-quality $f \mathrm{CO}_{2}$ data in version 3 of the Surface Ocean $\mathrm{CO}_{2}$ Atlas (SOCAT). Earth Syst. Sci. Data, 8, 383-413, http://doi.org/10.5194/essd-8-383-2016.

Baldwin, M. P., and Coauthors, 2001: The quasi-biennial oscillation. Rev. Geophys., 39, 179-229, http://doi.org/10.1029/1999RG000073.
Ball, W. T., and Coauthors, 2018: Evidence for a continuous decline in lower stratospheric ozone offsetting ozone layer recovery. Atmos. Chem. Phys., 18, 1379-1394, http://doi.org/10.5194/acp-18-1379-2018.

Banzon, V. F., and R. W. Reynolds, 2013: Use of WindSat to extend a microwave-based daily optimum interpolation sea surface temperature time series. J. Climate, 26, 2557-2562, http://doi.org/10.1175/jcli-d-12-00628.1.

Barbero, R., H. J. Fowler, G. Lenderink, and S. Blenkinsop, 2017: Is the intensification of precipitation extremes with global warming better detected at hourly than daily resolutions? Geophys. Res. Lett., 44, 974-983, http://doi.org/10.1002/2016GL071917.

Baringer, M. O., and Coauthors, 2017: Meridional overturning and oceanic heat transport circulation observations in the North Atlantic Ocean [in "State of the Climate in 2016"]. Bull. Amer. Meteor. Soc., 98 (8), S84-S87, http://doi.org/10.1175/2017BAMSStateoftheClimate.1.

Barnes, E. A., A. M. Fiore, and L. W. Horowitz, 2016: Detection of trends in surface ozone in the presence of climate variability. J. Geophys. Res. Atmos., 121, 6112-6129, http://doi.org/10.1002/2015JD024397.

Barrett, K., T. Loboda, A. D. McGuire, H. Genet, E. Hoy, and E. Kasischke, 2016: Static and dynamic controls on fire activity at moderate spatial and temporal scales in the Alaskan boreal forest. Ecosphere, 7, e01572, http://doi.org/10.1002/ecs2.1572.

Bauer-Marschallinger, B., W. A. Dorigo, W. Wagner, and A. I. J. M. van Dijk, 2013: How oceanic oscillation drives soil moisture variations over mainland Australia: An analysis of 32 years of satellite observations. J. Climate, 26, 10,159-10,173, http://doi.org/10.1175/jcli-d-13-00149.1.

Baxter, S., S. Weaver, J. Gottschalck, and Y. Xue, 2014: Pentad evolution of wintertime impacts of the Madden-Julian oscillation over the contiguous United States. J. Climate, 27, 7356-7367, http://doi.org/10.1175/jcli-d-14-00105.1.

- C. J. Schreck, and G. D. Bell, 2017: Tropical intraseasonal activity [in "State of the Climate in 2016"]. Bull. Amer. Meteor. Soc., 98 (8), S98-S101, http://doi.org/10.1175 /2017BAMSStateoftheClimate.1.

BCRP (Banco Central de Reserva del Perú), 2017: Reporte de Inflación marzo 2017: Panorama actual y proyecciones macroeconómicas 2017-2018 [Inflation Report March 2017: Current Panorama and Macroeconomic Projections 2017-2018]. 116 pp., www.bcrp.gob.pe/docs/Publicaciones /Reporte-Inflacion/2017/marzo/reporte-de-inflacion -marzo-2017.pdf.

Beck, F., A. Bárdossy, J. Seidel, T. Müller, E. Fernandez Sanchis, and A. Hauser, 2015: Statistical analysis of subdaily precipitation extremes in Singapore. J. Hydrol.: Reg. Stud., 3, 337-358, http://doi.org/10.1016/j.ejrh.2015.02.001. 
Becker, A., P. Finger, A. Meyer-Christoffer, B. Rudolf, K. Schamm, U. Schneider, and M. Ziese, 2013: A description of the global land-surface precipitation data products of the Global Precipitation Climatology Centre with sample applications including centennial (trend) analysis from 1901-present. Earth Syst. Sci. Data, 5, 71-99, http://doi.org/10.5194/essd-5-71-2013.

Beckley, B. D., P. S. Callahan, D. W. Hancock, G. T. Mitchum, and R. D. Ray, 2017: On the "Cal-Mode" correction to TOPEX satellite altimetry and its effect on the global mean sea level time series. J. Geophys. Res. Oceans, 122, 8371-8384, http://doi.org/10.1002/2017JC013090.

Beerling, D. J., and D. L. Royer, 2011: Convergent Cenozoic $\mathrm{CO}_{2}$ history. Nat. Geosci., 4, 418-420, http://doi.org/10.1038/ngeo1186.

Behera, S. K., J. J. Luo, S. Masson, S. A. Rao, H. Sakuma, and T. Yamagata, 2006: A CGCM study on the iteraction between IOD and ENSO. J. Climate, 19, 1688-1705, http://doi.org/10.1175/jcli3797.1.

Behrenfeld, M. J., and Coauthors, 2006: Climate-driven trends in contemporary ocean productivity. Nature, 444, 752-755, http://doi.org/10.1038/nature05317.

— , and Coauthors, 2016: Revaluating ocean warming impacts on global phytoplankton. Nat. Climate Change, 6, 323-330, http://doi.org/10.1038/nclimate2838.

Behringer, D. W., M. Ji, and A. Leetmaa, 1998: An improved coupled model for ENSO prediction and implications for ocean initialization. Part I: The ocean data assimilation system. Mon. Wea. Rev., 126, 1013-1021, http://doi.org/10.1175/1520-0493(1998)126<1013:aicmfe>2.0.co;2.

Bell, G. D., and M. Chelliah, 2006: Leading tropical modes associated with interannual and multidecadal fluctuations in North Atlantic hurricane activity. J. Climate, 19, 590-612, http://doi.org/10.1175/jcli3659.1.

—, M. S. Halpert, C. F. Ropelewski, V. E. Kousky, A. V. Douglas, R. C. Schnell, and M. E. Gelman, 1999: The 1998 North Atlantic and eastern North Pacific hurricane season [in "Climate Assessment for 1998”]. Bull. Amer. Meteor. Soc., 80 (5), S24-S28.

_- and Coauthors, 2000: The 1999 North Atlantic and eastern North Pacific hurricane season [in "Climate Assessment for 1999”]. Bull. Amer. Meteor. Soc., 81 (6), S19-S22, http://doi.org/10.1175/1520-0477(2000)081<1328:caf>2.3.co;2.

_- S. Goldenberg, C. Landsea, E. Blake, R. Pasch, M. Chelliah, and K. Mo, 2004: Tropical storms: Atlantic hurricane season [in "State of the Climate in 2003"]. Bull. Amer. Meteor. Soc., 85 (6), S20-S24.

—, E. Blake, K. C. Mo, C. W. Landsea, R. Pasch, M. Chelliah, and S. B. Goldenberg, 2006: Tropical cyclones: Atlantic basin [in "State of the Climate in 2005"]. Bull. Amer. Meteor. Soc., 87 (6), S33-S37.
,-- , S. B. Goldenberg, T. Kimberlain, C. W. Landsea, R. Pasch, and J. Schemm, 2009: Tropical cyclones: Atlantic basin [in "State of the Climate in 2008"]. Bull. Amer. Meteor. Soc., 90 (8), S79-S83.

— — - T. B. Kimberlain, C. W. Landsea, J. Schemm, R. J. Pasch, and S. B. Goldenberg, 2011: Tropical cyclones: Atlantic basin [in "State of the Climate in 2010"]. Bull. Amer. Meteor. Soc., 92 (6), S115-S121, http://doi .org/10.1175/1520-0477-92.6.s1.

$\longrightarrow,-$, C. W. Landsea, T. B. Kimberlain, S. B. Goldenberg, J. Schemm, and R. J. Pasch, 2012: Tropical cyclones: Atlantic basin [in "State of the Climate in 2011"]. Bull. Amer. Meteor. Soc., 93 (7), S99-S105, http://doi.org/10.1175 /2012BAMSStateoftheClimate.1.

—, C. W. Landsea, S. B. Goldenberg, R. J. Pasch, E. S. Blake, J. Schemm, and T. B. Kimberlain, 2014: Tropical cyclones: Atlantic basin [in "State of the Climate in 2013"]. Bull. Amer. Meteor. Soc., 95 (7), S86-S90, http://doi.org/10.1175 /2014BAMSStateoftheClimate.1.

— — - E. S. Blake, J. Schemm, S. B. Goldenberg, T. B. Kimberlain, and R. J. Pasch, 2015: Tropical cyclones: Atlantic basin [in "State of the Climate in 2014"]. Bull. Amer. Meteor. Soc., 96 (7), S105-S107, http://doi.org/10.1175 /2015BAMSStateoftheClimate.1.

,,,,,------ , and,- 2016 : Tropical cyclones: Atlantic basin [in "State of the Climate in 2015"]. Bull. Amer. Meteor. Soc., 97 (8), S105-S106, http://doi.org /10.1175/2016BAMSStateoftheClimate.1.

—, M. L'Heureux, and M. S. Halpert, 2017a: ENSO and the tropical Pacific [in "State of the Climate in 2016"]. Bull. Amer. Meteor. Soc., 98 (8), S93-S98, http://doi.org /10.1175/2017BAMSStateoftheClimate.1.

— , and Coauthors, 2017b: Tropical cyclones: Atlantic basin [in "State of the Climate in 2016"]. Bull. Amer. Meteor. Soc., 98 (8), S108-S112, http://doi.org/10.1175 /2017BAMSStateoftheClimate.1.

Bellouin, N., J. Quaas, J. J. Morcrette, and O. Boucher, 2013: Estimates of aerosol radiative forcing from the MACC re-analysis. Atmos. Chem. Phys., 13, 2045-2062, http://doi.org/10.5194/acp-13-2045-2013.

Bernhard, G., and Coauthors, 2015: Comparison of OMI UV observations with ground-based measurements at high northern latitudes. Atmos. Chem. Phys., 15, 7391-7412, http://doi.org/10.5194/acp-15-7391-2015.

Berry, D. I., and E. C. Kent, 2009: A new air-sea interaction gridded dataset from ICOADS with uncertainty estimates. Bull. Amer. Meteor. Soc., 90, 645-656, http://doi.org/10.1175/2008bams2639.1.

$\longrightarrow$, and — 2011: Air-sea fluxes from ICOADS: The construction of a new gridded dataset with uncertainty estimates. Int. J. Climatol., 31, 987-1001, http://doi .org/10.1002/joc. 2059 . 
Betts, R. A., C. D. Jones, J. R. Knight, R. F. Keeling, and J. J. Kennedy, 2016: El Niño and a record $\mathrm{CO}_{2}$ rise. Nat. Climate Change, 6, 806-810, http://doi.org/10.1038 /nclimate3063.

Bhartia, P. K., and C. W. Wellemeyer, 2002: TOMS-V8 total $\mathrm{O}_{3}$ algorithm. OMI Algorithm Theoretical Basis Document Vol II, 15-31 pp.

Bhatt, U. S., and Coauthors, 2010: Circumpolar Arctic tundra vegetation change is linked to sea ice decline. Earth Interactions, 14, 1-20, http://doi.org/10.1175/2010ei315.1.

- - and Coauthors, 2017: Changing seasonality of panarctic tundra vegetation in relationship to climatic variables. Environ. Res. Lett., 12, 055003, http://doi.org/10.1088 /1748-9326/aa6b0b.

Bichet, A., M. Wild, D. Folini, and C. Schär, 2012: Causes for decadal variations of wind speed over land: Sensitivity studies with a global climate model. Geophys. Res. Lett., 39, L11701, http://doi.org/10.1029/2012GL051685.

Biskaborn, B. K., J. P. Lanckman, H. Lantuit, K. Elger, D. A. Streletskiy, W. L. Cable, and V. E. Romanovsky, 2015: The new database of the global terrestrial network for permafrost (GTN-P). Earth Syst. Sci. Data, 7, 245-259, http://doi.org/10.5194/essd-7-245-2015.

Bjerke, J. W., and Coauthors, 2017: Understanding the drivers of extensive plant damage in boreal and Arctic ecosystems: Insights from field surveys in the aftermath of damage. Sci. Total Environ., 599-600, 1965-1976, http://doi.org/10.1016/j.scitotenv.2017.05.050.

Bjerknes, J., 1969: Atmospheric teleconnections from the equatorial Pacific. Mon. Wea. Rev., 97, 163-172, http://doi.org/10.1175/1520-0493(1969)097<0163:atftep>2.3.co;2.

Blake, E. S., and D. A. Zelinsky, 2018: Hurricane Harvey (AL092017): 17 August-1 September 2017. National Hurricane Center Tropical Cyclone Report, 76 pp., www.nhc.noaa.gov/data/tcr/AL092017_Harvey.pdf.

—, E. J. Gibney, D. P. Brown, M. Mainelli, J. L. Franklin, and T. B. Kimberlain, 2009: Tropical cyclones of the eastern North Pacific basin, 1949-2006. Historical Climatology Series 6-5, $162 \mathrm{pp}$.

Blanchard-Wrigglesworth, E., S. L. Farrell, T. Newman, and C. M. Bitz, 2015: Snow cover on Arctic sea ice in observations and an Earth System Model. Geophys. Res. Lett., 42, 10,342-10,348, http://doi.org/10.1002/2015GL066049.

Blunden, J., and D. S. Arndt, Eds., 2015: State of the Climate in 2014. Bull. Amer. Meteor. Soc., 96 (7), Si-S257, http://doi.org/10.1175/2015BAMSStateoftheClimate.1.

— , and — Eds., 2016: State of the Climate in 2015. Bull. Amer. Meteor. Soc., 97 (8), Si-S275, http://doi.org/10 $.1175 / 2016$ BAMSStateoftheClimate.1.

— and - Eds., 2017: State of the Climate in 2016. Bull. Amer. Meteor. Soc., 98 (8), Si-S278, http://doi.org/10 $.1175 / 2017$ BAMSStateoftheClimate.1.
Boden, T. A., R. J. Andres, and G. Marland, 2017: Global, Regional, and National Fossil-Fuel $\mathrm{CO}_{2}$ Emissions. Carbon Dioxide Information Analysis Center, Oak Ridge National Laboratory, http://doi.org/10.3334/CDIAC/00001_V2017.

Boening, C., J. K. Willis, F. W. Landerer, R. S. Nerem, and J. Fasullo, 2012: The 2011 La Niña: So strong, the oceans fell. Geophys. Res. Lett., 39, L19602, http://doi.org/10.1029/2012GL053055.

Boike, J., and Coauthors, 2018: A 20-year record (1998-2017) of permafrost, active layer and meteorological conditions at a high Arctic permafrost research site (Bayelva, Spitsbergen). Earth Syst. Sci. Data, 10, 355-390, http://doi.org/10.5194/essd-10-355-2018.

Bojinski, S., M. Verstraete, T. C. Peterson, C. Richter, A. Simmons, and M. Zemp, 2014: The concept of essential climate variables in support of climate research, applications, and policy. Bull. Amer. Meteor. Soc., 95, 1431-1443, http://doi.org/10.1175/bams-d-13-00047.1.

Bonaccorso, B., and G. T. Aronica, 2016: Estimating temporal changes in extreme rainfall in Sicily $\mathrm{Re}$ gion (Italy). Water Resour. Manage., 30, 5651-5670, http://doi.org/10.1007/s11269-016-1442-3.

Bond-Lamberty, B., S. D. Peckham, D. E. Ahl, and S. T. Gower, 2007: Fire as the dominant driver of central Canadian boreal forest carbon balance. Nature, 450, 89-92, http://doi.org/10.1038/nature06272.

Böning, C. W., A. Dispert, M. Visbeck, S. R. Rintoul, and F. U. Schwarzkopf, 2008: The response of the Antarctic Circumpolar Current to recent climate change. Nat. Geosci., 1, 864-869, http://doi.org/10.1038/ngeo362.

Bonjean, F., and G. S. E. Lagerloef, 2002: Diagnostic model and analysis of the surface currents in the tropical Pacific Ocean. J. Phys. Oceanogr., 32, 2938-2954, http://doi.org/10.1175/1520-0485(2002)032<2938:dmaaot>2.0.co;2.

Bosilovich, M. G., and Coauthors, 2015: MERRA-2: Initial evaluation of the climate. NASA/TM-2015-104606, Vol. 43, 136 pp., https://gmao.gsfc.nasa.gov/reanalysis /MERRA-2/docs/.

Bourassa, M. A., and Coauthors, 2013: High-latitude ocean and sea ice surface fluxes: Challenges for climate research. Bull. Amer. Meteor. Soc., 94, 403-423, http://doi.org/10.1175/bams-d-11-00244.1.

Box, J. E., and K. Hansen, 2015: Survey of Greenland glacier area changes. PROMICE Newsletter, 8, 1-2, http://promice.org/Newsletter_08.pdf.

- D. van As, K. Steffen, and The PROMICE Project Team, 2017: Greenland, Canadian and Icelandic land-ice albedo grids (2000-2016). Geol. Surv. Den. Greenl. Bull., 38, 53-56, www.geus.dk/DK/publications/geol-survey-dk -gl-bull/38/Documents/nr38_p53-56.pdf. 
Boyer, T., and Coauthors, 2013: World ocean database 2013. NOAA Atlas NESDIS 72, 209 pp., www.nodc.noaa.gov /OC5/WOD13/.

Bracegirdle, T. J., and G. J. Marshall, 2012: The reliability of Antarctic tropospheric pressure and temperature in the latest global reanalyses. J. Climate, 25, 7138-7146, http://doi.org/10.1175/jcli-d-11-00685.1.

Brainard, R. E., and Coauthors, 2018: Ecological impacts of the 2015/16 El Niño in the central equatorial Pacific. Bull. Amer. Meteor. Soc., 99 (1), S21-S26, http://doi .org/10.1175/BAMS-D-17-0128.1.

Brakenridge, G. R., 2018: Global Active Archive of Large Flood Events. https://floodobservatory.colorado.edu /Archives/index.html. Accessed January 17, 2018.

Brasnett, B., 1999: A global analysis of snow depth for numerical weather prediction. J. Appl. Meteor., 38, 726740, http://doi.org/10.1175/1520-0450(1999)038<0726 :agaosd $>2.0 . c 0 ; 2$.

Brito, S. S. B., A. P. M. A. Cunha, C. C. Cunningham, R. C. Alvalá, J. A. Marengo, and M. A. Carvalho, 2018: Frequency, duration and severity of drought in the semiarid Northeast Brazil region. Int. J. Climatol., 38, 517-529, http://doi.org/10.1002/joc.5225.

Bromwich, D. H., A. J. Monaghan, and Z. Guo, 2004: Modeling the ENSO modulation of Antarctic climate in the late 1990s with the polar MM5. J. Climate, 17, 109-132, http://doi.org/10.1175/1520-0442(2004)017<0109 :mtemoa $>2.0 . c o ; 2$.

— , R. L. Fogt, K. I. Hodges, and J. E. Walsh, 2007: A tropospheric assessment of the ERA-40, NCEP, and JRA-25 global reanalyses in the polar regions. J. Geophys. Res., 112, D10111, http://doi.org/10.1029/2006JD007859.

—, J. P. Nicolas, and A. J. Monaghan, 2011: An assessment of precipitation changes over Antarctica and the Southern Ocean since 1989 in contemporary global reanalyses. J. Climate, 24, 4189-4209, http://doi .org/10.1175/2011jcli4074.1.

Brown, B. E., 1997: Coral bleaching: Causes and consequences. Coral Reefs, 16, S129-S138, http://doi.org/10.1007 /s003380050249.

Brown, R. D., B. Brasnett, and D. Robinson, 2003: Gridded North American monthly snow depth and snow water equivalent for GCM evaluation. Atmos.-Ocean, 41, 1-14, http://doi.org/10.3137/ao.410101.

- , and Coauthors, 2017: Arctic terrestrial snow cover. Snow, Water, Ice and Permafrost in the Arctic (SWIPA) 2017, Arctic Monitoring and Assessment Programme (AMAP), 26-64, www.amap.no/documents/doc /Snow-Water-Ice-and-Permafrost-in-the-Arctic -SWIPA-2017/1610.
Brun, E., and Coauthors, 2013: Simulation of Northern Eurasian local snow depth, mass, and density using a detailed snowpack model and meteorological reanalyses. J. Hydrometeor., 14, 203-219, http://doi.org/10.1175 /jhm-d-12-012.1.

Brust, A., 2017: Barker, Addicks releases still frustrating residents but officials say flooding was inevitable. Community Impact Newspaper, 25 October. http://communityimpact.com/houston/katy /development-construction/2017/10/25/barker-addicks -releases-still-frustrating-residents-but-officials-say -flooding-was-inevitable/.

Brutsaert, W., 2017: Global land surface evaporation trend during the past half century: Corroboration by Clausius-Clapeyron scaling. Adv. Water Res., 106, 3-5, http://doi.org/10.1016/j.advwatres.2016.08.014.

Buckley, M. W., and J. Marshall, 2016: Observations, inferences, and mechanisms of the Atlantic Meridional Overturning Circulation: A review. Rev. Geophys., 54, 5-63, http://doi.org/10.1002/2015RG000493.

Burn, D. H., R. Mansour, K. Zhang, and P. H. Whitfield, 2011: Trends and variability in extreme rainfall events in British Columbia. Can. Water Resour. J., 36, 67-82, http://doi.org/10.4296/cwrj3601067.

Butchart, N., and E. E. Remsberg, 1986: The area of the stratospheric polar vortex as a diagnostic for tracer transport on an isentropic surface. J. Atmos. Sci., 43, 13191339, http://doi.org/10.1175/1520-0469(1986)043<1319 :taotsp>2.0.co;2.

Camargo, S. J., and A. H. Sobel, 2005: Western North Pacific tropical cyclone intensity and ENSO. J. Climate, 18, 2996-3006, http://doi.org/10.1175/jcli3457.1.

— , K. A. Emanuel, and A. H. Sobel, 2007: Use of a genesis potential index to diagnose ENSO effects on tropical cyclone genesis. J. Climate, 20, 4819-4834, http://doi .org/10.1175/jcli4282.1.

—, M. C. Wheeler, and A. H. Sobel, 2009: Diagnosis of the MJO modulation of tropical cyclogenesis using an empirical index. J. Atmos. Sci., 66, 3061-3074, http://doi .org/10.1175/2009jas3101.1.

Cangialosi, J. P., A. S. Latto, and R. Berg, 2018: Hurricane Irma (AL112017): 30 August-12 September 2017. National Hurricane Center Tropical Cyclone Report, 111 pp., www.nhc.noaa.gov/data/tcr/AL112017_Irma.pdf.

Capotondi, A., and Coauthors, 2015: Understanding ENSO diversity. Bull. Amer. Meteor. Soc., 96, 921-938, http://doi.org/10.1175/bams-d-13-00117.1.

Cappelen, J., B. M. Vinther, C. Kern-Hansen, E. V. Laursen, and P. V. Jørgensen, 2018: Greenland - DMI Historical Climate Data Collection 1784-2017. DMI Report 18-04, 118 pp., www.dmi.dk/fileadmin/user_upload/Rapporter /TR/2018/DMIRep18-04.pdf. 
Carpenter, L. J., and Coauthors, 2014: Update on ozonedepleting substances (ODSs) and other gases of interest to the Montreal Protocol. Scientific Assessment of Ozone Depletion: 2014, World Meteorological Organization, 1.1-1.101, www.esrl.noaa.gov/csd/assessments/ozone/2014 /chapters/chapter1_2014OzoneAssessment.pdf.

Carranza, L., 1891: Contra-corriente maritima observada en Paita y Pacasmayo. Bol. Soc. Geográf. Lima, 1, 344-345.

Carrea, L., O. Embury, and C. J. Merchant, 2015: Datasets related to in-land water for limnology and remote sensing applications: Distance-to-land, distance-to-water, waterbody identifier and lake-centre co-ordinates. Geosci. Data J., 2, 83-97, http://doi.org/10.1002/gdj3.32.

Carrillo, C. N., 1893: Hidrografía oceánica: Disertación sobre las correientes oceánicas y estudios de la correient peruana ó de Humboldt. Bol. Soc. Geográf. Lima, 2, 72-110.

Carsey, F. D., 1980: Microwave observation of the Weddell polynya. Mon. Wea. Rev., 108, 2032-2044,http://doi .org/10.1175/1520-0493(1980)108<2032:mootwp >2.0.co;2.

Carter, B. R., and Coauthors, 2017: Two decades of Pacific anthropogenic carbon storage and ocean acidification along Global Ocean Ship-based Hydrographic Investigations Program sections P16 and P02. Global Biogeochem. Cycles, 31, 306-327, http://doi.org/10.1002/2016GB005485.

Cassou, C., 2008: Intraseasonal interaction between the Madden-Julian oscillation and the North Atlantic oscillation. Nature, 455, 523-527, http://doi.org/10.1038/nature07286.

Castro de la Guardia, L., X. Hu, and P. G. Myers, 2015: Potential positive feedback between Greenland Ice Sheet melt and Baffin Bay heat content on the West Greenland Shelf. Geophys. Res. Lett., 42, 4922-4930, http://doi.org/10.1002/2015GL064626.

Cavalieri, D. J., C. L. Parkinson, P. Gloersen, and H. Zwally, 1996, updated yearly: Sea Ice Concentrations From Nimbus-7 SMMR and DMSP SSM/I-SSMIS Passive Microwave Data (1981-2011). National Snow and Ice Data Center, http://doi.org/10.5067/8GQ8LZQVL0VL.

Chambers, D. P., and Coauthors, 2017: Evaluation of the global mean sea level budget between 1993 and 2014. Surv. Geophys., 38, 309-327, http://doi.org/10.1007 /s10712-016-9381-3.

Chandra, S., J. R. Ziemke, W. Min, and W. G. Read, 1998: Effects of 1997-1998 El Niño on tropospheric ozone and water vapor. Geophys. Res. Lett., 25, 3867-3870, http://doi.org/10.1029/98GL02695.

— — _ B. N. Duncan, T. L. Diehl, N. J. Livesey, and L. Froidevaux, 2009: Effects of the 2006 El Niño on tropospheric ozone and carbon monoxide: Implications for dynamics and biomass burning. Atmos. Chem. Phys., 9 , 4239-4249, http://doi.org/10.5194/acp-9-4239-2009.
Chang, K.-L., I. Petropavlovskikh, O. R. Cooper, M. G. Schultz, and T. Wang, 2017: Regional trend analysis of surface ozone observations from monitoring networks in eastern North America, Europe and East Asia. Elementa, 5, 50, http://doi.org/10.1525/elementa.243.

Chelton, D. B., and M. G. Schlax, 1996: Global observations of oceanic Rossby waves. Science, 272, 234-238, http://doi.org/10.1126/science.272.5259.234.

Chen, A. A., and M. A. Taylor, 2002: Investigating the link between early season Caribbean rainfall and the El Niño + 1 year. Int. J. Climatol., 22, 87-106, http://doi.org/10.1002 /joc.711.

Chen, Y., and Coauthors, 2013: Long-term trends and interannual variability of forest, savanna and agricultural fires in South America. Carbon Manage., 4, 617-638, http://doi.org/10.4155/cmt.13.61.

Chen, Y.-R., B. Yu, and G. Jenkins, 2013a: Secular variation in rainfall intensity and temperature in eastern Australia. J. Hydrometeor., 14, 1356-1363, http://doi.org/10.1175 /jhm-d-12-0110.1.

— — - and — 2013b: Secular variation in rainfall and intensity-frequency-duration curves in Eastern Australia. J. Water Climate Change, 4, 244-251, http://doi.org/10.2166 /wcc.2013.138.

Cheng, L., K. E. Trenberth, J. Fasullo, T. Boyer, J. Abraham, and J. Zhu, 2017: Improved estimates of ocean heat content from 1960 to 2015. Sci. Adv., 3, e1601545, http://doi.org/10.1126/sciadv.1601545.

Cheon, W. G., Y.-G. Park, J. R. Toggweiler, and S.-K. Lee, 2014: The relationship of Weddell polynya and open-ocean deep convection to the Southern Hemisphere westerlies. J. Phys. Oceanogr., 44, 694-713, http://doi.org/10.1175/jpo-d-13-0112.1.

— , S.-K. Lee, A. L. Gordon, Y. Liu, C.-B. Cho, and J. J. Park, 2015: Replicating the 1970s' Weddell polynya using a coupled ocean-sea ice model with reanalysis surface flux fields. Geophys. Res. Lett., 42, 5411-5418, http://doi .org/10.1002/2015GL064364.

Chia, H. H., and C. F. Ropelewski, 2002: The interannual variability in the genesis location of tropical cyclones in the northwest Pacific. J. Climate, 15, 2934-2944, http://doi.org/10.1175/1520-0442(2002)015<2934:tivitg>2.0.co;2.

Chipperfield, M. P., and Coauthors, 2017: Detecting recovery of the stratospheric ozone layer. Nature, 549, 211-218, http://doi.org/10.1038/nature23681.

—- and Coauthors, 2018: On the cause of recent variations in lower stratospheric ozone. Geophys. Res. Lett., 45, http://doi.org/10.1029/2018GL078071.

Christiansen, H. H., and Coauthors, 2010: The thermal state of permafrost in the nordic area during the international polar year 2007-2009. Permafr. Periglac. Process., 21, 156-181, http://doi.org/10.1002/ppp.687. 
Christy, J. R., 2016: Lower and midtropospheric temperature [in "State of the Climate in 2015"]. Bull. Amer. Meteor. Soc., 97 (8), S13-S15, http://doi.org/10.1175 /2016BAMSStateoftheClimate.1.

_ , 2017: Lower and mid-tropospheric temperature [in "State of the Climate in 2016"]. Bull. Amer. Meteor. Soc., 98 (8), S16-S17, http://doi.org/10.1175 /2017BAMSStateoftheClimate.1.

— mean lower-stratospheric temperatures. J. Climate, 7 , 106-120, http://doi.org/10.1175/1520-0442(1994)007<0106 :Vidzml>2.0.CO;2.

_ , and R. T. McNider, 2017: Satellite bulk tropospheric temperatures as a metric for climate sensitivity. Asia-Pac. J. Atmos. Sci., 53, 511-518, http://doi.org/10.1007/s13143 -017-0070-z.

Chung, E.-S., B. J. Soden, and V. O. John, 2013: Intercalibrating microwave satellite observations for monitoring long-term variations in upper- and midtropospheric water vapor. J. Atmos. Oceanic Technol., 30, 2303-2319, http://doi.org/10.1175/jtech-d-13-00001.1.

$\ldots,-$ _ X. Huang, L. Shi, and V. O. John, 2016: An assessment of the consistency between satellite measurements of upper tropospheric water vapor. J. Geophys. Res. Atmos., 121, 2874-2887, http://doi.org/10.1002/2015JD024496.

Ciais, P., and Coauthors, 2013: Carbon and other biogeochemical cycles. Climate Change 2013: The Physical Science Basis, T. F. Stocker et al., Eds., Cambridge University Press, 465-570, http://doi.org/10.1017 /CBO9781107415324.015.

Clark, J. E., 1936: The history of British phenology. Quart. J. Roy. Meteor. Soc., 62, 19-24, http://doi.org/10.1002 /qj.94706226304.

Coffroth, M. A., H. R. Lasker, and J. K. Oliver, 1990: Coral mortality outside of the eastern Pacific during 1982-1983: Relationship to El Niño. Elsevier Oceanography Series, P. W. Glynn, Ed., Elsevier, 141-182, http://doi.org/10.1016 /S0422-9894(08)70035-7.

Coldewey-Egbers, M., and Coauthors, 2015: The GOMEtype total ozone essential climate variable (GTO-ECV) data record from the ESA Climate Change Initiative. Atmos. Meas. Tech., 8, 3923-3940, http://doi.org/10.5194 lamt-8-3923-2015.

Collier, K., 2017: In Harvey-swamped Houston, rescues by canoe, kayak - even monster truck. The Texas Tribune, 30 August. www.texastribune.org/2017/08/30/swamped -houston-enthusiastic-citizen-rescuers/.

Collins, J. M., and I. M. Mason, 2000: Local environmental conditions related to seasonal tropical cyclone activity in the northeast Pacific Basin. Geophys. Res. Lett., 27, 3881-3884, http://doi.org/10.1029/2000GL011614.
Comiso, J. C., and A. L. Gordon, 1987: Recurring polynyas over the Cosmonaut Sea and the Maud Rise. J. Geophys. Res., 92 (C3), 2819-2833, http://doi.org/10.1029 /JC092iC03p02819.

—, R. A. Gersten, L. V. Stock, J. Turner, G. J. Perez, and K. Cho, 2017: Positive trend in the Antarctic sea ice cover and associated changes in surface temperature. J. Climate, 30, 2251-2267, http://doi.org/10.1175/jcli-d-16-0408.1.

Conway, D., C. Dalin, W. A. Landman, and T. J. Osborn, 2017: Hydropower plans in eastern and southern Africa increase risk of concurrent climate-related electricity supply disruption. Nat. Energy, 2, 946-953, http://doi.org/10.1038/s41560-017-0037-4.

Cooper, O. R., and J. R. Ziemke, 2013: Tropospheric ozone [in "State of the Climate in 2012"]. Bull. Amer. Meteor. Soc., 94 (8), S38-S39, http://doi.org/10.1175 /2013BAMSStateoftheClimate.1.

$\longrightarrow$, and — 2014: Tropospheric ozone [in "State of the Climate in 2013"]. Bull. Amer. Meteor. Soc., 95 (7), S42, http://doi.org/10.1175/2014BAMSStateoftheClimate.1.

$\longrightarrow$, and — 2015: Tropospheric ozone [in "State of the Climate in 2014"]. Bull. Amer. Meteor. Soc., 96 (7), S48-S49, http://doi.org/10.1175/2015BAMSStateoftheClimate.1.

— , and Coauthors, 2014: Global distribution and trends of tropospheric ozone: An observation-based review. Elementa, 2, 29, http://doi.org/10.12952/journal .elementa.000029.

CORDIO-EA, 2016: Responding to coral bleaching [web site]. Coastal Oceans Research and Development - Indian Ocean (CORDIO) East Africa. http://cordioea.net /bleaching_resilience/wio-bleaching-2016/.

Couch, C. S., and Coauthors, 2017: Mass coral bleaching due to unprecedented marine heatwave in Papahānaumokuākea Marine National Monument (Northwestern Hawaiian Islands). PLOS ONE, 12, e0185121, http://doi.org/10.1371 /journal.pone.0185121.

Cullather, R. I., D. H. Bromwich, and M. L. V. Woert, 1998: Spatial and temporal variability of Antarctic precipitation from atmospheric methods. J. Climate, 11, 334-367, http://doi.org/10.1175/1520-0442(1998)011<0334 :Satvoa $>2.0 . \mathrm{CO} ; 2$.

Dai, A., 2006: Recent climatology, variability, and trends in global surface humidity. J. Climate, 19, 3589-3606, http://doi.org/10.1175/jcli3816.1.

DAR, 2014: Coral bleaching 2014 [web site]. Hawaii Division of Aquatic Resources (DAR). http://dlnr.hawaii.gov /reefresponse/current-rapid-responses/coral-bleaching-2014/.

Darby, D. A., 2008: Arctic perennial ice cover over the last 14 million years. Paleoceanography, 23, PA1S07, http://doi.org/10.1029/2007PA001479. 
de Jong, M. F., and L. de Steur, 2016: Strong winter cooling over the Irminger Sea in winter 2014-2015, exceptional deep convection, and the emergence of anomalously low SST. Geophys. Res. Lett., 43, 7106-7113, http://doi.org/10.1002/2016GL069596.

de Steur, L., D. M. Holland, R. D. Muench, and M. G. McPhee, 2007: The warm-water "Halo" around Maud Rise: Properties, dynamics and Impact. Deep-Sea Res. I, 54, 871-896, http://doi.org/10.1016/j.dsr.2007.03.009.

Dee, D. P., and Coauthors, 2011a: The ERA-Interim reanalysis: Configuration and performance of the data assimilation system. Quart. J. Roy. Meteor. Soc., 137, 553-597, http://doi.org/10.1002/qj.828.

— - and Coauthors, 2011b: The use of reanalysis data for monitoring the state of the climate [in "State of the Climate in 2010”]. Bull. Amer. Meteor. Soc., 92 (6), S34-S35, http://doi.org/10.1175/1520-0477-92.6.s1.

Deeter, M. N., and Coauthors, 2013: Validation of MOPITT Version 5 thermal-infrared, near-infrared, and multispectral carbon monoxide profile retrievals for 2000-2011. J. Geophys. Res. Atmos, 118, 6710-6725, http://doi.org/10.1002/jgrd.50272.

Demarée, G. R., and T. Rutishauser, 2009: Origins of the word "phenology". Eos, Trans. Amer. Geophys. Union, 90, 291-291, http://doi.org/10.1029/2009EO340004.

DeMaria, M., R. T. DeMaria, J. A. Knaff, and D. Molenar, 2012: Tropical cyclone lightning and rapid intensity change. Mon. Wea. Rev., 140, 1828-1842, http://doi.org/10.1175/mwr-d-11-00236.1.

Deser, C., and J. M. Wallace, 1987: El Niño events and their relation to the Southern Oscillation: 1925-1986. J. Geophys. Res., 92 (C13), 14,189-14,196, http://doi.org/10.1029 /JC092iC13p14189.

Deshpande, N. R., A. Kulkarni, and K. Krishna Kumar, 2012: Characteristic features of hourly rainfall in India. Int. J. Climatol., 32, 1730-1744, http://doi.org/10.1002/joc.2375.

Dessler, A. E., M. R. Schoeberl, T. Wang, S. M. Davis, K. H. Rosenlof, and J. P. Vernier, 2014: Variations of stratospheric water vapor over the past three decades. J. Geophys. Res. Atmos., 119, 12,588-12,598, http://doi.org/10.1002/2014JD021712.

Dettinger, M. D., F. M. Ralph, T. Das, P. J. Neiman, and D. R. Cayan, 2011: Atmospheric rivers, floods and the water resources of California. Water, 3, 445-478, http://doi.org/10.3390/w3020445.

Dewitte, B., and K. Takahashi, 2017: Diversity of moderate El Niño events evolution: Role of air-sea interactions in the eastern tropical Pacific. Climate Dyn., http://doi.org/10.1007/s00382-017-4051-9.
Dewitte, S., D. Crommelynck, and A. Joukoff, 2004: Total solar irradiance observations from DIARAD/VIRGO. J. Geophys. Res., 109, A02102, http://doi.org/10.1029/2002JA009694.

Di Girolamo, L., A. Menzies, G. Zhao, K. Mueller, C. Moroney, and D. J. Diner, 2010: Multi-angle imaging spectroradiometer level 3 cloud fraction by altitude algorithm theoretical basis document. JPL Publ. D-62358, 23 pp.

Di Liberto, T., 2017: Heavy summer rains flood Peru. Climate.gov Event Tracker, 17 January 2017. www.climate .gov/news-features/event-tracker/heavy-summer-rains -flood-peru.

Diamond, H. J., and J. A. Renwick, 2015: The climatological relationship between tropical cyclones in the southwest Pacific and the southern annular mode. Int. J. Climatol., 35, 613-623, http://doi.org/10.1002/joc.4007.

— Climate in 2015”]. Bull. Amer. Meteor. Soc., 97 (8), S93S130, http://doi.org/10.1175/2016BAMSStateoftheClimate.1.

— , and — Eds. 2017: The tropics [in "State of the Climate in 2016"]. Bull. Amer. Meteor. Soc., 98 (8), S93-S128, http://doi.org/10.1175/2017BAMSStateoftheClimate.1.

—, A. M. Lorrey, K. R. Knapp, and D. H. Levinson, 2012: Development of an enhanced tropical cyclone tracks database for the southwest Pacific from 1840 to 2010. Int. J. Climatol., 32, 2240-2250, http://doi.org/10.1002/joc.2412.

Dieng, A. L., S. M. Sall, L. Eymard, M. Leduc-Leballeur, and A. Lazar, 2017: Trains of African easterly waves and their relationship to tropical cyclone genesis in the eastern Atlantic. Mon. Wea. Rev., 145, 599-616, http://doi.org/10.1175/mwr-d-15-0277.1.

Dlugokencky, E., 2018: Trends in atmopsheric methane. NOAA Earth System Research Laboratory. Accessed 5 May 2018. www.esrl.noaa.gov/gmd/ccgg/trends_ch4/.

—, E. G. Nisbet, R. Fisher, and D. Lowry, 2011: Global atmospheric methane: Budget, changes and dangers. Philos. Trans. Roy. Soc., A369, 2058-2072, http://doi.org/10.1098 /rsta.2010.0341.

Dohan, K., G. Goni, and R. Lumpkin, 2015: Surface currents [in "State of the Climate in 2014"]. Bull. Amer. Meteor. Soc., 96 (7), S76-S78, http://doi.org/10.1175 /2015BAMSStateoftheClimate.1.

Doherty, R. M., D. S. Stevenson, C. E. Johnson, W. J. Collins, and M. G. Sanderson, 2006: Tropospheric ozone and El Niño-Southern Oscillation: Influence of atmospheric dynamics, biomass burning emissions, and future climate change. J. Geophys. Res., 111, D19304, http://doi.org/10.1029/2005JD006849. 
Domingues, C. M., J. A. Church, N. J. White, P. J. Gleckler, S. E. Wijffels, P. M. Barker, and J. R. Dunn, 2008: Improved estimates of upper-ocean warming and multi-decadal sealevel rise. Nature, 453, 1090-1093, http://doi.org/10.1038 /nature07080.

Domingues, R., and Coauthors, 2015: Upper ocean response to Hurricane Gonzalo (2014): Salinity effects revealed by targeted and sustained underwater glider observations. Geophys. Res. Lett., 42, 7131-7138, http://doi.org/10.1002/2015GL065378.

—, M. Baringer, and G. Goni, 2016: Remote sources for year-to-year changes in the seasonality of the Florida Current transport. J. Geophys. Res. Oceans, 121, 7547-7559, http://doi.org/10.1002/2016JC012070.

Donat, M. G., and Coauthors, 2013a: Updated analyses of temperature and precipitation extreme indices since the beginning of the twentieth century: The HadEX2 dataset. J. Geophys. Res. Atmos., 118, 2098-2118, http://doi.org/10.1002/jgrd.50150.

—, L. V. Alexander, H. Yang, I. Durre, R. Vose, and J. Caesar, 2013b: Global land-based datasets for monitoring climatic extremes. Bull. Amer. Meteor. Soc., 94, 997-1006, http://doi.org/10.1175/bams-d-12-00109.1.

Dong, J., and Coauthors, 2017: Impact of assimilating underwater glider data on Hurricane Gonzalo (2014) forecasts. Wea. Forecasting, 32, 1143-1159, http://doi.org/10.1175 /waf-d-16-0182.1.

Dong, S., M. O. Baringer, G. J. Goni, C. S. Meinen, and S. L. Garzoli, 2014: Seasonal variations in the South Atlantic meridional overturning circulation from observations and numerical models. Geophys. Res. Lett., 41, 4611-4618, http://doi.org/10.1002/2014GL060428.

Dorigo, W. A., and Coauthors, 2017a: Soil moisture [in "State of the Climate in 2016"]. Bull. Amer. Meteor. Soc., 98 (8), S30-S32, http://doi.org/10.1175 /2017BAMSStateoftheClimate.1.

_ , and Coauthors, 2017b: ESA CCI soil moisture for improved Earth system understanding: State-of-the art and future directions. Remote Sens. Environ., 203, 185-215, http://doi.org/10.1016/j.rse.2017.07.001.

Drozdov, D., and Coauthors, 2015: Monitoring of permafrost in Russia and the international GTN-P project. Proc. 68th Canadian Geotechnical Conf. and Seventh Canadian Conf. on Permafrost (GEOQuébec 2015), Quebec, Canada, GEOQuébec 2015, Paper 617.

Duchesne, C., S. L. Smith, M. Ednie, and P. P. Bonnaventure, 2015: Active layer variability and change in the Mackenzie Valley, Northwest Territories. Proc. 68th Canadian Geotechnical Conf. and Seventh Canadian Conf. on Permafrost (GEOQuébec 2015), Quebec, Canada, GEOQuébec 2015, Paper 117.
Duchez, A., and Coauthors, 2016: Potential for seasonal prediction of Atlantic sea surface temperatures using the RAPID array at $26^{\circ} \mathrm{N}$. Climate Dyn., 46, 3351-3370, http://doi.org/10.1007/s00382-015-2918-1.

Dufour, C. O., A. K. Morrison, S. M. Griffies, I. Frenger, H. Zanowski, and M. Winton, 2017: Preconditioning of the Weddell Sea polynya by the ocean mesoscale and dense water overflows. J. Climate, 30, 7719-7737, http://doi.org/10.1175/jcli-d-16-0586.1.

Dunkerton, T. J., 2016: The quasi-biennial oscillation of 2015-2016: Hiccup or death spiral? Geophys. Res. Lett., 43, 10,547-10,552, http://doi.org/10.1002/2016GL070921.

Dunn, R. J. H., and Coauthors, 2012: HadISD: A qualitycontrolled global synoptic report database for selected variables at long-term stations from 1973-2011. Climate Past, 8, 1649-1679, http://doi.org/10.5194/cp-8-1649-2012. —, C. Azorin-Molina, C. A. Mears, P. Berrisford, and T. R. McVicar, 2016a: Surface winds [in "State of the Climate in 2015”]. Bull. Amer. Meteor. Soc., 97 (8), S38-S40, http://doi.org/10.1175/2016BAMSStateoftheClimate.1.

— , K. M. Willett, D. E. Parker, and L. Mitchell, 2016b: Expanding HadISD: Quality-controlled, sub-daily station data from 1931. Geosci. Instrum. Method. Data Syst., 5, 473-491, http://doi.org/10.5194/gi-5-473-2016.

Durack, P. J., S. E. Wijffels, and P. J. Gleckler, 2014: Longterm sea-level change revisited: The role of salinity. Environ. Res. Lett., 9, 114017, http://doi.org/10.1088 /1748-9326/9/11/114017.

Dvorak, V. F., 1984: Tropical cyclone intensity analysis using satellite data. NOAA Tech. Rep. NESDIS 11, 46 pp.

Eakin, C. M., J. M. Lough, and S. F. Heron, 2009: Climate variability and change: Monitoring data and evidence for increased coral bleaching stress. Coral Bleaching: Patterns, Processes, Causes and Consequences, M. J. H. van Oppen, and J. M. Lough, Eds., Springer Berlin Heidelberg, 41-67, http://doi.org/10.1007/978-3-540-69775-6_4.

— 2017? Status and an appeal for observations. Reef Encounter, 31 (1), 20-26, http://coralreefs.org/wp-content /uploads/2014/03/Reef-Encounter-43-April-2016-HR.pdf.

— , and Coauthors, 2017: Ding, dong, the witch is dead (?)-Three years of global bleaching 2014-17. Reef Encounter, 32 (1), 33-38, http://coralreefs.org/wp-content /uploads/2014/03/Reef-Encounter-August-2017-FINAL-Lo-Res.pdf.

Ebita, A., and Coauthors, 2011: The Japanese 55-year reanalysis "JRA-55": An interim report. SOLA, 7, 149-152, http://doi.org/10.2151/sola.2011-038.

Ednie, M., and S. L. Smith, 2015: Permafrost temperature data 2008-2014 from community based monitoring sites in Nunavut. Geological Survey of Canada, Open File 7784, 18 pp. http://doi.org/10.4095/296705. 
Edson, J. B., and Coauthors, 2013: On the exchange of momentum over the open ocean. J. Phys. Oceanogr., 43, 1589-1610, http://doi.org/10.1175/jpo-d-12-0173.1.

Emanuel, K. A., 1988: The maximum intensity of hurricanes. J. Atmos. Sci., 45, 1143-1155, http://doi.org/10.1175 /1520-0469(1988)045<1143:tmioh>2.0.co;2.

— , and D. S. Nolan, 2004: Tropical cyclone activity and the global climate system. Proc. 26th Conf. on Hurricanes and Tropical Meteor., Miami, FL, Amer. Meteor. Soc., 10A.2. https://ams.confex.com/ams/26HURR/techprogram /paper_75463.htm.

ENFEN (Estudio Nacional del Fenómeno El Niño), 2012: Definición operacional de los eventos El Niño y La Niña y sus magnitudes en la costa del Perú [Operational definition of El Niño and La Niña events and their magnitudes on the coast of Perú]. Nota Técnica Abril 2012. www.imarpe.pe/imarpe/archivos/informes/imarpe _inftco_nota_tecnico_abril2012.pdf.

_ 2017: El Niño costero 2017 [The 2017 Coastal El Niño]. Informe Técnico Extraordinario N001-2017/ENFEN 31 pp., www.imarpe.pe/imarpe/archivos/informes/imarpe _inftco_informe_tecnico_extraordinario_001_2017.pdf.

Enfield, D. B., and A. M. Mestas-Nuñez, 1999: Multiscale variabilities in global sea surface temperatures and their relationships with tropospheric climate patterns. J. Climate, 12, 2719-2733, http://doi.org/10.1175 /1520-0442(1999)012<2719:mvigss >2.0.co;2.

England, J. H., D. J. A. Evans, and T. R. Lakeman, 2017: Holocene history of Arctic ice shelves. Arctic Ice Shelves and Ice Islands, L. Copland, and D. Mueller, Eds., Springer Netherlands, 185-205, http://doi.org/10.1007 1978-94-024-1101-0_7.

England, M. H., and Coauthors, 2014: Recent intensification of wind-driven circulation in the Pacific and the ongoing warming hiatus. Nat. Climate Change, 4, 222-227, http://doi.org/10.1038/nclimate2106.

Esaias, W. E., and Coauthors, 1998: An overview of MODIS capabilities for ocean science observations. IEEE Trans. Geosci. Remote Sens., 36, 1250-1265, http://doi.org/10.1109/36.701076.

Estilow, T. W., A. H. Young, and D. A. Robinson, 2015: A long-term Northern Hemisphere snow cover extent data record for climate studies and monitoring. Earth Syst. Sci. Data, 7, 137-142, http://doi.org/10.5194/essd-7-137-2015.

Etheridge, D. M., L. P. Steele, R. L. Langenfelds, R. J. Francey, J. M. Barnola, and V. I. Morgan, 1996: Natural and anthropogenic changes in atmospheric $\mathrm{CO}_{2}$ over the last 1000 years from air in Antarctic ice and firn. J. Geophys. Res., 101 (D2), 4115-4128, http://doi.org/10.1029/95JD03410.
— , L. P. Steele, R. L. Langenfelds, R. J. Francey, J.-M. Barnola, and V. I. Morgan, 1998: Historical $\mathrm{CO}_{2}$ record from the Law Dome DE08, DE08-2, and DSS ice cores. Trends Online: A Compendium of Data on Global Change, Carbon Dioxide Information Analysis Center, Oak Ridge National Laboratory, http://cdiac.ess-dive.lbl.gov/trends /co2/lawdome.html.

Falkowski, P. G., R. T. Barber, and V. Smetacek, 1998: Biogeochemical controls and feedbacks on ocean primary production. Science, 281, 200-206, http://doi.org/10.1126 /science.281.5374.200.

Farbrot, H., K. Isaksen, B. Etzelmüller, and K. Gisnås, 2013: Ground thermal regime and permafrost distribution under a changing climate in northern Norway. Permafr. Periglac. Process., 24, 20-38, http://doi.org/10.1002/ppp.1763. Fauchald, P., T. Park, H. Tømmervik, R. Myneni, and V. H. Hausner, 2017: Arctic greening from warming promotes declines in caribou populations. Sci. Adv., 3, e1601365, http://doi.org/10.1126/sciadv.1601365.

Fellenius, K., 2014: Republic of the Marshall Islands Coral Bleaching Report. UNIHI-SEAGRANT-TT-14-01, 29 pp., https://eos.ucs.uri.edu/EOS_Linked_Documents/hawau /TT-14-01.pdf.

Fennig, K., A. Andersson, S. Bakan, C.-P. Klepp, and M. Schröder, 2012: Hamburg Ocean Atmosphere Parameters and Fluxes from Satellite Data - HOAPS 3.2 - Monthly Means / 6-Hourly Composites. Satellite Application Facility on Climate Monitoring (CM SAF), http://doi.org/10.5676/EUM_SAF_CM/HOAPS/V001.

Fernandes, D., 2017: Before Houston flooded, there was Piura, Peru. PRI's The World, September 14. www.pri.org/stories/2017-09-14/houston-flooded-there -was-piura-peru.

Ferreira, D., J. Marshall, C. M. Bitz, S. Solomon, and A. Plumb, 2015: Antarctic Ocean and sea ice response to ozone depletion: A two-time-scale problem. J. Climate, 28, 1206-1226, http://doi.org/10.1175/jcli-d-14-00313.1.

Fetterer, F., K. Knowles, W. Meier, M. Savoie, and A. K. Windnagel, 2017, updated daily: Sea Ice Index, Version 3. National Snow and Ice Data Center, http://doi.org/10.7265/N5K072F8.

Field, C. B., M. J. Behrenfeld, J. T. Randerson, and P. Falkowski, 1998: Primary production of the biosphere: Integrating terrestrial and oceanic components. Science, 281, 237-240, http://doi.org/10.1126/science.281.5374.237.

Fioletov, V. E., G. E. Bodeker, A. J. Miller, R. D. McPeters, and R. Stolarski, 2002: Global and zonal total ozone variations estimated from ground-based and satellite measurements: 1964-2000. J. Geophys. Res., 107, 4647, http://doi.org/10.1029/2001JD001350. 
_- and Coauthors, 2008: Performance of the groundbased total ozone network assessed using satellite data. J. Geophys. Res., 113, D14313, http://doi .org/10.1029/2008JD009809.

Fisher, J. B., and Coauthors, 2017: The future of evapotranspiration: Global requirements for ecosystem functioning, carbon and climate feedbacks, agricultural management, and water resources. Water Resour. Res., 53, 2618-2626, http://doi.org/10.1002/2016WR020175.

Flato, G., and Coauthors, 2013: Evaluation of climate models. Climate Change 2013: The Physical Science Basis, T. F. Stocker et al., Eds., Cambridge University Press, 741-866, http://doi.org/10.1017/CBO9781107415324.020.

Fleming, Z., R. Doherty, and Coauthors, 2018: Tropospheric Ozone Assessment Report: Present-day ozone distribution and trends relevant to human health. Elementa, 6 (1), 12, http://doi.org/10.1525/elementa.273.

Flemming, J., and Coauthors, 2017: The CAMS interim reanalysis of carbon monoxide, ozone and aerosol for 2003-2015. Atmos. Chem. Phys., 17, 1945-1983, http://doi.org/10.5194/acp-17-1945-2017.

Fofonoff, N. P., and E. L. Lewis, 1979: A practical salinity scale. J. Oceanogr. Soc. Japan, 35, 63-64, http://doi.org/10.1007/bf02108283.

Fogt, R. L., D. H. Bromwich, and K. M. Hines, 2011: Understanding the SAM influence on the South Pacific ENSO teleconnection. Climate Dyn., 36, 1555-1576, http://doi.org/10.1007/s00382-010-0905-0.

Folland, C. K., J. A. Renwick, M. J. Salinger, and A. B. Mullan, 2002: Relative influences of the Interdecadal Pacific Oscillation and ENSO on the South Pacific Convergence Zone. Geophys. Res. Lett., 29, 21-1-21-4, http://doi.org/10.1029/2001GL014201.

_ , J. Knight, H. W. Linderholm, D. Fereday, S. Ineson, and J. W. Hurrell, 2009: The summer North Atlantic oscillation: Past, present, and future. J. Climate, 22, 1082-1103, http://doi.org/10.1175/2008jcli2459.1.

Font, J., and Coauthors, 2013: SMOS first data analysis for sea surface salinity determination. Int. J. Remote Sens., 34, 3654-3670, http://doi.org/10.1080/01431161.2012.716541.

Fore, A. G., S. H. Yueh, W. Tang, B. W. Stiles, and A. K. Hayashi, 2016: Combined active/passive retrievals of ocean vector wind and sea surface salinity with SMAP. IEEE Trans. Geosci. Remote Sens., 54, 7396-7404, http://doi.org/10.1109/TGRS.2016.2601486.

Foster, M. J., and A. Heidinger, 2013: PATMOS-x: Results from a diurnally corrected $30-y r$ satellite cloud climatology. J. Climate, 26, 414-425, http://doi.org/10.1175 /jcli-d-11-00666.1.

Frajka-Williams, E., 2015: Estimating the Atlantic overturning at $26^{\circ} \mathrm{N}$ using satellite altimetry and cable measurements. Geophys. Res. Lett., 42, 3458-3464, http://doi.org/10.1002/2015GL063220.
Frank, W. M., and P. E. Roundy, 2006: The role of tropical waves in tropical cyclogenesis. Mon. Wea. Rev., 134, 2397-2417, http://doi.org/10.1175/mwr3204.1.

Franz, B. A., M. J. Behrenfeld, D. A. Siegel, and S. R. Signorini, 2017: Global ocean phytoplankton [in "State of the Climate in 2016”]. Bull. Amer. Meteor. Soc., 98 (8), S87-S89, http://doi.org/10.1175/2017BAMSStateoftheClimate.1.

French, N. H. F., L. K. Jenkins, T. V. Loboda, M. Flannigan, R. Jandt, L. Bourgeau-Chavez, and M. Whitley, 2015: Fire in arctic tundra of Alaska: Past fire activity, future fire potential, and significance for land management and ecology. Int. J. Wildland Fire, 24, 1045-1061, http://doi.org/10.1071/WF14167.

Frith, S. M., N. A. Kramarova, R. S. Stolarski, R. D. McPeters, P. K. Bhartia, and G. J. Labow, 2014: Recent changes in total column ozone based on the SBUV version 8.6 merged ozone data set. J. Geophys. Res. Atmos., 119, 9735-9751, http://doi.org/10.1002/2014JD021889.

—, R. S. Stolarski, N. A. Kramarova, and R. D. McPeters, 2017: Estimating uncertainties in the SBUV Version 8.6 merged profile ozone data set. Atmos. Chem. Phys., 17, 14,695-14,707, http://doi.org/10.5194/acp-17-14695-2017.

Frost, G. V., H. E. Epstein, D. A. Walker, G. Matyshak, and K. Ermokhina, 2017: Seasonal and long-term changes to active-layer temperatures after tall shrubland expansion and succession in Arctic tundra. Ecosystems, http://doi.org/10.1007/s10021-017-0165-5.

FRRP, 2015: Florida Reef Resilience Program [FRRP] disturbance response monitoring quick look report: Winter 2015. 5 pp., http://frrp.org/wp-content/uploads/2016/07 /2015-Winter-DRM-Quick-Look-Report.pdf.

_ , 2016: Florida Reef Resilience Program [FRRP] disturbance response monitoring quick look report: Winter 2016. 8 pp., http://frrp.org/wp-content/uploads/2016/07 /2016-Winter-DRM-Quick-Look-Report.pdf.

Fu, D., P. Chang, and C. M. Patricola, 2017: Intrabasin variability of east Pacific tropical cyclones during ENSO regulated by Central American gap winds. Sci. Rep., 7, 1658, http://doi.org/10.1038/s41598-017-01962-3.

Fu, Q., C. M. Johanson, S. G. Warren, and D. J. Seidel, 2004: Contribution of stratospheric cooling to satellite-inferred tropospheric temperature trends. Nature, 429, 55-58, http://doi.org/10.1038/nature02524.

Fujibe, F., N. Yamazaki, M. Katsuyama, and K. Kobayashi, 2005: The increasing trend of intense precipitation in Japan based on four-hourly data for a hundred years. SOLA, 1, 41-44, http://doi.org/10.2151/sola.2005-012.

Fung, I., J. John, J. Lerner, E. Matthews, M. Prather, L. P. Steele, and P. J. Fraser, 1991: Three-dimensional model synthesis of the global methane cycle. J. Geophys. Res., 96, 13,033-13,065, http://doi.org/10.1029/91JD01247. 
Gao, L., S. R. Rintoul, and W. Yu, 2018: Recent wind-driven change in Subantarctic Mode Water and its impact on ocean heat storage. Nat. Climate Change, 8, 58-63, http://doi.org/10.1038/s41558-017-0022-8.

Garane, K., and Coauthors, 2018: Quality assessment of the Ozone_cci Climate Research Data Package (release 2017): 1. Ground-based validation of total ozone column data products. Atmos. Meas. Tech., 11, 1385-1402, http://doi.org/10.5194/amt-11-1385-2018.

Gardner, A. S., and Coauthors, 2011: Sharply increased mass loss from glaciers and ice caps in the Canadian Arctic archipelago. Nature, 473, 357-360, http://doi.org/10.1038 /nature10089.

— contributions to sea level rise: 2003 to 2009. Science, 340, 852-857, http://doi.org/10.1126/science.1234532.

Garreaud, R. D., 2018: A plausible atmospheric trigger for the 2017 coastal El Niño. Int. J. Climatol., 38 (S1), e1296e1302, http://doi.org/10.1002/joc.5426.

— , and Coauthors, 2017: The 2010-2015 mega drought in central Chile: Impacts on regional hydroclimate and vegetation. Hydrol. Earth Syst. Sci., 21, 6307-6327, http://doi.org/10.5194/hess-21-6307-2017.

Gattuso, J.-P., and Coauthors, 2015: Contrasting futures for ocean and society from different anthropogenic $\mathrm{CO}_{2}$ emissions scenarios. Science, 349, aac4722, http://doi.org/10.1126/science.aac4722.

Gaubert, B., and Coauthors, 2017: Chemical feedback from decreasing carbon monoxide emissions. Geophys. Res. Lett., 44, 9985-9995, http://doi.org/10.1002/2017GL074987.

Gaudel, A., and Coauthors, 2018: Tropospheric Ozone Assessment Report: Present-day ozone distribution and trends relevant to climate and global model evaluation. Elementa, 6 (1), 39, http://doi.org/10.1525/elementa.291.

GBRMPA, 2017: About the reef: Reef health [web site]. Great Barrier Reef Marine Park Authority [Australia] (GBRMPA) 2018. www.gbrmpa.gov.au/about-the-reef/reef-health. GCOS, 2003: The second report on the adequacy of the global observing systems for climate in support of the UNFCCC. GCOS-82 (WMO/TD-1143), 74 pp., www.wmo.int/pages /prog/gcos/Publications/gcos-82_2AR.pdf.

_ 2010: Implementation plan for the global observing system for climate in support of the UNFCCC (2010 Update). GCOS-138 (GOOS-184, GTOS-76, WMO/TD-1523), 180 pp., www.wmo.int/pages/prog/gcos/Publications /gcos-138.pdf.

- 2016: The global observing system for climate: Implementation needs. GCOS-200 (GOOS-214), 315 pp., https://unfccc.int/files/science/workstreams /systematic_observation/application/pdf/gcos _ip_10oct2016.pdf.
Gelaro, R., and Coauthors, 2017: The Modern-Era Retrospective Analysis for Research and Applications, version 2 (MERRA-2). J. Climate, 30, 5419-5454, http://doi.org/10.1175/JCLI-D-16-0758.1.

Ghilain, N., A. Arboleda, and F. Gellens-Meulenberghs, 2011: Evapotranspiration modelling at large scale using near-real time MSG SEVIRI derived data. Hydrol. Earth Syst. Sci., 15, 771-786, http://doi.org/10.5194/hess-15 $-771-2011$.

Giglio, L., J. T. Randerson, and G. R. van der Werf, 2013: Analysis of daily, monthly, and annual burned area using the fourth-generation global fire emissions database (GFED4). J. Geophys. Res. Biogeosci., 118, 317-328, http:// doi.org/10.1002/jgrg.20042.

—, W. Schroeder, and C. O. Justice, 2016: The collection 6 MODIS active fire detection algorithm and fire products. Remote Sens. Environ., 178, 31-41, http://doi .org/10.1016/j.rse.2016.02.054.

Gillett, N. P., A. J. Weaver, F. W. Zwiers, and M. D. Flannigan, 2004: Detecting the effect of climate change on Canadian forest fires. Geophys. Res. Lett., 31, L18211, http://doi. org/10.1029/2004GL020876.

GISTEMP Team, 2016: 2016 GISS Surface Temperature Analysis (GISTEMP). NASA Goddard Institute for Space Studies. Accessed 9 February 2018. https://data.giss.nasa .gov/gistemp/.

Glynn, P. W., 1990: Coral mortality and disturbances to coral reefs in the tropical eastern Pacific. Global Ecological Consequences of the 1982-83 El Niño-Southern Oscillation, P. W. Glynn, Ed., Elsevier Oceanography Series 52, Elsevier, 55-126, http://doi.org/10.1016 /S0422-9894(08)70033-3.

Gobron, N., and M. Robustelli, 2013: Monitoring the state of the global terrestrial surfaces. Proc. 2013 ESA Living Planet Symp., Edinburgh, United Kingdom, European Space Agency, SP-722.

- - A. Belward, B. Pinty, and W. Knorr, 2010: Monitoring biosphere vegetation 1998-2009. Geophys. Res. Lett., 37, L15402, http://doi.org/10.1029/2010GL043870.

Goldenberg, S. B., and L. J. Shapiro, 1996: Physical mechanisms for the association of El Niño and West African rainfall with Atlantic major hurricane activity. J. Climate, 9, 1169-1187, http://doi.org/10.1175 /1520-0442(1996)009<1169:pmftao>2.0.co;2.

—, C. W. Landsea, A. M. Mestas-Nuñez, and W. M. Gray, 2001: The recent increase in Atlantic hurricane activity: Causes and implications. Science, 293, 474-479, http://doi.org/10.1126/science.1060040.

Goni, G. J., and J. A. Trinanes, 2003: Ocean thermal structure monitoring could aid in the intensity forecast of tropical cyclones. Eos, Trans. Amer. Geophys. Union, 84, 573-578, http://doi.org/10.1029/2003EO510001. 
_- and J. A. Knaff, 2009: Tropical cyclone heat potential [in "State of the Climate in 2008"]. Bull. Amer. Meteor. Soc., 90 (8), S54-S56, http://doi.org/10.1175 /BAMS-90-8-StateoftheClimate.

_ , S. Kamholz, S. Garzoli, and D. Olson, 1996: Dynamics of the Brazil-Malvinas confluence based on inverted echo sounders and altimetry. J. Geophys. Res., 101, 16,273-16,289, http://doi.org/10.1029/96JC01146.

— , and Coauthors, 2009: Applications of satellite-derived ocean measurements to tropical cyclone intensity forecasting. Oceanography, 22 (3), 190-197, http://doi .org/10.5670/oceanog.2009.78.

_ , F. Bringas, and P. N. DiNezio, 2011: Observed low frequency variability of the Brazil Current front. J. Geophys. Res., 116, C10037, http://doi.org/10.1029/2011JC007198.

Gordon, A. L., 1978: Deep Antarctic convection west of Maud Rise. J. Phys. Oceanogr., 8, 600-612, http://doi .org/10.1175/1520-0485(1978)008<0600:Dacwom>2.0.CO;2.

— , and B. A. Huber, 1995: Warm Weddell Deep Water west of Maud Rise. J. Geophys. Res., 100 (C7), 13,747-13,753, http://doi.org/10.1029/95JC01361.

—, M. Visbeck, and J. C. Comiso, 2007: A possible link between the Weddell polynya and the southern annular mode. J. Climate, 20, 2558-2571, http://doi.org/10.1175 /jcli4046.1.

Granier, C., and Coauthors, 2011: Evolution of anthropogenic and biomass burning emissions of air pollutants at global and regional scales during the 1980-2010 period. Climatic Change, 109, 163, http://doi.org/10.1007 /s10584-011-0154-1.

Granskog, M. A., A. Rösel, P. A. Dodd, D. Divine, S. Gerland, T. Martma, and M. J. Leng, 2017: Snow contribution to first-year and second-year Arctic sea ice mass balance north of Svalbard. J. Geophys. Res. Oceans, 122, 25392549, http://doi.org/10.1002/2016JC012398.

Gray, W. M., 1968: Global view of the origin of tropical disturbances and storms. Mon. Wea. Rev., 96, 669700, http://doi.org/10.1175/1520-0493(1968)096<0669 :gvotoo $>2.0$. co;2.

- 1984: Atlantic seasonal hurricane frequency. Part I: El Niño and $30 \mathrm{mb}$ quasi-biennial oscillation influences. Mon. Wea. Rev., 112, 1649-1668, http://doi .org/10.1175/1520-0493(1984)112<1649:Ashfpi>2.0.CO;2.

Grounds, M. A., J. E. LeClerc, and S. Joslyn, 2018: Expressing flood likelihood: Return period versus probability. Wea. Climate Soc., 10, 5-17, http://doi.org/10.1175 /wcas-d-16-0107.1.

Gruber, A., W. A. Dorigo, W. Crow, and W. Wagner, 2017: Triple collocation-based merging of satellite soil moisture retrievals. IEEE Trans. Geosci. Remote Sens., 55 , 6780-6792, http://doi.org/10.1109/TGRS.2017.2734070.
Gruber, S., M. Hoelzle, and W. Haeberli, 2004: Rock-wall temperatures in the Alps: modelling their topographic distribution and regional differences. Permafr. Periglac. Process., 15, 299-307, http://doi.org/10.1002/ppp.501.

Gstalter, M., 2017: Thousands still await clean water after Harvey. Beaumont Enterprise, 4 December. www.beaumontenterprise.com/news/article/Thousands -still-await-clean-water-after-Harvey-12403612.php.

Guglielmin, M., M. R. Worland, F. Baio, and P. Convey, 2014: Permafrost and snow monitoring at Rothera Point (Adelaide Island, Maritime Antarctica): Implications for rock weathering in cryotic conditions. Geomorphology, 225, 47-56, http://doi.org/10.1016/j.geomorph.2014.03.051.

Guo, Y., X. Jiang, and D. E. Waliser, 2014: Modulation of the convectively coupled Kelvin waves over South America and the tropical Atlantic Ocean in association with the Madden-Julian oscillation. J. Atmos. Sci., 71, 1371-1388, http://doi.org/10.1175/jas-d-13-0215.1.

Hajani, E., A. Rahman, and E. Ishak, 2017: Trends in extreme rainfall in the state of New South Wales, Australia. Hydrolog. Sci. J., 62, 2160-2174, http://doi.org/10.1080 /02626667.2017.1368520.

Häkkinen, S., P. B. Rhines, and D. L. Worthen, 2013: Northern North Atlantic sea surface height and ocean heat content variability. J. Geophys. Res. Oceans, 118, 3670-3678, http://doi.org/10.1002/jgrc.20268.

Hamlington, B. D., S. H. Cheon, P. R. Thompson, M. A. Merrifield, R. S. Nerem, R. R. Leben, and K. Y. Kim, 2016: An ongoing shift in Pacific Ocean sea level. J. Geophys. Res. Oceans, 121, 5084-5097, http://doi.org/10.1002/2016JC011815.

Hanel, M., A. Pavlásková, and J. Kyselý, 2016: Trends in characteristics of sub-daily heavy precipitation and rainfall erosivity in the Czech Republic. Int. J. Climatol., 36, 1833-1845, http://doi.org/10.1002/joc.4463.

Hansen, J., R. Ruedy, M. Sato, and K. Lo, 2010: Global surface temperature change. Rev. Geophys., 48, RG4004, http://doi.org/10.1029/2010RG000345.

Harris, I., P. D. Jones, T. J. Osborn, and D. H. Lister, 2014: Updated high-resolution grids of monthly climatic observations - the CRU TS3.10 Dataset. Int. J. Climatol., 34, 623-642, http://doi.org/10.1002/joc.3711.

Harris, J. M., and J. D. Kahl, 1990: A descriptive atmospheric transport climatology for the Mauna Loa Observatory, using clustered trajectories. J. Geophys. Res., 95, 13,65113,667, http://doi.org/10.1029/JD095iD09p13651.

Harris, N. R. P., and Coauthors, 2014: Scenarios and information for policymakers. Scientific Assessment of Ozone Depletion: 2014, World Meteorological Organization, 5.1-5.58, www.esrl.noaa.gov/csd/assessments/ozone/2014 /chapters/chapter5_2014OzoneAssessment.pdf. 
Hart, R. E., R. N. Maue, and M. C. Watson, 2007: Estimating local memory of tropical cyclones through MPI anomaly evolution. Mon. Wea. Rev., 135, 3990-4005, http://doi.org/10.1175/2007mwr2038.1.

Hartmann, D. L., and Coauthors, 2013: Observations: Atmosphere and surface. Climate Change 2013: The Physical Science Basis, T. F. Stocker et al., Eds., Cambridge University Press, 159-254, http://doi.org/10.1017 /CBO9781107415324.008.

Harvey, C., 2016: Why dead coral reefs could mark the beginning of 'dangerous' climate change. The Washington Post, April 12. www.washingtonpost.com/news /energy-environment/wp/2016/04/12/why-dead-coral -reefs-stir-fears-of-dangerous-climate-change/?utm _term=.52ea8e02938d.

_ 2017: More than 70 percent of Japan's largest coral reef has died. The Washington Post, January 13. www.washingtonpost.com/news/energy-environment /wp/2017/01/13/more-than-70-percent-of-japans-largest -coral-reef-has-died/?utm_term=.d479de400122.

Haumann, F. A., N. Gruber, M. Münnich, I. Frenger, and S. Kern, 2016: Sea-ice transport driving Southern Ocean salinity and its recent trends. Nature, 537, 89-92, http://doi.org/10.1038/nature19101.

Hausfather, Z., K. Cowtan, D. C. Clarke, P. Jacobs, M. Richardson, and R. Rohde, 2017: Assessing recent warming using instrumentally homogeneous sea surface temperature records. Sci. Adv., 3, e1601207, http://doi.org/10.1126 /sciadv.1601207.

Heidinger, A. K., M. J. Foster, A. Walther, and X. Zhao, 2014: The Pathfinder atmospheres-extended AVHRR climate dataset. Bull. Amer. Meteor. Soc., 95, 909-922, http://doi.org/10.1175/bams-d-12-00246.1.

Heim Jr., R. R., 2017: A comparison of the early twenty-first century drought in the United States to the 1930s and 1950s drought episodes. Bull. Amer. Meteor. Soc., 98, 2579-2592, http://doi.org/10.1175/bams-d-16-0080.1.

Held, I. M., and B. J. Soden, 2000: Water vapor feedback and global warming. Annu. Rev. Energy Environ., 25, 441-475, http://doi.org/10.1146/annurev.energy.25.1.441.

Helfrich, S. R., D. McNamara, B. H. Ramsay, T. Baldwin, and T. Kasheta, 2007: Enhancements to, and forthcoming developments in the Interactive Multisensor Snow and Ice Mapping System (IMS). Hydrol. Proc., 21, 1576-1586, http://doi.org/10.1002/hyp.6720.

Hendon, H. H., C. Zhang, and J. D. Glick, 1999: Interannual variation of the Madden-Julian oscillation during austral summer. J. Climate, 12, 2538-2550, http://doi.org/10.1175/1520-0442(1999)012<2538 :ivotmj>2.0.co;2.
Herold, N., L. V. Alexander, M. G. Donat, S. Contractor, and A. Becker, 2016: How much does it rain over land? Geophys. Res. Lett., 43, 341-348, http://doi.org/10.1002/2015GL066615.

Heron, S., and Coauthors, 2016a: Validation of reef-scale thermal stress satellite products for coral bleaching monitoring. Remote Sens., 8, 59, http://doi.org/10.3390 /rs8010059.

— J. A. Maynard, R. van Hooidonk, and C. M. Eakin, 2016b: Warming trends and bleaching stress of the world's coral reefs 1985-2012. Sci. Rep., 6, 38402, http://doi.org/10.1038 /srep38402.

Heuzé, C., K. J. Heywood, D. P. Stevens, and J. K. Ridley, 2013: Southern Ocean bottom water characteristics in CMIP5 models. Geophys. Res. Lett., 40, 1409-1414, http://doi.org/10.1002/grl.50287.

— , J. K. Ridley, D. Calvert, D. P. Stevens, and K. J. Heywood, 2015: Increasing vertical mixing to reduce Southern Ocean deep convection in NEMO3.4. Geosci. Model Dev., 8, 3119-3130, http://doi.org/10.5194/gmd-8-3119-2015.

Ho, S.-P., Y.-H. Kuo, W. Schreiner, and X. Zhou, 2010a: Using SI-traceable global positioning system radio occultation measurements for climate monitoring [in "State of the Climate in 2009"]. Bull. Amer. Meteor. Soc., 91 (7), S36S37, http://doi.org/10.1175/BAMS-91-7-StateoftheClimate. —, X. Zhou, Y.-H. Kuo, D. Hunt, and J.-H. Wang, 2010b: Global evaluation of radiosonde water vapor systematic biases using GPS radio cccultation from COSMIC and ECMWF analysis. Remote Sens. Environ., 2, 1320-1330, http://doi.org/10.3390/rs2051320.

Hobbs, W. R., and J. K. Willis, 2012: Midlatitude North Atlantic heat transport: A time series based on satellite and drifter data. J. Geophys. Res., 117, C01008, http://doi.org/10.1029/2011JC007039.

—, R. Massom, S. Stammerjohn, P. Reid, G. Williams, and W. Meier, 2016: A review of recent changes in Southern Ocean sea ice, their drivers and forcings. Global Planet. Change, 143, 228-250, http://doi.org/10.1016 /j.gloplacha.2016.06.008.

Hoegh-Guldberg, O., 1999: Climate change, coral bleaching and the future of the world's coral reefs. Mar. Freshwater Res., 50, 839-866, http://doi.org/10.1071/MF99078.

Hofmann, D. J., and S. A. Montzka, 2009: Recovery of the ozone layer: The ozone depleting gas index. Eos, Trans. Amer. Geophys. Union, 90, 1-2, http://doi.org/10.1029/2009EO010001.

— J. J. Butler, E. J. Dlugokencky, J. W. Elkins, K. Masarie, S. A. Montzka, and P. Tans, 2006: The role of carbon dioxide in climate forcing from 1979 to 2004: Introduction of the annual greenhouse gas index. Tellus, 58B, 614-619, http://doi.org/10.1111/j.1600-0889.2006.00201.x. 
Holland, D. M., 2000: Transient sea-ice polynya forced by oceanic flow variability. Prog. Oceanogr., 48, 403-460, http://doi.org/10.1016/S0079-6611(01)00010-6.

Hong, C.-C., T. Li, LinHo, and J.-S. Kug, 2008: Asymmetry of the Indian Ocean dipole. Part I: Observational analysis. J. Climate, 21, 4834-4848, http://doi .org/10.1175/2008jcli2222.1.

Hörner, T., R. Stein, K. Fahl, and D. Birgel, 2016: Post-glacial variability of sea ice cover, river run-off and biological production in the western Laptev Sea (Arctic Ocean) - A high-resolution biomarker study. Quat. Sci. Rev., 143, 133-149, http://doi.org/10.1016/j.quascirev.2016.04.011.

Horstkotte, T., and Coauthors, 2017: Human-animal agency in reindeer management: Sámi herders' perspectives on vegetation dynamics under climate change. Ecosphere, $\mathbf{8}$, e01931, http://doi.org/10.1002/ecs2.1931.

Hossaini, R., M. P. Chipperfield, S. A. Montzka, A. A. Leeson, S. S. Dhomse, and J. A. Pyle, 2017: The increasing threat to stratospheric ozone from dichloromethane. Nat. Comm., 8, 15962, http://doi.org/10.1038/ncomms15962.

Hou, A. Y., and Coauthors, 2014: The Global Precipitation Measurement Mission. Bull. Amer. Meteor. Soc., 95, 701-722, http://doi.org/10.1175/bams-d-13-00164.1.

Hrbáček, F., and Coauthors, 2018: Active layer monitoring in Antarctica: an overview of results from 2006 to 2015. Polar Geogr., 1-16, http://doi.org/10.1080 /1088937X.2017.1420105.

Huaman, L., and K. Takahashi, 2016: The vertical structure of the eastern Pacific ITCZs and associated circulation using the TRMM Precipitation Radar and in situ data. Geophys. Res. Lett., 43, 8230-8239, http://doi .org/10.1002/2016GL068835.

Huang, B., and Coauthors, 2015: Extended reconstructed sea surface temperature version 4 (ERSST.v4). Part I: Upgrades and intercomparisons. J. Climate, 28, 911-930, http://doi.org/10.1175/jcli-d-14-00006.1.

_ tifying uncertainties for extended reconstructed sea surface temperature (ERSST) version 4 (v4). J. Climate, 29, 3119-3142, http://doi.org/10.1175/jcli-d-15-0430.1.

—, M. L'Heureux, Z.-Z. Hu, and H.-M. Zhang, 2016b: Ranking the strongest ENSO events while incorporating SST uncertainty. Geophys. Res. Lett., 43, 9165-9172, http://doi.org/10.1002/2016GL070888.

_ - and Coauthors, 2017: Extended Reconstructed Sea Surface Temperature, Version 5 (ERSSTv5): Upgrades, validations, and intercomparisons. J. Climate, 30, 8179-8205, http://doi.org/10.1175/jcli-d-16-0836.1.

Huang, C.-Y., W.-H. Teng, S.-P. Ho, and Y.-H. Kuo, 2013: Global variation of COSMIC precipitable water over land: Comparisons with ground-based GPS measurements and NCEP reanalyses. Geophys. Res. Lett., 40, 5327-5331, http://doi.org/10.1002/grl.50885.
Huffman, G. J., R. F. Adler, D. T. Bolvin, and G. Gu, 2009: Improving the global precipitation record: GPCP Version 2.1. Geophys. Res. Lett., 36, L17808, http://doi .org/10.1029/2009GL040000.

Hughes, T., and J. Kerry, 2017: Back-to-back bleaching has now hit two-thirds of the Great Barrier Reef. The Conversation, April 11. http://theconversation.com /back-to-back-bleaching-has-now-hit-two-thirds-of-the -great-barrier-reef-76092.

— , and Coauthors, 2017: Global warming and recurrent mass bleaching of corals. Nature, 543, 373-377, http://doi.org/10.1038/nature21707.

_ - and Coauthors, 2018: Spatial and temporal patterns of mass bleaching of corals in the Anthropocene. Science, 359, 80-83, http://doi.org/10.1126/science.aan8048.

Huijnen, V., and Coauthors, 2016: Fire carbon emissions over maritime southeast Asia in 2015 largest since 1997. Sci. Rep., 6, 26886, http://doi.org/10.1038/srep26886.

Huss, M., and R. Hock, 2018: Global-scale hydrological response to future glacier mass loss. Nat. Climate Change, 8, 135-140, http://doi.org/10.1038/s41558-017-0049-x.

— , and Coauthors, 2017a: Toward mountains without permanent snow and ice. Earth's Future, 5, 418-435, http://doi.org/10.1002/2016EF000514.

— - A. Bauder, C. Marty, and J. Nötzli, 2017b: Schnee, Gletscher und Permafrost 2015/16 - La neige, les glaciers et le pergélisol 2015/16 - Neve, ghiacciai e permafrost 2015/16 [in German, French, and Italian]. Die Alpen Les Alpes - Le Alpi, 93 (8), 45-51, http://swiss-glaciers .glaciology.ethz.ch/publications.html.

IMARPE (Instituto del Mar del Perú), 2017: Informe integrado de la Operación EUREKA LXIX (21-23 de Febrero 2017) [Integrated Report of the EUREKA LXIX Operation]. 23 pp., www.imarpe.pe/imarpe/archivos /informes/Informe_Operacion_EUREKA_LXIX\%20 _21_23feb_2017.pdf.

Insurance Council of Australia, 2017: \$1 billion paid in Cyclone Debbie insurance claims. 6 November. www .insurancecouncil.com.au/media_release/plain/436.

Inuit Circumpolar Council-Alaska, 2015: Alaskan Inuit food security conceptual framework: How to assess the Arctic from an Inuit Perspective. 116 pp., http://iccalaska.org /wp-icc/wp-content/uploads/2016/05/Food-Security-Full -Technical-Report.pdf.

- , 2016: Application of Indigenous Knowledge in the Arctic Council. 2 pp., http://iccalaska.org/wp-icc /wp-content/uploads/2016/03/Application-of-IK-in-the -Arctic-Council.pdf.

IPCC, 2014: Climate Change 2014: Synthesis Report. R. K. Pachauri, and L. A. Meyer, Eds. IPCC, 151 pp., www.ipcc .ch/report/ar5/syr/. 
Isaksen, K., J. L. Sollid, P. Holmlund, and C. Harris, 2007: Recent warming of mountain permafrost in Svalbard and Scandinavia. J. Geophys. Res., 112, F02S04, http://doi .org/10.1029/2006JF000522.

—_, and Coauthors, 2011: Degrading mountain permafrost in southern Norway: Spatial and temporal variability of mean ground temperatures, 1999-2009. Permafr. Periglac. Process., 22, 361-377, http://doi.org/10.1002/ppp.728.

Ishihara, K., 2006: Calculation of global surface temperature anomalies with COBE-SST. Sokko-jiho [Weather Service Bull.], 73 (Special Issue), S19-S25, (in Japanese).

Ishii, M., Y. Fukuda, S. Hirahara, S. Yasui, T. Suzuki, and K. Sato, 2017: Accuracy of global upper ocean heat content estimation expected from present observational data sets. SOLA, 13, 163-167, http://doi.org/10.2151/sola.2017-030.

Jacob, T., J. Wahr, W. T. Pfeffer, and S. Swenson, 2012: Recent contributions of glaciers and ice caps to sea level rise. Nature, 482, 514-518, http://doi.org/10.1038/nature10847.

Jacobson, A. R., S. E. Mikaloff Fletcher, N. Gruber, J. L. Sarmiento, and M. Gloor, 2007: A joint atmosphere-ocean inversion for surface fluxes of carbon dioxide: 1 . Methods and global-scale fluxes. Global Biogeochem. Cycles, 21, GB1019, http://doi.org/10.1029/2005GB002556.

Jakob, D., D. J. Karoly, and A. Seed, 2011: Non-stationarity in daily and sub-daily intense rainfall - Part 2: Regional assessment for sites in south-east Australia. Nat. Hazards Earth Syst. Sci., 11, 2273-2284, http://doi.org/10.5194 /nhess-11-2273-2011.

Jakobsson, M., and Coauthors, 2014: Arctic Ocean glacial history. Quat. Sci. Rev., 92, 40-67, http://doi.org/10.1016/j .quascirev.2013.07.033.

Jauregui, Y. R., and K. Takahashi, 2017: Simple physical-empirical model of the precipitation distribution based on a tropical sea surface temperature threshold and the effects of climate change. Climate Dyn., http://doi.org/10.1007 /s00382-017-3745-3.

Jiménez-Muñoz, J. C., and Coauthors, 2016: Record-breaking warming and extreme drought in the Amazon rainforest during the course of El Niño 2015-2016. Sci. Rep., 6, 33130, http://doi.org/10.1038/srep33130.

John, V. O., and B. J. Soden, 2007: Temperature and humidity biases in global climate models and their impact on climate feedbacks. Geophys. Res. Lett., 34, L18704, http://doi.org/10.1029/2007GL030429.

—, G. Holl, R. P. Allan, S. A. Buehler, D. E. Parker, and B. J. Soden, 2011: Clear-sky biases in satellite infrared estimates of upper tropospheric humidity and its trends. J. Geophys. Res. , 116, D14108, http://doi.org/10.1029/2010JD015355.

_- L. Shi, E.-S. Chung, R. P. Allan, S. A. Buehler, and B. J. Soden, 2017: Upper tropospheric humidity [in "State of the Climate in 2016"]. Bull. Amer. Meteor. Soc., 98 (8), S25-S26, http://doi.org/10.1175/2017BAMSStateoftheClimate.1.
Johnson, G. C., 2008: Quantifying Antarctic bottom water and North Atlantic Deep Water volumes. J. Geophys. Res., 113, C05027, http://doi.org/10.1029/2007JC004477.

—, and J. M. Lyman, 2012: Sea surface salinity [in "State of the Climate in 2011"]. Bull. Amer. Meteor. Soc., 93 (7), S68-S69, S72, http://doi.org/10.1175 /2012BAMSStateoftheClimate.1.

—_, and A. N. Birnbaum, 2017: As El Niño builds, Pacific warm pool expands, ocean gains more heat. Geophys. Res. Lett., 44, 438-445, http://doi.org/10.1002/2016GL071767. — - and Coauthors, 2014: Ocean heat content [in "State of the Climate in 2013”]. Bull. Amer. Meteor. Soc., 95 (7), S54-S57, http://doi.org/10.1175/2014BAMSStateoftheClimate.1.

- , and Coauthors, 2015: Ocean heat content [in "State of the Climate in 2014"]. Bull. Amer. Meteor. Soc., 96 (7), S64-S66, S68, http://doi.org/10.1175/2015BAMSStateoftheClimate.1.

Johnson, K. S., and Coauthors, 2017: Biogeochemical sensor performance in the SOCCOM profiling float array. J. Geophys. Res. Oceans, 122, 6416-6436, http://doi.org/10.1002/2017JC012838.

Johnston, M. A., and Coauthors, 2017: Long-Term Monitoring at East and West Flower Garden Banks: 2016 Annual Report. Marine Sanctuaries Conservation Series ONMS17-09, $132 \mathrm{pp}$. , https://sanctuaries.noaa.gov/science /conservation/east-west-flower-garden-banks-long-term -monitoring-2016.html.

Johnstone, J. F., T. N. Hollingsworth, F. S. Chapin, and M. C. Mack, 2010: Changes in fire regime break the legacy lock on successional trajectories in Alaskan boreal forest. Global Change Biol., 16, 1281-1295, http://doi.org/10.1111 /j.1365-2486.2009.02051.x.

Jones, B. M., G. Grosse, C. D. Arp, E. Miller, L. Liu, D. J. Hayes, and C. F. Larsen, 2015: Recent Arctic tundra fire initiates widespread thermokarst development. Sci. Rep., 5, 15865, http://doi.org/10.1038/srep15865.

Jones, D. A., W. Wang, and R. Fawcett, 2009: High-quality spatial climate data-sets for Australia. Aust. Meteor. Oceanogr. J., 58, 233-248, http://doi.org/10.22499/2.5804.003.

Jones, P. D., D. H. Lister, T. J. Osborn, C. Harpham, M. Salmon, and C. P. Morice, 2012: Hemispheric and largescale land-surface air temperature variations: An extensive revision and an update to 2010. J. Geophys. Res., 117, D05127, http://doi.org/10.1029/2011JD017139.

Jorgenson, M. T., and Coauthors, 2010: Resilience and vulnerability of permafrost to climate change. Can. J. Forest Res., 40, 1219-1236, http://doi.org/10.1139/X10-060.

Joyce, R. J., J. E. Janowiak, P. A. Arkin, and P. Xie, 2004: CMORPH: A method that produces global precipitation estimates from passive microwave and infrared data at high spatial and temporal resolution. J. Hydrometeor., 5, 487-503, http://doi.org/10.1175 /1525-7541(2004)005<0487:camtpg>2.0.co;2. 
Kaiser, J. W., and Coauthors, 2012: Biomass burning emissions estimated with a global fire assimilation system based on observed fire radiative power. Biogeosciences, 9 , 527-554, http://doi.org/10.5194/bg-9-527-2012.

— W. Xu, A. Heil, T. Nikonovas, I. Hüser, and M. J. Wooster, 2017: How to use SEVIRI fire radiative power in the Copernicus Atmosphere Monitoring Service. Proc. 2017 EUMETSAT Meteorological Satellite Conf., Rome, Italy, Session 4: Atmospheric composition: Recent advances in satellite products and applications, EUMETSAT, www.eumetsat.int/website/home/News/ConferencesandEvents /DAT_3212307.html.

Kalnay, E., and Coauthors, 1996: The NCEP/NCAR 40year reanalysis project. Bull. Amer. Meteor. Soc., 77, 437-471, http://doi.org/10.1175/1520-0477(1996)077<0437 :tnyrp $>2.0 . \mathrm{co} ; 2$.

Kanae, S., T. Oki, and A. Kashida, 2004: Changes in hourly heavy precipitation at Tokyo from 1890 to 1999. J. Meteor. Soc. Japan, 82, 241-247, http://doi.org/10.2151 /jmsj.82.241.

Kaplan, A., 2011: Patterns and indices of climate variability [in"State of the Climate in 2010"]. Bull. Amer. Meteor. Soc., 92 (6), S20-S25, http://doi.org/10.1175/1520-0477-92.6.s1.

Karl, T. R., and Coauthors, 2015: Possible artifacts of data biases in the recent global surface warming hiatus. Science, 348, 1469-1472, http://doi.org/10.1126/science.aaa5632.

Karlsson, K. G., and Coauthors, 2017: CLARA-A2: The second edition of the CM SAF cloud and radiation data record from 34 years of global AVHRR data. Atmos. Chem. Phys., 17, 5809-5828, http://doi.org/10.5194 /acp-17-5809-2017.

Kasischke, E. S., and M. R. Turetsky, 2006: Recent changes in the fire regime across the North American boreal region-Spatial and temporal patterns of burning across Canada and Alaska. Geophys. Res. Lett., 33, L09703, http://doi.org/10.1029/2006GL025677.

— , K. P. O’Neill, N. H. F. French, and L. L. BourgeauChavez, 2000: Controls on patterns of biomass burning in Alaskan boreal forests. Fire, Climate Change, and Carbon Cycling in the Boreal Forest, E. S. Kasischke, and B. J. Stocks, Eds., Springer New York, 173-196, http://doi.org/10.1007 1978-0-387-21629-4_10.

Kaspar, F., K. Zimmermann, and C. Polte-Rudolf, 2014: An overview of the phenological observation network and the phenological database of Germany's national meteorological service (Deutscher Wetterdienst). Adv. Sci. Res., 11, 93-99, http://doi.org/10.5194/asr-11-93-2014.

Kaufman, D. S., and Coauthors, 2004: Holocene thermal maximum in the western Arctic $\left(0-180^{\circ} \mathrm{W}\right)$. Quat. Sci. Rev., 23, 529-560, http://doi.org/10.1016 /j.quascirev.2003.09.007.
Kayano, M. T., and V. E. Kousky, 1999: Intraseasonal (30-60 day) variability in the global tropics: Principal modes and their evolution. Tellus, 51A, 373-386, http://doi.org/10.3402/tellusa.v51i3.13459.

Kearns, E. J., and M. Doutriaux-Boucher, 2015: International effort sustains and develops climate data records. Eos, Earth Space Sci. News, 96, http://doi.org/10.1029/2015EO042185.

Keller, L. M., S. Colwell, M. A. Lazzarra, and R. L. Fogt, 2017: Surface observations [in "State of the Climate in 2016”]. Bull. Amer. Meteor. Soc., 97 (8), S158-S159, http://doi.org/10.1175/2017BAMSStateoftheClimate.1.

Kendon, E. J., S. Blenkinsop, and H. J. Fowler, 2018: When will we detect changes in short-duration precipitation extremes? J. Climate, 31, 2945-2964, http://doi.org/10.1175 /jcli-d-17-0435.1.

Kennedy, J. J., and Coauthors, 2010: How do we know the world has warmed? [in "State of the Climate in 2009”]. Bull. Amer. Meteor. Soc., 91 (7), S26-S27, http://doi.org/10.1175/BAMS-91-7-StateoftheClimate.

_, N. A. Rayner, R. O. Smith, D. E. Parker, and M. Saunby, 2011a: Reassessing biases and other uncertainties in sea surface temperature observations measured in situ since 1850: 1 . Measurement and sampling uncertainties. J. Geophys. Res., 116, D14103, http://doi .org/10.1029/2010JD015218.

$-,-, \ldots, \ldots$, and —,$- 2011 \mathrm{~b}$ : Reassessing biases and other uncertainties in sea surface temperature observations measured in situ since 1850: 2. Biases and homogenization. J. Geophys. Res., 116, D14104, http://doi .org/10.1029/2010JD015220.

Kent, E. C., and Coauthors, 2017: A call for new approaches to quantifying biases in observations of sea surface temperature. Bull. Amer. Meteor. Soc., 98, 1601-1616, http://doi.org/10.1175/bams-d-15-00251.1.

Kępski, D., B. Luks, K. Migała, T. Wawrzyniak, S. Westermann, and B. Wojtuń, 2017: Terrestrial remote sensing of snowmelt in a diverse high-Arctic tundra environment using time-lapse imagery. Remote Sens., 9, 733, http://doi.org/10.3390/rs9070733.

Key, R. M., and Coauthors, 2004: A global ocean carbon climatology: Results from Global Data Analysis Project (GLODAP). Global Biogeochem. Cycles, 18, GB4031, http://doi.org/10.1029/2004GB002247.

— , and Coauthors, 2015: Global Ocean Data Analysis Project, Version 2 (GLO- DAPv2). ORNL/CDIAC-162, ND-P093. http://doi.org/10.3334/CDIAC/OTG.NDP093 _GLODAPv2.

Kiely, G., 1999: Climate change in Ireland from precipitation and streamflow observations. Adv. Water Res., 23, 141-151, http://doi.org/10.1016/S0309-1708(99)00018-4. 
Kiladis, G. N., and K. M. Weickmann, 1992: Circulation anomalies associated with tropical convection during northern winter. Mon. Wea. Rev., 120, 1900-1923, http://doi.org/10.1175/1520-0493(1992)120<1900 :caawtc $>2.0 . c 0 ; 2$.

- K. H. Straub, and P. T. Haertel, 2005: Zonal and vertical structure of the Madden-Julian oscillation. J. Atmos. Sci., 62, 2790-2809, http://doi.org/10.1175/jas3520.1.

—, M. C. Wheeler, P. T. Haertel, K. H. Straub, and P. E. Roundy, 2009: Convectively coupled equatorial waves. Rev. Geophys., 47, RG2003, http://doi .org/10.1029/2008RG000266.

Kim, H., 2017: River discharge [in "State of the Climate in 2016”]. Bull. Amer. Meteor. Soc., 98 (8), S28-S30, http://doi.org/10.1175/2017BAMSStateoftheClimate.1.

— , P. J. F. Yeh, T. Oki, and S. Kanae, 2009: Role of rivers in the seasonal variations of terrestrial water storage over global basins. Geophys. Res. Lett., 36, L17402, http://doi.org/10.1029/2009GL039006.

Kim, J., and K. Paik, 2015: Recent recovery of surface wind speed after decadal decrease: A focus on South Korea. Climate Dyn., 45, 1699-1712, http://doi.org/10.1007 /s00382-015-2546-9.

King, O., D. J. Quincey, J. L. Carrivick, and A. V. Rowan, 2017: Spatial variability in mass loss of glaciers in the Everest region, central Himalayas, between 2000 and 2015. The Cryosphere, 11, 407-426, http://doi.org/10.5194/tc-11-407-2017.

Kinnard, C., C. M. Zdanowicz, D. A. Fisher, E. Isaksson, A. de Vernal, and L. G. Thompson, 2011: Reconstructed changes in Arctic sea ice over the past 1,450 years. Nature, 479, 509-512, http://doi.org/10.1038/nature10581.

Kjellsson, J., and Coauthors, 2015: Model sensitivity of the Weddell and Ross seas, Antarctica, to vertical mixing and freshwater forcing. Ocean Modell., 94, 141-152, http://doi.org/10.1016/j.ocemod.2015.08.003.

Kjøllmoen, B., (Ed.), L. M. Andreassen, H. Elvehøy, M. Jackson, and K. Mlevold, 2017: Glaciological investigations in Norway 2016. NVE Rapport 2017-76, 95+ pp., https://publikasjoner.nve.no/rapport/2017/rapport2017_76.pdf.

Klein Tank, A. M. G., F. Zwiers, and X. Zhang, 2009: Guidelines on analysis of extremes in a changing climate in support of informed decisions for adaptation. World Meteorological Organization Tech. Doc. WMO-TD 1500, WCDMP-No. 72, 52 pp., http://library.wmo.int/pmb_ged /wmo-td_1500_en.pdf.

Klotzbach, P. J., M. A. Saunders, G. D. Bell, and E. S. Blake, 2017: North Atlantic seasonal hurricane prediction. Climate Extremes: Patterns and Mechanisms, S.-Y. S. Wang, J.-H. Yoon, C. C. Funk, and R. R. Gillies, Eds., AGU Geophysical Monograph Series 226, American Geophysical Union and John Wiley \& Sons, Inc., 315-328, http://doi.org/10.1002/9781119068020.ch19.
Knapp, K. R., M. C. Kruk, D. H. Levinson, H. J. Diamond, and C. J. Neumann, 2010: The international best track archive for climate stewardship (IBTrACS). Bull. Amer. Meteor. Soc., 91, 363-376, http://doi.org/10.1175/2009bams2755.1. —, J. A. Knaff, C. R. Sampson, G. M. Riggio, and A. D. Schnapp, 2013: A pressure-based analysis of the historical western North Pacific tropical cyclone intensity record. Mon. Wea. Rev., 141, 2611-2631, http://doi.org/10.1175 /mwr-d-12-00323.1.

Knutson, T. R., and K. M. Weickmann, 1987: 30-60 Day atmospheric oscillations: Composite life cycles of convection and circulation anomalies. Mon. Wea. Rev., 115, 1407-1436, http://doi.org/10.1175 /1520-0493(1987)115<1407:daoclc>2.0.co;2.

Ko, M. K. W., P. A. Newman, S. Reimann, and S. E. Strahan, 2013: Recommended values for steady-state atmospheric lifetimes and their uncertainties. SPARC Report on the Lifetimes of Stratospheric Ozone-Depleting Substances, Their Replacements, and Related Species, SPARC Report No. 6, WCRP-15/2013, 6.1-6.21, www.sparc -climate.org/fileadmin/customer/6_Publications/SPARC _reports_PDF/6_LifetimeReport_Ch6.pdf.

Kobayashi, S., and Coauthors, 2015: The JRA-55 reanalysis: General specifications and basic characteristics. J. Meteor. Soc. Japan, 93, 5-48, http://doi.org/10.2151 /jmsj.2015-001.

Kochtubajda, B., B. Julian, M. D. Flannigan, B. Morrow, and M. D. Greenhough, 2017: The extreme 2016 wildfire in Fort McMurray, Alberta, Canada [in "State of the Climate in 2016”]. Bull. Amer. Meteor. Soc., 98 (8), S176-S177, http://doi.org/10.1175/2017BAMSStateoftheclimate.1.

Kopp, G., and J. L. Lean, 2011: A new, lower value of total solar irradiance: Evidence and climate significance. Geophys. Res. Lett., 38, L01706, http://doi.org/10.1029/2010GL045777.

Kosaka, Y., and H. Nakamura, 2010: Mechanisms of meridional teleconnection observed between a summer monsoon system and a subtropical anticyclone. Part I: The Pacific-Japan pattern. J. Climate, 23, 5085-5108, http:// doi.org/10.1175/2010jcli3413.1.

Kossin, J. P., and D. J. Vimont, 2007: A more general framework for understanding Atlantic hurricane variability and trends. Bull. Amer. Meteor. Soc., 88, 1767-1781, http://doi.org/10.1175/bams-88-11-1767.

Koumoutsaris, S., I. Bey, S. Generoso, and V. Thouret, 2008: Influence of El Niño-Southern Oscillation on the interannual variability of tropospheric ozone in the northern midlatitudes. J. Geophys. Res., 113, D19301, http://doi.org/10.1029/2007JD009753. 
Kousky, V. E., and M. T. Kayano, 1994: Principal modes of outgoing longwave radiation and 250-mb circulation for the South American sector. J. Climate, 7, 11311143, http://doi.org/10.1175/1520-0442(1994)007<1131 :pmoolr $>2.0 . \mathrm{co} ; 2$.

Kratz, D. P., P. W. Stackhouse, Jr., S. K. Gupta, A. C. Wilber, P. Sawaengphokhai, and G. R. McGarragh, 2014: The fast longwave and shortwave flux (FLASHFlux) data product: Single-scanner footprint fluxes. J. Appl. Meteor. Climatol., 53, 1059-1079, http://doi.org/10.1175/jamc-d-13-061.1.

Krishnamurti, T. N., and D. Subrahmanyam, 1982: The 30-50 day mode at $850 \mathrm{mb}$ during MONEX. J. Atmos. Sci., 39, 2088-2095, http://doi.org/10.1175 /1520-0469(1982)039<2088:TDMAMD>2.0.CO;2.

Kurtz, N. T., and S. L. Farrell, 2011: Large-scale surveys of snow depth on Arctic sea ice from Operation IceBridge. Geophys. Res. Lett., 38, L20505, http://doi.org/10.1029/2011GL049216.

Kuttippurath, J., and P. J. Nair, 2017: The signs of Antarctic ozone hole recovery. Sci. Rep., 7, 585, http://doi.org/10.1038/s41598-017-00722-7.

Kwok, R., and D. A. Rothrock, 2009: Decline in Arctic sea ice thickness from submarine and ICESat records: 1958-2008. Geophys. Res. Lett., 36, L15501, http://doi.org/10.1029/2009GL039035.

L'Heureux, M., 2017: ENSO forecasters in offices getting coffee. ENSO Blog, 4 May 2017. www.climate.gov /news-features/blogs/enso/enso-forecasters-offices -getting-coffee.

_ 2018: The Madden Julian Oscillation has been active so far this winter. Here is why it matters. ENSO Blog, 22 February. www.climate.gov/news-features/blogs/enso /madden-julian-oscillation-has-been-active-so-far -winter-here-why-it-matters.

_- and Coauthors, 2017: Observing and predicting the 2015/16 El Niño. Bull. Amer. Meteor. Soc., 98, 1363-1382, http://doi.org/10.1175/bams-d-16-0009.1.

Landschützer, P., and Coauthors, 2013: A neural networkbased estimate of the seasonal to inter-annual variability of the Atlantic Ocean carbon sink. Biogeosciences, 10, 7793-7815, http://doi.org/10.5194/bg-10-7793-2013.

— , N. Gruber, D. C. E. Bakker, and U. Schuster, 2014: Recent variability of the global ocean carbon sink. Global Biogeochem. Cycles, 28, 927-949, http://doi .org/10.1002/2014GB004853.

Southern Ocean carbon sink. Science, 349, 1221-1224, http://doi.org/10.1126/science.aab2620.

Landsea, C. W., and J. L. Franklin, 2013: Atlantic hurricane database uncertainty and presentation of a new database format. Mon. Wea. Rev., 141, 3576-3592, http://doi.org/10.1175/mwr-d-12-00254.1.
— , G. D. Bell, W. M. Gray, and S. B. Goldenberg, 1998: The extremely active 1995 Atlantic hurricane season: Environmental conditions and verification of seasonal forecasts. Mon. Wea. Rev., 126, 11741193, http://doi.org/10.1175/1520-0493(1998)126<1174 :Teaahs $>2.0 . \mathrm{CO} ; 2$.

—_ B. A. Harper, K. Hoarau, and J. A. Knaff, 2006: Can we detect trends in extreme tropical cyclones? Science, 313, 452-454, http://doi.org/10.1126 /science.1128448.

Lau, K.-M., and S. Yang, 2002: Walker circulation. Encyclopedia of Atmospheric Sciences, J. R. Holton, J. Pyle, and J. A. Curry, Eds., Academic Press, 2505-2509

Lau, W. K.-M., and D. E. Waliser, 2012: Intraseasonal Variability in the Atmosphere-Ocean Climate System. Springer, $642 \mathrm{pp}$.

Lawson, B. D., and O. B. Armitage, 2008: Weather Guide for the Canadian Forest Fire Danger Rating System. Natural Resources Canada, Canadian Forest Service, 73 pp., http://cfs.nrcan.gc.ca/bookstore_pdfs/29152.pdf.

Laxon, S. W., and Coauthors, 2013: CryoSat-2 estimates of Arctic sea ice thickness and volume. Geophys. Res. Lett., 40, 732-737, http://doi.org/10.1002/grl.50193.

Le Bras, I. A., I. Yashayaev, and J. M. Toole, 2017: Tracking Labrador Sea Water property signals along the Deep Western Boundary Current. J. Geophys. Res. Oceans, 122, 5348-5366, http://doi.org/10.1002/2017JC012921.

Le Page, M., 2018: Cape Town is about to run out of waterhow did this happen? New Scientist, 3165.

Le Quéré, C., and Coauthors, 2018: Global carbon budget 2017. Earth Syst. Sci. Data, 10, 405-448, http://doi.org/10.5194/essd-10-405-2018.

Le Vine, D. M., E. P. Dinnat, G. S. E. Lagerloef, P. de Matthaeis, S. Abraham, C. Utku, and H. Kao, 2014: Aquarius: Status and recent results. Radio Sci., 49, 709-720, http://doi.org/10.1002/2014RS005505.

Leahy, P. G., and G. Kiely, 2011: Short duration rainfall extremes in Ireland: Influence of climatic variability. Water Resour. Manage., 25, 987-1003, http://doi.org/10.1007 /s11269-010-9737-2.

Lee, H.-T., 2014: Climate algorithm theoretical basis document (C-ATBD): Outgoing longwave radiation (OLR) - daily. NOAA's Climate Data Record (CDR) Program, CDRP-ATBD-0526, 46 pp., wwwl.ncdc.noaa.gov/pub /data/sd s/cdr/CDR s / O utgoing\%20 Longwave \%20Radiation\%20-\%20Daily/AlgorithmDescription.pdf.

Lefohn, A. S., and Coauthors, 2018: Tropospheric Ozone Assessment Report: Global ozone metrics for climate change, human health, and crop/ecosystem research. Elementa, 6 (1), 28, http://doi.org/10.1525/elementa.279. 
Lenaerts, J. T. M., and M. R. van den Broeke, 2012: Modeling drifting snow in Antarctica with a regional climate model: 2. Results. J. Geophys. Res., 117, D05109, http://doi.org/10.1029/2010JD015419.

Lenderink, G., H. Y. Mok, T. C. Lee, and G. J. van Oldenborgh, 2011: Scaling and trends of hourly precipitation extremes in two different climate zones - Hong Kong and the Netherlands. Hydrol. Earth Syst. Sci., 15, 3033-3041, http://doi.org/10.5194/hess-15-3033-2011.

Lenters, J. D., and K. H. Cook, 1997: On the origin of the Bolivian high and related circulation features of the South American climate. J. Atmos. Sci., 54, 656-678, http://doi.org/10.1175/1520-0469(1997)054<0656 :Otootb $>2.0 . \mathrm{CO} ; 2$.

Leuliette, E. W., and J. K. Willis, 2011: Balancing the sea level budget. Oceanography, 24 (2), 122-129, http://doi.org/10.5670/oceanog.2011.32.

Leung, F.-Y. T., J. A. Logan, R. Park, E. Hyer, E. Kasischke, D. Streets, and L. Yurganov, 2007: Impacts of enhanced biomass burning in the boreal forests in 1998 on tropospheric chemistry and the sensitivity of model results to the injection height of emissions. J. Geophys. Res., 112, D10313, http://doi.org/10.1029/2006JD008132.

Levitus, S., and Coauthors, 2012: World ocean heat content and thermosteric sea level change (02000 m), 1955-2010. Geophys. Res. Lett., 39, L10603, http://doi.org/10.1029/2012GL051106.

Li, B., M. Rodell, and J. S. Famiglietti, 2015: Groundwater variability across temporal and spatial scales in the central and northeastern U.S. J. Hydrol., 525, 769-780, http://doi.org/10.1016/j.jhydrol.2015.04.033.

Liang, Q., P. A. Newman, and S. Reimann, Eds., 2016: SPARC Report on the mystery of carbon tetrachloride. SPARC Report No. 7, WCRP-13/2016, 52 pp., www.sparc -climate.org/publications/sparc-reports/sparc-report-no7.

Lieb, G., and A. Kellerer-Pirklbauer, 2018: Gletscherbericht 2016/2017: Sammelbericht über die Gletschermessungen des Österreichischen Alpenvereins im Jahre 2017. Bergauf, 02/2018, 20-29, www.alpenverein.at/portal_wAssets /docs/service/presse/2018/gletscherbericht /Gletscherbericht-im-Mitgliedermagazin-Bergauf-zum -Download-PDF-.pdf.

Liebmann, B., and C. A. Smith, 1996: Description of a complete (interpolated) outgoing longwave radiation dataset. Bull. Amer. Meteor. Soc., 77, 1275-1277.

Lim, E.-P., and H. H. Hendon, 2017: Causes and predictability of the negative Indian Ocean dipole and its impact on La Niña during 2016. Sci. Rep., 7, 12619, http://doi.org/10.1038/s41598-017-12674-z.

Lin, H., G. Brunet, and J. Derome, 2009: An observed connection between the North Atlantic oscillation and the Madden-Julian oscillation. J. Climate, 22, 364-380, http://doi.org/10.1175/2008jcli2515.1.
Lin, I-I, and J. C. L. Chan, 2015: Recent decrease in typhoon destructive potential and global warming implications. Nat. Comm., 6, 7182, http://doi.org/10.1038/ncomms8182. —, C.-C. Wu, I.-F. Pun, and D.-S. Ko, 2008: Upper-ocean thermal structure and the western North Pacific category 5 Typhoons. Part I: Ocean features and the category 5 typhoons' intensification. Mon. Wea. Rev., 136, 3288-3306, http://doi.org/10.1175/2008mwr2277.1.

_- and Coauthors, 2013: An ocean coupling potential intensity index for tropical cyclones. Geophys. Res. Lett., 40, 1878-1882, http://doi.org/10.1002/grl.50091.

— I.-F. Pun, and C.-C. Lien, 2014: "Category-6" Supertyphoon Haiyan in global warming hiatus: Contribution from subsurface ocean warming. Geophys. Res. Lett., 41, 8547-8553, http://doi.org/10.1002/2014GL061281.

Lin, M., L. W. Horowitz, S. J. Oltmans, A. M. Fiore, and S. Fan, 2014: Tropospheric ozone trends at Mauna Loa Observatory tied to decadal climate variability. Nat. Geosci., 7, 136-143, http://doi.org/10.1038/ngeo2066.

— _ — R. Payton, A. M. Fiore, and G. Tonnesen, 2017: US surface ozone trends and extremes from 1980 to 2014: Quantifying the roles of rising Asian emissions, domestic controls, wildfires, and climate. Atmos. Chem. Phys., 17, 2943-2970, http://doi.org/10.5194/acp-17-2943-2017.

Linderholm, H. W., and C. K. Folland, 2017: Summer North Atlantic Oscillation (SNAO) variability on decadal to palaeoclimate time scales. PAGES Magazine, 25 (1), 57-60, http://doi.org/10.22498/pages.25.1.57.

Lindsay, R., and A. Schweiger, 2015: Arctic sea ice thickness loss determined using subsurface, aircraft, and satellite observations. The Cryosphere, 9, 269-283, http://doi.org/10.5194/tc-9-269-2015.

_, D. M. Holland, and R. A. Woodgate, 2004: Halo of low ice concentration observed over the Maud Rise seamount. Geophys. Res. Lett., 31, L13302, http://doi .org/10.1029/2004GL019831.

Linnaeus, C., 1753: Species Plantarum [The Species of Plants]. Laurentius Salvius, 2 vol pp.

Liston, G. E., and C. A. Hiemstra, 2011: The changing cryosphere: Pan-Arctic snow trends (1979-2009). J. Climate, 24, 5691-5712, http://doi.org/10.1175/jcli-d-11-00081.1.

Liu, C., and R. P. Allan, 2018: Unrealistic increases in wind speed explain reduced eastern Pacific heat flux in reanalyses. J. Climate, 31, 2981-2993, http://doi.org/10.1175 /jcli-d-17-0642.1.

Liu, G., and Coauthors, 2014: Reef-scale thermal stress monitoring of coral ecosystems: New $5-\mathrm{km}$ global products from NOAA Coral Reef Watch. Remote Sens., 6, 11579, http://doi.org/10.3390/rs61111579. 
- and Coauthors, 2017: NOAA Coral Reef Watch's 5km Satellite Coral Bleaching Heat Stress Monitoring Product Suite Version 3 and Four-Month Outlook Version 4. Reef Encounter, 32 (1), 39-45, http://coralreefs.org /wp-content/uploads/2014/03/Reef-Encounter-August -2017-FINAL-Lo-Res.pdf.

Liu, He., J. T. Randerson, J. Lindfors, and F. S. Chapin, 2005: Changes in the surface energy budget after fire in boreal ecosystems of interior Alaska: An annual perspective. J. Geophys. Res., 110, D13101, http://doi.org/10.1029/2004JD005158.

Liu, Ho., L. Wang, and K. C. Jezek, 2005: Wavelet-transform based edge detection approach to derivation of snowmelt onset, end and duration from satellite passive microwave measurements. Int. J. Remote Sens., 26, 4639-4660, http://doi.org/10.1080/01431160500213342.

,-- , and ——, 2006: Spatiotemporal variations of snowmelt in Antarctica derived from satellite scanning multichannel microwave radiometer and special sensor microwave imager data (1978-2004). J. Geophys. Res., 111, F01003, http://doi.org/10.1029/2005JF000318.

Liu, W., S.-P. Xie, Z. Liu, and J. Zhu, 2017: Overlooked possibility of a collapsed Atlantic meridional overturning circulation in warming climate. Sci. $A d v ., 3$, e1601666, http://doi.org/10.1126/sciadv.1601666.

Liu, Y. Y., and Coauthors, 2012: Trend-preserving blending of passive and active microwave soil moisture retrievals. Remote Sens. Environ., 123, 280-297, http://doi.org/10.1016/j.rse.2012.03.014.

Loeb, N. G., and Coauthors, 2009: Toward optimal closure of the Earth's top-of-atmosphere radiation budget. J. Climate, 22, 748-766, http://doi.org/10.1175/2008jcli2637.1.

— of-atmosphere radiation variability from satellite observations. Surv. Geophys., 33, 359-385, http://doi.org/10.1007 /s10712-012-9175-1.

_ - and Coauthors, 2018: Clouds and the Earth's Radiant Energy System (CERES) Energy Balanced and Filled (EBAF) Top-of-Atmosphere (TOA) Edition-4.0 Data Product. J. Climate, 31, 895-918, http://doi.org/10.1175 /jcli-d-17-0208.1.

Lozier, M. S., A. C. Dave, J. B. Palter, L. M. Gerber, and R. T. Barber, 2011: On the relationship between stratification and primary productivity in the North Atlantic. Geophys. Res. Lett., 38, L18609, http://doi.org/10.1029/2011GL049414.

— , and Coauthors, 2017: Overturning in the Subpolar North Atlantic Program: A new international ocean observing system. Bull. Amer. Meteor. Soc., 98, 737-752, http://doi.org/10.1175/bams-d-16-0057.1.
Lumpkin, R., and S. Garzoli, 2011: Interannual to decadal changes in the western South Atlantic's surface circulation. J. Geophys. Res., 116, C01014, http://doi.org/10.1029/2010JC006285.

Luo, J.-J., 2017: Indian Ocean dipole [in "State of the Climate in 2016”]. Bull. Amer. Meteor. Soc., 98 (8), S126-S128, http://doi.org/10.1175/2017BAMSStateoftheClimate.1.

—, S. Masson, S. Behera, and T. Yamagata, 2007: Experimental forecasts of the Indian Ocean dipole using a coupled OAGCM. J. Climate, 20, 2178-2190, http://doi.org/10.1175/jcli4132.1.

—, R. Zhang, S. K. Behera, Y. Masumoto, F.-F. Jin, R. Lukas, and T. Yamagata, 2010: Interaction between El Niño and extreme Indian Ocean dipole. J. Climate, 23, 726-742, http://doi.org/10.1175/2009jcli3104.1.

Luthcke, S. B., T. J. Sabaka, B. D. Loomis, A. A. Arendt, J. J. McCarthy, and J. Camp, 2013: Antarctica, Greenland and Gulf of Alaska land-ice evolution from an iterated GRACE global mascon solution. J. Glaciol., 59, 613-631, http://doi.org/10.3189/2013JoG12J147.

Lüthi, D., and Coauthors, 2008: High-resolution carbon dioxide concentration record 650,000-800,000 years before present. Nature, 453, 379-382, http://doi.org/10.1038 /nature06949.

Lyman, J. M., and G. C. Johnson, 2014: Estimating global ocean heat content changes in the upper $1800 \mathrm{~m}$ since 1950 and the influence of climatology choice. J. Climate, 27, 1945-1957, http://doi.org/10.1175/jcli-d-12-00752.1.

Ma, Z., J. Xu, W. Quan, Z. Zhang, W. Lin, and X. Xu, 2016: Significant increase of surface ozone at a rural site, north of eastern China. Atmos. Chem. Phys., 16, 3969-3977, http://doi.org/10.5194/acp-16-3969-2016.

MacCallum, S. N., and C. J. Merchant, 2012: Surface water temperature observations of large lakes by optimal estimation. Can. J. Remote Sens., 38, 25-45, http://doi.org/10.5589/m12-010.

MacFarling Meure, C., and Coauthors, 2006: Law Dome $\mathrm{CO}_{2}, \mathrm{CH}_{4}$ and $\mathrm{N}_{2} \mathrm{O}$ ice core records extended to 2000 years BP. Geophys. Res. Lett, 33, L14810, http://doi.org/10.1029/2006GL026152.

Macias-Fauria, M., S. R. Karlsen, and B. C. Forbes, 2017: Disentangling the coupling between sea ice and tundra productivity in Svalbard. Sci. Rep., 7, 8586, http://doi.org/10.1038/s41598-017-06218-8.

Madden, R. A., and P. R. Julian, 1971: Detection of a 40-50 day oscillation in the zonal wind in the tropical $\mathrm{Pa}$ cific. J. Atmos. Sci., 28, 702-708, http://doi.org/10.1175 /1520-0469(1971)028<0702:doadoi>2.0.co;2.

- and - 1972: Description of global-scale circulation cells in the tropics with a 40-50 day period. J. Atmos. Sci., 29, 1109-1123, http://doi.org/10.1175 /1520-0469(1972)029<1109:dogscc >2.0.co;2. 
- , and - 1994: Observations of the 40-50-day tropical oscillation-A review. Mon. Wea. Rev., 122, 814-837, http://doi.org/10.1175/1520-0493(1994)122<0814 :ootdto $>2.0 . \operatorname{co} ; 2$.

Madsen, H., K. Arnbjerg-Nielsen, and P. S. Mikkelsen, 2009: Update of regional intensity-duration-frequency curves in Denmark: Tendency towards increased storm intensities. Atmos. Res., 92, 343-349, http://doi.org/10.1016 /j.atmosres.2009.01.013.

Magaña, V., J. A. Amador, and S. Medina, 1999: The midsummer drought over Mexico and Central America. J. Climate, 12, 1577-1588, http://doi.org/10.1175 /1520-0442(1999)012<1577:Tmdoma>2.0.CO;2.

Magnin, F., P. Deline, L. Ravanel, J. Noetzli, and P. Pogliotti, 2015: Thermal characteristics of permafrost in the steep alpine rock walls of the Aiguille du Midi (Mont Blanc Massif, $3842 \mathrm{~m}$ a.s.l). The Cryosphere, 9, 109-121, http://doi.org/10.5194/tc-9-109-2015.

Mahoney, A. R., and Coauthors, 2017: Bridging the scientific and indigenous communities to study sea ice change in Arctic Alaska. 2017 Fall Meeting, New Orleans, LA, Amer. Geophys. Union, Abstract C13H-07. https://agu.confex .com/agu/fm17/meetingapp.cgi/Paper/260114.

Mainelli, M., M. DeMaria, L. K. Shay, and G. Goni, 2008: Application of oceanic heat content estimation to operational forecasting of recent Atlantic category 5 hurricanes. Wea. Forecasting, 23, 3-16, http://doi.org/10.1175/2007waf2006111.1.

Makshtas, A. P., I. I. Bolshakova, R. M. Gun, O. L. Jukova, N. E. Ivanov, and S. V. Shutilin, 2011: Climate of the hydrometeorological observatory Tiksi region [in Russian]. Meteor. Geophys. Invest., 2011, 49-74.

Mallick, K., and Coauthors, 2016: Canopy-scale biophysical controls of transpiration and evaporation in the Amazon Basin. Hydrol. Earth Syst. Sci., 20, 4237-4264, http://doi.org/10.5194/hess-20-4237-2016.

Maloney, E. D., and D. L. Hartmann, 2001: The Madden-Julian oscillation, barotropic dynamics, and North Pacific tropical cyclone formation. Part I: Observations. J. Atmos. Sci., 58, 2545-2558, http://doi.org/10.1175 /1520-0469(2001)058<2545:tmjobd>2.0.co;2.

Manabe, S., and F. Möller, 1961: On the radiative equilibrium and heat balance of the atmosphere. Mon. Wea. Rev., 89, 503-532, http://doi.org/10.1175 /1520-0493(1961)089<0503:otreah>2.0.co;2.

Mann, D. H., T. Scott Rupp, M. A. Olson, and P. A. Duffy, 2012: Is Alaska's boreal forest now crossing a major ecological threshold? Arctic, Antarctic, and Alpine Res., 44, 319-331, http://doi.org/10.1657/1938-4246-44.3.319.

Manney, G. L., and Coauthors, 2011: Unprecedented Arctic ozone loss in 2011. Nature, 478, 469-475, http://doi.org/10.1038/nature10556.
Manning, A., and R. F. Keeling, 2006: Global oceanic and land biotic carbon sinks from the Scripps atmospheric oxygen flask sampling network. Tellus, 58B, 95-116, http://doi.org/10.1111/j.1600-0889.2006.00175.x.

Mantua, N. J., and S. R. Hare, 2002: The Pacific Decadal Oscillation. J. Oceanogr., 58, 35-44, http://doi.org/10.1023/a:1015820616384.

,- — - Y. Zhang, J. M. Wallace, and R. C. Francis, 1997: A Pacific interdecadal climate oscillation with impacts on salmon production. Bull. Amer. Meteor. Soc., 78, 10691079, http://doi.org/10.1175/1520-0477(1997)078<1069 :apicow $>2.0$. co;2.

Marengo, J. A., L. M. Alves, R. C. S. Alvala, A. P. Cunha, S. Brito, and O. L. L. Moraes, 2017: Climatic characteristics of the 2010-2016 drought in the semiarid Northeast Brazil región. Ann. Brazilian Acad. Sci., Online, http://doi.org/10.1590/0001-3765201720170206.

Marshall, G. J., 2003: Trends in the southern annular mode from observations and reanalyses. J. Climate, 16, 41344143, http://doi.org/10.1175/1520-0442(2003)016<4134 :titsam>2.0.co;2.

Martens, B., and Coauthors, 2017: GLEAM v3: Satellitebased land evaporation and root-zone soil moisture. Geosci. Model Dev., 10, 1903-1925, http://doi.org/10.5194 /gmd-10-1903-2017.

Martin, A. C., E. S. Jeffers, G. Petrokofsky, I. Myers-Smith, and M. Macias-Fauria, 2017: Shrub growth and expansion in the Arctic tundra: An assessment of controlling factors using an evidence-based approach. Environ. Res. Lett., 12, 085007, http://doi.org/10.1088/1748-9326/aa7989.

Martin, R. V., B. Sauvage, I. Folkins, C. E. Sioris, C. Boone, P. Bernath, and J. Ziemke, 2007: Space-based constraints on the production of nitric oxide by lightning. J. Geophys. Res., 112, D09309, http://doi.org/10.1029/2006JD007831.

Martin, T., W. Park, and M. Latif, 2013: Multi-centennial variability controlled by Southern Ocean convection in the Kiel Climate Model. Climate Dyn., 40, 2005-2022, http://doi.org/10.1007/s00382-012-1586-7.

Martinson, D. G., P. D. Killworth, and A. L. Gordon, 1981: A convective model for the Weddell polynya. J. Phys. Oceanogr., 11, 466-488, http://doi.org/10.1175 /1520-0485(1981)011<0466:Acmftw>2.0.CO;2.

Marzeion, B., J. G. Cogley, K. Richter, and D. Parkes, 2014: Attribution of global glacier mass loss to anthropogenic and natural causes. Science, 345, 919-921, http://doi.org/10.1126/science.1254702.

Maslanik, J., and J. Stroeve, 1999, updated daily: Near-realtime DMSP SSM/I-SSMIS Daily Polar Gridded Sea Ice Concentrations. National Snow and Ice Data Center, nsidc.org/data/docs/daac/nsidc0081_ssmi_nrt_seaice .gd.html. 
- — — C. Fowler, and W. Emery, 2011: Distribution and trends in Arctic sea ice age through spring 2011. Geophys. Res. Lett., 38, L13502, http://doi .org/10.1029/2011GL047735.

Massom, R. A., T. A. Scambos, L. G. Bennetts, P. Reid, V. A. Squire, and S. E. Stammerjohn, 2018: Antarctic ice shelf disintegration triggered by sea ice loss and ocean swell. Nature, 558, 383-389, http://doi.org/10.1038 /s41586-018-0212-1.

Massonnet, F., T. Fichefet, H. Goosse, C. M. Bitz, G. Philippon-Berthier, M. M. Holland, and P. Y. Barriat, 2012: Constraining projections of summer Arctic sea ice. The Cryosphere, 6, 1383-1394, http://doi.org/10.5194 /tc-6-1383-2012.

Mayer, M., K. E. Trenberth, L. Haimberger, and J. T. Fasullo, 2013: The response of tropical atmospheric energy budgets to ENSO. J. Climate, 26, 4710-4724, http://doi.org/10.1175/jcli-d-12-00681.1.

Mazloff, M. R., and Coauthors, 2017: Southern Ocean [in "State of the Climate in 2016"]. Bull. Amer. Meteor. Soc., 97 (8), S166-S167, http://doi.org/10.1175 /2017BAMSStateoftheClimate.1.

McCabe, M. F., A. Ershadi, C. Jimenez, D. G. Miralles, D. Michel, and E. F. Wood, 2016: The GEWEX LandFlux project: Evaluation of model evaporation using towerbased and globally gridded forcing data. Geosci. Model Dev., 9, 283-305, http://doi.org/10.5194/gmd-9-283-2016.

_, and Coauthors, 2017a: The future of Earth observation in hydrology. Hydrol. Earth Syst. Sci., 21, 3879-3914, http://doi.org/10.5194/hess-21-3879-2017.

- , B. Aragon, R. Houborg, and J. Mascaro, 2017b: CubeSats in hydrology: Ultrahigh-resolution insights into vegetation dynamics and terrestrial evaporation. Water Resour. Res., 53, 10,017-10,024, http://doi.org/10.1002/2017WR022240.

McClain, C. R., 2009: A decade of satellite ocean color observations. Annu. Rev. Marine Sci., 1, 19-42, http://doi.org/10.1146/annurev.marine.010908.163650.

McKay, N. P., and D. S. Kaufman, 2014: An extended Arctic proxy temperature database for the past 2,000 years. Sci. Data, 1, 140026, http://doi.org/10.1038/sdata.2014.26.

McNeil, B. I., and R. J. Matear, 2008: Southern Ocean acidification: A tipping point at 450-ppm atmospheric $\mathrm{CO}_{2}$. Proc. Natl. Acad. Sci. USA, 105, 18860-18864, http://doi.org/10.1073/pnas.0806318105.

McVicar, T. R., T. G. Van Niel, L. T. Li, M. L. Roderick, D. P. Rayner, L. Ricciardulli, and R. J. Donohue, 2008: Wind speed climatology and trends for Australia, 1975-2006: Capturing the stilling phenomenon and comparison with near-surface reanalysis output. Geophys. Res. Lett., 35, L20403, http://doi.org/10.1029/2008GL035627.
- , and Coauthors, 2012: Global review and synthesis of trends in observed terrestrial near-surface wind speeds: Implications for evaporation. J. Hydrol., 416-417, 182205, http://doi.org/10.1016/j.jhydrol.2011.10.024.

Mears, C. A., D. K. Smith, L. Ricciardulli, J. Wang, H. Huelsing, and F. J. Wentz, 2018: Construction and uncertainty estimation of a satellite-derived total precipitable water data record over the world's oceans. Earth Space Sci., 5, 197-210, http://doi.org/10.1002/2018EA000363.

Meier, W. N., and Coauthors, 2014: Arctic sea ice in transformation: A review of recent observed changes and impacts on biology and human activity. Rev. Geophys., 52, 185-217, http://doi.org/10.1002/2013RG000431.

Meijers, A. J. S., N. L. Bindoff, and S. R. Rintoul, 2011: Frontal movements and property fluxes: Contributions to heat and freshwater trends in the Southern Ocean. J. Geophys. Res., 116, C08024, http://doi.org/10.1029/2010JC006832.

Mekis, É., L. A. Vincent, M. W. Shephard, and X. Zhang, 2015: Observed trends in severe weather conditions based on humidex, wind chill, and heavy rainfall events in Canada for 1953-2012. Atmos.-Ocean, 53, 383-397, http://doi.org/10.1080/07055900.2015.1086970.

Menemenlis, D., P. Heimbach, C. Hill, T. Lee, A. Nguyen, M. Schodlok, and H. Zhang, 2008: ECCO2: High-resolution global ocean and sea ice data synthesis. Mercator Ocean Quart. Newsletter, No. 31, 13-21, https://ecco2.org /manuscripts/reports/ECCO2_Mercator.pdf.

Menne, M. J., I. Durre, R. S. Vose, B. E. Gleason, and T. G. Houston, 2012: An overview of the global historical climatology network-daily database. J. Atmos. Oceanic Technol., 29, 897-910, http://doi.org/10.1175 /jtech-d-11-00103.1.

Menzel, W. P., R. A. Frey, E. E. Borbas, B. A. Baum, G. Cureton, and N. Bearson, 2016: Reprocessing of HIRS satellite measurements from 1980 to 2015: Development toward a consistent decadal cloud record. J. Appl. Meteor. Climatol., 55, 2397-2410, http://doi.org/10.1175 /jamc-d-16-0129.1.

Merrifield, M. A., 2011: A shift in western tropical Pacific sea level trends during the 1990s. J. Climate, 24, 4126-4138, http://doi.org/10.1175/2011jcli3932.1.

— , P. R. Thompson, and M. Lander, 2012: Multidecadal sea level anomalies and trends in the western tropical Pacific. Geophys. Res. Lett., 39, L13602, http://doi.org/10.1029/2012GL052032.

Meyers, G., P. McIntosh, L. Pigot, and M. Pook, 2007: The years of El Niño, La Niña, and interactions with the tropical Indian Ocean. J. Climate, 20, 2872-2880, http://doi.org/10.1175/jcli4152.1.

Millan, R., J. Mouginot, and E. Rignot, 2017: Mass budget of the glaciers and ice caps of the Queen Elizabeth Islands, Canada, from 1991 to 2015. Environ. Res. Lett., 12, 024016, http://doi.org/10.1088/1748-9326/aa5b04. 
Miller, B. R., and Coauthors, 2010: HFC-23 ( $\left.\mathrm{CHF}_{3}\right)$ emission trend response to $\mathrm{HCFC}-22\left(\mathrm{CHClF}_{2}\right)$ production and recent HFC-23 emission abatement measures. Atmos. Chem. Phys., 10, 7875-7890, http://doi.org/10.5194 /acp-10-7875-2010.

Minnis, P., and Coauthors, 2008: Cloud detection in nonpolar regions for CERES using TRMM VIRS and Terra and Aqua MODIS data. IEEE Trans. Geosci. Remote Sens., 46, 3857-3884, http://doi.org/10.1109/TGRS.2008.2001351.

— clear-sky radiation property dataset from the Advanced Very High Resolution Radiometer (AVHRR). CDRP-ATBD-0826 Rev 1, 159 pp. http://doi.org/10.789/V5HT2M8T.

Miralles, D. G., J. H. Gash, T. R. H. Holmes, R. A. M. de Jeu, and A. J. Dolman, 2010: Global canopy interception from satellite observations. J. Geophys. Res., 115 (D16), D16122, http://doi.org/10.1029/2009JD013530.

—, T. R. H. Holmes, R. A. M. De Jeu, J. H. Gash, A. G. C. A. Meesters, and A. J. Dolman, 2011: Global landsurface evaporation estimated from satellite-based observations. Hydrol. Earth Syst. Sci., 15, 453-469, http://doi.org/10.5194/hess-15-453-2011.

— trends in continental evaporation. Nat. Climate Change, 4, 122-126, http://doi.org/10.1038/nclimate2068.

—, and Coauthors, 2016: The WACMOS-ET project - Part 2: Evaluation of global terrestrial evaporation data sets. $\mathrm{Hy}$ drol. Earth Syst. Sci., 20, 823-842, http://doi.org/10.5194 /hess-20-823-2016.

Miyama, T., J. P. McCreary, T. G. Jensen, J. Loschnigg, S. Godfrey, and A. Ishida, 2003: Structure and dynamics of the Indian-Ocean cross-equatorial cell. Deep-Sea Res. II, 50, 2023-2047, http://doi.org/10.1016 /S0967-0645(03)00044-4.

Mo, K. C., 2000a: Relationships between low-frequency variability in the Southern Hemisphere and sea surface temperature anomalies. J. Climate, 13, 3599-3610, http://doi.org/10.1175/1520-0442(2000)013<3599 :Rblfvi>2.0.CO;2.

— 2000b: The association between intraseasonal oscillations and tropical storms in the Atlantic basin. Mon. Wea. Rev., 128, 4097-4107, http://doi.org/10.1175 /1520-0493(2000)129<4097:tabioa>2.0.co;2.

— lationship between circulation anomaly patterns and tropical convection. J. Geophys. Res., 98, 5103-5113, http://doi.org/10.1029/92JD02952.

Monks, P. S., and Coauthors, 2015: Tropospheric ozone and its precursors from the urban to the global scale from air quality to short-lived climate forcer. Atmos. Chem. Phys., 15, 8889-8973, http://doi.org/10.5194/acp-15-8889-2015.
Montzka, S. A., and Coauthors, 1996: Decline in the tropospheric abundance of halogen from halocarbons: Implications for stratospheric ozone depletion. Science, 272, 1318-1322, http://doi.org/10.1126/science.272.5266.1318.

_ , and Coauthors, 2018: An unexpected and persistent increase in global emissions of ozone-depleting CFC11. Nature, 557 (7705), 413-417, http://doi.org/10.1038 /s41586-018-0106-2.

Morice, C. P., J. J. Kennedy, N. A. Rayner, and P. D. Jones, 2012: Quantifying uncertainties in global and regional temperature change using an ensemble of observational estimates: The HadCRUT4 data set. J. Geophys. Res., 117, D08101, http://doi.org/10.1029/2011JD017187.

Mote, P. W., and Coauthors, 1996: An atmospheric tape recorder: The imprint of tropical tropopause temperatures on stratospheric water vapor. J. Geophys. Res., 101 (D2), 3989-4006, http://doi.org/10.1029/95JD03422.

Mote, T. L., 2007: Greenland surface melt trends 1973-2007: Evidence of a large increase in 2007. Geophys. Res. Lett., 34, L22507, http://doi.org/10.1029/2007GL031976.

Mpelasoka, F., J. L. Awange, and A. Zerihun, 2018: Influence of coupled ocean-atmosphere phenomena on the Greater Horn of Africa droughts and their implications. Sci. Total Environ., 610-611, 691-702, http://doi.org/10.1016 /j.scitotenv.2017.08.109.

Mu, Q., M. Zhao, and S. W. Running, 2013: MODIS Global Terrestrial Evapotranspiration (ET) Product (NASA MOD16A2/A3). Algorithm Theoretical Basis Document, Collection 5.55 pp., https://modis-land.gsfc.nasa.gov/pdf /MOD16ATBD.pdf.

Mühle, J., and Coauthors, 2010: Perfluorocarbons in the global atmosphere: Tetrafluoromethane, hexafluoroethane, and octafluoropropane. Atmos. Chem. Phys., 10, 5145-5164, http://doi.org/10.5194/acp-10-5145-2010.

Mullan, A. B., 2017: Intertropical convergence zones: Pacific [in "State of the Climate in 2016"]. Bull. Amer. Meteor. Soc., 98 (8), S101-S102, http://doi.org/10.1175 /2017BAMSStateoftheClimate.1.

Müller, J., K. Werner, R. Stein, K. Fahl, M. Moros, and E. Jansen, 2012: Holocene cooling culminates in sea ice oscillations in Fram Strait. Quat. Sci. Rev., 47, 1-14, http://doi.org/10.1016/j.quascirev.2012.04.024.

Müller, R., J. U. Grooß, C. Lemmen, D. Heinze, M. Dameris, and G. Bodeker, 2008: Simple measures of ozone depletion in the polar stratosphere. Atmos. Chem. Phys., 8, 251-264, http://doi.org/10.5194/acp-8-251-2008.

Muniche RE, 2016: Topics Geo: Natural catastrophes 2015: Analyses, assessments, positions. 82 pp., www.munichre.com/site/corporate/get/documents _E1273659874/mr/assetpool.shared/Documents 15_Touch/_Publications/302-08875_en.pdf. 
_ 2018: Loss events worldwide 2017: Geographical overview [NatCatSERVICE]. 1 pp., www.munichre.com/site / c or porate/get/params_E9 76667823 _Dattachment/1627370/MunichRe-NatCat-2017-World -Map.pdf.

Münnich, M., and J. D. Neelin, 2005: Seasonal influence of ENSO on the Atlantic ITCZ and equatorial South America. Geophys. Res. Lett., 32, L21709, http://doi.org/10.1029/2005GL023900.

Murphy, B. F., and J. Ribbe, 2004: Variability of southeastern Queensland rainfall and climate indices. Int. J. Climatol., 24, 703-721, http://doi.org/10.1002/joc.1018.

Murray, L. T., J. A. Logan, and D. J. Jacob, 2013: Interannual variability in tropical tropospheric ozone and $\mathrm{OH}$ : The role of lightning. J. Geophys. Res. Atmos., 118, 11,46811,480, http://doi.org/10.1002/jgrd.50857.

Muschinski, T., and J. I. Katz, 2013: Trends in hourly rainfall statistics in the United States under a warming climate. Nat. Climate Change, 3, 577-580, http://doi.org/10.1038 /nclimate1828.

Myers-Smith, I. H., D. S. Hik, and R. Aerts, 2018: Climate warming as a driver of tundra shrubline advance. J. Ecol., 106, 547-560, http://doi.org/10.1111/1365-2745.12817.

Myhre, G., and Coauthors, 2013: Anthropogenic and natural radiative forcing. Climate Change 2013: The Physical Science Basis, T. F. Stocker et al., Eds., Cambridge University Press, 659-740, http://doi.org/10.1017 /CBO9781107415324.018.

Nakazawa, T., and S. Hoshino, 2009: Intercomparison of Dvorak parameters in the tropical cyclone datasets over the western North Pacific. SOLA, 5, 33-36, http://doi.org/10.2151/sola.2009-009.

Nerem, R. S., B. D. Beckley, J. T. Fasullo, B. D. Hamlington, D. Masters, and G. T. Mitchum, 2018: Climate-changedriven accelerated sea-level rise detected in the altimeter era. Proc. Natl. Acad. Sci. USA, 115, 2022-2025, http://doi.org/10.1073/pnas.1717312115.

Neu, J. L., T. Flury, G. L. Manney, M. L. Santee, N. J. Livesey, and J. Worden, 2014: Tropospheric ozone variations governed by changes in stratospheric circulation. Nat. Geosci., 7, 340-344, http://doi.org/10.1038/ngeo2138.

Newchurch, M. J., E.-S. Yang, D. M. Cunnold, G. C. Reinsel, J. M. Zawodny, and J. M. Russell, 2003: Evidence for slowdown in stratospheric ozone loss: First stage of ozone recovery. J. Geophys. Res., 108 (D16), 4507, http://doi.org/10.1029/2003JD003471.

Newman, P. A., J. S. Daniel, D. W. Waugh, and E. R. Nash, 2007: A new formulation of equivalent effective stratospheric chlorine (EESC). Atmos. Chem. Phys., 7, 45374552, http://doi.org/10.5194/acp-7-4537-2007.

_ L. Loy, S. Pawson, and L. R. Lait, 2016: The anomalous change in the QBO in 2015-2016. Geophys. Res. Lett., 43, 8791-8797, http://doi.org/10.1002/2016GL070373.
Nilsen, F., R. Skogseth, J. Vaardal-Lunde, and M. Inall, 2016: A simple shelf circulation model: Intrusion of Atlantic Water on the West Spitsbergen Shelf. J. Phys. Oceanogr., 46, 1209-1230, http://doi.org/10.1175/jpo-d-15-0058.1.

Niquen, M., and M. Bouchon, 2004: Impact of El Niño events on pelagic fisheries in Peruvian waters. Deep-Sea Res. II, 51, 563-574, http://doi.org/10.1016/j.dsr2.2004.03.001.

_ _ _ S. Cahuin, and J. Valdez, 1999: Efectos del fenómeno "El Niño 1997-98" sobre los principales recursos pelágicos en la costa peruana. Rev. Peruana Biol., 6 (3), 85-96, http://doi.org/10.15381/rpb.v6i3.8434.

Nisbet, E. G., and Coauthors, 2016: Rising atmospheric methane: 2007-2014 growth and isotopic shift. Global Biogeochem. Cycles, 30, 1356-1370, http://doi.org/10.1002/2016GB005406.

Nitta, T., 1987: Convective activities in the tropical western Pacific and their impact on the Northern Hemisphere summer circulation. J. Meteor. Soc. Japan, 65, 373-390, http://doi.org/10.2151/jmsj1965.65.3_373.

NOAA, 2015: NOAA declares third ever global coral bleaching event: Bleaching intensifies in Hawaii, high ocean temperatures threaten Caribbean corals. October 8. www.noaanews.noaa.gov/stories2015/100815-noaa -declares-third-ever-global-coral-bleaching-event.html. _ 2017: Global coral bleaching event likely ending: But scientists forecast high ocean temperatures may persist in some areas. June 19. www.noaa.gov/media-release /global-coral-bleaching-event-likely-ending.

Nobre, P., and J. Shukla, 1996: Variations of sea surface temperature, wind stress, and rainfall over the tropical Atlantic and South America. J. Climate, 9, 24642479, http://doi.org/10.1175/1520-0442(1996)009<2464 :vosstw $>2.0 . c 0 ; 2$.

Noetzli , J., H. Christiansen, M. Gugliemin, V. Romanovsky, N. Shiklomanov, S. Smith, and L. Zhao, 2016: Permafrost thermal state [in "State of the Climate in 2015"]. Bull. Amer. Meteor. Soc., 97 (8), S20-S21, http://doi.org /10.1175/2016BAMSStateoftheClimate.1.

Northwest Territories (NWT), 2015: 2014 NWT Fire Season Review Report. 25 pp., www.enr.gov.nt.ca/sites/enr/files /web_pdf_fmd_2014_fire_season_review_report_4 _may_2015.pdf.

Notz, D., and J. Stroeve, 2016: Observed Arctic sea-ice loss directly follows anthropogenic $\mathrm{CO}_{2}$ emission. Science, 354, 747-750, http://doi.org/10.1126/science.aag2345.

O'Reilly, C. M., and Coauthors, 2015: Rapid and highly variable warming of lake surface waters around the globe. Geophys. Res. Lett., 42, 10,773-1,0781, http://doi.org/10.1002/2015GL066235. 
Olander, T. L., and C. S. Velden, 2007: The advanced Dvorak technique: Continued development of an objective scheme to estimate tropical cyclone intensity using geostationary infrared satellite imagery. Wea. Forecasting, 22, 287-298, http://doi.org/10.1175/waf975.1.

Oliver, E. C. J., J. A. Benthuysen, N. L. Bindoff, A. J. Hobday, N. J. Holbrook, C. N. Mundy, and S. E. Perkins-Kirkpatrick, 2017: The unprecedented 2015/16 Tasman Sea marine heatwave. Nat. Comm., 8, 16101, http://doi.org/10.1038 /ncomms16101.

Olsen, A., and Coauthors, 2016: The Global Ocean Data Analysis Project version 2 (GLODAPv2) - an internally consistent data product for the world ocean. Earth Syst. Sci. Data, 8, 297-323, http://doi.org/10.5194/essd -8-297-2016.

Oltmans, S. J., and W. D. Komhyr, 1976: Surface ozone in Antarctica. J. Geophys. Res., 81, 5359-5364, http://doi.org/10.1029/JC081i030p05359.

- , and Coauthors, 2006: Long-term changes in tropospheric ozone. Atmos. Environ., 40, 3156-3173, http://doi.org/10.1016/j.atmosenv.2006.01.029.

Onogi, K., and Coauthors, 2007: The JRA-25 reanalysis. J. Meteor. Soc. Japan, 85, 369-432, http://doi.org/10.2151 /jmsj.85.369.

Orr, J. C., and Coauthors, 2005: Anthropogenic ocean acidification over the twenty-first century and its impact on calcifying organisms. Nature, 437, 681-686, http://doi.org/10.1038/nature04095.

Osborn, T. J., J. Barichivich, I. Harris, G. van der Schrier, and P. D. Jones, 2017: Monitoring global drought using the self-calibrating Palmer drought severity index [in "State of the Climate in 2016"]. Bull. Amer. Meteor. Soc., 98 (8), S32-S33, http://doi.org/10.1175 /2016BAMSStateoftheClimate.1.

Osprey, S. M., and Coauthors, 2016: An unexpected disruption of the atmospheric quasi-biennial oscillation. Science, 353, 1424-1427, http://doi.org/10.1126/science.aah4156.

Overland, J. E., 2009: The case for global warming in the Arctic. Influence of Climate Change on the Changing Arctic and Sub-Arctic Conditions, J. C. J. Nihoul, and A. G. Kostianoy, Eds., Springer Netherlands, 13-23, http://doi.org/10.1007/978-1-4020-9460-6_3.

Pall, P., M. R. Allen, and D. A. Stone, 2007: Testing the Clausius-Clapeyron constraint on changes in extreme precipitation under $\mathrm{CO}_{2}$ warming. Climate Dyn., 28, 351-363, http://doi.org/10.1007/s00382-006-0180-2.

Palmer, M. D., K. Haines, S. F. B. Tett, and T. J. Ansell, 2007: Isolating the signal of ocean global warming. Geophys. Res. Lett., 34, L23610, http://doi.org/10.1029/2007GL031712.

Park, T., and Coauthors, 2016: Changes in growing season duration and productivity of northern vegetation inferred from long-term remote sensing data. Environ. Res. Lett., 11, 084001, http://doi.org/10.1088/1748-9326/11/8/084001.
Parkinson, C. L., 2014: Spatially mapped reductions in the length of the Arctic sea ice season. Geophys. Res. Lett., 41, 4316-4322, http://doi.org/10.1002/2014GL060434.

_- and J. C. Comiso, 2013: On the 2012 record low Arctic sea ice cover: Combined impact of preconditioning and an August storm. Geophys. Res. Lett., 40, 1356-1361, http://doi.org/10.1002/grl.50349.

— highlight new information on the contrasting Arctic and Antarctic sea-ice trends since the late 1970s. Remote Sens. Environ., 183, 198-204, http://doi.org/10.1016 /j.rse.2016.05.020.

Partain Jr., J. L., and Coauthors, 2016: An assessment of the role of anthropogenic climate change in the Alaska fire season of 2015. Bull. Amer. Meteor. Soc., 97 (12), S14-S18, http://doi.org/10.1175/bams-d-16-0149.1.

Paulson, K. S., 2010: Trends in the incidence of rain rates associated with outages on fixed links operating above $10 \mathrm{GHz}$ in the southern United Kingdom. Radio Sci., 45, RS1011, http://doi.org/10.1029/2009RS004193.

Pellichero, V., J.-B. Sallée, S. Schmidtko, F. Roquet, and J.-B. Charrassin, 2017: The ocean mixed layer under Southern Ocean sea-ice: Seasonal cycle and forcing. J. Geophys. Res. Oceans, 122, 1608-1633, http://doi.org/10.1002/2016JC011970.

Peña, M., and M. W. Douglas, 2002: Characteristics of wet and dry spells over the Pacific side of Central America during the rainy season. Mon. Wea. Rev., 130, 30543073, http://doi.org/10.1175/1520-0493(2002)130<3054 :Cowads $>2.0 . \mathrm{CO} ; 2$.

PERMOS, 2007: Permafrost in Switzerland 2002/2003 and 2003/2004. Glaciological Report (Permafrost) No. 4/5, 107 pp., https://sciencesnaturelles.ch /service/publications/53924-permafrost-in-switzerland -2002-2003-and-2003-2004.

— 2016: Permafrost in Switzerland 2010/2011 to 2013/2014. Glaciological Report (Permafrost) No. 12-15 of the Cryospheric Commission of the Swiss Academy of Sciences, 85 pp., www.permos.ch/downloads/permos10-14.pdf.

Peterson, T. C., and R. S. Vose, 1997: An overview of the global historical climatology network temperature database. Bull. Amer. Meteor. Soc., 78, 2837-2849, http://doi.org/10.1175/1520-0477(1997)078<2837 :aootgh $>2.0 . c 0 ; 2$.

Petty, A. A., P. R. Holland, and D. L. Feltham, 2014: Sea ice and the ocean mixed layer over the Antarctic shelf seas. The Cryosphere, 8, 761-783, http://doi.org/10.5194 /tc-8-761-2014.

Pfahl, S., P. A. O'Gorman, and E. M. Fischer, 2017: Understanding the regional pattern of projected future changes in extreme precipitation. Nat. Climate Change, 7, 423-427, http://doi.org/10.1038/nclimate3287. 
Pfeffer, W. T., and Coauthors, 2014: The Randolph Glacier inventory: A globally complete inventory of glaciers. J. Glaciol., 60, 537-552, http://doi.org/10.3189/2014JoG13J176.

Pinker, R. T., X. Niu, and Y. Ma, 2014: Solar heating of the Arctic Ocean in the context of ice-albedo feedback. J. Geophys. Res. Oceans, 119, 8395-8409, http://doi.org/10.1002/2014JC010232.

Pinty, B., 2012: Land surface albedo [in "State of the Climate in 2011"]. Bull. Amer. Meteor. Soc., 93 (7), S52-S53, http://doi.org/10.1175/2012BAMSStateoftheClimate.1.

- , and Coauthors, 2011a: Exploiting the MODIS albedos with the two-stream inversion package (JRC-TIP): 1. Effective leaf area index, vegetation, and soil properties. J. Geophys. Res., 116, D09105, http://doi.org/10.1029/2010JD015372.

— with the two-stream inversion package (JRC-TIP): 2. Fractions of transmitted and absorbed fluxes in the vegetation and soil layers. J. Geophys. Res., 116, D09106, http://doi. org/10.1029/2010JD015373.

Pinzon, J., and C. Tucker, 2014: A non-stationary 1981-2012 AVHRR NDVI3g time series. Remote Sens., 6, 6929, http:// doi.org/10.3390/rs6086929.

Pithan, F., and T. Mauritsen, 2014: Arctic amplification dominated by temperature feedbacks in contemporary climate models. Nat. Geosci., 7, 181-184, http://doi.org/10.1038/ngeo2071.

Polyak, L., and Coauthors, 2010: History of sea ice in the Arctic. Quat. Sci. Rev., 29, 1757-1778, http://doi.org/10.1016 /j.quascirev.2010.02.010.

— S. T. Belt, P. Cabedo-Sanz, M. Yamamoto, and Y.-H. Park, 2016: Holocene sea-ice conditions and circulation at the Chukchi-Alaskan margin, Arctic Ocean, inferred from biomarker proxies. The Holocene, 26, 1810-1821, http://doi.org/10.1177/0959683616645939.

Prather, M. J., and C. D. Holmes, 2017: Overexplaining or underexplaining methane's role in climate change. Proc. Natl. Acad. Sci. USA, 114, 5324-5326, http://doi.org/10.1073/pnas.1704884114.

Price, S., and J. C. Pales, 1963: Mauna Loa observatory: The first five years. Mon. Wea. Rev., 91, 665-680, http://doi.org/10.1175/1520-0493(1963)091<0665:Mlotf $\mathrm{f}>2.3 . \mathrm{CO} ; 2$.

Pryor, S. C., and Coauthors, 2009: Wind speed trends over the contiguous United States. J. Geophys. Res., 114, D14105, http://doi.org/10.1029/2008JD011416.

Prytherch, J., E. C. Kent, S. Fangohr, and D. I. Berry, 2015: A comparison of SSM/I-derived global marine surfacespecific humidity datasets. Int. J. Climatol., 35, 2359-2381, http://doi.org/10.1002/joc.4150.
Pun, I.-F., I. I. Lin, and M.-H. Lo, 2013: Recent increase in high tropical cyclone heat potential area in the western North Pacific Ocean. Geophys. Res. Lett., 40, 4680-4684, http://doi.org/10.1002/grl.50548.

Purkey, S. G., and G. C. Johnson, 2010: Warming of global abyssal and deep Southern Ocean waters between the 1990s and 2000s: Contributions to global heat and sea level rise budgets. J. Climate, 23, 6336-6351, http://doi.org/10.1175/2010jcli3682.1.

$\longrightarrow$, and — 2013: Antarctic bottom water warming and freshening: Contributions to sea level rise, ocean freshwater budgets, and global heat gain. J. Climate, 26, 6105-6122, http://doi.org/10.1175/jcli-d-12-00834.1.

Qiu, B., and S. Chen, 2005: Variability of the Kuroshio Extension jet, recirculation gyre, and mesoscale eddies on decadal time scales. J. Phys. Oceanogr., 35, 2090-2103, http://doi.org/10.1175/jpo2807.1.

Raga, G. B., B. Bracamontes-Cevallos, L. M. Farfán, and R. Romero-Centeno, 2013: Landfalling tropical cyclones on the Pacific coast of Mexico: 1850-2010. Atmosfera, 26, 209-220, http://doi.org/10.1016/S0187-6236(13)71072-5.

Rahmani, A., S. Golian, and L. Brocca, 2016: Multiyear monitoring of soil moisture over Iran through satellite and reanalysis soil moisture products. Int. J. Appl. Earth Obs. Geoinf., 48, 85-95, http://doi.org/10.1016 /j.jag.2015.06.009.

Rahmstorf, S., J. E. Box, G. Feulner, M. E. Mann, A. Robinson, S. Rutherford, and E. J. Schaffernicht, 2015: Exceptional twentieth-century slowdown in Atlantic Ocean overturning circulation. Nat. Climate Change, 5, 475-480, http:// doi.org/10.1038/nclimate2554.

Ramella Pralungo, L., L. Haimberger, A. Stickler, and S. Brönnimann, 2014: A global radiosonde and tracked balloon archive on 16 pressure levels (GRASP) back to 1905 - Part 1: Merging and interpolation to 00:00 and 12:00 GMT. Earth Syst. Sci. Data, 6, 185-200, http://doi.org/10.5194/essd-6-185-2014.

Ramírez, I. J., and F. Briones, 2017: Understanding the El Niño costero of 2017: The definition problem and challenges of climate forecasting and disaster responses. Int. J. Disaster Risk Sci., 8, 489-492, http://doi.org/10.1007 /s13753-017-0151-8.

Randel, W. J., and F. Wu, 1996: Isolation of the ozone QBO in SAGE II data by singular-value decomposition. J. Atmos. Sci., 53, 2546-2559, http://doi.org/10.1175/1520 -0469(1996)053<2546:Iotoqi>2.0.CO;2.

, L. Polvani, F. Wu, D. E. Kinnison, C. Z. Zou, and C. Mears, 2017: Troposphere-stratosphere temperature trends derived from satellite data compared with ensemble simulations from WACCM. J. Geophys. Res. Atmos., 122, 9651-9667, http://doi.org/10.1002/2017JD027158. 
Randerson, J. T., Y. Chen, G. R. van der Werf, B. M. Rogers, and D. C. Morton, 2012: Global burned area and biomass burning emissions from small fires. J. Geophys. Res., 117, G04012, http://doi.org/10.1029/2012JG002128.

Rasmusson, E. M., and T. H. Carpenter, 1982: Variations in tropical sea surface temperature and surface wind fields associated with the Southern Oscillation/El Niño. Mon. Wea. Rev., 110, 354-384, http://doi.org/10.1175 /1520-0493(1982)110<0354:vitsst>2.0.co;2.

Ravishankara, A. R., J. S. Daniel, and R. W. Portmann, 2009: Nitrous oxide $\left(\mathrm{N}_{2} \mathrm{O}\right)$ : The dominant ozone-depleting substance emitted in the 21st century. Science, 326, 123-125, http://doi.org/10.1126/science.1176985.

Ray, E. A., and Coauthors, 2017: Quantification of the SF6 lifetime based on mesospheric loss measured in the stratospheric polar vortex. J. Geophys. Res. Atmos., 122, 4626-4638, http://doi.org/10.1002/2016JD026198.

Raynolds, M. K., D. A. Walker, H. E. Epstein, J. E. Pinzon, and C. J. Tucker, 2012: A new estimate of tundra-biome phytomass from trans-Arctic field data and AVHRR NDVI. Remote Sens. Lett., 3, 403-411, http://doi.org /10.1080/01431161.2011.609188.

Read, L. K., and R. M. Vogel, 2015: Reliability, return periods, and risk under nonstationarity. Water Resour. Res., 51, 6381-6398, http://doi.org/10.1002/2015WR017089.

Reagan, J., T. Boyer, C. Schmid, and R. Locarnini, 2017: Subsurface salinity [in "State of the Climate in 2016"]. Bull. Amer. Meteor. Soc., 98 (8), S72-S75, http://doi.org /10.1175/2017BAMSStateoftheClimate.1.

Reager, J. T., A. S. Gardner, J. S. Famiglietti, D. N. Wiese, A. Eicker, and M.-H. Lo, 2016: A decade of sea level rise slowed by climate-driven hydrology. Science, 351, 699-703, http://doi.org/10.1126/science.aad8386.

Reichle, R. H., and Q. Liu, 2014: Observation-corrected precipitation estimates in GEOS-5. NASA/TM-2014-104606, Vol. 35, 18 pp., http://gmao.gsfc.nasa.gov/pubs.

—, C. S. Draper, Q. Liu, M. Girotto, S. P. P. Mahanama, R. D. Koster, and G. J. M. D. Lannoy, 2017: Assessment of MERRA-2 land surface hydrology estimates. J. Climate, 30, 2937-2960, http://doi.org/10.1175/jcli-d-16-0720.1.

Reid, P. A., S. Stammerjohn, R. A. Massom, J. L. Lieser, S. Barreira, and T. Scambos, 2017: Sea ice extent, concentration and seasonality [in "State of the Climate in 2016”]. Bull. Amer. Meteor. Soc., 97 (8), S163-S166, http://doi.org/10.1175/2017BAMSStateoftheClimate.1.

Remer, L. A., and Coauthors, 2005: The MODIS aerosol algorithm, products, and validation. J. Atmos. Sci., 62, 947-973, http://doi.org/10.1175/jas3385.1.

Reynolds, R. W., N. A. Rayner, T. M. Smith, D. C. Stokes, and W. Wang, 2002: An improved in situ and satellite SST analysis for climate. J. Climate, 15, 1609-1625, http://doi.org/10.1175/1520-0442(2002)015<1609 :aiisas $>2.0 . c 0 ; 2$.
—, T. M. Smith, C. Liu, D. B. Chelton, K. S. Casey, and M. G. Schlax, 2007: Daily high-resolution-blended analyses for sea surface temperature. J. Climate, 20, 5473-5496, http://doi.org/10.1175/2007jcli1824.1.

Rhein, M., and Coauthors, 2013: Observations: Ocean. Climate Change 2013: The Physical Science Basis, T. F. Stocker et al., Eds., Cambridge University Press, 255-316, www.climatechange2013.org/report/full-report/.

Riahi, K., and Coauthors, 2011: RCP 8.5-A scenario of comparatively high greenhouse gas emissions. Climatic Change, 109, 33, http://doi.org/10.1007/s10584-011-0149-y.

Richardson, A. D., J. P. Jenkins, B. H. Braswell, D. Y. Hollinger, S. V. Ollinger, and M.-L. Smith, 2007: Use of digital webcam images to track spring green-up in a deciduous broadleaf forest. Oecologia, 152, 323-334, http://doi.org/10.1007/s00442-006-0657-z.

— , and Coauthors, 2010: Influence of spring and autumn phenological transitions on forest ecosystem productivity. Philos. Trans. Roy. Soc., B365, 3227-3246, http://doi.org/10.1098/rstb.2010.0102.

— across diverse North American biomes using PhenoCam imagery. Sci. Data, 5, 180028, http://doi.org/10.1038 /sdata.2018.28.

— , K. Hufkens, T. Milliman, and S. Frolking, 2018b: Intercomparison of phenological transition dates derived from the PhenoCam Dataset V1.0 and MODIS satellite remote sensing. Sci. Rep., 8, 5679, http://doi.org/10.1038 /s41598-018-23804-6.

Ricker, R., S. Hendricks, V. Helm, H. Skourup, and M. Davidson, 2014: Sensitivity of CryoSat-2 Arctic sea-ice freeboard and thickness on radar-waveform interpretation. The Cryosphere, 8, 1607-1622, http://doi.org/10.5194 /tc-8-1607-2014.

Riddle, E. E., M. B. Stoner, N. C. Johnson, M. L. L'Heureux, D. C. Collins, and S. B. Feldstein, 2013: The impact of the MJO on clusters of wintertime circulation anomalies over the North American region. Climate Dyn., 40, 1749-1766, http://doi.org/10.1007/s00382-012-1493-y.

Rignot, E., G. Casassa, P. Gogineni, W. Krabill, A. Rivera, and R. Thomas, 2004: Accelerated ice discharge from the Antarctic Peninsula following the collapse of Larsen B ice shelf. Geophys. Res. Lett., 31, L18401, http://doi.org/10.1029/2004GL020697.

Ríos, A. F., and Coauthors, 2015: Decadal acidification in the water masses of the Atlantic Ocean. Proc. Natl. Acad. Sci. USA, 112, 9950-9955, http://doi.org/10.1073 /pnas.1504613112.

Riser, S. C., and Coauthors, 2016: Fifteen years of ocean observations with the global Argo array. Nat. Climate Change, 6, 145-153, http://doi.org/10.1038/nclimate2872. 
Risser, M. D., and M. F. Wehner, 2017: Attributable humaninduced changes in the likelihood and magnitude of the observed extreme precipitation during Hurricane Harvey. Geophys. Res. Lett., 44, 12,457-12,464, http://doi.org/10.1002/2017GL075888.

Rödenbeck, C., and Coauthors, 2015: Data-based estimates of the ocean carbon sink variability - first results of the Surface Ocean $\mathrm{CCO}_{2}$ Mapping intercomparison (SOCOM). Biogeosciences, 12, 7251-7278, http://doi.org/10.5194 /bg-12-7251-2015.

Roderick, M. L., L. D. Rotstayn, G. D. Farquhar, and M. T. Hobbins, 2007: On the attribution of changing pan evaporation. Geophys. Res. Lett., 34, L17403, http://doi.org/10.1029/2007GL031166.

Roemmich, D., and J. Gilson, 2009: The 2004-2008 mean and annual cycle of temperature, salinity, and steric height in the global ocean from the Argo Program. Progr. Oceanogr., 82, 81-100, http://doi.org/10.1016 /j.pocean.2009.03.004

- , and - 2011: The global ocean imprint of ENSO. Geophys. Res. Lett., 38, L13606, http://doi .org/10.1029/2011GL047992.

—, J. Church, J. Gilson, D. Monselesan, P. Sutton, and S. Wijffels, 2015: Unabated planetary warming and its ocean structure since 2006. Nat. Climate Change, 5, 240-245, http://doi.org/10.1038/nclimate2513.

Rogers, B. M., A. J. Soja, M. L. Goulden, and J. T. Randerson, 2015: Influence of tree species on continental differences in boreal fires and climate feedbacks. Nat. Geosci., 8 , 228-234, http://doi.org/10.1038/ngeo2352.

Romanovsky, V. E., W. L. Cable, and A. L. Kholodov, 2015: Changes in permafrost and active-layer temperatures along an Alaskan permafrost-ecological transect. Proc. 68th Canadian Geotechnical Conf. and Seventh Canadian Conf. on Permafrost (GEOQuébec 2015), Quebec, Canada, GEOQuébec 2015, Paper 479.

- , and Coauthors, 2017: Changing permafrost and its impacts. Snow, Water, Ice and Permafrost in the Arctic (SWIPA) 2017, Arctic Monitoring and Assessment Programme (AMAP), 65-102, www.amap.no/documents /doc/Snow-Water-Ice-and-Permafrost-in-the-Arctic -SWIPA-2017/1610.

Romps, D. M., J. T. Seeley, D. Vollaro, and J. Molinari, 2014: Projected increase in lightning strikes in the United States due to global warming. Science, 346, 851-854, http://doi.org/10.1126/science.1259100.

Rootzén, H., and R. W. Katz, 2013: Design life level: Quantifying risk in a changing climate. Water Resour. Res., 49, 5964-5972, http://doi.org/10.1002/wrcr.20425.
Rosinski, A., and Coauthors, 2017: Coral Bleaching Recovery Plan: Identifying Management Responses to Promote Coral Recovery in Hawai'i. 47 pp., https://dlnr.hawaii.gov /dar/files/2017/04/Coral_Bleaching_Recovery_Plan _final.pdf.

Rounce, D., C. Watson, and D. McKinney, 2017: Identification of hazard and risk for glacial lakes in the Nepal Himalaya using satellite imagery from 2000-2015. Remote Sens., 9, 654, http://doi.org/10.3390/rs9070654.

Russell, J. L., and Coauthors, 2018: Metrics for the evaluation of the Southern Ocean in coupled climate models and earth system models. J. Geophys. Res. Oceans, http://doi.org/10.1002/2017JC013461.

Russell, J. O., A. Aiyyer, J. D. White, and W. Hannah, 2017: Revisiting the connection between African Easterly Waves and Atlantic tropical cyclogenesis. Geophys. Res. Lett., 44, 587-595, http://doi.org/10.1002/2016GL071236.

Rydbeck, A. V., and E. D. Maloney, 2014: Energetics of East Pacific easterly waves during intraseasonal events. J. Climate, 27, 7603-7621, http://doi.org/10.1175 /jcli-d-14-00211.1.

Sabine, C. L., and Coauthors, 2004: The oceanic sink for anthropogenic $\mathrm{CO}_{2}$. Science, 305, 367-371, http://doi.org/10.1126/science.1097403.

Saha, S., and Coauthors, 2014: The NCEP climate forecast system version 2. J. Climate, 27, 2185-2208, http://doi.org/10.1175/jcli-d-12-00823.1.

Saji, N. H., B. N. Goswami, P. N. Vinayachandran, and T. Yamagata, 1999: A dipole mode in the tropical Indian Ocean. Nature, 401, 360-363, http://doi.org/10.1038/43854.

Salby, M. L., 2008: Involvement of the Brewer-Dobson circulation in changes of stratospheric temperature and ozone. Dyn. Atmos. Oceans, 44, 143-164, http://doi.org/10.1016 /j.dynatmoce.2006.11.002.

Sallée, J.-B., and Coauthors, 2016: Southern Ocean [in "State of the Climate in 2015"]. Bull. Amer. Meteor. Soc., 97 (8), S166-S168, http://doi.org/10.1175 /2016BAMSStateoftheClimate.1.

Sánchez-Lugo, A., C. P. Morice, P. Berrisford, and A. Argüez, 2017: Global surface temperatures [in "State of the Climate in 2016"]. Bull. Amer. Meteor. Soc., 98 (8), S11-S13, http://doi.org/10.1175 /2017BAMSStateoftheClimate.1.

Sapiano, M. R. P., C. W. Brown, S. Schollaert Uz, and M. Vargas, 2012: Establishing a global climatology of marine phytoplankton phenological characteristics. J. Geophys. Res., 117, C08026, http://doi.org/10.1029/2012JC007958.

Sasgen, I., and Coauthors, 2012: Timing and origin of recent regional ice-mass loss in Greenland. Earth Planet. Sci. Lett., 333-334, 293-303, http://doi.org/10.1016 /j.epsl.2012.03.033. 
Sauvage, B., R. V. Martin, A. van Donkelaar, and J. R. Ziemke, 2007: Quantification of the factors controlling tropical tropospheric ozone and the South Atlantic maximum. J. Geophys. Res., 112, D11309, http://doi.org/10.1029/2006JD008008.

Sayer, A. M., L. A. Munchak, N. C. Hsu, R. C. Levy, C. Bettenhausen, and M. J. Jeong, 2014: MODIS Collection 6 aerosol products: Comparison between Aqua's e-Deep Blue, Dark Target, and "merged" data sets, and usage recommendations. J. Geophys. Res. Atmos., 119, 13,965-13,989, http:// doi.org/10.1002/2014JD022453.

Scambos, T. A., C. Hulbe, M. Fahnestock, and J. Bohlander, 2000: The link between climate warming and break-up of ice shelves in the Antarctic Peninsula. J. Glaciol., 46, 516-530, http://doi.org/10.3189/172756500781833043.

,$- \ldots$, and — 2013: Climate-induced ice shelf disintegration in the Antarctic Peninsula. Antarctic Peninsula Climate Variability: Historical and Paleoenvironmental Perspectives, E. Domack, A. Levente, A. Burnet, R. Bindschadler, P. Convey, and M. Kirby, Eds., Antarctic Research Series, Vol. 79, American Geophysical Union, 79-92, http://doi.org/10.1029/AR079p0079.

Schaaf, C. B., and Coauthors, 2002: First operational BRDF, albedo nadir reflectance products from MODIS. Remote Sens. Environ., 83, 135-148, http://doi.org/10.1016/S0034 -4257(02)00091-3.

Schaefer, H., and Coauthors, 2016: A 21st-century shift from fossil-fuel to biogenic methane emissions indicated by ${ }^{13} \mathrm{CH}_{4}$. Science, 352, 80-84, http://doi.org/10.1126 /science.aad2705.

Schamm, K., M. Ziese, A. Becker, P. Finger, A. MeyerChristoffer, B. Rudolf, and U. Schneider, 2013: GPCC First Guess Daily Product at $1.0^{\circ}$ : Near Real-Time First Guess Daily Land-Surface Precipitation from RainGauges based on SYNOP Data http://doi.org/10.5676 /DWD_GPCC/FG_D_100.

Schanze, J. J., R. W. Schmitt, and L. L. Yu, 2010: The global oceanic freshwater cycle: A state-of-theart quantification. J. Mar. Res., 68, 569-595, http://doi.org/10.1357/002224010794657164.

Scharlemann, J. P. W., E. V. J. Tanner, R. Hiederer, and V. Kapos, 2014: Global soil carbon: understanding and managing the largest terrestrial carbon pool. Carbon Manage., 5, 81-91, http://doi.org/10.4155/cmt.13.77.

Schenzinger, V., 2016: Tropical stratosphere variability and extratropical teleconnections, Oxford University, $141 \mathrm{pp}$.

—, S. Osprey, L. Gray, and N. Butchart, 2017: Defining metrics of the Quasi-Biennial Oscillation in global climate models. Geosci. Model Dev., 10, 2157-2168, http://doi.org/10.5194/gmd-10-2157-2017.
Schlosser, E., F. A. Haumann, and M. N. Raphael, 2018: Atmospheric influences on the anomalous 2016 Antarctic sea ice decay. The Cryosphere, 12, 1103-1119, http://doi.org/10.5194/tc-12-1103-2018.

Schmidtko, S., K. J. Heywood, A. F. Thompson, and S. Aoki, 2014: Multidecadal warming of Antarctic waters. Science, 346, 1227-1231, http://doi.org/10.1126/science.1256117.

Schneider, D. P., C. Deser, and Y. Okumura, 2012: An assessment and interpretation of the observed warming of West Antarctica in the austral spring. Climate Dyn., 38, 323-347, http://doi.org/10.1007/s00382-010-0985-X.

Schneider, P., and S. J. Hook, 2010: Space observations of inland water bodies show rapid surface warming since 1985. Geophys. Res. Lett., 37, L22405, http://doi.org/10.1029/2010GL045059.

Schneider, T., T. Bischoff, and G. H. Haug, 2014: Migrations and dynamics of the intertropical convergence zone. Nature, 513, 45-53, http://doi.org/10.1038/nature13636.

Schneider, U., A. Becker, P. Finger, A. Meyer-Christoffer, and M. Ziese, 2015: GPCC Monitoring Product: Near RealTime Monthly Land-Surface Precipitation From RainGauges Based on SYNOP and CLIMAT Data. Deutscher Wetterdienst, http://doi.org/10.5676/DWD_GPCC /MP_M_V5_100.

Schreck, C. J., 2015: Kelvin waves and tropical cyclogenesis: A global survey. Mon. Wea. Rev., 143, 3996-4011, http://doi.org/10.1175/mwr-d-15-0111.1.

- 2016: Convectively coupled Kelvin waves and tropical cyclogenesis in a semi-Lagrangian framework. Mon. Wea. Rev., 144, 4131-4139, http://doi.org/10.1175 /mwr-d-16-0237.1.

— , and J. Molinari, 2011: Tropical cyclogenesis associated with Kelvin waves and the Madden-Julian oscillation. Mon. Wea. Rev., 139, 2723-2734, http://doi.org/10.1175 /mwr-d-10-05060.1.

,-- , waves and tropical cyclogenesis. Mon. Wea. Rev., 140, 774-788, http://doi.org/10.1175/mwr-d-11-00110.1.

—, J. M. Cordeira, and D. Margolin, 2013: Which MJO events affect North American temperatures? Mon. Wea. Rev., 141, 3840-3850, http://doi.org/10.1175 /mwr-d-13-00118.1.

— , K. R. Knapp, and J. P. Kossin, 2014: The impact of best track discrepancies on global tropical cyclone climatologies using IBTrACS. Mon. Wea. Rev., 142, 3881-3899, http://doi.org/10.1175/mwr-d-14-00021.1.

Schröder, M., and Coauthors, 2018: The GEWEX Water Vapor Assessment archive of water vapour products from satellite observations and reanalyses. Earth Syst. Sci. Data, 2018, 1-44, http://doi.org/10.5194/essd-2017-128. 
Schultz, M. G., and Coauthors, 2017: Tropospheric ozone assessment report: Database and metrics data of global surface ozone observations. Elementa, 5, 58, http://doi.org/10.1525/elementa.244.

Schulz, J., and Coauthors, 2017: Satellite data reprocessing at EUMETSAT. ERA-CLIM2 4th General Assembly, Bern, Switzerland, www.ecmwf.int/sites/default/files /medialibrary/2017-12/ERACLIM2_GA4_23_Schulz.pdf.

Schwietzke, S., and Coauthors, 2016: Upward revision of global fossil fuel methane emissions based on isotope database. Nature, 538, 88-91, http://doi.org/10.1038 /nature19797.

Sen Roy, S., 2009: A spatial analysis of extreme hourly precipitation patterns in India. Int. J. Climatol., 29, 345-355, http://doi.org/10.1002/joc.1763.

— and M. Rouault, 2013: Spatial patterns of seasonal scale trends in extreme hourly precipitation in South Africa. Appl. Geogr., 39, 151-157, http://doi.org/10.1016 /j.apgeog.2012.11.022.

SENAMHI, 2017: Monitoreo diario de precipitaciones en la región norte $\mathrm{N}^{\circ} 15$ [Daily monitoring of precipitation in the north region, no.15]. 52 pp., www.senamhi.gob.pe /load/file/02245SENA-5.pdf

Send, U., M. Lankhorst, and T. Kanzow, 2011: Observation of decadal change in the Atlantic meridional overturning circulation using 10 years of continuous transport data. Geophys. Res. Lett., 38, L24606, http://doi.org/10.1029/2011GL049801.

Seo, H., M. Jochum, R. Murtugudde, A. J. Miller, and J. O. Roads, 2008: Precipitation from African easterly waves in a coupled model of the tropical Atlantic. J. Climate, 21, 1417-1431, http://doi.org/10.1175/2007jcli1906.1.

Serinaldi, F., 2015: Dismissing return periods! Stoch. Environ. Res. Risk Assess., 29, 1179-1189, http://doi.org/10.1007 /s00477-014-0916-1.

Serreze, M. C., and R. G. Barry, 2011: Processes and impacts of Arctic amplification: A research synthesis. Global Planet. Change, 77, 85-96, http://doi.org/10.1016 /j.gloplacha.2011.03.004.

Shay, L. K., G. J. Goni, and P. G. Black, 2000: Effects of a warm oceanic feature on Hurricane Opal. Mon. Wea. Rev., 128, 1366-1383, http://doi.org/10.1175 /1520-0493(2000)128<1366:eoawof >2.0.co;2.

Shephard, M. W., E. Mekis, R. J. Morris, Y. Feng, X. Zhang, K. Kilcup, and R. Fleetwood, 2014: Trends in Canadian short-duration extreme rainfall: Including an intensity-duration-frequency perspective. Atmos.-Ocean, 52, 398-417, http://doi.org/10.1080/07055900.2014.969677.

Shepherd, T. G., and Coauthors, 2014: Reconciliation of halogen-induced ozone loss with the total-column ozone record. Nat. Geosci., 7, 443-449, http://doi.org/10.1038 /ngeo2155.
Shi, L., and J. J. Bates, 2011: Three decades of intersatellitecalibrated high-resolution infrared radiation sounder upper tropospheric water vapor. J. Geophys. Res., 116, D04108, http://doi.org/10.1029/2010JD014847.

Shiklomanov, N. I., D. A. Streletskiy, and F. E. Nelson, 2012: Northern Hemisphere component of the global Circumpolar Active Layer Monitoring (CALM) program. Proc. 10th Int. Conf. on Permafrost, Salekhard, Russia, 377-382.

Shiu, C.-J., S. C. Liu, and J.-P. Chen, 2009: Diurnally asymmetric trends of temperature, humidity, and precipitation in Taiwan. J. Climate, 22, 5635-5649, http://doi.org/10.1175/2009jcli2514.1.

Siegel, D. A., S. Maritorena, N. B. Nelson, M. J. Behrenfeld, and C. R. McClain, 2005: Colored dissolved organic matter and its influence on the satellite-based characterization of the ocean biosphere. Geophys. Res. Lett., 32, L20605, http://doi.org/10.1029/2005GL024310.

_- and Coauthors, 2013: Regional to global assessments of phytoplankton dynamics from the SeaWiFS mission. Remote Sens. Environ., 135, 77-91, http://doi.org/10.1016 /j.rse.2013.03.025.

SIF, 2017: Seychelles Islands Foundation [SIF] Newsletter, Issue 52, April. www.sif.sc/sites/default/files/downloads /SIF\%20Newsletter\%20Apr\%202017.pdf.

Simmons, A. J., and P. Poli, 2015: Arctic warming in ERAInterim and other analyses. Quart. J. Roy. Meteor. Soc., 141, 1147-1162, http://doi.org/10.1002/qj.2422.

—, K. M. Willett, P. D. Jones, P. W. Thorne, and D. P. Dee, 2010: Low-frequency variations in surface atmospheric humidity, temperature, and precipitation: Inferences from reanalyses and monthly gridded observational data sets. J. Geophys. Res., 115, D01110, http://doi.org/10.1029/2009JD012442.

—, P. Berrisford, D. P. Dee, H. Hersbach, S. Hirahara, and J. N. Thépaut, 2017: A reassessment of temperature variations and trends from global reanalyses and monthly surface climatological datasets. Quart. J. Roy. Meteor. Soc., 143, 101-119, http://doi.org/10.1002/qj.2949.

Singh, O. P., T. M. Ali Khan, and M. S. Rahman, 2000: Changes in the frequency of tropical cyclones over the north Indian Ocean. Meteor. Atmos. Phys., 75, 11-20, http://doi.org/10.1007/s007030070011.

Sinha, B., and Coauthors, 2018: The accuracy of estimates of the overturning circulation from basinwide mooring arrays. Progr. Oceanogr., 160, 101-123, http://doi.org/10.1016/j.pocean.2017.12.001.

Skliris, N., R. Marsh, S. A. Josey, S. A. Good, C. Liu, and R. P. Allan, 2014: Salinity changes in the World Ocean since 1950 in relation to changing surface freshwater fluxes. Climate Dyn., 43, 709-736, http://doi.org/10.1007 /s00382-014-2131-7. 
Slade, S. A., and E. D. Maloney, 2013: An intraseasonal prediction model of Atlantic and east Pacific tropical cyclone genesis. Mon. Wea. Rev., 141, 1925-1942, http://doi.org/10.1175/mwr-d-12-00268.1.

Smeed, D. A., and Coauthors, 2014: Observed decline of the Atlantic meridional overturning circulation 2004-2012. Ocean Sci., 10, 29-38, http://doi.org/10.5194 los-10-29-2014.

—, G. D. McCarthy, D. Rayner, B. I. Moat, W. E. Johns, M. O. Baringer, and C. S. Meinen, 2017: Atlantic Meridional Overturning Circulation Observed by the RAPID-MOCHA-WBTS (RAPID-Meridional Overturning Circulation and Heatflux Array-Western Boundary Time Series) Array at $26^{\circ} \mathrm{N}$ From 2004 to 2017. British Oceanographic Data Centre-Natural Environment Research Council, http://doi.org/10.5285/cfcm.

— a state of reduced overturning. Geophys. Res. Lett., 45, 1527-1533, http://doi.org/10.1002/2017GL076350.

Smith, S. L., A. G. Lewkowicz, C. Duchesne, and M. Ednie, 2015: Variability and change in permafrost thermal state in northern Canada. Proc. 68th Canadian Geotechnical Conf. and Seventh Canadian Conf. on Permafrost (GEOQuébec 2015), Quebec, Canada, GEOQuébec 2015, Paper 237.

- J. Chartrand, C. Duchesne, and M. Ednie, 2017: Report on 2016 field activities and collection of ground thermal and active layer data in the Mackenzie Corridor, Northwest Territories. Geological Survey of Canada, Open File 8303, 96 pp. http://doi.org/10.4095/306212.

Smith, T. M., R. W. Reynolds, T. C. Peterson, and J. Lawrimore, 2008: Improvements to NOAA's historical merged land-ocean surface temperature analysis (1880-2006). J. Climate, 21, 2283-2296, http://doi.org/10.1175/2007jcli2100.1.

Solomon, S., and Coauthors, 2017: Mirrored changes in Antarctic ozone and stratospheric temperature in the late 20 th versus early 21 st centuries. J. Geophys. Res. Atmos., 122, 8940-8950, http://doi.org/10.1002/2017JD026719.

Song, J.-J., Y. Wang, and L. Wu, 2010: Trend discrepancies among three best track data sets of western North Pacific tropical cyclones. J. Geophys. Res., 115, D12128, http://doi.org/10.1029/2009JD013058.

Sparks, T. H., and R. J. Smithers, 2002: Is spring getting earlier? Weather, 57 (5), 157-166, http://doi.org/10.1002 /wea.6080570504.

- , and J. Lines, 2008: Chapters in the Life of Robert Marsham (1708-1797). St. Margaret's Church, Stratton Strawless, $64 \mathrm{pp}$.

— H. Q. P. Crick, D. Bellamy, and C. Mason, 1998: Spring 1998: A summary of the first pilot year of a revived UK phenological network. Brit. Wildlife, 10, 77-81.
Spence, J. M., M. A. Taylor, and A. A. Chen, 2004: The effect of concurrent sea-surface temperature anomalies in the tropical Pacific and Atlantic on Caribbean rainfall. Int. J. Climatol., 24, 1531-1541, http://doi.org/10.1002/joc.1068.

Spielhagen, R. F., and Coauthors, 2011: Enhanced modern heat transfer to the Arctic by warm Atlantic water. Science, 331, 450-453, http://doi.org/10.1126 /science.1197397.

Spreen, G., L. Kaleschke, and G. Heygster, 2008: Sea ice remote sensing using AMSR-E $89-\mathrm{GHz}$ channels. J. Geophys. Res., 113, C02S03, http://doi.org/10.1029 /2005JC003384.

St. John, K., 2008: Cenozoic ice-rafting history of the central Arctic Ocean: Terrigenous sands on the Lomonosov Ridge. Paleoceanography, 23, PA1S05, http://doi.org/10.1029/2007PA001483.

Stackhouse, P. W., D. P. Kratz, G. R. McGarragh, S. K. Gupta, and E. B. Geier, 2006: Fast longwave and shortwave radiative flux (FLASHFlux) products from CERES and MODIS measurements. Proc. 12th Conf. Atmospheric Radiation, Madison, WI, Amer. Meteor. Soc., P1.10. https://ams.confex.com/ams/pdfpapers/113479.pdf.

— , T. Wong, D. P. Kratz, P. Sawaengphokhai, A. C. Wiber, S. K. Gupta, and N. G. Loeb, 2016: Earth radiation budget at top-of-atmosphere [in "State of the Climate in 2015”]. Bull. Amer. Meteor. Soc., 97 (8), S41-S43, http://doi.org/10.1175/2016BAMSStateoftheClimate.1.

Stammerjohn, S. E., and T. Scambos, Eds., 2017: Antarctica [in "State of the Climate in 2016"]. Bull. Amer. Meteor. Soc., 98 (8), S155-S172, http://doi.org/10.1175 /2017BAMSStateoftheClimate.1.

—, D. G. Martinson, R. C. Smith, X. Yuan, and D. Rind, 2008: Trends in Antarctic annual sea ice retreat and advance and their relation to El Niño-Southern Oscillation and southern annular mode variability. J. Geophys. Res., 113, C03S90, http://doi.org/10.1029/2007JC004269.

Stein, R., K. Fahl, and J. Müller, 2012: Proxy reconstruction of Cenozoic Arctic Ocean sea-ice history - From IRD to $\mathrm{IP}_{25}$. Polarforschung, 82, 37-71, http://epic.awi .de/31715/1/Polarforschung_82-1_37-71.pdf.

,-- I. Schade, A. Manerung, S. Wassmuth, F. Niessen, and S. I. Nam, 2017: Holocene variability in sea ice cover, primary production, and Pacific-Water inflow and climate change in the Chukchi and East Siberian Seas (Arctic Ocean). J. Quat. Sci., 32, 362-379, http://doi.org/10.1002/jqs.2929.

Steinbrecht, W., and Coauthors, 2017: An update on ozone profile trends for the period 2000 to 2016. Atmos. Chem. Phys., 17, 10,675-10,690, http://doi.org/10.5194 /acp-17-10675-2017. 
Stengel, M., and Coauthors, 2017: Cloud property datasets retrieved from AVHRR, MODIS, AATSR and MERIS in the framework of the Cloud_cci project. Earth Syst. Sci. Data, 9, 881-904, http://doi.org/10.5194/essd-9-881-2017. Stevenson, S. N., K. L. Corbosiero, M. DeMaria, and J. L. Vigh, 2018: A 10-year survey of tropical cyclone inner-core lightning bursts and their relationship to intensity change. Wea. Forecasting, 33, 23-36, http://doi.org/10.1175/waf-d-17-0096.1.

Stickley, C. E., K. St John, N. Koç, R. W. Jordan, S. Passchier, R. B. Pearce, and L. E. Kearns, 2009: Evidence for middle Eocene Arctic sea ice from diatoms and ice-rafted debris. Nature, 460, 376-379, http://doi.org/10.1038/nature08163. Strahan, S. E., and A. R. Douglass, 2018: Decline in Antarctic ozone depletion and lower stratospheric chlorine determined from Aura microwave limb sounder observations. Geophys. Res. Lett., 45, 382-390, http://doi.org/10.1002/2017GL074830.

,-- , P. A. Newman, and S. D. Steenrod, 2014: Inorganic chlorine variability in the Antarctic vortex and implications for ozone recovery. J. Geophys. Res. Atmos., 119, 14,098-14,109, http://doi.org/10.1002/2014JD022295.

Streletskiy, D. A., and Coauthors, 2017: Cryosphere: Permafrost thermal state [in "State of the Climate in 2016"]. Bull. Amer. Meteor. Soc., 98 (8), S19-S21, http://doi.org /10.1175/2017BAMSStateoftheClimate.1.

Stroeve, J., M. M. Holland, W. Meier, T. Scambos, and M. Serreze, 2007: Arctic sea ice decline: Faster than forecast. Geophys. Res. Lett., 34, L09501, http://doi.org/10.1029/2007GL029703.

Stroh, J. N., G. Panteleev, S. Kirillov, M. Makhotin, and N. Shakhova, 2015: Sea-surface temperature and salinity product comparison against external in situ data in the Arctic Ocean. J. Geophys. Res. Oceans, 120, 7223-7236, http://doi.org/10.1002/2015JC011005.

Stubenrauch, C. J., and Coauthors, 2013: Assessment of global cloud datasets from satellites: Project and database initiated by the GEWEX Radiation Panel. Bull. Amer. Meteor. Soc., 94, 1031-1049, http://doi.org/10.1175 /bams-d-12-00117.1.

Stuecker, M. F., C. M. Bitz, and K. C. Armour, 2017: Conditions leading to the unprecedented low Antarctic sea ice extent during the 2016 austral spring season. Geophys. Res. Lett., 44 (17), 9008-9019, http://doi.org/10.1002/2017GL074691.

Sudo, K., and M. Takahashi, 2001: Simulation of tropospheric ozone changes during 1997-1998 El Niño: Meteorological impact on tropospheric photochemistry. Geophys. Res. Lett., 28, 4091-4094, http://doi.org/10.1029/2001GL013335.
Sullivan, A., 2017: On dinghies and jet skis, volunteer flotilla comes to Houston's rescue. Reuters, 1 September. www.reuters.com/article/us-storm-harvey-rescuers /on-dinghies-and-jet-skis-volunteer-flotilla-comes-to -houstons-rescue-idUSKCN1BC3S0.

Sun, L., and Coauthors, 2016: Significant increase of summertime ozone at Mount Tai in central eastern China. Atmos. Chem. Phys., 16, 10,637-10,650, http://doi.org/10.5194/acp-16-10637-2016.

Sun, W., P. Hess, and B. Tian, 2014: The response of the equatorial tropospheric ozone to the Madden-Julian Oscillation in TES satellite observations and CAM-chem model simulation. Atmos. Chem. Phys., 14, 11,775-11,790, http://doi.org/10.5194/acp-14-11775-2014.

Sutton, A. J., R. Wanninkhof, C. L. Sabine, R. A. Feely, M. F. Cronin, and R. A. Weller, 2017: Variability and trends in surface seawater $p \mathrm{CO}_{2}$ and $\mathrm{CO}_{2}$ flux in the Pacific Ocean. Geophys. Res. Lett, 44, 5627-5636, http://doi.org/10.1002/2017GL073814.

Swart, S., S. Speich, I. J. Ansorge, and J. R. E. Lutjeharms, 2010: An altimetry-based gravest empirical mode south of Africa: 1. Development and validation. J. Geophys. Res., 115, C03002, http://doi.org/10.1029/2009JC005299.

Sweet, W. V., J. Park, J. J. Marra, C. Zervas, and S. Gill, 2014: Sea level rise and nuisance flood frequency changes around the United States. NOAA Tech. Rep. NOS CO-OPS 73, 58 pp., https://tidesandcurrents.noaa.gov /publications/NOAA_Technical_Report_NOS _COOPS_073.pdf.

Swiss Academy of Sciences, 2017: Rekordverdächtige Verluste der Schweizer Gletscher im Sommer 2017 [Recordbreaking losses of Swiss glaciers in the summer of 2017]. October 20.

Syafrina, A. H., M. D. Zalina, and L. Juneng, 2015: Historical trend of hourly extreme rainfall in Peninsular Malaysia. Theor. Appl. Climatol., 120, 259-285, http://doi.org/10.1007/s00704-014-1145-8.

Takahashi, K., 2005: The annual cycle of heat content in the Peru Current region. J. Climate, 18, 4937-4954, http://doi.org/10.1175/jcli3572.1.

— linear El Niño regimes. Climate Dyn., 46, 1627-1645, http://doi.org/10.1007/s00382-015-2665-3.

— Niño in 1925 in the far-eastern Pacific. Climate Dyn., http://doi.org/10.1007/s00382-017-3702-1.

Takahashi, T., S. C. Sutherland, and A. Kozyr, 2017: Global Ocean Surface Water Partial Pressure of $\mathrm{CO}_{2}$ Database: Measurements Performed During 1957-2017 (LDEO Database Version 2017) (NCEI Accession 0160492). Version Version 6.6. NOAA National Centers for Environmental Information, http://doi.org/10.3334/CDIAC /OTG.NDP088(V2015). 
Takala, M., and Coauthors, 2011: Estimating Northern Hemisphere snow water equivalent for climate research through assimilation of space-borne radiometer data and ground-based measurements. Remote Sens. Environ., 115, 3517-3529, http://doi.org/10.1016/j.rse.2011.08.014.

Tang, B. H., and J. D. Neelin, 2004: ENSO Influence on Atlantic hurricanes via tropospheric warming. Geophys. Res. Lett., 31, L24204, http://doi.org/10.1029/2004GL021072.

Tans, P., 2009: An accounting of the observed increase in oceanic and atmospheric $\mathrm{CO}_{2}$ and an outlook for the future. Oceanography, 22 (4), 26-35, http://doi.org/10.5670/oceanog.2009.94.

Tanskanen, A., A. Arola, and J. Kujanpaa, 2003: Use of the moving time-window technique to determine surface albedo from TOMS reflectivity data. Proc. SPIE, 4896, 239-250, http://doi.org/10.1117/12.483407.

Tapley, B. D., S. Bettadpur, J. C. Ries, P. F. Thompson, and M. M. Watkins, 2004: GRACE measurements of mass variability in the Earth system. Science, 305, 503-505, http://doi.org/10.1126/science.1099192.

Taylor, M. A., D. B. Enfield, and A. A. Chen, 2002: Influence of the tropical Atlantic versus the tropical Pacific on Caribbean rainfall. J. Geophys. Res., 107, 3127, http://doi.org/10.1029/2001JC001097.

Tedesco, M., 2009: Assessment and development of snowmelt retrieval algorithms over Antarctica from K-band spaceborne brightness temperature (1979-2008). Remote Sens. Environ., 113, 979-997, http://doi.org/10.1016/j.rse.2009.01.009.

— arctic melt record through 2009 and its linkages to high-latitude and tropical climate variability. Geophys. Res. Lett., 36, L18502, http://doi.org/10.1029/2009GL039186.

—, X. Fettweis, T. Mote, J. Wahr, P. Alexander, J. E. Box, and B. Wouters, 2013: Evidence and analysis of 2012 Greenland records from spaceborne observations, a regional climate model and reanalysis data. The Cryosphere, 7, 615-630, http://doi.org/10.5194 /tc-7-615-2013.

—, and Coauthors, 2017: Greenland ice sheet. Arctic Report Card 2017, NOAA's Arctic Program, various paging. www.arctic.noaa.gov/Report-Card /Report-Card-2017/ArtMID/7798/ArticleID/697 /Greenland-Ice-Sheet.

Templ, B., and Coauthors, 2018: Pan European Phenological database (PEP725): A single point of access for European data. Int. J. Biometeor., http://doi.org/10.1007/s00484-018-1512-8.
Teng, W.-H., C.-Y. Huang, S.-P. Ho, Y.-H. Kuo, and X.J. Zhou, 2013: Characteristics of global precipitable water in ENSO events revealed by COSMIC measurements. J. Geophys. Res. Atmos., 118, 8411-8425, http://doi.org/10.1002/jgrd.50371.

Thackeray, S. J., P. A. Henrys, H. Feuchtmayr, I. D. Jones, S. C. Maberly, and I. J. Winfield, 2013: Food web de-synchronization in England's largest lake: An assessment based on multiple phenological metrics. Global Change Biol., 19, 3568-3580, http://doi.org/10.1111/gcb.12326.

Thompson, D. W. J., S. Solomon, P. J. Kushner, M. H. England, K. M. Grise, and D. J. Karoly, 2011: Signatures of the Antarctic ozone hole in Southern Hemisphere surface climate change. Nat. Geosci., 4, 741-749, http://doi.org/10.1038/ngeo1296.

Thompson, P. R., C. G. Piecuch, M. A. Merrifield, J. P. McCreary, and E. Firing, 2016: Forcing of recent decadal variability in the equatorial and north Indian Ocean. J. Geophys. Res. Oceans, 121, 6762-6778, http://doi.org/10.1002/2016JC012132.

Thorne, P. W., and Coauthors, 2018: Towards a global land surface climate fiducial reference measurements network. Int. J. Climatol., http://doi.org/10.1002 /joc.5458.

Timbal, B., and W. Drosdowsky, 2013: The relationship between the decline of Southeastern Australian rainfall and the strengthening of the subtropical ridge. Int. J. Climatol., 33, 1021-1034, http://doi.org/10.1002/joc.3492.

Timmermans, M. L., 2015: The impact of stored solar heat on Arctic sea ice growth. Geophys. Res. Lett., 42, 6399-6406, http://doi.org/10.1002/2015GL064541.

—, 2017: Sea surface temperature [in "State of the Climate in 2016"]. Bull. Amer. Meteor. Soc., 98 (8), S135-S136, http://doi.org/10.1175 /2017BAMSStateoftheClimate.1.

—-, and Coauthors, 2013: Ocean temperature and salinity [in "State of the Climate in 2012"]. Bull. Amer. Meteor. Soc., 94 (8), S128-S130, http://doi.org /10.1175/2013BAMSStateoftheClimate.1.

Torralba, V., J. D.-R. Francisco, and G.-R. Nube, 2017: Uncertainty in recent near-surface wind speed trends: A global reanalysis intercomparison. Environ. Res. Lett., 12, 114019, http://doi.org/10.1088 /1748-9326/aa8a58.

Trenberth, K. E., A. Dai, R. M. Rasmussen, and D. B. Parsons, 2003: The changing character of precipitation. Bull. Amer. Meteor. Soc., 84, 1205-1217, http://doi.org/10.1175/bams-84-9-1205. 
Trepte, Q. Z., P. Minnis, C. R. Trepte, S. Sun-Mack, and R. Brown, 2010: Improved cloud detection in CERES edition 3 algorithm and comparison with the CALIPSO vertical feature mask. Proc. 13th Conf. Atmospheric Radiation and Cloud Physics, Portland, OR, Amer. Meteor. Soc., JP1.32.

Trewin, B., 2013: A daily homogenized temperature data set for Australia. Int. J. Climatol., 33, 1510-1529, http://doi.org/10.1002/joc.3530.

Tschudi, M., C. Fowler, J. Maslanik, and J. Stroeve, 2010: Tracking the movement and changing surface characteristics of Arctic sea ice. IEEE J. Sel. Topics Appl. Earth Obs. Remote Sens., 3, 536-540, http://doi.org/10.1109/JSTARS.2010.2048305.

,$- \ldots$, and —_ 2015: EASE-Grid Sea Ice Age, Version 2. National Snow and Ice Data Center, http://doi. org/10.5067/1UQJWCYPVX61.

— , J. Stroeve, and J. Stewart, 2016: Relating the age of Arctic sea ice to its thickness, as measured during NASA's ICESat and IceBridge campaigns. Remote Sens., 8, 457, http://doi.org/10.3390/rs8060457.

Turetsky, M. R., B. Benscoter, S. Page, G. Rein, G. R. van der Werf, and A. Watts, 2015: Global vulnerability of peatlands to fire and carbon loss. Nat. Geosci., 8 , 11-14, http://doi.org/10.1038/ngeo2325.

Turner, J., and J. Comiso, 2017: Solve Antarctica's sea-ice puzzle. Nature, 547, 275-277, http://doi.org/10.1038/547275a.

—, T. Phillips, G. J. Marshall, J. S. Hosking, J. O. Pope, T. J. Bracegirdle, and P. Deb, 2017: Unprecedented springtime retreat of Antarctic sea ice in 2016. Geophys. Res. Lett., 44, 6868-6875, http://doi.org/10.1002/2017GL073656.

Uhlhorn, E. W., and P. G. Black, 2003: Verification of remotely sensed sea surface winds in hurricanes. J. Atmos. Oceanic Technol., 20, 99-116, http://doi.org/10.1175/1520-0426(2003)020<0099 :Vorsss $>2.0 . \mathrm{CO} ; 2$.

UN General Assembly, 2007: United Nations Declaration on the Rights of Indigenous Peoples : resolution / adopted by the General Assembly, 2 October 2007, A/RES/61/295. United Nations. Accessed 15 February 2018. www.refworld.org/docid/471355a82.html.

Vallebona, C., E. Pellegrino, P. Frumento, and E. Bonari, 2015: Temporal trends in extreme rainfall intensity and erosivity in the Mediterranean region: A case study in southern Tuscany, Italy. Climatic Change, 128, 139-151, http://doi.org/10.1007/s10584 -014-1287-9.
Van As, D., R. S. Fausto, J. Cappelen, R. S. W. Van de Wal, R. J. Braithwaite, H. Machguth, and PROMICE project team, 2016: Placing Greenland ice sheet ablation measurements in a multi-decadal context. Geol. Surv. Denmark Greenland Bull. 35, 71-74 pp., www.geus.dk/DK/publications/geol-survey-dk-gl -bull/35/Documents/nr35_p71-74.pdf.

van de Wal, R. S. W., W. Boot, C. J. P. P. Smeets, H. Snellen, M. R. van den Broeke, and J. Oerlemans, 2012: Twenty-one years of mass balance observations along the K-transect, West Greenland. Earth Syst. Sci. Data, 4, 31-35, http://doi.org/10.5194/essd-4-31-2012.

van den Broeke, M., 2005: Strong surface melting preceded collapse of Antarctic Peninsula ice shelf. Geophys. Res. Lett., 32, L12815, http://doi.org/10.1029/2005GL023247.

van der A, R. J., M. A. F. Allaart, and H. J. Eskes, 2015: Extended and refined multi sensor reanalysis of total ozone for the period 1970-2012. Atmos. Meas. Tech., 8, 3021-3035, http://doi.org/10.5194 /amt-8-3021-2015.

van der Schrier, G., J. Barichivich, K. R. Briffa, and P. D. Jones, 2013: A scPDSI-based global data set of dry and wet spells for 1901-2009. J. Geophys. Res. Atmos., 118, 4025-4048, http://doi.org/10.1002/jgrd.50355.

van der Werf, G. R., and Coauthors, 2017: Global fire emissions estimates during 1997-2016. Earth Syst. Sci. Data, 9, 697-720, http://doi.org/10.5194 lessd-9-697-2017.

Van Oldenborgh, G. J., and Coauthors, 2017: Attribution of extreme rainfall from Hurricane Harvey, August 2017. Environ. Res. Lett., 12, 124009 , http://doi.org/10.1088/1748-9326/aaa343.

Vare, L. L., G. Massé, T. R. Gregory, C. W. Smart, and S. T. Belt, 2009: Sea ice variations in the central Canadian Arctic Archipelago during the Holocene. Quat. Sci. Rev., 28, 1354-1366, http://doi.org/10.1016 /j.quascirev.2009.01.013.

Vautard, R., J. Cattiaux, P. Yiou, J.-N. Thepaut, and P. Ciais, 2010: Northern Hemisphere atmospheric stilling partly attributed to an increase in surface roughness. Nat. Geosci., 3, 756-761, http://doi.org/10.1038 /ngeo979.

Vecchi, G. A., and B. J. Soden, 2007: Effect of remote sea surface temperature change on tropical cyclone potential intensity. Nature, 450, 1066-1070, http://doi.org/10.1038/nature06423.

Velicogna, I., T. C. Sutterley, and M. R. van den Broeke, 2014: Regional acceleration in ice mass loss from Greenland and Antarctica using GRACE time-variable gravity data. Geophys. Res. Lett., 41, 8130-8137, http://doi.org/10.1002/2014GL061052. 
Ventrice, M. J., C. D. Thorncroft, and M. A. Janiga, 2012a: Atlantic tropical cyclogenesis: A three-way interaction between an African easterly wave, diurnally varying convection, and a convectively coupled atmospheric Kelvin wave. Mon. Wea. Rev., 140, 1108-1124, http://doi.org/10.1175/mwr-d-11-00122.1.

$\longrightarrow, \ldots$, and C. J. Schreck, 2012b: Impacts of convectively coupled Kelvin waves on environmental conditions for Atlantic tropical cyclogenesis. Mon. Wea. Rev., 140, 2198-2214, http://doi.org/10.1175 /mwr-d-11-00305.1.

Veraverbeke, S., B. M. Rogers, M. L. Goulden, R. R. Jandt, C. E. Miller, E. B. Wiggins, and J. T. Randerson, 2017: Lightning as a major driver of recent large fire years in North American boreal forests. Nat. Climate Change, 7, 529-534, http://doi.org/10.1038 /nclimate3329.

Vickers, H., K. A. Høgda, S. Solbø, S. R. Karlsen, H. Tømmervik, R. Aanes, and B. B. Hansen, 2016: Changes in greening in the high Arctic: insights from a 30 year AVHRR max NDVI dataset for Svalbard. Environ. Res. Lett., 11, 105004, http://doi.org/10.1088/1748-9326/11/10/105004.

Vikhamar-Schuler, D., K. Isaksen, J. E. Haugen, H. Tømmervik, B. Luks, T. V. Schuler, and J. W. Bjerke, 2016: Changes in winter warming events in the Nordic Arctic region. J. Climate, 29, 6223-6244, http://doi.org/10.1175/jcli-d-15-0763.1.

Vincent, D. G., 1994: The South Pacific convergence zone (SPCZ): A review. Mon. Wea. Rev., 122, 1949-1970, http://doi.org/10.1175/1520-0493(1994)122<1949 :tspcza>2.0.co;2.

Von Storch, H., and F. W. Zwiers, 1999: Statistical Analysis in Climate Research. Cambridge University Press, $484 \mathrm{pp}$.

Vuille, M., R. S. Bradley, and F. Keimig, 2000: Interannual climate variability in the Central Andes and its relation to tropical Pacific and Atlantic forcing. J. Geophys. Res., 105 (D10), 12,447-12,460, http://doi.org/10.1029/2000JD900134.

Wahr, J., E. Burgess, and S. Swenson, 2016: Using GRACE and climate model simulations to predict mass loss of Alaskan glaciers through 2100. J. Glaciol., 62, 623-639, http://doi.org/10.1017/jog.2016.49.

Waliser, D. E., and C. Gautier, 1993: A satellite-derived climatology of the ITCZ. J. Climate, 6, 2162-2174, http://doi.org/10.1175/1520-0442(1993)006<2162 :asdcot $>2.0 . \operatorname{co} ; 2$.

Wan, H., X. L. Wang, and V. R. Swail, 2010: Homogenization and trend analysis of Canadian nearsurface wind speeds. J. Climate, 23, 1209-1225, http://doi.org/10.1175/2009jcli3200.1.
Wang, B., and Q. Ding, 2008: Global monsoon: Dominant mode of annual variation in the tropics. Dyn. Atmos. Oceans, 44, 165-183, http://doi.org/10.1016 /j.dynatmoce.2007.05.002.

—, J. Liu, H.-J. Kim, P. J. Webster, and S.-Y. Yim, 2012: Recent change of the global monsoon precipitation (1979-2008). Climate Dyn., 39, 1123-1135, http://doi.org/10.1007/s00382-011-1266-z.

Wang, C., C. Deser, J.-Y. Yu, P. DiNezio, and A. Clement, 2017: El Niño and Southern Oscillation (ENSO): A review. Coral Reefs of the Eastern Tropical Pacific: Persistence and Loss in a Dynamic Environment, P. W. Glynn, D. P. Manzello, and I. C. Enochs, Eds., Springer Netherlands, 85-106, http://doi.org/10.1007/978-94-017-7499-4_4.

Wang, J., L. Zhang, A. Dai, T. Van Hove, and J. Van Baelen, 2007: A near-global, 2-hourly data set of atmospheric precipitable water from ground-based GPS measurements. J. Geophys. Res., 112, D11107, http://doi.org/10.1029/2006JD007529.

Wang, K., and R. E. Dickinson, 2012: A review of global terrestrial evapotranspiration: $\mathrm{Ob}$ servation, modeling, climatology, and climatic variability. Rev. Geophys., 50, RG2005, http://doi.org/10.1029/2011RG000373.

Wang, L., and H. Liu, 2017: Seasonal melt extent and duration [in "State of the Climate in 2016"]. Bull. Amer. Meteor. Soc., 98 (8), S162-S163, http://doi.org/10.1175/2017BAMSStateoftheClimate.1.

Wang, M., and J. E. Overland, 2009: A sea ice free summer Arctic within 30 years? Geophys. Res. Lett., 36, L07502, http://doi.org/10.1029/2009GL037820.

Wang, S., X. Mo, S. Liu, Z. Lin, and S. Hu, 2016: Validation and trend analysis of ECV soil moisture data on cropland in North China Plain during 19812010. Int. J. Appl. Earth Obs. Geoinf., 48, 110-121, http://doi.org/10.1016/j.jag.2015.10.010.

Wang, T., L. Xue, P. Brimblecombe, Y. F. Lam, L. Li, and L. Zhang, 2017: Ozone pollution in China: A review of concentrations, meteorological influences, chemical precursors, and effects. Sci. Total Environ., 575, 1582-1596, http://doi.org/10.1016 /j.scitotenv.2016.10.081.

Wang, X., C. Wang, L. Zhang, and X. Wang, 2015: Multidecadal variability of tropical cyclone rapid intensification in the western North Pacific. J. Climate, 28, 3806-3820, http://doi.org/10.1175/jcli-d-14-00400.1. Wanner, H., and Coauthors, 2001: North Atlantic Oscillation - Concepts and studies. Surv. Geophys., 22, 321-381, http://doi.org/10.1023/a:1014217317898. 
Wanninkhof, R., 2014: Relationship between wind speed and gas exchange over the ocean revisited. Limnol. Oceanogr.: Methods, 12, 351-362, http://doi.org/10.4319/lom.2014.12.351.

— , and J. Triñanes, 2017: The impact of changing wind speeds on gas transfer and its effect on global air-sea $\mathrm{CO}_{2}$ fluxes. Global Biogeochem. Cycles, 31, 961-974, http://doi.org/10.1002/2016GB005592.

Warren, S. G., I. G. Rigor, N. Untersteiner, V. F. Radionov, N. N. Bryazgin, Y. I. Aleksandrov, and R. Colony, 1999: Snow depth on Arctic sea ice. J. Climate, 12, 1814-1829, http://doi.org/10.1175 /1520-0442(1999)012<1814:Sdoasi>2.0.CO;2.

Watanabe, S., K. Hamilton, S. Osprey, Y. Kawatani, and E. Nishimoto, 2018: First successful hindcasts of the 2016 disruption of the stratospheric Quasi-biennial Oscillation. Geophys. Res. Lett., 45, 1602-1610, http:// doi.org/10.1002/2017GL076406.

Weatherhead, B., A. Tanskanen, and A. Stevermer, 2005: Ozone and ultraviolet radiation. Arctic Climate Impact Assessment, Cambridge University Press, 151-182, www.acia.uaf.edu/PDFs/ACIA_Science _Chapters_Final/ACIA_Ch05_Final.pdf.

Weatherhead, E. C., and Coauthors, 1998: Factors affecting the detection of trends: Statistical considerations and applications to environmental data. J. Geophys. Res., 103 (D14), 17,149-17,161, http://doi.org/10.1029/98JD00995.

— need to overlap? Evaluation of climate data stability from overlapping satellite records. Atmos. Chem. Phys., 17, 15,069-15,093, http://doi.org/10.5194 /acp-17-15069-2017.

Weber, M., and Coauthors, 2011: The Brewer-Dobson circulation and total ozone from seasonal to decadal time scales. Atmos. Chem. Phys., 11, 11,221-11,235, http://doi.org/10.5194/acp-11-11221-2011.

_ , and Coauthors, 2018: Total ozone trends from 1979 to 2016 derived from five merged observational datasets - the emergence into ozone recovery. Atmos. Chem. Phys., 18, 2097-2117, http://doi.org/10.5194 /acp-18-2097-2018.

Webster, M. A., I. G. Rigor, S. V. Nghiem, N. T. Kurtz, S. L. Farrell, D. K. Perovich, and M. Sturm, 2014: Interdecadal changes in snow depth on Arctic sea ice. J. Geophys. Res. Oceans, 119, 5395-5406, http://doi.org/10.1002/2014JC009985.

Wells, N., S. Goddard, and M. J. Hayes, 2004: A self-calibrating Palmer drought severity index. J. Climate, 17, 2335-2351, http://doi.org/10.1175 /1520-0442(2004)017<2335:aspdsi>2.0.co;2.
Werner, K., R. F. Spielhagen, D. Bauch, H. C. Hass, and E. Kandiano, 2013: Atlantic Water advection versus sea-ice advances in the eastern Fram Strait during the last $9 \mathrm{ka}$ : Multiproxy evidence for a twophase Holocene. Paleoceanography, 28, 283-295, http://doi.org/10.1002/palo.20028.

Westergaard-Nielsen, A., M. Lund, S. H. Pedersen, N. M. Schmidt, S. Klosterman, J. Abermann, and B. U. Hansen, 2017: Transitions in high-Arctic vegetation growth patterns and ecosystem productivity tracked with automated cameras from 2000 to 2013. Ambio, 46 (Suppl 1), 39-52, http://doi.org/10.1007 /s13280-016-0864-8.

Westra, S., and S. A. Sisson, 2011: Detection of nonstationarity in precipitation extremes using a max-stable process model. J. Hydrol., 406, 119-128, http://doi.org/10.1016/j.jhydrol.2011.06.014.

— , and Coauthors, 2014: Future changes to the intensity and frequency of short-duration extreme rainfall. Rev. Geophys., 52, 522-555, http://doi.org/10.1002/2014RG000464.

Wever, N., 2012: Quantifying trends in surface roughness and the effect on surface wind speed observations. J. Geophys. Res., 117, D11104, http://doi.org/10.1029/2011JD017118.

WGMS, 2017: Fluctuations of Glaciers Database. http://doi.org/10.5904/wgms-fog-2017-10.

_ 2018: Latest glacier mass balance data. World Glacier Monitoring Service. http://wgms.ch /latest-glacier-mass-balance-data/.

Wheeler, M. C., and G. N. Kiladis, 1999: Convectively coupled equatorial waves: Analysis of clouds and temperature in the wavenumberfrequency domain. J. Atmos. Sci., 56, 374-399, http://doi.org/10.1175/1520-0469(1999)056<0374 :ccewao $>2.0 . c 0 ; 2$.

- , and H. H. Hendon, 2004: An all-season realtime multivariate MJO index: Development of an index for monitoring and prediction. Mon. Wea. Rev., 132, 1917-1932, http://doi.org/10.1175 /1520-0493(2004)132<1917:aarmmi>2.0.co;2.

WHO, 2002: Global solar UV index: A practical guide. WHO/SDE/OEH/02.2, 28 pp., www.who.int/uv /publications/en/GlobalUVI.pdf.

_ 2013: Review of evidence on health aspects of air pollution - REVIHAAP project: Final technical report. 302 pp., www.euro.who.int/_data/assets /pdf_file/0004/193108/REVIHAAP-Final-technical -report-final-version.pdf?ua=1. 
Wielicki, B. A., B. R. Barkstrom, E. F. Harrison, R. B. Lee, III, G. L. Smith, and J. E. Cooper, 1996: Clouds and the Earth's radiant energy system (CERES): An Earth observing system experiment. Bull. Amer. Meteor. Soc., 77, 853-868, http://doi.org/10.1175 /1520-0477(1996)077<0853:catere>2.0.co;2.

_ , and Coauthors, 1998: Clouds and the Earth's radiant energy system (CERES): Algorithm overview. IEEE Trans. Geosci. Remote Sens., 36, 1127-1141, http://doi.org/10.1109/36.701020.

Wijffels, S., D. Roemmich, D. Monselesan, J. Church, and J. Gilson, 2016: Ocean temperatures chronicle the ongoing warming of Earth. Nat. Climate Change, 6, 116-118, http://doi.org/10.1038/nclimate2924.

Willett, K. M., P. D. Jones, N. P. Gillett, and P. W. Thorne, 2008: Recent changes in surface humidity: Development of the HadCRUH dataset. J. Climate, 21, 5364-5383, http://doi.org/10.1175/2008jcli2274.1. — able land surface specific humidity product for climate monitoring. Climate Past, 9, 657-677, http://doi.org/10.5194/cp-9-657-2013.

— , and Coauthors, 2014: HadISDH land surface multi-variable humidity and temperature record for climate monitoring. Climate Past, 10, 1983-2006, http://doi.org/10.5194/cp-10-1983-2014.

Willett, K., D. I. Berry, M. Boxilovich, and A. Simmons, 2016: Surface humidity [in "State of the Climate in 2015”]. Bull. Amer. Meteor. Soc., 98 (8), S24-S25, http://doi.org/10.1175/2016BAMSStateoftheClimate.1.

$-, \ldots,-$, and ——, 2017: Surface humidity [in

"State of the Climate in 2016"]. Bull. Amer. Meteor. Soc., 98 (8), S23-S24, http://doi.org/10.1175 /2017BAMSStateoftheClimate.1.

Williams, N. L., R. A. Feely, C. L. Sabine, A. G. Dickson, J. H. Swift, L. D. Talley, and J. L. Russell, 2015: Quantifying anthropogenic carbon inventory changes in the Pacific sector of the Southern Ocean. Marine Chem., 174, 147-160, http://doi.org/10.1016 /j.marchem.2015.06.015.

Williams, T. D., and V. A. Squire, 2007: Wave scattering at the sea-ice/ice-shelf transition with other applications. SIAM J. Appl. Math., 67, 938-959, http://doi.org/10.1137/060659351.

Willis, J. K., 2010: Can in situ floats and satellite altimeters detect long-term changes in Atlantic Ocean overturning? Geophys. Res. Lett., 37, L06602, http://doi.org/10.1029/2010GL042372.

—, D. Roemmich, and B. Cornuelle, 2004: Interannual variability in upper ocean heat content, temperature, and thermosteric expansion on global scales. J. Geophys. Res., 109, C12036, http://doi.org/10.1029/2003JC002260.
Winker, D. M., W. H. Hunt, and M. J. McGill, 2007: Initial performance assessment of CALIOP. Geophys. Res. Lett., 34, L19803, http://doi .org/10.1029/2007GL030135.

WMO, 2014: Scientific assessment of ozone depletion, 2014. Global Ozone Research and Monitoring Project-Report No. 55, various pp., www.wmo.int/pages /prog/arep/gaw/ozone_2014/ozone_asst_report .html.

—_, 2017a: El Niño/La Niña update: 15 February 2017. 5 pp., www.wmo.int/pages/prog/wcp/wcasp /documents/WMO_ENSO_Feb17_Eng.pdf.

_, $2017 \mathrm{~b}$ : El Niño/La Niña update: 28 April 2017. 5 pp., www.wmo.int/pages/prog/wcp/wcasp/documents /WMO_ENSO_Apr17_Eng.pdf.

Wolter, K., and M. S. Timlin, 1998: Measuring the strength of ENSO events: How does 1997/98 rank? Weather, 53, 315-324, http://doi.org/10.1002/j.1477-8696.1998 .tb06408.x.

— behaviour since 1871 as diagnosed in an extended multivariate ENSO index (MEI.ext). Int. J. Climatol., 31, 1074-1087, http://doi.org/10.1002/joc.2336.

Woodgate, R. A., T. J. Weingartner, and R. Lindsay, 2012: Observed increases in Bering Strait oceanic fluxes from the Pacific to the Arctic from 2001 to 2011 and their impacts on the Arctic Ocean water column. Geophys. Res. Lett., 39, L24603, http://doi.org/10.1029/2012GL054092.

Woolway, R. I., and C. J. Merchant, 2017: Amplified surface temperature response of cold, deep lakes to inter-annual air temperature variability. Sci. Rep., 7, 4130, http://doi.org/10.1038/s41598-017-04058-0. _ - and Coauthors, 2017: Lake surface temperature [in "State of the Climate in 2015"]. Bull. Amer. Meteor. Soc., 98 (8), S13-S14, http://doi.org/10.1175 /2017BAMSStateoftheClimate.1.

Woosley, R. J., F. J. Millero, and R. Wanninkhof, 2016: Rapid anthropogenic changes in $\mathrm{CO} 2$ and $\mathrm{pH}$ in the Atlantic Ocean: 2003-2014. Global Biogeochem. Cycles, 30, 70-90, http://doi.org/10.1002/2015GB005248.

Worden, H. M., and Coauthors, 2013: Decadal record of satellite carbon monoxide observations. Atmos. Chem. Phys., 13, 837-850, http://doi.org/10.5194 lacp-13-837-2013.

Worden, J. R., and Coauthors, 2017: Reduced biomass burning emissions reconcile conflicting estimates of the post-2006 atmospheric methane budget. Nat. Comm., 8, 2227, http://doi.org/10.1038/s41467-017 -02246-0. 
Wouters, B., and Coauthors, 2015: Dynamic thinning of glaciers on the Southern Antarctic Peninsula. Science, 348 (6237), 899-903, http://doi.org/10.1126 /science.aaa5727.

Wu, D. L., and Coauthors, 2017: Toward global harmonization of derived cloud products. Bull. Amer. Meteor. Soc., 98, ES49-ES52, http://doi.org/10.1175 /bams-d-16-0234.1.

Wu, J., J. Zha, and D. Zhao, 2016: Estimating the impact of the changes in land use and cover on the surface wind speed over the East China Plain during the period 1980-2011. Climate Dyn., 46, 847-863, http://doi.org/10.1007/s00382-015-2616-z.

Wu, L., and Coauthors, 2012: Enhanced warming over the global subtropical western boundary currents. Nat. Climate Change, 2, 161-166, http://doi.org/10.1038/nclimate1353.

Wu, M.-C., K.-H. Yeung, and W.-L. Chang, 2006: Trends in western North Pacific tropical cyclone intensity. Eos, Trans. Amer. Geophys. Union, 87, 537-538, http://doi.org/10.1029/2006EO480001.

Wuebbles, D. J., and Coauthors, 2017: Our globally changing climate. Climate Science Special Report: Fourth National Climate Assessment, Volume I, D. J. Wuebbles, D. W. Fahey, K. A. Hibbard, D. J. Dokken, B. C. Steward, and T. K. Maycock, Eds., 35-72, http:// doi.org/10.7930/J08S4N35.

Wylie, D., D. L. Jackson, W. P. Menzel, and J. J. Bates, 2005: Trends in global cloud cover in two decades of HIRS observations. J. Climate, 18, 3021-3031, http://doi.org/10.1175/jcli3461.1.

Xie, P., and Coauthors, 2014: An in situ-satellite blended analysis of global sea surface salinity. J. Geophys. Res. Oceans, 119, 6140-6160, http://doi.org/10.1002/2014JC010046.

Xie, S.-P., and S. G. H. Philander, 1994: A coupled ocean-atmosphere model of relevance to the ITCZ in the eastern Pacific. Tellus, 46A, 340-350, http://doi .org/10.1034/j.1600-0870.1994.t01-1-00001.x.

_ , Y. Kosaka, and Y. M. Okumura, 2016: Distinct energy budgets for anthropogenic and natural changes during global warming hiatus. Nat. Geosci., 9, 29-33, http://doi.org/10.1038/ngeo2581.

Xu, H., 2006: Modification of normalised difference water index (NDWI) to enhance open water features in remotely sensed imagery. Int. J. Remote Sens., 27, 3025-3033, http://doi.org /10.1080/01431160600589179.

$\mathrm{Xu}, \mathrm{J}$, and Y. Wang, 2018: Dependence of tropical cyclone intensification rate on sea surface temperature, storm intensity, and size in the western North Pacific. Wea. Forecasting, 33, 523-537, http://doi.org/10.1175 /waf-d-17-0095.1.
Xu, W., W. Lin, X. Xu, J. Tang, J. Huang, H. Wu, and X. Zhang, 2016: Long-term trends of surface ozone and its influencing factors at the Mt. Waliguan GAW station, China - Part 1: Overall trends and characteristics. Atmos. Chem. Phys., 16, 6191-6205, http://doi.org/10.5194/acp-16-6191-2016.

Xue, Y., and A. Kumar, 2017: Evolution of the 2015/16 El Niño and historical perspective since 1979. Sci. China: Earth Sci., 60, 1572-1588, http://doi.org/10.1007/s11430-016-0106-9.

Yashayaev, I., and J. W. Loder, 2016: Recurrent replenishment of Labrador Sea Water and associated decadalscale variability. J. Geophys. Res. Oceans, 121, 8095-8114, http://doi.org/10.1002/2016JC012046.

Yim, S.-Y., B. Wang, J. Liu, and Z. Wu, 2014: A comparison of regional monsoon variability using monsoon indices. Climate Dyn., 43, 1423-1437, http://doi.org/10.1007/s00382-013-1956-9.

Yin, Y., F. Chevallier, P. Ciais, G. Broquet, A. Fortems-Cheiney, I. Pison, and M. Saunois, 2015: Decadal trends in global CO emissions as seen by MOPITT. Atmos. Chem. Phys., 15, 13,433-13,451, http://doi.org/10.5194/acp-15-13433-2015.

Ying, M., E.-J. Cha, and H. J. Kwon, 2011: Comparison of three western North Pacific tropical cyclone best track datasets in a seasonal context. J. Meteor. Soc. Japan, 89, 211-224, http://doi.org/10.2151/jmsj .2011-303.

Young, A. M., P. E. Higuera, P. A. Duffy, and F. S. Hu, 2017: Climatic thresholds shape northern highlatitude fire regimes and imply vulnerability to future climate change. Ecography, 40 (5), 606-617, http://doi.org/10.1111/ecog.02205.

Young, P. J., and Coauthors, 2013: Pre-industrial to end 21st century projections of tropospheric ozone from the atmospheric chemistry and climate model intercomparison project (ACCMIP). Atmos. Chem. Phys., 13, 2063-2090, http://doi.org/10.5194 /acp-13-2063-2013.

_- V. Naik, and Coauthors, 2018: Tropospheric Ozone Assessment Report: Assessment of global-scale model performance for global and regional ozone distributions, variability, and trends. Elementa, 6 (1), 10, http://doi.org/10.1525/elementa.265.

Yu, H., Y. Lu, P.-Y. Chen, and W.-C. Zhou, 2012: Intensity change characteristics of tropical cyclones in the western North Pacific as revealed by three different datasets. J. Trop. Meteor., 18, 119-126, http://doi.org/10.3969/j.issn.1006-8775.2012.02.002.

Yu, L., 2011: A global relationship between the ocean water cycle and near-surface salinity. J. Geophys. Res., 116, C10025, http://doi.org/10.1029/2010JC006937. 
Yu, L., and X. Jin, 2012: Buoy perspective of a high-resolution global ocean vector wind analysis constructed from passive radiometers and active scatterometers (1987-present). J. Geophys. Res., 117, C11013, http:// doi.org/10.1029/2012JC008069.

—, and —, 2014: Insights on the OAFlux ocean surface vector wind analysis merged from scatterometers and passive microwave radiometers (1987 onward). J. Geophys. Res. Oceans, 119, 5244-5269, http://doi.org/10.1002/2013JC009648.

—, and —, 2018: A regime-dependent retrieval algorithm for near-surface air temperature and specific humidity from multi-microwave sensors. Remote Sens. Environ., 215, 199-216, http://doi.org/10.1016 /j.rse.2018.06.001.

Yu, L., S. Zhong, L. Pei, X. Bian, and W. E. Heilman, 2016: Contribution of large-scale circulation anomalies to changes in extreme precipitation frequency in the United States. Environ. Res. Lett., 11, 044003, http://doi.org/10.1088/1748-9326/11/4/044003.

$\mathrm{Yu}, \mathrm{R}$., and J. Li, 2012: Hourly rainfall changes in response to surface air temperature over eastern contiguous China. J. Climate, 25, 6851-6861, http://doi.org/10.1175/jcli-d-11-00656.1.

— _ - W. Yuan, and H. Chen, 2010: Changes in characteristics of late-summer precipitation over eastern China in the past 40 years revealed by hourly precipitation data. J. Climate, 23, 3390-3396, http://doi.org/10.1175/2010jcli3454.1.

Yuan, X., 2004: ENSO-related impacts on Antarctic sea ice: A synthesis of phenomenon and mechanisms. Antarctic Sci., 16, 415-425, http://doi.org/10.1017 /S0954102004002238.

Yue, X., L. J. Mickley, J. A. Logan, R. C. Hudman, M. V. Martin, and R. M. Yantosca, 2015: Impact of 2050 climate change on North American wildfire: consequences for ozone air quality. Atmos. Chem. Phys., 15 (17), 10,033-10,055, http://doi.org/10.5194 /acp-15-10033-2015.

Zanowski, H., R. Hallberg, and J. L. Sarmiento, 2015: Abyssal ocean warming and salinification after Weddell polynyas in the GFDL CM2G coupled climate model. J. Phys. Oceanogr., 45, 2755-2772, http://doi.org/10.1175/jpo-d-15-0109.1.

Zemp, D. C., and Coauthors, 2017: Self-amplified Amazon forest loss due to vegetation-atmosphere feedbacks. Nat. Comm., 8, 14681, http://doi.org/10.1038 /ncomms14681.

Zemp, M., and Coauthors, 2015: Historically unprecedented global glacier decline in the early 21 st century. J. Glaciol., 61, 745-762, http://doi.org/10.3189/2015JoG15J017.
Zhang, C., 2005: Madden-Julian oscillation. Rev. Geophys., 43, RG2003, http://doi.org/10.1029 /2004RG000158.

_ 2013: Madden-Julian oscillation: Bridging weather and climate. Bull. Amer. Meteor. Soc., 94, 18491870, http://doi.org/10.1175/bams-d-12-00026.1.

—, and J. Gottschalck, 2002: SST anomalies of ENSO and the Madden-Julian oscillation in the equatorial Pacific. J. Climate, 15, 2429-2445, http://doi.org/10.1175/1520-0442(2002)015<2429 :saoeat $>2.0 . \operatorname{co} ; 2$.

Zhang, H., and P. Zhai, 2011: Temporal and spatial characteristics of extreme hourly precipitation over eastern China in the warm season. Adv. Atmos. Sci., 28, 1177, http://doi.org/10.1007/s00376-011-0020-0.

Zhang, J., and Coauthors, 2018: Stratospheric ozone loss over the Eurasian continent induced by the polar vortex shift. Nat. Comm., 9, 206, http://doi.org/10.1038 Is41467-017-02565-2.

Zhang, X., and Coauthors, 2003: Monitoring vegetation phenology using MODIS. Remote Sens. Environ., 84, 471-475, http://doi.org/10.1016 /S0034-4257(02)00135-9.

Zhang, X., and Coauthors, 2011: Indices for monitoring changes in extremes based on daily temperature and precipitation data. Wiley Interdiscip. Rev.: Climate Change, 2, 851-870, http://doi.org/10.1002/wcc.147.

Zhang, Y. G., M. Pagani, Z. Liu, S. M. Bohaty, and R. DeConto, 2013: A 40-million-year history of atmospheric $\mathrm{CO}_{2}$. Philos. Trans. Roy. Soc., A371, 20130096, http://doi.org/10.1098/rsta.2013.0096.

Zhang, Y., J. M. Wallace, and D. S. Battisti, 1997: ENSO-like interdecadal variability: 1900-93. J. Climate, 10, 1004-1020, http://doi.org/10.1175/1520 -0442(1997)010<1004:eliv>2.0.co;2.

Zhang, Y., O. R. Cooper, A. Gaudel, A. M. Thompson, P. Nedelec, S.-Y. Ogino, and J. J. West, 2016: Tropospheric ozone change from 1980 to 2010 dominated by equatorward redistribution of emissions. Nat. Geosci., 9, 875-879, http://doi.org/10.1038/ngeo2827.

Zhao, L., Q. Wu, S. S. Marchenko, and N. Sharkhuu, 2010: Thermal state of permafrost and active layer in Central Asia during the international polar year. Permafr. Periglac. Process., 21, 198-207, http://doi.org/10.1002/ppp.688.

Zhao, S.-P., Z.-T. Nan, Y.-B. Huang, and L. Zhao, 2017: The application and evaluation of simple permafrost distribution models on the Qinghai-Tibet Plateau. Permafr. Periglac. Process., 28, 391-404, http://doi.org/10.1002/ppp.1939. 
Zheng, Z.-W., I. I. Lin, B. Wang, H.-C. Huang, and C.H. Chen, 2015: A long neglected damper in the El Niño-typhoon relationship: A 'Gaia-like' process. Sci. Rep., 5, 11103, http://doi.org/10.1038/srep11103.

Zhou, L., and Coauthors, 2014: Widespread decline of Congo rainforest greenness in the past decade. $\mathrm{Na}$ ture, 509, 86-90, http://doi.org/10.1038/nature13265.

Ziel, R. H., J. Wolken, T. St. Clair, and M. Henderson, 2015: Modeling fire growth potential by emphasizing significant growth events: Characterizing a climatology of fire growth days in Alaska's boreal forest 11th Symp. on Fire and Forest Meteorology, Minneapolis, MN, Amer. Meteor. Soc., Session 1.2. https://ams.confex.com/ams/11FIRE/webprogram /Paper272864.html.

Ziemke, J. R., and O. R. Cooper, 2016: Tropospheric ozone [in "State of the Climate in 2015"]. Bull. Amer. Meteor. Soc., 97 (8), S53-S55, http://doi.org/10.1175 /2016BAMSStateoftheClimate.1.

—, and —, 2017: Tropospheric ozone [in "State of the Climate in 2016"]. Bull. Amer. Meteor. Soc., 98 (8), S52-S54, http://doi.org/10.1175 /2017BAMSStateoftheClimate.1.

— S. Chandra, R. D. McPeters, and P. A. Newman, 1997: Dynamical proxies of column ozone with applications to global trend models. J. Geophys. Res., 102 (D5), 6117-6129, http://doi.org/10.1029/96JD03783.

_ - _ - and P. K. Bhartia, 1998: Two new methods for deriving tropospheric column ozone from TOMS measurements: Assimilated UARS MLS/HALOE and convective-cloud differential techniques. J. Geophys. Res., 103, 22,115-22,127, http://doi.org/10.1029/98JD01567.
,-- B. N. Duncan, L. Froidevaux, P. K. Bhartia, P. F. Levelt, and J. W. Waters, 2006: Tropospheric ozone determined from Aura OMI and MLS: Evaluation of measurements and comparison with the Global Modeling Initiative's Chemical Transport Model. J. Geophys. Res., 111, D19303, http://doi.org/10.1029/2006JD007089.

—, A. R. Douglass, L. D. Oman, S. E. Strahan, and B. N. Duncan, 2015: Tropospheric ozone variability in the tropics from ENSO to MJO and shorter timescales. Atmos. Chem. Phys., 15, 8037-8049, http://doi.org/10.5194/acp-15-8037-2015.

Zwally, H. J., and P. Gloersen, 1977: Passive microwave images of the polar regions and research applications. Polar Record, 18, 431-450, http://doi.org/10.1017 /S0032247400000930.

— Antarctic surface melting. J. Glaciol., 40, 463-475, http://doi.org/10.3198/1994JoG40-136-463-375.

—, W. Abdalati, T. Herring, K. Larson, J. Saba, and K. Steffen, 2002: Surface melt-induced acceleration of Greenland ice-sheet flow. Science, 297, 218-222, http://doi.org/10.1126/science.1072708.

Zweng, M. M., and Coauthors, 2013: Salinity. Vol. 2, World Ocean Atlas 2013, NOAA Atlas NESDIS 74, 40 pp., www.nodc.noaa.gov/OC5/woa13/. 


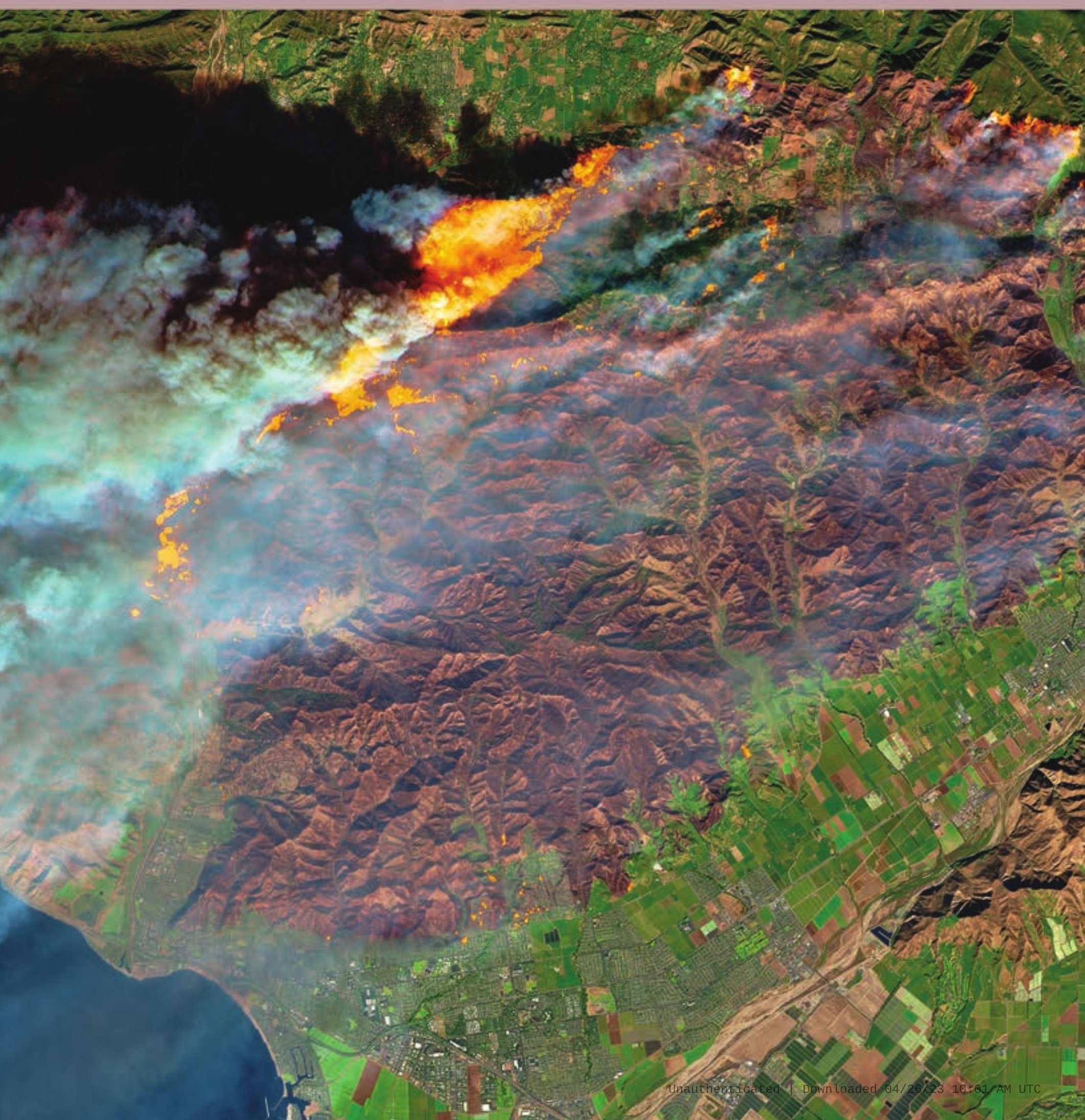

